UNIVERSIDAD DE SALAMANCA

DEPARTAMENTO DE LENGUA ESPAÑOLA

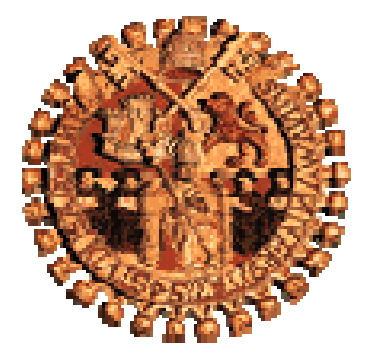

\title{
LAS GRAMÁTICAS DE LA \\ REAL ACADEMIA EsPaÑoLA: TEORÍA GRAMATICAL, SINTAXIS Y SUBORDINACIÓN (1854-1924)
}

Tesis Doctoral realizada por:

\section{GEMA BELÉN GARRIDO VÍLCHEZ}

\author{
Dirigida por:
}

Dr. D. JOSÉ J. GóMEZ ASENCIO 
A mis padres.

A mi madre, porque todo es gracias a ella.

También esta tesis.

Por su entrega.

Por su generosidad.

A mi padre, por protegerme siempre.

Por sus desvelos. 
Esta tesis ha sido posible por el apoyo y la confianza que muchas personas han depositado en mí.

El profesor Gómez Asencio me ha guiado durante estos años con su sabiduría, su cercanía y su honestidad. Siempre le estaré agradecida por haber supervisado mi trabajo con sincero interés y con respeto. También por haber seguido ahí cuando las circunstancias no fueron las mejores.

Los miembros del Archivo y la Biblioteca de la Real Academia Española, especialmente $\mathrm{M}^{\mathrm{a}}$ Elvira Fernández del Pozo y Rosa Genique, me han tratado siempre con amabilidad y paciencia, y me han aconsejado acerca de pequeños detalles en los que no hubiera reparado sin su ayuda.

Mis compañeros de la Asociación de Jóvenes Investigadores de Historiografía e Historia de la Lengua Española han estado pendientes de la evolución de esta tesis y me han demostrado su incondicional apoyo. Quiero mencionar especialmente a $\mathrm{M}^{\mathrm{a}}$ José García Folgado, por la información (siempre valiosa) y por sus permanentes ánimos; y a Mara Fuertes Gutiérrez, Ma Ángeles García Aranda, Esteban García Montoro y Sara Gómez Seibane. A todos ellos les agradezco el cariño que siempre me demuestran.

Lisana, con su energía, y Félix, con su prudencia, me han sabido transmitir su apoyo y su cariño cuando los he necesitado. Jimena, con su sonrisa, ha hecho el trabajo más llevadero.

Rafa ha sido mi motor durante todo este último año para que las fuerzas no me faltaran. Ha hecho suyo este proyecto mío como yo hago míos los suyos. 
Y que aún tienen que venir muchos gramáticos que seguirán durante años y años dando vueltas y más vueltas a las piezas del mismo rompecabezas.

(Bosque, 1997: 37) 



\section{ÍNDICE TEMÁTICO}

\section{PRELIMINARES}

Capítulo 1. INTRODUCCIÓN

1.1. Corpus central 6

1.2. Corpus secundario $\quad 9$

$\begin{array}{ll}\text { 1.3. Propósitos } & 13\end{array}$

II. LOS TEXTOS DEL CORPUS

Capítulo 2. LAS EDICIONES DE LA GRAMÁTICA 19

2.1. Cuántas ediciones hay y cuáles son 19

- Siglo XVIII 19

- Siglo XIX 26

- Siglo XX 35

2.2. Sobre las compilaciones $\quad 36$

2.3. Información y apuntes sobre las distintas ediciones 41

2.3.1. GRAE-1771 41

2.3.2. GRAE-1772 45

2.3.3. GRAE-1781 48

2.3.4. GRAE-1796 51

2.3.5. GRAE-1854 55

2.3.6. GRAE- 1858

2.3.7. GRAE-1862 62

2.3.8. GRAE-1864 64

2.3.9. GRAE- 1865

2.3.10. GRAE-1866 67

2.3.11. GRAE-1867 69

2.3.12. GRAE-1870 71

2.3.13. GRAE-1874 75

2.3.14. GRAE-1878 76

2.3.15. GRAE-1880 78

2.3.16. GRAE-1883 80

2.3.17. GRAE-1885 $\quad 82$

2.3.18. GRAE-1888 83

2.3.19. GRAE-1890 85

2.3.20. GRAE-1895 86

2.3.21. GRAE-1900

2.3.22. GRAE-1901 88

2.3.23. GRAE-1904 89 
2.3.24. GRAE-1906

2.3.25. GRAE-1908

2.3.26. GRAE-1909

2.3.27. GRAE-1911

93

2.3.28. GRAE-1913

94

2.3.29. GRAE-1916

95

2.3.30. GRAE-1917

96

2.3.31. GRAE- 1920

97

2.3.32. GRAE-1924

98

2.3.33. GRAE-1928

99

2.3.34. GRAE-1931

100

NOTA: ediciones de 1959 y 1962

101

2.4. Las gramáticas en tablas

102

Capítulo 3. EL LUGAR DE LA GRAMÁTICA EN EL QUEHACER ACADÉMICO

109

3.1. La Gramática, un proyecto secundario

3.2. Los documentos sobre regulación interna

3.2.1. Los Estatutos

3.2.2. El Reglamento

3.3. Los proyectos y las obras

3.3.1. Los proyectos

3.4. Los documentos sobre tareas cumplidas, dictámenes y revisiones

CONCLUSIONES PARCIALES

III. EL CONCEPTO DE GRAMÁTICA

Capítulo 4. EL CONCEPTO DE GRAMÁTICA EN LA OBRA LEXICOGRÁFICA Y GRAMATICAL DE LA RAE

4.1. Datos extraídos de los textos académicos 141

- Diccionarios 141

- Gramáticas 144

4.2. Interpretación de los datos 155

4.2.1. Propiedades inherentes a la disciplina gramatical 155

- Propiedades de la gramatica establecidas en Autoridades 156

- Desarrollo posterior 157

1. La Gramática es didáctica 158

Los años cincuenta y sesenta $\quad 166$

Los años setenta 173

Los ochenta y siguientes $\quad 175$

El último jalón 176 
2. La Gramática es normativa 179

2.1. Los conceptos de bien / correctamente / con 193 propiedad apicados a hablar / escribir.

2.2 Los modelos de lengua 209

3. La Gramática es general / particular 215

4. La Gramática es arte propedéutica 226

5. La Gramática abarca el estudio de distintos aspectos 228 de la lengua

4.2.2. Información adicional de los libros de Gramática

1. El artificio gramatical como fijación del esplendor de un idioma

2. La justificación de una Gramática de una primera lengua

3. Gramática más morfológica que sintáctica

4. Gramática de la lengua escrita (literaria)

CONCLUSIONES PARCIALES

\section{SINTAXIS Y RELACIONES DE DEPENDENCIA}

IV. 1. Los Diccionarios

Capítulo 5. EL CONCEPTO DE SINTAXIS Y LAS RELACIONES DE DEPENDENCIA EN LOS DICCIONARIOS DE LA RAE

5.1. Los conceptos de sintaxis y construcción

5.1.1. El camino iniciado en Autoridades y seguido en las primeras ediciones del DRAE

5.1.2. Los años de transición

5.1.3. El final del camino: los cambios

5.1.4. El recorrido completo

5.1.5. Los conceptos de sintaxis y construcción en otros diccionarios de la época

5.2. Relaciones de Dependencia

5.2.1. Relaciones de Régimen

5.2.2. Relaciones de Concordancia

5.2.3. Los conceptos de régimen y concordancia en otros diccionarios de la época

5.3. Los elementos de relación 


\section{2. Las Gramáticas}

Capítulo 6. EL CONCEPTO DE SINTAXIS Y LAS RELACIONES DE

6.1. Teoría sintáctica: generalidades

6.1.1. El lugar de la sintaxis dentro de la Gramática

6.1.2. Definición y concepto de sintaxis (como parte de la

Gramática)

6.1.2.1. El orden y la dependencia

6.1.2.2. Las unidades de estudio

6.1.3. División de la Sintaxis

6.1.4. Los conceptos de sintaxis y construcción

6.2. De $1854(<1796)$ a 1916

6.2.1.1. El concepto de régimen

- Caso (1) de Régimen: palabra Reg. = Sustantivo 413

a) Relaciones /Sust. $\longrightarrow$ sust./ 413

b) Relaciones /Sust. $\rightarrow$ adj./ $\quad 419$

c) Relaciones /Sust. $\rightarrow$ vb./ $\quad 425$

- Caso (2) de Régimen: palabra Reg. = Verbo 435

a) Relaciones / Vb. $\rightarrow$ sust./ $\quad 435$

b) Relaciones / Vb. $\rightarrow$ vb./ $\quad 446$

c) Relaciones / Vb. $\rightarrow$ adv./ $\quad 456$

- Caso (3) de Régimen: palabra Reg. = Participio 462

- Caso (4) de Régimen: palabra Reg. = Preposición 464

- Caso (5) de Régimen: palabra Reg. = Conjunción 477

- Caso (6) de Régimen: palabra Reg. = Adjetivo 481

- Caso (7) de Régimen: palabra Reg. = Gerundio 485

6.2.2. Reglas de Construcción 486

6.2.2.1. El concepto de construcción 486

6.2.2.2. Las reglas de construcción 493

1. «Construccion del nombre, pronombre, y otras partes 494 de la oracion ántes del verbo»

2. «Construccion del verbo con las demas partes de la 502 «Cocion»

$\begin{array}{ll}\text { 3. «Construccion de unos verbos con otros» } & 509 \\ \text { 4. «Construccion del verbo con el pronombre» } & 513\end{array}$

6.2.3. Reglas de Concordancia $\quad 514$

6.2.3.1. El concepto de concordancia 514

6.2.3.2. Las reglas de concordancia 522

1. ${ }^{a}$ Concordancia: nombre sustantivo y adjetivo 522 


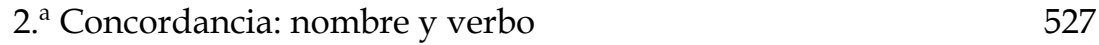

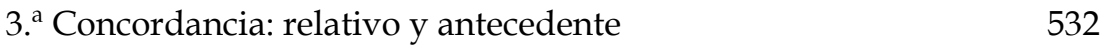

6.2.4. Los elementos de relación 533

6.2.4.1. La conjunción $\quad 533$

6.2.4.2. La preposición $\quad 540$

6.2.5. La oración y sus clases $\quad 545$

6.2.5.1. Primer jalón: la doctrina en 1854

1. Oraciones de sustantivo $\quad 550$

2. Oraciones de activa $\quad 550$

3. Oraciones de verbo recíproco 551

4. Oraciones de pasiva $\quad 552$

5. Oraciones de infinitivo 554

6. Oraciones de relativo o incidentales 555

7. Oraciones de gerundio 558

8. Oraciones de imperativo 560

6.2.5.2. Segundo jalón: la doctrina de 1870

6.3. La reforma de 1917

6.3.1. El cambio 581

- La coyuntura del cambio 585

- Los artífices del cambio 595

6.3.2. Análisis 607

6.3.2.1. Sintaxis: generalidades 609

6.3.2.2. Sintaxis de la Oración Simple $\quad 626$

6.3.2.3. Sintaxis de la Oración Compuesta 637

$\begin{array}{ll}\text { CONCLUSIONES PARCIALES } & 647\end{array}$

V. CONCLUSIONES GENERALES 653

VI. ANEXOS

Anexo 1. LAS COMPILACIONES SOBRE LAS GRAMÁTICAS 667

$\begin{array}{ll}\text { Anexo 2. GLOSARIO TERMINOLÓGICO } & 681\end{array}$

$\begin{array}{ll}\text { analogía } & 683\end{array}$

$\begin{array}{ll}\text { arte } & 688\end{array}$

$\begin{array}{ll}\text { bien } & 693\end{array}$

caso $\quad 697$

$\begin{array}{ll}\text { combinar } & 707\end{array}$

complemento $\quad 711$

$\begin{array}{ll}\text { concertar } & 722\end{array}$

$\begin{array}{ll}\text { concordancia } & 725\end{array}$

$\begin{array}{lr}\text { concordar } & 730\end{array}$

conformidad $\quad 734$

$\begin{array}{ll}\text { conjunción } & 738\end{array}$

$\begin{array}{ll}\text { construcción } & 748\end{array}$ 
$\begin{array}{ll}\text { construir } & 756\end{array}$

coordinación $r$

$\begin{array}{lr}\text { coordinar } & 762\end{array}$

correcto $\quad 765$

$\begin{array}{lr}\text { dependencia } & 768\end{array}$

$\begin{array}{lr}\text { enlazar } & 771\end{array}$

$\begin{array}{lr}\text { gramática } & 774\end{array}$

$\begin{array}{lr}\text { incidencia } & 782\end{array}$

$\begin{array}{lr}\text { incidir } & 785\end{array}$

incrustación $\quad 788$

$\begin{array}{ll}\text { incrustar } & 791\end{array}$

morfología $\quad 794$

$\begin{array}{ll}\text { o } & 797\end{array}$

$\begin{array}{lr}\text { objeto } & 803\end{array}$

$\begin{array}{lr}\text { oración } & 808\end{array}$

$\begin{array}{lr}\text { ortografía } & 814\end{array}$

predicado $r 20$

preposición $\quad 823$

$\begin{array}{lr}\text { propiedad } & 829\end{array}$

$\begin{array}{lr}\text { prosodia } & 834\end{array}$

régimen $\quad 840$

regir $\quad 845$

relación $\quad 849$

relacionar 856

$\begin{array}{lr}\text { retórica } & 859\end{array}$

sintaxis $\quad 862$

$\begin{array}{lr}\text { subordinación } & 873\end{array}$

$\begin{array}{lr}\text { subordinar } & 877\end{array}$

$\begin{array}{lr}\text { sujeto } & 881\end{array}$

$\begin{array}{lr}\text { unir } & 889\end{array}$

$\begin{array}{lr}\text { verbo } & 894\end{array}$

VII. $\quad$ REFERENCIAS BIBLIOGRÁFICAS 901 


\section{ÍNDICE DE CUADROS, ESQUEMAS, GRÁFICOS Y TABLAS}

\begin{tabular}{|c|c|c|c|}
\hline & Título & $\begin{array}{r}\text { CAPÍTULO } \\
\text { (Y APARTADO) }\end{array}$ & PÁG. \\
\hline Cuadro 1 & “La Prosodia en la Gramática de 1855 y en la GRAE-1870” & 2. (2.1.) & 34 \\
\hline Cuadro 2 & "GRAE-1771 en las compilaciones" & 2. (2.3.1.) & 41 \\
\hline Cuadro 3 & “GRAE-1772 en las compilaciones" & 2. (2.3.2.) & 45 \\
\hline Cuadro 4 & “GRAE-1781 en las compilaciones" & 2. (2.3.3.) & 48 \\
\hline Cuadro 5 & "Licencias de 1771, 1772 y 1781" & 2. (2.3.3.) & $49-50$ \\
\hline Cuadro 6 & “GRAE-1796 en las compilaciones" & 2. (2.3.4.) & 51 \\
\hline Cuadro 7 & "GRAE-1854 en las compilaciones" & 2. $(2.3 .5)$. & 55 \\
\hline Cuadro 8 & “GRAE-1858 en las compilaciones" & 2. (2.3.6.) & 59 \\
\hline Cuadro 9 & "GRAE-1862 en las compilaciones" & 2. $(2.3 .7)$. & 62 \\
\hline Cuadro 10 & “GRAE-1864 en las compilaciones" & 2. $(2.3 .8)$. & 64 \\
\hline Cuadro 11 & "GRAE-1865 en las compilaciones" & 2. (2.3.9.) & 66 \\
\hline Cuadro 12 & “GRAE-1866 en las compilaciones" & 2. $(2.3 .10)$. & 67 \\
\hline Cuadro 13 & “GRAE-1867 en las compilaciones" & 2. (2.3.11.) & 69 \\
\hline Cuadro 14 & "GRAE-1870 en las compilaciones" & 2. $(2.3 .12)$. & 71 \\
\hline Cuadro 15 & “GRAE-1874 en las compilaciones" & 2. $(2.3 .13)$. & 75 \\
\hline Cuadro 16 & "GRAE-1878 en las compilaciones" & 2. (2.3.14.) & 76 \\
\hline Cuadro 17 & “GRAE-1880 en las compilaciones" & 2. $(2.3 .15)$. & 78 \\
\hline Cuadro 18 & “GRAE-1883 en las compilaciones" & 2. $(2.3 .16)$. & 80 \\
\hline Cuadro 19 & “GRAE-1885 en las compilaciones" & 2. $(2.3 .17)$. & 82 \\
\hline Cuadro 20 & "GRAE-1888 en las compilaciones" & 2. (2.3.18.) & 83 \\
\hline Cuadro 21 & “GRAE-1890 en las compilaciones" & 2. $(2.3 .19)$. & 85 \\
\hline Cuadro 22 & “GRAE-1895 en las compilaciones" & 2. $(2.3 .20)$. & 86 \\
\hline Cuadro 23 & “GRAE-1900 en las compilaciones" & 2. $(2.3 .21)$. & 87 \\
\hline Cuadro 24 & “GRAE-1901 en las compilaciones" & 2. $(2.3 .22)$. & 88 \\
\hline Cuadro 25 & “GRAE-1904 en las compilaciones" & 2. $(2.3 .23)$. & 89 \\
\hline Cuadro 26 & “GRAE-1906 en las compilaciones" & 2. $(2.3 .24)$. & 90 \\
\hline Cuadro 27 & “GRAE-1908 en las compilaciones" & 2. $(2.3 .25)$. & 91 \\
\hline Cuadro 28 & “GRAE-1909 en las compilaciones” & 2. $(2.3 .26)$. & 92 \\
\hline Cuadro 29 & “GRAE-1911 en las compilaciones" & 2. (2.3.27.) & 93 \\
\hline Cuadro 30 & “GRAE-1913 en las compilaciones" & 2. (2.3.28.) & 94 \\
\hline Cuadro 31 & “GRAE-1916 en las compilaciones" & 2. (2.3.29.) & 95 \\
\hline Cuadro 32 & “GRAE-1917 en las compilaciones" & 2. $(2.3 .30)$. & 96 \\
\hline Cuadro 33 & “GRAE-1920 en las compilaciones" & 2. $(2.3 .31)$. & 97 \\
\hline Cuadro 34 & "GRAE-1924 en las compilaciones" & 2. $(2.3 .32)$. & 98 \\
\hline Cuadro 35 & "GRAE-1928 en las compilaciones" & 2. $(2.3 .33)$. & 99 \\
\hline Cuadro 36 & “GRAE-1931 en las compilaciones” & 2. $(2.3 .34)$. & 100 \\
\hline Cuadro 37 & "Diccionario vs. Gramática" & 4 (4.2.1., 2.) & 189 \\
\hline Cuadro 38 & "Definición de gramática en los Diccionarios" & 4 (4.2.1., 2.1.) & 193 \\
\hline Cuadro 39 & "Definición de gramática en las Gramáticas" & $4(4.2 .1 ., 2.1)$. & 194 \\
\hline Cuadro 40 & $\begin{array}{l}\text { "Partes de la Gramática (disciplina) y de la Gramática } \\
\text { (libro)" }\end{array}$ & 4 (4.2.1., 5.) & 229 \\
\hline Cuadro 41 & "Sintaxis vs. Construcción en los Diccionarios" & $5(5.1 .3)$. & 272 \\
\hline Cuadro 42 & “Sintaxis =/\# Construcción en los Diccionarios?” & $5(5.1 .4)$. & 275 \\
\hline Cuadro 43 & "Lema régimen" & 5 (5.2.1.) & 283 \\
\hline
\end{tabular}


Cuadro 44

"Componente lineal-funcional del régimen en los Diccionarios"

Cuadro 46

Cuadro 47

Cuadro 48

Cuadro 49

Cuadro 50

Cuadro 51

Cuadro 52

Cuadro 53

Cuadro 54

Cuadro 55

Cuadro 56

Cuadro 57

Cuadro 58

Cuadro 59

Cuadro 60

Cuadro 61

Cuadro 62

Cuadro 63

Cuadro 64

Cuadro 65

Cuadro 66

Cuadro 67

Cuadro 68

Cuadro 69

Cuadro 70

Cuadro 71

Cuadro 72

Esquema 1 "Método geométrico en la GRAE-1854"

Esquema 2 "Proceso de enseñanza-aprendizaje por niveles"

Esquema 3

Esquema 4

Esquema 5

Esquema 6

DRAE del XIX"

"Lema concordancia"

"Tratamiento del régimen en los DRAE y en el Vocabulario de Monlau"

"Conjunción y Preposición en los Diccionarios"

"Cambios en la definición de sintaxis (GRAE-1771, 1796 y 1854)"

"Distribución de contenidos sintácticos en la GRAE-1771"

"Distribución de contenidos sintácticos en la GRAE-1796"

"Papel de la preposición"

"Papel de la conjunción"

"Casos de Adyacente del Nombre en el apartado de Construcción"

"Casos de Adyacente del Adjetivo (y participio) en el apartado de Construcción"

"Casos de Predicado Nominal -Atributos- en el apartado de Construcción"

"Casos de Perífrasis verbales en el apartado de 6 (6.2.2.2.) Construcción"

"El concepto de caso y la concordancia Sustantivo-Adjetivo en las GRAE publicadas entre 1771 y 1916"

"Tratamiento de la conjunción en las GRAE publicadas entre 1854 y 1916"

"Tratamiento de la conjunción en las GRAE publicadas entre 1854 y $1916 "$

"Tipología de complementos en la doctrina de 1870"

"Tipología oracional en la doctrina de 1854"

“Tipología oracional en la doctrina de 1870"

$6(6.2 .3 .2$.

5 (5.3.)

6 (6.1.4.)

6 (6.1.4.)

6 (6.1.4.)

$6(6.2 .1 .2$.

$6(6.2 .1 .2$.

$6(6.2 .2 .2$.

$6(6.2 .2 .2$.

$6(6.2 .2 .2$.

"Teoría de la oración en las GRAE publicadas entre 1854 y 1916"

“Verbo reflexivo vs. Verbo recíproco en Cejador (1905) y la GRAE-1917"

$6(6.2 .4 .1$.

$6(6.2 .4 .2$.

$6(6.2 .5 .2$.

$6(6.2 .5 .2$.

$6(6.2 .5 .2$.

$6(6.2 .5 .2$.

6 (6.3.2.)

"Verbo unipersonal vs. Verbo impersonal en Cejador (1905) y la GRAE-1917"

"Sistema de complementaciones en la GRAE-1917"

"Sistema de oraciones en 1870 y 1917"

$6(6.3 .2$.

6 (6.3.2.)

$6(6.3 .2$.

"Coordinación de oraciones en Cejador (1905) y la GRAE- 6 (6.3.2.) 1917"

"Equivalencia oración simple oración compuesta"

6 (6.3.2.)

$6(6.3 .2$.

(1902), Cejador (1905) y la GRAE-1917"

"Partes de la disciplina gramatical"

"División de la Sintaxis en la GRAE-1771"

"División de la Sintaxis en la GRAE-1796"

"División de la Sintaxis en la GRAE-1854"

$\begin{array}{ll}4 \text { (4.2.1., 1.1.) } & 166 \\ 4(4.2 .1 ., 1.1 .) & 171 \\ 6(6.1 .1 .) & 323 \\ 6(6.1 .3 .) & 349 \\ 6(6.1 .3 .) & 349 \\ 6(6.1 .3 .) & 352\end{array}$

284

292

296

297

301

304

362

374

$375-$

376

476

480

495

498

502

505

525

534

541

573

576

577

579

$620-$

621

623

631

633

641

642

645 
Esquema 7 "División de la Sintaxis en la GRAE-1870"

$6(6.1 .3) \quad$.

Esquema 8 "División de la Sintaxis en la GRAE-1880"

$6(6.1 .3) \quad$.

Esquema 9 "División de la Sintaxis en la GRAE-1917"

6 (6.1.3.) $\quad 355$

Esquema 10 "Sistema de dependencias en oraciones con más de un

$6(6.2 .2 .1$.

Esquema 11 "Criterios complementarios de clasificación de las 6 (6.2.5.2.) oraciones en la doctrina de 1870"

Gráfico 1 "Peso relativo de los capítulos del libro"

6 (6.1.1.) $\quad 328$

Gráfico 2 "Peso relativo del estudio sintagmático y paradigmático dentro de los contenidos morfosintácticos"

Tabla 1 "Algunos estudios sobre las GRAE"

2. (2.4.) 104

Tabla 2 "Las Gramáticas del siglo XVIII"

2. (2.4.) 105

Tabla 3 "Las Gramáticas del siglo XIX"

2. (2.4.) 106

Tabla 4 "Las Gramáticas del siglo XX"

2. (2.4.) 107

Tabla 5 "Sistema de regencias en la GRAE-1854"

Tabla 6 "Sistema de regencias en la GRAE-1870"

6 (6.2.1.2.) $\quad 405$

6 (6.2.1.2.) $\quad 406$ 


\title{
ÍNDICE DE SIGLAS Y ACRÓNIMOS
}

\author{
AEF Anuario de Estudios Filológicos \\ AJIHLE Asociación de Jóvenes Investigadores de Historiografía e Historia de la \\ Lengua Española \\ ALH Anuario de Lingüística Hispánica. \\ ALM Anuario de Letras de México. \\ ARAE Archivo de la Real Academia Española. \\ BAC Biblioteca de Autores Cristianos. \\ BFUCh Boletín de Filología de la Universidad de Chile. \\ BL British Library. \\ http:/ / www.bl.uk/ \\ BNE Biblioteca Nacional Española. \\ http://www.bne.es/ \\ BNF Bibliothèque Nationale de France. \\ http:/ / www.bnf.fr/ \\ BNM Biblioteca Nacional de México. \\ http://www.bibliog.unam.mx/nbib/ \\ BRAE Boletín de la Real Academia Española. \\ CCFr Catalogue Collectif de France. \\ CRAE Compendio de la Real Academia Española. \\ CSIC Centro Superior de Investigaciones Científicas. \\ DRAE Diccionario de la Real Academia Española. \\ ELiEs Estudios de Lingüística del Español. \\ ELUA Estudios de Lingüística Universidad de Alicante \\ ERAE Epítome de la Real Academia Española. \\ GRAE Gramática de la Real Academia Española. \\ HEL Histoire Épistémologie Langage \\ HL Historiographia Lingüística. \\ LEA Lingüística Española Actual. \\ LLC La lengua de Cervantes. Gramática y diccionario de la lengua castellana en "El \\ ingenioso hidalgo don Quijote de la Mancha". \\ NTLLE Nuevo Tesoro Lexicográfico de la Lengua Española. \\ RAE Real Academia Española \\ REBIUN Red de Bibliotecas Universitarias. \\ http:/ / rebiun.crue.org/ \\ REL Revista Española de Lingüística. \\ RSEL Revista de la Sociedad Española de Lingüística. \\ SEHL Sociedad Española de Historiografía Lingüística \\ SGEL Sociedad General Española de Librería. \\ TH Thesaurus (Boletín del Instituto Caro y Cuervo). \\ TL Travaux de Linguistique
}




\section{I}

\section{PRELIMINARES}

El estudio y el conocimiento del lenguaje actual debe presuponer más ó menos clara y directamente el estudio y el conocimiento que hicieron sobre su propio lenguaje las generaciones que nos precedieron.

La Viñaza (1893: Advertencia: v) 

1.

\section{INTRODUCCIÓN}

Desde las últimas décadas del siglo XX, tanto el concepto de oración como el de oración compuesta y/o compleja han suscitado un interés creciente entre los estudiosos de la lengua y han sido analizados desde diversas perspectivas y metodologías ${ }^{1}$. El volumen colectivo editado por Hernández Paricio (1994a) constituye una buena muestra de la amplitud y disparidad de puntos de vista que, a modo de teselas de un mosaico, ofrece la comunidad científica dedicada al estudio de este objeto común.

Abordar un análisis pormenorizado de las llamadas oraciones subordinadas (tradicionalmente entendidas como subtipos de oración compuesta) no es tarea fácil, ya que exige delimitar con exactitud dos de los conceptos más problemáticos de la Sintaxis: oración y subordinación, a juzgar por los numerosos estudios monográficos publicados y la diversidad de opiniones que han suscitado entre nuestros más reconocidos gramáticos y lingüistas. Hasta tal punto conforman una parcela "rebelde" dentro de los estudios

${ }^{1}$ Los estudios de Álvarez (1999), Álvarez Martínez (1987), Báez San José (1972, 1974 y 1987), Blesa (1984), Boone (1994), Brucart (1994), Callas y Caragnon (2002), Carrillo Herrera (1963), Delbecque y Lamiroy (1999), Devís Márquez (1994 y 1997), Díaz (1994), Fernández Leborans (1992), Ferrer Torres (2002), Ferreres Maspla (1983), Flamenco García (1999), Fuentes Rodríguez (1985), Galán Rodríguez (1992 y 1999), Gardes Tamine (2003), Gómez Asencio (1987), González Calvo (1989, 1991 y 1998), González Escribano (1990), González Monllor y Bautista García (2004), González Ramírez (2003), Gutiérrez Ordóñez (1994a, 1994b, 1997a [1994], 1997b y 1999), Hernández Alonso (1980), Hernández Paricio (1994b), Herraiz Gallego (1999), Herrero (1992), Herrero Ruiz de Loizaga (1990), Isbăşescu Hăulică (1981), Jiménez Juliá (1992, 1994 y 1995), Lavacchi y Nicolás Martínez (1994), Le Goffic (1993), Le Men (1992), Leeman (2002), Léon (2003), Leonetti (1999), Lope Blanch (1979a, 1979b y 1981), López García (1994a, 1994b y 1999), Martínez (1996 [1994]), Martínez Álvarez (2002), Molina Redondo (1985 y 1997), Montolío Durán (1991 y 1999), Moreno de Alba (1979), Moya Corral (2002), Myre (1992), Narbona Jiménez (1989 y 1990), Osuna García (2007), Pellizza (2000), Peñalver Castillo (2002), Porroche Ballesteros (1994), Porto Dapena (1997), Quereuil (1996), Rivarola (1981), Rojo (1978), Suñer (1999), Val Álvaro (1994) y Vera Luján (1981 y 1989), entre otros, pueden servir de ejemplo. 
gramaticales que no ha faltado quien llegue a la conclusión, cuando menos sorprendente, de que «la oración subordinada no es ni oración ni subordinada» ${ }^{2}$, postura que evidencia las zonas en sombra que todavía hoy existen en el campo de la investigación morfosintáctica.

Las palabras con que Boone (1994: 9) abre el número monográfico de TL dedicado a la subordinación dan cuenta de la heterogeneidad de este tipo de estructuras y de las dificultades que plantea su estudio:

Si la subordination continue à susciter l'intérêt des chercheurs, c'est sans aucun doute parce qu'elle focalise un certain nombre de problèmes syntaxiques et sémantiques cruciaux [...] Les «propositions subordonnées» forment un ensemble hétérogène que les grammaires traditionnelles ne parviennent pas à délimiter de façon rigoureuse.

En este trabajo de investigación, haciéndome eco de las palabras de la Real Academia Española en el Prólogo de su primera Gramática³, parto de la idea de que entender la Gramática de una lengua, su porqué, ayuda a entender la propia lengua, en la cual se amalgaman aspectos formales ${ }^{4} \mathrm{y}$ semánticos, orales y escritos, normativos y "desviados", pasados y presentes. De ahí que considere imperativo básico, para el cabal entendimiento de este "submundo oracional", remontarnos al momento en que surge entre nuestros gramáticos el concepto de subordinación, analizar el contexto de su gestación y

\footnotetext{
2 Gutiérrez Ordóñez (1999: 60).

3 Conocian [los griegos y los romanos] la utilidad y necesidad del uso; pero conocian tambien que convenia perfeccionarle con el arte.

Lo mismo debemos nosotros pensar de nuestra lengua, en la qual hallamos que observar cada dia cosas nuevas por medio de la Gramática [...] Ella nos hace ver el maravilloso artificio de la lengua [...]
}

(GRAE-1771: II. El subrayado es mío)

\footnotetext{
4 En el sentido amplio de hechos morfológicos y sintáctico-colocacionales. En adelante, por "formales" se entenderá, en este trabajo, sólo lo relativo a cuestiones morfológicas.
} 
el uso que hicieron de él los primeros autores que lo acogieron para construir una base a partir de la cual poder hacer una proyección hacia el presente y futuro inmediato: ¿cuál ha sido la suerte del término y de la noción en la historia de nuestra Gramática?

Las páginas que siguen constituyen un estudio de historiografía gramatical que, parcialmente, podría servir de pórtico a una nueva propuesta de estudio de las oraciones subordinadas del español. Parto de la convicción de que el estudio historiográfico puede dar luz a algunas confusiones que hoy entorpecen la investigación lingüístico-gramatical, si no para resolverlas, al menos sí para comprender su alcance y su origen ${ }^{5}$. Y entiendo como un hecho evidente que la delimitación del concepto de subordinación es uno de los

5 Quizá esta convicción generalizada entre los investigadores de la lengua explica la proliferación de estudios de carácter histórico e historiográfico que se está dando en las últimas décadas. Parece que, efectivamente, entre los estudiosos de la Gramática -en particular- y de la lengua -en general- se impone cada vez con más fuerza la idea de que «mantenerse dentro de los cauces tradicionales bien probados puede ser garantía de acierto y aun de progreso -por cuanto que "el pasado es prólogo"-», palabras de Lope Blanch (1981: 30) recogidas algunos años después por Ramón Sarmiento (1989: 420). El testimonio de Taboada Cid (1984: 9) es bastante representativo de lo que digo: «Parece como si el conocimiento del pasado gramatical atrajese los minuciosos ojos de los investigadores para comenzar a descubrir si no teorías "novedosas", sí, por lo menos, insinuaciones e intuiciones gramaticales importantes que, además, permiten trazar las líneas maestras de nuestra historia gramatical». Y es que «no todo es tradición; no todo es aceptación de las técnicas de descripción y explicación gramaticales procedentes del mundo clásico». A finales de 1991, en una ponencia pronunciada en el Simposio Internacional de Investigadores de la Lengua Española, publicada años más tarde en un volumen monográfico sobre Estudios de Lingüística, Bosque (1997) ponía el acento en la atención preferente que muchas universidades españolas estaban prestando a la historia de nuestra tradición gramatical. Destacaba entre los frutos de la corriente "en boga" algunos estudios de conjunto de periodos concretos que hoy son puntos de referencia obligados en cualquier análisis gramaticográfico: los pioneros de Gómez Asencio (1981 y 1985) y los que los siguieron de Calero Vaquera (1986) y Ramajo Caño (1987), así como varios de los estudios sobre la gramática académica de los que aquí daremos cuenta (Sarmiento, 1978, 1979 y 1981; Taboada Cid, 1981; Domínguez Caparrós, 1986). En el mismo volumen, Esparza (1997) señalaba la historiografía lingüística como parcela de estudios que estaba experimentado un notable crecimiento, del cual ya eran reflejo en 1997 los numerosos trabajos publicados y las sociedades científicas y revistas/colecciones especializadas que promovían buena parte de las investigaciones. Desde 1997, se ha consolidado la entonces "recién nacida" Sociedad Española de Historiografía Lingüística (SEHL) y han nacido y crecido otras como la Asociación de Jóvenes Investigadores de Historiografía e Historia de la Lengua Española (AJIHLE). El número de tesis doctorales vinculadas a este campo de estudios sigue aumentando y los congresos periódicos de las dos sociedades más representativas cuentan en cada convocatoria con más asistentes y nuevos socios. 
grandes debates que nos ha legado el siglo $X X$, sin que podamos hablar aún de consenso entre los estudiosos, a pesar de las numerosas contribuciones (algunas muy serias y acertadas) que se han hecho en este campo específico de la investigación gramatical en los últimos tiempos.

\subsection{Corpus central}

Para llevar a cabo la investigación que presento en estas páginas, me he valido de un corpus básico que comprende las ediciones decimonónicas de la Gramática de la Real Academia Española (en adelante, GRAE) y las del primer cuarto del siglo XX. Este estudio de gramaticografía se centra, por tanto, en la evolución del concepto de subordinación (necesariamente precedido de la evolución de los conceptos de sintaxis y de gramática) dentro de la tradición gramatical de la RAE. La propuesta de análisis que aquí presento es susceptible de ampliación a la tradición no académica.

Sabido es que la doctrina sintáctica defendida por la Real Academia Española en su Gramática experimenta un giro radical en la edición de 1917, y que en el cambio es, precisamente, el concepto de subordinación el que cobra por primera vez protagonismo dentro de las páginas dedicadas a la Sintaxis. Conocer con detalle el camino que condujo a la nueva concepción, así como las posibles razones del cambio y los nombres que lo hicieron posible ha sido el objetivo de esta tesis doctoral.

No son pocos los autores que han dedicado páginas a la Gramática de la RAE, bien desde una perspectiva englobadora de varias de las ediciones, bien centrando la atención en algún texto concreto. La historia externa de elaboración de la edición princeps (1771) y los pormenores de publicación de 
distintas ediciones (sobre todo, las dieciochescas) ${ }^{6}$, la filosofía inspiradora de algunos de los libros $(1771,1854$ y 1870) o del conjunto de la GRAE7, la información contenida en los prólogos ${ }^{8}$, el tema del cuidado de la lengua a lo largo de la tradición académica9', la evolución de ciertas cuestiones de morfología ${ }^{10} \ldots$ han sido asuntos abordados con solvencia por estudiosos que han tratado monográficamente sobre la Gramática institucional. Tampoco han faltado autores que han atendido de forma más tangencial la GRAE, en estudios generales de época, en análisis de carácter comparativo entre algunas de las ediciones y textos coetáneos, o en reseñas ${ }^{11}$. La evolución del concepto de gramática ha sido recientemente el tema central del discurso de ingreso en la Real Academia de Salvador Gutiérrez Ordóñez (2008)12. En los apartados oportunos, volveré a referirme a los trabajos citados y a otros.

Mención especial merecen los análisis llevados a cabo por Martínez Linares (2006) y Rojo (2001), centrados, respectivamente, en la concepción sintáctica defendida por la Institución en tres ediciones del siglo XIX (1866, 1880 y 1888) y en la configuración del capítulo dedicado a la Sintaxis en las ediciones primera (GRAE-1771) y cuarta (GRAE-1796). También es de obligada mención el artículo de Iglesias Bango (1999), en el que se apunta una posible fuente de inspiración de la reforma de 1917. Los tres estudios los he tenido especialmente en cuenta a la hora de redactar este trabajo.

6 Uruburu Vidaurrázaga (1975), Domínguez Caparrós (1976), Sarmiento (1977a, 1983), Taboada Cid (1981 y 1991).

7 Rabanales (1965), Domínguez (1969), Seco (1973), Sarmiento (1978, 1979, 1981, 1984 a y b, 1986, 1997), García Pérez y Hoyos Puente (1999), Hernando García-Cervigón (2002).

8 Gómez Asencio (2000 a y b, 2002 a y b) y Ramajo Caño (2002).

${ }^{9}$ Fries (1989).

${ }^{10}$ Hernando García-Cervigón (2004 y 2006).

${ }^{11}$ Mourelle Lema (1968), Gómez Asencio (1981), Lázaro Mora (1981), Martínez Gavilán (1984), Abad Nebot (1986), Calero Vaquera (1986), Martí Sánchez (1988), Ridruejo (1989), Vázquez Rozas (1990), Niederehe (1997), Pons Bordería (1997), Hernando García-Cervigón (2003).

${ }_{12}$ Por estar prácticamente concluida la redacción de esta tesis en la fecha de su discurso (28 de febrero de 2008), no he podido tener en cuenta sus atinadas reflexiones. No obstante, algunas de las ideas que expone sobre el arte gramatical son tratadas en el capítulo 4 de este trabajo. La referencia del discurso la facilito en la bibliografía final. 
El hecho de centrar mi análisis en la obra institucional responde a un deseo de contribuir a un mejor conocimiento de la doctrina gramáticosintáctica de nuestra Real Academia, de la que tanto se ha hablado y de la que tanto queda por decir. Al objetivo de profundizar en el conocimiento de los textos académicos y al de hacer una evaluación conjunta y, a la vez, detallada (en los asuntos acotados) responde la selección del corpus, que abarca todas las ediciones de la Gramática publicadas entre 1854 (edición con la que se inaugura la doctrina decimonónica de la Corporación) y 1924 (edición que sigue inmediatamente a las dos reformas doctrinales de mayor envergadura en el seno de la Academia: la reforma sintáctica de 1917 y la reforma morfológica, que culmina en 1920).

Para mi análisis, hice una primera jerarquía de las ediciones en función de datos "externos" de cada libro que conducían a suponerlos como textos más o menos novedosos respecto de los precedentes. Aquellas ediciones presumiblemente más relevantes desde el punto de vista de la "innovación" doctrinal (marcadas en negrita en la lista que doy a pie de página) ${ }^{13}$ recibieron el rango de ediciones-jalón (J): son las que se presentan en portada como “nuevas ediciones" según el registro que de ellas hace Cotarelo y Mori (1928: 39-41). Siguiendo este criterio, las ediciones de 1854, 1870, 1880 y 1904 se perfilaban, en un primer momento, como los jalones previos a la reforma de 1917. Sin embargo, no eran estas las únicas Gramáticas presentadas en la portada como "nuevas ediciones", ni tampoco, en unas primeras calas,

${ }^{13}$ GRAE-1854 (5. ${ }^{\text {a }}$ edición -primera del siglo XIX-), GRAE-1858 (6. ${ }^{\mathrm{a}}$ edición), GRAE-1862 (7. ${ }^{\mathrm{a}}$

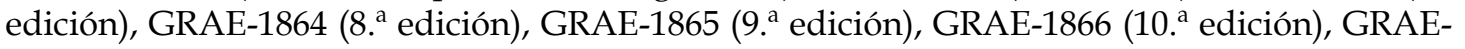
1867 (11. ${ }^{a}$ edición), GRAE-1870 (12. ${ }^{a}$ edición), GRAE-1874 (13. ${ }^{a}$ edición), GRAE-1878 $\left(14 .{ }^{a}\right.$ edición), GRAE-1880 (15. a edición), GRAE-1883 (16. ${ }^{a}$ edición), GRAE-1885 (17. a edición), GRAE-1888 (18. a edición), GRAE-1890 (19. a edición), GRAE-1895 (20. a edición), GRAE-1900 (21. a edición), GRAE-1901 (22. ${ }^{a}$ edición), GRAE-1904 (23. ${ }^{a}$ edición), GRAE-1906 (24. ${ }^{a}$ edición), GRAE-1908 (25. ${ }^{\text {a }}$ edición), GRAE-1909 (26. ${ }^{\text {a }}$ edición), GRAE- 1911 (27. a edición), GRAE-1913 (28. a edición), GRAE-1916 (29. a edición), GRAE-1917 (30. a edición) , GRAE-1920 (31. a edición), GRAE-1924 (32. ${ }^{\text {a edición). }}$ 
revelaban las cuatro el mismo grado de innovación. Es por ello que decidí hacer distinción entre tres tipos de versiones: las de rango J (que suponen un cambio general de modelo), rango E (que presentan cambios, pero mantienen el espíritu de la edición J precedente) y rango $\mathrm{R}$ (que debemos entenderlas como reimpresiones -ya idénticas al texto inmediatamente anterior, ya con mínimas modificaciones de redacción, puntuación, etc.-), en función de la declaración de principios doctrinales con que es presentado cada libro, así como de cuestiones de macroestructura y de calado teórico, y al margen de que la portada rece o no "nueva edición", lo cual, en algunos de los textos, parece interpretarse como consecuencia de que la copia (o el calco) de la edición anterior se hizo extensivo también a la primera página. En el capítulo 2, atenderé con detenimiento a todas las ediciones de la GRAE y daré cuenta de la jerarquización que puede establecerse.

\subsection{Corpus secundario}

Para llevar a cabo un análisis en profundidad de las ideas gramaticales de la Real Academia Española, he considerado necesario acudir también a un corpus auxiliar, pero no por ello poco significativo: los Diccionarios académicos del siglo XVIII (en cuanto textos que asientan los principios gramaticales vertidos en la tradición lexicográfica académica) y los del XIX y principios del XX (sobre todo, los estrictamente coetáneos de las Gramáticas del corpus primario -marcados en negrita en la lista de abajo-).

En un primer momento, descarté de la selección los cinco diccionarios que menos interés podían tener:

- La segunda edición del primer tomo de Autoridades (1770). 
- El DRAE-1783 (puesto que el siglo XVIII quedaba bien representado con Autoridades, el primer Diccionario reducido -1780- y el último de la centuria -1791-).

- Los DRAE de 1822 (6. ${ }^{\mathrm{a}}$ ed.), 1832 (7. . ed.) ${ }^{14}$ y 1837 (8. ${ }^{\mathrm{a}}$ ed.), los tres que median entre el DRAE-1817 y el DRAE-1843 (ya que, para la primera mitad del siglo XIX, al igual que para el siglo XVIII, lo más interesante parecía ser contar con el primer Diccionario de la centuria, con el último de la primera mitad -el inmediatamente anterior al período de mayor interés- y con uno intermedio).

En aquellos casos en que constaté que los cambios con respecto a las primeras ediciones del XIX se iniciaban a lo largo de la segunda mitad del siglo, no se hizo necesaria la consulta de las ediciones que quedaron fuera de la primera selección, pero sí lo fue cuando se observaba un cambio entre el DRAE-1817 y el de 1843, para poder asegurar si el giro lo marcaba el último Diccionario de la primera mitad o alguno de los anteriores. Fue en esos casos en los que recurrí al Nuevo Tesoro Lexicográfico de la Lengua Española (en adelante, NTLLE) para consultar las ediciones que descarté en un principio (sombreadas en la lista de abajo). Con el fin de mantener un sistema unitario, en el Glosario final he incluido, para todas las voces recogidas, todas las ediciones de los DRAE publicados entre 1780 y 1925.

Los libros consultados son, por tanto, los que siguen:

口 Del XVIII:

\section{Autoridades}

\footnotetext{
${ }^{14}$ En el catálogo de Cotarelo y Mori (1928: 37), encontramos un error en la datación inicial de este Diccionario (1823 por 1832). No dudo de que se trate de una errata de imprenta y no de una datación equivocada por parte del compilador, puesto que cuatro líneas más abajo aparece la fecha correcta (1832).
} 
DRAE15-1780 (1. ${ }^{\text {a }}$ edición)

DRAE-1783 (2. ${ }^{\text {a }}$ edición)

DRAE-1791 (3. a edición)

๑ Del XIX:

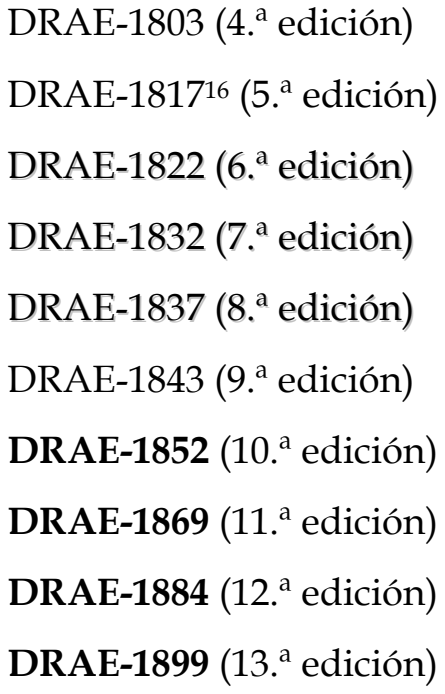

口 Del XX:

DRAE-1914 (14. a edición)

DRAE-1925 (15. ${ }^{a}$ edición)

Asumo, en esta investigación, que las ideas sintácticas (así como las ideas gramaticales en general) que la Academia decide recoger en el Diccionario de Autoridades, obra inaugural de su tradición lexicográfica y de toda su aportación al estudio de la lengua española, son ideas base, conceptos aceptados por la Corporación como pilar sobre el cual se montará la teoría

15 Llamaré así a todas las ediciones del Diccionario de la Lengua castellana (a partir de 1925, española), publicado, en un solo tomo para su más fácil uso, por primera vez en 1780 y cuya última edición -la 23. ${ }^{a}$ en orden cronológico- data de 2005. Este Diccionario (1780-2005) también es conocido como Diccionario usual.

${ }^{16}$ En la portada de esta quinta edición del Diccionario de la Lengua Castellana, aparece la fecha de 1837. Se trata de una errata de imprenta que, en el ejemplar de la Sala de Investigadores de la RAE, alguien (probablemente más de una persona, a juzgar por los tipos de letra que aparecen) intentó subsanar, sustituyendo el año impreso, sucesivamente, por el de 1914 y 1887. Ambas fechas aparecen hoy tachadas y, en su lugar, consta la de 1817, año con el que Cotarelo y Mori (1928: 37) data esta quinta edición. 
sintáctica (y gramatical) defendida en toda la obra académica posterior (y de forma desarrollada, en los libros de Gramática). Las ideas expuestas en esta primera obra institucional se recogerán posteriormente (¿con modificaciones? Tendremos que verlo) en los Diccionarios de Uso.

Parto de la hipótesis de que, desde el punto de vista doctrinal, se da un paralelismo y una interrelación entre las Gramáticas y los Diccionarios académicos. Varios aspectos justifican esta idea:

1. La propia Academia cita, entre sus fuentes de inspiración primarias para la elaboración de la primera Gramática (la GRAE-1771), el Diccionario publicado por la propia Institución ${ }^{17}$. Sus palabras son las que siguen:

Oxalá que como es fácil probar la utilidad de la Gramática lo fuese su composicion! [...] Conociendo esta dificultad se ha valido la Academia para componer esta Gramática [la de 1771] de las que han publicado otros autores propios y estraños: de un considerable número de disertaciones que han compuesto sus individuos: $\underline{\text { del }}$ copioso caudal que encierra el Diccionario [...]

(GRAE-1771: V-VI. El subrayado es mío)

2. La definición (o, en su defecto, explicación) que el lexicógrafo da a un lema que lleva la marca Gram., así como el propio hecho de marcar (o no) como gramatical un determinado lema, supone (o suele suponer) haber optado por un modo determinado de concebir la Gramática ${ }^{18}$. El

\footnotetext{
17 Esto es, el Diccionario de la lengua castellana, en que se explica el verdadero sentido de las voces, su naturaleza y calidad, con las phrases o modos de hablar, los proverbios o refranes, y otras cosas convenientes al uso de la lengua o Diccionario de Autoridades (1726-1739), y la segunda edición del mismo, de la que solo vio la luz el primer tomo -letras A y B-: Diccionario de la lengua castellana compuesto por la Real Academia Española. Segunda impresion corregida y aumentada. Tomo primero. A-B (1770).

18 A esto se añade el hecho de que un artículo lexicográfico requiere brevedad en las exposiciones $(\mathrm{o}$, al menos, mucha más brevedad que una gramática, cuyos corsés son más
} 
lexicógrafo parte, en definitiva, de una teoría gramatical (y, por tanto, morfológica y sintáctica) que sirve de sustento al Diccionario.

3. Gramática y Diccionario son obras de índole distinta pero complementaria; ambos $-\mathrm{y}$ esto es especialmente evidente en la Gramática y el Diccionario académicos- son textos corporativos, de consenso, de carácter pedagógico-normativo y, en cierta proporción, también descriptivo ${ }^{19}$. Es de suponer que esta coincidencia de concepción, de finalidad y de naturaleza conllevará, si no planteamientos exactamente idénticos, al menos sí una similitud de propuestas teóricas.

\subsection{Propósitos}

Las pretensiones del estudio que presento en las páginas que siguen son puramente filológicas (esto es, de cotejo de textos) y gramaticográficas (de contribución a la historia de los conceptos gramaticales ${ }^{20}$ ). Desde esta perspectiva, los libros académicos se contrastarán entre sí para observar la evolución doctrinal de la Institución en lo tocante a los conceptos de gramática y sintaxis y al tratamiento de los hechos de subordinación o dependencia que tienen lugar en el seno de la oración (para ver si realmente hay cambios y en qué sentido), al tiempo que se evaluará el grado de proximidad o de alejamiento de los mismos con respecto a los textos gramaticales coetáneos (los más sobresalientes de la primera mitad del siglo XIX, como antecedentes inmediatos, y los de la segunda mitad del XIX y primeros años del XX), así como su filiación con la tradición gramatical española, para lo cual será

amplios); esta brevedad obliga a una síntesis de los aspectos más relevantes (lo más discutible, lo accesorio, lo de minucia, se reserva para el libro de Gramática).

19 En esto coincido con Alvar Ezquerra (1982 y 1997).

20 Intento asumir la labor que Tusón (1996) asigna al historiador de la lingüística, quien, como historiador de las ideas (en este caso, gramaticales), debe rastrear los esfuerzos de pensamiento que se han dado a lo largo de la historia, mirando "con los ojos de la época", es decir, teniendo en cuenta, en la medida de lo posible, el paradigma intelectual en el que se desarrolla una actividad científica en un determinado período (véase también Hernández y Morant, 1996). 
imprescindible el cotejo con los grandes hitos gramaticales de los siglos XV al XVIII y, por supuesto, los propios textos académicos del XVIII (los de 1771 y 1796, como los más importantes), que servirán de continuo punto de referencia y que, por ello, estarán también recogidos en el Glosario final.

En esta mirada retrospectiva, no solo he tenido que saltar -como no podía ser de otra forma- la barrera del siglo XIX y llegar hasta los primeros gramáticos del español, también ha sido necesario atender a algunas de las ideas contenidas en las gramáticas greco-latinas (aunque a los textos clásicos he tenido solo un acceso indirecto, a través de obras generales de consulta y traducciones al español).

Al deseo de profundizar en el conocimiento de la teoría gramáticosintáctica de la Real Academia Española a lo largo de su historia responde la selección del corpus: tipo de textos (Gramáticas y Diccionarios, cuya visión conjunta es de gran interés para trazar la trayectoria de la doctrina institucional) y período (centrado, principalmente, en la segunda mitad del siglo XIX y primer cuarto del XX, por cuanto se trata de una etapa atendida por los estudiosos de la RAE, pero no con la profundidad suficiente).

Tres son los bloques principales que articulan el cuerpo de este trabajo de investigación. El primero de ellos (bloque II) responde a la necesidad de establecer (y esclarecer) el número y tipo de ediciones que existen de la Gramática académica: la labor de registro llevada a cabo por los que he considerado "compiladores oficiales" y los apuntes dados por los principales estudiosos de estos libros han sido conjugados con el fin de tipificar, caracterizar y jerarquizar las distintas ediciones de la GRAE. El segundo bloque (III) presenta un análisis conjunto de la aportación lexicográfica y gramatical de la Academia en lo tocante al concepto de gramática. El concepto de sintaxis y el tratamiento de las relaciones sintácticas de dependencia han sido 
examinados en el tercer bloque temático (IV), en esta ocasión, por razones de metodología, separando Diccionarios y Gramáticas. La visión conjunta, en este caso, queda expuesta en las conclusiones generales. Por otra parte, el Glosario final ha sido concebido para facilitar la consulta comparada de la información contenida en los textos lexicográficos y gramaticales: la disposición en columnas (a la izquierda, Diccionarios; a la derecha, Gramáticas) permite trazar el recorrido cronológico de los cambios en los dos tipos de libros, al tiempo que permite visualizar en qué ediciones y en qué tipo de obra se introducen los cambios, y si, efectivamente, la doctrina defendida corre paralela en la Gramática y el Diccionario.

Tanto en el bloque III como en el bloque IV, he ido dando cuenta de los puntos de anclaje de la doctrina académica con la tradición gramatical hispánica, así como su conexión o separación respecto de las teorías defendidas por autores coetáneos de los textos del corpus. En el bloque IV, junto con el análisis de la concepción sintáctica y de los hechos sintácticos de subordinación, he pretendido dar luz al asunto sobre la autoría de la GRAE1917. La Corporación, a lo largo de su historia, ha sido poco generosa en información (pública) sobre los pormenores de redacción y publicación de las distintas ediciones de la Gramática (no así para lo relativo al Diccionario). Se da, además, la circunstancia de que incluso uno de los más profundos conocedores de lo que ha acontecido en la trastienda institucional desde la fundación de la docta Casa, don Alonso Zamora Vicente, solo destaca en su ingente Historia de la Real Academia Española la labor desempeñada por los encargados de redactar la GRAE-1771, pero no menciona la ocupación gramatical de los académicos comisionados para las ediciones posteriores. Este silencio ha generado durante tiempo especulaciones sobre quién pudo ser el artífice de la reformadísima doctrina de 1917: el nombre de gramáticos de la talla de Eduardo Benot, vinculado a la Corporación en fechas muy próximas, 
ha rondado en la mente de más de un investigador. ¿Será el gaditano el artífice o uno de los artífices del gran cambio?

El trabajo de investigación que aquí presento pretende ser una modesta contribución a la historia de los conceptos gramaticales de la RAE, en particular, y a la historia de la Gramática española, en general. $\left(^{*}\right)$ 


\section{II}

\section{LOS TEXTOS DEL CORPUS}

Pero si las corporaciones viven, sus individuos desaparecen, y al cabo de dos o tres generaciones sólo queda la memoria confusa de lo que aquéllas hicieron, y sus trabajos yacen archivados en los legajos de sus secretarías o en las tablas de sus bibliotecas. Una especie de resurrección de tales memorias es lo que intenta ahora la Academia al presentarlas en forma visible y tangible de libros y folletos y ordenadas en las vitrinas de uno de sus salones.

Cotarelo y Mori (1928: 7) 



\subsection{Cuántas ediciones hay y cuáles son ${ }^{1}$}

\section{Siglo XVIII}

Las cuatro primeras ediciones de la Gramática académica vieron la luz en el último tercio del siglo XVIII (en los años 1771, 1772, 1781 y 1796, respectivamente). Estas cuatro son las ediciones dieciochescas de la GRAE reconocidas por nuestra tradición historiográfica ${ }^{2} \mathrm{y}$, oficialmente, por la propia Corporación durante más de dos siglos, si bien hay que mencionar dos ediciones no-oficiales: la edición “fantasma" de 1788 y la edición de 1793

El primer estudioso que llama la atención sobre una Gramática académica publicada en 1788 (que -de haber existido- correspondería cronológicamente a la cuarta edición) es Sarmiento (1977a y 1979), seguido de Taboada Cid (1981). Estos dos autores no dudan en aceptar una “GRAE”-1788

\footnotetext{
1 Para este punto, remito al estudio de Gómez Asencio y Garrido Vílchez (2005), donde se da cuenta del tipo y número de edición al que responde cada una de las GRAE. En adelante, este estudio será citado como Gómez Asencio (2005).

2 Son las cuatro aceptadas explícitamente por La Viñaza (1893), Cotarelo y Mori (1928), Palau y Dulcet (1948), Rabanales (1965), Mourelle-Lema (1968), Uruburu Vidaurrázaga (1975 y 1989), Domínguez Caparrós (1976), y Gómez Asencio (2002a, 2004 y 2005).

3 En esta investigación, utilizaré la sigla GRAE exclusivamente para las ediciones (o reimpresiones) que podemos entender como oficiales de cada periodo. Considero requisitos para la oficialidad, en orden de importancia: a) el reconocimiento explícito por parte de la Corporación; b) la publicación del texto por un editor de la RAE; c) la factibilidad de localización física del libro; y d) el registro por los compiladores de la obra académica.
} 
como cuarta impresión, lo que les lleva a afirmar que el texto de 1796 es, en orden de fechas, la quinta versión de la Gramática académica, no la cuarta:

La gramática de 1796 no es la cuarta impresión, sino la quinta, puesto que, si se tienen como ediciones las de 1772, 1781, no alcanzamos a ver razón alguna para que se excluya la de 1788.

(Sarmiento, 1979: 72, nota 21)

Si se considera la edición de 1781 como la "tercera impresión", a pesar de las leves variaciones que supone con respecto a la de 1771, no hay ninguna razón en contra para catalogar la de 1788 como la $4^{\mathrm{a}}$ impresión.

(Taboada Cid, 1981: 97)

En su tesis doctoral, Dagmar Fries (1989) incluye la reedición de 1788 en la bibliografía final, pero se limita a remitir al estudio de Sarmiento (1977a); no menciona esta supuesta Gramática en ninguna parte de su monografía sobre la Academia. Por su parte, Ridruejo (1989), en un análisis comparativo de los Rudimentos de gramática castellana de Jovellanos y la GRAE del siglo XVIII, demuestra haber leído de primera mano las cuatro ediciones oficiales y, aunque menciona esta "reimpresión sin modificación" de 1788, lo hace guiado -según sus propias palabras- por los datos de Taboada.

Años más tarde, Rojo (2001: 32) y -siguiendo a este- Gómez Asencio (2005: 596) han aludido a la posible existencia de una tirada de 1500 ejemplares, en ese año de 1788, en la que se habría mantenido la fecha de 1781 por no variar en nada respecto de la edición precedente. Igualmente se basan, en última instancia, en lo apuntado en su día por Sarmiento y Taboada Cid, pero aciertan en la prudencia de no afirmar la existencia de la presunta edición. 
En un libro de publicación más reciente, Hernando García-Cervigón (2006: 6 y 61) no solo se hace eco de la defensa hecha por Taboada Cid sobre una reimpresión en 1788, sino que incluye este texto entre las fuentes directas declaradas como corpus de su investigación. Sin embargo, no hay más mención a esta Gramática en todo el estudio.

El caso de la supuesta GRAE-1788 resulta bastante extraño, ya que la propia Academia habla solamente de las cuatro ediciones que nos son conocidas: en la Advertencia de las GRAE de 1870: XI, 1874: 5 y 1878: 5, la Institución declara que

en 1771 dió á la estampa la primera edicion de su Gramática, reimpresa luégo en $\mathbf{1 7 7 2}, 1781$ y $\mathbf{1 7 9 6}$, y repetidas veces tambien en el siglo actual [el XIX].

(La negrita es mía $)^{4}$

En realidad, para defender la existencia de una edición con fecha de 1788, Taboada Cid se basa en unas palabras que dan testimonio de la intención por parte de los académicos de sacar una nueva reimpresión en ese año, pero no acreditan que el propósito de la Corporación se llevara a cabo5:

\footnotetext{
${ }^{4}$ En estas palabras, se puede observar que la Academia usa indistintamente los términos reimpresión y edición. Los textos de 1772 y 1781 pueden considerarse reimpresiones (de hecho, se presentan en portada, respectivamente, como segunda y tercera impresión) a pesar de los ligeros cambios con respecto a la edición de 1771, de los que dio noticia detallada Uruburu Vidaurrázaga (1975) y después informó Taboada Cid (1981: 97-111). La GRAE-1796 se presenta como "edición corregida y aumentada" -numerada como cuarta- y es, en efecto, una versión distinta de la Gramática. De los cambios doctrinales que introduce la GRAE-1796 ya trató Domínguez Caparrós (1976: 85-102). En este trabajo, profundizaré en los cambios relativos a la concepción sintáctica, para lo cual tendré como estudios de base el discurso de Rojo (2001) y mi propio trabajo de grado (Garrido Vílchez, 2001a).

5 Sarmiento (1979) debe basarse en la misma declaración de intenciones, pero es Taboada quien facilita la referencia exacta de la fuente documental y quien reproduce las palabras del acta académica.
} 
Habiendose tratado de reimprimir la Gramática, teniendo presente la Academia, que si se aguarda á q.e se concluyan las correcciones q. e se estan haciendo, segun el corto numero q.e hay de exemplares, llegarian a faltar enteram.te acordó, que desde luego se haga una reimpresion sin alterar nada, y se tiren mil y quinientos exemplares.

(Libro 16 de Acuerdos, acta de 1 de julio de 1788)6

Creo que estas palabras no pueden interpretarse, en términos absolutos, como garantía de que, en efecto, se llevara a la práctica la "urgente" reimpresión de la Gramática en ese mismo año. La afirmación de que «cinco han sido las ediciones de la gramática de la RAE que han visto la luz durante el siglo XVIII: 1771, 1772, 1781, 1788 y 1796» (Taboada Cid, 1981: 97) resulta, por tanto, ligera y aventurada, en mi opinión, ya que no hay ninguna prueba determinante que demuestre que, efectivamente, existió la cuarta de las mencionadas:

$\left.1^{\circ}\right)$ La RAE habla, en los libros de Gramática, de cuatro ediciones en el XVIII y, además, la GRAE-1796 es presentada como cuarta edición, no como quinta (teniendo en cuenta que la Academia, hasta ese año, numera también las reimpresiones, según queda indicado en la nota 4). Esta última observación es para Rojo (2001: 32, nota 43) «buena prueba» de que, si llegó a realizarse, «fue una reimpresión en el sentido estricto del término» de la edición de 1781.

$2^{\circ}$ ) No hay rastro de la supuesta edición de 1788 en los fondos académicos (ni en la Biblioteca ni en el Archivo) ni en los de ninguna otra institución española, al menos que yo haya podido comprobar? ${ }^{7}$.

\footnotetext{
6 Ápud Taboada Cid (1981: 97).

7 No se encuentra en la RAE, en ninguna de las bibliotecas adscritas al CSIC ni en la BNE; tampoco en la BNF, en la BL ni en la BNM. El catálogo de REBIUN y el CCFr no la registran.
} 
$\left.3^{\circ}\right)$ No todos los estudiosos de la Gramática académica hacen mención de este texto, y los que se refieren a él (Fries, Ridruejo, Rojo y Gómez Asencio) no afirman su existencia, sino que se hacen eco de lo defendido por Sarmiento y Taboada, ninguno de los cuales aporta datos concretos que verifiquen la existencia de una edición de facto. Hernando GarcíaCervigón, por su parte, tampoco ofrece información determinante sobre este misterioso libro.

$4^{\mathrm{o}}$ ) El propio Taboada se contradice: asegura que «todas las ediciones están perfectamente documentadas», pero reconoce que no ha tenido acceso a ningún ejemplar de la de 1788 y que no está recogida en los compendios bibliográficos de La Viñaza, Cotarelo ni Palau y Dulcet. En el punto 2.3. y en los cuadros del Apéndice I, se puede comprobar que, efectivamente, ninguno de los tres compiladores da constancia de ella.

Puestas así las cosas, debemos pensar (con Rojo y Gómez Asencio) que, en el caso de haber sido reimpresa la Gramática en 1788, la Academia debió de optar por dejar la fecha de $1781^{8}$. De haber ocurrido así, no sería este un caso aislado: Vicente Salvá menciona una práctica similar a propósito de una edición del siglo XIX, caso que comentaremos más abajo.

Lo cierto es que la única pista sobre un libro "real" que pudiera responder a una posible quinta Gramática dieciochesca (que, colocada en orden, sería cuarta -pues lo único seguro es que precedería a la edición de 1796-) la dio Uruburu Vidaurrázaga en su Memoria de Licenciatura, presentada durante el curso académico 1974/1975 en la Universidad de Deusto. En su trabajo, consistente en la edición crítica de las tres primeras

No la he podido localizar en ningún sitio de internet y las librerías de viejo no disponen de ejemplares de esta supuesta edición.

${ }^{8}$ A esta misma conclusión llegué en mi trabajo de grado (Garrido Vílchez, 2001a: 9, nota 9). 
ediciones de la GRAE (1771 -modelo A de su investigación-; 1772 -modelo By 1781 -modelo $\mathrm{C}^{9}-$ ), da noticia sobre un cuarto modelo textual -que denomina D- del que concluye que debe entenderse como una tirada diferente del modelo C (lo cual vendría a apoyar la hipótesis que he defendido en el párrafo anterior). Uruburu ignora el año de la tirada, pues al ejemplar le faltan cinco hojas, incluida la portada, pero asegura que su texto coincide con el de los ejemplares de $\mathrm{C}^{10}$.

Hasta aquí, solo tenemos:

a) Un ejemplar incompleto (al que le falta la página que podría esclarecer la verdad sobre la existencia de una Gramática académica en 1788: la portada).

b) Y un texto que no es idéntico a $C$ pero que prácticamente coincide con él, con su esencia doctrinal. Por tanto, sin duda, un libro anterior a la GRAE1796 (primera edición que supone un cambio notable con respecto al texto de 1771).

Teniendo en cuenta que no es raro que de una misma edición (o reimpresión) se saquen varias tiradas (de la misma GRAE-1796 se hicieron, al menos, tres tiradas diferentes), seguimos sin poder afirmar la existencia de esa hipotética GRAE-1788 presupuesta por parte de la crítica. Quizá no sea demasiado aventurado imaginar que, si Sarmiento tuvo acceso al estudio de Uruburu -a pesar de no estar publicado en aquellos años- y vio las Actas de

\footnotetext{
${ }^{9}$ Es el modelo que considera más perfecto y en él se basa su edición crítica. Las variantes de A y B las anota a pie de página.

${ }^{10}$ La peculiaridad del texto reside, según este estudioso, en el mantenimiento del grupo culto -BS- y las abundantes erratas. Por otra parte, difiere de la GRAE-1781 en la distribución de las páginas (véase Uruburu Vidaurrázaga, 1975: XIV).
} 
1788, pudo dar por hecho que el ejemplar mutilado sería superviviente de la perdida edición.

Cuando quince años más tarde de su investigación se publica la edición crítica de Uruburu Vidaurrázaga, el propio autor afirma en el resumen inicial:

En la $4^{\text {a }}$ edición de la Gr. RAE (la de 1.796, que sería la $5^{\text {a }} \underline{\text { si se }}$ comprobara con claridad la existencia de algún ejemplar de la supuesta edición de 1.788) comprobé la existencia de tres tiradas diferentes $[\ldots]$.

(Uruburu Vidaurrázaga, 1989)

La afirmación es posterior a los estudios citados de Sarmiento y Taboada Cid. Dieciocho años después de estas palabras de Uruburu, no está comprobada con claridad la existencia de algún ejemplar de la supuesta edición de 1788.

$$
* * * *
$$

La Gramática de 1793 es también una reimpresión, pero sin numerar. En realidad, aunque se trata del texto académico, la reimpresión no se hizo en nuestro país ni corrió a cargo de la Real Academia Española, sino de la Real Sociedad Económica de la ciudad de Manila, según reza la portada. En la Sala de Investigadores de la RAE, se encuentra fotocopiada y encuadernada entre todas las ediciones de la Gramática, entre la de 1781 y 1796, con el número de registro 67059 y la signatura D 20-43811. En el catálogo informatizado de la Biblioteca también figura esta edición como “Gramática compuesta por la Real

${ }^{11}$ Frente a las ediciones oficiales del texto académico en el siglo XVIII, publicadas en $8^{\circ}$, esta Gramática aparece en $4^{\circ}$. 
Academia Española"12. Pero es evidente que no se trata de una edición oficial, puesto que solo cumple el tercero de los requisitos marcados en la nota 3.

\section{Siglo XIX}

El XIX es un siglo bastante fecundo en ediciones de la Gramática académica, no todas las cuales, sin embargo, pueden ser catalogadas como GRAE, es decir, como ediciones oficiales ${ }^{13}$. Sí lo son las dieciséis siguientes: $1854,1858,1862,1864,1865,1866,1867,1870,1874,1878,1880,1883,1885$, 1888, 1890 y 1895, que sumadas a las cuatro dieciochescas hacen un total de veinte ediciones publicadas por la Corporación al finalizar el siglo.

En cuanto a las ediciones decimonónicas, el texto que vio la luz en 1854 ha quedado registrado como la primera GRAE del siglo XIX. Es el primer texto publicado en el ochocientos que se presenta como "nueva edición". Sin embargo, entre 1796 y 1854 la Academia debió de dar varias veces a la imprenta su Gramática.

Amén de las supuestas cinco reimpresiones que la GRAE-1796 tuvo en el primer tercio del nuevo siglo, anotadas por Sarmiento (1977a: 89 y sigs.), y de las que se hacen eco Fries (1989: 189), Rojo (2001: 35) y Gómez Asencio (2005: 596)14, hay razones para afirmar que la de 1854 no fue la primera Gramática publicada por la Academia en esta centuria.

\footnotetext{
12 Puede comprobarse en la siguiente dirección electrónica: http://cronos.rae.es/Absys/, que corresponde a la página de búsqueda del fondo general de la Biblioteca de la RAE.

13 Recuerdo lo dicho en el capítulo 1: algunas de las ediciones que pueden llevar la etiqueta de "oficiales", en realidad, son una reimpresión de una versión anterior, independientemente de que se den a la estampa o no como "nuevas ediciones".

${ }^{14}$ Estas reimpresiones datan de 1800, 1802, 1817 (que coincide con la 5. a edición del DRAE), 1822 (que coincide con la 6. ${ }^{a}$ edición del DRAE) y 1831. No he conseguido confirmar la existencia de las cinco, pero sí pueden encontrarse ejemplares de la GRAE con el mismo pie de imprenta y distinta fuente tipográfica (los cuales, cuando menos, deben responder a distintas tiradas). Ya en Gómez Asencio (2005: 597) se advierte que «la Biblioteca General de la Universidad de Salamanca conserva cuatro ejemplares que presentan cuatro composiciones
} 
Si creemos la información que Vicente Salvá nos da repetidamente en el Prólogo de las distintas ediciones de su Gramática de la lengua castellana según ahora se habla, la Institución reprodujo una edición hacia 1821 (Salvá no habla de "reimpresión"), a la que, sin embargo, decidió dejar la fecha de 1796 por no variar en nada sustancial la doctrina expuesta en la cuarta edición -y última del siglo XVIII-15 (no parece forzado pensar que esta edición a la que se refiere pudiera ser la misma que la reimpresión de 1822 de la que habla Sarmiento) . Son las palabras de Salvá estas que siguen:

La misma Academia ha manifestado, con los deseos de mejorarla, la imposibilidad en que se ha visto de hacerlo, dejando en la edición que reprodujo hacia el 1821 la fecha de 1796 que llevaba la cuarta $^{16}$.

(Salvá, 1847 [1830]: 75)

Además de estas noticias indirectas sobre sendas publicaciones de la cuarta edición de la GRAE en cinco-seis años distintos comprendidos entre 1800 y 1831 (las cinco anotadas por Sarmiento y la indicada por Salvá) ${ }^{17}$, hay sobrada constancia de la existencia de una reproducción decimonónica del texto de 1796 con fecha de 1852, que se encuentra en la Sala de Investigadores de la Real Academia Española con la signatura 35-6-2 [R.35276] y de la cual

tipográficas diferentes, esto es, correspondientes a cuatro ediciones distintas con el mismo pie de imprenta».

15 A este caso es al que me he referido líneas más arriba como similar al de la edición "fantasma" de 1788.

${ }^{16}$ En todos los textos de la Gramática de Salvá comprendidos entre la edición cuarta -1839- y la octava -1847-, leemos estas mismas palabras. La noticia se da desde la primera versión, pero, en las ediciones primera $-1830-$, segunda -1835 - y tercera $-1837-$, encontramos ligeros cambios de redacción con respecto a la cita reproducida. Los cambios están recogidos en Lliteras (1988: 75, nota 39).

17 A las que podríamos añadir la edición (no oficial) de 1812, publicada en Palma de Mallorca por la Imprenta Brusi. El libro aparece registrado en REBIUN (donde consta que la portada reza «quinta edicion corregida y aumentada» y en el CCFr. También puede localizarse en Iberlibro -Librería anticuaria Farré- (cf. www.iberlibro.com). 
informan Cotarelo y Mori (1928: 39), y Palau y Dulcet (1948: I, 39)18. También hacen referencia a ella Uruburu Vidaurrázaga (1989: IV), Fries (1989: 189), Rojo (2001: 35), Gómez Asencio (2005: 595 y 597) y Hernando García-Cervigón (2006: 61) ${ }^{19}$. A pesar de que se trata de un texto registrado por la Academia, aceptado por la crítica y de posible localización, hay dudas para considerarla una versión "oficial" en sentido riguroso, ya que la portada reza que se trata de la cuarta edición -la de 1796- (no es la quinta ni una nueva) ${ }^{20}$. Además, el marqués de Molins (1870: 31), director de la Corporación en la segunda mitad del siglo, en su memoria trienal de 1869, no recoge el libro de 1852 entre las ediciones de la Gramática publicadas por la Institución entre 1847 y 1869. Hasta ese año, oficialmente se reconocen como GRAE las ediciones con fecha: $1854\left(1 .^{a}\right.$ ed. de la centuria ), $1858\left(2 .^{a}\right), 1862\left(3 .^{a}\right), 1864\left(4 .^{a}\right), 1865\left(5 .^{a}\right), 1866\left(6 .^{a}\right)$

18 Para la referencia exacta, véase la bibliografía final. En el cuadro del punto 2.3. relativo a la GRAE-1796 (Cuadro 6) y los del Apéndice I, transcribo la información que sobre esta Gramática ofrecen los dos compiladores.

${ }^{19}$ Este libro de 1852 no figura en los fondos de la BNE ni del CSIC. En el catálogo de REBIUN aparece un registro correspondiente a la Universidad de Santiago de Compostela, en cuya Biblioteca General aparece con la signatura RSE 3267 (el ejemplar puede consultarse en la Sala de Investigadores). No he podido localizar esta edición en el CCFr, en la BL ni en la BNM. Tampoco lo he encontrado en ninguna librería de viejo.

20 En el acta de 25 de junio de 1852, encontramos el testimonio escrito del acuerdo de reproducción "lo más fiel posible" del texto de 1796:

La Comision encargada de la formacion de la Gramatica manifesto que a pesar de sus esfuerzos no podia presentar su dictamen tan pronto como deseaba, y siendo indispensable por los Estatutos de la Academia y órdenes vigentes sobre libros de texto atender al servicio público, se acordó reimprimir la actual en igual forma y carácter de letra si es posible hasta el número de 500 ejemplares, poniendo una advertencia en que se manifiesten las poderosas razones que han frustrado hasta el dia los deseos de la Academia de hacer otra nueba [sic] publicacion, y su decision de satisfacer cuanto antes los muy justos que abriga hace tiempo la opinion pública.

(ARAE, Libro 22 de Actas: fols. 318 v. ${ }^{\circ}$ y 319 r. . . El subrayado es mío)

En efecto, el libro de 1852 se da a la estampa con la siguiente Advertencia, que precede a la Dedicatoria:

La Academia se prometia publicar ya en este año la nueva edicion de su Gramática; pero la grave y larga enfermedad de su digno Secretario [Juan Nicasio Gallego], encargado muy especialmente de la redaccion, ha impedido que pueda verificarlo al tiempo en que mas falta hace en las escuelas públicas, como libro de texto designado por el Gobierno. Para atender á este servicio tan urgente ha acordado reimprimir el número de ejemplares que ha creido necesario, en la misma forma $y$ carácter de letra que se empleó en la edicion precedente.

(El subrayado es mío) 
y $1867\left(7 .^{a}\right)$. A estas siete ediciones declaradas por el marqués de Molins debe referirse la Academia cuando dice «y repetidas veces tambien en el siglo actual» en las Advertencias de las GRAE de 1870, 1874 y 1878 (la cita está reproducida en la página 21 de este estudio) ${ }^{21}$.

Entre tanta edición decimonónica, no podíamos dejar de tener algún otro caso "extraño", como es el de una hipotética edición en 1899, registrada en el catálogo del CSIC, en la Biblioteca General de Humanidades, de la que el mismo catálogo nos dice que «no existen ejemplares disponibles para este registro ${ }^{22}$. No he logrado encontrar ningún indicio que avale una ligera posibilidad de que en este año se volviera a dar a la estampa el texto académico $^{23}$.

Para completar el complejo panorama decimonónico en lo relativo a versiones de la Gramática de la Academia, son de mención obligada tanto la traducción al francés que en 1821 hizo Chalumeau de Verneuil (de la cual

${ }^{21}$ En documentos académicos del siglo XIX, no falta alguna alusión al libro de 1852, pero siempre vinculada al último texto dieciochesco. Así, en la "Reseña histórica de la Academia Española", publicada en el tomo I de las Memorias de la Academia Española y firmada también por el marqués de Molins, se hace referencia a la publicación en 1852 de la edición de 1796. Es en el listado de académicos que han desempeñado el cargo de director desde la fundación de la Corporación donde leemos, a propósito de don Francisco Martínez de la Rosa, lo que sigue:

En su tiempo se han hecho las ediciones 9. ${ }^{\mathrm{a}}$ y $10 .^{\mathrm{a}}$ del Diccionario, la edicion última de la antigua Gramática en 1852, y dos de la nueva en 1854 y 1858. Las tres ediciones del Compendio de Gramática en 1857, 58 y 60. las siete del Epitome en 1857, 58, 58, 59, 59, 60, 60. Las ocho del Prontuario de Ortografía en 1844, 45, 50, 53, 54, 57, 58 y 59. Las Obras poéticas de D. Juan Nicasio Gallego en 1857, y las del Duque de Frias en 1854.

(RAE, 1870: 59)

22 El título registrado, Gramática castellana / publicada por la Real Academia de la Lengua Española, viene a confirmar la sospecha de que se trataría de una edición oficiosa. Remito a http://aleph.csic.es/F?func=file\&file_name=find-b, dirección correspondiente al catálogo bibliográfico del CSIC.

${ }^{23}$ En este caso, lo más lógico es pensar en un error informático, o en un descuido a la hora de introducir los datos en el servidor de internet. Errores similares he podido detectar en otros catálogos, por ejemplo, el de la BNE, donde encontramos signatura para una edición de la Gramática en 1907, cuando, en realidad, el libro responde a la GRAE-1917. 
informó a la Corporación Martín Fernández de Navarrete ${ }^{24}$ ) como las numerosas ediciones que en el siglo XIX vieron la luz fuera de nuestras fronteras, entre las que destaco, en orden cronológico, las de 1821 y 1826 (París), recogidas en el Manual del librero hispano-americano ${ }^{25}$; la de 1853 (Nueva York), que se encuentra en la BNE26; y las de 1855 y 1874 (París), de las que la RAE guarda sendos ejemplares ${ }^{27}$. El hecho de que haga mención de estas ediciones no-oficiales (como de la de 1793), y no de otros muchos libros que salieron como "gramáticas al modo de la Academia"28, se debe a que, en estos casos, efectivamente, podemos apreciar la voluntad de los editores de ofrecer al público el texto de la GRAE, si bien en alguna ocasión con ligeras modificaciones en preámbulos, introducción de los apartados, etc.; e, incluso, con apéndices añadidos al texto propiamente dicho de la Gramática institucional 29 .

${ }^{24}$ Del intenso itinerario intelectual de este por tres veces académico (de la RAE -donde ejerció de bibliotecario-, de la Real Academia de Bellas Artes -de la que fue secretario- y de la Real Academia de la Historia -de la que fue elegido director-) informa Zamora Vicente (1999: 22).

25 Vid. Palau y Dulcet (1948: 39).

${ }^{26}$ El ejemplar de esta Gramática lleva la signatura 1/240545, pero solo está disponible para la consulta la reproducción en fotogramas [Signatura: DGmicro/44341], que se encuentra en el Salón General. Se trata de la cuarta edición. Como complemento al texto de la GRAE-1796, el libro incluye:

- El Prontuario| de ortografía | De la lengua castellana | Dispuesto de Real orden | PARA EL USO DE LAS ESCUELAS PÚBLICAS | POR | LA ACADEMIA ESPAÑOLA | CON ARREGLO AL SISTEMA ADAPTADO EN LA NOVENA EDICIÓN | DE SU DICCIONARIO.| REIMPRESO DE LA CUARTA EDICIÓN DE MADRID. | NEW-YORK-1853

- La PROSOdia DE la lengua CASTEllana. POR DON Vicente SALVÁ.

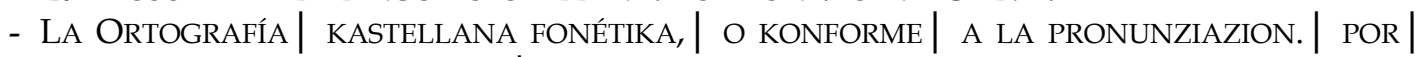
ANTONIO FRANCHI DE ALFARO.| NEW-YORK: 1853

${ }^{27}$ Estos ejemplares se encuentran en la Sala de Académicos, con las signaturas: 23-X-25 (para la edición de 1855) y 35-G-48 (para la de 1874). No debe confundirse este último libro con la GRAE-1874.

28 Por citar algún ejemplo, pueden mencionarse la Gramática de Gamboa (1893) y la de Abadie (1896), cuya referencia completa aparece en la bibliografía final.

29 Francia es, sin duda, el país en el que más ediciones de la Gramática académica encontramos. Solo en la BNF aparecen trece ediciones francesas (en años comprendidos entre 1824 y 1877) y dos publicadas simultáneamente en Madrid y París (en 1821 y 1825). Cf. http://www.bnf.fr/. En la BL encontramos una edición parisina con fecha de 1869 y la traducción que hizo al francés Chalumeau de Verneuil en 1821. Cf. http:// www.bl.uk/.

Pons Bordería (1997), que incluye en el corpus de su investigación prácticamente la totalidad de las ediciones de la GRAE, maneja una versión francesa de 1855, publicada en Saint-Cloud en la Imprenta de la Viuda de Belin. 


\section{$* * * *$ \\ UN TEXTO SINGULAR: LA GRAMÁTICA DE 1855}

Esta Gramática fue publicada en París por los herederos de Vicente Salvá y se presenta como "nueva edición" 30 . Su peculiaridad consiste en la distribución del libro en cuatro partes, una por cada división teórica de la disciplina, práctica que, en esa fecha, la RAE todavía no ha llevado a cabo en ninguna de las ediciones del libro de Gramática (según veremos en el capítulo 4 de esta tesis); por ello, los editores se jactan en la Advertencia inicial de haber sacado a la luz la más completa de las ediciones publicadas hasta el momento y de satisfacer de este modo las demandas del mercado americano ${ }^{31}$. No es casual, por tanto, que se publicara también en Méjico.

Se trata, en realidad, del texto de 1796 (no del de 1854, tal como cabría esperar por la fecha que aparece en el pie de imprenta) $)^{32}$ con la adición de la Ortografía y la Prosodia ${ }^{33}$, partes que tampoco responden a lo previsible.

30 GRAMÁtica | DE LA | LENGUA CASTELlaNA | COMPUESTA POR | LA REAL ACADEMIA ESPAÑOLA. | NUEVA EDICION, | Corregida con esmero, aumentada con el| Prontuario de Ortografía compuesto de real órden | por la misma Academia, que no se halla en ninguna de las anteriores, | y con unas Nociones de Prosodia, de que carecia| igualmente esta obra.| PARIS, LibRERÍA DE GARNIER HERMANOS, | SUCESORES DE D. V. SALVÁ| MÉJICO: J. M. ANDRADE, PORTAL DE AGUSTINOS, № $3 \mid \mathbf{1 8 5 5 .}$ 68989.

El número de registro del ejemplar que se encuentra en la Sala de Académicos es el

31 En la Advertencia se lee:

Muchas veces se ha reimpreso la Gramática de la Academia española; pero tanto en las ediciones de España como en las de Paris, se ha omitido la Ortografía, ó bien se ha puesto incompleta y de un modo arbitrario.

Esta circunstancia y el deseo de corresponder á las demandas que frecuentemente se nos hacen de América, nos han movido á publicar esta nueva edicion, á la cual hemos añadido por entero el Prontuario de Ortografía, compuesto de real órden por la misma Academia, así como unas Nociones de Prosodia de que carecia igualmente esta obra. Con estos aumentos nuestra edicion será la mas completa de las publicadas hasta el dia.

(Págs. V-VI)

32 Se confirma en la Dedicatoria al Rey, en el Prólogo y en las dos primeras partes del cuerpo de la Gramática (Analogía y Sintaxis).

33 En este añadido coincide con la Gramática publicada en Nueva York en 1853 (vid. supra). 
La Ortografía vigente en ese año es la edición corregida y aumentada de 1854 (<1853), pero, al revisar el texto de la Gramática-1855, comprobamos que coincide con el de la primera edición de la Ortografía (1844 > 1845 y 1850) y no con la última versión aprobada y publicada por la Academia ${ }^{34}$. Es curioso que la Gramática-1853 publicada en Nueva York sí tenga en cuenta la última edición de la Ortografía académica en esa fecha (que data del mismo año 1853) y que dos años más tarde los editores de París sigan teniendo como modelo la primera edición de la Ortografía.

La parte IV, de la Prosodia, ocupa algo más de cuatro páginas (de la 286 a la 290). En 1855, la Academia todavía no ha concluido el proyecto de publicación de la Prosodia de la lengua castellana (Molins, 1870: 16); de hecho, será en la GRAE-1870 cuando por primera vez la Corporación saque a la luz un tratado de prosodia, según anuncia en la Advertencia:

En cuanto á la Prosodia, será bien advertir que es la primera que publica la Academia, y que en medio de lo variable y movediza que de por sí es naturalmente la pronunciacion, fenómeno perceptible tan solo para el oido; y en medio de lo mucho, y discorde, que sobre Prosodia se ha escrito, ha juzgado este Cuerpo literario que debía limitarse á consignar lo más esencial acerca de la Ortología alfabética (letras, sílabas, diptongos y triptongos), la acentuacion y la cantidad. La Academia no renuncia, sin embargo, á nuevos estudios sobre esta materia difícil, é irá mejorando sucesivamente su obra.

(GRAE-1870: XV)

\footnotetext{
34 Prontuario de ortografía de la lengua castellana, dispuesto de real órden para el uso de las escuelas públicas por la Real Academia Española con arreglo al sistema adoptado en la novena edicion de su diccionario. Madrid: en la Imprenta Nacional. 1844. $2 .^{a}$ ed. $1845 ; 3 .{ }^{a}$ ed. $1850 ; 4{ }^{a}$ ed. corregida y aumentada $1853 ; 5$ a $^{\text {e }}$ d. 1854.
} 
¿De dónde proceden las páginas de la Prosodia? He podido comprobar que poco tiene que ver este mini-tratado con lo que será la Prosodia publicada en la GRAE-1870: el cotejo de los dos textos permite concluir que no debió de ser el borrador de la Comisión de Gramática la fuente para esas cuatro páginas, especialmente para los apartados que marco como e), f), g) y h) en el cuadro comparativo de abajo, los cuales constituyen más un Arte métrica que un estudio prosódico propiamente dicho ${ }^{35}$. Algunos años más tarde de la publicación de esta edición francesa, la Comisión de Gramática ${ }^{36}$ encargada de evaluar la versión antigua de la GRAE dictamina que el libro debe contar con un apartado de Prosodia en el que se deberán establecer «los principios más incuestionables sobre el acento, la cantidad y la aspiración», pero no hace ninguna mención a cuestiones métricas ni retóricas, de las que, efectivamente, no trata la GRAE-1870.

\footnotetext{
${ }^{35}$ No cabe duda de que Prosodia y Métrica están íntimamente relacionadas. De hecho, el sistema de Comisiones que establecieron los Estatutos de 1848 unifica ambas disciplinas en una misma Comisión (cf. RAE, 1848: 18-19. Capítulo IV, estatuto 52: De las tareas de la Academia).

${ }^{36}$ Me refiero a la Comisión que elaboró el Dictamen de 1861 (vid. RAE, 1861b), del que se hablará en próximos apartados.
} 


\begin{tabular}{|c|c|}
\hline Prosodia 1855 & Prosodia 1870 \\
\hline $\begin{array}{l}\text { - «Nociones de prosodia» } \\
\text { a) Diferencia entre Ortografía y Prosodia. } \\
\text { b) El acento sustituto de la cantidad. } \\
\text { c) Diferencia entre acento y cantidad. } \\
\text { d) Acento final: cadencia o ritmo. } \\
\text { e) Tipos de verso según la distribución del } \\
\text { acento final. } \\
\text { f) Versos asonantes, consonantes y libres. } \\
\text { g) Versos según el número de sílabas. } \\
\text { h) Reseña de las composiciones poéticas de } \\
\text { mayor uso: } \\
\text { COMPOSICIONES QUE NO EXCEDEN DE DIEZ } \\
\text { VERSOS } \\
\text { COMPOSICIONES CORTAS DE MAS DE DIEZ } \\
\text { VERSOS. } \\
\text { DE LAS LICENCIAS POÉTICAS. }\end{array}$ & $\begin{array}{l}\text { - «De la prosodia en general» } \\
\text { a) Definición de esta subdisciplina gramatical. } \\
\text { b) Proximidad Prosodia y Retórica. } \\
\text { c) Diferencia entre Prosodia (juez: el oido), Ortografía (juez: la vista), } \\
\text { Analogía y Sintaxis (jueces: inteligencia y raciocinio). } \\
\text { - «Capítulo primero. Del alfabeto» } \\
\text { a) Sonidos y letras. } \\
\text { b) Sonidos representados por letras vocales. } \\
\text { c) Sonidos representados por letras consonantes. } \\
\text { - «Capítulo II. De los acentos» } \\
\text { a) Definición de acento. } \\
\text { b) Tres formas de voces acentuadas. } \\
\text { c) Acento principal y acento secundario. } \\
\text { d) Impropiedad en la elocución. } \\
\text { e) Pautas de la acentuación prosódica: partes acentuadas y no } \\
\text { acentuadas de la oración. } \\
\text { f) Reglas de posición del acento (sujetas a la inflexión y } \\
\text { derivación). Conexión de la Prosodia con la Analogía y la } \\
\text { - «Capítulo III. De la cantidad» } \\
\text { a) Definición de cantidad. } \\
\text { b) Diferencias entre la cantidad prosódica castellana y la latina. } \\
\text { - Conclusión: } \\
\text { «[...] repetimos lo ya indicado: como la pronunciacion, el tono, el acento y } \\
\text { la cantidad se dirigen por el oido, la mejor norma será escuchar } \\
\text { atentamente y seguir el uso de Castilla, tomado, por supuesto, de las } \\
\text { personas doctas y bien educadas, que no tengan en su modo de hablar } \\
\text { vicios originados de algun defecto físico ó resabios evidentes» (Pág. 307). }\end{array}$ \\
\hline
\end{tabular}

Cuadro 1: La Prosodia en la Gramática de 1855 y en la GRAE-1870

La Prosodia de 1855 recuerda mucho a la aparecida en la Gramática americana de 1853, por lo que puede sospecharse la autoría de Salvá (no en vano los editores son los sucesores de don Vicente).

El pequeño bosquejo realizado confirma la peculiaridad de la Gramática-1855 (que no GRAE-1855). Materia hay de análisis e investigación para aclarar los pormenores de publicación de este curioso texto, pero ello, sin duda, excede los límites de esta tesis. 


\section{Siglo XX}

El siglo XX se inaugura con la 21. a edición de la GRAE, de 1900, a la que seguirán quince ediciones oficiales más: 1901, 1904, 1906, 1908, 1909, 1911, 1913, 1916, 1917, 1920, 1924, 1928, 1931, 1959 y 1962.

No todas estas ediciones son recogidas en las compilaciones principales, ni siquiera todas son reconocidas unánimemente por la crítica como ediciones oficiales. Por lo general, su localización es fácil, si bien alguna de ellas la ha perdido de vista la propia Academia.

Los casos más problemáticos son:

a) La GRAE-1906: no fichada por los compiladores, como se verá en el punto 2.3. (Cuadro 26).

b) La GRAE-1908, registrada en los catálogos, pero de la que no hay rastro en la RAE. Solo he podido localizar un ejemplar en la BNE.

c) Las GRAE de 1959 y 1962, habitualmente obviadas (e incluso a veces negadas -bajo la afirmación de que la última edición de la GRAE es la de 1931, seguida del Esbozo-) por los estudiosos.

En los apartados correspondientes del punto 2.3., volveré sobre estas ediciones. 


\subsection{Sobre las compilaciones}

Don Cipriano Muñoz y Manzano, conde de la Viñaza, y don Emilio Cotarelo y Mori pueden ser considerados los compiladores "oficiales" de la obra académica y los compiladores coetáneos de los textos en que se centra esta investigación. Dos son las razones fundamentales que apoyan esta consideración:

a) Ambos fueron académicos en un periodo de tiempo comprendido entre las fechas que flanquean el corpus principal de este estudio: el conde de la Viñaza, entre 1895 y 1933 (ocupó el sillón L); y Cotarelo y Mori, entre 1900 y 1936 (ocupó el sillón i) 37, lo cual les otorga una posición privilegiada para poder tener acceso a la información sobre los textos publicados.

b) Los dos catalogaron los libros con firma de la Institución en sendas obras auspiciadas por la propia Academia: el primero recoge la producción de la RAE en un catálogo general de obras relativas al estudio de la lengua castellana, la Biblioteca histórica de la filología castellana, premiada por unanimidad en certamen público de la docta Casa y publicada a sus expensas en 1893; el segundo recoge exclusivamente la producción institucional (tanto gramatical y literaria como de reglamento interno) en un Discurso acerca de las obras publicadas por la Real Academia Española, leído en junta pública, con motivo de la fiesta del libro, el 7 de octubre de 1928 y publicado el mismo año.

\footnotetext{
37 Véase Zamora Vicente (1999: 172 y 274) y la dirección electrónica de la web de la RAE: http://www.rae.es/rae/gestores/gespub000001.nsf/(voAnexos)/arch6D3211F8664070B7C12 5720900476B93/\$FILE/sillones.htm.

A los dos les dio la bienvenida en nombre de la Corporación Alejandro Pidal y Mon, que contestó al discurso «De la poesía satírico-política en España» leído por don Cipriano y al discurso de Cotarelo «Sobre las imitaciones castellanas del Quijote». Vid. Viñaza (1895) y Cotarelo y Mori (1900). Los dos académicos destacaron por su labor investigadora (vid. Zamora Vicente, 1999: 172 y 274).
} 
Veinte años transcurren entre el Discurso de Cotarelo y la tercera compilación que tendremos en cuenta: el Manual del librero hispano-americano, de don Antonio Palau y Dulcet, una magna bibliografía en 28 volúmenes (entre 1948 y 1977), en la que se hace acopio de libros publicados en España y Latinoamérica desde la invención de la imprenta hasta la fecha de edición de cada volumen.

A continuación, expongo brevemente algunas notas sobre estas compilaciones que pueden resultar de interés para el investigador de gramaticografía:

\section{La Viñaza (1893)}

Por su condición de "compilador oficial" que he defendido, lo esperable es que la información contenida en la Biblioteca histórica de la filología castellana esté presidida, más que ninguna otra, por el rigor; $\mathrm{y}$, en efecto, no podemos negar que don Cipriano es bastante escrupuloso en su ingente labor de acopio de obras y de aportación de información de gran interés, especialmente sobre los textos que considera de mayor relevancia. No obstante, con respecto a las GRAE, algunos de los datos que figuran en este catálogo deben ser sometidos a juicio. Son varios los problemas que presenta la información ofrecida por el conde de la Viñaza: 
$1^{\circ}$ ) Confusión en el registro de dataciones:

Las fechas de la quinta y novena ediciones de la GRAE aparecen equivocadas:

- La 5. ${ }^{\text {e ed. }}$ lleva la fecha de 1858 (en lugar de 1854).

- Como 9. ${ }^{\text {a }}$ ed. se registra el texto de 1854 (en lugar de la GRAE1865).

El error se extiende a las ediciones sexta (1862, en vez de 1858), séptima (1864, en lugar de 1862) y octava (1865, por 1864).

\section{$\left.2^{\circ}\right)$ Ediciones no registradas:}

Son tres las ediciones anteriores a 1893 (fecha de publicación de la Biblioteca) que no son recogidas por La Viñaza:

- Las de $1883\left(16 .^{\mathrm{a}}\right)$ y 1885 (17. $\left.^{\mathrm{a}}\right)$, de modo que, según este catálogo, la 16. ${ }^{a}$ edición sería la GRAE-1888 (que, en rigor, responde a la 18. ${ }^{a}$ edición).

- La GRAE-1890.

$3^{\circ}$ Información no exacta sobre ciertas ediciones:

Estas inexactitudes tienen que ver, fundamentalmente, con algunas afirmaciones del compilador sobre la identidad entre dos Gramáticas (vid. infra 2.3.). 


\section{Cotarelo y Mori (1928)}

El Discurso de Cotarelo adolece de pocos fallos en la información y ordenación de los datos, si bien puede comprobarse que en él falta el registro de alguna edición (caso de la GRAE-1906) y que, por lo general, es mucho más conciso que don Cipriano (y, por tanto, está menos expuesto que él al error o al descuido). Solo se detiene en dar ciertas notas explicativas -y breves- a propósito de algunas de las “ediciones jalón”.

\section{Palau y Dulcet (1948)}

El catálogo fundamental de obras académicas lo encontramos en el tomo I de su Manual del librero hispanoamericano (de 1948), bajo la voz "Academia"; a este listado debe sumarse la información adicional que aparece en el tomo XV (de 1962). Por la fecha de los textos recogidos en este último año (anteriores en su mayoría a 1948), el autor debió de aprovechar la publicación del volumen XV para añadir, bajo la voz "Real Academia Española", algunas de las publicaciones académicas que olvidó o de las que no tenía constancia a la hora de redactar el primer tomo. En lo relativo a la Gramática, son las ediciones de 1906 y 1913 las que no se recogen hasta 1962. También en ese año se anota la GRAE-1911, aunque esta edición ya aparece registrada en el listado de 1948, en la misma entrada de la GRAE-1904.

El catálogo de Palau y Dulcet, pese a ser bastante posterior a los dos anteriores, presenta no pocas omisiones y, en términos generales, se limita a dar información puramente "física" de los libros. No obstante, en él se puede encontrar alguna noticia de interés sobre reimpresiones, traducciones... hechas en el extranjero. 
Este Manual es, sin duda, el más "catálogo" de las tres obras; su compilador, el más lacónico. Por tanto, resulta ser la fuente documental más anodina para el especialista que busque información "de sustancia" sobre los libros de la Academia. El valor de la obra es innegable, eso sí, como repertorio de publicaciones. No en vano el título acota el destinatario fundamental: los libreros. 


\subsection{Información y apuntes sobre las distintas ediciones ${ }^{38}$}

\subsubsection{GRAE-1771}

INFORMACIÓN COMPILADA

\begin{tabular}{|c|c|c|c|}
\hline & $\begin{array}{c}\text { La Viñaza } \\
(\mathbf{1 8 9 3}) \\
\end{array}$ & $\begin{array}{c}\text { Cotarelo } \\
(1928) \\
\end{array}$ & $\begin{array}{c}\text { Palau y Dulcet } \\
(\mathbf{1 9 4 8 )} \\
\end{array}$ \\
\hline $\begin{array}{l}\text { N. }{ }^{\circ} \text { de } \\
\text { ed. }\end{array}$ & {$\left[1 .^{a}\right]$} & $1 .^{a}$ & {$\left[1 .^{\mathrm{a}}\right]$} \\
\hline 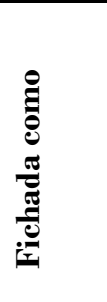 & $\begin{array}{l}\text { Gramática } \mid \text { de la } \mid \text { Lengua } \\
\text { Castellana, } \mid \text { compuesta|por la } \\
\text { Real Academia| Española. (Esc. } \\
\text { de la Acad.) Madrid.|Por D. } \\
\text { Joachin de Ibarra, Impresor |de } \\
\text { Camara de } \\
\text { M.DCC.LXXI. }\end{array}$ & $\begin{array}{l}\text { Gramática } \mid \text { de la } \mid \text { Lengua } \\
\text { Castellana,| compuesta| por la } \\
\text { Real Academia Española. } \\
\text { (Emblema de la Acad.) Madrid. } \\
\text { Por D. Joachin de Ibarra, } \\
\text { Impresor | de Cámara de S.M.| } \\
\text { M.DCC.LXXI. }\end{array}$ & $\begin{array}{l}\text { Gramática de la } \\
\text { lengua castellana. } \\
\text { Madrid, Por D. } \\
\text { Joachin de Ibarra, } \\
\text { Impresor de Cámara } \\
\text { de S.M. M.DCC.LXXI } \\
(1771) \text {. }\end{array}$ \\
\hline 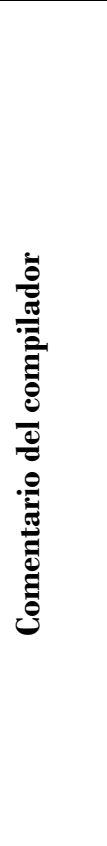 & $\begin{array}{l}\text { Descripción del tamaño, } \\
\text { paginación y distribución: } \\
\text { «8. }{ }^{\circ}-7 \text { hs. prels. + XXII págs. }+376 . \\
\text { - Signaturas } \uparrow-\Phi \uparrow \uparrow, A-Z, A a, \text { de } 8 \\
\text { hs., menos la segunda de } 3 \text { y la últ. } \\
\text { de } 4 . \\
\text { Port. - V. en b. - Ded. al Rey. - Lic. } \\
\text { Real, firmada por D. Francisco } \\
\text { Antonio de Angulo, su secretario: } \\
\text { Madrid } 7 \text { de Enero de } 1771 .- \text { Tabla } \\
\text { de los capítulos. - Prólogo. Se } \\
\text { encarece en él al comienzo la } \\
\text { necesidad del estudio de la } \\
\text { Gramática y luego dícese: [...] } \\
\text { Sigue el texto, dividido en dos } \\
\text { partes: Del número, propiedad y } \\
\text { oficio de las palabras, y De la } \\
\text { sintaxis ó construccion. } \\
\text { Indice alfabético de las voces } \\
\text { notables de esta Gramática». (Págs. } \\
\text { 590-592). }\end{array}$ & $\begin{array}{l}\text { Información sobre tipo de } \\
\text { volumen, número y distribución } \\
\text { de páginas: } \\
\text { «8. }{ }^{\circ} ; 7 \text { hojas prels. + XXII págs. + } \\
376 \text { de texto. } 1 .^{\text {a edic. Dedicatoria al }} \\
\text { Rey firmada por D. Francisco } \\
\text { Antonio de Angulo, secretario de la } \\
\text { Academia: Madrid, } 7 \text { de enero de } \\
\text { 1771». (Pág. } 39) .\end{array}$ & $\begin{array}{l}\text { Información sobre el } \\
\text { tipo de volumen y el } \\
\text { número de páginas, } \\
\text { seguida de una breve } \\
\text { información sobre la } \\
\text { recepción en el } \\
\text { extranjero y el } \\
\text { precio: } \\
\text { «8. } 7 \text { h. XXII-376 p. } \\
\text { En el extranjero se da } \\
\text { mucha importancia a } \\
\text { esta primera edición. } \\
\text { En tafilete rojo y con } \\
\text { las armas de Carlos III. } \\
12 \text { libras, } 2 \text { chelines. } \\
\text { Maggs. Bros en 1923». } \\
\text { (Pág. 39). }\end{array}$ \\
\hline
\end{tabular}

Cuadro 2: GRAE-1771 en las compilaciones

38 Para cubrir los propósitos de esta tesis, entiendo que lo interesante es poder contrastar la información que los catálogos de La Viñaza, Cotarelo y Palau contienen sobre cada una de las GRAE. Es por ello que la presentación que hago en este apartado responde al orden cronológico de cada una de las Gramáticas oficiales. En el Apéndice I, recojo la misma información (sin comentarios míos) ordenada por catálogos. El apéndice puede aligerar la tarea del investigador de historiografía gramatical. En los cuadros de este apartado, utilizo el sombreado gris en los casos en que una determinada edición no aparece registrada en alguna de las compilaciones. Si la edición es anterior a la fecha de publicación del catálogo, indico «NO LA REGISTRA»; si el catálogo es anterior a la fecha de edición de la Gramática, no indico nada y extiendo el sombreado al nombre del compilador. 


\section{APUNTES SOBRE LA INFORMACIÓN}

(1) Ya desde esta primera ficha se comprueba lo dicho más arriba sobre el menor grado de detalle en las descripciones de Cotarelo y Palau frente a las ofrecidas por el conde de la Viñaza. La información sobre el precio de las ediciones, que más de una vez veremos en las notas de Palau, se justifica bien por la observación final que he hecho a propósito de esta compilación (que -repito- es la más "catálogo" propiamente dicho y que tiene como principal destinatario a un librero, no a un filólogo ni a un estudioso interesado en cuestiones de doctrina gramatical y/o académica) $)^{39}$.

(2) Las siete páginas de preliminares las suman las cinco de la Dedicatoria y las dos de la Licencia. Siguen otras cinco páginas sin numerar con la Tabla de los capítulos, que no han sido computadas por ningún compilador.

(3) La Dedicatoria al Rey será la misma en las ediciones de 1771, 1772, 1781 y 179640. En ella, se hace explícita la pretensión de la Academia con la publicación de la Gramática:

\section{La Academia solo pretende en esta Gramática instruir á nuestra} Juventud en los principios de su lengua, para que hablándola con propiedad y correccion, se prepare á usarla con dignidad y eloqüencia; y se promete de amor de V.M. á su lengua y á sus vasallos, que aceptará benignamente esta pequeña obra.

(El subrayado es mío)

\footnotetext{
${ }^{39}$ Interesantes informaciones sobre el precio (en este caso, en moneda española de la época) de los distintos libros de Gramática publicados por la Corporación (GRAE, CRAE y ERAE) ofrece Gómez Asencio (2004).

${ }^{40}$ La Gramática de 1793 también reproduce esta Dedicatoria.
} 
(4) La Viñaza reproduce el texto del Prólogo comprendido entre las páginas V Y XIII. El prólogo de esta edición ha sido objeto de atención de varios estudiosos: Fries (1989: 99-107), Gómez Asencio (2000a) ${ }^{41}$ y Ramajo Caño (2002), por lo que me limito a remitir a las reflexiones contenidas en estos estudios.

(5) No es exactamente la Dedicatoria al Rey lo que firma Angulo42 en calidad de secretario -según dice Cotarelo-, sino la Licencia, tal como indica La Viñaza. La dedicatoria va firmada por la Corporación ${ }^{43}$.

LOCALIZACIÓN44: Es una de las Gramáticas académicas de más fácil localización. Ramón Sarmiento publicó una edición facsímil en $19844^{45}$. El texto se puede consultar en la Sala de Investigadores de la RAE

${ }^{41}$ Este investigador analiza minuciosamente las hojas preliminares de la GRAE-1771 en un estudio que constituye el primero de una serie de monografías sobre las partes introductorias de los libros de Gramática publicados por la Institución. De la referencia exacta de cada uno de los estudios daré cuenta en el lugar oportuno.

42 Francisco Antonio de Angulo fue académico entre 1746 y 1775; ocupó el sillón C, que quedó vacante tras la muerte de don Andrés Fernández Pacheco, marqués de Villena. Fue secretario de la Academia desde 1747. La información se puede encontrar en la siguiente dirección: http://www.rae.es/rae/gestores/gespub000001.nsf/(voAnexos)/arch6D3211F8664070B7C12 5720900476B93/\$FILE/sillones.htm y en Zamora Vicente (1999: 66), quien destaca entre sus actividades académicas la elaboración del proyecto de la Gramática en 1741. En el Ms. $314{ }^{8}$ están anotados el día exacto de nombramiento como numerario (30 de junio de 1746) y el de defunción (6 de agosto de 1775). El manuscrito lo he podido consultar en la Sala de Investigadores de la RAE, y de él tuve conocimiento gracias al catálogo de Crespo Tobarra (1991: 118).

${ }^{43}$ La licencia la encontraremos en las ediciones de 1771, 1772 y 1781. En la Gramática de 1793, no aparece licencia alguna, pese a que en la portada se dice que cuenta con las licencias necesarias. En la GRAE-1796, ya no hay ninguna alusión a licencias, ni licencia propiamente dicha.

${ }^{44}$ Solo indico las instituciones españolas RAE, BNE y CSIC. Todos los ejemplares de los que doy noticia que se encuentran en la Sala de Investigadores de la RAE los he podido consultar de primera mano; de los ejemplares que se encuentran en la BNE doy todas las referencias que la Biblioteca facilita en su página web, si bien me he limitado a comprobar que, al menos, hay uno físicamente. Con respecto a los ejemplares de las bibliotecas del CSIC, me limito a ofrecer las signaturas y bibliotecas correspondientes que figuran en el catálogo informatizado del Centro, pues las bibliotecas de Madrid han estado cerradas al público durante todo el año 2007 y no he podido acceder a ellas. La última consulta de los catálogos informatizados la hice en febrero de 2008.

45 Una reseña de esta edición fue publicada por Martínez Gavilán (1984) en Contextos. 
[Signatura: 35-G-01 D y Registro: 35.270] en una encuadernación fotocopiada del original. Otros ejemplares en Consultas, Sala de Académicos [signatura: 35-G-01] y Sala de Exposiciones. En la BNE, puede consultarse en la Sala Cervantes [Signaturas: 2/15341 y R/ 38876]. El CSIC46 dispone de la edición facsímil de 1984, que se encuentra en la biblioteca M-BG.Hum con la signatura 9/2348. Una versión digitalizada puede encontrarse en Gómez Asencio (comp., 2001). El texto íntegro de esta primera edición de la GRAE está colgado en Internet en la Biblioteca Virtual Miguel de Cervantes: http://cervantesvirtual.com/servlet/SirveObras/45771431102371451100080/index.htm

${ }^{46}$ Las distintas bibliotecas del Área de Humanidades y Ciencias Sociales del CSIC, en las cuales se pueden encontrar ejemplares de la GRAE, serán indicadas en las páginas que siguen con la forma abreviada que utiliza el CSIC en su catálogo informatizado. A continuación, facilito la lista e indico entre paréntesis la ciudad en la que se encuentra la biblioteca:

B-IMF: Instituto Milá y Fontanals (Barcelona).

C-IEGPS: Inst. de Estudios Gallegos “P. Sarmiento" (Santiago de Compostela).

CC-IHH: Instituto Histórico Hoffmeyer (Jaraiz de la Vera -Cáceres-).

CO-IESA: Instituto de Estudios Sociales de Andalucía (Córdoba).

M-BG.Hum: Biblioteca General de Humanidades (Madrid).

M-BibCen: Biblioteca Central del CSIC (Madrid).

M-ICCET: Biblioteca del Instituto de Ciencias de la Construcción "E. Torroja” (Madrid).

M-IFL: Instituto de Filología e Instituto de la Lengua Española (Madrid).

M-MNCN: Museo Nacional de Ciencias Naturales (Madrid).

M-Ortega: Fundación Ortega y Gasset (Madrid).

M-Resid: Biblioteca de la Residencia de Estudiantes (Madrid).

V-IHCD: Instituto de Historia de la Ciencia y Documentación “López Piñero” (Valencia). 


\subsubsection{GRAE-1772}

\section{INFORMACIÓN COMPILADA}

\begin{tabular}{|c|c|c|c|}
\hline & $\begin{array}{c}\text { La Viñaza } \\
(1893) \\
\end{array}$ & $\begin{array}{c}\text { Cotarelo } \\
(1928) \\
\end{array}$ & $\begin{array}{c}\text { Palau y Dulcet } \\
\text { (1948) } \\
\end{array}$ \\
\hline $\begin{array}{c}\text { N. } .^{\circ} \text { de } \\
\text { ed. }\end{array}$ & $2 .^{\mathrm{a}}$ & $2 .^{\mathrm{a}}$ & $2 .^{\mathrm{a}}$ \\
\hline 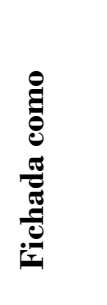 & $\begin{array}{l}\text { Segunda edición: por el } \\
\text { mismo impresor que } \\
\text { hizo la primera; año de } \\
1772 \text {. }\end{array}$ & 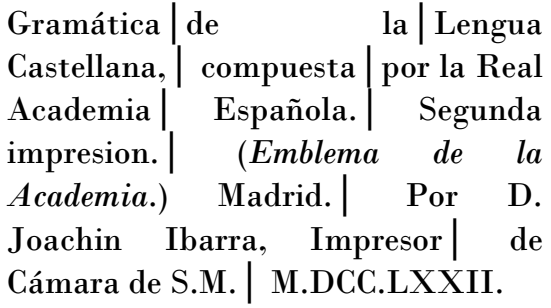 & $\begin{array}{l}\text { Gramática. Segunda } \\
\text { impresión. Madrid. Por } \\
\text { D. Joaquin Ibarra, } \\
\text { Impresor de la Cámara } \\
\text { de S.M. M.DCC.LXXII } \\
(1772) \text {. }\end{array}$ \\
\hline 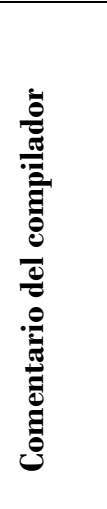 & 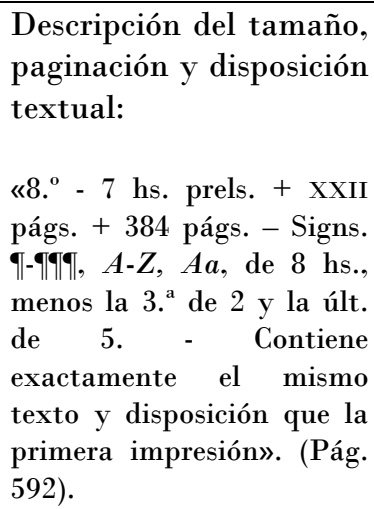 & $\begin{array}{l}\text { Información sobre características } \\
\text { físicas del libro y sobre el éxito } \\
\text { editorial que alcanzó la primera } \\
\text { edición: } \\
\text { «8. } 7 \text { hojas prels. + XXII págs. de pról. } \\
+384 \text { págs. de texto. El público se } \\
\text { apresuró a adquirir la nueva Gramática y } \\
\text { hubo que reimprimirla al año siguiente } \\
\text { sin poder modificarla ni aun corregirla } \\
\text { con algún esmero». (Pág. } 39 \text { ). }\end{array}$ & \begin{tabular}{llr} 
Escueta & \multicolumn{2}{c}{ información } \\
sobre & tamaño & y \\
páginas: & & \\
& & \\
«8. & 7h. XXII-384 & p.». \\
(Pág. 39). & &
\end{tabular} \\
\hline
\end{tabular}

Cuadro 3: GRAE-1772 en las compilaciones

\section{APUNTES SOBRE LA INFORMACIÓN}

(1) En la portada del libro se lee "segunda impresión". Queda manifiesto que también los compiladores de la GRAE (en este caso, La Viñaza) usan indistintamente los términos "impresión" y "edición".

(2) Igual que en la GRAE-1771, las siete hojas de preliminares las suman las cinco de la Dedicatoria y las dos de la Licencia. Siguen cinco páginas sin numerar con la Tabla de los capítulos, tampoco computadas en esta ocasión por los compiladores. 
(3) La identidad con respecto a la GRAE-1771 que afirma La Viñaza debemos ponerla en tela de juicio. En primer lugar, la licencia de esta obra, que aparece entre la dedicatoria al Rey y la tabla de los capítulos, no es la misma licencia que aparecía en 1771, si bien lleva igualmente la firma de D. Francisco Antonio de Angulo, secretario de la Corporación en esos años ${ }^{47}$.

(4) Según el análisis comparativo que hace Taboada (1981: 98) atendiendo al contenido y distribución del texto y de las páginas, tampoco podemos decir que la correspondencia sea idéntica entre las ediciones de 1772 y 1771. Hay pequeñas diferencias en la portada, variantes de contenido (en 1772 se añade, por ejemplo, la conjugación de algunos verbos irregulares), variantes de redacción (adición o supresión de ejemplos, aclaraciones...), diferencias en el índice, etc. Estas diferencias habían sido detectadas ya por Uruburu, quien afirma en su Memoria de Licenciatura:

La Segunda edición presenta respecto de la primera variantes de diversos tipos: gráficas, de redacción y de contenido; estudio estas divididas en tres apartados: adiciones, supresiones y reajustes. Difiere además en número de páginas (A, 376, B, 384).

(Uruburu Vidaurrázaga, 1975: 306)

(5) La propia información dada en la Biblioteca resulta extraña, ya que al conde de la Viñaza no se le escapa esa diferencia en el número de páginas y, efectivamente, anota en la segunda edición 8 páginas más (384) que en la primera (376); con todo, afirma que son textos idénticos.

47 Es duda razonable la de si La Viñaza tiene en cuenta la Licencia o no al afirmar que la edición «contiene exactamente el mismo texto y disposición que la primera impresión». No obstante, considero oportuna esta aclaración. 
La información ofrecida por Cotarelo resulta mucho más acertada, pues simplemente anota que no se pudo modificar ni corregir con esmero, lo cual no excluye algún posible cambio en el texto.

(6) El salto en el número de páginas entre las dos primeras ediciones se produce en la parte I, «Del número, propiedad y oficio de las palabras» (donde se ha añadido la conjugación de algunos verbos irregulares), que en 1771 ocupa de la pág. 1 a la 230; y en 1772, de la 1 a la 238.

LOCALIZACIÓN: En la Sala de Investigadores de la RAE, se encuentra un ejemplar fotocopiado con la signatura 35-G-28 y sin número de registro. El original se encuentra en la Sala de Académicos con la misma signatura. En la BNE, puede consultarse en el Salón General [Signatura: 2/15551] o en la Sala Cervantes [Signatura: R/37003]. De esta edición no se encuentra ningún ejemplar en el CSIC. 


\subsubsection{GRAE-1781}

INFORMACIÓN COMPILADA

\begin{tabular}{|c|c|c|c|}
\hline & $\begin{array}{c}\text { La Viñaza } \\
\text { (1893) }\end{array}$ & $\begin{array}{c}\text { Cotarelo } \\
\text { (1928) }\end{array}$ & $\begin{array}{c}\text { Palau y Dulcet } \\
\text { (1948) }\end{array}$ \\
\hline $\begin{array}{c}\text { N. }{ }^{\circ} \text { de } \\
\text { ed. }\end{array}$ & $3 .^{a}$ & $3 .^{a}$ & $3 .^{a}$ \\
\hline 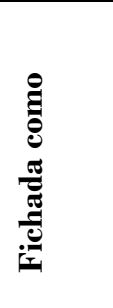 & $\begin{array}{l}\text { Tercera edición: por el } \\
\text { mismo impresor que la } \\
\text { primera; año de } 1781 \text {. }\end{array}$ & \begin{tabular}{l|lr} 
Gramática & de la $\mid$ & Lengua \\
castellana $|\ldots|$ & Tercera \\
impresion. $\mid$ & (Emblema) $\mid$ & Con \\
superior permiso: | en Madrid $\mid$ Por \\
D. Joaquin de Ibarra, Impresor de \\
Cámara de S.M. y de la Real \\
Academia | MDCCLXXXI.
\end{tabular} & $\begin{array}{l}\text { Gramática. Tercera impresión. } \\
\text { Con superior permiso: en } \\
\text { Madrid. Por D. Joaquin } \\
\text { Ibarra, Impresor de Cámara } \\
\text { de S.M. y de la Real } \\
\text { Academia. } \\
\text { (1781). }\end{array}$ \\
\hline 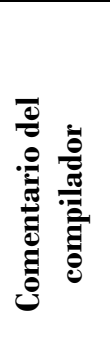 & $\begin{array}{l}\text { Información sobre el } \\
\text { número de páginas y el } \\
\text { contenido: } \\
\text { «Consta de igual número } \\
\text { de páginas que la anterior, } \\
\text { y contiene la misma } \\
\text { materia y disposición». } \\
\text { (Pág. 592). }\end{array}$ & $\begin{array}{l}\text { Información sobre tipo de volumen } \\
\text { y número de páginas: } \\
\text { «8. }{ }^{\circ} ; 7 \text { hojas prels.; XXI págs. de prólogo } \\
\text { y } 384 \text { págs. de texto». (Pág. } 39 \text { ). }\end{array}$ & $\begin{array}{l}\begin{array}{l}\text { Información } \\
\text { volumen y tipo } \\
\text { pómé } \\
\text { páginas: }\end{array} \\
\text { «8. }{ }^{\circ} \text { 7h. XXI-384 p.». (Pág. 39). }\end{array}$ \\
\hline
\end{tabular}

Cuadro 4: GRAE-1781 en las compilaciones

\section{APUNTES SOBRE LA INFORMACIÓN}

(1) La distribución de las hojas preliminares es igual que en las ediciones anteriores. La Tabla de los capítulos sigue ocupando cinco páginas sin numerar a continuación de la Licencia, pero no se tienen en cuenta.

(2) La licencia de 1781 está firmada por el secretario que sucedió en el cargo a Angulo, D. Manuel de Lardizábal y Uribe ${ }^{48}$. Como es de esperar, tampoco es

48 Académico entre 1775 y 1814. Ocupó el sillón C tras la muerte de Angulo (cf.http:// www.rae.es/rae/gestores/gespub000001.nsf/(voAnexos)/arch6D3211F8664070B7 C125720900476B93/\$FILE/sillones.htm). El Ms. $314^{8}$ indica que fue académico supernumerario el 13 de noviembre de 1770. Según el mismo manuscrito, consta como numerario desde el 8 de agosto de 1775 (Angulo había muerto dos días antes) y fallece el 20 de diciembre de 1820 (la fecha de defunción difiere de la dada por Zamora Vicente -1999: $117-$, quien afirma que murió el día de Navidad). Hay, por tanto, un desajuste de seis años entre su cese como académico y el momento de su fallecimiento. El desajuste encuentra explicación en el hecho de que Lardizábal, según informa Zamora Vicente (1999: 117), 
la misma licencia que en las dos ediciones anteriores, por lo que lo afirmado por La Viñaza vuelve a ser inexacto si tenemos en cuenta estas páginas. En el siguiente cuadro reproduzco las licencias de cada una de las ediciones.

\section{GRAE-1771}

Don Francisco Antonio de Angulo, del Consejo de S.M. su Secretario, Oficial mayor de la Secretaría del Real Patronato, Académico de número, y Secretario de la Real Academia Española: certifico que en papel del Excelentísimo Señor Marques de Grimaldi, del Consejo de Estado de S.M. y su primer Secretario del Despacho, se comunicó por mi mano á la expresada Real Academia la resolucion siguiente: Aplaudiendo el Rey el zelo con que la Real Academia Española, sin descaer en la asidua correccion y aumento de su Diccionario, ha dedicado sus desvelos á la formacion de una Gramática de la lengua castellana, se ha dignado de concederla el permiso que en su nombre solicita $V$.S. con fecha de siete del corriente para dár á luz aquella obra. El beneficio que en ello logrará el público, y el justo elogio que resultará á la Academia de subministrarle un tratado de tal importancia, aumentan la complacencia con que participo á V.S. esta nueva demostracion del singular aprecio que merecen á S.M. tan útiles tareas, y de su constante deseo de fomentarlas. Así podrá V.S. hacerlo presente á la Academia, y yo ruego á Dios guarde á V.S. muchos años como deseo. Palacio á diez y siete de Diciembre de mil setecientos y setenta. = El Marques de Grimaldi. = Señor Don Francisco Antonio de Angulo. Y esta Real resolucion queda original en los papeles de la Secretaría de la Academia que están á mi cargo, á que me refiero. Madrid siete de Enero de mil setecientos setenta y uno.

D. Francisco Antonio de Angulo.

\section{GRAE-1772}

Don Francisco Antonio de Angulo, Caballero pensionado de la Real y distinguida Orden Española de Carlos III, del Consejo de S.M. su secretario, Oficial mayor de la Secretaría de Cámara y Real Patronato, Académico del número, y Secretario de la Real Academia Española: certifico que en papel del Excelentísimo Señor Marques de Grimaldi, del Consejo de Estado de S.M. y su primer Secretario del Despacho, se comunicó por mi mano á la expresada Real Academia la resolucion siguiente: El Rey permite á la Academia Española haga reimprimir, todas las veces que lo juzgare conveniente, su Gramática Castellana: y lo participo á V.S. de órden de S.M. en respuesta de su papel de trece del corriente, para que cuide de comunicar á la Academia la complacencia con que el Rey la concede el permiso de reimprimir dicha obra, según lo ha solicitado por medio de V.S. á quien guarde Dios muchos años como deseo. Palacio á quince de Julio de mil setecientos setenta y uno. = El Marques de Grimaldi. = Señor Don Francisco Antonio de Angulo. Y esta Real resolucion queda original en los papeles de la Secretaría de la Academia que están á mi cargo, á que me refiero. Madrid primero de Agosto de mil setecientos setenta y dos.

D. Francisco Antonio de Angulo.

«renunció al cargo, debido a sus frecuentes y largas ausencias». Habría que añadir que, de no haber renunciado él, lo más probable es que se le hubiera excluido, pues los Estatutos de 1715 contemplaban artículos sancionadores para los casos de ausencia y/o ineficacia (remito al capítulo 2. ${ }^{\circ}$ de los Estatutos, relativo a los Académicos, fols. 12-13. Vid. RAE, 1715), y tales artículos fueron aplicados contra otros académicos: D. Jaime de Solís y Gante, y D. Manuel de Fuentes (los dos dados de alta como numerarios el 14 de octubre de 1714, ocupantes de los sillones T y U respectivamente) figuran como "excluidos" en el Ms. 3148. Es de nuevo Zamora Vicente (1999: 37) quien informa de la fecha de baja: la de don Jaime, el 1 de agosto de 1720; la de don Manuel, el 8 de octubre de 1716. 


\section{GRAE-1781}

Don Manuel de Lardizábal y Uribe, del consejo de S.M. su Alcalde del Crímen y de Hijosdalgo de a Real Chancillería de Granada, Académico de la Real Academia Geográfico Histórica de Caballeros de Valladolid, del número de la Española, y su Secretario perpetuo: certifico, que en papel del Excelentísimo Señor Marques de Grimaldi, del Consejo de Estado de S.M. y su primer Secretario del Despacho, se comunicó por mano de mi antecesor á la expresada Real Academia la resolucion siguiente: El Rey permite á la Academia Española haga reimprimir todas las veces que lo juzgare conveniente su Gramática castellana; y lo participo a V.S. de órden de S.M.[...] Y esta Real resolucion queda original en los papeles de la Secretaría de la Academia, que están a mi cargo, á que me refiero. Madrid á veinte y uno de Diciembre de mil setecientos y ochenta.

D. Manuel de Lardizábal y Uribe.

Cuadro 5: Licencias de 1771, 1772 y 1781

(3) En cuanto a la materia y disposición, remito a lo dicho sobre la edición anterior. Si La Viñaza afirma que el texto de 1781 es idéntico al de 1772, y este al de 1771 , se sobreentiende que considera iguales las ediciones $3 .^{\mathrm{a}}$ y $1 .^{\mathrm{a}}$, lo cual no es del todo exacto, como tampoco lo es que lo sean la 1. ${ }^{\mathrm{a}}$ y la 2. ${ }^{\mathrm{a}}$. Para los cambios (aunque mínimos) entre 1772 y 1781 remito también al estudio de Taboada (1981: 97-111). Uruburu (1975: IV) indica a este respecto que «La Tercera edición presenta respecto de la Segunda, muy pocas variantes, y casi todas ellas son gráficas».

LOCALIZACIÓN: De esta tercera impresión hay un original duplicado en la Sala de Investigadores de la RAE [Signatura: 35-G-0 y Registro: 50333]. En la BNE, existen originales y reproducciones en microficha que pueden consultarse en el Salón General [Signaturas: DGmicro/15604; 3/23806; 3/47885 y 3/52163]. El catálogo del CSIC registra erróneamente una edición en 1871, que corresponde, sin duda, a la edición de 1781, ya que se indica que se trata de la $3 .^{a}$ reimpresión y la publicación se hizo en la Imprenta de Ibarra, impresor en el siglo XVIII, no a finales del XIX. Además, este ejemplar consta de 384 páginas, que son las que, efectivamente, tiene la GRAE-1781. Puede encontrarse en la biblioteca M-Resid con la signatura R.1690. Una versión digitalizada por Google a partir del original puede consultarse en línea; la descarga en formato PDF puede realizarse desde la siguiente dirección:

http:// books.google.com/books?id=JtsFAAAAQAAJ\&printsec=titlepage\&dq=editions:0UHWC6us5Xdz wNrl\#PPP5,M1.

(*) De la GRAE-1771 y de las reediciones de 1772 y 1781 no es fácil encontrar ejemplares a la venta en las librerías de viejo, por lo que los pocos que hay se venden a un precio bastante elevado en comparación con el resto de textos académicos (aproximadamente, entre los doscientos y seiscientos euros). 


\subsubsection{GRAE-1796}

\section{INFORMACIÓN COMPILADA}

\begin{tabular}{|c|c|c|c|}
\hline & $\begin{array}{c}\text { La Viñaza } \\
\text { (1893) }\end{array}$ & $\begin{array}{c}\text { Cotarelo } \\
\text { (1928) }\end{array}$ & Palau y Dulcet (1948) \\
\hline $\begin{array}{c}\text { N. de } \\
\text { ed. }\end{array}$ & $4 .^{\mathrm{a}}$ & $4 .^{\mathrm{a}}$ & $4 .^{a}$ \\
\hline 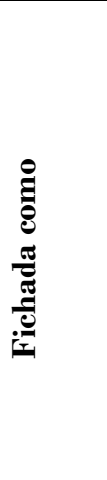 & $\begin{array}{l}\text { Cuarta edición: Gramática } \mid \text { de } \\
\text { la lengua | castellana } \\
\text { compuesta | por|la } \\
\text { Academia | Española. | Quarta } \\
\text { edicion | corregida } \\
\text { aumentada. | (Esc. de la } \\
\text { Acad.)| Con superior } \\
\text { permiso | por la viuda de D. } \\
\text { Joaquin Ibarra, |impresora de } \\
\text { la Real Academia. | Madrid } \\
\text { M.DCC.XCVI. }\end{array}$ & 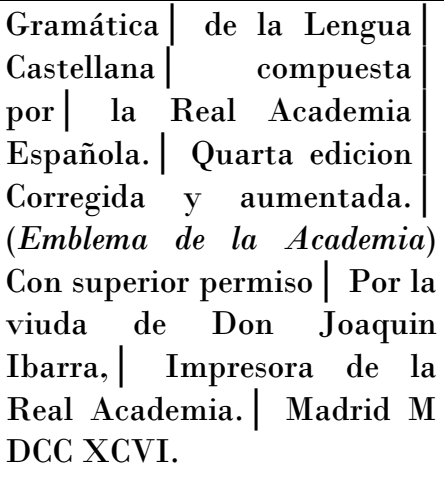 & $\begin{array}{l}\text { Gramática. Quarta edición. } \\
\text { Corregida y aumentada. Con } \\
\text { superior permiso. Por la } \\
\text { Viuda de D. Joaquin } \\
\text { Ibarra. Impresora de la } \\
\text { Real Academia, Madrid, } \\
\text { MDCCXCVI (1796) }\end{array}$ \\
\hline 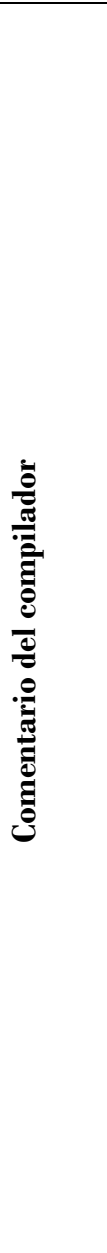 & $\begin{array}{l}\text { Descripción del tamaño, } \\
\text { paginación y distribución: } \\
\text { «8. }{ }^{\circ} \text { - } 3 \text { hs. prels. + XXV págs. + } \\
479 . \text { - Signs. *_**, A-Z, Aa-Gg, de } \\
8 \text { hs. } \\
\text { Port. - V. en b. - Ded. al Rey. - } \\
\text { Tabla de los capítulos. - Prólogo. } \\
\text { (Es el mismo de las ediciones } \\
\text { anteriores, pero con algunos } \\
\text { párrafos intercalados, en los cuales } \\
\text { se explican las adiciones hechas en } \\
\text { esta edición. He aquí los referidos } \\
\text { párrafos:) [...] } \\
\text { Texto, dividido en dos partes: De la } \\
\text { Analogía y De la Sintaxis. } \\
\text { Indice alfabético de las cosas } \\
\text { notables de esta Gramática». } \\
\text { (Págs. 592-594). }\end{array}$ & $\begin{array}{l}\text { Información } \\
\text { características físicas de la } \\
\text { edición y noticia de } \\
\text { novedades y reimpresión } \\
\text { posterior del texto: } \\
\text { «8. }{ }^{\circ} 4 \text { hojas prels. + XXV } \\
\text { págs. de prólogo, }+479 \text { págs. } \\
\text { de texto. } \\
\text { En esta edición se hicieron varias } \\
\text { adiciones de interés, que se } \\
\text { especifican en el prólogo. Se } \\
\text { reimprimió en "Madrid, } \\
\text { M.DCCCLII| Imprenta de la } \\
\text { Compañía de Impresores y } \\
\text { Libreros del Reino" a plana y } \\
\text { renglón de la anterior. Al } \\
\text { principio va una advertencia en } \\
\text { la que la Academia dice que en } \\
\text { este año de 1852 debía haberse } \\
\text { publicado una nueva edición de } \\
\text { la Gramática, pero que la larga y } \\
\text { grave enfermedad de su } \\
\text { Secretario (Gallego) lo había } \\
\text { impedido por ser él el } \\
\text { especialmente encargado de esta } \\
\text { obra. Pero a fin de satisfacer en } \\
\text { tanto la necesidad que el público } \\
\text { tenía de esta obra se repetía } \\
\text { exactamente la edición anterior } \\
\text { de 1796». (Pág. } 39 \text { ). }\end{array}$ & 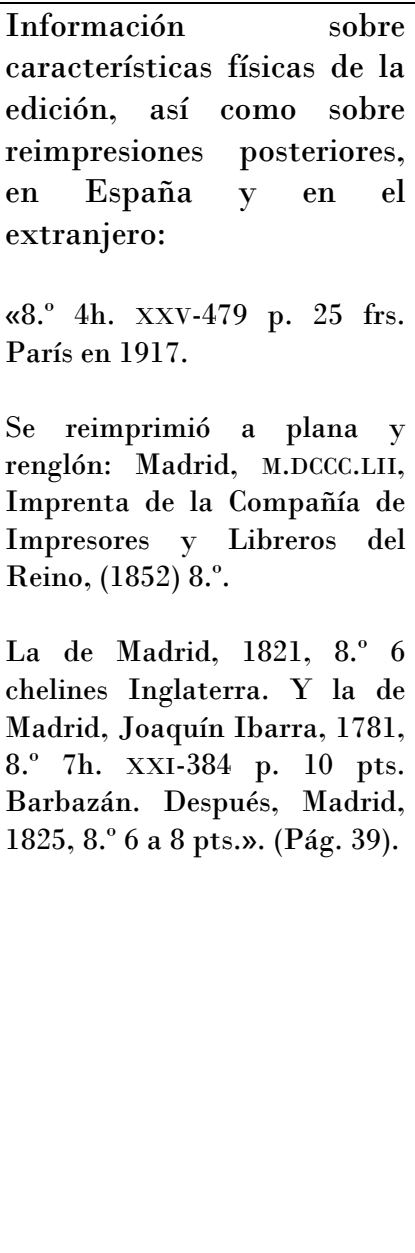 \\
\hline
\end{tabular}




\section{APUNTES SOBRE LA INFORMACIÓN}

(1) En las hojas preliminares de esta GRAE ya no aparece la licencia que presidía las tres primeras ediciones, según ha quedado indicado en la nota 43. Suprimida la Licencia, en rigor, los preliminares constarían de siete páginas (cinco de la Dedicatoria y dos de la Tabla de los capítulos). Todo parece indicar que los compiladores no han adoptado el mismo criterio que en las ediciones anteriores para realizar el cómputo de los preliminares; los tres han debido de atender al subíndice que aparece en estas páginas (y que las numera de dos en dos), pero han procedido de distinta forma: el conde de la Viñaza debió de seguir la práctica habitual de no tener en cuenta la Tabla de los capítulos -de ahí que registre 3 hojas de preliminares-; Cotarelo y Palau, por su parte, parecen haber decidido incluir en esta ocasión las dos páginas (numeradas conjuntamente en la edición como 4) de la Tabla de los capítulos que precede al Prólogo.

(2) La Viñaza vuelve a dar muestras de su gusto por la información exhaustiva y, en esta ocasión, reproduce los párrafos del prólogo en los que la Academia anuncia los cambios más significativos de esta cuarta edición. Para un conocimiento en profundidad sobre la información contenida en este prólogo, interesa el estudio de Gómez Asencio (2000b).

(3) La Advertencia de 1852 de la que habla Cotarelo precede a la dedicatoria habitual en todas las Gramáticas de la Institución (vid. supra nota 20), y en ella se pone de relieve el carácter oficial que en ese año ya tenía el texto académico, antes de la famosa Ley Moyano. Vuelvo a reproducir el fragmento de la Advertencia, esta vez para resaltar las palabras que dan cuenta de la oficialidad del texto institucional: 
La Academia se prometia publicar ya en este año la nueva edicion de su Gramatica; pero la grave y larga enfermedad de su digno Secretario, encargado muy especialmente de la redaccion, ha impedido que pueda verificarlo al tiempo en que mas falta hace en las escuelas públicas, como libro de texto designado por el Gobierno. Para atender á este servicio tan urgente ha acordado reimprimir el número de ejemplares que ha creido necesario, en la misma forma y carácter de letra que se empleó en la edicion precedente.

(El subrayado es mío)

Efectivamente, durante el reinado de Carlos III, en concreto en 1780, se decreta la obligatoriedad de uso de la Gramática de la Real Academia Española, lo que convierte a las GRAE en textos de especial relevancia en el ámbito de la enseñanza ${ }^{49}$. No será hasta 1857 (a raíz de la Ley Moyano) que se tengan libros diferentes para los distintos niveles de enseñanza.

(4) La edición de Madrid, 1821, que anota Palau y Dulcet podría ser la publicada simultáneamente en nuestro país y París en ese mismo año. Palau y Dulcet es el único que hace referencia a una edición en 1825, que podría sumarse a las supuestas reimpresiones que entre 1800 y 1831 se hacen de la última edición dieciochesca, de las que hemos hablado más arriba (vid. supra 2.1.).

${ }^{99}$ Según Lázaro Carreter (1985 [1949]: 189), la obligatoriedad se impone por Real Decreto. García Folgado (2004b: 101 y 2005/2006: 78) afirma que se trata de la aprobación, por parte de Carlos III, de los Estatutos del Colegio Académico de Primeras Letras. Martínez Alcalde (1998: 388) también se hace eco de la Provisión que ordenaba enseñar en las escuelas Gramática y Ortografía según lo establecido por la Real Academia Española y el reflejo de esta orden en los reglamentos de distintas instituciones escolares de la época. 
LOCALIZACIÓN: En la Sala de Investigadores de la RAE, hay un original duplicado [Signatura: 35-G-1 dupl. y Registro: 50334]. Más ejemplares, en Consultas, Sala de Académicos [Signatura: 35-G-1], Sala Dámaso Alonso [D 1-3-2-13] y Sala de Exposiciones. En la BNE, puede consultarse el ejemplar de la Sala Cervantes [Signatura: R/23545] o los ejemplares del Salón General (originales y microfilmados) con las signaturas: DGmicro/43426, 4/126649, 7/34423, 3/21871, 3/26538, 3/46204 y 3/47391. Cinco bibliotecas del CSIC registran esta Gramática: M-BG.Hum [Signatura: FA/87], M-IFL [Signatura: CVI/81], M-IH [Signatura: F.A.350], M-MNCN [Signatura: 1-5034] y M-Resid [Signatura: R.1628]. Una versión digitalizada puede encontrarse en Gómez Asencio (comp., 2001) y también en Google, desde donde puede descargarse una versión en PDF:

http:// books.google.com/books?id=w7IGAAAAQAAJ\&pg=PA3\&dq=editions:0UHWC6us5XdzwNrl\# PPP7,M1

(*) Es fácil encontrar ejemplares a la venta en Internet, pero con un precio, por lo general, bastante por encima del de otras ediciones (el de los ejemplares que he localizado oscila entre los sesenta y cinco y los quinientos euros). 


\subsubsection{GRAE-1854}

\section{INFORMACIÓN COMPILADA}

\begin{tabular}{|c|c|c|c|}
\hline & $\begin{array}{c}\text { La Viñaza } \\
(\mathbf{1 8 9 3}) \\
\end{array}$ & $\begin{array}{c}\text { Cotarelo } \\
(1928) \\
\end{array}$ & $\begin{array}{c}\text { Palau y Dulcet } \\
(\mathbf{1 9 4 8 )} \\
\end{array}$ \\
\hline $\begin{array}{c}\text { N. }{ }^{\circ} \text { de } \\
\text { ed. }\end{array}$ & ¡9. ${ }^{\mathrm{a}}$ ! & {$\left[5 .^{\mathrm{a}}\right]$} & {$\left[5 .^{a}\right]$} \\
\hline 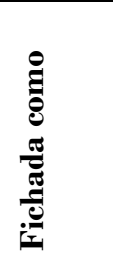 & $\begin{array}{l}\text { Novena edición: Gramática } \mid \text { de } \\
\text { la lengua castellana, | por | la } \\
\text { Real Academia } \\
\text { Española. | Nueva edición. (Esc. } \\
\text { de la acad.) Madrid.| En la } \\
\text { Imprenta Nacional. | } 1854 .\end{array}$ & 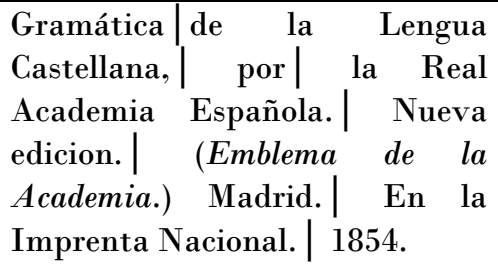 & $\begin{array}{l}\text { Gramática. Nueva } \\
\text { edición. M., En la } \\
\text { Imp. Nacional, } 1854 .\end{array}$ \\
\hline 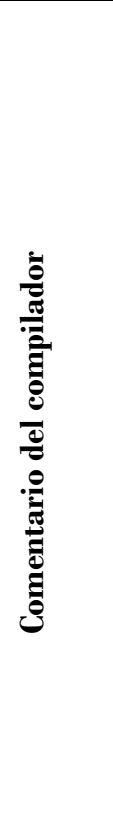 & $\begin{array}{l}\text { Información sobre el tamaño, } \\
\text { número de páginas, distribución } \\
\text { y contenidos: } \\
\text { «4. } .^{\circ} \text { - x-226 págs. } \\
\text { Port. - Prólogo [...] } \\
\text { Texto. - Índice. - Erratas. } \\
\text { Igual número de páginas y materia } \\
\text { que en las dos precedentes } \\
\text { impresiones». (Pags. } 594-599) .\end{array}$ & $\begin{array}{l}\text { Información sobre el volumen y } \\
\text { número de páginas, seguida de } \\
\text { una observación sobre la } \\
\text { práctica académica de numerar } \\
\text { las ediciones y una advertencia } \\
\text { sobre el error contenido en el } \\
\text { catálogo de la Viñaza y sobre la } \\
\text { novedad que supone esta edición } \\
\text { de la Gramática: } \\
\text { «4. }{ }^{\circ} \text { x-226 págs. Desde esta } \\
\text { impresión dejaron de numerarse las } \\
\text { ediciones: la que se ha puesto en la } \\
\text { Bibliogr. del Conde de la Viñaza } \\
\text { está equivocada, por haberse } \\
\text { colocado mal esta impresión de } \\
\text { 1854. Esta edición es muy distinta } \\
\text { de la de } 1796 \text {, pues se han tenido } \\
\text { presentes, entre otras, las } \\
\text { Gramáticas de D. Vicente Salvá y D. } \\
\text { Andrés Bello». (Págs. 39-40). }\end{array}$ & 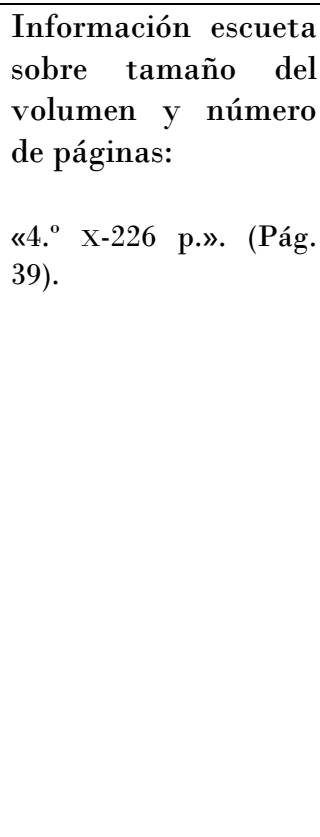 \\
\hline
\end{tabular}

Cuadro 7: GRAE-1854 en las compilaciones

\section{APUNTES SOBRE LA INFORMACIÓN}

(1) La Viñaza reproduce casi de forma íntegra el prólogo de esta edición ${ }^{50}$. Omite el último párrafo, en el que la RAE habla de la riqueza y variedad de la lengua castellana; apunta el objetivo fundamental de la labor de la Institución («sostener la grandeza de tan bello idioma») y recomienda encarecidamente a los jóvenes la lectura de los autores clásicos.

50 Sobre este prólogo y el de la GRAE-1858 ha tratado conjuntamente Gómez Asencio (2002a). 
(2) Ninguno de los compiladores hace constar que en la anteportada aparecen, por primera vez en la GRAE, los derechos de propiedad (que se repiten -con algunos cambios- en todas las ediciones siguientes) ${ }^{51}$.

(3) Sorprende bastante que La Viñaza anote la edición de 1854 tras la de 1865, como 9. a edición. Sorprende que afirme que contiene el mismo número de páginas que las tres ediciones anteriores (teniendo en cuenta que, debido al error en la ordenación, no debe referirse a las ediciones de 1796, 1781 y 1772 -las que le preceden realmente en la cronología-, sino a las GRAE de 1865, 1864 y 1862)52, cuando él mismo anota 226 páginas para el texto de 1854 y 254 páginas para los tres anteriores (sobre esto ya ha advertido Gómez Asencio,

51 Los cambios más importantes -de otros hablaremos en el apartado correspondientetendrán que ver, primero (en 1870), con el cumplimiento de la preceptiva legal por parte de la Institución y, después (en 1880), con el cambio de ley que rige los derechos de propiedad. Tres son, por tanto, los modelos de "declaración de derechos de propiedad" que encontramos en la GRAE (cito por la primera Gramática de cada grupo -los cambios entre las ediciones de un mismo grupo son ligeros: tipográficos, de puntuación y de redacción-):

$\left.1^{\circ}{ }^{\circ}\right)$ GRAE-1854, 1858, 1862, 1864, 1865, 1866 y 1867: parca declaración de derechos de exclusividad:

Esta Gramática es propiedad exclusiva de la Real Academia Española.

$2^{\circ}{ }^{\circ}$ ) GRAE-1870, 1874 y 1878: cumplimiento de la preceptiva de 1847 sobre propiedad literaria:

Esta obra es propiedad de la Academia Española, que ha cumplido con las prescripciones de la ley de 10 de Junio de 1847 sobre propiedad literaria, y hará uso de su derecho contra quien se lo usurpare.

(El subrayado es mío. Con variante de redacción en algunos de los libros del siguiente grupo)

3. $\left.{ }^{\circ}\right)$ GRAE-1880, 1883, 1885, 1888, 1890, 1895, 1900, 1901, 1904, 1906, 1908, 1909, 1911, 1913, 1916, 1917, 1920, 1924, 1928, 1931, 1959 y 1962: cumplimiento de la preceptiva de 1879 sobre propiedad literaria (desde 1885 "propiedad intelectual"):

Esta obra es propiedad exclusiva de la REAL ACADEMIA ESPAÑOLA, que se reserva cuantos derechos le corresponden con arreglo á la Ley de propiedad literaria de 10 de Enero de 1879 y á los convenios sobre esta materia celebrados por España con otras naciones. La ACADEMIA perseguirá á quien le usurpare cualquiera de estos derechos.

(Desde 1888, sin la parte que subrayo, sobre la que volveré)

52 En el cuadro correspondiente al conde de la Viñaza del Apéndice I puede verse con más claridad. 
2002a: 198). Sorprende igualmente que afirme que se trata del mismo texto que las dos ediciones anteriores porque la GRAE-1854 difiere de las dos que le preceden cronológicamente (1796 y 1781), pero también de las que supuestamente le preceden según este catálogo, las de 1865 y 1864, pues el texto de 1858 ya presenta cambios con respecto a la GRAE-1854. Estas diferencias (que son claras, sobre todo en lo relativo a disposición textual) no invalidan la afirmación hecha en Gómez Asencio (2005: 597) porque, efectivamente, la quinta edición es "respetuosa con el espíritu de 1796". Y tendremos oportunidad de confirmarlo en los apartados siguientes de esta investigación.

(4) Que Cotarelo ponga de relieve el error en la ordenación que figura en la Biblioteca del conde de La Viñaza y no lo haga, sin embargo, Palau y Dulcet lo entiendo como consecuencia de la coetaneidad de los dos primeros compiladores: Cotarelo tuvo, sin duda, más presente la obra de La Viñaza porque fueron colegas prácticamente en los mismos años y porque el catálogo de Cotarelo versa monográficamente sobre la labor académica, lo cual le impone un análisis más detenido de las posibles fuentes documentales. El carácter general del Manual del librero hispano-americano exime al autor de un análisis somero de fuentes indirectas sobre las obras.

(5) Es cierto que la costumbre de numerar las ediciones y reimpresiones se pierde en este libro de 1854. Cierto es, igualmente, que esta quinta edición difiere de forma visible de la cuarta -ya se ha dicho-, pero no es la razón fundamental del cambio el hecho de que se hayan tenido presentes las Gramáticas de Salvá y Bello, según se deduce de las palabras de Cotarelo. Para las deudas reales de la GRAE-1854 con estos dos gramáticos, remito a dos estudios míos (Garrido Vílchez, 2001b y 2002a). 
II. Los textos del corpus

LOCALIZACIÓN: El ejemplar de la Sala de Investigadores de la RAE es un original duplicado con registro 35277 y signatura 35-G-3. Puede encontrarse otro original en la Sala de Académicos (con la misma signatura) y en Consultas. En la BNE se encuentra esta GRAE con tres signaturas distintas y puede consultarse en el Salón General: DGmicro/9299; 1/43623 y 1/63262 -este último ejemplar procede del legado de Hartzenbusch-. La quinta edición no se localiza en ninguna de las bibliotecas del CSIC. Una versión digitalizada puede encontrarse en Gómez Asencio (comp., 2001). 


\subsubsection{GRAE-1858}

\section{INFORMACIÓN COMPILADA}

\begin{tabular}{|c|c|c|c|}
\hline & $\begin{array}{c}\text { La Viñaza } \\
\text { (1893) }\end{array}$ & $\begin{array}{c}\text { Cotarelo } \\
(1928) \\
\end{array}$ & $\begin{array}{c}\text { Palau y Dulcet } \\
\text { (1948) }\end{array}$ \\
\hline $\begin{array}{c}\text { N. }{ }^{\circ} \text { de } \\
\text { ed. }\end{array}$ & $5 .^{a}$ & {$\left[6 .^{\mathrm{a}}\right]$} & {$\left[6 .^{\mathrm{a}}\right]$} \\
\hline 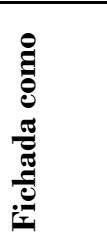 & $\begin{array}{l}\text { Quinta edición: Madrid. En la } \\
\text { Imprenta Nacional, 1858. }\end{array}$ & \begin{tabular}{l|c|r} 
Gramática & de la lengua \\
castellana, & por la $\mid \begin{array}{r}\text { Real } \\
\text { Academia Española. | (Emblema }\end{array}$ \\
de la Acad. $)$ Madrid. | En la \\
Imprenta Nacional. 1858.
\end{tabular} & $\begin{array}{l}\text { Gramática. M., en la } \\
\text { Imp. Nacional, } 1858 .\end{array}$ \\
\hline 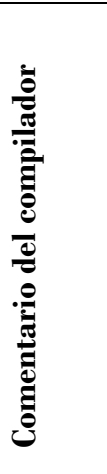 & $\begin{array}{l}\text { Breve información sobre } \\
\text { tamaño, páginas y contenidos } \\
\text { del texto: } \\
\text { «4. - VII-251 págs. - Reprodúcese en } \\
\text { general el texto de la anterior } \\
\text { impresión de 1854; pero contiene } \\
\text { algunas enmiendas que ya adoptó la } \\
\text { Academia en el Compendio y en el } \\
\text { Epítome de la Gramática Castellana, } \\
\text { reimpresos en el mismo año de } \\
\text { l858». (Pág. 594). }\end{array}$ & $\begin{array}{l}\text { Escueta información relativa al } \\
\text { tamaño del volumen y al } \\
\text { número de páginas: } \\
\text { «4. ; VII-25l págs». (Pág. } 40 \text { ). }\end{array}$ & $\begin{array}{lr}\text { La } & \text { misma } \\
\text { información } & \text { de } \\
\text { arriba: } & \\
& 4 .^{\circ} \text { VII-251 p.». (Pág. } \\
39) . & \end{array}$ \\
\hline
\end{tabular}

Cuadro 8: GRAE-1858 en las compilaciones

\section{APUNTES SOBRE LA INFORMACIÓN}

(1) Aunque no se presente en la portada como tal, la GRAE-1858 puede entenderse como "nueva edición" por cuanto supone una concepción distinta del libro de Gramática de la mantenida en 1854 (sobre este aspecto volveré en el apartado 1. del punto 4.2.1.).

(2) Según queda indicado en el apunte (2) del apartado 2.3.5., la edición de 1858 presenta en la anteportada una nota relativa a los derechos de autor (ídem GRAE-1854); a ella suma una información sobre la obligatoriedad del texto en las escuelas públicas, aviso derivado directamente de la Ley de Instrucción Pública de 9 de septiembre de 1857 (de hecho, la Institución transcribe letra por 
letra las líneas oportunas del artículo 88 de la Ley $)^{53}$. No hay duda de que la Ley Moyano contribuye a acentuar el carácter preferente de los libros académicos que, según ya se ha indicado, eran obligatorios desde 1780. Es tras la Ley Moyano cuando la Academia pone la advertencia (lo hará de forma ininterrumpida hasta la edición de 1867 -incluida-) y es a raíz de esta ley que ven la luz el CRAE y el ERAE.

(3) Esta Gramática reproduce los párrafos que se consideran más destacables del Prólogo de 1854. El apartado preliminar, en la nueva edición, lleva el epígrafe de Advertencias, si bien en el encabezado de las páginas que ocupa (tres en total) reza "PRÓLOGO".

(4) Aquí es donde se encuentra uno de los errores más llamativos de la información ofrecida por La Viñaza, que no dudo en atribuir a un despiste por parte del compilador. Hemos adelantado en 2.2. que el registrar la GRAE-1858 como quinta edición (en lugar de como sexta) arrastra cuatro errores más: a partir de aquí, quedarán mal registradas las ediciones de 1862, 1864, 1865 y 1854 (vid. supra apunte (3) de 2.3.5.) 54 .

${ }^{53}$ En la anteportada y debajo de los derechos de propiedad, se lee:

La Gramática y Ortografía de la Academia Española serán texto obligatorio y único para estas materias en la enseñanza pública.

(Ley de 9 de Setiembre de 1857, art. 88.)

En el Diccionario de legislación de primera enseñanza, de Fernández Ascarza (1924), se encuentra reproducida esta Ley y la que le sirvió de planta, la Ley de bases de 17 de julio de 1857. La ley de julio había sido discutida y aprobada por las Cortes; la de septiembre resultó del desarrollo e interpretación que el ministro de Fomento, D. Claudio Moyano, y sus hombres hicieron de las bases aprobadas por las Cortes. De ahí el nombre con que popularmente fue conocida esta última ley. Hasta 1924 poca y mala legislación conocerá la enseñanza pública, lo que lleva a Fernández Ascarza (1924: 723) a poner de relive la vigencia de la Ley Moyano, con estas palabras: «a pesar de su antigüedad, de las revueltas políticas y de los cambios de gobiernos, de ser derogada y restablecida de nuevo varias veces, sigue inspirando nuestra vida jurídica docente».

${ }^{54}$ Vuelvo a remitir, para una visión más clara, al cuadro correspondiente del Apéndice I. 
En este punto concreto, no creo que la interpretación de Gómez Asencio (2002a: 198) sea plausible, puesto que este estudioso plantea la posibilidad de que "alguien por razón desconocida cometió desliz" y aplicó a la edición de 1858 la información relativa a la GRAE-1865. ¿De la GRAE-1865 se iba a decir que era prácticamente igual que la "anterior impresión de 1854"? ¿Iba a esperarse hasta esta edición para hablar de los cambios en el CRAE y el ERAE? Efectivamente, el texto que precede a la GRAE-1858 es el de 1854, pero La Viñaza no repara en que ha dado como entrada anterior la edición de 1796. A partir de este punto, la numeración equivocada de las ediciones se extiende hasta la GRAE-1866, bien anotada ya como 10. ${ }^{a}$ edición.

LOCALIZACIÓN: Puede consultarse un ejemplar fotocopiado en la Sala de Investigadores de la RAE [Signatura: 35-G-4 dupl. y Registro -poco legible-: 35280 -?-]; el original se encuentra en la Sala de Académicos. En la BNE solo hay un ejemplar con la signatura 1/45243, que puede consultarse en el Salón General. El CSIC cuenta con un ejemplar en la biblioteca M-IFL [Signatura: LXV/250].

$\left(^{*}\right)$ Igual que ocurre con la edición anterior, es raro poder encontrar un ejemplar de esta Gramática a la venta. Sí se puede adquirir una versión digitalizada, la contenida en la compilación de textos gramaticales de Gómez Asencio (comp., 2001). 


\subsubsection{GRAE-1862}

INFORMACIÓN COMPILADA

\begin{tabular}{|c|c|c|c|}
\hline & $\begin{array}{c}\text { La Viñaza } \\
\text { (1893) }\end{array}$ & $\begin{array}{c}\text { Cotarelo } \\
(\mathbf{1 9 2 8})\end{array}$ & $\begin{array}{c}\text { Palau y Dulcet } \\
\text { (1948) }\end{array}$ \\
\hline $\begin{array}{l}\text { N. }{ }^{\circ} \text { de } \\
\text { ed. }\end{array}$ & $6 .^{a}$ & {$\left[7 .^{\mathrm{a}}\right]$} & {$\left[7 .^{\mathrm{a}}\right]$} \\
\hline 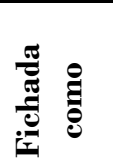 & $\begin{array}{l}\text { Sexta edición: Madrid. Imprenta } \\
\text { Nacional, } 1862 .\end{array}$ & \begin{tabular}{l|c|c} 
Gramática & $\ldots$ & (como la \\
anterior) ... Madrid. $\mid$ En la \\
Imprenta Nacional. $\mid 1862$.
\end{tabular} & $\begin{array}{l}\text { Gramática. M., } \quad \text { Imp. } \\
\text { Nacional, 1862. }\end{array}$ \\
\hline 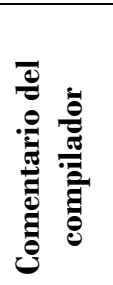 & $\begin{array}{l}\text { Escueta información sobre } \\
\text { tamaño, páginas y contenidos } \\
\text { del texto: } \\
\text { «4. }^{\circ}-254 \text { págs. - Igual texto que la } \\
\text { anterior pero sin las advertencias } \\
\text { preliminares» (Pág. } 594) \text {. }\end{array}$ & $\begin{array}{l}\text { Escueta información sobre } \\
\text { tamaño, páginas } \\
\text { contenidos del texto: } \\
\text { «4. } .^{\circ} ; 254 \text { págs. Se ha suprimido } \\
\text { el prólogo». (Pág. } 40) .\end{array}$ & $\begin{array}{l}\text { Escueta información } \\
\text { sobre tamaño y páginas: } \\
\left.\text { «4. }{ }^{\circ} 254 \text { p.». (Pág. } 39\right) .\end{array}$ \\
\hline
\end{tabular}

Cuadro 9: GRAE-1862 en las compilaciones

\section{APUNTES SOBRE LA INFORMACIÓN}

(1) El cambio de número de páginas con respecto a la edición anterior se debe a que, en la GRAE-1858, después de las páginas prologales, se inicia la numeración de página (la primera del cuerpo de la Gramática es la pág. 1), mientras que, en la GRAE-1862, la primera página responde a la número 5 . He podido comprobar que los distintos apartados ocupan idéntica extensión en ambos libros.

(2) Cotarelo utiliza la etiqueta de "prólogo" para estas páginas introductorias y La Viñaza la de "advertencia". Remito al apunte (3) del apartado anterior. Palau pasa por alto la supresión de estas páginas (cuestión importante en lo que afecta a la concepción de la disciplina y del libro sobre la disciplina).

(3) Es la segunda edición en la que, en la anteportada, encontramos dos notas: una relativa a los derechos de propiedad y otra relativa al carácter obligatorio de la Gramática académica. 
Las Gramáticas de la Real Academia Española: teoría gramatical, sintaxis y subordinación (1854-1924)

LOCALIZACIÓN: Esta edición se encuentra en la RAE con el registro 35281 y la signatura 35-G-29 dupl. Se trata de un ejemplar fotocopiado (en la Sala de Académicos se encuentra el original). La BNE dispone de un ejemplar procedente de la Biblioteca Barbieri [Signatura: 2/51513] y una reproducción microfilmada [Signatura: DGmicro/14985]; ambos pueden consultarse en el Salón General. No se encuentra ningún ejemplar en el CSIC. 


\subsubsection{GRAE-1864}

INFORMACIÓN COMPILADA

\begin{tabular}{|c|c|c|c|}
\hline & $\begin{array}{c}\text { La Viñaza } \\
(1893) \\
\end{array}$ & $\begin{array}{c}\text { Cotarelo } \\
(1928) \\
\end{array}$ & $\begin{array}{c}\text { Palau y Dulcet } \\
\text { (1948) }\end{array}$ \\
\hline N. ${ }^{\circ}$ de ed. & $7 .^{a}$ & {$\left[8 .^{\mathrm{a}}\right]$} & {$\left[8 .^{\mathrm{a}}\right]$} \\
\hline 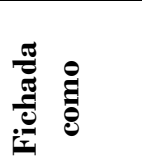 & $\begin{array}{l}\text { Séptima edición: Madrid. } \\
\text { Imprenta Nacional, } 1864 .\end{array}$ & \begin{tabular}{l|l|c|} 
Gramática & $\ldots$ & (como la \\
anterior)... & \multicolumn{2}{|c}{ Madrid. $\mid$} \\
Imprenta Nacional. $\mid 1864$.
\end{tabular} & $\begin{array}{l}\text { Gramática. M., } \quad \text { Imp. } \\
\text { Nacional, 1864. }\end{array}$ \\
\hline 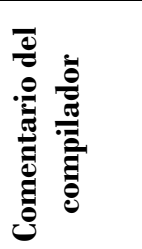 & $\begin{array}{l}\text { Identidad con respecto a la } \\
\text { edición precedente: } \\
\text { «Igual número de págs. y materia } \\
\text { que la precedente». (Pág. 594). }\end{array}$ & $\begin{array}{l}\text { Breve nota sobre volumen y } \\
\text { número de páginas: } \\
\left.\text { «4. }{ }^{\circ} ; 254 \text { págs». (Pág. } 40\right) .\end{array}$ & $\begin{array}{l}\text { Breve nota sobre } \\
\text { volumen y número de } \\
\text { páginas: } \\
\text { «4. }{ }^{\circ} 254 \text { p.». (Pág. 39). }\end{array}$ \\
\hline
\end{tabular}

Cuadro 10: GRAE-1864 en las compilaciones

\section{APUNTES SOBRE LA INFORMACIÓN}

(1) Aunque no lo indiquen ni Cotarelo ni Palau de ninguna forma (estos compiladores no suelen recurrir a señalar el carácter idéntico de un texto respecto de otro, como sí hace La Viñaza), esta edición, igual que la anterior, no presenta prólogo. En realidad, no volvemos a encontrar páginas prologales hasta la edición de 1870. De modo que las Gramáticas de los años sesenta se caracterizan, en conjunto, por la ausencia de estas páginas de presentación. Parece lógica la explicación de Gómez Asencio (2005: 597), y es que los libros publicados a lo largo de esta década no son más que reimpresiones del texto de 1858, con lo cual dejó de resultar pertinente el aviso preliminar sobre las novedades contenidas en la "nueva" edición (que, además, eran novedades de 1854, pues ya se ha dicho que la Advertencia de 1858 reproduce los párrafos más importantes de la edición anterior -cf. apunte (3) de 2.3.6.-).

(2) La de 1864 es la tercera Gramática que la Institución saca a la luz pública con las dos notas antes referidas sobre derechos de propiedad y carácter 
obligatorio, ambas, como en las dos ediciones precedentes, en la anteportada del libro.

LOCALIZACIÓN: Con la signatura 35-G-30 dupl., hay en la Sala de investigadores de la RAE una fotocopia del original que se encuentra en la Sala de Académicos. El número de registro no se ve en la reproducción fotocopiada. Esta edición no consta en los fondos de la BNE. Tampoco la he localizado en el CSIC. 


\subsubsection{GRAE-1865}

INFORMACIÓN COMPILADA

\begin{tabular}{|c|c|c|c|}
\hline & $\begin{array}{c}\text { La Viñaza } \\
(\mathbf{1 8 9 3 )}\end{array}$ & $\begin{array}{c}\text { Cotarelo } \\
(1928) \\
\end{array}$ & $\begin{array}{c}\text { Palau y Dulcet } \\
\text { (1948) }\end{array}$ \\
\hline N. ${ }^{\circ}$ de ed. & $8 .^{a}$ & {$\left[9 .^{\mathrm{a}}\right]$} & {$\left[9 .^{a}\right]$} \\
\hline 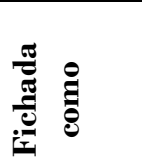 & $\begin{array}{l}\text { Octava edición: Madrid. } \\
\text { Imprenta Nacional, } 1865 .\end{array}$ & \begin{tabular}{l|ll} 
Gramática & $\ldots$ & (como las \\
anteriores $) \ldots .$. & \multicolumn{2}{c}{ Madrid. } \\
Impr. Nac. & 1865.
\end{tabular} & Idem. Id., id., 1865 \\
\hline 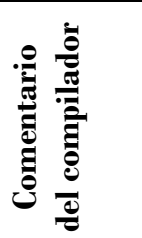 & Sin comentarios. & $\begin{array}{l}\text { Breve nota sobre volumen y } \\
\text { número de páginas: } \\
\left.\text { «4. } .^{\circ} ; 255 \text { págs». (Pág. } 40\right) .\end{array}$ & $\begin{array}{l}\text { Breve nota sobre } \\
\text { volumen y número de } \\
\text { páginas: } \\
\text { «4. }{ }^{\circ} \text { X-226 p.». (Pág. 39). }\end{array}$ \\
\hline
\end{tabular}

Cuadro 11: GRAE-1865 en las compilaciones

\section{APUNTES SOBRE LA INFORMACIÓN}

(1) Sin duda, hay un error en el número de páginas dado por Palau y Dulcet. La GRAE-1865 consta de 255 páginas (tal como indica Cotarelo) si consideramos la última de «Obras publicadas por la Real Academia Española, que se hallan de venta en su despacho de la calle de Valverde, en Madrid, número 26, y en el de la Imprenta Nacional, calle de Carretas», que va numerada $a^{55}$.

(2) Por cuarta vez la Academia incluye en la anteportada de la edición las advertencias sobre propiedad y obligatoriedad del texto.

LOCALIZACIÓN: En la Academia, encontramos un ejemplar fotocopiado con signatura 35-G-31 dupl. en la Sala de Investigadores (no se lee el número de registro); el original se halla en la Sala de Exposiciones. El ejemplar de la BNE, procedente de la B. ${ }^{a}$ de Osuna, puede consultarse en el Salón General [Signatura: 1/37773]. Ningún ejemplar en el CSIC.

55 La costumbre de incluir al final de la edición un catálogo de obras publicadas por la Academia se inicia con la GRAE-1858. Las 251 páginas que en esa $6 .^{a}$ edición dan los tres compiladores (cf. 2.3.6.) incluyen la última hoja del catálogo -que va numerada-. En la GRAE1862 anotan los tres 254 páginas ( $c f .2 .3 .7$ ), en esta ocasión sin tener en cuenta la del catálogo, pese a que también va numerada como la 255. Lo mismo sucede con la GRAE-1864 (cf. 2.3.8). 
2.3.10. GRAE-1866

INFORMACIÓN COMPILADA

\begin{tabular}{|c|c|c|c|}
\hline & $\begin{array}{c}\text { La Viñaza } \\
\text { (1893) }\end{array}$ & $\begin{array}{c}\text { Cotarelo } \\
\text { (1928) }\end{array}$ & $\begin{array}{c}\text { Palau y Dulcet } \\
\text { (1948) }\end{array}$ \\
\hline N. ${ }^{\circ}$ de ed. & $10 .^{a}$ & {$\left[10 .^{\mathrm{a}}\right]$} & {$\left[10 .^{\mathrm{a}}\right]$} \\
\hline 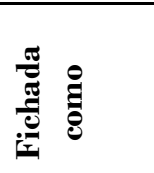 & $\begin{array}{l}\text { Décima edicion: } \\
\text { Imprenta Nacional. } 1866 .\end{array}$ & \begin{tabular}{l|ll} 
Gramática & $\ldots$ & (como las \\
anteriores $). .$. & \multicolumn{2}{c}{ Madrid $\mid$} \\
Imprenta Nacional. $\mid 1866$.
\end{tabular} & Idem. Id., id., 1866. \\
\hline 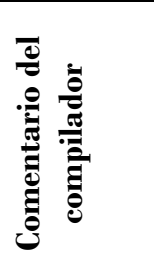 & $\begin{array}{l}\text { Identidad con respecto a las } \\
\text { ediciones precedentes: } \\
\text { «Igual número de páginas y } \\
\text { materia que en las tres } \\
\text { precedentes». (Pág. 599). }\end{array}$ & $\begin{array}{l}\text { Breve nota sobre volumen y } \\
\text { número de páginas: } \\
\text { «4. } ; 255 \text { págs». (Pág. } 40) .\end{array}$ & $\begin{array}{l}\text { Breve nota sobre } \\
\text { volumen y número de } \\
\text { páginas: } \\
\text { «4. } .^{\circ} 255 \text { p.». (Pág. 39). }\end{array}$ \\
\hline
\end{tabular}

Cuadro 12: GRAE-1866 en las compilaciones

\section{APUNTES SOBRE LA INFORMACIÓN}

(1) No puede darse como información correcta la ofrecida en la Biblioteca si entre "las tres precedentes" La Viñaza incluye, como parece ser, la edición de 1854.

(2) A partir de esta entrada, volvemos a tener una ordenación correcta de las ediciones en el primer catálogo.

(3) En cuanto al número de páginas, la indicación que hace La Viñaza nos lleva a las 254 de la GRAE-1862, pues de la edición de 1865 no da información alguna y de la GRAE-1864 decía que tenía el mismo número de páginas que la precedente. Por tanto, no coinciden los datos de los tres compiladores. No hay duda de que La Viñaza sigue sin computar la página del catálogo -numerada como la 255-; y Cotarelo y Palau, en esta ocasión, sí lo hacen. 
(4) Al igual que en las cuatro ediciones anteriores, encontramos en la anteportada notas que advierten sobre los derechos de propiedad del libro y sobre el carácter obligatorio del texto en la enseñanza pública.

LOCALIZACIÓN: Puede consultarse un original duplicado de esta Gramática en la Sala de Investigadores de la RAE [Signatura: 35-G-5 dupl. y Registro: 35284]. Otro original hay en la Sala de Académicos. La GRAE-1866 no figura en el catálogo de la BNE. Tampoco se encuentra esta edición en ninguna biblioteca del CSIC.

(*) De las Gramáticas de los años sesenta es muy difícil encontrar ejemplares en las librerías de viejo. Solo he podido localizar uno, de esta décima edición, por sesenta euros. 
2.3.11. GRAE-1867

INFORMACIÓN COMPILADA

\begin{tabular}{|c|c|c|c|}
\hline & $\begin{array}{c}\text { La Viñaza } \\
\text { (1893) }\end{array}$ & $\begin{array}{c}\text { Cotarelo } \\
(\mathbf{1 9 2 8})\end{array}$ & $\begin{array}{c}\text { Palau y Dulcet } \\
(1948)\end{array}$ \\
\hline N. ${ }^{\circ}$ de ed. & $11 .^{a}$ & {$\left[11 .^{a}\right]$} & {$\left[11 .^{\mathrm{a}}\right]$} \\
\hline 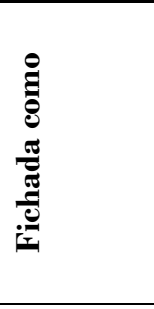 & $\begin{array}{l}\text { Undécima edicion: Madrid. } \\
\text { Imprenta de Miguel Ginesta, } \\
\text { calle de Isabel la Católica, } \\
\text { núm. } 4,1867 .\end{array}$ & \begin{tabular}{l|r|r} 
Gramática & de la & Lengua \\
Castellana, & por la $\mid$ Real \\
Academia & Española. \\
(Emblema) & Madrid \\
Imprenta de & Miguel \\
Ginesta $\mid$ calle de Isabel la \\
Católica, núm. 4. & 1867. \\
\end{tabular} & $\begin{array}{l}\text { Idem. M., Imp. de Miguel } \\
\text { Ginesta, calle de Isabel la } \\
\text { Católica, } 1867\end{array}$ \\
\hline 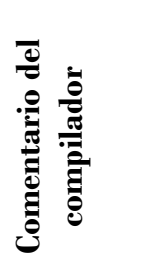 & $\begin{array}{l}\text { Identidad con respecto a las } \\
\text { ediciones precedentes: } \\
\text { «Igual número de páginas y } \\
\text { materia que en las cuatro } \\
\text { anteriores». (pág. 599). }\end{array}$ & $\begin{array}{l}\text { Escueta información sobre } \\
\text { las páginas de la edición: } \\
\text { «4. } ; 254 \text { págs. y una hoja de } \\
\text { anuncios de las demás obras de } \\
\text { la Academia». (Pág. } 40) \text {. }\end{array}$ & $\begin{array}{l}\text { Breve nota sobre } \\
\text { volumen y número de } \\
\text { páginas: } \\
\text { «4. } .^{\circ} \text { X-226 p.». (Pág. 39). }\end{array}$ \\
\hline
\end{tabular}

Cuadro 13: GRAE-1867 en las compilaciones

\section{APUNTES SOBRE LA INFORMACIÓN}

(1) En la anteportada, encontramos por última vez la declaración de propiedad (= copyright) junto con la relativa a la obligatoriedad del texto académico en las escuelas públicas (Ley Moyano). La segunda de estas notas desparece en la siguiente edición y no volverá a aparecer en este lugar en ningún otro texto.

(2) Sobre la identidad defendida por La Viñaza, remito al apunte (1) del apartado anterior.

(3) También en este registro, Palau y Dulcet da equivocado el número de páginas de que consta la edición. El número ofrecido por Cotarelo -e indirectamente por La Viñaza, al remitir a las ediciones anteriores- es exacto en lo que respecta al texto de la Gramática. En rigor, el libro consta de 256 páginas si consideramos el catálogo (de una página y media sin numerar, en 
esta ocasión) de «Obras publicadas por la Real Academia Española que se hallan en venta en su despacho de la calle de Valverde, en Madrid, número 26, y en la librería de Moya y Plaza, calle de Carretas, núm. 8».

LOCALIZACIÓN: La RAE tiene un original duplicado en la Sala de Investigadores [Signatura: 35-G-6 Dupl. y Registro: 35287]. El original se encuentra en la Sala de Académicos y existe un tercer ejemplar de esta Gramática con la signatura 35-G-6 tripl., que, según la información de la página web de la Academia (http://cronos.rae.es/Absys/), se encuentra en el Pasillo 2. En la BNE, hay un reproducción en microfichas con signatura DGmicro/14934 y un ejemplar con signatura 1/42669, que pueden consultarse en el Salón General. No se localiza ningún ejemplar de esta edición en el CSIC. 


\subsubsection{GRAE-1870}

\section{INFORMACIÓN COMPILADA}

\begin{tabular}{|c|c|c|c|}
\hline & $\begin{array}{c}\text { La Viñaza } \\
(1893) \\
\end{array}$ & $\begin{array}{c}\text { Cotarelo } \\
(1928) \\
\end{array}$ & $\begin{array}{c}\text { Palau y Dulcet } \\
\text { (1948) } \\
\end{array}$ \\
\hline $\begin{array}{c}\text { N. }{ }^{\circ} \text { de } \\
\text { ed. }\end{array}$ & $12 .^{a}$ & {$\left[12 .^{\mathrm{a}}\right]$} & {$\left[12 .^{\mathrm{a}}\right]$} \\
\hline 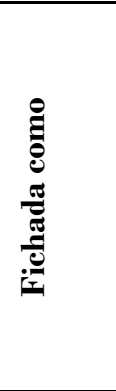 & $\begin{array}{l}\begin{array}{l}\text { Duodécima } \\
\text { edicion, } \\
\text { corregida }\end{array} \\
\text { aumentada. (Esc. de la } \\
\text { Acad.) Madrid, imprenta y } \\
\text { estereotipia de M. } \\
\text { Rivadeneyra, calle del Duque } \\
\text { de Osuna, núm. 3. 1870. }\end{array}$ & \begin{tabular}{l|cr|r} 
Gramática & de la & Lengua \\
Castellana, & por la & Real \\
Academia & Española. & Nueva \\
edicion, & corregida & y \\
aumentada. & \multicolumn{2}{c}{ (Emblema) } \\
Madrid, & Imprenta & y \\
estereotipia & de & M. \\
Rivadeneyra, & calle del Duque \\
de Osuna, número 3. & 1870.
\end{tabular} & 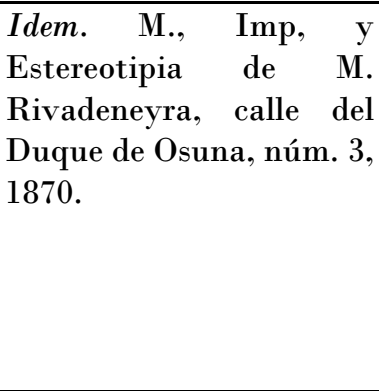 \\
\hline 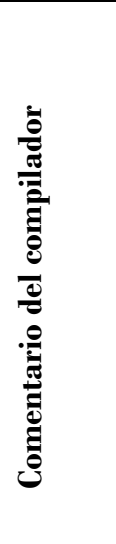 & $\begin{array}{l}\text { Información sobre el tamaño, } \\
\text { número de páginas, } \\
\text { distribución y contenidos: } \\
\text { «4. } .^{\circ} \mathrm{xv}+39[1] \text { págs. + una de } \\
\text { erratas. } \\
\text { Port. -Ind. de materias. - } \\
\text { Advertencia }[\ldots]-\text { Nociones } \\
\text { preliminares. - Texto. - Indice } \\
\text { alfabético. - Erratas.» (Págs. } \\
599-603) .\end{array}$ & $\begin{array}{l}\text { Información sobre volumen, } \\
\text { número de páginas y } \\
\text { principales cambios relativos al } \\
\text { contenido y a la doctrina: } \\
\text { «4. ; xv-391 págs., y } 2 \text { hojas para } \\
\text { erratas y anuncios. Tiene bastantes } \\
\text { innovaciones, como la de separar el } \\
\text { adjetivo del substantivo y } \\
\text { principalmente incluír ahora las } \\
\text { dos partes de la Gramática, } \\
\text { Prosodia y Ortografía, que faltaban } \\
\text { en las anteriores ediciones». (Pág. } \\
\text { 40). }\end{array}$ & 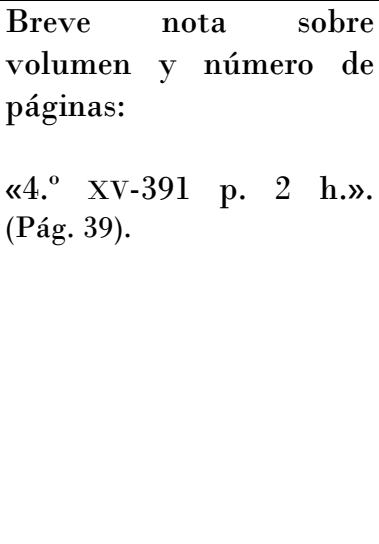 \\
\hline
\end{tabular}

Cuadro 14: GRAE-1870 en las compilaciones

\section{APUNTES SOBRE LA INFORMACIÓN}

(1) Tal como indican La Viñaza y Cotarelo, esta GRAE se presenta como "nueva edición" y, efectivamente, después de más de una década, la Academia saca una versión distinta de la Gramática. En realidad, hasta la fecha, el modelo doctrinal vigente ha sido el de la GRAE-1854 (que, en lo sustancial, no se altera con la edición de 1858, a pesar de lo dicho sobre el cambio de concepto de la finalidad del libro de Gramática -cf. apunte (1) del apartado 2.3.6.-). 
(2) Después de la hoja de erratas y enmiendas anotada por La Viñaza, volvemos a encontrar las obras publicadas por la RAE que están en venta (dos páginas sin numerar). Ninguna de estas hojas está computada en las 391 págs. numeradas.

(3) La GRAE-1870, antes del índice de materias, hace una mención de los derechos de propiedad, con un tono "más intimidatorio" que en ediciones anteriores (esta observación la hace Gómez Asencio, 2002b: 1230). Conviene recordar que, en las ediciones decimonónicas de los años setenta, la Corporación se expresa en estos términos:

Esta obra es propiedad de la ACADEMIA ESPAÑOLA, que ha cumplido con las prescripciones de la ley de 10 de Junio de 1847 sobre propiedad literaria, y hará uso de su derecho contra quien se lo usurpare.

(El subrayado es mío)

La simple alusión al cumplimiento por parte de la Institución de la ley de 1847, vigente -no lo olvidemos- ya en la edición que inaugura la costumbre de poner los derechos de propiedad (la GRAE-1854) pero callada hasta esta nueva edición, se podría interpretar por sí sola como sintomática de la voluntad de la Academia de tomar medidas legales contra los usurpadores. Sobre los derechos de propiedad -a los que me volveré a referir a propósito de ediciones siguientes-, remito a lo dicho en la nota 51.

(4) En esta edición, ha desaparecido de la anteportada la nota relativa al carácter obligatorio de los libros académicos. De modo que, a partir de la GRAE-1870, solo encontraremos la advertencia referida a la propiedad (que, además, cambia de lugar y aparece entre la portada y el índice de materias, no en la anteportada). 
(5) En esta ocasión, el conde de la Viñaza sí reproduce de forma íntegra la Advertencia que viene a sustituir al antiguo Prólogo, una nueva muestra -tras la parquedad de información para las ediciones de los años sesenta- de su gusto por la exhaustividad en las notas. En esta advertencia, la Academia anuncia las novedades de la $12 .^{\text {a }}$ edición.

(6) Es la primera vez que la Gramática académica introduce el apartado de “Nociones preliminares" (cinco páginas) antes de abordar el estudio pormenorizado de las partes constitutivas de la Gramática. En ellas, se tocan los siguientes asuntos: a) definición de idioma o lengua; b) razones por las que la lengua hablada en España se denomina española o castellana; c) definición del concepto de gramática y división en partes; d) repaso de las letras del alfabeto castellano -donde se aprecia una clara confusión entre letra y sonido-; f) concepto de sílaba; g) clasificación de las palabras según criterios prosódicos y de procedencia o formación; h) definición del concepto de oración; i) clasificación de las palabras atendiendo a la idea que representan o al oficio que desempeñan en la oración.

(7) La hoja de "erratas y enmiendas" va seguida de la ya tradicional lista de las obras publicadas por la Institución que se encuentran en venta en la calle Valverde y en la librería de Moya y Plaza (estos deben ser los "anuncios" que menciona Cotarelo).

(8) Efectivamente, tal como indica Cotarelo, esta es la primera edición que separa en cuatro apartados el libro de Gramática, frente a la división en dos de las ediciones anteriores. La Viñaza no llama la atención explícitamente sobre este cambio doctrinal porque -es de imaginar- ha decidido reproducir directamente las palabras de la propia Academia en la Advertencia de esta 
edición. Palau nos tiene acostumbrados al laconismo, de modo que no sorprende que pase por alto esta sustanciosa información.

LOCALIZACIÓN: Con la signatura 35-G-7 (D) y el registro 50336, se encuentra un original duplicado en la Sala de Investigadores de la RAE (otro original, en la Sala de Académicos). De esta edición hay un ejemplar en la BNE que puede consultarse en el Salón General [Signatura: 2/44342]. En el catálogo de la biblioteca M-Resid del CSIC, esta edición aparece con la signatura LE 3859. Una versión digitalizada puede encontrarse en Gómez Asencio (comp., 2001). 


\subsubsection{GRAE-1874}

\section{INFORMACIÓN COMPILADA}

\begin{tabular}{|c|c|c|c|}
\hline & $\begin{array}{c}\text { La Viñaza } \\
\text { (1893) }\end{array}$ & $\begin{array}{c}\text { Cotarelo } \\
\text { (1928) }\end{array}$ & $\begin{array}{c}\text { Palau y Dulcet } \\
\text { (1948) }\end{array}$ \\
\hline N. ${ }^{\circ}$ de ed. & $13 .^{a}$ & {$\left[13 .^{a}\right]$} & {$\left[13 .^{a}\right]$} \\
\hline 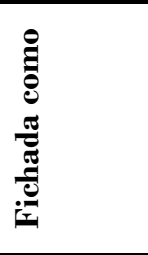 & $\begin{array}{l}\text { Décimatercia } \\
\text { Nueva edicion, corregida y } \\
\text { aumentada. } \\
\text { imprenta y fundicion de } \\
\text { Manuel Tello, Isabel la } \\
\text { Católica, 23, 1874. }\end{array}$ & $\begin{array}{l}\text { Gramática } \ldots \text { (como la } \\
\text { anterior) Madrid,| Imprenta y } \\
\text { fundicion de Manuel Tello, } \\
\text { Isabel la Católica, 23, | } 1874 .\end{array}$ & $\begin{array}{l}\text { Gramática. M., Imp. y } \\
\text { fundición de M. Tello, } \\
\text { Isabel la Católica, } 23 . \\
1874 .\end{array}$ \\
\hline 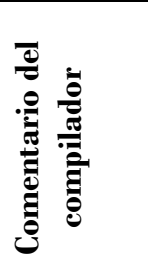 & $\begin{array}{l}\text { Escuetísima información } \\
\text { sobre el tamaño y el } \\
\text { número de páginas: } \\
\text { «4. }{ }^{\circ}-423 \text { págs. + } 1 \text { de errat.» } \\
\text { (Pág. 603). }\end{array}$ & $\begin{array}{l}\text { Escuetísima información sobre } \\
\text { el tamaño y el número de } \\
\text { páginas: } \\
\text { «4. }{ }^{\circ} ; 423 \text { págs. y } 2 \text { hojas más para } \\
\text { erratas y anuncios». (Pág. 40). }\end{array}$ & $\begin{array}{l}\text { Escuetísima información } \\
\text { sobre el tamaño y el } \\
\text { número de páginas: } \\
\text { «4. } 423 \text { p. } 2 \text { h.». (Pág. } 39 \text { ). }\end{array}$ \\
\hline
\end{tabular}

Cuadro 15: GRAE-1874 en las compilaciones

\section{APUNTES SOBRE LA INFORMACIÓN}

(1) La Viñaza es el único que indica que se presenta el texto como "Nueva edición". Lo será solo a medias.

(2) Sobre los derechos de propiedad, remito al apunte (3) del apartado anterior.

(3) Las "Nociones preliminares" son la mismas de 1870.

LOCALIZACIÓN: En la Sala de Investigadores de la RAE, puede consultarse un original duplicado con la signatura 35-G-8 (D) y el registro 50338. En la Sala de Académicos, se hallan dos originales distintos [Signaturas: 35-G-8 y 35-G-48]. La BNE dispone de varios ejemplares que pueden consultarse en el Salón General con las signaturas: 1/21412, 1/42126, 1/42957 y 1/44246. Puede encontrarse también en venta a través de www.iberlibro.com. El CSIC dispone de dos ejemplares de esta edición: uno de ellos se encuentra en la biblioteca M-BG.Hum [Signatura: 15/1408] y el otro, en la biblioteca M-Resid [Signatura: 31922]. 


\subsubsection{GRAE-1878}

INFORMACIÓN COMPILADA

\begin{tabular}{|c|c|c|c|}
\hline & $\begin{array}{c}\text { La Viñaza } \\
(1893)\end{array}$ & $\begin{array}{c}\text { Cotarelo } \\
(\mathbf{1 9 2 8}) \\
\end{array}$ & $\begin{array}{c}\text { Palau y Dulcet } \\
\text { (1948) }\end{array}$ \\
\hline $\begin{array}{c}\text { N. } \\
\text { ed. }\end{array}$ & $14 .^{\mathrm{a}}$ & {$\left[14 .^{\mathrm{a}}\right]$} & {$\left[14 .^{a}\right]$} \\
\hline 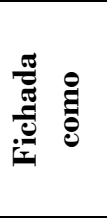 & $\begin{array}{l}\text { Décimacuarta edición: } \\
\text { Madrid, Gregorio Hernando, } \\
\text { impresor y librero de la Real } \\
\text { Academia Española. 1878. }\end{array}$ & 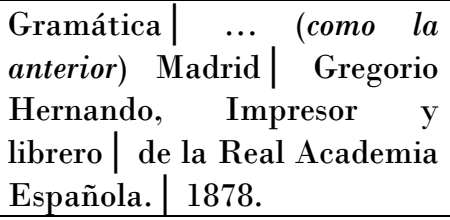 & 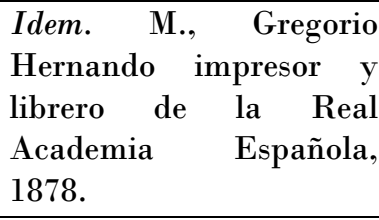 \\
\hline 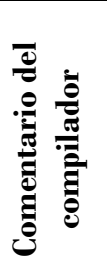 & $\begin{array}{l}\text { Información reducida al tipo } \\
\text { de volumen y } \mathbf{n} .^{\circ} \text { de páginas: } \\
\text { «4. - } 423 \text { págs.». (Pág. } 603 \text { ). }\end{array}$ & $\begin{array}{l}\text { Información reducida al tipo } \\
\text { de volumen y } n .^{\circ} \text { de páginas: } \\
\text { «4. } .^{\circ} 423 \text { págs. y } 2 \text { hojas más de } \\
\text { erratas y anuncios». (Pág. } 40) .\end{array}$ & $\begin{array}{l}\text { Información reducida al } \\
\text { tipo de volumen y } n .^{\circ} \text { de } \\
\text { páginas: } \\
\text { «4. } .^{\circ} 423 \text { p. } 2 \text { h.». (Pág. } 39 \text { ). }\end{array}$ \\
\hline
\end{tabular}

Cuadro 16: GRAE-1878 en las compilaciones

\section{APUNTES SOBRE LA INFORMACIÓN}

(1) Antes de la Advertencia y siguiendo la práctica iniciada en ediciones anteriores, la Institución hace constar sus derechos de propiedad exclusiva de la obra, acentuando el "tono intimidatorio" de 1870 con las palabras que siguen:

Esta obra es propiedad exclusiva de la REAL ACADEMIA ESPAÑOLA, que se reserva cuantos derechos le corresponden con arreglo á la Ley de propiedad literaria de 10 de Julio de 1847 y á los convenios sobre esta materia celebrados por España con otras naciones. LA ACADEMIA perseguirá á quien le usurpare cualquiera de estos derechos.

(El subrayado es mío) 
Debe de ser un descuido (o una errata) la mención a "julio", pues la ley a la que se refiere es de 10 de junio de 1847, según se indica en las demás ediciones ${ }^{56}$.

(2) Las mismas "Nociones preliminares" que en las dos ediciones anteriores. No volveremos a ver este apartado en ninguna GRAE57.

LOCALIZACIÓN: El ejemplar original de la Sala de Investigadores de la Academia presenta el número de registro 35293 y la signatura 35-G-9 Dupl. Otro original se localiza en la Sala de Académicos [Signatura: 35-G-9]. En el Salón General de la BNE, puede consultarse el ejemplar con signatura 2/53485, procedente de la biblioteca de Francisco Pi y Margall, o la versión en microfichas DG/14986. No se encuentra este libro en el CSIC.

$\left(^{*}\right)$ De las ediciones de los años setenta, esta es la más fácil de localizar en las librerías de viejo (el precio de las que he encontrado varía entre los quince y los cincuenta euros).

${ }^{56}$ Efectivamente, fue el 10 de junio de 1847 cuando se prescribieron las nuevas reformas sobre legislación de imprenta. Véase Eguízabal (1879: 198).

57 Del escaso éxito de esta práctica en el rutinario sistema de publicaciones de la Gramática advierte Gómez Asencio (2005: 598): «Las tres, y solo ellas tres [GRAE de 1870, 1874 y 1878], comparten una sección inicial nueva llamada "Nociones preliminares"». 


\subsubsection{GRAE-1880}

INFORMACIÓN COMPILADA

\begin{tabular}{|c|c|c|c|}
\hline & $\begin{array}{c}\text { La Viñaza } \\
(\mathbf{1 8 9 3 )}\end{array}$ & $\begin{array}{c}\text { Cotarelo } \\
(\mathbf{1 9 2 8})\end{array}$ & $\begin{array}{c}\text { Palau y Dulcet } \\
\text { (1948) } \\
\end{array}$ \\
\hline $\begin{array}{c}\text { N. } \\
\text { ed. }\end{array}$ & $15 .^{\mathrm{a}}$ & {$\left[15 .^{a}\right]$} & {$\left[15 .^{a}\right]$} \\
\hline 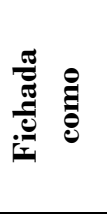 & $\begin{array}{l}\text { Décimaquinta } \\
\text { Madrid, edición: } \\
\text { Hernando, impresor y } \\
\text { librero de la Real } \\
\text { Academia Española, } 1880 .\end{array}$ & \begin{tabular}{l|rr} 
Gramática & $\ldots$ & (como la \\
anterior) Nueva & edición \\
$($ Emblema $)$ & & Madrid \\
Gregorio & Hernando... \\
1880. & &
\end{tabular} & $\begin{array}{l}\text { Gramática. M., } \quad \text { Gregorio } \\
\text { Hernando, } 1880 .\end{array}$ \\
\hline 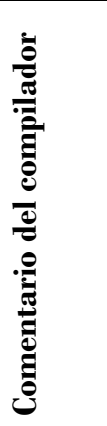 & $\begin{array}{l}\text { Escueta información sobre } \\
\text { tamaño del volumen y } \\
\text { número de páginas: } \\
\text { «4. - } 418 \text { págs. + } 1 \text { errat.». } \\
\text { (Pág. 603). }\end{array}$ & $\begin{array}{l}\text { «4. } .^{\circ} 418 \text { págs. y } 2 \text { hojas de } \\
\text { erratas y anuncios. Se ha } \\
\text { suprimido la "Advertencia" de } \\
\text { las anteriores impresiones». } \\
(\text { Pág. } 40) .\end{array}$ & $\begin{array}{l}\text { Información sobre el tipo de } \\
\text { volumen y páginas de la edición } \\
\text { más información sobre las dos } \\
\text { reimpresiones que se hicieron de } \\
\text { ella en los años siguientes: } \\
\text { «4. }{ }^{\circ} 418 \text { p. } 1 \text { h. } \\
\text { Después id. Id. } 1883,4 .^{\circ} 418 \text { p. } 1 \\
\text { h.; y Id. Id. } 1885,4 .^{\circ} 418 \text { p. } 1 \text { h.». } \\
\text { (Pág. 39). }\end{array}$ \\
\hline
\end{tabular}

Cuadro 17: GRAE-1880 en las compilaciones

\section{APUNTES SOBRE LA INFORMACIÓN}

(1) La portada reza "Nueva edición", según indica Cotarelo. Y, efectivamente, se trata de una nueva versión (de cambios sutiles en el cuerpo de doctrina respecto de la anterior) que reemplaza al modelo de los años setenta ${ }^{58}$.

(2) Conviene recordar que, en la nota sobre derechos de autoría, habitual ya

en esta fecha en todas las ediciones de la GRAE, encontramos un ligero

58 Es de interés traer a colación las palabras de Gómez Asencio (2005: 598) sobre los cambios estructurales de esta edición:

$1^{\circ}$ ] desaparecen para siempre las «Nociones preliminares» [...]; a cambio se añade, también para siempre, una sección inicial, igualmente de contenido lingüístico, técnico, denominada «Introducción» (entre una y dos páginas); $2^{\circ}$ ] entre 1880 y 1909 (doce ediciones) se prescinde de toda información prologal: no hay advertencias, ni prólogos, ni preámbulo alguno; $3^{\circ}$ ] en 1880 se introduce un capítulo titulado Vicios de dicción, cuya vigencia alcanza hasta 1931 (y virtualmente hasta una fecha no especificada). 
cambio de redacción que tiene que ver con la nueva ley vigente sobre propiedad literaria, la de 10 de enero de 187959.

(3) Antes del desarrollo de las distintas partes de la Gramática, aparece una Introducción, equivalente a las "Nociones preliminares" de las ediciones de 1870, 1874 y 1878, pero reducidas ahora a una sola página donde se habla de: a) definición del concepto de lengua o idioma, y por qué la de España se llama español o castellano; b) Definición y división de gramática; c) finalidad que persigue la gramática y cada una de sus partes constitutivas.

LOCALIZACIÓN: El ejemplar fotocopiado de la Sala de Investigadores de la RAE tiene la signatura 35-G-10 (D); el número de registro no se ve con claridad (parece ser el 35293). En la BNE no está disponible el ejemplar con signatura 1/84299, por lo que hay que consultar la versión en microfichas, con signatura DGmicro/14969, en el Salón General. En el CSIC, en la biblioteca M-IFL [Signatura: XXVII/221] o la biblioteca M-Resid [Signatura: 31691].

${ }^{59}$ Esta nueva ley fue publicada en La Gaceta de Madrid n. ${ }^{\circ} 12$, de 12 de enero de 1879. Consta de: diez artículos sobre disposiciones generales (art. 1-10); uno relativo a discursos parlamentarios (art. 11); cuatro sobre traducciones (art. 12-15); tres relativos a "pleitos y causas" (art. 16-18); siete que regulan lo tocante a obras dramáticas y musicales (art. 19-25); sendos artículos sobre obras anónimas, obras póstumas y colecciones legislativas (art. 26, 27 y 28); tres concernientes a periódicos (art. 29-31); uno para colecciones (art. 32); cinco dedicados al registro general de la propiedad intelectual, sito en el Ministerio de Fomento (art. 33-37); siete que versan sobre reglas de caducidad (art. 38-44); cinco en los que se establece la penalidad ante fraudes (art. 5051); dos tocantes a derecho internacional (art. 50 y 51); uno sobre efectos legales (art. 52); tres que tratan sobre el tránsito del antiguo al nuevo sistema (art. 53-55); uno concerniente al cumplimiento en ultramar (art. 56); y uno final con el reglamento (art. 57). Vid. Ley de 10 de enero de 1879. 


\subsubsection{GRAE-1883}

INFORMACIÓN COMPILADA

\begin{tabular}{|c|c|c|c|}
\hline & $\begin{array}{c}\text { La Viñaza } \\
(\mathbf{1 8 9 3 )} \\
\end{array}$ & $\begin{array}{c}\text { Cotarelo } \\
(1928) \\
\end{array}$ & $\begin{array}{c}\text { Palau y Dulcet } \\
(1948)\end{array}$ \\
\hline N. ${ }^{\circ}$ de ed. & & {$\left[16 .^{\mathrm{a}}\right]$} & {$\left[i^{16} .^{\mathrm{a}} ?\right]$} \\
\hline 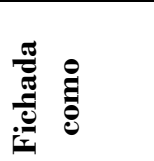 & & \begin{tabular}{l|l|l} 
Gramática & $\ldots$ & (como $l a$ \\
anterior $)$ & Madrid: | Gregorio \\
Hernando ... & 1883.
\end{tabular} & >> id. Id. 1883 \\
\hline 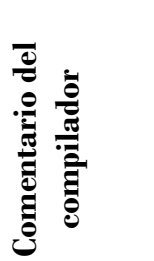 & & $\begin{array}{l}\text { Breve apunte sobre tamaño } \\
\text { del volumen y número de } \\
\text { páginas: } \\
\text { «4. }{ }^{\circ} \text {; } 418 \text { págs. y una hoja más». } \\
\text { (Pág. } 40) \text {. }\end{array}$ & $\begin{array}{l}\text { Breve apunte sobre } \\
\text { tamaño del volumen y } \\
\text { número de páginas: } \\
\text { «4. }^{\circ} 418 \text { p. } 1 \text { h.». (Pág. 39). }\end{array}$ \\
\hline
\end{tabular}

Cuadro 18: GRAE-1883 en las compilaciones

\section{APUNTES SOBRE LA INFORMACIÓN}

(1) Esa "hoja más" que tanto Cotarelo como Palau añaden al texto de la Gramática propiamente dicho corresponde al catálogo de obras publicadas por la RAE que, en la fecha, están en venta en la casa de la calle Valverde y en la librería Hernando. En realidad, el listado ocupa dos páginas sin numerar.

(2) Palau registra esta edición dentro de la entrada de la GRAE-1880.

(3) En la columna de Palau y Dulcet, coloco entre signos de interrogación el número de edición correspondiente porque no alcanzo a comprender el criterio utilizado por este compilador para conceder o no entrada independiente a las distintas ediciones. El sistema de registro id.id lo utiliza en varias ocasiones y siempre en ediciones que podrían entenderse como reimpresiones de fechas anteriores, pero ni todas las posibles reimpresiones llevan esta forma de registro (por ejemplo, la GRAE-1864) ni todas las que lo llevan están incluidas en la entrada de otra edición (por ejemplo, para la GRAE-1865 y la GRAE-1866, así marcadas, sí se dan entradas independientes). 
Por otra parte, procede de distinta manera a la hora de dar cuenta de las reimpresiones de la GRAE-1796, incluidas en la entrada de la cuarta edición pero de las que ofrece noticia ligeramente más detallada (cf. 2.3.4.).

LOCALIZACIÓN: En la Sala de Investigadores de la RAE, hay un ejemplar fotocopiado [Signatura: 35-G-11 (D); sin número de registro] del original, que se encuentra en la Sala de Académicos con la signatura 35G-11. En la BNE, no se localiza esta edición. Ninguna de las bibliotecas del CSIC dispone de ejemplares. 


\subsubsection{GRAE-1885}

INFORMACIÓN COMPILADA

\begin{tabular}{|c|c|c|c|}
\hline & $\begin{array}{c}\text { La Viñaza } \\
\text { (1893) }\end{array}$ & $\begin{array}{c}\text { Cotarelo } \\
(\mathbf{1 9 2 8}) \\
\end{array}$ & Palau y Dulcet (1948) \\
\hline N. ${ }^{\circ}$ de ed. & & {$\left[17 .^{a}\right]$} & {$\left[\dot{\delta}^{17} .^{\mathrm{a}} ?\right]$} \\
\hline 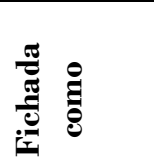 & & 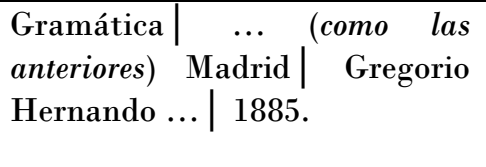 & >> Id. Id. 1885. \\
\hline 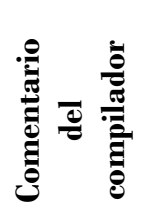 & & $\begin{array}{l}\text { «4. } .^{\circ} 418 \text { págs. y } 1 \text { hoja de } \\
\text { anuncios. Esta edición falta en la } \\
\text { Filología del Conde de la Viñaza». } \\
\text { (Pág. } 40) .\end{array}$ & $\begin{array}{l}\text { Breve apunte sobre tamaño del } \\
\text { volumen y número de páginas: } \\
\text { «4. } 418 \text { p. } 1 \text { h.» (Pág. } 39) \text {. }\end{array}$ \\
\hline
\end{tabular}

Cuadro 19: GRAE-1885 en las compilaciones

\section{APUNTES SOBRE LA INFORMACIÓN}

(1) En realidad, como ya hemos visto, en la Biblioteca de La Viñaza también falta la edición de 1883, pero Cotarelo solo anota esta ausencia.

(2) En Palau, recogida en la misma entrada de la edición de 1880. Sobre los signos de interrogación que empleo, remito a lo dicho en el apunte (3) del apartado anterior.

LOCALIZACIÓN: En la Academia, existe un original que se guarda en la Sala de Académicos [Signatura: 35-G-12]; de este original hay fotocopia en la Sala de Investigadores [Signatura: 35-G-12 (D) y Registro: 35299]. La BNE dispone de dos ejemplares que pueden consultarse en el Salón General [Signaturas: 1/27615 y 4/21201]. Dos ejemplares están registrados en el catálogo del CSIC: uno, en la biblioteca MIFL, con la signatura LII/255; y otro, en la biblioteca M-Resid, con la signatura 31690. 


\subsubsection{GRAE-1888}

\section{INFORMACIÓN COMPILADA}

\begin{tabular}{|c|c|c|c|}
\hline & $\begin{array}{c}\text { La Viñaza } \\
(\mathbf{1 8 9 3 )} \\
\end{array}$ & $\begin{array}{c}\text { Cotarelo } \\
(\mathbf{1 9 2 8}) \\
\end{array}$ & $\begin{array}{c}\text { Palau y Dulcet } \\
\text { (1948) } \\
\end{array}$ \\
\hline $\begin{array}{c}\text { N. }{ }^{\circ} \text { de } \\
\text { ed. }\end{array}$ & $16 .^{a}$ & {$\left[18 .{ }^{a}\right]$} & {$\left[18 .^{a}\right]$} \\
\hline$\frac{8}{3}$ & $\begin{array}{l}\text { Décimasexta edición: Madrid, viuda } \\
\text { de Hernando y Compañía, } \\
\text { impresores y libreros de la Real } \\
\text { Academia Española, 1888. }\end{array}$ & 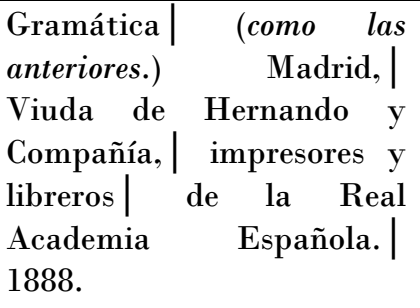 & $\begin{array}{l}\text { Idem. M., Viuda de } \\
\text { Hernando y Cía. } \\
\text { impresores y libreros } \\
\text { de la Real Academia } \\
\text { Española, } 1888\end{array}$ \\
\hline 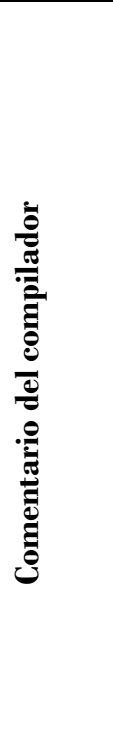 & $\begin{array}{l}\text { Tipo de volumen y número de } \\
\text { páginas, seguido de la información } \\
\text { contenida en las actas académicas } \\
\text { de } 4 \text { de diciembre de } 1888 \text { sobre la } \\
\text { publicación de la GRAE-1880: } \\
\text { «4. - } 418 \text { págs. } \\
\text { Acerca de las innovaciones introducidas } \\
\text { en estas dos últimas impresiones de la } \\
\text { Gramática de la Academia Española } \\
\text { (cuyo texto, en ambas, es idéntico), } \\
\text { véase lo que dice el insigne poeta y } \\
\text { Secretario perpetuo de la misma } \\
\text { Corporación, D. Manuel Tamayo y } \\
\text { Baus, en el Resumen de las actas de la } \\
\text { Academia leído en Junta pública de } 4 \\
\text { de diciembre de 1881 (Madrid, imprenta } \\
\text { de Manuel Tello, 1881), páginas 23-26: } \\
\text { [...]». (Pags. 603-607). }\end{array}$ & $\begin{array}{l}\text { Información sobre } \\
\text { tamaño del volumen y el } \\
\text { número de páginas: } \\
\text { «4. }{ }^{\circ} \text {; } 418 \text { págs. y } 1 \text { hoja de } \\
\text { anuncios». (Pág. 40). }\end{array}$ & $\begin{array}{l}\text { Información sobre el } \\
\text { tamaño del volumen y } \\
\text { el número de páginas: } \\
\text { «4. }{ }^{\circ} \text { VI-418 p. } 1 \text { h.». (Pág. } \\
39 \text { ). }\end{array}$ \\
\hline
\end{tabular}

Cuadro 20: GRAE-1888 en las compilaciones

\section{APUNTES SOBRE LA INFORMACIÓN}

(1) En la portada se presenta como "Nueva edición". Sorprende que ninguno de los compiladores lo indique.

(2) Aunque para La Viñaza esta edición se corresponde con la 16. a , en rigor se trata de la 18. ${ }^{\mathrm{a}}$, pues el compilador no registra las dos ediciones intermedias entre 1880 y 1888: la GRAE-1883 y la GRAE-1885, según se ha indicado en los cuadros correspondientes. 
II. Los textos del corpus

LOCALIZACIÓN: De esta edición puede consultarse un ejemplar fotocopiado en la Sala de Investigadores de la Academia [Signatura: 35-G-13 (D) y Registro: 35301 -?-]. En el Salón General de la Biblioteca Nacional hay dos ejemplares con signaturas 2/72738 y 4/22995. No se localiza en el CSIC.

(*) Es fácil encontrar las ediciones de los años ochenta en las librerías de viejo (por lo general, los ejemplares se pueden adquirir por un precio que oscila entre los treinta y los sesenta euros. Puede consultarse: $\underline{\text { www.iberlibro.com)}}$. 


\subsubsection{GRAE-1890}

\section{INFORMACIÓN COMPILADA}

\begin{tabular}{|c|c|c|c|}
\hline & $\begin{array}{c}\text { La Viñaza } \\
\text { (1893) } \\
\end{array}$ & $\begin{array}{c}\text { Cotarelo } \\
(1928) \\
\end{array}$ & $\begin{array}{c}\text { Palau y Dulcet } \\
\text { (1948) }\end{array}$ \\
\hline N. ${ }^{\circ}$ de ed. & & {$\left[19 .^{\mathrm{a}}\right]$} & {$\left[19 .^{\mathrm{a}}\right]$} \\
\hline 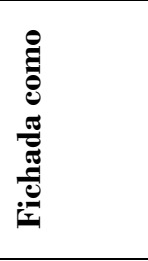 & NO LA REGISTRA & $\begin{array}{l}\text { Gramática } \mid \ldots \text { como las } \\
\text { anteriores) Madrid | Viuda de } \\
\text { Hernando y Compañía } \\
\text { Impresores y libreros | de la } \\
\text { Real Academia Española. } \\
1890 .\end{array}$ & Idem. Id. id. 1890. \\
\hline 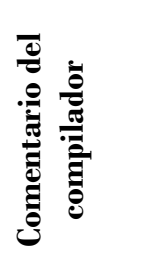 & & $\begin{array}{l}\text { Información sobre el tamaño } \\
\text { del volumen y el número de } \\
\text { páginas: } \\
\text { «4. } .^{\circ} 418 \text { págs. y } 1 \text { hoja de } \\
\text { anuncios». (Pág. 40). }\end{array}$ & $\begin{array}{l}\text { Información sobre el tamaño y } \\
\text { número de páginas, seguida de } \\
\text { información sobre reimpresión: } \\
\text { «4. }^{\circ} 418 \text { p. } 1 \text { h.; y completamente } \\
\text { igual en 1895». (Pág. } 39 \text { ). }\end{array}$ \\
\hline
\end{tabular}

Cuadro 21: GRAE-1890 en las compilaciones

LOCALIZACIÓN: En la RAE, existe un ejemplar original en la Sala de Académicos con la signatura 35-G-14, del cual hay reproducción fotocopiada en la Sala de Investigadores [Signatura: 35-G-14 (D) y Registro, poco visible: 35303]. En la BNE, el ejemplar lleva la signatura 1/82696 y se puede consultar en el Salón General. Tres bibliotecas del CSIC disponen de esta edición: M-IFL [Signatura: XLV/283], M-RJB [Signatura: 03 B] y M-Resid [Signauras: 30979; 31002 y 31692]. 


\subsubsection{GRAE-1895}

INFORMACIÓN COMPILADA

\begin{tabular}{|c|c|c|c|}
\hline & $\begin{array}{c}\text { La Viñaza } \\
\text { (1893) }\end{array}$ & $\begin{array}{c}\text { Cotarelo } \\
\text { (1928) }\end{array}$ & $\begin{array}{c}\text { Palau y Dulcet } \\
\text { (1948) }\end{array}$ \\
\hline N. ${ }^{\circ}$ de ed. & & {$\left[20 .^{\mathrm{a}}\right]$} & {$\left[\dot{\delta}^{20 .}{ }^{\mathrm{a}} ?\right]$} \\
\hline 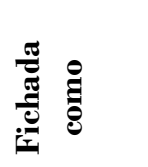 & & $\begin{array}{l}\text { Gramática } \mid . . . \text { (como las anteriores) } \\
\text { Madrid } \mid \text { Viuda de Hernando ... } \\
1895 .\end{array}$ & >> 1895. \\
\hline 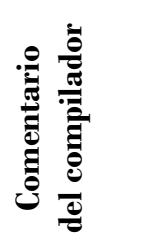 & & $\begin{array}{l}\text { Información sobre el tamaño del } \\
\text { volumen y el número de páginas: } \\
\text { «4. }{ }^{\circ} ; 418 \text { págs. y una hoja más». (Pág. } \\
41) .\end{array}$ & $\begin{array}{l}\text { Escueto apunte sobre la identidad con } \\
\text { respecto a la edición anterior: } \\
\text { «completamente igual [que la GRAE- } \\
\text { 1890]». (Pág. 39). }\end{array}$ \\
\hline
\end{tabular}

Cuadro 22: GRAE-1895 en las compilaciones

\section{APUNTES SOBRE LA INFORMACIÓN}

(1) La "hoja más" anotada por Cotarelo (dos páginas sin numerar) responde, como viene siendo habitual, al catálogo de obras publicadas por la Academia, que, en este año, ya se encuentran a la venta en la casa actual de la Corporación, en la calle Felipe IV, y en la librería de la Viuda de Hernando y C. ${ }^{\mathrm{a}}$.

(2) En Palau, la GRAE-1895 aparece recogida dentro de la entrada de la edición de 1890. Sobre los signos de interrogación, sobreentiéndase la misma explicación dada para la GRAE-1883 y la GRAE-1885.

LOCALIZACIÓN: En la Sala de Investigadores de la Academia, puede consultarse un ejemplar fotocopiado con signatura 35-G-15 (D) y número de registro -poco visible- 35305 (el original está en la Sala de Académicos [Signatura: 35-G-15]). Del legado de Hartzenbusch procede el ejemplar disponible en el Salón General de la BNE, con signatura 1/64601. El CSIC cuenta con dos ejemplares: en la biblioteca MBibC se encuentra el que tiene la signatura 806-4\% /67; en la M-IH, el registrado con la signatura HE-4585.

(*) De las ediciones de los noventa, solo he encontrado en las librerías de viejo la GRAE-1895. Es este quizá el libro que puede adquirirse por precios más dispares, según la librería (he localizado desde ejemplares que no llegan a costar ocho euros hasta ejemplares por los que se piden sesenta euros). 


\subsubsection{GRAE-1900}

\section{INFORMACIÓN COMPILADA}

\begin{tabular}{|c|c|c|c|}
\hline & $\begin{array}{c}\text { La Viñaza } \\
(1893)\end{array}$ & Cotarelo (1928) & $\begin{array}{c}\text { Palau y Dulcet } \\
(1948)\end{array}$ \\
\hline N. ${ }^{\circ}$ de ed. & & {$\left[21 .^{\mathrm{a}}\right]$} & {$\left[21 .^{\mathrm{a}}\right]$} \\
\hline 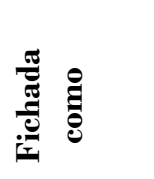 & & $\begin{array}{l}\text { Gramática } \mid \text {... (como las anteriores) } \\
\text { Madrid | Hernando y Compañía } \\
\text { Impresores y libreros } \mid \text { de la Real } \\
\text { Academia Española. | } 1900 .\end{array}$ & $\begin{array}{l}\text { Idem. M., Hernando y Cía. } \\
\text { Impresores y libreros de la Real } \\
\text { Academia Española, 1900. }\end{array}$ \\
\hline 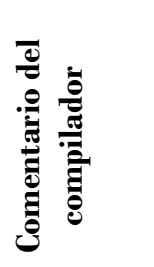 & & $\begin{array}{l}\text { Información sobre el tamaño del } \\
\text { volumen y el número de páginas: } \\
\text { «4. } .^{\circ} 418 \text { págs. y una hoja de anuncios». } \\
\text { (Pág. } 41) \text {. }\end{array}$ & 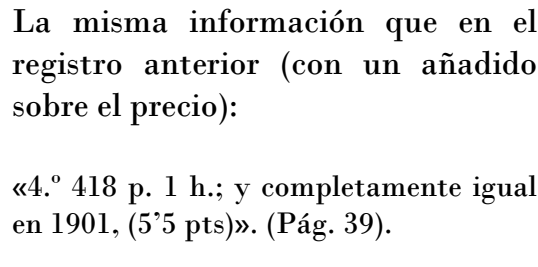 \\
\hline
\end{tabular}

Cuadro 23: GRAE-1900 en las compilaciones

LOCALIZACIÓN: El ejemplar fotocopiado de la Sala de Investigadores de la Academia tiene la signatura 35-G-32 y el númro de registro 38306. El original está en la Sala de Exposiciones de la Institución. En la BNE, se puede consultar en el Salón General [Signatura: 82693]. En la Biblioteca V-IHCD del CSIC, hay un ejemplar con la signatura Var/I-30/183. 


\subsubsection{GRAE-1901}

INFORMACIÓN COMPILADA

\begin{tabular}{|c|c|c|c|}
\hline & $\begin{array}{c}\text { La Viñaza } \\
(1893) \\
\end{array}$ & $\begin{array}{c}\text { Cotarelo } \\
(1928) \\
\end{array}$ & $\begin{array}{c}\text { Palau y Dulcet } \\
\text { (1948) } \\
\end{array}$ \\
\hline N." de ed. & & {$\left[22 .^{a}\right]$} & {$\left[i^{\left.22 .{ }^{a} ?\right]}\right.$} \\
\hline 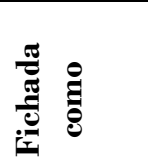 & & \begin{tabular}{l|cl} 
Gramática & $\ldots$ & (como las \\
anteriores) & Madrid & Hernando... \\
1901.
\end{tabular} & $>>1901$. \\
\hline 黄 & & $\begin{array}{l}\text { «4. }{ }^{\circ} ; 418 \text { págs. y una hoja más». (Pág. } \\
41 \text { ). }\end{array}$ & $\begin{array}{l}\text { Identidad con respecto a la edición } \\
\text { anterior: } \\
\text { «completamente igual [que la GRAE- } \\
\text { 1900]». (Pág. 39). }\end{array}$ \\
\hline
\end{tabular}

Cuadro 24: GRAE-1901 en las compilaciones

\section{APUNTES SOBRE LA INFORMACIÓN}

(1) Palau recoge esta edición en la entrada de la GRAE-1900.

LOCALIZACIÓN: En la Sala de Académicos de la RAE, se encuentra un ejemplar con la signatura 35-G-36, del que hay copia fotocopiada en la Sala de Investigadores con la misma signatura (el número de registro no se lee bien, pero parece ser el 35360). En la Biblioteca Nacional, hay un ejemplar con signatura 1/59, que puede consultarse en el Salón General. De esta edición hay dos ejemplares en el CSIC, con las signaturas 44337 y 33381, en la biblioteca M-Resid. 


\subsubsection{GRAE-1904}

\section{INFORMACIÓN COMPILADA}

\begin{tabular}{|c|c|c|c|}
\hline & $\begin{array}{c}\text { La Viñaza } \\
\text { (1893) }\end{array}$ & $\begin{array}{c}\text { Cotarelo } \\
\text { (1928) }\end{array}$ & $\begin{array}{c}\text { Palau y Dulcet } \\
\text { (1948) }\end{array}$ \\
\hline N. ${ }^{\circ}$ de ed. & & {$\left[23 .^{a}\right]$} & {$\left[23 .^{a}\right]$} \\
\hline 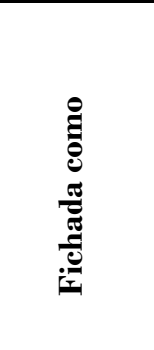 & & 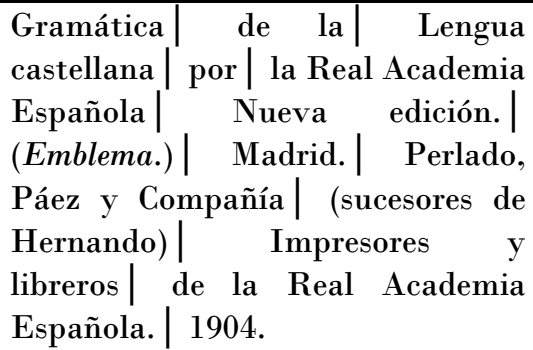 & $\begin{array}{l}\text { Idem. M., Perlado, Paez y } \\
\text { Compañía } \\
\text { (Sucesores de } \\
\text { Hernando) Impresores y libreros } \\
\text { de la Real Academia Española, } \\
\text { 1904. }\end{array}$ \\
\hline 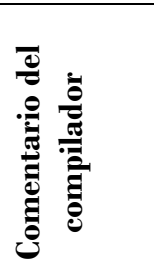 & & $\begin{array}{l}4 .{ }^{\circ} ; \text { 414 págs. y una hoja de } \\
\text { anuncios». (Pág. 41). }\end{array}$ & $\begin{array}{l}\text { Información sobre el tamaño y } \\
\text { número de páginas, seguida de } \\
\text { información sobre su reimpresión: } \\
\text { «4. }{ }^{\circ} 414 \text { p. } 1 \text { h. Después, id. id. 1911, } \\
4 .^{\circ} 1 \text { h. } 420 \text { p.». (Pág. } 39 \text { ). }\end{array}$ \\
\hline
\end{tabular}

Cuadro 25: GRAE-1904 en las compilaciones

\section{APUNTES SOBRE LA INFORMACIÓN}

(1) Efectivamente, tal como indica Cotarelo, esta Gramática se presenta como “Nueva edición".

(2) Según la información ofrecida en la entrada para esta GRAE, Palau y Dulcet no da cuenta de las tres ediciones que median entre 1904 (23. a) y 1911 $\left(27{ }^{a}\right)$ : GRAE-1906 $\left(24 .^{a}\right)$, GRAE-1908 $\left(25 .^{a}\right)$ y GRAE-1909 $\left(26 .^{a}\right)$. Como se verá en los cuadros siguientes, Cotarelo sí registra las dos últimas, pero no encontramos en su catálogo la GRAE-1906.

LOCALIZACIÓN: Con la signatura 35-G-17 Dupl. y el registro 35362, encontramos un ejemplar fotocopiado en la Sala de Investigadores de la RAE (el original, con signatura 35-G-17, está en la Sala de Académicos). En la BNE, el ejemplar de esta edición puede consultarse en el Salón General y lleva la signatura 1/9528. La GRAE-1904 no se localiza en el CSIC. 


\subsubsection{GRAE-1906}

INFORMACIÓN COMPILADA

\begin{tabular}{|c|c|c|c|}
\hline & $\begin{array}{c}\text { La Viñaza } \\
(1893) \\
\end{array}$ & $\begin{array}{c}\text { Cotarelo } \\
(\mathbf{1 9 2 8}) \\
\end{array}$ & $\begin{array}{c}\text { Palau y Dulcet } \\
(1948)\end{array}$ \\
\hline N. ${ }^{\circ}$ de & & & \\
\hline 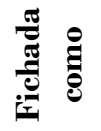 & & \multirow{2}{*}{ NO LA REGISTRA } & \multirow{2}{*}{ NO LA REGISTRA } \\
\hline 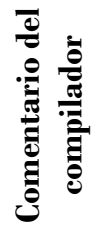 & & & \\
\hline
\end{tabular}

Cuadro 26: GRAE-1906 en las compilaciones

\section{APUNTES SOBRE LA INFORMACIÓN}

(1) La GRAE-1906 aparece recogida por Palau y Dulcet en el tomo XV (pág. 152) de su Manual del librero hispanoamericano (publicado en el año 1962), bajo la voz Real Academia Española, y de ella nos dice que está en 4. ${ }^{\circ}$, que consta de 410 páginas y que su precio es de 35 pts.

LOCALIZACIÓN: La edición de 1906 está disponible en fotocopias del original en la Sala de Investigadores de la Academia [Signatura: 35-V-51 (D) y Registro: 46679 -?-]. En la Sala de Académicos se guarda un ejemplar original y otro se encuentra en la Sala de Exposiciones. La Biblioteca Nacional cuenta con un ejemplar de esta Gramática que puede consultarse en el Salón General [Signatura: 1/21757]. En el CSIC, hay un ejemplar en la biblioteca M-Resid con signatura 31729.

$\left.{ }^{*}\right)$ Existen, además, originales que pueden encontrarse en las librerías de viejo. 


\subsubsection{GRAE-1908}

INFORMACIÓN COMPILADA

\begin{tabular}{|c|c|c|c|}
\hline & $\begin{array}{c}\text { La Viñaza } \\
(1893)\end{array}$ & $\begin{array}{c}\text { Cotarelo } \\
(1928)\end{array}$ & $\begin{array}{c}\text { Palau y Dulcet } \\
\text { (1948) }\end{array}$ \\
\hline N. ${ }^{\circ}$ de ed. & & {$\left[24 .^{\mathrm{a}}\right]$} & \\
\hline 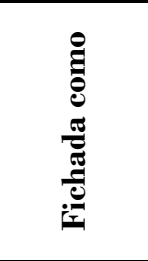 & & \begin{tabular}{l|cr} 
Gramática & $\ldots$ & (como las ants.) \\
Madrid $\mid$ & Perlado, Paez & y \\
Compañía $\mid$ & \multicolumn{2}{|c}{ (Sucesores } \\
Hernando) $\mid$ Impresores y libreros \\
de la Real Academia Española. \\
1908.
\end{tabular} & NO LA REGISTRA \\
\hline 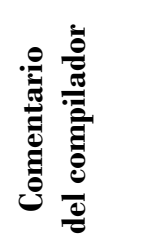 & & $\begin{array}{l}\text { «4. } .^{\circ} 414 \text { págs. y una hoja de anuncios». } \\
\text { (Pág. 41). }\end{array}$ & \\
\hline
\end{tabular}

Cuadro 27: GRAE-1908 en las compilaciones

APUNTES SOBRE LA INFORMACIÓN

(1) Esta edición tendría que ser la 25. a en orden cronológico. Cotarelo no ha registrado la edición inmediatamente anterior a esta, de 1906.

(2) Esta edición no se localiza en la RAE.

LOCALIZACIÓN: En la BNE se encuentra un ejemplar con signatura 1/36838, que puede consultarse en el Salón General. El CSIC no cuenta con ningún ejemplar. 


\subsubsection{GRAE-1909}

INFORMACIÓN COMPILADA

\begin{tabular}{|c|c|c|c|}
\hline & $\begin{array}{c}\text { La Viñaza } \\
(1893) \\
\end{array}$ & $\begin{array}{c}\text { Cotarelo } \\
(1928) \\
\end{array}$ & $\begin{array}{c}\text { Palau y Dulcet } \\
\text { (1948) }\end{array}$ \\
\hline N. ${ }^{\circ}$ de ed. & & {$\left[25 .^{a}\right]$} & \\
\hline 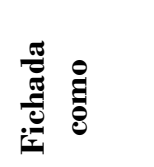 & & \begin{tabular}{l|ccc} 
Gramática & $\ldots$ & como & las \\
anteriores $) \mid$ & Madrid $\mid$ & Perlado ... \\
1909.
\end{tabular} & NO LA REGISTRA \\
\hline 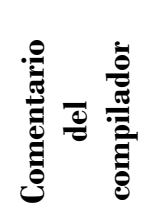 & & $\begin{array}{l}\text { «4. } .^{\circ} ; 14 \text { págs. y una hoja más». (Pág. } \\
41 \text { ). }\end{array}$ & \\
\hline
\end{tabular}

Cuadro 28: GRAE-1909 en las compilaciones

LOCALIZACIÓN: El ejemplar fotocopiado de la Sala de Investigadores de la RAE no presenta número de registro y lleva la signatura 35-G-18 Dupl. Un original se puede encontrar en la Sala de Académicos y hay otro en la Sala de Exposiciones. En la Biblioteca Nacional, hay dos reproducciones en microfichas de esta misma edición [Signaturas: DGmicro/49216 y DGmicro/5270] y dos ejemplares, de los cuales solo puede consultarse el que lleva la signatura 4/140665 (no está disponible el registrado con la signatura 1/60310). No se localiza en el CSIC. 
2.3.27. GRAE-1911

INFORMACIÓN COMPILADA

\begin{tabular}{|c|c|c|c|}
\hline & $\begin{array}{c}\text { La Viñaza } \\
(1893)\end{array}$ & $\begin{array}{c}\text { Cotarelo } \\
(\mathbf{1 9 2 8})\end{array}$ & $\begin{array}{c}\text { Palau y Dulcet } \\
\text { (1948) }\end{array}$ \\
\hline $\begin{array}{l}\text { N. }{ }^{\circ} \text { de } \\
\text { ed. }\end{array}$ & & {$\left[26 .^{a}\right]$} & {$\left[i^{\left.24 .{ }^{a} ?\right]}\right.$} \\
\hline 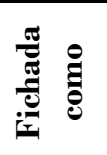 & & \begin{tabular}{l|rlll|} 
Gramática $\mid \ldots$ & (como las anteriores $) \mid$ Madrid $\mid$ \\
Perlado... | 1911. & & &
\end{tabular} & >> id. id. 1911. \\
\hline 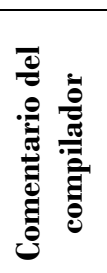 & & $\begin{array}{l}\text { Escueta información sobre tamaño y número de } \\
\text { páginas. Se hace constar que hubo cambios: } \\
\text { «4. }{ }^{\circ} ; 420 \text { págs. y } 2 \text { hojas más de anuncios de obras de la } \\
\text { Academia. Se hicieron algunas correcciones y adiciones». } \\
\text { (Pág. 41). }\end{array}$ & $\begin{array}{l}\text { Breve apunte } \\
\text { sobre volumen y } \\
\text { hojas: } \\
\text { «4. }{ }^{\circ} 1 \text { h. } 420 \text { p.». }\end{array}$ \\
\hline
\end{tabular}

Cuadro 29: GRAE-1911 en las compilaciones

\section{APUNTES SOBRE LA INFORMACIÓN}

(1) El libro consta, en realidad, de 420 páginas más dos páginas y media de catálogo de obras en venta.

(2) En Palau, la GRAE-1911 se recoge en la entrada de la edición de 1904.

(3) En rigor, se trataría de la edición 27. . En la lista de Cotarelo, esta Gramática es la 26. ${ }^{a}$ edición porque no registra la GRAE-1906. Respecto del orden que le hemos atribuido en el catálogo de Palau, conviene recordar que, para este compilador, sería la 24. ${ }^{\text {a }}$ si consideramos solo el primer volumen (en el que no recoge tres ediciones previas a la de 1911: GRAE-1906, 1908 y 1909), pues, según queda indicado, años más tarde incluye la GRAE-1906 en el tomo XV.

LOCALIZACIÓN: En la Sala de Investigadores de la RAE, puede encontrarse un ejemplar fotocopiado [Signatura: 35-G-19 Dupl; sin número de registro]. El original se encuentra en la Sala de Académicos [Signatura: 35-G-19]; otros, en la Sala de Exposiciones y la Sala Dámaso Alonso [6 ${ }^{\mathrm{a}}$ BA II-1-4-14]. La Biblioteca Nacional dispone de tres ejemplares [Signaturas: 1/57644, 7/26902 y 4/140655] que están 
disponibles en el Salón General. En la biblioteca M-BibCen del CSIC hay un ejemplar con signatura 806$4^{\circ} / 75$.

\subsubsection{GRAE-1913}

INFORMACIÓN COMPILADA

\begin{tabular}{|c|c|c|c|}
\hline & $\begin{array}{c}\text { La Viñaza } \\
\text { (1893) }\end{array}$ & $\begin{array}{c}\text { Cotarelo } \\
(\mathbf{1 9 2 8}) \\
\end{array}$ & $\begin{array}{c}\text { Palau y Dulcet } \\
\text { (1948) } \\
\end{array}$ \\
\hline N. ${ }^{\circ}$ de ed. & & {$\left[27 .^{\mathrm{a}}\right]$} & \\
\hline 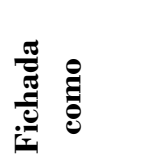 & & $\begin{array}{l}\text { Gramática } \ldots \text { (como las ants. }) \\
\text { Madrid | Perlado ... } \mid 1913 .\end{array}$ & NO LA REGISTRA \\
\hline 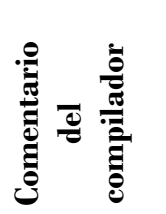 & & $\begin{array}{l}\text { Breve información sobre el tamaño } \\
\text { del volumen y el número de páginas: } \\
\text { «4. }{ }^{\circ} ; 420 \text { págs. y } 2 \text { hojas de anuncios». } \\
\text { (Pág. } 41) \text {. }\end{array}$ & \\
\hline
\end{tabular}

Cuadro 30: GRAE-1913 en las compilaciones

(1) De esta Gramática da cuenta Palau en el tomo XV (pág. 152); la registra como edición en $4 .^{\circ}$ de 420 páginas.

LOCALIZACIÓN: Con la signatura 35-G-20 D y el registro 48885, puede consultarse un original duplicado en la Sala de Investigadores de la Academia. Otros dos, en la Sala de Académicos y de Exposiciones. Los ejemplares con signatura 4/29224 y 1/64554 pueden consultarse en el Salón General de la BNE. Dos bibliotecas del CSIC disponen de un ejemplar de esta edición: la biblioteca M.BG-Hum [Signatura: 5/619] y la biblioteca M-Resid [Signatura: 31740]. 


\subsubsection{GRAE-1916}

INFORMACIÓN COMPILADA

\begin{tabular}{|c|c|c|c|}
\hline & $\begin{array}{c}\text { La Viñaza } \\
\text { (1893) } \\
\end{array}$ & $\begin{array}{c}\text { Cotarelo } \\
(1928) \\
\end{array}$ & $\begin{array}{c}\text { Palau y Dulcet } \\
(1948)\end{array}$ \\
\hline N. ${ }^{\circ}$ de ed. & & {$\left[28 .^{a}\right]$} & \\
\hline 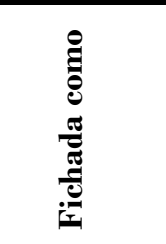 & & $\begin{array}{l}\text { Gram. de la lengua Castell. }{ }^{a} \text { por la R. } \\
\text { Acad. Esp. Nueva edic. Madr. Perlado } \\
\text { Paez y comp. }{ }^{\text {a }} \text { (Suces. de Hernando) } \\
\text { Impresores y libreros de la R. Acad. } \\
\text { Esp. } 1916 .\end{array}$ & NO LA REGISTRA \\
\hline 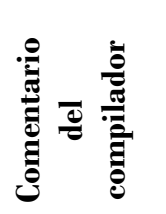 & & $\begin{array}{l}\text { Breve información sobre tamaño del } \\
\text { volumen y número de páginas: } \\
\text { «4. } ; 420 \text { págs.». (Pág. } 41 \text { ). }\end{array}$ & \\
\hline
\end{tabular}

Cuadro 31: GRAE-1916 en las compilaciones

LOCALIZACIÓN: De esta edición se puede consultar un ejemplar original en la Sala de Investigadores de la RAE, con signatura 35-G-21 dupl. y número de registro 48889. La Biblioteca Nacional cuenta con un ejemplar no disponible para consulta [Signatura: 1/72305], por lo que hay que consultar la reproducción en microfichas con signatura DGmicro/50442, que se encuentra en el Salón General. No se encuentra ningún ejemplar de esta edición en las bibliotecas del CSIC. 


\subsubsection{GRAE-1917}

INFORMACIÓN COMPILADA

\begin{tabular}{|c|c|c|c|}
\hline & $\begin{array}{c}\text { La Viñaza } \\
(1893) \\
\end{array}$ & $\begin{array}{c}\text { Cotarelo } \\
(1928) \\
\end{array}$ & $\begin{array}{c}\text { Palau y Dulcet } \\
(1948) \\
\end{array}$ \\
\hline N. ${ }^{\circ}$ de ed. & & {$\left[29 .^{a}\right]$} & {$\left[25 .^{a}\right]$} \\
\hline 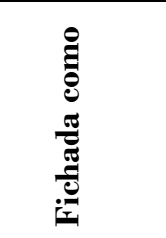 & & $\begin{array}{l}\text { Gram. de la leng. Cast. por la R. A. } \\
\text { E. nueva edic. reformada Madr. } \\
\text { Perlado Paez y Comp. }{ }^{\text {a }} \text { (sucesores } \\
\text { de Hernd.') Impresores y libreros de } \\
\text { la R. A. E., } 1917 \text {. }\end{array}$ & $\begin{array}{l}\text { Gramática... Nueva edición } \\
\text { reformada. M., Imp. de los } \\
\text { Sucesores de Hernando, } 1917 .\end{array}$ \\
\hline 兽 & & $\begin{array}{l}\text { Información solo relativa al tipo de } \\
\text { volumen y número de páginas: } \\
\text { «4. } .^{\circ} \text {, VIII-548 págs.». (Pág. } 41 \text { ). }\end{array}$ & $\begin{array}{l}\text { Información sobre tipo de } \\
\text { volumen, número de páginas y } \\
\text { precio: } \\
\text { «4. }{ }^{\circ} \text { VIII-548 p. }(5 \text { pts)». (Pág. } 39) .\end{array}$ \\
\hline
\end{tabular}

Cuadro 32: GRAE-1917 en las compilaciones

\section{APUNTES SOBRE LA INFORMACIÓN}

(1) Sorprende que Cotarelo no haga ninguna alusión a los cambios en cantidad y cualidad que se producen en esta nueva edición de la Gramática, especialmente en lo tocante a la teoría sintáctica, cambios que, además, son anunciados por la Corporación en la Advertencia preliminar.

(2) La GRAE-1917 es, en rigor, la edición 30. a, no la 25. (Palau) ni la 29. a (Cotarelo). De las omisiones de ambos catálogos ha quedado constancia en los apartados correspondientes.

LOCALIZACIÓN: El ejemplar fotocopiado de la Sala de Investigadores de la RAE lleva la signatura 35-G-22 Dupl. y el número de registro 35372. El original se encuentra en la Sala de Académicos. También hay ejemplares en la Sala de Exposiciones y en la de Comisiones (en esta última, con la signatura S. Com. 9B-1). En el catálogo de la Biblioteca Nacional no aparece registrada esta edición, pero el libro sí se encuentra en los fondos de la Biblioteca, mal fichado como GRAE-1907 [Signatura: 1/73292]. En la biblioteca M-Resid del CSIC hay un ejemplar con signatura PIN539. 
2.3.31. GRAE-1920

INFORMACIÓN COMPILADA

\begin{tabular}{|c|c|c|c|}
\hline & $\begin{array}{c}\text { La Viñaza } \\
(1893)\end{array}$ & $\begin{array}{c}\text { Cotarelo } \\
(1928)\end{array}$ & $\begin{array}{c}\text { Palau y Dulcet } \\
\text { (1948) }\end{array}$ \\
\hline N. ${ }^{\circ}$ de ed. & & {$\left[30 .^{a}\right]$} & {$\left[26 .^{\mathrm{a}}\right]$} \\
\hline 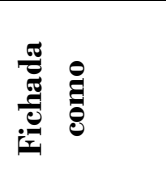 & & \begin{tabular}{l|ccc} 
Gramática & $\ldots$ & (como las \\
$\begin{array}{l}\text { anteriores }) \\
\text { reformada. }\end{array}$ & \multicolumn{2}{c}{ Nueva edición, } \\
Madrid, Perlado ... & $\mid 1920$.
\end{tabular} & $\begin{array}{l}\text { Idem. M., imp. de los Sucesores de } \\
\text { Hernando, } 1920 .\end{array}$ \\
\hline 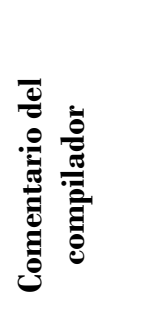 & & $\begin{array}{l}\text { «4. }{ }^{\circ} ; 564 \text { págs. y } 2 \text { hojas más. Como } \\
\text { se ve por el número de páginas esta } \\
\text { edición recibió grandes aumentos y } \\
\text { mejoras». (Pág. } 41 \text { ). }\end{array}$ & $\begin{array}{l}\text { Información sobre tipo de volumen, } \\
\text { número de páginas y precio, así } \\
\text { como de las dos reimpresiones que le } \\
\text { siguen: } \\
\left.\text { «4. }{ }^{\circ} 564 \text { p. ( } 7 \mathrm{pts}\right) \text { y id., id., 1924, } 4 .^{\circ}{ }^{\circ} \\
\text { gran } 8 .^{\circ} 564 \text { p. } 2 \text { h (7 pts). Después: id., } \\
\text { id., 1928, } 4 .^{\circ} 594 \text { p. (10 pts)». (Pág. 39). }\end{array}$ \\
\hline
\end{tabular}

Cuadro 33: GRAE-1920 en las compilaciones

\section{APUNTES SOBRE LA INFORMACIÓN}

(1) Los cambios de esta edición tienen que ver, en esencia, con la teoría morfológica. En este caso, el incremento en el número de páginas (dieciséis) llama la atención de Cotarelo, lo que hace que se comprenda menos que no haga mención explícita del aumento que supuso la GRAE-1917 respecto de la edición precedente (ciento veintiocho páginas más).

(2) En rigor, la GRAE-1920 es la edición 31. a .

LOCALIZACIÓN: Esta edición figura en la Sala de Investigadores, en fotocopias del original, con la signatura 35-G-33 D y el registro 35374. La Academia cuenta con dos ejemplares más, guardados en la Sala de Académicos y de Exposiciones. La BNE dispone de dos ejemplares: uno de ellos es el ejemplar del Registro de la Propiedad Intelectual [Signatura: 2/76979]; el otro ejemplar lleva la signatura 4/17796. Los dos se pueden consultar en el Salón General. No se localiza ningún ejemplar en el CSIC. Una versión digitalizada puede encontrarse en Gómez Asencio (comp., 2001). 


\subsubsection{GRAE-1924}

INFORMACIÓN COMPILADA

\begin{tabular}{|c|c|c|c|}
\hline & $\begin{array}{c}\text { La Viñaza } \\
\text { (1893) }\end{array}$ & $\begin{array}{c}\text { Cotarelo } \\
\text { (1928) }\end{array}$ & $\begin{array}{c}\text { Palau y Dulcet } \\
\text { (1948) }\end{array}$ \\
\hline N. ${ }^{\circ}$ de ed. & & {$\left[31 .^{a}\right]$} & {$\left[i^{27 .}{ }^{\mathrm{a}} ?\right]$} \\
\hline 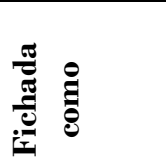 & & $\begin{array}{l}\text { Real Academia Española. } \mid \text { Nueva } \\
\text { edición, reformada. } \mid \text { (Emblema.) } \mid \\
\text { Madrid } \mid \text { Perlado ... } \mid 1924 .\end{array}$ & >> id., id., 1924. \\
\hline 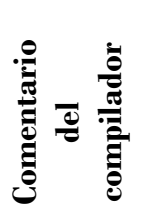 & & $\begin{array}{l}\text { Tamaño y páginas: } \\
\text { «4. ; } 564 \text { págs. y } 2 \text { hojas más». (Pág. 41). }\end{array}$ & $\begin{array}{l}\text { Tamaño, páginas y } \\
\text { precio: } \\
\text { «4. }{ }^{\circ} \quad \text { gran } 8 .^{\circ} 564 \text { p. } 2 \text { h }(7 \\
\text { pts)». }\end{array}$ \\
\hline
\end{tabular}

Cuadro 34: GRAE-1924 en las compilaciones

\section{APUNTES SOBRE LA INFORMACIÓN}

(1) En Palau, esta edición aparece recogida en la entrada de la GRAE-1920.

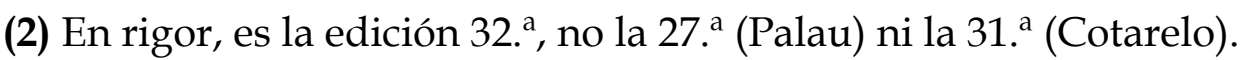

LOCALIZACIÓN: Hay un original duplicado en la Sala de Investigadores de la Academia [Signatura: 35-G23 y Registro: 50337]; otro, en la Sala de Comisiones [Signatura: S. Com. 9-B-2] y otro, en la Sala de Exposiciones. En el Salón General de la BNE, puede consultarse el ejemplar con signatura 1/85250 o la reproducción en microfichas DGmicro/18210. No se encuentra esta Gramática en el CSIC. 


\subsubsection{GRAE-1928}

\section{INFORMACIÓN COMPILADA}

\begin{tabular}{|c|c|c|c|}
\hline & $\begin{array}{c}\text { La Viñaza } \\
\text { (1893) }\end{array}$ & $\begin{array}{c}\text { Cotarelo } \\
(1928)\end{array}$ & $\begin{array}{c}\text { Palau y Dulcet } \\
\text { (1948) }\end{array}$ \\
\hline N. ${ }^{\circ}$ de ed. & & $32 .^{a}$ & [i28. $\left.{ }^{a} ?\right]$ \\
\hline 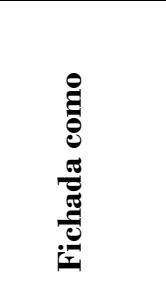 & & 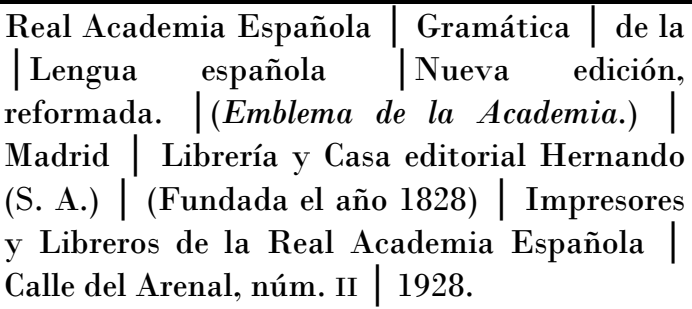 & >>id., id., 1928. \\
\hline 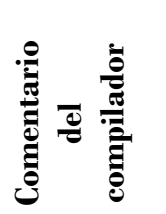 & & $\begin{array}{l}\text { Tamaño y páginas: } \\
\text { «4. ; } 564 \text { págs.». (Pág. 41). }\end{array}$ & $\begin{array}{l}\text { Tamaño, páginas y } \\
\text { precio: } \\
4 .^{\circ} 594 \text { p. }(10 \mathrm{pts})\end{array}$ \\
\hline
\end{tabular}

Cuadro 35: GRAE-1928 en las compilaciones

\section{APUNTES SOBRE LA INFORMACIÓN}

(1) En Palau, aparece recogida en la entrada de la edición de 1920.

(2) En rigor, la edición $33 .^{a}$, no la 28. a

LOCALIZACIÓN: La RAE dispone de tres originales: uno se encuentra en la Sala de Investigadores, con signatura 35-G-24 D y registro 50335; otro, en la Sala de Académicos, con signatura 35-G-24; y otro, en la Sala de Exposiciones. En la Biblioteca Nacional, puede consultarse, en el Salón General, el ejemplar con la signatura 1/89361. También se puede encontrar esta edición en tres bibliotecas distintas del CSIC: CIEGPS [Signatura: 1724], M-BibCen [Signatura: 4300] y M-Resid [Signatura: 3463]. 


\subsubsection{GRAE-1931}

\section{INFORMACIÓN COMPILADA}

\begin{tabular}{|c|c|c|c|}
\hline & $\begin{array}{c}\text { La Viñaza } \\
(1893)\end{array}$ & $\begin{array}{c}\text { Cotarelo } \\
(\mathbf{1 9 2 8}) \\
\end{array}$ & $\begin{array}{c}\text { Palau y Dulcet } \\
(1948)\end{array}$ \\
\hline N. ${ }^{\circ}$ de ed. & & & {$\left[29 .^{\mathrm{a}}\right]$} \\
\hline 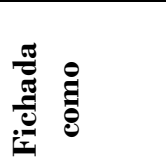 & & & Idem. M., Espasa-Calpe, 1931. \\
\hline 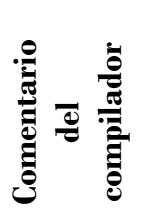 & & & $\begin{array}{l}\text { Información sobre características físicas de la edición y } \\
\text { el precio de la misma: } \\
\left.\text { «4. }{ }^{\circ} 534 \text { p. (11 pts. Tela } 13 ’ 50 \text { pts.)». (Pág. } 39\right) \text {. }\end{array}$ \\
\hline
\end{tabular}

Cuadro 36: GRAE-1931 en las compilaciones

\section{APUNTES SOBRE LA INFORMACIÓN}

\section{(1) En rigor, es la edición 34. .}

LOCALIZACIÓN: De esta edición es de la que más ejemplares dispone la Academia, algunos de ellos procedentes del legado de Dámaso Alonso. Se puede consultar el ejemplar fotocopiado de la Sala de Investigadores [Signatura: 35-G-25 A y Registro: 35380]. Otros ejemplares en los Depósitos 2 y 3 [Signaturas D 20-732 y DA-588, respectivamente], en la Sala de Consultas, en la Sala de Académicos, de Exposiciones y en la Sala Dámaso Alonso [Signatura: 34 D-1-4-1-11]. No se encuentran ejemplares en la Biblioteca Nacional. También el CSIC cuenta con bastantes ejemplares de esta edición: B-IMF [Signatura: J Aca 8], CC-IHH [Signatura: 811.134.2’36 REA gra], M-BG.Hum [Signatura: 5/1876], M-BibCen [no existen ejemplares disponibles para este registro], M-ICCET [Signatura: 400-7], M-Ortega [Signatura: 806.0-5 ACA] y M-Resid [Signatura: 3397].

(*) Las ediciones publicadas a partir de 1909 son relativamente fáciles de encontrar en las librerías de viejo. 
NOTA: Las ediciones de 1959 y 1962 (no recogidas, por razones evidentes, ni en los catálogos de La Viñaza y Cotarelo ni en el tomo I del Manual de Palau ${ }^{60}$ ) suelen ser obviadas por buena parte de los estudiosos de la Gramática académica. Es habitual considerar que la última GRAE es la de 1931 y que la Institución no vuelve a sacar un libro de Gramática (un Esbozo) hasta 1973. Sin embargo, es obligada la mención de estos dos textos, por cuanto no son ni siquiera una reimpresión a plana y renglón como tantas otras versiones anteriores (lo cual, por otra parte, no ha sido óbice para considerarlas "una Gramática más"): la propia portada anuncia que, en estas ediciones, se tiene en cuenta la última preceptiva sobre cuestiones prosódicas y ortográficas, de 1959. Los textos han quedado fuera de nuestro corpus, pero solo por lo dicho entiendo que mal hace la crítica si no tiene en consideración estos dos libros (uno con depósito legal en 1959 y otro en 1962) como las últimas ediciones (reimpresiones si se quiere) de la GRAE.

La GRAE-1959 puede localizarse en la BNE: 1/214261 y 1/214419. El texto de 1962 puede consultarse en la Sala de Investigadores de la RAE en un ejemplar fotocopiado [Signatura: 35-G-25 b]; un original se encuentra en la Sala de Académicos [Signatura: 35-G-25 B] y otro en la Sala de Exposiciones.

${ }^{60}$ En el tomo XV de su catálolgo (de 1962), Palau y Dulcet podría haberlas recogido (si no las dos ediciones, al menos sí la de 1959). 


\subsection{Las Gramáticas en tablas}

Sintetizo a continuación, en orden cronológico y por siglos, las distintas ediciones de la Gramática académica y en qué compiladores y estudiosos podemos encontrar referencia a ellas, o bien declaraciones explícitas sobre su existencia. Obviamente, han quedado fuera de la tabla investigadores que han analizado la GRAE, entre otros, Rabanales (1965), Calero Vaquera (1986), Martí Sánchez (1988), Vázquez Rozas (1990), Taboada Cid (1991), Iglesias Bango (2001), Ramajo Caño (2002) y Martínez Linares (2006), puesto que ellos han atendido a aspectos específicos y a ediciones concretas, sin que en sus trabajos encontremos un pronunciamiento sobre el conjunto total de las ediciones o sobre las de un determinado periodo, como tampoco una voluntad de hacer inventario de estos libros o historiar acerca de la Gramática académica $^{61}$.

Solamente las ediciones "oficiales", al margen del grado de innovación que presenten (esto es, al margen de si, en efecto, son ediciones distintas o se trata de reimpresiones), van acompañadas, en la columna de «Textos», por número de edición entre corchetes. Junto al número aparece una letra $(\mathrm{J}, \mathrm{E}, \mathbf{R})$ indicativa de si se trata de una edición Jalón, de una nueva Edición o de una

${ }^{61}$ Hago mención aparte del trabajo de Pons Bordería (1997). No ha sido incluido en los cuadros que siguen por ser un estudio que únicamente analiza los enlaces extraoracionales en la tradición académica en comparación con otros autores (en orden cronológico: Nebrija, Correas, Salvá, Bello y Gili Gaya). Tampoco pretende este autor historiar sobre la GRAE. No obstante, como ya se ha apuntado, recoge en la bibliografía final de su artículo un número elevadísimo de ediciones de la Gramática institucional, por lo que puede ser de interés anotar los libros que consulta y compararlos con los datos de los cuadros:

- Del siglo XVIII: las cuatro ediciones oficiales que he defendido $(1771,1772,1781 \mathrm{y}$ 1796). En su exhaustivo corpus no ha incluido la supuesta edición de 1788.

- Del siglo XIX: las dieciséis ediciones oficiales (las dos de los años cincuenta -1854 y 1858-, las cinco de los sesenta -1862, 1864, 1865, 1866 y 1867-, las tres ediciones de los setenta $-1870,1874$ y 1878-, los cuatro libros de los años ochenta $-1880,1883,1885$ y 1888- y los dos de los noventa (1890 y 1895).

- Del siglo XX: Todas las ediciones excepto las GRAE-1906, 1908, 1959 y 1962. Es decir, anota las ediciones de 1900, 1901, 1904, 1909, 1911, 1913, 1916, 1917, 1920, 1924, 1928 y 1931.

- También recoge el Esbozo y una edición francesa de 1855 (Saint-Cloud: Imprenta de la Viuda de Belin), a la que se ha hecho referencia en la nota 29 de este capítulo. 
Reimpresión del texto precedente, y esta marca es independiente de cómo se presente el libro en la portada. La jerarquización en los rangos J/E/R viene determinada por los apuntes ya hechos y por cuestiones de mayor calado doctrinal (referentes a la concepción gramático-sintáctica) que se comentarán con detenimiento en las páginas que siguen. Básicamente, esta jerarquización coincide con los modelos y submodelos marcados en Gómez Asencio (2005: 599).

También entre corchetes indico el número de edición que los compiladores o estudiosos atribuyen a una determinada GRAE, pero solo lo hago con las ediciones problemáticas (aquellas cuya existencia está por confirmar, aquellas mal ordenadas, etc.).

El signo (?) lo he usado en aquellos casos en que el propio estudioso vacila sobre la existencia de la edición y (N. ${ }^{\circ}$ ed. + ?) en los casos dudosos de Palau y Dulcet que han quedado comentados en los cuadros del punto 2.3.

En la columna de «Textos», dos fechas aparecen entre corchetes: en las “ediciones oficiales", la de 1852, por lo comentado en las páginas anteriores acerca de las dudas sobre su oficialidad; y en las "supuestas reimpresiones", un año 1821, por la posibilidad de que se trate de la reimpresión de 1822, según ha quedado apuntado también más arriba; el otro 1821 de ese mismo apartado -sin corchetes- es la edición registrada por Palau y Dulcet (vid. supra 2.3.4.).

En la columna de "Compiladores y estudiosos de los textos», he utilizado el sombreado gris como indicativo de que las ediciones, por fecha, son posteriores al año de publicación de las compilaciones (y, en consecuencia lógica, no las encontramos recogidas en ellas) o bien como marca de que quedan fuera del periodo atendido por un estudioso o de que, simplemente, 
un autor concreto no hace mención a un texto determinado, sin que podamos afirmar que no acepta, ignora u obvia la existencia del mismo.

Los compiladores aparecen en los tres cuadros (siglo XVIII, XIX y XX). Los estudiosos, solo en aquellos de cuyas ediciones (todas o algunas) hagan algún tipo de alusión (desde análisis pormenorizado -interpretación doctrinal, historia externa, etc.- hasta mero registro).

Los artículos o libros tenidos en cuenta de los distintos estudiosos, en su mayor parte, están indicados al comienzo del punto 2.1. De Ramón Sarmiento me he visto obligada a considerar más fechas de las dos indicadas en un primer momento, pues este autor ha vertido sus consideraciones sobre la GRAE en un buen número de entregas. Recuerdo las fechas de todos:

\begin{tabular}{|c||c|c|c|}
\hline & Siglo XVIII & Siglo XIX & Siglo XX \\
\hline $\begin{array}{c}\text { Uruburu } \\
\text { Vidaurrázaga }\end{array}$ & $1989[1975]$ & & \\
\hline Domínguez Caparrós & 1976 & & \\
\hline Sarmiento & $1977 b, 1979,1984 a$ & $1979,1984 b, 1986$ & $1979,1997 \mathbf{a}$ \\
\hline Taboada Cid & 1981 & & \\
\hline Ridruejo & 1989 & & 1989 \\
\hline Fries & 1989 & 1989 & 2004,2005 \\
\hline Rojo & 2001 & 2001 & 2006 \\
\hline Gómez Asencio & 2004,2005 & 2004,2005 & \\
\hline $\begin{array}{c}\text { Hernando García } \\
\text { Cervigón }\end{array}$ & 2006 & 2006 & \\
\hline \multicolumn{2}{c}{} & & \\
\hline
\end{tabular}

Tabla 1: Algunos estudios sobre las GRAE 


\begin{tabular}{|c|c|c|c|c|c|c|c|c|c|c|c|c|c|c|}
\hline \multicolumn{15}{|c|}{ Gramáticas del XVIII } \\
\hline \multicolumn{3}{|c|}{ TEXTOS } & \multicolumn{3}{|c|}{ COMPILADORES } & \multicolumn{9}{|c|}{ ESTUDIOSOS DE LOS TEXTOS } \\
\hline $\begin{array}{c}\text { Ediciones } \\
\text { oficiales } \\
\text { (declaradas por } \\
\text { la RAE y } \\
\text { fisicamente } \\
\text { localizables) }\end{array}$ & $\begin{array}{l}\text { Supues- } \\
\text { tas } \\
\text { reimpre- } \\
\text { siones } \\
\text { (informac. } \\
\text { indirecta } \\
\text { sobre ellas) }\end{array}$ & $\begin{array}{c}\text { Ediciones } \\
\text { publica- } \\
\text { das fuera } \\
\text { de } \\
\text { España }\end{array}$ & $\begin{array}{c}\text { La } \\
\text { Viñaza }\end{array}$ & Cotarelo & $\begin{array}{l}\text { Palau } \\
y \\
\text { Dulcet }\end{array}$ & 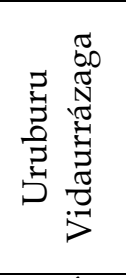 & 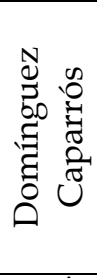 & 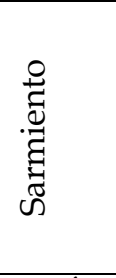 & 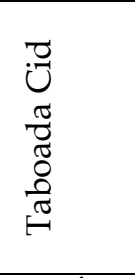 & 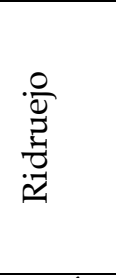 & 总 & $\stackrel{\circ}{\mathscr{0}}$ & 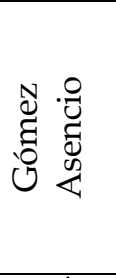 & 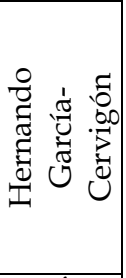 \\
\hline $1771\left[1 .{ }^{\mathrm{a}}\right]$ & & & SÍ & Sí & SÍ & SÍ & SÍ & Sí & Sí & Sí & Sí & Sí & Sí & Sí \\
\hline $1772\left[2^{\mathrm{a}}\right] \mathrm{R}$ & & & SÍ & Sí & sí & SÍ & sí & Sí & Sí & Sí & Sí & Sí & Sí & Sí \\
\hline $1781\left[3 .^{a}\right] \mathrm{R}$ & & & SÍ & SÍ & Sí & SÍ & sí & Sí & Sí & Sí & Sí & Sí & Sí & Sí \\
\hline & 1788 & & $\mathrm{NO}$ & NO & NO & (?) & NO & Sí $\left[4^{a}\right]$ & SÍ $\left[4^{\mathrm{a}}\right]$ & (?) & Sí & (?) & (?) & Sí \\
\hline & & 1793 & NO & NO & NO & NO & NO & $\mathrm{NO}$ & NO & NO & $\mathrm{NO}$ & NO & NO & NO \\
\hline $1796\left[4 .{ }^{a}\right] \mathrm{E}$ & & & SÍ & sí & SÍ & Sí $\left[4^{\mathrm{a}}\right]$ & Sí & Sí [ $\left.5^{a}\right]$ & Sí $\left[5^{\mathrm{a}}\right]$ & 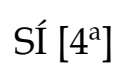 & sí & Sí [4] & Sí [4] & Sí \\
\hline
\end{tabular}




\begin{tabular}{|c|c|c|c|c|c|c|c|c|c|c|c|}
\hline \multicolumn{12}{|c|}{ Gramáticas del XIX } \\
\hline \multicolumn{4}{|c|}{ LOS TEXTOS } & \multicolumn{3}{|c|}{ COMPILADORES } & \multicolumn{5}{|c|}{ ESTUDIOSOS DE LOS TEXTOS } \\
\hline $\begin{array}{c}\text { Ediciones } \\
\text { oficiales } \\
\text { (declaradas por } \\
\text { la RAE y } \\
\text { físicamente } \\
\text { localizables) }\end{array}$ & $\begin{array}{c}\text { Supuestas } \\
\text { reimpre- } \\
\text { siones } \\
\text { (información } \\
\text { indiecta } \\
\text { sobre ellas) }\end{array}$ & $\begin{array}{c}\text { Eds. } \\
\text { publica- } \\
\text { das fuera } \\
\text { de } \\
\text { España }\end{array}$ & $\begin{array}{c}\text { Traduc- } \\
\text { ciones }\end{array}$ & $\begin{array}{c}\text { La } \\
\text { Viñaza }\end{array}$ & Cotarelo & $\begin{array}{c}\text { Palau } \\
\text { y } \\
\text { Dulcet }\end{array}$ & 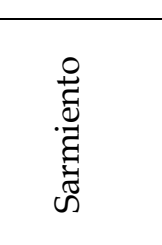 & 总 & $\frac{\circ}{\frac{a}{\pi}}$ & 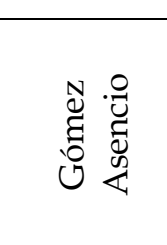 & 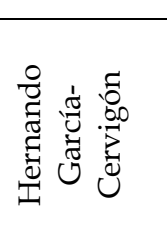 \\
\hline & 1800 & & & NO & NO & NO & Sí & Sí & Sí & Sí & NO \\
\hline & 1802 & & & NO & NO & NO & Sí & Sí & Sí & Sí & NO \\
\hline & 1817 & & & NO & NO & NO & Sí & Sí & Sí & Sí & NO \\
\hline & [1821] - 21 & 1821 & 1821 & $\mathrm{~N} / \mathrm{N} / \mathrm{N}$ & $\mathrm{N} / \mathrm{N} / \mathrm{N}$ & N/S/S & $\mathrm{N} / \mathrm{N} / \mathrm{S}$ & $\mathrm{N} / \mathrm{N} / \mathrm{N}$ & $\mathrm{N} / \mathrm{N} / \mathrm{N}$ & $\mathrm{N} / \mathrm{N} / \mathrm{N}$ & $\mathrm{N} / \mathrm{N} / \mathrm{S}$ \\
\hline & 1822 & & & NO & NO & NO & Sí & Sí & SÍ & Sí & NO \\
\hline & 1825 & & & NO & NO & Sí & NO & NO & NO & NO & NO \\
\hline & & 1826 & & NO & NO & Sí & NO & NO & NO & NO & NO \\
\hline & 1831 & & & $\mathrm{NO}$ & NO & NO & Sí & SÍ & Sí & Sí & NO \\
\hline \multirow[t]{2}{*}{ [1852] R } & & & & NO & sí & sí & NO & Sí & Sí & sí & sí \\
\hline & & 1853 & & NO & NO & NO & NO & NO & NO & NO & NO \\
\hline \multirow[t]{2}{*}{$1854\left[5 .{ }^{a}\right] \mathrm{J}$} & & & & Sí [9] & Sí & Sí & Sí & Sí & - & Sí & sí \\
\hline & & 1855 & & NO & NO & NO & NO & NO & - & NO & NO \\
\hline 1858 [6. $\left.{ }^{\mathrm{a}}\right] \mathrm{E}$ & & & & Sí [5] & Sí & Sí & - & sí & - & Sí & Sí \\
\hline 1862 [7. $\left.{ }^{a}\right] \mathbf{R}$ & & & & Sí [6] & Sí & Sí & _ & Sí & - & Sí & Sí \\
\hline $1864\left[8^{\mathrm{a}}{ }^{\mathrm{a}}\right] \mathrm{R}$ & & & & Sí [7] & Sí & Sí & - & Sí & - & SÍ & Sí \\
\hline $1865\left[9^{\mathrm{a}}{ }^{\mathrm{a}}\right] \mathrm{R}$ & & & & Sí [8] & sí & sí & _ & Sí & - & sí & sí \\
\hline $1866\left[10{ }^{a}\right] \mathbf{R}$ & & & & Sí [10] & Sí & Sí & - & Sí & - & Sí & Sí \\
\hline $\mathbf{1 8 6 7}\left[111^{\mathrm{a}}\right] \mathbf{R}$ & & & & SÍ & SÍ & SÍ & - & SÍ & - & SÍ & SÍ \\
\hline $1870\left[12^{a}\right]$ J J & & & & Sí & SÍ & Sí & Sí 1 & Sí & - & sí & sí \\
\hline $1874\left[13 .{ }^{a}\right] \mathrm{E}$ & & 1874 & & Sí/NO & SÍ/NO & Sí/NO & - & Sí/NO & - & SÍ/NO & Sí \\
\hline $1878\left[14 .{ }^{a}\right] \mathbf{R}$ & & & & Sí & Sí & Sí & - & Sí & - & Sí & Sí \\
\hline $1880\left[15 .^{\mathrm{a}}\right] \mathrm{J}$ & & & & sí & sí & sí & _ & Sí & - & sí & sí \\
\hline $1883\left[166^{\mathrm{a}}\right] \mathrm{R}$ & & & & NO & Sí & SÍ [¿16a? & - & Sí & - & Sí & Sí \\
\hline $1885\left[17 .^{\mathrm{a}}\right] \mathrm{R}$ & & & & NO & Sí & Sí [¿17ª?] & - & Sí & - & Sí & Sí \\
\hline $1888\left[18 .^{a}\right] \mathrm{R}$ & & & & Sí [16] & Sí & Sí & - & SÍ & - & SÍ & Sí \\
\hline $1890\left[19 .^{a}\right] R$ & & & & NO & sí & sí & _ & Sí & $\square$ & SÍ & SÍ \\
\hline $1895\left[200^{\mathrm{a}}\right] \mathrm{R}$ & & & & _ & Sí & Sí [¿20a?] & - & Sí & - & sí & sí \\
\hline
\end{tabular}

Tabla 3: Las Gramáticas del siglo XIX

${ }^{1}$ Me resulta difícil entender la numeración de ediciones que hace este autor. En las primeras líneas de su estudio de 1997 (Sarmiento, 1997a: 185), se lee:

[...] Viene esto a cuento de la gramática de la RAE. En el siglo pasado, en 1870, aparecía una nueva edición de esta obra: la cuarta de la serie iniciada en 1771; fueron necesarios cuarenta y siete años para que, en 1917, se emprendiera su reforma, se prosiguiera en 1920 y se culminara en 1924 con la quinta edición (la cual aparece sin apenas modificaciones en las reimpresiones de 1928, 1931 y 1962). También en este siglo se ha publicado el Esbozo de una Nueva Gramática de la Lengua Española.

No olvidemos que fue Sarmiento el primero en defender que la GRAE-1796 debe ser considerada la quinta edición del texto académico. ¿Ahora es la de 1870 la cuarta? Ni siquiera considerando que pueda estar refiriéndose a las ediciones que he etiquetado como "jalón" salen las cuentas. Solo si sumáramos las ediciones J y E $(1796,1854,1858,1870)$ podría entenderse esta numeración. Pero, ¿ya no contempla ninguna otra edición "mínimamente novedosa" entre 1870 y 1917. 


\begin{tabular}{|c|c|c|c|c|c|c|c|c|c|c|}
\hline \multicolumn{11}{|c|}{ Gramáticas del XX } \\
\hline \multicolumn{4}{|c|}{ LOS TEXTOS } & \multicolumn{3}{|c|}{ COMPILADORES } & \multicolumn{4}{|c|}{ ESTUDIOSOS DE LOS TEXTOS } \\
\hline $\begin{array}{c}\text { Ediciones } \\
\text { oficiales } \\
\text { (declaradas por la } \\
\text { RAE y físicamente } \\
\text { localizables) }^{1}\end{array}$ & $\begin{array}{l}\text { Supuestas } \\
\text { reimpre- } \\
\text { siones } \\
\text { (información } \\
\text { indirecta } \\
\text { sobre ellas) }\end{array}$ & $\begin{array}{c}\text { Eds. } \\
\text { Publi- } \\
\text { cadas } \\
\text { fuera } \\
\text { de } \\
\text { España }\end{array}$ & $\begin{array}{l}\text { Traduc- } \\
\text { ciones }\end{array}$ & $\begin{array}{c}\text { La } \\
\text { Viñaza }\end{array}$ & Cotarelo & $\begin{array}{c}\text { Palau } \\
\text { y } \\
\text { Dulcet }\end{array}$ & 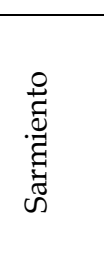 & 总 & 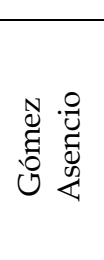 & 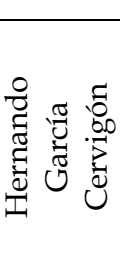 \\
\hline $1900\left[21 .{ }^{a}\right] \mathrm{R}$ & & & & _ & Sí & Sí & - & Sí & Sí & Sí \\
\hline $1901\left[22 .{ }^{a}\right] \mathrm{R}$ & & & & 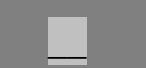 & sí & Sí [22.a?] & _ & sí & Sí & sí \\
\hline $1904\left[23 .{ }^{\mathrm{a}]} \mathrm{E}\right.$ & & & & - & sí & sí & _ & sí & Sí & sí \\
\hline 1906 [24. ${ }^{\mathrm{a}]} \mathrm{R}$ & & & & - & NO & Sí & _ & Sí & sí & Sí \\
\hline 1908 [25. $\left.{ }^{\mathrm{a}}\right] \mathrm{R}$ & & & & _ & Sí & NO & _ & Sí & sí & Sí \\
\hline $1909[26 . \mathrm{a}] \mathrm{R}$ & & & & - & Sí & NO & - & Sí & sí & Sí \\
\hline $1911\left[27 .^{\mathrm{a}}\right] \mathrm{E}$ & & & & - & Sí & Sí [24. $\left.{ }^{\text {a? }}\right]$ & _ & Sí & Sí & SÍ \\
\hline $1913\left[28 .{ }^{a}\right] \mathrm{R}$ & & & & - & Sí & Sí & _ & sí & Sí & Sí \\
\hline $1916\left[29 .{ }^{a}\right] \mathrm{R}$ & & & & - & Sí & NO & _ & Sí & Sí & SÍ \\
\hline $1917\left[300^{\mathrm{a}}\right] \mathrm{J}$ & & & & - & Sí & SÍ [25. $\left.{ }^{\mathrm{a}}\right]$ & Sí & Sí & Sí & Sí \\
\hline $1920\left[31 .{ }^{\mathrm{a}}\right] \mathrm{E}$ & & & & - & Sí & Sí & Sí & Sí & Sí & - \\
\hline $1924\left[32 .^{a}\right]_{\mathrm{R}}$ & & & & - & sí & Sí [27.a? $]$ & Sí & Sí & sí & 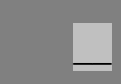 \\
\hline 1928 [33..$^{\mathrm{a}} \mathrm{R}$ & & & & - & Sí & Sí [28. ${ }^{\mathrm{a}}$ ?] & Sí & SÍ & Sí & 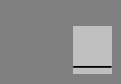 \\
\hline $1931\left[34 .{ }^{\mathrm{a}}\right] \mathrm{R}$ & & & & _ & - & Sí & Sí & sí & Sí & $\ldots$ \\
\hline $1959[35 . \mathrm{a}] \mathrm{E}$ & & & & - & _ & - & $\mathrm{NO}$ & Sí & Sí & - \\
\hline $1962\left[36 .^{\mathrm{a}}\right] \mathrm{R}$ & & & & _ & _ & - & Sí & Sí & Sí & $\ldots$ \\
\hline
\end{tabular}

Tabla 4: Las Gramáticas del siglo XX

${ }^{1}$ En la lista incluyo todas las ediciones hasta la última, aunque el corpus recoja hasta la GRAE-1924. 



\section{3.}

\section{EL LUGAR DE LA GRAMÁTICA EN EL QUEHACER ACADÉMICO}

No haré en este apartado un nuevo repaso de las vicisitudes de elaboración y publicación del primer texto de 1771 y los que lo siguen de forma inmediata, puesto que el tema ha sido suficientemente tratado por distintos investigadores: Domínguez Caparrós (1976), Sarmiento (1978, 1979, 1981), Taboada Cid (1991), Rojo (2001). Y una revisión de la historia externa de la GRAE hasta 1917 ha sido realizada con bastante documentación por Hernando García-Cervigón (2006: 1-25), a quien remito para detalles sobre este asunto.

No obstante, antes de pasar al análisis detenido del concepto de gramática que defiende la Institución, sí considero de interés hacer balance del peso que la elaboración del libro de Gramática tiene dentro de las tareas de los académicos, pues determinarlo puede dar luz a ciertas cuestiones sobre la concepción y el tratamiento de los hechos gramaticales que serán tratados a lo largo de esta tesis. 


\subsection{La Gramática, un proyecto secundario}

El epígrafe de este apartado no sorprenderá a nadie mínimamente familiarizado con la obra de la Academia, pues sabido es que, desde el momento de su fundación (incluso desde las vísperas), la docta Casa tiene como objetivo fundamental $-\mathrm{y}$ en un primer momento, casi exclusivo- la elaboración de un Diccionario, y que la importancia (y necesidad) de elaboración de una Gramática se empieza a sentir en el seno de la Institución una vez finalizado el primer (y principal) proyecto ${ }^{1}$.

Empiezo por las "vísperas". Sobre las tempranas reuniones celebradas en casa del marqués de Villena, previas a la fundación del real Instituto², se dice en la «Historia de la Real Academia Española» contenida en los preliminares del Diccionario de Autoridades lo que sigue:

Tenianfe eftas Juntas en la Poláda del Marqués, fin oblervar formalidád en afsientos, ni en votos. Reducianfe à tratar las matérias que ofrecía la converfación; bien que fiempre venían à parar los difcurlos en que fe formalle Académia, que tuvielfe por primero y principál inftituto el trabajar un Diccionario de la léngua. Efta idéa era generál; pero ella, y la Académia eftaban en un informe embrión, fiendo precifo que el defvélo y la fatíga vencieflen y allanaflen las grandes dificultades que le ofrecían para practicar lo que le ideaba $[\ldots]$

Deciale tambien fer jufto fijar la léngua [...] y no era decente à nolotros, que logrando la fortúna de encontrarla en nueftros dias tan perfecta, no eternizaffemos en las prenfas su memória formando un

\footnotetext{
${ }^{1}$ Diego (1963) ofrece por cincuentenas los periodos de ocupación institucional hasta el primer cuarto de milenio de vida de la Corporación. En Zamora Vicente (1999), más datos.

2 Para detalles sobre la fundación de la RAE, pueden consultarse los Estatutos de 1715 -citados en la bibliografía final como Real Academia Española (1715)-, los cuales fueron publicados junto con una síntesis de los pormenores de la fundación de la docta Casa. También sobre la fundación y elección de cargos informan Cotarelo Valledor (1946) y Zamora Vicente (1999).
} 


\section{Diccionario al exemplo de las dos celebradifsimas Académias de}

París y Florencia.

(Diccionario de Autoridades: X-XI. El subrayado es mío)

Por otra parte, la revisión de las fuentes primarias (Gramáticas) y secundarias (Diccionarios) del corpus, así como la de documentación de otra índole (proyectos preparatorios, discursos, resúmenes de tareas y actos, memorias, actas, estatutos...), permite afirmar:

a) Que la Gramática es, sin duda alguna, labor secundaria en el quehacer académico, siempre ensombrecida o postergada por los compromisos con el Diccionario, el «libro capital de todo pueblo: el catálogo de su idioma», en palabras de Cotarelo (1928: 7) ${ }^{3}$.

${ }^{3}$ Son muchos los testimonios que ponen de evidencia la prioridad del Diccionario, de su constante perfeccionamiento, frente al resto de tareas. Anticipo dos botones de muestra que se completarán con los puntos que siguen de este capítulo:

En el Censo Académico presentado en Junta el 21 de febrero de 1861, y publicado en 1870 en el primer tomo de las Memorias de la Academia Española, el marqués de Molins (Censor de la Institución en aquel año) establece cuatro secciones y, a propósito de la tercera (sobre los empleos académicos), empieza diciendo lo que sigue:

La 3. ${ }^{\mathrm{a}}$ seccion, dedicada á los empleos, contiene otras tantas listas cuantos han sido aquéllos en nuestra Academia, ya para su administración interior, ya para la perfeccion del permanente trabajo del Diccionario.

(RAE, 1870: 12. El subrayado es mío)

Siendo ya Director de la Corporación, el mismo marqués de Molins, en la Memoria trienal sobre el estado y los trabajos literarios de la RAE -presentada el 30 de diciembre de 1869-, destaca la elaboración del DRAE y de distintos diccionarios especializados como el primero y más trascendental de los trabajos literarios de la Corporación. Extracto sus palabras:

[...] llego, Señores [...] á la segunda y más importante parte del estatuto: á dar cuenta de sus [de la Academia] trabajos literarios.

El primero y más trascendental ha sido la 11. a edicion del Diccionario vulgar, que se ha dado á luz, enriquecida en voces y acepciones, más exacta en definiciones, sobre todo libre de dos propensiones opuestas [la de marcar como anticuadas voces que se encuentran en nuestros mejores autores y que no tienen reemplazo en el uso común, y la de dar equivalentes latinos hasta de nombres intraducibles].

Bien sé que la Comision laboriosa, ilustrada, infatigable, que ha entendido en esta edicion, halla en ella defectos [...] Pero puede gloriarse de que, así y todo, ha logrado un gran progreso en el grave asunto que le fué cometido [...]

No satisfechos, con todo, aquellos celosísimos individuos, han propuesto un nuevo método de redaccion para el futuro Diccionario, y aprobado ya su sistema por 
b) Que no solo es la elaboración del Diccionario la que se considera prioritaria sobre la Gramática, sino que, según las fechas, los esfuerzos de trabajo se concentran en distintos tipos de obras consideradas a la sazón de mayor urgencia: así, tras la publicación de Autoridades, se acaba dando preferencia a la de la Ortografía (Cotarelo, 1928: 10; Diego, 1963: 419); en los años sesenta del siglo XIX, a la publicación de nuevos diccionarios, de una Biblioteca de Autores Clásicos y de certámenes literarios (Bretón de los Herreros, 1860-1861-1862-1863-1864-1865-1866-1867-1868-1869)...

c) Las Comisiones de Gramática están integradas por miembros de los que se reconoce que, por los compromisos a los que los obligan los cargos públicos que desempeñan, no pueden dedicar todo el tiempo deseado a las labores encomendadas (Bretón de los Herreros, 1861: 5), pero hay que añadir que estos académicos suelen estar simultáneamente en varias comisiones de obras que se publican con antelación: distintos diccionarios, obras de Lope... Pongo por caso el de Hartzenbusch ${ }^{4}$.

la Academia, es de esperar que se logre por él una edicion áun más perfecta y
estimable.
El Diccionario de sinónimos está terminado y casi dispuesto para la imprenta. El
de Rima, concluido y pronto á darse á la estampa [...]

(Molins, 1870: 15-16)

${ }^{4}$ Según los resúmenes de las Actas de la década de los sesenta del siglo XIX, Hartzenbusch fue miembro integrante de las siguientes comisiones:

- Año académico 1859-1860: Comisión administrativa (cf. Bretón de los Herreros, 1860:5).

- Año académico 1860-1861: Comisión encargada de revisar la Gramática (cf. Bretón de los Herreros, 1861: 4-5).

- Año académico 1861-1862: Comisión encargada de redactar el nuevo libro de Gramática (cf. Bretón de los Herreros, 1862: 3).

- Año académico 1862-1863: Comisión encargada de redactar el informe sobre la librería de Durán (cf. Bretón de los Herreros, 1863: 9).

- Año académico 1863-1864: Comisión encargada de revisar y corregir los cuadernos para la publicación de la undécima edición del Diccionario vulgar de la Lengua Castellana (cf. Bretón de los Herreros, 1864: 3-4) y Comisión encargada de publicar el teatro completo de Lope de Vega (cf. Bretón de los Herreros, 1864: 4).

- Año académico 1865-1866: Comisión encargada de la publicación del Quijote (cf. Bretón de los Herreros, 1866: 10). 
d) Que la falta de acuerdo y la "inactividad" con respecto a la Gramática es denunciada por algunos miembros de la Corporación desde los primeros documentos disponibles 5 .

e) Que las reformas se hacen esperar un tiempo demasiado dilatado en ciertos casos...

Los puntos que siguen pretenden ilustrar las afirmaciones hechas.

${ }^{5}$ Esta afirmación que hago no invalida lo dicho en distintos artículos sobre las etapas de elaboración de la GRAE, algunas de ellas de especial intensidad, pero otras de prolongado silencio. 


\subsection{Los documentos sobre regulación interna}

\subsubsection{LOS ESTATUTOS6}

Que la Gramática es un proyecto secundario para la Corporación parece un hecho cierto, indiscutible. El primer documento regulador de la labor institucional (los Estatutos de 1715) resulta claramente revelador a este respecto. El «ESTATUTO ÚNICO» del Capítulo Primero («DEL INTENTO, Y MOTIVO DE LA fundacion de la Académia») dice así:

Siendo el fin principál de la Fundación de esta Académia, cultivár, y fijár la puréza, y elegancia de la lengua Castellána, desterrando todos los erróres, que en sus vocablos, en sus modos de hablár, ò en su construcción há introducído la ignoráncia, la vana afectación, el descuído, y la demasiáda libertád de innovár; será su empléo distinguír los vocablos, frases, ò construcciónes estrangéras de las próprias, las antiquádas de las usádas, las baxas, y rústicas de las Cortesánas, y lebantádas, las burlescas de las sérias, y finalmente las próprias de las figurádas. En cuya consecuéncia tiene por conveniente dár princípio desde luego por la formación de un Diccionário de la lengua, el mas copióso que pudiére hazerse: en el qual se annotarán aquellas vozes, y frases, que estàn recibídas debidamente por el uso cortesáno, y las que están antiquádas, como también las que fueren baxas, ò bárbaras: observando en todo las reglas, y preceptos, que están puestos en la planta acordáda por la Académia, impressa en el año 1713.

(RAE, 1715: fols. 11-12. El subrayado es mío) ${ }^{7}$

\footnotetext{
${ }^{6}$ Los primeros estatutos datan de 1715; se conocen como los estatutos del marqués de Villena y Squarzafigo, por ser estos, respectivamente, director y secretario de la Corporación en los primeros años de vida de la Academia. En 1848, aparecen unos nuevos Estatutos alentados por el marqués de Molins. En 1859, se lleva a cabo otra reforma estatutaria, en la que se impone la separación entre Estatutos y Reglamento. En 1904, se publicarán conjuntamente el articulado de 1859 y el Reglamento de 1861. La referencia completa a cada uno de estos libros de reglamento interno la doy en la bibliografía final. Para más información, véase Cotarelo y Mori (1928: 3334), Fries (1989: 62-77) y Zamora Vicente (1999: 35-47).
} 
Y en el «ESTATUTO PRIMERO» del Capítulo Quinto («DE LAS OBRAS DE LA ACADEMIA») se lee lo que sigue:

FENECIDO el Diccionário (que como vá expressádo en el Capítulo priméro, debe ser el primér objéto de la Académia) se trabajará en una Grammática, y una Poética Españólas, è História de la lengua, por la falta que hazen en Espáña. Y en quanto à la Retórica, podrá excusarse de trabajár de nuevo, porque hay bastante escríto.

(RAE, 1715: fol, 21. El subrayado es mío)

De esta declaración de intenciones hay que decir:

1. $)$ Que la Gramática -tal como se ha adelantado- no será la tarea que ocupe a los académicos de forma "prioritaria" tras la publicación del Diccionario, pues, entre otras actividades, cobra importancia la publicación de una Ortografía, no mencionada -casualmente- en el estatuto que se acaba de reproducir $\mathrm{y}$, en cierto modo, ya publicada con el primer tomo de Autoridades, cuyos preliminares contienen, entre otro tipo de documentos, un «Discurso proemial de la Orthographia de la lengua castellana» (págs. LXI-LXXXIV).

${ }^{7}$ Los Estatutos de 1715 aparecen reproducidos en la «Historia de la Real Academia Española» contenida en los preliminares del Diccionario de Autoridades (págs. IX-XLI). Yo cito y transcribo por el original de la BNE, que puede consultarse en la Sala Cervantes [Signatura: VC/1245/17]. En las Actas de la RAE (Libro 1, junta de 13 de octubre de 1713), encontramos el borrador de los Estatutos que el marqués de Villena encomendó a Álvarez de Toledo (reproducido en su totalidad por Fries, 1989: 28-29). Ya en el borrador figura el Diccionario como obra primera y capital de la Corporación:

[...] Se juntará la Academia vn dia en la semana: $\underline{Y}$ en estas juntas se trabajará desde luego en la formacion de vn Diccionario de la lengua española, el mas copioso que pudiere hacerse, y se anotarán en el aquellas voces y frases que estan reciuidas deuidamente por el vsso cortesano, y las que estan antiquadas, como tambien las que fueren baxas, ò barbaras.

Fenecido el Diccionario se trabajará en una Gramatica y una Poetica españolas, que son las que hacen falta en esta lengua. Y en quanto a la Retorica podra escusarse de trabajar de nuevo, por que ay bastante escrito [...].

(El subrayado es mío) 
2. $\left.{ }^{\circ}\right)$ Que la Poética y la $\mathrm{H}^{\mathrm{a}}$ de la lengua nunca verán la luz.

La primacía (estatutariamente otorgada) de la elaboración del Diccionario sobre otras obras queda igualmente patente en las reformas reglamentarias que, en el siglo XIX, sufrieron los artículos de 1715. En los Estatutos de $1848^{\circ}$, la elaboración del Diccionario vuelve a ser presentada como principal "programa de acción"9 para llevar a la práctica el fin primordial de cuidado de la lengua. El estatuto que nos interesa es el 52 del capítulo IV10:

Siendo el principal objeto de este cuerpo literario, como ya lo muestra el lema que le distingue, depurar el habla castellana de las palabras y locuciones que puedan afearla, fijar el verdadero significado de las que deban conservarse y adoptarse, ya como nuevas, ya como rejuvenecidas, distinguir las diferentes acepciones de una misma voz y trabajar asiduamente en pulir y perfeccionar nuestro rico y armonioso idioma sin mengua de su índole $y$ propiedades; todo estudio que á tales fines se dirija ocupará su constante atención, y para que simultáneamente se preparen y maduren las obras que la Academia ha de dar á luz, ora por primera vez, ora en nuevas ediciones, habrá constantemente cinco comisiones compuestas cada una de dos ó tres Académicos, á saber:

$1{ }^{\text {a }}$ De Diccionario de la Lengua Española, no para la minuciosa correccion del existente, artículo por artículo, pues esto ya se practica en la forma mas adecuada, sino para proponer las reformas que su $\underline{\text { mejor redaccion exija; la de otro mas manual si conviene publicarlo, } y}$ cuanto concierna á facilitar el conocimiento del inmenso tesoro en tantos y tantos preciosos volúmenes esparcido.

\footnotetext{
8 Esta reforma fue aprobada en Junta de Académicos celebrada el 23 de marzo de 1848, según informan los propios Estatutos (RAE, 1848: 23).

${ }^{9} \mathrm{El}$ término lo he tomado de Fries (1989).

${ }^{10}$ Transcribo del original. El estatuto también se encuentra reproducido en Fries (1989: 65-66).
} 
2. ${ }^{a}$ De Gramática y Ortografía.

3. a De Prosodia y Arte métrica.

4. ${ }^{\circ}$ De Etimología é historia de la lengua.

$5^{\text {a }}$ De reimpresion de autores clásicos, ilustrándolos con comentarios de los lugares que parezcan oscuros, notas biográficas y cuanto contribuya á la mayor fama de los escritos y de sus autores.

(RAE, 1848: 18-19. El subrayado es mío)

Se comprueba cómo la del Diccionario es la primera Comisión; cómo solo a la del Diccionario y a la de la reimpresión de autores clásicos se les da “instrucciones" de actuación"11; cómo solo estas dos comisiones serán las que trabajen sobre una única materia.

\subsubsection{EL REGLAMENTO12}

El Reglamento de 1861 se empezó a cumplir «en todas sus partes»a partir del 1 de marzo, según lo acordado en la Junta de Académicos del 18 de febrero de ese mismo año ${ }^{13}$. Desde su concepción, el Reglamento tiene la finalidad de matizar lo impuesto en el articulado de los Estatutos.

Al revisar sus páginas, no encontramos alusión alguna a las obligaciones contraídas por las distintas comisiones; las únicas referencias tocantes al quehacer académico (en materia lingüística) redundan en tareas concernientes al Diccionario y a la publicación de obras literarias, así como a los certámenes convocados por la Institución.

11 Sobre todos los documentos que contienen planes y reglas para la elaboración del Diccionario hasta 1928 informa Cotarelo (1928: 34). No encontramos documentos equivalentes para la Gramática.

${ }^{12}$ Los Estatutos de 1859 impusieron la separación de dos tipos de documentos reguladores de la actividad académica: los ya seculares Estatutos y el Reglamento, de nueva gestación, del que al año siguiente encontramos un proyecto, pero que se publicará en 1861.

${ }^{13}$ Remito a lo dicho en el propio Reglamento (RAE, 1861a: 34). 
En el ARTíCULO PRIMERO del CAPÍTULO PRIMERO («Deberes que impone á la Academia su instituto»), se establece que la finalidad preferente de los académicos ha de ser el acopio de materiales que les puedan facilitar un trabajo extenso y perfecto. Para ello deben procurar (sintetizo el artículo segundo del mismo capítulo):

1) Aumentar la biblioteca especializada en cuestiones filológicas y lingüísticas (con gramáticas y diccionarios de distinto tipo: de lenguas modernas, de lenguas antiguas, etimológicos, de idiotismos, etc.).

2) Enriquecer la colección de autores clásicos españoles.

3) Continuar y depurar el catálogo de autoridades «en que se funda el buen uso de cada palabra, locucion ó frase» de nuestra lengua.

4) Formar colecciones de palabras, idiotismos, refranes... (con su correspondiente autoridad) para poder abordar la elaboración del Diccionario histórico.

5) Hacer acopio de tratados antiguos especializados en artes y oficios para poder confeccionar un glosario de voces.

6) Reunir cualquier tipo de documento (impreso o inédito) sobre sinónimos de la lengua castellana.

7) Recopilar, por medio de sus individuos de número y de los Correspondientes, el mayor caudal posible de voces, locuciones, frases... de uso exclusivo de provincias españolas e hispano- 
americanas para poder abordar y llevar al cabo «el más completo Diccionario de provincialismos que le sea dado publicar» ${ }^{14}$.

De las siete tareas marcadas como prioritarias, seis repercuten directamente en la finalidad de continuar perfeccionando los trabajos relativos al estudio del vocabulario, tanto general como, sobre todo, especializado (diccionario de sinónimos, de voces técnicas, de provincialismos...); la última, además, ofrece evidencia de las pretensiones académicas: no basta con publicar cualquier diccionario, ha de ser el más grande y completo, el mejor. Solo la segunda prioridad es exclusivamente literaria, si bien podrá redundar en los trabajos de elaboración del Diccionario usual y de diccionarios especializados. Ninguna alusión a la Gramática.

${ }^{14}$ Sobre este último punto insiste el artículo $5 .^{\circ}$ del capítulo segundo («De las tareas literarias y su division. - Forma en que han de llevarse á cabo. - Premios generales. - Certámenes públicos»), que reproduzco:

Los Académicos Correspondientes españoles, además de cumplir con las obligaciones generales que les señala el artículo XII de los Estatutos, remitirán todos los años á la Academia índices de voces, giros y modismos provinciales, miéntras no creyeren agotado el caudal de los de su conocimiento, y procurando historiar el orígen y vicisitudes de cada provincialismo.

(RAE, 1861a: 3-4) 


\subsection{Los proyectos y las obras}

\subsubsection{LOS PROYECTOS}

Desde el comienzo de preparación del proyecto de elaboración de la Gramática, en los años cuarenta del siglo XVIII, se oyeron voces dentro de la Corporación que ponían el acento en la especial dificultad de la empresa. Dice el P. Ceballos ${ }^{15}$ en su revisión al proyecto de Gramática de Antonio Angulo ${ }^{16}$ :

Siempre he creido que la m.r dificultad que tiene la Academia al presente, es resolver y fixar el modo con que ha de producir la grande obra de la Gramática Española: me explicaré [...]

(ARAE, 1741b: pliego 1) ${ }^{17}$

Ceballos se refiere a dos cuestiones que ineludiblemente deben ser atendidas por la Corporación siempre que decida abordar la elaboración de una obra:

1) Cuidar de que la obra responde al honor de la Institución: para ello, las obras deben ser tan perfectas y cabales que la Academia se digne en todo momento de reconocerlas como suyas, «creyendo como debe creer, que en obras que travajan muchos ingenios y registran muchos ojos, no hay culpa leve y que el mas ligero descuido es pecado de enorme malicia».

\footnotetext{
${ }^{15}$ Ignacio de Ceballos no ingresará como académico numerario hasta el 14 de noviembre de 1747, según consta en el Ms. $314^{8}$. Ocupa el sillón T desde esta fecha hasta el día de su muerte el 4 de diciembre de 1784 .

16 Los proyectos de Angulo y Ceballos se encuentran en el Archivo de la RAE guardados conjuntamente en el legajo 219/1. Sarmiento (1984a: 497-535) los transcribe en un Apéndice documental. En este trabajo, cito por el original.

17 Para los proyectos y disertaciones sobre gramática redactados por distintos académicos,

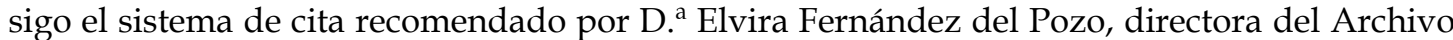
de la RAE. En la bibliografía final, indico entre corchetes el título atribuido a cada uno de estos papeles de gramática. Para su localización, anoto número de legajo/número de carpeta y, entre paréntesis, el número de documento.
} 
2) Cuidar de que la obra satisfaga las expectativas del público.

¿Por qué estos dos "requisitos", que lo son para cualquier obra institucional, se entienden especialmente acuciantes y llegan a sentirse como escollo a la hora de abordar la Gramática?

Con respecto al primer punto, Ceballos considera que, para salvaguardar su honor, la Institución debe sacar a la luz una Gramática completa, no una al modo de las francesas (de autores particulares: Chiflet, Buffier, Sobrino, Diego de la Encarnación), que son el modelo manifestado por Angulo en su proyecto, por cuanto: a) son obras de un solo autor -por tanto, y por necesidad, menos ambiciosas-; b) son pequeños tratados en que se fijan breves reglas acompañadas de ligeras explicaciones -cuando una obra digna de la Corporación debería dar razones extensas y todos los fundamentos de las reglas-. Este será el primer punto de discordia.

El segundo inconveniente planteado por Ceballos es el que sigue: Angulo y Carlos de la Reguera ${ }^{18}$ no han resuelto ni propuesto un plan de actuación concreto para esa gramática completa en la que ellos también han pensado, para la cual habría menester «un tomo en folio como los de su

\footnotetext{
18 Académico de número entre 1731 y 1742. Tras la muerte de Lorenzo Folch de Cardona, fue el tercer ocupante del sillón F, que había correspondido al académico fundador Bartolomé Alcázar. La información puede comprobarse en la dirección electrónica de la Academia: http://www.rae.es/rae/gestores/gespub000001.nsf/(voAnexos)/arch6D3211F8664070B7C12 5720900476B93/\$FILE/sillones.htm. En el Ms. 3148 se recogen las fechas de su incorporación como académico supernumerario (17 de enero de 1730), de su ingreso como numerario (20 de diciembre de 1731) y de su fallecimiento (22 de octubre de 1742). Sobre su oficio de maestro de matemáticas en el Colegio Imperial de la Corte quedó constancia en los Documentos inéditos para la historia de España, publicados por Miguel Salvá y Pedro Sainz de Baranda (cf. Salvá y Sainz de Baranda, 1852: 66). Carlos de la Reguera no figura en la Bibliothèque des écrivains de la Compagnie de Jésus publicada por Backer (1869-1876); es en la edición preparada por Sommervogel (1890-1900: VI, cols. 1611-1612) donde encontramos datos bio-bibliográficos sobre este académico. Más información sobre el jesuita puede encontrarse en Elizalde (1988: 250) y Zamora Vicente (1999: 71). El último destaca el papel activo de Carlos de la Reguera en la preparación del texto de la GRAE-1771.
} 
Diccionario» $\mathrm{y}$ «mucho tiempo [...] en que tal vez se consumira la paciencia delos que actualm. te estamos, y delos que nos sucedieran», advierte Ceballos.

Y es que el principal problema estriba en que no existe una disposición favorable por parte del conjunto de académicos para emprender tamaña labor. Las siguientes palabras de Ceballos, las últimas que reproduzco de su proyecto, se tiñen de tono casi melancólico, propio del que habla de empresa imposible, de sueño irrealizable:

Por la gramatica completa tratada en toda su extension votaria yo siempre si hallase entodos los Academicos una constante aplicacion, y una union inalterable dirigiendonos todos áeste fin: es $\underline{\text { menester hablar claro, señores, no veo esto en la Academia; Veo sí }}$ resolverse muchas cosas y executarse ninguna. Yo soy el primero que falto, pero no tubiera aliento para hazerlo sino huviera malos ejemplos que imitar; este incombeniente me amedrenta para no inspirar ála Academia desde luego una empresa que la juzgo gloriosisima y en que arrebatariamos ó nos llevariamos los laureles que no supieron ganar los Latinos ni los Griegos ni ninguna otra nacion delas cultas de Europa; porque hasta óra no se ha tratado por nadie completamente la nobilisima Arte dela Gramática.

(ARAE, 1741b: pliego 2. El subrayado es mío)

¿Será cierto que «la Academia ha llegado a la hora de nona», cuando los campos de la sabiduría están demasiado trillados y la gramática ha resultado ser la parte arrinconada y olvidada por los ingenios? Hasta ahora, el Arte de la Gramática ha sido tratado a retazos. La aspiración debe ser la de hacer un Arte de Gramática General, que ayude y enseñe a hacer artes de gramáticas particulares. Pero es mucho el esfuerzo que se requiere para lograrlo (y poca la disposición). Este es el lamento de Ceballos. 


\subsubsection{LAS OBRAS}

En este punto me extenderé poco, ya que en los bloques temáticos que siguen habrá oportunidad de volver sobre la información contenida en las obras (gramaticales y lexicográficas) de la Corporación.

No obstante, para completar la visión panorámica sobre el lugar de la Gramática en el quehacer académico, se impone adelantar aquí que, tanto en los propios libros de Gramática como en los Diccionarios, encontramos interesantes pistas que sumar a la defensa de que el Diccionario es la "obra mimada" de la Academia y que esta condición de continuo privilegio, de forma automática, convierte a la Gramática en obra secundaria.

De un lado, los prólogos académicos, en su conjunto, proporcionan pruebas de que las anunciadas novedades suelen ser de escasa entidad y suelen hacerse esperar demasiado en el caso de la Gramática, no tanto en el caso del Diccionario. Si se acepta que las novedades doctrinales, los cambios, las correcciones... no son sino producto del trabajo, de la atención continua a un determinado proyecto, hay que aceptar igualmente que la ausencia de enmiendas, de añadidos, de modificaciones doctrinales en general, cuando es ausencia dilatada en el tiempo, debe interpretarse como consecuencia de la falta de atención, del descuido en las labores encomendadas, o del poco énfasis puesto a la hora de encomendar labores. El hecho de que no sea raro que en las páginas introductorias del Diccionario se revele el nombre de quienes han desempeñado una labor determinada y que, por contra, en ningún prólogo de la Gramática encontremos siquiera una ligerísima alusión a la comisión redactora es otro dato, pequeño, pero uno más, que suma prestancia a una obra al tiempo que resta protagonismo a la otra. 
De otro lado, el análisis textual revela que un número considerable de ediciones de la Gramática (y hablo de las oficiales) son simple remedo unas de otras $^{19}$. De los Diccionarios no puede afirmarse exactamente lo mismo.

${ }^{19}$ En el punto 2.3. ya se ha adelantado esta observación, y quedará confirmada en los puntos que siguen. 


\subsection{Los documentos sobre tareas cumplidas, dictámenes y revisiones}

Si examinamos los Resúmenes de Tareas y Actos, nos damos cuenta de que, entre 1860 y 1870, la dedicación al proyecto de la Gramática no es tan intensa como en un primer momento cabría esperar: es lo que se deduce de las propias palabras del secretario de la Institución, el señor don Manuel Bretón de los Herreros, en sus informes anuales ${ }^{20}$.

En el resumen del año académico 1859-1860, se explicita cómo, a raíz de la Ley Moyano, la Institución ha sacado a la luz un Compendio y un Epítome, obras de las que, en el curso académico que se está cerrando, han vuelto a darse a la estampa una vez la primera y dos veces más la segunda ${ }^{21}$. A la Gramática no se le ha prestado atención -esta vez de forma justificada-, pues está recién salida la reforma de $1858^{22}$. Con respecto al Diccionario, no dejamos de tener también en este documento afirmaciones que revelan su carácter preferente. El siguiente fragmento es prueba de ello:

Aunque, por tratarse de tareas peculiares, más que otras de nuestro instituto, se han dado en la ejecucion del plan general la debida preferencia á los Diccionarios referidos, en consideracion á que, por lo mismo que tiene que ser muy lenta su composicion, convenia acometerla sin pérdida de tiempo, la Academia no ha perdido de vista la utilidad de otras publicaciones, en que ya se ocupa y que activará cuando y según lo permitan las circunstancias;

\footnotetext{
${ }^{20}$ Esta década nos sirve como representativa del ritmo general de tareas en torno a la Gramática: es una década en la que ven la luz cinco ediciones (de escasa o nula importancia en cuanto a novedad doctrinal) y es la década que culmina con la reforma de 1870, el segundo de los jalones decimonónicos marcados.

${ }^{21}$ En Cotarelo (1928: 43 y 45) aparecen correctamente fichadas estas ediciones.

22 De la que se habla como «segunda edición cuidadosamente revisada». Recordemos que a partir del siglo XIX se pierde la costumbre de numerar las ediciones y que la de 1854 (la inmediatamente anterior a la GRAE-1858) fue la primera que difería de la GRAE-1796.
} 
esto sin perjuicio de haber dado á luz durante el año académico á que me refiero dos nuevas ediciones del Epítome de la Gramática, otra del Compendio de la misma y otra del Prontuario de Ortografía.

(Bretón de los Herreros, 1860: 11. El subrayado es mío)

El curso académico 1860-1861 es el más prometedor para la GRAE. En él, la Institución se impone como principales tareas la discusión de su Reglamento y la redacción de una nueva versión de la Gramática:

Entre los varios asuntos de diferente índole que han debido ocupar á la Academia durante el año á que estos apuntes se refieren, los dos culminantes eran la discusion de su Reglamento y la redaccion de una Gramática Castellana que mejorase en lo que de ello es susceptible la que lleva el nombre de esta Corporacion.

(Bretón de los Herreros, 1861: 3)

Para el segundo de los cometidos, era de obligado cumplimiento la revisión meditada y detenida del antiguo texto y el criterio imparcial de los revisores. El concienzudo examen que requerían los libros sobre esta doctrina será encomendado a una comisión integrada por Hartzenbusch ${ }^{23}$, Fernández-

\footnotetext{
23 Académico numerario entre 1847 y 1880. Con su ingreso se estrena el sillón $l$ ( $c f$. http://www.rae.es/rae/gestores/gespub000001.nsf/(voAnexos)/arch6D3211F8664070B7C12 5720900476B93/\$FILE/sillones.htm.). Según informa Zamora Vicente (1999: 282), Juan Eugenio Hartzenbusch toma posesión de su plaza el 18 de marzo de 1847, el mismo día que otros dos académicos: Alejandro Oliván y Nicomedes Pastor Díaz (quienes inaugurarán, respectivamente, los sillones correspondientes a las letras $j$ y $k$-minúsculas-). Cf. http://www.rae.es/rae/gestores/gespub000001.nsf/(voAnexos)/arch6D3211F8664070B7C12 5720900476B93/\$FILE/sillones.htm. La fecha de ingreso de estos tres académicos coincide con la que se registra en el Ms. $314^{8}$ (en él, las letras de los sillones están escritas en mayúscula, pero el hecho de que no lleven superíndice indicando el número de ocupante debe interpretarse -deduzco- como que se trata de los nuevos sillones de letras minúsculas, estrenados a raíz del incremento de miembros de número de la Corporación). A Hartzenbusch le fue encomendado, entre otras tareas, dar la bienvenida a varios académicos, entre ellos, a Francisco Cutanda (vid. Cutanda, 1861: 39 y sigs.).
} 


\section{Guerra $^{24}$ y Monlau ${ }^{25}$. Pero el ritmo de trabajo de la comisión será más lento de lo que en principio se había previsto:}

Tan delicado y espinoso cometido exigia de los que con él fueron honrados no leves estudios y no pocas conferencias para venir á un comun acuerdo, precursoras de otras, luégo que sometiesen á la Academia su trabajo, tanto más vivas cuanto mayor iba á ser el

${ }^{24}$ Aureliano Fernández-Guerra y Orbe ocupó el sillón X entre los años ¿1860? y 1894 -el sillón había quedado vacante en 1855 tras la muerte de Jerónimo de la Escosura- (cf. http://www.rae.es/rae/gestores/gespub000001.nsf/(voAnexos)/arch6D3211F8664070B7C12 5720900476B93/\$FILE/sillones.htm.). Tengo serias dudas sobre el año de su ingreso en la RAE, pues, aunque la propia página web de la Academia y Zamora Vicente (1999: 222) dan el año 1860, existen datos de peso para poner en tela de juicio esta fecha:

$\left.1^{\circ}{ }^{\circ}\right)$ Su discurso de ingreso en la Real Academia Española está publicado con fecha de 1857. Cf. Fernández-Guerra (1857).

2. ${ }^{\circ}$ ) En 1859, Fernández-Guerra contestó al discurso leído por Tamayo y Baus el día de su toma de posesión de plaza. Cf. Tamayo y Baus (1859).

3. $\left.{ }^{\circ}\right)$ El Ms. $314^{8}$ da cuenta del ingreso como académico numerario de un Fernández-Guerra (Ambrosio -?-) el 17 de enero de 1856. Dado que es el único Fernández-Guerra que se registra, no parece descaminado pensar que se trata de Aureliano (y no Ambrosio) FernándezGuerra. Esta hipótesis hace que concuerde su fecha de ingreso en la Corporación con el año en que se publica su discurso de ingreso, en 1857, y hace posible que Fernández-Guerra fuera el encargado de dar la bienvenida a Tamayo y Baus. En la «lista general de los académicos» presentada por Molins en las Memorias de la Corporación (cf. RAE, 1870: 44), se anota, efectivamente, el 17 de enero de 1856 como fecha de su ingreso en la Institución (simultáneamente, en calidad de académico "honorario" y "de número"). Los datos de Molins se revelan como erróneos en lo que respecta al día y año de su fallecimiento (el 4 de enero de 1860). Aureliano Fernánez-Guerra y Orbe murió el 7 de septiembre de 1894 (su esquela puede verse en Miranda Valdés, 2005: 188).

De su exitosa carrera política (fue secretario de Claudio Moyano y Director general de Instrucción Pública) y de su reconocida labor en el ámbito de la erudición y de la crítica, así como de su "fracaso" como dramaturgo habla Zamora Vicente (1999: 222). Más datos sobre este académico, Anticuario de la Real Academia de la Historia y Archivero y Bibliotecario de la Real Academia Española, pueden encontrarse en Rada y Delgado (1894) y en el estudio monográfico de Miranda Valdés (2005).

${ }^{25}$ Pedro Felipe Monlau ingresó el 29 de junio de 1859. Fue académico de número casi doce años -hasta el día de su muerte, el 18 de febrero de 1871- (cf. Zamora Vicente, 1999: 124). Ocupó el sillón D al año siguiente de quedar vacante tras la muerte de Manuel López Cepero (cf.http:// www.rae.es/rae/gestores/gespub000001.nsf/(voAnexos)/arch6D3211F8664070B7 C125720900476B93/\$FILE/sillones.htm.). A su discurso de ingreso (Del origen y la formación del romance castellano) contestó Hartzenbusch, quien resaltó en el elogio del nuevo académico su sólida preparación científica (fue Doctor en Medicina y Cirugía por el Real Colegio de Barcelona, y Catedrático de Psicología y Lógica) y su buen conocimiento de las letras (contaba ya entre sus obras, en el momento de ingresar en la Corporación, un Diccionario etimológico de la lengua castellana, que se publicó en 1856 precedido de unos rudimentos de etimología). Vid. Monalu (1859: 31 y sigs.). Plata y Marcos (1882 [1879]: 220) ya destacó la notable actividad científico-literaria e intelectual de Monlau. Sobre la labor lingüística de este académico trataré en el capítulo 5 . 
número de los jueces. Áun sin levantar mano en su tarea la expresada Comision, compuesta de los Sres. Hartzenbusch, Fernández-Guerra y Monlau, en las horas que para discutir y extender su informe le dejaban libres las obligaciones de los cargos públicos que desempeñan, no les fué dado presentarle hasta el 14 de Enero último. Leido que fué á la Academia, se dispuso imprimirle para que de él se enterasen mejor los académicos, y entretanto se continuaron las discusiones sobre el Reglamento, ya muy adelantadas.

(Bretón de los Herreros, 1861: 5. El subrayado es mío)

Entre tanto, la Corporación publica la novena edición del Prontuario de Ortografía y la octava edición del ERAE, con la novedad de «ponerle todo en preguntas y respuestas, por ser este método el más generalmente seguido en las escuelas de primeras letras ${ }^{26 »}$ (Bretón de los Herreros, 1861: 10).

En el curso académico 1861-1862, se terminan las discusiones preliminares sobre la Gramática y se nombra otra comisión encargada de la redacción del nuevo texto. En la comisión seguirán Hartzenbusch y Monlau y a ellos se sumarán Segovia 27 , Catalina ${ }^{28}$ y Bretón de los Herreros ${ }^{29}$ (cf. Bretón de los Herreros, 1862: 3 y sigs.).

\footnotetext{
${ }^{26}$ En 1861, ven la luz dos ediciones del Epítome (8. ${ }^{\mathrm{a}}$ y 9.a), ambas «arregladas en preguntas y respuestas». De la octava edición dice Cotarelo: «En los anteriores [Epítomes] estaban las preguntas al final de los capítulos: ahora todo el texto está en preguntas y respuestas». He podido comprobar, revisando los ejemplares disponibles en la Sala de Investigadores de la $\mathrm{RAE}$, que, efectivamente, esta disposición íntegra del texto según el sistema de $\mathrm{P} / \mathrm{R}$ se encuentra hasta la edición 59. ${ }^{a}$, de 1928 (última edición catalogada por Cotarelo). En la 60. ${ }^{a}$ ed. (1929) se pierde la disposición en preguntas y respuestas, para ser recuperada en la edición siguiente (61. ${ }^{\mathrm{a}}$, de 1931) y volver a perderse en la edición 62. ${ }^{\mathrm{a}}$ (1938). Este último texto ya no recoge únicamente la Analogía y la Sintaxis -como es habitual en el ERAE-, sino las cuatro partes de la Gramática (sumando a las anteriores la Prosodia y la Ortografía), y solo mantiene el sistema de preguntas y respuestas en la parte cuarta, dedicada a la Ortografía. Un estudio detenido sobre los Epítomes de la Academia ha sido realizado por Encinas Manterola (2005).

${ }^{27}$ Antonio María Segovia, académico entre 1847 y 1874, fue el primer ocupante del sillón $i$ ( $c f$. http://www.rae.es/rae/gestores/gespub000001.nsf/(voAnexos)/arch6D3211F8664070B7C12 5720900476B93/\$FILE/sillones.htm.). El Ms. $314^{8}$ da la fecha exacta de su nombramiento como honorario (27 de febrero de 1845) y de su ingreso como numerario ( 25 de febrero de 1847, el mismo día que tomaron posesión otros cuatro académicos: Patricio de la Escosura, Eugenio Ochoa, el marqués de la Pezuela y Joaquín Francisco Pachecho). Fue secretario
} 
En el resumen del año académico 1862-1863, no tenemos ninguna noticia concreta sobre el avance de la Comisión de Gramática. En este año, las tareas que con más frecuencia han sido objeto de deliberación en las Juntas son las concernientes a la undécima edición del Diccionario vulgar ${ }^{30}$.

En el resumen presentado un año más tarde, seguimos sin encontrar alusión alguna a los avances en materia gramatical. Ya en las primeras líneas del resumen se vuelve a colocar al Diccionario en puesto de preferencia frente al resto de quehaceres académicos. Estas palabras iniciales revelan, además, que cuatro de los cinco integrantes de la Comisión de Gramática han estado ocupados con las enmiendas del Diccionario:

interino de la Academia durante la enfermedad de Bretón de los Herreros y murió un mes después de tener la plaza en propiedad, el 14 de enero de 1874. Destacó como autor teatral y fue conocido por sus colaboraciones (con artículos de tono satírico) en periódicos de la época. Cf. Zamora Vicente, 1999: 273.

${ }^{28}$ El 5 de noviembre de 1860, según consta en el Ms. 3148, ocupó la silla A el conquense Severo Catalina del Amo, que cubrió la vacante de Eugenio de Tapia (cf. http://www.rae.es/rae/gestores/gespub000001.nsf/(voAnexos)/arch6D3211F8664070B7C12 5720900476B93/\$FILE/sillones.htm.). No vaciló el nuevo académico a la hora de elegir el tema del discurso que leería en su recepción púbica el 25 de marzo de 1861: como no podía ser de otra forma, este orientalista habló «de las lenguas semíticas en su influencia sobre la castellana» (Catalina del Amo, 1861: 6). Le contestó D. Tomás Rodríguez Rubí (cf. Catalina del Amo, 1861: 39 y sigs.). Severo Catalina fue académico hasta su repentina y temprana muerte el 18 de octubre de 1871, a los 39 años. Destacó como periodista; fue catedrático de hebreo y Ministro de Marina y Fomento en el último gobierno de Isabel II (cf. Zamora Vicente, 1999: 110). También fue Director general de Instrucción Pública (cf. Bleiberg, 1979: 786).

29 Manuel Bretón de los Herreros fue académico honorario (8 de junio de 1837) y supernumerario (10 de mayo de 1839) antes de ser nombrado académico de número el 14 de mayo de 1840, según consta en el Ms. $314^{8}$ (el listado de Molins publicado en las Memorias da las mismas fechas de ingreso como honorario y como numerario -cf. RAE, 1870: 43-). La fecha de nombramiento como supernumerario que aparece en el Manuscrito (y de la que no da cuenta Molins) no coincide con la registrada por Zamora Vicente (1999: 114), quien apunta el año 1838. Conocida es la faceta de dramaturgo de Bretón y su importante constribución a la comedia de costumbres. Fue secretario perpetuo de la Academia desde 1853 y director de la Biblioteca Nacional entre 1847 y 1854. (Cf. Zamora Vicente, 1999: 114).

Bretón de los Herreros sucedió en la silla B -que ocupó entre 1840 y 1873- a Eugenio Eulalio Guzmán Palafox Portocarrero, conde de Teba y de Montijo ( $c f$. http://www.rae.es/rae/gestores/gespub000001.nsf/(voAnexos)/arch6D3211F8664070B7C12 5720900476B93/\$FILE/sillones.htm.).

${ }^{30}$ Véase Bretón de los Herreros (1863: 3 y sigs.). 
OBJETO preferente y rara vez interrumpido de nuestras tareas semanales ha sido, como en el anterior, en el año académico que terminó con el mes de Junio último, el exámen de las enmiendas, aumentos y supresiones que, desde que se publicó la décima edición de nuestro Diccionario vulgar de la Lengua castellana se han propuesto para que en la undécima se acerque más á la posible perfeccion. De los cuadernos en que la obra fue dividida, para que á la discusion en cuerpo precediese el estudio parcial de cada académico, más de la mitad ha pasado ya por el segundo trámite [...] Para que oportunamente pueda, cuando convenga, darse principio á dicha nueva impresión, que forzosamente ha de invertir bastante tiempo, como de libro tan minucioso y necesitado, más que otro cualquiera, de la mas escrupulosa correccion, se ha confiado la revision definitiva de los cuadernos y de las cédulas separadas á una Comision numerosa que, respetando los acuerdos de la Academia, repare tal cual descuido de mera redaccion donde lo advierta y dé la conveniente ilacion y necesaria uniformidad al conjunto. Son individuos de esta Comision los señores Valle, Segovia, Olivan, $\underline{\text { Hartzenbusch, Puente, Ferrer, Tamayo, Monlau y el autor de estos }}$ apuntes [Bretón de los Herreros].

(Bretón de los Herreros, 1864: 3-4. El subrayado es mío)

En el curso 1864-1865 otras dos tareas, distintas del Diccionario, colman el tiempo de trabajo de los académicos, hasta el punto de tener que aumentar el número de juntas semanales, a saber: la publicación de una selecta biblioteca de autores clásicos españoles y el acuerdo de celebrar un concurso literario ${ }^{31}$.

31 Véase Bretón de los Herreros (1865: 3 y sigs.). 
Los trabajos literarios y la sempiterna revisión del Diccionario vulgar ocupan a la Institución en los cuatro años académicos siguientes ${ }^{32}$. Y por fin, en el resumen de 1870, se da noticia de la conclusión de la nueva Gramática33. Sabemos, y lo hemos recordado en este mismo punto, que entre 1858 y 1870 han visto la luz cinco ediciones de la GRAE, de las que nada se dice en los resúmenes de la Corporación, de las que no he podido encontrar constancia en las actas. Sí hay, por el contrario, testimonio de las distintas ediciones de Compendios y Epítomes. El silencio a veces habla, y en esta ocasión parece querer decir que las ediciones de los años sesenta se publicaron "para cubrir expediente". Resulta curioso que la primera comisión nombrada para revisar el texto antiguo de la Gramática tuviera ya redactado su Dictamen en $1861^{34}$, y que, sin embargo, la década de los sesenta sea de las más anodinas en la historia de la GRAE.

La Academia no solo no aplica con premura lo dictaminado por la Comisión de Gramática (y sigue sacando textos que obvian las tesis defendidas en el propio seno de la Corporación), sino que también hace caso omiso de las revisiones que gramáticos de la época (algunos de ellos

32 Véase Bretón de los Herreros (1866, 1867, 1868 y 1869).

${ }^{33}$ El resumen de este año es leído en junta pública por Antonio María Segovia, secretario "accidental" de la Corporación, quien se refirió a las tareas gramaticales cumplidas en estos términos:

La Comisión de Gramatica después de algunos años de meditar, discutir, consultar con la Academia las reformas aconsejadas, tanto por los progresos de la Filología y la Lingüística, cuanto por las alteraciones que introduce el uso, ha dado fin á su tarea. La Prosodia castellana, nunca publicada, por la Academia Española, se ha incluido en esta edicion, aunque reducida á sus principios más generales: el estudio de esta parte de la Gramática ha sido objeto de largos é importantísimos debates, y muchos de sus preceptos han quedado establecidos por votacion de mayoría. Con no menor detenimiento se han discutido y planteado algunas reformas ortográficas, y se han hecho en la Analogía variaciones importantes por acomodarla á la opinion general de los más ilustres gramáticos y de los buenos escritores. Esta Gramática, y sus hijuelas, adaptadas á los diversos grados de enseñanza; á saber: un Compendio, un Epitome de Analogía y Sintáxis y un Prontuario de Ortografía, están ya concluidas, y las tres últimas a disposicion del público.

(Segovia, 1870: 7)

34 Tanto de la GRAE-1870 como del documento firmado por la Comisión de Gramática tendremos que volver a tratar en próximos apartados. 
vinculados a la docta Casa) hicieron de la Gramática institucional. En el lugar oportuno se sacarán a colación algunas de las anotaciones hechas por autores contemporáneos.

Los libros de Resúmenes correspondientes a los años sesenta no son los únicos que ponen de evidencia el celo con que la Corporación se entrega a sus tareas lexicográficas. Sirva como última muestra el siguiente fragmento, extraído del Resumen de las Actas del año 1881, presentado por Tamayo y Baus:

\section{[...] En todas nuestras juntas, salvas rarísimas excepciones, se} examinan y discuten cédulas de palabras para la nueva edición del Diccionario; de la cual está especialmente encargada una Comisión que se compone ahora de los Sres. Fernández-Guerra (D. Aureliano), Cañete, Nocedal, Valera, Canalejas, Arnao, Fernández-Guerra (Don Luis), Alarcón, y el que tiene la honra de hablar. Presídela el mayor de los Fernández-Guerra [Aureliano] y es su Secretario el señor Aranao.

(Tamayo y Baus, 1881: 14. El subrayado es mío)

Estamos en condiciones de afirmar que no es solo en 1881 cuando la práctica totalidad de las sesiones se ocupan del Diccionario: todos los años que he podido revisar en los Libros de Actas revelan que, en efecto, lo excepcional es no dedicar, total o parcialmente, el tiempo de las reuniones semanales a examinar y discutir cédulas para la nueva edición del Diccionario que toque publicar. Y es así incluso en los años y meses previos a las principales reformas de la Gramática. 


\section{Número y tipo de ediciones:}

I. En el siglo XVIII, cuatro ediciones pueden llevar la etiqueta GRAE: la de 1771, las de 1772 y 1781 (de rango R, en tanto que, básicamente, vienen a ser reimpresiones del primer texto) y la de 1796 (que debe entenderse como edición nueva, por tanto, de rango E). Ante la falta de pruebas concluyentes, de momento, no parece oportuno -pues sería faltar al rigor historiográficoaceptar la existencia de una GRAE-1788. Existe una edición dieciochesca publicada en el extranjero, con fecha de 1793, que puede localizarse en la RAE.

II. El siglo XIX es el más problemático a la hora de ordenar los textos, por la cantidad y variedad de ediciones (oficiales y dudosamente oficiales, reimpresiones no confirmadas, ediciones en el extranjero, traducciones). En total, podemos hablar de dieciséis ediciones oficiales, distribuidas en rangos de la siguiente forma:

- GRAE-1854 [J]

O GRAE-1858 [E]

- GRAE-1862, 1864, 1865, 1866 y 1867 [R]

- GRAE-1870 [J]

o GRAE-1874 [E]

- GRAE-1878 [R]

- GRAE-1880 [J]

- GRAE-1883, 1885, 1888, 1890 y 1895 [R]

Antes de la GRAE-1854 encontramos una edición de 1852 (calco de la GRAE-1796) y una serie de reimpresiones de las que cabe pensar que no llevaron un pie de imprenta distinto de la cuarta edición, con lo cual, más que de ediciones/reimpresiones distintas del texto académico, debería 
hablarse de tiradas de una misma edición (que pudieron hacerse en fechas diferentes). Igual que ocurre con la edición "fantasma" de 1788, los estudiosos mencionan estas reimpresiones haciéndose eco de lo afirmado por Sarmiento. Y si para el caso de 1788 solo Uruburu (1975) daba pistas sobre un libro físicamente localizable, en cuanto a las reimpresiones de la primera mitad del XIX, el único que da constancia de haber visto libros distintos con diferente tipografía pero con el mismo pie de imprenta es Gómez Asencio (2005).

El panorama decimonónico se completa con numerosas ediciones no-oficiales (muchas de ellas sacadas en el extranjero -y algunas, simultáneamente, en España y el extranjero-) y con una traducción francesa, de la que la Institución tuvo noticia de primera mano.

III. En el siglo XX, verán la luz dieciséis textos oficiales más, que, en términos generales, presentan pocos problemas de clasificación y de localización. El jalón de este periodo y la edición de rango E que lo sigue de forma inmediata responden a las ediciones que presentan las dos reformas de mayor calado doctrinal en la historia de la Gramática académica. La jerarquía de las GRAE es la que sigue:

- GRAE-1900, 1901 [R]

o GRAE-1904 [E]

- GRAE-1906, 1908, 1909 [R]

o GRAE-1911 [E]

- GRAE-1913, 1916 [R]

- GRAE-1917 [J]

o GRAE-1920 [E]

- GRAE-1924, 1928, 1931 [R]

o GRAE-1959 [E]

- GRAE-1962 [R] 


\section{Compiladores de los textos:}

IV. Las tres compilaciones cotejadas responden a finalidades distintas y, por tanto, no proporcionan el mismo tipo de información ni satisfacen el interés del mismo tipo de destinatario: la Biblioteca del conde de la Viñaza (dirigida principalmente a filólogos) es prolija en datos de interés para el investigador de gramaticografía, sobre todo en lo que respecta a algunas de las ediciones de rango J/E; el Discurso de Cotarelo y Mori responde a un término medio entre información "de catálogo" e información de interés para el estudioso de la GRAE; el Manual de Palau y Dulcet facilita un listado práctico (para su público principal) que deja insatisfecho al interesado en cuestiones sobre la estructura de estos libros, sobre su concepción, sobre las pretensiones académicas, las novedades introducidas...

V. Por otra parte, a la luz de los cuadros expuestos en el punto 2.3., podemos comprobar que, conforme avanzamos en el número de edición, los compiladores, los tres, van perdiendo interés en dar noticia detallada sobre los libros. Las Gramaticas del siglo XX prácticamente no reciben ningún comentario. Los casos más llamativos (y es el silencio de Cotarelo el que nos sorprende) son los de 1917 (año de la gran reforma sintáctica, como veremos en el punto correspondiente) y 1920 (año en que se completa la reforma morfológica de mayor entidad en la historia interna de la GRAE). Quizá el desinterés en las anotaciones sea fruto del desencanto ante la falta de renovación a lo largo de tantas ediciones; quizá los compiladores se han visto frustrados por el magnetismo de la tradición que se deja sentir a lo largo de las décadas, o quizá el peso de la inercia que domina el quehacer académico en materia de gramática ha pesado también sobre la labor compiladora. Eximimos de estas consideraciones a Palau y Dulcet, pues, ya lo sabemos, su propósito principal es hacer inventario, y un buen inventario (aunque incompleto) es lo que hace. 


\section{Lugar de la Gramática entre los proyectos académicos:}

VI. La Gramática es, dentro del quehacer académico, un proyecto secundario y, a menudo, ensombrecido por otras tareas: de manera permanente, por la constante revisión del Diccionario, obra a la que en ningún periodo se le deja de dedicar atención y la mayor parte del tiempo de trabajo; de forma circunstancial, por otros proyectos que, en ciertos periodos, se convierten en preferentes. Este carácter de "proyecto secundario" (según se desprende de la lectura de los libros de reglamento interno, de la documentación sobre tareas cumplidas y de las propias obras), sumado a la falta de conciliación de puntos de vista (reflejada en los proyectos de gramática), a la inactividad denunciada por algunos de los académicos y a las dificultades que conlleva la empresa de "producir la Grande obra de la Gramática Española», parece ser la razón fundamental de que las reformas doctrinales tarden en quedar plasmadas en el texto de la Gramática (y, por tanto, de que la mayoría de las ediciones de la GRAE que van viendo la luz sea de rango R). Dejamos pendiente la evaluación del número, tipo y alcance de los cambios introducidos en las ediciones de rango J y $\mathrm{E}$. 


\section{III}

\section{EL CONCEPTO DE GRAMÁTICA}

[Grammatica]

neccesaria pueris, iucunda senibus, dulcis secretorum comes, et quae vel sola omni studiorum in genere plus habeat operis quam ostentationis.

M. Qintiliano (Institutio Oratoria, Lib. I. c. IV) 



\section{4.}

\section{EL CONCEPTO DE GRAMÁTICA EN LA OBRA LEXICOGRÁFICA Y}

\section{GRAMATICAL DE LA RAE1}

De interés fundamental para comprender la labor gramatical de cualquier autor (individual o colectivo), en cualquier época y tradición en la que se inserte, es la concepción teórica que de la disciplina tenga el gramático (supuestos de los que parte, finalidad que persigue...), una concepción que suele quedar vertida en el libro de Gramática de distintas formas:

- Mediante la definición expresa de la disciplina.

- En los propios contenidos del libro titulado Gramática.

- En apuntes sobre la labor que compete al gramático, filtrados en distintos lugares de la obra: prólogo, secciones específicas, etc.

- A través de las definiciones y el tratamiento dados a las categorías lingüísticas.

- En las clasificaciones establecidas.

- En los ejemplos dados...

El modo de entender la disciplina gramatical condicionará, por tanto, la estructuración de la obra y la distribución y planteamiento de los contenidos de la misma. Es por ello por lo que parece justificado comenzar el estudio por este punto: qué entiende la Academia por gramática y qué se entendía por gramática

\footnotetext{
1 Para la historia del concepto, véanse, entre otros: Llorente Maldonado (1974), Arens (1976 [1969]), Gómez Asencio (1981: 17-88), Calero Vaquera (1986: 25-48), Bécares Botas (1987: 9-25), Ramajo Caño (1987: 27-46), Taylor (1987), Tusón (1987), Zamora (1987), Esparza y Sarmiento (1992: 34-55), Lozano Guillén (1992: 13-50), Robins (1992 [1969]), Marcos Marín (1994) y Swiggers (1997: 1-68).
} 
en la época en que la docta Casa publica los textos que constituyen el corpus central de este trabajo.

Para determinar la concepción que de la disciplina se defiende en los textos académicos (Gramáticas y Diccionarios, principalmente), habrá que prestar atención especial a dos aspectos, fundamentales a mi entender:

a) Cuáles son los objetivos de estos libros.

b) Qué puesto ocupa la Gramática -según la Institución- dentro de la escala epistemológica, esto es, a qué grado de conocimiento corresponde el estudio gramatical de la lengua. 


\subsection{Datos extraídos de los textos académicos}

\section{Diccionarios}

Autoridades (1734): «El arte de bien hablar y escribir. Es comun à todas las Lénguas, y particular à cada una, y principio y fundamento de

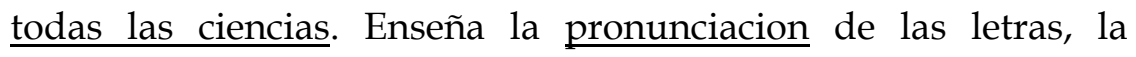

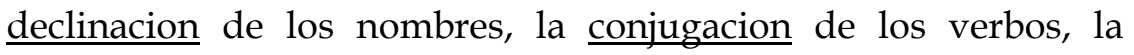
$\underline{\text { construccion de las partes de la oración, el sonido y accento }}$ diverso de las palabras, la distincion de las vocáles y consonantes, y la orden de hablar con propriedad, pureza y policía [...]

GRAMATICA. Por antonomásia se llama el estudio de la Léngua latina. Lat. Linguae latinae studium [...]». (Págs. 70,2-71,1. El subrayado es mío).

DRAE-1780: «El arte de bien hablar y escribir. Es comun á todas las lenguas, y particular á cada una, y principio y fundamento de todas las

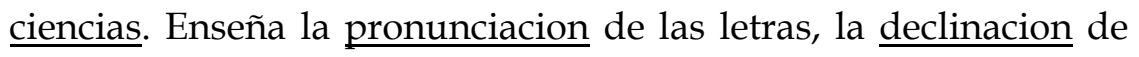
los nombres, la conjugacion de los verbos, la construccion de las partes de la oracion, el sonido y acento diverso de las palabras, la distincion de las vocales y consonantes, y la órden de hablar con propiedad, pureza y policía. Grammatica.

GRAMÁTICA. El estudio de la lengua latina. Linguae latinae studium». (Pág. 506,1. El subrayado es mío).

DRAE-1783: «El arte de bien hablar y escribir. Es comun á todas las lenguas, y particular á cada una, y principio y fundamento de todas las

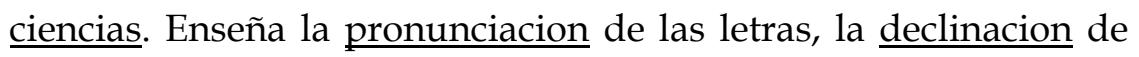
los nombres, la conjugacion de los verbos, la construccion de las partes de la oracion, el sonido y acento diverso de las palabras, la distincion de las vocales y consonantes, y la órden de hablar con propiedad, pureza y policía. Grammatica. 
GrAmÁtICA. El estudio de la lengua latina. Linguae latinae studium». (Pág. 519,2. El subrayado es mío).

DRAE-1791: «El arte de bien hablar y escribir. Es común á todas las lenguas, y particular á cada una, y prinicipio y fundamento de todas las

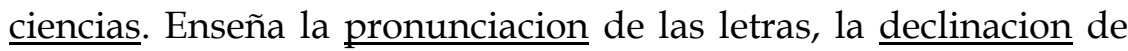
los nombres, la conjugacion de los verbos, la construccion de las partes de la oracion, el sonido y acento diverso de las palabras, la distincion de las vocales y consonantes, y la órden de hablar con propiedad, pureza y policía. Grammatica. 2. El estudio de la lengua latina. Linguae latinae studium». (Pág. 459,1. El subrayado es mío).

DRAE-1803: «El arte de hablar bien y escribir correctamente. Grammática. GRAMÁticA. El estudio de la lengua latina. Grammatica latina». (Pág. 437,3. El subrayado es mío).

DRAE-1817: «El arte de hablar bien y escribir correctamente. Grammatica. GRAMÁTICA. El estudio de la lengua latina. Grammatica latina». (Pág. 448,3. El subrayado es mío).

DRAE-1822: «El arte de hablar bien y escribir correctamente. Grammatica. GRAMÁTICA. El estudio de la lengua latina. Grammatica latina». (Pág. 416,3. El subrayado es mío).

DRAE-1832: «El arte de hablar bien y escribir correctamente. Grammatica. ๆ El estudio de la lengua latina. Grammatica latina». (Pág. 378,1. El subrayado es mío).

DRAE-1837: «El arte de hablar bien y escribir correctamente. Grammatica. ๆ El estudio de la lengua latina. Grammatica latina». (Pág. 377,3. El subrayado es mío). 
DRAE-1843: «El arte de hablar bien y escribir correctamente. Grammatica. a El estudio de la lengua latina. Grammatica latina». (Pág. 369,3. El subrayado es mío).

DRAE-1852: «El arte de hablar bien y escribir correctamente. Grammatica. ๆ El estudio de la lengua latina. Grammatica latina». (Pág. 353,1. El subrayado es mío).

DRAE-1869: «El arte de hablar con propiedad y escribir correctamente. If El estudio de la lengua latina». (Pág. 392,1. El subrayado es mío).

DRAE-1884: «Arte de hablar y escribir correctamente una lengua. ๆ Estudio de la lengua latina. If comparada. La que estudia dos ó más idiomas comparándolos entre sí. T general. Aquella en que se trata de los principios generales ó fundamentales de todos los idiomas». (Pág. 538,3. El subrayado es mío).

DRAE-1899: «Arte de hablar y escribir correctamente una lengua. I Estudio de la lengua latina. đI comparada. La que estudia dos ó más idiomas comparándolos entre sí. T general. Aquella en que se trata de los principios generales ó fundamentales de todos los idiomas». (Pags. 500,3-501,1. El subrayado es mío).

DRAE-1914: «Arte de hablar y escribir correctamente una lengua. If 2 Estudio de la lengua latina. đ comparada. La que estudia dos o más idiomas comparándolos entre sí. ๆ general. Aquella en que se trata de los principios generales o fundamentales de todos los idiomas». (Pags. 518,1. El subrayado es mío).

DRAE-1925: «Arte de hablar y escribir correctamente una lengua. I 2. Estudio de la lengua latina. ๆ comparada. La que estudia dos o más idiomas comparándolos entre sí. đI general. Aquella en que se trata de los principios generales o fundamentales de todos los idiomas». (Pags. 621,1. El subrayado es mío). 


\section{Gramáticas $^{2}$}

GRAE-1771²: «La GRAMÁTICA es arte de hablar bien». (pág. 1. El subrayado es mío).

«Divídese en dos partes: la primera trata del número, propiedad, y oficio de las palabras: la segunda del órden y concierto que deben tener entre si, para expresar con claridad los pensamientos». (Págs. 1-2. El subrayado es mío).

GRAE-1796: «La GRAMÁTICA es el arte de hablar bien». (Pág. 1. El subrayado es mío).

«Consta de quatro partes, que son Ortografía, Analogía, Sintáxis y Prosodia. La Ortografía enseña el número y valor de las letras de que se forman las sílabas y palabras: la Analogía el conocimiento de las palabras, que son partes de la oracion, con todos sus accidentes y propiedades: la Sintaxis el órden y dependencia de estas palabras en las oraciones, con que explicamos nuestros pensamientos: la Prosodia el sonido propio y verdadera pronunciacion de las letras, sílabas y palabras, de que se compone el lenguage. Al presente solo se trata de la Analogía y Sintaxis, omitiendo la Ortografía, porque anda en tratado separado, y la Prosodia, por no haber fixado todavía la Academia las reglas de la verdadera pronunciación de las voces castellanas». (Págs. 1-2. El subrayado es mío).

\footnotetext{
${ }^{2}$ Como ya se ha dicho, aunque el foco de atención lo comprenden las GRAE publicadas en la segunda mitad del siglo XIX y primer cuarto del XX, siempre se tendrá como punto de mira la información ofrecida en las GRAE de 1771 y 1796, que también aparecerán registradas en el Glosario final.

${ }^{3}$ Idéntica definición encontramos en la GRAE-1772 y 1781. Por tratarse de ediciones de rango $\mathrm{R}$ y por no pertenecer al periodo delimitado como foco de atención, omitimos reproducir las citas y entenderemos a partir de ahora que lo que se diga de la primera edición vale para la segunda y tercera.
} 
GRAE-1854: «La Gramática es el arte de hablar bien». (Pág. 1. El subrayado es mío).

«[...] divídese en analogía y sintáxis. La analogía enseña el conocimiento de las palabras, que son partes de la oracion, con todos sus accidentes y propiedades; la sintáxis, el órden y dependencia de estas palabras en las oraciones con que explicamos nuestros pensamientos». (Pág.1. El subrayado es mío).

GRAE-1858: «La Gramática es el arte de hablar con propiedad y escribir correctamente». (Pág. 1. El subrayado es mío).

«[...] divídese en analogía, sintáxis, ortografía y prosodia. La analogía enseña el valor gramatical de las palabras con todos sus accidentes y propiedades; la sintáxis, el órden y dependencia de estas palabras en las oraciones con que explicamos nuestros pensamientos; la ortografía establece reglas para el acertado uso de las letras y los demas signos con que se escribe un idioma, y es objeto de la prosodia la verdadera pronunciacion de los vocablos». (Pág. 1. El subrayado es mío).

GRAE-1862: «La Gramática es el arte de hablar con propiedad y escribir correctamente». (Pág. 5. El subrayado es mío).

«[...] divídese en analogía, sintaxis, ortografía y prosodia. La analogía enseña el valor gramatical de las palabras con todos sus accidentes y propiedades; la sintaxis, el órden y dependencia de estas palabras en las oraciones con que explicamos nuestros pensamientos; la ortografía establece reglas para el acertado uso de las letras y los demas signos con que se escribe un idioma, y es objeto de la prosodia la verdadera pronunciacion de los vocablos». (Pág. 5. El subrayado es mío). 
GRAE-1864: «La Gramática es el arte de hablar con propiedad y escribir correctamente». (Pág. 5. El subrayado es mío).

«[...] divídese en analogía, sintáxis, ortografía y prosodia. La analogía enseña el valor gramatical de las palabras con todos sus accidentes y propiedades; la sintáxis, el órden y dependencia de estas palabras en las oraciones con que explicamos nuestros pensamientos; la ortografía establece reglas para el acertado uso de las letras y los demas signos con que se escribe un idioma, y es objeto de la prosodia la verdadera pronunciacion de los vocablos». (pág. 5. El subrayado es mío).

GRAE-1865: «La Gramática es el arte de hablar con propiedad y escribir correctamente». (Pág. 5. El subrayado es mío).

«[...] divídese en analogía, sintáxis, ortografía y prosodia. La analogía enseña el valor gramatical de las palabras con todos sus accidentes y propiedades; la sintáxis, el órden y dependencia de estas palabras en las oraciones con que explicamos nuestros pensamientos; la ortografía establece reglas para el acertado uso de las letras y los demas signos con que se escribe un idioma, y es objeto de la prosodia la verdadera pronunciacion de los vocablos». (Pág. 5. El subrayado es mío).

GRAE-1866: «La Gramática es el arte de hablar con propiedad y escribir correctamente». (Pág. 5. El subrayado es mío).

«[...] divídese en analogía, sintáxis, ortografía y prosodia. La analogía enseña el valor gramatical de las palabras con todos sus accidentes y propiedades; la sintáxis, el órden y dependencia de estas palabras en las oraciones con que explicamos nuestros pensamientos; la ortografía establece reglas para el acertado uso de las letras y los demas signos con que se escribe un idioma, y es objeto de la prosodia la verdadera pronunciacion de los vocablos». (Pág. 5. El subrayado es mío). 
GRAE-1867: «La Gramática es el arte de hablar con propiedad y escribir correctamente». (Pág. 5. El subrayado es mío).

«[...] divídese en analogía, sintáxis, ortografía y prosodia. La analogía enseña el valor gramatical de las palabras con todos sus accidentes y propiedades; la sintáxis, el órden y dependencia de estas palabras en las oraciones con que explicamos nuestros pensamientos; la ortografía establece reglas para el acertado uso de las letras y los demas signos con que se escribe un idioma, y es objeto de la prosodia la verdadera pronunciacion de los vocablos». (Pág. 5. El subrayado es mío).

GRAE-1870: "Gramática es el arte de hablar y escribir correctamente». (Nociones preliminares, pág. 1. El subrayado es mío).

«El fin de toda GRAMÁTICA es enseñar á conocer, ordenar, pronunciar y escribir correctamente las oraciones y las partes todas de que constan, pues con las oraciones se forman los períodos, y con los períodos las obras literarias». (Nociones preliminares, pág. 5. El subrayado es mío).

GRAE-1874: «GRAMÁTICA es el arte de hablar y escribir correctamente». (Nociones preliminares, pág. 11. El subrayado es mío).

«El fin de toda GRAMÁTICA es enseñar á conocer, ordenar, pronunciar y escribir correctamente las oraciones y las partes todas de que constan; pues con la agregacion y enlace de las oraciones se forman los períodos, y con los períodos la conversacion ó plática, y toda clase de discurso hablado ó escrito, desde el más familiar hasta el de más elevado estilo literario: en todos los cuales nos conviene expresar nuestro pensamiento con claridad, propiedad y exactitud. Tal es el resultado del estudio de la gramática, cuya division en las cuatro partes arriba dichas procede naturalmente de los cuatro fines que le hemos atribuido, 
á saber: conocer (ANALOGÍA), ordenar (SINTAXIS), pronunciar (PROSODIA), y escribir (ORTOGRAFÍA) correctamente». (Nociones preliminares, pág. 16 . El subrayado es mío).

GRAE-1878: «GRAMÁTICA es el arte de hablar y escribir correctamente». (Nociones preliminaes, pág. 11. El subrayado es mío).

«El fin de toda Gramática es enseñar á conocer, ordenar, pronunciar y escribir correctamente las oraciones y las partes todas de que constan; pues con la agregacion y enlace de las oraciones se forman los períodos, y con los períodos la conversacion ó plática, y toda clase de discurso hablado ó escrito, desde el más familiar hasta el de más elevado estilo literario: en todos los cuales nos conviene igualmente expresar nuestro pensamiento con claridad, propiedad y exactitud.

Tal es el resultado del estudio de la GRAMÁTICA, cuya division en la cuatro partes arriba dichas procede naturalmente de los cuatro fines que le hemos atribuído, á saber: conocer (ANALOGÍA), ordenar (SINTAXIS), pronunciar (PROSODIA), y escribir (ORTOGRAFÍA) correctamente». (Nociones preliminares, pág. 16. El subrayado es mío).

GRAE-1880: «Gramática es el arte de hablar y escribir correctamente». (Introducción, pág.5. El subrayado es mío).

«El fin de la Gramática es enseñar á conocer el valor y oficio de las palabras, el modo de formar con ellas oraciones y el de pronunciarlas y escribirlas. Agregando y enlazando oraciones resultan los períodos; y con éstos la conversación ó plática y toda clase de discurso hablado ó escrito, desde el más familiar hasta el más pulcro y galano. Así, pues, aquellas cuatro partes corresponden á los cuatro indicados fines, de conocer (ANALOGÍA), ordenar (SINTAXIS), pronunciar (PROSODIA) y escribir correctamente (ORTOGRAFÍA)». (Introducción, pág. 5. El subrayado es mío). 
GRAE-1883: «Gramática es el arte de hablar y escribir correctamente». (Introducción, pág. 5. El subrayado es mío). «El fin de la Gramática es enseñar á conocer el valor y oficio de las palabras, el modo de formar con ellas oraciones y el de pronunciarlas y escribirlas. Agregando y enlazando oraciones resultan los períodos; y con éstos la conversación ó plática y toda clase de discurso hablado ó escrito, desde el más familiar hasta el más pulcro y galano. Así, pues, aquellas cuatro partes corresponden á los cuatro indicados fines, de conocer (ANALOGÍA), ordenar (SINTAXIS), pronunciar (PROSODIA) y escribir correctamente (ORTOGRAFÍA)». (Introducción, pág. 5. El subrayado es mío).

GRAE-1885: «GRAMÁTICA es el arte de hablar y escribir correctamente». (Introducción, pág. 5. El subrayado es mío). «El fin de la Gramática es enseñar á conocer el valor y oficio de las palabras, el modo de formar con ellas oraciones y el de pronunciarlas y escribirlas. Agregando y enlazando oraciones resultan los períodos; y con éstos la conversación ó plática y toda clase de discurso hablado ó escrito, desde el más familiar hasta el más pulcro y galano. Así, pues, aquellas cuatro partes corresponden á los cuatro indicados fines, de conocer (ANALOGÍA), ordenar (SINTAXIS), pronunciar (PROSODIA) y escribir correctamente (ORTOGRAFÍA)». (Introducción, pág. 5. El subrayado es mío).

GRAE-1888: «GRAMÁTICA es el arte de hablar y escribir correctamente». (Introducción, pág. VI).

«Propónese [la gramática], por tanto, enseñar á conocer el valor y oficio de las palabras, el modo de formar con ellas oraciones y el de pronunciarlas y escribirlas; y se divide en cuatro partes, llamadas Analogía, Sintaxis, Prosodia y Ortografía, las cuales corresponden á los cuatro indicados fines, de conocer (ANALOGÍA), 
ordenar (SINTAXIS), pronunciar (PROSODIA) y escribir correctamente (ORTOGRAFÍA)». (Introducción, pág. VI. El subrayado es mío).

GRAE-1890: «GRAMÁTICA es el arte de hablar y escribir correctamente». (Introducción, pág. VI. El subrayado es mío).

«Propónese [la gramática], por tanto, enseñar á conocer el valor y oficio de las palabras, el modo de formar con ellas oraciones y el de pronunciarlas y escribirlas; y se divide en cuatro partes, llamadas Analogía, Sintaxis, Prosodia y Ortografía, las cuales corresponden á los cuatro indicados fines, de conocer (ANALOGÍA), ordenar (SINTAXIS), pronunciar (PROSODIA) y escribir correctamente (ORTOGRAFÍA)». (Introducción, pág. VI. El subrayado es mío).

GRAE-1895: «GRAMÁTICA es el arte de hablar y escribir correctamente». (Introducción, pág. VI. El subrayado es mío).

«Propónese [la gramática], por tanto, enseñar á conocer el valor y oficio de las palabras, el modo de formar con ellas oraciones y el de pronunciarlas ó escribirlas; y se divide en cuatro partes, llamadas Analogía, Sintaxis, Prosodia y Ortografía, las cuales corresponden á los cuatro indicados fines, de conocer (ANALOGÍA), ordenar (SINTAXIS), pronunciar (PROSODIA) y escribir correctamente (ORTOGRAFÍA)». (Introducción, pág. VI. El subrayado es mío).

GRAE-1900: "GRAMÁTICA es el arte de hablar y escribir correctamente». (Introducción, pág. VI. El subrayado es mío).

«Propónese [la gramátical, por tanto, enseñar á conocer el valor y oficio de las palabras, el modo de formar con ellas oraciones y el de pronunciarlas ó escribirlas; y se divide en cuatro partes, llamadas Analogía, Sintaxis, Prosodia y Ortografía, las cuales corresponden á los cuatro indicados fines, de conocer (ANALOGÍA), ordenar (SINTAXIS), pronunciar (PROSODIA) y escribir correctamente (ORTOGRAFÍA)». (Introducción, pág. VI. El subrayado es mío). 
GRAE-1901: «GRAMÁTICA es el arte de hablar y escribir correctamente». (Introducción pág. VI. El subrayado es mío).

«Propónese [la gramátical, por tanto, enseñar á conocer el valor y oficio de las palabras, el modo de formar con ellas oraciones y el de pronunciarlas ó escribirlas; y se divide en cuatro partes, llamadas Analogía, Sintaxis, Prosodia y Ortografía, las cuales corresponden á los cuatro indicados fines, de conocer (ANALOGÍA), ordenar (SINTAXIS), pronunciar (PROSODIA) y escribir correctamente (ORTOGRAFÍA)». (Introducción, pág. VI. El subrayado es mío).

GRAE-1904: «Gramática es el arte de hablar y escribir correctamente». (Introducción, pág. VI. El subrayado es mío).

«Propónese [la gramátical, por tanto, enseñar á conocer el valor y oficio de las palabras, el modo de formar con ellas oraciones y el de pronunciarlas ó escribirlas; y se divide en cuatro partes, llamadas Analogía, Sintaxis, Prosodia y Ortografía, las cuales corresponden á los cuatro indicados fines, de conocer (ANALOGÍA), ordenar (SINTAXIS), pronunciar (PROSODIA), y escribir correctamente (ORTOGRAFÍA)». (Introducción, pág. VI. El subrayado es mío).

GRAE-1906: «Gramática es el arte de hablar y escribir correctamente». (Introducción, pág. VI. El subrayado es mío).

«Propónese [la gramática], por tanto, enseñar á conocer el valor y oficio de las palabras, el modo de formar con ellas oraciones y el de pronunciarlas ó escribirlas; y se divide en cuatro partes, llamadas Analogía, Sintaxis, Prosodia y Ortografía, las cuales corresponden á los cuatro indicados fines, de conocer (ANALOGÍA), ordenar (SINTAXIS), pronunciar (PROSODIA), y escribir correctamente (ORTOGRAFÍA)». (Introducción, pág. VI. El subrayado es mío). 
GRAE-1908: «GRAMÁTICA es el arte de hablar y escribir correctamente». (Introducción, pág. VI. El subrayado es mío). «Propónese [la gramática], por tanto, enseñar á conocer el valor y oficio de las palabras, el modo de formar con ellas oraciones y el de pronunciarlas ó escribirlas; y se divide en cuatro partes, llamadas Analogía, Sintaxis, Prosodia y Ortografía, las cuales corresponden á los cuatro indicados fines de conocer (ANALOGÍA), ordenar (SINTAXIS), pronunciar (PROSODIA) y escribir correctamente (ORTOGRAFÍA)». (Introducción, pág. VI. El subrayado es mío).

GRAE-1909: «GRAMÁTICA es el arte de hablar y escribir correctamente». (Introducción, pág. VI. El subrayado es mío).

«Propónese [la gramática], por tanto, enseñar á conocer el valor y oficio de las palabras, el modo de formar con ellas oraciones y el de pronunciarlas ó escribirlas; y se divide en cuatro partes, llamadas Analogía, Sintaxis, Prosodia y Ortografía, las cuales corresponden á los cuatro indicados fines, de conocer (ANALOGÍA), ordenar (SINTAXIS), pronunciar (PROSODIA), y escribir correctamente (ORTOGRAFÍA)». (Introducción, pág. VI. El subrayado es mío).

GRAE-1911: «GRAMÁTICA es el arte de hablar y escribir correctamente». (Introducción, pág. 6. El subrayado es mío). «Propónese [la gramátical, por tanto, enseñar a conocer el valor y oficio de las palabras, el modo de formar con ellas oraciones y el de pronunciarlas o escribirlas; y se divide en cuatro partes, llamadas Analogía, Sintaxis, Prosodia y Ortografía, las cuales corresponden a los cuatro indicados fines, de conocer (ANALOGÍA), ordenar (SINTAXIS), pronunciar (PROSODIA), y escribir correctamente (ORTOGRAFÍA)». (Introducción, pág. 6. El subrayado es mío). 
GRAE-1913: «GRAMÁTICA es el arte de hablar y escribir correctamente». (Introducción, pág. 6. El subrayado es mío). «Propónese [la gramática], por tanto, enseñar a conocer el valor y oficio de las palabras, el modo de formar con ellas oraciones y el de pronunciarlas o escribirlas; y se divide en cuatro partes, llamadas Analogía, Sintaxis, Prosodia y Ortografía, las cuales corresponden a los cuatro indicados fines, de conocer (ANALOGÍA), ordenar (SINTAXIS), pronunciar (PROSODIA), y escribir correctamente (ORTOGRAFÍA)». (Introducción, pág. 6. El subrayado es mío).

GRAE-1916: «GRAMÁTICA es el arte de hablar y escribir correctamente». (Introducción, pág. 6. El subrayado es mío). «Propónese [la gramática], por tanto, enseñar a conocer el valor y oficio de las palabras, el modo de formar con ellas oraciones y el de pronunciarlas o escribirlas; y se divide en cuatro partes, llamadas Analogía, Sintaxis, Prosodia y Ortografía, las cuales corresponden a los cuatro indicados fines, de conocer (ANALOGÍA), ordenar (SINTAXIS), pronunciar (PROSODIA), y escribir correctamente (ORTOGRAFÍA)». (Introducción, pág. 6. El subrayado es mío).

GRAE-1917: «GRAMÁTICA es el arte de hablar y escribir correctamente». (Introducción, pág. VII. El subrayado es mío).

«Propónese [la gramátical, por tanto, enseñar a conocer el valor y oficio de las palabras, el modo de formar con ellas oraciones y el de pronunciarlas o escribirlas; y se divide en cuatro partes, llamadas Analogía, Sintaxis, Prosodia y Ortografía, las cuales corresponden a los cuatro indicados fines, de conocer (ANALOGÍA), ordenar (SINTAXIS), pronunciar (PROSODIA), y escribir correctamente (ORTOGRAFÍA)». (Introducción, pág. VII. El subrayado es mío). 
GRAE-1920: «GRAMÁTICA es el arte de hablar y escribir correctamente». (Introducción, pág. 7. El subrayado es mío). «Propónese [la gramática], por tanto, enseñar a conocer el valor y oficio de las palabras, el modo de formar con ellas oraciones y el de pronunciarlas o escribirlas; y se divide en cuatro partes, llamadas Analogía, Sintaxis, Prosodia y Ortografía, las cuales corresponden a los cuatro indicados fines, de conocer (ANALOGÍA), ordenar (SINTAXIS), pronunciar (PROSODIA), y escribir correctamente (ORTOGRAFÍA)». (Introducción, pág. 8. El subrayado es mío).

GRAE-1924: «GRAMÁTICA es el arte de hablar y escribir correctamente». (Introducción, pág. 7. El subrayado es mío). «Propónese [la gramática], por tanto, enseñar a conocer el valor y oficio de las palabras, el modo de formar con ellas oraciones y el de pronunciarlas o escribirlas; y se divide en cuatro partes, llamadas Analogía, Sintaxis, Prosodia y Ortografía, las cuales corresponden a los cuatro indicados fines, de conocer (ANALOGÍA), ordenar (SINTAXIS), pronunciar (PROSODIA), y escribir correctamente (ORTOGRAFÍA)». (Introducción, pág. 8. El subrayado es mío). 


\subsection{Interpretación de los datos}

\subsubsection{Propiedades inherentes a la disciplina gramatical}

La consulta al Diccionario de Autoridades, la primera obra que la Institución saca a la luz, revela que la Academia se suma a la larga tradición gramatical de Occidente y recoge, en forma de síntesis, algunas ideas generalizadas en la época de publicación del Diccionario (primera mitad del siglo XVIII) $)^{4}$.

Como puede comprobarse al comienzo del punto 4.1., en Autoridades encontramos dos acepciones bajo el lema gramática, de las cuales interesa someter a análisis la primera, por ser esta la definición que ofrece datos relevantes para poder profundizar en la concepción gramatical sostenida por la Academia.

En la segunda acepción, se identifica, por antonomasia, la Gramática con la gramática latina, identificación que viene de lejos. Sabido es que la gramática latina sirvió de modelo teórico a las gramáticas vernáculas y que ese modelo gramatical latino es paralelo a un modelo literario también latino: tal como informa Buceta (1925: 85), «el siglo XV trae a la literatura española un ansia viva y marcada por moldear la lengua castellana, según los cánones de la latina». Esta horma latina será también muy evidente en el artificio gramatical, y tanto en Autoridades como en los DRAE encontramos vestigios de ello, como prueba el hecho de que, en todos los Diccionarios del corpus, encontremos la identificación gramática $=$ estudio del latín como acepción secundaria. De ello ha quedado constancia en los fragmentos expuestos en 4.1.

\footnotetext{
${ }^{4}$ En los DRAE de 1780, 1783 y 1791 se reproducen las mismas palabras que en Autoridades (cf. citas de 4.1.), por lo que, para la concepción de gramática recogida en la obra lexicográfica del siglo XVIII, me referiré siempre a Autoridades, entendiendo que lo que se diga vale igualmente para las ediciones primera, segunda y tercera del Diccionario reducido.
} 
La identificación explícita que se establece en el Diccionario no encuentra paralelo (esto parece obvio) en la Gramática (que -no lo olvidemos- es una Gamática castellana), si bien la huella latina se dejará sentir en ella, como no podía ser de otra forma, en tanto que heredera y eslabón de una tradición secular. El grado de latinización/deslatinización de las distintas ediciones de la GRAE se irá indicando y comentando en los momentos oportunos ${ }^{5}$. Tales comentarios tendrán como propósito principal establecer el tipo de latinización de la Gramática académica: si se trata, en términos de Gómez Asencio (1999 y 2001), de una «latinización del marco» (o latinización global del soporte conceptual y teórico), de una «latinización descriptiva» o de una «latinización lingüística» (o latinización del uso de la lengua por medio de la gramática).

$* * * * * * *$

\section{PROPIEDADES DE LA GRAMÁTICA ESTABLECIDAS EN AUTORIDADES}

Las principales ideas recogidas en el artículo lexicográfico de Autoridades, en la acepción que nos interesa (la primera), pueden resumirse en los siguientes cinco puntos:

- Carácter de la Gramática:

1. Pedagógico (arte que enseña).

2. Prescriptivo (ese arte enseña a hacer algo bien, conforme a unas pautas o modelos).

\footnotetext{
5 Sobre tradición y latinización en gramática, interesan los estudios de Lliteras (1998) y Gómez Asencio (1999 y 2001). En Delgado (1977), Martínez Gavilán (1994), Bosque (1997), Niederehe (1997), Sarmiento (1997b) y Esparza (2004) se encuentra también información de interés en lo que atañe al diálogo entre tradición e innovación sostenido a lo largo de nuestra historia lingüística y gramatical.
} 
- Doble dimensión de la Gramática:

3. General y particular.

- Finalidad última de la Gramática:

4. Arte propedéutica (llave de acceso a otros conocimientos -sobre todo, el latín, a partir del cual se accede a "todo lo demás"-).

- Contenidos de la Gramática:

5. Los propios de la Prosodia (pronunciación, sonido, acento, vocales y consonantes), la Morfología o Analogía (declinación, conjugación de las categorías gramaticales) y la Sintaxis (cuestiones de construcción y orden). De las cuatro partes clásicas de la Gramática, parece que a la que no se hace referencia es a la Ortografía: la única alusión la tenemos en la enseñanza de la pronunciación de las letras, pero esto bien puede ser entendido por la Academia dentro del estudio prosódico y no del ortográfico, como se comentará más abajo ${ }^{6}$.

\section{DESARROLLO POSTERIOR}

¿Cómo toman cuerpo en las Gramáticas, Diccionarios y otros textos académicos (disertaciones, proyectos, etc.) posteriores las ideas expuestas en Autoridades? Veamos, por separado, cada uno de estos puntos.

6 Podemos adelantar aquí que la propia Academia, en la primera GRAE en que trata de la Prosodia, la define como «aquella parte de la Gramática que enseña la recta pronunciacion y acentuacion de las letras, sílabas y palabras» (GRAE-1870: 287. El subrayado es mío). 


\section{LA GRAMÁTICA ES DIDÁCTICA}

El carácter pedagógico (objetivo de enseñanza) que, en concepción de los académicos, debe ser consustancial al estudio gramatical, puede observarse en todos los textos publicados por la Institución:

- En los Diccionarios y las Gramáticas (así como en Discursos, Proyectos, etc.), en la propia definición de la disciplina, que se reconoce como arte, lo cual va a implicar un componente indudablemente prescriptivo -vid. infra apartado 2.-, pero también un componente didáctico, una enseñanza previa de conceptos teóricos básicos.

- En los libros de Gramática concretamente, de un lado, en la declaración explícita (desde la GRAE-1870) de que "el fin de la Gramática es enseñar a conocer, ordenar, pronunciar, escribir, etc." (remito a los fragmentos de 4.1.) y otras declaraciones en la misma línea que veremos en este punto del estudio; de otro, en la constante búsqueda de claridad y precisión.

El objetivo de transmitir de la forma más sencilla y accesible posible los conceptos gramaticales, la preocupación por lograr una adecuada llaneza expositiva, es algo en lo que se insiste constantemente en todas las GRAE, de forma especial hasta la sexta edición, de 1858. Las calas hechas en las distintas ediciones de la Gramática parecen confirmar este interés pedagógico: 


\section{1}

«Para allanar en lo posible esta dificultad se han puesto despues de los exemplos de los regulares todos los verbos irregulares, y los tiempos y personas en que lo son: de suerte que solo con buscar por el índice la página en que esté el verbo irregular en cuya conjugacion haya duda, se podrá salir facilmente de ella». (Págs. X-XI. El subrayado es mío).

«De estos y otros arbitrios ha usado la Academia en varias partes de la Gramática para facilitar á todos su estudio; pero ha excusado entrar en un prolixo exâmen de las varias opiniones de los gramáticos, prefiriendo á esta erudicion la brevedad y la claridad, pues se trata de ilustrar y enseñar, no de ofuscar ni confundir á la Juventud». (Págs. XII-XIII. Idéntico fragmento lo encontramos en 1796, págs. XII-XIII. El subrayado es mío).

1796

«Uno de los tratados mas principales que abraza esta primera parte de la Gramática es el Nombre, cuyas propiedades y accidentes si se explican con la mayor claridad, facilitan mucho la inteligencia de la Sintáxîs, así natural como figurada, de nuestra lengua». (Pág. IX. El subrayado es mío).

«Y si acaso por descuido se ha omitido alguna [regla], que ocasione dificultad, se ocurre á ella con la lista alfabética de Varia construccion, que va al final ordenada en tres columnas [...] con lo qual apénas habrá duda alguna sobre el régimen de que no se pueda salir á primera vista». (Págs. XV-XVI. El subrayado es mío). 


\section{4}

«Los tiempos de los verbos estaban en la primitiva Gramática de la Academia suficientemente divididos y desligados, sin las nuevas subdivisiones, que léjos de facilitar su estudio, quizá lo embarazan: por eso preferimos el método ya experimentado al reciente, bien que sin omitir precepto ninguno importante. Establecer las reglas con la posible

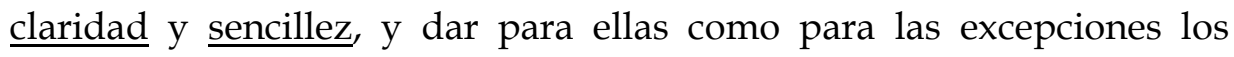
necesarios ejemplos, ha sido el principal objeto de la Academia [...]». (Págs. VII-VIII. El subrayado es mío).

«Huyendo de ambos extremos, la Academia ha ordenado su nueva Gramática en tales términos, que ni peque de excesivamente corta, ni de prolija; que sirva á los niños y á los adultos. Para ello ha empleado en la impresion dos grados de letra [...] Ciertas explicaciones ménos esenciales se ponen como notas al pié de las páginas respectivas». (Págs. VIII-IX. El subrayado es mío).

«Para mejor empleo de las preposiciones se conserva, notablemente ampliado y corregido, el Apéndice de construcciones que acompañaba á las ediciones anteriores». (Pág. IX. El subrayado es mío).

Comprobamos cómo, entrados en el siglo XIX, la Academia no sólo deja constancia de su propósito de facilitar, en la medida de lo posible, el estudio de la Gramática (elaborando listas y tablas; graduando la información; ejemplificando; etc.), también -y frente a la GRAE dieciochesca- se toma postura (conservadora) ante soluciones teóricas y terminológicas que se consideran inútiles (precisamente, por no facilitar el conocimiento de la lengua). En la edición siguiente a esta última de 1854, encontraremos una actitud muy parecida: 


\section{8}

«[...] se ha abstenido la Academia de adoptar ciertas novedades, muy encarecidas por algunos de útiles, y en realidad harto insignificantes. Clasificar las partes de la oracion gramatical de otro modo y aplicar á los tiempos del verbo distintos nombres podrá dar originalidad ó extrañeza á las nuevas Gramáticas, mas no enseñarán por esto mejor nuestro idioma: además los reformadores distan mucho de convenir en las enmiendas que han de hacerse á la organizacion y nomenclatura de la Gramática... Establecer las reglas con la posible claridad y sencillez [...]». (Pág. VI).

Esta misma edición también ofrece un testimonio que prueba que los recursos pedagógicos de que se ha valido la Academia hasta la fecha no son gratuitos:

Destinados á la enseñanza de la niñez y de la juventud el Epítome y el Compendio citados, no hay necesidad de imprimir la Gramática en los diferentes grados de letra que se emplearon en la edición de 1854 .

(GRAE-1858: VII)

A partir de 1870, sin embargo, parece difuminarse más esa insistente búsqueda de claridad y concisión, que caracterizaba las ediciones anteriores (especialmente -repito- hasta la quinta edición) en aras de una finalidad fundamentalmente pedagógica. Las novedades se rechazan ahora por otros motivos distintos del didactismo y la inmanencia descriptiva, que es lo que hacía rechazarlas en 1854 y 1858 : 
La Academia se halla en un caso muy distinto que los autores particulares. Éstos últimos son libres, pueden dar rienda suelta á su imaginación, y áun á su capricho, sin incurrir en responsabilidad alguna, y sin que tengan trascendencia mayor sus yerros ó extravíos; pero la Academia no puede ni debe aventurarse tanto... es una Corporación oficial, á quien está encomendada la vigilante custodia de la lengua patria 7 , y fuera en ella imperdonable indiscrecion lo que en un autor irresponsable puede pasar por osadía plausible.

(GRAE-1870: XII-XIII. El subrayado es mío) ${ }^{8}$

La finalidad didáctica, tan característica de la disciplina gramatical desde los primeros tiempos, preside las Gramáticas académicas de forma indiscutible hasta, al menos, la primera edición del XIX, ésta inclusive (GRAE1854); de ahí los cuadros, las tablas, las distintas tipografías empleadas, las notas aclaratorias, etc. A partir de 1857, la publicación de Epítomes (para la primera enseñanza) y de Compendios (para la segunda enseñanza) irá eximiendo a las Gramáticas del empleo de recursos pedagógicos, y ya desde la GRAE-1870 las propias declaraciones de los académicos indican que, para

\footnotetext{
7 En 1854, encontramos una ligera alusión a esta misión de cuidado de la lengua, que se repetirá en 1858:

La lengua castellana, hija del latin, pero enriquecida con voces [...] ocupa el primer lugar entre los dialectos que se formaron al transfigurarse y desaparecer el habla de la estirpe de Rómulo. Sostener la grandeza de tan bello idioma es y debe ser el único afan de esta Real Academia [...]

(GRAE-1854: IX-X y GRAE-1858: VII. El subrayado es mío),
}

palabras éstas («sostener la grandeza») carentes de todo propósito coercitivo, matiz que sí impregna ya las palabras de 1870 («vigilante custodia»). Sobre la "coerción" como propósito en la GRAE-1870, vid. apartado 2. .

8 En los trabajos preparatorios del Esbozo, encontramos argumentaciones que recuerdan esta línea de prudencia ante las novedades teóricas. En la comunicación presentada por Salvador Fernández Ramírez en el Tercer Congreso de Academias de la Lengua Española, el académico, sumándose a la línea iniciada años antes por el también académico Rafael Lapesa en el Segundo Congreso de la misma Asociación, se expresa en los siguientes términos:

\footnotetext{
Se ha tratado, por consiguiente, de renovar y remozar la doctrina [...] y de introducir puntos de arranque sistemáticos. Al mismo tiempo se ha tenido en cuenta la conveniencia de no "encajar el estudio de nuestro idioma en el esquema teórico de ninguna escuela".
}

(Fernández Ramírez, 1987: 14. El subrayado es mío) 
alcanzar el objetivo final, se prima menos lo pedagógico y más lo normativo (remito al apartado 2..) ${ }^{9}$.

Relacionado con este didactismo podría entenderse el recurso al llamado método geométrico, considerado por Ramón Sarmiento (1984a: 27-28) método articulador de la primera Gramática académica. Efectivamente, en el Proyecto de Gramática de 1741, Angulo, miembro de la primera Comisión de Gramática, reconoce las ventajas del método propio de la Geometría y la conveniencia de aplicarlo en las tareas gramaticales. Reproduzco el fragmento que nos interesa:

[...] me parece que el libro $1^{\circ}$., que ha de tratar como he dicho dela Orthographia, y Prosodia, debe empezar por alguna otra cosa, que diga lo que es la obra, y haga relacion á toda ella: para esto es lo mas propio la explicacion dela Gram.ca y de los terminos de ella por que en una breve y unida colección de difinizínes se hallen las que conduzcan al conocim.to de las partes, y havian de estar esparcidas en el discurso de la obra: este methodo sigue el P.e Chiflet en su Gram.ca franzesa, y tambien el Pe Bufier en la suya tan celebrada, diciendo este, que en un estudio tal como es la Gram.ca que es el primero detodos, y en que por consequencia se debe suponer que el estudiante no tiene tintura alguna de las letras, parece ciertam.te mui estraño no se haya empleado el methodo simple, y seguro de la Geometria, la qual no emplea termino alguno que no haya explicado netamente.

(ARAE, 1741a: pliego 33. ${ }^{\circ}$ El subrayado es mío) ${ }^{10}$

\footnotetext{
${ }^{9}$ A propósito de la transición entre GRAE, CRAE y ERAE, he hablado más detenidamente en Garrido Vílchez (2002b y 2003a).

${ }^{10}$ Pongo en cita unas palabras de Buffier que resultan ilustrativas de su afán pedagógico (la numeración de las páginas es mía; en el ejemplar que he utilizado solo están numeradas las páginas del cuerpo de la Gramática):
}

[...] j'ai taché d'expofer les principes de notre langue, conformément a l'ufage prélent de la maniere la plus exacte $\sigma$ la plus juste, $\sigma$ en même -temps la plus nette $\sigma$ la plus airée.

(Buffier, 1709: PREFACE: IV) 
La lectura de las páginas preliminares que sirven de pórtico a las obras de Chiflet (1680) y Buffier (1709), así como la revisión del planteamiento que dan a sus libros, confirma que el propósito didáctico está muy presente en estos autores y que por esta razón (entre otras) Angulo debió de ver un buen modelo en ellos.

El auxilio de los procedimientos propios de la geometría, como forma de esclarecimiento de conceptos a los niños y jóvenes que se iniciaban en los estudios de gramática, ya lo encontramos en el Nuevo método para aprender fácilmente y en poco tiempo la lengua latina de Lancelot $(1644)^{11}$. El que será coautor de la famosa Gramática de Port-Royal aconseja, en la Advertencia al lector de su Método Latino, que el latín debe explicarse en la primera lengua del alumno y que, como recurso de apoyo a las enseñanzas, será bueno valerse de cuadros sinópticos, versificaciones de las reglas... y, sobre todo, valerse de lo ya conocido para acceder a lo nuevo. Es por ello por lo que la metodología de la

\footnotetext{
Avant que de finir cette préface, il eft bon que j'avertiße encore de quelques points.

1. ${ }^{\circ}$ Certaines matieres plus dificiles reviennent quelquefois dans les diférentes parties de ce livre; mais c'eft pour les expofer fous diférens jours, qui ferviront à les faire mieux entendre.
}

(Buffier, 1709: PREFACE: VI-VII)

También Chiflet aspiraba a la claridad y facilidad de la exposición, propósito al que responde el capítulo primero de su Grammaire, dedicado a «L'Explication des termes de la Grammaire». Manifiesta en él su obligación (como gramático) de comenzar la exposición estableciendo los conceptos básicos de la disciplina:

Je fuis contraint d'expliquer, avant toute chole, les termes de la Grammaire, pour la commodité de ceux, qui, n'ayant jamais apris le Latin, n'entendent point ce que veut dire.

(Chiflet, 1680: CHAPITRE I, pág. I)

11 Este opúsculo pedagógico se utilizó para la educación del joven rey Luis XIV. Fue revisado en profundidad en cinco ediciones que se sucedieron entre 1644 y 1656, en las cuales se aprecia el aprovechamiento de la doctrina del Brocense. De hecho, en el Método ya encontraremos definidos algunos principios fundamentales de la Grammaire de Port-Royal. Más información, en Laborda Gil (1981). 
Grammaire va a seguir, en lo fundamental, el procedimiento de la geometría, recomendado por Pascall2.

¿Cómo toma cuerpo el llamado método geométrico en las GRAE de la segunda mitad del siglo XIX y primer cuarto del XX? Lo vemos esquemáticamente a través de las ediciones-jalón.

12 Para una ampliación de este punto, puede verse Morillo-Velarde (1980: 21-25). 


\subsection{Los años cincuenta y sesenta}

GRAE-1854 13

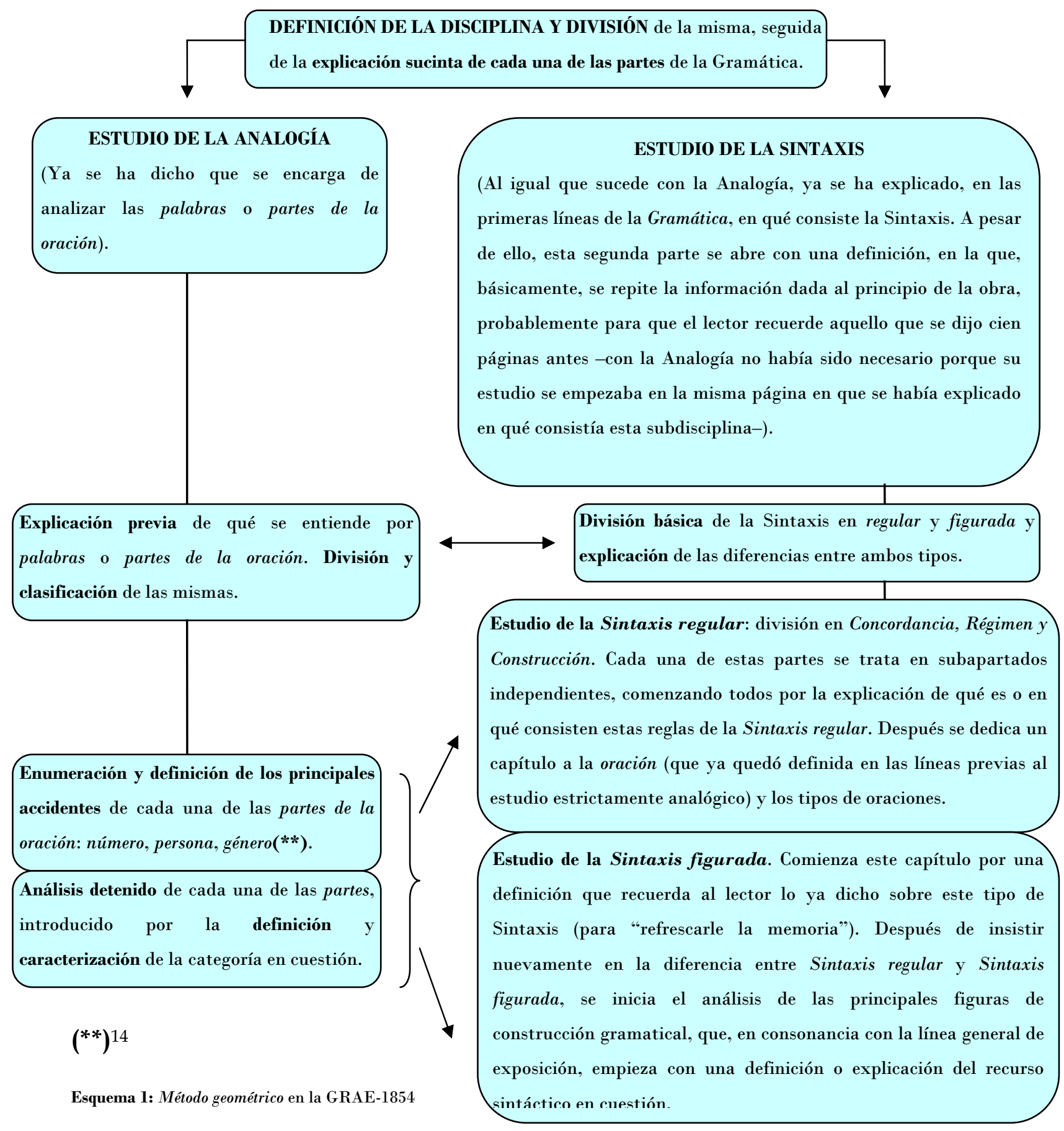

${ }^{13}$ Este esquema es extensivo a las GRAE de 1858, 1862, 1864, 1865, 1866 y 1867.

${ }^{14}$ Estas líneas previas al estudio detenido de cada una de las partes de la oración, en las que se exponen los conceptos básicos con los que se va a trabajar en la Analogía, es algo que la GRAE1854 recoge de la última Gramática dieciochesca (GRAE-1796), en la cual se hizo este añadido con la intención -se supone- de dar al texto una mayor claridad expositiva, frente a la GRAE1771, en la que, por ejemplo, se habla de sustantivos masculinos y femeninos y de adjetivos de dos terminaciones antes de explicar qué es el género (vid. GRAE-1771: 6 y 9). 
La declaración de intenciones (didácticas, en este caso) está hecha en las páginas introductorias de los libros y el método, en lo esencial, aplicado en el cuerpo de la obra. Pero ¿se logra el fin perseguido? ¿Responde el libro de Gramática, en lo que a presentación y tratamiento de la disciplina se refiere, a las expectativas creadas?

Un gramático contemporáneo de las primeras GRAE decimonónicas no duda en hacer crítica punzante del texto académico. Se refieren sus palabras a la GRAE-1854 y son estas que reproduzco:

$\underline{\text { En vano se buscan en la Gramática reformada la sencillez, la }}$ claridad, la precision y el método didáctico, que exige una obra elemental, destinada para la instrucción primaria. La nueva Gramática de la Academia es una miscelánea de conversacion, de circumloquios y de oscura y embrollada doctrina, y á imitacion de las de D. Vicente Salvá y D. Andres Bello, está tambien adornada de abundantes notas y largos comentarios que, en vez de ilustrar, ofuscan.

(Vicente García, 1855: 12-13. El subrayado es mío).

¿Es que teoría y práctica caminan por senderos divergentes en la obra institucional? El principal lastre de la GRAE-1854, en el aspecto que nos ocupa, es su aspiración a satisfacer o servir a un público demasiado amplio: jóvenes y mayores, versados y legos en materia de Gramática. Esta concepción determina la distinta asignación de tareas que encontramos, de un lado, entre la GRAE1854 y la GRAE-1858 y, de otro, entre GRAE, CRAE y ERAE a partir de 185715.

\footnotetext{
15 Expongo a continuación, de forma parcial, conclusiones a las que llegué en mi primer estudio comparativo entre GRAE, CRAE y ERAE. El trabajo lo presenté en las III Jornadas de Reflexión Filológica del Departamento de Lengua Española de la Universidad de Salamanca (febrero de 2002), cuyas actas aún no han sido publicadas (el artículo aparece citado como Garrido Vílchez, 2002b). Estas conclusiones pueden completarse con las de la segunda parte de mi estudio, expuesta en el II Congreso Nacional de la AJIHLE en abril de 2002 (Garrido Vílchez, 2003a).
} 


\section{MISIÓN DEL GRAMÁTICO Y OBJETIVOS DEL LIBRO EN 1854-1858}

La insistencia en que el fin último es facilitar el aprendizaje, la constante búsqueda de claridad, la pretendida sencillez... todo parece indicar que, en 1854, la Institución entiende que la labor del gramático es, ante todo, una labor pedagógica, aunque, eso sí, el didactismo debe ofrecerse en su justa medida. Y es que, en la quinta edición, se concibe la Gramática como libro que debe contener la información justa pero toda la información necesaria y, además, la disposición idónea para que sea "libro apto" para todos los públicos. Así se entienden las siguientes palabras del Prólogo:

El epítome de una lengua como la nuestra sería un enigma para los jóvenes, y querérsela enseñar en un libro muy extenso sería fatigar demasiado su memoria [...] Huyendo de ambos extremos, la Academia ha ordenado su nueva Gramática en tales términos, que ni peque de excesivamente corta, ni de prolija; que sirva á los niños y á $\underline{\text { los adultos. }}$

(GRAE-1854: VIII-IX. El subrayado es mío)

Esta preocupación por llegar a un público lo más amplio posible (eco del concepto de gramática sostenido por Quintiliano ${ }^{16}$ ) desaparece en la GRAE1858. En la sexta edición del texto de la Gramática, se nos informa de tres $\operatorname{cosas}^{17}$ :

a) Entre la edición anterior y esta nueva se han publicado un compendio y un epítome (y ello pese a lo afirmado en la cita de arriba).

b) La publicación de estos libros menores tiene consecuencias directas, tanto en la forma (tipografía) como en el fondo de la Gramática.

16 Vid. Quntiliano (h. 95: 35-45).

${ }^{17}$ Cf. GRAE-1858: VII 
c) Las modificaciones experimentadas vienen obligadas, en buena medida, por el nuevo público-meta.

Si en 1854 el criterio imperante era el pedagógico ${ }^{18}$, en 1858 este aspecto ya no se considera imprescindible, aunque tampoco se perderá de vista el didactismo. Desde la sexta edición de la GRAE, por tanto, se libera -en parteal gramático de la tarea pedagógica y parece que el libro titulado Gramática empieza a entenderse como libro destinado a un estudio más especializado. Efectivamente, la publicación del CRAE y el ERAE conlleva, de un lado, la puesta de relieve del importante papel desempeñado por los maestros en la tarea de enseñanza gramatical en sus dos primeras fases de estudio ${ }^{19} \mathrm{y}$, de otro, la gradación (al menos, supuesta) de dicha enseñanza en tres niveles progresivos de dificultad, que culminan en la GRAE.

La obsesión por lograr hacer de la Gramática el "libro panacea" del estudio-enseñanza gramatical (válido para cualquier público, desde los alumnos del curso elemental hasta los maestros y especialistas) se deja traslucir en el Prólogo de la GRAE-1854 y condiciona las características físicas del libro: en esta edición, por ejemplo, se concede a la tipografía un papel fundamental en la clasificación de las informaciones (se marca visualmente el grado de importancia de las nociones expuestas mediante la combinación de distintos tamaños -«grados»- de letras). Todo el juego formal de presentación de los contenidos, que descansa en los distintos «grados» de letra, hace de la GRAE1854 un libro apto -en teoría- para el autoaprendizaje, puesto que, según propias declaraciones, la Comisión de Gramática se ha preocupado de disponer todo el material de una forma idónea para que quien quiera se quede en la superficie y quien lo necesite o lo desee profundice en el conocimiento de los

18 En palabras de Gómez Asencio (2002a: 205), «la pedagogía es arma de primer orden en la trabazón de este texto».

${ }^{19}$ Cf. CRAE-1857: Advertencia y ERAE-1857: VI-VII. 
mecanismos de la lengua. En la GRAE-1858, sin embargo, ya no es necesaio establecer una jerarquía de contenidos, por lo que está fuera de lugar recurrir a la marcación tipográfica: para los nuevos destinatarios de la Gramática (alumnos de grado superior, especialistas, maestros, etc.) adquiere carácter de esencial toda la información recogida en el cuerpo del libro, y la que no lo es tanto se recoge en notas al pie.

\section{EL PROCESO ENSEÑANZA-APRENDIZAJE EN ERAE, CRAE Y GRAE}

La importancia que en el Compendio y el Epítome se le concede explícitamente a la figura del maestro en los primeros niveles del proceso de enseñanza-aprendizaje gramatical explica algunas afirmaciones -cuando menos curiosas- que encontramos en el ERAE; pongo por caso la de que, frente a la sencillez de la exposición de las reglas, en los ejemplos hay una dificulatd pretendida, usando vocablos y frases que -se sabe- son desconocidos para los niños, con el objetivo de «excitar su curiosidad y provocar las aclaraciones de los maestros» (ERAE-1857: VII). Esto hace de los "libros menores" (de forma especial, del Epítome) herramientas de trabajo para la clase de gramática, no textos concebidos para el estudio individual.

Si se equipara el proceso de enseñanza-aprendizaje con el acto de comunicación, los siguientes esquemas podrían ser representativos de cada uno de los tres niveles delimitados: 


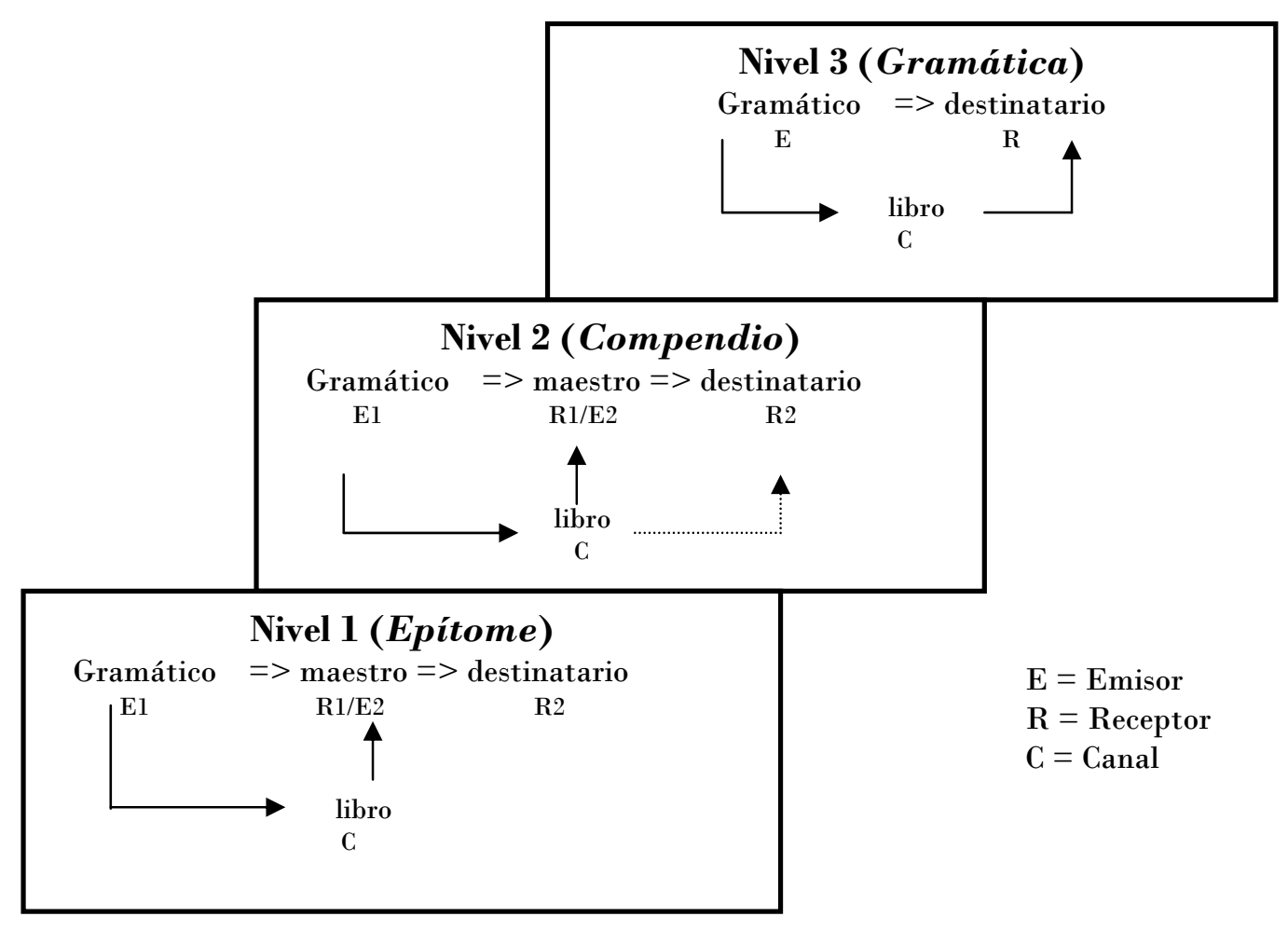

Esquema 2: Proceso de enseñanza-aprendizaje por niveles

Desde 1857, la Academia considera que la obligación del gramático ya no es tanto la claridad cuanto el rigor en la descripción de usos y reglas; el hacer accesibles los conocimientos a lo alumnos es tarea del profesor ${ }^{20}$. En este sentido, en los estudios de primer grado, el peso de la labor de enseñanza recae de forma decisiva en el maestro; la Institución declina, así, responsabilidades pedagógicas, y es que, en una primera fase de estudio, «conviene dejar poco al libro» (ERAE-1857: VI). En el segundo grado, el alumno puede aprender con el libro de Gramática, pero la figura del maestro sigue siendo clave en el proceso de enseñanza-aprendizaje para «resolver dudas que el texto pueda ofrecer» (CRAE-1857: Advertencia) ${ }^{21}$. Por fin, en el tercer nivel, es el gramático el que, a

${ }^{20}$ Cf. CRAE-1857: Advertencia y ERAE-1857: VI.

21 Y estas dudas -intuyo- podrían haber sido muchas, puesto que poco esfuerzo de adaptación se aprecia en el Compendio: la eliminación sistemática de ciertos párrafos, la supresión puntual de algunos otros y la reducción de las listas de ejemplos parecen ser la base predagógica de la labor académica. No resulta difícil pensar que la Academia establece límites puramente cuantitativos: la diferencia de niveles está más en el cuánto se enseña que en el 
través del libro, enseña a los destinatarios (personas versadas en materia gramatical: maestros, alumnos de grado superior...).

La frecuencia con que en el CRAE y -sobre todo- el ERAE aparecen sugerencias a los maestros, bajo fórmulas del tipo «aproveche el maestro la coyuntura para...»; «repítase aquí a los niños que...»; «hágase notar que...», permite sospechar que, quizá, para la Institución, los verdaderos receptores de estos libros son precisamente ellos, los profesores (a pesar de que las manifestaciones explícitas aludan a los alumnos de primera y segunda enseñanza). Cumpliendo con lo previsible, este tipo de "guiños" al maestro son mucho más directos y numerosos en el libro de primer grado 22 .

Tanto la frecuencia de este tipo de "advertencias al lector" como su lugar de aparición (indistintamente, notas al pie o cuerpo del texto) parecen ser indicio claro de que ni el Compendio, ni mucho menos el Epítome, han sido pensados como libros para el autoaprendizaje; más bien resultan unos "librosguía" del profesor que, además, pueden ser utilizados también por los niños para seguir las explicaciones de la clase.

cómo se transmite esa enseñanza (al menos, por lo que respecta a la labor del gramático y a los objetivos del libro).

22 Sirvan como ejemplo las siguientes referencias: CRAE-1857: 6 (nota 1) y 84-85; ERAE-1857: 14 (nota 1), 21 (nota 1), 27 (nota 1), 50 (nota 2), 52, 54 (nota 2), 59, 61 (notas 1 y 2). 


\subsection{Los años setenta}

\section{GRAE-1870}

La DEFINICIÓN Y DIVISIÓN DE LA DISCIPLINA, que en las ediciones anteriores ocupaba unas breves líneas previas a la parte dedicada a la Analogía, toman cuerpo en esta edición y se convierten en un capítulo previo a la parte primera del libro de Gramática, que seguirá estando dedicada al estudio analógico. En las cinco páginas que ocupa este nuevo apartado de Nociones Preliminares, se definen y explican los conceptos básicos de la disciplina gramatical, desde lo que es idioma y gramática, hasta la explicación de las partes esenciales de la misma y de las unidades objeto de estudio de cada una de ellas ${ }^{23}$.

Sigue el ESTUDIO DE LA ANALOGÍA, que, en esta edición, sí se inicia con una definición de la misma (vid. Glosario final), pese a que, en las líneas inmediatamente anteriores, se ha dicho que consiste en "la explicación de la índole de las partes de la oración".

- Tras esta definición, seguimos teniendo la explicación de las nociones básicas en el estudio analógico: palabras variables e invariables, género, número, etc.

- Después, se tratarán separadamente las diferentes categorías gramaticales, sin olvidar definirlas una a una.

La segunda parte, dedicada a la SINTAXIS, comienza con una visión conjunta y en contraste de lo que aportan el estudio analógico y el sintáctico al conocimiento gramatical de la lengua, y se define la

\footnotetext{
${ }^{23}$ Entiendo que este mayor detenimiento en la exposición de nociones básicas para el estudio gramatical no sólo responde al objetivo didáctico, o mejor, no está presidido por tal objetivo; también es un esfuerzo de precisión científica. Quizá en esta introducción general tengamos una de las materializaciones de dos de los propósitos marcados por la Academia en el Prólogo de esta edición: perfeccionar su obra ( $\mathrm{y}$, al mismo tiempo, salir al paso de las críticas recibidas) e intentar sintonizarla con los avances de la lingüística.
} 
Sintaxis repitiendo la idea expuesta en el apartado de Nociones Preliminares.

- La división de la Sintaxis en regular y figurada, y la explicación de la diferencia entre ambas preceden a los apartados dedicados a las reglas de la Sintaxis regular (Concordancia, Régimen y Construcción) que, como en las ediciones anteriores, irán encabezados por una definición o explicación de las mismas.

- El capítulo dedicado a la oración (también definida al principio de la obra) y sus tipos sirve de puente entre la Sintaxis regular y la Sintaxis figurada.

- La Sintaxis figurada presentará la misma disposición que en las ediciones anteriores, esto es, definición de este tipo "anómalo" de construcciones y explicación detallada de cada una de las figuras.

El tercer bloque lo constituye el estudio de la PROSODIA. Lo encabeza una definición de esta subdisciplina (vid. Glosario final) y siguen tres apartados (dedicados al alfabeto, los acentos y la cantidad), en los que se insiste en ideas ya adelantadas en las primeras páginas de la Gramática y se estudian con detenimiento las letras y las sílabas.

El apartado ortográfico lo abre una definición etimológica de ORTOGRAFÍA y una exposición de sus fundamentos y objetivos. Con el repaso del uso de las letras mayúsculas, el empleo de algunas letras dudosas y las reglas de acentuación y puntuación, concluye esta cuarta -y última- parte de la Gramática (disciplina y libro) ${ }^{24}$.

\footnotetext{
${ }^{24}$ Vale lo dicho para las GRAE de 1874 -de rango E- y 1878 -de rango R-. En ambas ediciones, se ha doblado el número de páginas del apartado de Nociones Preliminares, que pasan de cinco a once. Los añadidos se cifran, sobre todo, en notas al pie en que se aclaran ciertos conceptos o se exponen casos excepcionales; también han aumentado los ejemplos -se especifican ahora los tipos de combinaciones vocálicas-; y, por último, se atiende, en estas páginas introductorias, a los accidentes de género y número. Este último añadido no constituye en rigor
} 


\subsection{Los ochenta y siguientes}

\section{GRAE-1880}

Nuevamente encontramos un trasvase de contenidos:

Introducción, de una sola página, en la que SE DEFINEN LOS CONCEPTOS de idioma y gramática y se exponen los fines de ésta, estableciendo las partes en que se divide y la competencia de cada una de estas partes.

ESTUDIO DE LA ANALOGÍA, iniciado con la definición de rigor y continuado con la exposición de los conceptos básicos que se manejarán en este apartado, al modo de la GRAE-1870. El resto de esta primera parte no varía su esquema expositivo: un apartado para cada categoría encabezado por la definición o explicación de la misma.

La estructura de las partes restantes tampoco varía con respecto a la edición de $1870^{25}$.

un cambio doctrinal de base con respecto a la GRAE-1870, ya que no se trata de información nueva, añadida, sino de información reubicada en el libro: se ha adelantado el lugar de exposición de estos accidentes, que ya no se explicarán al comienzo del estudio analógico. De modo que ahora la primera parte de la Gramática pasará directamente al estudio de las distintas partes de la oración tras definir, eso sí, la Analogía.

${ }^{25}$ Nada nuevo aportan las ediciones comprendidas entre la GRAE-1880 y la GRAE-1917 (las de 1883, 1885, 1888, 1890, 1895, 1900, 1901, 1904, 1906, 1908, 1909, 1911, 1913 y 1916 -no olvidemos que las de 1904 y 1911 son GRAE de rango E- ). 


\subsection{El útimo jalón}

\section{GRAE-1917}

\section{INTRODUCCIÓN (ídem 1880).}

> Parte primera: estudio de la ANALOGÍA (ídem 1880).

> Parte segunda: estudio de la SINTAXIS. Esta parte comienza con una visión contrastada de la Analogía y la Sintaxis, similar a la comentada a propósito de la GRAE-1870. Después, se señala el objeto de estudio de la Sintaxis: la oración, y, en virtud de él, se establece una estructuración básica de esta segunda parte del libro en Sintaxis de la oración simple y Sintaxis de la oración compuesta.

- Estudio de la oración gramatical (simple). En primer lugar, se da una definición de la unidad que articula todo el estudio sintáctico $\mathrm{y}$, después, se procede a analizar con detenimiento cada una de sus partes integrantes, análisis donde la función desempeñada por cada categoría adquiere una importancia especial. En el estudio de las relaciones que entablan las palabras en el marco de la oración, se atenderá también a la concordancia y el caso. Es obvia la voluntad de hacer una presentación clara de la materia, de que los conceptos queden bien explicados, pero la distribución de la información ya no resulta tan sistemática como en las ediciones anteriores.

- Estudio de la oración compuesta: se inicia con un pequeño apartado introductorio en el que se explica en qué consisten, básicamente, las relaciones de coordinación y subordinación, que se estudiarán por separado. En el análisis detenido de estos dos tipos de estructuras complejas, volveremos a encontrar una primera explicación sucinta 
de los rasgos característicos de la coordinación y de la subordinación, seguida del estudio de los distintos tipos.

En la Sintaxis de esta Gramática, podemos apreciar un cambio esencial en la exposición de los contenidos: mientras que en la Analogía se mantiene básicamente el sistema de las GRAE anteriores (esto es, comenzar cada capítulo por la definición de la categoría), en esta segunda parte de la Gramática se suele empezar la explicación de cada concepto a partir de un ejemplo. También han variado radicalmente los contenidos de la Sintaxis (de ello se hablará en el capítulo 6).

- Apartado final dedicado a la Sintaxis figurada, que vuelve a recordarnos el sistema seguido en las GRAE anteriores: definición introductoria y estudio de cada una de las figuras, precedido de una definición o explicación de la misma.

Parte tercera: estudio de la PROSODIA. La definición de prosodia va seguida de unas líneas en las que se habla de la importancia de su estudio dentro de la Gramática de una lengua. El resto del capítulo se divide en seis apartados -físicamente independientes- en los que se estudia el alfabeto, las sílabas, los diptongos y triptongos, las palabras, los acentos, y, finalmente, el ritmo y la expresión. Como era de esperar, cada uno de estos apartados comienza con la definición del objeto de estudio o la remisión al lugar donde se dio la definición (es lo que sucede, por ejemplo, al tratar de la sílaba).

Parte cuarta: estudio de la ORTOGRAFÍA. En esencia, la exposición (contenidos y planteamiento) no difiere de la de 1870. Sólo se ha 
sustituido la definición etimológica ${ }^{26}$ por una aclaración de la finalidad de esta última parte de la Gramática (disciplina) y del libro.

Podemos concluir que, efectivamente, el esquema expositivo de las GRAE del corpus responde al espíritu didáctico (de facilitación del estudio) del llamado método geométrico. Este método, sin embargo, va perdiendo progresivamente protagonismo desde 1771 a 191727, no tanto porque desaparezca la finalidad didáctica (que es inherente a toda la actividad gramaticográfica y que, de hecho, se mantiene en todos los textos del corpus), cuanto porque ese objetivo pedagógico irá cediendo parte de su terreno y acabará compartiendo protagonismo con metas de carácter cada vez más científico, a lo que se suma, desde 1857, la publicación, por parte de la RAE, de Compendios y Epítomes, dirigidos a un público diferente del de las Gramáticas y presididos de una forma más evidente -al menos en teoría- por el criterio pedagógico. De manera que, también en teoría, la actitud de la Academia ante la enseñanza gramatical (en lo que al método se refiere) se va a ver modificada en el salto cualitativo que va desde la Gramática como texto único para la enseñanza de la disciplina hasta la Gramática como texto correspondiente a la enseñanza del último nivel.

\footnotetext{
${ }^{26}$ Que ya se había perdido en la GRAE-1880.

${ }^{27}$ La GRAE-1920 (de rango E) presenta la misma disposición que la GRAE-1917 excepto en la parte de la Analogía. La reforma del estudio morfológico es similar, en el asunto que ahora nos interesa, al cambio en el apartado sintáctico de 1917: hay voluntad de claridad, pero la disposición no es tan sistemática como lo ha sido hasta la fecha, ni la exposición tan "geométrica" (por ejemplo, se habla de los sufijos sin dar una definición o explicación previa).
} 


\section{LA GRAMÁTICA ES NORMATIVA}

Si volvemos a los datos expuestos en 4.1., comprobamos que, en el artículo lexicográfico extraído de Autoridades, se da, en primer lugar, una definición de gramática según la tradicional fórmula de Diomedes (recte loquendi scribendique) y se asigna a la labor gramatical la finalidad didáctico-prescriptiva que esta definición clásica comporta. La misma concepción será recogida en los Diccionarios posteriores. La Gramática es, además, definida como arte, lo cual concuerda con el normativismo del que hablamos (sin olvidar que todo arte implica una enseñanza previa de conceptos básicos $\mathrm{y}$, por tanto, un componente didáctico, de enseñanza, del que acabamos de tratar) ${ }^{28}$.

No cabe duda de que la concepción de la Gramática como arte, o dicho de otra forma, el artificio de la Gramática lleva aparejado en la tradición gramatical de Occidente una finalidad de índole normativa. No olvidemos que

${ }^{28}$ El debate sobre si la Gramática es arte o ciencia quiso dejarlo zanjado el padre José Casani en su disertación (s.a.) previa a la publicación de la primera edición de la Gramática. En $\S 3^{\circ}$ (fol. 8), recurriendo a la autoridad de Santo Tomás y San Isidoro, expone sus argumentos en defensa de entender la disciplina gramatical como arte, a saber:

a. La Gramática es ciencia solo si tomamos el término en un sentido lato (equivalente a 'noticia, conocimiento o ilustración del entendimiento'). Este sentido, según afirma el propio Casani, no lo recoge el Diccionario, «falta que se debe enmendar, pues en una delas authoridades, con que comprueba la voz, y es la de Cerbantes en su novela de Persiles y Sygismunda, esta clarissimo este sentido, quando al arte de navegar le llama ciencia de los marineros».

Este sentido amplio es, efectivamente, el que encontramos en San Isidoro cuando define la Gramática como «scientia recte loquendi [scribendique ratio]» (Etymologiarum I,5. San Isidoro, h.620: 284. Véase también la pág. 276)

b. En el sentido riguroso de ciencia, el que sí ofrece el Diccionario («conocimiento cierto de alguna cosa por sus causas, y principios»), la Gramática no puede ser entendida como tal, por no poder tener de ella noticia cierta adquirida por demostración (es como Santo Tomás explica el concepto de ciencia).

Conviene recordar que la concepción tomista de lo que es ciencia le supone las características de certeza, universalidad y necesidad: «es un conocimiento cierto por las causas mediante la demostración. Trata de los universales, no de los singulares. Asimismo se ocupa de lo necesario, no de lo contingente» (Santo Tomás, h.1265-1273: 826); ni la gramática (que es discutible, opinable) ni mucho menos la gramática de la Academia (que es una Gramática de la lengua castellana, una gramática particular) responden a este concepto.

c. Define mejor la Gramática el término disciplina por ser sus preceptos y objeto de estudio contingentes (concepción que se encuentra en San Isidoro -remito a las páginas arriba indicadas-).

d. La Gramática es arte, pues todos sus preceptos y reglas nacen de la observación.

e. No hay ningún autor clásico que, hablando en términos precisos, no califique la gramática de arte. 
la concepción se remonta al periodo humanista, cuando la codificación de las lenguas vernáculas tenía como propósitos, de un lado, imprimir a los vulgares una dignidad que acortara distancias con la excelencia de las lenguas cultas (a las que, hasta la fecha, se había reservado la etiqueta de "arte"29) y, de otro, fijarlas para salvaguardarlas de la corrupción y, en última instancia, de la desaparición. Instalado en esta convicción estaba Cristóbal de Villalón cuando escribió las siguientes palabras que presidieron su obra:

Señor, enlos ratos perdidos y hurtados a mi continuo eftudio dela fagrada efcriptura que tēgo en efta aldea, vine a foñar efte borron: enel qual prefumo reduçir a arte la lengua Caftellana, en imitaçion dela Latina y Griega.

(Villalón, 1558: Carta para el Licenciado Sanctander, pág. 3)

Penfando muchas vezes enel valor, elegançia y perfeçion de la lengua castellana [...] Todos cuantos hazen cuēta de las lenguas y de fu auctoridad dizen, que la perfeçion y valor dela lengua fe deue tomar y deduçir de poder fer reduçida a arte.

(Villalón, 1558: Prohemio al lector, pág. 5)

En lo que concierne a la tradición académica, la definición de arte que encontramos en Autoridades es bastante reveladora en el sentido apuntado de "normativismo": «la facultád que prescribe reglas y preceptos para hacer rectamente las cosas»(Diccionario de Autoridades, 1726: 422,2, s.v. arte). En el DRAE-1780, se mantiene la misma idea con una formulación muy parecida: arte es «el conjunto de preceptos y reglas para hacer bien alguna cosa» (pag. $102,3)^{30}$. Esta definición se calca en las ediciones siguientes del Diccionario hasta la de 1884, en la que será sustituida por la de «virtud, fuerza, disposición é

\footnotetext{
29Sobre los orígenes del concepto de ars grammatica y su desarrollo en la Edad Media, interesa Lozano Guillén (1992).

${ }^{30}$ Esta definición es la que aparece ya en el Suplemento de Autoridades, de 1770 (pág. 344,2).
} 
industria ${ }^{31}$ para hacer alguna cosa», que no supone cambio sustancial y que se mantendrá en los DRAE de 1899, 1914 y 1925 (remito al Glosario final, s.v. arte).

El carácter normativo de la disciplina gramatical es defendido por los académicos ya en los proyectos preparatorios del libro de Gramática, como se comprueba al leer los manuscritos de Antonio Angulo (1741) y José Casani (s.a.) ${ }^{32}$. En sendos trabajos, la alusión al normativismo como deber implícito de toda Gramática (y, de forma especial, de la Gramática de una corporación como la RAE) la encontramos en las líneas en que se habla del uso, hecho este que revela una vez más la huella de Quintiliano en el pensamiento académico ${ }^{33}$. Así, Angulo, siguiendo a Horacio, ensalza el uso como verdadero dueño y árbitro de las lenguas, pero aclara que

este uso [...] es una delas cosas dela maior importancía, y estudio de qualquíera Gram.ca para poder establecer que vozes, phrases, y locucíones se deben seguír y quales excusar. En confirmacion de esto Seneca en la Epistola 25. dice, que los Grammaticos son guardas, y no autores del lenguaje latino [...]

(ARAE, 1741a: pliego 12. ${ }^{\circ}$ El subrayado es mío)

\footnotetext{
31 Industria es «maña y destreza ó artificio para hacer una cosa» (DRAE-1884: 594,2).

32 De Antonio Angulo ya se ha dado noticia en el capítulo 2 (nota 42). José Casani (redactor de la disertación sobre si la Gramática es arte o ciencia -resumida en la nota 28 de este capítulo-) es uno de los ocho académicos fundadores, según se informa en la Fundación y Estatutos de la Real Academia Española de 1715. Del padre Casani se dice que fue «de la Compañía de Jesús, Calificadór del Suprémo Conséjo de Inquisición, su Visitadór de Librerías, y Maestro de Mathemáticas en el Colégio Imperiál» (RAE, 1715: 4). En el Ms. 3148, leemos que ocupó el sillón G y que el día de su muerte fue el 12 de noviembre de 1750 (Véase también http://www.rae.es/rae/gestores/gespub000001.nsf/(voAnexos)/arch6D3211F8664070B7C12 5720900476B93/\$FILE/sillones.htm). Zamora Vicente (1999:72-73) menciona la activa participación de Casani en la elaboración del Diccionario (de la que da fe Freixas Alás, 2003: 57, 93-96, 160, 164, 195, 197, 318, 319, 335, 347, 359, 385, 413, 442), así como su autoría de la «Historia de la Academia» contenida en el prólogo de Autoridades, pero no hace ninguna alusión a su colaboración para el texto de la Gramática. Dice Zamora Vicente, eso sí, que «su nombre surge con extrarodinaria frecuencia en el largo periodo de su vida que dedicó a la Corporación». No olvidemos que desde 1713 -fundación de la Academia- hasta 1750 -año en que muere Casani- transcurren treinta y siete años. Sobre este académico jesuita puede encontrarse más información en Backer (1869-1876: I, cols. 1107-1109) y Sommervogel (18901900: II, cols. 812-815).

${ }^{33}$ Sobre la relación norma-uso volveré en 2.2.
} 
Por su parte, Casani afirma que los preceptos del arte se deben arreglar según el uso (de los varones doctos) 34

para evitar aquel los barbarismos, y malas expresiones, con que el vulgo inferior corrompe la hermosura del lenguaje [...] y como sea imposible huir, o escusar enteramente el trato y comercio delos indoctos, y zafios [...] se invento, y se ordeno este arte que con reglas y preceptos dirigiesse, y enseñasse el uso delas vozes, delas oraciones, y de la explicacion pura, clara, nativa, y sin defecto alguno, que la afeasse, ó la confundiesse».

(ARAE, s. a.: fols. 1 y 2. El subrayado es mío)

Este normativismo, anunciado desde los trabajos previos a la GRAE1771, cobrará especial intensidad en discursos posteriores, como puede apreciarse en el leído, en 1875, por Galindo y de Vera en su toma de posesión de plaza de Académico de número ${ }^{35}$. El discurso del nuevo académico versó sobre «la autoridad de la Academia Española en materia de lenguaje» y en él, en la línea de las declaraciones de Angulo y de Casani, pero con una insistencia y énfasis bastante mayores, se pone de relieve el papel regulador y legislador que la Academia está obligada a desempeñar. Merece la pena transcribir algunos fragmentos de este discurso, publicado en 1875 y 1886 (para las citas, me valgo de esta última edición):

\footnotetext{
${ }^{34}$ Sobre el modelo de uso (que Casani sí especifica), se hablará en 2.2.

${ }^{35}$ El barcelonés León Galindo y de Vera ocupó entre 1875 y 1889 el sillón N, en sustitución de Salustiano de Olózaga. A su discurso de ingreso en la real Corporación, leído el 24 de febrero de 1875, contestó Fermín de la Puente Apezechea. Cf. Galindo y de Vera (1875) y http://www.rae.es/rae/gestores/gespub000001.nsf/(voAnexos)/arch6D3211F8664070B7C12 5720900476B93/\$FILE/sillones.htm. Zamora Vicente (1999: 180) llama la atención sobre un hecho curioso: algunos de los neologismos criticados en su discurso todavía hoy son rechazados a veces, pese a haberse generalizado su uso. Galindo y de Vera murió el 12 de abril de 1889.
} 
Autoridad y reglas han de existir en materia de lenguaje. Y tanto más cuanto el lenguaje, instrumento maravilloso que manejan todos, es lo más expuesto por ello á perturbaciones y errores [...] $\underline{\text { si no }}$

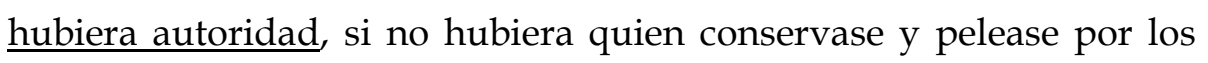
fueros del buen decir, el idioma entregado al capricho universal se

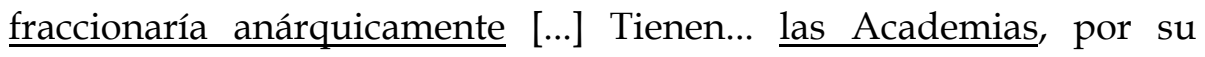
misma naturaleza, mayor aptitud para perfeccionar el lenguaje, enmendando incesantemente los errores.

(Galindo y de Vera, 1886: 353-359. El subrayado es mío).

Y este movimiento de transformación [de la lengua], irreflexivo y ciego [...] ha de encontrar un dique robustísimo en la Academia.

(Galindo y de Vera, 1886: 374. El subrayado es mío)

Al transcurrir algunos siglos, el lenguaje se encuentra modificado: en perjuicio suyo, si la transformación se debe á la casualidad ó á la ignorancia; con ventaja si la ciencia la dirige; si una

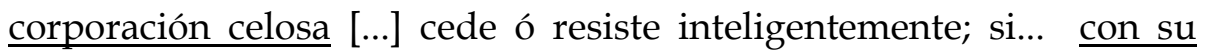
recto juicio y su inflexible criterio limpia, fija y da esplendor á la lengua castellana.

(Galindo y de Vera, 1886: 379-380. El subrayado es mío)

En las GRAE del siglo XIX (al igual que en las del XVIII), resulta difícil encontrar afirmaciones en estos términos; en las Gramáticas, es evidente la voluntad normativa, reguladora, pero no hay manifestaciones que revelen, por parte de la Institución, una consciente actitud de "guardiana inflexible" de la lengua (excepción hecha de tres ediciones, de las que hablaré más abajo). De modo que podemos decir que los textos firmados por la Corporación liman la dureza de las propuestas individuales. Al igual que sucede con los discursos, también en las GRAE, el paso de los años hará más firmes (con respecto a las ediciones anteriores) las manifestaciones en la línea normativista, pero el consenso de los académicos no supone una toma de postura tan rígida como la 
adoptada individualmente por algunos de ellos, por ejemplo, Galindo y de Vera $^{36}$.

En realidad, en las Gramáticas del corpus (de forma especial, hasta las últimas GRAE decimonónicas), el normativismo debe entenderse como consustancial a cualquier obra didáctica ${ }^{37}$, no como actitud propia de autoridad máxima e intransigente frente al uso de la lengua, que, como se sabe, se ha convertido en tópico caracterizador de la labor (no sólo gramatical, pero también gramatical) de la $\mathrm{RAE}^{38}$.

36 Con respecto a esta distinta actitud mantenida por la Corporación, de un lado, y los miembros de la misma por otro (más firme e intransigente la de estos; más moderada y comedida la de aquella) traigo a colación -y vuelvo con ello a lo dicho en el capítulo 2 sobre las declaraciones de propiedad literaria/intelectual- el siguiente ejemplo que viene a confirmar que los individuos son más rígidos en sus afirmaciones que el conjunto de los académicos. Ya se dieron datos sobre la creciente actitud intimidatoria de la Academia en sus declaraciones (vid. supra [3] de 2.3.12. y [1] de 2.3.14.), véase ahora cómo esa actitud se tiñe de total intransigencia en las advertencias plasmadas en el Vocabulario gramatical de Pedro Felipe Monlau (1870), en las cuales se sorprende al lector con artículos tomados no solo de la reforma legislativa de 1847, sino incluso del Código Penal de 1850:

ART. 10. Nadie podrá reproducir una obra ajena con pretexo [sic] de anotarla, comentarla, adicionarla, ó mejorar la edicion sin permiso del autor.

ART. 11. El permiso del autor es igualmente necesario para hacer un extracto ó compendio de su obra.

ART. 19. Todo el que reproduzca una obra ajena, sin el consentimiento del autor, queda sujeto: $1 .^{\circ}$ á perder todos los ejemplares fraudulentos, los cuales se entregarán al autor de la obra ó á sus derecho-habientes; $2 .^{\circ}$ al resarcimiento de daños y perjuicios, no pudiendo la indemnizacion bajar del valor de dos mil ejemplares; y 3. ${ }^{\circ}$ á las costas del proceso.

(Extracto de la LEY de 10 de junio de 1847.)

ART. 457. Incurrirán asimismo en las penas señaladas en el art. 455 (multa igual al triplo del importe del perjuicio irrogado) los que cometieren alguna defraudacion de la propiedad literaria ó industrial.

Los ejemplares, máquinas ú objetos contrahechos, introducidos ó expendidos fraudulentamente, se aplicarán al perjudicado, y tambien las láminas ó utensilios empleados para la ejecucion del fraude, cuando sólo pudieren usarse para cometerle. Si no pudiere tener efecto esta disposicion, se impondrá al culpable la multa del duplo del valor de la defraudacion, que se aplicará al perjudicado.

(CóDIGo PENAL, edicion reformada de 1850)

${ }^{37}$ Sobre el componente didáctico-normativo en la GRAE he tratado de forma conjunta en Garrido Vílchez (2003b).

${ }^{38}$ En este sentido, interesa dejar constancia de las no pocas ocasiones en que la Institución sólo describe el uso o bien se limita a aconsejar, sin imponer, como cuando apunta que una determinada estructura, expresión, etc. "es muy común usarla", "se suele aplicar", "es preferible"... A ello hay que sumar el reconocimiento explícito, en más de una página, de que la arbitrariedad del uso, juez irrecusable en materia lingüística, autoriza el empleo de distintas 
Los fragmentos transcritos de Angulo y de Casani podrían llevar a pensar que el simple hecho de defenderse, en las GRAE, que el uso es juez irrecusable en materia lingüística forma parte del normativismo académico; no obstante, es apunte obligado el hecho de que, en los textos propiamente gramaticales, no se aclara (hasta muy adentrados en el cuerpo de la obra) qué uso constituye el modelo de corrección ${ }^{39}$. Esta falta de precisión, unida a la ausencia de declaraciones explícitas en la línea reguladora, resta -en mi opinión- poder normativo (en el sentido de prescripción conscientemente "prohibitiva") a las GRAE decimonónicas.

Bien es cierto, sin embargo, que en las últimas décadas del siglo XIX, el talante regulador y normativo empieza a ser más explícito en algunas de las GRAE, concretamente en las de los años setenta (1870, 1874 y 1878), ediciones que, en este aspecto concreto que ahora comentamos, destacan entre las que ven la luz en la segunda mitad del siglo XIX y primeros años del XX. Efectivamente, en los Prólogos o Advertencias de las ediciones del corpus previas y posteriores a estas, la Academia insiste muy poco en su propósito normativo:

expresiones o estructuras y que, por tanto, no pueden darse reglas seguras y fijas en ciertas cuestiones de Gramática (por ejemplo, a propósito de los diminutivos, el género de los nombres griegos, el uso de los pronombres átonos, etc., etc.). Creo que, teniendo en cuenta lo dicho, podría hacerse extensiva a las Gramáticas aquella afirmación de Gili Gaya (1963: 20) a propósito del Diccionario académico: «La Academia ha oscilado siempre entre si su diccionario (y su Gramática, me atrevo a añadir) debe ser normativo, como guía del buen uso, o debe ser un inventario general del idioma». Esto explicaría la convivencia, en el cuerpo de las Gramáticas, de numerosas expresiones en la línea de las transcritas arriba con otras -no poco frecuentes- en términos similares a "no se puede decir", "es forzoso usar", "es locución viciosa", etc.

39 Vid. infra 2.2. 


\section{GRAE-1854-58}

En estas ediciones, se declara que el objetivo principal de la RAE es enseñar a la juventud con reglas claras y sencillas [remito a las matizaciones hechas en 1.]. Al final de ambos Prólogos, encontramos una referencia al deseo, por parte de la Academia, de mantener la grandeza del idioma, su esplendor, para lo cual se ofrecen estas nuevas ediciones de la Gramática y se recomienda el estudio y observación de los escritores ${ }^{40}$.

\section{GRAE-1862-64-65-66-67}

En los libros de los años sesenta, no hay ningún tipo de introducción en la que la Academia exponga los propósitos que persigue con la obra que saca a la luz pública (según se ha indicado en los puntos 2.3.7 a 2.3.11.). En la primera página, se define la Gramática y se inicia inmediatamente el estudio de la Analogía.

\section{GRAE-1870-74-78}

En 1870, encontramos la primera manifestación explícita, en la Gramática académica, de la vigilancia que debe ejercer la Institución sobre la lengua: «la Academia es una Corporacion oficial, á quien está encomendada la vigilante custodia de la lengua patria, y fuera en ella

\footnotetext{
40 Podemos hacer extensiva a estas Gramáticas la conclusión a la que llega Gómez Asencio a propósito de las GRAE de 1771 y 1796: «[en el Prólogo de la GRAE-1771] hay mucho de cuidado de la lengua, pero poco de coerción, poco de prescripción» (2000a: 45); «la preocupación o la presión normativas están literalmente ausentes del prólogo de la GRAE-1796: no es la norma ni el "cuidado de la lengua" lo que parece inquietar -en las partes introductorias se entiende- a los académicos que aprobaron esta edición» (2000b: 80-81). Y es que, como bien dice el mismo autor (2002a: 205), «el mayor hincapié del prólogo [de 1854] se hace, sin duda, en el aspecto pedagógico».
} 
imperdonable indiscrecion lo que en un autor irresponsable puede pasar por osadía plausible» (GRAE-1870: XIII. El subrayado es mío). La cita se calca, con una insignificante modificación al final de ella, en las GRAE de 1874 y 1878: 6-741.

Esta nueva actitud de férrea vigilancia, de marcado normativismo, por parte de los académicos coincide con el tono progresivamente más "intimidatorio" del que se teñían los derechos de propiedad en estas tres ediciones (recuérdese el apunte [3] del punto 2.3.12. y el apunte [1] de 2.3.14. También lo dicho en la nota 7 de este capítulo).

\section{GRAE-1880-83-85-88}

En 1880, se pierde la referencia anotada en las GRAE de los años setenta, referencia que no volverá a aparecer en ninguna de las ediciones de esta década.

En mi trabajo de grado (2001: 38), apunté en nota al pie, a propósito de estas ediciones y de la actitud normativista de la Academia, una observación a la que ahora concedo más relevancia -explicaré por qué-: «a pesar de esta pérdida [de las declaraciones explícitas de los años setenta], a partir de la GRAE-1880 encontraremos un nuevo dato que parece apoyar la tesis de que el normativismo académico va cobrando consistencia, de forma paulatina, desde finales del siglo XIX: la Institución decide dar entrada a un capítulo de Vicios de dicción, que podemos encontrar en todas las Gramáticas del corpus desde la edición de $1880 \gg 42$. Lo que en su día consideré como "dato que sumar, que tener en cuenta a modo de información complementaria" hoy lo entiendo

41 Estas tres ediciones constituyen la excepción a la que me he referido más arriba.

42 Cf. La misma idea, no la cita textual, también en Garrido Vílchez (2003b: 633). 
como evidencia de la prolongación por parte de los académicos de una postura crecientemente autoritaria en materia de lenguaje (aunque se hayan suavizado las declaraciones explícitas relativas a esta actitud). Y surge esta convicción de la lectura detenida del exhaustivo análisis que Gómez Asencio (2006) ha hecho del asunto ${ }^{43}$. Sus conclusiones son determinantes en esta cuestión. Afirma (con razón) este autor, a propósito del nuevo capítulo de Vicios de dicción, que

rezuma un autoritarismo normativista y una seguridad en los dictados propios tan distantes de la postura descriptivista y positiva de un Salvá, como de la actitud tolerante y abierta que se percibe en los tratados gramaticales dieciochescos de la propia RAE [cabría añadir: "y decimonónicos hasta los años setenta"]. Los vientos que comenzaron a soplar en GRAE-1870 han adquirido mayor fuerza.

(Gómez Asencio, 2006: 25-26)

Sospecha Gómez Asencio (2006: 64) que este capítulo ni obedeció a plan meditado ni guarda sintonía con el Diccionario, lo que le lleva a pensar que los dos pilares de la obra académica (GRAE y DRAE) se usan como herramientas independientes e inconexas de limpieza y fijación idiomáticas. Que Gramática y Diccionario van por caminos distintos en más de una cuestión "de norma" es un hecho comprobable: se confirma, pongo por caso, a propósito de la adscripción de ciertos sustantivos a un género determinado. Ejemplo ilustrativo es el de huésped:

${ }^{43}$ Presentado como ponencia en el V Congreso Internacional de la Sociedad Española de Historiografía Lingüística (Murcia, 7-11 de noviembre de 2005). 


\begin{tabular}{|c|c|c|}
\hline & $\begin{array}{c}\text { DRAE } \\
(1899-1914-1925)\end{array}$ & $\begin{array}{c}\text { GRAE } \\
(1911-1917-1920-1924)\end{array}$ \\
\hline Género & "MASCULINO44 & COMÚN45 \\
\hline Uso normativo & $\begin{array}{l}\text { Con flexión para indicar } \\
\text { femenino: huéspeda }{ }^{46} \text {. }\end{array}$ & $\begin{array}{l}\text { Sin flexión, combinando con artículo } \\
\text { masculino o femenino según se refiera a } \\
\text { varón o a hembra, como homicida, mártir } \\
\text { o testigo } 0^{47} \text {. }\end{array}$ \\
\hline
\end{tabular}

Cuadro 37: Diccionario vs. Gramática

\section{GRAE-1890-95}

Seguimos sin encontrar referencias explícitas (a modo de declaración de intenciones) a la función reguladora de la Gramática académica. No obstante, la coerción se sigue ejerciendo desde ese capítulo de Vicios de dicción.

\section{GRAE-1900-1916}

Tampoco en estas ediciones se habla de la "misión normativa", pero el capítulo condenador de "usos defectuosos" sigue teniendo espacio reservado en estas ediciones.

\section{GRAE-1917-1924}

Quizá podría interpretarse como recuperación de la línea iniciada en 1870 (y perdida -en declaraciones explícitas- en 1880) el hecho de que, en la GRAE-1917, la Institución decide recuperar (primero) y trasladar

44 Cf. DRAE-1899: 539, 3; DRAE-1914: 557,1 y DRAE-1925: 668,2.

45 Cf. GRAE-1911: 17; GRAE-1917: 8 y GRAE-1920: 16. En la GRAE-1924: 16, se suprime la afirmación de que huésped es común, pero tampoco se afirma que sea masculino (¿debemos entender que se considera femenino, género al que responden, como regla general, los sustantivos acabados en $-d$ ?).

46 Cf. DRAE-1899: 539, 3; DRAE-1914: 557,1 y DRAE-1925: 668,2.

47 Cf. GRAE-1911: 10; GRAE-1917: 3; GRAE-1920: 11. 
(después) a las primeras líneas de la Advertencia preliminar la información sobre el carácter oficial de su Gramática ${ }^{48}$ :

La ley de 9 de septiembre de 1857, en su artículo 88 declara que la GRAMÁTICA de la Academia Española es texto obligatorio y único en las escuelas de enseñanza pública. Para cumplir las graves obligaciones que esta soberana disposición impone, ha hecho la Academia en varias épocas y en anteriores ediciones de su GRAMÁTICA algunas reformas, acerca de las cuales creyó que no debía llamar la atención del público porque las consideraba, y eran en realidad, reformas de detalle más bien que de conjunto.

(GRAE-1917: V)

Si se acepta que los cambios en la distribución de la información rara vez son gratuitos, como no suelen ser tampoco gratuitos los cambios en la información misma (ya se trate de eliminar, modificar o recuperar datos), habrá que preguntarse qué razón puede justificar que sea en 1917 cuando la RAE decide reservar un lugar privilegiado a la información sobre la oficialidad de que goza su Gramática desde hace sesenta años, lapso de tiempo en el que han visto la luz 23 nuevas ediciones (algunas de ellas, en rigor, reimpresiones) de la GRAE, de las cuales sólo seis hacen alusión a aquella ley de 1857 (la edición que ve la luz al año siguiente -GRAE-1858- y las publicadas en la década de los sesenta), junto con los "derechos de autor", en la página previa a la portada y con una tipografía mínima.

¿Por qué recuperar ahora esta nota informativa y por qué darle, además, una nueva ubicación? No sería descabellado -en mi opiniónpensar en un intento, por parte de la Academia, de respaldar, justificar,

48 Recordemos que esta información aparecía por última vez en la anteportada de la GRAE1867 (quedó indicado en el punto 2.3.11., apunte [1]). 
legitimar o dar consistencia a un normativismo que quizá ahora pretenda ser más firme (aunque en la GRAE-1917 no encontramos afirmaciones en los términos de las vistas en las Gramáticas de los años setenta).

En cuanto al capítulo de Vicios de dicción, la GRAE-1917 inaugura el modelo II en el análisis tipológico que hace Gómez Asencio, modelo que no supone modificación sustancial del primer patrón (GRAE-1880 a GRAE-1916) ${ }^{49}$. Para este estudioso (2006: 65-66), resulta difícil entender la conjunción, en el nuevo libro, de las novedades sintácticas y el mantenimiento de esta actitud prescriptiva. Las posibilidades que expone para explicar este proceder son válidas -hago una paráfrasis de sus palabras-:

a) Son compatibles, en efecto, la innovación doctrinal y el conservadurismo normativo.

b) Es probable que el mantenimiento del capítulo responda a la estrategia de dosificar las novedades.

c) Quizá la Corporación no quiere dejar de satisfacer las expectativas del público (que espera el ya tradicional capítulo).

d) O puede que los académicos quieran evitar la confusión que para los hablantes supondría la simple eliminación del capítulo (lo que les hubiera podido dar pie a pensar que el silencio suponía cese de la prohibición y, por tanto, luz verde para ciertos usos).

49 Para los detalles sobre los cambios concretos que se producen en el Modelo II respecto del Modelo I, véase Gómez Asencio (2006: 28-39). 
Quizá habría que completar estas posibles justificaciones con la observación sobre el "nuevo" comienzo de los preliminares de las GRAE a partir de 1917. Porque abrir la Gramática recuperando la antigua mención a la Ley Moyano parece no responder solo al deseo de "no modificar en exceso" el nuevo libro, de que el público no tuviera recelos para aceptar la reforma de la doctrina decimonónica que suponía el nuevo texto ${ }^{50}$ : puede ser que se trate de una estrategia ante la amenaza de derogación del privilegio de monopolio que siempre ha disfrutado la Corporación ${ }^{51}$ (vid. infra 6.3.); pudiera ser, además, que la remozada mención supusiera en sí misma un ligero cambio de actitud en una línea "respaldadora" del normativismo. Probablemente, esta aparente mayor firmeza normativista formó parte de la estrategia.

${ }^{50}$ Las palabras que cierran la Advertencia buscan claramente la consecución de este objetivo:

En la Analogía se han hecho algunas importantes reformas, nada más que algunas, las absolutamente necesarias para aclarar ciertos puntos doctrinales y para poner en armonía el contenido de esta parte de la GRAMÁTICA con la reforma introducida en la Sintaxis, reforma que se imponía, que no podía aplazarse por más tiempo, y que la Academia pretende plantear en nuestras escuelas sin el aparato de innovaciones peregrinas, porque en realidad no es otra cosa que una restauración de la doctrina tradicional; restauración que se ha realizado fundiendo la doctrina antigua en los moldes que para los estudios gramaticales han abierto los modernos adelantos de la Filología y la Lingüística.

(GRAE-1917: Advertencia, VI. El subrayado es mío)

51 Vid. Gómez Asencio (2004). 


\subsection{Los conceptos de bien / correctamente / con propiedad aplicados a hablar/escribir}

El ingrediente normativo (no importa el grado en el que se dé) implica que la Gramática es un arte que "enseña a realizar bien una actividad", concepción que será acogida en todos los textos lexicográficos y gramaticales que integran el corpus, como puede verse en los datos extraídos en 4.1.

Pero, si bien la Corporación mantiene intacta -en todas las ediciones del Diccionario y la Gramática- la concepción de que al gramático compete instruir, a través de su obra, a los hablantes de la lengua para que empleen el idioma de forma adecuada, la formulación de tal idea experimenta modificaciones relevantes que interesa comentar con detenimiento. Los siguientes cuadros dan cuenta de los cambios que se producen en la definición de la disciplina a lo largo de los Diccionarios y los libros de Gramática:

\section{DICCIONARIOS}

(DEFINICIÓN)

\begin{tabular}{|c|c|c|}
\hline EDICIÓN & PLANO DE LA LENGUA & COMPLEMENTO \\
\hline $\begin{array}{c}\text { Autoridades (1734) } \\
\text { a } \\
\text { DRAE-1791 }\end{array}$ & Hablar y escribir & Bien \\
\hline $\begin{array}{c}\text { DRAE-1803 } \\
\text { a } \\
\text { DRAE-1852 }\end{array}$ & $\begin{array}{l}\text { Hablar } \ldots \ldots \ldots . . . . \\
\text { Escribir }\end{array}$ & $\begin{array}{l}\ldots \ldots . \text { Bien } \\
\ldots . . \text { Correctamente }\end{array}$ \\
\hline DRAE-1869 & $\begin{array}{c}\text { Hablar ................. } \\
\text { Escribir .................. }\end{array}$ & $\begin{array}{l}\text {... Con propiedad } \\
\text {.... Correctamente }\end{array}$ \\
\hline $\begin{array}{c}\text { DRAE-1884 } \\
\text { a } \\
\text { DRAE-1925 }\end{array}$ & Hablar y escribir & Correctamente \\
\hline
\end{tabular}

Cuadro 38: Definición de gramática en los Diccionarios 
GRAMÁTICAS

(DEFINICIÓN)

\begin{tabular}{|c|c|c|}
\hline EDICIÓN & PLANO DE LA LENGUA & COMPLEMENTO \\
\hline $\begin{array}{l}\text { GRAE-1771 } \\
\text { a } \\
\text { GRAE-1854 }\end{array}$ & Hablar & Bien \\
\hline $\begin{array}{c}\text { GRAE-1858 } \\
\text { a } \\
\text { GRAE-1867 }\end{array}$ & 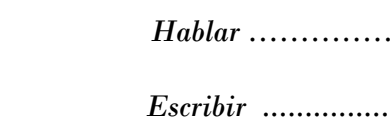 & $\begin{array}{l}\text {...... Con propiedad } \\
\text {............ Correctamente }\end{array}$ \\
\hline $\begin{array}{c}\text { GRAE-1870 } \\
\text { a } \\
\text { GRAE-1924 }\end{array}$ & Hablar y escribir & Correctamente \\
\hline
\end{tabular}

Cuadro 39: Definición de gramática en las Gramáticas

\section{LOS PROBLEMAS:}

La información obtenida de los textos obliga a plantear dos preguntas:

1. ¿ ¿Las Gramáticas que solo aluden a la modalidad hablada de la lengua en su definición de la disciplina están descartando la lengua escrita, o bajo hablar entienden hablar y escribir?

2. ¿ ¿Se entiende lo mismo, en estas definiciones, por bien, correctamente y con propiedad?

\section{LAS SOLUCIONES:}

La PRIMERA PREgUNTA puede tener dos respuestas, ninguna de las cuales está libre de inconvenientes. Analicemos las dos posibilidades: 


\section{A. Hablar = hablar + escribir}

Varias razones permiten apoyar esta interpretación (la más plausible desde mi punto de vista):

1. Todos los Diccionarios publicados por la Institución y todas las GRAE posteriores a 1854 recogen, en la definición de gramática, tanto la lengua hablada como la lengua escrita, lo que hace extraña la defensa de una Gramática centrada exclusivamente en la lengua hablada en las GRAE del siglo XVIII (1771 y 1796) y la primera GRAE del XIX (1854). Por otra parte, en el punto 4.2.2., veremos que, en todas las Gramáticas del corpus (y, por tanto, también en las que solo se menciona el hablar en la definición), se concede importancia especial a la lengua escrita (literaria).

2. Otros gramáticos anteriores a 1771 habían podado la conocida fórmula de Diomedes (recte loquendi scribendique), bajo la asunción de que hablar entraña o implica escribir (son autores que, en su obra, también prestan atención a lo escrito) ${ }^{52}$. Es posible que la Academia, en su primera

52 Recordemos el caso de Correas (1625: 137 y 1627: 111. El subrayado es mío):

ARTE de gramática se llama la que trata, i enseña los prezetos i rreglas para entender, i hablar una lengua. Dixose gramatica de gramma, que en griego sinifica letra: i es zienzia de hablar concertadamente.

En la segunda mitad del XIX, las declaraciones de Avendaño (1886: 42. El subrayado es mío) confirman lo que se está defendiendo:

Los sabios de Port-Royal, al manifestar el origen de la misma [la Gramática], se expresan así: "La Gramática es el arte de hablar. Hablar es expresar los pensamientos por medio de signos que los hombres han inventado con este objeto. Echóse de ver que los más cómodos eran los sonidos y las voces; pero como los sonidos son fugaces, inventaron otros signos para hacerlos duraderos y visibles, que son los caracteres de la escritura, llamados por los griegos grammata, de donde se deriva y trae origen la palabra GRAMÁTICA".

Avendaño, igual que hizo Correas, dedicará algunas páginas de su obra a la lengua escrita, pese a la definición -centrada en el hablar- que dan ambos de la disciplina. Las palabras citadas por Avendaño abren, efectivamente, la Grammaire genérale et raisonnée, de 1660. Pero es ya en el Prefacio escrito por Lancelot donde se asienta que la obra es un arte de hablar: 
Gramática, decidiera sumarse a la corriente marcada por estos autores anteriores y que, desde la GRAE-1858, por el contrario, optara por seguir su propia tradición (la iniciada con Autoridades, donde se recogía la secular fórmula bimembre).

3. En el Proyecto de gramática escrito por Angulo (1741), parece confirmarse que este académico se suma a la corriente de pensamiento según la cual hablar y escribir son una misma cosa, por lo que basta con definir la Gramática como arte de hablar. Quizá en este punto concreto sí se siguieron las sugerencias de Angulo a la hora de redactar la primera GRAE, y las nuevas ediciones de 1796 y 1854 se limitaron a seguir la propia tradición impuesta por los académicos anteriores, los de 1771. Transcribo los fragmentos que interesan del citado Proyecto de Angulo:

[...] Elio Donato, Victorino, Valerio Probo, Priscíano y otros Autores antiguos de la lengua Latina, que escrivieron gramas, no trataron en ellas dela exposiz. on de los poetas, é Historiadores, ni miraron esta como parte suía, ciñendose solo ala que mira ala razon de bien hablar, ó de hablar rectamente...

(ARAE, 1741a: pliego 3.․ El subrayado es mío)

[...] y ala verdad el hablar, y escribir aque se reduce la Gram.ca, $\underline{\text { son dependientes reciprocos, porque las letras son signos dela }}$ pronunciacion, por la qual fueron inventados los nombres, y figuras de ellas, y asi tienen una precisa relacíon, y correspondencia que las haze inseparables, y en confirmacion de esto Quintiliano dice, que el

habiendo encontrado en ello [en el deslinde razonado de hechos lingüísticos generales y particulares] dificultades que me entorpecían, se las comuniqué en algunas entrevistas a un amigo [Arnauld] que, aunque no se ha dedicado nunca a este tipo de dudas, e incluso mis preguntas fueron la causa de que él hiciera ciertas reflexiones sobre los verdaderos fundamentos del arte de hablar [...]

Las dos citas (la reproducida por Avendaño, con otras palabras) están en la edición de Morillo-Velarde (1980: 40 y 39, respectivamente. El subrayado es mío). 
negocío detoda la Gram. ${ }^{\text {ca }}$ consiste principalm. ${ }^{\text {te }}$ en dos cosa, hablar, y escribir rectamente, y Gerardo Vosío que el nombre de Gram.ca combiene propiam. ${ }^{\text {te }}$ a la Orthographia, pero que por synedoche se atribuye atodo el Arte.

(ARAE, 1741a: pliego 6.‥ El subrayado es mío) ${ }^{53}$

No es Francisco Angulo el único académico en defender por escrito este parecer. El Padre José Casani, en su disertación (s.a.) sobre el concepto de gramática, su división y "estatus", aunque no ofrece una definición propiamente dicha, también da muestras claras de que, para él la Gramática responde a la lengua hablada y a la escrita. Después de manifestar su concepción de la disciplina como arte (vs. Ciencia) ${ }^{54}$, unas líneas más abajo leemos:

La Grammatica es arte, y no ciencia, por q. sus preceptos y sus reglas nacen todas dela observacion de cómo han hablado los que precedieron, y dirige ala imitacion de hablar, y escribir como ellos hablaron, y escribieron: sus principios y sus conclusiones no pueden ser evidentes, pues todas penden del contingente uso, yla libre

53 Ramón Sarmiento (1981: 59 y 1984a: 40) reproduce este último fragmento. En los dos estudios citados, Sarmiento intenta justificar por qué la Academia no acoge, en las primeras ediciones de la Gramática, la definición bimembre, tal como aparece en Autoridades. Encuentra la primera explicación en el hecho de que «la Academia había emprendido, al mismo tiempo que la obra lexicográfica, otra concebida como "un arte por sí independiente" y destinada a ser el norte de la instrucción pública: la Ortografía». No creo que el hecho de publicar en tratado separado la Ortografía sea la razón de esa definición centrada en la modalidad oral de la lengua. De ser así, lo lógico hubiera sido que la adopción de la fórmula bimembre se hubiera hecho coincidir con la incorporación en el libro de Gramática de cuestiones ortográficas, algo que ocurre por primera vez en 1870. En esta edición, efectivamente, tenemos una definición que ampara tanto las manifestaciones habladas como las escritas de la lengua, pero no olvidemos que la definición de gramática como "arte de hablar y escribir" la encontramos por primera vez en la GRAE-1858, cuando todavía la Ortografía y la Prosodia eran objeto de estudio de tratados independientes y no del libro de Gramática (reducido a Morfología y Sintaxis). Tampoco es razón que en 1858 se defienda una división cuatripartita de la disciplina (con independencia de la estructuración del libro en dos partes): es en la GRAE-1796 donde por primera vez encontramos la división de la Gramática en cuatro subdisciplinas de estudio -vid. infra 5.-, y, en este texto, la definición está centrada en el hablar. ${ }^{54}$ Vid. supra nota 28 de este capítulo. 
significacion que los hombres han querido dar alas palabras, ó alas vozes, con que no goza privilegio alguno de ciencia.

(ARAE, s.a.: $\S 3^{\circ}$, fols. 8-9. El subrayado es mío) $)^{55}$

4. Más de un siglo después del Proyecto de Angulo, y en el mismo año en que ve la luz la 12. ${ }^{a}$ edición de la GRAE (1870), otro académico publica un Vocabulario gramatical de la lengua castellana. Se trata de Pedro Felipe Monlau ${ }^{56}$, coautor -recordemos- del Dictamen de la Comisión de Gramática de 1861. Aunque en la fecha de publicación del Vocabulario ya está arraigada en la Gramática la definición bimembre, Monlau recuerda que, etimológicamente, Gramática es «ciencia ó arte de las letras, por cuanto estas son los elementos del lenguaje y de la escritura» (Monlau, 1870: 76) ${ }^{57}$. De modo que, al margen de la fórmula de definición, el estudio gramatical siempre implica una dimensión escrita. Siempre lo han entendido así los miembros de la Corporación, según puede deducirse de sus propias declaraciones.

5. En el período que centra la atención de este estudio (segunda mitad del XIX y primer cuarto del $\mathrm{XX}$ ) encontramos otros autores que registran también en su definición de gramática sólo la modalidad hablada de la lengua (al igual que hace la Academia entre 1771 y 1854), a pesar de que no dudan en incluir en la disciplina gramatical el discurso escrito ${ }^{58}$. Valgan como ejemplo el caso de Salleras (1887 [1876]) y el de Avendaño (1886). El

55 Casani, como Angulo, no olvida mencionar en su Disertación que

\footnotetext{
Algunos [maestros de gamática] escusan en la definición la voz escribir, juzgando que basta saver hablar rectamente, porque el escribir es hablar por escrito, esto es hablar por zifras ó por signos.
}

\footnotetext{
56 A esta obra ya he hecho referencia en la nota 36 de este capítulo. Del Vocabulario de Monlau trataré con más detalle en el capítulo 5.

57 Obligado es entender, en esta definición, el concepto de ciencia en el sentido lato apuntado más arriba (Vid. nota 28 de este capítulo).

${ }^{58}$ Dedicando, además, un apartado del libro al estudio ortográfico, algo que la RAE no hará hasta las últimas décadas del XIX (sobre esto se volverá en 5.).
} 
primero de ellos dice que la gramática «es el conjunto de principios y reglas que nos enseñan á expresar nuestros pensamientos y afecciones con propiedad y perfecta corrección» (pág. 9), sin aclarar si por expresar entiende un acto oral, escrito o ambos; pero líneas más abajo parece que se decanta por la lengua oral al sentenciar que «dos son los móviles que nos impulsan cuando hablamos: la razón y la sensibilidad» (pág. 9. El subrayado es mío). Avendaño, por su parte, recuerda claramente a la GRAE anterior a 1858: «La Gramática castellana debe ser el arte de expresar bien el pensamiento en castellano, ó simplemente el arte de

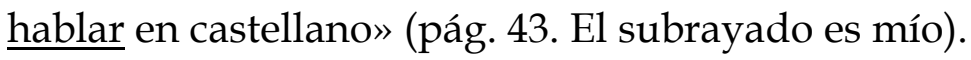

Posturas como estas conviven, no obstante, con otras (las más habituales, por tradición) que, desde la misma definición de la disciplina, subrayan la doble dimensión de la lengua y, por tanto, del estudio gramatical de la misma. La Gramática elemental de la lengua castellana de Giró y Roma se suma, entre otras muchas, a esta "corriente", que será la adoptada por la GRAE a partir de su sexta edición (1858) y la que mantienen todas las ediciones del Diccionario académico: si «el objeto de la Gramática es enseñar á expresarse bien de palabra y por escrito» (Giró y Roma, 1857: V y 1871: v), la Gramática castellana será concebida, consecuentemente, como «el arte que enseña á hablar y escribir bien en castellano» (Giró y Roma, 1857: 11 y 1871: 11. El subrayado es mío) ${ }^{59}$.

\footnotetext{
59 Pons y Argentó (1850: 4), Martínez Sevilla (1851: 5), Herrainz (1869: 21 y 1885: XII), Gómez de Salazar (1874: 1), Ruiz Morote (1880: 9), Martínez García (1896: 17), Nonell (1909: IX), M. Fernández y A. Retortillo (1909: 1), Dublé (1911: 5), Pontes y Fernández (1911: 8), Raboso de la Peña (1912: 7)... son gramáticos coetáneos que también formulan sus definiciones y explicaciones de la disciplina gramatical contemplando tanto la lengua hablada como la escrita. Otros autores del periodo que ofrecen definiciones parecidas son mencionados por Calero Vaquera (1989: 29): Boned (1853), Eguílaz (1869), Orío (1869), López y Anguta (1882), Suárez (1886), Parral (1902) y Lemus (¿1919?).
} 
Estos datos parecen confirmar que, en la segunda mitad del XIX y primer cuarto del XX, por gramática se entiende, de manera generalizada, la disciplina que contempla el hablar y el escribir, aunque a veces la definición se reduzca a "el arte de hablar".

Los problemas que plantea esta primera posibilidad interpretativa son los que a continuación se exponen. Si se defiende que hablar = hablar + escribir:

- La GRAE-1771 seguiría tanto la tradición gramatical externa (desde Diomedes) como la tradición interna de la propia Institución (desde Autoridades) ${ }^{60}$, aunque el texto en sí incurriría en la incoherencia de no acoger, ni como parte de la disciplina gramatical ni como parte del libro de Gramática, la Ortografía (remito al Cuadro 40 -apartado 5.--) ${ }^{61}$.

- La GRAE-1796 continuaría con lo establecido en los textos anteriores y, además, sería coherente con su división cuatripartita de la disciplina gramatical, en la que se da cabida a la Ortografía (remito al Cuadro 40 -apartado 5.-).

- La GRAE-1854, al igual que la primera edición, supondría un seguimiento de lo ya establecido, pero no sería coherente (como tampoco lo era la GRAE-1771) con su división de la disciplina gramatical (ni con su división del libro de Gramática), en la que no se reserva lugar para la Ortografía.

\footnotetext{
${ }^{60}$ Entiéndase por "seguir" una continuación teórico-doctrinal (defensa de que la Gramática recoge tanto el estudio de la lengua hablada como el de la lengua escrita), no de formulación, ya que, en este sentido, la GRAE-1771 se sumaría a la propuesta de autores como Correas y otros, que centran su definición en el hablar, aunque por hablar entienden hablar y escribir.

${ }^{61}$ El mismo comentario es extensivo a las ediciones segunda (1772) y tercera (1781) de la Gramática, según se ha anunciado al comienzo del capítulo.
} 


\section{B. Hablar = hablar (no escribir)}

Esta segunda posibilidad interpretativa daría coherencia interna a las GRAE de 1771 y 1854 y convertiría a la GRAE-1771 en un "texto de ruptura" con respecto a la tradición anterior (interna y externa a la Academia). Los textos de 1796 y 1854 se limitarían a seguir la tradición interna de la GRAE, iniciada en 1771 (y contraria -no lo olvidemos- a la propia tradición lexicográfica de la Academia -que, en la definición de gramática, recoge el hablar y el escribir-). La cuarta edición (GRAE-1796) sería la que presentara, en este caso, posturas contradictorias: de un lado, en la división teórica que hace de la disciplina, reconocería que el estudio ortográfico forma parte del estudio gramatical; pero, de otro, estaría definiendo la Gramática exclusivamente como arte de hablar (sin que bajo hablar se suponga escribir).

La coherencia total, dentro de los textos gramaticales, no llegará hasta la sexta edición de la GRAE (1858), en la que ya encontramos la formulación bimembre (hablar y escribir) en la definición de gramática y la defensa de que la disciplina gramatical comprende el estudio ortográfico, aunque el libro de Gramática no dedique un apartado a la Ortografía hasta la 12. a edición $($ GRAE-1870)62.

Es evidente que las dos soluciones presentan problemas, pero parece que hay más argumentos de peso para apoyar la primera propuesta, esto es, que hablar, en las ediciones de 1771, 1796 y 1854 debe estar suponiendo o implicando la doble faceta, hablada y escrita, de la lengua.

${ }^{62}$ Sobre las partes de la disciplina y del libro se hablará en el apartado 5. y en el punto 6.1. 
No terminan aquí los escollos interpretativos a los que tiene que enfrentarse el lector que desee entender cabalmente la concepción de Gramática defendida por la Institución en estos libros. Toca ahora llamar la atención sobre otro inconveniente que presentan las ediciones dieciochescas, excluida la cuarta (GRAE-1796), y la edición de 1854. Independientemente de la lectura interpretativa que hagamos de ese «hablar» de la definición, hablar bien una lengua exige el conocimiento teórico de los patrones de entonación que rigen su uso oral; el «arte de hablar bien» (suponga o no el arte de escribir), por tanto, debe contemplar el estudio prosódico. En la GRAE-1796, la Academia se excusa de no incluir en el libro de Gramática esta parte porque aún no ha perfilado las reglas que lo deben preceptuar (vid. supra 4.1.); de modo que, en esta edición, hay reconocimiento explícito de que la Prosodia es subdisciplina gramatical y de que solo cuestiones de calendario justifican que el libro no le dedique unas páginas. Sin embargo, en 1771 y 1854, no solo no hay un capítulo de Prosodia en el libro de Gramática, sino que:

- En la primera edición (1771), no hay intento alguno de justificar esa ausencia. Y es el silencio y la división expresa de la disciplina en dos partes (Analogía y Sintaxis) lo que hace pensar que la Prosodia queda fuera de las competencias del estudio gramatical.

- En la quinta edición (1854), unas palabras en nota al pie parecen ser presentadas como manifestación explícita por parte de la Institución de que los asuntos prosódicos no son materia concerniente al estudio gramatical (como tampoco lo son los ortográficos). La nota dice así: 
Los preceptistas suelen dividir la Gramática en cuatro partes, á saber, ortografía, analogía, sintáxis y prosodia; pero la $\underline{\text { Academia considera á la primera y la última como objeto de }}$ tratados especiales.

(GRAE-154: 1)

Ni la "falta" -en la definición- de una mención de la lengua escrita ni esta ausencia -en el libro- de unas nociones de prosodia las pasó por alto Vicente García (1855) en su severo análisis crítico de la quinta edición del texto académico -al que ya se ha aludido a propósito del carácter didáctico de la disciplina-: con respecto a este punto, sentencia que «como esta Gramática carece de prosodia, la definicion [de la disciplina] es falsa» (pág. 6) ${ }^{63}$.

Para responder a la SEGUNDA PREGUNTA que planteábamos a propósito de la información expuesta en los Cuadros 38 y 39 (la recuerdo: ¿Denotan la misma idea los términos con que se modifican los verbos hablar y escribir en las definiciones?), es necesario consultar, en los Diccionarios académicos del período, qué entiende la Institución por bien, por correcto y por propiedad.

${ }^{63}$ Reproduzco la crítica completa que este autor hace de la definición de Gramática ofrecida en la GRAE-1854:

En el primer párrafo trata de la Gramática en general, y la define arte de hablar bien. Esta definicion es incompleta, porqué [sic] la Gramática general abraza los signos articulados lo mismo que los escritos, y debió añadirse y de escribir correctamente. No obstante, aunque aquella sucinta definicion se aplique esclusivamente á la Gramática de la lengua castellana, es inexacta, porqué [sic] el hablar bien exige el conocimiento teórico de las entonaciones diferentes del acento oral que tiene nuestro idioma; y como esta Gramática carece de prosodia, la definicion es falsa. La antigua Academia, al clasificar su Gramática en cuatro partes, manifestó que omitia la prosodia, por no haber fijado todavía las reglas de la verdadera pronunciacion de las voces castellanas. La actual Academia no hace mencion de la prosodia [en realidad, sí la hace, en la nota al pie que se ha reproducido arriba], tal vez por no considerarla parte integrante de la Gramática. 
De las definiciones de gramática, dos aspectos llaman la atención:

- Las primeras y últimas ediciones, tanto del Diccionario como de la Gramática64, aplican el mismo complemento a hablar y escribir; ese complemento es, en las primeras ediciones, bien $^{65} \mathrm{y}$, en las últimas, correctamente.

- Las ediciones intermedias, sin embargo, aplican modificadores distintos a hablar (bien y con propiedad en los DRAE; con propiedad en las GRAE) y escribir (correctamente, en los DRAE y las GRAE).

Teniendo en cuenta que, en las ediciones intermedias, con propiedad nunca aparece en la misma definición de gramática junto con bien, sino que da la impresión de que sustituye a este término, parece legítimo pensar que bien y con propiedad vienen a denotar conceptos similares entre sí pero distintos del significado por correctamente, pues no tendría sentido aplicar dos términos diferentes pero sinónimos a hablar y escribir (salvo el puramente estilístico, que no parece ser el caso).

Que, para la Institución, hablar con propiedad y hablar correctamente son cosas distintas lo confirma la lectura del Dictamen de 1861, en el cual los académicos que constituían en aquel año la Comisión de Gramática (recordemos: Hartzenbusch, Fernández-Guerra y Orbe, y Monlau) se expresan en los términos que siguen:

\footnotetext{
${ }^{64}$ Entiéndanse por tales las recogidas, respectivamente, en la primera y última celdilla de ambos cuadros.

${ }^{65}$ Esto sólo puede defenderse en las GRAE si, como propongo, se entiende que hablar = hablar + escribir.
} 
Esta [la Gramática] no es el arte de hablar con propiedad, como se establece en la página $1^{\mathrm{a}}$, sino el arte de hablar conforme á reglas ó con corrección. Por demas sabido es que se puede hablar con la mayor impropiedad del mundo $\mathrm{y}$, sin embargo, hablar muy correcta ó gramaticalmente. En ninguna obra didáctica, y menos en una Gramática, deben confundirse los significados de las palabras pureza, corrección, propiedad, precisión, exactitud, concisión, claridad, etc.

(RAE, 1861b: 3. El subrayado es mío) ${ }^{66}$.

Conviene llamar la atención sobre el hecho de que, pese al criterio defendido por los académicos comisionados, cinco Gramáticas y un Diccionario posteriores a este Dictamen (las GRAE-1862-1864-1865-1866-1867 y el DRAE1869), seguirán definiendo la disciplina como "arte de hablar con propiedad" (vuelvo a remitir a los cuadros 38 y 39). Ya se adelantó en el bloque anterior (capítulos 2 y 3) que lo dispuesto por la Comisión de Gramática en 1861 no se llevará a la práctica hasta 1870 y que durante la década de los sesenta no dejan de publicarse ediciones de la GRAE que vienen a ser un remedo de la sexta edición, la de 1858. En este apartado, queda confirmada esta afirmación en lo que concierne a la definición de la disciplina.

El primer Diccionario que incluye una acepción semántica de propiedad (encabezada con la marca Gram.) es el DRAE-1832 (vid. Glosario final, s.v. propiedad). Teniendo en cuenta que con propiedad sustituye a bien en textos posteriores a esta fecha (el primero es la GRAE-1858), es de suponer que, en ellos, se le está dando un sentido gramatical (se está considerando la acepción marcada con Gram. en la entrada propiedad). Por tanto, en las definiciones de la disciplina, por propiedad se entiende 'el significado o el sentido peculiar y

${ }^{66}$ El fragmento puede encontrarse reproducido en Fries (1989: 118). De esta fuente lo tomé para mi artículo de 2003: 635, pues no había tenido oportunidad de consultar el original. Que Gómez Asencio (2006: 71) conceda también carta de naturaleza a este mismo fragmento como prueba de que propiedad y corrección nunca fueron conceptos confundidos por la Academia, reafirma su valor testimonial en el asunto que ahora nos ocupa. 
exacto de una voz o expresión', lo cual se considera cualidad necesaria solo del arte de hablar, ya que con propiedad únicamente sustituye -o parece sustituir- a bien en definiciones bimembres, en las cuales escribir será calificado con otro complemento adverbial.

Por correcto, en los Diccionarios del corpus (desde la primera edición del DRAE, esto es, la de 1780), se entiende lo que es exacto y conforme a las reglas, en concreto al hablar de escritos, estilo, etc. (vid. Glosario final, s.v. correcto). A partir del DRAE-1884, se suprime, en las entradas de correcto, la alusión a "los escritos" y se mantiene solo la alusión al "lenguaje" introducida en la edición de 1843 (lo que en su día parece que implicaba una ampliación del concepto de correcto a la lengua hablada). La supresión de "los escritos" en la edición de 1884 puede interpretarse como una ampliación de la noción de "lenguaje", que engloba desde ahora la lengua oral y la lengua escrita. Efectivamente, es a partir del año 1884 cuando los textos lexicográficos, en la definición de gramática, aplican el complemento correctamente tanto a hablar como a escribir, algo que hacía ya la GRAE-1870.

Por último, queda apuntar qué entiende la Academia por bien, complemento que desaparece de las definiciones de gramática en la segunda mitad del XIX. En los Diccionarios, lo encontramos hasta el DRAE-1852 (en el siglo XVIII, aplicado a hablar y escribir; desde la primera mitad del XIX, sólo a hablar) y, en las Gramáticas, hasta la edición de 1854 (aplicado siempre a hablar -que, por lo argumentado arriba, parece implicar también el escribir-). Según las definiciones que los Diccionarios dan al lema bien, este adverbio podemos aplicarlo a "lo que está realizado con acierto, con perfección, justamente, de buena manera..." (vid. Glosario, s.v. bien). En realidad, el concepto de bien puede englobar el de con propiedad y el de correctamente, si bien estos últimos términos suponen una especialización mayor: el primero tiene que ver con la semántica y el segundo, con las reglas gramaticales. 
Teniendo en cuenta todo lo dicho, no parece aventurado plantear la siguiente hipótesis: las modificaciones de formulación que experimentan las sucesivas definiciones de gramática (que, en un primer momento, pueden entenderse como insignificantes, como puramente estilísticas) parecen estar condicionadas por -o ser acordes con- la cambiante y progresiva actitud que la Academia va adoptando con respecto al talante normativo que se supone o se debe suponer a una Gramática como la suya. Así, podemos hablar de cuatro momentos o etapas en esa creciente actitud de conciencia normativa:

1. Siglo XVIII (Diccionarios y Gramáticas): la Gramática se considera disciplina que, por su carácter pedagógico-normativo, debe servir de guía a los hablantes para que estos hablen y escriban bien (de forma adecuada, "con perfección, justamente, de buena manera").

2. Primera mitad del XIX (Diccionarios): la fórmula bimembre en la definición de gramática que presentan todos los Diccionarios permite introducir, en ellos, una nota más claramente coercitiva, que, en principio, sólo se aplicará al plano de la lengua más susceptible de ser regulado: la escritura. La Gramática tiene que enseñar a hablar bien pero a escribir correctamente, esto es, según reglas fijas.

3. Segunda mitad del XIX (Diccionarios y Gramáticas): la GRAE-1854, por mantener una definición de gramática centrada en la lengua hablada (aunque esto no quiera decir que se descarte la lengua escrita), no se ve influida por los Diccionarios que la preceden de forma inmediata y, en ella, al igual que en los Diccionarios y las Gramáticas del XVIII, se utiliza únicamente el adverbio bien. En este sentido, podemos decir que los textos 
lexicográficos se adelantan a las GRAE y dan el primer paso en la línea "normativista" en su definición de gramática.

La primera GRAE que presenta una definición bimembre (1858) sustituye el bien (que todavía el DRAE-1852 aplicaba a hablar) por con propiedad y mantiene el correctamente para escribir (el mismo complemento que dan los Diccionarios desde principios del siglo XIX para escribir). Este cambio en el complemento modificador de hablar, que no supone tanto un mayor grado de normativismo cuanto de precisión en la definición de gramática (hablar bien es hablar con propiedad, utilizando las palabras precisas y exactas), se mantendrá en los seis textos posteriores a la GRAE1858, esto es, las GRAE-1862-1864-1865-1866-1867 y el DRAE-1869.

4. Finales del XIX - principios del XX (Diccionarios y Gramáticas): en consonancia con la mayor firmeza en el propósito normativo que, en declaraciones explícitas, presenta la GRAE-1870 (según se ha comentado ya), es en este jalón donde por primera vez encontramos el adverbio correctamente aplicado a hablar y escribir67. El ejemplo de la Gramática lo seguirán los Diccionarios desde el DRAE-1884, el primero que se publica tras la 12. ${ }^{a}$ edición de la GRAE (el DRAE anterior es el de 1869) ${ }^{68}$.

\footnotetext{
${ }^{67}$ Recuérdese que no es hasta 1870 cuando se lleva a la práctica, en la definición de Gramática, el apunte del Dictamen de 1861 (transcrito más arriba): la Gramática «no es el arte de hablar con propiedad... sino el arte de hablar conforme á reglas ó con corrección». Ya se ha adelantado que las reformas recomendadas por la Comisión de 1861 se harán esperar: se comprueba en este aspecto y se confirmará a propósito de otras cuestiones.

${ }^{68}$ Aunque todas las ediciones que siguen de la Gramática (hasta la de 1924) mantienen esta definición, en los fragmentos traídos a colación en 4.1., encontramos un indicio que podría ser confirmación del "retroceso" que parece suponer la GRAE-1880 (desde el punto de vista prescriptivo-coercitivo y en lo que respecta a declaraciones explícitas) con respecto a las ediciones de los años setenta (según se ha dicho en las primeras páginas de este apartado 2.): las GRAE de 1874 y 1878 declaran que los fines de la Gramática son «conocer (ANALOGÍA), ordenar (SINTAXIS), pronunciar (PROSODIA), y escribir (ORTOGRAFÍA) correctamente», donde correctamente se aplica a todos los fines señalados; frente a ellas, desde la GRAE-1880, leemos que los indicados fines de la Gramática son conocer (ANALOGÍA), ordenar (SINTAXIS), pronunciar (PROSODIA) y escribir correctamente (ORTOGRAFÍA)», donde correctamente parece afectar, a partir
} 


\subsection{Los modelos de lengua}

Una gramática normativa, como es la académica, siempre apoya (o suele apoyar) sus principios en una base de autoridad, de modo que la GRAE deberá presentar unos modelos de lengua que sirvan al lector de patrón de seguimiento. Parece que la Institución, al menos en principio, no lo hace. Así, una vez leída la definición que a lo largo de todas las GRAE se repite de gramática, el lector/alumno pasa al estudio específico de la primera de sus partes, la Analogía, con varias dudas: ¿qué es lo correcto?; ¿qué es bien aplicado a la lengua?; ¿de dónde se pueden o se deben extraer las pautas para alcanzar una dicción/escritura pulida y perfecta desde el punto de vista gramatical?

La Academia, a la hora de definir la Gramática, no solo recoge de la tradición clásica la fórmula ("arte de hablar -y escribir- bien"), también acoge en su obra la imprecisión de la misma, una imprecisión que o bien los académicos no apreciaron $-\mathrm{y}$ por tanto no juzgaron necesario enmendar- $\mathrm{o}$ bien asumieron respetuosamente en honor de los venerados antiqui.

Se sabe que la cuestión concerniente a la norma que debía servir de guía a los hablantes y por la que debía regirse el arte de la Gramática fue de importancia crucial en la teoría lingüística del siglo XVI; también se sabe que Quintiliano es el punto de referencia habitual para los gramáticos y tratadistas del español ${ }^{69}$. Hemos tenido oportunidad de comprobar que los primeros académicos que se pronuncian sobre el carácter normativo que debe tener el libro de Gramática, Angulo y Casani, siguen de cerca al autor de la Institutio Oratoria:

de ahora, únicamente a escribir. Insisto en la idea de que los cambios en el lugar que ocupa la información no deben entenderse como gratuitos, porque rara vez lo son.

${ }^{69}$ Véanse, para este asunto, Pozuelo Yvancos (1984 y 1986), Martínez Gavilán (1990) y Satorre Grau (1996). 
1. $\mathrm{Al}$ vincular el aspecto normativo con las cuestiones de uso de la lengua.

2. Al soslayar el uso común y apuntar en sus notas a una idea de selección (como modelo de uso no vale cualquiera -es inaceptable, por ejemplo, el del vulgo inferior- y todo parece indicar que es la norma culta, la de los eruditos, la que sirve de patrón y autoridad).

Los papeles preparatorios de la Gramatica instalan a la Corporación, como no podía ser de otra forma, en la primera de las tres corrientes renacentistas señaladas por Pozuelo Yvancos (1984 y 1986): la línea normativista, defensora del uso culto como norma de conducta gramatical. Es la línea iniciada por Nebrija y continuada de cerca por el licenciado Villalón (1558), Diego de la Encarnación (1624) o Juan Villar (1651), que será su máximo exponente ${ }^{70}$.

Sin embargo, en la definición de la disciplina y en los preliminares de la GRAE no encontramos ningún dato que pueda sacar de dudas al lector sobre dónde o en quién reside el modelo de lengua.

\footnotetext{
${ }^{70}$ La segunda corriente, la "antinormativista", será representada, en el XVI, por Francisco de Robles (con una actitud conciliadora entre el pensamiento de Quintiliano y el modelo del uso común), Juan de Valdés (enfrentando la norma culta-escolar a la norma común del vulgo) y Bernardo de Aldrete (que llega a defender un modelo de lengua basado en el uso individual de los hablantes, postura que se justifica por su convencimiento de que es inútil intentar fijar el innato dinamismo de la lengua); en el XVII, Correas será el máximo exponente de la defensa del uso común (si bien se distancia de Valdés y Aldrete en considerar necesaria la codificación de la lengua, la fijación de una preceptiva gramatical en un arte). La tercera corriente señalada por Pozuelo Yvancos es la "racionalista", representada en la figura del Brocense y conciliadora de las dos anteriores. No faltarán autores eclécticos como Juan López de Velasco, quien reconoce «la norma apoyada en la tradición gramatical (doctos y curiosos) dando prioridad a aquélla que viene corregida por la razón (que para él suele ser la etimología, pues cuando apela a la razón es para defender una ortografía etimológica), aunque reconoce el valor del uso y costumbre como el gran motor de los cambios, que acaban imponiéndose» (Pozuelo Yvancos, 1986: 90).
} 
En realidad, la Academia de 1854 (no olvidemos que es en esta fecha cuando se inicia la verdadera contribución gramatical de la Institución en el siglo XIX) contaba con claros, inmediatos e importantes precedentes que, aun no distanciándose demasiado de lo comúnmente admitido (como veremos, sobre todo en la formulación de uno de ellos), supieron dar los apuntes necesarios, las aclaraciones precisas, para que el lector no dudara de en qué consistía el estudio gramatical, cuáles eran sus fines y sus ventajas, y cuáles los modelos dignos de ser seguidos para hacerlo productivo. Me refiero a los dos grandes hitos gramaticales del siglo XIX, Vicente Salvá y Andrés Bello, autores que, por cierto, son declarados fuente de inspiración primaria para los académicos en el comienzo del Prólogo de la GRAE-185471. La definición de gramática que encontramos en las obras de don Vicente y de don Andrés son, respectivamente, las que siguen:

La gramática de la actual lengua castellana no es otra cosa que el conjunto ordenado de las reglas de lenguaje que vemos observadas en los escritos o conversación de las personas doctas que hablan el castellano o español.

(Salvá, 1847 [1830]: 121. El subrayado es mío)

${ }^{71}$ En sendos trabajos parciales, a los que ya he hecho referencia (Garrido Vílchez, 2001b y 2002a) he esbozado un análisis de los posibles influjos de ambos maestros en el primer texto académico del siglo XIX, que los blande como modelos, y en los dos he llegado a la conclusión de que, al menos en el aparato teórico-doctrinal, el influjo de estos gramáticos es mucho menor de lo que presume la GRAE-1854 y de lo que el lector puede suponer a partir de la afirmación del Prólogo. ¿Por qué, entonces, citarlos como "guías de reformas"? La respuesta parece clara: tanto la autoridad del valenciano como la del caraqueño eran garantía de calidad y de modernidad, y la Academia lo sabía. Así que, si bien es cierto que las dos Gramáticas fueron leídas por los académicos, todo apunta a que estos decidieron utilizar los nombres de don Vicente y don Andrés no tanto porque en la quinta edición de la GRAE (1854) se siguieran de forma notable sus preceptos, cuanto por dar respaldo al nuevo texto, que veía la luz después de casi sesenta años sin haber sido renovados los planteamientos doctrinales expuestos en el siglo anterior, y cuya caducidad era ya más que evidente en algunos puntos concretos. 
La GRAMÁticA de una lengua es el arte de hablarla correctamente, esto es, conforme al buen uso, que es el de la gente educada.

(Bello, 1860 [1847]: 165. El subrayado es mío) ${ }^{72}$

Frente a estos predecesores, en la Gramática de la Academia no encontramos nada del uso de las personas cultas (Salvá) ni de la gente educada (Bello), al menos, nada en el Prólogo ni en la definición de la disciplina, lugares reservados -se supone- a la exposición de los principios doctrinales que rigen la obra (o, al menos, lugares privilegiados para ello $)^{73}$. Cuestión distinta es la

${ }^{72}$ Anterior a las definiciones de Salvá y Bello es ésta de Benito de San Pedro, que bien pudo haber inspirado las declaraciones expuestas:

Se llama Gramatica el Arte que enseña a hablar i escrivir bien; esto es, conforme a las reglas autorizadas por el uso de los doctos.

(San Pedro, 1769: XXIV)

En fecha anterior, el Licenciado Villalón deja establecida, desde el principio de su obra, la norma que debe seguirse en la tarea de bien hablar y escribir (aunque él, a diferencia de los autores que estamos mencionando, no lo hace en una definición propiamente dicha de la disciplina, que no encontramos en su Gramática). Tras el Proemio al lector, el análisis gramatical se abre con el epígrafe:

Arte, o Gramatica para saber hablar y escrevir enla lengua castellana: colegida de la auctoridad delos sabios, conforme ala costumbre y uso comun dela lengua no corrompida.

(Villalón, 1558: 11)

La línea de Villalón se remonta hasta Quintiliano a través del cauce de Nebrija, autor que tampoco es demasiado explícito en su Gramática Castellana: la autoridad está en aquellos que tienen poder para hacer uso (1492: fol. 4 r.). No obstante, Nebrija había delimitado claramente el concepto de bien hablar en sus Institutiones Latinae, en una definición de la disciplina (que no se encuentra en la Gramática Castellana) recogida por Angulo:

La Gram.ca es ciencia de hablar, y escribir rectam. te segun el uso, y autoridad delas Personas mas doctas.

(ARAE, 1741a: pliego 3. ${ }^{\circ}$ )

Ni Nebrija (fuente declarada explícitamente en la GRAE-1771), ni Salvá y Bello (fuentes declaradas en 1854), ni otras fuentes -como Villalón- (no declaradas en las GRAE, pero tenidas en cuenta) han influido en la Academia para precisar nítidamente, desde el comienzo de su Gramática, qué se entiende en ella por bien hablar, fin último de la disciplina en todos los textos académicos que estudiamos.

${ }^{73} \mathrm{Y}$ es de suponer también (por la finalidad didáctico-normativa atribuida a la Gramática) que uno de esos principios fundamentales que rigen la obra es el modelo de lengua que debe ser seguido. 
poca precisión que entraña la idea de personas cultas o la de gente educada; lo importante es que Salvá y Bello acotan diastráticamente el concepto de hablar bien (por muy parcial y relativa que pueda resultar la acotación) y plantean esa precisión desde el comienzo de su exposición gramatical, elevando a prioridad metodológica la delimitación del campo de estudio de sus obras. La Academia, sin embargo, parece asumir como consabido el concepto de bien hablar $^{74}$.

No obstante, bien adentrados ya en el cuerpo de la GRAE-1854, recibimos información de cuál debe ser el modelo de habla que sirva de pauta: el uso de los autores clásicos y de los que hablan bien, que son las personas doctas (vid. GRAE-1854: 174 y 177). También en las GRAE del XVIII se apelaba a «la autoridad de los auctores clásicos, y el uso de los que hablan con elegancia y energía» (GRAE-1796: 356) ${ }^{75}$. La Institución podía haber otorgado más importancia a esta información y asumir, desde el mismo Prólogo o desde la definición de la disciplina, el seguimiento de esos modelos como principio rector de la labor gramatical (ya contaba en 1854 con precedentes que lo habían hecho de forma muy clara $\left.{ }^{76}\right)$, lo cual restaría imprecisión a la formulación seguida casi por inercia a lo largo de las distintas épocas de nuestra historia gramatical. Tampoco las ediciones posteriores a esta fecha van a conceder relevancia doctrinal a la información sobre cuáles son o deben ser

${ }_{74}$ Esta presuposición fue tema del discurso de ingreso leído por Eduardo Benot en la Recepción Pública de la Academia del día 14 de abril de 1889. Cf. Benot (1889).

${ }^{75}$ Es el consensum eruditorum de Quintiliano; el uso recomendado por Casani y por la corriente normativista en la que la Institución está inserta.

${ }^{76}$ Las precisiones de Bello, por ejemplo, van más allá de la estricta definición de gramática: dos párrafos más abajo de dicha definición, encontramos un añadido que no deja de ser significativo, y del que la RAE también hace caso omiso a la hora de formular qué es, o en qué consiste, la disciplina gramatical. La Academia no dice dónde se puede encontrar esa corrección idiomática, qué uso debe servir de guía, o qué procedimientos se deben seguir para salvaguardar la perfección del idioma. En Bello sí tenemos esas precisas orientaciones; el venezolano expone con claridad (ya en el primer apartado de Nociones Preliminares) que

el bien hablar comprende la estructura material de las palabras, su derivación y composición, la concordancia o armonía que entre varias clases de ellas ha establecido el uso, y su régimen o dependencia mutua.

(Bello, 1860 [1847]: 166) 
los modelos de corrección idiomática; en ellas, se seguirá apelando a la autoridad de los clásicos y de la gente elegante, pero siempre en el cuerpo de la obra, una vez entrados -y bastante- en materia (sobre todo, encontramos estas alusiones a los modelos de lengua en el apartado sintáctico). 


\section{LA GRAMÁTICA ES GENERAL / PARTICULAR}

En Autoridades, también se hace referencia, tras la definición propiamente dicha, a la doble dimensión de la disciplina:

Es comun à todas las Lénguas, y particular à cada una, y principio y fundamento de todas las ciencias ${ }^{77}$.

La Gramática es, por tanto, general y particular al mismo tiempo, pese a haber sido definida -dentro de la escala de conocimiento- solo como arte, no como ciencia, según se ha comentado en los dos puntos anteriores ${ }^{78}$.

El reconocimiento de una doble dimensión en la Gramática tampoco es nuevo en nuestra tradición; más de un siglo antes, Correas (1625) advertía que las lenguas

convienen en lo xeneral, i maior parte de la Gramatica aunque sean sus vocablos $i$ frases diferentes [...] i desconvienen en propiedades i cosas particulares. Arte de Gramatica se dize la que contiene i enseña los prezetos xenerales que convienen á todas las lenguas, $\mathrm{i}$ los particulares que pertenecen á sola aquella de que trata

(Correas, 1625: 129. El subrayado es mío) ${ }^{79}$

\footnotetext{
77 Val Álvaro (1992: 28) interpreta esta doble dimensión atribuida a la Gramática como un eco de la distinción entre la Gramática metódica natural y metódica artificial «que, atribuida a los alejandrinos, intenta difundir en el siglo XVII Gerardus I. Vossius».

78 Recordemos que los gramáticos griegos establecieron «cuatro niveles, progresivamente ascendentes, en el acceso al conocimiento: peîra o "habilidad", empeiría o "conocimiento práctico", téchnē o "arte" y epistēmē o "ciencia", es decir, conocimiento de las causas, propio del filósofo» (Tusón, 1987: 25). Los dos últimos conceptos serán recogidos por la tradición gramatical posterior hasta convertirlos en caracterizadores de las dos formas básicas de abordar el estudio gramatical: como estudio particular, la Gramática será un arte; entendida en términos generales, será calificada de ciencia. De esta tendencia generalizada en los gramáticos de nuestra tradición dan cuenta Gómez Asencio (1981: 18-33) y Calero Vaquera (1989: 33-35).

${ }^{79}$ Martínez Gavilán (1990: 142 y 1997: 93) ha llamado la atención sobre el hecho de que Correas es el primer autor dentro de la tradición hispánica que admite expresamente en su obra la convivencia de universales lingüísticos junto con peculiaridades idiomáticas.
} 
Esta convicción le hace otorgar a la disciplina gramatical el doble carácter de arte y de ciencia ${ }^{80}$. La apreciación de Gonzalo Correas trae a la mente la actitud ante el estudio gramatical tomada siglos atrás por los modistas; en el siglo XIII, encontramos ya concepciones cifradas en los términos que siguen: «La gramática es una y la misma, en lo esencial, para todas las lenguas; aunque en lo accidental puedan darse variaciones» ${ }^{81}$.

De modo que, en la Academia de 173482, al igual que anteriormente en Correas o Patón83, por ejemplo, encontramos la confluencia de dos de los principales "programas de investigación" (en términos de Swiggers) 84 de nuestra historia lingüística: el racional (centrado en el estudio de las relaciones y correspondencias entre la lengua, el pensamiento y los objetos) y el empírico (interesado por dar cuenta de las particularidades de un sistema lingüístico concreto, por describir la realidad idiomática observada en el uso de los hablantes, aunque se trate de unos hablantes privilegiados) ${ }^{85}$.

Avanzando el tiempo, en los útimos años del siglo XVIII y primera mitad del XIX, Jovellanos (inspirado por Condillac), Mata, Amézaga y

\footnotetext{
80 La Gramatica es arte, ó zienzia de hablar concertada i propiamente en la orden de las palavras, considerada i sacada de la conformidad i conzierto del hablar natural ó usual de las xentes en sus lenguas.
}

(Correas, 1625: 129)

\begin{abstract}
${ }^{81}$ Así se expresa Roger Bacon. La cita la he tomado prestada de Tusón (1987: 41), quien, en lo relativo a los modistas, sigue básicamente el estudio que Bursill-Hall publicó en 1971 bajo el título de Speculative Grammars of the Middle Ages. The Doctrine of «Partes Orationis» of the Modistae.

82 Es en este año cuando vio la luz el tomo IV de Autoridades (letras G-N).

83 Sobre la influencia de Bartolomé Jiménez Patón en Gonzalo Correas, véase Quilis y Rozas (1963). También tenemos noticia de la conexión entre ambos gramáticos en Zas (1992) y Marcos Marín (1994: 71-76).

${ }^{84}$ El concepto de programa de investigación fue habilitado en lingüística por Swiggers (1981a y b) para hacer alusión a las principales vías o concepciones del estudio gramatical que se han dado a lo largo de la historia.

${ }^{85}$ El caso de Patón (1614) es menos evidente que el de Correas, dadas las características y dimensiones de sus Instituciones. No obstante, en los "apuntes gramaticales" del autor manchego, se puede apreciar la doble perspectiva general y particular que defiende en la gramática.
\end{abstract}


Alemany conciben la Gramática General y la Gramática Particular como campos de estudio del lenguaje complementarios entre sís6.

En lo que respecta a la obra de la Institución, la diferencia entre la dimensión general y particular de la Gramática a la que se alude en Autoridades se pierde en el primer Diccionario del siglo XIX (DRAE-1803), edición a partir de la cual (y hasta el DRAE-1869 -inclusive-), en el artículo correspondiente a gramática, solo encontramos (amén de la acepción “estudio de la lengua latina") la definición propiamente dicha. Tendremos que esperar al DRAE-1884 para que la Academia, en su obra lexicográfica, vuelva a hacer referencia -ahora de forma más explícitamente diferenciada- a esas dos formas distintas (general y particular) de abordar el estudio gramatical (vid. supra fragmentos de 4.1.) ${ }^{87}$.

En cuanto a los libros de Gramática que centran nuestro interés, hay que decir que no participan de la práctica general del momento. En buena parte de los autores que publican sus obras en la segunda mitad del siglo XIX y primer cuarto del XX, encontramos una distinción explícita entre Gramática General y Gramática Particular88; la distinción se formula en términos similares a los que siguen:

${ }^{86}$ Más detalles sobre la concepción de estos autores, en Gómez Asencio (1981: 26-29).

${ }^{87}$ En estos artículos, encontramos la mención (rezagada) de una tercera forma de gramática: la gramática comparada. La referencia era casi obligada en las fechas a las que responden los Diccionarios: a finales del XIX ya había alcanzado su auge la Filología Comparada y la omisión en el Diccionario quizá ruborizaba a algunos de los miembros de la Corporación.

88 Sirvan de ejemplo Giró y Roma (1871: 11), Martínez García (1883: 13 y 1896: 17), Avendaño (1886: 43), Dobranich (1893: 1-2) o Raboso de la Peña (1912: 7). 
Gramática general es la ciencia que trata de las leyes fundamentales del lenguaje, y Gramática paticular es el arte de hablar bien un idioma.

(Giró y Roma, 1871: 11. El subrayado es mío)

Divídese la Gramática en general y particular: la primera es una ciencia; la segunda, un arte [...] GRAMÁTICA GENERAL es la ciencia

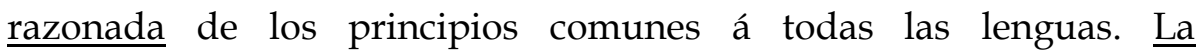
GRAMÁTICA PARTICULAR, el arte de expresar el pensamiento conforme á las leyes generales de la ciencia gramatical, y á las particulares de la lengua, autorizadas por el uso de sus buenos hablistas.

(Avendaño, 1886: 43. El subrayado es mío)

Las declaraciones de Giró y Avendaño sirven de botón de muestra de lo que son una concepción y una práctica generalizadas en la época: casi la totalidad de autores coincide en asignar la etiqueta de arte al estudio gramatical de una lengua específica y en considerar la Gramática General como disciplina legítimamente científica; y buena parte de ellos, además, aprovecha las primeras páginas de los libros para dar cuenta de esta doble vertiente de los estudios gramaticales. Pero no solo se trata de una concepción bien deslindada entre parcelas de estudio independientes: muchos de los gramáticos del periodo entienden (y declaran en sus libros) que lo general y lo particular en gramática van, por necesidad, de la mano: la gramática general está supuesta en la particular, y la particular es una ramificación de la general. Ofrecen declaraciones en esta línea, entre otros autores, Pons y Argentó (1850: 5), Herrainz (1869: 20 y 1885: XIII), Salleras (1887 [1876]: 11) y Raboso de la Peña (1912: 7).

En las GRAE, sin embargo, difícilmente vamos a encontrar (metodológica y terminológicamente hablando) una formulación expresa de este deslinde. 
La distinción explícita entre Gramática General y Gramática Particular se remonta a la escuela de Port-Royal ${ }^{89}$, y será acogida en España en la primera mitad del siglo XIX por figuras como Gómez Hermosilla (1841 [1835]), posiblemente siguiendo a Beauzée ${ }^{90}$, autor en cuya Grammaire Générale (1767: IX-XVI) ofrece una detallada comparación entre la ciencia de la Gramática General y el arte de la Gramática Particular.

Efectivamente, ya en los Principios de gramática general de Gómez Hermosilla (1841: v) queda establecido que la Gramática General «no da reglas... es un tratado teórico sobre el lenguaje... contiene la ciencia, no el arte, de la palabra» (el arte lo recogerá la Gramática Particular). Pero quien asienta, en la tradición gramatical española, de forma firme y definitiva, con formulaciones contundentes e inequívocas, la separación entre estos dos modos distintos de hacer gramática es Vicente Salvá, quien toma partido decididamente por la elaboración de una Gramática Particular (la primera propiamente dicha de nuestra tradición) y ofrece, por primera vez también, una delimitación precisa de las competencias del gramático que decide escribir sobre una lengua concreta ${ }^{91}$. Su concepción y tratamiento de la

89 Destutt de Tracy (1822: 433), siguiendo esta corriente, afirma que su Gramática (a la que pone el título de Gramática general) «no es un arte de hablar, sino un tratado de la ciencia de los signos». Y es que sólo a la Gramática entendida como arte (la Gramática Particular) compete enseñar el uso correcto del idioma; entendida como ciencia (Gramática General), solo se debe dedicar a examinar los mecanismos comunes a las lenguas que sirven para manifestar los pensamientos.

90 En este punto, interesa Gómez Asencio (1981: 23-25). En opinión de este autor, en los preludios del siglo XIX, «Jovellanos es... el primer gramático en la historia de la gramática española que define la gramática general y que contempla este campo de estudio del lenguaje como complementario con el de la gramática particular» (págs. 26-27). Creo que los autores que, como hemos dicho, en fechas anteriores observaban una doble dimensión en el análisis gramatical (Patón y, sobre todo, Correas) también estaban defendiendo, implícitamente, esa complementariedad, aunque no deslindaran los conceptos de gramática general y gramática particular como disciplinas (o subdisciplinas) diferentes, con su propia metodología de estudio.

91 A Salvá lo seguirá muy de cerca, en tiempo y planteamientos, Andrés Bello: 
Gramática (descriptiva de un sistema lingüístico particular -en sus dos modalidades: hablada y escrita-, sincrónica, actual, inmanente, de corpus, empirista) constituye un claro desmarque de la tradición gramatical española. Partiendo de estos supuestos, es lógico que el valenciano considere inoperante la secular fórmula de Diomedes (que la Academia recoge en todos los textos del corpus), por no responder al momento presente de una lengua concreta: el arte de bien hablar y escribir respondería mejor a lo que debe ser la Retórica, cuyos principios son generales y atemporales. La Gramática que pretende estudiar todo aquel que titule su libro como Gramática castellana (o inglesa, francesa, etc.) no es "la Gramática" en sentido abstracto, sino "la Gramática concreta y particular" de una lengua dada (la española, en este caso). Su propuesta de definición se ciñe a estos principios (la definición se ha dado en 2.2. $)^{92}$.

No resulta extraño que la Academia acoja sin reservas la definición de "arte de hablar (y escribir) bien", sin importarle la posible confusión con la Retórica, ya que, según propias declaraciones de los académicos, los límites entre estas disciplinas son imperceptibles:

El habla de un pueblo es un sistema artificial de signos, que bajo muchos respectos se diferencia de los otros sistemas de la misma especie: de que se sigue que cada lengua tiene su teoría particular, su gramática. No debemos, pues, aplicar indistintamente a un idioma los principios, los términos, las analogías en que se resumen bien o mal las prácticas de otro. Esta misma palabra idioma está diciendo que cada lengua tiene su genio, su fisonomía, sus giros [...] Una cosa es la gramática general, y otra la de un idioma dado: una cosa comparar entre sí dos idiomas, y otra considerar un idioma como es en sí mismo [...].

(Bello, 1847: 153-154. El subrayado es mío)

92 Tanto la definición, que empieza por un cambio de formulación evidente con respecto a lo anterior: la gramática de la actual lengua castellana...., como el título que da a su obra: Gramática de la lengua castellana, según ahora se habla, son prueba fehaciente de que Salvá se despega de forma voluntaria de lo tradicionalmente asentado, de que quiere dar un enfoque totalmente distinto del que los siglos anteriores han dado a la gramática del español (y que, en buena medida, sigue dando la RAE en la segunda mitad del XIX y primer cuarto del XX). 
[...] pero aun cuando el examinar con amplitud este vicio (el de monotonía o pobreza) corresponde principalmente á la Retórica, allí donde trata de la elocución, no huelga censurarlo también en la Gramática, puesto que infinitas veces se confunden los límites y fronteras de la Gramática, de la Retórica y de la Métrica, siendo muy difícil y aun imposible en algún caso determinarlos con entera seguridad.

(GRAE-1880: 286. El subrayado es mío)

Sin embargo, en 1880 (año en que, en la GRAE, se sigue reconociendo el límite confuso entre Gramática y Retórica), la Academia ya establecía distinciones cualitativas entre estas dos disciplinas en los Diccionarios (vid. Glosario final, s.v. gramática y retórica) ${ }^{93}$. Lo que distancia la Gramática de la Retórica son las pretensiones de ambas, más "modestas" las de aquella que las de esta. La Gramática tiene como objetivo primordial enseñar a hablar y escribir de forma clara y correcta en los usos generales de la vida; la Retórica aspira a dar principios y reglas para lograr una expresión elegante y bella (en

${ }^{93}$ En todos los Diccionarios del corpus, hasta la edición de 1837 -inclusive-, se define la Retórica parcamente como «arte de bien hablar». Esta definición es idéntica a la definición de gramática que encontramos en las GRAE correspondientes a estos años, tal como hemos visto (los Diccionarios coetáneos, sin embargo, definen la disciplina gramatical como arte de hablar y escribir bien -caso que encontramos desde Autoridades hasta 1791- o de hablar bien y escribir correctamente -caso de los DRAE publicados entre 1803 y 1837-). Los DRAE de 1843, 1852 y 1869 no definen la Retórica, sino que la identifican con la Oratoria y remiten al lector al lema correspondiente, donde la Oratoria queda definida como arte de hablar y escribir (= Gramática) con propiedad, elegancia (y persuasión -desde 1852-). Se le han añadido, por tanto, a la Retórica notas diferenciales con respecto a la Gramática: lo ornamental (y lo persuasivo), mientras que la Gramática sigue centrando su atención en lo que está bien / lo que se expresa con propiedad y lo que es correcto. Por fin, a partir del DRAE-1884 (el más cercano en fecha a la GRAE-1880, de la que hemos sacado la cita transcrita arriba) se atribuyen a la Retórica -ahora en la entrada correspondiente a este lema- los contenidos defendidos para la Oratoria en los DRAE anteriores: embellecer la expresión para deleitar, conmover y persuadir al auditorio es su fin último. Y este fin dista del defendido para la Gramática en las GRAE y los DRAE desde 1858: la Gramática busca la corrección (y la propiedad -hasta 1870, exclusive-), no el embellecimiento, de la lengua -tanto en su modalidad hablada como en la escrita-.

Angulo (ARAE, 1741a: pliegos $3^{\circ}-4^{\circ}$ ), siguiendo a Patón, determinaba que la diferencia entre Retórica y Gramática estriba en que esta cuida exclusivamente de que, a través de sus reglas, se formen oraciones congruas, sin solecismos, mientras que aquella (a la que también llama Elocuencia) se encarga de adornar y hermosear esas oraciones bien formadas gramaticalmente. 
este sentido, la Retórica constituye una disciplina minoritaria, frente a la Gramática, que formaría parte de una enseñanza general). Se confirma que bien (es decir, lo que se realiza justamente, con perfección) supone cosas distintas en la Gramática y en la Retórica.

No ha faltado quien asegure que, ya en la GRAE-1854 se aceptan los principios inmanentistas y sincrónicos con que Salvá define "la Gramática de la lengua castellana"94. Tal conclusión ha sido extraída de unas palabras del Prólogo académico, en las que la Institución declara el propósito de la obra. El fragmento en cuestión dice así:

Establecer las reglas con la posible claridad y sencillez [...] ha sido el principal objeto de la Academia, desentendiéndose de las sutilezas metafísicas á que algunos, con más ingenio que fruto verdadero para la enseñanza, se han entregado...

(GRAE-1854: VIII) ${ }^{95}$

En estas palabras, se ponen de manifiesto -en mi opinión- dos cosas: el principio de sencillez, algo que la RAE pretende desde 1771, y el rechazo del método especulativo (= Salvá -y Bello, posteriormente-). Pero no se justifica esa oposición a las sutilezas metafísicas: parece que se desaprueban exclusivamente por razones pedagógicas. En Salvá, ese mismo rechazo tenía doble justificación: "no a la metafísica" en aras de la sencillez y "no a la metafísica", sobre todo, porque no es compatible con una Gramática Particular. El valenciano deslinda con nitidez el campo de estudio de la Gramática Particular y el de la Gramática General (donde sí tiene cabida la especulación). En 1854, no hay ninguna declaración explícita que nos permita concluir que la RAE diferencia con claridad estas dos disciplinas. En la quinta

\footnotetext{
94 Lliteras (1992: 32).

${ }^{95}$ Idéntico fragmento aparece reproducido en el Prólogo de 1858 (pág. VI).
} 
edición de la GRAE, todavía no se han asimilado los supuestos de Salvá. La asunción de principios doctrinales semejantes a los del valenciano no la encontraremos hasta 1870, edición en la que el cambio de orientación -al menos en teoría- parece claro, según acierto a extraer de las siguientes palabras, también del Prólogo:

[...] es una necesidad ir ajustando los preceptos á la lenta, pero continua variacion, que experimentan las lenguas vivas y escritas [...] Así es que, tratándose de la GRAMÁTICA, ó del arte que establece las reglas segun las cuales se habla y escribe el castellano de una época

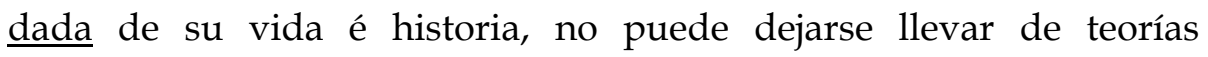
generales, sino que ha de atenerse á los hechos, á lo que real y prácticamente es, prescindiendo de lo que filosóficamente debiera ó pudiera ser [...] ha de limitarse á consignar el estado real y presente del idioma, á registrar las leyes instintivas á que obedece en su curso y desenvolvimiento, y á sancionar con su autoridad las prácticas regulares y constantes del buen uso...

(GRAE-1870: XII-XIII. El subrayado es mío) ${ }^{96}$

En estas palabras, sí late el pulso de Salvá97; se recoge en ellas claramente la concepción del valenciano en lo relativo a ciertos aspectos básicos que deben considerarse en el estudio de la Gramática de una lengua:

- Las lenguas evolucionan lentamente, de modo que las gramáticas particulares tienen fecha de caducidad (por eso hay que ir ajustando los preceptos) $)^{98}$.

\footnotetext{
96 Véanse también GRAE-1874 y 1878: 6-7.

${ }^{97}$ Es curioso que, precisamente en estas páginas introductorias de 1870, ya no se haga mención a Salvá (ni a Bello), lo cual parece confirmar la sospecha antes apuntada: casi con toda seguridad, la Academia aduce sus nombres en la GRAE-1854 simplemente como garantía de éxito.

98 No me resisto a reproducir unas palabras de Aldrete que también hacen alusión a esta misma idea:
} 
- La Gramática de una lengua concreta debe ser una gramática sincrónica del momento actual, en la que se registren tanto los usos orales como los escritos.

- El uso real y efectivo siempre debe ser el principio rector de una Gramática centrada en una lengua específica. Las teorías filosóficas sobre el lenguaje no sirven para dar cuenta de una realidad lingüística particular (en este caso, la española).

Pero, sorprendentemente, pese a esta declaración de principios, en la que parece indudable la huella del gramático valenciano, seguimos teniendo en 1870 la manida definición «arte de hablar y escribir correctamente» de siempre $^{99}$. Y, como se ha visto en el Cuadro 39 de 2.1., la seguiremos teniendo hasta la última edición del corpus (vid. también Glosario final).

La misma declaración de principios se reproduce en las ediciones de 1874 y 1878, pero desaparece en la de 1880 y no volvemos a encontrarla.

Puestas así las cosas, podemos concluir que, en ninguna de las GRAE de la segunda mitad del XIX y principios del XX (excepto en la de $1870-y$, por extensión, en las de 1874 y 1878-) podemos apreciar una distinción

\section{Deue se pues aduertir, que la lengua vulgar naturalmente con el tiempo enuejece, i muda, i en ciento o doscientos años se trueca.}

(Aldrete, 1606: 176-177)

Conviene, no obstante, marcar la distancia entre un autor y otro: esta seguridad de que las lenguas evolucionan sin prisa pero sin pausa lleva a Salvá a defender la necesidad de ir ajustando los preceptos gramaticales, frente a posturas como la de Aldrete, que negaban la posibilidad de reducir a artificio una lengua, ya que «mucho se engaña, por çierto, quien en la cosa más inestable, i flaca, busca perpetuidad i firmeça».

${ }^{99}$ Además, por duplicado: cerrando el Prólogo (pág. XV) y en las Nociones Preliminares (pág.1). 
metodológica explícita100 entre Gramática General (filosófica) y Gramática particular (empírica y sincrónica), aunque sí habrá en ellas una decantación clara por una de estas dos posibilidades de abordar el estudio gramatical (parece que sí hay una distinción conceptual, aunque no se formula explícitamente): tanto el título del libro (Gramática de la Lengua castellana / española), como la definición de la disciplina (arte), los fenómenos estudiados y los ejemplos dados constituyen una prueba evidente de que la Institución había optado por una forma concreta de hacer gramática: Gramática Particular.

En lo que respecta a declaraciones que, de forma expresa, den cuenta de una distinción entre Gramática General y Gramática Particular, parece que los Diccionarios han recogido el testigo de las Gramáticas: el apunte dado en las tres GRAE de los años setenta se pierde en las Gramáticas de los ochenta, pero se recoge en el primer Diccionario publicado después de la GRAE-1870. Efectivamente, el DRAE-1884 es el primer Diccionario académico que distingue la Gramática (se supone que Particular ${ }^{101}$ ) de la Gramática General (vid. supra 4.1.).

En este asunto concreto, podemos decir que, pese a la decantación de los académicos, la Gramática de la Institución no parece "hija de su tiempo", pues -como ya se ha visto- es práctica generalizada en la época la distinción conceptual, terminológica y -a veces- metodológica, en formulaciones expresas (en las primeras páginas del libro, normalmente), entre las dos formas de estudio gramatical.

\footnotetext{
100 Distinción terminológica (al modo, por ejemplo, de Giró y Avendaño, -vid. supra página 190-) no la encontramos en ninguna de las ediciones del corpus, tampoco en las de los años setenta.

101 No hay duda en esta interpretación, ya que la Gramática, sin más (y frente a la General), es definida como «Arte de hablar y escribir correctamente una lengua» (vid. Glosario final. El marcado es mío).
} 


\section{LA GRAMÁTICA ES ARTE PROPEDÉUTICA}

En Autoridades, la Gramática es entendida como arte propedéutica, como llave de acceso a otros conocimientos (en primer lugar, el latín, que se considera "pórtico" de entrada a otros saberes) o como ayuda para los mismos. Esta característica, de raigambre clásica, la encontramos también en las GRAE del siglo XVIII, como revelan las siguientes palabras:

Los que hubiesen de emprender carrera literaria necesitan saber la lengua latina, y lo conseguirian con mayor facilidad llevando ya sabidos por su Gramática propia los principios que son comunes á todas las lenguas ${ }^{102}$. No hay edad, estado, ni profesion alguna en que no sea conveniente la Gramática [...]

(GRAE-1771: IV y GRAE-1796: IV)

Niederehe (1997: 42-44) ha afirmado que en una época en la que el conocimiento del latín ya no es un valor indiscutible (de hecho, su estudio se mantiene de forma "artificial", como estrategia administrativa contra el creciente desinterés "científico" por esta lengua muerta), las gramáticas monolingües están consideradas como pertenecientes a la fase propedéutica de la didáctica de los idiomas. El ingrediente propedéutico está, efectivamente, en la GRAE dieciochesca y en obras como la de Martínez Gómez Gayoso (1769 [1743]) y Benito de San Pedro (1769), pero en ningún caso este ingrediente es el fundamental: en todos estos textos, se descubre la convicción de que el estudio de la lengua propia tiene sentido como meta en sí mismo y no solo como medio de alcanzar el conocimiento de otra materia.

\footnotetext{
102 En estas palabras se ve claramente que, para la Academia, la gramática particular supone la gramática general, como antes se ha dicho.
} 
La idea de la Gramática como herramienta propedéutica desaparece de los textos académicos en el siglo XIX, tanto de los Diccionarios como de las Gramáticas (las cosas han cambiado en el nuevo siglo y los textos de la Corporación son sensibles a esos cambios). El hecho de que, en la GRAE-1854, haya desaparecido la cita transcrita en este apartado quizá podría entenderse como una consecuencia de la enseñanza aprendida de Salvá (el estudio de la Gramática de una lengua tiene que tener como única finalidad dar cuenta de la realidad de ese código lingüístico concreto, no aprender principios comunes ni facilitar el acceso a otros conocimientos). Pero -como queda indicado en 3.no hay datos explícitos que confirmen un calado de la doctrina de don Vicente en la quinta edición del texto institucional, ni tampoco en las siguientes ediciones, salvando lo dicho de las GRAE de los años setenta. 


\section{LA GRAMÁtICA ABARCA EL ESTUDIO DE DISTINTOS ASPECTOS DE LA LENGUA}

Tales aspectos parecen concernir, según la cita de Autoridades, solo a la Prosodia, Morfología y Sintaxis. ¿Cómo evoluciona el pensamiento de la RAE a partir de los supuestos iniciales expuestos en el primer Diccionario académico?

Como puede apreciarse en el cuadro de la página siguiente103, a través de los textos gramaticales, la Institución muestra una actitud cambiante en cuanto a las materias que deben ser recogidas en las obras que llevan (o aspiran a que se les sobreentienda) la etiqueta Gramática. La misma vacilación se aprecia a lo largo de las distintas ediciones del DRAE: el cotejo de las diferentes entradas del lema gramática y las entradas relativas a las partes tradicionales de la misma (esto es, las entradas de los lemas analogía, sintaxis, prosodia y ortografía) evidencian que no hay una postura firme por parte de los académicos. (Vid. Glosario final, s.v. correspondiente).

103 Para evitar una prolijidad gratuita, se han puesto en esquema las propuestas de las ediciones de la GRAE que ofrecen información más relevante. 


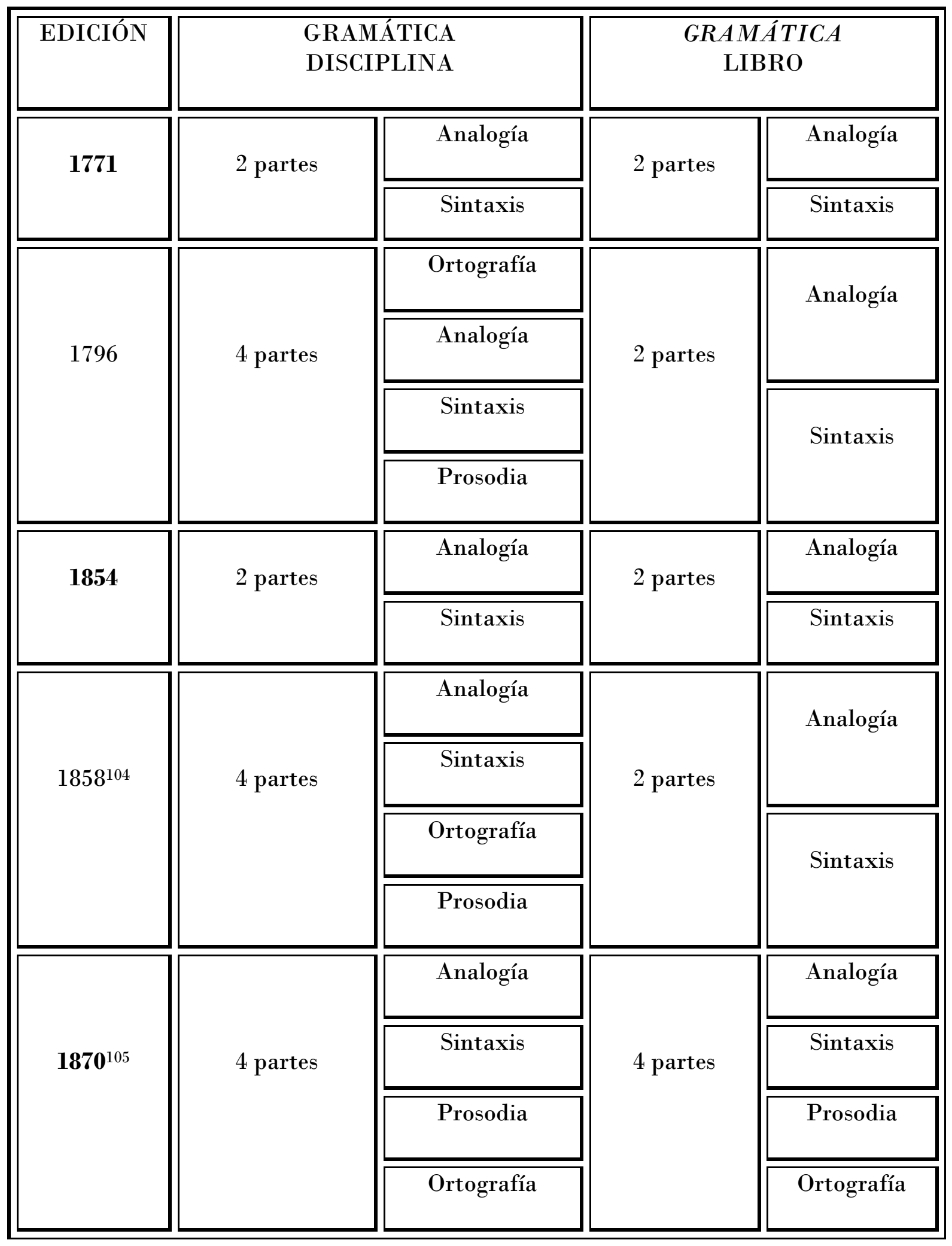

Cuadro 40: Partes de la Gramática (disciplina) y de la Gramática (libro)

104 Las ediciones de 1862, 1864, 1865, 1866 y 1867 son idénticas a esta.

105 Las ediciones de 1874, 1878, 1880, 1883, 1885, 1888, 1890, 1895, 1900, 1901, 1904, 1906, 1908, $1909,1911,1913,1916,1917,1920$ y 1924 son idénticas a esta. 
Ya en el Proyecto de Gramática de 1741, Angulo se refiere al establecimiento de las partes de la disciplina como uno de los puntos conflictivos a la hora del consenso de los estudiosos. Sus palabras son las que siguen:

Quantas, y quales sean las partes de la Gram.ca es otro punto no $\underline{\text { menos grave, }}$ y dificultoso de apuntar: Quintiliano la dividio en dos partes [...] Diomedes gram.co dixo que heran tambien dos sus partes, una exegetica, esto es, Methodica, y otra Historica, aunque esta no la incluye en sus reglas [...] Vosío la divide en las mismas quatro partes que Nebrixa [Ortografía, Prosodia, Etimología y Sintaxis], y Juan Bilstemo, Autor de diferentes Gram.cas, pone solas dos, etimología, y sintaxis; Pero el Brocense en su Minerva impugna largamente todas estas divisíones, con la de Quintiliano, aunque concluie sin dar division alguna [...] lo cierto es que este es uno de los mas peligrosos escollos de la Gram.ca, y como tal le han temido, y huído muchos delos Gram. ${ }^{c o s}$ modernos.

(ARAE, 1741a: pliego 5.․ El subrayado es mío)

Quizá este mismo temor al que se refiere Angulo es el que explica la vacilación de los académicos a la hora de establecer partes en la disciplina y en el libro de Gramática. Puede decirse que la Corporación intenta respetar la clasificación tradicional en cuatro partes (de una $\mathrm{u}$ otra forma, se hace mención de ella en todos los textos, excepto en la GRAE-1771106), pero la adhesión a lo establecido por la tradición más generalizada no es total.

106 En la GRAE-1854 (la única que, junto al texto de 1771, considera dos partes, tanto en la disciplina como en el libro de Gramática) se hace alusión, en nota al pie, a la tradicional división cuatripartita. La cita ya se ha dado, pero no sobra recordarla aquí:

los preceptistas suelen dividir la Gramática en cuatro partes, á saber, ortografía, analogía, sintáxis y prosodia; pero la Academia considera á la primera y la última como objeto de tratados especiales.

(GRAE-1854: 1) 
En cuanto a los Diccionarios, solo los del siglo XVIII hacen referencia a los contenidos de la disciplina gramatical. Como ya se ha visto (remito, de nuevo, a los fragmentos extraídos de los Diccionarios en 4.1.), los DRAE de 1780, 1783 y 1791 prácticamente calcan el artículo de Autoridades, que será sustituido a partir de 1803 por la estricta definición de gramática («arte de hablar bien y escribir correctamente»). De las cuatro partes amparadas por la larga tradición de Occidente, la Prosodia y la Sintaxis son las únicas que, en todos los Diccionarios del corpus, se vinculan con la Gramática (bien se definen como "partes" o "tratados" de la Gramática, bien se encabeza la acepión con la marca Gram., bien se suman los dos procedimientos anteriores) ${ }^{107}$. En este sentido, comprobamos que no hay correspondencia exacta entre la obra lexicográfica y la estrictamente gramatical de la Academia, puesto que la Prosodia no se incluye en el libro de Gramática hasta la GRAE-1870, aunque se mencionara en ediciones anteriores -no todas consecutivas- (GRAE de 1796, 1858 a 1867) como parte de la disciplina.

Las partes menos favorecidas en los Diccionarios (como partes legítimas del estudio gramatical) son la Analogía y la Ortografía. La Analogía empieza a considerarse "voz propia de la Gramática" en los DRAE a partir de 1803, primera edición en la que la entrada analogía incluye una acepción en términos gramaticales (con marca Gram.); esta parte, sin embargo, será la que goce de más protagonismo en las Gramáticas (vid. infra 6.1.1.). La Ortografía es quizá la parte más desatendida en el sentido que comentamos, tanto en los Diccionarios (en los que no se considera "parte de la Gramática" hasta el DRAE-1884) como en las Gramáticas (donde, al igual que la Prosodia, no encontrará un lugar "físico" hasta 1870).

107 Como puede comprobarse en el Glosario final (s.v. sintaxis), solo en cinco ediciones del DRAE (las de 1832, 1837, 1843, 1852 y 1869) no se define la Sintaxis ni como "parte" ni como "tratado" de Gramática, pero en las cinco tenemos, al principio del artículo, la marca Gram., de "voz perteneciente a la Gramática". 
Si difícil resulta delimitar qué partes reales considera la Academia dentro de la Gramática (disciplina y libro), no menos arriesgado es asignar competencias, esto es, determinar los contenidos de cada una de las partes, en especial los asuntos propios de la Prosodia y de la Ortografía. Y es que las informaciones que he podido extraer de los distintos Diccionarios y Gramáticas no permiten una delimitación estricta de cometidos (incluso se llegan a solapar los campos de estudio de una y otra).

El cotejo de los textos académicos que estamos considerando demuestra que, para la Academia, no hay una separación evidente entre Prosodia y Ortografía:

- La GRAE-1870 entiende la pronunciación de las letras como tarea que acerca a Ortografía y Prosodia. A partir de esta fecha, las GRAE incluyen -como se ha indicado en apartados anteriores- estas dos subdisciplinas gramaticales, y se establecen las siguientes diferencias entre ellas:

De lo mucho que pudiera decirse acerca de esta parte de ella, tercera de las cuatro en que hemos dividido el Arte de hablar y escribir correctamente (pág.1), esto es, acerca de la Prosodia, sólo contiene el presente libro los principios fundamentales y las reglas más precisas; éstas no pueden observarse sin tomar por juez al oido, á diferencia de la Ortografía, sobre la cual juzga la vista, pues que leyendo es como se advierte si los sonidos están fielmente representados por escrito.

(GRAE-1870: 287. El subrayado es mío)

Los sonidos son objeto de la Prosodia; los signos ó letras lo son de la Ortografía.

(GRAE-1870: 288, nota [1]. El subrayado es mío) 
Prosodia y Ortografía difieren en su objeto de estudio y en el plano de la lengua, enseñanza que ha llegado hasta nosotros. La separación no es rigurosa, sin embargo: los fragmentos recogidos de la GRAE-1870 anuncian que la pronunciación de las letras será punto de encuentro de estas dos subdisciplinas gramaticales, puesto que la pronunciación es competencia de la Prosodia y la letra es el objeto de estudio de la Ortografía. Pero no solo la pronunciación de las letras, también la pronunciación de las sílabas, que, en principio, es asunto propio de la Prosodia, tiene importancia en la práctica ortográfica. Los siguientes fragmentos dan idea de la proximidad e interrelación entre estas dos partes del estudio gramatical:

$\underline{\text { La Prosodia es aquella parte de la Gramática que enseña la recta }}$ pronunciacion y acentuacion de las letras, sílabas y palabras.

(GRAE-1870: 287. El subrayado es mío) ${ }^{108}$

Tres principios dan fundamento á la Ortografía castellana: la pronunciación de las letras y sílabas, la etimología, ú origen de las voces, y el uso de los que mejor han escrito.

(GRAE-1870: 310. El subrayado es mío) ${ }^{109}$

${ }^{108}$ Monlau (1870: 177) aclara sobre esta subdisciplina que

en los idiomas neolatinos, es el tratado de la aspiracion, la cantidad y el acento, de la recta pronunciacion, de la ortología ú ortoépia de cada lengua. Aplicada la prosódia á la lectura en alta voz, la declamacion oratoria, etc., constituye el tratado especial de la Pronunciacion; - y aplicada al verso constituye la Métrica.

De ahí la conexión habitual Prosodia-Arte métrica (recuérdese el sistema de Comisiones establecido en los Estatutos de 1848 -vid. supra 3.2.1.-).

${ }^{109}$ Estas palabras prácticamente coinciden en la definición/explicación ofrecida por Monlau (1870: 140-141) en su Vocabulario gramatical:

[La Ortografía es] Parte de la Gramática que da reglas para escribir correctamente, conforme al buen uso, fundado en la pronunciacion y la etimología de las voces.

(Pág. 140) 
- Los Diccionarios establecen una separación más clara, aunque tampoco faltan en ellos ciertas "vacilaciones". En todos, se asigna invariablemente a la Prosodia la tarea de la pronunciación (frente a la Ortografía, que se encargaría de enseñar la recta utilización de las letras y otros signos de la lengua escrita $\left.{ }^{110}\right)$, pero con distintos matices en cada una de las ediciones que merecen ser tenidos en cuenta: desde Autoridades hasta el DRAE1837, se le atribuye la pronunciación en general; en los DRAE de 1843 y 1852, parece que se le asigna solo la pronunciación de las sílabas; en el DRAE-1869, la pronunciación de los vocablos (posiblemente, por influjo de la GRAE anterior, la de 1867 -reimpresión de la de 1858-111); a partir de 1884, a la Prosodia pertenece la pronunciación de las letras, sílabas y palabras (la nueva formulación parece sugerir que la Prosodia vuelve a atender a la pronunciación en general). Vid. Glosario final s.v. prosodia.

También en este punto, como en otros de los tratados hasta el momento, pueden resultar reveladoras las palabras de Angulo en su citado Proyecto de Gramática. La lectura de estas páginas elimina cualquier duda sobre la aceptación o no, por parte de este académico, de la Ortografía y la Prosodia dentro de la Gramática (disciplina y libro) ${ }^{112}$. Ambas son partes legítimas: la Ortografía, porque su fin es enseñar a escribir de forma adecuada (y la Gramática es para Angulo, siguiendo a Nebrija, «arte de hablar y escribir rectamente»-pliego 3. ${ }^{\circ}-$ ) y la Prosodia, porque es reconocida "parte de la Gramática" entre todos los autores (aunque no haya consenso en cuanto a los

Las bases de toda ortografía, en lenguas derivadas y escritas, como la castellana, son, y no pueden dejar de ser otras, que la pronunciacion, el orígen de las voces, y el uso de los doctos.

(Pág. 141)

\footnotetext{
110 Empleo correcto de las mayúsculas, del acento ortográfico, de los signos de puntuación y de ciertas letras problemáticas: $b / v, g / j, c / k / q u, c / z, i / y$, etc.

111 Vid. infra nota 114.

112 Lo que evidencia que, en este asunto concreto, como en otros, las ideas de Angulo no cobraron cuerpo en la GRAE-1771: en ella, ni Ortografía ni Prosodia se recogen ni como parte del libro ni como parte de la disciplina.
} 
contenidos de la misma). Angulo es consciente de los problemas de delimitación con que se han encontrado los que le han precedido en el intento y, para sortear este obstáculo a la hora de elaborar la Gramática (libro), intenta asentar él una distinción que cree fundamental:

\section{[...] seva atratar de la Orthographia con distincíon, y} separacion de la Prosodía, como partes diferentes, y suxetas a la Gram.ca, y asi son otras las medidas: por esto señalando terminos a cada una digo que la Orthographia como parte de la Gram.ca española debe comprehender supuesta una breve introduccíon, y el Alphabeto, la pronuncíacíon de las letras simples por que este es uno delos accidentes de ellas, segun Nebrixa: desp. las reglas de escritura reducidas á aquellas letras ó Characteres equivocos enla pronunciacíon, quando forman sylaba, como la b, y la v, la f. y la ph. $\&^{a}{ }^{a}$ de las quales solo se enseñara el uso que se deba hazer en lo escrito [...] sín transcender á otra cosa, por que todo lo demás perteneciente ala pronunciacíon de estas mismas letras, y de las demas ha de quedar ala Prosodia [...] por lo pertenez.te ala Prosodia, y pronuncíaz. ${ }^{\mathrm{n}}$ en que con separacíon de letras se notaran todas las pronunciacíones que cada una puede tener en ntro Idioma en concurrencía con las demas letras formando sylaba [...]

(ARAE, 1741a: pliegos $34^{\circ}$ y $35^{\circ}$. El subrayado es mío)

En el Proyecto de Angulo, sí se delimita con claridad la separación entre Ortografía y Prosodia en esa "materia común" que es la pronunciación de las letras: la Ortografía atiende a la pronunciación aislada de las letras; la Prosodia, a la pronunciación de las letras en combinación silábica. La teoría recogida en Autoridades es anterior a esta declaración ${ }^{113}$, por lo que la aportación de Angulo supone un añadido de información y de precisión que no fue tenido en cuenta para la Gramática.

113 En 1734, se publica el tomo de la letra G (Gramática) y, en 1737, el de las letras O y P (Ortografía y Prosodia). 
La propuesta de Angulo de dar cabida en el libro de Gramática a la Ortografía y la Prosodia no se llevará a la práctica hasta la GRAE-1870114, y ello pese a que la Comisión de Gramática formada por Hartzenbusch, Fernández-Guerra y Monlau había dictaminado en 1861 que la Gramática «deberia contener unos elementos de Prosódia y de Ortografía» (RAE, 1861b: 15). En la GRAE-1870, la distinción básica entre ambas subdisciplinas gramaticales (que, en puntos conflictivos como lo es el de la pronunciación de las letras, establece el Proyecto de 1741) sólo será recogida implícitamente, ya que las declaraciones explícitas que se leen en los apartados correspondientes podrían llevar a la "confusión" de competencias, tal como se ha visto.

114 Las declaraciones de las GRAE anteriores a 1870 que reconocen la Ortografía y la Prosodia como partes de la disciplina (GRAE de 1796, 1858 a 1867) se limitan a marcar la diferencia escritura (Ortografía) / pronunciación (Prosodia), sin mayores precisiones:

La Ortografía enseña el número y valor de las letras de que se forman las sílabas y palabras [...] la Prosodia el sonido propio y verdadera pronunciacion de las letras, sílabas y palabras, de que se compone el lenguage.

(GRAE-1796: 1-2. El subrayado es mío)

[...] la ortografía establece reglas para el acertado uso de las letras y los demas

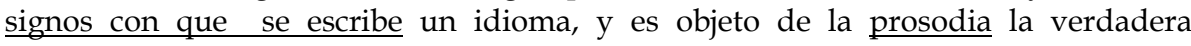
pronunciacion de los vocablos.

(GRAE-1858: 1 y GRAE-1867: 5. El subrayado es mío) 


\subsubsection{Información adicional de los libros de Gramática}

Una vez visto cómo toma cuerpo a lo largo de la tradición académica (hasta 1925) la concepción de gramática vertida en Autoridades, debe hacerse mención de otras ideas sobre la disciplina, de las que también tenemos conocimiento a través de las Gramáticas. Tanto las ideas que se mantienen como las que se modifican $\mathrm{o}$, incluso, las que se pierden dan noticia de la evolución doctrinal de la Institución en lo tocante a su concepción de la labor gramatical. Resumo las ideas más destacadas:

\section{EL ARTIFICIO GRAMATICAL COMO FIJACIÓN DEL ESPLENDOR DE UN IDIOMA}

En su primera Gramática, la Academia parece asumir como principio que el estudio gramatical es el medio más eficaz de fijar una lengua en su momento de esplendor. El uso no basta: la lengua debe reducirse a artificio.

En esta línea de argumentación, los académicos -como Nebrijaatribuyen el prestigio de lenguas como el latín y el griego a que, en el período clásico, se disponía de gramáticas de la lengua propia y de escuelas para estudiarlas. Y es que

conocian [los griegos y los romanos] la utilidad y necesidad del uso; pero conocian tambien que convenia perfeccionarle con el arte.

(GRAE-1771: II. el subrayado es mío)

Para que la lengua alcance su máximo esplendor y quede fijada, es necesario, además, el respaldo oficial, de modo que la Institución se sumará en el siglo XVIII a la práctica ya cultivada por Nebrija en su Gramática 
Castellana cuando encomendaba el futuro de la lengua a la reina Isabel ${ }^{115}$. La declaración de la Academia es la que sigue:

Ninguna [lengua], Señor, podrá contarse en esta clase con mejor título que la nuestra [...] y ya que la ha llevado [V.M., Carlos III y Carlos IV, respectivamente] con su valor á los últimos términos del orbe, debe ponerla con su estudio en el alto punto de perfección á que puede llegar.

(GRAE-1771 y GRAE-1796. Dedicatoria al Monarca)

A partir del siglo XIX, no tenemos ninguna insinuación de esta idea. Se pierde, por tanto, en las Gramáticas de nuestro corpus central, uno de los tópicos inaugurales de la tradición gramatical española116.

Pero no es solo que dejemos de tener declaraciones que apunten o insinúen que el artificio gramatical (especialmente, si cuenta con un respaldo oficial) es procedimiento idóneo para la fijación de las lenguas, es que, precisamente, en la segunda mitad del XIX, algunas de las GRAE declaran de forma explícita que es imposible fijar una lengua. En este sentido, interesa recordar aquella reflexión que la Institución hacía en la GRAE-1870 (muy posiblemente por influjo de Salvá) acerca de cómo las lenguas cambian

115 Con estas palabras solicitaba el lebrijano auspicio a la corona:

[...] a ninguno mas justa mente pude consagrar este mi trabajo: que a aquella: en cuia mano $\tau$ poder no menos esta el momento dela lengua: que el arbitrio de todas nuestras cosas.

(Nebrija, 1492: fol. 3v. $\left.{ }^{\circ}\right)$

116 La omisión de esta solicitud de amparo es ya en estas fechas de obligado cumplimiento (aunque -o precisamente porque- la Academia gozaba de privilegios de oficialidad desde su fundación y los había logrado muy pronto para el libro de Gramática, según queda indicado en el capítulo 2, punto 2.3.). Contra este favor gubernamental se rebelan algunos gramáticos coetáneos de los textos que estamos analizando; en uno de ellos, incluso, leemos que el respaldo oficial que reciben ciertas obras (de todo tipo) bloquea el desarrollo de la ciencia, y que esa fiscalización oficial se da en proporción especialmente importante en el estudio de la lengua (remito, para constatación de lo que digo, a Herrainz, 1869: VII-XI). 
continuamente, lo que convierte en absurda la pretensión del gramático de "estancar" con su obra el sistema lingüístico estudiado (remito a lo dicho en 4.2.1., 3.).

\section{JUSTIFICACIÓN DE UNA GRAMÁTICA DE UNA PRIMERA LENGUA}

En el siglo XVIII, la Academia siente la necesidad de justificar por qué escribe una Gramática del castellano, en castellano y para hablantes nativos; en el siglo XIX, no.

En las dos ediciones dieciochescas que estamos considerando, leemos:

Pocos habrá que nieguen la utilidad de la Gramática si se considera como medio para aprender alguna lengua estraña; pero muchos dudarán que sea necesaria para la propia, pareciéndoles que basta el uso.

No lo pensaban así los Griegos ni los Romanos, pues sin embargo de que para ellos eran tan comunes la lengua griega y latina como para nosotros la castellana, tenian Gramáticas, y escuelas para estudiarlas.

Conocian la utilidad y necesidad del uso; pero conocian tambien que convenia perfeccionarle con el arte.

Lo mismo debemos pensar nosotros de nuestra lengua, en la qual hallamos que observar cada dia cosas nuevas por medio de la Gramática [...] Ella nos hace ver el maravilloso artificio de la lengua.

(GRAE-1771: I-II; GRAE-1796:I-II)

¿Todavía es necesario, en estos años, seguir justificando la elaboración de obras gramaticales de una primera lengua? En fecha cercana, 
comprobamos que Martínez Gómez Gayoso (1769 [1743]) ${ }^{117}$ también parece sentir la necesidad de explicar su labor, algo que Correas, sin embargo, no había hecho más de un siglo antes ${ }^{118}$. Podríamos entender actitudes como las de la Academia o Gómez Gayoso como epígonos del tópico y típico movimiento de revalorización de los vulgares que preside el Siglo de Oro (especialmente, el español119). Tal vez, como opina Gómez Asencio (2000a) ya no exista verdadera necesidad de justificación por parte del gramático, quizá estemos ante una de tantas aceptaciones de lo establecido (el modelo de prólogo iniciado por Nebrija y seguido muy de cerca por Villalón) o bien se trate de una estrategia para zanjar debates que ya se sentían estériles. El caso es que esta "necesidad", real o pretendida, se siente solo en las GRAE del XVIII. En el XIX, mantener un tópico de este tipo o -lo peor- sentir realmente como necesaria una justificación estaría totalmente fuera de lugar; el gramático tendría que explicar por qué se justifica de lo que hace. Y es que, en la segunda mitad del siglo XIX, cuando la RAE reanuda públicamente su labor gramatical, la oportunidad (y necesidad) de escribir una Gramática de una primera lengua está más que probada y aceptada científica, social y pedagógicamente.

Por otra parte, no debemos dejar de mencionar que, en el siglo XVIII y pese a la decisión institucional de justificación -expresa en los primeros libros

117 Sus palabras podrían haber inspirado las de la Academia:

Pocos habrá que tengan por necessaria esta Gramatica, sino para las Lenguas Estrangeras, creyendo, por falta de meditacion, y lectura, que no se halla diferencia en saber rudamente la Lengua materna como el vulgo, y en saber el artificio de ellas, y sus reglas.

Ápud López Martínez y Hernández Sánchez (1994: 17).

118 Tampoco San Pedro dos años antes de publicarse la primera GRAE.

119 Pastor (1929) y Bleiberg (1951) reúnen una interesante antología de elogios y apologías que, en nuestra Edad Dorada, se hicieron del castellano, por parte de gramáticos, filólogos, poetas, políticos, oradores, místicos, etc. (el último estudioso amplía la muestra hasta el siglo XIX). Estos testimonios no solo encierran una alabanza del español, también sirven de muestra de la preocupación lingüística del momento, preocupación tanto por el idioma nacional como por la lengua en general. 
de Gramática-, hubo dentro de la Corporación voces en contra de esta práctica, tales como la de Ceballos en su proyecto de Gramática, quien se opone a la propuesta de Carlos de la Reguera:

[...] hay mucho que rebajar âel Proyecto del Sr Angulo conq. ${ }^{\mathrm{n}}$ me estrecho mas y convengo desde luego enque la Gramatica se trate en español y no en otro idioma por todas las razones que este cavallero apunta que ala verdad estan solida y juiciosamente ponderadas pero de ninguna manera convengo enque en el Arte se ponga el Prefacio ô Prologo que quiere el P.e M.o Reguera recomendando la necesidad y utilidad de esta obra; porque nadie ignora que hasta ôra no tenemos Gramatica Española, y todos saben que para pulir y hermosear un Idioma es menester que la âya, y âsi de echo se convenze la necesidad y utilidad sinque sea necesario por convencer alos ignorantes agraviar alos sabios.

(ARAE, 1741b: pliegos 3 y 4. El subrayado es mío)

\section{GRAMÁTICA MÁS MORFOLÓGICA QUE SINTÁCTICA}

La Morfología (en los textos, Analogía) es la parte declarada más difícil y a la que, por ello, más extensión se dedica; a la Morfología pertenece la clasificación de las palabras y todo lo relacionado con sus accidentes. Esta concepción es la que encontramos en las GRAE del XVIII y la que, básicamente, se mantiene en la primera Gramática del XIX (GRAE-1854). Lo dicho se comprueba con la lectura de los propios textos académicos. Destaco el siguiente fragmento:

Se ha dado á la primera parte, esto es, á la Analogía, más extensión que á la segunda, ó sea á la Sintáxis, porque en aquella están las más notables anomalías, y por consiguiente las mayores

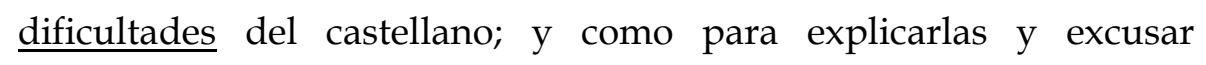
frecuentes remisiones ha sido forzoso anticipar más de una vez 
nociones de construccion, aparecerán algunas de éstas en ambas partes del Tratado, lo cual si algo perjudica á su más rigorosa y matemática division, ofrece evidentemente más ventajas que el sistema contrario, segun el cual serian incomprensibles muchos preceptos sobre la índole, la significacion y el uso de las diferentes partes de la oracion.

(GRAE-1854: IX. El subrayado es mío) ${ }^{120}$

En 1854, se sigue insistiendo en la conveniencia -y necesidad- de una visión conjunta de los apartados rotulados Analogía y Sintaxis, idea ya apuntada en las GRAE de 1771 y 1796. No obstante, la Academia concibe todavía ambos apartados como objetos de estudio bien diferenciados y separados aún; no de otra forma se explica que se excuse por romper «la rigorosa y matemática división» de la Gramática121.

Además, entiende la Academia -con toda la tradición anterior y posterior- que la clasificación de las partes de la oración compete a la Analogía, aunque tenga ésta como auxilio la Sintaxis, una prueba evidente de que estamos ante una Gramática donde el peso se carga, sobre todo, en una de las partes de la disciplina (la primera del libro): la Analogía. Y, a pesar de que, en efecto, ahora se entiende ( $\mathrm{y}$, de hecho, se lleva a la práctica) que el estudio de la Sintaxis puede iluminar el de la Analogía -al contrario de lo dicho en 1796122_, veremos, en el capítulo correspondiente, cómo las GRAE del XIX no siguen el paso, en cuanto al alcance de su teoría y de su descripción sintácticas y en cuanto a la importancia concedida de facto -no en teoría- a estas dos partes en su obra, a autores que debían ser bien conocidos por la Institución.

\footnotetext{
120 Idéntico fragmento en la GRAE-1858: VI.

121 Alusión clara al método geométrico, del que ya se ha hablado (vid. supra 4.2.1., 1.).

$122[\ldots]$ Se ha procurado que todas las reglas de la Analogía y Sintáxis formen un sistema completo, que tengan entre sí una perfecta correspondencia, y que las unas sirvan de fundamento á las otras, dando las de la primera parte luz para entender las de la segunda, y refiriéndose las de esta á los principios sentados en la precedente
} 
Así, por ejemplo, en la Analogía, haciendo caso omiso de posturas como la de Bello, la Academia presenta una clasificación semántico-formal de las palabras (y no funcional), según su práctica habitual. Esta clasificación se hará siguiendo criterios funcionales -al menos en teoría- a partir de la GRAE-1870 (sobre estos aspectos se volverá en el punto 6.2.).

En la segunda mitad del siglo XIX, la Academia presenta una Gramática que, en el sentido apuntado, está todavía en la línea de la tradición iniciada con Nebrija, esto es, una Gramática con más carga analógica que sintáctica. El cambio en los planteamientos académicos no se dejará sentir hasta la $30 .^{\text {a }}$ edición de la GRAE, la de 1917, donde el peso se invierte y la desproporción ahora privilegia a la Sintaxis (de ello se tratará con más detenimiento en el punto 6.3.).

\section{GRAMÁTICA DE LA LENGUA ESCRITA (LITERARIA)}

Prueba de ello son los modelos de lengua de que se vale la Institución. La RAE parece perder en ocasiones la perspectiva de la lengua hablada, como se puede comprobar en la declaración de principios que encontramos en el Prólogo de 1854, donde no se dice nada del uso oral de la lengua. Las palabras a las que me refiero son las que siguen:

[...] no puede explicarse en un breve compendio... el sinnúmero de locuciones $\mathrm{y}$ frases que han usado y usan nuestros buenos escritores $[\ldots]$

(GRAE-1854: VIII. El subrayado es mío)

Sostener la grandeza de tan bello idioma es y debe ser el único afan de esta Real Academia, la cual... le recomienda [a la Juventud española] con el mayor encarecimiento el estudio y observacion 
$\underline{\text { constante de los escritores, }}$ prez y orgullo de nuestra patria. La aprovechada lectura de las obras con que han inmortalizado su nombre Fray Luis de Granada y Miguel de Cervantes, Mariana y Solís, Lope y Rioja, Moratin y Jovellanos, enseñará á los estudiosos lo que no es dado á un libro, destinado sólo á franquear las puertas del saber humano.

(GRAE-1854: x y GRAE-1858: VII. El subrayado es mío)

En ediciones posteriores, encontramos afirmaciones que redundan en esta misma idea:

El fin de toda GRAMÁTICA es enseñar á conocer, ordenar, pronunciar y escribir correctamente las oraciones y las partes todas de que constan, pues con las oraciones se forman los períodos, y con los períodos las obras literarias.

(GRAE-1870: 5. El subrayado es mío)

Continúa vigente, por tanto, en el último tercio del siglo XIX, uno de los postulados académicos: la forma escrita literaria de la lengua es preferible a la oral, porque es más perfecta. La RAE sigue confiando en la autoridad de los escritores, incluso en la de aquellos que ya han "caducado"123: encontramos ejemplos de Lope, Góngora, Garcilaso, Calderón, Cervantes, etc. ${ }^{124}$.

\footnotetext{
123 Salvá defendía que, en una gramática castellana (en tanto gramática particular) se debía ejemplificar con autores coetáneos, debido a la caducidad de los preceptos del arte.

${ }^{124}$ La Autoridad de los escritores clásicos parece indiscutible. Sirvan de ejemplo los siguientes datos, entre los muchos que podrían darse:

- En todas las GRAE del corpus: uso de puente como femenino (Lope, Calderón, Góngora), elipsis (Lope, Cervantes, Calderón).

- Hasta la GRAE-1911: pleonasmo (Cervantes y Moratín), concordancia relativoantecedente (Cervantes).

- En las GRAE-1917 y 1924: omisión de la cópula (Cervantes, Fray Luis de León), concordancia adjetivo y verbos con nombres colectivos (Cervantes); etc., etc.
} 
En realidad, esta defensa de la lengua literaria como modelo de perfección idiomática puede entenderse como corolario de la defensa de un modelo lingüístico basado en el consensum eruditorum de Quintiliano. La autoridad de la lengua reside en las mejores obras literarias porque, en rigor, son los escritores los que inventan y dignifican el idioma (no tanto los sabios, los preceptistas, etc.). Normal es también, por otra parte, que esta defensa la encontremos pasado el Siglo de Oro: en el XVI, cuando las primeras gramáticas, no cuenta nuestra lengua con autoridades literarias de la talla de las del Trecento italiano y por ello el modelo de seguimiento en nuestro país se elegirá dentro de la lengua oral; de ahí que Nebrija apele al «común consentimiento de los que tienen poder para hacer uso» (fol. $10 \mathrm{v}$.).

Volviendo a la concepción académica, el fragmento que hemos reproducido de la GRAE-1870 se repite con ciertas modificaciones de importancia en las dos ediciones que le siguen:

El fin de toda GRAMÁTICA es enseñar á conocer, ordenar, pronunciar y escribir correctamente las oraciones y las partes todas de que constan; pues con la agregacion y enlace de las oraciones se forman los períodos, y con los períodos la conversacion ó plática, y toda clase de discurso hablado ó escrito, desde el más familiar hasta el de más elevado estilo literario: en todos los cuales nos conviene expresar nuestro pensamiento con claridad, propiedad y exactitud.

(GRAE-1874 y 1878: 16)125

A partir de la $13 .^{\text {a }}$ edición de la GRAE (1874), parece ampliarse la mirada hacia las manifestaciones orales de la lengua, pero los ejemplos de

\footnotetext{
${ }^{125}$ La misma idea subrayada -con una redacción casi idéntica- se encuentra en GRAE-1880, 1883 y 1885: 5. La mención explícita de la lengua oral y escrita la seguiremos encontrando con otra redacción- en todas las ediciones hasta la última del corpus: GRAE-1888 a GRAE1909: VI; GRAE-1911 a GRAE-1916: 6; GRAE-1917: VII; GRAE-1920 y 1924: 8. (Vid.. supra 4.1.).
} 
textos escritos seguirán siendo los protagonistas; y ello hasta las últimas ediciones de nuestro corpus, en las que incluso parece cobrar brío la concepción que defiende la preeminencia de la lengua escrita sobre la oral. En la GRAE-1917, junto con declaraciones donde el discurso hablado y el escrito están en equilibrio (uno de los objetivos de la Gramática es “enseñar a pronunciar y escribir oraciones"126), encontramos otras en las que la balanza vuelve a inclinarse por el platillo de la lengua escrita:

Lo que sí ha variado... es... el método y plan de exposición de la doctrina sintáctica [...] y además la doctrina gramatical se presenta confirmada por mayor número de autoridades de los más eminentes escritores españoles de todas las épocas.

(GRAE-1917: VI. El subrayado es mío)

Lo que parecía haber empezado a difuminarse en 1874 cobra relevancia en 1917, edición en la que se sigue defendiendo la primacía de la lengua escrita (literaria) y la validez de legitimar los usos descritos con ejemplos tomados de autores antiguos (más de un siglo) ${ }^{127}$.

\footnotetext{
126 Vid. supra 4.1.

${ }^{127}$ El gusto por lo antiguo se deja ver en otros aspectos. Así, la Academia parece mostrar complacencia en la descripción de usos obsoletos (por ejemplo, en todas las GRAE del corpus, se dedica un apartado a dar cuenta de usos antiguos de tiempos verbales). En algunas ocasiones, se avisa al lector de que se trata de usos pasados, pero en ningún caso se sancionan, ni se advierte sobre lo poco recomendable que es su empleo. ¿Se está poniendo la Gramática al servicio de la interpretación de textos antiguos?
} 


\section{CONCLUSIONES PARCIALES}

I. La Gramática es, para la Academia, un arte no una ciencia; en consonancia con esto, la GRAE es concebida, desde su gestación, con un fin utilitario (de enseñanza) bastante definido, y no como investigación científica que tenga como meta un conocimiento riguroso y exacto de los mecanismos de la lengua. La finalidad didáctica es obvia, sobre todo en los textos del siglo XVIII y mediados del XIX. A partir de las últimas décadas del siglo XIX, el objetivo didáctico se empieza a difuminar, al tiempo que aumenta el interés de la Academia por armonizar su Gramática con los últimos avances en el campo de la investigación lingüística; seguiremos teniendo, eso sí, listas, tablas, cuadros, y otro tipo de recursos que buscan una exposición clara de los contenidos gramaticales, pero, desde 1857, los textos que, principalmente, se van a regir por la finalidad pedagógica y didáctica son los Epítomes y los Compendios, y no tanto las Gramáticas.

II. La Academia reconoce que sus obras son susceptibles de mejora y, en las distintas ediciones de la Gramática, expone su disposición de llevar a cabo esas mejoras, pero dentro de unos límites porque:

- La Gramática académica, por su condición de texto "oficial", nunca podrá limitarse a defender una doctrina de carácter teórico-científico, ha de ser una Gramática ecléctica con finalidad práctica y alcance normativo (un arte, por tanto, tal como se ha dicho).

- Desde el punto de vista teórico, es aconsejable (y casi obligatorio para la Institución), mantenerse a una distancia prudente de las distintas doctrinas de escuela que van surgiendo, y no dejarse impresionar por novedades clasificatorias, terminológicas, etc., que -dicen- no aportan ningún beneficio al estudio gramatical de la lengua ni a la 
comprensión del funcionamiento de la misma. Pese a las necesarias reformas, los académicos están convencidos de que la Gramática cuenta con un cuerpo de doctrina que, en lo esencial, debe mantenerse (los siglos de tradición han demostrado que muchas de las explicaciones funcionan y que sustituir lo que hasta el momento ha dado buenos resultados conlleva el riesgo de no solo no mejorar, sino de entorpecer, además, el estudio de la lengua).

- La tradición gramatical española es digna de respeto y de seguimiento (quizá de ahí el apego a los autores clásicos, el mayor peso de la primera parte de la GRAE -Analogía- etc.). La Academia mantiene una actitud conservadora en sus doctrinas.

El caso es que las mejoras se anuncian mucho y tardan en llegar (hasta el punto de que, en la década más anodina de labor gramatical de la Institución -la de los años sesenta-, incluso se suprimen los anuncios de cambios).

III. La Gramática va desviando su atención desde el didactismo hacia la reglamentación lingüística, tendencia que empieza a despuntar de una forma más o menos evidente en la GRAE-1870, edición en la que, por primera vez, el objetivo pedagógico comparte protagonismo con el afán normativo en la declaración de principios que abre la obra. Podemos entender como paralelos dos hechos, que se inician en la misma edición:

- toma de conciencia (en las GRAE de 1870, 1874 y 1878) de la labor normativa (que se pierde en 1880 -en declaraciones explícitas-) y

- correspondencia entre la definición de la disciplina (que engloba el hablar y escribir -de forma correcta-) y los contenidos que se recogen 
tanto en la disciplina como en el libro de Gramática (en los que ya se consideran la Ortografía y la Prosodia). La vacilación anterior no era compatible con una consciente postura reguladora del uso lingüístico en todas sus manifestaciones.

También en la GRAE-1870 encontramos el primer intento de distinción metodológica explícita entre Gramática General y Gramática Particular. Y, aunque ya se ha dicho que, a partir de 1880, dejamos de tener declaraciones de principios doctrinales en esta línea en las Gramáticas, podemos considerar que, desde el DRAE-1884, la Academia entiende por gramática (sin adjetivo) la de una lengua concreta (esto es, una Gramática Particular) y que el estudio de los universales debe rotularse como Gramática General. Si esto es así, coincidirían también en la GRAE de 1870 (la inspirada en el Informe de la Comisión de 1861) dos hechos: la apuesta metodológica -por primera vez declarada explícitamente- por una Gramática Particular y la toma de conciencia del normativismo que debe regir toda Gramática (particular). En la GRAE-1880, no tenemos ni lo uno ni lo otro, es decir, ni declaración explícita de labor normativa ni deslinde de disciplinas gramaticales; pero, implícitamente, puede que ambas concepciones estén madurando en el seno de la Corporación, ya que, de un lado, seguiremos encontrando datos que apuntan a una actitud consciente de la labor normativa y reguladora a la que se debe una Institución de la talla de la $\operatorname{RAE}^{128}$ y, de otro, la distinción entre gramática (que es como la Academia llama a su obra) y gramática general no se perderá en los textos lexicográficos de la Corporación -y, por tanto, debemos entender que tampoco se pierde en la concepción académica, aunque no haya un pronunciamiento en las GRAE-.

128 No olvidemos que se mantiene la definición de gramática de «hablar y escribir correctamente» (vid. supra lo dicho en 4.2.1., 2.) y que, desde 1880, encontramos un capítulo dedicado a los Vicios de dicción, por ejemplo. 
IV. El jalón que sigue a la GRAE-1870 en cuanto avance en la concepción de la disciplina (y el máximo exponente de (r)evolución sintáctica, como se ha anunciado y como se verá detenidamente), la GRAE-1917, recupera manifestaciones explícitas de carácter regulador o normativo ${ }^{129}$. De modo que parece confirmarse que lo uno (el avance en descripción lingüística) y lo otro (el incremento de regulación, de vigilancia) parecen correr paralelos.

${ }^{129} \mathrm{Y}$ vuelve a poner el acento en la lengua escrita, según se ha expuesto en el último apartado. 


\section{IV}

\section{SINTAXIS}

$Y$

RELACIONES DE DEPENDENCIA 



\section{CRITERIO TERMINOLÓGICO \\ $Y$ \\ DE REPRESENTACIÓN DE RELACIONES}

Dada la inexistencia de una terminología única y de una propuesta comúnmente aceptada en el terreno de la investigación lingüístico-gramatical, y con el objetivo de evitar -en la medida de lo posible- la ambigüedad de conceptos, propongo, en este trabajo, el siguiente criterio terminológico, que será el adoptado en las páginas que siguen:

$\Rightarrow$ Relaciones de dependencia / complementación / subordinación intraoracional se usará sistemáticamente para hacer referencia a los vínculos que tienen lugar dentro de un esquema /(S) + P/. Intraoracional se opone, así, a interoracional, que hace alusión a relaciones entre dos o más esquemas $/(\mathrm{S})+\mathrm{P} /$, sin que ninguno de ellos sea elemento integrante del otro o de alguno de los otros.

$\Rightarrow$ Complemento de + categoría modificada (p. ej., Complemento de Nombre; Complemento de Adjetivo; Complemento de Verbo; Complemento de Adverbio; Complemento de Oración) será empleado cuando interese marcar qué tipo de categoría recibe la modificación o complementación, no qué tipo de elemento lleva a cabo dicha modificación. Así, Complemento de Nombre significa "un nombre recibe un complemento".

$\Rightarrow$ Complemento $+-a l$ (p. ej., Complemento nominal; Complemento adjetival; Complemento adverbial; Complemento oracional) se utilizará para hacer referencia a la categoría que desempeña la modificación o complementación. Así, Complemento nominal significa "un nombre hace las veces de complemento". 
Según lo dicho:
(1) Me gusta el chocolate blanco.
(2) Me pidió que la acompañara.

En casos como (1), se dirá que blanco es un Complemento adjetival que funciona como Complemento de Nombre. En (2), el Complemento del Verbo es un complemento oracional. A este último caso de complementación también me referiré con el término dependencia oracional, esto es, la categoría dependiente de otra es una oración (un esquema $/(S)+P /$ ), teniendo en cuenta que, en este trabajo de investigación, solo se va a atender con detenimiento a relaciones de dependencia dentro de la oración gramatical, esto es, a relaciones sintagmáticas intraoracionales.

La dependencia intraoracional puede ser, por tanto:

- No oracional (hoy, casos de "complementación"),

- Oracional (hoy, casos de "subordinación").

Ambos tipos (no oracional y oracional) son iguales desde el punto de vista funcional, pero diferentes desde el punto de vista categorial: en la dependencia intraoracional no oracional, el elemento dependiente es un sintagma (elemento simple); en la dependencia intraoracional oracional, el elemento dependiente es una oración, esto es, un esquema /(S) + P/ (elemento complejo). 
Se etiquetarán, por tanto, como casos de dependencia oracional las relaciones sintagmáticas intraoracionales que responden a los esquemas: $\mathrm{N} \hookleftarrow /(\mathrm{S})+\mathrm{P} /($ El chico del que te hable $) ; \mathrm{ADJ} . \hookleftarrow /(\mathrm{S})+\mathrm{P} /$ (Harto de que le tomen el pelo); $\mathrm{V} \longleftrightarrow /(\mathrm{S})+\mathrm{P} /$ (Pensaba que no volvería a verte; Saldremos cuando llegue); $/(\mathrm{S})+\mathrm{P} / \Longrightarrow \mathrm{V}$ (Actuar así con ellos no le ayudará; Quien acierte dos gana el premio), según el esquema marcado por Hjelmslev (1969 y 1976) para la subordinación (relaciones de dependencia unidireccional, frente a las relaciones bidireccionales de interdependencia o solidaridad).

NOTA: En adelante, se utilizarán los símbolos $\Rightarrow / \hookleftarrow$ para indicar la dirección de la complementación $(\mathrm{A} \Rightarrow \mathrm{B}: \mathrm{A}$ complementa o modifica a B; $\mathrm{A} \hookleftarrow \mathrm{B}: \mathrm{B}$ complementa o modifica a A) y el símbolo $\rightarrow$ para marcar la dirección de una relación de regencia $(\mathrm{A} \rightarrow \mathrm{B}: \mathrm{A}$ es el elemento Regente y B, el regido). Por tanto, la dirección de la complementación podrá ser de izquierda a derecha o de derecha a izquierda, pero la de la regencia solo podrá darse de izquierda a derecha. 

IV. 1

\section{Los Diccionarios}

En el diccionario está continuamente presente la gramática, y ello es así porque no se puede aislar el léxico de la gramática, de la morfosintaxis. Es más, la lexicografía no es una disciplina independiente, al menos como práctica, sino que hace uso de las otras ramas de la lingüística: gramática y diccionario se complementan, se entrecruzan necesariamente, tanto en su forma como en sus contenidos, debido al carecer descriptivo que poseen, y a las necesidades didácticas que han de atender.

Alvar Ezquerra (1997: 128-129) 



\section{EL CONCEPTO DE SINTAXIS Y LAS RELACIONES DE DEPENDENCIA EN LOS DICCIONARIOS DE LA RAE}

Comienzo, en este capítulo, el estudio de la concepción sintáctica defendida por la Real Academia Española en el período delimitado (segunda mitad del siglo XIX y primer cuarto del XX), abordando, en primer lugar, el análisis de la información sobre sintaxis y sobre relaciones sintácticas de dependencia vertida en la tradición lexicográfica de la RAE. Los conceptos de sintaxis, construcción, concordancia, régimen, coordinación, subordinación, incidencia, incrustación, complemento, preposición y conjunción (vid. Glosario final) han sido el foco de atención para este repaso a la doctrina académica en materia sintáctica desde Autoridades ${ }^{1}$ hasta el DRAE de $1925^{2}$.

En este punto de la investigación, cabe plantearse las siguientes preguntas: ¿los principios establecidos en Autoridades serán acogidos de forma paralela en los Diccionarios y las Gramáticas posteriores? ¿Irán, por el contrario, los planteamientos sintácticos de las obras lexicográficas por un camino y los de las obras estrictamente gramaticales por otro?

\footnotetext{
1 Al igual que en el apartado anterior, me veo obligada a analizar los textos académicos precedentes al período acotado para poder hacer una evaluación fundamentada.

2 En este capítulo, no puedo dejar de mencionar los estudios sobre lexicografía académica (centrados en Autoridades) de Gili Gaya (1963), Lázaro Carreter (1972), Esteve Serrano (1982), Val Álvaro (1992), Azorín Fernández (2000: 159-199), Freixas Alás (2003) y Blecua (2006) -a los que se podría añadir la circunstancial atención de Rico (1986) al primer Diccionario académico-; algunos de ellos los he tenido especialmente presentes a la hora de redactar estas páginas, para lo cual también me han sido útiles los trabajos de Alvar Ezquerra (1982 y 1997), Ahumada Lara (1988) y Rojo (1997) sobre la relación entre las informaciones ofrecidas por los diccionarios y por las gramáticas. Otros estudios de lexicografía académica que interesa tener en cuenta son el de Alvar Ezquerra (2002 [1993]) sobre los prólogos de las distintas ediciones del DRAE y el de Campos Souto y Pérez Pascual (2006).
} 
Partiendo de los supuestos expuestos en el capítulo 1, y con el objetivo de trazar una visión completa de la doctrina sintáctica defendida por la Institución, he procedido a examinar:

$\left.1^{\circ}\right) \mathrm{Si}$, efectivamente -tal como cabe suponer-, coinciden los planteamientos del Diccionario y de la Gramática.

$2^{\circ}$ ) Si los planteamientos de las GRAE y de los Diccionarios coetáneos evolucionan o quedan estancados; y, en caso de evolucionar, si lo hacen paralelamente o de forma independiente.

$\left.3^{\circ}\right)$ Si los cambios vienen impulsados por el tipo de obra o por la fecha de publicación de la misma. Esto es, si las modificaciones doctrinales -aunque se den de forma paralela- se introducen sistemáticamente en una de las dos obras (siempre en el Diccionario o siempre en la Gramática) y de ahí pasan a la otra; o si la adopción de novedades con respecto a la doctrina establecida puede encontrarse indistintamente en cualquiera de los dos libros (y depende, por tanto, de la fecha en que se decida dar cabida a un determinado cambio y del tipo de obra que vaya a salir antes a la luz en ese momento).

El primer paso será trazar la evolución de los conceptos referentes a las relaciones sintácticas en Autoridades y en los DRAE. De ello darán cuenta las páginas de este capítulo3 ${ }^{3}$ En el capítulo siguiente se completará la visión con la información obtenida de los libros de Gramática.

\footnotetext{
${ }^{3}$ La evolución en los textos lexicográficos de la RAE será contrastada, en cada uno de los puntos de este capítulo, con la doctrina que sobre los mismos conceptos exponen dos diccionarios decimonónicos: el primero de ellos es el Vocabulario gramatical de Pedro Felipe Monlau, del cual se extrae información de máximo interés para esta investigación por cuanto es un diccionario de tecnicismos gramaticales $\mathrm{y}$, además, un diccionario elaborado por uno de los académicos más relevantes en las labores gramaticales de la Institución en la segunda mitad del XIX (recordemos una vez más que estuvo en la Comisión que redactó el Dictamen
} 


\subsection{Los conceptos de sintaxis y construcción}

La concepción que sobre la Sintaxis se defiende en los Diccionarios académicos solo puede extraerse considerando conjuntamente los lemas sintaxis y construcción, que, en los textos lexicográficos del corpus, se entienden como equivalentes ${ }^{4}$ (en su momento, comprobaremos si lo son también en las Gramáticas).

\subsubsection{El camino iniciado en Autoridades y seguido en las primeras ediciones del DRAE}

Desde Autoridades hasta el DRAE-1822 -inclusive-, se define invariablemente la Sintaxis como el «modo de coordinar las oraciones, ó el tratado de Gramatica que enseña los casos, que pide cada verbo, y las oraciones latinas» (vid. Glosario final, s.v. sintaxis) ${ }^{5}$. Para desentrañar la verdadera concepción que de sintaxis se está defendiendo en estas palabras, tendremos que resolver dos cuestiones.

\section{Cuestión primera: partes articuladoras de la definición}

Según esta definición, y tal como hoy interpretamos los términos definitorios desde el punto de vista gramatical, la unión de oraciones sería, en principio, el objeto de estudio de la Sintaxis, si bien esta primera afirmación perdería validez tanto en una concepción propia de una Gramática General como de una Gramática Particular del español -según ha señalado Esteve

de 1861 y en la que se encargó de redactar la GRAE-1870). El segundo diccionario que se tendrá como punto de referencia es el Diccionario de construcción y régimen de Rufino J. Cuervo. No parece necesario justificar su consulta.

4 Veremos que, en el siglo XVIII y primeras décadas del XIX, la equivalencia puede ser discutible, mientras que parece indudable a partir de la cuarta década del siglo XIX. No obstante, también será necesario hacer ciertas matizaciones a propósito de las últimas ediciones.

5 También en todos ellos encontramos una misma segunda acepción, de carácter "extragramatical", según la cual, la Sintaxis es «la ordinacion que artificiosamente tienen las cosas entre sí» (vid. Glosario final, s.v. sintaxis). 
Serrano (1982: 143)-, ya que inmediatamente después queda establecido que la Sintaxis es un tratado de gramática latina.

Sin embargo, dicha invalidez es discutible, en mi opinión: sólo puede defenderse si se entiende la $o$ de la definición como nexo identificativo, no si se entiende como disyuntivo en sentido estricto. La puntuación hoy nos haría pensar en el primer valor -identificativo- y el uso de artículo determinando a "tratado de Gramática", en el segundo -disyuntivo-; pero, en los siglos XVIII y XIX, tanto los criterios de puntuación como los de uso de determinantes y artículos eran distintos de los imperantes hoy, y, además, en el DRAE-1817 se elimina la coma delante de la conjunción, sin que podamos afirmar que la supresión se deba a un cambio de concepción (entre otras razones, porque la coma se recupera en la edición de $1822^{6}$ ).

No es necesario, sin embargo, dilucidar el valor del sistema de puntuación $^{7}$ ni el uso de determinantes en la época que nos ocupa; basta -creo- con ojear los Diccionarios en cuestión y atender a la información dada en la entrada correspondiente al lema 0 . Al hacerlo, comprobamos que, en todos ellos (desde Autoridades hasta el DRAE-1822) se reconoce el valor de conjunción/partícula disyuntiva ${ }^{8}$, pero en ninguno encontramos el mínimo indicio de reconocimiento de un valor identificativo o de equivalencia implícito en $o$ (un valor aproximado a "esto es", "es decir", “o sea”) ${ }^{9}$. Por tanto, y frente

\footnotetext{
${ }^{6}$ Cf. Glosario final, s.v. sintaxis.

7 Un sistema que, cuando menos, contaba con cierta dosis de arbitrariedad (es lo que se deduce de los artículos de los propios Diccionarios), como hoy también nuestra puntuación es, en cierto modo, arbitraria.

8 Los Diccionarios no dan ningún tipo de definición o de explicación de lo que es una conjunción disyuntiva hasta el DRAE-1884, donde leemos que este tipo de conjunción «denota separación, diferencia ó alternativa entre dos ó más personas, cosas ó ideas» (vid. Glosario final, s.v. conjunción).

${ }^{9}$ Este valor no se encuentra en los Diccionarios del corpus hasta la edición de 1884, donde ya podemos leer que esta conjunción «denota además idea de equivalencia, significando ó sea, ó lo que es lo mismo. El protagonista, ó el personaje principal de la fábula, es Hércules» (vid. Glosario final, s.v.o).
} 
a lo sostenido por Esteve Serrano, debemos entender que la definición se articula en dos partes. Por Sintaxis se entiende:

1..$^{\circ}$ un procedimiento, una actividad: la coordinación de oraciones, en sentido general, $\mathrm{y}$

2. ${ }^{\circ}$ un resultado de esa actividad, una parte de un libro: el tratado de oraciones latinas, en particular ${ }^{10}$.

En todos los Diccionarios que estamos considerando, tras la definición propiamente dicha, se da el equivalente constructio (término latino con el que se tradujo el griego sintaxis). En la entrada correspondiente del lema construcción, comprobamos que esta se define, en términos propios de una Gramática General, como «la recta composición/disposición de las partes de la oración entre sí» (vid. Glosario final, s.v. construcción). Según las definiciones, sintaxis y construcción parecen diferir, en principio, en:

- El nivel sintáctico que estudian: la primera analiza la unión de oraciones y la segunda, la unión de palabras dentro de la oración.

- El alcance de su “campo de acción": la lengua latina, en la primera11, y cualquier lengua, en la segunda.

No podemos ocultar, sin embargo, que en la GRAE-1771 (es decir, más de un siglo antes) encontramos usos de la conjunción $o$ que no parecen tener otra interpretación que la de valor identificativo (Vid capítulo 6).

10 Esta segunda parte de la definición sería una especie de "tributo" último a la secular tradición, que identificaba los estudios gramaticales con los estudios de la lengua latina, según se ha visto al analizar el concepto de gramática. Esta "doble definición" que da Autoridades y que se mantiene hasta el DRAE-1822 estaría también en consonancia con la doble dimensión (general y particular) atribuida a la Gramática que se comentó en el capítulo 4. 
El segundo punto de discordancia queda eliminado argumentando el valor disyuntivo (y no identificativo) del nexo $o$ en los propios textos lexicográficos de la RAE comprendidos entre 1737 (Tomo V de Autoridades -letra O-) y 1822 (último Diccionario que presenta la "problemática" definición que hemos comentado). En este caso, si se acepta la interpretación que propongo, la Sintaxis, en la primera parte de la definición (esto es, entendida como modo de coordinar las oraciones), coincidiría con la Construcción en su “campo de acción” (cualquier gramática, no importa de qué lengua sea), pero el nivel estudiado por cada una de ellas seguiría siendo distinto (Sintaxis: oración; Construcción: palabra), según la primera impresión que de la definición puede sacar el lector actual.

Cabe plantearse ahora si realmente la definición de Autoridades habla de la suma de oraciones entre sí. La clave interpretativa está en el concepto de coordinación. Es la segunda cuestión que nos planteamos.

\section{Cuestión segunda: qué se entiende por "coordinar oraciones"}

En ninguno de los diccionarios comprendidos entre Autoridades y el DRAE-1822 encontramos una acepción gramatical para los términos coordinar y coordinación ${ }^{12}$. En este periodo, es la idea (extragramatical) de "colocar, poner en orden" la que subyace bajo estos conceptos.

El concepto de coordinar en los diccionarios del periodo nos obliga a replantear la interpretación que le habíamos dado a la primera parte de la definición de sintaxis: a la luz de este nuevo dato, parece que por "coordinar las oraciones" no debe entenderse la unión de oraciones (coordinación en

\footnotetext{
${ }^{11}$ Si nos decantamos por el valor identificativo del nexo $o$, como hace Esteve Serrano, lo cual no parece que sea lo más acertado.

${ }^{12}$ Cf. Glosario final, s.v. coordinación y coordinar.
} 
términos actuales), sino el ordenamiento interno de las mismas. La nueva interpretación evoca claramente esa idea de "disposición de las partes de la oración entre sí" que descubríamos bajo el lema construcción.

En consecuencia, Sintaxis y construcción también coinciden en el nivel sintáctico de análisis: ambas tienen como objeto de estudio la unión de palabras dentro de la oración.

Las cuestiones planteadas permiten defender la equivalencia Sintaxis = Construcción en Autoridades y las primeras ediciones del DRAE. 


\subsubsection{Los años de transición}

Parece que, en la obra lexicográfica de la Academia, es a partir del DRAE-1832 cuando los conceptos de sintaxis y construcción empiezan a asimilarse de manera menos equívoca: el primero ya no se asocia en modo alguno a la Gramática latina y se define como «coordinación de las palabras en el discurso», y el segundo sigue siendo definido como «la recta disposicion de las partes de la oración entre sí» ${ }^{13}$. Sintaxis y construcción coinciden ahora, por definición, tanto en las unidades objeto de estudio (las palabras o partes de la oración) como en el alcance general de su aplicación.

Esta concepción de la Sintaxis, formulada ya de forma explícita y sin la "doble definición" de Autoridades, es la que heredan los tres Diccionarios siguientes (DRAE-1837, 1843 y 1852) y la que se mantiene casi de forma invariable en la segunda mitad del siglo XIX hasta los años ochenta.

El DRAE-1852 es el último que da la equivalencia de constructio tras la definición estricta de sintaxis, una equivalencia que, de seguir la tesis defendida por Esteve Serrano, sólo podríamos considerar en las ediciones séptima (1832), octava (1837), novena (1843) y décima (1852) del DRAE, donde la construcción queda definida, como hemos visto, en términos muy similares a los que encontramos en la entrada correspondiente a sintaxis.

En el DRAE-1869 se mantiene la definición de sintaxis de la edición inmediatamente anterior (la de 1852), pero desaparece la equivalencia constructio. No obstante esta pérdida, construcción sigue definiéndose, en términos gramaticales, como «la recta disposicion de las partes de la oracion entre sí». Constatamos que no hay cambio en las formulaciones de los dos conceptos que estamos considerando: las definiciones de la edición anterior se

${ }^{13}$ Cf. Glosario, s.v.sintaxis y construcción. 
mantienen e implícitamente, por tanto, también se mantendrá la identificación sintaxis = construcción, a pesar de que, en este Diccionario, ya no se indique de forma expresa la equivalencia (vid. Glosario final, s.v.sintaxis y construcción: DRAE-186914).

En conclusión, en los años de transición, pese a los cambios (o mejor dicho, en virtud de los cambios) que experimentan las definiciones, se sigue defendiendo (ahora de forma inequívoca) la equivalencia Sintaxis = Construcción.

${ }^{14}$ En esta undécima edición del Diccionario reducido se tomó la decisión de suprimir «las correspondencias latinas que siempre habia llevado el Diccionario» (Viñaza, 1893: col. 1510). Efectivamente, en la página preliminar dedicada «AL LECTOR», la Institución anuncia esta supresión como la principal novedad respecto de las ediciones anteriores y justifica la decisión con tres argumentos: 1) adolecían de inexactitudes, que podían conducir a error; 2) ocupaban gran espacio y 3 ) no eran equivalentes a la etimología por cuanto la mayor parte del léxico patrimonial procede del latín vulgar (y las correspondencias se tomaban del latín clásico) y para los neologismos -de origen no latino- no existe equivalente latino. 


\title{
5.1.3. El final del camino: los cambios
}

Los cambios sustanciales en la definición de sintaxis vienen de la mano del DRAE-188415, edición en la que, por primera vez, la Sintaxis es reconocida y definida de forma expresa como «parte de la gramática» ${ }^{16}$, a la que se sigue reservando la misión de ordenar las palabras para formar las oraciones, con un añadido: «y expresar conceptos». También ahora en el lema construcción se hace referencia a la expresión de conceptos. Este añadido paralelo en las entradas correspondientes a las dos voces que estamos tratando viene a confirmar la identificación que defiendo (sintaxis = construcción), identificación que, a finales del XIX, sigue vigente (aunque la equivalencia explícita con el término latino la encontremos por última vez en 1852 -como ya se ha dicho-, último Diccionario que presenta la práctica generalizada de dar los equivalentes latinos).

\begin{abstract}
En esta edición da la Academia las etimologías de casi todos los vocablos españoles; hace un considerable aumento de palabras técnicas, ya bien formadas ó ya aceptadas de un modo permanente en el uso general; mas no acoge los tecnicismos completos de toda arte y ciencia, por suponerlo fuera de su objeto [...] Esta mejora de consignar en el Diccionario las raíces etimológicas de las voces castellanas, fué propuesta por D. Juan Valera en la Junta celebrada por la Academia el 24 de febrero de 1876, en lo relativo a los orígenes griegos y latinos de las palabras. $Y$ habiendo sido aceptada, se acordó también que se hiciese el estudio de las etimologías bascuences y arábigas, á proposición de los Sres. D. Antonio Cánovas del Castillo y D. Cándido Nocedal, y de las modernas por indicación del Sr. D. Desiderio de la Escosura, resolviendo al fin la Corporación incluir todas las averiguadas que no diesen lugar á duda ó controversia.
\end{abstract}

(Viñaza, 1893: cols. 1511-1512)

16 Desde Autoridades hasta el DRAE-1822, hemos visto que se definía, sin marcación alguna, como «modo de coordinar las oraciones» y como «tratado de Gramática (latina)»; a partir de 1817, esta doble definición irá acompañada de la marca Gram., que se mantiene en 1832, 1837, 1843, 1852 y 1869, diccionarios que, como queda dicho, ya definen la sintaxis de forma distinta de Autoridades (se suprime en ellos la segunda acepción). Aunque desde la primera mitad del siglo XIX la Sintaxis se considera voz relativa a la Gramática (tal como indica la marcación), no es hasta las últimas décadas del siglo cuando, en las obras lexicográficas, se le concede explícitamente el rango de parte constituyente esencial del estudio gramatical, puesto que, como puede comprobarse en el glosario que aparece al final de esta investigación, la fórmula "parte de la gramática" no viene a sustituir a la marca Gram., que se mantiene, sino a reforzar -entiendo- la importancia de esta subdisciplina en el estudio de la Gramática de una lengua. 
Al atribuir una vez más a la Sintaxis la misión de "coordinar palabras en la oración", esto es, de "ordenarlas metódicamente" (según se desprende de la definición de coordinación que dan los Diccionarios de este último periodo $\left.{ }^{17}\right)$, da la impresión de que el componente sintáctico de la lengua se sigue concibiendo como puro ordenamiento lineal, no como entramado de vínculos entre las palabras (concepción que no ha cambiado en lo que llevamos de recorrido). Parece que la Academia reduce la Sintaxis a relaciones de tipo conectivo (relaciones sintagmáticas lineales de unas partes con otras), sin considerar relaciones de tipo constitutivo y/o funcional (relaciones sintagmáticas no necesariamente lineales entre la parte y el todo en el que se integran $)^{18}$. Las definiciones que se ofrecen de oración, cifradas en términos puramente semánticos en todos los Diccionarios del corpus ("sentido perfecto" /"concepto cabal"), vienen a reforzar la idea de que el enfoque funcional-formal está ausente en los planteamientos sintácticos de la Academia en el periodo acotado para esta investigación (vid. Glosario final, s.v. oración $)^{19}$.

\footnotetext{
17 Cf. Glosario final, s.v. coordinación y coordinar. En realidad, como puede comprobarse, el concepto de coordinar no ha cambiado con respecto a los diccionarios anteriores. Solo se ha modificado ligeramente la redacción.

18 Guillermo Rojo (1983: 46 y sigs.) establece una diferenciación entre dos tipos de relaciones sintácticas: las denominadas conexiones (relaciones lineales parte-parte) y las calificadas como funciones (relaciones no lineales parte-todo, semejantes aunque no idénticas a las relaciones constitutivas). Las relaciones funcionales y las constitutivas son de naturaleza distinta pero inseparables por cuanto «no cabe hablar de función si no hay una constitución ni se puede concebir una relación constitutiva que no lleve a su lado la realización de una determinada función» (pág. 52).

19 La consulta de los lemas sujeto y predicado demuestra que la concepción de estos dos términos también está lejos de ser una concepción funcional-formal. En primer lugar, predicado no se entiende en ninguno de los Diccionarios del corpus como término gramatical (es voz de la lógica); por su parte, el lema sujeto recibirá la marca Gram. a partir del DRAE-1884, pero, hasta el último Diccionario del corpus, se definirá únicamente en términos semánticonocionales. Interesa contrastar las definiciones de 1925 (vid. Glosario, s.v. sujeto y predicado) con las que encontramos en el DRAE-2001 (22. ${ }^{a}$ edición) para calcular los pasos que separan la teoría defendida en el primer cuarto del siglo XX y la de principios del siglo XXI:
}

sujeto: \ 6. Gram. Función oracional desempeñada por un sustantivo, un pronombre o un sintagma nominal en concordancia obligada de persona y de número con el verbo. Pueden desempeñarla también cualquier sintagma o proposición sustantivados, con concordancia verbal obligada de número en tercera persona. $\mathbb{\text { If }} 7$. 
Sin embargo, la definición de sintaxis presenta en el DRAE-1884 un cambio de formulación con respecto a las ediciones anteriores que no debe ser pasado por alto. La nueva definición, de un lado, nos reafirma en la idea de que por coordinación de oraciones se entiende $-\mathrm{y}$ se ha entendido en las ediciones anteriores del Diccionario- la ordenación secuencial de sus elementos integrantes (las palabras) y, de otro, pone de evidencia que es en esta fecha cuando se produce el primer cambio sustancial en la concepción (más amplia ahora) de esta subdisciplina gramatical.

La sintaxis es, desde la 12. a edición del DRAE, la «parte de la gramática, que enseña á coordinar $\underline{\text { unir }}$ las palabras para formar las oraciones y expresar conceptos». El nexo copulativo sugiere que, para la RAE, coordinar y unir no son la misma cosa: efectivamente, según el Diccionario, coordinar es “ordenar metódicamente" y unir, "vincular, atar, trabar cosas para formar un todo o un compuesto" (vid. Glosario final, s.v. coordinar y unir). En 1884, por tanto, la definición de sintaxis está apuntando ya dos cosas:

- El factor orden (relaciones lineales parte-parte: relación entre palabras sin más) y

- el factor vínculo, trabazón (relaciones parte-todo: relación entre palabras que da lugar a otra unidad -"superior" a la palabra-) ${ }^{20}$.

Gram. Elemento o conjunto de elementos lingüísticos que, en una oración, desempeñan la función de sujeto.

Predicado: m. Fil. Aquello que se afirma del sujeto en una proposición. đI 2. Ling. Segmento del discurso que, junto con el sujeto, constituye una oración gramatical.

(DRAE-2001: 1820)

[Cf. http:/ / buscon.rae.es/draeI/SrvltConsulta?TIPO_BUS=3\&LEMA=predicado] 20 Idéntica definición de sintaxis seguimos encontrando en el DRAE-2001, s.v. sintaxis: 
Comprobamos que también la definición de construcción dada en los últimos diccionarios (desde la edición de 1884) incide en dos ideas no idénticas: si la construcción es el «ordenamiento y disposición á que se han de someter las palabras», debemos sospechar que son dos las misiones encomendadas a la construcción: una, la de ordenar, y otra distinta, la de disponer. En este punto, debemos reconocer que la búsqueda en el Diccionario nos empieza a introducir en una suerte de laberinto de matices significativos. Verdad es que entre «poner en orden, concierto y buena disposición» las palabras (idea de ordenar) y «colocarlas, ponerlas en orden y situación conveniente» (significado de disponer) ${ }^{21}$ no parece haber diferencia. No obstante, tampoco parece que aludan a lo mismo la buena disposición y la situación conveniente, por cuanto la idea de conveniencia apunta a la conformidad entre cosas distintas. Quizá, llegados a este punto, sean los étimos latinos los que nos den la pista interpretativa más fiable: por primera vez en las definiciones del Diccionario el ordo, la ordinatio ('fila, hilera') se combina con la dispositio, término que lleva a pensar ineludiblemente en el discurso retórico (que es orden pero proyectado hacia un todo). En palabras de Lausberg:

La dispositio interna de la obra, que, en cuanto actividad $\underline{\text { ordenadora, }}$ es un medio de la dispositio externa [la orientada a lograr el objetivo del discurso, la persuasión], consiste, así, en la elección

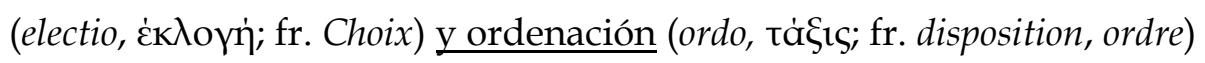
de las partes capaces de función (res et verba) y formas artísticas (figurae) para la totalidad del discurso (de la obra).

(Lausberg, 1993 [1975]: 37. El subrayado es mío)

Parte de la gramática que enseña a coordinar y unir las palabras para formar las oraciones y expresar conceptos. 
Así entendida la dispositio, esa «situación conveniente» de la definición, respondería al aptum o virtus dispositionis ${ }^{22}$.

De modo que, con todas las precauciones, estableceremos una equivalencia entre el ordenamiento de la definición de construcción con el factor orden de la definición de sintaxis, por una parte,y, por otra, la disposición que requiere la construcción con el factor vínculo que arriba hemos asociado a sintaxis. Lo vemos de forma esquemática:

\begin{tabular}{||c||c|c|c|c||}
\hline \multirow{2}{*}{$\begin{array}{c}\text { Términos } \\
\text { definidores }\end{array}$} & \multicolumn{2}{|c||}{ Lemas } & Factor & Tipo relación \\
\cline { 2 - 5 } & sintaxis & Construcción & & \\
\hline \hline $1^{\circ}$ & Coordinar $\approx$ Ordenamiento & Unir & orden & Parte-Parte \\
\hline $2^{\circ}$ & Disposición vínculo & Parte-Todo \\
\hline
\end{tabular}

Cuadro 41: Sintaxis vs. Construcción en los Diccionarios

En conclusión, en los Diccionarios del último periodo (1884-1925) también puede defenderse, en un sentido amplio, la equivalencia Sintaxis = Construcción: las dos voces incorporan la nota relativa a la expresión de conceptos, y las dos presentan ahora definiciones bimembres (que pueden entenderse como paralelas), sumando dos ideas que no son idénticas y que nos hacen pensar en una ampliación de los tipos de relación entre las palabras dentro de la oración.

Pero las cosas se han complicado y ahora las diferencias también son dos: 1) la Sintaxis se define explícitamente como parte de la Gramática; la Construcción, no, aunque lleva la marca Gram (remito a lo dicho al final de la nota 16); 2) la Construcción implica la concordancia y el régimen; la Sintaxis, no.

22 Véase Lausberg (1993 [1975]: 234-235). 
Aclaremos esta última diferencia:

Desde 1884, ninguna de las dos entradas por sí sola (ni la de sintaxis ni la de construcción) da perfecta cuenta de la doctrina sintáctica expuesta por los Diccionarios académicos; la necesidad de atender conjuntamente a la información repartida entre ambos artículos lexicográficos es ahora (desde el DRAE-1884) especialmente evidente: bajo el lema sintaxis se nos informa de la división de la misma en regular y figurada, pero es en el artículo correspondiente al lema construcción donde se alude a las reglas principales de la Sintaxis: las reglas de Régimen y las de Concordancia ${ }^{23}$. No se puede decir, por la información que nos dan los Diccionarios (tanto en estas dos entradas como en las correspondientes a régimen y concordancia), si la Construcción equivale a la Sintaxis en general o solo a la Sintaxis regular, con la que se vincula en las GRAE (lo veremos). Sin embargo, en los primeros DRAE del siglo XX, los de 1914 y 1925, se añade, en la entrada construcción, una segunda acepción con marca Gram, en la que se remite a las figuras de construcción, lo que supone que, al menos en un sentido, la llamada Construcción tiene que ver con la Sintaxis figurada.

\footnotetext{
${ }^{23}$ Sobre las reglas de Régimen y Concordancia hablaré en el punto 5.2. En cuanto a la división de la Sintaxis en regular y figurada (distinción a la que me volveré a referir a propósito de las Gramáticas), interesa apuntar que la concepción de ambos tipos de sintaxis es la misma desde el DRAE-1884 hasta el DRAE-1925. La diferencia entre una y otra estriba en la sencillez de expresión que busca la primera frente a las licencias de construcción que se permiten en la segunda con el objetivo de adornar el discurso. Sin embargo, la Academia advierte, en todos estos Diccionarios, que la elegancia buscada por la Sintaxis figurada no la convierte en una sintaxis artificiosa, todo lo contrario, es de uso bastante frecuente en la lengua coloquial, precisamente por su mayor valor expresivo (vid. Glosario final, s.v. sintaxis).
} 


\subsubsection{El recorrido completo}

Desde Autoridades hasta el DRAE-1925, la Academia entiende que la palabra es la unidad en la que se centra la Sintaxis, el ladrillo de la construcción sintáctica. La Sintaxis o Construcción, al igual que la Analogía ${ }^{24}$, tiene como objeto de estudio la palabra, pero considerada de forma relacional dentro de los márgenes de la oración, punto de llegada del estudio sintáctico.

Que la palabra es la unidad sintáctica por excelencia resulta indudable a partir de los años 30 del siglo XIX, momento en el que la definición de Autoridades es sustituida por la de «coordinación de las palabras en el discurso», como ya hemos visto. Pero también parece indudable en las ediciones anteriores al DRAE-1832, ya que por coordinación de oraciones no debe entenderse unión de iguales (tal como entendemos hoy la coordinación en el análisis sintáctico), sino ordenamiento interno de las oraciones (esto es, de los elementos constitutivos de las mismas; ordenamiento de las palabras o partes de la oración).

Una vez aceptado que la palabra es la unidad básica del estudio sintáctico en toda la obra lexicográfica de la RAE hasta 1925, tenemos un argumento sólido para poner en tela de juicio las primeras impresiones sobre la, al parecer, dudosa equivalencia entre sintaxis y construcción en las ediciones comprendidas entre Autoridades y el DRAE-1822: ambas parcelas de la Gramática coincidirían tanto en el "campo de acción” (cualquier lengua), según ha quedado argumentado, como en la unidad objeto de estudio (la palabra).

\footnotetext{
24 Recuérdese que, en los textos lexicográficos, la Analogía no se define en términos gramaticales hasta el primer Diccionario del siglo XIX, el DRAE-1803 (vid. Glosario final, s.v. analogía).
} 
A modo de recapitulación de lo dicho sobre este asunto concreto, recordemos esquemáticamente las posibilidades de interpretación de aquella definición de Autoridades, según la cual la Sintaxis es «el modo de coordinar las oraciones, ò el tratado de Gramática, que enseña los casos, que pide cada verbo, y las oraciones latinas»:

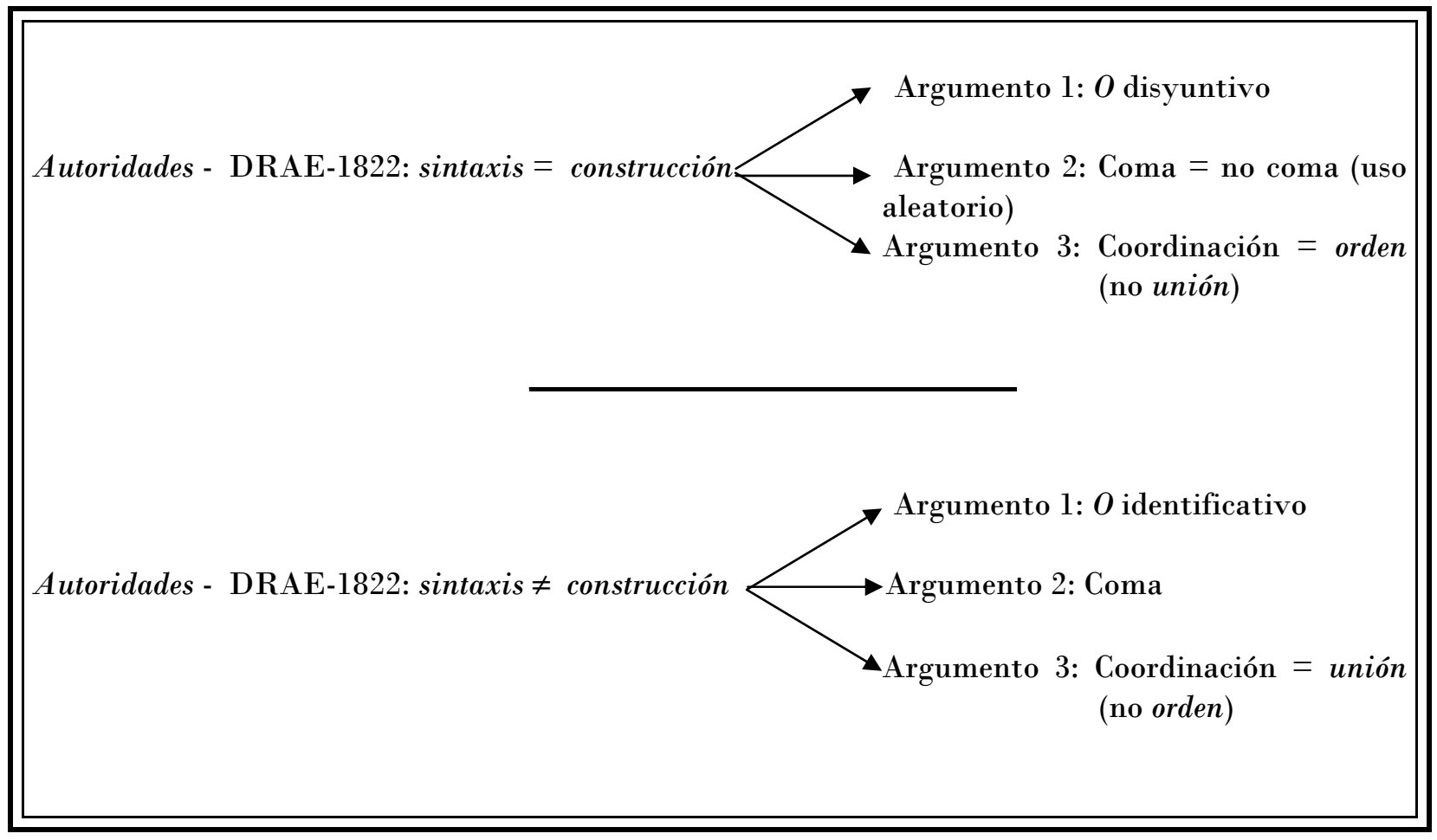

Cuadro 42: ¿Sintaxis $=/ \neq$ Construcción en los Diccionarios?

Entre Autoridades y el DRAE-1822, a pesar de la "problemática" definición de sintaxis, la identidad sintaxis = construcción se cumple sin duda en cuanto al nivel sintáctico al que ambas atienden: las palabras dentro de la oración, ya que la propia concepción académica de coordinación hace pensar en la ordenación interna de las oraciones (hasta el DRAE-1822) y en la ordenación de las palabras -dentro de la oración- (desde el DRAE-1832), no en un tipo de unión sindética de oraciones, tal como la entendemos hoy en términos gramaticales. Y la misma equivalencia podría ser discutible en 
cuanto al alcance de ambas, construcción y sintaxis, según el valor que le asignemos a la $o$-tal como ha quedado dicho-, hasta la edición de 1822. A partir del DRAE- 1832, no hay duda de la operatividad de la equivalencia entre sintaxis y construcción en los Diccionarios académicos, si bien se incorporan notas diferenciales en las respectivas definiciones de estos conceptos que ya han sido comentadas.

Por otra parte, la Academia defiende, a lo largo de todos los Diccionarios del corpus, una concepción de la Sintaxis de carácter, fundamentalmente, colocacional -no funcional- y nocional (se atiende básicamente a las relaciones lineales y a la transmisión de un sentido completo). Podemos decir que esta concepción coincide con la sostenida sobre la Construcción (teniendo en cuenta las salvedades hechas a propósito de los primeros Diccionarios -hasta el de 1822- y los matices diferenciales que aparecen en los últimos -desde 1884-). 


\subsubsection{Los conceptos de sintaxis y construcción en otros diccionarios de la época ${ }^{25}$}

\section{El Vocabulario gRAMATICAL DE PEDRO FELIPE MONLAU (1870)}

La definición que este libro ofrece de la «parte de la Gramática» llamada Sintaxis es una definición basada en la "acumulación de competencias": la sintaxis atiende al estudio de la concordancia, el régimen, las oraciones y la construcción ${ }^{26}$. Según esta definición, construcción no es concepto sinónimo de sintaxis (como sí podemos entenderlo en los diccionarios académicos), sino que alude a una parcela del estudio sintáctico.

En los puntos siguientes atenderemos a los conceptos de régimen y concordancia. En este se impone la consulta al lema construcción con objeto de confirmar si, efectivamente, para Monlau, se trata de una subdisciplina integrada en el ámbito del estudio sintáctico. Y comprobamos que se cumple la previsión al aparecer definido este término como «parte de la sintaxis». La Construcción debe dar cuenta del «ordenamiento y disposición» (términos idénticos a los que utilizan los DRAE del último periodo, desde 1884 -vid. supra-) de las palabras dentro de una oración concreta («revestidas de una forma oracional», dice Monlau) y una vez que se han establecido entre ellas las relaciones de concordancia y régimen necesarias ${ }^{27}$.

${ }^{25}$ El Diccionario de construcción y régimen de Cuervo no registra estas entradas, de modo que, a propósito de sintaxis y construcción, solo expondré la doctrina contenida en el Vocabulario de Monlau (1870). Sí podemos entender, por lo deducido de distintas afirmaciones dispersas por el Diccionario, que el concepto de construcción en Cuervo equivale al de disposición $u$ organización concreta de una estructura lingüística, a cada una de las combinaciones que circunstancialmente se pueden dar en la sintaxis particular de un idioma, en virtud de las distintas funciones y significados que adhieren los vocablos en su combinación con otras palabras.

26

Sintáxis. f. parte de la Gramática que trata de la concordancia, del régimen, de las formas oracionales y de la construccion.

(Monlau, 1870: 220)

Construcción. f. Parte de la sintáxis que trata del ordenamiento y disposicion de las palabras cuando se hallan ya concordadas, relacionadas por el régimen correspondiente, y revestidas de una forma oracional.

(Monlau, 1870: 42) 
Hasta aquí, puede deducirse que la diferencia entre sintaxis y construcción radica en que la primera (que es el TODO) se encarga de dar la teoría sobre las relaciones de concordancia-régimen así como la tipología oracional, y la segunda (una PARTE del todo) se encargaría del estudio de estructuras y combinaciones concretas. Lo general frente a lo particular, o lo abstracto frente a lo concreto, parecen ser binomios que sintetizan la diferencia inicial entre los conceptos de sintaxis y construcción ${ }^{28}$.

Pero Monlau no se limita a definir estos dos términos. Al repasar las explicaciones que sobre uno y otro ofrece para completar la definición propiamente dicha, descubrimos que, según la doctrina defendida por este autor:

- La Sintaxis, en rigor, debe ocuparse solo de las relaciones de concordancia y régimen (que es lo invariable).

- El estudio de las estructuras oracionales (lo variable) corresponde a la Construcción.

- Dentro de la Construcción tenemos que diferenciar la directa (natural y lógica) de la inversa (afectiva y oratoria).

- Dos oraciones distintas por construcción pueden tener la misma sintaxis.

- Cada lengua tiene su forma peculiar de construir las relaciones sintácticas.

No hay duda de que Sintaxis y Construcción son cosas distintas y claramente diferenciables en la concepción de este académico, quien, en la entrada de Sintaxis advierte de la confusión sinonímica que se produce entre los estudiosos a la hora de analizar estas dos parcelas (de distinta dimensión, 
por cuanto la segunda está integrada en la primera) del estudio gramatical, confusión que radica en el hecho de que los latinos tradujeran por con-structio el griego syn-taxis ('con estructura, con orden') 29 .

En conclusión, para Monlau, Sintaxis ₹ construcción: ni se solapan los conceptos de las definiciones (en ellas queda muy claro que la construcción es una parte de la sintaxis) ni sus declaraciones explícitas dejan el más mínimo resquicio a la duda. Su propuesta teórica volverá a ser objeto de nuestra atención en el capítulo $6^{30}$.

${ }^{29}$ No podemos ocultar que Monlau parece entender la idea de unión y ordenación de forma inversa a como se han interpretado estos términos en los DRAE. Dice al final del artículo dedicado a Sintaxis:

Casi suenan lo mismo sintesis que sintáxis; con todo, la síntesis no hace más que unir, al paso que la sintáxis ordena, une ordenadamente.

(Monlau, 1870: 220)

Por el concepto de sintaxis que se defiende en este Diccionario (vid. supra) y por estas palabras, lo acertado es interpretar que para Monlau la unión es lo meramente colocacionallineal, mientras que el ordenamiento implica una unión ¿jerarquizada?

${ }^{30}$ Veremos que, en la Gramática, la separación de estos conceptos se produce en la cuarta edición. Antes de conocer el Vocabulario de Monlau, en mi trabajo de Grado (2001) llegué a conclusiones parecidas a las defendidas por Monlau a propósito de las relaciones sintaxisconstrucción en la GRAE-1796 (parcialmente expuestas en Garrido Vílchez, 2006), conclusiones que retomaré y desarrollaré en el capítulo que sigue. 


\subsection{Relaciones de Dependencia}

La entrada construcción apunta, desde el DRAE-1884, a la concordancia y el régimen como apartados básicos que fundamentan las relaciones sintácticas ${ }^{31}$. Veamos qué se entiende en los Diccionarios académicos por cada una de estas voces y desde qué fecha. Atendemos, en primer lugar, a las que ofrecen información más interesante para esta investigación.

\subsubsection{Relaciones de Régimen}

Como se puede apreciar en el primer cuadro (vid. infra Cuadro 43), la voz régimen no se considera término gramatical en los Diccionarios de la Academia hasta el siglo XIX32: en 1803, encontramos la primera definición alusiva a una acepción específicamente gramatical ${ }^{33}$ y, en 1817, tenemos ya la primera marcación explícita (Gram.), que se suma a la definición dada en 1803. Entre el DRAE-1803 y el de 1843 (último Diccionario de la primera mitad del siglo), el concepto de régimen se centra en dos tipos de palabras, el verbo y la preposición: serán relaciones de régimen todas aquellas en las que un verbo pida una determinada preposición, caso o modo, y aquellas en las que una preposición exija un caso concreto (después de sí, según la naturaleza reconocida a la preposición).

\footnotetext{
31 Aunque hablaré de ello con detenimiento en el capítulo 6, interesa señalar que, en este aspecto, los Diccionarios van a la zaga de las Gramáticas, todas las cuales, desde 1771 hasta los primeros años del siglo XX, centran el estudio sintáctico en las relaciones de Régimen y Concordancia.

32 Desde Autoridades hasta el DRAE-1791, es definido, en sentido general, como «el modo de gobernarse ò regirse en alguna cosa» (vid. Glosario final, s.v. régimen).

33 La construccion de un verbo con la preposicion y caso, ó modo que pide, y de una preposicion con su caso correspondiente.
}

(DRAE-1803: 730, s.v. régimen) 
Entrados ya en la segunda mitad del siglo, en el artículo del lema régimen, el DRAE-1852 ofrece dos acepciones de orden gramatical: según una, el Régimen es entendido, en sentido restringido, como la relación del verbo con su objeto (medie o no preposición entre ellos) ${ }^{34}$ y, en sentido amplio, como la relación de dependencia que guardan entre sí las partes de la oración, según informa la segunda acepción ${ }^{35}$. Esta doble concepción (restringida y amplia) de régimen la encontraremos hasta el último Diccionario del corpus (con ciertas modificaciones de interés que se comentarán más adelante).

Pese a que entre Autoridades y el DRAE-1791 no encontremos una acepción gramatical en la voz régimen, los diccionarios del siglo XVIII no ignoran el concepto sintáctico de regencia: tal concepción la encontramos registrada bajo el lema regir (vid. infra Cuadro 44). Según la información que ofrecen los Diccionarios dieciochescos, podemos hablar de un cambio de concepción -en apariencia, insignificante- entre Autoridades y los DRAE del siglo XVIII.

El paso entre el primer texto académico y los Diccionarios reducidos consiste en una ampliación del concepto de regencia, aunque tal ensanche de perspectiva se cifra en una merma de precisión: en Autoridades, sólo se consideran casos de régimen aquellas estructuras gramaticales en las que un verbo (palabra Regente) determina la aparición de un determinado caso o modo (es decir, el verbo puede gobernar el caso de una categoría nominal o el

\footnotetext{
${ }^{34}$ A pesar de que esta acepción presenta la marca Gram., en ninguno de los Diccionarios del corpus se encontrará una acepción gramatical para el lema objeto (vid. Glosario final, s.v. objeto).

${ }^{35}$ La misma concepción encontramos en los DRAE siguientes: en el de 1869, con idénticas palabras: el Régimen es, en términos gramaticales, «la relacion gramatical que requiere cada verbo respecto del objeto á que se refiere, ya sea con preposicion ó sin ella» $\mathrm{y}$ «la dependencia que segun las reglas gramaticales tienen entre sí las partes de la oracion»; y, a partir de 1884, con las que siguen: «Dependencia que entre sí tienen las palabras en la oración. Determínase por el oficio de unos vocablos respecto de otros, ya estén relacionados ó no por medio de las preposiciones». Vid. Glosario final, s.v. régimen.
} 
modo de una categoría verbal); a partir del DRAE-1780 y hasta finales del siglo XVIII, la fórmula de definición empleada no especifica qué tipo o tipos de palabras son los que pueden regir caso o modo (ya no se menciona al verbo, ni a ninguna otra parte de la oración). Esta imprecisión (seguramente no deliberada, producto de una supresión) hace legítimo pensar que cualquier categoría que pida detrás de sí un nombre (para llevarlo a un caso concreto) o un verbo (para determinar su modo) puede ser palabra Regente, esto es, primer elemento de una relación de regencia.

Con el primer Diccionario del siglo XIX (DRAE-1803) encontramos una nueva modificación en la definición de regir, que viene a dar información idéntica a la comentada sobre el lema régimen en esta edición (vid. supra): las palabras que pueden regir (que funcionan como Regentes) son el verbo y la preposición. El primero rige una determinada preposición, caso o modo; la segunda, un caso concreto. El DRAE-1803 acaba con la imprecisión de los DRAE del XVIII.

Desde 1803 hasta 1925, la definición de regir irá experimentando ligeras modificaciones que no siempre van a coincidir con los cambios en la información ofrecida bajo el lema régimen. Se comprueba en los cuadros que siguen. 


\section{RÉGIMEN}

\begin{tabular}{|c|c|c|c|c|c|c|}
\hline & DICCIONARIO & $\begin{array}{l}\text { Acep. } \\
\text { Gram. }\end{array}$ & MARCA & DEFINICIÓN & EQUIVALENCIA & EJEMPLOS \\
\hline 巨 & $\begin{array}{l}\text { Autoridades } \\
\text { a } \\
\text { DRAE-1791 }\end{array}$ & NO & NO & "El modo de gobernarse ó regirse en alguna cosa". & Lat. Regimen & NO \\
\hline \multirow{3}{*}{ 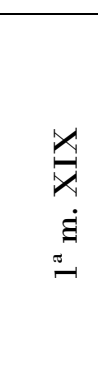 } & DRAE-1803 & 1 & NO & $\begin{array}{l}\text { "La construccion de un verbo con la preposicion y caso, ó modo que pide, y de } \\
\text { una preposicion con su caso correspondiente". }\end{array}$ & NO & NO \\
\hline & $\begin{array}{l}\text { DRAE-1817 } \\
\text { a } \\
\text { DRAE-1832 }\end{array}$ & 1 & Gram. & $\begin{array}{l}\text { "La construccion de un verbo con la preposicion y caso ó modo que pide, y de } \\
\text { una preposicion con su caso correspondiente". }\end{array}$ & NO & NO \\
\hline & $\begin{array}{l}\text { DRAE-1837 } \\
\text { a } \\
\text { DRAE-1843 }\end{array}$ & 1 & Gram. & $\begin{array}{l}\text { "La construccion de un verbo con la preposicion y caso ó modo que pide, y de } \\
\text { una preposicion con su caso correspondiente". }\end{array}$ & $\begin{array}{l}\text { Lat.Constructio, } \\
\text { Lat.Syntaxis }\end{array}$ & NO \\
\hline \multirow{2}{*}{$\begin{array}{l}\underset{x}{x} \\
\dot{g} \\
\text { ă }\end{array}$} & DRAE-1852 & 2 & Gram. & $\begin{array}{l}\text { "La relacion gramatical que requiere cada verbo respecto del objeto á que se } \\
\text { refiere, ya sea con preposicion ó sin ella". } \\
\text { "La dependencia que segun las reglas gramaticales tienen entre sí las partes de la } \\
\text { oracion". }\end{array}$ & $\begin{array}{l}\text { Lat.Constructio, } \\
\text { Lat.Syntaxis }\end{array}$ & NO \\
\hline & DRAE-1869 & 2 & Gram. & $\begin{array}{l}\text { "La relacion gramatical que requiere cada verbo respecto del objeto á que se } \\
\text { refiere, ya sea con preposicion ó sin ella". } \\
\text { "La dependencia que segun las reglas gramaticales tienen entre sí las partes de la } \\
\text { oracion". }\end{array}$ & NO & NO \\
\hline 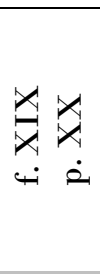 & $\begin{array}{l}\text { DRAE-1884 } \\
\text { a } \\
\text { DRAE-1925 }\end{array}$ & 2 & Gram. & $\begin{array}{l}\text { "Dependencia que entre sí tienen las palabras en la oración. Determínase por el } \\
\text { oficio de unos vocablos respecto de otros, ya estén relacionados ó no por medio } \\
\text { de las preposiciones". } \\
\text { "Preposición que pide cada verbo, ó caso que pide cada preposición". }\end{array}$ & NO & $\begin{array}{l}\text { Respeto á mis padres; amo la } \\
\text { virtud; saldré á pasear; } \\
\text { quiero comer. } \\
\text { Atentar á + Dat./Ac. } \\
\text { [1925: aspirar a } \\
\text { Dat./Ac./Abl.] }\end{array}$ \\
\hline
\end{tabular}

Cuadro 43: Lema régimen 


\section{REGIR}

\begin{tabular}{|c|c|c|c|c|c|}
\hline & DICCIONARIO & Acep.Gram. & MARCA & DEFINICIÓN & EJEMPLOS \\
\hline \multirow{2}{*}{ 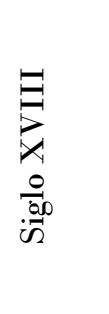 } & Autoridades & 1 & NO & $\begin{array}{l}\text { "En términos gramáticos, vale llevar, ò gobernar el verbo à cierto } \\
\text { caso ù modo". }\end{array}$ & NO \\
\hline & $\begin{array}{l}\text { DRAE-1780 } \\
\text { a } \\
\text { DRAE-1791 }\end{array}$ & 1 & Gram. & "Llevar, ó gobernar á cierto caso, ó modo". & NO \\
\hline 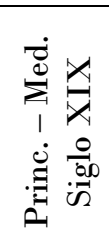 & $\begin{array}{l}\text { DRAE-1803 } \\
\text { a } \\
\text { DRAE-1852 }\end{array}$ & 3 & Gram. & $\begin{array}{l}\text { "Pedir un verbo tal ó tal preposicion, ó tal ó tal caso ó modo..." } \\
\text { "... ó pedir una preposicion este ó el otro caso". } \\
\text { "En los estudios de gramática colocar todas las palabras de un autor } \\
\text { en su órden natural y dar razon de lo que es cada una de ellas, y de la } \\
\text { construccion que pide". }\end{array}$ & NO \\
\hline \multirow{2}{*}{ 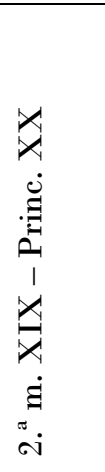 } & DRAE-1869 & 3 & Gram. & $\begin{array}{l}\text { "Pedir un verbo ú otro vocablo tal ó tal preposicion tal ó tal caso ó } \\
\text { modo". } \\
\text { "Pedir o representar una preposicion este ó el otro caso". } \\
\text { "En los estudios de gramática colocar todas las palabras de un autor } \\
\text { en su órden natural y dar razon de lo que es cada una de ellas, y de la } \\
\text { construccion que pide". }\end{array}$ & NO \\
\hline & $\begin{array}{l}\text { DRAE-1884 } \\
\text { a } \\
\text { DRAE-1925 }\end{array}$ & 3 & Gram. & $\begin{array}{l}\text { "Tener una palabra bajo su dependencia otra palabra de la oración". } \\
\text { "Pedir una palabra tal ó cual preposición, caso de la declinación ó } \\
\text { modo verbal". } \\
\text { "Pedir ó representar una preposición este ó el otro caso". }\end{array}$ & NO \\
\hline
\end{tabular}


El cotejo de los dos cuadros permite trazar la siguiente evolución:

\section{S. XVIII (Autoridades - DRAE-1791)}

$\Rightarrow$ El lema que nos ofrece información (que recoge una acepción gramatical, lleve o no la marca Gram.) es regir.

$\Rightarrow \mathrm{El}$ concepto de régimen es restringido: determinación de un caso nominal o un modo verbal.

$\Rightarrow$ La palabra regente es el verbo (Autoridades) y cualquier palabra -parece- que pueda exigir un caso/modo especial (DRAE-1780 a DRAE-1791).

\section{1. ${ }^{a}$ m. XIX - (DRAE-1803 a DRAE-1843)}

$\Rightarrow$ Los lemas que interesan son regir y régimen (ambos ofrecen la misma información).

$\Rightarrow$ Se mantiene una concepción de régimen restringida a casos de determinación de preposición/caso/modo (por parte de un verbo) y caso (por parte de una preposición).

$\Rightarrow$ Las palabras que pueden actuar de regentes son, por tanto, el verbo $\mathrm{y}$ la preposición.

$\Rightarrow$ Las únicas diferencias son dos y las encontramos en tres diccionarios distintos: la primera diferencia, en el DRAE-1803, el único que no presenta la marca Gram.; la segunda diferencia, en los DRAE de 1837 
y 1843, los únicos que presentan equivalentes latinos (Constructio y Siyntaxis en los dos) $)^{36}$.

\section{2. ${ }^{a}$ m. XIX (DRAE-1852 y DRAE-1869)}

$\Rightarrow$ En estos Diccionarios, también encontramos información de interés tanto en la voz regir como en la voz régimen. La información ofrecida en estos dos lemas no coincide, aunque sí será paralela en ambos diccionarios ${ }^{37}$.

$\Rightarrow$ En la entrada régimen comprobamos que la concepción académica se ha hecho más abarcadora respecto de los Diccionarios de la primera mitad del siglo. Por régimen se entienden dos cosas: la relación Verbo-

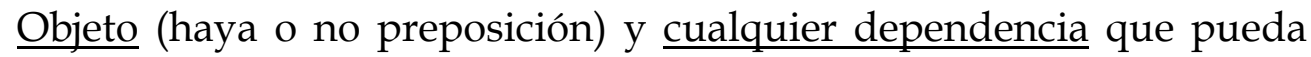
establecerse entre las partes de la oración. Respecto del primer tipo de relación (V-O), es interesante ver que la Academia ha abandonado, al menos en teoría, la noción de caso (que en el paso del latín al español perdió operatividad, como la propia Academia reconoce en su Gramática desde 185438), y parece apuntar ya hacia la idea de complementación del verbo ${ }^{39}$. El segundo tipo de regencia

\footnotetext{
${ }^{36}$ Recordemos que estos dos Diccionarios, por fecha, forman parte de los años de transición (cf. 5.1.2.) en los que parece no haber duda en la identidad Sintaxis = Construcción.

${ }^{37}$ La voz régimen es idéntica en ambos; bajo el lema regir, el DRAE-1869 introduce, con respecto al DRAE-1852, ligeras modificaciones, que comentaré.

${ }^{38}$ Aunque mantendrá hasta la última GRAE del corpus, esto es, la de 1924, el término caso en su nomenclatura para «distinguir los distintos oficios que el nombre desempeña en la oración» (GRAE-1924: 184). Volveremos sobre ello.

${ }^{39}$ Hay que decir que este abandono de la noción de caso es solo aparente. Al igual que sucede con las Gramáticas, también los Diccionarios van a mantener un concepto gramatical de caso, como podemos comprobar en todos los textos de nuestro corpus. Desde Autoridades hasta el DRAE-1925, se aprecia un cambio en la concepción de este término legado por la Gramática clásica. Así, en el primer Diccionario académico, encontramos una definición que parece estar pensando en la lengua latina, pero que se da como válida para la española (en realidad, para cualquier lengua, dada la imprecisión de la definición: por caso se entiende en la Gramática -debemos suponer que de cualquier lengua- las diferencias que experimenta un nombre en su terminación y significación). Con el primer Diccionario reducido (DRAE-1780), la definición se hace más precisa y claramente se "destierra" de la Gramática española el concepto de caso,
} 
(dependencia entre las partes de la oración) desborda por completo los límites del concepto tradicional de régimen, ya que, según la formulación, serán igualmente casos de regencia todas las relaciones de dependencia que se dan entre las palabras, por ejemplo: las relaciones entre Sustantivo y Verbo, entre Sustantivo y Adjetivo, entre Verbo y Adverbio, entre Verbo y Sustantivo, entre Verbo y Verbo, etc., etc. En definitiva, todas las relaciones de dependencia existentes entre las palabras se etiquetan como casos de régimen (en este sentido, régimen parece entenderse como sinónimo de "dependencia mutua" (intercategorial y multicategorial): cualquier categoría puede entablar lazos de dependencia con cualquier categoría. La ausencia de ejemplos impide precisar, pero es de suponer que, en este sentido amplio, la regencia amparará casos de

que ahora se define como término privativo de la Gramática griega y latina (vid. Glosario final, s.v. caso). La idea es lo que no varía: el caso se sigue concibiendo como aquellas variaciones flexivas que implican un cambio funcional. El último Diccionario del XVIII, el DRAE-1791, vuelve a traer la imprecisión, aunque la aclaración primera de «en la gramática de algunas lenguas» parece descartar la lengua española. En este Diccionario, se pierde, además, la referencia al cambio de significado que implican las variaciones flexionales del nombre: el caso parece entenderse ahora como un fenómeno puramente formal -al menos, según las declaraciones explícitas-. En los Diccionarios del siglo XIX (desde el DRAE-1803 hasta el DRAE-1869), volvemos a tener el doble carácter semántico-formal aplicado a la noción de caso, con un añadido importante (en la medida en que, por primera vez, se da cuenta de la realidad de la lengua española): las variaciones en el significado de las palabras no sólo vienen dadas por cambios de flexión, también por la combinación con preposiciones. Tanto un hecho como el otro se consideran propios del español, ya que no hay ningún tipo de aclaración al respecto, sólo la marca Gram. (que debe entenderse en sentido general). El DRAE-1869 es el primero que supone un paso claro en la descripción del fenómeno en lo que afecta al español: en él se nos viene a decir que los pronombres personales son las palabras que varían su significación en virtud de sus diferentes terminaciones, y que los nombres tienen esa misma facultad de modificar su significación juntándose con preposiciones. Será, por fin, a partir del DRAE-1884 cuando la explicación del concepto de caso se haga realmente precisa: ya no se habla de cambios en el significado de las palabras, sino en su oficio o relación con el resto de palabras. Y para marcar estos cambios, se aclara que las distintas lenguas cuentan con procedimientos diferentes: algunas se valen de la variación morfemática y otras, como el español, de distintos métodos (cambio de desinencia -pronombres-; combinación con artículos y/o preposiciones; simple enlace de palabras). Vid. Glosario final.

El planteamiento de finales del XIX se mantendrá hasta el último Diccionario del corpus, y, básicamente, es el que seguimos encontrando en el DRAE-1992 (s.v.caso, pág. 433). En el DRAE-2001: 473. encontramos dos acepciones gramaticales para caso: «marca flexiva que, en muchas lenguas, sirve para expresar relaciones sintácticas» $\mathrm{y}$ «función expresada por esas marcas».

Cf. $\underline{\text { http: / / buscon.rae.es/draeI/SrvltConsulta?TIPO_BUS=3\&LEMA=caso }}$ 
complementación $^{40}$ de todo tipo: nominal, adjetival, adverbial. ¿También casos de subordinación (en sentido tradicional): oraciones subordinadas en función de sujeto, complemento (de nombre, de verbo, de adjetivo) $)^{41}$, atributo, predicativo...?

$\Rightarrow$ En la información contenida bajo el lema regir, sin embargo, estos Diccionarios se mantienen en la misma línea de los DRAE de la primera mitad del siglo XIX. No obstante, el DRAE-1869, al hablar de la determinación de preposición / caso / modo, señala que la palabra determinante o Regente puede ser el verbo «ú otro vocablo» ${ }^{42}$. Hasta el DRAE-1852, el inmediatamente anterior a este de 1869, la capacidad para determinar o regir un modo verbal concreto únicamente se le reconocía al verbo (en terminología actual, equivaldría a reconocer solo casos de complementos del verbo “determinación de preposición y caso"- y de oraciones subordinadas sustantivas y adverbiales dependientes de un núcleo verbal “determinación de modo"-). Parece que esta afirmación de 1869 puede interpretarse como el primer reconocimiento, en los textos lexicográficos de la RAE, de que una estructura oracional del tipo /(S) $+\mathrm{V} /$ puede funcionar también como complemento de un núcleo no verbal $^{43}$.

\footnotetext{
40 Todavía en estos Diccionarios (DRAE de 1852 y 1869) seguimos sin tener una consideración gramatical del término complemento, que no encontraremos hasta el DRAE-1884 (vid. Glosario final, s.v. complemento).

${ }^{41}$ Recuérdese que las subordinadas en función de complemento es lo que hemos etiquetado en esta investigación como casos de complementación oracional.

${ }^{42}$ La tercera acepción del cuadro, común a los DRAE decimonónicos hasta la edición de 1869, tiene un valor meramente testimonial.

43 A partir de este momento, se empezarían a considerar casos de regencia similares estructuras como Quiero que vengas -donde el verbo querer rige el modo subjuntivo de veniry El deseo de que vengas -donde el sustantivo deseo rige el modo subjuntivo de venir- (los ejemplos son míos).
} 


\section{F. XIX - P. XX (DRAE-1884 a DRAE-1925)}

$\Rightarrow$ Nuevamente, hay que atender a las informaciones que nos dan las entradas correspondientes a los lemas regir y régimen.

$\Rightarrow$ Es a partir de 1884 cuando, bajo regir, encontramos claramente un concepto amplio de las relaciones de regencia, concepto que, sin embargo, no va coincidir con el visto en los Diccionarios anteriores: la acepción que, desde 1852, entendía el régimen, en sentido amplio, como «dependencia que según las reglas gramaticales tienen entre sí las partes de la oracion», la encontramos en 1884, en la voz regir, formulada como «tener una palabra bajo su dependencia otra palabra de la oración». El Régimen ya no es tanto "cualquier dependencia que se establece entre palabras", sino "cualquier dependencia que se establece entre una palabra 'superior' jerárquicamente y otra dependiente de ella". La fórmula de definición pone por primera vez el acento en la naturaleza jerárquica de las relaciones de Régimen (en las que siempre hay una palabra que rige o gobierna y otra que es regida o gobernada). Este sentido convive con los dos habituales, de carácter más restringido: $\mathrm{Vb}$. (o cualquier palabra) $\rightarrow$ preposición / caso / modo; Prep. $\rightarrow$ caso.

$\Rightarrow$ La información ofrecida en régimen también presenta modificaciones de interés: en la concepción amplia se introduce el factor oficio (= función) y ahora los elementos regidos, en la concepción restringida, sólo son la preposición (por el verbo -que ya no rige el modo ni el caso como en los Diccionarios anteriores-) y el caso (por la preposición). Vemos que esta concepción ya está más próxima a lo que hoy se suele entender por régimen (en español: aparición obligada 
de una preposición con un determinado verbo), aunque se mantiene vivo el concepto latino de $\mathrm{caso}^{44}$.

Los cambios que se introducen, en el DRAE-1884, en la definición de la voz régimen serán fundamentales, ya que toda la información dada en este artículo se mantendrá como definición de régimen, en términos sintácticos, hasta las dos últimas ediciones del DRAE (1992 y 2001). Resulta interesante contrastar las palabras de finales del XIX con las de finales del XX y principios del XXI:

DRAE-1884: m. Gram. Dependencia que entre sí tienen las palabras en la oración. Determínase por el oficio de unos vocablos respecto de otros, ya estén relacionados ó no por medio de las preposiciones; v. gr. Respeto á mis padres; amo la virtud; saldré á pasear; quiero comer. Gram.

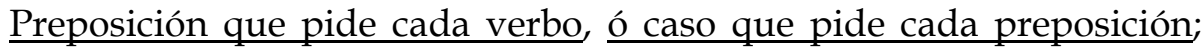
por ejemplo, el régimen del verbo atentar es la preposición á y el de esta preposición el caso de dativo ó el de acusativo.

(Pág. 913, s.v. régimen. El subrayado es mío)

${ }^{44}$ Esta concepción restringida que presentan los DRAE de este último período (1884-1925) es la que todavía hoy podemos encontrar en las definiciones de régimen. Valgan como ejemplo las dadas por Ramón Cerdá y Fernando Lázaro Carreter:

Relación de dependencia entre un complemento y un verbo, un caso o una preposición. Dícese más estrictamente cuando el complemento verbal es introducido por preposición; p.ej. En cuanto le tiraron la cuerda, él tiró de ella.

(Cerdá, 1986: s.v.régimen, pág. 251)

Preposición que debe seguir necesariamente a un verbo, o caso en que debe ir el sustantivo que sigue a una preposición o sirve de complemento a un verbo; así, $a$ es el régimen de referirse; el ablativo, el régimen de la preposición latina $a b$, y el acusativo, el régimen que corresponde al complemento directo del verbo transitivo.

(Lázaro Carreter, 1987 [1953]: s.v.régimen, pág. 348) 
DRAE-1992: 5. Gram. Dependencia que entre sí tienen las palabras en la oración. Determínase por el oficio de unos vocablos respecto de $\underline{\text { otros, }}$ estén relacionados o no por medio de las preposiciones; v.gr.: respeto a mis padres; amo la virtud; saldré a pasear; quiero comer. 6. Gram. $\underline{\text { Preposición que pide cada verbo, o caso que pide cada preposición; }}$ por ejemplo: el régimen del verbo aspirar es la preposición $a$, y el de esta preposición, el caso de dativo, el de acusativo o el de ablativo.

(Pág. 1755, s.v. régimen. El subrayado es mío)

DRAE-2001: 5. Gram. Dependencia que tienen entre sí las palabras en la oración, determinada por el oficio de unos vocablos respecto de otros, estén relacionados o no por medio de las preposiciones; p. ej. Respeto a mis padres. Amo la virtud. Saldré a pasear. Quiero comer. 6. m. Gram. Preposición que pide cada verbo, o caso que pide cada preposición.

(Pág. 1929, s.v. régimen. El subrayado es mío)

V. complemento de régimen: m. Gram. complemento preposicional exigido o seleccionado por un verbo, adjetivo o sustantivo.

(Pág. 605, s.v. régimen. El subrayado es mío) [http://buscon.rae.es/draeI/SrvltConsulta?TIPO_BUS=3\&LEMA=régimen]

Como se puede ver a la luz de estos fragmentos, desde 1884 ya hay un reconocimiento explícito de que la dependencia viene dada por el oficio de las palabras en relación con otras (dentro de la estructura oracional). La concepción establecida en el último cuarto del siglo XIX se mantiene prácticamente intacta (la misma formulación y ejemplos casi idénticos) más de un siglo después. 
En los DRAE de 1837, 1843 y 1852, se da para régimen el equivalente de constructio y sintaxis, cosa que no sucede con concordancia (el otro grupo de reglas que fundamentan la Sintaxis, de las que se hablará en el punto siguiente). Si construcción = sintaxis, y si ambos términos se consideran "sinónimos" de régimen, es fácil hacer extensivo al Régimen lo dicho sobre la concepción sintáctica de la Academia y pensar que la Institución entiende por régimen un tipo de dependencia sintáctica de carácter fundamentalmente lineal (habrá que ver qué sucede en las Gramáticas).

El concepto de regencia parece confirmar, por tanto, lo que decíamos sobre las relaciones de tipo conectivo y no funcional, al menos hasta 1884, año en el que se hace mención al «oficio de unos vocablos respecto de otros» como requisito para establecer relaciones de Régimen. En este sentido, el DRAE-1869 podría ser "puente" entre el DRAE-1852 (donde no se alude al oficio en la definición y donde se dan los equivalentes constructio, syntaxis) y el DRAE1884 (donde han desaparecido los equivalentes y se habla de la función de las palabras). En este Diccionario de transición, el Régimen ya no se considera equivalente de los términos sintaxis y construcción (progresivo abandono de lo "lineal"), pero todavía no hay un reconocimiento explícito de la importancia del oficio de las palabras en las relaciones de dependencia (progresivo acercamiento a lo "funcional”). Lo vemos esquemáticamente:

\begin{tabular}{|c|c|c|c|c|c|}
\hline \multicolumn{6}{|c|}{$\begin{array}{c}\text { Progresiva pérdida del carácter colocacional-lineal } \\
\text { en las relaciones de Régimen }\end{array}$} \\
\hline \multicolumn{2}{|c|}{ CONCEPCIÓN LINEAL } & \multicolumn{2}{|c|}{ TRANSICIÓN } & \multicolumn{2}{|c|}{$\begin{array}{c}\text { ACOGIDA DEL COMPONENTE } \\
\text { "FUNCIONAL" }\end{array}$} \\
\hline \multicolumn{2}{|c|}{ DRAE-1852 } & \multicolumn{2}{|c|}{ DRAE-1869 } & \multicolumn{2}{|c|}{ DRAE-1884 } \\
\hline $\begin{array}{c}\underline{\text { Sí }} \\
\text { equivalencia }\end{array}$ & $\frac{\text { No }}{\text { oficio }}$ & $\frac{\text { No }}{\text { equivalencia }}$ & $\begin{array}{l}\text { No } \\
\text { oficio }\end{array}$ & $\frac{\text { No }}{\text { equivalencia }}$ & $\begin{array}{c}\text { Sí } \\
\text { oficio }\end{array}$ \\
\hline
\end{tabular}

Cuadro 45: Componente lineal-funcional del régimen en los Diccionarios 
Por los ejemplos dados a partir de 1884, podemos ver que, bajo la noción de régimen, se consideran casos de:

$\Rightarrow$ Complementación, con SN o con SN precedido de preposición (tanto obligatoria, esto es, impuesta por el esquema argumental del verbo o exigida por otra palabra, como facultativa).

$\Rightarrow$ Subordinación, con SV precedido o no de preposición (complementación / dependencia oracional).

La preposición, en ambos casos, puede ser obligatoria (esto es, impuesta por el esquema argumental del verbo) o facultativa.

En ninguno de los Diccionarios revisados funciona la oposición coordinación vs. subordinación (ninguno de los dos términos se entiende en sentido gramatical, como tampoco los conceptos de incidencia e incrustación) ${ }^{45}$. Sólo complemento aparece definido en términos gramaticales a partir de 1884, fecha en la que podemos decir que se inicia tímidamente, en los Diccionarios, la maduración por parte de la Academia de una sintaxis basada en la función. ¿Por influjo de la Gramática? Tendremos que verlo ${ }^{46}$.

45 Vid. Glosario final, s.v. coordinación, coordinar, subordinación, subordinar, incidenca, incidir, incrustación.

46 Entre el DRAE-1869 y 1884 no hay ningún otro Diccionario y, sin embargo sí hay cinco GRAE (1870, 1874, 1878, 1880 y 1883), por lo que es fácil deducir que los cambios pueden haberse producido en el seno de la Gramática y, desde allí, haber sido llevados al Diccionario. 


\subsubsection{Relaciones de Concordancia}

El otro tipo de reglas que, junto con las de Régimen, fundamentan las relaciones sintácticas según la concepción académica, son las reglas de Concordancia.

Al igual que sucede con las relaciones de Régimen, la información que se puede obtener de los Diccionarios a propósito de la Concordancia no es demasiado generosa, especialmente entre los DRAE de 1780 y 1869 (remito al Cuadro 47).

Hasta el DRAE-1869, los Diccionarios académicos definen la concordancia como "debida colocación" (Autoridades), como "modo de concordar" (1780 y 1783) o como "conformidad o correspondencia" (1791-1869) de palabras.

El término colocación lo encontramos en el primer Diccionario académico, diccionario que con su definición no aclara qué aspecto es el que diferencia la concordancia de la sintaxis (entendida esta en la primera parte de su definición: la que concibe la sintaxis, en términos generales, como la "coordinación de las oraciones", esto es, el "metódico ordenamiento" interno de las mismas). Aunque se mencionan tres tipos de concordancia (los que marca la tradición ${ }^{47}$ ), no se aclara en qué consiste esta relación sintagmática:

${ }^{47}$ Desde Nebrija (1492: fol. 44 v. ${ }^{\circ}$. El subrayado es mío), en la tradición gramatical española, se habla de tres tipos básicos de concordancia:

[...] la primera concordia $\tau$ concierto es entre un nombre con otro. $\tau$ es cuando el nombre que significa algun accidente: que los gramaticos llaman adjectivo se aiunta con el nombre que significa substancia: que llaman substantivo. por que a de concertar con el en tres cosas. en genero. en numero. en caso. [...] La segunda concordia es del nominativo con el verbo. por que an de concertar en numero $\tau$ en persona. [...] La tercera concordia es del relativo conel antecedente. por que an de concertar en genero. numero. $\tau$ persona [...]

En gramáticos posteriores, como Patón (1614: 104-105) -de quien la Academia toma su ejemplo de autoridad-, Correas (1625: fol. 131 r y v., pp. 359-360; 1627: 193) y San Pedro (1769: 
¿es relación meramente colocacional, funcional, formal? ¿Qué requisitos deben cumplir las palabras para poder decir que están en relación de concordancia? ¿Qué es lo que diferencia estas relaciones de las relaciones sintácticas en general? Son preguntas a las que no se da respuesta en esta entrada lexicográfica. Lo único que queda claro es que la concordancia solo se produce entre tres parejas posibles de palabras: a) un nominativo y un verbo; b) un sustantivo y un adjetivo; c) un relativo y su antecedente (cualquier otra pareja, por tanto, podrá establecer relaciones sintácticas de otro tipo, pero no de concordancia).

Los DRAE, desde 1780 hasta la segunda mitad del siglo XIX, modifican notoriamente y reducen la información dada en Autoridades, limitándose a dar una definición más carente de precisión: la concordancia es, en abstracto, una conciliación entre palabras $(1780 \text { y 1783 })^{48}$ o una correspondencia de conformidad que se da entre las palabras (1791-1869), según dicten las reglas de la Gramática. Seguimos sin saber en qué consiste esa correspondencia, en qué han de ser conformes.

El término concordar no nos saca de dudas: ajustar las palabras (pero ¿cómo, en qué aspectos?). Tampoco concertar ni conformidad (vid. Glosario final, s.v. concordancia, concordar, concertar y conformidad).

No será hasta finales del XIX, nuevamente con el DRAE-1884, cuando tengamos información más detallada de lo que es la concordancia entre palabras. Este Diccionario mantiene la base de definición de las ediciones

98-104), seguimos encontrando esta misma concepción de las relaciones de concordancia. No faltarán tampoco posturas que recojan la herencia sólo en parte, así, por ejemplo, el licenciado Villalón (1558: 57-58) establece cuatro tipos de concordancia: entre Nombre y Verbo; entre Pronombre y Verbo; entre Nombre y Pronombre demostrativo; entre Nombre Adjetivo y Nombre Sustantivo.

${ }^{48}$ Cf. Glosario, s.v. concordancia y concordar (DRAE-1780). 
anteriores («conformidad o correspondencia de unas palabras con otras en la oración»), pero la información es ahora más rica y precisa. Esta información, que en su esencia se mantiene en las ediciones posteriores del Diccionario, será en parte modificada en el DRAE-1899. Sintetizo los cambios en el cuadro comparativo que sigue:

\begin{tabular}{||l|l||}
\hline \multicolumn{1}{|c|}{ DRAE-1884 } & \multicolumn{1}{|c|}{ DRAE-1899 } \\
\hline Relación intraoracional & $\begin{array}{l}\text { [el apunte desaparece en esta edición y no lo } \\
\text { volvemos a encontrara en los Diccionarios } \\
\text { del corpus] }\end{array}$ \\
\hline $\begin{array}{l}\text { Relación de carácter formal: el requisito } \\
\text { para que las palabras puedan entablar } \\
\text { relaciones de concordancia es que sean } \\
\text { variables (la concordancia consiste en la } \\
\text { correspondencia flexiva entre palabras }-\mathrm{no} \\
\text { se aclara si entre dos o más-). }\end{array}$ & $\begin{array}{l}\text { Relación de carácter formal: el requisito } \\
\text { para que las palabras puedan entablar } \\
\text { relaciones de concordancia es que sean } \\
\text { variables (la concordancia consiste en la } \\
\text { correspondencia flexiva entre palabras } \\
\text {-apartir de esta edición, se aclara que puede } \\
\text { darse entre dos palabras o más-). }\end{array}$ \\
\hline $\begin{array}{l}\text { Tipos: verbo (n y persona); resto palabras } \\
\text { variables (género, número y caso). }\end{array}$ & $\begin{array}{l}\text { Tipos: verbo (número y persona); resto de } \\
\text { palabras variables (género y número }{ }^{49} \text { ). }\end{array}$ \\
\hline
\end{tabular}

Cuadro 46: Cambio en el concepto de concordancia en los últimos DRAE del XIX

Es también a partir de 1884 cuando, bajo el lema concertar, se ofrece información pertinente para lo relativo a la Gramática. La nueva acepción con marca Gram. no resulta demasiado explícita en esta edición («concordar gramaticalmente entre sí dos ó más vocablos»), pero en el DRAE-1899 la definición gana en precisión: «concordar en los accidentes gramaticales dos ó más palabras variables». El lema concordar no ofrece información de interés. Solo las ediciones de 1899, 1914 y 1925 recogen una acepción con marca Gram.: «Formar concordancia».

\footnotetext{
49 Resulta extraña esta diferencia con respecto al Diccionario anterior, pues el no hacer referencia a la concordancia de caso en 1899 no coincide con un cambio en la concepción de caso con respecto a 1884: en ambos Diccionarios encontramos la misma definición (vid. nota 39 de este capítulo y Glosario final, s.v. caso).
} 


\section{CONCORDANCIA}

\begin{tabular}{|c|c|c|c|c|c|c|}
\hline & DICCIONARIO & $\begin{array}{l}\text { Acep. } \\
\text { Gram. }\end{array}$ & $\begin{array}{c}\boldsymbol{M A R} \\
\boldsymbol{C A A}\end{array}$ & DEFINICIÓN & TIPOS & EJEMPLOS \\
\hline $\begin{array}{l}\Xi \\
\dot{x} \\
\dot{n}\end{array}$ & Autoridades & 1 & NO & $\begin{array}{l}\text { "En la Gramática es aquella debida } \\
\text { colocación que han de tener las palabras } \\
\text { unas con otras". }\end{array}$ & $\begin{array}{l}\Rightarrow \text { Nom. y Vb. } \\
\Rightarrow \text { Subs. y Adj. } \\
\Rightarrow \text { Relat. y Antec. }\end{array}$ & $\begin{array}{l}\text { "Las concordancias son tres (como en latin) [...] } \\
\text { la cortesía Españóla tiene algunos modos de } \\
\text { hablar que pervierten de estas concordáncias, } \\
\text { usando de plurál por singulár, y de la tercéra } \\
\text { por segunda persona" [Patón. Eloq. fol. 174] }\end{array}$ \\
\hline$\underline{-x}$ & DRAE-1780-83 & 1 & Gram. & $\begin{array}{l}\text { "El modo de concordar las palabras, segun } \\
\text { las reglas de la gramática de cada lengua". }\end{array}$ & NO & NO \\
\hline$\stackrel{\check{E}}{\Xi}$ & $\begin{array}{l}\text { DRAE-1791 } \\
\text { a } \\
\text { DRAE-1869 }\end{array}$ & 1 & Gram. & $\begin{array}{l}\text { "La conformidad, ó correspondencia de las } \\
\text { palabras, según las reglas de la gramática de } \\
\text { cada lengua" }\end{array}$ & NO & NO \\
\hline \multirow{2}{*}{$\begin{array}{l}\ddot{x} \\
\ddot{x} \\
\dot{x} \\
\dot{x} \\
\dot{x}\end{array}$} & DRAE-1884 & 1 & Gram. & $\begin{array}{l}\text { "Conformidad ó correspondencia de unas } \\
\text { palabras con otras en la oración. Sólo puede } \\
\text { haberla entre las partes variables. Todas } \\
\text { éstas, menos el verbo, concuerdan en } \\
\text { género, número y caso; y el verbo con las } \\
\text { demás en número y persona" }\end{array}$ & NO & NO \\
\hline & $\begin{array}{l}\text { DRAE-1899 } \\
\text { a } \\
\text { DRAE-1925 }\end{array}$ & 1 & Gram. & $\begin{array}{l}\text { "Conformidad de accidentes entre dos ó más } \\
\text { palabras variables. Todas éstas, menos el } \\
\text { verbo, concuerdan en género y número; y el } \\
\text { verbo con su nominativo, en número y } \\
\text { persona". }\end{array}$ & NO & NO \\
\hline
\end{tabular}

Cuadro 47: Lema concordancia 


\subsubsection{Los conceptos de régimen y concordancia en otros diccionarios de la época}

\section{El Vocabulario gramatical De PEDRO FELIPE Monlau (1870)50}

Monlau define el régimen como «dependencia mutua» entre las palabras, una dependencia que entiende como reflejo de la que guardan entre sí las ideas que las palabras representan ${ }^{51}$. Su concepción del régimen se resume en los siguientes puntos:

- Las palabras (en tanto que reflejo de las ideas) relacionadas por régimen forman parte de un concepto total (justamente, el representado por el conjunto de las palabras en cuestión).

- Esa «relación mutua» no es una relación entre iguales: siempre hay una palabra principal (o regente) y una palabra «subordinada»-la etiqueta es de Monlau- (o regida). Se trata, por tanto, de una relación jerarquizada.

- Las relaciones de régimen, por lo general, se expresan mediante preposiciones o dando a las palabras una colocación determinada.

- En principio, las palabras regentes por excelencia son el sustantivo y el verbo, pero también se le reconoce capacidad de regencia a la

${ }^{50}$ La teoría sobre estas relaciones se extrae de los lemas régimen, complemento y concordancia.

51 Las siguientes palabras que transcribo son del autor:

Régimen. m. Es la dependencia mútua que tienen las palabras como significacion de la que tienen entre sí las ideas. Estas, además de relacionarse como partes de un concepto total, se corresponden entre sí como dependientes unas de otras. Y tal dependencia, bien que puede nacer de infinidad de aspectos, hace que de las dos ideas siempre hay una principal respecto de la otra, que es menos principal y no pasa de accesoria ó complementaria. La palabra principal (como signo de la idea principal) se llama regente, porque como que rige ó gobierna la otra; - y esta última se llama regida, subordinada. 
preposición y a cualquier palabra que necesite de otras para completar su sentido.

- Las relaciones de régimen son relaciones de complementación ${ }^{52}$. Las funciones de CD y CI/CC (en terminología actual) son, respectivamente, los casos de régimen directo e indirecto distinguidos por Monlau. Los ejemplos que da son los que siguen:
(a) Escribo un $\frac{\text { VOCABULARIO }}{\text { Régimen directo }}$
(b) Escribo un vocabulario para los aficionados á la Gramática
Régimen indirecto

En la entrada correspondiente a complemento, se confirma la proximidad entre las relaciones de régimen y las de complementación. El complemento vendría a equivaler, contemporáneamente, a lo que antes era el caso regido. En principio, el cambio de un término por otro parece responder a una simple renovación de etiquetas en busca de una mayor precisión terminológica ${ }^{53}$. Pero Monlau establece la siguiente distinción:

52 De la explicación que Monlau da sobre el régimen después de la definición propiamente dicha, traigo a colación el siguiente párrafo:

En una palabra, son voces regentes el nombre, el verbo, en cierto modo la preposición, y en general todas las que de rigor necesitan otra que complete su sentido; -y voces regidas las que son complemento de las completadas. Y hé aquí como el régimen no es mas, ni menos, que la mútua dependencia de las palabras en la oracion.

(Monlau, 1870: 193).

Modernamente se ha introducido la palabra complemento, porque, como en l. el régimen se significaba por casos, y en romance no los hay, pareció una irregularidad decir que tal nombre, ó tal verbo, etc. rigen dativo, acusativo, etc. Ello es, sin embargo, que el complemento directo apénas se distingue del acusativo 1., el indirecto corresponde al dativo, y el circunstancial viene á ser el ablativo.

(Monlau, 1870: 35) 
régimen se dice principalmente de los complementos del verbo y de la preposición; y complemento, voz mas extensiva se dice no sólo del verbo y de la preposicion sino de todo lo que completa. - Otra diferencia entre estas dos palabras sinónimas: el complemento se refiere á la idea, y el régimen se refiere á la forma gramatical.

(Monlau, 1870: 194)

\section{Ejemplos:}

« ¡Pluguiera á Dios que todos fuésemos amantes del bien del prójimo!»

En esta frase, lo que hay que completar es amantes, y lo que completa es el bien del prójimo (= complemento). El régimen será la forma con que se refleja en el lenguaje la dependencia entre amante y bien, que en castellano es la interposicion de la preposición de. Por tanto, «de es el régimen: de es la preposicion que rige, pide, etc. el adjetivo ó participio amante» (pág. 195). Según este ejemplo, el régimen sería un complemento preposicional, pero más arriba hemos dado otros ejemplos (también del autor) que prueban que las relaciones de régimen, en la doctrina de Monlau, no necesitan obligatoriamente de preposición.

Por otra parte, en el Vocabulario gramatical también se subraya la idea de que dos palabras que guarden concordancia entre sí -como reflejo de haber contraído relación mutua- no son ejemplo de complementación (en Pedro ama y hombre virtuoso, ninguna de las palabras subrayadas es complemento de la otra). Por tanto, Monlau establece una frontera entre las relaciones de concordancia, de un lado y las de régimen/complementación de otro.

Podemos comparar la teoría del régimen defendida por Monlau con la expuesta en los Diccionarios de la RAE de la siguiente forma: 


\begin{tabular}{|c|c|c|}
\hline & Academia & Monlau \\
\hline $\begin{array}{l}\text { Palabra } \\
\text { regente }\end{array}$ & $\begin{array}{l}\text { XVIII: Verbo (Autoridades) o cualquier } \\
\text { palabra (DRAE) que pueda } \\
\text { exigir caso o modo. }\end{array}$ & $\begin{array}{l}\text { Sustantivo: se nombra en un primer } \\
\text { momento como palabra Regente junto } \\
\text { con el verbo, pero no se dan ejemplos. } \\
\text { Verbo, palabra regente por excelencia. } \\
\text { Preposición (o cualquier palabra que } \\
\text { necesite ser complementada en su } \\
\text { significado). En principio parece que es } \\
\text { palabra Regente de segundo orden, pero } \\
\text { en el conjunto de su doctrina, Monlau le } \\
\text { otorga casi el mismo protagonismo que al } \\
\text { verbo. }\end{array}$ \\
\hline $\begin{array}{c}\text { Tipo } \\
\text { de } \\
\text { relación }\end{array}$ & $\begin{array}{l}\text { - Hasta 1852: lineal } \\
\text { - En 1869: imprecisión entre lo } \\
\text { colocacional-lineal y lo "funcional". } \\
\text { - Desde 1884, relación jerárquica en la } \\
\text { que el protagonismo lo tiene la } \\
\text { función. }\end{array}$ & $\begin{array}{l}\text { - Jerárquica: palabra Regente } \longrightarrow \\
\text { palabra subordinada }\end{array}$ \\
\hline $\begin{array}{l}\text { Rég./ } \\
\text { Compl. }\end{array}$ & $\begin{array}{l}\text { - Puede empezar a deducirse desde } \\
\text { 1884. }\end{array}$ & $\begin{array}{l}\text { - Explícitamente manifiesta por parte del } \\
\text { autor (delimitación). }\end{array}$ \\
\hline
\end{tabular}

Cuadro 48: Tratamiento del régimen en los DRAE y en el Vocabulario de Monlau

En lo que concierne a las relaciones de concordancia, la información que encontramos en el Vocabulario de Monlau coincide, en esencia, con la dada por el DRAE-1884:

- Información del nivel al que responde esta relación (intraoracional): la concordancia es relación que se da dentro de los márgenes de la oración.

- Información de carácter formal: la concordancia consiste en la conveniencia de accidentes entre palabras variables ${ }^{54}$. 
- Información (fuera de la definición) sobre los tipos:

1) Sustantivo y adjetivo -o participio-: en los accidentes de género y número.

2) Sujeto y verbo: en los accidentes de número y persona.

3) Relativo y antecedente: en los accidentes de género y número.

El sistema de ejemplos de Monlau combina tanto casos que se sujetan a la regla como casos que la incumplen:

1) Comer a costa ajena.

2) *Pedro aman; *Yo amas.

3) *El soldado a quienes premiaron.

\section{El DicCIONARIO DE CONSTRUCCIÓN Y RÉGIMEN DE RUFINO JOSÉ CUERVO}

También Cuervo establece explícitamente una conexión entre las relaciones de regencia y las de complementación. En la séptima acepción de la entrada régimen se lee: «gram. exigir una palabra un determinado complemento o relación gramatical».

No podemos extraer una teoría cabal sobre las relaciones de complementación, pues no se le dedica ninguna entrada a complemento. Pero parece deducirse de la exposición general del Diccionario que ese «determinado complemento» que supone la relación de regencia es de carácter preposicional. Cuando la relación gramatical implica una complementación modal se habla de «proposiciones subordinadas». 
Cuervo tampoco recoge en su diccionario el lema concordancia, pero sí encontramos el lema concordar, para el que se dan tres acepciones, una de ellas con marca Gram. A partir de esta definición, podemos afirmar que la concordancia es entendida como "la armonía de accidentes gramaticales entre dos palabras". No se especifica que estas palabras deben ser (o son, si es que pueden concordar) variables desde el punto de vista formal ${ }^{55}$. No ofrece una tipología, solo da como ejemplo el segundo de los tipos marcado por la Academia y el primero de Monlau: la concordancia entre sustantivo y adjetivo. Y dice que los accidentes en los que tienen que convenir son tres: género, número y caso. La voz caso tampoco aparece recogida en el Diccionario.

55 Podemos imaginar las razones por las que no se ofrece de forma explícita esta información: no olvidemos que el Diccionario de Cuervo es un diccionario «de construcción y régimen» (esto es, un diccionario especializado) y que, por lo tanto, al destinatario se le suponen los conocimientos sintácticos básicos. 


\subsection{Los elementos de relación}

Desde el comienzo de su tradición gramatical, la Academia ha considerado las preposiciones y las conjunciones elementos de relación dentro del marco oracional. El valor nexivo de estas palabras o partes de la oración es, sin embargo, de índole diferente, según se reconoce en los Diccionarios del corpus. Así, la preposición es entendida como partícula que lleva a cabo o que marca relaciones de Régimen, esto es, de dependencia, mientras que la conjunción -según parece desprenderse de las definiciones dadas en sendos Diccionarios- es, simplemente, un elemento de unión ( $i=$ dependencia?) $\sin$ mayor especificación (vid. supra. lo dicho sobre unir en 5.1.3.).

A esta diferencia, presente en todos los textos lexicográficos que analizamos, se añade otra a partir del siglo XIX: desde el DRAE-1803, se admite que la conjunción no solo traba palabras, también es elemento de unión entre oraciones, valor que no se concede a la preposición.

Se reconocen, por tanto, dos diferencias básicas entre estas dos categorías gramaticales: una tiene que ver con los elementos que ponen en relación y otra, con el tipo de relación que se entabla entre dichos elementos. El siguiente cuadro ilustra estas diferencias.

$\begin{array}{lll}\text { ELEMENTOS RELACIÓN DICGIONARIOS } & \text { R }\end{array}$

\begin{tabular}{lccc}
\hline \multirow{2}{*}{ CONJUNCIÓN } & Palabras & unión & Autorid. -1799 \\
\cline { 2 - 4 } & $\begin{array}{c}\text { palabras y } \\
\text { oraciones }\end{array}$ & unión & $1803-1925$ \\
\cline { 2 - 4 } & palabras & $\begin{array}{c}\text { régionen } \\
(\text { dependencia })\end{array}$ & TODOS \\
& Cuadro 49: Conjunción y Preposición en los Diccionarios &
\end{tabular}




\subsubsection{La conjunción}

La conjunción no se define, en su entrada, como parte de la oración hasta el siglo XIX56, curiosamente cuando se le empieza a reconocer un papel de intermediaria entre oraciones, cuando se le concede, por tanto, lo que se podría considerar un lugar "fuera" de la oración propiamente dicha o más elemental. En realidad, desde el DRAE-1780, la acepción gramatical del lema conjunción invita a pensar que, para los académicos, es esta "otra parte de la oración", puesto que es palabra o partícula encargada de «juntar, atar, ó trabar entre sí las demas partes [...]» (vid. Glosario final. El subrayado es mío). Es, curiosamente, la fórmula de definición empleada en Autoridades la que desliga esta categoría de los elementos constituyentes de la oración: es «voz que traba $\mathrm{y}$ ata las partes de la oracion entre si milmas» (vid. Glosario final). Bien podría haberse mantenido la misma fórmula en el DRAE-1803, con el añadido «y (las) oraciones unas con otras» que leemos a partir de esta fecha.

En el DRAE-1869, tímidamente se empieza a apuntar una clasificación de las conjunciones, clasificación que responde a criterios puramente semánticos: no hay atisbo de distinción entre conjunciones coordinantes (que unen oraciones a un mismo nivel) y subordinantes (que incrustan una oración en otra). Desde 1884, y sin que volvamos a tener modificaciones hasta el último Diccionario del corpus, se amplía la nómina y se definen los tipos. La clasificación sigue siendo de orden nocional o semántico, sin tener en cuenta en ningún momento las peculiaridades de funcionamiento de estos elementos nexivos ${ }^{57}$, pero se añadirá una nota formal, ausente en los Diccionarios anteriores: la conjunción es definida como «parte invariable de la oración». Si

\footnotetext{
${ }^{56}$ Pero sí se registra en todos los Diccionarios como tal (lo vemos bajo el lema parte).

${ }^{57}$ Esta situación, que la Academia mantiene desde sus primeros tiempos y que no va a variar en la segunda mitad del XIX y primer cuarto del XX, está en sintonía con la actitud mantenida por importantes figuras de nuestra historia gramatical, algunas de las cuales la Academia conoció bien, como don Vicente Salvá. Al menos por la información que nos ofrecen los Diccionarios, parece que la RAE no tendrá en cuenta en su teoría de la conjunción la aportación de don Andrés Bello, gramático en el que ya hay una clara voluntad de deslinde de los dos tipos básicos de relaciones sintácticas reconocidos hoy: coordinación y subordinación.
} 
buscamos en el último Diccionario publicado por la Academia en el siglo XX, comprobamos que, después de más de un siglo, no se han modificado nada los planteamientos del DRAE (y la formulación de la definición, demasiado poco):

DRAE-1884: 4. Gram. Parte invariable de la oración, que denota la relación que existe entre dos oraciones, ó entre miembros ó vocablos de una misma oración, juntándolas ó enlazándolas siempre gramaticalmente, aunque á véces signifique contrariedad ó separación de sentido entre unas y otras.

(Pág. 276, s.v. régimen) $)^{58}$

DRAE-1992: 4. Gram. Parte invariable de la oración, que denota la relación que existe entre dos oraciones o entre miembros o vocablos de una de ellas, juntándolos o enlazándolos siempre gramaticalmente, aunque a veces signifique contrariedad o separación de sentido entre unos y otros....59

(Pág. 542, s.v. conjunción)

En el DRAE-2001 es cuando, por fin, encontramos una formulación distinta alusiva a los dos tipos básicos de relaciones sintácticas: coordinación y subordinación:

DRAE-2001: 4. Gram. Palabra invariable que encabeza diversos tipos de oraciones subordinadas o que une vocablos o secuencias sintácticamente equivalentes.

(Pág. 625, s.v. conjunción. El subrayado es mío)

[http://buscon.rae.es/draeI/SrvltConsulta?TIPO_BUS=3\&LEMA=conjunción]

${ }^{58}$ En 1925, ya tenemos palabras idénticas a las reproducidas en el DRAE-1992 (vid. Glosario final, s.v. conjunción).

59 Sigue la misma nómina de tipos con las mismas explicaciones para cada uno de ellos (definición semántica). 


\subsubsection{La Preposición}

En el tratamiento de la preposición, se aprecian dos momentos o etapas en la tradición lexicográfica de la RAE. La primera se extiende desde Autoridades hasta el DRAE-1869; la segunda se inicia a finales del XIX, con el DRAE-1884, y llega hasta el último Diccionario del corpus:

\section{$\underline{1^{a} \text { etapa: } 1734 \text { (tomo V de Autoridades) a } 1869}$}

Las palabras de la Academia permiten deducir que, en estos años, por preposición se entienden dos cosas: lo que podemos llamar "preposición propiamente dicha" y lo que podría considerarse "pseudopreposición”.

El primero de los conceptos (la preposición "auténtica") es definido desde una triple perspectiva (vid. Glosario final, s.v. preposición):

- formal: parte indeclinable (hasta 1852) / invariable (desde 1869);

- colocacional: precede al nombre (hasta 1791) / cualquier palabra (desde 1803) ${ }^{60}$;

- funcional: rige o determina a la palabra que le sigue.

\footnotetext{
${ }^{60}$ Vemos que, al entrar en el siglo XIX, la Academia amplía las posibilidades combinatorias de la preposición, que ya no sólo precede al nombre. Es posible -como apunta Val Álvaro (1992)que la visión restringida de Autoridades (heredada por todos los Diccionarios dieciochescos que le siguen) se deba a un influjo de la Instituciones de la gramática española de Patón (1614). Efectivamente, Patón es una de las principales autoridades en materia gramatical en el primer Diccionario de la Corporación. Las distintas ediciones del DRAE dan testimonio de los cambios en la concepción gramatical académica y también, por tanto, de los cambios en la vinculación con las distintas ideas defendidas a lo largo de nuestra historia gramatical. Así, a partir de 1803, la Academia parece apartarse de Patón para encauzarse en la línea marcada por Nebrija, según la cual la «preposicion es una delas diez partes dela oracion: la cual se pone delante delas otras por aiuntamiento o por composicion» (fol. 41 v., pág. 261).
} 
La segunda idea que se asocia a preposición (lo que he llamado “pseudopreposición”) es la idea de elemento de composición (correspondería a lo que hoy se denomina prefijo, por esa posición precedente que se le adjudica a la preposición -como su propio nombre indica-) ${ }^{61}$.

\section{$\underline{2^{a} \text { etapa: } 1884 \text { a } 1925}$}

Los últimos Diccionarios del siglo XIX (1884 y 1899) establecen una diferencia explícita entre dos tipos de preposiciones atendiendo a su carácter autónomo o inseparable, diferencia que quedaba latente en los Diccionarios del primer período delimitado. En los Diccionarios del siglo XX (1914 y 1925), se mantiene esta distinción, si bien sólo se usa la etiqueta de inseparable para un tipo secundario o marginal de preposiciones, tipo que, además, queda sin definir (ambos Diccionarios nos remiten al lema prefijo).

Las preposiciones separables (las "legítimas", cuando no ejercen de prefijos) quedan definidas por un doble criterio (vid. Glosario final, s.v. preposición):

- formal: parte invariable.

- Semántico-funcional: denota el régimen o relación que entre sí tienen las palabras o términos (a partir de 1914, se especifica que esa relación de régimen es de carácter binario).

61 Val Álvaro (1992: 106) comenta esta doble concepción de la preposición en Autoridades asociándola a una jerarquía entre los criterios de definición. Este autor señala cuatro criterios: 1) naturaleza morfológica, 2) autonomía o separabilidad, 3) posición y 4) función; y entiende que, en el artículo en cuestión, «queda destacada en una primera parte lo que cabe interpretar como la definición general, y relegada a una segunda parte la mención de una ampliación de sus funciones atendiendo a su separabilidad». 
Parece que la Academia entiende como consabido el requisito colocacional de anteposición y por ello no lo menciona explícitamente. La ausencia de una nota colocacional en la definición (al modo de los Diccionarios del primer grupo) no puede entenderse en ningún caso como negación de ese carácter, ni como un descuido lexicográfico. Parece algo deliberado y fácilmente justificable por la obviedad etimológica (es, justamente, en los libros de este segundo grupo en los que se ofrece información sobre la etimología al comienzo de cada artículo lexicográfico).

A partir de 1884, por tanto, se pierde en la definición el criterio colocacional y sólo se alude a sus características morfo-sintácticas de invariabilidad y de índice o marcador de relaciones de régimen. Este segundo rasgo es especialmente importante por cuanto implica un nuevo cambio en la concepción académica: la preposición no es artífice de la regencia (no es palabra regente o determinante -Sintaxis esencialmente lineal-), sino índice o marca de regencia (señala que entre las palabras que une existe tal relación de dependencia -Sintaxis más funcional-).

Al igual que veíamos con la conjunción, también los planteamientos académicos en lo concerniente a la preposición han soportado el paso de más de un siglo (desde 1884) con una pequeña variación, introducida en el DRAE-1914:

DRAE-1884: Gram. Parte invariable de la oración, cuyo oficio es denotar el régimen ó relación que entre sí tienen las palabras ó términos. Las preposiciones se dividen en separables é inseparables. Las primeras son las que para este fin se emplean aisladas; como á, con, de, etc., aunque también sirven de prefijos en voces compuestas; v.gr.: Aclamar, CONvenir, Deponer: Las segundas hállanse únicamente en composición; v. gr. DESpropósito, INcapaz, SUPERabundancia.

(Pág. 860, s.v. preposición) 
DRAE-1914: Gram. Parte invariable de la oración, cuyo oficio es denotar el régimen o relación que entre sí tienen dos palabras ó términos. También se usa como prefijo. Inseparable. Gram. Prefijo, $2^{\mathrm{a}}$ acep.

(Pág. 829, s.v. preposición. El subrayado es mío)

DRAE-1992: Gram. Parte invariable de la oración, cuyo oficio es denotar el régimen o relación que entre sí tienen dos palabras ó términos. También se usa como prefijo. I inseparable. Gram. Prefijo que funcionaba primitivamente como preposición. No se pueden utilizar solas : intra, extra, etc.

(Pág. 1659, s.v. preposición. El subrayado es mío)

En el DRAE-1992, una vez más, comprobamos que no se han movido los planteamientos de finales del XIX: las preposiciones pueden ser separables o inseparabes. Las primeras unen palabras y las segundas funcionan como prefijos. Es en 2001 cuando ya se les concede a las preposiciones separables la facultad de introducir complementos oracionales:

DRAE-2001: f. Gram. Palabra invariable que introduce elementos nominales $\mathrm{u}$ oraciones subordinadas sustantivas haciéndolos depender de alguna palabra anterior. Varias de ellas coinciden en su forma con prefijos. inseparable.1. f. Gram. Prefijo que en sus orígenes funcionaba como preposición. No se puede utilizar sola; p. ej., intra, sub.

(Pág. 1825, s.v. preposición. El subrayado es mío) [http://buscon.rae.es/draeI/SrvltConsulta?TIPO_BUS=3\&LEMA=preposición] 


\subsubsection{Conjunción y preposición en otros diccionarios de la época}

\section{El Vocabulario gramatical DE PEDRo FeliPe Monlau (1870)}

Monlau caracteriza la conjunción y la preposición desde el punto de vista formal como palabras invariables. Pero, frente a la doctrina académica, en este Vocabulario gramatical se le concede un rango distinto a conjunción y preposición en virtud de las distintas unidades que tienen la facultad de unir.

A la conjunción se le asigna el rango de interparte: no se puede definir como parte de la oración propiamente dicha puesto que su misión, siempre, es la de unir oraciones. Monlau niega que la conjunción tenga capacidad de enlazar palabras dentro de la oración: haciendo uso de una omnipresente teoría de la elipsis, en todos los casos en que una conjunción media -en apariencia, según este autor- entre dos palabras, se reconstruyen dos oraciones subyacentes.

En cuanto a la preposición, esta sí es «parte de la oracion», cuyo oficio es «expresar la relacion en que se hallan dos vocablos de una misma frase» (Monlau, 1870: 163). La preposición expresa la relación que hay entre el antecedente y el consecuente. La preposición es, por tanto, índice de relación intraoracional entre dos palabras.

\section{El DicCIONARIO DE CONSTRUCCIÓN Y RÉGIMEN DE RUFINO JOSÉ CUERVO}

Tenemos noticia de las características y misiones que Cuervo atribuye a estas dos clases de palabras a través de la información contenida en la Introducción al tomo I de su Diccionario.

En cuanto a la conjunción, el Diccionario establece claramente la diferencia entre conjunciones coordinantes (que unen elementos análogos) y subordinantes (que ligan proposiciones subordinantes y subordinadas). 
Cuervo señala la deuda contraída con Andrés Bello. Sobre la distancia que existe entre la doctrina de la RAE y la del venezolano hablaré en 6.2.4. Basta, de momento, con dejar constancia de los más de cien años de ventaja que la teoría de Cuervo les saca a las declaraciones académicas (vid. supra).

La preposición, por su parte, es entendida como índice de una relación de regencia. 


\section{CONCLUSIONES PARCIALES}

I. Sintaxis y construcción son términos equivalentes en los Diccionarios del corpus. En Autoridades y las primeras ediciones del DRAE, la definición de sintaxis se articula en dos partes, y es la primera de las ideas expresadas (la de coordinación de oraciones) la que permite vincular el concepto de sintaxis y el de construcción: con ambos términos se alude al ordenamiento interno de las partes de la oración (en cualquier lengua). En los que hemos llamado “años de transición" (desde 1837 hasta 1852), el cambio que experimentan las definiciones pone de evidencia (ahora de una manera inequívoca) la identidad sintaxis = construcción . Lo mismo puede decirse del DRAE-1869: la identidad parece indiscutible, y ello pese a que ha desaparecido de esta edición la "equivalencia latina" constructio que cerraba el artículo dedicado a sintaxis en los diccionarios anteriores. A partir de 1884, encontramos notas diferenciales claras entre la información recogida en el lema sintaxis y la dada para construcción. Pero, por encima de las diferencias, se descubren los puntos de conexión que siguen vinculando ambos conceptos.

II. El período que centra el interés de este trabajo (2. ${ }^{a}$ mitad del siglo XIX y primer cuarto del $\mathrm{XX}$ ) resulta especialmente relevante en el desarrollo de la concepción académica sobre las Relaciones de Dependencia que tienen lugar en el seno de la oración.

Un año sirve de gozne en la teoría sintáctica defendida por la Institución a través de sus textos lexicográficos: los planteamientos que ofrece el DRAE-1884 suponen un importante avance en la concepción funcional de las relaciones sintácticas, en general, y de las relaciones sintácticas de dependencia intraoracional, en particular, en los Diccionarios del corpus. El avance se cifra, básicamente, en un mayor rigor descriptivo y una mayor exhaustividad clasificatoria (lo hemos visto a propósito de las 
nociones de régimen, complemento, caso, conjunción, preposición). Hemos visto también que el concepto de sintaxis empieza a acoger la idea de unión (el factor relación, vínculo) junto con la secular idea de orden; que las relaciones de régimen dejan de verse como relaciones de "mutua dependencia entre palabras" para empezar a entenderse como "relación jerárquica" (una palabras -la regida- depende de otra -la Regente- que es superior jerárquicamente, y se empieza a poner el énfasis en el oficio ( $\approx$ función); que por primera vez se incluye una acepción con marca Gram. en el artículo de complemento; que se empieza a dar información precisa sobre las relaciones de concordancia y sobre la tipología de las conjunciones...

En ciertas cuestiones, la información ofrecida en el DRAE-1869 y el DRAE-1899 sirve, respectivamente, de anticipo o matización de la doctrina expuesta en 1884: recordemos, por ejemplo, que es en 1869 cuando se esboza por primera vez una clasificación de las conjunciones, o que la teoría de la concordancia se termina de perfilar en el último Diccionario del siglo XIX.

III. Los planteamientos académicos no están en total consonancia con la doctrina mantenida por autores contemporáneos:

- Monlau niega de forma expresa la equivalencia sintaxis = construcción, sostenida explícita o implícitamente por los Diccionarios de la Institución. Y Cuervo también defiende una idea de construcción diferenciada de las relaciones sintácticas en términos generales o abstractos.

- En cuanto a las relaciones de régimen, hemos visto un avance sustancial a partir del DRAE-1884 (que se acerca a los planteamientos de Monlau), sin embargo, en esta fecha todavía no encontramos en la Academia una 
teoría de la complementación vinculada a la de regencia, como sí la tenemos en Cuervo y Monlau. Y mucho tiene que andar el tiempo para que el DRAE modifique la fórmula de definición (y la teoría) del régimen. Tiene que llegar el siglo XXI para que en el DRAE encontremos una definición de régimen en los términos de Cuervo.

- El tratamiento de los elementos nexivos también separa a la Academia de sus coetáneos.

- La teoría de la coordinación expuesta en los Diccionarios académicos sí comparte sus cimientos con la de los dos autores decimonónicos que nos han servido de punto de referencia.$$
* * * *
$$

Como cierre de este capítulo, cabe plantearse la siguiente pregunta: ¿responde el cambio de 1884 a una nueva perspectiva en las GRAE inmediatamente anteriores y, por consiguiente, a un giro en la concepción global que la RAE sostiene de estos asuntos de Sintaxis? Es lo que tendremos que ver en el siguiente capítulo.
\end{abstract}




\section{2.}

\section{Las Gramáticas}

Los gramáticos no son unánimes en torno al tema de cuáles son y en qué consisten las relaciones sintácticas; en este sentido se puede observar que el tratamiento de estas relaciones es cada vez más refinado, entra en mayor detalle; síntoma de ello serían la progresiva ampliación del campo de las relaciones percibidas por nuestros gramáticos, la progresiva complicación de la naturaleza de las mismas, el aumento gradual -aunque no siempre coincidente con el desarrollo cronológico- de los contenidos incluidos en la parte de los libros llamada sintaxis y el progresivo perfeccionamiento de las definiciones, propuestas y tratamientos que recibe esta «parte» de la gramática.

(Gómez Asencio, 1981: 42-43) 



\section{EL CONCEPTO DE SINTAXIS Y LAS RELACIONES DE DEPENDENCIA EN LAS GRAMÁTICAS DE LA RAE}

\subsection{Teoría sintáctica: generalidades}

\subsubsection{El lugar de la Sintaxis ${ }^{1}$ dentro de la Gramática}

Para determinar el lugar que ocupa la Sintaxis dentro de la Gramática en la doctrina de la Real Academia, hay que partir de la división de la disciplina que se defiende en los libros de Gramática publicados por la Institución (vid. 5. de 4.2.1.).

Hemos visto que en la quinta edición de la GRAE (1854) encontramos una división bipartita -en Analogía y Sintaxis² - que supone un cambio con respecto al texto anterior (GRAE-1796), en el que se se afirmaba que «la GRAMÁTICA... consta de quatro partes, que son Ortografía, Analogía, Sintáxis y Prosodia» (pág. 1) ${ }^{3}$. Con esta división en dos partes, la Academia vuelve, en el primer texto del siglo XIX, a lo defendido en su primera Gramática (1771)4.

1 Para la historia del concepto, véase Llorente Maldonado (1967: 214-370), Chevalier (1968), Drăganu (1970), Stati (1979 [1976]), Gómez Asencio (1981: 42-88), Calero Vaquera (1986: 183212 y 2007), Ramajo Caño (1987: 211-217), Graffi (2001) y García Folgado (2002 y 2004), entre otros.

$2 \quad$ [...] divídese [la Gramática] en analogía y sintáxis.

Los preceptistas suelen dividir la Gramática en cuatro partes, á saber, ortografía, analogía, sintáxis y prosodia; pero la Academia considera á la primera y la última como objeto de tratados especiales.

(GRAE-1854: 1 -nota (1)-)

${ }^{3}$ Aunque el libro, como en las ediciones anteriores, quede dividido, circunstancialmente, en dos bloques.

$4 \quad$ Divídese [la Gramática] en dos partes: la primera trata del número, propiedad, y oficio de las palabras: la segunda del órden y concierto que deben tener entre si, para expresar con claridad los pensamientos.

(GRAE-1771: 1-2) 
En las ediciones posteriores a 1854, sin embargo, se abandona por segunda vez (y ya para siempre) la partición en dos, para retomar (de manera definitiva) la división cuatripartita establecida en 1796. No obstante, en un primer momento, esta división se queda en la pura defensa teórica (se reconoce que la disciplina consta de cuatro subdisciplinas), ya que, en la práctica (en el libro de Gramática), se analizarán únicamente cuestiones analógicas y sintácticas 5 .

No será hasta 1870 cuando, por primera vez, se defienda, en la teoría y en la práctica, la división de la Gramática en cuatro subdisciplinas y la estructuración del libro en cuatro partes o secciones (una por cada subdisciplina). En el Prólogo de la 12. ${ }^{a}$ edición, se advierte de esta novedad doctrinal con respecto al procedimiento seguido en los libros anteriores:

Si bien la Prosodia y la Ortografía son partes esenciales de la Gramática, y como tales han sido siempre consideradas, solían las Gramáticas de las lenguas modernas limitarse á tratar de la Analogía y la Sintáxis, dejando para tratados especiales el estudio de las dos últimas partes. Esta misma práctica siguió la Academia Española en las ediciones anteriores; mas ha parecido conveniente separarse ya de aquélla, é incluir en un mismo volúmen las cuatro secciones que integran el arte de hablar y escribir correctamente.

(GRAE-1870: XIV-XV. El subrayado es mío)

Con respecto a estas dos partes reconocidas en la Gramática, creo acertada la observación de Rojo (2001: 46-47) de que ninguna de ellas recibe la etiqueta habitual (Analogía / Sintaxis) con la que comúnmente eran nombradas. La crítica ha tendido a considerar que, en la GRAE-1771, es la primera parte la que no recibe nombre, mientras que la segunda lleva el título de Sintaxis. Pero un análisis textual detenido permite afirmar que, en esta primera edición, la Academia no utiliza el término sintaxis como nombre de subdisciplina / parte del libro de Gramática, sino como fenómeno gramatical (atendido por una subdisciplina -y, en el tratado de Gramática, en un capítulo- que habitualmente recibe el mismo nombre).

${ }^{5}$ En 1858: 1 ( $6^{\mathrm{a}}$ ed.), 1862: 5 ( ( ${ }^{\mathrm{a}}$ ed.), 1864: 5 ( $8^{\mathrm{a}}$ ed.), 1865: 5 ( $9^{\mathrm{a}}$ ed.), 1866: $5\left(10^{\mathrm{a}}\right)$ y 1867: $5\left(11^{\mathrm{a}}\right.$ ed.), leemos: «La Gramática es el arte de hablar con propiedad y escribir correctamente: divídese en analogía, sintáxis, ortografía y prosodia». Y, en nota al pie, «La índole y extensión de las dos últimas han aconsejado á la Academia formar de ellas tratados especiales». 
Pese a lo afirmado en las primeras líneas de la cita reproducida (que «solían las Gramáticas de las lenguas modernas limitarse á tratar de la Analogía y la Sintáxis»), la Institución, en su primer texto, había optado por una solución novedosa dentro de nuestra tradición a la hora de decidir los contenidos de la disciplina gramatical (morfológicos y sintácticos) y, en coherencia con estos contenidos, la distribución del libro dedicado a su estudio. No olvidemos que la división nebrisense en Ortografía, Prosodia, Morfología y Sintaxis (con antecedentes en el Doctrinale de Alexander de Villa Dei) es la que cuenta con más defensores a lo largo de nuestra historia gramatical $^{6}$. Frente a su primera postura, la Academia no tardará en tomar la legitimidad de la tradición como asidero también en este aspecto, primero (1796), con una tímida asunción teórica -se reconoce que los estudios gramaticales engloban cuatro materias distintas-, y después (1870), con una aplicación práctica -el libro reserva una parte a cada una de las cuatro materias gramaticales- que mantendrá hasta la última Gramática del período que nos ocupa7.

En lo tocante a la división de la disciplina, se da, por tanto, la paradoja de que sea la primera edición de la GRAE (y, por extensión, la segunda y la tercera) la que defiende una concepción más próxima a la actual: los asuntos estrictamente gramaticales son los concernientes a cuestiones de morfología y de $\operatorname{sintaxis}^{8}$. A partir de la GRAE-1796, todas las ediciones (exceptuando la de

\footnotetext{
${ }^{6}$ No obstante -y tal como se deduce del fragmento arriba transcrito-, la concepción bipartita que de la Gramática presenta el texto de 1771, de carácter morfosintáctico, contaba con precedentes. Según Gómez Asencio (1981 y 2002b), esta concepción aparece por primera vez en Occidente en la obra de Petrus Ramus, pero dentro de la tradición hispánica es el texto académico el primero en defender la división en dos (del primer estudio citado, interesan las páginas 33-42, en las que se exponen las distintas particiones de la disciplina gramatical que los autores coetáneos de la GRAE-1771 establecen en sus Gramáticas).

${ }^{7}$ Y, en realidad, hasta la útima edición de la GRAE.

8 Anoto por periodos otras divisiones bipartitas (morfo-sintácticas) de la Gramática:

- 2. ${ }^{a}$ mitad del XVIII - 1. ${ }^{a}$ mitad del XIX: Jovellanos (parte sin etiqueta correspondiente a la Analogía y "Sintaxis"), Saqueniza ("Análisis" y "Sintaxis"), Martínez López ("Lexigrafía" y "Sintaxis"), Hermosilla (primera parte -Libro I-: "De las palabras, consideradas cada
} 
1854) se suman a la tradicional división en cuatro subdisciplinas gramaticales. Sin entrar en consideraciones sobre las competencias exactas de cada una de las partes, Rojo (2001: 39) ha recordado, a propósito de esta clásica organización, que «pretende lograr el paralelismo total, la correlación explícita entre las unidades lingüísticas que considera y las partes de la Gramática que han de ocuparse de cada una de ellas» ${ }^{9}$.

Desde el punto de vista teórico, y atendiendo solo a las declaraciones explícitas contenidas en los libros de Gramática, se puede decir que la doctrina académica experimenta una evolución en zig-zag, que podría quedar representada en el siguiente esquema:

una de por sí" y segunda parte -Libro II-: “De la coordinacion de las palabras"). Más detalles, en Gómez Asencio (1981: 38-39).

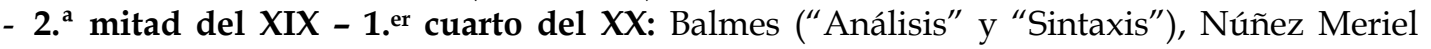
("Analogía" y "Sintaxis")... (Más detalles en Calero Vaquera, 1986: 37-38).

Sobre las particiones de la disciplina gramatical defendidas en libros coetáneos de las GRAE que constituyen el foco de atención de nuestro trabajo, véase Calero Vaquera (1989: 36$48)$.

[...] la letra (es decir, tanto el sonido como su representación gráfica), la sílaba, la palabra y las agrupaciones de palabras (oraciones) son estudiadas por, respectivamente, la Ortografía, la Prosodia, la Analogía (o Etimología) y la Sintaxis. Esa distribución evoluciona posteriormente en el sentido de ir reduciendo la Ortografía al estudio de los aspectos puramente gráficos, dejando a la Prosodia todo lo relacionado con la cara fónica. 


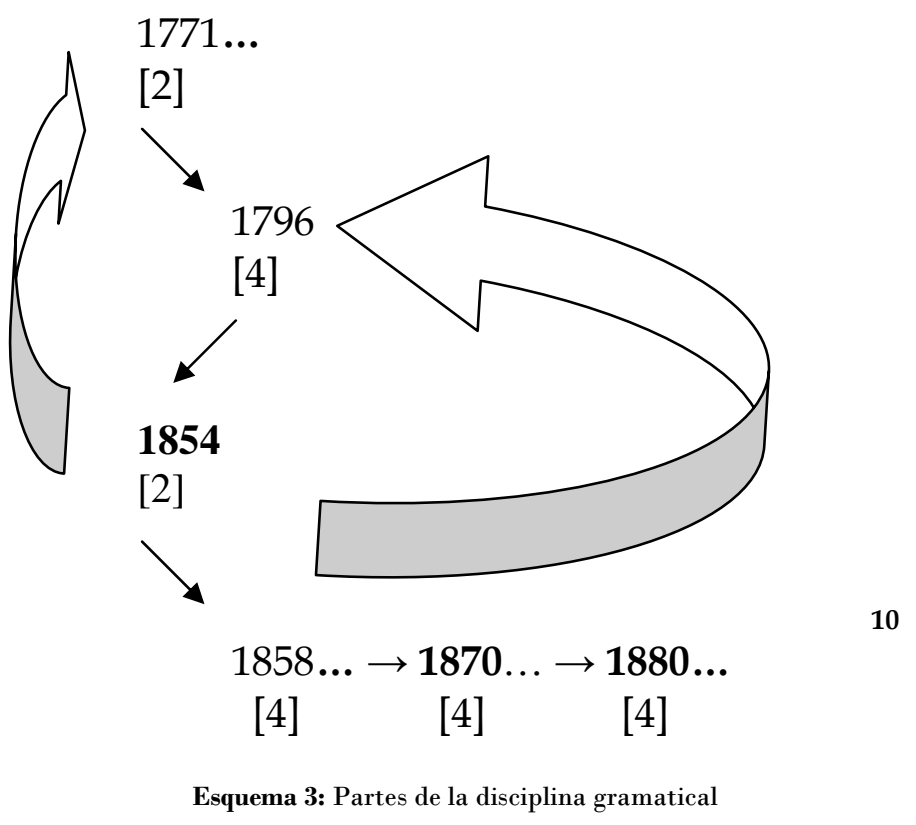

Con independencia de las razones que motivan la postura teórica (bipartita) adoptada por los académicos de 1771 y la recuperación de la misma -en declaraciones explícitas, al menos- en la GRAE-1854 (que, en este asunto concreto, se presenta como texto aislado entre las ediciones publicadas a partir de 1796), y con independencia también de la decisión de dividir en partes distintas la disciplina (4) y el libro (2) hasta la edición anterior al jalón de 1870 (excepción hecha de los casos de 1771 y 1854)11, lo que ahora nos interesa sobre la división de la disciplina es la constatación de que la Sintaxis es parte doctrinal (de facto) de la Gramática académica desde que esta vio la luz por primera vez.

No obstante el privilegio otorgado de ser considerada parte indudable -tanto de la disciplina como del libro- desde la GRAE-1771 (privilegio del

${ }^{10}$ Los puntos suspensivos indican que hubo ediciones intermedias. Conviene hacer hincapié en que el número indicado entre corchetes alude a las partes de la disciplina, no del libro (que no serán cuatro hasta 1870).

${ }^{11}$ Sobre estas cuestiones he tratado de forma pormenorizada en otro lugar (Garrido Vílchez, 2007). 
que no gozaron la Ortografía y la Prosodia, -vid. supra 4.2.1., 5.-), el apartado sintáctico no será atendido en profundidad hasta la segunda década del siglo XX (en concreto, hasta la GRAE-1917). La Academia tarda en renovar una doctrina sobre cuyos vacíos y limitaciones llama la atención, ya en la primera mitad del siglo XIX, uno de los más insignes gramáticos de la centuria, don Vicente Salvá, de quien son estas palabras:

[...] Mas los sabios que han pertenecido en los sesenta años últimos a aquel cuerpo, distraídos por tareas más gratas y de mayor gloria, o faltos de constancia para reducir a reglas los principios de lenguaje que tan bien han sabido observar en la práctica, no han llenado hasta hoy los muchos vacíos de su Gramática, ni han encerrado en la sintaxis todo lo que a ella pertenece [...] La misma Academia ha manifestado, con los deseos de mejorarla, la imposibilidad en que se ha visto de hacerlo [...]

(Salvá, 1847 [1830]: 75. El subrayado es mío)

Hemos visto ( $c f$. capítulo 4) que la GRAE defiende una concepción de la disciplina más morfológica que sintáctica. La propia Institución reconoce en los prólogos de algunas ediciones de la GRAE la mayor atención prestada al apartado de Analogía frente al de Sintaxis, y da las razones de este proceder:

Se ha dado á la primera parte, esto es, á la Analogía, más extension que á la segunda, ó sea á la Sintáxis, porque en aquella están las más notables anomalías, y por consiguiente las mayores dificultades del castellano. 
En este tratamiento desigual de las materias relativas a las categorías verbales (materia privilegiada) y a la sintaxis (materia relegada a segundo plano), los textos académicos no constituyen excepción ni dentro de nuestra tradición ni fuera del ámbito hispánico ${ }^{12}$. En efecto, hasta el siglo XIX (excluidas contadas excepciones del ochocientos ${ }^{13}$ ), la sintaxis es poco atendida en nuestros tratados de Gramática14:

Entre los primeros tratados, no faltan los que ni siquiera le dedican un apartado específico (en ellos, los apuntes sobre sintaxis aparecen dispersos en distintos lugares del libro) ${ }^{15}$.

En los tratados que sí dedican una sección al estudio de la Sintaxis (la mayoría), hay que tener en cuenta que:

\footnotetext{
12 Véase Kukenheim (1974 [1932]: 160), Stati (1979 [1976]: 31-40), Graffi (2001: XI) y Calero Vaquera (2007a: 90).

${ }^{13}$ Lo son las obras de Benot (1853 y c.1889), el tratado de Pérez y Aguado (1872), el de Orío y Rubio (1897 [1875]) y la Sintaxis de Ruiz de la Peña (1889). Estas obras anuncian desde el título una atención predominante a los hechos sintácticos. En el gozne entre los siglos XIX y XX, el tratado de Gisbert y Höel (1902 [1900]) se suma a la serie enumerada.

${ }_{14} \mathrm{Y}$ tendremos que esperar al siglo XX para que su desarrollo sea similar al de otras disciplinas lingüísticas. Stati (1979 [1976]: 31) recordó que la sintaxis «se ha encontrado, hasta la segunda posguerra, en una condición de descuido e inferioridad, similar a la de la semántica. En la década de 1930 se la definía como "la más atrasada entre las partes de la Gramática"». Años antes, Drăganu (1970) había apuntado la necesidad de renovar los estudios sintácticos.

${ }^{15}$ Es el caso de los Anónimos de Lovaina (1555 y 1559), Sotomayor (1565), Meurier (1568), Salazar (1614), Juan de Luna (1623) y Franciosini (1624 y 1733), entre otros (vid. Ramajo Caño, 1987: 35-36). Todos ellos dividen su obra en dos partes, Ortografía y Morfología. Esta partición no es exclusivamente española: «las primeras gramáticas francesas se ocupan exclusivamente de Ortografía o Fonética y de Morfología. Y una de las primeras gramáticas italianas, las Regole de Fortunio contiene sólo las dos secciones mencionadas» (Ramajo Caño, 1987: 35). También en la tradición inglesa la atención a la sintaxis es casi inexistente hasta el siglo XIX: en los tratados de gramática, el objeto prioritario de estudio es, sin duda, la palabra de forma aislada (Stati, 1979 [1976]: 35 y Martínez Linares, 2006: 2). Volviendo a la gramática española, a finales del XVIII todavía encontramos manuales de enseñanza que, como el de Castillo (1787) y el de Balbuena (1791), solo atienden a la Analogía, según informa García Folgado (2002: 131).
} 
a) Cuantitativamente, este apartado es -de forma sistemática- menor que el dedicado a la Analogía / Etimología / Lexicología16.

b) Cualitativamente, la materia sintáctica responde a conceptos y estructuraciones manidas y de limitado alcance descriptivo.

c) Jerárquicamente, la Sintaxis suele concebirse como materia complementaria de la Analogía.

Las Gramáticas de la Academia engrosan este segundo grupo; en ellas (hasta la mencionada edición de 1917, que excluimos), se constatan las tres afirmaciones de arriba:

(a) ${ }^{17}$ En todas las GRAE del XVIII, XIX y principios del XX (hasta la GRAE-1916, inclusive), el apartado de Sintaxis ocupa una extensión considerablemente menor que el apartado dedicado a la Analogía. Además, llama la atención que, en el paso del siglo XVIII al XIX, el "peso relativo" que tiene la Sintaxis dentro de los libros experimente un sensible decrecimiento: pasa de representar un 31,28\% (media de las GRAE dieciochescas) a ocupar una media del 25,04\% en las Gramáticas del XIX y principios del XX. Los picos más altos los tenemos en la GRAE-1796 (33,92\%), GRAE-1870 (29,31\%) y GRAE-1874 (28,13\%).

Los gráficos que siguen pretenden ilustrar los datos correspondientes a las ediciones $1 .^{\mathrm{a}} \mathrm{y} 4 .^{\mathrm{a}} \mathrm{y}$ a las ediciones de rango $\mathrm{E} \mathrm{y} \mathrm{J}$

\footnotetext{
16 Sabido es que fueron varias las etiquetas utilizadas para nombrar a la subdisciplina (y al apartado del libro de Gramática) dedicada a estudiar de forma independiente las categorías verbales. Sobre esta cuestión terminológica, véase Lliteras (1996).

${ }^{17}$ Los datos están en Gómez Asencio (2005: 601).
} 
del corpus central18. Dado que el objetivo es mostrar el "peso relativo" de los contenidos sintácticos dentro del estudio gramatical, para la obtención de los datos, he depurado el cómputo de las páginas de cada libro, descartando índices, páginas prologales, etc. y considerando (en el caso del Gráfico 1) de forma exclusiva las páginas en las que se presenta la doctrina estrictamente gramatical ${ }^{19}$. Debe tenerse en cuenta que las ediciones publicadas entre la GRAE-1771 y la GRAE-1858 (incluidas) están estructuradas en dos partes, mientras que las ediciones que salen a la luz a partir de 1870 ya constan de cuatro partes. Por ello, el gráfico 1 debe completarse con el gráfico 2, en el que se da constancia, únicamente, del porcentaje relativo de las materias de Analogía y Sintaxis dentro de los contenidos rigurosamente morfosintácticos, que son los comunes a todos los libros.

\footnotetext{
18 Aunque los datos numéricos en asuntos gramaticales pueden ser entendidos como información superficial y de limitado alcance interpretativo, y pese a que en ningún caso deben ser tomados como criterio único, ni tan siquiera determinante, a la hora de extraer conclusiones de calado doctrinal (para lo cual se impone un examen en profundidad de los fenómenos atendidos y del modo de tratarlos), coincido con Rojo (2001: 50) en la opinión de que el simple número de páginas dedicadas a la Sintaxis, cuando menos, puede resultar indicativo de la importancia concedida a la materia que hoy tendemos a considerar como el núcleo de los fenómenos gramaticales.

19 Esto es, las páginas que ocupan las partes de Analogía, Sintaxis (Prosodia y Ortografía -a partir de 1870-). En las ediciones de 1870 y 1874, también he contabilizado, en el total de páginas de contenido rigurosamente gramatical, las dedicadas a Nociones preliminares.
} 


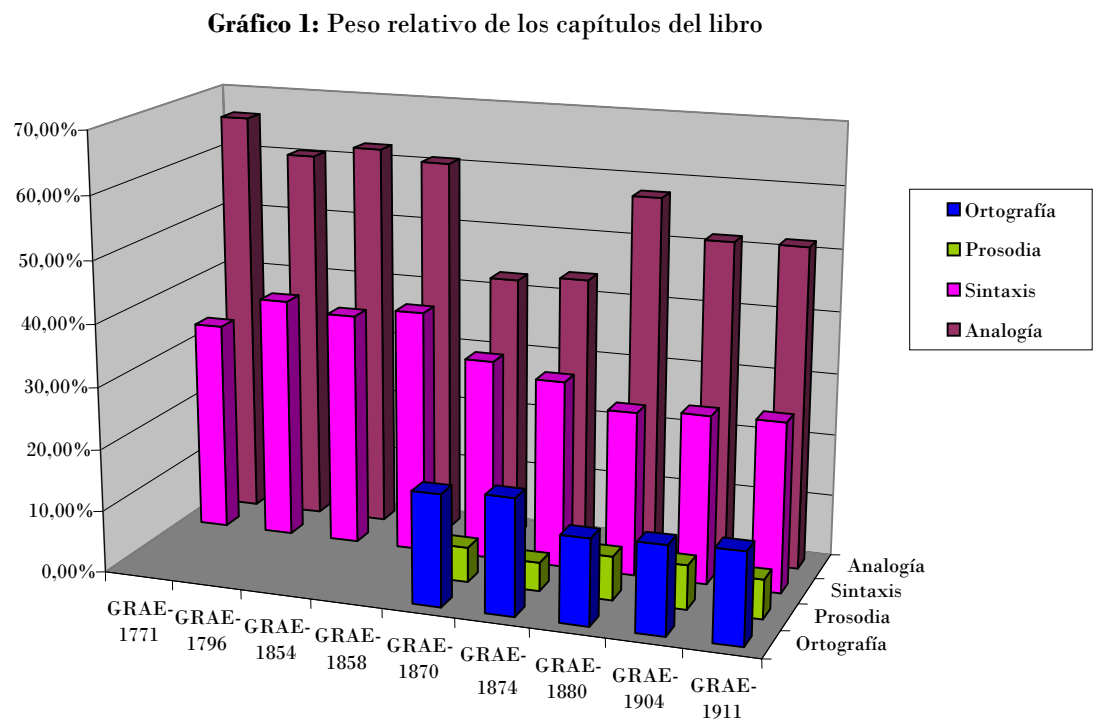

Grafico 2: Peso relativo del estudio sintagmático y paradigmático dentro de los contenidos morfosintácticos

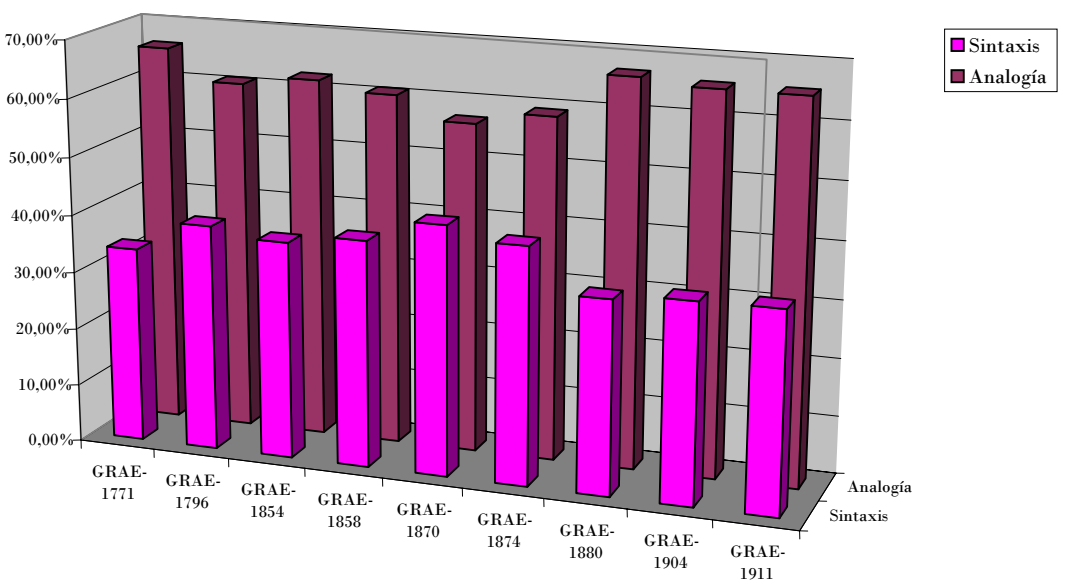

Los datos porcentuales permiten confirmar que en ninguna de las ediciones de la GRAE previas a la reforma de 1917 los contenidos sintácticos superan a los morfológicos. Es en el jalón de 1870 donde menos distancia hay entre el peso del estudio paradigmático $(56,93 \%$ sobre el total de páginas dedicadas a la morfo-sintaxis) y el del estudio sintagmático (43,06\% de la parte de contenidos morfo-sintácticos). 
(b) Todas las ediciones de la GRAE hasta la 29. (1916), incluida, articulan la teoría sintáctica sobre la base de los conceptos de concordancia y régimen, que no dan respuesta a todo el complejo entramado de relaciones intraoracionales $-y$ mucho menos interoracionales- y tienen como principio rector fundamental (con matizaciones que tendremos que analizar) el criterio del orden, heredado de la sintaxis latina.

(c) La información sobre cuestiones sintácticas es ancilla del estudio analógico, de ahí que la Institución decida incluso "alterar la rigurosa y matemática división" de la obra, anticipando nociones de sintaxis en el capítulo de la Analogía, en beneficio del mejor entendimiento de las partes de la oración:

[...] como para explicarlas [las anomalías y dificultades de la Analogía] y excusar frecuentes remisiones ha sido forzoso anticipar más de una vez nociones de construccion, aparecerán algunas de éstas en ambas partes del Tratado, lo cual si algo perjudica á su más rigorosa y matemática division, ofrece evidentemente más ventajas que el sistema contrario, según el cual serian incomprensibles muchos preceptos sobre la índole, la significacion y el uso de las diferentes partes de la oracion.

(GRAE-1854: IX y GRAE-1858: VI) ${ }^{20}$

\footnotetext{
20 No obstante, esta "ruptura del riguroso orden" supone asumir la inseparabilidad de las cuestiones morfo-sintácticas y poner en tela de juicio (muy tímidamente) la oportunidad metodológica de adelantar de forma sistemática los contenidos de analogía. Lejos estamos todavía, sin embargo, de doctrinas como la de Bello, una de las fuentes declaradas en el libro de 1854. Ya en la GRAE-1771 la Institución se expresaba en términos parecidos para advertir al lector que algunas de las reglas de la parte II del tratado se habían adelantado en la parte I. Pero las palabras que encontramos en la primera Gramática parecen subrayar más la dependencia mutua entre las cuestiones analógicas y sintácticas que la supeditación de estas a aquellas:
} 
Por otra parte, el hecho de que la unidad básica del estudio sintáctico sea la palabra (unidad sobre la que trabaja la Analogía) ${ }^{21}$ permite confirmar que, en la Gramática académica, la Sintaxis es concebida -conforme a la tradición- como estudio complementario (auxiliar, si se quiere) de la Analogía.

Aunque la mayor atención a los hechos analógicos o morfológicos (al estudio paradigmático, en definitiva) que se observa en las GRAE hasta la segunda década del siglo XX sea generalizada en la tradición gramatical española y de Occidente, no debemos olvidar que, ya desde los primeros tiempos de los estudios filológico-gramaticales, la Sintaxis fue oportunamente reivindicada como centro del estudio lingüístico ${ }^{22}$.

Aunque mucho de esto [reglas sobre el orden con que deben juntarse las palabras] se ha tratado en varios lugares de la primera parte por la conexîon que tiene el oficio de las palabras con su construccion, se ha reservado lo mas general para esta segunda parte.

(GRAE-1771: 232)

En el Prólogo de la GRAE-1796, volvemos a encontrar referencias a la conexión existente entre las dos partes del tratado de Gramática (que, en este año, ya no son las únicas partes de la disciplina), y en las palabras de la Comisión parece traslucirse una ligera inclinación por la Analogía como primer pilar:

[...] se ha procurado que todas las reglas de la Analogía y Sintáxîs formen un sistema completo, que tengan entre sí una perfecta correspondencia, y que las unas sirvan de fundamento á las otras, dando las de la primera luz para entender las de la segunda, y refiriéndose las de esta á los principios sentados en la precedente.

(GRAE-1796: XIII-XIV. El subrayado es mío)

${ }^{21}$ Cf. Gómez Asencio (1981: 348), Martínez Linares (2006: 13) y Calero Vaquera (2007a: 95).

${ }^{22}$ Sabido es que el primer testimonio que conservamos de una dedicación seria y consciente a un estudio de carácter sintagmático data del siglo II de nuestra era: lo encontramos en la Sintaxis de Apolonio Díscolo, para quien la Sintaxis (entendida como la construcción de las palabras con vistas a la coherencia de la oración perfecta) es «de la más absoluta necesidad para la interpretación de los poemas» (I, 1, pág. 73); es, por tanto, imprescindible para el objetivo primero (de carácter filológico) de la Gramática en su período de gestación. La enseñanza de Apolonio caló en la tradición posterior a él, como prueba el hecho de que la mayor parte de los autores que le siguen van a atender, en distinta proporción y con distinta perspectiva, al estudio sintagmático en sus respectivas Gramáticas. 
En los textos académicos que analizamos, la Sintaxis no es sólo "parte fija" de la Gramática, también parece tener reservado un lugar: la parte II del libro. En esta distribución sistemática de las partes constituyentes del estudio gramatical (primero Analogía y después Sintaxis ${ }^{23}$ ), puede apreciarse un nuevo vínculo de la GRAE con la tradición de la que forma parte. Efectivamente, tanto en la división de la disciplina gramatical como en la forma de plantear el comienzo de la exposición de la doctrina sintáctica, la Gramática institucional no oculta un sedimento de sabor antiguo (como no se podía esperar de otra forma), una concepción teórica que sirve de sustento a toda la obra. Este principio teórico concibe la lengua segmentada en partes o elementos (las palabras o partes de la oración) que, a su vez, están interrelacionados (son elemenos que se pueden identificar y aislar teóricamente, pero no en la práctica de la lengua). Esto hace pensar en Apolonio Díscolo, cuya obra, pese a ser un tratado de sintaxis, no concibe el estudio lingüístico como estudio exclusivo de las combinaciones: primero se impone una selección de los elementos integrantes. Las palabras con que se abre su tratado conducen a pensar que «Apolonio entendió su obra como un cuerpo articulado», tal como indica Bécares (1987: 32). Las palabras del Díscolo son las que siguen:

En los estudios que anteriormente hemos hecho públicos, $\underline{\text { se }}$ trató, como la razón de las mismas exigía, la doctrina relativa a las palabras. La exposición presente comprenderá la construcción que de ellas se hace con vistas a la coherencia de la oración perfecta; lo que me he propuesto exponer con todo detalle por ser de la más absoluta necesidad para la interpretación de los poemas.

${ }^{23}$ Seguidas de Prosodia y Ortografía desde 1870. 
Las ideas de Apolonio, que Occidente heredó a través de la obra de Prisciano y que, en España, se encargará de recoger en buena parte Nebrija, encuentran eco en la Gramática académica. Así, el modelo teórico «seleccióncombinación» (Bécares, 1987: 32) está presente ya en la primera edición de la GRAE y se mantendrá en todas las comprendidas entre 1854 y 1924. En todas ellas, se hace alusión, en el capítulo de Sintaxis, a que previamente se han estudiado las partes del discurso por separado (la única excepción la tenemos en la edición de 1916) ${ }^{24}$. Parece que tal procedimiento responde a un ritual y la Academia quiere dejar constancia de que lo ha seguido respetuosamente ${ }^{25}$.

${ }^{24}$ Hasta 1867 -inclusive-, esta observación se hace al comienzo del capítulo dedicado a la Concordancia; a partir de 1870, al principio del apartado sintáctico. Vid. GRAE de 1854: 138; 1858: 148; 1862: 152; 1864: 152; 1865: 152; 1866: 152; 1867: 151; 1870: 167; 1874: 195; 1878: 195; 1880: 215; 1883: 215; 1885: 217; 1888: 215; 1890: 215; 1895: 215; 1900: 215; 1901: 215; 1904: 209; 1906: 209; 1908: 209; 1911: 213; 1913: 213; 1917: 147; 1920: 167; 1924: 167.

Como queda apuntado arriba, en la GRAE-1916, no encontramos la alusión explícita al estudio analógico en el comienzo de la Sintaxis. Compárense los siguientes fragmentos extraídos de las ediciones de 1913, 1916 y 1917:

La ANALOGía nos ha enseñado en cuántas clases se dividen y qué denominaciones llevan los vocablos, y cuáles son sus propiedades y accidentes. La SINTAXIS nos enseña a enlazar unos vocablos con otros, o sea la acertada construcción de las oraciones gramaticales.

(GRAE-1913: 213)

Es la SINTAXIs la parte de la Gramática que enseña a enlazar los vocablos unos con otros, o sea la acertada construcción de las oraciones gramaticales.

(GRAE-1916: 214)

La ANALOGía nos ha enseñado en cuántas clases se dividen las palabras, la denominación que lleva cada una de éstas y las distintas formas que pueden tener las variables. La SINTAXIS nos enseña el modo como deben enlazarse unas palabras con otras para formar la oración gramatical, y también las oraciones entre sí para formar la oración compuesta ó período. El objeto de la Sintaxis es, pues, el estudio de la oración gramatical, y según sea ésta simple o compuesta, se divide en Sintaxis de la oración simple y Sintaxis de la oración compuesta.

(GRAE-1917: 147)

${ }^{25}$ Recordemos las palabras de Nebrija, que sin duda parecen ser las inspiradoras del proceder de la Academia:

$\mathrm{N}$ el libro passado diximos apartadamente de cada una delas diez partes dlã oraciõ agora eneste libro cuarto diremos como estas diez partes se an de aiuntar $\tau$ concertar entre si.

(Nebrija, 1492: fol. 44 v.) 
Analogía y Sintaxis son, así, desde el primer momento, las partes indiscutibles de la Gramática: no se puede entender una obra gramatical que no trate de hechos morfológicos (de las palabras por separado) y de hechos sintácticos (de las palabras en combinación). No parece casual que, en 1870 (la primera edición -no lo olvidemos- que trata de las cuatro partes clásicas de la Gramática), solo sea la exposición de la segunda parte la que comienza haciendo referencia a la necesidad de sumar a las consideraciones hechas en el apartado anterior (Analogía) las que se expondrán en este segundo apartado (Sintaxis):

A estas tan precisas nociones es fuerza añadir las de la Sintáxis, sin las cuales no sabríamos combinar y relacionar entre sí aquellos primordiales elementos del idioma, de forma que, prestándose mutuo auxilio, concurran á que seamos comprendidos cuando hablamos ó escribimos.

(GRAE-1870: 167)

Da la impresión de que los académicos consideran que la Ortografía y la Prosodia son "añadidos" complementarios del estudio gramatical. De hecho, estos dos apartados comienzan como si fueran tratados independientes (y, ciertamente, lo fueron) y como si su inserción en la Gramática fuera puramente física: se les ha hecho espacio en el "gran libro", nada más.

Este dato apoya la idea -que he expuesto en otro lugar- de que la división bipartita defendida por la Academia en su primera Gramática no parece justificarse, como afirma Rojo (2001: 42-44), por una simple cuestión de estrategia. Frente a lo sugerido por este autor, entiendo que sí estamos ante un problema de calado teórico: es la concepción teórica (composición morfosintáctica de la disciplina) la que parece justificar, en un primer momento, la 
publicación por separado de las cuestiones ortográficas, y el proyecto de publicación independiente de la Prosodia ${ }^{26}$. No obstante, cierto es que la Institución no mantiene una postura coherente entre las afirmaciones hechas en distintos tipos de libros y documentos (por ejemplo, no coinciden la doctrina de Diccionario y Gramática), como tampoco coinciden estas afirmaciones con los proyectos llevados a cabo ni con lo defendido por algunos académicos a título individual ${ }^{27}$.

${ }^{26}$ La defensa bipartita en 1854 constituye un caso más complejo.

${ }^{27}$ Los detalles sobre las dos divisiones de la disciplina defendidas en la GRAE -bipartita en 1771 y ¿1854?, y cuatripartita en las restantes ediciones- están en Garrido Vílchez (2007). Resumo aquí las ideas principales que defiendo en el artículo:

i. La GRAE-1771 concibe la disciplina gramatical dividida en dos partes, las mismas que articulan el libro (las correspondientes a Analogía y Sintaxis, que, en este año, no reciben etiqueta -Rojo, 2001-).

ii. Esta defensa teórica se aleja de la corriente más generalizada: aunque hay precedentes de la división bipartita, la división en cuatro es la imperante en la fecha.

iii. Es cierto que sorprende que la Institución no anuncie en el prólogo de la obra esta novedad doctrinal (Rojo, 2001); pese a ello, no parece que la solución adoptada se justifique por el deseo de la Corporación de no interferir en sus propios proyectos -los de publicación por separado de la Ortografía y la Prosodia- porque:

a) Si se tratara de una estrategia para salvaguardar el éxito de los otros libros, la división en dos se habría mantenido en la GRAE-1796. Sin embargo, en la cuarta edición, la división cuatripartita se impone en la doctrina académica, y se dan las razones de que el tratado titulado Gramática solo contemple dos materias: la primera razón, que la Academia ya ha publicado un tratado de Ortografía; la segunda, que aún no están fijadas las reglas que deben regular la Prosodia (¿no debería deducirse de esto que, en el momento en que estén fijadas las reglas, la Prosodia se integrará en la Gramática?). Este proceder hace pensar que el ánimo de no frustar los otros proyectos (¿sus ventas?) como mucho justificaría la división en dos del libro, no de la disciplina: el lector interesado en conocer las reglas ortográficas -(y prosódicas)- tendrá que hacerse de un ejemplar de ese otro tratado. Aquí puede estar la estrategia.

b) Las ediciones publicadas entre 1858 y 1867 también concilian la división teórica cuatripartita y la estructuración del libro en dos partes: en estas ediciones, son razones de "índole y espacio" las que se argumentan para excluir de la Gramática los asuntos ortográficos y prosódicos.

iv. Si rescatamos el plan inicial de la Corporación, el establecido en los Estatutos de 1715, descubrimos que en él no se hace mención de la Ortografía, y que la Gramática y la Prosodia (materia que, en buena medida, integraría la Poética) son concebidas desde un primer momento (antes de que haya ningún tratado elaborado, ni siquiera un proyecto en marcha que pudiera quedar ensombrecido) como materias separadas.

v. Cabe preguntarse, además, cuál fue la motivación de esos planes inicialmente trazados por la Academia que separaban Gramática por un lado, Ortografía por otro y Prosodia por otro.

vi. No puede ocultarse que la defensa hecha en la primera GRAE (avalada, al parecer, por los Estatutos y por su práctica editorial posterior: libros distintos para las distintas materias) no coincide con exactitud con la doctrina contenida en el Diccionario: ni en Autoridades ni en los DRAE del XVIII (recordemos que la última edición se publica tres años antes que la GRAE-1796) se considera la Ortografía materia gramatical (hasta aquí, todo encaja), pero sí se define invariablemente la Prosodia como "parte de la Gramática".

vii. La defensa bipartita en la GRAE-1854 ofrece más problemas de interpretación. Algunos años antes de publicarse la quinta edición de la Gramática, han salido a la luz los Estatutos que inauguran el sistema de Comisiones para organizar el trabajo de la Corporación; el sistema ideado parece sugerir de nuevo que las cuestiones de Ortografía y -ahora especialmente- de Prosodia superan los límites de competencia de la Gramática. Resulta coherente que en la primera edición de la GRAE que ve la 


\subsubsection{Definición y concepto de sintaxis (como parte de la Gramática)}

Para analizar los cambios en el concepto de sintaxis que se dan a lo largo de las GRAE en el período que nos ocupa, se impone hacer una presentación en contraste de las definiciones (explicaciones, en algunos casos) de esta parte de la Gramática dadas en las tres ediciones-jalón de la segunda mitad del siglo XIX y en la edición de 1917, clave -como ya se ha dicho y como veremos en el punto 6.3.- en la evolución de la teoría sintáctica a lo largo de la tradición gramatical de la Academia ${ }^{28}$.

luz tras la reciente reforma estatutaria se recupere la concepción de la disciplina gramatical constituida únicamente por las materias de Analogía y Sintaxis. Es en el ERAE-1857:11 donde encontramos la manifestación explícita más clara que confirmaría una concepción teórica bipartita por parte de los académicos. Los términos de la declaración cambian, sin embargo, aunque de manera sutil, en el ERAE-1858:11 (no en vano la Gramática publicada ese mismo año habla de cuatro subdisciplinas gramaticales).

viii. Si interpretamos las palabras que aparecen en nota al pie en la edición de 1854 (vid. supra nota 2 de este capítulo) no tanto como posicionamiento frente a la práctica habitual cuanto como reconocimiento o asunción teórica de la división tradicional ("los preceptistas suelen dividir") y toma de postura práctica por parte de la Institución ("pero la Academia considera"), podemos sospechar que, quizá, la GRAE-1854 está copiando la letra pero no el espíritu de 1771. Deben tenerse en cuenta, además, otros dos datos: i) en la primera Gramática no se hacía alusión alguna a la división cuatripartita; ii) en las ediciones que median entre 1854 y 1870 (la primera en la que el libro se estructura en cuatro partes), los académicos reconocen cuatro materias gramaticales y, en nota al pie, aluden a la solución práctica (bipartita) adoptada.

ix. La defensa en 1854 de una división bipartita supondría una evolución doctrinal en zig-zag (vid. supra Esquema 3) hasta cierto punto caprichosa en la historia de la GRAE. Entender, por el contrario, que, desde 1796, la Academia abandona su "moderna" visión (morfo-sintáctica) de la Gramática para seguir también en este asunto el camino trazado por la tradición (y defendido por varios académicos a título individual en los trabajos previos a la GRAE-1771) puede sorprender -incluso desilusionar- al lector de hoy, pero supondría una coherencia interna de doctrina: se trataría de una evolución (o, si se quiere, de una involución) de la propia tradición gramatical de la docta Casa.

$\mathrm{x}$. Son muchos los problemas que presentan las posturas adoptadas por la Academia en las ediciones de la Gramática que inauguran el siglo XVIII y el XIX. El rastreo en la documentación disponible no da luz a las incógnitas que se nos van planteando. Y las escasas declaraciones que encontramos en el texto de la GRAE a propósito de este asunto ayudan mucho menos (basta con recordar por último, en esta síntesis del problema de la división de la disciplina, las palabras que se leen en el Prólogo de la GRAE-1870 a propósito de esta cuestión. -vid. supra página 322-) .

28 En este punto, he atendido a las partes introductorias de las distintas ediciones y a las páginas primeras del apartado sintáctico, que es donde se ofrece información sobre la concepción general de esta subdisciplina gramatical. El análisis detenido de la teoría sintáctica expuesta en las GRAE objeto de estudio será abordado en los puntos siguientes (6.2. y 6.3.). 


\section{GRAE-1854}

Sintáxis es el órden y la dependencia que las palabras deben tener entre sí para formar la oracion.

(Pág. 137. El subrayado es mío)

La sintáxis [enseña], el órden y dependencia de estas palabras en las oraciones con que explicamos nuestros pensamientos.

(Pág. 1. El subrayado es mío) ${ }^{29}$

\section{GRAE-1870}

[sin las nociones de la Sintaxis] no sabríamos combinar y relacionar entre sí aquellos primordiales elementos del idioma, de forma que, prestándose mutuo auxilio, concurran á que seamos comprendidos cuando hablamos ó escribimos. Es la Sintáxis, en suma, la acertada construccion de las oraciones gramaticales.

(Pág. 167. El subrayado es mío)

Divídese [la Gramática] en Analogía, Sintáxis, Prosodia y Ortografía.

(Pág. 1. El subrayado es mío)

El fin de toda GRAMÁTICA es enseñar á conocer, ordenar, pronunciar y escribir correctamente las oraciones y las partes todas de que constan [...] De aquí nace la division de la GRAMÁTICA en las cuatro partes antedichas.

(Pág. 5. El subrayado es mío) ${ }^{30}$

29 Ídem GRAE-1858: 147 y 1; GRAE-1862: 151 y 5; GRAE-1864: 151 y 5; GRAE-1865: 151 y 5; GRAE-1866: 151 y 5; y GRAE-1867: 150 y 5.

30 Idéntica idea se expone (no con palabras exactamente iguales) en: GRAE-1874: 195 y 16; GRAE-1878: 195 y 16. 


\section{GRAE-1880}

La Sintáxis nos enseña á enlazar unos vocablos con otros, ó sea la acertada construcción de las oraciones gramaticales.

(Pág. 215. El subrayado es mío)

Así, pues, aquellas cuatro partes corresponden á los cuatro indicados fines, de conocer (ANALOGÍA), ordenar (SINTAXIS), pronunciar (PROSODIA) y escribir correctamente (ORTOGRAFÍA).

(Pág. 5. El subrayado es mío) ${ }^{31}$

\section{GRAE-1917}

La SINTAXIS nos enseña el modo como deben enlazarse unas palabras con otras para formar la oración gramatical, y también las oraciones entre sí para formar la oración compuesta o período. El objeto de la sintaxis es, pues, el estudio de la oración gramatical, y según sea ésta simple o compuesta, se divide en Sintaxis de la oración simple y Sintaxis de la oración compuesta.

(Pág. 147. El subrayado es mío)

Se divide [la Gramática] en cuatro partes, llamadas Analogía, Sintaxis, Prosodia y Ortografía, las cuales corresponden a los cuatro indicados fines de conocer (ANALOGÍA), ordenar (SINTAXIS), pronunciar (PROSODIA) y escribir correctamente (ORTOGRAFÍA).

(Pág. VIII. El subrayado es mío) ${ }^{32}$

Los fragmentos reproducidos muestran que la primera edición decimonónica de la GRAE (texto con el que la Academia reanuda, tras casi sesenta años, su aportación gramatical al estudio de la lengua española)

31 Ídem GRAE-1883: 215 y 5; GRAE-1885: 217 y 5; GRAE-1888: 215 y vI; GRAE-1890: 215 y vI; GRAE-1895: 215 y vI; GRAE-1900: 215 y vI; GRAE-1901: 215 y VI; GRAE-1904: 209 y VI -edición de rango E-; GRAE-1906: 209 y vI; GRAE-1908: 209 y VI; GRAE-1909: 209 y VI; GRAE1911: 213 y 6; GRAE-1913: 213 y 6; GRAE-1916: 213 y 6.

32 Ídem GRAE-1920: 167 y 8; GRAE-1924: 167 y 8. 
presenta una concepción de la Sintaxis basada en las nociones de orden y dependencia ${ }^{33}$. La unidad central del estudio sintáctico es la palabra y la unidad última -la resultante tras la ordenación de las palabras-, la oración. La Sintaxis, o el "orden y dependencia de las palabras en la oración", tiene, además, implicaciones de tipo semántico-nocional: el ordenamiento de los elementos oracionales tiene como objetivo final la expresión de los pensamientos $^{34}$.

Esta teoría sintáctica expuesta en 1854 es idéntica a la que ya presentaba la Institución en su última Gramática del siglo XVIII ${ }^{35}$, y podemos decir que, en esencia, no va a cambiar hasta la segunda década del siglo XX,

33 Concepción que podemos encontrar en textos coetáneos de las GRAE comprendidas entre 1854 y 1924; valga como ejemplo la definición ofrecida por Gómez de Salazar:

Sintáxis es el conjunto de las reglas que establecen el órden y dependencia que las palabras deben tener entre sí para formar la oracion.

(Gómez de Salazar, 1869: 121)

Calero Vaquera (1986: 185-198) da cuenta de las distintas concepciones que sobre sintaxis se exponen en la época que centra nuestra atención. Antes de estas fechas, otros autores habían definido la Sintaxis sobre la base de los conceptos de orden y dependencia -si bien son más los que se apoyan de forma casi exclusiva en la idea de orden-: Jaramillo (1798: 25) y la propia GRAE-1796: 273 sirven de antecesores de la definición dada en la quinta edición de la Gramática académica.

34 Orden y pensamiento son ideas dominantes en las definiciones dieciochescas y decimonónicas de sintaxis: Cristóbal y Jaramillo (1793: 48), Jovellanos (1795: 112), Rubel y Vidal (1797: 69), Herranz y Quirós (1815: 67), entre otros, son autores que formulan sus definiciones en torno a estos conceptos, como lo hicieron los académicos de 1771 (vid. infra). Avanzado el siglo XIX, encontramos las definiciones de Ruiz Morote y Avendaño como botón de muestra de una práctica habitual entre los autores coetáneos de nuestro corpus:

[Sintaxis es] la segunda parte de la Gramática que enseña á construir las palabras para expresar debidamente los pensamientos.

[Contruir es] colocar las palabras en el lugar correspondiente para formar las oraciones, objeto principal de la Gramática.

(Ruiz Morote, 1880: 52. El subrayado es mío)

1. SINTÁXIS es una voz griega que significa arreglo, coordinación. Trata, pues, de coordinar las palabras para expresar correctamente los pensamientos.

2. Coordinar es poner en orden y método una cosa $[\ldots]$

(Avendaño, 1886: 230)

En Calero Vaquera (1989: 185-188) se encuentra una nómina detallada de gramáticos que ofrecen definiciones cifradas en términos similares.

35 Vid. GRAE-1796: 273 y 1-2. 
con la GRAE-1917, a pesar de que, en las dos ediciones-jalón que suceden a la de 1854 (esto es, las de 1870 y 1880), encontremos cambios de formulación (que se mantendrán en las ediciones que las siguen de forma inmediata).

Así, la doctrina sintáctica defendida hasta principios del siglo XX será sustancialmente la misma: seguimos ante una sintaxis centrada en la ordenación y la dependencia de las palabras dentro de la oración ${ }^{36}$ y ante una Sintaxis que, al menos hasta 1880, está al servicio de una finalidad semántico"comunicativa".

En la GRAE-1880, como vemos, el cambio de formulación en la explicación de lo que es la Sintaxis va acompañado de la supresión de aquel matiz último que añadían las ediciones anteriores con las coletillas «con que explicamos nuestros pensamientos» $\mathrm{y}$ «que seamos comprendidos cuando hablamos y escribimos». Esta supresión supone que, al menos en teoría, la Sintaxis se desprende, en principio, de aspectos ajenos al análisis estricto de

\footnotetext{
36 Así es como creo que debe interpretarse, respectivamente, lo de «combinar» y lo de «relacionar» los elementos básicos del idioma, que leemos en el fragmento seleccionado de la GRAE-1870. No creo que se preste a dudas esta interpretación, pues, ya en la GRAE-1771: 235, se establece la equivalencia relación = dependencia. Por lo que respecta a los Diccionarios, la Academia no registra una acepción gramatical del término relación hasta el DRAE-1884, diccionario en el que claramente, por el ejemplo dado («amor de madre», donde se defiende que hay relación gramatical entre los dos términos amor y madre), se concibe la relación como vínculo de dependencia entre dos palabras (además, en las Gramáticas, se atenderá a este tipo de estructura en los apartados dedicados a los casos de Régimen y Construcción, concebidos como distintas formas de dependencia entre las partes de la oración). En cuanto al término combinar, es muy plausible interpretarlo como mera unión, junción; el ejemplo dado en la mayoría de los Diccionarios que preceden a la GRAE-1870 hace pensar en esto: «y así se COMBINAN las letras para formar una diccion, y los números para formar una cantidad». Según estas palabras, parece claro -a mi juicio- que cuando la Academia, en 1870, dice que la sintaxis enseña a "combinar entre sí aquellos primordiales elementos del idioma», está pensando en un hilvanado, en una unión o en una mera ordenación sucesiva (las palabras serían con respecto a la oración como las letras con respecto a la palabra). Por su parte, la GRAE-1880 habla de «enlazar unos vocablos con otros», lo que podría hacer pensar sólo en cuestiones de orden; pero, al hablar de la «construcción de las oraciones» se está garantizando la referencia a las relaciones de dependencia, por cuanto el concepto de construcción se entiende, efectivamente, como relación de dependencia (distinta del Régimen) en todas las GRAE, si bien es una relación claramente condicionada -mucho más que las de concordancia y régimen- por el orden. (Vid. Glosario final, s.v. combinar, relación y relacionar).
} 
los esquemas oracionales. Tal análisis se seguirá entendiendo, eso sí, de la misma manera que en las ediciones precedentes (desde finales del XVIII).

El cambio, en efecto, es solo aparente, de formulación, puesto que el concepto de oración (que sigue siendo el punto de llegada de la Sintaxis) se apoya todavía, en la edición de 1880, en los parámetros clásicos de la oratio perfecta, que, además de la corrección gramatical, implican la coherencia semántica de la misma, es decir, la transmisión de un sentido inteligible y completo $^{37}$ (lo veremos al tratar de la oración) ${ }^{38}$.

Aceptando, por tanto, la semejanza (que no plena identidad, como se irá viendo) de las GRAE comprendidas entre 1796 y 1916 en lo tocante a la teoría sintáctica que en ellas se expone, paso a comentar los conceptos que sirven de sustento a esta teoría.

37 Las oraciones se entienden todavía como «fórmulas necesarias para la más oportuna expresión de los pensamientos» (GRAE-1880: 245).

38 Los orígenes del concepto se remontan al mismo Dionisio de Tracia, para quien " proposizione è la composizione del discorso in prosa (perciò "l'unione di alcune parole") che

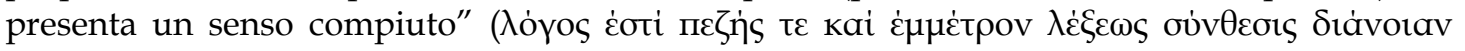

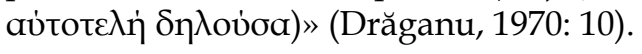




\subsubsection{El orden y la dependencia}

Desde Nebrija, en la tradición gramatical española, se concibe la Sintaxis como cuestión relativa al $\underline{\boldsymbol{o r d e n}}^{39}$ de palabras. En este sentido, la competencia sintáctica del análisis gramatical se centra, principalmente, en la adopción de criterios de colocación, de ordenación de los elementos en el interior de la oración o frase.

El que los gramáticos de nuestra tradición asuman este criterio (heredado) del orden como principio rector de la relaciones sintácticas (hasta el punto de que, en virtud del ordenamiento de las palabras dentro de la oración, se establece la primera división de la Sintaxis: en natural y figurada) supone una "latinización del marco" -en términos de Gómez Asencio (1999 y 2001)de la que participan los textos académicos de nuestro corpus ${ }^{40}$.

Sobre el concepto de orden se ha pronunciado Rojo (2001) para advertir de la lectura reduccionista -en clave lineal- que los estudiosos han hecho del orden sintácico. Según este autor, por orden debe entenderse, desde Apolonio y Prisciano:

\footnotetext{
39 Para Nebrija, lo que los griegos llamaron sintaxis «nos otros podemos dezir orden o aiuntamiento de partes» (1492: fol. 44 v.). El orden ya era para Prisciano elemento básico en la definición de sintaxis, que no es otra cosa sino la disposición de las palabras para la constitución de un enunciado perfecto: «de ordinatione earum (dictionum), quae solet fieri ad constructionem orationis perfectae» (Ápud. Lozano Guillén, 1992: 57). Esta idea bien la pudo aprender Prisciano del griego Apolonio Díscolo, quien expone en su obra que, de la misma forma que no se admiten combinaciones de letras al azar, sino según un orden necesario, tampoco deben admitirse estas combinaciones en los niveles más altos: las sílabas, para constituir palabras, tienen que presentar una adecuada ordenación; asimismo, las palabras, «que son parte de la oración perfectamente construida, reciben la ordenación coherente; pues el significado subyacente a cada palabra es, en cierta medida, una «letra» de la oración» (I,2, págs. 75-76).

40 Esta atención al orden, sin embargo, rara vez trasciende de la simple constatación de las distintas combinaciones posibles para hacer una lectura interpretativa de las mismas y extraer conclusiones. Casielles Suárez (2000) ha estudiado la atención que algunos de los gramáticos más influyentes del siglo XIX y principios del XX conceden al orden de las palabras en el discurso y las reflexiones que hacen sobre las distintas posibilidades combinatorias.
} 
a) Un concepto amplio: el conjunto de relaciones que se estabecen entre las palabras dentro de una secuencia determinada. Recoge este concepto tanto las relaciones constitutivas y funcionales (esto es, relaciones todo-parte) como las conectivas y secuenciales (es decir, relaciones parte-parte) ${ }^{41}$.

b) Un doble concepto restringido: de un lado, cierto tipo de construcciones sintácticas: / $\mathrm{Vb} .+\mathrm{CD} / \ldots$, esto es, relaciones funcionales y conectivas (ya sean casos de determinación, interdependencia o constelación); de otro, ordenación lineal de los elementos en la frase, es decir, relaciones secuenciales.

Sin negar la interpretación amplia ni el primero de los conceptos restringidos, entiendo que es la idea de ordenación lineal la que impera en nuestra tradición y la que preside en buena medida (no de forma exclusiva, ciertamente) los textos académicos del corpus hasta la reforma de 1917, según veremos en las páginas que siguen. Esta ordenación, además, descansará sobre principios lógicos -como es habitual en nuestra tradición gramaticalhasta el período que centra el interés de este estudio (segunda mitad del XIX y primer cuarto del $X X)^{42}$. En efecto, hasta las primeras ediciones de la GRAE publicadas en el siglo $X X$-estas incluidas-, la Sintaxis es el ordenamiento de las palabras para formar la oración, y el orden de aparición de las mismas dependerá del concepto lógico que denoten (sustancia, accidente, agente, etc.): aquella palabra que exprese una idea lógica más importante ocupará el primer lugar.

\footnotetext{
${ }^{41}$ En terminología del propio Rojo (1983 y 1989).

42 Sobre el carácter sintáctico-lógico que lleva implícito el concepto de orden en nuestra tradición, véanse Calero Vaquera (2007: 90-91) y García Folgado (2002: 132-137).
} 
Que, en los textos académicos, la Gramática, y más concretamente la Sintaxis, descansan sobre un logicismo secular lo demuestra el hecho de que, desde la primera GRAE hasta la última de nuestro corpus, encontramos una división básica del apartado sintáctico en Sintaxis natural y Sintaxis figurada (vid. infra 6.1.3.). La primera recoge aquellas estructuras que respetan el ordenamiento lógico y las reglas dictadas por él; la segunda registrará todas las construcciones que, de una u otra forma, se desvían de los principios de ordenamiento lógico.

La Sintaxis es, como vemos, orden (lógico), pero también es dependencia, según las definiciones dadas. En los estudios de historia de la gramática, se ha convertido en lugar común la reflexión de que, en nuestra tradición, el orden de las palabras dentro de la oración es un orden que implica una jerarquía (es índice de relación, por tanto): la palabra que precede es jerárquicamente superior a la que le sigue (es más importante lógica, semántica y sintácticamente); y viceversa: la importancia de los conceptos expresados por las distintas palabras determina su lugar de aparición en la frase. De manera que el sustantivo, al denotar una idea sustancial, debe ir siempre delante del adjetivo, que, por significar siempre 'accidente', irá detrás del sustantivo y dependerá de él. Se trata de una espeie de "círculo tautológico": por el lugar ocupado, deducimos el oficio (palabra Regente/Determinante, palabra regida/determinada, etc.) y, según la importancia (lógica) del significado, asignamos lugar a cada palabra. En definitiva, el oficio no se entiende tanto como función sintáctica (en concepción actual) cuanto como aportación significativa ${ }^{43}$.

\footnotetext{
43 Obligado es mencionar que los académicos de 1854 contaban con posibles modelos de referencia que habían dado importantes pasos en el avance de la descripción de las relaciones sintácticas. En los Elementos de gramática española, de Román Martínez Sevilla (1851), obra que sigue sustentando el estudio sintáctico en los tradicionales conceptos de concordancia, régimen y construcción, encontramos una interesante teoría, en la que ya se utilizan con familiaridad y cierto rigor términos y conceptos como función gramatical, complemento, oración subordinada, etc.
} 
Según lo dicho, es fácil deducir que, en los textos del corpus publicados antes de la reforma de 1917, se va a defender que las relaciones de dependencia son relaciones determinadas, en mayor o menor grado, por el orden de las palabras en el discurso: si el adjetivo va detrás del sustantivo (hombre bueno), quiere decir que depende de él, como el adverbio depende del verbo (crece mucho), el sustantivo del verbo (busco criado), el verbo del sustantivo (Antonio escribe), etc., etc. Del orden y de su importancia como factor determinante de las relaciones de dependencia se volverá a tratar en los puntos que siguen.

El estrecho vínculo entre los conceptos de orden y dependencia se puede apreciar, en los textos académicos, hasta la GRAE-1917 (edición en la que tampoco se pierde por completo la conexión), pero creo que, entre la GRAE1771 y la GRAE-1796, se da una pequeña -aunque no insignificante- diferencia de planteamiento a la que interesa atender, por cuanto la Gramática que abre el corpus básico de este trabajo (GRAE-1854) se hace eco del cambio. De manera que podríamos establecer tres grupos, o dos momentos de cambio, en las Gramáticas institucionales publicadas entre 1771 y el primer cuarto del siglo XX (aceptando que el logicismo nunca desaparece por completo de los textos académicos):
a) GRAE-1771.
b) GRAE-1796 a GRAE-1916.
c) GRAE-1917 a GRAE-1924.

El primer cambio se dará en 1796 (cambio que hereda el primer texto de nuestro corpus) y el segundo, en 1917. De ambas modificaciones en los planteamientos sintácticos de la Academia se tratará, respectivamente, en los puntos 6.1.4. y 6.3.2. 


\subsubsection{Las unidades de estudio}

En cuanto a las unidades sintácticas, podemos decir que, en los siglos XVIII y XIX, estamos ante una Sintaxis centrada en la palabra y que, por su marcado sedimento lógico (las palabras en la oración tienen que seguir la disposición de las ideas en el pensamiento), no se preocupa de analizar y jerarquizar las imbricaciones que se dan en el cuerpo de la oración. En este sentido, podemos hablar de una sintaxis colocacional (de ordenamiento de palabras) que todavía no alcanza un desarrollo funcional (de relaciones, de imbricaciones). Este escaso alcance funcional en las GRAE es especialmente evidente hasta las últimas décadas del siglo XIX: hasta la edición de 1867 (inclusive), encontramos, por ejemplo, que la clasificación de las partes de la oración (básica para el análisis gramatical) no se establece según un criterio sintáctico sino formal-nocional ${ }^{44}$; el criterio seguido justifica la no distinción categorial entre sustantivo y adjetivo, distinción que encontramos por primera vez en el texto de 1870. En esta 12. ${ }^{\text {a }}$ edición de la GRAE, puede apreciarse un tímido cambio de perspectiva, en virtud de una mayor atención -todavía incipiente- al oficio de las palabras dentro de la oración: tanto en la Advertencia como en las Nociones Preliminares, la Academia quiere dejar constancia del sutil, pero importante, giro doctrinal que sustenta la nueva Gramática. Este giro afecta, fundamentalmente, al criterio de clasificación de las palabras, que ahora, frente a la edición de $1854^{45}$, atenderá a «las ideas que representan... ó el oficio que en la oracion hacen» (GRAE-1870: 5). Si esto es así, es coherente que sea ahora cuando la Academia decide escindir la antigua categoría de nombre en sustantivo y adjetivo, puesto que la «significacion y oficio real» (pág. XIV) de éste es distinta de la de aquél: el adjetivo denota una mera cualidad y su oficio es, por tanto, determinar al sustantivo. Esta peculiaridad es suficiente por sí

\footnotetext{
${ }^{44}$ Lo que muestra que la Institución, en sus Gramáticas decimonónicas (hasta la de 1867), obvió la aportación que, en la primera mitad del siglo XIX, hizo don Andrés Bello, supuesta fuente de inspiración, como ya se ha comentado (vid. supra nota 70 del capítulo 4), de la GRAE-1854. ${ }^{45}$ La GRAE-1870 es la primera que se presenta como «nueva edición» después de la GRAE1854.
} 
sola para conferirle rango de parte independiente de la oración, del que no había gozado hasta el momento ${ }^{46}$. La Corporación siempre entendió el adjetivo como elemento modificador del sustantivo, pero hasta las últimas décadas del XIX no concede al oficio (a la función) la importancia suficiente como para elevarlo a criterio clasificador. Tendremos que comprobar si este nuevo enfoque expuesto en las páginas introductorias de la GRAE-1870 realmente se lleva a la práctica en el cuerpo de la obra.

La palabra será unidad básica de la Sintaxis hasta la reforma que tiene lugar en 1917. Este absoluto protagonismo de la palabra en el estudio sintáctico de la Academia ha llevado a Martínez Linares (2006) a hablar de "enfoque atomístico" en las ediciones de 1866, 1880 y 1888. La autora utiliza con acierto la conocida frase benotiana a la hora de establecer el tipo de sintaxis defendido en las Gramáticas decimonónicas de la Institución ("sintaxis atomística" que añado- también presentan las primeras ediciones del siglo XX, hasta la GRAE$1916)^{47}$.

En la GRAE-1917 las cosas cambian: según las declaraciones explícitas que encontramos en la primera página de la Parte II del libro, la mirada está puesta doblemente en la palabra y la oración. Recordemos la declaración hecha por la Comisión de Gramática:

\footnotetext{
${ }^{46}$ Los académicos de 1870 no dejan de justificar a sus predecesores, los cuales -dicen- no estuvieron del todo "descaminados" al considerar conjuntamente al sustantivo y al adjetivo, dada la paridad de accidentes gramaticales y la frecuencia con que cada uno de ellos se tiñe de las peculiaridades significativas del otro. Pero ahora se tiene conciencia -o eso parece por las declaraciones de las páginas primeras de la Gramática- de que no sólo vale el criterio formal de variabilidad o invariabilidad para establecer una distinción primera entre las palabras, ni, dentro de cada uno de estos dos grupos, el criterio semántico para establecer clases categoriales.

47 Efectivamente, una sintaxis atomística es, en la teoría gramatical desarrollada por Benot, una sintaxis centrada en la unión de vocablos, una sintaxis que no atiende a la combinación de las distintas "uniones de vocablos".
} 
La SINTAXIS nos enseña el modo como deben enlazarse unas palabras con otras para formar la oración gramatical, y también las oraciones entre sí para formar la oración compuesta ó período. El objeto de la sintaxis es, pues, el estudio de la oración gramatical, y según sea ésta simple ó compuesta, se divide en Sintaxis de la oración simple y sintaxis de la oración compuesta.

(GRAE-1917: 147. El subrayado es mío)

La doble perspectiva que se puede apreciar en estas líneas de 1917 la encontramos en autores de la segunda mitad del XIX que, en este aspecto, se adelantaron a la Academia. Sirva como ejemplo el caso de Giró (1871. $3^{\mathrm{a}}$ ed.), para quien el estudio de la lengua tiene dos objetos, el primero de los cuales es «enseñar el modo de espresar las relaciones que hay entre las palabras, los miembros y las oraciones entre sí» (pág. 195). Y, consecuentemente con esta afirmación, tratará, en los dos capítulos dedicados a las relaciones de dependencia ${ }^{48}$, del régimen y construcción tanto de las oraciones como de los miembros y de las partes de la oración entre sít9.

Podemos afirmar, por tanto, que la Gramática académica va a la zaga en el abandono del modelo gramatical denominado por Hockett (1954: 210) palabra y paradigma. Este modelo (característico de la tradición grecolatina) empieza a perder seguidores entre nuestros gramáticos desde las primeras décadas del siglo XIX, por influjo de la gramática filosófica francesa, que destierra la palabra como unidad de la Sintaxis y convierte a la oración en

48 Según Giró, las relaciones que se dan entre las palabras son de dos tipos: de identidad (expresada mediante la concordancia) y de dependencia (expresada mediante el llamado régimen y la construcción).

${ }^{49}$ Otros gramáticos decimonónicos que contemplan la oración no solo como unidad de llegada, sino también como unidad de partida del estudio sintáctico son: Fernández Monje (1854) Salleras (1887 [1876]), Avendaño (1886), Ruiz Morote (1880) y Araújo (1880). Todos ellos son deudores de la gramática filosófica francesa del XVIII. También conviene recordar que estos autores tuvieron antecedentes dentro de nuestra tradición, como es el caso de Correas (1627), para quien «el fin de la Gramatica es la oracion, o razón congrua y bien conzertada» (pág. 111) o del mismo Brocense (1587), quien afirmaba que «la oracion o sintaxis es el fin de la gramática» (pág. 48). 
IV. Sintaxis y Relaciones de Dependencia

unidad objeto de estudio per se, en unidad de partida del análisis sintáctico. Deja de entenderse ya como mero resultado de la unión de palabras ${ }^{50}$.

50 Vid. Calero Vaquera (2007a. 95-98). 


\subsubsection{División de la Sintaxis}

La división de la subdisciplina sintáctica defendida en los libros de Gramática varía a lo largo de las distintas ediciones, aunque son pocos (y más bien tímidos) los cambios que se producen entre la GRAE-1771 y la edición inmediatamente anterior a la reforma de 1917.

Expongo a continuación, en esquemas, la propuesta de división que se encuentra en las ediciones jalón del corpus y en los dos textos del siglo XVIII que nos sirven de referencia:

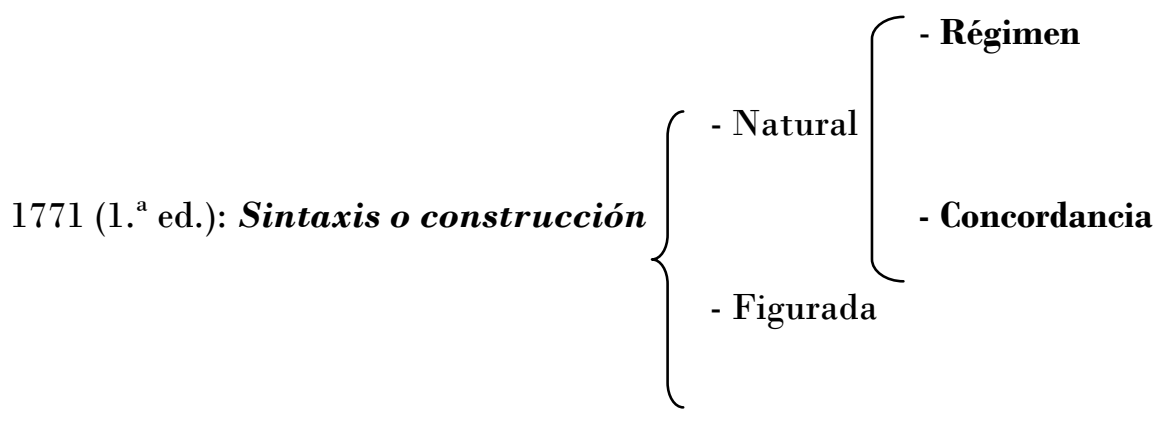

Esquema 4: División de la Sintaxis en la GRAE-1771

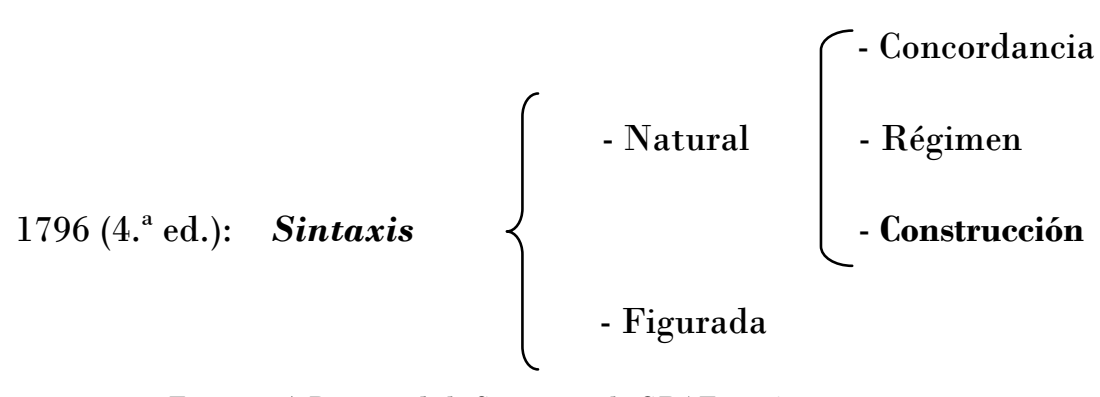

Esquema 5: División de la Sintaxis en la GRAE-1796

En la cuarta edición de la GRAE, la Sintaxis, como parte del tratado de Gramática (no ya como subdisciplina gramatical), incluye al final una Lista de palabras que se construyen con preposición. En la edición de 1771, esta lista formaba parte del capítulo dedicado al Régimen, cuyo artículo v -intitulado «De los verbos, participios, adjetivos, y adverbios que rigen preposicion, y qual»- 
estaba destinado íntegramente a dar cuenta de esta lista de palabras que piden tras de sí una preposición. La lista, además, había sido anunciada en el prólogo, donde era presentada como recurso para solventar la principal dificultad de la sintaxis de nuestra Gramática, que, a juicio de la Institución, era conocer el régimen preposicional de las distintas categorías verbales ${ }^{51}$ :

Otro punto difícil de nuestra Gramática, y en que consiste la parte principal de la sintáxîs es saber qué preposiciones piden después de sí algunos verbos y otras partes de la oracion.

A esta dificultad se ocurre con una lista alfabética ordenada en tres columnas [...] con lo qual apenas habrá duda alguna sobre el régimen, de que no se pueda salir á primera vista.

(GRAE-1771: XI-XII. El subrayado es mío)

El nuevo tratamiento que la GRAE-1796 da al listado de regímenes (complemento que cierra la parte II del libro) es considerado por Rojo (2001) la consecuencia más visible de un importante cambio de percepción de las relaciones sintácticas por parte de los académicos finiseculares ${ }^{52}$. Cierto es que la lista no constituye ya en este año el núcleo de las relaciones que se establecen entre las palabras dentro de los márgenes de la oración: su

\footnotetext{
${ }^{51}$ Gómez Asencio (2000a: 43) ha hecho los cálculos que permiten determinar el peso de esta lista en la doctrina gramatical -en general- y sintáctica -en particular- de la primera GRAE: las más de 68 páginas que ocupa (de la 253 a la 321 del libro) representan un 19' $8 \%$ del total de los contenidos estrictamente gramaticales y un $58^{\prime} 5 \%$ de la parte de Sintaxis. No le falta razón al concluir que se trata de «asunto mimado y de entidad», por lo que «su anuncio en el preámbulo queda plenamente justificado por el texto de la gramática».

${ }^{52}$ Las palabras de Rojo (2001: 93) son las que siguen:

En línea -aunque sin duda a gran distancia tanto en lo teórico como en lo descriptivo- con las gramáticas francesas de estos años, se habla de organizar la sintaxis con arreglo a ciertos principios, de dar la razón de los fenómenos y de integrar las dos partes de la Gramática en un conjunto homogéneo. Relegar la lista de palabras que rigen preposición a una especie de apéndice de la obra es la consecuencia más visible de lo que realmente es un fuerte desplazamiento del centro de gravedad de toda esta parte, lo cual implica, sin duda, que estamos ante una perspectiva más madura.
} 
reubicación (se ha llevado al final del apartado dedicado a la Sintaxis) y la forma de aludir a ella en el Prólogo así lo demuestran:

Otro de los puntos difíciles de nuestra Gramática es arreglar la Sintáxîs á principios ciertos y constantes, y al mismo tiempo breves y

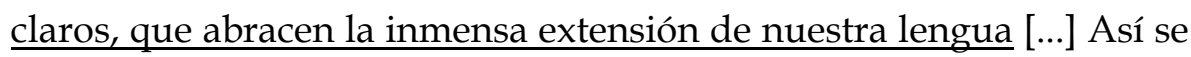
han dividido, para mayor claridad, las reglas de la Sintáxîs en tres capitulos, que son Concordancia, Régimen y Construccion. Se han fixado en cada uno las reglas correspondientes, con ejemplos que las comprueben; y se ha procurado, en quanto ha sido posible, establecerlas de modo, que no haya concordancia, régimen ni construccion de que con estas reglas no se pueda dar razon en lo que pertenece á su artificio y formacion gramatical.

$\underline{Y}$ si acaso por descuido se ha omitido alguna, que ocasione $\underline{\text { dificultad, se ocurre á ella con la lista alfabética de Varia construccion, }}$ que va al final ordenada en tres columnas. [...] con lo qual apénas habrá duda alguna sobre el régimen de que no se pueda salir á primera vista.

(GRAE-1796: XIII-XV. El subrayado es mío)

Estas palabras del Prólogo de 1796 son, en efecto, testimonio de un cambio de concepción en la doctrina sintáctica defendida por la docta Casa, que veinticinco años antes entendía que el centro del estudio sintáctico se concentraba en la relación de regímenes preposicionales. Esta observación ya la hizo Gómez Asencio (2000b) subrayando el carácter mixto (léxico-sintáctico) del fenómeno del régimen preposicional, lo que pudo ser razón del desplazamiento que sufrió en el cuerpo de la Gramática53.

53 Reproduzco la cita entera de Gómez Asencio (2000b: 79):

Las novedades que a este respecto se aportan en 1796 en relación con 1771 se esbozan a continuación. Esto del régimen preposicional ha perdido el carácter de «parte principal de la sintáxîs» que se le había atribuido la edición princeps (GRAE1771: XI) y pasa a ser tratado como una cuestión, en cierto modo marginal a la 
No obstante, conviene advertir que todavía en 1796 la Lista de varia construccion está, en rigor, integrada en el cuerpo de la teoría sintáctica (aunque le sirva de cierre, de "especie de apéndice"); no ha adquirido todavía el rango de apéndice propiamente dicho. Su ubicación dentro de la parte II del libro no deja de resultar extraña, pues, si bien queda clara la intención por parte de la Comisión de Gramática de desplazarla del centro del estudio sintáctico, la redacción y estructuración del texto hace que quede recogida como apartado integrante del capítulo V (\$ 33), el dedicado a la Sintaxis figurada.

En las ediciones J del corpus, la división de la Sintaxis es la que sigue:

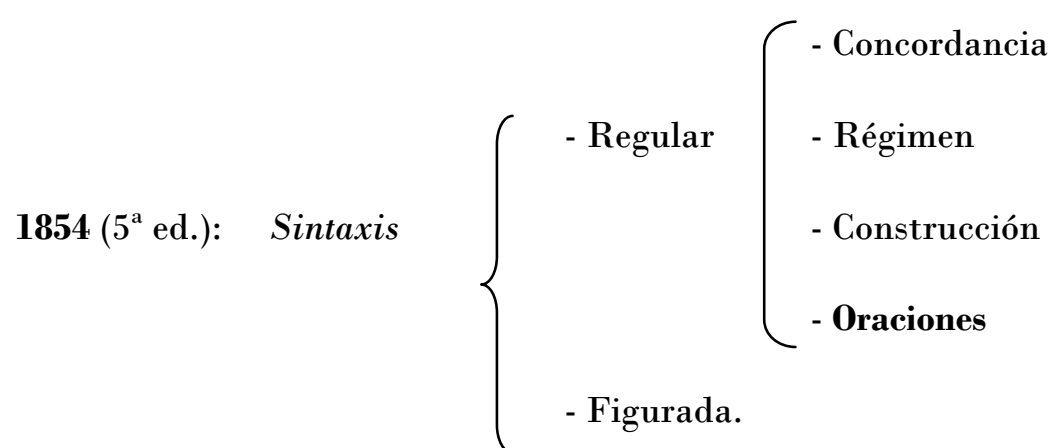

Esquema 6: División de la Sintaxis en la GRAE-1854

En la primera edición decimonónica, La Lista de palabras que se construyen con preposición constituye, ahora sí, un Apéndice (por primera vez encontramos este rótulo) de la Parte II del libro ${ }^{54}$. El Apéndice se mantendrá en las seis

gramática, de carácter léxico, como en cierta medida idiotismos que escapan a las reglas generales y «razonadas» de la gramática.

Se cambia la perspectiva, el punto de vista y, de ahí, el rango jeráquico concedido a este fenómeno de caráctr léxico-sintáctico: el régimen preposicional ha salido del cuerpo de la sintaxis, ha dejado de constituir un capítulo nuclear y ha sido llevado al final (detrás de la «Sintaxis figurada» y con el carácter de mero apéndice), casi físicamente fuera de la gramática, tal vez en lugar de nadie a caballo entre ésta y el diccionario. En 1796 se llevó a un rincón de la gramática este tema tan idiosincrásico (y por consiguiente: descriptivo e idiomático) del español.

${ }^{54}$ Cf. GRAE-1854: 185-218. 
ediciones siguientes ${ }^{55}$. Pero, al margen de esta nueva etiqueta, la disposición coincide con la de la GRAE-1796: es al final del capítulo dedicado a la Sintaxis figurada (capítulo VI de la Parte II) donde se explica el criterio seguido en la lista de Varia construccion y el porqué de su interés en el estudio de la Gramática $^{56}$. También coincide con la cuarta edición el peso que tiene la lista dentro del apartado sintáctico: aproximadamente un $40 \% 57$.

Sin embargo, la mención que se hace en el prólogo al ya tradicional listado pone de manifiesto la progresiva pérdida de importancia que el fenómeno del régimen preposicional experimenta en la doctrina sintáctica de la GRAE: ya no es ni «la parte principal de la sintáxîs» (1771) ni la nómina que encierra toda la posible casuística sobre el régimen -relación sintáctica por excelencia- (1796); ahora es, simplemente, un apéndice complementario que ayudará en el correcto uso de las preposiciones:

Para el mejor empleo de las preposiciones se conserva, notablemente ampliado y corregido, el Apéndice de construcciones que acompañaba á las ediciones anteriores.

(GRAE-1854: IX)

Idéntica estructura a la expuesta en el esquema de arriba encontramos en el texto de 1858 y los cinco de los años sesenta. Y, en términos generales, podemos decir que se mantiene la misma disposición hasta la GRAE-1916, aunque las dos ediciones de rango J que siguen a la de 1854 incorporan algún pequeño cambio que no afecta a la esencia de la doctrina sintáctica defendida.

${ }^{55}$ Cf. GRAE-1858: 207-241; 1862: 211-245; 1864: 211-245; 1865: 211-245; 1866: 211-245 у 1867: 211-245).

${ }^{56}$ Cf. GRAE-1796: 374-377 y GRAE-1854: 183-185.

${ }^{57}$ En la GRAE-1796, supone el 40’23\% (70 páginas de las 174 de Sintaxis) y, en la GRAE-1854, un $41^{\prime} 46 \%$ (34 páginas de 82). 


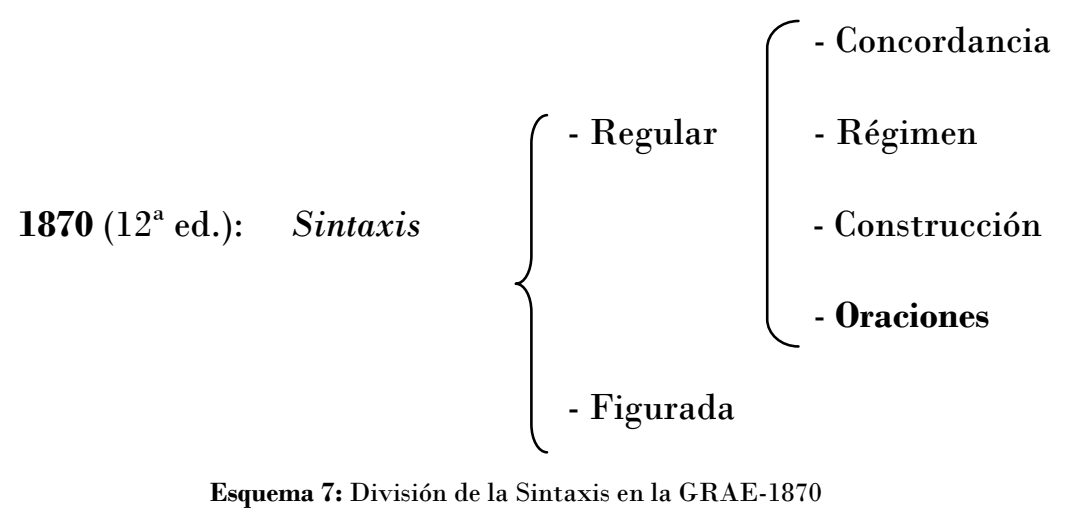

A partir de la GRAE-1870, la Lista de palabras que se construyen con preposición deja de ser rotulada como Apéndice, pero se separa físicamente del capítulo de Sintaxis figurada (tanto la lista propiamente dicha como los criterios seguidos para su confección). La misma estructura presentan las ediciones de 1874 y 1878.

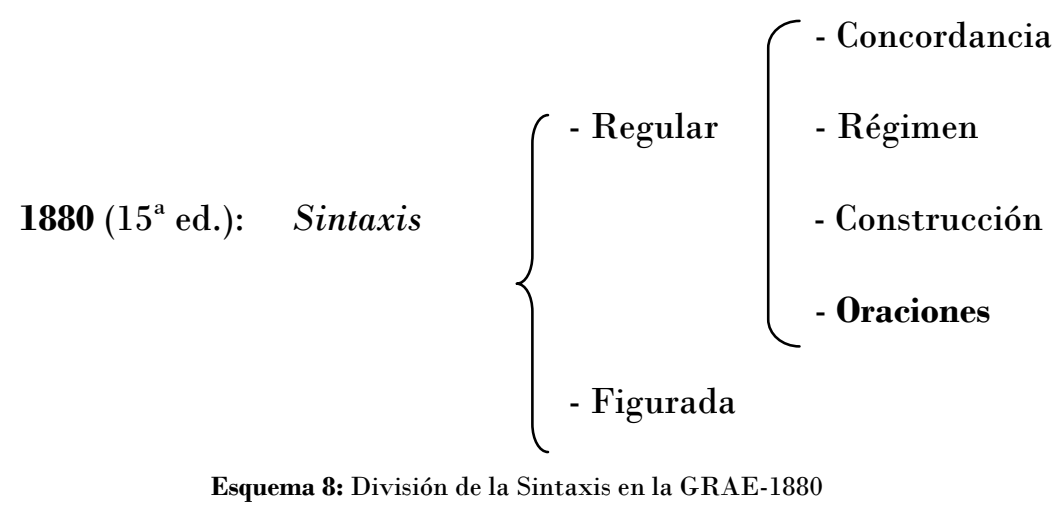

A partir de este jalón, se añade un capítulo, entre la Sintaxis figurada y la Lista de palabras que rigen preposición, dedicado a los Vicios de dicción ${ }^{58}$. Ya se comentó en el lugar oportuno que esta incorporación debía interpretarse como una prolongación del normativismo que domina la labor gramatical de la Corporación en la década de los setenta, pero, en rigor, este añadido no supone un cambio doctrinal en la concepción sintáctica. La misma estructura

${ }^{58}$ Cf. GRAE-1880: 277-289. 
que la GRAE-1880 presentan las trece ediciones que median entre este jalón y la GRAE-1917.

$1917\left(30^{\text {a }} \text { ed. }\right)^{59}:$ Sintaxis
Esquema 9: División de la Sintaxis en la GRAE-1917

\section{Observaciones generales a propósito de los esquemas}

1. $^{\mathbf{0}}$ ) La distinción entre Sintaxis natural y Sintaxis figurada se mantiene desde 1771 hasta la última edición de la GRAE incluida en el corpus ${ }^{60}$, lo que supone que, a lo largo de un siglo y medio -prácticamente-, los parámetros lógicos son operativos en la Gramática académica61.

Desde el perídodo renacentista, es una constante en los estudios gramaticales la distincion entre una gramática normativa (natural, regular) y una gramática permisiva (excepcional, figurada) ${ }^{62}$. La Academia no duda en adoptar tal distinción y mantenerla en todas las Gramáticas del corpus, aunque, a partir de 1917, no se presente la división en natural y figurada como división básica desde las primeras líneas. Así, de la afirmación «Divídese [la sintaxis] en regular y figurada», que todavía en 1916 encontramos en el

59 Ídem GRAE de 1920 y 1924.

${ }^{60}$ En realidad, hasta la última edición de la GRAE.

61 Calero Vaquera (2007: 91), siguiendo a Michael (1970), apunta al origen común de Sintaxis, Lógica y Retórica como razón de la doble deuda que aquélla tiene con estas dos últimas disciplinas: la primera deuda se cifra en la distinción habitual entre sintaxis natural y sintaxis figurada; la segunda, en la atención, en la sintaxis figurada, a figuras retóricas tales como hipérbaton, elipsis, pleonasmo o silepsis.

${ }^{62}$ Esta doble visión de los hechos lingüísticos no es más que un eco de la antigua división tripartita de la gramática en preceptiva, permisiva y prohibitiva, una división que respondía al deseo de marcar con claridad los límites de dos disciplinas muy próximas, como eran la Gramática y la Retórica. 
segundo párrafo de la Parte II, pasamos a la afirmación «se divide [la sintaxis] en Sintaxis de la oración simple y Sintaxis de la oración compuesta», en 1917. En esta última Gramática, no se deja de mencionar la secular división en regular y figurada, pero será dos páginas más adelante y de una forma "no comprometida":

y este orden es el que, según los gramáticos, se llama Sintaxis regular, en oposición a la Sintaxis figurada, en que aquél no se observa.

(GRAE-1917: 149. El subrayado es mío)

A pesar de todo, la 30a ed. de la GRAE sigue reservando un capítulo a la Sintaxis figurada.

2. ') En las Gramáticas académicas comprendidas entre 1771 y 1924, se producen dos cambios realmente significativos en cuanto a la división de la Sintaxis: el primero, en 1796 y el segundo, en 1917. Puede parecer que en 1854 se da un cambio teórico sustancial con respecto a la edición anterior, consistente en la inclusión del estudio de las oraciones. En realidad, esta inclusión se produce en la GRAE-1796, dentro del capítulo dedicado a la Construcción; en la edición de 1854, parece concederse, eso sí, más relevancia doctrinal al estudio de la oración y sus tipos, y quizá por esta razón se le dedica un apartado independiente ${ }^{63}$. Pero veremos que el planteamiento en el estudio de las oraciones no cambia de manera sustancial entre estos dos textos.

$3^{\mathbf{0}}$ ) En lo tocante a la división de la llamada sintaxis natural o regular, los esquemas muestran también que, en la última edición del XVIII (GRAE-1796),

${ }^{63}$ No es en la edición de 1870, como ha afirmado Iglesias Bango (2001: 575-576), donde se introduce un nuevo capítulo titulado De las oraciones; aunque el estudio de los esquemas oracionales es más completo (cosa esperable) en esta 12. ${ }^{a}$ edición que en la GRAE-1854. 
la Academia se suma a la corriente más extendida en la centuria dieciochesca y establece una división tripartita en Concordancia, Régimen y Construcción (capítulos fundamentales de la parte dedicada a la Sintaxis hasta la reforma de 1917, a los que se sumará, desde 1854, el dedicado a las oraciones -véase la consideración hecha arriba sobre este "nuevo" capítulo-), mientras que, en 1771, había optado por mantenerse en la línea renacentista al considerar que la sintaxis o construcción la constituyen los casos de Concordancia y Régimen. A qué se puede deber y en qué consiste este cambio -al parecer, teórico- es asunto del que tratará el punto que sigue.

Antes de analizar el cambio que se produce en la cuarta edición de la Gramática, interesa traer a colación la opinión expresada por Luzán ${ }^{64}$ en 1746 acerca de la división de la Sintaxis. El objetivo no es otro que el de constatar que, en más de una cuestión de doctrina, la propuesta que se defiende a partir de la GRAE-1796 (frente al texto de 1771) coincide con planteamientos expuestos en proyectos y disertaciones previos a la primera edición. Lo vimos en la propuesta de división de la disciplina ( $c f$. 5. de 4.2.1.) y lo comprobamos una vez más a la luz de estas palabras:

[En] Quanto a la división, si se me permite, diré que la fyntaxis comprehende otra parte mas, que la Concordancia, y el Regimen, que es a mi ver la Colocación, y disposicion delas voces: por manera que me parece se deberá dividir la fyntaxis en tres partes que son

${ }^{64}$ Ignacio de Luzán Claramunt de Suelves y Gurrea fue académico de número entre el 15 de abril de 1751 y el 15 de mayo de 1754. Ocupó el sillón E. En el Ms. $314^{8}$ hay anotadas otras dos fechas, correspondientes, respectivamente, a los días de su nombramiento como Honorario (el 15 de octubre de 1741) y como Supernumerario (el 14 de abril de 1746). Sobre este escritor y teorizador de las ideas del Neoclasicismo escribió Lázaro Carreter (1960). Para datos biográficos, puede consultarse Arias Solís (2004). El tratado de preceptiva neoclásica que publicó en 1737 bajo el título Poética o reglas de la poesia en general y de sus principales especies ha sido digitalizado por la Biblioteca Virtual Miguel de Cervantes a partir de las ediciones de Zaragoza (1737) y Madrid (1789). Más información sobre este académico, en Zamora Vicente (1999: 69 y 103, nota 12), quien apunta la colaboración de Luzán en las tareas correspondientes a la Gramática. 
Concordancia, Regimen, y Colocacion. En efecto si bien se advierte, no basta la sola concordancia y Regimen para la perfecta Construcción de una Oracion: pruebase claramente con este exemplo y con otros muchos semejantes: si yo digo: $\underline{\text { las }} \underline{\text { Virtudes son estimadas }}$

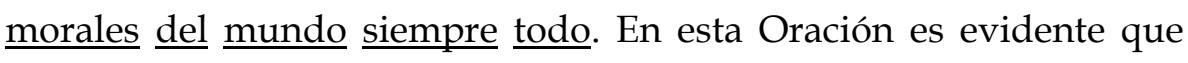
hay Concordancia y Régimen: la concordancia en el participio passivo estimadas, y en el verbo son, con virtudes; Regimen en el ablativo, o genitivo del mundo que es regido por el passivo son estimadas: y no obstante esso, la Oracion es mala en español, y con mala Construcción, y Syntaxis; y esso solo porque le falta la buena Colocacion de las voces ajustada al uso dela lengua, y alas reglas dela claridad: las quales piden que en este caso se diga: las virtudes

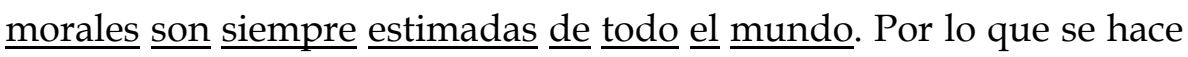
evidente que la Colocación delas voces es una parte essencial dela Syntaxis: no deteniéndome deteniéndome ahora en probar mas difusamente este punto, por no ser prolixo; y porque ya el por si es claro.

(ARAE, 1746c)

No hay duda de que, a juicio de Luzán, la Sintaxis se divide en tres partes: Concordancia, Régimen y Colocación. La última coincide con la parte etiquetada Construcción a partir de 1796.

Obligado es decir que el asunto de la división de la Sintaxis también fue punto de desencuentro entre los miembros de la Casa. Una vez más, al igual que sucede con la división de la disciplina (vid. supra 5. de 4.2.1.), los apuntes que pueden localizarse en el Archivo de la RAE, firmados por académicos de la época, defienden posturas distintas: en la misma carpetilla de documentos de gramática, del año 1746, encontramos una pequeña disertación de Zapata65

${ }^{65}$ Franciso Antonio Zapata fue, entre el 17 de julio de 1726 y el 18 de marzo de 1754, el segundo ocupante del sillón N. Sucedió a D. Vicente Bacallar, marqués de San Felipe ( $c f$. http://www.rae.es/rae/gestores/gespub000001.nsf/(voAnexos)/arch6D3211F8664070B7C12 
en la que se habla de «la división de la sintaxis en concordancia y regimen, lo que importan estas voces entre grammaticos, y quantas concordancias ay en Castellano, con sus excepciones» y otra disertación de Angulo donde expone también su idea de la concordancia y el régimen. En este asunto concreto de la división de la Sintaxis, se impuso, en la GRAE-1771, la propuesta de Angulo y de Zapata66.

En la junta de 22 de marzo de 1746 -según consta en la propia carpetilla- se acordó que estos papeles pasaran a los señores académicos que se iban a encargar de formar la Gramática.

5720900476B93/\$FILE/sillones.htm. y Ms. 3148). Zamora Vicente (1999: 80), en la breve información que da sobre este académico, destaca su participación en los trabajos preparatorios de la Gramática.

${ }^{66}$ Así es como entiende Angulo las dos partes de que consta el estudio sintáctico:

[...] este oficio le hace la syntaxis por medio dela concordancia, y regimen delas mismas partes dela Oracion, con esta diferencia: la Concordancia tiene por objeto proprio suyo la conformidad, ó conveniencia destas partes en orden a su genero, numero, caso, ó persona: y el regimen ira solo alos casos.

(ARAE, 1746b) 


\subsubsection{Los conceptos de sintaxis y construcción}

En el capítulo 5, hemos visto que los conceptos de sintaxis y construcción parecen entenderse como prácticamente equivalentes en los Diccionarios académicos. Esta indistinción no resulta extraña, pues sabido es que, a lo largo de la tradición gramatical de Occidente, ambas nociones tienden a confundirse desde que Prisciano tradujera por constructio lo que Apolonio Díscolo llamaba oúvtaろı $\varsigma^{67}$.

En cuanto a las Gramáticas del corpus, comprobamos que la primera que se publica en el período que centra el interés de esta investigación (GRAE1854) presenta los conceptos de sintaxis y construcción de una forma bien diferenciada, al menos según la división expuesta en las primeras páginas de la segunda parte del libro: sintaxis es el "todo" de las relaciones que se establecen entre las partes de la oración y construcción, una porción de ese "todo", un tipo de reglas específicas que forman parte de la llamada Sintaxis regular. Así se expresa en el texto de la Gramática:

Sintáxis es el órden y la dependencia que las palabras deben tener entre sí para formar la oracion. Este órden es de dos modos, regular y figurado. [...] Las reglas de la Sintáxis no figurada, se reducen á tres capítulos, que son concordancia, régimen y construccion.

(GRAE-1854: 137. El subrayado es mío)

En este punto concreto, los académicos de 1854 no hacen más que recoger algo que ya habían establecido sus predecesores de finales del XVIII. Efectivamente, tal como se observa en los esquemas expuestos en el apartado anterior, entre la primera Gramática (1771) y la última edición dieciochesca

${ }^{67}$ Más detalles, en Gómez Asencio (1981: 42-56). 
(1796), se observa un cambio en la concepción sintáctica consistente en dejar de identificar los hechos de construcción con la sintaxis en general.

La pregunta, de casi obligada formulación (según lo dicho a propósito de los Diccionarios), es: ¿se trata de un verdadero cambio de concepción o de un simple desplazamiento de rótulos?

De tratarse de un verdadero cambio, estaríamos ante un distanciamiento entre los planteamientos de las Gramáticas y de los Diccionarios coetáneos, por cuanto en estos últimos parece defenderse una identidad sintaxis = construcción desde Autoridades hasta el DRAE-1925. Si no hay cambio doctrinal con respecto a lo defendido en los textos lexicográficos, ¿a qué se deben esta nueva distribución de los contenidos vertidos en la segunda parte de la Gramática y esta "separación de etiquetas"?

Si se confirma la segunda hipótesis, es decir, si se comprueba que el cambio consiste en una mera redistribución de contenidos sin implicaciones sustanciales de tipo teórico en lo tocante a la distinción de los conceptos de sintaxis y construcción, habrá que precisar qué tienen en común sintaxis y construcción para considerar viable en las GRAE la identidad defendida en los Diccionarios e, igualmente, qué hay de diferente entre ambas o qué razón permite justificar la creación de este nuevo apartado dedicado exclusivamente a la construcción a partir de la GRAE-1796.

Las variantes de formulación en la definición de sintaxis que se dan entre la primera (1771) y cuarta ediciones (1796) de la Gramática son fundamentales para poder interpretar el cambio producido en el último libro del XVIII, cambio del que se hará eco la primera GRAE decimonónica (1854). El siguiente cuadro sintetiza las variantes a las que me refiero: 


\begin{tabular}{|c||c|c|c|c|}
\hline & $\begin{array}{c}\text { Nombre 2 } \\
\text { Del libro de } \\
\text { Gramática }\end{array}$ & Definida como & Dividida en & Integrada por \\
\hline \hline GRAE-1771 & $\begin{array}{c}\text { S.n. } \\
\text { (parte que trata de } \\
\text { Sintaxis o construcción) }\end{array}$ & $\begin{array}{c}\text { Unión, trabazon, o } \\
\text { enlace }\end{array}$ & $\begin{array}{c}\text { Natural } \\
\text { figurada }\end{array}$ & $\begin{array}{c}\text { Concordancia } \\
\text { Régimen }\end{array}$ \\
\hline GRAE-1796 & Sintaxis & orden y dependencia & $\begin{array}{c}\text { Natural } \\
\text { figurada }\end{array}$ & $\begin{array}{c}\text { Concordancia } \\
\text { Régimen } \\
\text { Construcción }\end{array}$ \\
\hline GRAE-1854 & Sintaxis & orden y dependencia & Natural & Concordancia \\
figurada & $\begin{array}{c}\text { Cégimen } \\
\text { Construcción }\end{array}$ \\
\hline
\end{tabular}

Cuadro 50: Cambios en la definición de sintaxis (GRAE-1771, 1796 y 1854)

En el texto de 1771, en la segunda parte del libro, esto es, en la que trata de la Sintaxis o Construcción, esta subdisciplina gramatical queda definida como unión, trabazón o enlace de palabras dentro de la oración:

En la primera parte se ha tratado separadamente de cada una de las partes de la oracion. En esta segunda se ha de tratar del modo de unirlas, trabarlas, ó enlazarlas entre sí de manera que formen la misma oracion de que son partes. Esta union, trabazon, ó enlace, se llama entre los gramáticos Sintáxîs, ó construccion [...]

(GRAE-1771: 231-232. el subrayado es mío)

Los dos términos que se están analizando (sintaxis y construcción) son, por tanto, términos sinónimos ${ }^{68}$ y por tales se entiende la unión o enlace de palabras (como queda apuntado) que, siguiendo un orden lógico, forman una

\footnotetext{
68 Se impone recordar que, en el Diccionario, a la conjunción "o" se le atribuye un valor exclusivamente disyuntivo hasta el DRAE-1884; y el uso que se hace de esta conjunción en las definiciones parece invitar, en la mayor parte de los casos, a una interpretación como elemento de disyunción. En cuanto a su valor en el primer texto gramatical, ya dijimos (vid. supra. 5.1.1., nota 9) que, en él, se encuentran usos que no pueden interpretarse sino con valor identificativo: es el caso de «relacion ó dependencia». Al mismo caso responde «Sintáxîs, ó construccion», si se tiene en cuenta que, según la acertada observación de Rojo (vid. supra 6.1.1., nota 137), no se trata de verdaderas etiquetas de esta segunda parte de la Gramática (lo cual, de haber sido así, hubiera permitido la interpretación "o bien etiquetada como Sintaxis o bien etiquetada como Construcción"), sino del nombre del fenómeno gramatical estudiado.
} 
oración perfecta. A continuación del fragmento arriba reproducido, los académicos establecen cuál es la finalidad de la sintaxis o construcción:

\section{[...] sus reglas se reducen á declarar el órden con que deben} juntarse las palabras para expresar con claridad los pensamientos [...] Como este órden tiene por principal objeto la claridad, pide tambien que no haya falta, ni sobra de palabras, y que tengan entre sí la debida concordancia.

(GRAE-1771: 232-234. El subrayado es mío)

La perfección oracional viene dada por el orden de palabras con vistas a la coherencia semántica (la transmisión de los pensamientos) y por dos tipos de reglas: las reglas del Régimen y las de la Concordancia. El Régimen, por su parte, es definido como gobierno o precedencia, cuyo fin es determinar la relación o dependencia de unas palabras con otras (la proximidad entre los conceptos de orden y dependencia es aquí evidente -vid. Glosario final, s.v. régimen-); y, curiosamente, comprobamos que, a lo largo de estas páginas, se acaban utilizando los términos régimen y construcción de forma indistinta ${ }^{69}$.

Podemos hablar, por tanto, de una triple equivalencia en la GRAE-1771: sintaxis $=$ construcción $=$ régimen, que se basa en el orden $(\approx$ dependencia $)$. La Sintaxis se reduciría, en definitiva, al orden de las palabras -su sentido etimológico- (que es el que determina la conexión o dependencia entre las partes de la oración); ello parece desterrar conceptualmente la concordancia del terreno sintáctico, pese a ser tratada en esta segunda parte de la Gramática, probablemente porque así lo habían hecho los autores precedentes, como ya

\footnotetext{
${ }^{69}$ Así, en los epígrafes de los diferentes apartados del capítulo dedicado al Régimen leemos: «De la construccion del nombre y pronombre, y otras partes de la oracion ántes del verbo»; «De la construccion del verbo y el adverbio y otras partes de la oracion ántes del nombre»; «De la construccion de unos verbos con otros»; «De la construccion del verbo con el pronombre»; «De los verbos, participios, adjetivos y adverbios que rigen preposicion y qual» (GRAE-1771: 235-252. El subrayado es mío).
} 
apuntó Gómez Asencio (1981). En efecto, la concordancia no es un tipo de relación de dependencia (no lo es hoy y tampoco la Academia la define en sentido estricto como tal en las Gramáticas del corpus); es una exigencia morfológica (de correspondencia en los accidentes gramaticales) impuesta por las relaciones de Régimen, o -si se quiere- un indicio formal de que entre dos palabras hay una relación de dependencia. ${ }^{70}$.

Si aceptamos este "destierro" de la concordancia (de índole conceptual, que no física) del terreno sintáctico, podemos entender la observación hecha por Martínez Linares (2006: 18) de que, en la GRAE-1888, la concordancia «se presenta básicamente como una relación entre "clases" de palabras, sin atender al tipo de relación sintáctica que marca realmente la concordancia».

El cambio que se produce en la GRAE-1796 supone la separación de los conceptos de sintaxis y construcción, entendiendo ahora esta como parte integrante de aquella, según hace pensar la nueva estructuración del apartado sintáctico y el no dar ya como equivalentes, en el epígrafe de la segunda parte del libro, los términos sintaxis y construcción ${ }^{71}$. A esto se añade la nueva

${ }^{70}$ A esta conclusión llegué ya en mi Trabajo de Grado (Garrido Vílchez, 2001). En ese mismo año, Rojo afirmaba en su discurso de ingreso como académico numerario lo siguiente:

La concepción de régimen y concordancia que presenta el texto académico de 1771 está un tanto distanciada de la que constituye la línea mayoritaria de la tradición gramatical de la época en un punto que me parece fundamental. En efecto, régimen y concordancia no son considerados en el mismo nivel jerárquico, no responden exactamente a la estructuración de la sintaxis en las dos grandes ramas denominadas habitualmente en esta época 'sintaxis de concordancia' y 'sintaxis de rección' [...] sin que exista intersección de los conjuntos respectivos. En el texto académico [...] la concordancia parece ser considerada... más bien como la marca de una determinada relación sintáctica (el régimen), de modo que ocupa, frente a la tradición mayoritaria [...] una posición inferior y la rección es, en realidad, la única relación sintáctica reconocida en la obra.

(Rojo, 2001: 79-80)

${ }^{71}$ Sabido es (Chevalier, 1968: 689-694; Gómez Asencio, 1981: 51-56; Calero Vaquera, 1986: 183; Delesalle et Chevalier, 1986: 54-60) que el primer autor que, en la tradicción gramatical de Occidente, separa de forma nítida los conceptos de sintaxis y construcción (habitualmente confundidos o solapados) es Du Marsais. De su Logique et principes de Grammaire (1769: 159) son las siguientes palabras: 
formulación en la definición de sintaxis, que ya no es «unión o enlace» (= orden [ $\approx$ dependencia]), sino «orden y dependencia». No hay duda de que, en la cuarta edición de la GRAE (1796), los vínculos que se establecen entre las palabras (es decir, los casos de dependencia sintagmática) y el lugar que estas ocupan en la oración (esto es, las cuestiones de orden) están todavía muy interrelacionados, pero parece que el cambio en la definición de sintaxis es un indicio de que ya no se defiende la identidad entre los hechos de orden y los de dependencia. En definitiva, se está ampliando la visión de las relaciones sintácticas: son orden y son dependencia (que tiene que ver con el orden, pero que es algo más).

La inclusión de un nuevo capítulo en el apartado sintáctico parece deberse, más que a una verdadera y nítida distinción conceptual entre sintaxis y construcción, a un intento, si no de separar el orden de la dependencia -algo que, efectivamente, no se hace-72, sí de dar carta de naturaleza a un tipo especial de relaciones de dependencia intraoracional que, desde este momento

En termes de Grammaire, ou appelle conftruction, l'arrangement des mots dans le difcours. Le mot eft pris ici dans un fens metaphorique, \& vient du latin, conftruere, conftruire, batir, arranger.

La conftruction eft vicieufe, quand les mots d'une phrase ne font pas arrangés felon l'usage d'une langue. Ou dit qu'une conftruction eft grecque ou latine, lorfque les mots font rangés dans un ordre conforme à l'usage, au tour, au génie de la langue grecque, ou à celui de la langue latine.

Je crois qu'on ne doit pas confondre conltruction avec fyntaxe. Conftruction ne prélente que l'idée de combinaifon \& d'arrangement [...] La fyntaxe eft donc la partie de la Grammaire qui donne la connoiffance des fignes établis dans une langue pou exciter un fens dans l'efprit.

(Págs. 160-161)

72 Es bastante sintomática, en este sentido, la afirmación de que «este órden y dependencia es de dos modos, natural y figurado» (el subrayado es mío). Esta afirmación parece responder a la inercia de asociar lo uno y lo otro, cuando, en sentido estricto, sólo el orden se considera natural -lógico- o figurado -no lógico-. A continuación, la propia Academia acaba eliminando el término dependencia de las definiciones siguientes: «órden natural se llama aquel [...]. Órden figurado es aquel [...]» (GRAE-1796: 273-274). Y ya en la GRAE-1854: 137 leemos: «Este órden es de dos modos, regular y figurado. Regular se llama aquel [...]; figurado es el que [...]» (el subrayado es mío). 
(GRAE-1796) y hasta la GRAE-1917 -exclusive- se entenderán como casos de Régimen. Varias razones conducen a este pensamiento:

1. El nuevo capítulo que, en el apartado sintáctico, presenta la GRAE1796, rotulado como «De la Construccion», lo integran contenidos que, en 1771, se recogían en las páginas dedicadas al Régimen. En este trasvase de contenidos, se han llevado al capítulo de Construcción muchos casos de relaciones sintagmáticas intraoracionales, tanto de dependencia de elementos simples como de lo que venimos llamando dependencia oracional (sistema de complementación en el SV: CI, CC, Atributos, Predicativos... y sistema de adyacencias dentro del SN: Adyacentes del Nombre, del Adjetivo...). De manera que, frente a la primera GRAE, en la que se recogían bajo el capítulo de Régimen relaciones sintagmáticas de la más diversa naturaleza ${ }^{73}$, en esta cuarta edición del texto institucional (1796), se decide reservar el capítulo del Régimen para unos tipos muy específicos de relaciones intraoracionales (S-V; V-O; N-N., etc.) con dos características: son relaciones que sistemáticamente tienen lugar entre dos palabras y, en su mayoría, relaciones "de primer orden" (tienen que ver con la relación predicativa, los esquemas argumentales de los verbos... $\left.{ }^{74}\right)$. En los cuadros 51 y 52, se expone con detalle el trasvase de contenidos entre la primera y la última GRAE del XVIII, trasvase en el que encontramos el germen de la concepción y distribución del apartado sintáctico que presentan las GRAE de la segunda mitad del XIX y principios del XX.

\footnotetext{
${ }^{73}$ Ante la disparidad de hechos recogidos, considero acertada la observación de Rojo (2001: 83) de que, frente a la tradición anterior (en la que el concepto de régimen estaba bien delimitado), la noción de régimen «pierde carácter y deja de tener auténtica entidad teórica» en el texto académico. Es, precisamente, esta falta de entidad la que intenta subsanarse en el libro de 1796, según se ha dicho más arriba.

${ }^{74}$ No faltan excepciones a esta segunda "característica"; por ejemplo, se recogen casos de CC y de Adyacente de Nombre (que también se llevarán al capítulo de la Construcción).
} 
2. La Construcción, en 1796, queda definida de una forma imprecisa: es «otra especie de dependencia». Los Académicos no dudan en el concepto de régimen (= dependencia); sin embargo, no parecen tener un concepto tan claro de construcción, o, al menos, eso da a entender la definición dada, una definición que no resulta demasiado comprometida y que, además, es suficientemente ambigua y amplia para acoger la gran variedad de relaciones que se van a registrar en este nuevo capítulo. Por las palabras que leemos al principio del mismo, parece ser que la Construcción es toda relación de dependencia que no sea relación estricta de Régimen entre dos palabras:

LA CONSTRUCCION de las partes de la oracion es otra especie de dependencia que las une, no con tanta precision como el régimen, sino con alguna mayor anchura y libertad; ya añadiendo unas, ya introduciendo otras entre las que van enlazadas por el régimen $[\ldots]$

(GRAE-1796: 326-327. El subrayado es mío)

3. Los académicos dejan claro, por otra parte, que la Construcción tiene que tener en cuenta las reglas del Régimen y de la Concordancia:

[...]para dar energía á las oraciones, y evitar la uniformidad que resultaria, si se guardaran constantemente en el uso las reglas del régimen y concordancia de las palabras. Sin faltar, pues, á estas reglas establece el uso las de la construccion, de que resulta una inmensa variedad de oraciones [...]

(GRAE-1796: 327. El subrayado es mío)

Por tanto, si la Construcción tiene que atender al orden (imperativo impuesto tanto por el sentido etimológico del término como por la tradición gramatical -interna y externa a la Institución-) y 
también -según se declara- a la dependencia (=régimen) y a la concordancia, viene a ser un concepto bastante próximo al de sintaxis (que es «orden y dependencia» y que, además, tiene que dar cuenta de las reglas de concordancia).

4. Esa «especie de dependencia» que es la Construcción tiene como finalidad -según declaraciones explícitas- dar viveza y energía a la oración, evitar la uniformidad. En este sentido, está muy cerca de la Sintaxis figurada. De hecho, en el apartado de Sintaxis figurada se habla de construcción figurada -no de régimen figurado ni de concordancia figurada-, lo que creo que puede ser un indicio de la indistinción o, al menos, gran proximidad entre los términos sintaxis y construccion ${ }^{75}$. También se reconoce que la Construcción -al igual que la Sintaxis, añado- puede ser regular (si cumple las reglas de la Concordancia y el Régimen) o figurada (si se desvía de ellas y se dan casos de silepsis, pleonasmos, hipérbatos) ${ }^{76}$.

5. Se dice que de las reglas de Construcción resulta una inmensidad de oraciones. También la Sintaxis tiene como finalidad la formación de oraciones (aunque la tipología no sea tan variada). Es curioso observar que, frente al Régimen (capítulo en el que los ejemplos se limitan -casi

\footnotetext{
${ }^{75}$ En este sentido, no parece gratuito, de un lado, que haya contenidos comunes al capítulo de construcción y al de Sintaxis figurada: por ejemplo, las estructuras pleonásticas; de otro, que sea en estos dos capítulos en los únicos en que la Academia explicita las Autoridades en materia de lengua, que, por cierto, coinciden: los autores clásicos y «los que hablan con elegancia y energía» o «las personas cultas» (GRAE-1796: 327 y 356). Las reglas de la Construcción no serán, por tanto, tan constantes como las del Régimen, porque los estilos y hábitos de lengua no son únicos.

En el exemplo siguiente se podrá conocer con facilidad en que se diferencia la construccion natural, ó regular de la figurada. El premio y el castigo son convenientes en la guerra, asi como la justicia y la clemencia son convenientes en la paz [...] este mismo exemplo pasa á ser de construccion figurada en uno de los autores clásicos de nuestra lengua. Asi como son convenientes en la paz la justicia y la clemencia, son en la guerra el premio y el castigo.
}

(GRAE-1796: 353-355. El subrayado es mío) 
en su totalidad- a mostrar la estructura que interesa explicar en cada momento), en la Construcción, prácticamente todos los ejemplos responden a oraciones completas. Pongo por caso el de Adyacente del Nombre, una de las estructuras comunes a ambos capítulos: en el primero de ellos (Régimen), se nos dan ejemplos del tipo La casa de Pedro; El amor de mi padre, mientras que, en el segundo (Construcción), los ejemplos dados son del tipo El hombre de bien cumple su palabra; El soldado, amante de las fatigas de la guerra, goza los frutos de la victoria.

Puestas así las cosas, podemos sospechar que es la distinción de los conceptos de régimen (que es dependencia vinculada a un orden, pero no necesariamente orden) y construcción (que es, sobre todo, orden -aunque tiene que tener en cuenta las relaciones de dependencia que se establecen entre las palabras-) lo que lleva a crear un apartado dedicado a la construcción (esto es, a las posibilidades combinatorias de los constituyentes oracionales). La creación de este nuevo apartado en la GRAE-1796, en definitiva, viene a privilegiar o destacar de alguna forma las relaciones de Régimen (aunque no hay datos explícitos que nos permitan saber si era esta la intención de la Corporación), puesto que es el Régimen el que realmente ha logrado separarse de los conceptos de construcción y de sintaxis (con los que le acababa relacionando -prácticamente identificando- la GRAE-177177) y ha cobrado entidad.

Bien es cierto que seguimos encontrando un ejemplo que puede hacer pensar que los términos régimen y construcción no responden todavía a conceptos deslindados con absoluta nitidez (o, simplemente, que son etiquetas que, por inercia tal vez, siguen usándose indistintamente): no olvidemos que la Lista de varia construccion da cuenta de los distintos casos de regímenes

${ }_{77} \mathrm{Y}$ algunos de los Diccionarios de la primera mitad del XIX (remito a lo dicho en 5.2.1.). 
preposicionales, y, como ha observado Gómez Asencio (2000b: 78), «se notará que en las tres columnas de la lista aparecen términos de la familia de regir»" (el subrayado es mío). Creo que este caso concreto puede justificarse por las conclusiones que expongo más abajo (vid. infra).

Por su parte, los términos sintaxis y construcción se siguen solapando, pese a lo cual se puede apreciar una cierta distinción, si tenemos en cuenta que, cuando se habla de construcción, sistemáticamente se está haciendo referencia a una estructura lingüística concreta, específica, puntual, idiosincrásica, mientras que sintaxis puede entenderse en un sentido más abstracto, más general (como un molde o marco). Así, dos estructuras que presenten las mismas relaciones de dependencia siempre tendrán la misma sintaxis, aunque puedan presentar construcciones distintas (en este sentido, la construcción está más claramente condicionada por el orden "superficial”).

En definitiva, a finales del XVIII (GRAE-1796), y frente a la primera edición de la Gramática (1771), se está defendiendo que la Sintaxis natural está basada en las reglas de Régimen (dependencia), apoyadas, a su vez, en criterios lógicos de ordenamiento, que son los principales determinantes de los casos de adyacencias y complementaciones, tanto de carácter oracional como entre elementos simples. Uno de los índices de estas relaciones de dependencia (sea o no de carácter oracional) es la concordancia y el reflejo lo tenemos en la construcción (que podríamos entender como un "ordenamiento ocasional"). Y es ocasional tanto la construcción natural, que respeta las reglas de la Sintaxis (Régimen, Concordancia) como la construcción figurada, que hace caso omiso de dichas reglas. Lo vemos con los siguientes datos:

A. (1) Me salgo a divertir.

(2) Sálgome á divertir.

(3) Salgo a divertirme. 
[GRAE-1796: 343. «Quando se usan así dos verbos, uno determinante $\underline{\text { de otro, }}$ se pueden colocar los pronombres ántes del primer verbo, ó despues de qualquiera de ellos». El subrayado es mío].

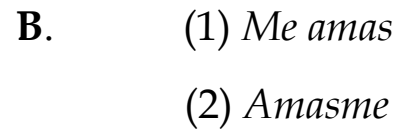

[GRAE-1796: 341. «Quando los pronombres personales son término

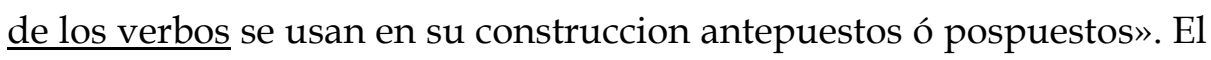
subrayado es mío].

Los distintos ejemplos de A y de B presentan diferentes construcciones en las que, sin embargo, se dan las mismas relaciones de régimen, la misma sintaxis, por tanto (interesa atender a los subrayados). Estos ejemplos demuestran:

$\left.1^{\circ}\right)$ Que, efectivamente, las relaciones de Régimen en sentido estricto se establecen sistemáticamente entre dos palabras, tal como ya se ha dicho.

$2^{\circ}$ ) Que las relaciones de Construcción pueden darse entre dos palabras (ejemplos de B) o más (ejemplos de A), esto es, en ellas puede estar implicado un solo caso de Régimen o más de uno.

$3^{\circ}$ ) Que el orden es factor determinante para hablar de una construcción concreta, mientras que el Régimen, pese a estar en estrecha relación con el orden, no se ve afectado si este se altera. Un cambio en el orden sólo implica un cambio de estructura (= construcción), no de relación. 
Podemos entender ahora que el listado de regímenes preposicionales que cierra el apartado sintáctico lleve el nombre de Varia construccion: en esta lista se ofrecen construcciones concretas que pueden responder a los distintos casos de la relación de régimen:

$\mathrm{Vb} /$ Adj. (Reg. $\left.{ }^{1}\right) \rightarrow$ prep. (reg. ${ }^{1} /$ Reg. $^{2}$ ) $\rightarrow$ sust./pr./vb. $\left(\right.$ reg. $\left.{ }^{2}\right)$

El régimen preposicional implica un doble régimen. Según qué Verbo/Adjetivo desempeñe la función de Regente (Reg.), la preposición regida (reg.) será una u otra, y esta preposición regirá bien un sustantivo, bien un pronombre... En esta variada casuística, se tiene en consideración que un mismo Verbo/Adjetivo puede pedir más de una preposición distinta. Cuando esto ocurre, pueden darse dos casos:

a) Que las distintas preposiciones regidas puedan regir, a su vez, al mismo término:

$$
\begin{aligned}
& \text { Cansarse... de/con... el trabajo } \\
& \text { Disgustarse... de/con ... alguna cosa } \\
& \text { Distraerse... de/en... la conversación } \\
& \text { Impropio... de/en/para... su edad }
\end{aligned}
$$

b) Que cada una de las preposiciones regidas rija términos diferentes:

$$
\begin{aligned}
& \text { Confesarse... á... Dios } \\
& \text { Confesarse... con... alguno [persona] } \\
& \text { Confesarse... de... sus culpas [cosa] } \\
& \text { Contender... con... alguno [persona] } \\
& \text { Contender... sobre... alguna cosa [cosa] } \\
& \text { Dividir... entre... muchos [persona] } \\
& \text { Dividir... en ... partes [cosa] }
\end{aligned}
$$


Además, en la lista encontramos no pocos casos de regímenes que van acompañados de la estructura pertinente indicada entre paréntesis:

$$
\begin{aligned}
& \text { Bordar (algo)... de/con ... plata } \\
& \text { Bordar (algo)... al... tambor } \\
& \text { Dar (algo)... á... alguno } \\
& \text { Dar (á alguno)... de... palos } \\
& \text { Desahogarse (con alguno)... de... su pena } \\
& \text { Disuadir (á alguno)... de... alguna cosa } \\
& \text { Impeler (á alguno)... á... alguna cosa }
\end{aligned}
$$

Podemos concluir que, en lo tocante a la distinción entre sintaxis y construcción, la tesis de Du Marsais no empezará a ser tenida en cuenta por los académicos hasta la edición de 1796. El texto institucional va a la zaga en materia de descripción sintáctica: la primera edición de la Gramática no participa, en este aspecto concreto, de la "moda" francesa que empieza a permear en los tratados españoles en las últimas décadas del siglo XVIII. Sabido es que, dos años antes de la publicación de la primera GRAE, Benito de San Pedro se había hecho eco de las enseñanzas de los autores racionalistas y había dado un paso que los académicos tardarán casi treinta años en dar ${ }^{78}$.

78 Rojo (2001: 87) lo ha expresado con las siguientes palabras:

[...] Da la sensación de que lo que ocurre en esta Gramática [GRAE-1771] es que se aproxima a los hechos sintácticos con las mismas herramientas que manejaba Nebrija (o Ximénez Patón o Correas), esto es, sin la organización resultante de las aportaciones de Sánchez de las Brozas, la Grammaire générale et raisonnée y mucho menos, como es lógico, Du Marsais, que, en cambio, han tenido efecto sobre la obra de San Pedro. Tales herramientas podían ser útiles para la descripción de un conjunto de fenómenos bastante reducido, que son, precisamente, los que están tratados en las obras de estos autores. El intento de ampliar el espectro de fenómenos sintácticos sometidos a consideración tropieza con la reducida capacidad explicativa de los mecanismos empleados para ello, de modo que se hace necesario arbitrar soluciones que contienen el germen de la contradicción, con lo cual el resultado es, como he indicado en varias ocasiones, pobre en logros y muy confuso en la expresión. 


\title{
TRASVASE DE CONTENIDOS SINTÁCTICOS \\ ENTRE 1771 Y 1796 \\ (SINTAXIS =/vs.CONSTRUCCIÓN)
}

\begin{abstract}
\begin{tabular}{||c||}
\hline GRAE-1771 \\
\hline RÉGIMEN (Y CONSTRUCCIÓN) \\
\hline \hline
\end{tabular}
1. «De la construccion del nombre y pronombre, y otras partes de la oracion ántes del verbo». (Pág. 236).

- El sustantivo o pronombre sujeto rige al verbo principal de la oración (estructura bimembre de la oración: (S+V/): Antonio escribe; yo amo.

- Uso de determinantes con el nombre: nombres comunes con artículo (el Rey, la Reyna), nombres propios sin él (Antonio lee), demostrativos (Este caballo corre; esa espada reluce; aquel monte arde).

- Adyacentes del nombre: La misericordia de Dios alienta (S.P.); la muger virtuosa cuida de su casa (S. Adj.); el hombre de bien cumple su palabra (modos adverbiales); la muger que vela, medra (dependencia oracional: oración de relativo); el soldado amante de la guerra goza el fruto de la victoria: hecho á la fatiga, y acostumbrado al riesgo, no reusa volver á campaña (dependencia oracional: oración de participio).

- Adyacentes del adjetivo: El pueblo distante del mar comercia poco; los hombres propensos á la ambición nunca sosiegan (SP); el caballo malo para correr suele ser bueno para andar (dependencia oracional: oración de infinitivo).

- Sujeto múltiple: Juan y Francisco vinieron; el padre ó el hijo no faltarán.
\end{abstract}

2. «De la construccion del verbo y adverbio y otras partes de la oracion ántes del nombre».

(Pág. 240).

- CD: Amo á mi enemigo; Los codiciosos atesoran riquezas.

- CD + CI: Yo escribo una carta á mi padre.

- CD + CC: envio mis cartas á Cádiz.

- Verbos pronominales («recíprocos» para la RAE) con suplemento: el Rey se apiada de sus vasallos; me arrepiento de mis culpas; arrepiéntome de mis culpas.

- CC (de modo, tiempo, cantidad): Quiero bien á mis amigos; estimo mucho la justicia; arrepintióse tarde. (S. Adv.); lleva con paciencia la ingratitud; arrepintióse por fuerza (SP).

- Sistema de adyacencias: El hombre soberbio con su fortuna, desprecia al que es humilde por virtud.

3. «De la construccion de unos verbos con otros». (Pág. 244).

- Posibles casos de dependencia oracional: creyó peligrar en la batalla; se cansa de jugar; disputa sin porfiar (oración de infinitivo); escogió morir peleando (oración de infinitivo + gerundio).

- Posibles casos de perífrasis verbales: no podía sufrir el calor (modal); voy á comer (aspectual).

4. «De la construccion del verbo con el pronombre». (Pág. 245).

- Anteposición y posposición de clíticos: se matan; respétanla; búsquenmele; le voy á buscar/voyle á buscar/voy á buscarle.

- Funciones de los pronombres átonos: los alcanzaron ó alcanzáronlos (CD); á los dos capitanes les hirieron algunos soldados (CI).

- Estructuras pleonásticas: yo me culpo á mí.

5. «De los verbos, participios, adjetivos, y adverbios que rigen preposicion, y qual». (Pág. $250)$. 


\section{GRAE-1796}

\section{RÉGIMEN}

1. «El nombre sustantivo rige á otro nombre sustantivo, y al verbo». (Pág. 288).

- Adyacente de nombre (SP en función de CN): La casa de Pedro (el sustantivo casa rige al sustantivo Pedro, que está en genitivo).

2.«El nombre sustantivo rige al verbo». (Pág. 289).

- El sustantivo sujeto rige al verbo principal de la oración (estructura bimembre de la oración: (S+VI): Antonio escribe.

3. «El verbo rige al nombre sustantivo». (Pág. 290).

- CD: amo á Dios; aborrecer el vicio.

- Verbos pronominales («recíprocos» para la RAE): se arrepiente; marcharse.

4.«El verbo rige á otro verbo». (Pág. 293).

- Posibles casos de dependencia oracional quiero estudiar; pretendemos que se haga justicia (CD); no se arrepentirá de emplear el tiempo en esto (Término de un SP en función de Suplemento); el hombre nace para morir (CC).

- Posibles casos de perífrasis verbales: las lenguas deben aprenderse (modal); volvió el miedo á apoderarse de él; el brazo estaba para descargar el golpe (aspectuales).

5. «El verbo rige al adverbio». (Pág. 300).

- CC: No llegará jamás; Soy así; aquí vivo; creció mucho más; Sí podrá.

6. «El participio, por lo que participa del verbo, rige al nombre». (Pág. 302).

- Complemento de Participio: obediente á las leyes; tocante á esta cosa ó la otra.

7.«Preposicion». (Pág. 311): rige al nombre sustantivo o pronombre, al verbo y al adverbio.

8. «Conjuncion». (Pág. 319): rige el tiempo o el modo del verbo.

\section{CONSTRUCCIÓN}

1. «Construccion del nombre, pronombre, y otras partes de la oracion ántes del verbo». (Pág. 328).

- Adyacente del nombre: El hijo de Pedro viene (S.P.); El hombre bueno ama la virtud (S. Adj.); El hombre de bien cumple su palabra (modo adverbial); El sugeto, de quien formas queja, te favorece (dependencia oracional: oración de relativo); El soldado, amante de las fatigas de la guerra, goza los frutos de la victoria (dependencia oracional: oración de participio).

- Adyacente de adjetivo: El hombre lleno de dinero; Los pueblos cercanos á la Corte; La fruta buena de comer.

- Sujeto múltiple: Juan y Francisco vinieron.

- Interjecciones y oraciones intercaladas: Mi hijo ;ah! ya habra perecido. 
2. «Construccion del verbo con las demas partes de la oracion». (Pág. 331).

- Oraciones de Predicado Nominal: Pedro es pintor; Estoy bueno y oraciones pasivas: Yo era amado.

- Perífrasis verbales: estoy por marcharme.

- CD + CI: El Maestro da leccion al discípulo.

- CD + CI + CC: El Rey encarga la justicia á sus ministros, con particular cuidado, para bien de sus vasallos.

- C. Pvo.: El hombre nace cubierto de infelicidad y miseria.

- C. Régimen: Me arrepiento de mis culpas.

- CC (SP o S. Adv.): Quiero entrañablemente á mi amigo; Lleva con paciencia la ingratitud.

- Adyacentes de nombres y adjetivos: La codicia atormenta á los hombres llenos de riquezas.

3.«Construccion de unos verbos con otros». (Pág. 336).

- Dependencia oracional (oraciones con formas no personales): Quiso hacer correr al caballo; Escogió morir peleando.

4.«Construccion del verbo con el pronombre». (Pág. 340).

- Anteposición y posposición de clíticos (funciones de los pronombres átonos: CD y CI): Me amas; hallarme; Fulano me mira; Fulano me escribe.

- Estructuras pleonásticas: él se desprecia á sí propio.

Cuadro 52: Distribución de contenidos sintácticos en la GRAE-1796 


\subsection{De $1854(<1796)$ a 1916}

En este apartado, atenderé con detenimiento a los principios que articulan la doctrina sintáctica defendida en las Gramáticas del corpus central hasta la reforma de 1917, de la que me ocuparé en el punto 6.3.

De lo dicho hasta ahora a propósito de la parte II del libro de Gramática, podemos sintetizar que, en todas las ediciones comprendidas entre las dos fechas marcadas (1854 y 1916), la teoría sintáctica se caracteriza por:

1. Separar los conceptos de sintaxis y construcción.

2. Dividir la Sintaxis en natural y figurada.

3. Distinguir conceptualmente (dentro de la sintaxis natural) los hechos de régimen y los de construcción.

4. Fundamentar la sintaxis natural en tres tipos de reglas: de concordancia, de régimen y de construcción (según el orden de aparición en los libros).

5. Dividir la sintaxis natural en cuatro capítulos: uno por cada una de las reglas que la sustentan (concordancia, régimen y construcción) y un cuarto capítulo dedicado al estudio de las oraciones.

6. Atender en la sintaxis figurada a una serie de figuras retóricas que, por definición, no cumplen las reglas de la sintaxis natural. 
7. Incluir al final de la parte II un apéndice dedicado al régimen preposicional en el que se recogen las distintas construcciones posibles que responden a este tipo de relación sintáctica79.

En este punto de la investigación, interesa analizar los capítulos que integran la llamada sintaxis natural, esto es, hacer un examen en profundidad de los tres tipos de reglas que fundamentan las relaciones sintácticas y examinar igualmente la teoría sobre la oración, en tanto que es unidad de llegada de la Sintaxis en la doctrina académica ${ }^{80}$. Para ello, no voy a seguir el orden de aparición de las reglas sintácticas dentro de los tratados (que es, como ya se ha dicho: concordancia, régimen y construcción), con el fin de hacer una presentación lo más paralela posible a la expuesta a propósito de los Diccionarios.

${ }^{79}$ La Lista de palabras que se construyen con preposición, a la que nos hemos referido en 6.1.3., fue material utilizado por algunos autores contemporáneos posiblemente como ingrediente que imprimiera un refrendo de autoridad a la doctrina defendida. Y el recurso a ella (con mención a la fuente académica en algunos casos) lo encontramos no solo en gramáticos academicistas del XIX y principios del XX, también en otros que superaron (en descripción y casuística) la teoría institucional. Es el caso de Giró (1857: 305-319 y 1871: 315-331).

${ }^{80}$ En esta investigación, no atenderé de forma pormenorizada a la llamada sintaxis figurada por ser concebida por los académicos como un desvío de la sintaxis natural (si bien se reconoce en todos los libros que «se emplea con mayor ó menor latitud áun en el lenguaje más familiar y sencillo» y que la regular o natural «rara vez es observada en todo rigor»). Sobre este punto, podemos hacer extensiva a los textos de nuestro corpus la consideración hecha por Rojo a propósito de la GRAE-1771:

Dado que todo lo referente a la 'sintaxis figurada' es presentado como una especie de 'perturbación' (sin matiz forzosamente peyorativo...) de algunas de las características propias de la 'sintaxis natural', no parece inadecuado considerar los mecanismos conceptuales y operativos descritos en la 'sintaxis natural' como las herramientas de que disponen los académicos que elaboran la edición de 1771 para entender y explicar todo lo que sucede en español (o cualquier otra lengua) a partir del punto en que una palabra entra en relación con otra $u$ otras para constituir elementos más complejos y, en términos contemporáneos, más altos en la escala de unidades gramaticales. Como hemos visto ya, tales herramientas se reducen a las nociones de régimen y concordancia»"

(Rojo, 2001: 78. El subrayado es mío)

A partir de la GRAE-1796, tenemos que sumar a las herramientas mencionadas, las reglas de construcción. 


\subsubsection{Reglas de Régimen}

\subsubsection{El concepto de régimen}

El primer testimonio sobre el concepto de régimen defendido en el seno de la Academia lo encontramos en las disertaciones sobre la división de la Sintaxis que se leyeron en la junta de 22 de marzo de 1746. De estas reflexiones, que forman parte de los trabajos previos a la elaboración de la GRAE-1771, interesan de forma especial los apuntes firmados por Luzán¹. En ellos se defiende que

Regimen en los verbos, y nombres es aquella particula, que los verbos piden después de sí para determinar, o modificar su significacion. En la lengua Latina el Regimen consiste en los casos de los nombres, que pide despues de sí cada verbo, o nombres: de manera que se dice que muchos verbos como los de apreciar, rigen el genitivo; otros, como los de dar, piden el dativo; otros, como los de acusar, piden el acusativo: pero en la Lengua Española no se puede decir que los verbos piden genitivo, o dativo \&c. porque no tenemos distinción de casos si no es por medio de los articulos, o particulas. Y assi me parece, que nuestro Regimen se reduce a las particulas de, a, para, por y con. De modo que unos nombres, y verbos se construyen con la particula de (que equivale al genitivo delos latinos) como amigo de la verdad: gozo me de tu felicidad: otros con la particula $\underline{a}$, como dispuesto $\underline{a}$

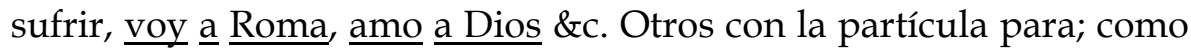
bueno para amigo; vinose para mi \&c. Otros con la particula por: como estimado por su virtud, vóyme por no verte \&c. Otros con la particula con: como soñar con alguno \&c.

(ARAE, 1746c. La cursiva es mía)

81 Los otros dos documentos que aparecen en la misma carpetilla están firmados, respectivamente, por Zapata y Angulo (vid. ARAE, 1746a, b, y c). A las disertaciones de estos tres académicos nos hemos referido en 6.1.3. 
Según este académico, régimen no es otra cosa que aquella palabra (en concreto, aquella preposición) que exigen después de sí determinados verbos y nombres (= sustantivos y adjetivos) ${ }^{82}$ para completar su significación. Son los Complementos del nombre (amigo de la verdad), del adjetivo (bueno para amigo) y del verbo (CD: amo a Dios; CC: vóyme por no verte; C.Rég. gozo me de tu felicidad; soñar con alguno) desempeñados por un SP los que se consideran casos de régimen.

Luzán entiende el régimen, por tanto, como casos de complementación semántica con una exigencia formal: la presencia de preposición. En la obligatoriedad de que el régimen responda a una estructura encabezada por una preposición, la defensa de Luzán está más cercana a nuestra actual visión del Complemento de Régimen que la que se expondrá en los textos de la Gramática, pues en los libros se reconocen como casos de regencia estruturas en las que no media ningún elemento nexivo (vid. infra).

En las ediciones de la GRAE que constituyen el corpus de esta investigación, no se da una definición propiamente dicha del concepto de régimen (vid. Glosario final), como sí encontramos, sin embargo, en la primera versión de la Gramática:

RÉGIMEN es el gobierno ó precedencia que tienen unas palabras respecto de otras: las que estan ántes rigen: las que estan despues son regidas.

Esta general significacion de la voz régimen se ciñe en la Gramática á determinar la relacion ó dependencia de unas palabras con otras.

(GRAE-1771: 235. El subrayado es mío)

\footnotetext{
82 No hay duda de que Luzán está usando nombre como etiqueta englobadora de las categorías nombre sustantivo y nombre adjetivo: los ejemplos dados lo ponen de evidencia (amigo de la verdad / bueno para amigo) y sabemos, además, que en esas fechas estas dos categorías de naturaleza nominal no han sido aún deslindadas en el seno de la Corporación.
} 
Según la definición, esta relación de dependencia tiene que reflejarse en un orden fijo de las palabras implicadas en ella: primero, la que gobierna y después, la gobernada. El régimen es concebido (a la inversa que en las notas firmadas por Luzán, para quien el régimen es la palabra regida) con la mirada puesta en la palabra Regente: régimen es gobierno de una palabra sobre otra -que le sigue en el discurso- (lo que implica, no obstante, la dependencia de la segunda respecto de la primera).

Siguiendo a la definición, se exponen las características de este tipo de dependencia:

a) Puede expresarse solamente con verbos y sustantivos.

En principio, todo hace pensar que ambas categorías pueden ocupar tanto el primer lugar (ser las que rigen según la definición) como el segundo (ser las categorías regidas), pero el ejemplo propuesto en estas primeras líneas dedicadas al régimen responde a la relación /Vb. $\rightarrow$ sust./: busco dinero, «donde el verbo buscar rige al sustantivo dinero que es el buscado»(GRAE-1771: 235). Al explicar más detenidamente este caso de régimen ${ }^{83}$, se aclara que no hay intervención de preposición por no referirse el término del verbo activo o transitivo a una persona. Lo mismo sucede en «los Santos aman la virtud: aborrecen el vicio: los codiciosos atesoran riquezas» (GRAE-1771: 241).

En el artículo I del capítulo del Régimen, se tratan casos de rección del sustantivo y del pronombre personal sobre el verbo: a la

83 Se hace en el artículo II del capítulo dedicado al Régimen, que lleva el epígrafe De la construcción del verbo y adverbio y otras partes de la oracion ántes del nombre. Recuérdese que, en 1771, el término construcción y régimen se usan indistintamente (vid. supra 6.1.4., nota 69). 
relación /Sust.-Pr. $\longrightarrow$ vb./ responden los ejemplos Antonio escribe; Yo amo. De modo que es el Sustantivo Sujeto el que rige al verbo.

b) Puede darse el caso de que la relación de dependencia se exprese mediante una preposición.

Por la información ofrecida en los primeros párrafos y por el ejemplo que se da, se deduce que la preposicion mediará entre una categoría verbal y una sustantiva: busco á Pedro. En este caso, también estamos ante la relación entre Verbo Regente y sustantivo regido. Páginas más adelante se aclara que, cuando el término de un verbo activo o transitivo es nombre de persona, siempre se establece la dependencia mediante la preposición $a$, como en «amo á Dios, á mi próximo, á mi enemigo» (GRAE-1771: 241).

c) El verbo puede llevar un régimen principal y otro accesorio.

Se deduce que el régimen principal es el que no lleva preposición y el secundario, aquel que se expresa mediante el auxilio de una preposición. En Doy pan a mis hijos, «el primer régimen es pan: el segundo á mis hijos». (GRAE-1771: 236).

Lo más importante de la distinción entre régimen principal y régimen secundario es que supone el reconocimiento (aunque ligero) de que no todas las palabras regidas por el verbo tienen el mismo grado de vinculación con él ${ }^{84}$.

84 Vid. Martí Sánchez (1988: 452-457). 
Hasta aquí, la doctrina del régimen se presenta de forma clara en el texto de 1771: definición precisa (régimen = gobierno de unas palabras sobre otras -o dependencia de las segundas respecto de las primeras- que se refleja en un orden fijo) y categorías participantes bien delimitadas: sustantivo y verbo, como categorías Regente y regida indistintamente, y preposición, como elemento de enlace en determinadas estructuras (al parecer, siempre que la palabra Regente sea un verbo).

Sin embargo, a la hora de explicar con detenimiento la casuística de este tipo de relación, las cosas se empiezan a complicar bastante. Hemos visto que el capítulo del Régimen es, en la primera edición, un cajón de sastre que intenta organizarse, en parte, en la GRAE-1796 (vid. supra. 6.1.3.). La Academia no solo amalgama bajo el llamado Régimen una amplia y heterogénea gama de relaciones, también expone una teoría contradictoria (o, cuando menos, confusa). El punto más conflictivo es el que atañe al papel desempeñado por la preposición: esta palabra es presentada, en un primer momento, como elemento de relación y en varios párrafos se destaca su papel de enlace (vid. supra apartados b) y c)) ${ }^{85}$, pero se le acaba concediendo capacidad de regencia ${ }^{86}$

$85 \mathrm{O}$ de simple elemento interpuesto entre dos palabras relacionadas. Es lo que parece interpretarse en:

Todos los verbos se pueden juntar unos con otros mediando alguna preposicion, como: voy á comer: vengo de dormir: salgo á cazar: entro á divertirme: se cansa de jugar: trabaja por ganar: pelea para adquirir: estudia para instruirse: disputa $\sin$ porfiar.

(GRAE-1771: 245)

Los nombres comunes ó apelativos admiten tambien nombres propios con la preposicion de, como: las obras de Ciceron muestran su eloqüencia: el reyno de España abunda en grandes ingenios [...]

(GRAE-1771: 239. El subrayado es mío)

Sin embargo, las dudas asoman al leer los dos párrafos que reproduzco a continuación (párrafos que van seguidos en el texto de la Gramática):

Algunos de estos adjetivos admiten despues otros nombres sustantivos con la preposicion de, como: el hombre lleno de dinero quiere mas [...] 
(recordemos que Luzán la considera palabra regida, el régimen propiamente dicho de ciertos verbos y sustantivos), lo que implica ampliar a tres el número de categorías que pueden ejercer de Palabra Regente. Los casos en los que se afirma que la preposición no es un simple elemento de enlace son:

* Casos de complementación de un sustantivo. Al sustantivo se le concede capacidad regente frente al verbo principal de la oración, pero no se dice que rija ni al adjetivo ni al sustantivo que lo modifican. Así, según la doctrina institucional, en El hijo de Pedro viene, hijo rige a viene, y la preposición de rige a Pedro (cf. GRAE-1771: 238). De esta lectura se concluye (como del reconocimiento de que el verbo puede tener un régimen principal y otro accesorio) que, para los académicos, la palabra regida debe seguir a la Regente, pero no necesariamente ir pegada a ella.

* Casos de complementación de un adjetivo. El marcado logicismo que impera en el texto académico conduce a interpretaciones forzadas con el fin de no conceder capacidad rectora a una palabra, el adjetivo, que significa 'accidente', 'cualidad', etc. Así, las estructuras en las que un adjetivo es modificado por un SP (ya sea su término un nombre o un verbo en infinitivo) se interpretan como casos de regencia de la preposición sobre el segundo elemento de la relación. Son casos del

\footnotetext{
Otros admiten nombres regidos de la preposicion á, como: los pueblos próximos á la Corte venden bien sus frutos [...]

(GRAE-1771: 238. El subrayado es mío)
}

Ante la identidad estructural de los ejemplos dados en esta última cita (que debe conducir a una misma interpretación, por tratarse de un mismo fenómeno lingüístico), podemos pensar que, en el primer párrafo, no se dice que el sustantivo va regido de la preposición por una simple cuestión de estilo. No obstante, no deja de resultar extraño que se separen estos ejemplos en dos párrafos y se les dé una redacción distinta. No acierto a descubrir el porqué de este proceder.

${ }^{86}$ De forma expresa o aludiendo a su posición "precedente". Si régimen se ha definido como "gobierno o precedencia», parece legítimo interpretar que una preposición rige a una palabra cuando leemos que la "precede". 
tipo: el pueblo distante del $\underline{\underline{\text { mar }}}$ comercia poco; los pueblos próximos a la Corte venden bien sus frutos o el caballo malo para correr suele ser $\underline{\text { bueno }}$ para andar (cf. GRAE-1771: 238-239).

* Casos de complementación de un verbo. Se trata de complementos que hoy etiquetamos como CI (El maestro da leccion al discípulo; escribo una carta á mi padre) o CC (envio mis cartas á Cádiz; remito esos libros para mi hermano).

En lo que respecta a este último caso de complementación, la postura de la Academia resulta especialmente confusa, a juzgar por los siguientes datos:

- «Doy pan á mis hijos»: se afirma que, en esta oración, el verbo tiene dos regímenes, uno principal (pan) y otro accesorio (a mis hijos). (Cf. GRAE-1771: 236)

- «El maestro da leccion al discípulo»: de esta frase se dice que el verbo, después del término de la acción, admite otro nombre (al que se dirige la significación verbal) regido de una preposición. (Cf. GRAE-1771: 241).

¿En las estructuras que hoy analizamos como Predicados constituidos por / $\mathrm{Vb} .+\mathrm{CD}+\mathrm{CI} /$, a quién corresponde la regencia del término del CI, al verbo o a la preposición que lo precede?

Pese a todo, no podemos negar el mérito de los académicos que dieron a luz el texto de 1771, quienes supieron exponer una concepción del régimen presidida, por encima de incoherencias casi inevitables en la época a la hora de 
dar cuenta de la casuística, por la claridad conceptual y terminológica (en lo que atañe a la definición y las reglas básicas establecidas).

Gómez Asencio (1981: 59) destaca esta primera edición académica «por la novedad de sus asertos en comparación con la tradición española anterior y por centrar el tema del régimen precisamente en el apriorismo lógico-sintáctico del orden natural de las palabras en la enunciación». Con respecto a lo primero, al carácter novedoso de la doctrina institucional en lo tocante a las relaciones de régimen, el mismo estudioso recordaba que importantes nombres de nuestra tradición gramatical (Villalón, el Anónimo de Lovaina o Jiménez Patón) ni siquiera tratan de él ${ }^{87}$; otros, como Nebrija y Correas, atendieron a ciertas cuestiones relativas al régimen, pero no lo definieron ${ }^{88}$. En el Arte del

${ }^{87}$ Cf. Anónimo (1555), Villalón (1558: 44), Anónimo (1559) y Jiménez Patón (1614: 102). Más información, en Ramajo Caño (1987: 212-215).

${ }^{88}$ Cf. Nebrija, 1492: fols. 45 r.-48 r. y Correas, 1625: 359-373.

En Nebrija, se solapan los conceptos de orden, sintaxis, construcción y régimen, y la idea de regencia se centra en la imposición de casos como sucedía en latín. Como muestra, este botón:

Todos los nombres substantivos de cualquier caso pueden regir genitivo que significa cuia es aquella cosa. como diziendo el siervo de dios. del siervo de dios. al siervo de dios. el servio [sic] de dios. o siervo de dios. Mas esto se entiende cuando el substantivo que a de regir el genitivo es comun o apelativo. por que si es propio no se puede conel ordenar.

(Nebrija, 1492: fol. 47 r.)

En Correas, la idea de régimen (casual) también está asociada a la de un orden natural, y al igual que en Nebrija y, después, en la Academia de 1771, los hechos de régimen son referidos con el nombre construccion, y se tratan bajo los epígrafes: «construzion del nonbre», «construzion del verbo» $\mathrm{y}$ «costruzion [sic] de la particula». Antes de estos apartados leemos:

La orden i contestura natural de las palavras, ó partes, es, que el nombre esté primero, i luego el verbo, i tras este el acusativo, que declara la azion del verbo, si es tranzitivo, i el caso ó parte que pide la ocasión: tras el nombre sustantivo, el adxetivo ó adxetivos que se le añidieren, $\mathrm{i}$ el genitivo que del se rrixiere: que el nombre antezedente esté primero, i despues el rrelativo: i el adverbio despues de su verbo: la preposizion antes de su caso: el articulo antes de su nombre.

(Correas, 1625: 362. El subrayado es mío)

Sin definir ni desarrollar el concepto de régimen, Correas adelanta algunas ideas que estarán presentes en la sintaxis académica: el nombre sustantivo regirá a otro en genitivo, mientras que se le pueden añadir adjetivos (que -debemos suponer- no van regidos por él); el nombre que rige ocupa un lugar precedente y tras él aparecen las palabras con que se puede combinar o los elementos por él regidos. 
romance castellano, de Benito de San Pedro, ya encontramos definida esta relación sobre la base de la idea de "dependencia" 89 y, al igual que hicieron Nebrija y Correas, San Pedro centra su visión del régimen en la exigencia de casos al modo latino (consecuencia de ello es la concepción de que la palabra regida es siempre nombre o pronombre, según se dice en la propia definición) ${ }^{90}$. Precisamente, el cambio de visión (reflejado en un evidente cambio de formulación) es el segundo mérito que Gómez Asencio reconoce en la GRAE1771: al centrar el régimen en el apriorismo lógico-sintáctico, los académicos están dejando a un lado la concepción formal heredada de las gramáticas clásicas.

En la cuarta edición de la GRAE (1796), la doctrina sobre el régimen comienza con una exposición distinta: se suprime la definición de este tipo de relación ${ }^{91}$ y se vuelve la mirada hacia la tradición latina, lo que hace que las

${ }^{89}$ El capítulo II del libro III está dedicado a la Sintaxis de regencia y en él encontramos la siguiente definición:

$$
\begin{aligned}
& \text { Por regimen o regencia del verbo se entiende aquel nombre o pronombre, por } \\
& \text { el que se expressa aquello, a que la accion del verbo hace relacion. }
\end{aligned}
$$

(San Pedro, 1769: 107)

Hay que advertir que, frente a Nebrija y Correas, el escolapio concibe el caso no tanto desde una perspectiva formal, sino como índice de relación sintáctica, según ha observado García Folgado (2000: 131). Sobre los conceptos de régimen y caso en las primeras gramáticas de nuestra tradición, puede encontrarse más información en García-Miguel Gallego (1996).

91 El apartado del Régimen comienza en la cuarta edición con estas palabras:

ADEMAS de la concordancia que se ha explicado de la partes declinables de la oracion, para formarse esta debidamente se han de enlazar entre sí de tal manera, que se sigan unas de otras con una dependencia precisa: que unas rijan á otras, y estas sean regidas de las primeras baxo de ciertas reglas, quebrantadas las quales, ó alguna de ellas, quede la oracion con un defecto muy considerable. Estos defectos enseña á evitar el régimen de las partes de la oracion. Veamos, pues, que partes de la oracion rigen á otras, quáles son regidas, y de que modo.

(GRAE-1796: 286. El subrayado es mío) 
relaciones de régimen se planteen no solo como dependencia sintácticosemántica ${ }^{92}$, sino también como imposición de formas que ciertas categorías ejercen sobre otras (impera, en este sentido, lo que podríamos llamar régimen (asual) ${ }^{93}$. Es esta segunda concepción la que ha destacado Rojo (2001) como dominante en la última edición dieciochesca de la Gramática94.

Aunque no tengamos una definición propiamente dicha, al igual que en 1771, el régimen sigue siendo concebido como dependencia.

92 Se les niega capacidad rectora (esto es, se consideran solo palabras regidas) a aquellas categorías que siempre van referidas a otras o cuya presencia en la oración depende de la aparición de otras partes.

Exclúyese de tener régimen el artículo, porque siempre que se usa es aplicado al nombre sustantivo: el nombre adjetivo, y el participio en quanto tiene de adjetivo, por la misma razon, y porque el régimen de las palabras que se juntan con él, ó pertenece al sustantivo con quien concierta, ó depende de otras partes de la oracion: el verbo en la voz pasiva, porque en esta tienen su régimen propio las partes que se le juntan: el adverbio, porque así como él no es necesario para formar la oracion, así ninguna de sus partes tienen de él inmediata dependencia [...]

(GRAE-1796: 287. El subrayado es mío)

${ }^{93}$ En varios apartados de este capítulo del Régimen leemos:

(a) El nombre sustantivo rige á otro nombre sustantivo, y al verbo.

3 El nombre sustantivo en qualquier caso que se le considere, ó quiera ponerse en la oracion, puede regir á otro nombre sustantivo en genitivo, v. g. la casa de Pedro. Este nombre Pedro está en genitivo del singular regido del nombre sustantivo casa, con la nota del genitivo, que es la preposicion de.

(GRAE-1796: 288. El subrayado es mío)

(b) [...] todo genitivo está regido en la oracion de la preposicion de, como nota del genitivo, y de un nombre sustantivo anterior expreso ó suplido. $\underline{Y}$ si este no está expreso, ni puede suplirse, ó el sentido de la oracion no le necesita, aunque se halle un caso con la preposicion de, no será genitivo, sino ablativo, como se dirá en su lugar.

(c) El verbo rige al nombre sustantivo.

(GRAE-1796: 289. El subrayado es mío)

5 Todo verbo activo transitivo rige un nombre sustantivo, ó pronombre, que es termino de su accion, en acusativo con preposicion, ó sin ella. Quando el término significa persona, se expresa con la preposicion á, como: amo á Dios, al próximo, á mi enemigo. Quando significa cosa, se expresa en acusativo sin preposicion, v. g. amar la virtud, aborrecer el vicio.

(GRAE-1796: 290-291. El subrayado es mío)

(d) 23 Las preposiciones rigen al nombre sustantivo, ó pronombre, al verbo y al adverbio [...]

28 La preposicion por rige acusativo quando se junta con palabras que significan movimiento; y ablativo quando se junta con palabras que significan quietud, por exemplo: hablar por un amigo: ser recomendado por otro; los nombres un amigo y otro están en ablativo regidos de la preposicion por [...] viajar por diversas tierras: trabajar por la ganancia, los nombres diversas tierras, y ganancia, están en acusativo regidos de la misma preposicion $[\ldots]$

(GRAE-1796: 306 y 310. El subrayado es mío) 
El sistema de regencias que se establece en 1796 anuncia la doctrina sobre el régimen defendida en los libros del XIX y primeros años del XX, sistema que analizaremos en 6.2.1.2. Ahora interesa destacar de esta cuarta edición la idea central que sobre el régimen tienen los académicos finiseculares. Hemos visto que lo más interesante de la GRAE-1796, a propósito del asunto que estamos tratando, es la reubicación de parte de los contenidos tratados hasta la fecha en el capítulo del Régimen, que pasan a integrar un nuevo capítulo de la Sintaxis, el dedicado a las reglas de Construcción.

Sobre la distinción entre régimen y construcción en el texto de 1796 (vid. supra 6.1.4.) se han pronunciado Gómez Asencio (1981: 53-56) y Rojo (2001: 105-109). El segundo, sin desacreditar la tesis de Gómez Asencio, sí ha puesto en tela de juicio su conclusión de que la esencia del Régimen está en ser una relación de a dos, mientras que la Construcción puede coincidir con un solo caso de régimen o combinar varios regímenes (en una relación de construcción pueden estar implicadas, en definitiva, más de dos palabras). Esta interpretación es matizada por Rojo, quien entiende que el Régimen, según la exposición que de él se hace en el texto de 1796, no es tanto una relación entre parejas de palabras, sino «una relación uno a uno, de modo que un elemento

A la luz de estos ejemplos, conviene matizar lo dicho sobre que las relaciones de régimen son también concebidas como "imposición" de formas: se trata, en todo caso, de una imposición relativa, en la medida en que muchos de los complementos no son obligatorios en primera mención; lo que es obligatorio es que, en caso de aparecer, vayan precedidos de una determinada preposición.

${ }^{94}$ Lo ha expresado con estas palabras:

En mi opinión, los redactores de la Gramática de 1796 pretenden utilizar régimen en el segundo de estos sentidos (el de exigencia de una determinada forma), pero la obra contiene también, como sucede en buena parte de la gramática tradicional, algunas utilizaciones del término régimen que solo pueden ser entendidas desde un significado próximo al actual de subordinación.

(Rojo, 2001: 115) 
determinado solo puede regir a otro», lo que hoy equivaldría a considerar que «un verbo, por ejemplo, solo puede tener un argumento».

Creo que estas conclusiones no son excluyentes entre sí: la interpretación de Rojo parece correcta para lo concerniente, precisamente, a los regímenes del verbo, pero no explica otro tipo de relaciones que se producen en construcciones concretas, para las cuales encontramos respuesta en la lectura de Gómez Asencio. Veamos con más detenimiento el alcance de ambas propuestas.

Según lo expuesto en el texto de la Gramática, las relaciones que tienen como palabra Regente un verbo (/Vb. $\rightarrow$ sust./, /Vb. $\rightarrow$ vb./ y / Vb. adv./) solo pueden contar con un término de la relación, lo que vendría a coincidir con la idea de que un verbo solo puede tener un argumento, en términos actuales. De hecho, en la GRAE-1796, no encontramos vacilación a la hora de interpretar, ya en el capítulo dedicado a la Construcción, estructuras del tipo El maestro da lección al discípulo o Doy pan a mis hijos (vid. supra doble interpretación de la GRAE-1771). Por lo dicho expresamente en la cuarta edición de la GRAE, tenemos que concluir con Rojo (2001: 106-107) que, en casos como los dados, los verbos da y doy solo rigen al primer sintagma (lección y pan, respectivamente) y están en construcción con los SP que siguen (al discípulo y a mis hijos). Los fragmentos que reproduzco a continuación, extraídos del capítulo IV («De la Construccion»), no dejan lugar a la duda:

Muchos verbos activos transitivos admiten despues del término

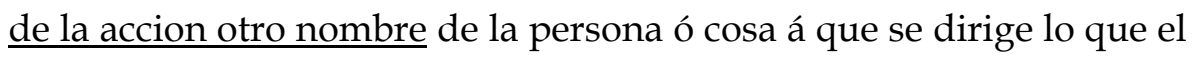
verbo significa, los quales van regidos de las preposiciones que les corresponden segun la significacion y uso de ellas, que queda ya explicado, v. g. El Maestro da leccion al discipulo: remito esos libros para mi hermano: envio mis cartas á Cádiz; al discipulo está en dativo 
regido de la preposicion á; mi hermano lo mismo regido de para; Cádiz en acusativo, regido de á. Tambien se suelen seguir al término del verbo otros nombres con diversas preposiciones, que significan circunstancias ó modos que puede recibir la accion, y forman los diferentes casos de los nombres, v. g. El Rey encarga la justicia á sus ministros, con particular cuidado, para bien de sus vasallos. El régimen del verbo no pasa del acusativo justicia: las demas palabras van regidas de las preposiciones á los casos respectivos conforme á su uso y significacion.

(GRAE-1796: 332-333. El subrayado es mío)

Ya queda explicado en el régimen del verbo y de la preposicion, que clase de verbos rige por sí á otros sin preposicion, y que preposiciones rigen a los verbos, y de que modo; resta añadir ahora, que el régimen del verbo no pasa del nombre ó pronombre que es su término, ó del verbo determinado respecto del determinante; y las demas palabras que se añadan á estos tendrán su régimen separado»

(GRAE-1796: 336. El subrayado es mío) ${ }^{95}$

Sin embargo, la propuesta de Rojo no explica ciertas construcciones en las que se dan relaciones sintácticas tratadas por la Academia. Pongo por caso estructuras del tipo (el ejemplo es mío):

\footnotetext{
95 Tanto Gómez Asencio como Rojo aducen este mismo párrafo: el primero, como refrendo de su tesis de que «la Construcción no es más que la combinación y composición de varios regímenes» (1981: 54); el segundo (2001: 110), para subrayar que, sea cual sea la interpretación hecha (régimen = relación entre dos elementos, o bien régimen $=$ obligatoriedad de un solo elemento regido por cada elemento Regente), de lo que no hay duda es de que la Academia impone un límite de elementos en las relaciones de régimen, mientras que en los casos de construcción no hay límite alguno.
} 


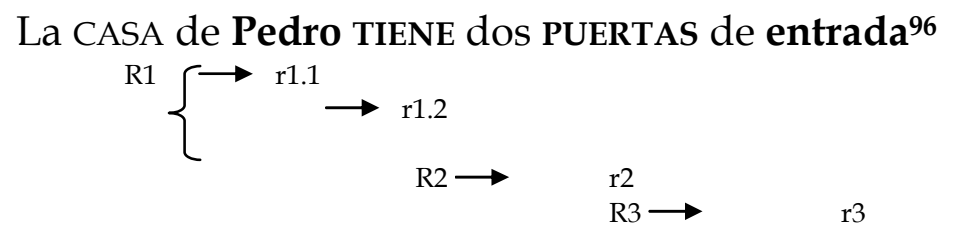

Los casos 2 (/Vb. $\rightarrow$ sust./), y 3 (/Sust. $\rightarrow$ sust./) de regencia no ofrecen -en principio- problema, pues tanto la opción de que el régimen sea concebido como relación entre parejas de palabras, como la de que el régimen obliga a que un elemento Regente solo determine a un regido, admiten que una misma palabra sea a la vez Regente (de otra) y regida (por otra diferente) en una construcción dada ${ }^{97}$. Sin embargo, el caso 1 de régimen que encontramos en la oración propuesta solo tiene explicación si aceptamos como válida la interpretación de Gómez Asencio, esto es, si aceptamos que, para la Academia de finales del XVIII, en una determinada construcción (donde pueden entrar en relación más de dos palabras), podemos encontrar varios casos de régimen, incluso varios regímenes de un mismo término Regente. Y es que, a la luz de las declaraciones explícitas, según el texto de 1796, ante estructuras como la que tenemos, solo cabe interpretar que casa rige a Pedro y

\footnotetext{
${ }_{96}$ Con versalita indico Palabra Regente (en el esquema, $\mathrm{R}$ ); con negrita, palabra regida (en el esquema, r); y con versalita y negrita, palabra regida por un elemento Regente $y$, a su vez, Regente de otra palabra de la oración.

97 Hay que decir que el caso que hemos marcado como 3 podría interpretarse, en lugar de como relación de régimen (por la que me inclino), como relación de construcción del sustantivo entrada con el sustantivo puerta, con la marca de de genitivo. El problema es que el texto no ofrece suficiente información para descartar con seguridad la relación de regencia, pero tampoco para afirmar con certeza absoluta que puertas regiría a entradas en esta oración. En el apartado dedicado a la regencia (/Sust. $\rightarrow$ sust./), a propósito del ejemplo dado (Casa de Pedro), se dice:
}

Llámase este genitivo de posesion, porque verdaderamente la significa, pues expresa ser Pedro poseedor de la casa; y significa igualmente accion que pasion, v. g. el amor de mi padre, de mi hijo, significa del mismo modo el amor de mi padre y de mi hijo hácia mí, que mi amor hácia mi padre ó mi hijo.

(GRAE-1796: 288-289)

Ante estas palabras, creo que cabe plantearse lo siguiente: ¿el no mencionar otro tipo de genitivos -aparte del de posesión (que, por otro lado, es el matiz semántico más habitual desde Nebrija)- se debe a que los académicos consideran que el sustantivo sólo rige a otro sustantivo si está en genitivo y significa posesión? ¿O la mención exclusiva al genitivo de posesión se debe a que es el tipo de genitivo al que responde el ejemplo dado? 
también a tiene, pues, en el apartado dedicado a los regímenes del nombre, se afirma:

$\underline{\text { El nombre sustantivo en cualquier caso que se le considere }{ }^{98} \text {, ó }}$ quiera ponerse en la oracion, puede regir á otro nombre sustantivo en genitivo, v. g. la casa de Pedro. Este nombre Pedro está en genitivo del singular regido del nombre sustantivo casa, con la nota del genitivo, que es la preposicion de.

(GRAE-1796: 288. El subrayado es mío)

Todo nombre sustantivo ó pronombre que se pone para representar persona ó cosa, como principio ó móvil de alguna accion ó pasion, rige un verbo que exprese esta accion ó pasion; y así no puede haber oracion ni sentido alguno donde falte verbo regido de un nombre sustantivo, ó pronombre expreso ó suplido.

(GRAE-1796: 289. El subrayado es mío)

Bien es cierto que, en el apartado en que se habla de la «Construccion del nombre, pronombre, y otras partes de la oracion ántes del verbo», leemos igualmente:

Todos los nombres comunes admiten ántes del verbo otros nombres sustantivos en genitivo, v. g. El hijo de Pedro viene; y asimismo nombres adjetivos que conciertan con ellos, v. g. El hombre bueno ama la virtud: la muger virtuosa cuida de su casa.

(GRAE-1796: 328. El subrayado es mío)

Al no mencionar en este párrafo que hijo rige a Pedro, cabría pensar que, si en el capítulo del Régimen solo se da como ejemplo el SN la casa de Pedro, y es en la Construcción donde encontramos una estructura oracional propiamente

\footnotetext{
98 Si un sustantivo, esté en el caso que esté, puede ser Regente de otro sustantivo en la oración, puertas (que está en Acusativo) puede regir perfectamente a entrada en la oración de arriba ( $L a$ casa de Pedro tiene dos puertas de entrada).
} 
dicha, es porque la relación de regencia que prima es la del Sustantivo Sujeto sobre el verbo, y en caso de tener una oración, debemos entender que el genitivo de Pedro está en construcción con el sustantivo casa, no regido por él, del mismo modo que el régimen de hombre no es el adjetivo bueno, sino el verbo ama. Esta interpretación estaría en la línea pretendida por Rojo, pero creo que tiene un inconveniente que no debemos pasar por alto. $Y$ es que, frente a la hipotética relación /Sust. $\rightarrow$ adj./, no reconocida en ningún lugar de la Gramática, la relación /Sust. $\rightarrow$ sust./, en ejemplos idénticos al de El hijo de Pedro, es declarada de forma expresa en la GRAE-1796 en el capítulo del Régimen. Por otro lado, no hay ninguna declaración explícita, como sí las hay a propósito de los regímenes del verbo, que nos permita negar la regencia de hijo sobre Pedro en el ejemplo que estamos considerando. En definitiva, en la línea de la tesis de Gómez Asencio (y en consonancia con lo dicho en 6.1.4.), El hijo de Pedro viene sería considerado un caso de construcción en el que se combinan dos casos distintos de régimen (cuyo requisito es que sean relaciones establecidas entre dos palabras): /hijo $\rightarrow$ Pedro/ e /hijo $\rightarrow$ viene/. Al contar solo con la palabra y la oración como unidades operativas para la descripción en materia sintáctica, las relaciones de dependencia solo pueden concebirse entre pares de palabras, de manera que tienen que justificarse los vínculos establecidos en El hijo de Pedro viene como dos regímenes sucesivos de una misma palabra Regente. El no considerar unidades intermedias (de grupos de palabras que no constituyan oración, esto es, de sintagmas o frases) hace que la doctrina académica esté lejos aún de una interpretación del tipo: / [hijo $\longrightarrow$ Pedro] $\rightarrow$ viene/. Y, debido al concepto formal imperante en esta edición, dista mucho más de la propuesta que sería más cercana a un análisis actual: /[hijo $\Longleftrightarrow$ Pedro] $\Rightarrow$ viene/.

En cuanto a la relación que se da entre un sustantivo y un adjetivo (hombre bueno), hay que decir que, en la Sintaxis académica de finales del XVIII, no se tiene en cuenta como caso de regencia. De hecho, la única alusión a la 
relación de un adjetivo con un sustantivo, dentro de la Sintaxis, la encontramos en la última cita reproducida (vid.supra) y en el apartado dedicado a la regencia del tipo /Vb. $\rightarrow$ adv./:

Todos los verbos, á excepcion de los auxiliares, como tales, rigen adverbios, y estos se refieren á los verbos del mismo modo, $\mathrm{y}$ con la misma precision que el adjetivo se refiere el [sic.] sustantivo: pues así como no puede haber adjetivo, que no haga relacion á un nombre sustantivo expreso ó suplido; así no puede haber un adverbio que subsista por sí solo en la oracion, sin que se refiera á un verbo expreso ó suplido.

(GRAE-1796: 300. El subrayado es mío)

El vínculo necesario que se reconoce entre un adjetivo y un sustantivo parece encajar con el concepto de régimen como dependencia o subordinación semántico-sintáctica de elementos, pero no con el concepto dominante en esta cuarta edición de la Gramática: el de régimen entendido como exigencia formal (de caso, modo o tiempo, pero no de marcas flexivas) que una palabra impone sobre otra de la oración. Es por ello que esta relación /Sust. + Adj./ será tratada en la Concordancia, como es habitual en los tratados de la época, y en la Construcción, según queda reflejado en la última cita reproducida en la página 393.

$* * * * * * *$

En lo que respecta a las ediciones comprendidas entre 1854 y 1916, ya hemos dicho que, en ellas, no encontramos una fórmula de definición en sentido estricto, pero, por las explicaciones y las distintas referencias a este tipo de relación, sabemos que: 
1. «El órden regular [...] pide que no haya falta ni sobra de palabras en la oracion; que tengan todas su propia y natural dependencia, y ocupen respectivamente el lugar que les corresponde. Pide que el nombre sustantivo se anteponga al adjetivo; que la palabra regente preceda á la regida, y que cuando ocurre expresar dos ó más cosas, de las cuales la una tiene antelacion por naturaleza, dignidad ó importancia, no se perturbe este órden [...]» (GRAE-1854: 137. El subrayado es mío) ${ }^{99}$.

Esto es, el régimen se da entre dos palabras (es relación binaria), la primera de las cuales es la Regente (Reg.) y la segunda, la regida (reg.).

Este concepto de régimen como relación binaria de carácter lineal (en sentido de izquierda a derecha), que ya aparecía en la GRAE-1771, es deuda directa con el logicismo subyacente en la sintaxis desde el siglo XVIII: la palabra más importante semánticamente será la más importante sintácticamente (será la que rija a otra) y, en consecuencia, ocupará el primer lugar en la relación de dependencia.

99 Cf. GRAE-1858: 147, 1862: 151, 1864: 151, 1865: 151, 1866: 151, 1867: 150, 1870: 167 (en esta edición, encontramos un ligero cambio en la cita reproducida: se utiliza el término nombre como sinónimo de sustantivo (vs. adjetivo) sin especificar ya nombre sustantivo), 1874: 195 (en este año, se sigue usando nombre vs. adjetivo y se deja de hablar de orden regular para hablar de sintaxis regular), 1878: 195 (en esta edición, la redacción de la cita mantiene los dos cambios que se introdujeron en sendas ediciones precedentes).

En la GRAE-1880, se pierde esta mención explícita a la posición que deben ocupar palabra Regente y palabra regida, pero se sigue haciendo alusión a la necesidad de seguir un orden determinado en las relaciones de dependencia:

Divídese [la Sintaxis] en regular y figurada: la regular, cuyo principal objeto es la claridad, pide que no haya falta ni sobra de palabras en la oración; que tengan todas su propia y natural dependencia, y ocupen respectivamente el lugar que les corresponde $[\ldots]$

(GRAE-1880: 215. El subrayado es mío)

Cf. GRAE-1883: 215, 1885: 217, 1888: 215, 1890: 215, 1895: 215, 1900: 215, 1901: 215, 1904: 209, 1906: 209, 1908: 209, 1909: 209, 1911: 213, 1913: 213 у 1916: 213. 
2. «Es necesario que las palabras se enlacen y combinen de tal manera, que tengan entre sí una justa dependencia; que unas rijan á otras

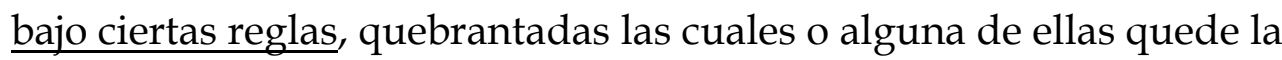
oracion defectuosa» (GRAE-1854: 143. El subrayado es mío) ${ }^{100}$.

Por tanto, las relaciones de régimen son relaciones de dependencia ${ }^{101}$ entre las dos palabras (es de suponer -esto parece obvio- que la regida depende de la Regente), y estas relaciones deben establecerse siguiendo una serie de reglas para que la oración no adolezca de fallo.

3. «Esto [el defecto en la oración] se evita conociendo bien el régimen de las partes de la oracion. [...] Exclúyense de tener régimen el artículo, el nombre adjetivo, el pronombre cuando no es personal, y el participio cuando hace oficios de adjetivo, porque todos ellos están

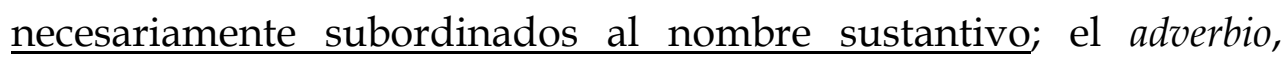
porque ninguna parte de la oracion tiene de él inmediata dependencia; la interjeccion, porque más bien es una exclamacion aislada, que parte esencial de la oracion» (GRAE-1854: 143. El subrayado es mío) ${ }^{102}$.

100 Cf. GRAE-1858: 155, 1862: 159, 1864: 159, 1865: 159, 1866: 159, 1867: 158, 1870: 176, 1874: 204, 1878: 204, 1880: 222, 1883: 222, 1885: 224, 1888: 222, 1890: 222, 1895: 222, 1900: 222, 1901: 222, 1904: 216, 1906: 216, 1908: 216, 1909: 216, 1911: 220, 1913: 220 у 1916: 220.

101 A partir de la GRAE-1880, en lugar del punto y coma, tenemos un marcador o sea entre las dos oraciones de la parte subrayada en la cita; de manera que el hecho de que las palabras tengan entre sí una justa dependencia equivale (ahora de forma inequívoca según la redacción) a que haya entre ellas relaciones de régimen.

102 Cf. GRAE-1858: 155, 1862: 159, 1864: 159, 1865: 159, 1866: 159, 1867: 158-159, 1870: 176 (en esta edición, se reconocen ya como Reg. ciertas categorías que hasta ahora no han gozado de este rango -vid. infra-), 1874: 204, 1878: 204, 1880: 222, 1883: 222, 1885: 224, 1888: 222, 1890: 222, 1895: 222, 1900: 222, 1901: 222, 1904: 216, 1906: 216, 1908: 216.

En la GRAE-1909, cambia la redacción de este párrafo, que queda como sigue: 
Con estas palabras, queda confirmada la identidad palabra regida = palabra dependiente de otra o subordinada a otra. Por otro lado, se insiste en que la rección solo puede darse entre partes constituyentes de la oración. Esta concepción es bastante habitual en los textos coetáneos de nuestro corpus, pero no será la única, como enseguida veremos 103 y 104 .

El régimen no se vincula a variación formal de las palabras, concepto defendido por algunos autores de la segunda mitad del siglo XIX y primer cuarto del XX, cuyas gramáticas están más apegadas a los esquemas de las latinas, según informa Calero Vaquera (1989: 206-210)105. Efectivamente, a partir de la GRAE-1854, frente al último texto dieciochesco, se reducen considerablemente las

Carecen de régimen el artículo; el pronombre, cuando no representa al nombre; el adverbio, porque ninguna de las palabras de la oración tienen de él inmediata dependencia; y la interjección, porque más bien es una exclamación aislada que parte esencial de la oración.

(GRAE-1909: 216)

Ídem GRAE-1911: 220 y 1913: 220. En el texto de 1916: 220, se invierte el orden: primero se menciona el pronombre y luego, el artículo.

${ }_{103}$ Calero Vaquera, en su análisis de textos gramaticales comprendidos entre 1847 y 1920, concluye que

A lo largo del periodo podemos constatar cómo paulatinamente nuestros gramáticos se van desligando de la preocupación por la forma y comienzan a entender el régimen como dependencia, relación, subordinación, trabazón, etc. no formal, sino sintáctica y semántica. Las definiciones más elementales que en este sentido se formularon se limitan a señalar que tal dependencia se establece entre las palabras [...] Hay quien introduce la precisión de que tal relación o dependencia se produce en el marco de la oración [...]

Calero Vaquera (1986: 207)

104 En Santiago Vicente García, autor que arremete en más de una ocasión contra la doctrina académica, encontramos, paradójicamente, la que quizá sea mejor formulación del concepto de régimen defendido por la RAE en los años que estamos considerando (1854-1916):

\footnotetext{
Régimen es la asociación subordinada de una voz con otra que la determina, para espresar la dependencia relativa de su combinacion.

(Vicente García, 1854: 68. El subrayado es mío)
}

105 Esta autora menciona, entre los gramáticos que defienden la concepción formal del régimen, a Balmes (1847), Núñez de Arenas (1847), Pahissa (1863), Pérez Barreiro (1897) y Núñez Meriel (1905). 
alusiones a los casos en el capítulo del Régimen ${ }^{106}$ (aunque se siga hablando de nominativo, y esporádicamente de acusativo -usos que debemos interpretar como estela terminológica, no doctrinal-). Valgan como botón de muestra las dos citas que siguen, que pueden compararse, respectivamente, con los fragmentos (a) y (c) reproducidos en la nota 93107 :

\section{El nombre sustantivo rige á otro nombre sustantivo}

Este régimen se verifica con el auxilio de una preposicion, como Casa DE Pedro , Luis CONTRA Juan [...]

(GRAE-1854: 144)

\section{El verbo rige al nombre sustantivo}

Todo verbo activo, ó sea transitivo, rige un nombre sustantivo, ó pronombre personal, que es término de su accion, con preposicion ó sin ella. [...] Cuando el término significa persona, se expresa con la preposicion á, como: Amo Á Dios, $\mathrm{AL}$ prójimo, Á mi padre. Cuando significa cosa, se expresa sin preposicion, v. gr.: Amar la virtud, aborrecer el vicio.

(GRAE-1854: 144)

No obstante, la idea de régimen como imposición de formas no se ha desterrado completamente de las ediciones decimonónicas de la GRAE y a veces parece solaparse con la idea de subordinación. Lo veremos.

El régimen responde, en definitiva, a los casos de dependencia intraoracional que se dan entre las distintas categorías gramaticales. Veremos, en las páginas que siguen, que estas relaciones de dependencia son concebidas

\footnotetext{
106 Si bien la noción de caso no se abandona en estas ediciones (vid. infra). 107 Los fragmentos (b) y (d) desaparecen en la GRAE-1854.
} 
como relaciones jerárquicas de unos elementos sobre otros, de modo que el primero rige (es jerárquicamente superior) y el segundo es regido (reponde a una categoría “inferior").

Poco tiene que ver el sistema de regencias establecido por la RAE con el que se expone en algunas Gramáticas coetáneas de nuestro corpus (1854-1924) que interesa traer a colación. De mediados del XIX es la obra de Giró, y ya este autor defiende que

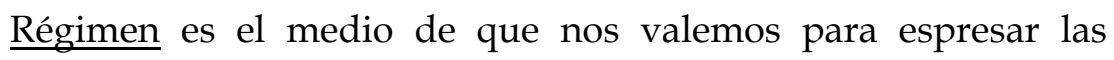
relaciones de dependencia, y consiste generalmente en interponer ya mediata ya inmediatamente alguna preposicion ó conjuncion entre las palabras, miembros ú oraciones cuya relacion debemos espresar.

(Giró y Roma, 1857: 207 y 1871: 212. El subrayado es mío)

Salvando las diferencias con lo escrito por Luzán (vid. supra), sí coinciden sus defensas y las de Giró en la tendencia general a que las relaciones de rección se caractericen por la presencia de un elemento nexivo, aunque se reconozca que pueden darse casos donde no media preposición ni conjunción, como en el llamado ya por Giró Complemento Directo.

Pero lo más interesante de la doctrina de Giró (frente a la expuesta por Luzán y a la defendida años después en el texto de la GRAE) es que contempla el hecho de que las relaciones de dependencia pueden darse no solo entre elementos de la oración, sino también entre distintas oraciones. No es el único autor del periodo que defiende tales ideas: en dos obras distintas, Herrainz (1869: 133 y 1885: 130) afirma que «los materiales del régimen son las palabras, las frases, las oraciones, las partes de estas, las cláusulas y sus componentes». Y años antes, en 1851, Martínez Sevilla exponía que el régimen es 
La reclamacion de una palabra ú oracion á otra palabra ú oracion que perfeccione y complete su sentido. Las palabras ú oraciones que reclaman otras se llaman regentes; y las que perfeccionan y completan su sentido regidas; asi v. gr. en juego de café, espero que me oirás, la palabra juego y la oración elíptica espero son regentes, y repectivamente regidas la palabra café y la oracion también elíptica me oirás.

(Martínez Sevilla, 1851: 74-75. El subrayado es mío)

Sin embargo, y según ya se ha adelantado, la postura académica no es, en modo alguno, aislada; de hecho, la GRAE representa la línea "oficial" y buena parte de los autores decimonónicos estarán insertos en una corriente academicista. Tales como Mariano de Rementería (1843) o Gómez de Salazar (1874), quienes, al igual que la docta Casa, entienden que el régimen, o relación de dependencia de las categorías verbales dentro de los márgenes de la oración, conduce a una clasificación sintáctica básica entre palabras Regentes y palabras regidas ${ }^{108}$. Y sus teorías se limitarán, en esencia, a dar cuenta de la nómina de unas y otras, así como a describir y ejemplificar brevemente los distintos casos de relación entre cada una de las palabras Regentes con las distintas palabras por ella regida.

108 La siguiente cita, extraída de las Conferencias gramaticales sobre la lengua castellana, ó elementos esplanados de ella, permite ilustrar la postura de los autores pertenecientes a la corriente no academica pero sí academicista que dominó (y tuvo que convivir con posturas independientes y con otras antiacademicistas) a finales del XVIII y durante el siglo XIX:

Se llama régimen la dependencia precisa que deben tener entre sí las partes de la oracion para anunciar con claridad los pensamientos. $[\ldots]$

Las partes regentes de la oracion son: el nombre sustantivo, el verbo activo, el participio, la preposicion y la conjuncion; las regidas son las demás.

(Mariano de Rementería, 1843: 140. El subrayado es mío) 
De la generalidad de la postura académica a propósito de las relaciones de régimen da cuenta Giró (1871). Al final del capitulo II de la Sintaxis, el dedicado al Régimen, este gramático incluye una nota en la que sintetiza la teoría sobre el régimen que suele exponerse en los tratados de la época, con el fin de ayudar a aquellos lectores que aspiren a examinarse oficialmente de gramática castellana. $\mathrm{Y}$ es que Giró es consciente de que su propuesta no cuenta todavía con el suficiente respaldo entre los posibles examinadores y no garantiza, por tanto, el éxito del opositor ${ }^{109}$. Por esta razón, siente la necesidad de añadir en su libro unas páginas en las que, siguiendo el procedimiento de $\mathrm{P}$ / $R$, expone con brevedad y en la línea de la rutinaria costumbre, una teoría sobre el régimen ceñida a las relaciones entre dos palabras dentro de la oración. No deja de resultar curiosa esta postura: Giró no renuncia a hacer una propuesta personal, pero tampoco a sumarse a lo convenido.

NOTA. Hemos tratado el régimen de un modo bastante diferente de como se acostumbra; pero creemos que si no lo hemos hecho con la perfeccion que seria de desear, lo hemos hecho mejor de como se hace. Pero como entre las personas que se precian de instruidas reina tambien algo de rutina y preocupacion tanto mas dificiles de combatir cuanto mayores sean sus pretensiones, darémos en esta nota una idea del régimen tal como se acostumbra tratar esta importante parte de la sintáxis, con el objeto de que se enteren de ella los que hayan de examinarse de gramática castellana. Para sufrir un exámen no basta saber; es preciso saber tambien lo que los examinadores creen que es saber. Y como es muy probable que varios de los examinadores seguirán entendiendo el régimen tal como lo aprendieron, sus preguntas estarán arregladas á sus conocimientos; y estas preguntas no podrian ser contestadas impunemente sino con arreglo á las ideas de los que las hacen.

109 La Gramática elemental de la lengua castellana de Giró y Roma está destinada a «servir de texto en las escuelas normales de instrucción primaria del reino», según reza la portada. Véase la referencia completa en la bibliografía final. 
No teniendo esta nota mas objeto que guiar á los que hayan de sufrir exámen de gramática, vamos á compendiar por preguntas y respuestas el régimen tal cual se acostumbra tratar.

(Giró y Roma, 1871: 227-228)

Es en las dos páginas y media que siguen a esta nota donde encontramos la habitual clasificación de las partes de la oración en palabras Regentes y palabras regidas, clasificación que, por todo lo dicho, no debe considerarse fundamento de la teoría del régimen expuesta por este autor, como sí lo es en los gramáticos academicistas $\mathrm{y}$, por supuesto, en la propia tradición académica $^{110}$.

110 Calero Vaquera (1989: 208) afirma que «todos nuestros gramáticos sin excepción convienen en distinguir entre palabras regentes y palabras regidas. Los desacuerdos surgen a la hora de dilucidar cuáles son las partes de la oración que rigen á otras, y cuáles las que son regidas por aquéllas»; sin embargo, en el listado que hace con las propuestas de los distintos gramáticos que estudia no incluye el texto de Giró ni el de la GRAE que forman parte del corpus de su trabajo.

Podemos decir que la clasificación que expone Giró (de forma accesoria a su doctrina) no coincide con ninguna de las que se encuentran en los textos analizados por Calero Vaquera, pero sí con la defendida por la RAE en las ediciones comprendidas entre 1854 y 1867 (vid. infra Tabla 5):

P. Qué es régimen?

$\mathrm{R}$. La dependencia que tienen unas palabras con otras.

P. Qué partes de la oración rigen á otras?

R. El nombre sustantivo, el pronombre personal, el verbo, el participio, la preposición y la conjunción.

P. Qué partes de la oración son regidas?

R. El nombre sustantivo, el pronombre, el verbo, el adverbio y la preposición.

(Giró, 1871: 228. el subrayado es mío) 


\subsubsection{El sistema de regencias}

La casuística recogida en la primera Gramática académica del siglo XIX (1854) coincide, básicamente, con la exposición de 1796. El sistema de regencias establecido por la Institución en la quinta edición de la GRAE es el que se representa en la Tabla $5^{111}$.

Este sistema se incrementará en la 12. ${ }^{a}$ edición de la Gramática (1870), añadiendo a la nómina de palabras Regentes (Reg.) dos nuevas categorías: el adjetivo -recién admitido como palabra autónoma- y el gerundio -que, en realidad, es una subforma del verbo-, y atendiendo, en los regímenes del nombre, al adjetivo como palabra regida (reg.). El planteamiento de la GRAE1870 es el que aparece esquematizado en la Tabla 6 (en ella, marco en negrita y numero solo los añadidos).

111 En las tablas se coloca a la izquierda de las flechas la palabra Regente (Reg.) y a la derecha, la categoría regida (reg.), según el criterio de representación de las relaciones de regencia establecido al comienzo del bloque IV. 


\begin{tabular}{|c|c|}
\hline \multicolumn{2}{|c|}{ SISTEMA DE REGENCIAS EN LA GRAE-1854112 } \\
\hline Palabras Regentes (Reg.) & palabras regidas (reg.) \\
\hline
\end{tabular}

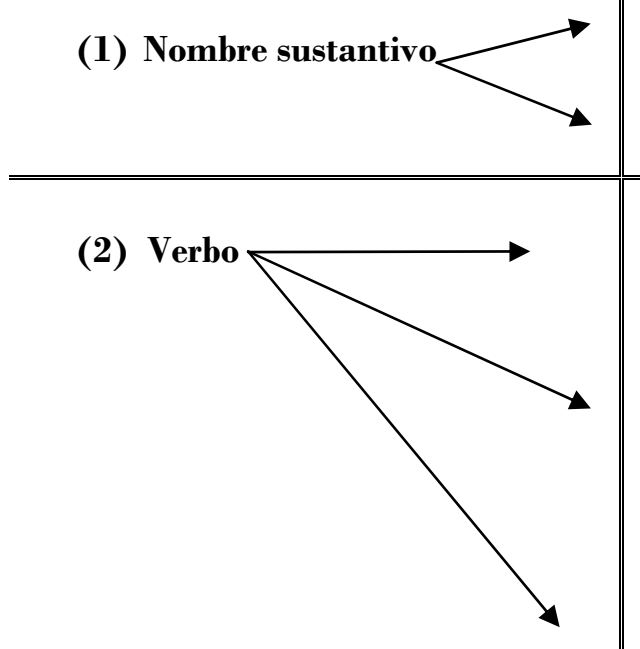

(a) nombre sustantivo: «Casa DE $\underline{\text { Pedro; }}$ callejón SIN salida; uvas EN cierne».

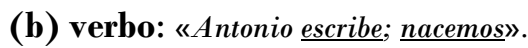

(a) nombre sustantivo / pronombre: «Amo $A L$ prójimo; Aborrecer el vicio; ganar amigos; Convidé Á Lúcas; Un día sigue Á otro»".

(b) verbo: «Quiero estudiar; Deseo QUE aprendas; Vamos Á cazar liebres; El hombre nace PARA morir; Obstinarse EN trasnochar; Ven cuando quieras; Si para fin de año no HUBIERE PAGADO, le APREMIAS, APRÉMIALE, ó le APREMIARÁS».

(c) adverbio: «es TEMPRANO; $\underline{A Q U I ́}$ vivo».

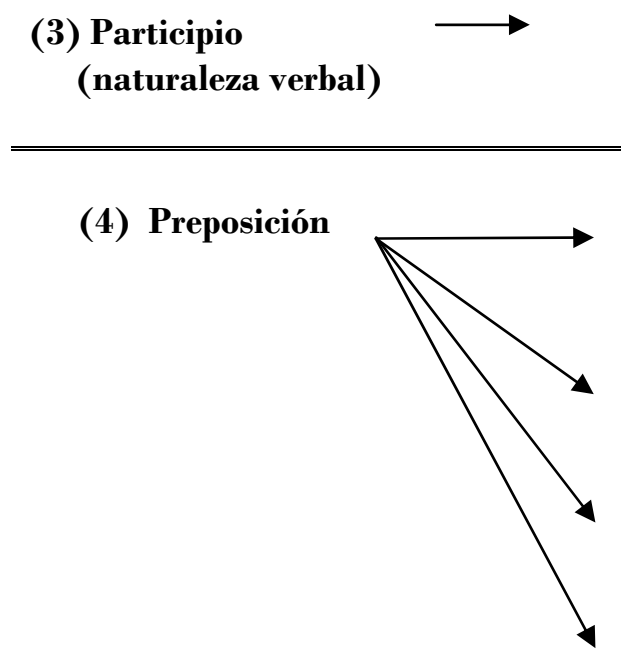

nombre: «Amante DE las letras; Complaciente CON sus subalternos».

(a) sustantivo / pronombre: «No me he acordado de él PARA BUENO ni PARA MALO; Le tengo POR ( VALIENTE».

(b) verbo: «Me contento CON QUE me des la mitad; Se trata DE QUE lo hagas pronto; Quiere saber HASTA SI cómo [sic] bien ó mal; Te lo digo PARA QUE te sirva de gobierno».

(c) adverbio: «DE $\underline{A Q U I ́}$ á Toledo; HÁCIA DENTRO; POR CERCA que sea».

(d) preposición: «Huir DE CON su padre; Correr POR ENTRE abrojos».

\section{(5) Conjunción}

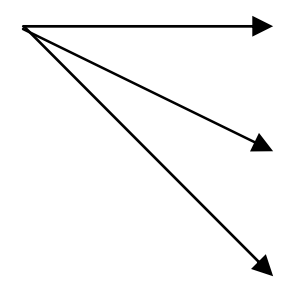

(a) sustantivo / pronombre: «Ni $\amalg U A N$, ni tres $\underline{\text { UUANES; }}$ Bien EL, bien sus HERMANOS».

(b) verbo: «La AMO y LA AMARÉ miéntras viva; Ora te QUEDES, ora te VAYAS».

(c) adverbio: no se dan ejemplos.

Tabla 5: Sistema de regencias en la GRAE-1854

112 Ídem GRAE de 1858: 155-172, 1862: 159-176, 1864: 159-176, 1865: 159-176, 1866: 159-176 у 1867: 158-175. 


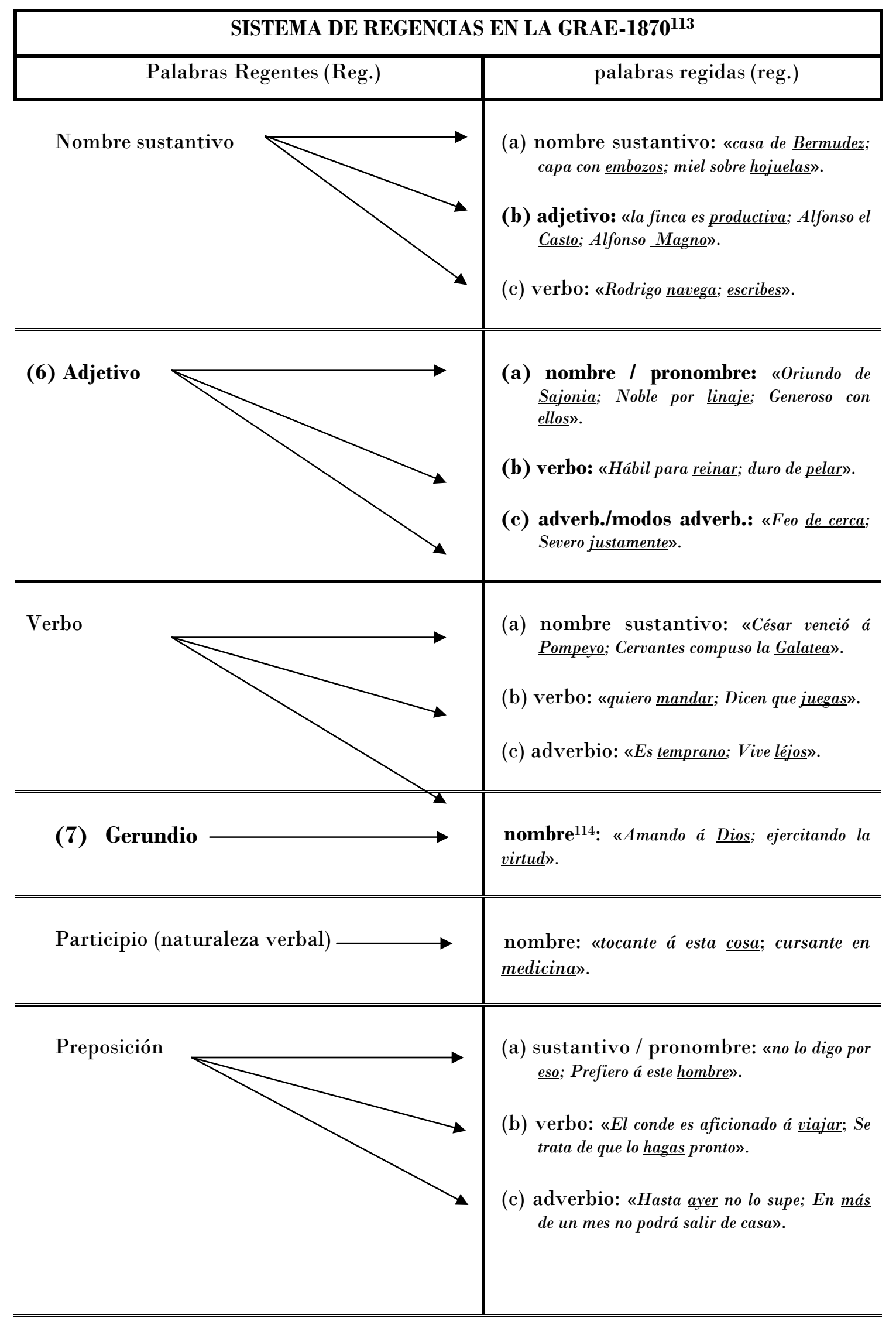

113 Ídem GRAE de 1874: 204-223 y 1878: 204-223. 


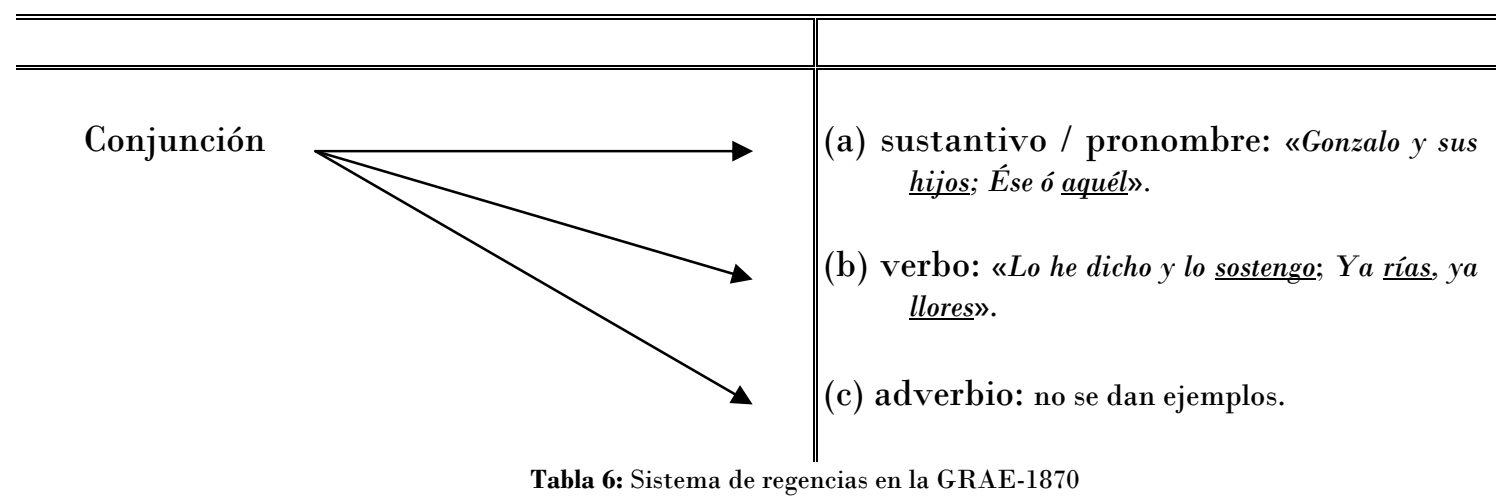

Tal como queda reflejado en las dos tablas, la Real Academia entiende, en todas sus Gramáticas publicadas entre 1854 y 1916, que nombre, verbo, participio, preposición y conjunción son categorías que pueden ocupar el primer lugar en una relación de dependencia, esto es, son palabras Reg.

La GRAE-1870 introduce la novedad de considerar también como categorías susceptibles de ser primer elemento de rección al adjetivo y al gerundio. Además de esto, hace una pequeña concesión (también novedosa en las ediciones del corpus) al adverbio, ya que, aunque en general -según se afirma- ninguna palabra tiene inmediata dependencia de él dentro de la oración, existen excepciones a esta regla: ciertos adverbios, ya directamente ya mediante una preposición, rigen a otras palabras. Hablo de "pequeña concesión" porque no es más que una observación en los párrafos introductorios del capítulo del Régimen, en los que se expone qué categorías funcionan como palabras Reg. y cuáles solo como palabras reg.:

Las partes de la oracion que rigen á otras son el nombre, ó un pronombre que le represente, el adjetivo, el verbo, el participio, la preposicion y la conjuncion.

114 En la GRAE-1880: 222-235, se añaden dos regímenes al gerundio: el verbo (por ejemplo: queriendo SALTAR la zanja -pág. 228-) y otro gerundio (estando COMIENDO -pág. 228-). En este añadido consiste la única diferencia con respecto a lo establecido en 1870. Idéntica exposición tendremos en las GRAE de 1883: 222-235, 1885: 224-237, 1888:222-235, 1890: 222-235, 1895: 222235, 1900: 222-235, 1901: 222-235, 1904: 216-229, 1906: 216-229, 1908: 216-229, 1909: 216-229, 1911: 220-234, 1913: 220-234 y 1916: 220-234. 
Exclúyense de tener régimen el artículo, el pronombre cuando no representa al nombre, y el participio cuando hace oficio de adjetivo115, porque todos están necesariamente subordinados al nombre; $\underline{\text { el }}$ $\underline{\text { adverbio en general, }}$ porque ninguna de las partes de la oracion tiene de él inmediata dependencia; la interjeccion, porque más bien es una exclamacion aislada que parte esencial de la oracion.

$\underline{\text { Son excepciones de esta regla los adverbios ántes, cerca, }}$ despues, dentro, fuera, léjos, y otros que, por medio de la preposicion de, tienen régimen algunas veces; v.gr. ántes de tiempo, cerca de Granada, despues de misa, etc.; y asimismo las interjecciones ah y ay, cuando decimos: ¡Ah de casa! jAy de mí!

(GRAE-1870: 176. El subrayado y la negrita son míos) $)^{116}$

No obstante este reconocimiento, no encontramos un apartado dedicado a la regencia del adverbio, como sí se dedica a los regímenes del adjetivo y del gerundio (vid. supra. De ellos trataremos en las páginas que siguen). Por los ejemplos dados en todas las GRAE desde 1870 (antes de tiempo; cerca de Granada; después de misa), debemos entender que el adverbio sólo puede tener como régimen un nombre, porque no se dice que la palabra reg. sea la preposición, sino que esta es una especie de puente o instrumento de enlace en la relación de dependencia entre el adverbio y la palabra por él regida.

Conviene advertir que la concesión (aunque limitada) de la categoría de palabra Reg. al adverbio es una novedad que introduce el texto de 1870 con respecto a los libros que le preceden desde la GRAE-1796, pero cuenta con antecedentes en la propia tradición institucional. En la cuarta edición de la

115 A partir de la GRAE-1874, el participio se considera palabra Reg. sin ningún tipo de excepción.

116 La misma cita, suprimiendo la exclusión del participio como palabra Reg. cuando hace las veces de adjetivo, en GRAE-1874: 204, 1878: 204, 1880: 222, 1883: 222, 1885: 224, 1888: 222, 1890: 222, 1895: 222, 1900: 222, 1901: 222, 1904: 216, 1906: 216, 1908: 216, 1909: 216, 1911: 220, 1913: 220, 1916: 220. 
Gramática, los académicos suprimieron unos párrafos de 1771 muy interesantes, por cuanto suponían la misma defensa que encontramos, en los textos del corpus, a partir de 1870117. Tampoco en la GRAE-1771, como es de esperar, se va a dedicar un apartado a la regencia del adverbio. De hecho, la aceptación de que puede ser palabra Regente la encontramos no en la parte dedicada a la Sintaxis, sino en el estudio analógico de las categorías verbales $^{118}$.

Pese a la brevedad y a lo incidental de la afirmación en el libro de 1870, este reconocimiento (recuperado) de la capacidad rectora de algunos adverbios, junto con la inclusión del adjetivo y el gerundio en la nómina de palabras Reg., supone un paso adelante en el tratamiento de las relaciones sintagmáticas intraoracionales (y, en consecuencia, en el de las relaciones de dependencia oracional) llevado a cabo por la Academia en la $12^{\mathrm{a}}$ edición de la Gramática. El hecho de que, desde la GRAE-1870, se admita, por ejemplo, que el adjetivo puede regir al verbo, podría entenderse como un tímido amago de reconocimiento de casos de dependencia oracional (de subordinación) con

117 En el mismo año en que se publicó la cuarta edición de la GRAE, Ballot reconoce al adverbio como palabra Regente y dedica un apartado, dentro del capítulo del Régimen, a los regímenes del adverbio. En este apartado, admite que solo ciertos adverbios tienen capacidad de regencia, «los más de ellos no llevan régimen alguno» (Ballot, 1842 [1796]: 196).

118 Después de la clasificación del adverbio y antes de comentar de forma individual las propiedades significativas y combinatorias de algunos adverbios concretos, encontramos dos párrafos que interesa reproducir:

El adverbio puede estar en la oracion sin régimen, esto es, sin otra palabra despues de sí, y en esto se diferencia de la preposicion, que requiere despues de sí algun nombre, pronombre, ó verbo que perfeccione el sentido: v.g. quando decimos: el caballo corre bien: el adverbio bien no pide despues de sí otra palabra para formar sentido cabal; pero si en lugar del adverbio se usa una preposicion diciendo: el caballo corre por, queda imperfecto el sentido, y es necesario que la preposicion por tenga su régimen, esto es, otra palabra que denote el parage por donde corre, como: corre por el prado, por el campo.

No por esto se debe entender que los adverbios no puedan tener algunas veces su régimen mediante preposicion, porque se dice: Fulano habló ántes de tiempo: se sentó despues de su compañero; pero debe entenderse, que el régimen no es forzoso como en las preposiciones, pues se dice: Fulano habló ántes: su compañero habló despues.

(GRAE-1771: 191-192. El subrayado es mío) 
respecto a un núcleo no verbal (en este caso concreto, adjetival), algo que, hasta la fecha, no se había hecho -al menos, en el capítulo del Régimen-, ya que, al hablar de la relación /Sust. $\rightarrow$ vb./, no se registran, en ninguna GRAE, casos de dependencia oracional del tipo $N \hookleftarrow /$ (Suj.) + Pred./ (lo que hoy se conoce comúnmente como subordinación adjetiva) ${ }^{119}$. Incluso entre 1870 y 1916, los únicos casos que se recogen de verbo dependiente de (= regido por) un núcleo adjetival se limitan a ejemplos con infinitivo, en los que el infinitivo está muy cerca de ser un sustantivo.

No obstante la última observación apuntada, también en este apartado comprobamos que la GRAE-1870 supone un avance en la exhaustividad descriptiva de los planteamientos académicos: reconocer al adjetivo $y$, excepcionalmente, al adverbio capacidad rectora implica que las relaciones de dependencia o régimen empiezan a desprenderse del marcado logicismo que presidía este capítulo en las ediciones anteriores, en las cuales se descartaba toda posibilidad de que un término que denotara accidente, circunstancia, etc. (caso del adjetivo y el adverbio) pudiera gobernar sobre otro concepto.

El paso adelante del que hablo no está libre, sin embargo, de contradicciones y limitaciones descriptivas: no deja de sorprender que, en las primeras líneas del Régimen (vid. supra última cita reproducida de la GRAE1870), se niegue capacidad rectora al participio «cuando hace oficio de adjetivo», pues, en este año, tanto el participio como el adjetivo se consideran palabras Reg. Todo hace sospechar que debemos de estar ante un descuido de redacción. Hasta la GRAE-1867 leemos las mismas palabras que hemos reproducido de la GRAE-1870, lo cual conduce a pensar que la Comisión encargada de elaborar el texto de la 12. edición copió (con desacierto) las

\footnotetext{
119 Veremos que, en el apartado de Construcción, sí se reconocen, desde la primera GRAE que nos ocupa (1854), casos de $\mathrm{N} \hookleftarrow$ / (Suj.) + Pred./ (dependencia oracional con respecto a un núcleo no verbal -concretamente, nominal-: oraciones de relativo).
} 
palabras de la versión anterior. No es el único caso en el que se percibe una cierta inercia por parte de los académicos a la hora de redactar el cuerpo de la Gramática, pero, en esta ocasión, el descuido se convierte en una importante incoherencia de doctrina. En las ediciones que preceden a este jalón, se justificaba (por coherencia doctrinal) la exclusión del participio como palabra Regente cuando funciona como adjetivo, pues a la categoría adjetivo no se le reconocía todavía capacidad rectora. Compárese la siguiente cita con la última reproducida de la GRAE-1870:

Las partes de la oracion que rigen á otras son: el nombre sustantivo, ó el pronombre personal en representacion suya; el verbo, el participio, la preposicion y la conjuncion.

Exclúyense de tener régimen el artículo, el nombre adjetivo, el pronombre cuando no es personal, y el participio cuando hace oficios de $\underline{\text { adjetivo, }}$ porque todos ellos están necesariamente subordinados al nombre sustantivo; el adverbio porque ninguna parte de la oracion tiene de él inmediata dependencia; la interjeccion, porque más bien es una exclamacion aislada, que parte esencial de la oracion (1).

(1) Solo tienen régimen algunas veces las interjecciones ay y ah por medio de la preposicion de, como cuando decimos ay DE mí! Ah DE casa!

(GRAE-1854: 143. El subrayado es mío) ${ }^{120}$

La incoherencia de 1870 se corrige (como queda indicado en las notas 115 y 116 -vid. supra-) en la edición que le sigue de forma inmediata, la GRAE1874. En el texto enmendado ya se lee:

120 Ídem GRAE-1858: 155, 1862: 159, 1864: 159, 1865: 159, 1866: 159. Y con variantes de redacción en 1867: 158-159. 
Las partes de la oracion que rigen á otras, son el nombre (ó un pronombre que le represente), el adjetivo, el verbo, el participio, la preposicion y la conjuncion.

Exclúyense de tener régimen el artículo, el pronombre, cuando no representa al nombre; el adverbio, porque ninguna de las partes de la oracion tiene de él inmdiata dependencia; y la interjeccion, porque más bien es una exclamacion aislada que parte esencial de la oracion.

(GRAE-1874: 204. El subrayado es mío)

Las consideraciones hechas permiten destacar, de momento, la GRAE1870 como jalón que marca el punto de inflexión, dentro de la gramaticografía académica, en lo relativo al concepto y al tratamiento de las relaciones de rección. Teniendo en cuenta estas consideraciones, paso a comentar detenidamente cada uno de los casos de Régimen atendidos por la Institución. 


\section{CASO (1) DE RÉGIMEN: palabra Reg. = Nombre Sustantivo}

Sistemáticamente, las GRAE consideran palabras regidas por el nombre sustantivo tanto al nombre sustantivo (casos de adyacencia nominal) como al verbo (relación predicativa que fundamenta toda oración). Solo a partir de la edición de 1870, como queda indicado en los esquemas de arriba, se incluye al adjetivo entre las palabras regidas por el sustantivo.

\section{(a) Palabra reg. = nombre sustantivo}

$$
\text { Relaciones /Sust. } \rightarrow \text { sust./ }
$$

En todas las ediciones comprendidas entre 1854 y 1916, este primer caso de régimen tiene como característica sine qua non la mediación de una preposición entre Sustantivo Regente y sustantivo regido: «este régimen se verifica con el auxilio de una preposicion», se dice en la GRAE-1854 (pág. 144)121; y, en el jalón de 1870, leemos: «la relacion directa entre dos substantivos se expresa siempre con el auxilio de una preposicion» (pág. 177) 122 y 123 .

Todos los ejemplos dados responden, efectivamente, a estructuras del tipo /Sust./ + /prep. + Sust./:

121 Ídem GRAE-1858: 155, 1862: 159, 1864: 159, 1865: 159, 1866: 159, 1867: 159.

122 Ídem GRAE-1874: 204, 1878: 204, 1880: 223, 1883: 223, 1885: 225, 1888: 223, 1890: 223, 1895: 223, 1900: 223, 1901: 223, 1904: 216, 1906: 216, 1908: 216, 1909: 216, 1911: 220, 1913:220 y 1916: 220.

123 Defensa similar encontramos en otros autores decimonónicos: Mariano de Rementería (1843: 140-141), Gómez de Salazar (1869: 124 y 1874: 146) o Ruiz Morote (1880: 56-57) pueden valernos como muestra. 
Casa DE Pedro [Bermudez]; Luis CONTRA Juan; callejon SIN salida; uvas EN cierne; contienda ENTRE muchos; capa CON embozos; miel SOBRE hojuelas.

(GRAE-1854: 144 y 1858: 155-156)124

De modo que la Institución no agota todas las posibilidades descriptivas de este tipo de dependencia desde el punto de vista teórico. La relación de regencia de un sustantivo sobre otro debe suponer casos de adyacencia nominal (esto es, de SN dependiente de un núcleo sustantivo); en el texto de la GRAE, sin embargo, solo se registran casos de Complementos del Nombre desempeñados por un SP: ni se dan ejemplos de Sintagmas Nominales en construcción apositiva, ni se contemplan estos casos desde el punto de vista teórico (puesto que se afirma explícitamente que la presencia de preposición es requisito indispensable para que un sustantivo rija a otro -y, por extensión, para que el segundo de los sustantivos modifique al primero-).

También hay que decir que, hasta la GRAE-1867 (incluida), se ignoran igualmente los casos de adyacencia adjetival (de S. Adj. complementando a un núcleo sustantivo) ${ }^{125}$. Parece normal que, a partir de la GRAE-1870, este tipo

124 Ídem GRAE-1862: 159-160, 1864: 159-160, 1865: 159-160, 1866: 159-160, 1867: 159. En la GRAE-1870: 177, se cambian los ejemplos con las preposiciones en y entre:

uvas en cierne > Sol en Aries; contienda entre muchos > Sierpe entre flores

Ídem GRAE-1874: 204-205, 1878: 204-205, 1880: 223, 1883: 223, 1885: 225, 1888: 223, 1890: 223, 1895: 223, 1900: 223, 1901: 223, 1904: 216-217, 1906: 216-217, 1908: 216-217, 1909: 216-217, 1911: 220-221, 1913: 220-221 у 1916: 220-221.

125 Se ignoran en la parte de Sintaxis y desde el punto de vista de la descripción de relaciones sintácticas de dependencia; obviamente, sí se hace mención explícita a la facultad calificadora del adjetivo sobre el sustantivo. Es en la Analogía donde se da noticia de las características significativas (calificadoras y explicativas) y colocacionales (de inseparabilidad del sustantivo) de esta categoría:

Nombre sustantivo es el que expresa los objetos de un modo absoluto, prescindiendo de sus calidades, como Felipe, piedra, provincia, ciencia, virtud. Nombre adjeivo es el que se junta al sustantivo para calificarle, explicando alguno de sus accidentes y propiedades, como cuarto, dura, lejana, útil, laudable, que aplicados á los sustantivos anteriores, dan razon de alguna de sus circunstancias.

De esto se infiere naturalmente que, no pudiendo haber circunstancias ó propiedades sin sujeto al cual se atribuyan, el nombre sustantivo puede subsistir por $\underline{\text { sí solo en la oracion; pero no el adjetivo, á no emplearse en el género neutro, como se }}$ 
de relación no sea tratada en este primer caso de régimen, pues al considerar el adjetivo como categoría independiente, se dedicará un apartado a la regencia /Sust. $\rightarrow$ adj./ (vid. infra apartado $b$ ). Pero hasta la 12. ${ }^{a}$ edición, la categoría nombre engloba a sustantivo y adjetivo, y se rechaza (por omisión) que este segundo pueda depender del primero (y modificarlo). El adjetivo, en definitiva, no recibe el rango ni de palabra Reg. ni de palabra reg. en los libros publicados entre 1854 y 1867126.

verá más adelante. Cuando decimos: Salgo de CASA; Voy á la IGLESIA, estos nombres tienen una significacion clara y completa; no así grande, magnífico, sin sustantivos que requieran las calificaciones de grandeza y magnificencia.

(GRAE-1854: 10. El subrayado es mío)

Cf. GRAE-1858: 10-11, 1862: 14-15 1864: 14-15, 1865: 14-15, 1866: 14-15 у 1867: 14-15.

126 En autores coetáneos que siguen los preceptos académicos, sin embargo, sí encontramos reconocida la relación /Sust. $\longrightarrow$ adj./. Por ejemplo, Gómez de Salazar apunta el adjetivo como primer régimen que puede tener el nombre (sustantivo), tanto cuando funciona como Adyacente como cuando es el Atributo de una oración copulativa:

¿Cuál es el régimen del nombre?

El nombre rige á su calificacion (cuando la lleva), v. gr., papel blanco; el callar con oportunidad es provechoso. En este segundo ejemplo, callar con oportunidad hace veces de nombre y rige á la calificacion provechoso.

(Gómez de Salazar, 1869: 124. El subrayado es mío)

Otros autores decimonónicos anteriores a las fechas de nuestro corpus reconocen al adjetivo como palabra Regente. En Ballot (1842 [1796]), que mantiene un doble concepto de régimen: como exigencia de caso por parte de una palabra y como dependencia entre palabras (concepción que recuerda la de la GRAE-1796), encontramos un apartado dedicado al Régimen del nombre adjetivo, en el que se dice:

No todo nombre adjetivo pide ó rige caso; pues hay muchos que se hallan privados de esta virtud ó potestad. Solo piden caso los que incluyen en sí alguna relacion por ejemplo, los adjetivos de abundancia y carestía, de alabanza y vituperio que admiten genitivo con de, como: lleno de riqueza: este niño será digno de la corona.

[...]

El comparativo no tiene régimen particular, y solo admite el nombre que le sigue en el mismo caso en que él se encuentra, como: el padre es mayor que el hijo [...] no hay mejor cirujano, que el bien acuchillado [...]

[Los nombres adjetivos superlativos] Algunos rigen genitivo con de, como: el mácsimo de los doctores: el mínimo de los hermanos; otros no hacen mas que espresar la calidad en grado superior, como cuando decimos: el maestro es doctísimo [...]

(Ballot, 1842: 180-182. El subrayado es mío) 
En nuestra tradición gramatical, encontramos autores que equiparan la complementación que sobre un sustantivo ejerce la estructura / prep. + sustantivo/127 y la que lleva a cabo un adjetivo, aunque solo etiqueten como caso de regencia la incidencia del SP sobre el sustantivo. En la Gramática de Gómez Gayoso, leemos:

Junto con el nombre sustantivo se há de poner el Adjetivo, ó Adjetivos que se le juntaran; y el Genitivo que de él se rigiere. Después del verbo se há de poner Adverbio; la preposicion antes de su caso; y el Artículo antes de cualquier Nombre, con quien deba juntarse.

(Martínez Gómez Gayoso, 1769 [1743]: 273. El subrayado es mío)

La equivalencia funcional que Gómez Gayoso establece entre adjetivo (S. Adj.) y genitivo (SP - con de-) coincide con la identidad significativa que reconoce entre estas categorías. Referido a un sustantivo:

Possesivo es el que significa possesion, y vale tanto como el Genitivo del Nombre principal de donde viene; v. g. Casa Real, Casa del Rey Español, de España [...]

(Martínez Gómez Gayoso, 1769 [1743]: 65)

La consideración de Sintagmas Adjetivales y Sintagmas Preposicionales con de como distintos tipos de complementación del nombre sustantivo ya es costumbre, como ha indicado Martí Sánchez (1988: 387), entre nuestros gramáticos del Siglo de Oro ${ }^{128}$.

${ }^{127}$ La modificación que el SP ejerce sobre el sustantivo es tratada por la práctica totalidad de los autores desde Nebrija.

${ }^{128}$ Más información, en Martí Sánchez (1988: 192-374). 
La falta de atención a la incidencia de un adjetivo sobre un sustantivo la hereda la GRAE decimonónica del texto de 1796. En la primera edición de la Gramática, sí se reconocían estos casos de adyacencia adjetival en el capítulo dedicado al régimen (que -recuerdo- equivalía a construcción), aunque no se detuviera en el análisis de la misma, como tampoco lo hacía en casi ningún fenómeno sintáctico ${ }^{129}$. En el trasvase de contenidos que se lleva a cabo en la GRAE-1796 para configurar el nuevo apartado dedicado a la construcción, casos del tipo hombre bueno serán sacados del capítulo del régimen para ser tratados no como fenómenos de rección (/Sust. $\rightarrow$ adj./), sino como fenómenos de construcción (/Sust. + Adj./). Hemos visto que la concepción marcadamente formal-casual que se tiene del régimen en esta edición explica que se destierre de este capítulo la relación entre sustantivo y adjetivo. En las

${ }^{129}$ Interesa comparar las siguientes citas extraídas de los dos textos del XVIII que nos están sirviendo de constante punto de referencia:

[...] Aunque los nombres que se ponen, como queda dicho para representar persona ó cosa, como principio ó móvil de alguna accion ó significacion, piden verbo, no es preciso que este siga inmediatamente al nombre, pues sin faltar al órden natural pueden interponerse otras palabras en esta forma.

$\underline{\text { Todos los nombres comunes admiten ántes del verbo otros nombres regidos }}$ de la preposicion de para expresar la relacion que tiene una cosa con otra, como: el hijo de Pedro viene: el dueño de la casa entra [...] virtud $[\ldots]$

Tambien admiten adjetivos ántes del verbo, como: el hombre bueno ama la

(GRAE-1771: 237-238. El subrayado es mío)

Como se ve, en la primera edición, la preposición no es solo elemento auxiliar de enlace entre palabra Reg. y palabra reg., sino que actúa como palabra que rige al segundo sustantivo.

En la GRAE-1796, en la parte dedicada a los regímenes del nombre sustantivo, ya leemos unas palabras que anticipan claramente la doctrina decimonónica:

El nombre sustantivo en qualquier caso que se le considere, ó quiera ponerse en la oracion, puede regir á otro nombre sustantivo en genitivo, v. g. la casa de Pedro. Este nombre Pedro está en genitivo del singular regido del nombre sustantivo casa, con la nota del genitivo, que es la preposicion de [...] De esta regla resulta que todo genitivo está regido en la oracion de la preposicion de, como nota del genitivo, y de un nombre sustantivo anterior expreso ó suplido. Y si este no está expreso, ni puede suplirse, ó el sentido de la oracion no le necesita, aunque se halle un caso con la preposicion de, no será genitivo, sino ablativo, como se dirá en su lugar.

(GRAE-1796: 288-289)

Ninguna mención, como vemos, al adjetivo regido por un sustantivo. 
ediciones decimonónicas de los años cincuenta y sesenta, la combinación /sustantivo + adjetivo/ seguirá siendo tratada en el capítulo dedicado a la construcción (vid. infra 6.2.2.).

A propósito de este primer caso de regencia /Sust. $\rightarrow$ sust./, hay que hacer una última observación: en todas las ediciones que preceden a la de 1870, se dice que estas construcciones /Sust./ + /prep. + Sust./ son elípticas. Así:

Casa de Pedro = casa que es de Pedro

Callejón sin salida = callejón que está sin salida

Miel sobre hojuelas $=$ [miel que está sobre hojuelas $]$

Capa con embozos $=[$ capa que es con $/$ tiene embozos $]$

En virtud de la elipsis se omiten, en este tipo de estructuras, un pronombre relativo y el verbo ser / estar. El recurso a la elipsis es una deuda evidente con el logicismo, que, a partir de la GRAE-1870, empieza a perder fuerza en el texto académico. 
(b) Palabra reg. $=$ adjetivo

$$
\text { Relaciones /Sust. } \rightarrow \text { adj./ }
$$

Este otro caso de Adyacente del Nombre (desempeñado ahora por un Sintagma Adjetival) constituye, como se viene diciendo, uno de los añadidos de la 12. ${ }^{a}$ edición de la Gramática (1870), que se mantendrá hasta la GRAE-1916 dentro de los regímenes del nombre. Interesa recordar, igualmente, que es en la GRAE-1870 donde por primera vez aparecen deslindadas las categorías sustantivo y adjetivo, recogidas hasta la fecha -como se ha indicado arribabajo la etiqueta conjunta nombre ${ }^{130}$.

Cuatro estructuras pueden responder a este caso concreto de Régimen ${ }^{131}$ :

- $\quad$ /SN + Vb. Cop. + S. Adj./: se trata de casos de Predicado Nominal (Atributos): La finca es productiva.

- /SN + Vb. Pred. + S. Adj./: casos de Predicado Verbal con Complemento Predicativo (C. Pvo.): El hombre nace desnudo.

130 A partir de la GRAE-1870, al adjetivo se le dedica un capítulo independiente dentro de la Analogía. La "nueva" categoría es definida como «aquella parte de la oracion que se junta á los sutantivos para calificarlos ó para determinarlos». (GRAE-1870: 33).

La separación sustantivo / adjetivo ya había sido defendida desde el siglo XVIII y principios del XIX por autores españoles influidos por la gramática francesa. Es el caso, entre otros, de Jovellanos, Lacueva, Calleja y Mata. Más información, en Gómez Asencio (1981: 141153).

131 Literalmente, en el texto de la Gramática se dice que «de tres maneras se verifica este régimen». Las dos primeras estructuras que indico se recogen bajo un mismo caso: «la intervención del verbo ser o de uno intransitivo» (entre la GRAE-1874 y la GRAE-1883, leemos solo "con la intervención de un verbo intransitivo", pero en todas las ediciones se da como primer ejemplo La finca es productiva).

Cf. GRAE-1870: 177, 1874: 205, 1878: 205, 1880: 223, 1883: 223, 1885: 225, 1888: 223, 1890: 223, 1895: 223, 1900: 223, 1901: 223, 1904: 217, 1906: 217, 1908: 217, 1909: 217, 1911: 221, 1913: 221, 1916: 221. 
- /Sust. + art. + Adj./: responde a casos de Aposición especificativa del tipo Isabel la Católica (no se tiene en cuenta la metábasis).

- /Sust. + Adj./: caso típico de Adyacente o Complemento del Nombre, como, por ejemplo, Felipe Quinto, Alejandro Magno.

Vemos que, bajo la regencia /Sust. $\rightarrow$ adj/, se aúnan las funciones (hoy bien delimitadas) de Complemento del Nombre (desempeñado tanto por Sintagma Adjetival -determinador o caracterizador- como por Sintagma Nominal -adjetivos sustantivados- en construcción apositiva), Atributo y Complemento Predicativo. Pero, entre 1870 y 1916, los ejemplos más habituales de adyacencia desempeñada por un Sintagma Adjetival (del tipo hombre bueno; niños mimados) siguen siendo tratados en el capítulo de la construcción (cf. 6.2.2.) $)^{132}$.

La explicación que se da de las dos últimas estructuras (Isabel la Católica; Alejandro Magno) hoy no nos satisface, pues la Institución vuelve a recurrir a la

132 En los tratados de autores contemporáneos a los textos de nuestro corpus encontramos recogido este tipo de relaciones en el llamado Régimen. Reyna (1914) es uno de esos gramáticos:

El nombre y el pronombre que hace sus veces son regentes:

1. ${ }^{\circ}$ De otro nombre ó pronombre, por simple unión ó por medio de una preposición tácita ó expresa. Ej.: El monte Ararat, Teatro de San Fernando, Bola de nieve, Rosa sin espinas, Miel sobre hojuelas, Tú conmigo.

2. ${ }^{\circ}$ Del adjetivo, por yuxtaposición por medio del artículo ó de un verbo. Ej. Amor filial. El niño es dócil. Capítulo tercero. Vive apresurado. Pipino el Breve. Estoy acatarrado.

Cuando el adjetivo está substantivado, puede ser regido también por medio de preposición. Ej.: conocedor de lo bueno; vengador de los oprimidos.

(Reyna, 1914: 185-186. El subrayado es mío)

Comprobamos que Reyna recoge todas los posibles casos de la relación de regencia del sustantivo sobre el adjetivo: Adyacente (amor filial), Atributo (el niño es dócil; estoy acatarrado), C. Pvo. (vivo apresurado) y adjetivo sustantivado en construcción apositiva (Pipinio el Breve). También recoge, como vemos, dentro de los regímenes del sustantivo, sustantivos en construcción apositiva (monte Ararat), estructura que no se recoge en los textos institucionales en los regímenes del nombre. 
elipsis, esta vez en todas las ediciones publicadas hasta 1916 y de una forma muy poco precisa:

[...] pero es de advertir que en las dos últimas formas hay elipsis, esto es, se sobrentienden otras palabras.

(GRAE-1916: 221) 133

En la relación /Sust. $\rightarrow$ adj/, Vázquez Rozas (1990: 430) ha visto una prueba de la confluencia que en las Gramáticas académicas se da entre dos sentidos de régimen:

1) Régimen = determinación de la expresión de un elemento (el regido) por otro elemento (el Regente).

Vendría a coincidir, en esencia, con lo que estamos llamando régimen formal (que impone, por parte de la palabra Regente, una determinación casual, temporal o modal en la palabra regida) ${ }^{134}$,

133 Para las ediciones anteriores a 1916 publicadas desde 1870, las páginas son las indicadas en la nota 131.

${ }^{134}$ Este concepto, habitual -como se sabe- en una tradición deudora de la gramática latina, es mantenido por autores decimonónicos (en la nota 105 hemos mencionado a algunos de ellos también a autores de principios del $\mathrm{XX}-$ ) que, aun reconociendo que en español no existen casos al modo del latín y defendiendo, además, que las relaciones de régimen son relaciones de subordinación y/o de complementación significativa, siguen explicando el llamado régimen como imposición de un caso por parte de la palabra Reg. sobre la palabra reg. En los tratados dirigidos a las escuelas y estruturados en forma de $\mathrm{P} / \mathrm{R}$ es especialmente habitual este planteamiento. Así sucede en los textos de Herranz y Quirós (1834) y Ballot (1842). Del último es el siguiente fragmento:

P. Los nombres de la lengua castellana tienen casos?

R. No tienen propios y verdaderos casos // como los nombres latinos, sino equivalentes y solo distinguidos por la variedad de preposiciones antepuestas, como á, de, para \&c. (pags. 47-48. El subrayado es mío)

P. Qué entiende Vmd. por régimen?

R. Entiendo la propiedad que tienen las palabras ó partes de la oración de regir casos; ó bien la relacion ó dependencia de unas palabras con otras, como amo la

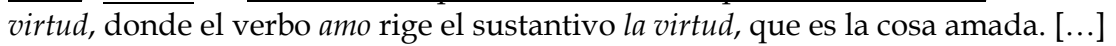


pero incluyendo -según esta autora- en los condicionamientos de expresión las marcas flexivas de género y número.

2) Régimen = dependencia semántica de un elemento (el regido) con respecto a otro elemento (el Regente).

Esta dependencia se establece de modo que el regido solo tiene razón de ser referido al Regente, pero, a su vez, el Regente necesita del regido para completar su significación. Sería este una suerte de régimen semántico-lógico ${ }^{135}$.

Siempre y cuando una palabra por sí misma no cierra el sentido de una oracion, nos vemos entónces obligados á poner la palabra determinante ó esencial para tener todo el sentido entero y perfecto [...]

P. Qué caso puede regir el nombre sustantivo? [...]

P. Qué caso rigen los nombres adjetivos? [...]

P. Qué caso rige el pronombre? [...]

(Ballot, 1842: 178-183. El subrayado es mío)

En Salvá encontramos la mejor fórmula de definición de un concepto formal del régimen adaptado a la realidad lingüística del español:

Régimen es la dependencia que una parte de la oración tiene de otra: llámase ésta la que rige y aquélla la regida. Regir es, según esto, pedir la diccion principal que se halle en tal modo o en tal tiempo la que de ella pende, o bien reclamar tal adverbio, tal preposición o tal conjunción [...]

(Salvá, 1830: 297. El subrayado es mío)

${ }^{135}$ Es el concepto defendido por los herederos de la gramática filosófica. En nuestra tradición decimonónica, encontramos esta identificación régimen = complementación semántica en autores como Saqueniza (1832) o Noboa (1839), quienes desligan las relaciones de dependencia denominadas régimen de la concepción formal clásica. Al basar el régimen en la complementación significativa, recogen bajo las relaciones de regencia no solo casos de dependencia entre palabras, sino también entre oraciones, como harán años más tarde Martínez Sevilla, Giró o Herrainz (vid. supra).

Rejir una palabra á otra es necesitar de ella de un modo determinado para completar, ampliar, modificar, \&c. su sentido. La palabra que necesita de otra se llama rejente ó principal; la que completa el sentido de la frase se llama rejida.

Segun esto, el réjimen gramatical será, respecto de la palabra rejente, la necesidad que tiene una palabra de otra para completar ó esplicar mas el sentido de una frase; respecto de la palabra rejida, será a dependencia que esta tiene de la rejente, v. g. perdonar á su enemigo: en este ejemplo la palabra rejente será perdonar, i la rejida á su enemigo.

El réjimen no solo puede ser de una palabra á otra, como en el ejemplo propuesto, sino tambien de una oracion con otra, como en este: creo que tú tienes razon, en el cual la oracion tú tienes razon está rejida del verbo creo por medio de la conjuncion que; pues si solo se le añadiese una palabra diciendo creo que tú, i aun 
En efecto, la necesidad semántica de que un adjetivo vaya referido (directa o indirectamente) a un sustantivo (expreso u omitido) explica que sea siempre el adjetivo la palabra regida de un sustantivo Regente (es el adjetivo el que «se junta» al sustantivo y no puede aparecer solo en la oración). Y esa "inferioridad" semántico-sintáctica obliga al adjetivo a «tener los mismos accidentes gramaticales que el sustantivo (número y género)» (GRAE-1870: $33)^{136}$.

La concepción que mantiene la Academia en el siglo XIX y principios del XX sobre las relaciones entre Sustantivo y adjetivo (sobre todo, desde que empieza a tratarlas también en el capítulo del Régimen) podemos verla hoy como el eco en el tiempo de lo que, en opinión de Gómez Asencio (1981), fue el estatus primitivo de la Sintaxis en la tradición gramatical de Occidente, en el que concordancia (= coincidencia de accidentes -entre palabras que siguen un orden concreto-) y régimen (= dependencia entre palabras sujeta a un orden fijo) son manifestaciones distintas de un mismo hecho lógico subyacente ${ }^{137}$. Y es que desde que Prisciano establece que el objetivo de la Sintaxis es la consecución de la oración perfecta (el discurso ordenado, congruo -en el plano

cuando se le añadiesen dos, v. g. que tú tienes, no quedaria completo el sentido hasta añadir toda la oracion, según está en el citado ejemplo: creo que tú tienes razon.

(Noboa, 1839: 213. El subrayado es mío)

136 Vid. infra 6.2.3.

137 A saber:

[...] el orden lógico o natural impone que la segunda palabra dependa de la primera: la dependencia lógica de las ideas impone una dependencia sintáctica de las palabras, dependencia que se manifiesta formalmente de dos maneras, como concordancia (la ordenación que ha de ser equus albus, porque la primera idea es más importante que // la segunda y le impone ciertas condiciones formales), $\underline{\text { o }}$ como régimen (la ordenación ha de ser (ille) amat Deum, también porque la primera palabra es más importante $y$, en consecuencia, impone otras condiciones formales a la segunda).

(Gómez Asencio, 1981: 57-58)

Para llegar a esta conclusión, Gómez Asencio se vale de información obtenida de Chevalier (1968: 28-42). 
formal- y de sentido completo -en el plano semántico-), la lógica se hizo inseparable del estudio sintáctico ${ }^{138}$.

Siendo viable la observación de Vázquez Rozas, considero, sin embargo, que el hecho de que sea a partir de 1870 cuando el texto de la GRAE atiende a la relación entre Sustantivo y adjetivo dentro del Régimen (cuando desde siempre la ha tratado en la Concordancia y la Construcción -y lo seguirá haciendo-) puede ser indicativo de una evolución paulatina del concepto de régimen, en virtud de la cual se va entendiendo cada vez más como subordinación / complementación semántico-sintáctica y menos como imposición de formas (casuales-modales-temporales). Recordemos (vid. supra página 419) que, en 1771 (cuando la idea de regencia no se asociaba a formas), se reconocían estas relaciones Sustantivo-adjetivo en el capítulo dedicado al Régimen, aunque no se destinara un apartado a las relaciones /Sust. $\rightarrow$ adj/ (lo cual se justifica, entre otras razones, por no ser reconocido aún el adjetivo como categoría independiente). Recordemos también que fue en la GRAE-1796 (en la que el régimen es entendido, fundamentalmente, como petición de casos) donde se decide que las relaciones entre un sustantivo y un adjetivo solo son materia del capítulo de la Concordancia y del recién estrenado capítulo de la Construcción. Teniendo en cuenta estos precedentes, no parece descaminado entender que la recuperación de las combinaciones / sustantivo-adjetivo/ para el capítulo del Régimen puede ser indicio de que el régimen empieza a ser concebido, ya de forma inequívoca, como relación de complementación semántico-sintáctica (que implicará, en ciertos casos, requisitos de tipo formal).

\footnotetext{
138 Para más información sobre los principios de ordinatio (orden), congruitas (gramaticalidad) y perfectio (perfección, sentido completo) como principios que fundamentan la sintaxis desde la Antigüedad hasta el Renacimiento, es de especial utilidad el estudio de Lozano Guillén (1992).
} 


\section{(c) Palabra reg. = verbo}

\section{Relaciones /Sust. $\rightarrow$ vb./}

Decir que el verbo está regido por el nombre que es «principio ó movil de alguna accion, pasion, accidente, etc.» (GRAE-1854: 144)139 conlleva, en la doctrina académica, la defensa del sustantivo sujeto como miembro indispensable para hablar de oración, o lo que es lo mismo, la concepción de que la unidad oración responde siempre a una estructura bimembre /Sust. + $\mathrm{Vb}$./ donde el sustantivo es el elemento primordial, pues «no puede haber oracion ni sentido alguno donde falte verbo regido de un nombre sustantivo, expreso ó suplido» (GRAE-1854: 144)140 y 141.

Esta idea aparece en todos los libros de Gramática publicados por la Institución desde 1771. De la primera edición es la siguiente cita, que permite comprobar que los planteamientos académicos no han cambiado -en la concepción de la estructura oracional (bimembre)- en más de ochenta años.

139 Cf. GRAE-1858: 156, 1862: 160, 1864: 160, 1865: 160, 1866: 160, GRAE-1867: 159 y 1870: 179. 140 No son pocos los gramáticos del XIX que afirman la regencia del sustantivo sujeto (o pronombre) sobre el verbo de la oración, entre otros: Salvá (1830: 297), Herranz y Quirós (1834: 112-114), Rementería (1843: 141), Antequera (1848: col. 1779), Gómez de Salazar (1869: 124-125 y 1874: 146-147). Y, ya entrados en el siglo XX, Dublé (1911: 148), Cortejón (1911: 192) o Reyna (1914: 186). De los autores mencionados, Salvá es el único que no desarrolla un capítulo sobre el régimen; se limita a definir el concepto (vid. supra nota 134), indicar las categorías Regentes y poner algunos ejemplos:

En la sentencia La mano del criador sacó a los hombres de la nada, decimos que la mano rige a la preposicion de y por su medio al sustantivo Criador, no menos que al pretérito absoluto de indicativo sacó, el cual rige por su parte a la preposicion a y con ella al caso objetivo los hombres, al mismo tiempo que a la preposición de y al nombre la nada para complemento de la idea que nos habíamos propuesto enunciar.

Las palabras que pueden regir a otras son el nombre, el verbo, las preposiciones y las conjunciones; pero ninguna rigen los adverbios ni las interjecciones, salvo la ay en ciertos casos.

(Salvá, 1830: 297-298. El subrayado es mío)

${ }^{141}$ La concepción platónica según la cual es ineludible la presencia de nombre y verbo para que la oración esté completa la encontramos desde Prisciano. Vid. Baratin (1989) y Lozano Guillén (1992). 
Tampoco la forma de expresar tal concepción ha experimentado modificaciones:

Todo nombre sustantivo ó pronombre que se pone para representar persona ó cosa, como principio ó móvil de alguna accion ó significacion, pide despues de sí un verbo que exprese esta accion ó significacion; y así no puede haber proposicion ni sentido alguno donde falte verbo precedido de nombre sustantivo ó pronombre expreso ó suplido. Si decimos solamente Antonio, no hacemos mas que pronunciar este nombre; pero si añadimos el verbo escribe, denotamos con él la accion de Antonio. El pronombre yo tampoco hace sentido por sí solo; pero junto con el verbo amo, manifiesta que yo tengo amor. Algunas veces se pone el verbo solo y hace sentido, pero es porque se suple algun sustantivo ó pronombre. En estas proposiciones: nacemos, morimos, se suple: los hombres, ó nosotros.

(GRAE-1771: 236-237. El subrayado es mío).

No obstante, la primera edición de la GRAE destaca, de entre todas las partes de la oración, al verbo como palabra por excelencia. En la Part. I. Cap. VI. Art. I., leemos a propósito de la definición de esta categoría:

El verbo es una parte tan principal de la oracion, que sin él no se puede formar sentido, ni expresar concepto alguno. Así lo manifiesta su mismo nombre verbo, que quiere decir palabra; pues aunque las demas partes de la oracion se llaman palabras, esta lo es por excelencia. Sobre su definicion hay una variedad casi infinita de opiniones, dimanadas acaso de que unos han querido ceñirla á la exîstencia, otros á la accion, y pasion, otros á la afirmacion. Una definicion mas extensa podria ser mas exâcta, y de menos inconvenientes: tal es la que aquí se propone. El verbo es una parte principal de la oracion que sirve para significar la esencia, la exîstencia, la 
accion, pasion, y afirmacion de todas las cosas animadas, é inanimadas, y el exercicio de qualquiera facultad que tienen estas cosas, ó se les atribuye.

(GRAE-1771: 56-57. El subrayado es mío)

Martí Sánchez (1988: 437) ha observado que, pese a esta posición privilegiada del verbo dentro de las categorías verbales, no podemos decir que se le considere elemento nuclear de la oración frente al nombre. En efecto, en la misma cita traída a colación, en la propuesta explícita de definición se dice del verbo que es «una parte principal de la oración» (se ha subrayado en el fragmento de arriba), no "la parte principal". Pasado el tiempo, en las ediciones comprendidas entre 1854 y 1916, ni siquiera se define como categoría de rango mayor dentro de la estructura oracional: es, simplemente y por definición, una parte más de la oración, como se la definía ya en la GRAE$1796^{142}$, si bien es cierto que es la categoría a la que se le dedica cuantitativamente más atención.

La defensa de la estructura oracional bimembre (haya o no sujeto expreso) -que en nuestra tradición ya defendió de manera explícita Correas $^{143}$ - parece estar en consonancia con la interpretación que el texto de la

142 Cf. GRAE-1796: 87, 1854: 45, 1858: 44, 1862: 48, 1864: 48, 1865: 48, 1866: 48, 1867: 49, 1870: 50 (en esta edición se incluyen, por primera vez, los accidentes de tiempo y persona en la definición de la categoría verbo), 1874: 72, 1878: 72, 1880: 61, 1883: 61, 1885: 61, 1888: 61, 1890: 61, 1895: 61, 1900: 61, 1901: 61, 1904: 61, 1906: 61, 1908: 61, 1909: 61, 1911: 59, 1913: 59 y 1916: 59 .

143 El nonbre está en la orazion para mover, i acompañar al verbo, i hazer anbos la orazion, porque sin el uno, ó el otro, no se puede hazer sentenzia, ni dezir nada.

(Correas, 1625: 366 y 1627: 195)

También en Benito de San Pedro (1769) encontraremos la idea de que el nominativo sujeto es elemento imprescindible de la oración. Esta defensa la lleva al extremo de negar de forma explícita la existencia de verbos impersonales (si por tales se entienden verbos sin sujeto lógico):

[...] el nominativo acompaña fiempre en la oracion un verbo que fe refiere a él. I por la mifma razon todo verbo fe rige de algun nominativo expreffo u oculto.

(San Pedro, 1769: III: 117)

Verbo imperfonal no ai en propiedad, porque no puede aver afirmacion fin fugeto o nominativo de ella. 
Gramática da a los verbos unipersonales en la parte de Analogía144: que sea Dios, el cielo o la nube los que amanecen, anochecen o llueven resulta hoy una interpretación inviable, por su marcado poso logicista, pero es la que ofrece el texto de la GRAE desde la primera edición hasta la última que estamos considerando en este apartado 145 y 146.

Sin embargo, no podemos olvidar que el recurso a un sustantivo elíptico no es sistemático: la Institución reconoce como verbos impersonales

Pero aquellos en que no fe expreffa el nominativo $u$ el fugeto fe llaman imperfonales, como: Llueve, nieva, truena, importa, conviene, parece, fucede, ai. I folo fe llaman tales cuando fe ufan en la tercera perfona del fingular del prefente. I a efta imitacion fe llaman (aunque no con verdad) imperfonales todos los verbos precedidos del nombre general fe, como: fe dice, Je cree, fe ama, fe lee, fe oye, \&c. [...]

(San Pedro, 1769: III, 114-115)

En el siglo XIX, Andrés Bello se suma a la corriente de autores que conciben la unidad oracional articulada en Sujeto y Predicado. Frente a San Pedro, Bello no niega la realidad lingüística y acepta que existen casos en los que la oración carece de sujeto «no sólo porque no lo lleva expreso, sino, porque según el uso de la lengua, o no puede tenerlo o regularmente no lo tiene» (pág. 482). Como bien ha apuntado Martí Sánchez (1988: 541), Bello hizo una interesante reflexión sobre los miembros constituyentes de la proposición, y sorprende que estas observaciones no lo llevaran a replantear su teoría de la no existencia de oración sin sujeto. La reflexión a la que me refiero es la que sigue:

la proposicion puede carecer de sujeto; de atributo nunca; si no lo tiene expreso, hay siempre alguno que puede fácilmente suplirse.

(Bello, 1847: 483)

Pero, al igual que hicieron (y que harán) otros gramáticos que defienden la estructura bimembre de la oración, encuentra sujetos lógicos a los verbos atmosféricos, a los que ya aplica la etiqueta de "unipersonales" (que considera más apropiada que la de "impersonales"). Vid Bello (1847: 499).

${ }^{144}$ Cf. Martí Sánchez (1988: 435-436).

145 Cf. GRAE-1771: 165-167, 1796: 199-201, 1854: 97, 1858: 99, 1862: 103, 1864: 103, 1865: 103, 1866: 103, 1867: 102, 1870: 117, 1874: 142, 1878: 142, 1880: 151, 1883: 151, 1885: 151, 1888: 149, 1890:149, 1895: 149, 1900: 149, 1901: 149, 1904: 145, 1906: 145, 1908: 145, 1911: 146, 1913: 145-146 y 1916: 145-146.

146 En otros autores coetáneos encontramos la misma explicación para los verbos unipersonales, explicación que argumentan, en el capítulo dedicado al Régimen, como prueba de la relación /Sust. $\longrightarrow$ vb./. Así, en la Gramática de la lengua castellana de Gómez de Salazar, leemos:

Este régimen [el del nombre sustantivo sobre el verbo] es forzoso, porque no puede haber nominativo sin verbo, ni éste puede existir sin aquel, pues un nombre para ser nominativo requiere indispensablemente un verbo; y cuando decimos, por ejemplo, amanece, se suple el nominativo Dios ó el día.

(Gómez de Salazar, 1869: 124-125 y 1874: 146-147) 
(lo que supone aceptar tácitamente la existencia de oraciones unimembres): ser $\mathrm{y}$ hacer en expresiones temporales (es tarde; hace mal tiempo), y una serie de verbos que hoy no interpretamos como impersonales, pues son verbos que cumplen sin problema alguno el criterio de la concordancia, tales como parecer (en Parece que llueve), importar (en Importa trabajar), o convenir (en Conviene leer $)^{147}$. Es el concepto semántico-nocional lo que lleva a la afirmación de que, en estos casos, «no se descubre sujeto á quien se puedan referir las terceras personas de los verbos» (GRAE-1854: 98). Que los criterios formalesfuncionales no son los tenidos en cuenta por la RAE a la hora de determinar el sujeto de la oración se comprueba también en la interpretación dada a oraciones del tipo:

ASEGURAN que será buena la cosecha

\section{Allí RIÑEN}

¿Qué DIRÁN?148

Los verbos de estas oraciones son vistos como impersonales al no contar con «sujeto preciso que los ponga en accion» ${ }^{149}$. A la luz de estas interpretaciones, resulta evidente que los académicos consideran casos de impersonalidad los que, en rigor, son casos de indeterminación semántica. De hecho, en los verbos atmosféricos o unipersonales, el argumento único que daban para justificar la etiqueta de "impersonales" era el de que «el agente no se determina y la imaginación tiene que suplir alguno» ${ }^{150}$.

\footnotetext{
147 Hemos visto (vid. supra nota 143) que San Pedro, pese a negar la impersonalidad propiamente dicha, reconoce lo que podríamos llamar "usos impersonales" de algunos verbos $\mathrm{y}$, en esta concesión, considera de la misma forma verbos como parecer, etc. y verbos que hoy se interpretan como impersonales o unipersonales (haber y los verbos atmosféricos). ${ }_{148}$ Cf. GRAE-1854: 98, 1858: 100, 1862: 104, 1864: 104, 1865: 104, 1866: 104, 1867: 103, 1870: 118, 1874: 143, 1878: 143, 1880: 151, 1883: 151, 1885: 151, 1888: 149-150, 1890: 149-150, 1895: 149-150, 1900: 149-150, 1901: 149-150, 1904: 145, 1906: 145, 1908: 145, 1909: 145.

${ }^{149}$ La cita se encuentra en las páginas indicadas en la nota 148.

${ }^{150} \mathrm{La}$ cita se encuentra en las páginas indicadas en la nota 145.
} 
No obstante, en esta confusión entre impersonalidad sintáctica e indeterminación semántica, encontramos una edición anterior a la reforma de 1917 que incorpora una importante observación por parte de los miembros de la Comisión de Gramática. En la GRAE-1911, entre los verbos impersonales y los defectivos, se habla, como en los libros anteriores, de los casos que hemos destacado arriba (Aseguran que será buena la cosecha; Allí riñen); pero, en esta ocasión, la información se presenta en apartado independiente, bajo el rótulo «VERBOS CON SUJETO INDETERMINADO Y TÁCITO», y modificada de forma sutil pero sustancial: si hasta la fecha se había defendido que «los verbos, en su mayor parte, se pueden usar como impersonales, valiéndose para ello de la tercera persona del plural, también sin sujeto preciso que los ponga en accion», ahora leemos:

Los verbos, en su mayor parte, se pueden usar sin referirse a un sujeto determinado, pero sin que por esto sean impersonales; y para ello se ponen en la tercera persona del plural; por ejemplo: ASEGURAN que será buena la cosecha; CUENTAN de un sabio...

(GRAE-1911: 146. El subrayado es mío) ${ }^{151}$

Eso sí, la negación de que estas oraciones sean impersonales vuelve a basarse en criterios semántico-nocionales, no en el criterio formal de la concordancia: el que habla -dicen los académicos- supone evidentemente que todas estas acciones proceden de un sujeto personal.

Con independencia del grado de aceptación que hoy le demos a los criterios tenidos en cuenta por la Academia a la hora de determinar los casos de impersonalidad, el reconocimiento de este tipo de estructuras entra en conflicto con la defensa de que no hay verbo sin Sustantivo Regente. Bien es cierto que la afirmación de que todo verbo va necesariamente precedido (=

151 Ídem GRAE-1913: 146 y GRAE-1916: 143. 
regido) por un sustantivo, ya se encuentre éste expreso u omitido, se pierde, en este apartado concreto, en la 6. ${ }^{a}$ edición de la GRAE (1858) y no volvemos a encontrarla en el capítulo del Régimen (vid. infra. 6.2.3.). Se sigue defendiendo, no obstante, que, siempre que una oración se articula en /Sust. + Vb./, el sustantivo es "más importante" que el verbo (el sustantivo es la palabra Reg. y el verbo, la reg.). La siguiente cita está sacada de la GRAE-1854 (puede comprobarse su similitud con la primera de las reproducidas en la página 428, de 1771); en ella, aparece entre corchetes y sombreada la parte que se suprime en la edición de 1858:

Todo nombre sustantivo, ya represente persona ó cosa, como principio ó móvil de alguna accion, pasion, accidente, \&c., rige á un verbo que exprese esto mismo; [y así no puede haber oracion ni sentido alguno donde falte verbo regido de un nombre sustantivo, expreso ó suplido]. Si decimos solamente Antonio, no hacemos más que pronunciar este nombre; pero añadiendo el verbo escribe, denotamos con él la accion de Antonio. En el ejemplo anterior está expreso el nombre; en estos: escribes, nacemos, están suplidos, tú en el primer caso, nosotros en el segundo, pues queda ya advertido que lo que se dice del nombre sustantivo se dice tambien del pronombre personal $[\ldots]$

(GRAE-1854: 144 y GRAE-1858: 156)152 y 153

152 Pese a la supresión de la parte sombreada entre corchetes, hasta la GRAE-1870 -inclusivese defiende en el capítulo II de la Sintaxis, el dedicado a la Concordancia, que

estas dos partes [nominativo y verbo] son tan precisas para formar la oracion, que ni puede haberla sin ellas, ni tampoco verbo sin nominativo, ó nominativo sin verbo, callados ó expresos. No se exceptúan de esta regla ni áun los verbos que hemos llamado impersonales, pues siempre se les suple un nominativo.

Con estas palabras, la RAE se inserta en una línea de tradición que, desde Nebrija, cimienta todo el estudio de la oración en los dos pilares conocidos: sustantivo y verbo.

Cf. GRAE-1854: 140, 1858: 150 (cambia ligeramente la redacción), 1862: 154, 1864: 154, 1865: 154, 1866: 154, 1867: 153 y 1870: 171-172. (El subrayado es mío).

153 Declaraciones muy semejantes a la que encontramos ya en la GRAE-1858 (con la supresión hecha) ofrecen otros autores de la época. Las siguientes palabras, extraídas de las conferencias 
La idea de que el sustantivo es el que rige al verbo (y no a la inversa) es, según Vázquez Rozas (1990: 430), otra consecuencia de confundir los dos sentidos de rección arriba indicados (vid. supra. Relaciones /Sust. $\rightarrow$ adj./): la rección de expresión (de carácter formal) y la rección semántica. En efecto, el hecho de que sea el verbo el que tiene que concertar con el sustantivo en número y persona (según se afirma en el texto de la GRAE) no conduce necesariamente a una relación de rección del tipo /Sust. $\rightarrow$ vb./. Esta sería la interpretación resultante de un concepto estrictamente formal del régimen (no ceñido exclusivamente, como quedó indicado arriba, a determinación casual, modal o temporal), en virtud del cual, estas relaciones de dependencia se traducen en rasgos formales impuestos por la palabra Reg. sobre la palabra reg. Entendiendo, sin embargo, el régimen como dependencia sintácticosemántica, es claramente el sustantivo el que necesita del verbo para poder significar en la oración, para tener "razón de ser" (no se trata de que el verbo "complete" su significado. Recordemos que la propia Institución defiende, en todas las ediciones que nos ocupan, que Antonio por sí solo no es más que un nombre que poca información transmite; sin embargo, si le añadimos un verbo podemos denotar una acción realizada por Antonio). Por tanto, la

gramaticales de Mariano de Rementería, prueban que este autor sigue muy de cerca (en fondo y forma) la doctrina de la Gramática institucional:

\footnotetext{
El nombre sustantivo ó pronombre, que es móvil de alguna accion, rige á un verbo que esprese dicha accion.

El hombre discurre; el sustantivo hombre nada puede espresar por sí mismo, sino [sic] se une con el verbo discurrir, al cual rige: porque el pensamiento no puede anunciarse sin el verbo [...]
}

(Rementería, 1843: 141)

Aunque anteriores en feha a la GRAE-1858, las Conferencias coinciden más en la forma con esta edición que con las dieciochescas (que le debieron servir de fuente a su autor) por no hacer mención explícita a que no puede existir oración sin verbo regido de sustantivo (expreso o suplido). 
relación de regencia, desde la perspectiva de dependencia semánticosintáctica, debería invertirse y representarse: / sust. $\longleftarrow$ Vb./.

En este apartado dedicado a la regencia del tipo /Sust. $\rightarrow$ vb./, la primera edición del XIX (GRAE-1854) presenta un añadido importante, con respecto a la Gramática inmediatamente anterior (GRAE-1796), en lo tocante a las relaciones de dependencia oracional. Ahora se reconoce que el elemento Reg. no necesariamente tiene que responder a la categoría de nombre, pues

[...] lo que se dice del nombre sustantivo se dice también del pronombre personal, que siempre se pone en su lugar, y de otras palabras y áun cláusulas enteras que hacen también oficios de nominativo.

(GRAE-1854: 144. El subrayado es mío) ${ }^{154}$.

Este reconocimiento supone aceptar estructuras del tipo /[Sust. + Vb.] $\rightarrow$ vb./ (Hoy /[(Suj.) + Pred.] $\Longrightarrow$ Vb./ -Hjelmslev (1976)-. Nuestras subordinadas sustantivas en función de sujeto), pero no se da ningún ejemplo, y resulta sorprendente que esta afirmación se vuelva a reducir desde la GRAE1870, en la que solo se habla de la equivalencia sintáctica del nombre y el pronombre, sin hacer mención alguna a la posibilidad de que una oración / cláusula haga las veces de sustantivo:

Todo nombre, ya represente persona ó cosa, como principio ó móvil de alguna accion, designio, accidente, etc., rige á un verbo que exprese esto mismo. Si decimos solamente Rodrigo, no hacemos más

154 También en GRAE-1858: 156, 1862: 160, 1864: 160, 1865: 160, 1866: 160 y GRAE-1867: 159 (en esta última GRAE, se utiliza el término oración en lugar del de cláusula). 
que pronunciar este nombre; pero añadiendo el verbo navega, denotamos una accion de Rodrigo. Por lo mismo, la palabra regente es aquí Rodrigo y la regida navega, concertando ambas en el número gramatical, única concordancia que admiten entre sí nombre y verbo. En este ejemplo está expreso el nombre; en los que siguen, escribes, nacemos, están suplidos tú en el primer caso, y nosotros en el segundo, pues queda ya advertido que lo que se dice del nombre, se dice $\underline{\text { tambien del pronombre que se pone ó se supone en su lugar. }}$

(GRAE-1870: 179. El subrayado es mío) ${ }^{155}$

155 Cf. GRAE de 1870: 179, 1874: 207, 1878: 207, 1880: 224 (edición a partir de la cual se suprime la observación que hasta la fecha encabeza este apartado del Régimen: «Todo nombre, ya represente persona ó cosa, como principio ó móvil de alguna accion, designio, accidente, etc., rige á un verbo que exprese esto mismo»), 1883: 224, 1885: 226, 1888: 224, 1890:224, 1895: 224, 1900, 224, 1901: 224, 1904: 218, 1906: 218, 1908: 218, 1909: 218, 1911: 222-223, 1913: 222-223 y 1916: 222-223. 


\section{CASO (2) DE REGIMEN: palabra Reg. = Verbo}

Este segundo tipo de regencia también es constante en todas las Gramáticas publicadas entre 1854 y 1916.

\section{(a) Palabra reg. = nombre}

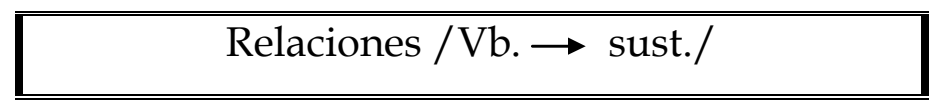

Según la Academia, sólo tienen régimen, en sentido estricto ${ }^{156}$, aquellos verbos "cuya accion pasa a otra persona o cosa", es decir, los verbos activos o transitivos, que son "los únicos que pueden volverse por pasiva"157 y 158. En este sentido, sólo lo que hoy etiquetamos CD se podría interpretar como caso de nombre regido por un Verbo. Son ejemplos del tipo:

\footnotetext{
156 Es lo que llaman régimen obligado (GRAE-1854) o régimen directo (desde la GRAE-1870). 157 Cf. GRAE-1854: 144-46, 1858: 156-157, 1862: 160-161, 1864: 160-161, 1865: 160-161, 1866: $160-$ 161, 1867: 159-161, 1870: 179-181 (en esta edición, pese a la supresión que hemos señalado -desde 1858- a propósito de la relación /Sust. $\rightarrow$ vb./ -vid. supra página 433-, leemos, al comienzo del apartado dedicado a la relación / Vb. $\rightarrow$ sust./, que «necesariamente todo verbo ha de ser regido de un nombre cuando no lo es de otro verbo». Esta afirmación añadida se mantiene hasta la GRAE-1916), 1874: 207-209, 1878: 207-209, 1880: 225-226, 1883: 225-226, 1885: 227-228, 1888: 225-226, 1890: 225-226, 1895: 225-226, 1900: 225-226, 1901: 225-226, 1904: 219-220, 1906: 219-220, 1908: 219-220, 1909: 219-220, 1911: 223-224, 1913: 223-224, 1916: 223-224. 158 La Academia sigue considerando la conversión a pasiva como prueba inequívoca de régimen obligado (entendiendo como tal nuestro $\mathrm{CD}$ ). Bello, sin embargo, ya había advertido sobre que la prueba de la pasiva no era infalible para determinar la transitividad de un verbo, puesto que ciertos verbos que rigen acusativo no admiten construcción pasiva y, a la inversa, verbos que habitualmente no responden a estructuras transitivas sí permiten la transformación a pasiva. Cierto es que el ejemplo dado por Bello para probar la inviabilidad de inversión a pasiva (El avestruz no puede volar) no es ejemplo afortunado, pues se trata de una perífrasis modal /poder + infinitivo/, no de una estructura transitiva. (Cf. Bello, 1860 [1847]: 484).
} 
Amo a mi padre (con mediación de una preposición por referirse el término a una persona).

Busco criado (con posibilidad de suprimir la preposición por no ser criado nombre propio. Vs. ${ }^{\star}$ Desconozco Mariano $\left.{ }^{159}\right)$.

Aborrezco el vicio (sin preposición por referirse el término a 'cosa'160).

En las ediciones de los años cincuenta y sesenta, los académicos se refieren a este régimen de los verbos transitivos como término de la acción. A partir de la GRAE-1870, se utilizará la etiqueta complemento/complemento directo.

No obstante, la Institución aprovecha este apartado dedicado a la regencia / Vb. $\rightarrow$ sust./ para exponer dos concepciones sobre el Régimen del verbo, una restringida y otra de carácter más amplio. Según la primera, únicamente tienen régimen los verbos transitivos (el caso que se acaba de exponer en los párrafos de arriba); en un sentido lato, sin embargo, se puede decir que todos los verbos tienen régimen (no obligado) cuando se expresa alguna circunstancia que modifique su acción ${ }^{161}$. Según los ejemplos de este segundo tipo de regencia que ofrecen todas las ediciones de la GRAE hasta la

159 Cuando el nombre propio es de lugar y lleva incorporado el artículo sí puede omitirse la preposición: entre 1854 y 1867, se advierte que es indiferente decir dejo EL Ferrol o dejo AL Ferrol; a partir de la GRAE-1870, se aclara que puede y suele omitirse la preposición (dejo EL Ferrol); y en la edición de 1883, se da como regla que «si estos nombres de lugares van precedidos de artículo, se omite la preposición, diciendo, por ejemplo, dejo EL Ferrol; prefiero LA Coruña» (el subrayado es mío).

160 En todas las ediciones se reconoce que hay excepciones a esta regla: se comprueba en $\mathrm{el}$ nombre rige AL verbo o la noche sigue AL día. Estos ejemplos confirman que, a veces, los nombres de cosa que llevan artículo van precedidos de preposición.

${ }^{161}$ La doble consideración (amplia y restringida) también la encontramos (en términos distintos de los de la Academia) en actuales definiciones sobre el régimen. En el Diccionario de lingüística de Ramón Cerdá (1986, s.v. régimen), se dice de él que es

Relación de dependencia entre un complemento y un verbo, un caso o una preposición. Dícese más estrictamente cuando el complemento verbal es introducido por preposición, p. ej. "En cuanto le tiraron la cuerda, él tiró de ella". 
de 1880 (excluida ${ }^{162}$ ), pueden considerarse relaciones de régimen del verbo casos típicos de CC, ya sea desempeñado por un gerundio (caso que se podría considerar como dependencia oracional): Juan duerme roncando; por un SP: Pedro nació en un monte; o por un S. Adv.: Anoche heló terriblemente. Entre estos ejemplos de régimen no obligado (accesorio o indirecto, desde la GRAE-1870) no se incluye ninguno de CI (lo que la GRAE-1771 llamaba régimen accesorio): al igual que en 1796, estos casos serán tratados en el capítulo dedicado a la Construcción. Las afirmaciones que allí encontramos a propósito de oraciones del tipo El maestro da lección al discípulo muestran que los académicos mantienen viva e intacta (hasta la última edición de los años sesenta) la doctrina de 1796 sobre esta cuestión. Siguiendo los preceptos de finales del XVIII, se defiende:

- Que los verbos activos transitivos admiten después del término de la acción (esto es, después del régimen obligado -nuestro CD-), otro nombre de persona/cosa a la que se dirige la acción verbal (nuestro CI).

- Que esos otros nombres que se pueden añadir tras el término van regidos de la preposición a o para (no del verbo, por tanto).

- Que, además, existe la posibilidad de incrementar el número de sustantivos (siempre precedidos de preposición -no se especifica cuál-) que añadan circunstancias a la acción del verbo.

Previas estas consideraciones, se concluye que, en una oración como $E l$ Rey encarga la justicia á sus ministros, CON PARTICULAR CUIDADO, PARA BIEN DE LOS PUEBLOS

162 A partir de esta edición, el apartado dedicado a la regencia / Vb. $\rightarrow$ sust./ solo trata del régimen obligado (= complemento) que tienen los verbos transitivos $\mathrm{y}$, muy brevemente, de los verbos reflexivos o recíprocos, de los que hablaré más abajo. 
el régimen del verbo no pasa del acusativo justicia; las demas palabras van regidas de las preposiciones á los casos respectivos, conforme á su uso y significacion.

(GRAE-1854: 160. El subrayado es mío) ${ }^{163}$

En definitiva, los académicos del XIX -como sus predecesoresincurren en la contradicción de reconocer (en la teoría) que el verbo puede tener dos tipos de regímenes (directo e indirecto) y negar al mismo tiempo, de forma expresa y por partida doble, en la interpretación de ejemplos concretos, el segundo de ellos: se afirma que el verbo sólo rige al término y se atribuye la regencia de los demás sustantivos a la preposición que los introduce ${ }^{164}$.

163 Estas líneas cierran un párrafo en el que se recogen las ideas que hemos expuesto arriba. Interesa reproducirlo para poder compararlo con lo que diremos enseguida sobre los cambios producidos en la GRAE-1870:

Los verbos activos transitivos admiten despues del término de la accion otro nombre de la persona ó cosa á que se dirige lo que el verbo significa, v. gr.: El maestro da leccion AL DISCÍPULO; Remito esos libros PARA MI HERMANO. Discípulo y mi hermano están en dativo, regidos respectivamente de las preposiciones á y para. También se suelen seguir al término del verbo otros nombres con diversas preposiciones, que significan circunstancias ó modificaciones que puede recibir la accion, v. gr.: El Rey encarga la justicia á sus ministros, con particular cuidado, para bien de los pueblos. El régimen del verbo no pasa del acusativo justicia [...]

(GRAE-1854: 159-160. El subrayado es mío)

${ }^{164}$ En contra de esta idea de que la regencia del verbo se limita al acusativo inmediato se pronunció Herrainz. En su Gramática castellana teórico-práctica, en todas sus partes, escribe:

Algunos gramáticos establecen que el régimen verbal no pasa del primer complemento ó circunstancia, rigiéndose entre sí todos los demás; pero que esto no es así se comprende observando que el verbo marca la naturaleza de la partes [sic] de la oracion que le han de seguir, que estas se refieren a él y que en tal concepto admiten el cambio ordinal del sitio que en la frase ocupan. Unicamente en las oraciones de infinitivo el régimen del verbo determinante afecta solo á las partes con él relacionadas, quedando para el determinado las que le correspondan.

(Herrainz, 1869: 137)

Y en el Tratado de gramática razonada, con aplicación decidida y constante al estudio del idioma español, expone:

Contra lo que afirman varios gramáticos, la regencia del verbo atributivo no termina en su complemento inmediato; trasciende á lo que subsiga con el solo objeto de completar ó detallar la acepción verbal - En Compré un tiro de caballos á Roque para mi hijo, con mis ahorros, en la feria de Turégano; compré rige á todo aquello que responda 
En la GRAE-1870, sin embargo, se modifica el párrafo que hemos reproducido en la nota 163 . Frente a la defensa (dilatada en el tiempo) de que el verbo únicamente rige a su término, ahora la Institución se limita a apuntar que

Los verbos transitivos admiten, después del complemento directo de la accion, otro nombre de la persona ó cosa á que se dirige lo que el verbo significa; v. gr.: El vencido dio REHENES AL VENCEDOR; Remito esos libros PARA MI HERMANO165. Tambien se suelen seguir al complemento directo del verbo otros nombres con diversas preposiciones, que significan circunstancias ó modificaciones que pueden recibir la accion: Grecia aumenta su territorio CON LAS ISLAS JÓNICAS, CEDIDAS POR LA GRAN BRETAÑA.

(GRAE-1870: 199)

Por fin se han cambiado los manidos ejemplos de décadas atrás y, con ellos, la teoría (al menos en apariencia): puesto que en el capítulo del Régimen, en la relación / Vb. $\rightarrow$ sust./, se ha reconocido que todos los verbos pueden tener régimen indirecto «cuando se expresa alguna circunstancia que modifique su accion... por medio de gerundios, adverbios, modos adverbiales y nombres precedidos de cualquiera preposicion», y puesto que, además, se

á pregunta formulada con relacion á tal verbo ó á un tiro de caballos, á Roque, á mi hijo, á mis ahorros, á feria de Turégano, interponiéndose los conexivos correspondientes [...]

(Herrainz, 1885: 133)

La consideración de que el verbo tiene dos tipos básicos de régimen: uno directo y otro indirecto, la encontramos en otros gramáticos de la época, como Vicente García (1854: 68) y Fernández / Fernández Navamuel (1909: 101). En la primera mitad del XIX, Noboa (1839: 218-222) utilizaba ya el término complemento y consideraba que el verbo puede tener como régimen un objeto directo, un objeto indirecto o un complemento. A mediados de siglo, Giró (1857 y 1871) habla de complemento directo, complemento indirecto y complemento circunstancial, términos que -podemos imaginarlo- anticipan pero no coinciden plenamente con los actuales CD, CI y CC. Por los ejemplos dados, están más próximos a las etiquetas actuales los casos de complemento directo, complemento indirecto y complemento circunstancial marcados por Reyna (1914: 186-187).

165 La tipografía parece usada de forma arbitraria, o bien, si se tenía intención de distinguir el complemento directo del otro nombre de persona o cosa, ha habido descuido de imprenta. 
ha suprimido del capítulo de la Construcción aquella afirmación que invalidaba la posibilidad de que el verbo tenga más de un régimen, debemos entender que, en dio rehenes al vencedor, tenemos un caso de construcción integrada por dos regímenes distintos del mismo término Regente: / dio $\longrightarrow$ rehenes $/$ (régimen obligado o directo $=$ complemento directo) $\mathrm{y} /$ dio $\rightarrow$ al vencedor/ (régimen accesorio o indirecto). A la luz de los datos que se extraen de los textos, a partir de 1870, se amplían las posibilidades de regencia del verbo, que ya no se limitan al acusativo inmediato. La interpretación que Gómez Asencio (1981) daba para el régimen en la GRAE-1796, y que hemos aceptado para los regímenes del sustantivo en esa edición (vid. supra. 6.2.1.1.), la podemos hacer extensiva, a partir de la 12. ${ }^{a}$ edición de la Gramática, a los regímenes del verbo.

Si aceptamos, como propongo, que los académicos de 1870 amplían su visión del régimen del verbo, reconociendo más y más variados casos de complementaciones (en esencia, y sin que se utilicen exactamente estas etiquetas: directas, no directas y circuntanciales), no entenderemos como gratuito el párrafo añadido justo en esta edición de la GRAE:

Cuando semejante régimen accesorio es el único con que se expresa un concepto en que interviene verbo activo, éste pasa á la condicion de neutro; como en los ejemplos que siguen: Leer mucho; Comer con apetito; Romper en llanto; Atropellar por todo.

Pero indirecto se puede decir que todos los verbos le tienen $[\ldots]$

(GRAE-1870: 180. El subrayado es mío)

Aparte de lo interesante que es la nueva observación de que un verbo activo (transitivo) pueda tener usos como neutro (intransitivo), lo que coadyuva a la idea de que no todos los casos de complementación suponen el 
mismo grado de relación del término regido con el Regente (y esto no solo cuando hay más de un término regido, sino también en aquellos casos en que la regencia se ejerce sobre un único elemento: puede que se esté produciendo un vínculo "fuerte" -como lo sería en leer una novela (el ejemplo es mío)- o "débil" -en leer mucho-, de ahí que el complemento o régimen sea «accesorio»), este párrafo viene a confirmar el reconocimiento de que el verbo no solo rige al ya llamado complemento directo.

Si, desde el siglo XIX, el régimen es considerado por la Academia una dependencia semántico-sintáctica (esto es, el elemento regido depende del Regente para tener razon de ser y, al mismo tiempo, el Regente completa su significación con el regido -frente a la concepción formal imperante en la GRAE-1796-) y si se acepta que el término regido no tiene que estar pegado obligatoriamente al Regente sino solo detrás de él (como se defendía ya en la GRAE-1771 -vid. supra 6.2.1.1.-), la doctrina sintáctica adolece de contradicción y de inconsistencia en las ediciones en que solo se acepta la regencia del acusativo inmediato (aunque tímidamente apunten -para luego negarlo- que el verbo puede tener varios regímenes o puede regir de distintas formas). Precisamente, uno de los méritos del jalón de 1870 consiste en la mayor coherencia que imprime a esta parte de la Sintaxis.

Como hemos indicado en la nota 162, en la GRAE-1880 la doctrina académica vuelve a verse modificada en el apartado del capítulo del Régimen dedicado a la regencia del Verbo sobre el nombre. La modificación consiste en una reducción cuantitativa que -cabe imaginar- se traduce en un empobrecimiento de la teoría (o, al menos, en un paso atrás en el camino de la consolidación del cuerpo de doctrina). Al suprimir el párrafo que añadía la GRAE-1870 (reproducido en la última cita que hemos traído a colación) y al omitir toda referencia al régimen indirecto, este apartado se centra en la mención y explicación del régimen directo $(\approx$ complemento - con o sin 
preposición-) de los verbos transitivos. ¿Significa esta ausencia la negación de otro tipo de regencias del verbo? ¿Una vuelta, quizá, al planteamiento de que el régimen verbal no pasa del acusativo inmediato? En principio, es innegable el empobrecimiento teórico que conlleva el omitir, justo en el apartado dedicado a las relaciones / $\mathrm{Vb}$. $\rightarrow$ sust./, las distintas posibilidades de regencia contempladas en las ediciones de los años setenta. Sin embargo, el reconocimiento de que el verbo puede tener distintos tipos de regímenes o complementos no se ha perdido en texto de la Gramática; es en el apartado de la Construcción donde encontramos la huella de lo que fue un importante cambio en la GRAE-1870 (vid. supra penúltima cita reproducida de la GRAE1870). En la misma línea que en la 12. a edición, pero con palabras más precisas desde la GRAE-1874, los redactores del texto de 1880 dicen que

Los verbos transitivos admiten, despues del complemento directo de la accion, otro indirecto: el vencido dió rehenes AL VENCEDOR; remito esos libros PARA MI HERMANO. Tambien suelen seguir al complemento directo del verbo otros nombres con diversas preposiciones, que significan circunstancias ó modificaciones que puede recibir la accion: España aumentó su territorio CON UN NUEVO MUNDO, DESCUBIERTO POR COLÓN.

(GRAE-1880: 238-239. El subrayado es mío) ${ }^{166}$

166 En la edición de 1874, en la que se introduce la nueva redacción de este párrafo, encontramos una formulación incluso más detallada:

Los verbos transitivos admiten, despues del complemento directo de la accion, otro indirecto concerniente á la persona ó cosa á que se dirige lo que el verbo significa: el vencido dió rehenes AL VENCEDOR; remito esos libros PARA MI HERMANO [...]

(GRAE-1874: 227) 
El último punto referido a las relaciones /Vb. $\rightarrow$ sust./, sobre el que se pronuncian todas las ediciones de la Gramática previas a la reforma de 1917, tiene que ver con los verbos pronominales. Una vez más, la información dada (con la misma redacción, en este caso, en todos los libros) conduce al lector a la duda sobre la verdadera concepción de los académicos. Sobre las relaciones que contraen los pronombres con sus verbos cuando estos tienen calidad de pronominales («recíprocos» para la RAE; desde 1870, «reflexivos o recírocos»), hay unanimidad, en todas las declaraciones de la Corporación entre 1854 y 1916, en considerar que el pronombre es término de la acción del verbo. Así se afirma en este apartado del capítulo del Régimen y en el dedicado a la «construcción del verbo con las demás partes de la oración». Es en la Construcción donde, a partir de la GRAE-1870, se utiliza ya el término complemento directo aplicado a estos pronombres. Sin embargo, los verbos reflexivos solo pueden llamarse transitivos en cierto modo -advierte la docta Casa-, puesto que

como dicho pronombre se refiere al mismo sujeto ó nominativo de la oracion, esta circunstancia los constituye en la clase de neutros, impidiéndoles ser vueltos por pasiva; y así no podríamos decir: Madrid ES AUSENTADO por Francisco.

(GRAE-1854: 145-146) $)^{167}$

Lo coherente dentro de la doctrina institucional es, en efecto, considerar estos verbos como verbos neutros: no admiten la prueba de la pasiva (básica en la teoría académica -prueba refutable para nosotros-) y su acción no pasa de una persona o cosa a otra (el requisito impuesto por la Institución para que un verbo se entienda como activo o transitivo). El problema está en que los verbos neutros o intransitivos solo pueden tener régimen accesorio o indirecto, según

${ }^{167}$ En la GRAE-1870: 181, cambia la parte final del párrafo reproducido: por Francisco. 
declara la propia Academia; sin embargo, se afirma invariablemente que el pronombre de los verbos reflexivos es su término o complemento directo (su régimen obligado, por tanto). Quizá lo que los académicos están observando es la imposibilidad de funcionamiento del verbo sin el pronombre (*ausentar), pero las herramientas descriptivas disponibles no son las adecuadas.

La distinción, dentro de la relación / Vb. $\rightarrow$ sust./, de dos nociones de regencia (una amplia y otra restringida) procede de la tradición francesa y, entre nuestros gramáticos, la encontramos ya en Benito de San Pedro, para quien el régimen del verbo (siempre una categoría nominal) puede ser directo o indirecto ${ }^{168}$. Dos años después de la publicación del Arte del romance castellano, la RAE recogerá en la primera edición de su Gramática las dos mismas posibilidades de complementación del significado verbal, según hemos visto más arriba: mediante el régimen principal (pan en Doy pan a mis hijos) y el régimen accesorio (a mis hijos en la misma oración). Ya hemos comentado las dos interpretaciones que se dan para este tipo de estructuras en la GRAE-1771 y los problemas que plantea su convivencia en un mismo cuerpo de doctrina (por resultar irreconciliables y hacer confusa la exposición de la teoría del régimen). Igualmente, hemos destacado el mérito de la fe exprefla aquello, a que la accion del verbo hace relacion.

De dos modos fe puede concebir efta relacion entre el nombre i verbo, es a saber directa o indirectamente. Un verbo fe refiere o termina directamente a un nombre, cuando por èl le puede refponder a la pregunta a quièn o què cofa? V. gr. El hijo ama, a quièn? A fu Padre. Yo codnozco, què cofa? la verdad. Los verbos ama, i conozco fe refieren directamente a los nombres Padre, i verdad. Si no fe puede refponder a eftas preguntas fe terminarà entonces la accion indirectamente; v. gr. El mendigo carece de què cofa? de fuftento.

Según efto ai dos fuertes de regencia, efto es directa u abfoluta, e indirecta o $\underline{\text { relativa. }}$ La primera folo conviene al verbo activo; porque folo èl puede expreffar una accion, que fe termina a un obgeto diferente del fugeto o nominativo del verbo.

La regencia directa fe pone fiempre en Acufativo; la indirecta en Dativo, Ablativo i a veces Genitivo. De aquí nacen las reglas figuientes pertenecientes al regimen. [...]

(San Pedro, 1769: III, 107-108. El subrayado es mío) 
primera Gramática académica al apuntar (aunque sea de forma muy tímida) la idea de que existen distintos grados de complementación del verbo, o expresado en términos de la época, la idea de que no todas las palabras regidas tienen el mismo grado de vinculación con la palabra Regente. Esta idea, que se pierde en la última Gramática del XVIII, se recupera, dentro de los textos del corpus, en la GRAE-1870: es a partir de esta edición cuando se aceptan como régimen del verbo (sin incoherencias de doctrina, sin contraafirmaciones) complementos/regímenes que modifican la significación verbal expresando cualquier tipo de circunstancia (tiempo, modo, lugar...).

Las estructuras / Vb. + prep. + sust./ no solo se van a tratar en las páginas dedicadas a los regímenes del Verbo, sino que también encontraremos ejemplos que responden a este esquema en las relaciones /Prep. $\rightarrow$ sust./. Lo veremos a propósito del Caso (4) de Régimen. 
(b) Palabra reg. = verbo

Relaciones /Vb. $\rightarrow$ vb./

Bajo esta regencia $/ \mathrm{Vb} . \rightarrow$ vb./ se recogen casos de dependencia oracional169 (concretamente, ejemplos correspondientes al esquema / Vb. [(Suj.)+Pred.]/ -en terminología actual, subordinación sustantiva y subordinación adverbial-) y, junto a ellos, casos de perífrasis verbales, tanto aspectuales como modales. Valgan como muestra los siguientes ejemplos:

169 En nuestra tradición gramatical, Salvá (1830) y Saqueniza (1832) fueron abanderados en tratar de forma detenida sobre la oración compuesta: el primero lo hace al abordar las relaciones entre Verbo Determinante y verbo determinado; el segundo, en el capítulo del Régimen, al hablar de la regencia del verbo, y en el dedicado a las oraciones.

Saqueniza no contempla casos de oraciones subordinadas de infinitivo. Para él, el verbo solo rije al sustantivo (lo que, al hablar del concepto de régimen en Benito de San Pedro, hemos entendido como corolario del tradicional tratamiento casual del régimen -vid. supra 6.2.1.1.-, según ya observó Gómez Asencio, 1981: 60), y entre las palabras que pueden hacer las veces de sustantivo están los infinitivos, «que son verdaderos nombres de lo que cada verbo significa considerado en abstracto» (Saqueniza, 1832:. 86). Sí acepta las relaciones que nosotros hemos esquematizado / $\mathrm{Vb}$. $\rightarrow$ vb./ en caso de que el segundo verbo esté conjugado e introducido por la conjunción que: también pueden sustituir al sustantivo regido

\footnotetext{
Las oraciones que sirven de complemento á un verbo, y están enlazadas con él por medio del conjuntivo que, como quiero que vengas. Dijo que lo haría. Los verbos de estas oraciones se llaman determinados, y el que las rige determinante. En los ejemplos anteriores los verbos quiero, dijo, son determinantes; vengas, haria, son determinados.
}

(Saqueniza, 1832: 86)

Como sucede en la Gramática académica, es en la regencia del verbo donde encontramos el empleo del término "complemento". (Más información sobre este punto, en Martí Sánchez, 1988: 494-502). 


\section{i. Actuales casos de Complemento de Régimen o Suplemento cuyo término es una proposición de infinitivo.}

\begin{tabular}{|c|}
\hline Ejemplos \\
\hline \\
Pedro le enseña á bailar \\
García aprende á bailar \\
Aspiran á ascender \\
Vacilaba en resolver \\
\hline
\end{tabular}

Hasta 1867 -inclusive-, se dice únicamente que bailar, en casos como los dos primeros que tenemos, es «término» del primer verbo, «que rige al determinado con el auxilio de la preposición á»; a partir de 1870, se da ya la etiqueta de «complemento directo» también para estos casos de regencia ${ }^{170}$.

Con este último dato se confirma que el término complemento empieza a ser usado en la Gramática académica como equivalente de régimen, de una forma más o menos sistemática, a partir de 1870171, el auxilio de la preposición á, siendo Pedro el nominativo, y el acusativo una tercera persona representada por el pronobre $l e$.

(GRAE-1854: 146)

García aprende á bailar. Bailar es complemento directo, ó acusativo, del verbo aprende, que rige al otro con el auxilio de la preposición á, siendo García el sujeto ó nominativo.

(GRAE-1870: 181)

171 Ya en la edición de 1854 encontramos el término complemento (equivalente al concepto de régimen, tanto restringido como amplio), en el apartado dedicado a las oraciones, pero se trata de un uso prácticamente aislado:

La oracion primera de verbo recíproco se compone de nominativo, verbo, $y$ un complemento, que puede ser otro verbo, ó un nombre, regido por preposicion... o un simple adverbio.

(GRAE-1854: 165-166).

En 1870, por complemento se seguirá entendiendo régimen directo (= obligado) e indirecto (= facultativo). Remito a lo que se dirá más abajo en este mismo apartado. 
edición que, según estamos comprobando, incorpora notas diferenciales de interés con respecto a la edición que le precede de forma inmediata (GRAE-1867), en lo tocante a los hechos de dependencia intraoracional, tanto desde el punto de vista terminológico como descriptivo y explicativo ${ }^{172}$.

En la edición siguiente (GRAE-1874), este apartado del capítulo dedicado al régimen $/ \mathrm{Vb}$. $\rightarrow \mathrm{vb}$./se inicia diciendo que «el verbo rige á otro verbo, cuando éste es complemento ó régimen directo del primero» (GRAE-1874: 209). En este año, se da una nueva "regla", relativa a los complementos, que supone una distinción rigurosa entre los SP que pueden desempeñar tal función: dependiendo de qué preposición los introduzca, hablaremos de régimen directo del verbo que vaya delante (si la preposición es a) o de régimen indirecto (si es otra preposición cualquiera). Y, en consonancia con esto, la RAE suprimirá de este apartado de relaciones $/ \mathrm{Vb}$. $\rightarrow \mathrm{vb} . /$, desde 1874 , ejemplos del tipo Ingeniarse para vivir; vacilaban en resolver; obstinarse en trasnochar, que todavía encontramos en la GRAE-1870 etiquetados como casos de

\footnotetext{
172 Años antes, el término complemento ya estaba consolidado en nuestra tradición. Volvemos a poner como botón de muestra, dentro de las fechas de nuestro corpus, el caso de Giró (1857: 207-223), quien, en el apartado dedicado al régimen de los miembros (vs. régimen de las oraciones), analiza los casos de complemento directo, complemento indirecto y complemento circunstancial.

En gramáticos anteriores a nuestro corpus también encontramos el uso sistemático del término complemento. Son, en su mayoría, autores empapados de la tradición francesa (Beauzée), que ya en el siglo XVIII diferenciaba claramente el concepto de régimen y el de complemento (cf. Beauzée, 1767: 80-84). Diez años antes que Giró, Bello sustituía los antiguos casos latinos por la etiqueta complemento (no es raro leer en su Gramática alusiones al complemento acusativo, complemento dativo...) y presentaba una moderna teoría de la complementación, en la que distinguía terminológica y conceptualmente las funciones de modificador y complemento. Su teoría se sustentaba en criterios semánticos, funcionales y formales. Contaba Bello con el precedente de Saqueniza (1832), quien, para Gómez Asencio (1981), da el paso decisivo en una concepción semántico-sintáctica del régimen (como complementación), librando al concepto de ataduras formales. Saqueniza da el nombre complemento tanto a nuestro CD -también llamado por él objeto- como a nuestro CI -que etiqueta igualmente como término-; además, este autor parece aceptar que los incrementos del sustantivo y del adjetivo son otro tipo de complementos. (Más información, en Gómez Asencio, 1981: 61-62 y Martí Sánchez, 1988: 480-502).
} 
régimen o complemento directo (puesto que, en la edición de 1870, directo $=$ obligado, no tiene que ver todavía con el tipo de preposición).

¿Qué diferencia hay entre estas estructuras /Vb. + prep. + vb./ analizadas en la relación / Vb. $\rightarrow$ vb./ y estructuras similares que se consideran en los regímenes de la preposición? Dicho de otra forma: ¿cuándo una preposición que media entre dos verbos es entendida exclusivamente como enlace o índice de relación, y cuándo se considera palabra regida por el primer verbo y regente del 2. ${ }^{\circ}$ ? Contestaremos a esta pregunta al tratar del caso (4) de Régimen.

\section{ii. Actuales casos de proposiciones subordinadas sustantivas en función de CD.}

\begin{tabular}{|c|}
\hline Ejemplos \\
\hline \\
Quiero estudiar \\
Quiero mandar \\
Teme que le engañen \\
Pretendo que me premien \\
Recelo que caiga \\
\hline
\end{tabular}

En consonancia con lo dicho en el apartado anterior, en la GRAE1870 se introduce una nueva terminología para describir casos como los que se reflejan en los dos primeros ejemplos (/verbo conjugado + infinitivo en función de CD/). En las ediciones de los años cincuenta y sesenta, el infinitivo es el «término» del verbo conjugado y, en 1870, ya se le da la etiqueta de «complemento directo» ${ }^{173}$. nominativo yo del verbo determinante.

(GRAE-1854: 146)

Quiero mandar. Mandar es complemento directo del verbo quiero, y su significacion se refiere al agente yo (que se suple) del verbo regente.

(GRAE-1870: 181) 
Por lo que respecta a los otros ejemplos (/verbo conjugado + que + verbo conjugado/), por su equivalencia con las estructuras con infinitivo expuestas arriba, se consideran también casos de «régimen directo». Nuevamente, la GRAE-1870 supone un punto de inflexión o de cambio en este asunto concreto: desde ahora se remite al capítulo de las oraciones para dar cuenta detallada de las reglas que determinan si el verbo reg. o determinado debe aparecer en indicativo o subjuntivo . A pesar de ello, se sigue advirtiendo, en estas mismas páginas dedicadas a los casos de régimen /Vb. $\rightarrow \mathrm{vb} . /$, que

cuando el agente expreso ó suplido del primer verbo es otra persona ó cosa que el sujeto del segundo... no pide ya el régimen de infinitivo, sino el de indicativo ó subjuntivo, por medio de una conjuncion, y principalmente de la copulativa que.

(GRAE-1870: 183) ${ }^{174}$

En la GRAE-1911, encontramos el segundo cambio en la redacción de este párrafo del apartado dedicado a las relaciones /Vb. $\rightarrow$ vb./. Esta vez no se trata solo de ligeros retoques de redacción; también aparecen añadidos: se reconoce que existen excepciones a la tendencia general de

174 Esta misma advertencia la encontramos en las ediciones siguientes con un cambio de redacción:

Regla general, que fija cuándo un verbo de los que pueden ser determinantes ha de regir al determinado en infinitivo, es que el agente sea uno mismo para los dos. Así se dice, quiero DORMIR, deseaste APRENDER, sin que en estos ejemplos sea dable llevar el segundo verbo á indicativo ni á subjuntivo, ni decirse, por tanto, quiero que yo duerma, deseaste que aprendieses. Por el contrario, si el agente del primer verbo es distinto del agente del segundo, no cabe usar infinitivo, y ha de recurrirse al subjuntivo con la partícula que. Ejemplos: quiero QUE DUERMAS; deseaste QUE APRENDIERA Pedro; sin que pueda decirse, quiero tu dormir; deseaste Pedro aprender.

(GRAE-1874: 210)

Cf. GRAE-1878: 210, 1880: 227-228, 1883: 227-228, 1885: 229-230, 1888: 227-228, 1890: 227-228, 1895: 227-228, 1900: 227-228, 1901: 227-228, 1904: 221-222, 1906: 221-222, 1908: 221-222, 1909 : 221-222. 
que el verbo regido vaya en infinitivo si su agente coincide con el del verbo Regente, como excepciones hay a la regla de que el verbo regido tenga que ir conjugado y precedido de la conjunción que en caso de tener un agente distinto del que tiene el verbo Regente.

Un verbo de los que pueden ser determinantes suele regir al determinado en infinitivo, cuando el agente es uno mismo para los dos. Así, se dice: quiero DORMIR; deseaste APRENDER, sin que en estos ejemplos sea dable llevar el segundo verbo a indicativo ni a subjuntivo, ni decirse, por tanto, quiero que yo duerma; deseaste que aprendieses. No obstante, cabe decir: pienso SALIR mañana, o pienso QUE SALDRÉ; espero LOGRAR eso, o espero QUE lo LOGRARÉ; prometió PAGARME, o prometió QUE me PAGARÍA. Si el agente del primer verbo es distinto del agente del segundo, se usa más el subjuntivo que el infinitivo: quiero QUE DUERMAS; deseaste QUE APRENDIERA Pedro; sin que pueda decirse quiero tú dormir; deseaste Pedro aprender. $\underline{\text { Otros }}$ verbos admiten el infinitivo: mandó QUE PRENDIERAN al agresor, o mandó PRENDERLE.

(GRAE-1911: 226. El subrayado es mío) ${ }^{175}$

Interesa apuntar que, ya en la GRAE-1854, precisamente en esas observaciones sobre el uso de indicativo o subjuntivo en el verbo reg. (que, desde 1870, se llevan al capítulo de las oraciones), encontramos, por primera vez en la Obra académica, el término verbo subordinado en el sentido que hoy le damos (y como equivalente a verbo regido en una relación de regencia en que el primer término es otro Verbo) ${ }^{176}$, término que, no obstante, no va a triunfar hasta el siglo XX.

175 Cf. GRAE-1913: 226 y 1916: 226.

$176 C f$. GRAE de 1854: 148; 1858: 161, 1862: 165, 1864: 165, 1865: 165, 1866: 165 y 1867: 165. En 1870: 219, vuelve a usarse, sin embargo, el término verbo regido. Ídem GRAE-1874: 246, 246, 


\section{iii. Actuales casos de perífrasis verbales (en sentido amplio ${ }^{177}$ ).}

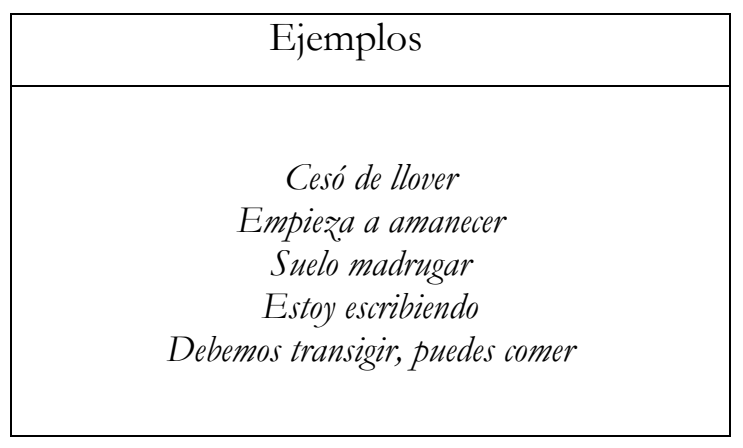

Estos últimos ejemplos son representativos de la indistinción que hay en los textos académicos entre la relación $/ \mathrm{Vb}$. $\rightarrow$ vb./ y la fusión que supone una perífrasis verbal 178 .

En los textos del corpus -hasta el modelo de los años setenta, incluido-, todos estos casos (hoy, generalmente, considerados perífrasis verbales) se interpretan como relación de regencia del primer verbo (cesar, empezar, soler, estar, deber y poder) sobre el infinitivo o el gerundio.

1880: 256, 1883: 256, 1885: 258, 1888: 256, 1890: 256, 1895: 256, 1900: 256, 1901: 256, 1904: 250251, 1906: 250-251, 1908: 250-251, 1909: 250-251, 1911: 257, 1913: 257, 1916: 257.

177 En este apartado, se recogen tanto las hoy llamadas por algunos perifrasis aspectuales (empezar + inf.) como las perífrasis modales (soler + inf.; poder + inf.).

178 Salvá, que trata por extenso de las relaciones /Vb. $\rightarrow$ vb./ (Verbo Determinante o Regente y verbo determinado o regido), tampoco establece límites precisos y nítidos entre lo que hoy entendemos como perífrasis verbales y oraciones subordinadas a un verbo. Frente a Saqueniza, el valenciano sí reconoce como casos de regencia de un verbo sobre otro (= subordinación) las relaciones entre un verbo conjugado y un infinitivo. Las relaciones $/ \mathrm{Vb}$. $\rightarrow$ vb./ se establecen de tres formas distintas en la propuesta de Salvá:

Tres son las formas de unión entre ambos verbos [Determinante $\mathrm{y}$ determinado]: primera, por medio de un relativo: segunda, llevando el consiguiente al infinitivo con preposicion ó sin ella: y tercera, cuando los enlaza una conjuncion ó un adverbio, aunque lo último se verifica pocas veces.

(Salvá, 1847 [1830]: 188)

Más información, en Martí Sánchez (1988: 523-526). 
A partir de la GRAE-1880, las estructuras /Vb. + (prep.) + Inf./, de un lado, y /Vb. + Ger./, de otro, empiezan a recibir explicación diferente. Por primera vez, en esta edición se reconoce que un verbo conjugado y un verbo no conjugado pueden fundirse. Pero tal reconocimiento sólo se da en la explicación de las construcciones de gerundio. Así, en este año, dos estructuras que hoy entendemos como casos de perífrasis aspectuales son analizadas de forma muy distinta bajo este tipo de relación / Vb. $\rightarrow$ vb./:

\section{(1) Estoy escribiendo \\ (2) Empieza á amanecer 179}

Mientras que (1) se considera una «locución compuesta» de estar y gerundio (aunque no deja de afirmarse que el gerundio está regido del verbo estar), (2) sigue viéndose como caso típico de regencia del primer verbo sobre el infinitivo: á amanecer es «complemento directo» (= régimen obligatorio con preposición a) de empieza. Este análisis tan distinto de estructuras tan semejantes desde el punto de vista funcional -según las entendemos hoy- es indicativo de que la Institución sigue basando su doctrina, en ciertos puntos, en criterios más secuenciales-formales (las mismas categorías en idéntica colocación) que funcionales; de ahí que se agrupen como estructuras idénticas empieza a amanecer y aspiran a ascender (vid. supra apartado $i)^{180}$. La razón fundamental -parece- que explica el hecho de considerar (1) como locución es que los dos verbos juntos equivalen a la significación del gerundio (aunque el tiempo lo marque el primer verbo). ¿Se habrán planteado los académicos si la suma empieza + $a+$ amanecer equivale significativamente a amanece (tiempo presente

179 Cf. GRAE-1880: 226 y 227.

180 También se interpretan de la misma forma (como régimen directo del primer verbo) pudiera querer (hoy considerado perífrasis modal) y quieres salir (hoy subordinación sustantiva desempeñada por un infinitivo). 
marcado por el verbo conjugado y significación del infinitivo)? El criterio semántico, pese a ser el argumentado, no se revela como el determinante en esta cuestión concreta. El planteamiento se mantendrá igual hasta la GRAE-1916181.

La explicación que se da en 1880 de las estructuras /Vb. + prep + Inf./ es la de que, por ser siempre el verbo. un verbo neutro (= no transitivo), necesita del auxilio de una preposición para poder regir un infinitivo (cuando el verbo. es transitivo sólo se pone infinitivo en casos de coincidencia de los respectivos nominativos del verbo. y del Inf.). Esta afirmación no coincide con otras que se hacían en ediciones anteriores en el apartado dedicado a los regímenes de la preposición, donde, por ejemplo, puede leerse que «la preposicion á rige al verbo determinado siempre que éste es término de la accion del determinante, por ejemplo: Voy Á pasear (...)» (GRAE-1854: 152)182. Parece, por tanto, que la GRAE-1880 continúa la línea de abandono de la idea de que la preposición es palabra Reg. y se pone más el acento en su naturaleza nexiva (téngase en cuenta lo que se dirá en el Caso (4) de Régimen).

Aun así, seguimos encontrando afirmaciones que confirman la falta de consistencia (o la contradicción, si se quiere) de la teoría académica en ciertos puntos. El apartado dedicado a las relaciones / Vb. $\rightarrow$ vb./ se cierra con el siguiente párrafo:

181 Cf. GRAE-1883: 226 y 227, 1885: 228-229, 1888: 226-227, 1890: 226-227, 1895: 226-227, 1900: 226-227, 1901: 226-227, 1904: 220-221, 1906: 220-221, 1908: 221, 1909: 220-221, 1911: 224-225, 1913: 224-225 y 1916: 224-225.

182 Cf. GRAE de 1858: 165, 1862: 169, 1864: 169, 1865: 169, 1866: 169, 1867: 169; 1870: 189 (a partir de esta edición, no se dice que la preposición rige, sino afecta, lo que podría entenderse como "consecuencia terminológica" del hecho de que, a partir de ahora, se empieza a poner en tela de juicio la labor rectora de la preposición -remito al Caso (4) de Régimen-. No olvidemos, por otra parte, que en la cita reproducida se habla, desde 1854, de Verbo Determinante y verbo determinado); 1874: 216; 1878: 216. Desde la GRAE-1880, no encontramos detallados los regímenes de cada una de las preposiciones, por lo que la cita transcrita arriba se pierde. 
$\underline{\text { Rige también el verbo al verbo por medio de otras }}$ preposiciones; pero en dejando ésta de ser á (hoy la única de acusativo propiamente), el régimen no es ya directo, y toca en rigor á

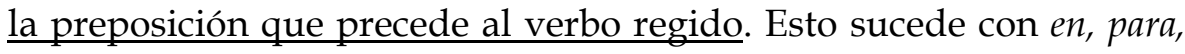
hasta, y otras varias preposiciones.

(GRAE-1880: 228. El subrayado es mío)

El régimen, si la preposición que media entre dos verbos es distinta de $a$, «no es ya directo». Pero, ¿sigue siendo régimen del primer verbo o no? En la edición de 1880, la posibilidad de que la regencia del verbo vaya más allá del acusativo inmediato / complemento directo está reconocida. ¿Por qué volver a atribuir a la preposición competencias que ya se han reconocido al verbo? 
(c) Palabra reg. = adverbio

$$
\text { Relaciones /Vb. } \rightarrow \text { adv./ }
$$

Las Gramáticas comprendidas entre 1854 y 1916, sin excepción, coinciden en considerar que todos los verbos, salvo los auxiliares, rigen al adverbio, que viene a ser una especie de adjetivo del verbo, puesto que se refiere a él «del mismo modo y con la misma precisión» con que el adjetivo se refiere al sustantivo 183 y 184 . El adverbio determina las circunstancias de lugar, tiempo, modo, cantidad, comparación, afirmación o duda que modifican o completan la significación verbal.

Interesa no pasar por alto que algunos de los ejemplos dados en este tipo de relación / Vb. $\rightarrow$ adv./ son los únicos que contravienen la linealidad (en sentido izquierda-derecha) defendida por la Corporación para las relaciones de dependencia bajo la fórmula "régimen = gobierno $\mathrm{o}$ precedencia". Los ejemplos a los que me refiero son:

$$
\text { AQUí (reg.) vivo (Reg.); AYER MAÑANA (reg.) murió (Reg.) }
$$

\footnotetext{
183 Esta similitud defendida en todas las ediciones hace inexplicable que, en las GRAE de los años cincuenta y sesenta, la relación sustantivo-adjetivo (frente a la relación verbo-adverbio) no sea considerada caso de régimen (vid. supra Caso (1) de Régimen, apartado (b)). En todas las ediciones -recordamos- la combinación / sustantivo + adjetivo/ es tratada en la Concordancia y la Construcción.

resulta curiosa (sobre todo, en las GRAE publicadas entre 1854 y 1867), pues, como se ha dicho más arriba (vid. supra Caso (1) de Régimen, apartado (b)), la relación sustantivo-adjetivo (frente a la relación verbo-adverbio) no se considera caso de régimen hasta la GRAE-1870, mientras que en todas las ediciones se considera caso de concordancia (cf. Caso (6) de Régimen). 184 Dentro de nuestra tradición gramatical, es costumbre definir y caracterizar la categoría adverbio de forma paralela a la categoría adjetivo. Vid. Gómez Asencio (1981: 218-237), para la segunda mitad del siglo XVIII y primera mitad del XIX, y Calero Vaquera (1989: 139-149), para el periodo comprendido entre 1847 y 1920.
} 
En estos casos, la relación de regencia debe representarse, excepcionalmente, en sentido derecha-izquierda: /adv. $\leftarrow \mathrm{Vb}$./.

No parece extraño que los contraejemplos de la idea de precedencia de la palabra Reg. empiecen a aparecer, en las ediciones decimonónicas, a propósito de una categoría que goza de gran movilidad dentro de la estructura oracional y que tiende a ocupar posiciones preverbales cuando actúa como Complemento Marco o Circunstancial Escénico (es el caso de muchos adverbios de lugar y tiempo), o bien, como otras categorías, en casos de focalización ${ }^{185}$.

Es en 1870 cuando se introduce una referencia explícita a la libertad colocacional (limitada, por supuesto) de este constituyente, libertad que -se advierte- no debe atentar contra el sentido de la frase ni crear ambigüedad en la interpretación de la misma. Así se expresa en el texto de la Gramática:

No es condicion precisa que en la frase haya de seguir siempre el adverbio al verbo que le rige; pero se ha de procurar que, ya le preceda, ya le siga, diste de él lo ménos posible: así se evitarán conceptos ambiguos. Por ejemplo, en la cláusula, prometió ayer, ó ayer prometió pagarme, el adverbio ayer denota el dia de la promesa, y debe, por consiguiente, unirse al primer verbo, no al segundo. Por el contrario, en esta otra, prometió pagarme AYER, el día del pago es lo esencial, concreto,y por lo mismo, pagarme es el verbo modificado por el adverbio, y á su lado, no al del otro, se debe colocar.

(GRAE-1870: 184. El subrayado es mío)

185 Sabemos que los adverbios de lugar y tiempo tienden a ocupar posiciones posverbales, como auténticos CC (aunque algunos puedan ser argumentales, como es el caso de Vivo aquî). Para más información, véase Kovacci (1999) y Fernández Leborans (2005), entre otros. 
En lo tocante a la función del adverbio, podemos decir que las ediciones publicadas entre 1854 y 1867 (igual que las ediciones dieciochescas) consideran que solo incide de forma segura sobre un verbo ${ }^{186}$, pues:

- Solo se reconoce como palabra reg. de Vb., Prep. y Conj. (vid. supra Tabla 5).

- En las relaciones /Prep. $\rightarrow$ adv./, la regencia parece entenderse exclusivamente como precedencia obligatoria o facultativa de un elemento preposicional ante determinados tipos de adverbios, esto es,

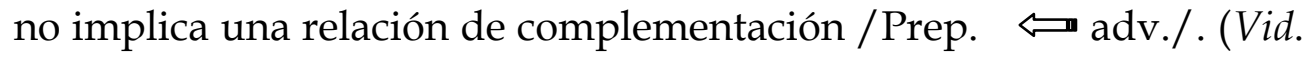
infra Caso (4) de Régimen).

186 Es la idea que se encuentra ya en Dionisio de Tracia y que acogió Nebrija tomando como fuente a Donato (vid. Ramajo Caño, 1987: 185). Esta concepción, que suele fundamentarse en la propia etimología de adverbio (así la justificaban los académicos de 1771 y 1796), triunfó en la tradición gramatical de Occidente hasta el Renacimiento. Entre nuestros gramáticos, Jiménez Patón y Correas parecen ser los primeros en contemplar la posibilidad de que el verbo se refiera a otras palabras distintas del verbo: el primero es más preciso y apunta al nombre (= sustantivo y adjetivo) como categoría que también puede recibir modificaciones por parte del adverbio (1614: 94); el segundo deja abierta la posibilidad de que el adverbio no solo se refiera a un verbo al afirmar que «el adverbio es una partícula que comúnmente se xunta al verbo" (1625: 338 y 1627: 187. El subrayado es mío). Ya en el siglo XVIII, por influjo de la Grammaire de Port-Royal (en la que hay ecos de la propuesta del Brocense, según ha señalado Ramajo Caño, 1987: 186-187), Benito de San Pedro afirma que se junta al verbo, al adjetivo y al participio.

Una vez aceptado que el adverbio no solo modifica al verbo, el paso hacia concepciones más flexibles es fácil de dar. En el siglo XIX encontramos la visión más abierta de la facultad modificadora del adverbio. Es Salvá quien la formula:

\footnotetext{
Llámase de esta manera, porque se junta con cualqier palabra (ad verbum), esto es, con cualquier parte de la oración, menos con las conjunciones e interjecciones, para modificar su significado en virtud del que tiene el mismo adverbio. En poco diestro; hablaste bien; menos prontamente; más hacia el bosque, lo vemos en efecto junto con un nombre, con un verbo, con otro adverbio y con una preposición.
}

(Salvá, 1847 [1830]: 284)

Posiblemente, el antecedente inmediato de Salvá sea González de Valdés. A finales del XVIII, este autor defiende que verbo, sustantivo, adjetivo, participio y adverbio son susceptibles de ser modificados por el adverbio. Gómez Asencio (1981: 231) apunta la posibilidad de que sea el primer gramático español en tener tan amplia visión. 
- De las relación /Conj. $\rightarrow$ adv./ no se dan ejemplos, solo se menciona al adverbio como palabra reg. en el epígrafe del apartado dedicado a la regencia de la conjunción. (Vid. infra Caso (5) de Régimen).

Además, en el apartado dedicado al régimen $/ \mathrm{Vb} . \rightarrow \mathrm{adv} . /$, se afirma invariablemente que

así como no puede haber adjetivo que no haga relacion á un nombre sustantivo, nombrado ó supuesto, así no puede haber adverbio que no se refiera á un verbo tácito ó expreso.

(GRAE-1867: 166. El subrayado es mío) ${ }^{187}$

Esta afirmación la encontramos hasta la GRAE-1880 -excluida-, de modo que, a partir de 1870, convive en los libros con un apartado dedicado a la relación /Adj. $\rightarrow$ adv./. Una vez más, la contradicción interna (que, en este punto concreto, es especialmente llamativa en las ediciones de los años setenta). En el jalon de 1880, se suprimen del párrafo introductorio las líneas reproducidas arriba, si bien el apartado dedicado a la regencia del Verbo sobre el adverbio se sigue abriendo (como sucede desde 1854) con la afirmación de que

Todos los verbos, á excepción de los auxiliares, como tales, rigen adverbios, y éstos se refieren á los verbos, del mismo modo y con igual precisión que el adjetivo se refiere al nombre [...]

(GRAE-1880: 228)

Teniendo en cuenta la inercia a la que habitualmente tienden los académicos encargados de la elaboración de la Gramática, su apego a lo ya

187 GRAE-1854: 149, 1858: 163, 1862: 167,1864: 167; 1865: 167, 1866: 167, 1870: 183-184, 1874: 210 y 1878: 210 . 
establecido (incluso a lo ya redactado), creo que debemos otorgar más importancia a la supresión de que no hay adverbio que no se refiera a un verbo tácito o expreso que al mantenimiento de las líneas introductorias. Por otra parte, que todos los verbos rigen adverbios puede interpretarse como que "todos los verbos tienen esa capacidad", no necesariamente como que "si hay adverbio en una oración, este adverbio va referido al verbo".

Al borrar del texto la referencia de que todo adverbio supone un Verbo Regente, se está imprimiendo coherencia (o, al menos, se le está restando incoherencia) al apartado sintáctico, pues reconocer que el Adjetivo puede regir un adverbio (y ser modificado por él), como sucede desde la GRAE-1870, invalida la supuesta necesidad de que el adverbio vaya referido a un Verbo. Por otra parte, esta supresión concilia la teoría sintáctica con lo defendido en la Analogía.

En efecto, frente a la doctrina expuesta en la parte de Sintaxis, en la Analogía se defiende, en todas las ediciones que preceden al jalón de 1870, que, aparte de modificar la significación del verbo, el adverbio también incide sobre el adjetivo ${ }^{188}$. Y en la GRAE-1870 ya se reconoce que

El adverbio es aquella parte de la oracion que sirve para modificar la significación del verbo, ó de cualquier otra palabra que tenga un sentido calificativo ó atributivo.

Modifica, por lo tanto, el adverbio los adjetivos, los verbos, los participios, y, á veces á otro adverbio. Así, en las frases horriblemente feo, -comer bien, -bastante mejorado, -demasiado tarde, las palabras horriblemente, bien, bastante y demasiado modifican la significacion de aquellas con las cuales se junta. Lo más comun, no obstante, es juntarse al verbo, y de ahí su nombre de adverbio (del latin ad-verbum).

188 Cf. GRAE-1854:109, GRAE-1858: 114, GRAE: 1862: 117, GRAE-1864:117, GRAE-1865: 117, GRAE-1866: 117, GRAE-1867: 116. 
(GRAE-1870: 132. El subrayado es mío) $)^{189}$

El reconocimiento de la facultad del adverbio para incidir sobre un verbo, un adjetivo (y participio) $\mathrm{u}$ otro adverbio trae a la memoria del lector de hoy (salvando las distancias) la visión de Jespersen, en cuya Teoría de los rangos el adverbio es etiquetado como "categoría de rango terciario". Dentro de nuestra tradición, esta triple incidencia reconocida al adverbio la encontramos por primera vez en Jovellanos ${ }^{190}$, y tras él la acogerá buena parte de los gramáticos del siglo XIX y principios del XX191.

La función desempeñada por el adverbio dentro de la oración también recibe el nombre de complemento en las ediciones de los años setenta ${ }^{192}$, lo que muestra que, al igual que en la GRAE-1854, este término vale tanto para régimen directo (= necesario) como para régimen indirecto (= facultativo). No olvidemos que el adverbio, aunque reconocido como palabra reg. de un Verbo Reg. en todas las Gramáticas que nos están ocupando, sería, según la propia doctrina académica, régimen accesorio. Hoy también lo entenderíamos así (con independencia de la terminología) puesto que, en términos generales (excluyendo nuestros casos de Circunstanciales Argumentales), no es elemento imprescindible para salvaguardar la gramaticalidad de la oración ni para completar la significación del verbo; expresa, simplemente, circunstancias de su acción.

189 Ídem GRAE-1874: 158, 1878: 158, 1880: 180, 1883: 180, 1885: 180, 1888: 178, 1890: 178, 1895 : 178, 1900: 178, 1901: 178, 1904: 173, 1906: 173, 1908: 173, 1909: 173, 1911: 174, 1913: 174 y 1916: 174.

190 Le siguen, en la primera mitad del XIX, Calleja, Lacueva y Calderón. Vid Gómez Asencio, 1981: 231-232.

191 Calero Vaquera (1989: 145) menciona a Bello, Eguílaz, Caballero, Ruiz Morote, Galí, Blanco, Sanmartí, Pogonoski y Lemus.

$192 \quad[. .$.$] y áun muchas oraciones tienen por único complemento uno, dos y hasta tres$ adverbios.

(GRAE-1870: 184, 1874: 210, 1878: 210)

Esta referencia desaparece en la GRAE-1880 y no volvemos a encontrarla. 


\section{CASO (3) DE REGIMEN: palabra Reg. = Participio}

Hasta la GRAE-1870 -inclusive-, solo se le concede categoría de palabra Reg. al participio activo en su calidad de verbo, no de adjetivo. Este participio mantendrá, en ocasiones, el régimen que le es propio al verbo de donde resulta (p.ej. participante de la desgracia de su amigo < [participar de algo]), pero, en otras ocasiones, lo cambiará (amante de las letras vs. [amar algo]) ${ }^{193}$. Como se ve en los dos ejemplos dados, la única palabra que puede funcionar como reg. en una relación de regencia cuyo primer miembro sea el Participio es el nombre (introducido por preposición: el participio es modificado por un SP) $)^{194}$.

En las primeras páginas de este punto 6.2.1.2., antes de abordar el análisis de cada uno de los casos de régimen, se ha adelantado la confusa teoría (diseminada en afirmaciones difícilmente conciliables) que se defiende en la GRAE-1870 a propósito de la capacidad de rección de adjetivo y participio. Recordemos que, en las ediciones de los años cincuenta y sesenta, el adjetivo no forma parte de la nómina de palabras Reg., por tanto, es coherente que, en estos libros, la facultad de regir a otra categoría solo le sea concedida al participio en su calidad de verbo. Sin embargo, en el jalón de 1870, por primera vez, se reconoce que el adjetivo puede funcionar como primer elemento de una relación de regencia, pero, al mismo tiempo, se mantiene que «el participio activo... como adjetivo no tiene régimen». Sabemos que no es el único caso en que la Institución incurre en contradicciones internas de doctrina; también sabemos que, en esta ocasión, la contradicción queda superada en el texto inmediatamente posterior (GRAE-1874), en el que se lee

\footnotetext{
193 El texto de la Gramática sólo da los ejemplos en cursiva; el añadido entre corchetes es mío. 194 Interesa recordar en este punto que, según lo comentado en el Caso (2) de Régimen, en las ediciones previas a la GRAE-1870, el SP de algo en Participar de algo no sería considerado verdadero régimen del verbo. Sería su régimen accesorio $\mathrm{y}$, por tanto, la regencia correspondería a la preposición. Sin embargo, en la estructura con participio no hay duda interpretativa: la palabra Regente es el participio.
} 
que «el participio activo... como adjetivo tiene el régimen de esta parte de la oracion» (GRAE-1874: 211-212)195. Aunque no se da ningún ejemplo, no parece descaminado suponer que un participio como entendido, cuando se usa con valor activo como en hombre entendido (donde entendido equivale a inteligente, según se dice explícitamente en el texto de la Gramática), puede admitir modificadores (o, en terminología académica, puede regir otro elemento), por ejemplo, un sustantivo (uno de los regímenes reconocidos al adjetivo) introducido por preposición: hombre entendido en matemáticas.

En cuanto al participio pasivo, en su calidad de adjetivo, solo se dice, en este apartado del capítulo dedicado al Régimen, que tiene como oficio «juntarse con nombres y concertar con ellos»: hombre perdido, obra acabada, caudales heredados, alabanzas merecidas son los ejemplos que encontramos hasta la edición de 1916. Ya hemos tratado de las combinaciones /Sust. + Adj./ (vid. supra Caso (1) de Régimen, apartados (a) y (b)), cabe preguntarse ahora si la Academia acepta la posibilidad de que perdido, acabada, heredados y merecidas puedan recibir modificadores, puedan ejercer de palabras Reg.

195 Cf. GRAE de 1878: 211-212, 1880: 229, 1883: 229, 1885: 231, 1888: 229, 1890: 229, 1895: 229, 1900: 229, 1901: 229, 1904: 223, 1906: 223, 1908: 223, 1909: 223, 1911: 227, 1913: 227 y 1916: 227. 


\section{CASO (4) DE REGIMEN: palabra Reg. = Preposición}

Desde 1771, el papel de la preposición se ha revelado como el principal punto por el que hace aguas la teoría del régimen defendida por la RAE. También en la primera edición de la Gramática, la que muestra una más firme voluntad de exponer de forma clara -al menos desde el punto de vista teórico- este apartado de la Sintaxis, los académicos incurrieron en contradicciones a la hora de interpretar los distintos casos de dependencia (vid. supra 6.2.1.1.), dando a la preposición ya el papel de enlace, ya el de palabra Regente. Estas contradicciones, sumadas a la heterogeneidad de relaciones tratadas, ensombrecieron la doctrina.

Por lo que respecta a las ediciones del corpus (herederas en buena medida de la GRAE-1796), en ellas, el paso de los años no se ha traducido, precisamente, en claridad expositiva (ni doctrinal). Las sombras siguen estando presentes. Ya hemos comentado, a propósito del Caso (2) de Régimen, que, hasta la GRAE-1870, los mismos ejemplos son explicados, en distintos lugares de la Gramática, como régimen indirecto del Verbo y como régimen de la Preposición. Recordemos que esta doble interpretación se ha dado, por ejemplo, a Nació en un monte: /Nació $\rightarrow$ monte/ y /en $\rightarrow$ monte/.

No faltan, cierto es, estructuras con preposición que, en todas las ediciones, se interpretan en un solo sentido. Son las que siguen:

- Las estructuras que responden a casos de complementación del sustantivo (nuestro $\mathrm{CN}$ ): Casa de Pedro, callejón sin salida, que se interpretan, de forma invariable, como regencia del primer sustantivo sobre el segundo (preposición = elemento auxiliar para establecer la relación). 
- Las estructuras que responden a casos del llamado régimen directo del verbo (nuestro CD): Amo a mi padre. También aquí la preposición es entendida, sin excepción, como mero enlace de la relación que se establece entre Verbo Regente y sustantivo regido.

Los problemas vienen dados, sobre todo, por el llamado régimen indirecto. En términos generales, a partir de 1870, las interpretaciones se unifican; pero en ciertos casos no es así. En la 12. a edición, se reconoce definitivamente como régimen del Verbo (y no de la preposición) nuestro CI (Dio rehenes al vencedor). Este paso es seguro en el capítulo del Régimen. Sin embargo, no desaparecen los problemas: los más llamativos los encontramos a propósito de estructuras que hoy interpretamos como proposiciones de infinitivo en función de Complemento de Régimen. Destaco dos casos:

\section{(i) /obstinarse en + infinitivo/}

Esta estructura, hasta la edición de 1870 -incluida-, se sigue considerando ejemplo de la relación $/ \mathrm{Vb}$. $\rightarrow \mathrm{vb} . /$, pero se recoge igualmente en el apartado dedicado a la regencia de la Preposición (donde aparece desde la GRAE-1854 y donde la encontraremos hasta la GRAE-1878, incluida).

\footnotetext{
(ii) /aspirar $a+$ infinitivo/,/atreverse $a+$ infinitivo/

vs.

/ingeniarse para + infinitivo/, /obstinarse en + infinitivo/
}

Los ejemplos de la primera línea, de un lado, y los de la segunda, de otro, reciben una lectura diferente a partir de 1874: las preposiciones distintas de $a$ son propias -se dice- del régimen indirecto $\mathrm{y}$, como en esta edición se vuelve a afirmar que los casos de régimen indirecto son, en rigor, regímenes de la preposición, /obstinarse en + infinitivo/ se destierra del capítulo del 
Régimen del Verbo (y se mantiene en el apartado dedicado al Régimen de la Preposición).

El análisis de la casuística correspondiente a los regímenes del Verbo (en concreto, a las relaciones / Vb. $\rightarrow$ sust./ y / Vb. $\rightarrow$ vb./) pone de manifiesto, sin duda, la inconsistencia de la doctrina académica en lo tocante a las relaciones de dependencia. Veamos si el concepto de preposición y los apartados dedicados a la Regencia de esta categoría pueden dar alguna luz.

En el capítulo 5, se ha visto que, dentro de la tradición lexicográfica de la RAE, podemos distinguir dos momentos o etapas en el tratamiento de la preposición: en la primera (hasta el DRAE-1869), se defiende que es palabra Reg.; en la segunda (desde el DRAE-1884), que funciona como índice o marca de relación o regencia.

Ambas concepciones (palabra Reg. e índice de relación) conviven, como puede verse en el Cuadro 53 (vid. nfra), en los textos gramaticales publicados hasta 1916, en todos los cuales encontramos afirmaciones explícitas en los dos sentidos apuntados. Este hecho demuestra que, respecto de la categoría preposición, las Gramáticas no presentan una doctrina coherente ${ }^{196}$.

196 Frente a propuestas de autores coetáneos en las que queda claramente establecido el papel de la preposición, como sucede en la Gramática de Ruiz Morote (1880: 56-60), donde se le atribuye la categoría de medio de régimen (ni palabra Reg. ni palabra reg.), o en el Tratado de Herrainz (1885: 130-131), quien le da el nombre y la función de elemento conexivo. Otros autores conceden a la preposición la posibilidad de cumplir distintas funciones, pero especifican de forma precisa las circunstancias en que desempeñan un papel $\mathrm{u}$ otro. Así ocurre en los Elementos de gramática española de Martínez Sevilla (1851):

Qué es régimen gramatical? La reclamacion de una palabra ú oracion á otra palabra ú oracion // que perfeccione y omplete su sentido. Las palabras u oraciones que reclaman otras se llaman regentes; y las que perfeccionan y completan su sentido regidas: asi v.gr. en juego DE café, espero QUE me oirás, la palabra juego y la oracion 
En efecto, en todas las ediciones comprendidas entre 1854 y 1916, en la Analogía, se dice al lector que la preposición denota la índole de las relaciones que se establecen entre dos palabras (o también entre dos cláusulas, desde la

elíptica espero son regentes, y respectivamente regidas la palabra café y la oracion tambien elíptica me oirás. (1).

$[\ldots]$

(1) No obstante que las paabras relativas son solamente medios de régimen, como ya hemos dicho en otra parte, pueden considerarse como regentes las ideorelativas [nuestras preposiciones] cuando con su segundo término forman una expresion circunstancial, $y$ asi mismo las críseo-relativas [nuestras conjunciones] cuando la frase ú oracion se empieza por ellas. V. gr.: $\underline{\text { POR fin }}$ ¿QUÉ respondes?

(Martínez Sevilla, 1851: 74-75. El subrayado es mío)

Noboa (1839), por su parte, expone tres modos de régimen: i) sin preposición, ii) con preposición y iii) con conjunción. Y plantea una interesante pregunta (la misma que los lectores de hoy nos hacemos en muchos de los párrafos de la doctrina académica sobre el régimen): cuando el régimen se establece por el modo ii y iii, ¿qué palabra debemos considerar Regente, la que precede a la preposición cuyo sentido se ha de completar o la preposición / conjunción que sirve de enlace de la relación? La respuesta a esta pregunta la resuelve el mismo Noboa y, lógicamente, es respuesta esperable dentro de una doctrina que considera el régimen como complementación, como dependencia sintáctico-semántica:

Se debe decir que la palabra rejente es aquella cuya significacion se ha de completar ó esplicar, en cuyo caso la preposicion ó conjuncion es solo un medio de hacer este enlace entre las palabras. Sin embargo de esto, consideradas fuera de la oracion, se pueden tambien llamar rejentes, principalmente la preposicion, i la palabra rejida complemento suyo; y con mucha mas propiedad en aquella clase de complementos que no completan á otra palabra, sino que son frases ó espresiones adverbiales, conjuntivas, \&c., v. g. á la fuerza, por último, en fin, Ec.

(Noboa, 1839: 214)

Teniendo en cuenta estos precedentes, no sorprende demasiado la beligerancia de ciertas declaraciones de Herrainz, quien muy probablemente está pensando en los académicos de los años sesenta (y en los gramáticos academicistas) cuando afirma:

No falta quien establece principios opuestos á los que anteceden [entre ellos, que las preposiciones y conjunciones son medios de enlace, sin subordinar ni subordinarse nunca a otro elemento]... _ Que la preposicion y la conjuncion rigen al segundo término; ¿pero acaso los vínculos de enlace entre dos seres relacionados, podrán presentar nunca funcion principal ni subordinada? La primera de estas funciones pertenece al término que dirige la relacion y la última al que depende de él [...] Los mismos gramáticos que tan torpemente preceptuan, caen por esta causa en notable contradiccion, diciendo que el sustantivo rige á otro de su clase, mediante preposicion, como sombrero rige á copa, en sombrero de copa, y además añaden que la preposicion rige entre otras palabras al sustantivo, valiéndose para probarlo del ejemplo anterior ó de otro con él identificado. Pero ¿en qué quedamos? ¿La regencia pertenece á sombrero ó al monosílabo de? ¿O es que copa se acomoda á las prescripciones de dos superiores?

(Herrainz, 1869: 135) 
GRAE-1883) ${ }^{197}$ y, en la parte de Sintaxis, se recogen los distintos regímenes de la preposición: sustantivo, pronombre, verbo y adverbio (y preposición, hasta la GRAE-1867) $)^{198}$.

Bien es cierto que 1870 vuelve a ser, también en lo concerniente a este asunto, fecha de cambios. Una vez más, cabe considerar dos posibles grupos, separados por un suave amago de giro doctrinal. Los datos que nos llevan a esta escisión entre las Gramáticas de los cincuenta y sesenta, de un lado, y las publicadas a partir de 1870, de otro, son estos:

- Solo hasta la GRAE-1867 leemos, en la Analogía, que la preposición sirve para dos cosas: la segunda misión asignada es la que se mantiene en las ediciones posteriores y coincide con la que hemos expresado más arriba (denotar la diferente relación que se establece entre la palabra que precede y la que sigue a la preposición). La función que ahora nos interesa resaltar es la que se marca como primer cometido de la preposición, que no es otro que el de guiar a la palabra que le sigue en el discurso al caso que debe tener en la oración.

- En la GRAE-1870, se exime a la preposición del cometido de "marcar casos" (precisamente, su oficio es el de suplir la falta de declinaciones en español, por lo que no puede imponer un caso a otra palabra).

\footnotetext{
${ }^{197}$ Cf. GRAE-1854: 119, 1858: 124, 1862: 128, 1864: 128, 1865: 128, 1866: 128, 1867: 127, 1870: 143, 1874: 170, 1878: 170, 1880: 191, 1883: 191, 1885: 191, 1888: 189, 1890: 189, 1895: 189, 1900: 189, 1901: 189, 1904: 184, 1906: 184, 1908: 184, 1909: 184, 1911: 185, 1913: 185, 1916: 185.

198 Cf. 1854: 151-155, 1858: 164-170, 1862: 168-174, 1864: 168-174, 1865: 168-174, 1866: 168-174, 1867: 168-173, 1870: 188-193, 1874: 214-223 (a partir de esta edición, se incluyen en este apartado unas observaciones sobre preposiciones que admiten en composicion la compañía de otras y un cuadro de las preposiciones dobles), 1878: 214-223, 1880: 214-223, 1883: 231-234 (desde esta edición, el añadido de la GRAE-1874 se reduce a un apartado dentro de esta regencia sobre preposiciones que admiten o rechazan la compañía de otras), 1885: 233-236, 1888: 231-234, 1890: 231234, 1895: 231-234, 1900: 231-234, 1901: 231-234, 1904: 225-228, 1906: 225-228, 1908: 225-228, 1909: 225-228, 1911: 230-233, 1913: 230-233, 1916: 230-233.
} 
Además, se dice que es signo representativo o exponente de la relación entre un antecedente (que debemos entender como la Palabra Regente) y un consecuente (o palabra regida) ${ }^{199}$.

El cambio que, ya desde la Analogía, se intuye en la GRAE-1870 se confirma en la parte de Sintaxis. En esta $12 .^{a}$ edición de la Gramática, la Institución inicia el apartado dedicado al régimen de la preposición advirtiendo que se trata de un régimen «muy secundario», incluso "dudoso", lo que implica quitar peso de un lado de la balanza para inclinarla hacia la postura de que la preposición es, ante todo, marca de relación:

Áun más secundario que el del adjetivo es el régimen activo de la preposicion, si así se le puede llamar, pues ya hemos visto que viene á la oracion regida de nombre, de adjetivo, de verbo, de participio, de adverbio y hasta de interjecion alguna vez.

(GRAE-1870: 188. El subrayado es mío)200

La Corporación parece poner en tela de juicio, por primera vez de una forma explícita, la capacidad rectora de la preposición, aunque se le siga dedicando un apartado en el capítulo del Régimen (¿porque así se había hecho siempre? $)^{201}$. Otro paso más en esta misma dirección parece darse al suprimir

199 Esto último, en un párrafo no exento de otras afirmaciones problemáticas (vid. infra nota 206).

200 Ídem: 1874: 214, 1878: 214, 1880: 231 (en esta edición, encontramos la misma idea expresada con otras palabras: «El régimen activo de la preposicion, si así se le puede llamar, es muy secundario, pues ya hemos visto que viene á la oración regida de nombre, de adjetivo, de verbo, de participio, de adverbio y hasta de interjección alguna vez»), 1883: 231, 1885: 233, 1888: 231, 1890: 231, 1895: 231, 1900: 231, 1901: 231, 1904: 225, 1906: 225, 1908: 225, 1909: 225, 1911: 230, 1913: 230 y 1916: 230.

${ }^{201}$ Una vez más, los académicos de 1870 dan muestras de un intento de asentar principios doctrinales (no en vano, esta edición se presenta como la más ambiciosa de todas las decimonónicas en cuanto a pretensiones de calado teórico), pero su voluntad se desvanece en el mismo párrafo. Justo debajo de las líneas que ponen en duda la capacidad rectora de la preposición (y después de suprimir -con acierto- esa supuesta función "orienta-casos"), se recuerda al lector que en las anteriores secciones del capítulo se ha dado cuenta de cómo la preposición rige al nombre (las anteriores secciones -recordemos nosotros- estaban 
el apartado dedicado a la relación /Prep. $\rightarrow$ prep. $/{ }^{202}$ y, en su lugar, apuntar que, en determinadas expresiones, se hace obligada la concurrencia de dos preposiciones (sin dar noticia alguna del tipo de relación que se establece entre ambas). En la edición siguiente (GRAE-1874), se desarrolla este apunte y se crea un apartado rotulado «preposiciones que admiten en composicion la compañía de otras», en el que se reconoce que «esta union o consorcio» que ocasionalmente puede darse entre dos preposiciones permite, bien expresar con más propiedad determinadas ideas, bien dar cuenta de alguna relación que no puede expresarse de otro modo; en definitiva, «tropezamos... con las que filológicamente podrian llamarse relaciones complexas ó mixtas, que solo asi pueden representarse» (GRAE-1874: 220) ${ }^{203}$.

Por lo que respecta a la relación /Prep. $\rightarrow$ vb./, bajo la cual la Academia vuelve a recoger casos de dependencia oracional, se advierte, en todas las GRAE hasta la de 1878 -inclusive- (y los ejemplos dados lo confirman), que la preposición por sí misma sólo puede regir al verbo al infinitivo (que, en estos casos, adquiere carácter de sustantivo). Para que el verbo reg. aparezca en indicativo o subjuntivo, la preposición necesita del auxilio de una conjunción, sobre todo que y si. Los ejemplos aducidos responden a casos de lo que hoy se llama generalmente subordinación sustantiva del tipo / $[($ Suj. $)+$ Pred. $] /$ o $/$ Adj. $\Longleftrightarrow[($ Suj. $)+$ Pred. $] /:$

destinadas a los regímenes de otras categorías Regentes) y se dan como ejemplos de la relación /Prep. $\rightarrow$ sust./tanto los casos de las ediciones anteriores (que suponían un sustantivo elíptico): No me he acordado de él para bueno ni para malo (= cosa buena ni mala), como otros nuevos casos (en los que también se habla de elipsis): Prefiero a este (hombre/soldado). Ejemplos como el úlimo vuelven a dar a la GRAE (precisamente en la edición que pretende y que muestra avances más importantes) otra dosis de contradicción interna: los ejemplos responden a regímenes directos del verbo.

202 Apartado que encontramos hasta la GRAE-1867, inclusive. Cf. GRAE-1854: 155, 1858: 170, 1862: 174, 1864: 174, 1865: 174, 1866: 174 y 1867: 173.

${ }^{203}$ En la GRAE-1880, han desaparecido ya las observaciones que en las dos ediciones anteriores (1874 y 1878) se hacían en ese nuevo apartado; ahora se da un epígrafe diferente: «Preposiciones que admiten ó rechazan la compañía de otras» y se limita la información a la que en 1874 y 1878 se daba en el «cuadro de las preposiciones dobles». 
- /(Suj.) + Pred./ en función de Término de Suplemento: «Se trata DE QUE lo hagas pronto».

- $\quad$ /(Suj.) + Pred./ en función de CD: «Quiere saber HASTA SI cómo [sic] bien ó mal».

- Infinitivo en función de Término de Complemento del Adjetivo: «Fácil DE $\underline{\text { lograr»", }}$

o bien a casos de lo que hoy se suele analizar como perífrasis verbales:

- Modales: «He de hablar; Debe de estar nevando en la sierra».

- Aspectuales: «Voy á pasear».

En el repaso pormenorizado que la RAE hace de los regímenes de las distintas preposiciones, encontramos algunos datos que permiten sospechar que las relaciones / Prep. $\rightarrow$ vb./ responden, en rigor, a relaciones / Vb. $\rightarrow$ $\mathrm{vb./,} \mathrm{que,} \mathrm{en} \mathrm{determinadas} \mathrm{circunstancias,} \mathrm{exigen} \mathrm{preposición.} \mathrm{Se} \mathrm{trata,} \mathrm{en}$ definitiva, de las estructuras /Vb. + prep. + vb./ que hemos comentado más arriba. El primero de los dos verbos es el Determinante y el segundo, el determinado:

La preposicion á rige [> afecta] al verbo determinado [> regido] siempre que éste es término [> objeto] de la accion del determinante [regente], por ejemplo: Voy á pasear; Te niegas á escibir; Apostó á correr \&c., \&c. [> etc., etc.]

(GRAE-1854: 132 [> GRAE-1870: 189]) 204 y 205

204 Ídem GRAE-1858: 165, 1862: 169, 1864: 169, 1865: 169, 1866: 169, 1867: 169, 1870: 189, 1874: 216 y 1878: 216.

205 Otros párrafos plantean más dudas de interpretación, pero también contienen una redacción ambigua que, cuando menos, hace pensar que el régimen no corresponde solo a la preposición, sino también al verbo precedente:

El principal empleo de esta preposicion [para], cuando se halla entre dos verbos, es determinar con el segundo el objeto del primero, como: Trabajo ahora PARA 
No parece casualidad que sea en los regímenes de a donde encontramos una explicación que hace pensar en la Regencia de un verbo sobre otro. En la edición anterior a 1854, se leía:

La preposicion á rige al verbo en infinitivo en todos aquellos casos en que este es término de la accion del determinante, como si entre la preposicion y el verbo formaran su acusativo, por exemplo: voy á pasear, á estudiar, á jugar.

(GRAE-1796: 312. El subrayado es mío)

El reconocimiento de que la preposición $a$ se fusiona con el verbo que le sigue para formar el acusativo del primer verbo (que es el verdadero elemento Regente) explica que los ejemplos con a sean los que reciben una interpretación más unitaria en todas las ediciones, y que, en virtud de esa interpretación, la preposición ejerza de enlace o medio de regencia, no de palabra Regente propiamente dicha. Es a la preposición que aparece en amo a mi padre (/Vb. $\rightarrow$ sust./); atreverse a pelear $(/ \mathrm{Vb} . \rightarrow \mathrm{vb} . /)$ y dar lección al

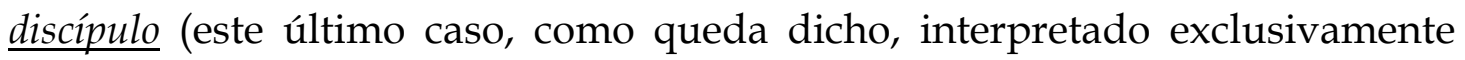
como régimen indirecto de una relación /Vb. $\rightarrow$ sust./ desde 1870). La misma interpretación (la fusión con el segundo verbo para constituir el objeto del primero) podría darse a la función de para en el fragmento reproducido en la nota 205 (vid. supra).

De la misma forma que a (¿y para en los textos del corpus?) se fusiona con el sustantivo que le sigue para constituir el régimen (directo) del verbo, la 
preposición de, cuando media entre dos sustantivos, es marca de genitivo: no rige, estrictamente hablando, al segundo sustantivo (o, al menos, la capacidad de regencia no la tiene por sí sola):

La preposicion de rige genitivo quando significa este posesion, accion ó pasion, como queda dicho; pero no por sí sola, sino pendiente de un nombre sustantivo anterior expreso ó suplido, ó alguna otra palabra que haga veces de tal. Por exemplo: la casa de mi padre: este genitivo está regido de la preposicion de, y el nombre sustantivo anterior casa: Pedro es amante de las letras: el genitivo letras está regido de la preposicion de, y el participio amante sustantivado, como si se dixera amador. Pero si la preposicion de no va pendiente de $\underline{\text { nombre sustantivo anterior, }}$ sino de otra parte de la oracion, en especial de un verbo, no rige genitivo, sino ablativo, v. g. hablar de noticias: hacer una casa de piedra: los nombres noticias y piedra están en ablativo regidos de la preposicion de por sí sola, porque no depende de nombre sustantivo anterior. Y si se dixera: el hablar de noticias es agradable; aunque el verbo hablar hace en esta expresion veces de sustantivo por el artículo, todavía queda el nombre noticias en ablativo, porque en ella la preposicion de equivale á sobre, que en tal significacion rige ablativo.

(GRAE-1796: 308-310. El subrayado es mío)

De afirmar que, en las estructuras /Sust. + prep. + sust./, el segundo sustantivo va regido conjuntamente por la preposición y el primer sustantivo (porque la preposición, en realidad, pende de un sustantivo anterior), se pasa, en las ediciones del corpus, a considerar que estos casos responden, sin excepción, a la relación /Sust. $\rightarrow$ sust./, donde la preposición es marca de relación sin más. Esta interpretación, como hemos visto, se extiende a otras preposiciones distintas de $a$ que median entre dos nombres sustantivos (capa CON embozos, miel SOBRE hojuelas, callejón SIN salida...). 
Con la GRAE-1880, la Academia comienza una nueva "costumbre" (que mantendrá hasta la GRAE-1916), consistente en recoger, en el apartado dedicado al régimen de la preposición, únicamente casos de regencia /Prep. $\rightarrow$ adv./ y remitir a lo dicho en la Analogía para el resto de los regímenes de la preposición (esto es, para los casos en que la palabra reg. es un nombre, un pronombre o un verbo). Con esta remisión, una vez más, la Institución juega a la incoherencia interna de su propia doctrina, "juego" que mantiene desde ediciones anteriores:

$\mathbf{1}^{\mathbf{0}}$ : Hay incoherencia entre la definición dada en la Analogía (según la cual, a partir de la edición de 1870, la preposición sirve únicamente «para denotar el régimen ó dependencia que tienen entre sí dos palabras ó términos»-cf. Cuadro 53-) y la defensa que, en la Sintaxis, se hace de la preposición como palabra Reg.

$\mathbf{2}^{\mathbf{0}}$ : También se dan incoherencias en el propio capítulo de Analogía: tras la definición dada se pueden leer dos manifestaciones de interés, una de ellas en apoyo de lo dicho en la definición (preposición = marca de relación de dependencia) y otra defendiendo la idea contraria (la preposición no es índice, sino artífice de la regencia) ${ }^{206}$. No me resisto a reproducir las dos citas:

\footnotetext{
206 Esta incoherencia la encontramos por primera vez en la GRAE-1870. En ella, frente a la edición anterior (GRAE-1867), se dice que en Amor de madre, madre es el consecuente o complemento de la preposición (es la afirmación problemática a la que me refería en la nota 199). En la Gramática inmediatamente anterior a ésta (GRAE-1867), sin embargo, el capítulo de la Analogía sí mantiene, con la interpretación de los ejemplos, la coherencia en la tesis de que la preposición no es más que índice de relación, y así, se entiende que en Me enseñó a leer, leer es término del verbo enseñar. Los problemas en las ediciones previas a la GRAE-1870 vienen,
} 
Así, en las frases compadezco Á usted; litiga CON empeño; uno CONTRA cuatro; el jardin DE mi amigo... las preposiciones á, con, contra, de... demuestran la índole de la relación que tienen usted con compadecer, empeño con litigar, etc., etc.

(GRAE-1880: 191. El subrayado es mío)

Tanto las inseparables como las separables preceden siempre al vocablo á que afectan, y de ahí su nombre de pre-posición, porque siempre se ponen antes.

No se concibe relación gramatical sin dos partes ó miembros que se llaman términos; y de éstos, denomínase antecedente el primero, y consecuente ó complemento el segundo. En esta expresión, amor DE madre, hay dos términos, amor, que es el antecedente, y madre, que es el consecuente ó complemento de la preposición de.

(GRAE-1880: 192. El subrayado es mío)

Sobre la preposición volveremos en el apartado 6.2.4.2., dedicado a esta categoría como elemento de relación.

como hemos visto, por el reconocimiento de la preposición como palabra que impone casos a otras palabras. 
PREPOSICIÓN ¿índice o artífice de regencia?

\begin{tabular}{|c|c|c|c|c|}
\hline Edición & $\begin{array}{l}\text { Parte de la } \\
\text { Gramática }\end{array}$ & Función & Declaración & Ejemplos \\
\hline \multirow{2}{*}{$\begin{array}{c}\text { GRAE- } \\
1854\end{array}$} & Analogía & Índice & $\begin{array}{l}\text { «Preposicion es una parte invariable de la oracion, que se } \\
\text { antepone á otras para denotar la relacion que tienen éstas } \\
\text { con el sujeto principal de la cláusula» (pág. 119) }\end{array}$ & $\begin{array}{l}\text { Voy á misa; Estudié con Pedro; El } \\
\text { sombrero de Juan; } \underline{\text { Por mi no hay }} \\
\text { inconveniente; yo amo á Pedro... }\end{array}$ \\
\hline & Sintaxis & $\begin{array}{c}\text { Palabra } \\
\text { Reg. }\end{array}$ & $\begin{array}{l}\text { «Las preposiciones rigen al nombre sustantivo,ó } \\
\text { pronombre que le representa» (pág. 151) }{ }^{208} \text {. «La } \\
\text { preposicion rige al verbo» (pág. 151 }{ }^{209} \text {. «La preposicion } \\
\text { rige al adverbio» (pág. 153) }{ }^{210} \text {. «Una preposicion rige á } \\
\text { otra» (pág. 155) }\end{array}$ & $\begin{array}{l}\text { No me he acordado de él para } \\
\text { bueno ni para malo; Se reduce a si } \\
\text { es bueno o malo; De acá para allá; } \\
\text { Dar por de juan lo que era de } \\
\text { Pedro. }\end{array}$ \\
\hline \multirow{2}{*}{$\begin{array}{c}\text { GRAE- } \\
1870\end{array}$} & Analogía & Índice & $\begin{array}{l}\text { «Preposicion es una parte de la oracion que sirve para } \\
\text { denotar la relacion que tienen entre sí las palabras dentro } \\
\text { de una misma oracion gramatical» (pág. 143) }{ }^{212} \text {. }\end{array}$ & $\begin{array}{l}\text { Compadezco á usted; Se contenta } \\
\text { con poco; El jardin de mi amigo; } \\
\text { Pleitea por pobre. }\end{array}$ \\
\hline & Sintaxis & $\begin{array}{c}\text { Palabra } \\
\text { Reg. }\end{array}$ & $\begin{array}{l}\text { «La preposicion rige al nombre ó al pronombre que le } \\
\text { representa» (pág. 188) }{ }^{213} \text {. «La preposicion rige al verbo» } \\
\text { (pág. 188) } 14 \text {. «La preposicion rige al adverbio» (pág. } \\
191)^{215} \text {. }\end{array}$ & $\begin{array}{l}\text { Prefiero á éste ó á aquél; } L \text { La duda } \\
\text { está en si vendrá hoy o mañana; } L a \\
\text { cama está por hacer; Eso se bace en } \\
\text { ménos de seis minutos... }\end{array}$ \\
\hline \multirow{2}{*}{$\begin{array}{c}\text { GRAE- } \\
1880\end{array}$} & Analogía & Índice & $\begin{array}{l}\text { «Preposicion es una parte indeclinable de la oracion, que } \\
\text { sirve para denotar el régimen ó la dependencia que tienen } \\
\text { entre sí dos palabras ó términos» (pág. 191) }{ }^{216} \text {. }\end{array}$ & $\begin{array}{l}\text { Nos veremos en el teatro; De fuera } \\
\text { vendrá quien de casa nos echará; } \\
\text { Socorre á los menesterosos... }\end{array}$ \\
\hline & Sintaxis & $\begin{array}{c}\text { Palabra } \\
\text { Reg. }\end{array}$ & $\begin{array}{l}\text { «La preposicion rige al nombre, ó al pronombre que le } \\
\text { representa, al verbo y al adverbio» (pág. 231). } \\
\text { «Preposiciones que admiten o rechazan la compañía de } \\
\text { otras» (pág. 233). }\end{array}$ & $\begin{array}{l}\text { Entre mañana y pasado mañana lo } \\
\text { acabaré; No se alegra con nada; } \\
\text { Por sí ó por no... }\end{array}$ \\
\hline
\end{tabular}

Cuadro 53: Papel de la preposición

207 Ídem GRAE-1858: 124.

En la GRAE-1862 cambia la fórmula de definición, que ahora es:

Preposicion es una parte invariable de la oracion, llamada así porque siempre se antepone á otras.

Su oficio es denotar la relacion que tienen entre sí dos nombres, dos verbos, un nombre con un verbo, \&c. (pág. 128)

La misma definición encontramos en las ediciones de 1864:128, 1865: 128, 1866: 128, y 1867: 127.

208 Ídem GRAE-1858: 164, 1862: 168, 1864: 168, 1865: 168, 1866: 168 y 1867: 168.

${ }^{209}$ Ídem GRAE-1858: 165, 1862: 169, 1864: 169, 1865: 169, 1866: 169 y 1867: 168.

210 Ídem GRAE-1858: 168, 1862: 172, 1864: 172, 1865: 172, 1866: 172 y 1867: 171.

211 Ídem GRAE-1858: 170, 1862: 174, 1864: 174, 1865: 174, 1866: 174 y 1867: 173.

212 En la GRAE-1874: 170, se dice:

Preposicion es una parte indeclinable de la oracion, que sirve para denotar el régimen ó

Ídem GRAE-1878: 170

dependencia que tienen entre sí dos palabras ó términos.

213 Ídem GRAE-1874: 214 y 1878: 214.

214 Ídem GRAE-1874: 215 y 1878: 215.

215 Ídem GRAE-1874: 218 y 1878: 218. Estas dos Gramáticas añaden, con respecto a la edición de 1870, un apartado dedicado a las «Preposiciones que admiten en composicion la compañía de otras» (pág. 219 en ambas) y otro rotulado como «Cuadro de las preposiciones dobles» (pág. 221 en ambas). Este segundo apartado será el único que se mantenga desde la GRAE-1880, con un título diferente que recuerda al primero de los aquí mencionados, como ya se ha comentado (vid. supra página 404).

${ }_{216}$ En la GRAE-1883: 191, leemos:

Preposicion es una parte indeclinable de la oracion, que sirve para denotar el régimen ó dependencia que tienen entre sí dos palabras ó cláusulas.

Ídem GRAE de 1885: 191, 1888: 189, 1890: 189, 1895: 189, 1900: 189, 1901: 189, 1904: 184, 1906: 184, 1908: 184, 1909: 184, 1911: 185, 1913: 185 y 1916: 185. 


\section{CASO (5) DE REGIMEN: palabra Reg. = Conjunción}

Estamos ante un caso muy similar a (4). También en esta ocasión, las declaraciones de la Analogía y las hechas en la Sintaxis no son conformes entre sí, por cuanto en cada una de estas partes de la Gramática se defiende una característica de la conjunción que excluye o entra en conflicto con la defendida en la otra parte.

Al igual que sucede con la preposición, en la Analogía, se define la conjunción como palabra que enlaza (o como indice de enlace en algunas GRAE) ${ }^{217}$, mientras que, en las páginas de Sintaxis, se acepta que puede ejercer como palabra Reg. ${ }^{218}$ (vid. infra Cuadro 54).

En los ejemplos dados, se registran los siguientes tipos de estructuras:

- /Sust.+ conj. + Sust./: «Pedro y sus hijos»; «Elvira ó sus criadas».

- / conj. + Sust. + conj. + Sust./: «Ora el oficial, ora los soldados»; «ya el látigo, ya las espuelas».

- / / Vb. + conj. + Vb./: «Le defiendo y le defenderé».

- /conj. + Vb. + conj. + Vb./: «Ni trabaja ni deja trabajar»; «Ó lo hago hoy, ó no lo haré nunca».

${ }^{217}$ Cf. GRAE-1854: 126, 1858: 136, 1862: 140, 1864: 140, 1865: 140, 1866: 140, 1867: 139, 1870: 155, 1874: 183 («palabra ó frase que sirve para denotar la relacion que hay entre dos oraciones ó entre dos proposiciones de una misma oracion [...] Las conjunciones no solo denotan una relacion de enlace, sino que determinan tambien la naturaleza de este enlace»), 1878: 183, 1880: 205 («parte de la oración que sirve para enlazar las palabras y las oraciones unas con otras»), 1883: 205 («parte de la oracion que sirve para denotar el enlace entre dos ó más palabras, cláusulas ú oraciones»), 1885: 206, 1888: 204, 1890: 204, 1895: 204, 1900: 204, 1901 : 204, 1904: 199, 1906: 199, 1908: 199,1909: 199, 1911: 201, 1913: 201, 1916: 201.

${ }^{218}$ Cf. GRAE-1854: 155-156, 1858: 170-172, 1862: 174-176, 1864: 174-176, 1865: 174-176, 1866: 174-176, 1867: 173-175, 1870: 193-195, 1874: 221-223, 1878: 223-223, 1880: 234-235, 1883: 234-235, 1885: 236-237, 1888: 234-235, 1890: 234-235, 1895: 234-235, 1900: 234-235, 1901: 234-235, 1904: 228-229, 1906: 228-229, 1908: 228-229, 1909: 228-229, 1911: 233-234, 1913: 233-234, 1916: 233-234. 
Vemos que se comentan casos de enlace (coordinación concretamente) de elementos y de oraciones, pero no se recoge ningún ejemplo de dependencia oracional. No obstante, se hace mención a ciertos tipos de conjunciones introductorias de relaciones de dependencia oracional, por ejemplo, que, si bien no encontramos ejemplos ilustrativos en ninguna de las GRAE publicadas entre 1854 y 1916. La razón parece estar en que, en otro lugar, ya se ha hablado con detenimiento de las propiedades y la sintaxis de este que (tal como se recuerda al lector), por lo que únicamente se apunta que «sólo se une á los verbos, sirviendo de auxiliar á unos para regir á otros».

Y esta última afirmación lleva de nuevo a la duda: ¿la conjunción es sólo índice y medio de regencia, o tiene capacidad rectora?

Las declaraciones explícitas hacen pensar que la Academia se decanta por la primera posibilidad, como prueban los siguientes fragmentos (el primero de ellos abre el apartado de los Regímenes de la Conjunción en todas las GRAE que estamos atendiendo -las diferencias entre unas ediciones y otras son de redacción-):

Poca dificultad ofrece el régimen de las copulativas y disyuntivas, que así unen nombres, como verbos y adverbios, excepto que, aplicable únicamente á los verbos $[\ldots]$

[...] cuando unen [las conjunciones ora, ya y bien] dos verbos, necesariamente han de estar ambos en el mismo tiempo [...]

El enlace de las palabras por medio de conjunciones pide que aquéllas sean homogéneas, y no de distinta naturaleza; esto es, que la relacion sea de sustantivo á sustantivo, de verbo á verbo, de adverbio á adverbio, \&c.

(GRAE-1854: 155. El subrayado es mío)219

219 Ídem GRAE-1858: 170, 1862: 174, 1864: 174, 1865: 174, 1866: 174, 1867: 173-174, 1870: 193-194, 1874: 221-222, 1878: 222, 1880: 234, 1883: 234-235, 1885: 236 (en esta edición, se incorpora en la 
De igual condicion son todas las demas conjunciones áun no nombradas, tanto adversativas, como condicionales, causales, continuativas, \&c., en cuanto á regir solamente verbos expresos ó de propósito omitidos, y todas ellas se diferencian tambien de las copulativas (ménos que) y de las disyuntivas en enlazar únicamente oraciones, y no simples vocablos.

(GRAE-1854: 156. El subrayado es mío)220

Pero, a la vez que se está insistiendo en la idea de enlace (no de regencia), se sigue manteniendo un apartado, dentro del Régimen, dedicado a los regímenes de la conjunción (de hecho, las declaraciones están tomadas de ese apartado).

De la conjunción y de la preposición se volverá a hablar en el punto 6.2.4.

redacción de este párrafo la referencia al pronombre como categoría equivalente del nombre sustantivo: «[...] esto es, que a relación sea de nombre á nombre, ó pronombre que le sustituye, de verbo á verbo, de adverbio á adverbio, etc.»), 1888: 235, 1890: 234-235, 1895: 235, 1900: 235, 1901: 235, 1904: 228-229, 1906: 228-229, 1908: 229, 1909: 229, 1911: 233, 1913: 233 у 1916: 233.

220 Ídem GRAE-1858: 171, 1862: 175, 1864: 175, 1865: 175, 1866: 175, 1867: 174-175, 1870: 194, 1874: 222-223, 1878: 222-223, 1880: 235, 1883: 235, 1885: 237, 1888: 235, 1890: 234-235, 1895: 235, 1900: 235, 1901: 235, 1904: 229, 1906: 229, 1908: 229, 1909: 229, 1911: 234, 1913: 234 y 1916: 234. 


\section{CONJUNCIÓN ¿índice de relación / nexo de unión o artífice de regencia?}

\begin{tabular}{|c|c|c|c|c|}
\hline Edición & $\begin{array}{l}\text { Parte de la } \\
\text { Gramática }\end{array}$ & Función & Declaración & Ejemplos \\
\hline GRAE-1854221 & $\begin{array}{l}\text { Analogía } \\
\text { Sintaxis }\end{array}$ & $\begin{array}{l}\text { Nexo } \\
\text { Palabra } \\
\text { Reg. }\end{array}$ & $\begin{array}{l}\text { «Conjuncion es una parte de la oracion, que sirve } \\
\text { para enlazar las palabras y las oraciones unas } \\
\text { con otras» (pág. 126). } \\
\text { «Las conjunciones, en general, lo mismo que las } \\
\text { preposiciones, rigen nombre sustantivo ó } \\
\text { pronombre personal, verbo y adverbio» (pág. } \\
\text { 155). }\end{array}$ & $\begin{array}{l}\text { Tú y yo; Se proponen los premios } \\
\text { de la virtud, para que la amemos; } \\
\text { El juez, aunque severo, es justo. } \\
\text { Pedro y sus bijos; Ni trabaja ni } \\
\text { deja trabajar. }\end{array}$ \\
\hline GRAE-1870 222 & $\begin{array}{l}\text { Analogía } \\
\text { Sintaxis }\end{array}$ & $\begin{array}{l}\text { Índice } \\
\\
\text { Palabra } \\
\text { Reg. }\end{array}$ & $\begin{array}{l}\text { «Conjuncion es aquella palabra ó frase que sirve } \\
\text { para denotar la relacion que hay entre dos } \\
\text { oraciones ó entre dos proposiciones de una } \\
\text { misma oracion [...] La relacion que denotan las } \\
\text { conjunciones es siempre una relacion de enlace } \\
{[\ldots] » \text { (pág. 155). }} \\
\text { «Las conjunciones en general, lo mismo que las } \\
\text { preposiciones, rigen nombre ó pronombre que } \\
\text { le representa, verbo y adverbio» (pág. 193). }\end{array}$ & $\begin{array}{l}\text { Padres é hijos profesan la } \\
\text { misma doctrina; Juan no } \\
\text { vendrá porque está enfermo. } \\
\text { Ni Juan ni tres juanes; La amo \y } \\
\text { la amaré mientras viva. }\end{array}$ \\
\hline GRAE-1880 & $\begin{array}{l}\text { Analogía } \\
\text { Sintaxis }\end{array}$ & $\begin{array}{l}\text { Nexo } \\
\text { Palabra } \\
\text { Reg. }\end{array}$ & $\begin{array}{l}\text { «Conjunción es aquella parte de la oración que } \\
\text { sirve para enlazar las palabras y las oraciones } \\
\text { unas con otras» (pág. 205). } \\
\text { «Las conjunciones rigen nombre, ó pronombre } \\
\text { que les representa, verbo y adverbio» (pág. 234). }\end{array}$ & $\begin{array}{l}\text { Horacio } \ \text { V irgilio fueron dos } \\
\text { grandes poetas; Juan no vendrá } \\
\text { porque está enfermo. } \\
\text { Elvira ó sus criadas; Ese ó aquel; } \\
\text { Ora te vayas, ora te quedes. }\end{array}$ \\
\hline GRAE-1883 ${ }^{223}$ & $\begin{array}{l}\text { Analogía } \\
\text { Sintaxis }\end{array}$ & $\begin{array}{l}\text { Índice } \\
\text { Palabra } \\
\text { Reg. }\end{array}$ & $\begin{array}{l}\text { «Conjunción es aquella parte de la oración que } \\
\text { sirve para denotar el enlace entre dos ó más } \\
\text { palabras, cláusulas ú oraciones» (pág. 205). } \\
\text { «Las conjunciones rigen nombre, ó pronombre } \\
\text { que les representa, verbo y adverbio» (pág. 234). }\end{array}$ & $\begin{array}{l}\text { Horacio y Virgilio fueron dos } \\
\text { grandes poetas; Juan no vendrá } \\
\text { porque está enfermo. } \\
\text { Gonzalo y sus bijos; lo be dicho y } \\
\text { lo sostengo. }\end{array}$ \\
\hline
\end{tabular}

Cuadro 54: Papel de la conjunción

${ }^{221}$ Ídem GRAE-1858: 136 y 170, 1862: 140 y 174, 1864: 140 y 174, 1865: 140 y 174, 1866: 140 y 174, y 1867: 139 y 173.

222 Ídem GRAE-1874: 183 y 221; GRAE-1878: 183 y 221.

223 Ídem GRAE-1885: 206 y 236, 1888: 204 y 234, 1890: 204 у 234, 1895: 204 у 234, 1900: 204 у 234, 1901: 204 у 234, 1904: 199 у 228, 1906: 199 у 228, 1908: 199 у 228, 1909: 199 у 228, 1911: 201 у 233, 1913: 201 у 233, у 1916: 201 у 233. 


\section{CASO (6) DE REGIMEN: palabra Reg. = Adjetivo}

Ya sabemos que la GRAE-1870 es la primera edición de la Gramática académica en que se concede al adjetivo el carácter de categoría independiente. Al mismo tiempo, se le empieza a tener en cuenta no sólo como segundo elemento en una relación de regencia (elemento reg.), sino también en calidad de palabra Reg.224

Con respecto a lo primero, desde siempre, la Real Academia ha aceptado -según se colige de propias declaraciones- que el adjetivo es una subclase de palabra cuya misión es modificar al nombre sustantivo; pero, hasta la 12. a edición de la Gramática (1870), no se incluye, en el capítulo del Régimen, un apartado en el que se dé cuenta de las relaciones del tipo /Sust. $\rightarrow \operatorname{adj} . /$.

224 Años antes, Ballot (1842 [1796]) reconocía al adjetivo como palabra con capacidad de regencia, según quedó apuntado en la nota 126 de este capítulo. En la primera mitad del XIX, también prestaron atención a los distintos regímenes del adjetivo Saqueniza (1832: 84) y Noboa (1839: 217-218).

No son pocos los autores de nuestra tradición que bien reconocen explícitamente al adjetivo como palabra Regente, bien atienden a la posibilidad de que esta categoría reciba complementación. Es el caso de Nebrija, quien, como ya hemos dicho (vid. supra 6.2.1.1.), no definió ni trató de forma pormenorizada las relaciones de régimen. No obstante, no pasa por alto que

Ai esso mesmo algunos nombres adjectivos de cierta significación: que se pueden ordenar conlos genitivos delos nombres substantivos cuales son estos.

Entero de vjda.

Limpio de pecados.

Prodigo de dineros.

Escasso de tiempo.

[...]

Ai otros nombres adjectivos que se aiuntan con dativos de sustantivos. Como Enojoso alos buenos.

(Nebrija, 1492: fol. 47 v.).

Correas, siguiendo a Nebrija, apunta también casos de complementación del adjetivo. En el siglo XVIII, Gayoso y San Pedro reconocerán igualmente capacidad de regencia a esta clase de palabra.

La mayoría de los gramáticos del periodo correspondiente a las fechas que sirven de flanco para nuestro corpus incluyen al adjetivo entre las palabras Regentes (vid. Calero Vaquera, 1986: 206-210). 
Este caso (6) de regencia (el adjetivo, ahora, en su calidad de palabra Reg.) es considerado por la Academia como ocasional, «pues aunque afecte el adjetivo á otras partes de la oración, va siempre regido de un nombre», esto es, se reconoce que el adjetivo puede funcionar en determinados momentos como palabra Reg., pero siempre será, al mismo tiempo, palabra reg., porque su propia naturaleza hace de él una categoría dependiente (que, sin dejar de serlo, puede ir en ocasiones acompañado de otra categoría que dependa de él).

La inclusión de casos de dependencia en los que el primer elemento de la relación es un Adjetivo supone que la Institución acoge, por primera vez en su obra gramatical dentro el capítulo del Régimen, estructuras del tipo:

- /Adj. + prep. + Sust. - Pr./, bajo la relación /Adj. $\rightarrow$ sust./: limítrofe con Francia; propio para el caso; libre sin costas; generoso con ella; enemigo de aquel; ridículo entre nosotros.

- /Adj. + prep. + Adv./: vacío por dentro; feo de cerca, que responderían a la relación /Adj. $\rightarrow$ adv./.

- /Adj. + prep. + Vb./: ágil para correr; harto de esperar, tenaz en pretender o contenta con bailar.

En definitiva, en los apartados dedicados a los regímenes del adjetivo, encontramos nuevos ejemplos de relaciones sintagmáticas intraoracionales: Adyacente del Adjetivo (en los dos primeros casos) y dependencia o complementación oracional respecto de un núcleo adjetivo (en el tercer esquema).

A propósito del último caso, se impone advertir, no obstante, que el verbo regido por un adjetivo es siempre un infinitivo -que la Academia 
considera teñido de las propiedades del nombre-, por lo que la relación / Adj. $\rightarrow$ vb./ no es equivalente exacto (por abarcar menos estructuras posibles) de nuestras subordinadas dependientes de un núcleo adjetivo. Por otra parte, la estructura / Adj. + prep. + inf./ la hemos visto recogida en el Caso (4) de Régimen hasta la GRAE-1878 (Fácil de lograr), de modo que, en las dos ediciones de los años setenta, se interpreta como relación /Prep. $\rightarrow$ vb./ y como relación /Adj. $\rightarrow$ vb./.

Con respecto a las relaciones /Adj. $\rightarrow$ adv./ (Vacío por dentro; Loco a sabiendas; Avaro sobradamente, etc.) conviene comentar una distinción que hacen los redactores de la Gramática. Si no he leído mal, teniendo en cuenta los ejemplos dados, el adjetivo rige un averbio si este va precedido de preposición (o si se trata de locución adverbial). La secuencia / Adj. + Adv./ (o, al menos, la secuencia / Adj. + Adv. en -mente/, ya que es el único ejemplo que se pone de adverbio no precedido de preposición) no responde a la relación / Adj. $\rightarrow$ adv./. Reproduzco el párrafo que interesa:

Lo prueban [lo que reza el epígrafe: «EL ADJETIVO RIGE Á ALGUNOS ADVERBIOS Y MODOS ADVERBIALES»] estas cláusulas: Vacío por dentro; Loco á sabiendas; Oscuro de léjos; Feo de cerca; Bueno para hoy; Viuda desde ayer, etc. Los adverbios acabados en mente rechazan toda preposicion. Nos ceñimos á decir: Severo ó benigno justamente; Avaro ó pródigo sobradamente, etc. Bien es verdad que tales adverbios ni rigen

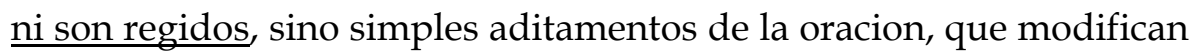
su concepto en un sentido ó en otro, pero sin influencia en la sintáxis.

(GRAE-1870: 179. El subrayado es mío)225

225 Ídem GRAE-1874: 207. En la GRAE-1878: 207 se afirma también que «tales adverbios ni rigen ni son regidos» y se remite a las páginas 165 y 166, donde -se dice- se ha dado la explicación de ello. Estas páginas corresponden, efectivamente, al capítulo que, en la Analogía, se dedica al Adverbio (capítulo que se extiende desde la página 158 a la 167), pero en él no he encontrado explicación de por qué los adverbios de los ejemplos que estamos comentando «ni rigen ni son regidos». 
La interpretación que propongo (solo hay relación / Adj. $\rightarrow$ adv./. si media una preposición) parece confirmarse con el cambio que este apartado experimenta en la GRAE-1880: a partir de esta edición, se elimina el párrafo reproducido y el apartado dedicado a las relaciones / Adj. $\rightarrow$ adv./ se reduce a dos líneas, donde se dan simplemente ejemplos que confirman esta "regencia" (que se limita «á algunos adverbios y modos adverbiales» -GRAE1880: 224-). Todos los ejemplos, en todas las ediciones que siguen, presentan la estructura /Adj. + prep. + Adv./: Vacío por dentro; Feo de cerca; Bueno para hoy; Viuda desde ayer 226.

226 Idéntica exposición encontraremos hasta el libro de 1916. Cf. GRAE-1883: 224, 1885: 226, 1888: 224, 1890: 224, 1895: 224, 1900: 224, 1901: 224, 1904: 218, 1906: 218, 1908: 218, 1909: 218, 1911: 222, 1913: 222 y 1916: 222. 


\section{CASO (7) DE REGIMEN: palabra Reg. = Gerundio}

Poco comentario merece este último tipo de regencia, añadido también de la 12. ${ }^{a}$ edición de la Gramática (GRAE-1870). Del gerundio se dice que mantiene el mismo régimen del verbo al que pertenece, advirtiendo, eso sí, en todas las ediciones publicadas desde la fecha hasta 1916, que este gerundio con su régimen «no forma oracion completa sin el auxilio de otro verbo, precediéndole ó siguiéndole» (GRAE-1870: 228)227. Parece que se está apuntando una idea similar a la defendida del adjetivo: el gerundio puede regir, pero siempre irá, al mismo tiempo, regido por otra palabra.

227 Ídem GRAE de 1874: 211, 1878: 211, 1880: 228, 1883: 228, 1885: 228, 1888: 228, 1890: 228, 1895 : 228, 1900: 228, 1901: 228, 1904: 222, 1906: 222, 1908: 222, 1909: 222, 1911: 227, 1913: 227, 1916 : 227. 


\subsubsection{Reglas de Construcción}

Teniendo en cuenta lo dicho a propósito de los conceptos de sintaxis y construcción (vid. supra 6.1.4.), veamos cómo se define la construcción y qué tipo de relaciones sintácticas se recogen bajo el capítulo titulado De la Construcción en las GRAE publicadas entre 1854 y 1916.

\subsubsection{El concepto de construcción}

En las páginas correspondientes al punto 6.1.4., se adelantó que el concepto de construcción se definía de forma vaga e imprecisa en la cuarta edición de la Gramática (1796), la primera -recordamos- que separaba este concepto del de sintaxis 228 .

Las ediciones decimonónicas no superan la imprecisión de la definición dieciochesca229: la construcción sigue siendo «otra especie de dependencia» que

${ }^{228}$ Interesa volver a traer a colación las palabras de los académicos:

LA CONSTRUCCION de las partes de la oracion es otra especie de dependencia [como el Régimen] que las une, no con tanta precision como el régimen, sino con alguna mayor anchura y libertad; ya añadiendo unas, ya introduciendo otras entre las que van enlazadas por el régimen, para dar energía á las oraciones, y evitar la uniformidad que resultaria, si se guardaran constantemente en el uso las reglas del régimen y concordancia de las palabras.

(GRAE-1796: 326-327. El subrayado es mío)

${ }^{229}$ La similitud de las definiciones es, de hecho, más que notoria. Compárese la propuesta de 1796 con esta otra, redactada cincuenta y ocho años después:

La construccion de las partes de la oracion es otra especie de dependencia [como el Régimen] que las une, no con tanta precision como el régimen, sino con alguna mayor libertad; ya añadiendo unas, ya introduciendo otras entre las que van enlazadas por el régimen, para explicar mejor los pensamientos, y evitar la uniformidad que resultaria si se guardaran constantemente en el uso las reglas del régimen y concordancia de las palabras.

(GRAE-1854: 156-157. El subrayado es mío)

Ídem GRAE-1858: 172 (en esta edición, se sustituye el término dependencia por el de vínculo), 1862: 176, 1864: 176, 1865: 176, 1866: 176, 1867: 175, 1870: 196, 1874: 224, 1878: 224, 1880: 236, 1883: 236, 1885: 238, 1888: 236, 1890: 236, 1895: 236, 1900: 236, 1901: 236, 1904: 230, 1906: 230, 1908: 230, 1909: 230, 1911: 235, 1913: 235 y 1916: 235. 
une las distintas partes de la oración ${ }^{230}$. Esta suerte de relación de dependencia intraoracional difiere de las relaciones de régimen en los siguientes aspectos 231 :

1. En primer lugar, no es tan precisa, tan rígida: las palabras relacionadas por la construcción entrañan lazos de dependencia «con alguna mayor libertad» que los que unen a Palabra Regente y palabra regida.

2. Esa mayor libertad implica la adición de palabras (delante, detrás o entre los términos relacionados por el régimen) «para explicar mejor los pensamientos y evitar la uniformidad».

3. La construcción, además, debe respetar las reglas gramaticales de concordancia y régimen (de donde se deduce que el régimen es

${ }^{230}$ Como ya indicó Gómez Asencio (1981: 51-56), y después Calero Vaquera (1986: 210-212), la propuesta de definición de la Academia destaca por su extrañeza entre los gramáticos de la época (tanto los de finales del siglo XVIII y primera mitad del XIX -la definición se formula, como acabamos de señalar, en 1796-, como los de la segunda mitad del XIX y principios del XX -la misma definición se va a mantener en las ediciones comprendidas entre 1854 y 1916-). La construcción suele ser definida con precisión por los autores coetáneos: habitualmente, en términos de orden o colocación de palabras que permita dar cuenta de la dependencia existente entre las mismas (Herrainz, 1869: 145-151 y Gómez de Salazar, 1869: 131-136 y 1874: 154-159, entre otros), pero también encontramos gramáticos que la conciben como el estudio y formación de las oraciones (es el caso de Noboa, 1839: 186-212, quien de forma explícita rechaza la identificación entre construcción y colocación -cf. 1939: 184-185-). Para los puntos de originalidad en la concepción gramático-sintáctica de Noboa, interesa el estudio de Maquieira (1997).

En los textos estrictamente contemporáneos del corpus central de esta investigación, no dejamos de encontrar, sin embargo, definiciones que siguen fielmente la imprecisión de la Academia, entre ellas, la que ofrece Ruiz Morote (1880: 60. El subrayado es mío):

[Construcción] Es otra especie de vínculo que permite añadir ó introducir otras palabras entre las regentes y regidas para expresar mejor y con más libertad los pensamientos.

Calero Vaquera (1989: 211) también menciona como seguidores de la definición académica a Herranz y Quirós, Fandiño, Sánchez y Carmena, y Sanmartí. $231 \mathrm{Vid}$. para las ediciones del corpus, las páginas señaladas en la nota 229. 
requisito de cumplimiento previo para que podamos hablar de construcción).

4. El fin perseguido por la construcción es la variedad de oraciones. Esta variedad debe servir de alarde de la propiedad y elegancia de nuestra lengua.

5. Por último, la construcción debe tomar como modelo los autores clásicos y el uso de las personas cultas. Estas fuentes confirman que las reglas de construcción no pueden ser ni uniformes ni fijas, «por la diversidad de estilo de los autores y el gusto peculiar de cada uno».

Esta falta de precisión en torno a la idea de construcción alentó uno de los párrafos más incisivos del Examen crítico que Santiago Vicente García hizo de la GRAE-1854. Si la doctrina académica del régimen le merece a este autor la consideración de auténtico «embolismo», de la construcción dice que

es una invencion estravagante é incomprensible, y su definicion vaga, oscura y difusa, no esplica en lo que consiste ni cómo se emplea, refiriéndose para conocer sus diversos y variados giros á la lectura de los autores clásicos, y al uso de las personas cultas. En los ejemplos que se citan en confirmacion de esta rara doctrina, no se reconocen mas que la observancia de la reglas generales de la concordancia, y el régimen con los agregados completivos.

(Vicente García, 1855: 12. El subrayado es mío) ${ }^{232}$

\footnotetext{
${ }^{232}$ En su Gramática de la lengua española, Vicente García mantiene la identidad sintaxis = construcción defendida por la Academia en la primera edición de la GRAE. La Sintaxis (que puede ser lógica o figurada) cuenta con tres medios para la coordinación de las palabras: concordancia y régimen (con los términos variables) y complemento (con los invariables -excepto la preposición, que se une a palabras variables-). El régimen es dividido, a su vez, en nominal, pronominal y verbal, y en cada uno de ellos se pueden distinguir distintas clases: directo,
} 
Poco caso hizo la Institución de estas duras acusaciones a su doctrina: en todas las GRAE decimonónicas y en las primeras del siglo XX (hasta nueve) mantuvo intactas las definiciones, casi idéntica la casuística y muy poco cambiados los ejemplos. Algún párrafo con información adicional será el único cambio evidente entre dos grupos de Gramáticas nuevamente delimitados por el año 1870.

Entre los cinco principios señalados arriba (constantes en todas las ediciones que estamos considerando), la GRAE-1870 introduce un párrafo que interesa reproducir:

Constructiva es la concordancia, constructivo el régimen; pero sin esta otra parte, á la cual se da por antonomasia el nombre de construccion (que es etimológicamente sinónimo de sintáxis), si pueden formarse oraciones sencillas, no las complexas; ménos aún dos ligadas entre sí, ó una más larga serie de ellas. Enseña, pues, este capítulo á combinar y completar los elementos explicados en los anteriores, concurriendo la doctrina de todos ellos á dar variedad y soltura á la frase, sin lo cual carecería de nervio y de atractivo el lenguaje.

(GRAE-1870: 196)233

indirecto, simple, doble, articulado, concordante, prepositivo, compuesto. Vid. Vicente García (1854: 66-75).

233 En las ediciones comprendidas entre 1874 y 1916, la cita se encuentra en la página indicada en la nota 229.

En la GRAE-1911 se mantiene la misma idea expuesta en el párrafo reproducido de la GRAE-1870, pero la redacción cambia:

Hay construcción en la concordancia y en el régimen; pero sin esta otra parte, a la cual se da por antonomasia el nombre de construcción, si pueden formarse oraciones sencillas no las complejas, y menos aún dos ligadas entre sí, o una larga serie de ellas. Enseña, pues, este capítulo a combinar y completar los elementos explicados en los anteriores. 
El nuevo párrafo (que se mantiene con idénticas palabras hasta la GRAE-1909 y, a partir de la edición de 1911, con los cambios de redacción que quedan reflejados en la nota 233), supone:

- Una vuelta (en declaraciones explícitas hasta la edición de 1909), si no a la defensa sintaxis = construcción al modo de la GRAE-1771, sí a la idea de que construcción y sintaxis no son cosas muy distintas, aunque en los libros del XIX (herederos de la GRAE-1796, que impuso la distinción de las dos etiquetas), se use de forma restringida y especializada el término construcción ${ }^{234}$.

- La confirmación de las conclusiones a las que llegamos en 6.1.4.: la construcción implica el régimen y la concordancia y, además, relaciones de orden, que aquí son especialmente importantes por cuanto cualquier alteración de la secuencia (por adición de palabras, por incrustación de palabras entre término Reg. y término reg., por supresión de elementos, o por dislocación del orden de los mismos) supondrá un cambio de construcción, pero no necesariamente un cambio de sintaxis.

- La confirmación de que las relaciones de régimen solo contemplan, dentro de la doctrina institucional, relaciones de dependencia intraoracional 235 (y sabemos, por lo visto en los distintos apartados de 6.2.1., que son relaciones entre elementos sueltos -palabras-, no entre constituyentes; de hecho, los ejemplos que encontramos de oraciones

\footnotetext{
${ }^{234}$ No obstante, conviene tener presente la interpretación que propuse en 6.1.4.: en 1796, el nuevo uso del término construcción (diferenciado de sintaxis) parece responder más a un intento de dar carta de naturaleza a las relaciones de régimen que a una deliberada distinción conceptual nítida entre sintaxis y construcción.

235 Haciendo excepción de la ligera mención a la coordinación de oraciones (en términos nuestros, no de la Institución) en los regímenes de la conjunción (vid. supra. Caso (5) de Régimen).
} 
subordinadas -en una concepción actual- también se ofrecen como casos de relaciones binarias de dependencia).

En 1870, se reconoce explícitamente, además, que las reglas de régimen (y las de concordancia -de las que luego hablaremos-) solo conducen a la formación de “oraciones sencillas": ¿nuestras simples? Son las reglas de construcción las que parecen garantizar la formación de unidades superiores a la oración, las que van a permitir la combinación de esquemas /(Suj.) + Pred./ relacionados entre sí. Al menos es lo que sugieren las palabras de presentación de este último capítulo de la Sintaxis. Y hablamos de "sugerencia" porque, una vez más, la teoría se expone en términos faltos de concreción doctrinal.

En el periodo que centra el interés de esta investigación, se encuentran definiciones precisas sobre qué es construcción y qué contempla su estudio (vid. supra nota 230). Martínez Sevilla (1851: 75), que se hace eco de la concepción más extendida, entiende esta parte de la Sintaxis como colocación -es lo distintivo de la construcción frente al régimen, que es 'dependencia'- de palabras y oraciones (consideradas las últimas como elementos del discurso, es decir, como constituyentes de una oración). En Martínez Sevilla, nuestras oraciones subordinadas formaban parte de las relaciones de régimen (según declaraciones explícitas) y también se estudiaban en la construcción, donde interesaba atender, sobre todo, a cuestiones de orden, lo que explica la atención a figuras como el hipérbaton.

La conexión construcción $\approx$ sintaxis figurada es evidente en otros tratados de la época. Ejemplo paradigmático de esta ligazón es el dado por Herrainz (1885) sobre las decenas de permutaciones que admite la oración Pepe compone muchos versos, algunas de las cuales rayan lo inadmisible desde el punto de 
vista de la ordenación gramatical o regular, siendo, sin embargo, aceptables con intenciones figuradas o retóricas ${ }^{236}$. (Vid, supra 6.1.4.).

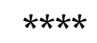

En las páginas anteriores hemos podido comprobar que no le falta razón a Vicente García al señalar la teoría del Régimen como parte especialmente confusa dentro de los libros académicos. Es nuestro objetivo ahora analizar qué grado de dificultad, incomprensión y oscuridad (términos que utiliza en su crítica) existe en lo atinente a la llamada construcción. ménos que á la categoría de lo incontable, según prácticamente vamos á demostrar.

Cuatro palabras producirán su séxtuplo de permutaciones, así:

Versos muchos Pepe compone. Muchos versos Pepe compone. Muchos Pepe versos compone. Muchos Pepe compone versos. Versos Pepe muchos compone Pepe versos muchos compone. Pepe muchos versos compone. Pepe muchos compone versos. Versos Pepe compone muchos. Pepe versos compone muchos. Pepe compone versos muchos. Pepe compone muchos versos. Versos muchos compone Pepe. Muchos versos compone Pepe. Muchos compone versos Pepe. Muchos compone Pepe versos. Versos compone muchos Pepe. Compone versos muchos Pepe. Compone muchos versos Pepe. Compone muchos Pepe versos. Versos compone Pepe muchos. Compone versos Pepe muchos. Compone Pepe versos muchos. Compone Pepe muchos versos.

Cierto que varios de los giros anteriores son anómalos ó inusuales; más innegable tambien que la serie proporciona entre los aceptables, estructuras bastantes para ajustarse á lo ordinario ó á lo extraño, para conseguir consonancias ó evitar sonsonetes; para los fines especiales que uno pueda proponerse.

(Herrainz, 1885: 143) 


\subsubsection{Las reglas de construcción}

La estructuración básica del apartado de Construcción se repite a lo largo de todas las Gramáticas del siglo XIX y las de principios del XX previas al jalón de 1917. Esta estructuración viene a corresponderse (no completamente, como cabe imaginar) con el análisis separado de:

- El SN (Sujeto).

- El SV (Predicado).

- La dependencia oracional, tanto del tipo / es, casos de dependencia de un elemento "complejo" con respecto a un núcleo verbal -básicamente, nuestras subordinadas sustantivas y adverbiales-), como del tipo /N dependencia de una estructura oracional respecto de un núcleo no verbal -en concreto, nuestras subordinadas adjetivas o de relativo-).

- Los verbos pronominales y el uso de pronombres con los verbos.

La propuesta de la Academia en el siglo XIX repite, en esencia, lo establecido en la última GRAE dieciochesca (1796) en aquel apartado de Construcción que por primera vez aparecía en la Gramática del real Instituto. Frente a la mayoría de los casos de régimen, la aparición de estas estructuras es opcional; su empleo tiene como finalidad matizar significados o dar viveza y elegancia a la lengua $(\approx$ Sintaxis figurada). Entre los casos recogidos, encontramos algunos que, en el capítulo anterior del libro, se han considerado también relaciones de régimen, lo que, en ocasiones (no siempre), supondrá incoherencia de doctrina. La inclusión simultánea de una misma estructura en el capítulo del Régimen y de la Construcción no es incompatible en tanto que las 
relaciones de régimen y las de construcción, según lo dicho en las páginas anteriores, se distancian en virtud de la dicotomía relaciones en abstracto ("profundas") / relaciones superficiales. Serán una vez más, afirmaciones explícitas (producto o no de la inercia en la redacción o del consciente mantenimiento de lo establecido) las responsables de ciertas inconsecuencias en el proceder de los académicos.

\section{1. «Construccion del nombre, pronombre, y otras partes de la oracion ántes $\underline{\text { del verbo» }}^{237}$}

Bajo este epígrafe, se registran aquellas estructuras (palabras o grupos de palabras) que pueden mediar entre la relación de regencia directa que se establece entre el Sustantivo Sujeto y el verbo principal de la oración (relación de dependencia del tipo /Sust. $\rightarrow$ vb./). Sin que la Academia haga ninguna alusión a ello, podemos decir que, en este primer apartado de la Construcción, mediante las estructuras explicadas (en concreto, las aquí recogidas en (a) y (b)), se va a dar cuenta de la tipología de adyacencias que puede establecerse en el SN (Sujeto).

Los ejemplos dados permiten hacer la siguiente clasificación:

${ }^{237}$ Cf. GRAE-1854: 157, 1858: 173, 1862: 177, 1864: 177, 1865: 177, 1866: 177 ,1867: 176, 1870: 197, 1874: 225, 1878: 225, 1880: 237, 1883: 237, 1885: 239, 1888: 237, 1890: 237, 1895: 237, 1900: 237, 1901: 237, 1904: 231, 1906: 230, 1908: 230, 1909: 230, 1911: 236, 1913: 236 y 1916: 236. 
(a) Adyacente del Nombre:

\begin{tabular}{|c|c|}
\hline ESTRUCTURAS & EJEMPLOS \\
\hline /Sust. + prep. + Sust./ & $\begin{array}{l}\text { Un niño SIN PADRE pide limosna. } \\
\text { Sus oraciones CONTRA CATILINA son obras } \\
\text { maestras. }\end{array}$ \\
\hline $\begin{array}{l}\text { /Sust. + Adj./ o } \\
\text { /Sust. + Partic./ }\end{array}$ & $\begin{array}{l}\text { El hombre BUENO ama la virtud. } \\
\text { Los niños MIMADOS no se aficionan al estudio. }\end{array}$ \\
\hline $\begin{array}{c}\text { /Sust. }+ \text { Or.I } \\
\text { (dependencia oracional del tipo } \\
\mathrm{N} \Leftarrow /(\text { Suj.)+Pred./) } \\
\text { subordinación adjetiva } \\
\text { oración de relativo- }\end{array}$ & $\begin{array}{l}\text { La mujer, QUE CUIDA DE SU CASA Y FAMILIA, es } \\
\text { muy estimada de todos. }\end{array}$ \\
\hline
\end{tabular}

Cuadro 55: Casos de Adyacente del Nombre en el apartado de Construcción

\section{/Sust. + Or./}

La última estructura es recogida por la Institución desde la primera GRAE que centra nuestro interés $(1854)^{238}$, pero siempre se va a considerar (hasta 1916) un caso de construcción, no de régimen, según ha quedado dicho en las primeras páginas de 6.2.1.2. Posiblemente, su carácter incidental y su valor explicativo (que la hace suprimible) justifica la inclusión de este tipo de oraciones en la construcción. En efecto, cumple con lo establecido: es un grupo de palabras que se intercala entre palabra

${ }^{238}$ Y hemos visto que también daba cuenta de ella la GRAE-1796 (remito al último cuadro de 6.1.4.). 
Reg. (mujer) y palabra reg. (es); en esta ocasión, además, ayuda a «explicar mejor los pensamientos».

Con independencia de la imprecisión de que adolece la doctrina académica en lo relativo a la construcción, y dejando a un lado los puntos de inestabilidad de la teoría del régimen, la inclusión de las oraciones de relativo únicamente en el capítulo de Construcción se justifica, en principio, por el concepto habitual que en la época se tenía de la incidencia (vid. Salazar García, 1999), que supone siempre un vínculo con respecto a otra unidad más laxo que el supuesto por la subordinación ${ }^{239}$. Tendremos que completar la visión de los académicos sobre este tipo de estructuras con lo expuesto en el capítulo dedicado a las oraciones.

\section{/Sust. + Adj. o Partic./}

Esta combinación se incluye entre los casos de construcción ${ }^{240}$ desde la GRAE-1796. Recordemos que, a partir de 1870, se empiezan a estudiar bajo el Régimen relaciones del tipo /Sust. $\rightarrow$ adj./, de las que los sintagmas hombre bueno y niños mimados serían ejemplos paradigmáticos. Sin embargo, hemos visto que en la regencia del sustantivo sobre el adjetivo se registra otro tipo de estructuras (vid. supra 6.2.1.2. relaciones /Sust. $\rightarrow$ sust./, Caso (1) de Régimen -apartado (a)-, y relaciones /Sust. $\rightarrow$ adj./, Caso (1) de Régimen -apartado (b)-). Las relaciones de construcción /Sust. + adj./ cumplen el requisito previo de

239 Dentro de nuestra tradición, es Bello quien, a partir de la 4. a edición de su Gramática (1857), expone con claridad esta diferencia:

La proposición especificativa se llama subordinada, y la proposicion de que ésta depende subordinante. La proposición explicativa se llama incidente, y la de que ésta depende principal. Las proposiciones incidentes son en cierto modo independientes, y así es que sin alterar en nada el sentido del anterior ejemplo [«Las señoras, que deseaban descansar, se retiraron»], se podría decir: «Las señoras deseaban descansar y se retiraron».

(Bello, 1860 [1847]: 301)

${ }^{240}$ Y también de concordancia en todas las GRAE publicadas hasta 1916 (vid. infra 6.2.3.). 
seguir las reglas de concordancia: bueno y mimados concuerdan (en género y número), respectivamente, con hombre y niños, que, a su vez, son los términos Regentes de sendas relaciones /Sust. $\rightarrow$ vb./).

\section{/Sust. + prep. + Sust./}

El primero de los esquemas indicados es recogido de forma simultánea en los capítulos de Régimen (relaciones /Sust. $\rightarrow$ sust./) y Construcción desde 1854. Insisto una vez más en la idea de que Un niño sin padre pide limosna debería ser interpretado (en coherencia con afirmaciones explícitas vertidas en distintos lugares de las Gramáticas) como ejemplo de relaciones de construcción en tanto que combina tres casos de régimen, dos de ellos con el mismo término Regente: / niño $\rightarrow$ padre/, /niño $\rightarrow$ pide/ y /pide $\rightarrow$ limosna/). Que la Academia marque, en casos como este, el SP en función de CN -usando términos actualescomo ejemplo de palabras en construcción (cumpliendo el requisito previo del régimen: se aclara que padre va regido por la preposición) que se intercalan en la relación /Sust. $\rightarrow$ vb./ supone negar la relación /Sust. $\rightarrow$ sust./ (en el ejemplo propuesto, /niño $\rightarrow$ padre/) que tan claramente se defiende en el primer apartado del capítulo del Régimen en todas las ediciones.

En este punto concreto, la GRAE-1854 suma (en el capítulo de Construcción) una contradicción (a lo dicho en el Regimen) frente al texto de 1796, en el cual no se decía explícitamente que la preposición rigiera al segundo sustantivo. Conviene volver a traer a colación el párrafo de la 4 . $^{\text {a }}$ edición (reproducido en 6.2.1.1.) y compararlo con el mismo fragmento en la primera edición del siglo XIX: 
Todos los nombres comunes admiten ántes del verbo otros nombres sustantivos en genitivo, v. g. El hijo de Pedro viene; y asimismo nombres adjetivos que conciertan con ellos, v. g. El hombre bueno ama la virtud: la muger virtuosa cuida de su casa.

(GRAE-1796: 328. El subrayado es mío)

Todos los nombres sustantivos, de cualquier especie que sean, admiten ántes del verbo otros nombres sustantivos regidos de una preposicion, $v$. gr.: Un niño SIN PADRE pide limosna; Las obras DE CICERON manifiestan su gran talento [...]; y asimismo nombres adjetivos ó participios que conciertan con ellos, v.gr.: El hombre BUENO ama la virtud [...]

(GRAE-1854: 157. El subrayado es mío)

(b) Adyacente del Adjetivo (y Participio):

\begin{tabular}{|c||c|}
\hline \hline ESTRUCTURAS & EJEMPLOS \\
\hline \hline IAdj. + prep. + Sust.I & Un cántaro lleno DE AGUA pesa más de lo que parece. \\
\hline /Partic. + prep. + Sust.I & Un joven criado ENTRE GENTE RÚSTICA no pierde \\
& fácilmente sus hábitos groseros. \\
\hline IAdj. + prep. + Inf.I & Un caballo malo PARA CORRER puede ser bueno PARA \\
& TIRAR de un carro. \\
&
\end{tabular}

Cuadro 56: Casos de Adyacente del Adjetivo (y Participio) en el apartado de Construcción 
También los casos de Adyacente del Adjetivo se recogen desde el primer momento en la Gramática institucional, pero no dentro de las relaciones de régimen, por las razones que se apuntaron en su lugar (vid. supra 6.2.1.2): el Régimen, en las primeras ediciones del corpus, está más presidido por el logicismo, lo que explica que el adjetivo, en un primer momento, no se considere apto para funcionar como palabra Reg. (por significar 'cualidad', 'accidente', no 'sustancia') ${ }^{241}$. Sin embargo, en la Construcción lo determinante parece ser (la imprecisa exposición de la doctrina impide afirmarlo taxativamente) el orden superficial, visible, externo (desde luego, no el significado “lógico” de las palabras).

\section{/Adj. + prep. + Inf./}

En la explicación que se da de los esquemas / Adj. + prep. + Inf./, volvemos a encontrar un nuevo dato que sumar a la sucesión de contradicciones internas por las que hace aguas la doctrina académica del Régimen (concretamente, en lo que atañe al papel desempeñado por la preposición en este tipo de relaciones). En este primer apartado de la Construcción, se dice al lector que es la preposición la que rige al infinitivo ${ }^{242}$, lo cual está en consonancia con la inclusión de ejemplos del tipo fácil de lograr dentro de los regímenes de la preposición (vid. supra

${ }^{241} \mathrm{Y}$ recordemos que, hasta la GRAE-1870 -incluida-, al participio se le concede capacidad de regencia solo en su calidad de verbo, no de adjetivo (vid. supra Caso (3) de Régimen).

${ }^{242}$ Hasta la GRAE-1878, encontramos estas palabras (El subrayado es mío):

Otros llevan despues de sí el infinitivo de un verbo regido de la preposicion que le pertenece ántes del verbo de la oracion; v.gr. La fruta buena DE COMER y fácil DE DIGERIR no hace daño [...]

Cf. GRAE de 1854: 158, 1858: 173, 1862: 177, 1864: 177, 1865: 177, 1866: 177, 1867: 176, 1870: 197, 1874: 225, 1878: 225.

A partir de 1880, se lee:

Entre los nombres, de cualquier especie que sea, y los verbos que denoten su acción, pueden interponerse: [...] Adjetivos ó participios y verbos en infinitivo regidos de preposición $[\ldots]$ 
Caso (4) de Régimen, página 405). No olvidemos, sin embargo, que la misma estructura /Adj. + prep. + Inf./ se presenta desde 1870 en el apartado del régimen del adjetivo, defendiéndose en aquellas páginas la tesis contraria: la palabra Reg. es el adjetivo y la preposición, un mero auxilio $^{243}$.

$$
\text { /Adj. + prep. + Sust./ }
$$

Con respecto a las estructuras / Adj. + prep. + Sust./, las ediciones del corpus dicen de ellas que pueden insertarse (por construcción) entre un Sustantivo Regente y un verbo regido, y que estas estructuras previamente cumplen con los requisitos del régimen pero no especifican que la preposición sea la que rige al sustantivo (aunque se deduce -según leo- que es la preposición la categoría Regente):

Todos los nombres sustantivos, de cualquier especie que sean, admiten ántes del verbo otros nombres sustantivos regidos de una preposicion [...] y asimismo nombres adjetivos ó participios que conciertan con ellos [...] Estos adjetivos ó participios admiten tambien otros sustantivos con su régimen ántes del verbo, como: Un cántaro lleno DE AGUA pesa más de lo que parece $[\ldots]$, Los hombres PROPENSOS Á LA AMBICION no sosiegan nunca. Otros llevan despues de sí el infinitivo de un verbo regido de la preposicion que le pertenece, ántes de verbo de a oracion.

(GRAE-1854: 157-158)

243 [el adjetivo] afecta al verbo en infinitivo, tambien con el auxilio de una preposicion. Ejemplos: ágil para correr; Harto de esperar;... 
Desde la GRAE-1870, el apartado dedicado a las relaciones / Adj. $\rightarrow$ sust./ incluye casos similares a estos: oriundo de Sajonia o noble por linaje responden, en efecto, a la estructura / Adj. + prep. + Sust./, que, en el capítulo del Régimen, reciben una interpretación diferente: según lo dicho en estas páginas del libro, la palabra Reg. es el Adjetivo.

\title{
(c) Sujeto múltiple:
}

\author{
JUAN Y FRANCISCO, Y TODOS LOS QUE LOS ACOMPAÑABAN, \\ llegaron juntos a casa.
}

La coordinación de elementos del tipo Juan y Francisco también la hemos encontrado en el apartado dedicado a la regencia de la conjunción, pero en el capítulo del Régimen no se recogían casos de dependencia oracional (vid. supra. Caso (5) de Régimen).

\section{(d) Interjecciones y oraciones intercaladas:}

Mi hijo, AH! Ya habrá perecido; El último plazo, TENLO PRESENTE, se cumple mañana. 


\section{2. «Construccion del verbo con las demas partes de la oracion» ${ }^{244}$ y 245}

En este apartado, encontramos estructuras de muy distinta naturaleza: desde casos llamados por la propia Institución régimen indirecto, accesorio o secundario (complementos del verbo de carácter facultativo: CC, CI., etc.) y casos de «complemento directo» (etiqueta que, según hemos adelantado, se aplica al pronombre de los llamados «verbos recíprocos», etc.), hasta casos de perífrasis verbales, sin olvidar tampoco la formación de los tiempos verbales compuestos.

Básicamente, los ejemplos dados se reducen a los siguientes tipos:

\section{(a) Predicado Nominal -Atributo-:}

\begin{tabular}{|c||c|}
\hline \hline ESTRUCTURAS & EJEMPLOS \\
\hline \hline /Sust. + Ser + Sust./ o & Juan FUE militar. \\
/Sust. + Ser + prep. + Sust./ & Juan es DE MADRID. \\
& Es DE DICTAMEN. \\
& \\
\hline /Sust. + ser + Adj./ & El laurel es VERDE. \\
& Angel SERÁ bueno. \\
& \\
\hline /(Sust. $)+$ Estar + Adj./ & Estoy BUENO. \\
& Estaba DORMIDA. \\
&
\end{tabular}

Cuadro 57: Casos de Predicado Nominal-Atributos-en el apartado de Construcción

244 Se supone que excluido el verbo.

${ }^{245}$ Cf. GRAE-1854: 158-160, 1858: 174-176, 1862: 178-180, 1864: 178-180, 1865: 178-180, 1866: 178-180, 1867: 177-179, 1870: 198-200, 1874: 226-228, 1878: 226-228, 1880: 237-239, 1883: 237-239, 1885: 239-241, 1888: 237-239, 1890: 237-239, 1895: 237-239, 1900: 237-239, 1901: 237-239, 1904: 231-233, 1906: 231-233, 1908: 231-233, 1909: 231-233, 1911: 236-238 , 1913: 236-238 y 1916: 236238. 
Todas las ediciones del corpus incluyen unos párrafos destinados a establecer las diferencias de significado y uso que existen entre los verbos ser y estar. Estas diferencias tienen que ver con las posibilidades que tienen ambos verbos de combinarse con otras categorías (un adjetivo puede ser atributo tanto de ser como de estar, pero solo ser puede «tener por término un substantivo») y con el matiz significativo que aportan a la oración ('cualidad permanente' de ser frente a 'estado transitorio' significado por estar). En virtud de estas características combinatorias y significativas, podemos establecer como reglas:

- Un atributo desempeñado por un SN o un SP solo puede aparecer en un Predicado Nominal cuyo núcleo sea ser. Se considerará, por tanto, agramatical la oración construida con estar como verbo copulativo:

\footnotetext{
* Estoy pintor

* Está de dictamen
}

- Si el atributo es un S. Adj., la aparición de ser o estar dependerá del carácter permanente o transitorio de la cualidad referida:

- Juan es bueno (con esta frase manifestamos que a Juan «le es propia é inherente esta cualidad»).

$$
\text { Vs. }
$$

Juan está bueno (con ella «damos á entender que actualmente tiene salud») 246 .

246 Juan es / está bueno aparece como ejemplo en las GRAE-1854: 159, 1858: 175, 1862: 179, 1864: 
- Está ciego (para designar al «infeliz que por lesión o enfermedad perdió la vista... mientras no se desesperaba que la recobrase»).

Vs.

Es ciego (se usa «perdida ya la esperanza de su curación»)247.

Con respecto a las oraciones de Predicado Nominal, conviene recordar, por último, que ejemplos del tipo Ángel será bueno eran los dados para la relación /Sust. $\rightarrow$ adj./ desde 1870. En este caso concreto, no encontramos conflicto en que la misma estructura se incluya en los dos capítulos, pues: i) no hay contra-afirmaciones entre lo dicho en uno y otro, y ii) parece claro que la inclusión de oraciones atributivas en la Construcción tiene como principal finalidad indicar las diferencias de uso de los dos verbos copulativos («sustantivos») por excelencia, así como las distintas estructuras que puede presentar el Atributo.

\section{(b) Voz pasiva:}

\section{Antonio era temido \\ Graciela había sido engañada}

Ejemplos como estos se dan en este apartado de la Construcción, en todas las ediciones que nos ocupan, para recordar que cuando el verbo ser «compone los tiempos de la voz pasiva, el sujeto forma concordancia con el participio pasivo del verbo que se le junta».

247 Es / está ciego lo encontramos desde la GRAE-1870 como ejemplo de que lo accidental puede llegar a ser constante. Cf. GRAE-1870: 199, 1874: 227, 1878: 227, 1880: 238, 1883: 238, 1885: 240, 1888: 238, 1890: 238, 1895: 238, 1900: 238, 1901: 238, 1904: 232, 1906: 232, 1908: 232, 1909: 232, 1911: 237, 1913: 237 y 1916: 237. 


\section{(c) Haber formando tiempos verbales compuestos.}

Solo en las ediciones de los años cincuenta y sesenta encontramos la mención al empleo de haber como verbo auxiliar en el capítulo de la Contrucción. A partir del jalón de 1870, desaparece de este capítulo la alusión a que el uso de haber como auxiliar «se limita á formar los tiempos compuestos de los demas verbos». Bien excluido está de un capítulo de construcción (de estructuras, de colocaciones...) lo que no es sino un uso como morfema verbal.

\section{(d) Perífrasis verbales:}

\begin{tabular}{|c||c|}
\hline \hline ESTRUCTURAS & EJEMPLOS \\
\hline \hline \multicolumn{1}{|c||}{$/$ Estar + prep. + Inf./ } & Estoy PARA MARCHAR. \\
& Estoy POR DECLARARME. \\
\hline Estar + gerundio/ & Estoy ESPERANDO a mi padre. \\
& \\
\hline
\end{tabular}

Cuadro 58: Casos de Perífrasis verbales en el apartado de Construcción

Estas estructuras solo las encontramos en las Gramáticas publicadas entre 1854 y 1867. Con respecto a las primeras (/Estar + prep. + Inf./), no se dice que sea la preposición la que rige al infinitivo; tampoco se dice expresamente que sea estar el Verbo Regente. Pero sí se afirma que estar rige al gerundio en la segunda estructura marcada: 
El verbo estar puede construirse con infinitivo por medio de las preposiciones á, para, por, sin, como: Estoy Á VER VENIR, PARA MARCHAR, POR DECLARARME, SIN HACER NADA. Rige tambien, y con mucha frecuencia, al gerundio, al paso que el verbo ser lo repugna siempre, v. gr.: Estoy ESPERANDO á mi padre; Cuando llegué estaban COMIENDO.

(GRAE-1854: 159)

Conviene recordar en este punto que, en las relaciones / Vb. vb./, es a partir de la GRAE-1880 cuando empezamos a encontrar interpretaciones de /estar + gerundio/ que sugieren la idea de perífrasis (vid. supra. 6.2.1.2., Caso (2) de Régimen, apartado c. Vid. infra apartado 3.a).

(e) $\mathrm{CD}+\mathrm{CI}$ :

/Vb. act. tr. + Sust. + prep. + Sust./: El maestro da LECCIÓN al discípulo; El vencido dió rehenes AL VENCEDOR.

En este apartado de la Construcción, hasta la GRAE-1867, leemos que la regencia corresponde a la preposición; a partir de 1870, se omite tal afirmación y se limitan los académicos a apuntar que tras el complemento directo pueden ir otros sustantivos con diversas preposiciones. (Vid. supra. 6.2.1.2., Caso (2) de Régimen, apartado a).

(f) $\mathrm{CD}+\mathrm{CC}$ :

Remito esos libros PARA MI HERMANO.

Hasta la edición de 1870 -excluida-, en este capítulo de la Sintaxis se dice que para rige a mi hermano (que está en dativo). Esta afirmación 
desaparece en la 12. ${ }^{a}$ edición de la Gramática (se habla de complemento indirecto).

\section{(g) $\mathrm{CD}+\mathrm{CI}+\mathrm{CC}$ :}

El Rey encarga la justicia a sus ministros, CON PARTICULAR CUIDADO, PARA BIEN DE LOS PUEBLOS.

Al complemento directo, que puede ir seguido de un complemento indirecto, se le pueden añadir «otros nombres con diversas preposiciones». Igual que en los casos de (f), hasta la edición previa al jalón de 1870, se dice que, en frases como la propuesta, con y para rigen a los nombres que les siguen (que expresan circunstancias o modificaciones de la acción verbal). A partir de la GRAE-1870, se pierde esta referencia al papel de la preposición como palabra Reg. (Vid. supra. 6.2.1.2., Caso (2) de Régimen, apartado $a$ ).

(h) Vb. intr. + C. Pvo.:

\section{El hombre nace CUBIERTO DE INFELICIDAD Y MISERIA.}

Esta estructura es considerada caso de régimen del nombre /Sust. $\rightarrow$ adj. o part./ desde 1870. En la Construcción, solo se marca la concordancia existente entre hombre y cubierto, sin especificar que el Sustantivo rige al participio. En este capítulo, el ejemplo se da como prueba de que un verbo neutro solo puede tener como régimen directo el infinitivo de otro verbo (recordemos que, salvo en las combinaciones /Vb. neutro + Inf./, los verbos intransitivos necesitan del auxilio de una preposición para poder regir a otra palabra $-y$ ese régimen será indirecto o accesorio-) $)^{248}$. La 
interpretación que se da a esta oración en todas las ediciones del corpus es la que sigue:

El verbo no hace otra cosa en esta oracion que expresar el nacimiento del hombre; cubierto concierta con el nominativo; infelicidad está en ablativo, regido de la preposicion de; miseria lo mismo, porque se enlaza con el otro sustantivo por medio de la conjuncion $y$.

(GRAE-1854: 160) 249

\section{(i) Verbo pronominal + Suplemento:}

Te desvives POR COMPLACERME (dependencia oracional: / Pred.]/); Se esmera EN LA LABOR; Me arrepiento DE MIS CULPAS.

Los ejemplos responden a casos de lo que, desde 1874, se considera régimen indirecto. Conviene recordar que, a partir de esta edición, nuestros Suplementos no se interpretan como régimen directo, aunque, al igual que los $C D$, sean necesarios para completar la

(GRAE-1854: 160)

Ídem GRAE-1858: 175; 1862: 179, 1864: 179, 1865: 179 y 1866: 179.

En la GRAE-1867 encontramos un primer cambio en la redacción de este párrafo:

Los verbos neutros ó intransitivos sólo tienen régimen propio llamando á otros en infinitivo, v. gr.: Voy á escribir; por consiguiente, no depende de ellos la construccion que forman con diferentes palabras. Por ejemplo: El hombre nace CUBIERTO DE INFELICIDAD Y MISERIA

(GRAE-1867: 179)

Y en el jalón de 1870 se vuelve a modificar

Los verbos neutros ó intransitivos no tienen régimen directo [= obligatorio], fuera de los casos en que rige al infinitivo de otro verbo; por consiguiente, la construcción que forman con diferentes palabras tendrá su régimen de ellas mismas; v. gr.: El hombre nace CUBIERTO DE INFELICIDAD Y MISERIA.

(GRAE-1870: 239)

Ídem 1874: 227; 1878: 227; 1880: 239; 1883: 239; 1885: 241; 1888: 239; 1890: 239; 1895: 239; 1900: 239, 1901: 239, 1904: 232-233; 1906: 232-233, 1908: 232-233, 1909: 232-233, 1911: 238, 1913: 238 y 1916: 238.

${ }^{249}$ La cita se encuentra, en las demás ediciones, en la página indicada en la nota anterior. 
significación verbal, puesto que suelen estar introducidos por preposiciones distintas de $a$ (remito a lo dicho a propósito del caso (2) de Régimen, apartado b). En este sentido, podemos decir que la visión que Nebrija tenía de los complementos que hoy etiquetamos como "suplementos" estaba más próxima a nuestra concepción -incluso a la idea de doble transitividad- que la expuesta por la Academia en el último cuarto del siglo XIX250 y 251.

\section{3. «Construccion de unos verbos con otros» ${ }^{252}$}

\section{(a) Oraciones de infinitivo y participio:}

En este apartado de la Construcción, leemos la advertencia de que el régimen del verbo no va más allá del elemento que funciona como término (sea nombre, pronombre o verbo), de modo que el resto de palabras que se añadan a la construcción tendrán su régimen separado. Esto es, el régimen se vuelve a entender, en este apartado de la Sintaxis, en sentido restringido (vid. Caso (2) de Régimen, apartado $a)$

\footnotetext{
${ }^{250}$ Nebrija, al hablar «Dela construcion delos verbos después de si» (1492: fols. 45 v. y 46 r.), establece una clasificación básica de los verbos en personales e impersonales, y divide los personales en transitivos y absolutos. Para él, los verbos transitivos, que son «los que passan en otra cosa» pueden ir seguidos de distintos casos: genitivo (recuerdo me de ti; carezco de libros), dativo (Sirvo a dios; agrado alos amigos), acusativo (amo las virtudes; aborrezco los vicios). También pueden ir seguidos de dos casos distintos: de acusativo + dativo (enseño la gramatica al niño) y de acusativo + genitivo (son ejemplos equivalentes a nuestros casos de convivencia de CD con suplemento): hincho la casa de vino; Uazio la panera detrigo; E compassion de ti.

${ }^{251}$ Sobre la idea de suplemento en la Historia de la Gramática, interea el estudio de Martí Sánchez (1992).

${ }^{252}$ Cf. GRAE-1854:160-161, 1858: 176-177, 1862: 180-181, 1864: 180-181, 1865: 180-181, 1866: 180181, 1867: 179-180 (desde esta edición, el epígrafe reza: «CONSTRUCCION DE UNOS VERBOS CON OTROS, Y CON LOS PARTICIPIOS», 1870: 200, 1874: 228, 1878: 228, 1880: 239-240, 1883: 239-240, 1885: 241-242, 1888: 239-240, 1890: 239-240, 1895: 239-240, 1900: 239-240, 1901: 239-240, 1904: 233-234, 1906: 233-234, 1908: 233-234, 1909: 233-234, 1911: 238-239, 1913: 238-239 y 1916: $238-$ 239.
} 
Veamos algunos de los ejemplos dados y la interpretación que se hace de ellos:

(1) Pudo hacer VENIR el coche; Quiso hacer trotar al caballo.

Pudo y quiso rigen a hacer;

hacer rige a coche (en la primera oración) y a caballo (en la segunda);

coche y caballo rigen (se supone, por las explicaciones dadas) a venir y trotar, respectivamente (lo que implica un cambio en el sentido de la regencia que, en este caso, será de derecha a izquierda);

venir y trotar no rigen ninguna palabra porque son verbos neutros.

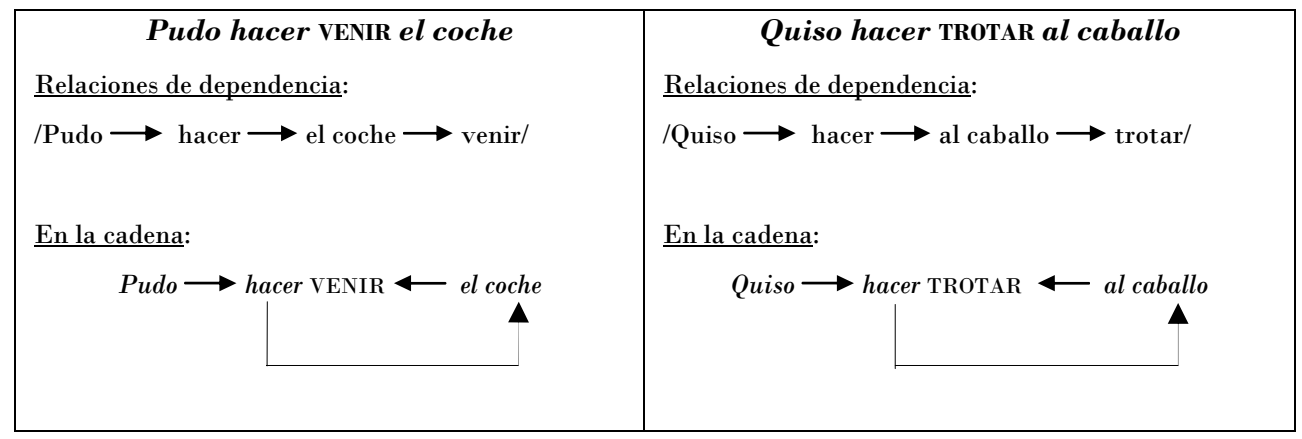

Esquema 10: Sistema de dependencias en oraciones con más de un verbo

(2) Era sufrido en la adversidad/Venía hecho pedazos.

En estos casos en que el verbo se une a un participio (nuestros Atributos y Complementos Predicativos), «no admite régimen con estos, sino concordancia como de sustantivo y adjetivo 
con el nombre»; en este caso concreto «hecho concierta con el que venía» (GRAE-1854: 161).

Con respecto a la construcción de verbos con participios, encontramos un cambio en la GRAE-1867:

Cuando se unen á participios [se refiere tanto a oraciones de predicado nominal: era sufrido en la adversidad, como a oraciones de predicado verbal con Complemento Predicativo: venía hecho pedazos], no admiten régimen con estos, sino concordancia como de sustantivo y adjetivo con el nominativo, v. gr.: Venía hecho pedazos. Hecho concierta con el que venía. Era sufrido en la adversidad. Sufrido concierta con el nominativo suplido del verbo era. Juana estaba corrida de vergüenza. Corrida concierta con Juana, que es el nominativo de estaba. Así pues, se ha de tener mucho cuidado en observar este término de los verbos, y cuáles son los que no pueden tenerle, aunque lo parezca por la construccion. Si no se tienen bien presentes las reglas del régimen del verbo, podrá creerse que en esta expresión: El General no DEJA dormir á los soldados, soldados es término del infinitivo dormir, porque la construccion lo pide después de él; y no lo es, sino del verbo deja, que es el que puede regir un término, y no dormir, que es neutro y no le puede regir 253

(GRAE-1858: 176-177)

Finalmente, de lo que hemos explicado en más de un lugar acerca de la índole y condiciones de los participios, resulta que nunca pueden ser sujeto de una oracion; complemento, sí; ya solos en construcciones semejantes á estas: Rita es obediente; Mateo quedó cesante; Bruno fué postergado; ya con la agregación de otras palabras, v. gr.: Rita es obediente á sus amos; Mateo quedó cesante por reforma; Bruno fué

${ }^{253}$ Vid. supra interpretación de los ejemplos de (1). 
postergado en la última promocion; Alberto venía hecho pedazos; Juana estaba corrida de vergüenza.

(GRAE-1867: 180)

En esta ocasión, es el texto anterior al jalón de 1870 el que introduce el cambio en la explicación de este tipo de estructuras: si en las ediciones comprendidas entre 1854 y 1866 (incluida) se apunta, implícitamente, la idea de que Atributos y Complementos Predicativos -en terminología actual- no son tanto complementos del núcleo verbal cuanto modificadores de un elemento sustantivo de la oración (que, por lo general, desempeña la función de Sujeto), a partir de la GRAE-1867 los académicos se limitan a marcar la función exclusiva de estos participios como complementos (sin especificar la categoría a la que complementan o se refieren). A los ejemplos se incorporarán casos de lo que hoy etiquetamos “Complementos Seudopredicativos o Seudoatributos" (Mateo quedó cesante por reforma). Por otra parte, se reconoce en la ejemplificación la posibilidad de que el participio vaya acompañado (¿complementado para la Corporación?) por otras palabras. La recursividad del sistema de complementaciones aún no es reconocido explícitamente en la GRAE.

\section{(b) Dependencia oracional $/ \mathrm{V} \hookleftarrow[($ Suj. $)+$ Pred. $]$}

Es en la GRAE-1870 cuando, por primera vez, los académicos reconocen explícitamente en el apartado de Construcción que una oración funciona como complemento de otra. Se reconoce en el ejemplo: Vengo á que me pagues, donde tenemos «dos oraciones, sirviendo la segunda de complemento á la primera» (GRAE-1870: 200). 


\section{4. «Construccion del verbo con el pronombre» ${ }^{254}$}

Básicamente, se trata de una casuística del uso de los pronombres (proclíticos, enclíticos, etc.), cuyo análisis pormenorizado (descriptivo y normativo) escapa a los objetivos de este trabajo.

254 Cf. GRAE-1854: 161-164, 1858: 177-182, 1862: 181-186, 1864: 181-186, 1865: 181-186, 1866: 181-186, 1867: 180-185, 1870: 200-205, 1874: 228-233, 1878: 228-233, 1880: 240-244, 1883: 240-244, 1885: 242-246, 1888: 240-244, 1890: 240-244, 1895: 240-244, 1900: 240-244, 1901: 240-244, 1904: 234-238, 1906: 234-238, 1908: 234-238, 1909: 234-238, 1911: 239-244, 1913: 239-244 у 1916: $239-$ 244. 


\subsubsection{Reglas de Concordancia}

\subsubsection{El concepto de concordancia}

En los apuntes de Sintaxis firmados por Luzán en 1746, se define la concordancia como

la conformidad, o correspondencia que debe tener el adjetivo con el substantivo, a quien se refiere, en genero, y numero; y el verbo con el nombre que le rige, en numero, y persona.

(ARAE, 1746c)

No cabe duda de que este académico entiende la concordancia vinculada necesariamente a las relaciones de régimen (relaciones de dependencia semántico-sintáctica); en virtud de esta conexión, y según se deduce de los términos de la definición, es la palabra regida la que debe acomodar sus morfemas a los de la palabra Regente. Esta última idea hace pensar en la concordancia como dependencia unilateral, concepción que «está echada sobre bases filosóficas»(Gómez Asencio, 1981: 72). Efectivamente, a principios del siglo XIX, encontraremos esta misma concepción en autores empapados de la gramática filosófica francesa, como Calleja, Noboa o Lacueva255 y 256.

\footnotetext{
255 Son los autores señalados por Gómez Asencio (1981: 71).

256 Beauzée, en cuya Grammaire générale se explican de forma detenida las reglas y los fundamentos de las relaciones de concordancia, expone de forma clara el vínculo existente entre las relaciones de rección y las de concordancia:
}

[...] la Concordance qui doit régner entre l'adjectif \& le nom appellatif, entre le verbe \& le sujet, il faut d'abord déterminer, par un principe de régime, l'inflexion de l'un des deux corrélatifs: les autres corrélatifs fe reyêtent enfuite des inflexions correfpondantes, par imitation \& pour s'accorder avec le premier terme qui leer Pert comme d'original; celui-ci eft dominant, les autres font fubordonnés. C'eft un nom appellatif que eft le corrélatif dominant pour les adjectifs, c'eft un nom quelconque ou un pronom pour les verbes; les adjectifs \& les verbes font fubordonnés: c'eft à eux à s'accorder, \& la Concordance de leurs inflexions avec celles du terme dominant eft comme une livrée qui attefte leer depéndanse.

Cette depéndanse eft fondée fur un rapport, qui eft, felon les meilleurs grammairens modernes, un rapport d'identité [...]

(Beauzée, 1767: 382) 
Para los académicos encargados de redactar la Gramática en la segunda mitad del XIX, igual que para sus predecesores del XVIII, el estudio de las relaciones sintácticas que se establecen entre las palabras obliga a analizar, en primer lugar257, las relaciones marcadas por la llamada Concordancia, que consiste en el ajuste, correspondencia o conformidad -términos similares a los empleados por Luzán- de los accidentes gramaticales (género, número, [caso] y persona) que deben guardar las palabras vinculadas entre sí. Esta correspondencia morfemática se dará entre palabras «declinables» o «variables» (la terminología cambia según las ediciones) ${ }^{258}$. Frente a la doctrina de Luzán, en los libros de Gramática, la Institución expone una idea de la concordancia que hace pensar, en un primer momento, en una acomodación recíproca (bilateral, si se quiere) de accidentes ${ }^{259}$. Sin embargo,

257 A la Concordancia se dedica el primer capítulo de la Sintaxis desde la GRAE-1796 (en 1771, a la concordancia se le dedica el artículo VI del capítulo II de la Sintaxis, capítulo titulado Del régimen, y construccion natural). Ya expusimos las razones que han llevado a tratar en primer lugar del Régimen en este trabajo (vid. supra 6.2.).

258 [...] lo primero que enseña la Sintáxis es á concertar unas palabras con otras; esto es, á establecer entre ellas la correspondencia y conformidad debidas. De las nueve partes de la oracion, solo pueden concertar entre sí las que se han llamado declinables, y son artículo, nombre, pronombre, verbo y participio, todas las cuales están sujetas á una de estas tres concordancias: primera, de sustantivo y adjetivo; segunda, de nominativo y verbo; tercera, de relativo y antecedente.

(GRAE-1854: 138. El subrayado es mío)

Lo primero que enseña la Sintaxis es a concertar unas palabras con otras; esto es, a establecer entre ellas la correspondencia y conformidad debidas. De las diez partes de la oración, sólo pueden concertar entre sí las que se llaman variables, y son: substantivo, adjetivo, pronombre, artículo, verbo y participio, las cuales están sujetas a una de estas tres concordancias: primera, de nombre y adjetivo; segunda, de nombre y verbo; tercera, de relativo y antecedente.

(GRAE-1916: 214. El subrayado es mío)

Para las ediciones publicadas entre estas dos fechas, véase: GRAE de 1858: 148; 1862: 152, 1864: 152, 1865: 152, 1866: 152,1867: 151; 1870: 169; 1874: 197; 1878: 197; 1880: 216; 1883: 216; 1885: 218; 1888: 216; 1890: 216; 1895: 216; 1900: 216, 1901: 216, 1904: 210, 1906: 210, 1908: 210, 1909: 210, 1911: 214, 1913: 214.

${ }^{259}$ La idea de que la concordancia consiste en el ajuste y concierto de unas palabras con otras está presente en la GRAE desde su primera edición (vid. GRAE-1771: 321). Los académicos encargados de redactar el texto de la Gramática tuvieron en cuenta, en este aspecto, las observaciones de Zapata (1746) vertidas en sus apuntes sobre la división de la Sintaxis y los conceptos de concordancia y régimen, los cuales, siguiendo el acuerdo de la junta de 22 de marzo de 1746 -vid. supra 6.1.3. y 6.2.1.1-, pasaron, junto con los papeles firmados por Luzán y Angulo a «los señores que habían de formar la Gramática» (recuérdese que el sistema de Comisiones no se establecerá hasta el siglo XIX -vid. supra 3.2.-). 
las referencias a los hechos de concordancia se formulan en términos como: «el artículo, el pronombre y el participio concuerdan con el sustantivo» (sobre la concordancia primera, de «sustantivo/nombre y adjetivo»), «la concordancia de nombre y verbo pide que este concierte con el nombre» (a propósito de la segunda concordancia, de «nominativo/nombre y verbo»), «el relativo el cual está en el mismo género masculino y en el mismo número singular que el antecedente reo» (en la concordancia «relativo y antecedente»). Fórmulas todas ellas que parecen encubrir una idea próxima a la de Luzán: es la palabra dependiente la que acomoda sus accidentes a los de la palabra principal (semántica y sintácticamente hablando) ${ }^{260}$. No deben de responder a un sistema meditado los "nombres" dados a las distintas concordancias, pues en la primera y segunda el orden es "palabra principal (sustantivo) + palabra dependiente (adjetivo y verbo)" y en la tercera, al contrario, "palabra dependiente (relativo) + palabra principal (antecedente)".

En los accidentes de las palabras declinables/variables que deben concordar entre sí, algunas ediciones de la Gramática posteriores a 1771 incluyen el caso (vid. infra). Luzán, en los apuntes referidos, se había

\footnotetext{
260 Una vez más tenemos que traer a colación el estudio de Gómez Asencio (1981). En él se nos informa de la tendencia, por parte de los gramáticos de finales del XVIII y primera mitad del XIX, a presentar las relaciones de concordancia en términos similares a los que emplea la Academia (concordancia de tal categoría con el sustantivo/antecedente/sujeto). Sin dejar de contemplar la posibilidad de que se trate de una mera copia de la fórmula empleada por Nebrija (una redacción "de inercia" o un apego consciente a lo ya establecido), Gómez Asencio concluye que
}

Son, desde luego, síntoma de que en algún momento se consideró que era el verbo, el adjetivo o el relativo los que adquirían los accidentes del sustantivo, los que «concertaban con él»; esto debe llevarnos a pensar, si no que verbo, adjetivo y relativo eran consideradas las palabras subordinadas o dependientes en las relaciones de concordancia, sí al menos que el sustantivo era la palabra principal en ellas.

(Pág. 71)

En definitiva, incluso en las exposiciones más "formalistas" de la concordancia (entre ellas, las de la GRAE. Vid infra), podemos intuir un poso de concepción jerárquica de las palabras cuyo vínculo debe tener reflejo en la concordancia. 
pronunciado claramente sobre la pertinencia de considerar el caso como accidente participante en los fenómenos de concordancia:

Los Gramaticos Latinos añadian ala concordancia de genero, y numero la concordancia de caso: pero en nuestra lengua Española me parece ocioso el añadir el caso, porque nuestros nombres no tienen distincion alguna de casos, que solo se conocen, y distinguen por las particulas, o articulos.

(El subrayado es mío)

Frente a esta postura, Zapata (cuyas notas, como ya hemos adelantado, fueron aceptadas en Junta para ser tenidas en cuenta en el texto de la Gramática) afirma que la concordancia entre sustantivo y adjetivo supone el concierto de caso (y los consabidos de género y número) ${ }^{261}$. En este punto concreto, los redactores de 1771 no siguieron sus consideraciones.

En las GRAE atendidas en este apartado, la concordancia ni se define como dependencia ${ }^{262}$ ni se relaciona de forma expresa con ella; tampoco tiene que ver con cuestiones de orden 263 y 264 . De modo que estas reglas de la Sintaxis
$261[\ldots]$ La [concordancia] de nominativo y verbo a de concertar en numero y persona, de modo que ambos an de ser de un mismo numero, y pertenecer a una misma persona, vg tu enseñas [...]
La de suftantivo, y adjetivo, an de concertar en genero, numeo, caso vg hombre prudente [masc., sing., nom.] [...]
La de relativo y antecedente concuerdan en genero y numero, vg tienes muchas riquezas las quales, te á dado Dios [...]

(ARAE, 1746a. El subrayado es mío)

262 En realidad, ninguna de las ediciones de la Gramática, salvo la de 1771, define en sentido estricto el concepto de concordancia.

${ }^{263}$ Este dato pone de evidencia otro aspecto en el que los encargados de elaborar la GRAE1771 no siguieron lo establecido en los apuntes de Zapata: en ellos, se define la concordancia como «orden y concierto que entre si deben tener las partes de la oracion».

${ }^{264}$ En este sentido, los textos académicos son un fiel reflejo de la evolución general que el concepto de concordancia experimentó en nuestra tradición, en la que, en palabras de Gómez Asencio (1981: 59): 
no parecen responder exactamente a un tipo de relación sintáctica (como sí son tipos de relaciones diferentes el Régimen y la Construcción), sino a una marca de que existe relación de dependencia entre ciertas palabras ${ }^{265}$.

Es, precisamente, esta peculiar "naturaleza" de la concordancia (que la distingue de las relaciones de régimen y construcción) lo que explica que no sea incompatible el tratamiento de un mismo fenómeno sintáctico como relativo a las reglas de concordancia $\mathrm{y}$, al mismo tiempo, a las reglas de régimen/construcción: de hecho, en todas las ediciones del corpus, estructuras idénticas a las recogidas en el primer capítulo de la Sintaxis se incluyen también en alguno de los otros dos, sin que, en esta ocasión, implique una incoherencia de doctrina, puesto que, como bien dice Rojo, concordancia, de un lado, y régimen/construcción, de otro, «no son espacios excluyentes».

De las dos relaciones sintácticas fundamentales [régimen y concordancia], la única que conservó incólume a lo largo de toda la tradición su carácter de dependencia (en la mayor parte de los casos ligada al orden de las palabras en la oración) fue el régimen.

Años más tarde, Calero Vaquera (2007: 92-94) ha recordado esta idea y también la de que, como es habitual, no faltan autores que van contracorriente. Ya Gómez Asencio (1981: 69) reivindicó la figura de Saqueniza como gramático que concibe (y define) la concordancia como relación de dependencia ( $c f$. Saqueniza, 1832: 80) y anticipa (con la distancia esperable entre ambas teorías) la distinción que un siglo después hará Hjelmslev (1976) entre rección pura y rección compleja. Entre los gramáticos estrictamente coetáneos a nuestro corpus, podemos destacar a Herrainz y Salleras como autores que también entienden concordancia y régimen como modalidades diferentes de los fenómenos de rección (vid. Calero Vaquera, 1986: 201). 265 Esta conclusión ya la expuse en mi trabajo de grado (Garrido Vílchez, 2001: 156) y coincide con las siguientes palabras del discurso de ingreso en la RAE de Guillermo Rojo (2001: 95):

Lo mismo que en la primera edición, la concordancia no es un apartado en el que se estudien fenómenos que no son tratados luego desde otras perspectivas. La combinación de un sustantivo en nominativo con un verbo (predicado) aparece tanto en la concordancia como en en el capítulo dedicado al régimen; la del adjetivo con sustantivo es mencionada en la primera concordancia y más tarde en el capítulo dedicado a la construcción. No estamos, pues, ante espacios excluyentes, de modo que es forzoso considerar que la concordancia no es tratada aquí tampoco como una relación sintáctica, sino como una de las marcas formales posibles de esa relación. 
En todas las GRAE publicadas entre 1854 y 1916 (< GRAE-1796) se señalan tres concordancias:

1. ${ }^{\text {) }) ~ d e ~ n o m b r e ~ s u s t a n t i v o ~ y ~ a d j e t i v o, ~}$

2. $\left.{ }^{a}\right)$ de nombre y verbo, $y$

3. $\left.{ }^{a}\right)$ de relativo y antecedente 266 .

La última es un añadido que el texto de la Gramática hace a los tipos establecidos por Luzán (que responden a las concordancias $1 .^{a}$ y $\left.2 .^{a}\right)^{267}$.

266 En la GRAE-1771 se consideraba una cuarta concordancia, de artículo y nombre común (en género y número), que ya no encontramos en 1796, fecha a partir de la cual esta cuarta concordancia se recoge en la de nombre sustantivo y adjetivo:

En esta concordancia [de nombre sustantivo y adjetivo] se comprehenden el artículo, el pronombre y el participio, los quales, para este fin de concertar, todos se consideran como adjetivos [...]

(GRAE-1796: 277)

${ }^{267}$ Las dos concordancias establecidas por Luzán coinciden con las que se señalan como comunes a todas las lenguas en la Grammaire de Port-Royal. En el texto de 1660, Arnauld y Lancelot establecen las reglas de concordancia en los siguientes términos:

Ainfi la diftinction des deux nombres, fingulier \& plumier a obligé d'accorder le fubftantif avec l'adjectif en nombre, c'eft à dire de mettre l'vn au fingulier ou au plurier, quãd l'autre y eft. Car le fubftantif eftant le fujet que eft marqué confulément, quoy que directement par l'adjectif, fi le mot fubftantif marque plufieurs, il y a plufieurs fujets de la forme marquée par l'adjectif; \& par confequent il doit eftre au plumier: homines docti, hommes doctes.

La diftinction du feminin \& mafculin a oblige de melme de mettre en melme genre le subftantif \& l'adjectif, ou l'vn \& l'autre quelquefois au neutre, dans les Langues qui en ont; car ce n'eft que pour cela qu'on a inuenté les genres.

Les Verbes de mefme doiuent auoir la conuenance des nombres \& des perfonnes auec les noms \& les pronoms.

Que s'il fe reencontré vuelque chofe de contraire en aparéense à ces regles, $c^{\prime}$ eft par figure $[\ldots]$

(Arnauld y Lancelot, 1660: 141)

Un siglo después, Beauzée defiende también una concepción de la concordancia reducida a dos reglas (frente a propuestas como la de Lancelot en su Método Latino -que señala cuatro concordancias- o Du Marsais -quien añade una quinta regla-). Sin embargo, en la doctrina de Beauzée se reconocen, en rigor, las tres reglas que encontramos en la GRAE desde 1796, que son las habitualmente señaladas en nuestra tradición desde Nebrija. El gramático francés considera la tercera concordancia (relativo-antecedente) dentro de la primera (adjetivo-nombre):

Je crois devoir réduire cette doctrine de la Concordance à deux chefs feulmente: $1^{\circ}$. la Concordance de l'adjectif avec le nom; ce qui comprend auffi celle de l'article conjonctif avec l'antécédent, parce que l'article eft une forte d'adjectif: $2^{\circ}$. la Concordance du verbe perfonnel avec fon fujet, \& non pas du fujet avec le verbe, 
En la tipología tripartita que se establece en la concordancia sí se impuso la opinión de Zapata, quien aceptó las clases comúnmente reconocidas en nuestra tradición. Desde el Renacimiento, los autores españoles que atienden a cuestiones de sintaxis en sus tratados hablan de la concordancia, y es esta tipología la que encontramos casi sin excepción hasta la segunda mitad del siglo XIX, periodo en que los gramáticos empiezan a proponer clasificaciones más dispares 268 y 269 . La triple clasificación de los hechos de concordancia la

comme le difent nos deux grammairiens[Lancelot y Du Marsais], parce que ce font en effet les terminaifon du verbe perfonnel, qui s'adaptent aux vûes indiquées par le fujet.

(Beauzée, 1767: 353-354)

268 Entre los autores decimonónicos, la defensa de dos tipos de concordancia (adjetivosustantivo y verbo-sustantivo sujeto) la encontramos en Salvá (1830), Noboa (1839) y Bello (1847):

La armonía de las diversas terminaciones de las palabras declinables constituye la concordancia, la cual es la correspondencia que guardan entre sí los nombres concertando en género y número, o bien los nombres con el verbo conviniendo en número y persona.

(Salvá, 1847 [1830]: 298. El sbrayado es mío)

Se llama concordancia gramatical la conformidad que tienen que guardar las partes variables de la oracion con el nombre sustantivo, ó el pronombre, en sus variaciones accidentales.

Las palabras que tienen que guardar esta conformidad son los nombres adjetivos, los artículos o el verbo.

(Noboa, 1839: 239)

La concordancia es la armonía que deben guardar entre sí el adjetivo con el sustantivo, y el verbo con el sujeto.

(Bello, 1860 [1847]: 535)

La formulación de Noboa se desarrolla en tres apartados, dedicados, respectivamente, a la concordancia del adjetivo (con el sustantivo-pronombre), del artículo (con el sustantivopronombre) y del verbo (con el sustantivo-pronombre sujeto). No obstante esta exposición, queda claro que la teoría defendida por este gramático puede reducirse a dos concordancias, pues los artículos «tienen forma de adjetivos» y «conciertan con el sustantivo del mismo modo que ellos» (Noboa, 1839: 241). Al hacer mención aparte de nombre, pronombre y artículo, Noboa está más cerca de la forma de exposición de la concordancia que encontramos en la primera edición de la Gramática de Salvá (1830), en la que todavía el autor no engloba bajo la etiqueta nombre a pronombre y artículo:

Llámase así la correspondencia que guardan entre sí los artículos, los nombres y los pronombres, concertando en género y número; o bien los artículos, los nombres y los pronombres, conviniendo en número y persona con el verbo.

(Salvá, 1847 [1830]: 298, nota 12)

269 Vid. Ramajo Caño (1987: 215-216), Gómez Asencio (1981: 66-72) y Calero Vaquera (1989: 200-206 y 2007: 94). 
encontramos también en las primeras gramáticas vernáculas del francés y del italiano $^{270}$.

${ }^{270}$ Kukenheim (1974: 160) señala esta tendencia y destaca a los autores españoles como los más sistemáticos a la hora de establecer este sistema de tres concordancias:

Les autres grammairiens quie s'occupent de l'accord, comme Corso, Dolce et Giambullari, distinguent dans ce chapitre trois cas; l'accord du sujet et du verbe, celui de l'adjectif et du substantif, et celui du relatif avec l'antécédent. Ce sont surtout les théoriciens de la langue espagnole, Nebrija, Villalon et Miranda qui suivent ce système d'une façon très méthodique. Parmi les grammairiens français, Palsgrave aussi admet ces trois genres d'accord, Ramus, au contraire, a préféré traiter la syntaxe dans l'ordre des parties du discours, et cela d'une façon très détaillée dans quatorze chapitres, dont les cinq premiers (sauf le Chap. III) traitent "de la conuenance du nom avec le nom", "de la conuenance des articles", "de la conuenance des pronoms" et "de la conuenance du nom avec le verbe" [...] 


\subsubsection{Las Reglas de concordancia}

\section{$\underline{1^{a} \text { Concordancia: nombre sustantivo y adjetivo (artículo, pronombre } y}$ participio)}

Las líneas dedicadas a esta primera concordancia son prácticamente iguales en todas las GRAE publicadas entre 1854 y 1916, si bien, a partir de 1880, encontramos un añadido importante que nos permite establecer dos grupos:
A) GRAE-1854 a GRAE-1878.
B) GRAE-1880 a GRAE-1916.

En las Gramáticas del primer grupo, se defiende que la concordancia entre sustantivo y adjetivo debe darse en los accidentes de género y número 271. Al suprimir la concordancia de caso, la Academia vuelve a sus planteamientos iniciales (los de 1771), frente a lo sostenido en la GRAE-1796272.

La propuesta de la última Gramática del XVIII se recuperará a partir de 1880, edición en la que volvemos a leer que «el adjetivo ha de concertar con el sustantivo en género, número y caso» (pág. 216) ${ }^{273}$. En consecuencia con esta afirmación, se considera que, en una oración como la ley es justa, justa concierta con ley en género femenino, número singular y caso nominativo.

\footnotetext{
${ }^{271}$ Cf. GRAE de 1854: 138; 1858: 148; 1862: 152, 1864: 152, 1865: 152, 1866: 152, 1867: 151; 1870: 169; 1874: 197 y 1878: 197.

272 Este hecho, entre otros, hace ver que la última GRAE del XVIII está más apegada a lo latino que la primera Gramática publicada por la Institución. Podemos decir, en este sentido, que la cuarta edición supone un "paso atrás" en la tarea de descripción del romance castellano (es más "conservadora", si se quiere) y responde, en su conjunto, a una «latinización descriptiva», en términos de Gómez Asencio (1999 y 2001).

273 Ídem GRAE de 1883: 216; 1885: 218; 1888:216; 1890: 216; 1895: 216; 1900: 216, 1901: 216, 1904: 210, 1906: 210, 1908: 210, 1909: 210, 1911: 214, 1913: 214 у 1916: 214.
} 
A propósito de esta primera concordancia, ésta es la única diferencia evidente que separa lo que podríamos llamar el espíritu de 1771 (seguido en las ediciones del grupo A) y el de 1796 (recuperado en las GRAE que se han recogido bajo el grupo B). Es de esperar que ambas posturas estén relacionadas con el concepto de caso expuesto en las Gramáticas de cada uno de estos dos grupos. En el cuadro que sigue (vid. infra), puede apreciarse cómo, efectivamente, el concepto de caso que se defiende en cada uno de los libros repercute en la consideración de esta primera concordancia.

Los datos del cuadro muestran que, a propósito de la concordancia sustantivo-adjetivo, las Gramáticas que presentan una actitud más coherente son la GRAE-1771 y las recogidas en el grupo A, puesto que:

- En todas se defiende un concepto formal de caso (aunque en algunas de ellas también se recoja un concepto semántico-funcional).

- Incluso en aquellas ediciones en que podemos apreciar un matiz funcional en el concepto de caso, esta idea no se extiende a las reglas de concordancia, pues, efectivamente, la concordancia es concierto de accidentes gramaticales, tiene que ver con la flexión, con la variación morfemática, que en español sólo se da para indicar género y número, no oficio ni significado.

El rasgo caracterizador del grupo B (siguiendo la edición de 1796) está en la extrapolación del concepto semántico-funcional de caso. Es cierto que el adjetivo que concierta con un sustantivo está en su mismo caso, si por tal se entiende función u oficio dentro de la oración; pero no puede decirse que se dé una concordancia de caso, si por concordancia se entiende «correspondencia y conformidad» morfemáticas entre las partes variables de la oración. Llegados 
a este punto, podemos matizar lo dicho hasta ahora de la GRAE-1796: en ella, efectivamente, impera una idea formal del régimen -como hemos visto- pero esa idea de régimen vinculada a caso parece próxima a la defendida por San Pedro (vid.supra 6.2.1.1.) $)^{274}$.

El cuadro nos permite comprobar también que las últimas GRAE de las que en este punto estamos tratando (las ediciones de 1880 a 1916) presentan una actitud similar a la del DRAE-1884: en ellas, se defiende que las palabras variables, excepto el verbo, conciertan en género, número y caso (remito a lo dicho en el punto 5.2.2). El cambio que -sin explicación aparente- se produce en el DRAE-1899, en el que volvemos a leer que esta concordancia se da sólo en género y número, no tiene eco en las Gramáticas de los primeros años del siglo XX (hasta 1916, inclusive) ${ }^{275}$.

${ }^{274}$ No obstante, el texto académico está lejos de la precisión de San Pedro a la hora de exponer el concepto de caso. Para el escolapio, que en este punto sigue la doctrina de Port-Royal (1660: 62-66 -vid. también Donzé, 1970: 165-179-) y del Brocense (1572), «los casos sirven para expresar los diferentes respetos que tienen las cosas unas con otras» (San Pedro, 1769, II: 126). 275 El concepto de caso defendido en cada una de estas Gramáticas no siempre va a coincidir con la terminología utilizada: por ejemplo, en la GRAE-1771 y las publicadas entre 1854 y 1867, a pesar de reconocer que no existe verdadera declinación (ni caso) en español, se habla de una clasificación básica de las palabras en declinables e indeclinables, quizá por la inercia de la costumbre, al tiempo que, por ejemplo, la preposición es definida como palabra invariable. En 1870, se introduce el término variable en la clasificación general de las palabras, lo que da una mayor coherencia a los planteamientos: hay palabras que, efectivamente, presentan variación morfemática (y entre esas palabras tiene que establecerse una concordancia cuando las une una relación de dependencia), pero esa variación de morfemas sólo indica cambios de género y número, nunca cambios de significado, entendido éste como oficio dentro de la oración. Los términos variable/invariable se mantendrán hasta la edición de 1916 en esta primera clasificación de las palabras, aunque, como hemos visto, a partir de 1874 se vuelve a defender la existencia de caso en español, y así, leemos que la preposición es palabra indeclinable (en la GRAE-1874 podemos encontrar la gestación de las ideas que se recogerán en el Diccionario bajo el lema caso a partir de 1884 -remito a la nota 39 del capítulo 5-). 


\begin{tabular}{|c|c|c|c|c|}
\hline \multicolumn{5}{|c|}{ EL CONCEPTO DE CASO Y LA CONCORDANCIA SUSTANTIVO-ADJETIVO } \\
\hline GRAE & $\begin{array}{c}\text { Concepto } \\
\text { de caso }\end{array}$ & Declaración explícita & Indicios & $\begin{array}{l}\text { Reflejo en la } \\
\text { concordancia }\end{array}$ \\
\hline 1771 & FORMAL & $\begin{array}{l}\text { «nuestra lengua no admite esta variedad de casosos ó terminaciones en los nombres, y solo conoce diferencia entre el singular, yel plural de ellos [...] Para } \\
\text { expresar el differente oficio que cada caso tiene en latin nos servimos de preposiciones») (pág. 24). }\end{array}$ & $\begin{array}{l}\text { No se declina ni el artículo ni el nombre (sólo se da un modelo de declinación latina, pero no se hace } \\
\text { extensiva al españo). }\end{array}$ & En género y número. \\
\hline 1796 & $\begin{array}{l}\text { SEMÁNTICO } \\
\text { ¿FUNCIONAL? }\end{array}$ & $\begin{array}{l}\text { «Estos diferentes modos de significar, ó lo que es igual, las variaciones de significado, que admiten las partes declinables de que hablamos, á excepcion } \\
\text { del verbo, se llaman casos. Daseles este nombre, porque ciertamente distinto caso es el de una palabra quando significa la cosa de un modo, que quando } \\
\text { la signififica de otro, ó no está en el mismo caso una vez que otray (pág. 6). }\end{array}$ & $\begin{array}{l}\text { Se declina tanto el artículo como el nombre. } \\
\text { Las oraciones de primera constan de /Nominativo + Verbo + Nominativo/ y las de segunda de } \\
\text { /Nominativo + Verbo/. }\end{array}$ & En género, número y caso. \\
\hline $\begin{array}{c}1854 \\
a \\
1867\end{array}$ & $\begin{array}{l}\text { FORMAL } \\
\text { SEMÁNTICO- } \\
\text { FUNCIONAL }\end{array}$ & 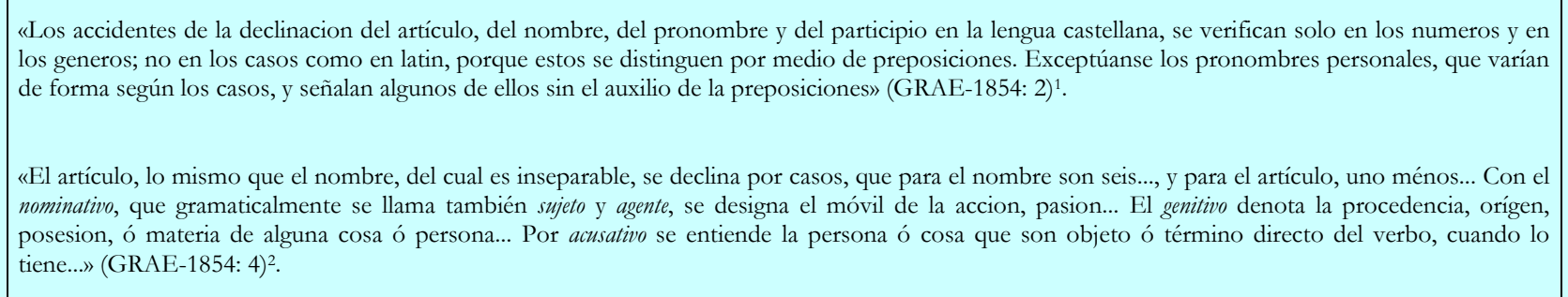 & 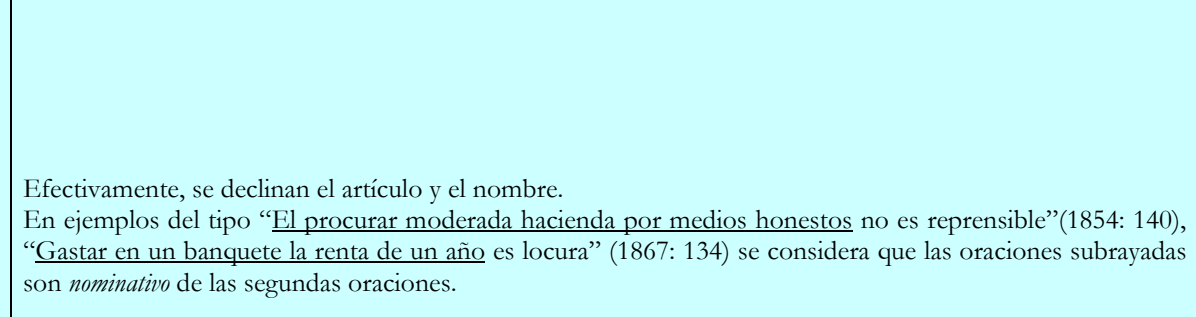 & En género y número. \\
\hline 1870 & FORMAL & 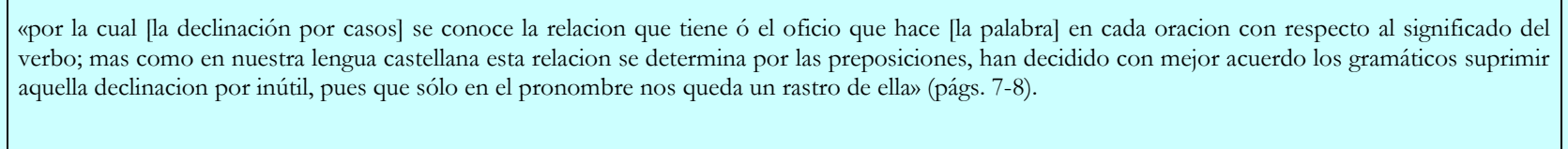 & $\begin{array}{l}\text { Efectivamente, se suprime de esta edición la declinación del artículo y del nombre. } \\
\text { En oraciones del tipo "'Gastar en un banquete la renta de un año es locura" (pág.172), ya no se dice que la } \\
\text { oración subrayada es nominanatioo de la segunda, sino "agente ó sujeto". }\end{array}$ & En género y número. \\
\hline $\begin{array}{c}1874 \\
\mathrm{y} \\
1878\end{array}$ & FORMAL & 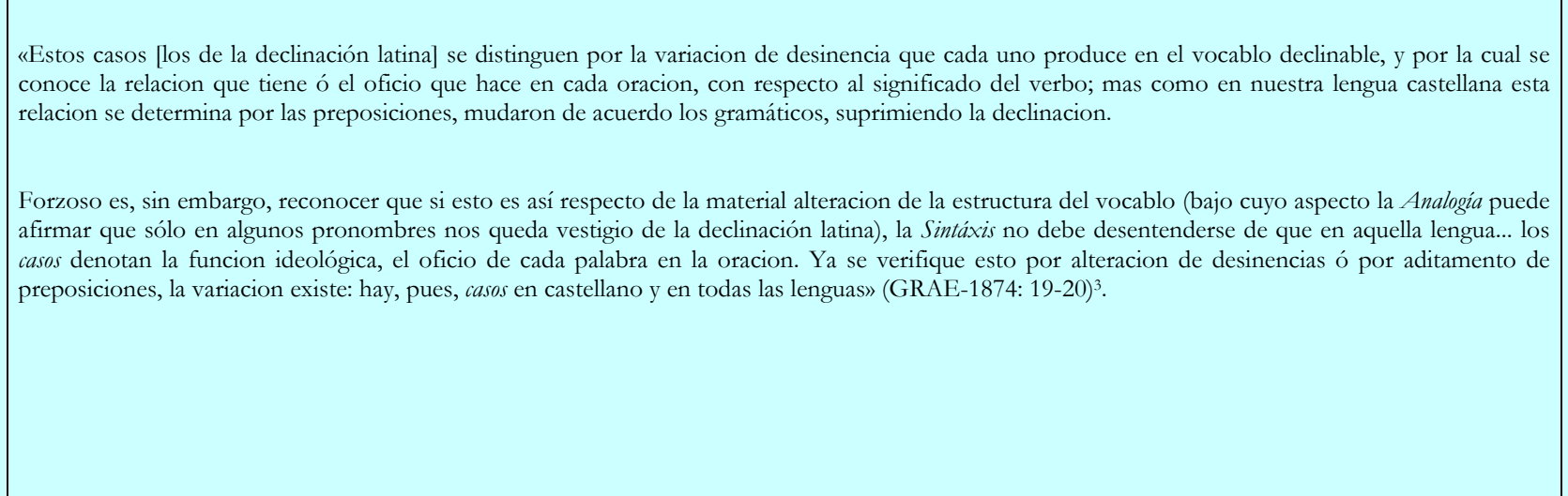 & 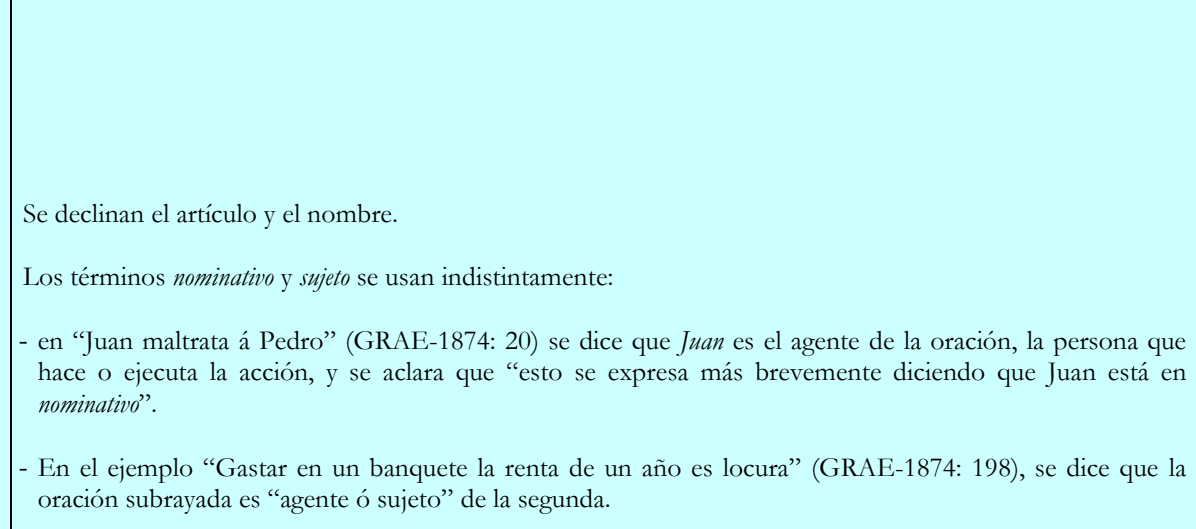 & En género y número. \\
\hline $\begin{array}{c}1880 \\
a \\
1916\end{array}$ & $\begin{array}{l}\text { SEMÁNTICO- } \\
\text { FUNCIONAL }\end{array}$ & 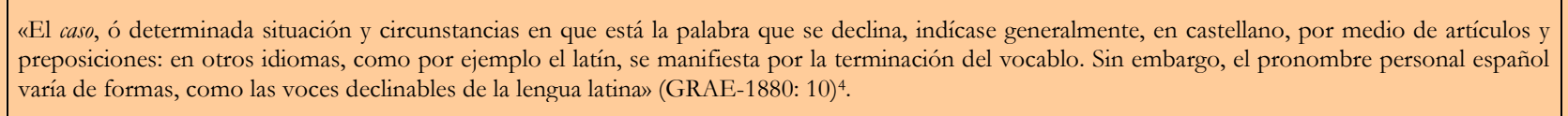 & Se declinan el artículo y el nombre. & En género, número y caso. \\
\hline
\end{tabular}

Cuadro 59: El concepto de caso y la concordancia Sustantivo-Adjetivo en las GRAE publicadas entre 1771 y 1916

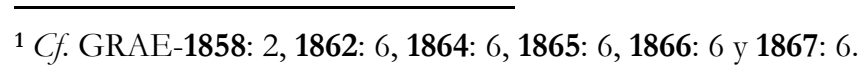

${ }^{2}$ Cf. GRAE-1858: 4, 1862: 8, 1864: 8, 1865: 8, 1866: 8 y 1867: 8.

I Cf. GRAE-1883: 10, 1885: 10, 1888: 10, 1890: 10, 1895: 10, 1900: 10, 1901: 10, 1904: 10, 1906: 10-11, 1908: 10-11, 1909:10-11, 1911: 10, 1913: 10 y $1916: 10$.

Capítulo 6. El concepto de sintaxis y las Relaciones de Dependencia en las Gramáticas de la RAE 
Estamos todavía lejos del concepto funcional de caso al estilo de Benot. En su obra, «los casos representan las funciones que unas palabras ejercen respecto de otras», decía Torres Reina en el Prólogo a la publicación póstuma de la Gramática filosófica del gaditano (cf. Benot, 1910: XXI) . En Este sentido, Benot hizo suya la noción que ya Benito de San Pedro (siguiendo las tesis de Arnauld y Lancelot, y del Brocense) había expuesto, de la que hemos dado cuenta más arriba, pero reformulándola en un sentido estrictamente funcional, desprovisto por completo de consideraciones formales ${ }^{276}$.

En todas las GRAE hasta 1916, se dice que el sustantivo, al ser elemento dominante sobre el adjetivo, artículo, pronombre y participio, es el que marca las variaciones morfemáticas de estas categorías. Parece sugerirse que debemos conocer a priori el género del sustantivo, según un criterio categorial o lexical (¿tenemos que sabernos el género de memoria?) para poder aplicarle el artículo y el adjetivo adecuados 277.

\section{$2^{\text {a }}$ Concordancia: nombre y verbo}

A propósito de la concordancia entre nombre y verbo, en los Apuntes de Sintaxis de 1746, leemos lo siguiente:

\footnotetext{
276 Más información sobre la concepción benotiana de caso, en Hurtado Valero (2002: 94-136 y 2006: 9-12).

277 En la segunda mitad del XIX, ya se habían dado teorías bastante ingeniosas a propósito del género y del reconocimiento del mismo en los sustantivos. Por ejemplo, Bello (1847), a quien la Academia debió de conocer bien, proponía un criterio práctico y de carácter morfosintáctico para el reconocimiento del género de los sustantivos: observar con qué terminación del adjetivo se junta el sustantivo (observar, en definitiva, la combinación y la flexión). La Academia en este punto muestra una gran firmeza de planteamientos y mantiene la idea de sustantivo = marca de género hasta 1916.
} 
La concordancia del verbo con el nombre que le rige ha de ser (como en la lengua latina) en numero, y persona: si el nombre es primera persona singular, el verbo ha de ser primera persona singular y assi delas demas: Yo, se ha de juntar, por exemplo, con amo, amaba, amé \&c., y no con amas, o amamos, o amaron \&c.

Hay algunas excepciones en la concordancia de los verbos: el nombre parte aunque es singular, no obstante quando comprehende a muchos, se junta en nuestra lengua, assi como en la Latina, con la tercera persona plural delos verbos: assi se dice: parte fueron hechos prisioneros, parte muertos, y parte huyeron, \&c.

Tambien el verbo haber en las terceras personas singulares tiene la irregularidad de juntarse con nombres plurales: como, hay muchos hombres: habia muchos, hubo muchos, habrá muchos, \&c. Esto se entiende quando este verbo se toma en significacion de ser, y no es auxiliar.

(ARAE, 1746c. La cursiva es mía)

También en el texto de la Gramática se afirma que el concierto, en este segundo tipo de concordancia, tiene que establecerse en número y persona ${ }^{278}$. En las ediciones del corpus comprendidas entre 1854 y 1870, esta segunda concordancia se da en toda oración, pues no puede haber nunca «verbo sin nominativo, ó nominativo sin verbo, callados ó expresos» (GRAE-1854: 140) ${ }^{279}$. $\mathrm{Y}$ es que, como queda indicado (vid. supra), hasta el texto de 1870 -incluido-, la estructuración bimembre de la oración en /Sust. + Vb./ se defiende incluso en aquellos casos en que hay un verbo llamado por la propia Academia impersonal, al cual sistemáticamente se le va a suplir un nominativo 280 .

278 En algunas ediciones, esta afirmación no coincide con la que se hace en el apartado dedicado al Régimen /Sust. $\rightarrow$ vb./, donde se indica que el concierto es sólo en número (Vid. GRAE de 1870: 179; 1874: 207 y 1878: 199).

${ }^{279}$ Cf. GRAE de 1858: 150; 1862: 154, 1864: 154, 1865: 154, 1866: 154, 1867: 153 y 1870: 171-172.

${ }^{280}$ Algo que, como se dijo a propósito del Régimen (vid. supra ap. c) del Caso (1) de Régimen), a lo largo de nuestra tradición gramatical, hizo Correas siguiendo al Brocense. En este punto, confirmamos que la Institución, en la segunda mitad del XIX y primeros años del XX, ignora posturas como las de Salvá y Bello, que aceptaron, en la primera mitad de la centuria, la 
En la GRAE-1874, encontramos, por primera vez, la aceptación -al menos, en este apartado de la Gramática- de que no siempre la oración se articula en /Sust $+\mathrm{Vb}$./; ahora se afirma que «no puede haber nombre sin verbo, ni verbo sin nombre, si se exceptúan los verbos impersonales» (pág. $199)^{281}$.

En este segundo tipo de concordancia, todas las Gramáticas que estamos considerando en este apartado (hasta la GRAE-1916) atienden a la llamada concordantia ad sensum. Para los académicos del período, el nombre impone los rasgos flexionales de número y persona al verbo (al igual que hace con el adjetivo) de manera que concierten las terminaciones de ambos, pero se reconoce la existencia de estructuras en las que el verbo aparece en distinto número que el sustantivo sujeto (de la misma forma que puede suceder con el adjetivo que modifica al sustantivo). Frente a las ideas apuntadas por Luzán -vid. supra-, la GRAE no mezclará, en esta consideración de los posibles casos de no-concordancia entre sustantivo y verbo, estructuras con sustantivo colectivo y oraciones con el verbo haber (en usos impersonales reconocidos en la parte de Analogía).

Los casos de concordancia de sentido son recogidos por la Academia desde el siglo XVIII (en 1771, solo bajo la Sintaxis figurada -otro aspecto en el que no se siguen las indicaciones de Luzán. Vid. supra-; en la edición de 1796, también en la concordancia ${ }^{282}$ ). Pero, en la primera Gramática del XIX, se puede

existencia de estructuras oracionales unimembres (las que constan únicamente de un elemento verbal, con o sin modificaciones).

${ }^{281}$ Cf. GRAE-1878: 199; 1880: 218; 1883: 218; 1885: 220; 1888: 218; 1890: 218; 1895: 218; 1900: 218, 1901: 218, 1904: 212; 1906: 212, 1908: 212 (hay una errata en la numeración de esta página: *112, entre 211 y 213), 1909: 212, 1911: 216, 1913: 216 y 1916: 216.

${ }^{282}$ Lo cual supone un avance en la voluntad de descripción de la realidad del uso de la lengua. A finales del XVIII es habitual incluir estas observaciones en la sintaxis figurada, cajón al que, como sabemos, iban a parar todos los usos "anómalos" o "dislocados", los que no se ceñían a la sintaxis natural. Vid. Gómez Asencio (1981: 66). 
leer una advertencia que supone una interesante reflexión sobre el funcionamiento de la lengua: además del requisito semántico de que el nombre sea un sustantivo colectivo, se impone el requisito sintácticocolocacional de que el sustantivo y el verbo no estén juntos -esto es, en la misma proposición-, salvo que el colectivo (o un sustantivo del tipo parte, resto, etc.) esté modificado por un complemento preposicional cuyo término indique también pluralidad y esté en plural. Reproduzco el fragmento del libro en el que se establece esta regla:

[...] debe evitarse que en tales locuciones vayan juntos el nombre y el verbo, pues disonaría el decir, por ejemplo. EL EJÉRCITO quedaron prisioneros. Sin embargo, cuando á uno de estos nombres colectivos, en número singular sigue inmediatamente otro nombre en plural, podrá ponerse tambien en plural el verbo, aunque continúe rigiéndole el colectivo, v.gr.: Un tropel DE FORAGIDOS invadieron el territorio...

(GRAE-1854: 141)

En estas palabras puede rastrearse un posible influjo de Salvá o de Bello, dos autores que, en la primera mitad del XIX, hacen esta misma advertencia. El influjo de Salvá es más plausible, en mi opinión, ya que tanto el valenciano como la Institución hablan de una "prohibición de proximidad física"; Bello, por su parte, apunta más finamente y señala la inviabilidad de que sustantivo colectivo y verbo plural aparezcan en la misma proposición. La precisión del venezolano al hablar de casos de complementación del colectivo (que supone decir mucho más que "cuando el colectivo va junto a un sustantivo plural", tal como viene a decir la Academia) también conduce a 


\author{
pensar que fue la lectura de Salvá la que pudo inspirar la redacción de estas \\ "normas" para la concordancia 283.
}

\title{
Los requisitos para la viabilidad de que los colectivos concuerden en plural los encontramos por primera y última vez en la GRAE-1854, lo cual la
}

${ }^{283}$ Los fragmentos que interesan de Salvá y Bello para el cotejo con la doctrina de 1854 son los siguientes:

Alguna vez los nombres llamados colectivos, por significar en el singular una muchedumbre o pluralidad, conciertan con un adjetivo o un verbo del plural; en cuyas locuciones se atiende más a la idea que concibe el entendimiento, que a formar una buena concordancia; y a esto damos el nombre de silepsis: Se agolpó el pueblo y amotinados se dirigieron a casa del gobernador; La gente que acá no saben leer ni escribir, ha dicho Capmany en la página 99 del discurso preliminar del Teatro de la elocuencia.

Para que esto pueda hacerse, son necesarios dos requisitos: primero, que los nombres colectivos signifiquen muchedumbre de cosas o personas indeterminadas, como gente, infinidad, multitud, pueblo, pues no diremos El rebaño siguió su camino y entraron en el redil, ni El ejército, después de haber peleado, se retiraron a la ciudad, porque rebaño y ejército comprenden una muchedumbre de cosas determinadas, como lo son las ovejas y los soldados. Segundo, que el nombre colectivo no vaya pegado al adjetivo o verbo, pues nadie dice El pueblo amotinados se agolparon, ni $\mathrm{La}$ gente no saben leer. Explícase con esto por qué nos suena bien que diga Hurtado de Mendoza La gente que sacó fueron ochocientos infantes, y parece un descuido [...] el que haya puesto La misma gente salieron en público [...]

Hay otros nombre que, sin ser colectivos, se revisten del carácter de tales unidos a un nombre plural o a dos singulares por medio de la preposición de, como clase, especie, género, parte, etc. por esto decimos Parte de los enemigos picaron nuestra retaguardia $[\ldots]$

(Salvá, 1847 [1830]: 305-306. El subrayado es mío)

Otra aplicación de la misma figura [silepsis] es a los colectivos de número $\underline{\text { singular, }}$ los cuales pueden concertar con un adjetivo o verbo en plural, concurriendo dos requisitos. Que el colectivo signifque colección de personas o cosas de especie indeterminada, como número, multitud, infinidad, gente, pueblo, y que el adjetivo o verbo no forme una misma proposición con el colectivo. Faltaría, por ejemplo, el primer requisito, si se dijera: «Habiendo llegado el regimiento a deshora, no se les pudo proporcionar alojamiento»; porque regimientosignifica colección de personas de especie determinada, es a saber, de soldados; y por falta del segundo no sería permitido decir: «El pueblo amotinados», «La gente huyeron». Al contrario, reunidas ambas circunstancias se diría bien: «Amotinóse la gente, pero a la primera descarga de la tropa huyeron despavoridos».

Sin embargo, cuando el colectivo es modificado por un complemento con de, que tiene por termino las personas o cosas de que consta el conjunto, designadas en plural, puede hacerse la concordanciaen este número, aunque el adjetivo o verbo forme una misma proposición con el singular colectivo: «Cubrían la ciudad por aquel lado una especie de fortificaciones construidas a la ligera» [...] Cncordancia que se extrañará todavía meno, si el complemento está inmediato al verbo: «considerable número de los indios murieron» $[. .$.

Parte, resto, mitad, tercio, y otros sustantivos semejantes, pueden concertar con el verbo y con el adjetivo en plural: «Agolpóse el populacho; parte venían sin armas; parte armados de puñales» $[\ldots]$

(Bello, 1860 [1847]: 536. El subrayado es mío) 
destaca como la única Gramática con intenciones claramente explicativas (no solo testimoniales) del fenómeno de la concordantia ad sensum (también recogido en todas las GRAE del corpus hasta 1916 en el capítulo dedicado a la silepsis) y da apoyo a la hipótesis de un influjo eventual de don Vicente -más probable- y/o don Andrés.

\section{$\underline{3}^{\text {a }}$ Concordancia: relativo y antecedente ${ }^{284}$}

En esta ocasión, la relación o dependencia entre las dos palabras concordantes debe marcarla el ajuste de género y número.

En este punto no sólo se atiende a las escuetas reglas de concordancia de relativo y antecedente, sino que se aprovecha para exponer de una forma más o menos detallada toda una casuística del uso de los relativos, que se va ampliando a partir de 1858, haciendo así de este apartado un complemento del capítulo dedicado a los pronombres relativos en la Analogía.

${ }^{284}$ Cf. GRAE-1854: 141-143, 1858: 151-154, 1862: 155-159, 1864: 155-159, 1865: 155-159, 1866: 155-159, 1867: 155-158, 1870: 172-175, 1874: 200-203, 1878: 200-203, 1880: 218-221, 1883: 218-221, 1885: 220-223, 1888: 218-221, 1890: 218-221, 1895: 218-221, 1900: 218-221, 1901: 218-221, 1904: 212-215, 1906: 212-215, 1908: 212 ( $\left.{ }^{*} 112\right)-215$, 1909: 212-215, 1911: 217-219, 1913: 217-219 y 1916: 217-219. 


\subsubsection{Los elementos de relación}

Al igual que veíamos en los Diccionarios, desde la primera edición de la GRAE, la Academia presenta -entre otras unidades- las preposiciones y conjunciones como elementos de enlace, unión o relación, naturaleza que entra en conflicto con el estatus de palabras Regentes que también se les concede en todas las Gramáticas del corpus, según se ha visto.

\subsubsection{LA CONJUNCIÓN}

La conjunción es reconocida, en los textos gramaticales de la Academia, como elemento de unión tanto de oraciones como de palabras desde la GRAE$1796^{285}$. En este aspecto concreto -como en otros-, comprobamos que la Gramática se adelanta al Diccionario (remito a lo dicho en 5.3. y al Glosario final).

A la noticia sobre el "oficio" de la conjunción dentro de la oración se reducen las definiciones de esta palabra que encabezan el capítulo correspondiente a su estudio; no encontramos, por tanto, en la definición propiamente dicha, una caracterización formal. La información sobre aspectos formales se da bien en las páginas primeras de la Gramática, concretamente, en la introducción del apartado sobre la Analogía (hasta la edición de 1867 -inclusive-286), bien en esas páginas primeras (que pueden ser las introductorias de la Analogía o las correspondientes a las Nociones Preliminares) y en los párrafos que siguen a la definición de conjunción, antes de abordar el estudio detenido de cada una de las clases (desde 1870 hasta 1916287).

\footnotetext{
285 En la edición de 1771: 222, sin embargo, se decía que «Conjuncion es una palabra que sirve para juntar, atar, ó trabar entre sí las demas partes de la oracion». Esta definición de la Gramática debió inspirar la del DRAE-1780.

$286 \mathrm{Vid}$. GRAE de 1854: 2; 1858: 2, 1862: 6, 1864: 6, 1865: 6, 1866: 6 y 1867: 6.

${ }^{287}$ Cf. GRAE de 1870: 7 y 155; 1874: 19 y 183; 1878: 19 y 183; 1880: 9 y 205; 1883: 9 y 205; 1888: 9 y 204; 1890: 9 y 204; 1895: 9 y 204; 1900: 9 y 204, 1901: 9 y 204, 1904: 9 y 199, 1906: 9 y 199, 1908: 9 y 199, 1909: 9 y 199, 1911: 8-9 y 201, 1913: 8-9 y 201, y 1916: 8-9 y 201.
} 
Desde el punto de vista formal, a la conjunción se le aplica siempre la etiqueta de indeclinable y/o invariable 288.

Veamos, en esquema, la información que sobre la conjunción ofrecen las Gramáticas del corpus publicadas entre 1854 y 1916:

\begin{tabular}{|c|c|c|c|c|}
\hline & FORMA & OFICIO & $\begin{array}{c}\text { UNIDADES } \\
\text { RELACIONADAS }\end{array}$ & TIPOS \\
\hline 1854-1867 & indeclinable & enlazar & $\begin{array}{c}\text { palabras y } \\
\text { oraciones }\end{array}$ & semánticos 289 \\
\hline $1870-1878$ & $\begin{array}{c}\text { indeclinable / } \\
\text { invariable }\end{array}$ & $\begin{array}{l}\text { denotar la } \\
\text { relación entre }{ }^{290}\end{array}$ & $\begin{array}{c}\text { oraciones y } \\
\text { proposiciones }\end{array}$ & $\begin{array}{l}\text { ¿formales? } \\
\text { semánticos } \\
292\end{array}$ \\
\hline 1880 & $\begin{array}{c}\text { indeclinable / } \\
\text { invariable }\end{array}$ & enlazar & $\begin{array}{l}\text { palabras y } \\
\text { oraciones }\end{array}$ & $\begin{array}{c}\text { formales }{ }^{293} \\
\text { semánticos }^{294}\end{array}$ \\
\hline 1883-1916 & $\begin{array}{c}\text { indeclinable / } \\
\text { invarible }\end{array}$ & denotar el enlace & $\begin{array}{c}\text { palabras y } \\
\text { oraciones }\end{array}$ & $\begin{array}{c}\text { formales } 295 \\
\text { semánticos }^{296}\end{array}$ \\
\hline
\end{tabular}

Cuadro 60: Tratamiento de la conjunción en las GRAE publicadas entre 1854 y 1916

288 Ya hemos dicho (vid. supra. nota 275) que, desde 1870, la GRAE sustituye los términos declinable/indeclinable por los de variable/invariable en la clasificación primera -de tipo formalque hace de las palabras. Sin embargo, tanto en ésta como en todas las GRAE que le siguen hasta la de 1916, en el capítulo de la conjunción, se dice que es palabra indeclinable.

${ }^{289}$ Copulativas, disyuntivas, adversativas, condicionales, causales, continuativas, comparativas, finales e ilativas.

${ }^{290}$ Líneas más abajo se aclara que «la relacion que denotan las conjunciones es siempre una relacion de enlace» (GRAE de 1870: 155; 1874: 183 y 1878: 183).

291 Parece que se está apuntando a una distinción formal entre conjunciones simples y locuciones conjuntivas cuando se dice que «Conjuncion es aquella palabra ó frase que sirve para...» (GRAE de 1870: 155; 1874: 183 y 1878: 183. El subrayado es mío).

${ }^{292}$ Los mismos que en las ediciones anteriores.

293 Simples (= las que constan de una sola palabra) y compuestas ó modos conjuntivos (= las que constan de dos o más palabras).

${ }^{294}$ Los mismos que en las ediciones anteriores.

295 Ídem GRAE-1880.

${ }^{296}$ Los mismos que en las ediciones anteriores. 
Como se puede observar, la GRAE-1870 introduce algunos cambios con respecto a las ediciones anteriores en su teoría de la conjunción: uno de ellos tiene que ver con las unidades que enlaza; otro, con su clasificación y otro, con la misión de este tipo de palabra. Sólo el segundo de estos cambios (que no deja de ser una simple insinuación en las ediciones de los años 70) será acogido de forma definitiva en todas las Gramáticas posteriores, en las que ya encontramos una clasificación formal explícita de las conjunciones en simples (tipo: $y, n i$, si, etc.) y compuestas (tipo: para que, por consiguiente, pues que, etc.).

En cuanto a las unidades enlazadas por la conjunción, las ediciones de los años setenta son las únicas que no reconocen explícitamente la unión de palabras. También son las primeras Gramáticas institucionales en las que encontramos una referencia al enlace de proposiciones, término que parece estar usado en el sentido actual de elemento oracional (estructurado en /(Suj.) + Pred./) que es constituyente de una oración (es decir, nuestras oraciones o proposiciones subordinadas). La afirmación que encabeza el capítulo dedicado a la conjunción hace pensar que oración y proposición son unidades distintas (la segunda integrada en la primera), si bien los ejemplos dados a continuación no marcan ningún tipo de diferencia entre ambas. Creo oportuno reproducir el párrafo en cuestión:

Conjuncion es aquella palabra ó frase que sirve para denotar la relacion que hay entre dos oraciones ó entre dos proposiciones de una misma oracion. - Así, en las oraciones Juan no vendrá, porque está enfermo; No se lo cuentes, pues no ha de creerlo, las palabras porque y pues son conjunciones.

(GRAE-1870: 155. El subrayado es mío) 
El uso tan esporádico que se hace del término proposición en el texto ofrece pocas pistas para poder precisar el concepto defendido por la Academia. Estas pistas, en principio -y según lo leído en el fragmento que hemos reproducido arriba-, conducen a pensar que proposición y oración son unidades distintas (aquélla integrada en ésta). Sin embargo, en la ejemplificación no se aclara qué están uniendo las conjunciones porque y pues (¿oraciones o proposiciones?) ni tampoco si en los dos ejemplos dados unen las mismas unidades. Parece que la Institución considera que tanto Juan no vendrá, porque está enfermo como No se lo cuentes, pues no ha de creerlo son oraciones, pero:

$\left.1^{\circ}\right)$ Si consideramos que Juan no vendrá y está enfermo son las proposiciones que enlaza porque, y No se lo cuentes y no ha de creerlo, las enlazadas por pues, faltaría algún ejemplo que diera cuenta de la unión de oraciones por medio de conjunciones.

$2^{\circ}$ ) Si, por el contrario, entendemos que las conjunciones están uniendo oraciones 297 : Juan no vendrá y está enfermo, en el primer caso; No se lo cuentes y no ha de creerlo, en el segundo, quedaría sin ejemplificar el enlace de proposiciones.

Esta segunda posibilidad (la de que la RAE esté ejemplificando la unión de oraciones) cobra fuerza si atendemos a la doctrina defendida líneas más abajo, según la cual siempre que hay una conjunción hay que suponer

\footnotetext{
${ }^{297}$ No sería descartable esta interpretación, pues, en todas las ediciones comprendidas entre 1854 y 1916, es muy frecuente encontrar el término oración referido a constituyentes de una oración estructurados internamente en /(Suj.) + Pred./ (ya sean Sujeto, Adyacente del Nombre o Complemento del Verbo) y a estructuras /(Suj.) + Pred./ funcionando como complementos de oración (los que inciden sobre toda una oración). Por otra parte, en la GRAE1870, encontramos la etiqueta proposición aplicada a ejemplos del tipo No hay ningún remedio para esa enfermedad y Ningún hombre viene.
} 
pluralidad de oraciones, incluso «aunque muchas veces se encuentre juntando palabras dentro de una oracion al parecer única» (GRAE-1870: 155). La conjunción, en estos casos, es, en definitiva, indicio de que se ha producido una elipsis. Así, en Homero y Virgilio fueron dos grandes poetas, no podemos hablar de unión de elementos simples, sino que es la forma abreviada de decir Homero fue un gran poeta y Virgilio fue un gran poeta. Una vez más, se trata de un enlace de oraciones (hay que tener en cuenta, además, que, en las GRAE de los años setenta, no se considera que la conjunción sea elemento de enlace entre palabras -vid. supra Cuadro 60-).

Esta doctrina se defiende por primera vez en la GRAE-1870 y sólo se mantendrá en las dos ediciones siguientes ${ }^{298}$, de modo que, con la GRAE-1880 volvemos a encontrar la teoría defendida entre 1854 y 1867: la conjunción puede unir tanto palabras como oraciones. El párrafo antes transcrito será sustituido por el siguiente:

Conjunción es aquella parte de la oración que sirve para enlazar las palabras y las oraciones unas con otras; v.gr.: Horacio Y Virgilio fueron dos grandes poetas; Juan no vendrá PORQUE está enfermo.

(GRAE-1880: 205)

La nueva formulación que presenta la GRAE-1883 se mantendrá hasta la última edición que nos ocupa en este apartado (GRAE-1916). La definición que ahora se lee de conjunción presenta dos cambios de interés:

- Se añade el término cláusula, que, a juzgar por las palabras de la Institución, se entiende como unidad distinta de la palabra y de la oración (y posiblemente a medio camino entre ambas).

298 Vid. GRAE de 1874: 183 y 1878: 183. 
- La conjunción vuelve a no ser -según la formulación- elemento que lleve a cabo el enlace, sino elemento que denota el enlace o vínculo que se da entre las palabras / cláusulas / oraciones ${ }^{299}$. Con este cambio de formulación, la GRAE-1883 (y todas las que le siguen hasta 1916) se suma a las publicadas en los años setenta. Ocho ediciones (GRAE de 1854 -J-, 1858 -E-, 1862 -R-, 1864 -R-, 1865 -R-, 1866 -R-, 1867 -R- y 1880 -J-) son, por tanto, las únicas que de una forma expresa defienden que la conjunción es nexo de unión, es elemento que tiene como finalidad enlazar (palabras, oraciones...).

En la teoría de la conjunción expuesta por la Institución en la segunda mitad del XIX y primeros años del XX (hasta 1916) no se aprecia una distinción entre tipos de enlace sintáctico, como prueba la sistemática clasificación de las conjunciones basada en criterios puramente semánticos (y formales a partir de 1880), sin tener en cuenta criterios de tipo funcional. Una prueba clara de que la Academia no presta atención a los valores funcionales de los constituyentes de la oración la tenemos en el hecho de que, en todas las GRAE que se están cotejando, los que de los siguientes ejemplos se recogen en el mismo grupo de conjunciones:

(1) Le rogó que fuese a su casa.

(2) Y ella dale que dale. 
Según leemos en todos los textos académicos que en este apartado nos ocupan, estos dos que son conjunciones copulativas ${ }^{300}$. La Institución no atiende al hecho de que en (1) hay una relación de dependencia oracional: el que y todo lo que le sigue desempeñan una función con respecto a rogó, mientras que en (2) se da una relación de coordinación, de pura unión entre los elementos que enlaza el que: el primer dale y el segundo dale son funcionalmente análogos e independientes entre sí. A la Academia no parece importarle que las conjunciones desempeñen oficios distintos, para su clasificación sólo interesan las notas de significado. Muy lejos queda la doctrina académica de la precisión y claridad con que Bello había expuesto la diferencia existente entre las relaciones de coordinación y las de subordinación. A propósito de que, leemos en la Gramática del venezolano:

El neutro que, anunciativo de proposición subordinada, como en "Creo que exite un Dios", tiene en casi todas las gramáticas el título de conjunción, que de ningún modo le conviene; porque no es el oficio de la conjunción ligar como quiera, sino ligar vocablos o frases análogas, que ocupan un mismo lugar, i se refieren de una misma manera a las otras palabras, sin que uno de los elementos o miembros ligados dependa del otro [...] Llamar pues conjunción al demostrativo que anuncia la subordinada, me parece tan inexacto como lo sería llamar conjunción al artículo el en la fruta del árbol. El

300 Cf. GRAE de 1854: 129; 1858: 139; 1862: 143, 1864: 143, 1865: 143, 1866: 143, 1867: 142; 1870: 158; 1874: 186; 1878: 186; 1880: 208; 1883: 208 (Le rogó que fuese á su casa); 1885: 209; 1888: 207; 1890: 207 (Le rogó que fuese á Cádiz); 1895: 207; 1900: 207, 1901: 207, 1904: 202; 1906: 202, 1908: 202, 1909: 202, 1911: 204, 1913: 204 y 1916: 204.

Pons Bordería (1997: 97) ha puesto de relieve la indistinción entre el plano semántico y el sintáctico en el tratamiento que la Academia da a las conjunciones en el siglo XVIII:

Sin embargo, el estatus de dichas conjunciones no es igual al que poseía en Nebrija o en Correas, porque, al no incorporarse en ninguna de las ediciones la coletilla por la que se igualaban los tipos anteriores de conjunciones a las continuativas, se dejan de distinguir los planos sintáctico y semántico que aparecían separados en gramáticas anteriores. De ahí se derivará el que las continuativas se reinterpreten como un subgrupo semántico de las conjunciones, cuyo estatus es idéntico al de las copulativas, disyuntivas o adversativas [...] La nómina de conjunciones continuativas, tal y como queda en 1796 (pues, así que, puesto, supuesto que) perdurará, con adiciones, hasta 1917. 
que anunciativo es como un artículo de la proposición subordinada; en realidad es un verdadero artículo, porque la demuetra; i no se diferencia del artículo definido sino en que la lengua lo ha destinado exclusivamente al enlace de una proposición incidente con la principal; especie de enlace propio de los relativos i no de las conjunciones.

Sin entrar a valorar el acierto o no de Bello al negar la cateoría de conjunción a que, lo cierto es que, como señala Moreno de Alba (1979: 16), estas palabras suponen un importante avance en la concepción y descripción de los fenómenos de hipotaxis como hechos diferenciados (y opuestos, en cierto sentido) a los de coordinación o parataxis.

\subsubsection{LA PREPOSICIÓN}

La información que se da de ella entre la GRAE-1854 y la GRAE-1916 puede someterse a la siguiente estructuración: 


\section{I.DEFINICIÓN}

\begin{tabular}{|c|c|c|}
\hline GRAE & CRITERIOS & RASGO DEFINIDOR \\
\hline 1854 & Formal & Parte invariable $^{302}$. \\
\hline $\mathbf{y}$ & Colocacional & Anteposición. \\
\hline $1858^{301}$ & $\begin{array}{l}\text { "Funcional" } \\
\text { (oficio) }\end{array}$ & $\begin{array}{l}\text { Denotar la relación de las palabras a las que se antepone con el sujeto principal de la } \\
\text { oración. }\end{array}$ \\
\hline $\begin{array}{c}1862 \\
\text { a } \\
1867^{303}\end{array}$ & $\begin{array}{l}\text { Formal } \\
\text { Colocacional } \\
\text { "Funcional" (oficio) }\end{array}$ & $\begin{array}{l}\text { Parte invariable. } \\
\text { Anteposición. } \\
\text { Denotar la relación que tienen entre sí dos nombres, dos verbos, un nombre con un } \\
\text { verbo, etc. }\end{array}$ \\
\hline $1870^{304}$ & "Funcional" (oficio) & Denotar la relación que tienen entre sí las palabras dentro de una misma oración. \\
\hline $\begin{array}{l}1874 \\
\text { a } \\
1880^{305}\end{array}$ & $\begin{array}{l}\text { Formal } \\
\text { "Funcional" (oficio) }\end{array}$ & $\begin{array}{l}\text { Palabra indeclinable }^{306} \text {. } \\
\text { Denotar el régimen o dependencia que tienen entre sí dos palabras o términos. }\end{array}$ \\
\hline $\begin{array}{l}1883 \\
\text { a } \\
1916^{307}\end{array}$ & $\begin{array}{l}\text { Formal } \\
\text { "Funcional" (oficio) }\end{array}$ & $\begin{array}{l}\text { Palabra indeclinable / invariable } \\
\text { Denotar el régimen o dependencia que tienen entre sí dos palabras o cláusulas. }\end{array}$ \\
\hline
\end{tabular}

Cuaro 61: Tratamiento de la conjunción en las GRAE publicadas entre 1854 y 1916

301

Preposicion es una parte invariable de la oracion, que se antepone á otras para denotar la relacion que tienen éstas con el sujeto principal de la cláusula, v. gr.: Voy Á misa; Estudié CON Pedro; El sombrero DE Juan; Estuvimos EN Aranjuez; Uno POR otro; No sirve PARA eso.

(GRAE-1854: 119)

Ídem GRAE-1858: 124.

302 Este término, curiosamente, se utiliza en las Gramáticas que establecen una distinción básica de las palabras en declinables e indeclinables en las páginas introductorias del libro (GRAE de 1854: 2 y 119, 1858: 2 y 124, 1862: 6 y 128, 1864: 6 y 128, 1865: 6 y 128, 1866: 6 y 128 y 1867: 6 y 127).

303 Preposicion es una parte invariable de la oracion, llamada así porque siempre se antepone á otras. Su oficio es denotar la relacion que tienen entre sí dos nombres, dos verbos, un nombre con un verbo, \&c.

Cf. GRAE-1862: 128, 1864: 128, 1865: 128, 1866: 128 y 1867: 127.

(GRAE-1862: 128)

304

Preposicion es una parte de la oracion que sirve para denotar la relacion que tienen entre sí las palabras dentro de una misma oracion gramatical. Así, en las frases Compadezco Á usted; Se contenta CON poco; El jardin DE mi amigo; Nos verémos EN el teatro; Pleitea POR pobre; Ahorrar PARA la vejez; Uno CONTRA cuatro, etc., las preposiciones á, con, de, en, por, para, contra, marcan la índole de la relacion que tienen usted con compadecer, poco con contentar, mi amigo con jardin, etc., etc.

(GRAE-1870: 143)

Preposicion es una parte indeclinable de la oracion, que sirve para denotar el régimen ó dependencia que tienen entre sí dos palabras ó términos. Así, en las frases compadezco á usted; litiga con empeño; uno contra cuatro; el jardin de mi amigo; nos veremos en el teatro; ahorrar para la vejez; pleitea por pobre, etc., las preposiciones á, con, contra, de, en, para, por, marcan la índole de la relacion que tienen usted con compadecer, empeño con litigar, etc., etc.

(GRAE-1874: 170)

Cf. GRAE-1878: 170 y 1880: 194.

306 Término utilizado en las GRAE que hablan de una primera división de las palabras en variables e invariables: GRAE de 1874: 19 y 170, 1878: 19 y 170, 1880: 9 y 194, 1883: 9 y 191, 1885: 8-9 y 191, 1888: 8-9 y 189, 1890: 8-9 y 189, 1895: 8-9 y 189, 1900: 8-9 y 189, 1901: 8-9 y 189, 1904: 9 y 184, 1906: 9 y 184, 1908: 9 y 184, 1909: 9 y 184, 1911: 8-9 y 185. En los libros de 1913: 8-9 y 185 y 1916: 8-9 y 185, solo se utiliza el término invariable, tanto en la clasificación inicial de las palabras como en la definición de preposición.

También la GRAE-1870: 143 utilizará el término indeclinable (y hace una primera clasificación en palabras variables e invariables -pág. 7-), aunque no en la definición propiamente dicha.

$307 \quad$ Preposición es una parte indeclinable de la oración, que sirve para denotar el régimen ó dependencia que tienen entre sí dos palabras ó cláusulas. Asi, en las frases compadezco Á usted; litiga CON empeño; uno CONTRA otro; el jardin DE mi amigo; nos veremos EN el teatro; ahorrar PARA la vejez; pleitea POR sostener el buen nombre de su familia; etc., las preposiciones á, con, contra, de, en, para, por, demuestran la índole de la relación que tienen usted con compadecer, empeño con litigar, etc., etc.

(GRAE-1883: 191)

Cf. GRAE-1885: 191, 1888: 189, 1890: 189, 1895: 189, 1900: 189, 1901: 189, 1904: 184, 1906: 184, 1908: 184, 1909:

184, 1911: 185, 1913: 185 y 1916: 185. 


\section{Observaciones:}

1) Excepcionalmente, la GRAE-1870 basa la definición de preposición solo en el oficio que esta palabra desempeña dentro de la oración, pero no se olvidará de la caracterización formal (indeclinable) y colocacional (anteposición) en los párrafos siguientes a la definición propiamente dicha.

2) El criterio de colocación deja de ser criterio definidor desde la 12. ${ }^{a}$ edición de la Gramática (1870), pero seguirá presente como rasgo caracterizador de la preposición en todas las ediciones publicadas hasta 1916.

3) En cuanto al criterio "funcional", se comprueba que todas las GRAE definen la preposición como marca de relación o marca de dependencia, si bien líneas más abajo de la definición que abre el capítulo, todas las Gramáticas aluden, de una $\mathrm{u}$ otra forma, a la capacidad rectora de la preposición. (Vid. apartado 6.2.1. -Caso (4) de Régimen-).

4) Las unidades enlazadas por preposición son:

- Las palabras dentro de la oración (a partir de 1867, se especifica que la relación es entre dos palabras).

No deja de resultar extraña (por su limitación descriptiva) la teoría expuesta en las GRAE de 1854 y 1858, según la cual, en expresiones del tipo Yo amo á Pedro, «la preposicion á denota que Pedro es el término de la acción del nominativo yo»; en Yo estoy con Pedro, «con denota relacion de compañía entre el nominativo yo y el ablativo Pedro», etc ${ }^{308}$. ¿Qué ocurre cuando la preposición introduce constituyentes que no guardan relación directa alguna con el nominativo de la oración («Volvió la cara Á

308 Más extraño aún resulta que la GRAE-1867, aunque ya ha cambiado la fórmula de definición -como se ve en el cuadro de arriba- dé una explicación idéntica a estos ejemplos. 
la pared») o cuando en la oración hay un verbo impersonal («No hay inconveniente en hacer eso»)?

- 2 palabras o 2 cláusulas (desde la GRAE-1883).

Desde esta 16. ${ }^{a}$ edición, junto con ejemplos del tipo El sombrero de Juan; Estuvimos en Aranjuez; Pleitea por pobre; etc., encontramos otros como Pleitea por sostener el buen nombre de su familia. Pleitea, de un lado, y sostener el buen nombre de su familia, de otro, son consideradas cláusulas unidas por preposición.

\section{CLASIFICACIÓN}

Preposiciones que sólo tienen significado cuando entran en la composición de otros vocablos (inseparables, desde1870309). Se trata de preposiciones latinas del tipo $e x, o b, r e$, dis, etc.

Preposiciones que tienen significado por sí mismas, aunque algunas de ellas puedan participar a veces en la composición de otras palabras (separables, desde $1870^{310}$ ).

${ }^{309}$ En esta edición también se les da el nombre de compositivas, pero tal etiqueta desaparece en 1874.

310 Esta edición es la única que, en la clasificación, no hace referencia a la posibilidad de que las preposiciones separables se utilicen en los procedimientos de composición, aunque en el capítulo del nombre sí se reconoce la existencia de nombres compuestos por preposición. 


\section{OTRAS INFORMACIONES}

- Se llama la atención sobre el hecho de que las preposiciones son sustitutos del caso latino.

- Se incluye la nómina de preposiciones separables y un análisis de los usos y valores de cada una de ellas.

- Desde la GRAE-1870, se especifica que la preposición media entre los lamado términos de la relación: el antecedente y el consecuente o complemento -hasta la GRAE-1909- / consecuente o consiguiente -desde la GRAE-1911-).

- Se apunta que la mayoría tiene origen latino (dato que se añade en la edición de 1874). 


\subsubsection{La oración y sus clases}

\subsubsection{1. $\quad$ Primer jalón: la doctrina en 1854}

Como ya se ha apuntado en 6.1.3., la GRAE-1854 (y no la de 1870) es la primera Gramática académica que dedica un apartado independiente al estudio de las oraciones ${ }^{311}$. La creación del nuevo capítulo hace que el sistema oracional adquiera más autonomía e identidad dentro de la Sintaxis a partir del primer texto del XIX. Sin embargo, la teoría no presenta importantes cambios (cambios en la esencia doctrinal) con respecto a los planteamientos que habían defendido los académicos de finales del XVIII: la inclusión de un nuevo tipo de oraciones y alguna que otra aclaración constituyen las diferencias con respecto a la GRAE-1796. En poco más de cuatro páginas se sintetiza toda la teoría de las oraciones.

La decisión de reunir en capítulo independiente la información relativa a los tipos oracionales (en rigor, la decisión de añadir un epígrafe precediendo a los párrafos en los que se hablaba de las oraciones en 1796) parecía ineludible entrados ya en la segunda mitad del siglo XIX. En las primeras décadas de la centuria, Hermosilla (1841), Saqueniza (1832), Herranz y Quirós (1834), y Noboa (1839) habían sido pioneros en incluir dentro de la Sintaxis un

311 Sorprende que Calero Vaquera (1986: 188-189) incluya las ediciones de 1854 y 1870 de la GRAE entre los tratados que estructuran la sintaxis según la ordenación segunda de las quince que distingue en su estudio, caracterizada -como otras de la tipología- por no dedicar un apartado o capítulo del libro al estudio de las oraciones y dividir la parte de sintaxis según el esquema:

\begin{tabular}{l|l||l} 
SINTAXIS & $\begin{array}{l}\text { Concordancia } \\
\text { Régimen } \\
\text { Construcción }\end{array}$ \\
& Figurada
\end{tabular}

Remito de nuevo al punto 6.1.3. de este estudio, en el que queda esquematizada la propuesta académica de división de la Sintaxis en estas dos ediciones jalón (vid. Esquemas 4 y $5)$. 
capítulo destinado exclusivamente a estudiar la unidad oración ${ }^{312}$. Y ya en el ecuador del siglo, en fechas muy próximas a la publicación de la primera GRAE decimonónica (incluso coincidiendo alguno de los tratados con su mismo año de publicación), Calderón (1852 [1843]), Pons y Argentó (1850), Martínez Sevilla (1851) y Fernández Monje (1854) reservarán también un apartado dentro de la Sintaxis para atender al examen de las oraciones.

La brevedad con que la Academia resuelve el estudio de la oración contrasta con la atención prioritaria que se presta a esta unidad en la obra de los últimos autores citados (los cuatro, deudores de la gramática filosófica en su formulación más sensista ${ }^{313}$ ), sobre todo, en el Curso elemental de la lengua

312 De estos autores, es Hermosilla el que de forma evidente privilegia el estudio de la oración entre los asuntos tratados en la Sintaxis. Destina el capítulo I del Libro II («DE LA COORDINACION DE LAS PALABRAS») a tratar de las varias especies de oraciones. En total, 38 páginas de 55, lo que supone el 69\% del estudio sintáctico. En la Gramática de Saqueniza, la parte de Sintaxis solo ocupa 26 páginas y de ellas, 6 (el 23\%) tratan «De las especies de oraciones». Herranz y Quirós, por su parte, dedica 54 páginas al estudio sintáctico, de las cuales 21 (el $38 \%$ ) quedan reservadas para las consideraciones sobre la oración. Por último, Noboa reserva para el estudio de la oración los capítulos I y II del Tratado primero de la Sintaxis (el dedicado a la Construcción), que suman un total de 24 páginas (el 26\%) de las 92 que ocupa la materia sintáctica.

Antes de estas fechas, el mismo Herranz y Quirós (1815), Jaramillo (1800) y Muñoz (1799) también hablan de la oración, pero al modo de la GRAE-1796. Vid. García Folgado $(2005 / 2006)$

313 Recordemos que el sensismo de Condillac, continuado por otros ideólogos como Destutt de Tracy, supuso un nuevo planteamiento en los estudios sintácticos, en virtud del cual se invierte el procedimiento seguido: se va abandonando el uso exclusivo del método sintético (que sumaba unidades menores hasta formar una unidad superior) para abrir paso al procedimiento analítico o de descomposición de unidades superiores (las visibles, el producto dado). La propuesta de los ideólogos caló en España en el primer cuarto del siglo XIX, a lo cual contribuyó, sin duda -y entre otras muchas traducciones que se hicieron, desde finales del XVIII, de obras fundamentales del empirismo francés-, la versión española de la Gramática general de Destutt de Tracy, firmada por Juan Ángel Caamaño. De esta traducción de 1822 he extractado los siguientes fragmentos, representativos del método analítico seguido por Destutt:

Todo discurso es la manifestación de nuestras ideas, y por tanto solo el conocimiento perfecto de éstas puede hacer descubrir la verdadera organización del discurso, y mostrarnos en todas sus partes el secreto mecanismo de su composicion.

(Pág. 73. El subrayado es mío)

Todo discurso $[\ldots]$ se forma de proposiciones, y entonces siempre explica juicios; ó se compone de signos ó conjuntos de signos, sin enlace entre sí, en cuyo caso representa ideas de cuaquiera otra especie, menos de juicios. 
española, de Fernández Monje, para quien la oración o proposición es unidad de partida (no de llegada) del estudio sintáctico 314.

En la GRAE-1854, el capítulo de las oraciones se inicia con un reconocimiento de que el interés de todo el estudio gramatical, esto es, de la Analogía y la Sintaxis¹5 («el conocimiento de las partes de la oracion con sus accidentes y propiedades, y el de la concordancia, régimen y construccion de ellas»-pág. 165-), es la formación de la oración, unidad última o límite del estudio sintáctico. En estas páginas, no encontramos una definición propiamente dicha de lo que es oración, pero la lectura de las primeras líneas permiten deducir que:

En esta última suposicion, decimos que el discurso no tiene sentido, que nada significa; pero esta expresion no es muy correcta, pues hace á la voz sentido sinónima de la voz juicio $[\ldots]$

(Págs. 80-81. El subrayado es mío)

La esencia del discurso, por tanto, es componerse de proposiciones de juicios. Estos son realmente sus elementos verdaderos é inmediatos; y lo que llaman con impropiedad elementos, ó partes del discurso ó de la oracion, son efectivamente los elementos ó partes de la proposicion. Esto nos avisa que para seguir nuestras investigaciones, debemos ahora examinar la proposicion, estudiándola especialmente en el lenguaje articulado, resecto á ser este el que mas la ha descompuesto, y en el que sus elementos son mas varios y distintos. Pasemos, pues, á descomponer la proposicion.

(Págs. 83-87. El subrayado es mío)

Sobre la introducción y los frutos del pensamiento de los ideólogos franceses en España, puede consultarse Hassler (1990), Ridruejo (1997) y Calero Vaquera (2007b).

314 Fernández Monje, siguiendo a los ideólogos, comienza el estudio de la Gramática por el análisis de la proposición en unidades más pequeñas. Pero el análisis se completará con la posterior sintesis (que, frente a la tradición anterior, en este gramático supone la combinación de las unidades superiores a la palabra -proposiciones- hasta llegar a constituir el discurso).

Analizando la proposicion, hemos descendido á las palabras, y de estas por las sílabas hasta sus primeros elementos, los sonidos y articulaciones. La SíNTESIS procede en sentido inverso, para lo cual no se detiene en las proposiciones, nuestro primer punto de partida, sinó que las combina entre sí para componer períodos, coordina los períodos para formar discursos, y reune los diversos discursos que se necesiten para el desarrollo de un asunto estenso.

(Fernández Monje, 1854: 196)

315 No olvidemos que, en 1854, tanto la disciplina como el libro de Gramática se estructuran en estas dos partes. 
- El concepto de oración se basa en criterios lógico-semánticos ${ }^{316}$ : las oraciones son fórmulas que «sirven para declarar nuestros pensamientos» (pág. 165). La concepción semántica que de la oración defienden los académicos de mediados del XIX se descubre desde las primeras páginas del libro: en el capítulo primero de la Analogía, podemos leer que «dos ó más palabras, con que se expresa un concepto cabal, forman lo que gramaticalmente se llama oración» (pág. 2). El sentido cabal como requisito indispensable para hablar de oración es herencia de la secular tradición latina, que tiene como arranque -y como eslabón con la gramática griega de Dionisio de Tracia- la figura de Prisciano. El concepto de oratio perfecta de Prisciano es el que subyace en la Gramática académica hasta 1916.

- Parece que se consideran equivalentes de oración los términos proposición y enunciación, aunque a lo largo del capítulo sólo se van a utilizar los términos oración y cláusula.

Al igual que ocurre con los Diccionarios hasta los primeros años del siglo XIX (vid. Glosario final, s.v. oración), en la GRAE-1854, esta suerte de definición de carácter semántico-nocional se completa con criterios de otra índole a la hora de ofrecer una tipología de las oraciones. Para la clasificación de las estructuras oracionales, la RAE parte de un criterio básico de carácter colocacional-formal: según el número y tipo de constituyentes, se habla de oraciones de primera (Nominativo + Verbo + Nominativo/Acusativo/Ablativo)

\footnotetext{
316 Tampoco se ofrecía definición exacta de oración en la cuarta edición de la Gramática y, sin embargo, por las declaraciones que se hacen en el texto de 1796, también podemos decir que el concepto de oración es, sobre todo, semántico-nocional, aunque la clasificación de la misma atienda a criterios de otra naturaleza. Conviene matizar a este respecto lo que afirmó en su día Lope Blanch (1979: 33), pues si bien es cierto que el criterio formal está presente en la caracterización de oración en la GRAE dieciochesca, no podemos decir que sea criterio exclusivo (vid. Glosario final, s.v. oración).
} 
$\mathrm{y}$ de segunda (Nominativo + Verbo) ${ }^{317}$. Cada una de estas dos clases puede dividirse, a su vez, en varios tipos atendiendo a la naturaleza verbal, y así, se distingue entre oraciones de sustantivo, de activa, de pasiva, de infinitivo, de gerundio y de participio, de imperativo y de relativo o incidental (teniendo en cuenta que este último tipo no responde, en realidad, al criterio de "naturaleza verbal").

Aunque la clasificación que se expone como básica es la que distingue oraciones de primera y de segunda, la Academia aborda el estudio de las diferentes estructuras analizando de forma independiente los distintos tipos de oraciones según su predicado y dando, en cada uno de ellos, ejemplos de oraciones de primera y de segunda. La propuesta académica de 1854 queda sintetizada de esta forma:

317 El criterio de distinción de estos dos grupos oracionales se reoge ya en Autoridades (vid. Glosario final), en unos términos más precisos que los que encontramos en el primer texto gramatical que atiende a la tipología de las oraciones, la GRAE-1796, donde se lee:

Para distinguir todas las oraciones entre sí, las llamarémos primeras, y segundas, no porque la una sea en realidad primera ó segunda respecto de la otra, sino puramente para diferenciar la que requiere mas palabras de la que requiere ménos; á las quales suelen otros llamar perfectas é imperfectas, no con mayor propiedad, y solo para el fin de darlas á conocer con distinción.

(GRAE-1796: 347. El subrayado es mío)

En la GRAE-1854, se hace la distinción sin dar más explicaciones. Será en la atención individual a cada uno de los tipos donde tengamos noticia de la diferencia existente entre la clase de primera y la clase de segunda:

Para distinguir las oraciones entre sí, las llamaremos primeras y segundas, conformándonos con el uso más general entre los gramáticos, sea ó nó activo el verbo que las componga. 


\section{Oraciones de sustantivo}

Se llama así a la oración constituida por el verbo ser o verbos neutros "semejantes" (estar, existir, caer, venir, etc.). La etiqueta oración de sustantivo de primera se aplica a dos tipos de estructuras: las de Predicado Nominal (Atributos) y las de Complemento Predicativo, en terminología actual.

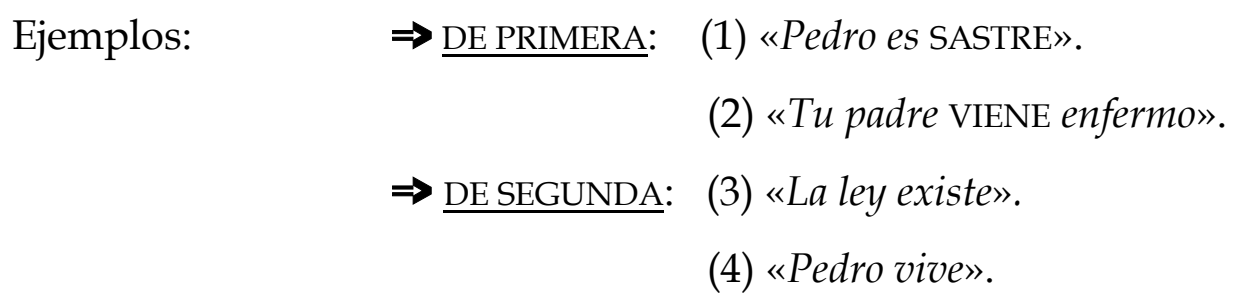

\section{Oraciones de activa}

Aunque la Academia usa indistintamente el término activo y transitivo para referirse a lo que hoy entendemos por verbo transitivo, en esta clasificación de las oraciones, parece que activo adquiere el sentido actual de voz activa o no pasiva, sin perder el sentido apuntado de transitivo.

$$
\begin{array}{lll}
\text { Ejemplos: } & \Rightarrow \text { DE PRIMERA: } & \text { (5) «Pedro ama la virtud». } \\
& \Rightarrow \text { DE SEGUNDA: } & \text { (6) «Pedro ama». }
\end{array}
$$

Se aclara que, en oraciones del tipo (6), difícilmente se distingue el verbo (que es activo o transitivo) de un verbo neutro (nuestros intransitivos). Las palabras que leemos podrían estar apuntando muy tímidamente a un reconocimiento de usos (en lugar de verbos) transitivos y no transitivos 318 , aunque la Institución, en esta fecha, 
plantea todavía la transitividad/intransitividad como rasgo caracterizador de los verbos, esto es, como cualidad inherente de los mismos.

\section{Oraciones de verbo recíproco ${ }^{319}$}

Se trata de estructuras cuyo verbo principal es pronominal.

$\begin{aligned} \text { Ejemplos: } \Rightarrow \text { DE PRIMERA: } & \text { (7) «Tú te abstienes de votar». } \\ & (8) \text { (Pablo se atreve á todo». } \\ & \text { (9)«Los poderosos se engrien fácilmente». }\end{aligned}$

Se recogen aquí estructuras que, tal como la propia Academia reconoce, responden al esquema /Nominativo + Verbo + Complemento ${ }^{320}$ (verbo -regido por preposición-, nombre -regido por preposición- o adverbio)/. Encontramos casos, por tanto, de lo que se podría entender como complementación o dependencia oracional, concretamente, el Complemento del núcleo verbal en el ejemplo (7) hoy recibiría -por lo general- la etiqueta de oración subordinada sustantiva en función de Suplemento. Los otros dos ejemplos muestran casos de dependencia o complementación no oracional: Suplemento (á todo), en el caso (8) y Complemento Circunstancial o Aditamento (fácilmente), en (9).

los neutros, como cuando se dice: Fulano COME y BEBE; Fulano GANA ó PIERDE, sin añadir ni áun insinuar cuánto ni qué.

319 De las oraciones de verbo recíproco no se hablaba en 1796 . Conviene advertir que en la doctrina decimonónica de la GRAE no se establece distinción entre reflexividad y reciprocidad. En 1854, la secuencia "verbo recíproco" debe entenderse, básicamente, como "verbo reflexivo".

320 Por primera vez aparece el término en la Gramática académica. 
$\Rightarrow$ DE SEGUNDA: $\quad(10)$ «Miguel se ausenta».

\section{Oraciones de pasiva}

En este tipo de oraciones, el verbo principal es una "forma compuesta" por el verbo ser y un participio pasivo o bien un verbo activo precedido de se (lo que hoy algunos llaman estructura de pasiva refleja).

\section{Ejemplos: $\Rightarrow$ DE PRIMERA: (11) La sabiduría es alabada de/por todos. \\ (12) La sabiduría se alaba por todos.}

Cuando se trata de oraciones de pasiva, las estructuras de primera no constan de /Nominativo + Verbo + Nominativo/, sino de /Nominativo + Verbo + Ablativo/. Y la Academia advierte que, en ejemplos como (11), el Ablativo va regido indistintamente de las preposiciones por o de; pero, en el caso (12), sólo por puede actuar de Regente. La Institución da como regla que toda oración primera de pasiva tiene la característica de poder transformarse en primera de activa, haciendo los siguientes cambios:

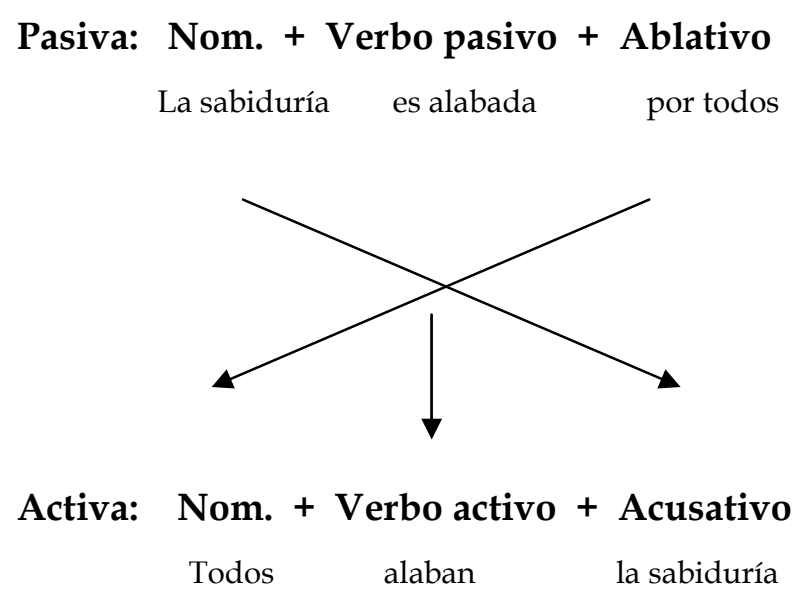


$\Rightarrow$ DE SEGUNDA: (13) La sabiduría es alabada.

(14) Se alaba la sabiduría.

La segunda de pasiva, al igual que la primera, también puede transformarse en oración de activa, pero para ello será necesario «suplir un nominativo de nombre genérico en plural». De esta forma podemos hacer la oración Los hombres/los pueblos alaban la sabiduría.

La Academia advierte sobre la posibilidad de confundir las oraciones segundas de pasiva -tipo (14)- con estucturas de verbo recíproco (verbo pronominal para nosotros) y con construcciones de impersonal, que son las formadas con se pronombre indeterminado (nuestro se "marca de impersonalidad"). Tras esta advertencia, se dan una serie de indicios que pueden ayudar en la distinción ${ }^{321}$ :

* Sabremos, por ejemplo, si una estructura tipo (14) es pasiva o recíproca (= reflexiva) según el tipo de nombre que acompañe al verbo y las palabras que acompañen a ese nombre. Si se trata de un nombre que denota ser inanimado o concepto abstracto, como el ejemplo dado en (14), obviamente estaremos ante un caso de pasividad (hoy también lo calificamos como pasiva refleja), puesto que dicho nombre no tiene capacidad agentiva, no puede realizar ninguna acción y hacer que repercuta sobre sí mismo. En caso de que el nombre denote un ser animado, capaz de llevar a cabo una acción que tenga como término él mismo (p. ej. Antonio se alaba), estaremos ante una oración de verbo reflexivo, a no ser que ese nombre vaya precedido de la preposición $a$, en cuyo caso

321 Tanto la advertencia de posibles confusiones como la explicación que se ofrece a continuación para evitarlas es un añadido que hace la Comisión de 1854 respecto de la edición anterior (GRAE-1796). 
volveríamos a hablar de oración segunda de pasiva (p. ej. Se alaba á Antonio).

* Tampoco se considera problemática la distinción entre oraciones tipo (14) y otras como En Madrid SE VIVE mejor que en Hortaleza o En los cafés SE MIENTE mucho. En construcciones como las dos últimas, ni se están expresando conceptos pasivos como en (14) ni los verbos que aparecen en ellas pueden teñirse de carácter recíproco, pues «no admiten otras conjugaciones y otros pronombres, como los que lo son de suyo ó se emplean con este carácter» (pág. 167).

\section{Oraciones de infinitivo}

Bajo esta etiqueta se recogen nuevos casos posibles de dependencia oracional (concretamente, subordinaciones sustantivas de infinitivo en función de CD). Aquellas oraciones cuyo verbo en infinitivo rija a su vez un acusativo serán de primera («Todos desean tener amigos»), y las que no tengan acusativo tras el infinitivo, de segunda («El trabajador necesita descansar»), considerándose el infinitivo, en estos casos últimos, término del verbo conjugado. Cuando el infinitivo es el verbo ser o estar, la oración -se deducesiempre será de primera $\mathrm{y}$, en lugar de regir acusativo -se dice explícitamente-, regirá nominativo tras él, puesto que no dejan de ser verbos sustantivos (p. ej. «Quiero ser arquitecto»; «Deseo estar solo»).

En la GRAE-1854 se suprime una interesante aclaración que sí encontramos en el texto de 1796: la alternancia de estas estructuras de infinitivo con la estructura Que + Ind./Subj. Además, en la cuarta edición se dice explícitamente que el infinitivo es el verbo determinado (por tanto, regido por el verbo conjugado que le precede). Compárense los siguientes 
fragmentos, el primero, de la última edición del XVIII y el segundo, de la primera del XIX:

Pueden hacerse oraciones de infinitivo con el verbo ser determinado, no determinante como se dixo arriba, v. g. Quiero ser arquitecto: este término es nominativo, como ya queda dicho en la construccion del verbo ser.

$\underline{\text { Todas estas oraciones pueden hacerse en los modos indicativo }}$ y subjuntivo con la conjuncion que con aquellos verbos que le admiten, segun queda advertido en el régimen del verbo y de esta conjuncion. V. g. Espero que te apliques, ó que te aplicarás: quisiera que te dedicaras, ó dedicases al dibuxo: creo que habré logrado mi pretensión.

Quando el pensamiento que se quiere declarar [...]

(GRAE-1796: 349-350. El subrayado es mío)

Pueden hacerse oraciones de infinitivo con los verbos ser y estar; pero no perderán por eso su carácter, y regirán por consiguiente á un nominativo, v. gr.: Quiero ser arquitecto; Deseo estar solo.

(GRAE-1854: 167)

Como vemos, en la primera edición decimonónica, no interesa tanto marcar la relación entre verbo conjugado y verbo en infinitivo, como la posibilidad de que el infinitivo rija otro elemento (esto es, que lleve su propio complemento).

\section{Oraciones de relativo o incidentales ${ }^{322}$}

Tal nombre se aplica a parte de las hoy también llamadas oraciones de relativo (o, mejor, estructuras con relativos). El concepto que se tiene de estas estructuras no resulta demasiado claro para el lector actual, dada la extrema

$322 \mathrm{El}$ término incidental lo encontramos por primera vez, dentro de la tradición académica, en esta Gramática; la GRAE-1796 sólo utiliza el término oración de relativo (Vid. GRAE-1796: 350). 
brevedad con que se expone. Parece que, al contrario de lo que hoy se defiende, se considera que la oración sin relativo sirve de complemento a la introducida por el pronombre relativo:

Cuando el pensamiento que se quiere declarar no se puede comprender en una oracion, sino que ha de ir pendiente de una á otra, se introduce un pronombre relativo, y de él toma este nombre la oracion, v.gr.: Pedro, QUE ESTÁ VIAJANDO, desea aprender. La primera $\underline{\text { de estas oraciones, que es la que forma el relativo, dejaria suspenso el }}$

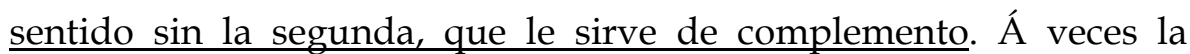
oracion incidental ó de relativo no es una sola, sino que son dos ó más, v.gr.: Pedro, Á QUIEN ESCRIBO, DE CUYA AMISTAD ESTOY SEGURO, POR QUIEN AHORA SUPLO, vendrá dentro de un mes.

(GRAE-1854: 167. El subrayado es mío) ${ }^{323}$

La Academia reconoce que las oraciones incidentales pueden ser una o más:

\section{Pedro, Á QUIEN ESCRIBO, DE CUYA AMISTAD ESTOY SEGURO, POR} QUIEN AHORA SUPLO, vendrá dentro de un mes.

¿Debemos entender también que, en casos de incidencia múltiple, la oración sin relativo es complemento de las varias oraciones con relativo? Es una duda con la que nos quedamos, pues los académicos no dicen nada al

323 La explicación que en 1796 se da al ejemplo de oración de relativo resulta más clara y nos saca de la duda sobre cuál es "la primera de las oraciones" y cuál es la que funciona como complemento:

[...] se introduce el pronombre relativo, y se llama la oracion de relativo, v.g. Pedro, que está viajando, desea aprender: hay dos oraciones, la primera es de relativo concertado en género, número y caso con el nominativo Pedro [...]

(GRAE-1796: 350)

La primera oración es, por tanto, que [< Pedro] está viajando y su complemento, Pedro desea aprender. 
respecto. En una doctrina coherente (la consideremos acertada o no), Pedro vendrá dentro de un mes serviría de complemento a las introducidas por "a quien", "de cuya" y "por quien".

Tal como ha señalado Salazar García (1999: 1421), el término incidencia «aparece ya en las primeras reflexiones sobre la subordinación desarrolladas por el racionalismo lingüístico». En los autores franceses del siglo XVIII y principios del XIX, encontramos dos nociones diferentes de incidencia: i) oración incidente $=$ oración de relativo y ii) oración incidente $=$ oración subordinada ${ }^{324}$. Este último uso (amplio) del concepto de incidencia contribuyó a desdibujar el estudio y la clasificación de la oración compuesta y pudo ser el motivo de que acabara triunfando el término subordinación para dar cuenta de las relaciones hipotácticas.

En la tradición española, antes de la publicación de la GRAE-1854, Bello ya había defiendido un concepto de incidencia diferenciado del de subordinación. Reserva la etiqueta de "incidente" para la oración de relativo explicativa, que tiene un grado de independencia mayor que las especificativas (que son propiamente subordinadas). Prueba del ligero vínculo que une a la proposición incidente con la principal (frente al más estrecho que ata a la subordinada con su subordinante) es su construcción parentética ${ }^{325}$.

\footnotetext{
${ }^{324}$ El primero de estos conceptos (que supone necesariamente la idea de incrustación de la oración incidente en la oración principal) es el que aparece en las primeras caracterizaciones de la gramática racionalista y el que encontramos en autores como Condillac (1798: 96-104). El segundo, que es habitual en la gramática escolar francesa, lo defienden Domergue, Noël y Chapsal o Bescherelle (Chervel, 1977: 79), y antes de estas fechas, Beauzée (1767, II: 18-44). Frente a la doctrina de Beauzée, los autores de la gramática escolar recurren a la elipsis («carente de todo alcance teórico», como ha observado Salazar García, 1999:1422) como recurso exclusivamente pedagógico: lo importante es que los alumnos sepan reconocer la proposición incidente como aquella que actúa sobre la principal y que se caracteriza por una serie de marcas formales (nexo, pausas, etc.).

325 Las proposiciones ligadas a otras por medio de relativos, unas veces especifican y otras explican; a las primeras hemos llamado subordinadas, a las segundas incidentes ( $\$ \$ 155$ y 156). El relativo que acarrea la proposición incidente hace en cierto modo el oficio de la conjunción y; y la proposición, no obstante el vínculo material que la enlaza con otra, pertenece a la clase de
} 
La Academia (en una edición que se declara deudora de la doctrina de Bello) ni desarrolla ni perfila tanto el concepto de oración incidente (tampoco se hace eco de la distinción de Bello entre oración y proposición), que debemos entender, en principio, como oración encabezada por un relativo, sin más.

\section{Oraciones de gerundio}

Con los gerundios pueden formarse oraciones de infinitivo (p.ej.: Queriendo partir; Deseando ser bien quisto), que tienen en común con las incidentales el necesitar de otra oración que complete su significado, por ejemplo: «QUERIENDO PARTIR, se lo estorbó la gota»; «DESEANDO SER BIEN QUISTO, trataba con afabilidad á sus dependientes»326. La Academia no solo parece entender que estas oraciones formadas por gerundio e infinitivo guardan semejanza con las incidentales, sino que -al menos- un tipo de ellas (las que presentan dos gerundios) son realmente oraciones incidentales (aunque no vayan introducidas por un relativo), a juzgar por las palabras que se leen a continuación:

las independientes; así es que en ella las formas del verbo (a lo menos del verbo principal, si hay más de uno) son las que convienen a las proposiciones independientes.

[..]

Entre las proposiciones enlazadas por el relativo, cuando una de ellas no hace más que explicar su antecedente, se hace siempre una pausa más perceptible que la que separa la proposición especificativa de la subordinante [principal], pausa que puede marcarse a veces hasta con un punto redondo.

(Bello, 1860 [1847]: 673-674)

326 En la GRAE-1796: 350-351, no se habla de la proximidad existente entre las oraciones de gerundio y las de relativo. En lugar de esto, encontramos dos informaciones que se suprimen en 1854: la equivalencia de las estructuras /gerundio + infinitivo/ y /como + subjuntivo/ (p.ej. «Queriendo partir» = «Como quiera, ó quisiese partir»), de un lado, $\mathrm{y}$, de otro, la atención a las llamadas oraciones de futuro de infinitivo de activa (p.ej. «tengo de ir») y de futuro de infinitivo de pasiva (p.ej. «tengo de ser amado»). 
También hay oraciones incidentales que se forman con dos gerundios, de los cuales suele ser el primero el del verbo estar, por ejemplo: ESTANDO COMIENDO, le dieron la noticia.

(GRAE-1854: 167)

La decisión de aplicar el marbete de "incidente" también a estas estructuras no encabezadas por un relativo pone de manifiesto que, para los académicos, es quizá (la seguridad, una vez más, no podemos tenerla por falta de explicitud) el carácter parentético, aislado, lo que caracteriza la incidencia. En este segundo tipo de oraciones incidentales, el gerundio en posición parentética viene a hacer las veces de adjetivo.

Los gerundios, al igual que los participios, cuando forman estructuras absolutas, «pueden resolverse en otras oraciones, según lo requiera el tiempo en que se halle el verbo de la oracion complementaria» (pág. 168). Por ejemplo: la oración Hablando/estando hablando, le dio una congoja equivaldría a Cuando hablaba le entró una congoja; la oración Yendo en coche, llegaré más pronto puede sustituirse por Si voy en coche llegaré más pronto. No podemos afirmar con seguridad que los académicos estén pensando en la dicotomía principal (oración de gerundio) / subordinada (oración con verbo conjugado) -interpretación opuesta, por otro parte, a la que hoy sería más generalizada-, pero sí parece claro que la Institución está defendiendo con estas palabras que la oración de gerundio necesita ser completada (desde el punto de vista significativo) con la otra oración, que hoy sería mayoritariamente interpretada (sobre todo, en el primer ejemplo: estando hablando, le dio una congoja) como "oración principal". 


\section{Oraciones de imperativo}

Las líneas dedicadas a este último tipo de estructura oracional constituyen, en realidad, un complemento del apartado de la Analogía en que se explicaba el uso del imperativo. Así, se habla de la incompatibilidad de este modo verbal con una negación expresa en la misma cláusula; del uso de los pronombres con el imperativo; del lugar que puede o debe ocupar el imperativo en la oración; de la inviabilidad de enunciados interrogativos con modo imperativo...

El capítulo de las oraciones se cierra con un brevísimo párrafo en el que se expone una tipología de la oración según los tipos de conjunciones que las introducen, tipología que consiste en una simple nómina incompleta (pues en el capítulo de la conjunción se establecen más tipos de conjunciones de los aquí mencionados) ${ }^{327}$. 


\subsubsection{Segundo jalón: la doctrina de 1870}

La doctrina de 1854, heredera en buena medida de la de 1796, se mantiene intacta hasta la GRAE-1870328, edición que ya muestra novedades de interés ${ }^{329}$. Un primer dato cuantitativo: el incremento de páginas dedicadas al estudio de la oración ${ }^{330}$, es indicativo de que algo ha cambiado.

El comienzo del capítulo responde a la costumbre de hacer síntesis de todo lo visto hasta el momento y recordar que tanto el estudio de la Analogía como el de las reglas que fundamentan la Sintaxis, esto es, Concordancia, Régimen y Construcción, tienen como objetivo último la formación de oraciones. También comparte esta 12. a edición de la GRAE con las anteriores el concepto semántico-nocional que se defiende de la oración, tanto en las primeras líneas de este capítulo como en las Nociones Preliminares ${ }^{331}$.

Junto a los evidentes puntos en común que la GRAE-1870 mantiene con los textos que le preceden, ya al comienzo de este capítulo se introducen novedades que no pasan desapercibidas: así, antes de abordar el estudio de los distintos tipos oracionales, se definen -por primera vez en la Gramática institucional- los constituyentes esenciales de la oración, que son /Sujeto + Verbo + Complemento/, si la oración es de primera, y /Sujeto + Verbo/, si es de segunda. El verbo quedó definido en la Analogía ${ }^{332}$, por lo que ahora se definen únicamente el sujeto y el complemento. Estas definiciones concuerdan, por su carácter semanticista, con la de oración, cuya esencia y finalidad sigue

328 Cf. GRAE-1858: 182-187, 1862: 186-191, 1864: 186-191, 1865: 186-191, 1866: 186-191 у 1867: 185-190.

${ }^{329}$ Para las bases doctrinales de las GRAE de 1854 y 1870, véase Sarmiento (1984b y 1986, respectivamente).

${ }^{330}$ Este incremento se cifra en 11 páginas, lo que significa que casi se ha cuadruplicado el espacio dedicado al estudio de las oraciones: el capítulo de poco más de cuatro páginas en 1854 pasa a ocupar ahora algo más de quince.

331 Cf. GRAE-1870: 206 y 5 (los fragmentos que interesan se encuentran en el Glosario final).

332 La GRAE-1870 introduce la novedad de introducir en la definición de verbo la referencia a sus morfemas de tiempo y persona (vid. Glosario final, s.v. verbo). 
siendo, en el jalón de 1870 y en las ediciones posteriores, «la más oportuna expresión de los pensamientos».

Sujeto de la oracion es la palabra, ó conjunto de ellas, que da accion ó aplicación al verbo; y por complemento se entiende la palabra, ó conjunto de ellas, en que termina la accion ó aplicación del verbo, ya directa, ya indirectamente.

(GRAE-1870: 206) $)^{333}$.

En la edición de 1911 (de rango E), encontramos el siguiente cambio de redacción, en virtud del cual la definición de sujeto se acerca ligeramente a nuestra actual concepción (al sugerirse ahora que es el constituyente de la oración al que va referida la predicación):

Sujeto de la oracion es la palabra, o conjunto de ellas, que realiza la acción o en que se cumple la atribución expresada por el verbo: JUAN corre, JUAN es bajo; y complemento es la palabra, o conjunto de ellas, que recibe la acción o que completa o determina la atribución expresada por el verbo, ya directa, ya indirectamente: Juan parte LEÑA; Juan es más bajo que PEDRO.

(GRAE-1911: 245) 334

En cuanto a la clasificación de los tipos oracionales, básicamente se mantiene la misma de 1854: seguimos con la distinción entre primeras y segundas en cada una de las clases de oraciones establecidas atendiendo a la naturaleza verbal 335 :

${ }^{333}$ Cf. GRAE-1874: 234, 1878: 234 (en esta edición, encontramos un cambio de redacción: «Sujeto de la oracion es la palabra, ó conjunto de ellas, que pone en accion al verbo; y por complemento [...]»), 1880: 245, 1883: 245, 1885: 247, 1888: 245, 1890: 245, 1895: 245, 1900: 245, 1901: 245, 1904: 239, 1906: 239, 1908: 239, 1909: 239.

334 Ídem GRAE-1913: 245 y 1916: 245.

335 No olvidemos que, como en 1854, las llamadas de relativo o incidentales no responden a este criterio. 
- de verbo en voz activa

- de verbo en voz pasiva.

- de verbo sustantivo.

- de verbo neutro.

- de verbo reflexivo 336 o recíproco.

- de modo imperativo.

- de infinitivo.

- de gerundio (y de participio).

- Impersonales.

- de relativo.

Debido a la escasa novedad que presenta la exposición y explicación de cada uno de estos tipos oracionales con respecto a lo dicho de la primera GRAE del XIX, me detendré en comentar sólo tres de las estructuras señaladas (de los ligeros cambios detectados en los restantes grupos doy cuenta en el Cuadro 64): las impersonales, que por primera vez son recogidas como grupo independiente 337 ; las de infinitivo, en cuya explicación encontramos un interesante apunte relativo a los hechos de subordinación; y las de relativo, cuyo análisis presenta ciertas modificaciones que interesa apuntar. Con respecto a las oraciones de verbo neutro, que hemos marcado en negrita, hay que recordar que, en realidad, no constituyen un tipo nuevo, aunque se les haya dado rótulo independiente (lo que no es poco): en 1854 eran parte integrante de las oraciones de sustantivo.

En la GRAE-1870, reciben el nombre de IMPERSONALES aquellas oraciones que responden a uno de los siguientes esquemas:

- Un solo verbo (de los llamados por la Institución impersonales). La Academia considera en este primer grupo las oraciones con verbos

336 En las ediciones anteriores sólo se hablaba de verbo recíproco.

337 Cierto es que ya en 1854 se hablaba de ellas, pero de una forma incidental. 
meteorológicos del tipo llueve, nieva, amanece, etc. Aunque se reconoce que ciertas oraciones constan de una sola palabra, todavía existe una resistencia a abandonar la concepción formal bimembre de la oración (/Suj.+Vb./), como prueba la aclaración de que, aunque callemos el sujeto en estas oraciones, en todas se entienden como suplidas palabras del tipo el cielo, la nube, el día, etc. Sorprende que sea justamente la primera GRAE que admite como grupo independiente las oraciones impersonales la que también introduce, por primera vez, una afirmación categórica, en las primeras líneas del capítulo de la oración, sosteniendo que ésta siempre se articula en /Suj. + Vb./338.

- Pronombre indeterminado se + verbo. Se trata de oraciones como En Madrid se vive cómodamente; En los cafés se miente mucho, de las que se aclara que nunca expresan conceptos pasivos ni su verbo adquiere carácter de reflexivo $(=1854$. Vid. supra $)$.

Este segundo grupo parece empezar a recibir una interpretación distinta a partir de la edición de 1911, en la que se pierde la afirmación explícita que las hacía integrantes de las oraciones impersonales y se dice de ellas que se trata de «oraciones de sujeto indeterminado que se forman con el pronombre indeterminado se»(GRAE-1911: 249). Estas oraciones se caracterizan por: i) no expresar conceptos pasivos y ii) no tener carácter reflexivo sus verbos.

338 En realidad nunca hay oracion sin sujeto ni verbo; pero muy á menudo suele omitirse el primero, y á veces el segundo.

(GRAE-1870: 206)

Afirmaciones en este sentido hemos encontrado en distintas partes del libro también en ediciones anteriores (vid. supra 6.2.1. a 6.2.3.). Pero es a partir del jalón de 1870 cuando empezamos a leerla al comienzo del capítulo de las oraciones.

Vid. GRAE de 1874: 234; 1878: 234; 1880: 245; 1883: 245; 1885: 247; 1888: 245; 1890: 245; 1895:

245; 1900: 245, 1901:245, 1904: 239, 1906: 239, 1908: 239, 1909: 239, 1911: 245, 1913: 245 y 1916: 245. 
La nueva interpretación (o, si no ha habido realmente cambio de concepción, la nueva forma de etiquetar estas oraciones: como de sujeto indeterminado en lugar de como impersonales) pone de evidencia que no existe una distinción conceptual clara entre la idea de indeterminación semántica del agente y la idea de impersonalidad (que supone la indeterminación como una de sus caracterísitcas). En este sentido, si En Madrid se vive cómodamente es oración "de sujeto indeterminado", no habrá distinción entre este tipo de estructura y la que se refleja en Se dice que... (nuestras pasivas reflejas).

Sorprende esta confusión, pues ya indicamos al hablar del Régimen que, el texto de 1911, en el capítulo dedicado al Verbo, es el primero que separa los casos de indeterminación semántica (comentados ahora en apartado independiente) de los casos de impersonalidad: así, en Aseguran que será buena la cosecha, ya no se considera que haya verbo impersonal, sino verbo sin sujeto determinado. En este mismo grupo se incluirán aquellas oraciones en las cuales «se expresa la indeterminación del sujeto mediante el pronombre se y el verbo puesto en tercera persona del singular» (GRAE-1911: 146). Son ejemplos de se "marca de indeterminación": Se asegura...; se cuenta... De estas oraciones (nuestras pasivas reflejas) se dice, efectivamente, que son reflexivas solo en cuanto a la forma y que equivalen a una oración segunda de pasiva.

En la explicación de las oraciones de INFINITIVO (divididas, como en 1854, en primeras y segundas), encontramos señales significativas del cambio en la concepción sintáctica de la Institución. Si en el primer texto del XIX, la interpretación de los ejemplos estaba presidida por la linealidad característica de la noción de régimen, a partir de la GRAE-1870 la lectura no hace pensar en relaciones palabra-palabra, sino en relaciones entre grupos de palabras (aunque 
el concepto de regencia siga presidiendo las relaciones intraoracionales). Los siguientes esquemas dan cuenta de lo que decimos:

\section{4}

De primera. Ejemplo: Todos desean tener amigos.

Interpretación: /Todos $\rightarrow$ desean $\longrightarrow$ tener $\rightarrow$ amigos/

1870

De primera. Ejemplo: Todos pretenden obtener la preferencia.

Interpretación: /Todos $\longrightarrow$ pretenden $\rightarrow$ [obtener $\longrightarrow$ la preferencia]/

Según los términos explícitos de la interpretación que se da al ejemplo de 1870, obtener la preferencia es el complemento directo de pretenden. Dentro del complemento directo, el infinitivo (o «primer término») rige al «segundo término» (la preferencia). En las oraciones de segunda (El trabajador necesita descansar), el infinitivo es el complemento del verbo conjugado.

Los cambios no se limitan a la nueva terminología (complemento en lugar de término regido, por ejemplo) y a la nueva lectura que lleva aparejada. Además, la Comisión de 1870 introduce un párrafo que interesa transcribir:

Fácil es conocer que las oraciones de infinitivo se reducen á las primeras de activa, porque los complementos obtener la preferencia y descansar ocupan el puesto que llenarian dos nombres cuando en el primer caso nos limitáramos á decir: Todos pretenden la preferencia; y quisiéramos decir en el segundo: El trabajador necesita descanso.

(GRAE-1870: 209) 
Hasta la fecha, es esta la declaración que, en el texto de la Gramática, apunta a la equivalencia funcional entre una categoría nominal y la suma de /Infinitivo + sustantivo/.

La exposición de las llamadas ORACIONES DE RELATIVO, por su parte, gana en precisión explicativa. Frente a la GRAE-1854, ahora se concibe claramente la oración que no presenta pronombre relativo como la principal. $\mathrm{Y}$, respecto a la oración de relativo (también llamada intercalar, incidental o accesoria), se destaca la doble función que desempeñan los relativos en este tipo de estructuras: el relativo es elemento introductorio de la oración y, además, desempeña, dentro de esa oración, la misma función que su antecedente -a quien representa el relativo- en la oración principal. Por último, se reconoce que estas estructuras pueden presentar una gran movilidad, no necesariamente tienen que ir intercaladas.

En lo tocante a la doctrina sintáctica, y concretamente a este capítulo dedicado al estudio de las oraciones, la GRAE-1870 supone la reforma de mayor entidad que se produce en el siglo XIX. Los planteamientos se repetirán casi de idéntica forma en las ediciones que le siguen, hasta la de 1916 (inclusive). Los “avances” pueden cifrarse en los siguientes:

\section{Terminología}

Uno de los cambios principales con respecto a la práctica habitual de la Institución hasta la fecha consiste en la sustitución casi total de la terminología clásica alusiva al sistema casual latino por una terminología estrictamente sintáctica:

- El antiguo nominativo recibirá distintas etiquetas según su posición u oficio en la oración: será Sujeto (p.ej. San Fernando en San Fernando 
conquistó á Sevilla) o Complemento calificativo ó circunstancial (que equivale a nuestros Atributos: p.ej. todopoderoso en Dios es todopoderoso).

- Por primera vez encontramos el uso sistemático del término complemento (término que ya se encuentra -muy esporádicamente- en la GRAE-1854), sustituyendo a acusativo, ablativo y dativo. A partir del jalón de 1870, las oraciones de primera constan de /Sujeto + verbo + complemento/ y las de segunda se caracterizan por "carecer de complemento".

En la 12. a edición de la GRAE, se hace uso de una terminología que ya resulta familiar al lector de hoy y que hace referencia a funciones oracionales "de primer orden": sujeto y complemento se usan de una forma sistemática en el capítulo de la oración y casi sistemática en el resto del libro 339 .

\section{Clasificación de las oraciones y de los constituyentes oracionales}

A la habitual clasificación de las oraciones en primeras y segundas (completada con una tipología basada, sobre todo, en la naturaleza verbal), se suman dos clasificaciones paralelas (que, todavía en 1870, podemos considerar "secundarias", puesto que se da en las últimas páginas del capítulo), según las cual la oración puede ser: completa o incompleta, y simple o compuesta.

La primera distinción se hará en virtud de que todos los constituyentes aparezcan expresos (en la oración completa) o de que alguno esté elidido (lo que convertirá a la oración en incompleta).

339 A pesar de todo, no dejaremos de encontrar (fuera del capítulo de las oraciones) algún uso de nominativo por sujeto, por ejemplo. 
La diferencia entre oración simple y oración compuesta reside en la capacidad de tener sentido completo por sí misma (simple) o en la necesidad de completar su significado con otra -o bien en la ayuda que presta para completar el significado de otra- (compuesta).

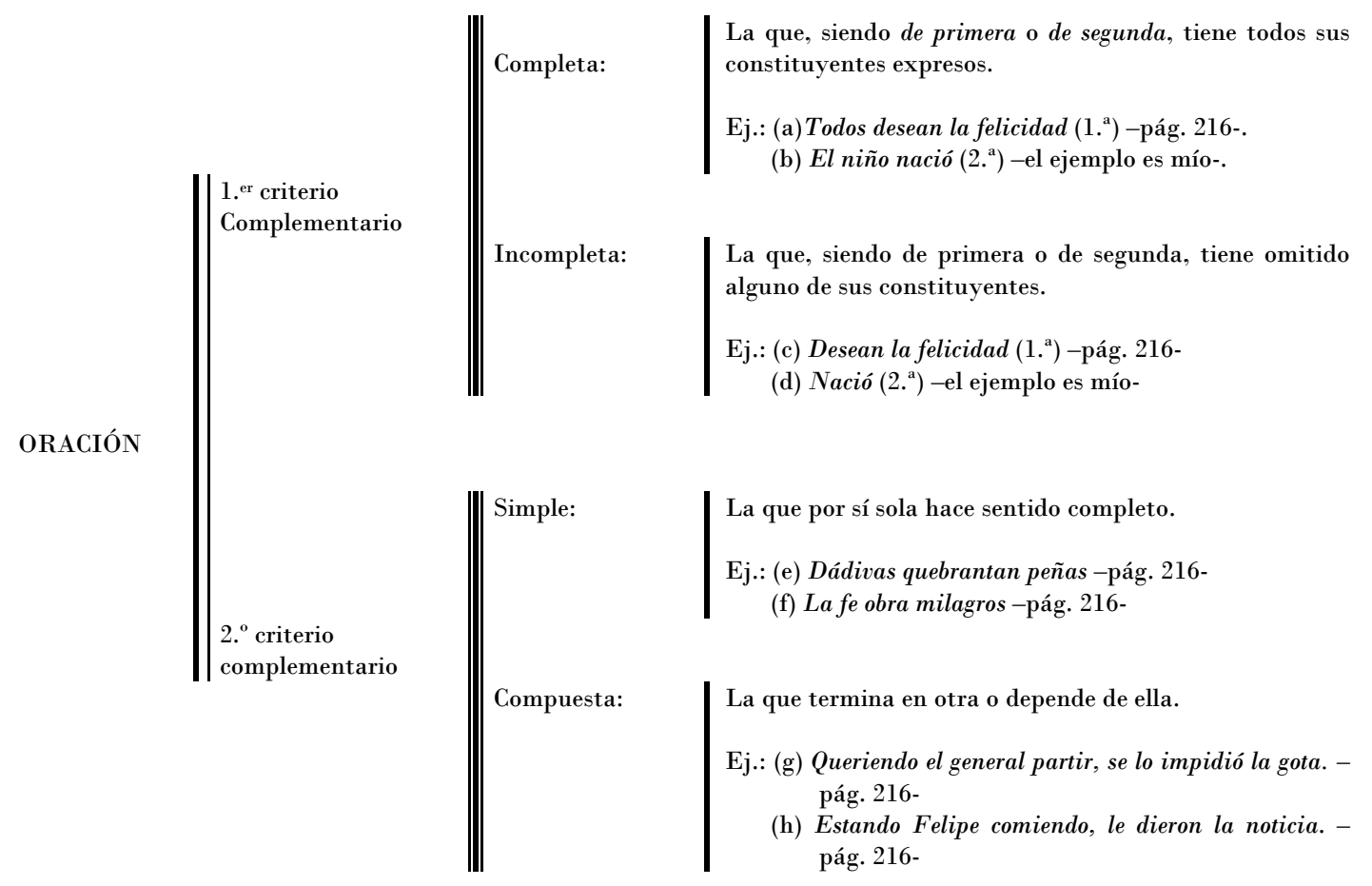

Esquema 11: Criterios complementarios de clasificación de las oraciones en la doctrina de 1870

No deja de sorprender esta idea de oración compuesta, que implica atribuir tal etiqueta a toda estructura /Sujeto + Verbo/ (según la terminología usada por los académicos) que complete su significado con (o, también, que complete el significado de) otra estructura /Sujeto + Verbo/. Según la definición, los ejemplos dados ( $\mathrm{g}$ y h) no deben interpretarse en bloque como dos ejemplos distintos de oración compuesta, sino que, en (g) -pongo por caso-, solo el segmento Queriendo el general partir sería oración compuesta. No obstante, una vez más, los académicos se limitan a formular una definición (extraña y poco clara) y a poner ejemplos sin dar más explicaciones de la teoría defendida. 
En el último tercio del siglo XIX, no son pocos los autores que ya han propuesto definiciones de oración compuesta que hoy nos parecen más acertadas. Basta mencionar de nuevo a Saqueniza o Noboa ${ }^{340}$. La Academia, sin embargo, mantendrá intacta la fórmula oración que termina en otra o depende de otra hasta la reformada (en fondo y forma) edición de 1917.

340 Saqueniza define la oración simple de forma muy parecida a la definición que encontramos en el texto académico, pero acierta a dar una definición de oración compuesta que hace coherente la oposición:

Oracion simple es la que espresa por sí sola y con un solo verbo el pensamiento que se desea comunicar [...]

Oracion compuesta es la que necesita mas de un verbo para espresar el pensamiento completo.

(Saqueniza, 1832 [1828]: 101)

Noboa, por su parte, parece calcar la definición de Saqueniza, si bien en su Gramática encontramos más desarrollada la teoría de la oración:

[Oración] Compuesta será la que necesite mas de un verbo para esplicar todo el pensamiento completo.

(Noboa ,1839: 202)

Partiendo de esta definición, Noboa considera casos de oración compuesta: i) las de verbo conjugado + infinitivo (en este grupo incluye tanto perífrasis -Todos debemos perdonar a nuestros enemigos- como subordinadas sustantivas de infinitivo en función de Término de un SP -La batalla se perdió por llegar tarde el General-, pero Noboa hace notar que el grado de fusión de verbo conjugado e infinitivo es distinto en los ejemplos dados); ii) las que incluyen una proposición de gerundio con valor temporal -Estando yo cenando, llamaron a la puerta-; iii) Las que contienen oraciones de participio absoluto (nomenclatura usada por el autor) -Empezada la función llegaron los músicos-; iv) Las que incluyen una oración encabezada por que o nexos derivados de él: porque, etc. -No quiero que vayas; Lo digo para que lo entiendas-); v) Las unidas por conjunciones causales, condicionales, adversativas, etc.; vi) Las que incluyen una oración introducida por artículo conjuntivo (nuestro pronombre relativo).

Avanzado ya el siglo XIX, encontramos definiciones semejantes a la de Noboa en autores que podemos considerar insertos en la corriente academicista. Pongo el caso de Gómez de Salazar (1874), para quien las oraciones compuestas son

llamadas así porque se componen de dos ó más oraciones ligadas entre sí para expresar un pensamiento, v.gr., Concluir tú ese trabajo y pagarte yo, se verificará al mismo tiempo. Aprendiendo los niños la leccion, complacen á sus padres y maestros. El hombre acaudalado que no favorece á sus semejantes, no merece los dones de la fortuna.

(Pág. 162) 
No obstante lo desafortunado de la definición y ejemplificación primeras (que dejan al lector con la duda de hasta dónde abarca realmente la oración que podemos rotular como compuesta), conforme se avanza en la lectura de este capítulo, la teoría parece ir aclarándose y el concepto de oración compuesta queda mejor perfilado. Así, por ejemplo, al explicar el uso de la conjunción que, la Institución ofrece las primeras señales de que por oración compuesta entiende la que consta de más de un verbo:

La conjunción que sirve a cada paso en las oraciones compuestas, para enlazar los verbos que se llaman regidos, con los regentes. Ejemplo: te agradeceré que me busques ese libro [...]

(GRAE-1874: 243, GRAE-1890: 254)

Es esta la primera referencia clara a que se necesita de la suma de dos verbos para tener oración compuesta y a que entre esos dos verbos existe una relación de dependencia, por cuanto uno es Regente y otro, regido. Otras afirmaciones en la misma línea encontramos en los párrafos dedicados a las oraciones introducidas por si "conjunción completiva" y si "conjunción condicional":

$\underline{\text { Cuando á la oración que sirve de complemento directo á una }}$ compuesta precede inmediatamente la conjuncion $s i$, y se expresa duda que puede resolver el que habla, irá el verbo regido á cualquier modo y tiempo $[\ldots]$

(GRAE-1870: 218)

Cuando la conjuncion si no es dubitativa, sino condicional, el verbo regente, ó ha de estar en cualquier tiempo de indicativo (ménos en futuro), ó ha de estar en las terminaciones $r a$ y se del pretérito imperfecto de subjuntivo, ó en uno de sus futuros; v.gr.: Si yo temo; Si tú temías; Si Gaspar temió; Si Diego ha temido; Si mi hermano temiera ó 
temiese; Si tu hijo temiere ó hubiere temido, etc. En los cuatro primeros casos, el verbo regido en la oracion que sirva de complemento directo á éstas puede ir á cualquier tiempo, exceptuando los futuros de subjuntivo. Así las oraciones, de sentido incompleto, arriba insertas, pueden formar una cabal compuesta, concluidas del modo siguiente: Si yo temo, tambien tú temes, temías, temiste, has temido [...]

(GRAE-1870: 218-219. El subrayado es mío)

Una vez leídas estas palabras, podemos afirmar -sin temor a yerroque el concepto de oración compuesta en el jalón de 1870 se sustenta en la idea de subordinación semántico-sintáctica (complementación) vinculada a las relaciones de regencia / Vb. $\rightarrow$ vb./. El problema está en la falta de acomodación que se descubre entre la terminología usada y la idea de oración -como unidad con sentido completo- que se defiende en todas las ediciones: los académicos admiten que las oraciones complementarias son semánticamente incompletas y que solo la oración compuesta (como la simple) tiene sentido cabal.

En cuanto a la clasificación de los constituyentes oracionales (reducidos a las funciones de sujeto y complemento, que son las que acompañan al verbo en la oración), también encontramos una distinción entre simples y compuestos:

- Sujeto simple: responde a las estructuras /Sust./, /Art. + Sust./, etc.

- Sujeto compuesto: no equivale a nuestro "sujeto múltiple", sino a estructuras en que el núcleo del SN Sujeto está modificado por un Adyacente («adjunto calificativo» para la Academia). 
- Complementos simples: /Adj./, /Sust./, /Art. + Sust./, /Art. + Sust. + Adj./...

- Complementos compuestos: constan de varios términos.

Entre los constituyentes etiquetados como complemento, se distinguirá, además, entre complemento directo y complemento indirecto, que viene a coincidir en parte con la diferenciación que se hacía en las ediciones anteriores entre el régimen obligado y el régimen accesorio:

\begin{tabular}{|c|c|c|}
\hline GRAE 1870-1916 & Criterios & $\begin{array}{c}\text { EQUIVALENTE } \\
\text { ACTUAL } \\
\end{array}$ \\
\hline $\begin{array}{c}\text { Complemento } \\
\text { Directo }\end{array}$ & 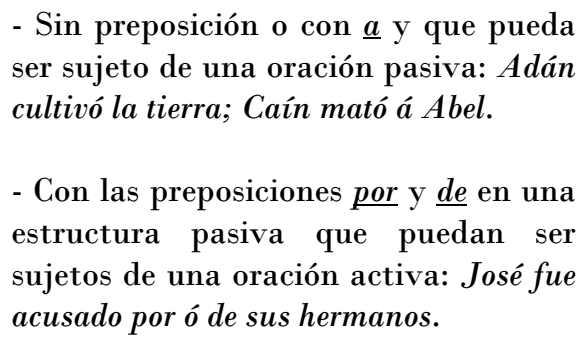 & $\begin{array}{l}\text { C.D. } \\
\text { C. Agente. }\end{array}$ \\
\hline $\begin{array}{l}\text { Complemento } \\
\text { Indirecto }\end{array}$ & $\begin{array}{l}\text { - Con las preposiciones por o de en una } \\
\text { estructura pasiva que no puede ser } \\
\text { sujeto de una oración activa: José fue } \\
\text { acusado de soberbia. } \\
\text { - Con cualquier otra preposición: con, } \\
\text { sin, entre, para, etc.: De Cádiz á } \\
\text { Málaga viajé por mar. }\end{array}$ & $\begin{array}{c}\text { C.I. } \\
\text { C.C. } \\
\text { Suplemento }\end{array}$ \\
\hline
\end{tabular}

Cuadro 62: Tipología de complementos en la doctrina de 1870

\section{$\underline{\text { Relaciones de complementación y de dependencia oracional }}$}

De las clasificaciones que se acaban de exponer, interesan, para el objetivo último de este estudio, las implicaciones teóricas que conllevan: 
1. Tras dar la clasificación de los constituyentes oracionales, se afirma que «puede haber sujetos y complementos que formen oraciones enteras» (GRAE-1870: 212), lo que supone el reconocimiento explícito, fuera ya del capítulo del Régimen, de lo que venimos llamando relaciones de dependencia oracional, concretamente relaciones que responden a estructuras del tipo: /(Suj.) + Pred./ $\Longrightarrow$ Vb.; Vb. $/ /($ Suj.) + Pred./ (las comúnmente conocidas como oraciones subordinadas sustantivas y oraciones subordinadas adverbiales), ya que por complemento todavía se entiende sólo complemento de verbo (no complemento de nombre, lo que deja fuera las oraciones adjetivas o de relativo -complementarias de un núcleo no verbal-). Recordemos que, tanto en la doctrina de 1854 como en la de 1870, sí se reconocen algunas de nuestras subordinadas adjetivas: las de relativo explicativas, que constituyen el grupo de las incidentales.

2. El concepto de oración compuesta también conduce al reconocimiento explícito de la existencia de «oraciones complementarias» ${ }^{341} \mathrm{y}$ al estudio -novedoso en la Gramática académica- de la unión de oraciones, un estudio que todavía es muy superficial, algo confuso y que aún no distingue tipos de enlace entre las oraciones (algo que está en consonancia con lo dicho sobre la "teoría de la conjunción"): unión de oraciones sintácticamente independientes frente a inclusión sintáctica de una oración en otra.

3. La Academia se detiene en la exposición de casos de dependencia oracional (casos de unión de oraciones de las cuales se dice que una funciona como complemento de la otra); concretamente, se atiende, sobre todo, a las uniones llevadas a cabo por la conjunción que

341 En la GRAE-1854: 168, encontramos una brevísima alusión a este tipo de oraciones, a propósito de las construcciones absolutas de infinitivo y gerundio. 
(nuestras oraciones subordinadas sustantivas) y por si (nuestras oraciones condicionales, que hoy tendemos a considerar no tanto complementos oracionales -constituyentes /(S) + P/- de un verbo, es decir, caso de oración subordinada sintácticamente, cuanto complementos de oración). La consideración de las oraciones con que y las oraciones con si es completamente distinta:

(1) Imagina que le harán justicia.

(2) Si viniere, será bien recibido.

Para la RAE, en (1), la oración complementaria es que le harán justicia; en (2), será bien recibido (remito a lo dicho sobre las oraciones de gerundio en 6.2.5.1.).

4. Se sigue hablando de Verbos Regentes y verbos regidos (recordemos que la GRAE-1854 introduce, tímidamente y sin éxito alguno, el término verbo subordinado), pero la atención ya no se centra en la dependencia entre palabras aisladas.

En los cuadros que siguen, se sintetiza la teoría de las oraciones defendida por la Institución en las ediciones del corpus comprendidas entre 1854 y 1916. El Cuadro 65 contiene dos gráficos en los que queda constancia del peso que el estudio de las oraciones tiene dentro del apartado sintáctico (también, de la atención dedicada a cada uno de los tres tipos de reglas de la Sintaxis que hemos analizado más arriba). 


\begin{tabular}{|c|c|c|c|c|}
\hline \multicolumn{5}{|c|}{$\begin{array}{l}\text { TIPOLOGÍA ORACIONAL } \\
\text { (doctrina de 1854) }\end{array}$} \\
\hline $\begin{array}{l}\text { NOMBRE DE } \\
\text { LA ORACIÓN } \\
\text { (según } \\
\text { naturaleza del } \\
\text { verbo) }\end{array}$ & $\begin{array}{l}\text { CLASES } \\
\text { (según n. }{ }^{\circ} \text { de } \\
\text { constitu- } \\
\text { yentes) }\end{array}$ & EJEMPLOS & $\begin{array}{l}\text { EQUIVA- } \\
\text { LENTE } \\
\text { EN } 1796\end{array}$ & $\begin{array}{l}\text { CARACTERÍSTICA DEFINITORIA } \\
\text { (Y ADVERTENCIAS) }\end{array}$ \\
\hline \multirow{2}{*}{ De sustantivo } & De primera & $\begin{array}{l}\text { Pedro es sastre. } \\
\text { Tu padre viene enfermo. }\end{array}$ & \multirow{2}{*}{ De verbo sustantivo } & $\begin{array}{l}\text { 1854: Núcleo verbal: ser o verbos neutros semejantes (estar, } \\
\text { existir...). }\end{array}$ \\
\hline & De segunda & $\begin{array}{l}\text { La ley existe. } \\
\text { Pedro vive. }\end{array}$ & & $\begin{array}{l}\text { 1796: No se explicita el tipo de verbo que la constituye, pero } \\
\text { los ejemplos se limitan a ser y estar. }\end{array}$ \\
\hline \multirow{3}{*}{ De activa } & De primera & Pedro ama la virtud. & \multirow{3}{*}{ De activa } & \multirow{3}{*}{$\begin{array}{l}\text { 1854: Verbo transitivo. } \\
\text { 1796: Tampoco se dice expresamente qué tipo de verbo la } \\
\text { forma. Se deduce que verbo activo transitivo (el ej. dado es } \\
\text { Pedro ama }-2^{2}-\text { - } \text { la virtud }-1^{2}-\text { ) }\end{array}$} \\
\hline & & & & \\
\hline & De segunda & Pedro ama. & & \\
\hline \multirow{2}{*}{$\begin{array}{l}\text { De verbo } \\
\text { recíproco }\end{array}$} & De primera & Tú te abstienes de votar. & \multirow{2}{*}{ NO } & \multirow{2}{*}{ Verbo pronominal. } \\
\hline & De segunda & Miguel se ausenta. & & \\
\hline \multirow[b]{2}{*}{ De pasiva } & De primera & $\begin{array}{l}\text { La sabiduría es alabada de/por } \\
\text { todos. } \\
\text { La sabiduría se alaba por todos. }\end{array}$ & \multirow{2}{*}{ De pasiva } & \multirow{2}{*}{$\begin{array}{l}\text { 1854: verbo en voz pasiva: } \\
\text { /Vb. Ser + Participio pasivo/ } \\
\text { /Pr. Se + Verbo activo/ (hoy: pas. refleja) } \\
\text { Se advierte que, en la pasiva refleja, las oraciones de } 1^{\text {a }} \text { solo } \\
\text { pueden llevar el Abl. (hoy: C. Agente) con por. Se advierte } \\
\text { también sobre la posible confusión de las pasivas reflejas } \\
\text { con las oraciones de se impersonal y las de verbo } \\
\text { reflexivo/recíproco. } \\
\text { 1796: Como en los tipos anteriores, no se especifican las } \\
\text { características de la forma verbal. Pero los requisitos ya son } \\
\text { los mismos que en } 1854 \text {. También la advertencia de que el } \\
\text { Abl. solo puede ir con por en la segunda estructura. }\end{array}$} \\
\hline & De segunda & $\begin{array}{l}\text { La sabiduría es alabada. } \\
\text { La sabiduría se alaba. }\end{array}$ & & \\
\hline \multirow{2}{*}{ De infinitivo } & De primera & $\begin{array}{l}\text { Todos desean tener amigos. } \\
\text { Quiero ser arquitecto }\end{array}$ & \multirow[t]{2}{*}{ De infinitivo } & \multirow{2}{*}{$\begin{array}{l}\text { 1854: /Vb. conjugado + Infinitivo/ } \\
\text { 1796: /Vb. Determinante + vb. determinado en inf./ } \\
\text { En esta edición se hablaba de la equivalencia entre las } \\
\text { estructuras de infinitivo y las de / que + Ind./Subj./ }\end{array}$} \\
\hline & De segunda & El trabajador necesita descansar. & & \\
\hline $\begin{array}{l}\text { De relativo / } \\
\text { incidental }\end{array}$ & $\begin{array}{l}\text { NOSE HACE } \\
\text { DISTINCIÓN }\end{array}$ & $\begin{array}{l}\text { Pedro, que está viajando, desea } \\
\text { aprender. } \\
\text { Pedro, á quien escribo, de cuya } \\
\text { amistad estoy seguro, por quien } \\
\text { abora suplo, vendrá dentro de un } \\
\text { mes. }\end{array}$ & De relativo & $\begin{array}{l}\text { 1854: /Vb. conjugado + relativo + Verbo conjugado/ } \\
\text { - Necesita completar su significado con otra oración. } \\
\text { - Posición parentética (no se dice explícitamente). } \\
\text { 1796: lo mismo que en } 1854 .\end{array}$ \\
\hline Con gerundio & $\begin{array}{l}\text { NO SE HACE } \\
\text { DISTINCIÓN }\end{array}$ & $\begin{array}{l}\text { Deseando ser bienquisto, trataba } \\
\text { con afabilidad á sus dependientes. }\end{array}$ & Con gerundio & $\begin{array}{l}\text { 1854: } \\
\text { - oraciones de infinitivo con gerundio } \\
\text { - oraciones incidentales con dos gerundios }\end{array}$ \\
\hline De imperativo & $\begin{array}{l}\text { NO SE HACE } \\
\text { DISTINCIÓN }\end{array}$ & $\begin{array}{l}\text { Sepa yo qué ha sido eso. } \\
\text { Seamos justos. } \\
\text { Acerca una silla. } \\
\text { Venid mañana. }\end{array}$ & NO & $\begin{array}{l}\text { 1854: } \\
\text { - El imperativo no se puede usar con negación. } \\
\text { - El imperativo no es compatible con la modalidad } \\
\text { interrogativa. } \\
\text { - En } 2^{\mathrm{a}} \text { y } 3^{\mathrm{a}} \text { persona, el sujeto del imperativo es siempre un } \\
\text { pronombre personal. Si el pronombre se omite, el verbo } \\
\text { tiene que ocupar el primer lugar de la oración. }\end{array}$ \\
\hline \multirow{2}{*}{$\begin{array}{l}\text { Copulativa } \\
\text { Disyuntiva } \\
\text { Adversativa } \\
\text { Causal } \\
\text { Condicional }\end{array}$} & \multicolumn{4}{|c|}{ CRITERIO COMPLEMENTARIO (SECUNDARIO Y NO DESARROLLADO NI EJEMPLIFICADO) } \\
\hline & \multicolumn{4}{|c|}{ Nombre de la conjunción que habitualmente introduce la oración. } \\
\hline
\end{tabular}




\begin{tabular}{|c|c|c|c|c|c|c|}
\hline \multicolumn{7}{|c|}{$\begin{array}{l}\text { TIPOLOGÍA ORACIONAL } \\
\quad \text { (doctrina de 1870) }\end{array}$} \\
\hline & NOMBRE & $\begin{array}{c}\text { CLASE } \\
\text { (según n. }{ }^{\circ} \text { de } \\
\text { constituyentes) } \\
\end{array}$ & & EJEMPLOS & $\begin{array}{l}\text { EQUIVALENTE } \\
\quad \text { EN } 1854 \\
\end{array}$ & $\begin{array}{l}\text { CARACTERÍSTICAS DEFINITORIAS / ADVERTENCIAS DE LOS NUEVOS TIPOS } \\
\text { (Y CAMBIOS EN LOS RESTANTES TIPOS) }\end{array}$ \\
\hline \multirow{13}{*}{$\begin{array}{l}\text { Tipos según la } \\
\text { naturaleza del } \\
\quad \text { verbo }\end{array}$} & $\begin{array}{l}\text { De verbo } \\
\text { en voz activa }\end{array}$ & De primera & $\begin{array}{l}\text { Lafe ob } \\
\text { San Fer }\end{array}$ & $\begin{array}{l}\text { ra milagros. } \\
\text { nando conquistó a Sevilla. }\end{array}$ & De activa & $\begin{array}{l}\text { - Se suprime la advertencia de } 1854 \text { sobre la posible confusión de las segundas de activa con las } \\
\text { oraciones de verbo neutro. } \\
\text { - El primero de los ejemplos de las oraciones de segunda (Luis pretende) no responde a una } \\
\text { estructura equivalente a la de Malvina escribe (o a la de Pedro ama, que léamos en 1854). El verbo } \\
\text { pretender, en rigor, solo admite oraciones de primera, pues sin el complemento la oración no tiene } \\
\text { sentido completo (que es requisito necesario para cualquier estructura oracional, } \\
\text { independientemente del número de constituyentes que tenga). Luis pretende hubiera sido mejor } \\
\text { ejemplo de oración de primera de activa incompleta (vid. infra). }\end{array}$ \\
\hline & $\begin{array}{l}\text { De verbo } \\
\text { en vozpasiva }\end{array}$ & De segunda & $\begin{array}{l}\text { Las pa. } \\
\text { por los } \\
\text { La felic } \\
\text { La felic } \\
\text { La felic } \\
\text { Se desea }\end{array}$ & $\begin{array}{l}\text { es fueron firmadas / se firmaron } \\
\text { blenipotenciarios. } \\
\text { dad es deseada de todos. } \\
\text { dad se desea por todos. } \\
\text { dad es deseada. } \\
\text { la felicidad. }\end{array}$ & De pasiva & $\begin{array}{l}\text { - Se mantiene la advertencia sobre la posible confusión de las segundas de pasiva con las } \\
\text { oraciones de verbo impersonal (advertencia más lacónica que la de } 1854 \text { y que será suprimida } \\
\text { en la GRAE-1911), pero se suprime el comentario sobre las diferencias existentes entre las } \\
\text { segundas de pasiva y las oraciones de verbo reflexivo o rećṕroco. } \\
\text { - En la GRAE-1911, la primera información que se da sobre estas oraciones, antes de distinguir } \\
\text { las de primera y de segunda, es la inversión en el orden de aparición que se produce entre el sujeto } \\
\text { y el complemento. En las ediciones posteriores, los párrafos dedicados a las oraciones con } \\
\text { verbo pasivo estarán encabezados también por esta advertencia. }\end{array}$ \\
\hline & $\begin{array}{l}\text { De verbo } \\
\text { sustantivo }\end{array}$ & De primera & \multicolumn{2}{|c|}{$\begin{array}{l}\text { Dios es todopoderoso. } \\
\text { Lope de Vega fue sacerdote. }\end{array}$} & \multirow{3}{*}{ De sustantivo } & $\begin{array}{l}\text { - Las oraciones de sustantivo siempre tienen que construirse con el verbo ser colocado «entre el } \\
\text { sujeto y un complemento calificativo o circunstancial (nuestro Atributo)». } \\
\text { - Se separan las oraciones con ser y las oraciones con estar. En } 1854, \text { los ejemplos con ser/ estar se } \\
\text { daban para las oraciones de verbo sustantivo. Ahora se ejemplifica solo con ser y se indica que } \\
\text { con el verbo estar pueden construirse oraciones semejantes en la forma. }\end{array}$ \\
\hline & \multirow[t]{2}{*}{ De verbo neutro } & De primera & \multicolumn{2}{|c|}{$\begin{array}{l}\text { Ambrosio cayó soldado. } \\
\text { Tu bermana viene enferma. }\end{array}$} & & \multirow[t]{2}{*}{$\begin{array}{l}\text { - Se identifican las oraciones de verbo neutro con las segundas de activa. La Academia equipara } \\
\text { explícitamente la frase Luis pretende con El manantial fluye o Mi padre ba muerto. }\end{array}$} \\
\hline & & De segunda & \multicolumn{2}{|c|}{$\begin{array}{l}\text { El manantial fluye. } \\
\text { Mi padre ba muerto. }\end{array}$} & & \\
\hline & $\begin{array}{l}\text { De verbo } \\
\text { reflexivo o } \\
\text { reciproco }\end{array}$ & De segunda & \multicolumn{2}{|c|}{$\begin{array}{l}\text { Yo me arrepiento. } \\
\text { Miguel se quejaba. }\end{array}$} & De verbo recíproco & $\begin{array}{l}\text { - La distinción que en } 1854 \text { se hacía entre oraciones de verbo recíproco de primera y de segunda se } \\
\text { sustituye por un párrafo en el que se afirma que «La oración de verbo reflexivo ó recíproco se } \\
\text { compone de uno que lo sea, ó se use como tal, regido por el sujeto correspondiente». } \\
\text { - Es en la edición de } 1874 \text { donde se introduce por primera vez (entre los ejemplos que hoy } \\
\text { consideramos de verbo pronominal) una oración que responde a la noción de reciprocidad: Juan y } \\
\text { Pedro se tutean. }\end{array}$ \\
\hline & \multirow{2}{*}{$\begin{array}{l}\text { De modo } \\
\text { imperativo }\end{array}$} & De primera & \multicolumn{2}{|c|}{$\begin{array}{l}\text { Hijo, reverencia a tu padre. } \\
\text { Españoles, bonremos la memoria del Cid. }\end{array}$} & & \multirow{2}{*}{ 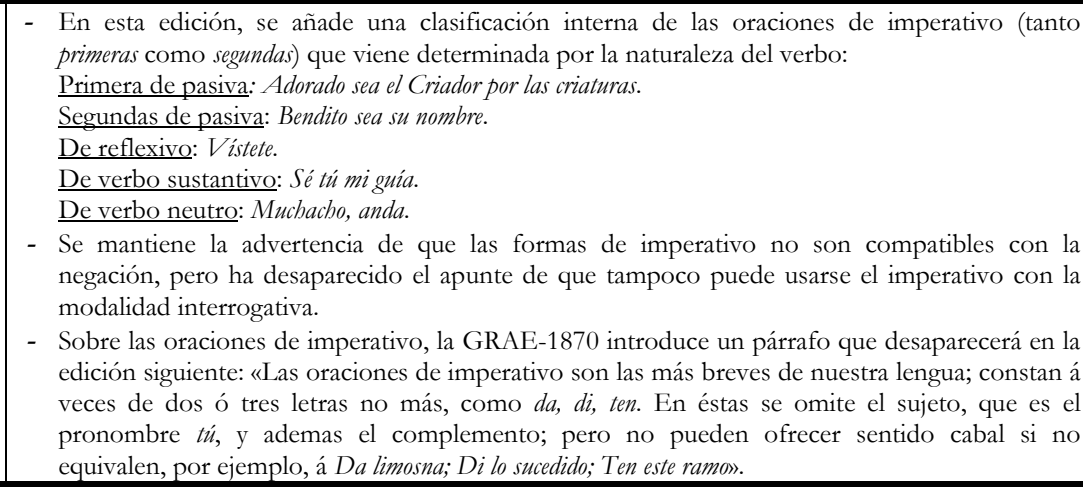 } \\
\hline & & De segunda & \multicolumn{2}{|c|}{$\begin{array}{l}\text { Amigos, trabajemos. } \\
\text { Prosiga el orador. }\end{array}$} & De imperativo & \\
\hline & \multirow{2}{*}{ De infinitivo } & De primera & \multicolumn{2}{|c|}{ Todos pretenden obtener la preferencia. } & \multirow[b]{2}{*}{ De infinitivo } & \multirow{2}{*}{$\begin{array}{l}\text { En la nueva explicación de este tipo de estructuras se empieza a esbozar una concepción más } \\
\text { funcional que colocacional de la sintaxis: las relaciones de dependencia ya no son entre palabras } \\
\text { aisladas, sino entre palabras y grupos de palabras. }\end{array}$} \\
\hline & & De segunda & \multicolumn{2}{|c|}{ El trabajador necesita descansar. } & & \\
\hline & Con gerundio & $\begin{array}{l}\text { NO SE HACE } \\
\text { DISTINCIÓN }\end{array}$ & \multicolumn{2}{|c|}{$\begin{array}{l}\text { Pudiendo yo llegar temprano. } \\
\text { Debiendo amarse los hombres. }\end{array}$} & Con gerundio & $\begin{array}{l}\text { Las oraciones con gerundio responden a oraciones incompletas según la nueva tipología (vid. infra), } \\
\text { pues «tales oraciones no hacen por sí solas cabal sentido, y necesitan ir unidas á otras que se lo } \\
\text { completen; v. gr.: Queriendo partir el General, se lo estorbó la gotą). }\end{array}$ \\
\hline & Impersonal & $\begin{array}{l}\text { NO SE HACE } \\
\text { DISTINCIÓN }\end{array}$ & \multicolumn{2}{|c|}{$\begin{array}{l}\text { Llueve. } \\
\text { Amanece. } \\
\text { En Madrid se vive cómodamente. }\end{array}$} & NO & $\begin{array}{l}\text { - } \text { Oraciones que constan de una sola palabra. } \\
\text { - Se construyen con verbos impersonales (unipersonales atmosféricos):llheve, nieva, graniza, etc., o } \\
\text { bien con el «pronombre indeterminado se» }\end{array}$ \\
\hline & De relativo & $\begin{array}{l}\text { NO SE HACE } \\
\text { DISTINCIÓN }\end{array}$ & \multicolumn{2}{|c|}{$\begin{array}{l}\text { Tu padre, que estuvo presente, no me } \\
\text { desmentirá. }\end{array}$} & $\begin{array}{ll}\text { De relativo o } \\
\text { incidental }\end{array}$ & $\begin{array}{l}\text { - La función de la oración de relativo es servir de complemento a otra oración. } \\
\text { - Se destaca a doble función desempeñada por el pronombre relativo. }\end{array}$ \\
\hline & & & & CRITE & IOS COMPLEMEN & TARIOS \\
\hline \multirow{3}{*}{$\begin{array}{l}\text { Tipos según la } \\
\text { enunciación de } \\
\text { los constituyentes }\end{array}$} & \multirow[b]{2}{*}{ Completa } & Característic & & Ejemplo & \multirow{3}{*}{$\mathrm{NO}$} & \\
\hline & & $\begin{array}{l}\text { Tiene expresos el } \\
\text { el verbo } \\
\text { Complemento. }\end{array}$ & $\begin{array}{r}\text { Sujeto, } \\
\text { el }\end{array}$ & Todos desean la felicidad. & & $\begin{array}{l}\text { El aceptar que podemos tener una oración incompleta con el verbo omitido equivale a la indistinción } \\
\text { entre enunciados oracionales y no oracionales (o frases). Parece claro que el concepto de oración } \\
\text { reside más en criterios semántico-nocionales que en criterios formales. }\end{array}$ \\
\hline & Incompleta & $\begin{array}{l}\text { Alguno/s de } \\
\text { constituyentes (in } \\
\text { verbo) está/n omi }\end{array}$ & \begin{tabular}{r|r|} 
sus \\
luso el \\
ido/s.
\end{tabular} & $\begin{array}{l}\text { Sujeto omitido: Desean la } \\
\text { felicidad. } \\
\text { Sujeto y Complemento } \\
\text { Omitidos: Ten; } D i \text {. } \\
\text { Verbo omitido: } A \text { ellos. }\end{array}$ & & \\
\hline $\begin{array}{l}\text { Tipos según la } \\
\text { completud de }\end{array}$ & Simple & $\begin{array}{l}\text { La oración que } \\
\text { sola hace } \\
\text { completo. }\end{array}$ & $\begin{array}{l}\text { por sí } \\
\text { entido }\end{array}$ & $\begin{array}{l}\text { La fe obra milagros. } \\
\text { Dádivas quebrantan peñas. }\end{array}$ & NO & $\begin{array}{l}\text { También esta clasificación, tal como se formula en un principio, revela el componente significativo } \\
\text { como el determinante de qué es oración y de sus tipos básicos. }\end{array}$ \\
\hline & Compuesta & $\begin{array}{l}\text { La oración que } \\
\text { en otra }\end{array}$ & ermina & $\begin{array}{l}\text { Estando Felipe comiendo, le } \\
\text { dieron la noticia. }\end{array}$ & & \\
\hline $\begin{array}{l}\text { Tipos según la } \\
\text { palabra que las }\end{array}$ & $\begin{array}{l}\text { Adversativa y } \\
\text { de relativo }\end{array}$ & $\begin{array}{l}\text { Pero yo, que aunque } \\
\text { no quiero irme con la }\end{array}$ & sarezcopa & $\begin{array}{l}\text { dre, soy padrastro de Don Quijote, } \\
\text { el uso. }\end{array}$ & Adversativa & $\begin{array}{l}\text { - En 1870, esta última clasificación no responde al criterio de «los nombres de las conjunciones } \\
\text { que suelen dar principio á las oraciones» (GRAE-1854: 169). Ahora se introducen estos tipos } \\
\text { oracionales con las siguientes palabras: «De los nombres, de los adverbios y de las }\end{array}$ \\
\hline introduce & Copulativa & Y no eran sus adorno & de $\operatorname{los} q u$ & abora se usan. & Copulativa & $\begin{array}{l}\text { preposiciones que suelen dar principio á las oraciones, se llaman unas comparativas, otras } \\
\text { condicionales...) (GRAE-1870: 215). }\end{array}$ \\
\hline & Comparativa & $\begin{array}{l}\text { Mucho mejor me sal } \\
\text { respetos, aunque sea } \\
\text { mesas. }\end{array}$ & $\begin{array}{l}\text { lo que ca } \\
\text { pan } y \text { ce }\end{array}$ & $\begin{array}{l}\text { mo en mi rincón, sin melindres ni } \\
\text { bolla, que los gallipavos de otras }\end{array}$ & $\begin{array}{c}\text { NO SE } \\
\text { MENCIONA }\end{array}$ & $\begin{array}{l}\text { - Es evidente la indistinción entre los tipos funcionales de conjunciones (coordinantes y y } \\
\text { subordinantes) y la mezcla de criterios: ¿Por qué se ejemplifican conjuntamente las oraciones } \\
\text { condicionales y las interrogativas ¿ ¿Por qué se marca la modalidad interrogativa si la }\end{array}$ \\
\hline & $\begin{array}{l}\text { Condicional e } \\
\text { interrogativa }\end{array}$ & $\begin{array}{l}\text { Si en las escuelas no } \\
\text { Si en poder de aquel } \\
\text { Tu banda siempre fu } \\
\text { ¿Por qué seguir procu }\end{array}$ & $\begin{array}{l}\text { Prendiste } \\
\text { Lomine ped } \\
\text { la desgrac } \\
\text { as adelan }\end{array}$ & & Condicional & $\begin{array}{l}\text { clasificación sigue el criterio de la conjunción o pronombre que la introduce? } \\
\text { - Los ejemplos son un añadido de la } 122^{2} \text { edición (en } 1854 \text { encontrábamos solamente un listado). }\end{array}$ \\
\hline & Disyuntiva & Ó be de matar ó mor & & & Disynntiva & \\
\hline & $\begin{array}{c}\text { Ilativa o } \\
\text { continuativa }\end{array}$ & Pues mirad cómo ba & & & $\begin{array}{c}\text { NOSE } \\
\text { MENCIONA } \\
\end{array}$ & \\
\hline & Casual & Que yo no lo be de de & & & Causal & \\
\hline
\end{tabular}





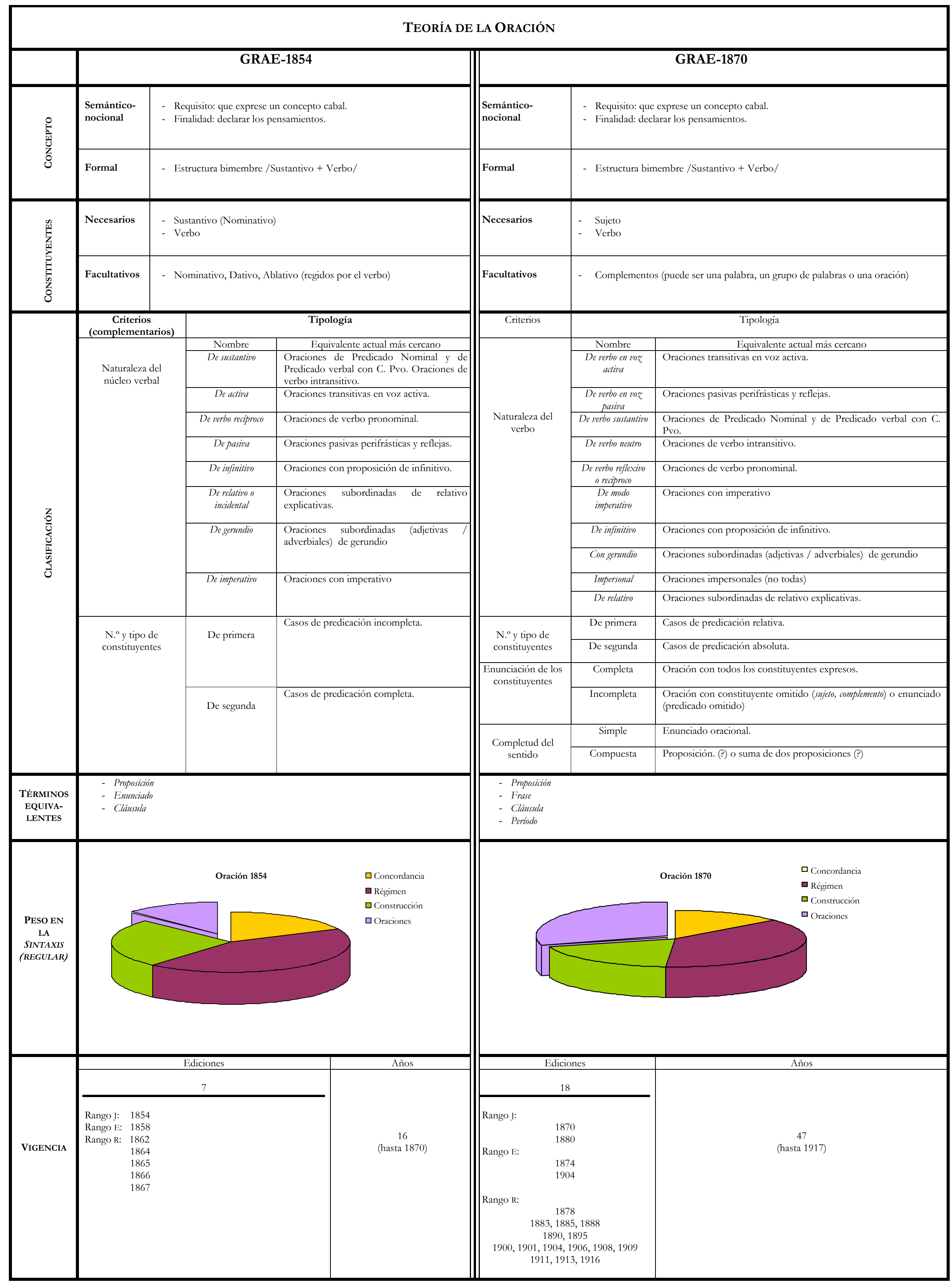

Cuadro 65: Teoría de la oración en las GRAE publicadas entre 1854 y 1916 



\subsection{La reforma de 1917}

\subsubsection{El cambio}

El Sr. Commelerán leyó y quedó aprobado, el prólogo de la nueva edición de la Gramática y, a propuesta suya, se acordó elevar el precio de esta a 5 pesetas.

(ARAE, Libro 41 de Actas: 466)

En Junta ordinaria de 28 de junio de 1917, se considera finalizada la que será edición fundamental en la historia de la GRAE. El libro que saldría a la luz pública como 30. a edición de la Gramática institucional iba a constituir una auténtica ruptura (la primera y la única) con los planteamientos tradicionales de la Corporación en lo tocante a la concepción y tratamiento de la Sintaxis. Después de esta fecha, ninguna "nueva" versión del texto modifica de forma sustancial la doctrina: las únicas aportaciones realmente nuevas que quedan por venir solo afectarán a la parte de morfología y llegarán tres años después, con la GRAE-1920. La Gramática que cierra nuestro corpus (GRAE-1924) es la primera que se publica tras las dos reformas de mayor entidad.

El cambio de 1917, como se ha venido adelantando en las páginas anteriores, supone, en efecto, un salto cuantitativo y cualitativo (frente a los pequeños pasos -casi imperceptibles en algunas ediciones- que se dan entre 1854 y 1916) en la evolución de la doctrina sintáctica defendida por la Real Academia $^{342}$. Puede sorprender que sea este el jalón que presenta la verdadera (r)evolución de los planteamientos institucionales, pues es el único que se publica con solo un año de distancia de la edición que le precede de forma

\footnotetext{
${ }^{342}$ El giro doctrinal que supone el texto de 1917 dentro de la propia tradición académica ha sido señalado por distintos estudiosos: Iglesias Bango (1997: 578) recoge la opinión de Santos Río (1981), quien la rotula como "edición sintactista". El propio Iglesias Bango (págs. 578 y sigs.) subraya su novedad (de carácter eminentemente sintáctico) no solo respecto de los textos académicos precedentes, sino también en relación con las gramáticas contemporáneas.
} 
inmediata $^{343}$. Pero hemos tenido oportunidad de comprobar que los cambios de enjundia se hacen esperar en el seno de la docta Casa (Vid. capítulo 3) 344 y 345 y que, según las épocas, el dilatado (y casi siempre interrumpido) proceso de

343 Todas las demás ediciones separadas por un año son de rango R:

- GRAE-1864-1865-1866-1867

- GRAE-1900-1901

- GRAE-1908-1909

Recordemos que el jalón de 1854 dista 58 años de la edición inmediatamente anterior (GRAE-1796); que el de 1870 se publica tres años después del texto que le precede (GRAE1867); y el de 1880 ve la luz dos años más tarde que la edición anterior (GRAE-1878).

${ }^{344}$ Como recuerdo de lo que decimos, podemos volver a traer a colación el hecho de que las reformas propuestas por la Comisión de Gramática constituida en 1861 no se materializaron hasta nueve años después (en la GRAE-1870), tras una década de continuas reediciones/impresiones del texto de 1858.

345 Otro dato podemos sumar a los muchos (algunos ya comentados) que confirman la larga espera de las reformas en el texto de la Gramática:

En el acta correspondiente a la reunión de Junta ordinaria de 15 de abril de 1896, el académico ocupante del sillón R, Antonio María Fabié, manifestó que «á su juicio era ya necesario que la Academia compusiera una nueva Gramática con arreglo á todos los adelantos de la moderna filología» (Libro 35 de Actas: fols. 122 v. ${ }^{\circ}$ y 123 r. ${ }^{\circ}$ ). Unos meses antes había salido la última edición de la Gramática (GRAE-1895), que no suponía avance -ni cambio- alguno respecto de las ediciones anteriores (especialmente, desde el jalón de 1880). Tampoco se modificará el texto en las ediciones que quedan por venir hasta 1904 ("nueva edición" nada novedosa) y, de forma más visible -pero solo en aspectos aislados-, 1911 (texto en el que destaca más el anuncio de cambios que los cambios reales). Y tendrán que publicarse dos ediciones más hasta que vea la luz el libro que muestre por primera vez una doctrina sintáctica remozada y más acorde con las teorías de la época (una, en 1913 y otra, en 1916). En resumidas cuentas, la petición de Fabié no se ve satisfecha hasta veinte años después. Era, por otra parte, lo esperable, según se deduce del debate que suscitó en la reunión del 15 de abril su propuesta de replantear todo el texto de la Gramática:

El Sr. Censor llamó la atención de la Academia acerca de los graves inconvenientes que pudiera tener alterar radicalmente y de pronto el sistema hasta ahora seguido en la enseñanza de su importante asignatura, y proponer que las reformas que la Academia estimara oportunas, no se hicieran de una vez, sino paulatinamente.

Objetó el Sr. Fabié que la nueva obra difería esencialmente de la antigua y que en esta no podrían, por consiguiente, introducirse alteraciones particulares ajustadas al plan que se formase para la obra.

Pareció al punto que se discutía de suma gravedad y se convino en que nada debía resolverse en definitiva sin previo y muy detenido estudio.

(ARAE, Libro 35 de Actas: fol. 123 r. ${ }^{\circ}$ )

A la propuesta de reforma paulatina por parte de Núñez de Arce, Censor de la Academia en ese año, debe responder la Advertencia de la GRAE-1911, que se cierra con el propósito explícito por parte de la Corporación de incluir reformas «de más trascendencia»en sucesivas ediciones (vid. infra). Sin embargo, la modificación en bloque (no de forma graduada) de la Sintaxis se producirá en un libro que se distancia pocos meses de la edición anterior. 
elaboración de las versiones reformadas coincide bien con un largo silencio editorial (el que media, por ejemplo, entre la GRAE-1796 y la de 1854) ${ }^{346}$, bien con la publicación de sucesivas reediciones-tiradas (casi impresiones estereotípicas) de la Gramática, que intentan satisfacer las exigencias del mercado (las cinco de los años sesenta son un buen ejemplo, entre otras muchas ediciones $)^{347}$.

Con estos precedentes, parece necesario buscar el comienzo de la reforma de 1917 antes de que se publicara la GRAE-1916 y entender, en consecuencia, que la 29. ${ }^{a}$ edición fue una de tantas publicaciones de urgencia que la Corporación se vio obligada a dar al público (esta sospecha inicial quedará confirmada con la lectura de las actas -vid. infra-).

Al igual que las ediciones de rango J del siglo XIX, y a diferencia de las muchas ediciones $\mathrm{R}$ que configuran nuestro corpus, la GRAE-1917 será producto de un proyecto (en principio, parcial) de planta ${ }^{348}$.

\footnotetext{
346 Por lo que se expuso en el capítulo 2 a propósito de las ediciones de la Gramática, no podemos hablar de inactividad editorial (pues se hicieron reimpresiones/tiradas de la GRAE1796 en la primera mitad del siglo XIX: la última de ellas -de la única que hemos encontrado reconocimiento por parte de la Institución (RAE, 1870: 59)-, en 1852). Aquí utilizo "silencio editorial" referido únicamente a las ediciones oficiales, a los textos que pueden llevar la etiqueta GRAE.

${ }^{347}$ En este asunto concreto de la demanda del texto académico, no parece casualidad que las ediciones de la GRAE empiecen a sucederse en cortos periodos de tiempo a partir de 1858, tras la publicación de la Ley Moyano (Vid. capítulos 2 y 4). Todas las ediciones del corpus central tienen una media de intervalo de treinta y un meses (poco más de dos años y medio de supuesto trabajo en la elaboración del nuevo texto de la Gramática).

${ }^{348}$ Ya nos hemos referido (vid. capítulo 3) al proyecto de la GRAE-1870, encomendado, en un primer momento, a una Comisión integrada por Hartzenbusch, Fernández Guerra y Monlau, y hecho extensivo a Segovia, Catalina y Bretón de los Herreros para la redacción definitiva (en la que ya no participó Fernández Guerra). Sinteticemos ahora algunos de los pormenores de la elaboración de la GRAE-1854, por ser el libro que abre nuestro corpus.

Es esta la primera edición de la Gramática que ve la luz después de haberse constituido el sistema de Comisiones permanentes para atender los diversos trabajos de la Corporación. En el acta de 2 de junio de 1848, se dio cuenta del nombramiento de los académicos que iban a configurar cada una de las Comisiones, según lo establecido en el estatuto 52 de los Estatutos de 1848 (está reproducido en el apartado 3.2.1.):
} 
Comisión 1. ${ }^{\mathrm{a}}$

Del Diccionario, en orden á las reformas y alteraciones que convenga hacer en su redaccion

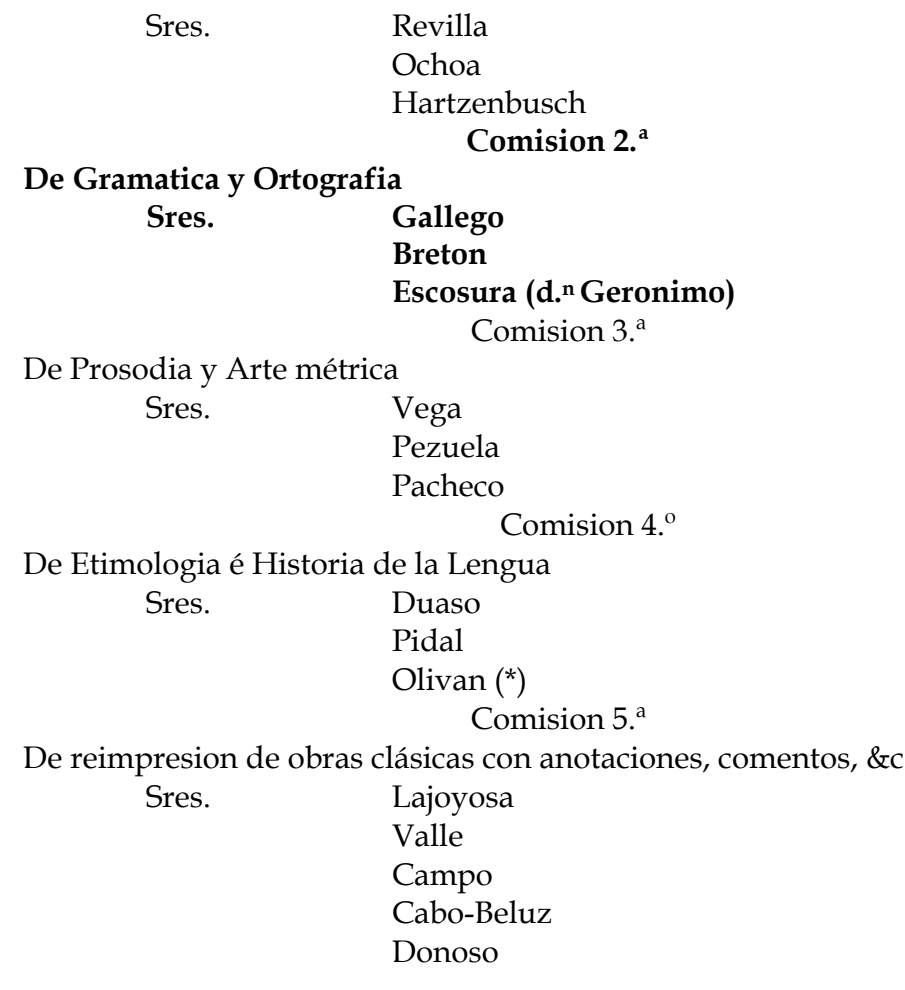

(ARAE, Libro 22 de Actas: fols. 171 v. ${ }^{\circ}$ y 172 r. ${ }^{\circ}$ La negrita es mía)

Tres años después de constituida la primera Comisión permanente de Gramática, en sesión de Junta ordinaria del jueves 4 de septiembre de 1851, «el Sr. Antonio Gil de Zárate hizo varias observaciones acerca de lo util y conveniente que seria que la Academia se dedicase con actividad á la formación de la Gramática». Ante esta sugerencia -que más tenía de petición- la Comisión se comprometió a «redoblar su celo para abreviar en lo posible los trabajos que les estaban encomendados» (ARAE, Libro 22 de Actas: fol. 278 r. ${ }^{\circ}$ ). A partir de este momento, se inicia el proyecto de elaboración de la quinta edición de la GRAE -la primera del XIX-, que no será presentado a la Junta hasta el jueves 1 de septiembre de 1853, según queda reflejado en el acta correspondiente:

La comision correspondiente presenta al examen de la Academia un nuevo tratado de Gramática Castellana escrito con arreglo á las instrucciones que al efecto tiene recibidas. La Academia bien penetrada de lo urgente que es ya esta publicacion, determinó ocuparse en la lectura y discusión del referido trabajo con preferencia á otro cualquiera

(ARAE, Libro 22 de Actas: fol. $379 \mathrm{v} .{ }^{\circ}$ )

En los dos años transcurridos entre la petición de Gil de Zárate y la presentación del borrador de la que será GRAE-1854, se siente urgencia de atender a la demanda de la Gramática (libro de texto para la enseñanza pública) y, ante el retraso en los trabajos de la Comisión, se decide hacer una reimpresión del texto vigente (GRAE-1796). En el acta de 25 de junio de 1852, queda anotado lo que sigue:

La Comision encargada de la formacion de la Gramatica manifesto que a pesar de sus esfuerzos no podia presentar su dictamen tan pronto como deseaba, y siendo indispensable por los Estatutos de la Academia y órdenes vigentes sobre libros de 
El examen de la documentación permite concluir que, en el camino que lleva a la reforma de 1917, podemos destacar un año: 1915, un nombre: José Alemany Bolufer ${ }^{349}$, y una serie de circunstancias, que son las que expongo a continuación.

\section{LA COYUNTURA DEL CAMBIO}

En el acta de 7 de octubre de 1915, queda constancia de la recepción de 36 ejemplares de unas Ligeras anotaciones en la última edición de la "Gramática de la lengua castellana" por la Real Academia Española, hechas por D. Esteban Oca y Merino ${ }^{350}$. Estas anotaciones las hizo el autor sobre la GRAE-1911, y tuvo oportunidad de cotejar las partes por él "corregidas" con el texto de la GRAE1913 (última reedición en la fecha) antes de dar a la imprenta sus apuntes y reflexiones. El cotejo ponía de evidencia que poco o nada aportaba de nuevo la ultimísima edición de la Gramática. En efecto, en ella no se encuentra ninguna de esas «otras reformas de más trascendencia» (GRAE-1911: Advertencia) que

\footnotetext{
texto atender al servicio público, se acordó reimprimir la actual en igual forma y carácter de letra si es posible hasta el número de 500 ejemplares, poniendo una advertencia en que se manifiesten las poderosas razones que han frustrado hasta el dia los deseos de la Academia de hacer otra nueba [sic] publicacion, y su decision de satisfacer cuanto antes los muy justos que abriga hace tiempo la opinion pública.
}

(ARAE, Libro 22 de Actas: fol. 318 v. ${ }^{\circ}$ y 319 r..$\left.^{\circ}\right)$

Ninguno de los ejemplares de la nueva tirada se puede etiquetar propiamente como GRAE, según los criterios que se expusieron en el capítulo 2.

${ }^{349}$ Académico de número entre 1909 y 1934. Ocupó el sillón S tras la muerte de Liniers (cf. http://www.rae.es/rae/gestores/gespub000001.nsf/(voAnexos)/arch6D3211F8664070B7C12 5720900476B93/\$FILE/sillones.htm.). Pronunció su discurso de ingreso («Orden de las palabras en relación con el orden de las ideas») el 14 de marzo de 1909 y le contestó el entonces censor de la Corporación, don Francisco Commelerán, miembro de la Comisión de Gramática. En Zamora Vicente (1999: 206) encontramos la siguiente información sobre este académico: «Alemany había nacido en Cullera (Valencia, 1866) y estudió en el Seminario de Valencia. El discurso de Commelerán nos da información muy detenida sobre la vida y formación de Alemany [...] Alemany ingresó en el profesorado universitario en 1891, catedrático de griego en la Universidad de Granada, y más tarde en la de Madrid. [...] Es autor de una monografía sobre la formación de palabras en español y fue el encargado de la edición de Diccionario Manual (1927). Murió en Madrid el 24 de octubre de 1934».

${ }^{350}$ Cf. ARAE, Libro 41 de Actas: 105. 
se proponía hacer la Corporación en sucesivas ediciones ${ }^{351}$. Ni siquiera se corregían algunas erratas de bulto 352 .

Podemos afirmar que la GRAE-1913 se suma a la lista de ediciones que se dieron a la imprenta como medida de atención a la demanda existente: las Actas dan noticia de la solicitud por parte de la Casa Perlado, Páez y Compañía para sacar una tirada de 20.000 ejemplares $^{353}$ y de la concesión del permiso por parte de la Corporación. Casi cuatro meses se hizo esperar la aprobación de la nueva edición ${ }^{354}$. El tiempo transcurrido no se debió de

351 «Por lo pronto se ha visto que en la edición de 1913 no se ha hecho más reforma que suprimir la advertencia», dice Oca y Merino (1915: 5).

352 Oca (1915: 5) señala cuatro erratas no corregidas en el texto de 1913:

$>$ «Conte-ner» en lugar de con-tener (GRAE-1911: 25). He podido comprobar que esta errata se introduce en la GRAE-1904 (pág. 33) y se mantiene hasta la edición de 1916 (pág. 25).

$>$ «Moo» por moho (GRAE-1911: 148). Esta errata se introduce en la edición de 1911 y se mantiene en las dos siguientes, GRAE-1913: 148 y GRAE-1916: 148.

$>$ «Debió ser» por debió de ser (GRAE-1911: 31). No debe de ser esta una errata propiamente dicha, sino el uso habitual (con matiz de probabilidad) que la Academia hace de la perífrasis /deber + ser/. En todas las ediciones he encontrado esta forma empleada con este valor.

> «Consonantes» por vocales -se habla de $i$, u- (GRAE-1911: 340). Esta errata se introduce también en la GRAE-1904 (pág. 335): hasta esta edición, se habla de "vocales débiles".

Vemos que, tanto en la última de las erratas señaladas como en la primera, los descuidos tienen una repercusión especialmente importante, puesto que podrían llevar, respectivamente, a la "confusión" de conceptos básicos (sonidos vocálicos vs. consonánticos) y, sobre todo, a la confusión en la segmentación y el reconocimiento de elementos constituyentes de la palabra compuesta (que es como se interpretan los derivados con preposición prefijada).

353 En el acta (sin firma) del jueves 27 de febrero de 1913, el secretario en funciones deja constancia de:

Di cuenta de que la Casa Perlado, Páez y Compañía había pedido autorización para hacer una nueva tirada de 30.000 ejemplares del Prontuario de Ortografía Castellana y otra de 20.000 de la Gramática lata. Se acordó que ambas peticiones pasaran a estudio de la Comisión de Gramática de la Academia.

(ARAE, Libro 40 de Actas: fol. 193 v. ${ }^{\circ}$ )

354 Es en el Acta del jueves 12 de junio de 1913 (firmada por Cotarelo) donde leemos que:

El Sr. Commelerán propuso y lo aceptó la Academia que se concediera a los Sres. Perlado, Páez y Compañía, impresores de la casa, las autorizaciones para hacer una impresión de la nueva Gramática de 20.000 ejemplares y otra de 30.000 del Prontuario de Ortografía castellana reformado.

(ARAE, Libro 40 de Actas: fol. 221 r. $^{\circ}$ ) 
invertir en revisar con detenimiento el texto vigente (en las actas de las juntas de esos meses no se da cuenta del proceso de corrección y, además, no se han enmendado fallos -algunos llamativos- de 1911), lo cual confirma una vez más que la Gramática no es proyecto prioritario de la Institución, salvo en momentos muy puntuales.

Tampoco la GRAE-1911 había supuesto avance en la doctrina institucional (la mayor parte de las críticas de Oca son aplicables a las ediciones precedentes): hay cambios 355 , pero ninguno de ellos tiene suficiente entidad para poder hablar de un libro diferente de los anteriores. Es este, por el contrario, un texto que decepciona, por dos motivos:

- Aunque en la Advertencia se aclara que las correcciones hechas en esta nueva edición (de rango E en nuestro corpus) no alteran «el plan y disposición antiguos de la obra», la lectura de esta página genera en el lector unas expectativas que no se cumplen:

Al dar a luz esta nueva edición de la Gramática, la Academia ha creído necesario hacer en ella correcciones, limitándose por ahora a aquellas que no alteran, sino rara vez, el plan y disposición antiguos de la obra, y rehaciendo sólo las partes que el transcurso del tiempo había dejado más necesitadas de reformas.

Se han corregido bastantes definiciones; se ha rectificado la manera de analizar algunas palabras y frases, y se han eliminado ciertos errores que se habían deslizado en la antigua redacción.

(GRAE-1911: Advertencia)

El análisis textual descubre que, en realidad, las definiciones que cambian (no demasiadas -vid. Glosario final-) en la GRAE-1911

355 De los que atañen a la Sintaxis hemos hablado en 6.2. 
respecto de la edición anterior (GRAE-1909) lo hacen más en virtud de añadidos que de correcciones (es lo que sucede con la definición de analogía, por ejemplo) ${ }^{356}$; el análisis de hechos sintácticos (la parte que "el tiempo había dejado más necesitada de reforma") no implica rectificaciones de la teoría precedente: solo, en contados casos, añadidos aislados o arreglos en la formulación de la teoría (vid. supra 6.2.); se mantienen errores de la antigua redacción y se introduce alguno nuevo (vid. supra lo dicho a propósito de las erratas detectadas por Oca y Merino -nota 352-), si bien es cierto que algunos descuidos de 1909 quedan subsanados.

- Las palabras de la Advertencia, de un lado, y el texto de la GRAE-1911, de otro, pueden entenderse como el eco de lo que sucedió en las reuniones semanales de la Junta de Académicos, de las que, en principio, se espera un acuerdo de proyecto integral para reformar la Gramática, pero que pronto desvían la atención a otros asuntos. La lectura del acta de 1 de diciembre de 1910 hace pensar en un plan de reforma similar al que precedió a los jalones decimonónicos:

El Sr. Saavedra hizo presente que el Sr. Menéndez Pidal tenía terminada la revisión y corrección de la Gramática que le había encomendado la Comisión de ésta. El Sr. Menéndez Pidal expuso el alcance de las enmiendas hechas en la doctrina de la Gramática, en su método y en otros interesantes pormenores. Se autorizó á la dicha Comisión para publicar esta Gramática, pero con la obligación de dar cuenta á su debido tiempo de las reformas propuestas para que sean examinadas por la Academia.

(ARAE, Libro 39 de Actas: fols. 246 v. ${ }^{\circ}-247$ r. ${ }^{\circ}$. El subrayado es mío)

\footnotetext{
$356 \mathrm{Y}$ algunos de estos añadidos, además, no mejoran, precisamente, la doctrina, más bien al contrario (aunque esto es asunto distinto).
} 
Sin embargo, una vez más, la Gramática se vuelve a dar a la estampa para cubrir la demanda de ejemplares. Es el cinco de octubre de 1911 cuando

\section{La Academia acordó :}

Poner a la venta inmediatamente la nueva edición de la Gramática con las reformas introducidas en ella, en vista de no haber ejemplares de la anterior hace ya varios meses.

(ARAE, Libro 40 de Actas: fols. 57 r. ${ }^{\circ}$ y v..$^{\circ}$ )

En las actas de las sesiones que se celebraron entre diciembre de 1910 y octubre de 1911 no he encontrado ninguna alusión a las reformas anunciadas por Menéndez Pidal. Y una vez tomado el acuerdo de publicación, tampoco se encuentra testimonio de una continuidad en los trabajos de la Gramática. Y el silencio sobre trabajos gramaticales impera hasta $1915^{357}$.

El de Oca y Merino no es el primer juicio que recibe la GRAE por parte de un gramático contemporáneo (recordemos la invectiva que don Santiago Vicente García hizo del texto de 1854, o los ataques velados de Herrainz -vid. supra-) ${ }^{358}$. Sin embargo, esta obrita, de crítica más constructiva que hiriente, no

357 No significa esto que no se encuentre alusión alguna a la labor de la Comisión de Gramática. Esta labor, sin embargo, no parece encaminada (según se deduce de los datos disponibles) a la consecución de un nuevo texto, el que debía surgir de la ya urgente reforma de los preceptos decimonónicos (heredados, en buena medida, de los establecidos en la GRAE del XVIII). Es una labor, por el contrario, que se centra en la elaboración de informes sobre tratados gramaticales de diversa índole (libros elementales, gramáticas de lenguas extranjeras y clásicas, tratados de nivel superior) enviados a la Corporación, así como en la resolución de dudas concretas que remitían los ciudadanos y a las cuales debía dar respuesta la Academia. 358 En el mismo año de 1915, en enero, la Corporación había recibido también un "cuaderno de notas y observaciones" a la Gramática extensa, remitidos por su autor, don Pedro Romero y García. Se acordó "contestarle con las debidas gracias y que pase el asunto a estudio de la Comisión de Gramática» (ARAE, Libro 41 de Actas: 22).

Dos años antes habían llegado a la Institución una serie de anotaciones que el mismo autor hizo de la GRAE: 
solo llega directamente (y por dos veces) a manos de los académicos ${ }^{359}$, sino que es, además, producto del trabajo minucioso de un Académico Correspondiente 360 , de cuya participación en trabajos de la Real Academia

Al Sr. Director del Instituto general y Técnico de Huesca, que ha remitido unas notas y observaciones, del Sr. D. Pedro Romero y García, a la útima edición de la Gramática lata, se tomó acuerdo de darle las más amplias gracias, para que le comunique al interesado, y que dichas observaciones pasen al estudio de la Comisión de Gramática dicha.

(ARAE, Libro 40 de Actas: fols. 193 v. ${ }^{\circ}$ y 194 r. $^{\circ}$ )

No podemos estar seguros de que se trate de los mismos comentarios (dos veces remitidos). Por las fechas, es de imaginar que las notas enviadas en 1913 se hicieron sobre el texto de 1911 (el acuerdo de impresión de la GRAE-1913 se toma el 12 de junio -vid. ARAE, Libro 40 de Actas: fol. 221 r. ${ }^{\circ}$ ) y que las de 1915 las apuntó el autor sobre la última edición.

Aparte de las meticulosas revisiones que gramáticos contemporáneos hicieron del libro oficial, el texto académico tampoco escapó de la punzante crítica de pensadores de la talla de Miguel de Unamuno, quien en un artículo sobre "La enseñanza de la Gramática», publicado en el número 561 del Boletín de la Institución Libre de Enseñanza, de fecha 31 de diciembre de 1906, declara de la GRAE:

La Gramática grande, la no epítome, es decir, la peor -por ser la que tiene más cantidad de malo-, dice que en castellano todas las palabras tienen acento; es decir, que la tal Gramática está escrita por sordo mudos, pues quien tenga oído advertirá al punto cuán grosero es ese error.

(Unamuno, 1906: 355. El subrayado es mío)

Lo acerado de estas palabras no le restan acierto al diagnóstico que hace Unamuno, en este artículo, tanto de la Gramática extensa como de la breve, el Epítome.

${ }^{359} \mathrm{El}$ mismo autor de las Anotaciones menciona en su libro el primer envío a la Corporación y la intención de hacer llegar un ejemplar para cada uno de los académicos:

Durante el verano pasado puse estas notas en cuartillas, y las remití a la Real Academia. Como sólo hice un ejemplar, difícilmente pueden haberlas leído y examinado, con la GRAMÁTICA a la vista, circunstancia importantísima, todos los individuos de la docta Corporación: hoy, impresas, puedo ofrecer un ejemplar a cada uno de los señores Académicos.

(Oca y Merino, 1915: 3)

También en los Libros de Actas encontramos referencia a la recepción de las primeras cuartillas. Es el 4 de marzo de 1915 cuando el Secretario de la Corporación, don Emilio Cotarelo y Mori, lleva a la Junta los papeles del señor Oca, de lo que dejó constancia en el acta correspondiente a la sesión de ese jueves:

Presenté a la Academia varios trabajos de adiciones y enmiendas a la Gramática extensa, remitidas por su autor el Sr. D. Esteban Oca. Fué acuerdo que pasasen a estudio de la Comisión de Gramática.

(ARAE, Libro 41 de Actas: 39)

360 Don Esteban de Oca y Merino fue nombrado Académico Correspondiente en Logroño en 1892. Esta categoría se creó con los Estatutos de 24 de agosto de 1859 y aparece definida en el Reglamento de 1861, en cuyo artículo 26 queda establecido que 
queda constancia en las Actas ${ }^{361}$. Estos dos hechos permiten pensar que las Ligeras anotaciones de Oca serían leídas por los miembros (cada uno de los cuales dispondría de un ejemplar) y serían tenidas en cuenta por la Corporación, si no para aplicar las correcciones sugeridas por el autor, al menos sí para no demorar más en el tiempo el replanteamiento integral del estudio de la disciplina y su reflejo en el libro de Gramática ${ }^{362}$.

Los académicos Correspondientes españoles deberán ser personas establecidas fuera de Madrid, bien reputadas, y de conocida aficion á las investigaciones y estudios filológicos, y que presenten ó hayan publicado algun escrito que así lo acredite.

Procurará la Academia hacer los nombramientos de esta clase de manera que tenga Correspondientes en las capitales y pueblos notables de la monarquía, y que no falten en ninguna de las provincias de la antigua división territorial.

(RAE, 1861: 13)

Para más información sobre este académico, puede consultarse el estudio de Bañuelos Martínez (2000).

$361 \mathrm{Vid}$. , por ejemplo, las de 1895 (ARAE, Libro 35 de Actas).

En el artículo XII de los Estatutos de 1859 se recogían las obligaciones de las distintas categorías de académicos. Entre las que incumbían a los Académicos Correspondientes, figuraba la de cumplir todos los encargos encomendados por la Institución:

Será obligacion de los individuos de número contribuir con sus trabajos literarios á los fines de la Academia; desempeñar las comisiones que la misma les encomiende; asistir á las Juntas, y votar en todos los asuntos que lo requieran.

Los correspondientes y honorarios estarán obligados tambien á llenar el mismo objeto con sus noticias y luces, manteniendo buenas relaciones con el Cuerpo, y cumpliendo los encargos que les diere. Con autorizacion del Director podrán asistir á las juntas de la Academia sólo cuando se trate de materias literarias, en las cuales tendrán voz.

Se pierde el carácter y título de Académico correspondiente dejando de cumplir los encargos de la Corporacion, ó de remitir en el espacio de tres años trabajos propios del instituto.

Los Académicos podrán usar de este título en los escritos y obras que publiquen, pero con obligacion de expresar la clase á que pertenezcan.

(RAE, 1859: 7)

362 No obstante, ciertos cambios que se producen en la GRAE-1917 bien podrían responder a la consideración en que los académicos debieron de tener la obra de Oca (ya fuera por una valoración real de sus juicios o, simplemente, por las molestias que se había tomado en hacerles llegar las Anotaciones). En la nota 3 de su librito, Oca propone que se suprima de la definición de analogía la alusión a los oficios de las palabras (incorporada en la GRAE-1911), puesto que «éstos corresponden a la Sintaxis, donde se trata de los regímenes en general y de los casos en particular, esto es, de los oficios» (Oca y Merino, 1915: 8). Y, en efecto, en la GRAE1917 encontramos una nueva fórmula de definición de analogía, en la que no se da cabida a la función de las palabras:

La ANALOGÍA es la parte de la Gramática que enseña el valor de las palabras consideradas aisladamente, con todos sus accidentes y según sus varios oficios.

(GRAE-1911: 7, GRAE-1913: 7 y GRAE-1916: 7) 
Las reformas empezaron por la parte más descuidada hasta la fecha: la Sintaxis. En el mes de mayo de 1916, haciendo excepción a la costumbre, las reuniones semanales tienen como tema importante la reforma sintáctica de la Gramática $^{363}$. En el acta del día 11, se anota:

El Sr. Alemany dió lectura a un capítulo de la Sintaxis de la Gramática según la nueva reforma en que trabaja la Comisión de ella. Se acordó que en la próxima junta se estudiaría el modo de que la Academia tenga noticia de dichas reformas.

(ARAE, Libro 41 de Actas: 269)

En la siguiente sesión, de 18 de mayo, Alemany continúa la lectura del borrador y se acuerda que para la reunión del día 25 se haya repartido un índice en el que quede reflejada la configuración que la parte de Sintaxis tendrá en la nueva Gramática. La petición del índice por parte de la Junta es un claro indicativo del alcance de los cambios ${ }^{364}$.

La ANALOGÍA es la parte de la Gramática que enseña el valor de las palabras consideradas aisladamente, con todos sus accidentes.

(GRAE-1917: 1)

El resto de la Analogía se mantiene sin llamativos cambios (aunque habrá modificaciones -vid. infra-) respecto de las ediciones anteriores: no olvidemos que la reforma de 1917 es, en su concepción inicial y en su concreción final, fundamentalmente sintáctica.

En lo que atañe a la Sintaxis, la sugerencia de Oca de que tras la definición de oración se den dos o tres ejemplos parece ser escuchada por los académicos (vid. Oca y Merino, 1915: 9 y GRAE-1917: 150). También la nueva formulación del concepto de oración compuesta como la que consta de dos o más oraciones (vid. infra), y no la que termina en otra ni la que depende de otra (vid. supra 6.2.5.2.) podría ser "deuda" con el librito de Oca (Vid. Oca y Merino, 1915: 69-70 y GRAE-1917: 291-292).

${ }^{363}$ Es tema importante por cuanto en cuatro de las cinco sesiones ordinarias del mes -las de los días 11, 18, 25 y 31- se reserva tiempo para la lectura del nuevo texto de la Gramática. Sin embargo, sigue sin ser tema prioritario: se trata a última hora de la tarde y se deja pendiente para la siguiente sesión (en la que no será el primer tema abordado).

$364 \quad$ Continuó el Sr. Alemany la lectura del nuevo texto de la Gramática y se acordó que para el próximo jueves estuviese repartido el índice de lo que comprende la Sintaxis según la reforma que la Comisión propone.

(ARAE, Libro 41 de Actas: 272) 
La consulta de los Libros de Actas permite también saber que la GRAE-1916 fue otra edición de urgencia. En la junta de 8 de junio de 1916, tras cuatro semanas de lectura de las reformas introducidas en la Sintaxis para la nueva Gramática, Emilio Cotarelo anota en el acta de la sesión:

No pudiéndose acabar, en lo que resta de curso el estudio y aprobación de las reformas de la Gramática se acordó preguntar a los editores si hay bastantes ejemplares de la Gramática para cubrir los pedidos, en el próximo mes de octubre y, en caso contrario, hacer una reimpresión del número de ejemplares que estimen necesarios para atender a las primeras necesidades.

(ARAE, Libro 41 de Actas: 293)

El acuerdo de reedición de la Gramática no va a suponer esta vez el abandono de los trabajos sobre el plan de reforma que se había comenzado (a diferencia de lo que pasó, por ejemplo, con el proyecto anunciado por Menéndez Pidal a finales de 1910). Prueba de que estamos ante un verdadero proceso de cambio de la doctrina gramatical (el más importante en materia sintáctica desde el siglo XVIII) son las siguientes líneas de la misma acta del 8 de junio:

El Sr. Director [Antonio Maura] manifestó que para que cada uno de los Sres. Académicos tomara razón en las reformas proyectadas por la Comisión de Gramática, convendría que de ellas se diera un ejemplar a cada Académico para que las estudien en el verano y puedan discutirse en el próximo otoño, con cabal conocimiento de su alcance.

(ARAE, Libro 41 de Actas: 293-294)

En el acta correspondiente a la sesión del día 25 de mayo solo encontramos el apunte de que «El Sr. Alemany continuó la lectura de las reformas introducidas en la Gramática por la Comisión» (ARAE, 1916: 277). Lo mismo sucede en el acta del 31 de mayo (vid. ARAE, 1916: 285). No queda constancia de la entrega a la Junta del índice solicitado ni de las consideraciones que sobre él hicieron los académicos no comisionados. 
En efecto, el resto de las alusiones a la Comisión de Gramática en lo que queda de mes de junio solo tienen que ver con consultas dirigidas a la Comisión (sobre ortografía, sobre uso de términos, etc.) y contestaciones a las consultas. Será en otoño cuando volvamos a encontrar noticia de la reforma que se está gestando:

Continuó la discusión acerca de la reforma y nueva redacción de la Gramática; y después de las advertencias del Director sobre la importancia de este asunto y que los Académicos diesen francamente su opinión, expusieron los Sres. Ribera, Picón y el que suscribe [Emilio Cotarelo] algunas observaciones relativas al nuevo método y forma con que aparece redactada la Gramática y quedó pendiente el tema para discutirlo en las sesiones sucesivas.

(Acta de 9 de noviembre de 1916. ARAE, Libro 41 de Actas: 349)

En la sesión del 23 de noviembre, se aprobaron algunas propuestas que hizo Ribera «en cuanto al método de exposición de la doctrina» (ARAE, Libro 41 de Actas: 356). Cotarelo también hizo «ligeras indicaciones sobre el plan y distribución de las partes en que aparece dividida la porción que se ha comunicado a los Académicos de la nueva Sintaxis» (ARAE, Libro 41 de Actas: 356). Las observaciones de Cotarelo quedaron pendientes de examen para la siguiente junta, en la cual se toma la decisión de que la reforma tuviera un mayor alcance y no solo se centrara en la Sintaxis:

Continuando la discusión acerca de la reforma de la Gramática y por virtud de algunas observaciones del que suscribe suscitóse la conveniencia de extender la mencionada reforma no solo a la Sintaxis sino a toda ella. Y después de algunas palabras dichas por los Sres. Rodríguez Marín y Menéndez Pidal en pro de aquel pensamiento, el 
Sr. Director, visto lo avanzado de la hora, acordó dejar para la junta próxima la definitiva resolución del punto.

(Acta de 30 de noviembre de 1916. ARAE, Libro 41 de Actas: 359)

La idea de que la reforma se haga extensiva a todo el libro queda aprobada en la junta siguiente, de 7 de diciembre. Sin embargo, las actas posteriores a esta reunión no ofrecen datos que conduzcan a pensar que se comenzara de forma inmediata la reforma de las otras partes de la Gramática: las menciones a la Comisión solo tienen que ver, nuevamente, con respuestas a consultas o con informes sobre diversos libros gramaticales. Así es hasta la sesión en que Commelerán lee y la Junta aprueba el prólogo de la GRAE1917365 .

\section{LOS ARTÍFICES DEL CAMBIO}

Las actas de las sesiones de mayo de 1916 revelan que es Alemany el encargado de dar cuenta a la Junta de Académicos de las reformas sintácticas sobre las que está trabajando la Comisión de Gramática, de la cual es secretario ya en 1915, año que sirve de gozne en los trabajos gramaticales de la Corporación.

Fue el 21 de marzo de 1912 cuando D. José Alemany Bolufer entró a formar parte de la Comisión permanente de Gramática. Una vez más, los Libros de Actas dan testimonio de ello:

A propuesta del Sr. Director [Alejandro Pidal] quedó nombrado el Sr. Alemany vocal de la Comisión de Gramática [...]

(ARAE, Libro 40 de Actas: fol. 101 v. ${ }^{\circ}$ )

\footnotetext{
365 No obstante, los cambios que presenta el texto de 1917 no se limitan a la Sintaxis. En lo relativo a la Analogía, se modifica, por ejemplo, la forma de exponer la teoría sobre los elementos de relación (mucho más concisa ahora); cambian también los criterios de definición de ciertas categorías, como el artículo o el pronombre, y se reorganiza la información relativa al verbo. (Para más información, vid. Iglesias Bango, 2001).
} 
Alemany sustituyó en la Comisión a Eduardo Saavedra, que había muerto ese mismo año ${ }^{366}$. Desde su entrada en la Comisión, el nombre de Alemany figura a menudo en las Actas como encargado de la revisión de tratados gramaticales que llegan a la Casa y como portavoz de la Comisión a la hora de dar respuesta a las consultas planteadas por maestros de escuela y ciudadanos movidos por la curiosidad en torno al uso de la lengua.

Formaban la Comisión de Gramática, en el momento de ingreso de Alemany, Menéndez Pelayo (que morirá un mes y medio después, el dos de mayo del mismo año) ${ }^{367}$, Mariano Catalina ${ }^{368}$, Francisco Commelerán (que

366 Saavedra entró a formar parte de la Comisión de Gramática, junto con Francisco Commelerán, el 12 de octubre de 1899. En la Junta de ese día, se aprobó la propuesta de Menéndez Pelayo de incrementar en dos el número de miembros de la Comisión de Gramática, constituida en ese momento por Mariano Catalina (que había ingresado un año antes en sustitución de Tamayo y Baus), Benot y el propio Menéndez Pelayo:

El Sr. Menéndez y Pelayo uso luego de la palabra para proponer á la Academia que aumentara hasta cinco el número de tres individuos que componen la Comisión de Gramática, y con este propósito hizo una brillante y erudita narración histórica de los estudios gramaticales de España desde Nebrija hasta nuestros días comparándolos con otros hechos en el extranjero. Hablo asimismo de las gramáticas históricas y hasta donde habian llegado los trabajos sobre esta materia, deduciendo las dificultades con que hoy tropezamos al intentar hacer una española. Propuso , como consecuencia de sus atinadísimas observaciones, que la Academia se limitara á corregir y á ampliar con ejemplos prácticos la nueva edición de su gramática.

El Sr. Benot se adhirió á la primera parte de lo propuesto por el Sr. Menéndez y Pelayo y la Academia nombró individuos de la Comisión de Gramática á los Sres. Saavedra y Commelerán.

(ARAE, Libro 35 de Actas: fols. 136 v. ${ }^{\circ}$ y 137 r. $^{\circ}$ )

En la junta de 23 de noviembre del mismo año, «el Sr. Fabié hizo varias observaciones sobre la forma que debe darse á la redacción de la nueva Gramática para que la Comisión las tuviera presentes» (ARAE, Libro 35 de Actas: fol. 147 v. ${ }^{\circ}$ ). Las GRAE-1900 y 1901, sin embargo, no presentarán modificaciones. Pudo estar en estas reuniones de 1899 el germen de los cambios (pocos) que cristalizarán en la GRAE-1904 (rango E en el corpus).

367 Treinta y dos años fue académico de número. En su nombramiento jugó un papel decisivo su gran amigo Juan Valera, quien en carta de 4 de agosto de 1880 le hace partícipe de su deseo de que forme parte de la Corporación:

Mi querido D. Marcelino: Creo llegada la ocasión de que sea usted nombrado académico de la Española. Don Juan Eugenio Hartzenbusch ha muerto. Aunque tiene usted poco que hacer, no se descuide y acabe de recoger los votos que le faltan. No tengo necesidad de repetir que cuenta usted con mi voto. 
llevaba más de doce años en ella -vid. supra nota 366-) ${ }^{369}$ y Menéndez Pidal (que había ocupado en la Comisión la vacante dejada por la muerte de Benot $\left.^{370}\right)$.

Supongo que no tiene usted compromiso con nadie para que conteste a su discurso de entrada, y que, en ese caso, me dará usted el gusto de ser yo quien le conteste.

Esta carta no adelanta nada con ser escrita en La Granja. Es probable que saldrá conmigo para Madrid; pero yo no he querido retardar el escribir a usted y saludarle, en profecía casi segura, como compañero. Tan por segura la doy, que me atrevo a aconsejarle que puede ya escribir su discurso.

(Artigas y Sainz-Rodríguez, 1930: 64)

368 Sobrino de Severo Catalina del Amo, académico ocupante del sillón A entre 1860 y 1871, y miembro de la Comisión de 1870. Mariano Catalina ocupó la silla $j$ tras la muerte de Oliván; fue académico entre 1881 y 1913. Los datos sobre tío y sobrino pueden confirmarse en: http://www.rae.es/rae/gestores/gespub000001.nsf/(voAnexos)/arch6D3211F8664070B7C12 5720900476B93/\$FILE/sillones.htm.

Mariano Catalina será Secretario perpetuo de la Corporación tras la muerte de Tamayo y Baus (vid. Zamora Vicente, 1999: 275). Su firma, en efecto, aparece en los libros de actas desde el 20 de octubre de 1898. Desde el 23 de junio -día en que se da cuenta de la muerte de Tamayo- hasta el 20 de octubre, encontramos actas sin firmar y alguna firmada por Miguel Mir (vid. ARAE, Libro 35 de Actas).

Catalina también sustituye a Tamayo en la Comisión de Gramática, de la que formará parte desde el 24 de noviembre de 1898:

Acto continuo e Sr. Presidente nombró al infrascrito individuo de la Comisión de Gramática en reemplazo del Sr. Tamayo.

(ARAE, Libro 35 de Actas: fol. 68 v. $\left.{ }^{\circ}\right)$

De su destacada labor como editor, señalada también por Zamora Vicente (1999: 275), encontramos referencias en el Epistolario Valera - Menéndez Pelayo (vid. Artigas y Sainz Rodríguez, 1930).

369 El latinista Franciso Commelerán fue académico entre 1890 y 1919; se entó en el sillón M (cf. http://www.rae.es/rae/gestores/gespub000001.nsf/(voAnexos)/arch6D3211F8664070B7C12 5720900476B93/\$FILE/sillones.htm). Sobre su discurso de ingreso, leído el 25 de mayo de 1890 (cf. Commelerán, 1890), y sobre su figura ha escrito Zamora vicente (1999: 177):

Un latinista es el nuevo académico de la silla $\mathrm{M}$ tras Villahermosa: Francisco Commelerán Gómez, catedrático del instituto madrileño Cardenal Cisneros, plaza que obtuvo en 1878. Era natural de Zaragoza (nació en 1848), donde realizó sus estudios. Asiduo colaborador de algunos periódicos, intervino en las polémicas provocadas por Antonio de Valbuena (véase pág. 520). Fue Consejero de Instrucción Pública, senador por Segovia y Cuenca, y por la propia Academia Española (1912). Ingresó en la Corporación el 25 de mayo de 1890. su discruso, largo y denso, se tituló «Leyes que regulan las transformaciones fonéticas en castellano» (lo reduzco bastante). Es toda una gramática histórica dentro de los conocimientos y métodos filológicos vigentes en su tiempo. Le contestó Juan Valera, quien elogió, sobre todo, el Diccionario latino (1886), obra del nuevo académico, libro que fue muy manejado entre los estudiantes de lenguas clásicas. Commelerán fue también autor de una Gramática comparada de las lenguas castellana y latina (1889). [...] Murió en Madrid, el 24 de octubre de 1919.

${ }^{370} \mathrm{El}$ acta del 12 de diciembre de 1907 da cuenta de su nombramiento: 
Entre 1915 y 1917, trabajan en activo en la Gramática Alemany, Commelerán, Menéndez Pidal y Carracido (vid. ARAE, 1915: 189/2, 1916: 196/ 6 y 1917: 192/2). Estos son los nombres que, a la luz de los datos de que dispongo, cabe considerar autores del libro de $1917^{371}$.

Sorprende que entre los artífices de la gran reforma sintáctica (y de la principal reforma del texto de la GRAE en su conjunto, la que supone un replanteamiento de la disciplina) figure un destacado científico, como lo fue José Rodríguez Carracido ${ }^{372}$. Quizá sorprenda más que gramáticos de la talla

Propuestos por las Comisiones de Gramática y del Diccionario Vulgar, fueron nombrados por el Sr. Director, para ocupar las plazas vacantes en las mismas por el fallecimiento del Sr. D. Eduardo Benot, el Sr. D. Ramón Menéndez Pidal para la primera, y el Sr. Conde de Liniers para la otra.

(ARAE, Libro 38 de Actas: fol. 239 v. ${ }^{\circ}$ )

371 En las Liquidaciones de la Comisión de Gramática de 1915, aparece también el nombre de Mariano Catalina, muerto en 1913, y es su testamentario el que firma la nómina. De este dato podemos deducir que en 1915, junto con los honorarios correspondientes a ese año, se saldaron trabajos de la Comisión que estaban pendientes de pago. En la nómina de 1916, sigue apareciendo el nombre de Catalina, pero no hay firma; esta ausencia pudiera hacer pensar, en un principio, en un despiste rutinario a la hora de hacer la relación de académicos comisionados. Sin embargo, las hipótesis planteadas parecen perder razón al leer la nómina de 1917: en ella, se vuelve a anotar el nombre de Mariano Catalina, y firma como testamentario Juan A. Maldonado. No he logrado encontrar la razón de que siga figurando el nombre de este académico. Considerar que todas las liquidaciones son de años anteriores al corriente sería una hipótesis poco sólida (por ausencia de datos) que ensombrecería más la cuestión de la autoría del texto de 1917 (¿cuántos años de retraso podrían llevar los pagos?). Por otra parte, nombres seguros de la Comisión de Gramática (cuya pertenencia está corroborada con las Actas), no figuran en todas las liquidaciones: por ejemplo, la firma de Commelerán no aparece en todos los años en que, según las Actas, coincidió en la Comisión con Menéndez Pelayo, Mariano Catalina y Benot (vid., por ejemplo, ARAE, 1903, 1904, 1907 y 1910).

372 Fue nombrado Académico de número el 5 de diciembre de 1907, para ocupar el sillón Z, vacante desde la muerte de Benot. (Vid. ARAE, Libro 38 de Actas: 235 r. ${ }^{\circ}$ ). Según consta en el acta de 31 de octubre de 1907,

Menéndez Pelayo, Echegaray y Pidal proponen a José Rodríguez Carracido para la vacante de Benot.

(ARAE, Libro 38 de Actas: fol. 226 r. ${ }^{\circ}$ )

Sobre este eminente científico, académico de la RAE entre 1908 y 1928 (cf. http://www.rae.es/rae/gestores/gespub000001.nsf/(voAnexos)/arch6D3211F8664070B7C12 5720900476B93/\$FILE/sillones.htm), dice Zamora Vicente (1999: 226):

Quizá la tarea más significativa de Carracido fue la introducción en España de nuevos conceptos, nuevas interpretaciones, tanto de su propia disciplina como de 
de Eduardo Benot hubieran pasado sin pena ni gloria por la Comisión de Gramática. La razón de esto último bien pudo estar en la falta de conciliación que debió de existir entre los académicos comisionados en los mismos años que el gaditano. Conocida es la animadversión que sentía Menéndez Pelayo hacia su persona y la oposición de don Marcelino al nombramiento de Benot ${ }^{373}$ y de Francisco Commelerán como académicos de número (el último nombramiento enfrentó a Menéndez Pelayo con Mariano Catalina) $)^{374}$. Pocos

otras próximas o afines. Se han reconocido sus aportaciones a determinados temas: la coagulación de la sangre, los ácidos biliares, la fermentación glicérica, etc. [...] Fue Consejero de Instrucción Pública (1900) y perteneció (y varias veces presidió) a numerosas entidades científicas y culturales (Sociedad Española de Física y Química, fue creador de la Asociación Española para el Progreso de las Ciencias, etc.). Perteneció a la Academia de Ciencias, que llegó a presidir (1922), a la de Medicina (1906), y figura en lugar destacado en la fundación de la Academia de Farmacia (1920).

Ingresó en la Española el 14 de junio de 1908. a su discurso «Valor de la literatura científica hispanoamericana», aún interesante por los comentarios a las expediciones científicas a América, contestó Alejandro Pidal y Mon, director de la Corporación en aquellos días. [...] Carracido murió el 3 de enero de 1928.

${ }^{373}$ En carta dirigida por Menéndez Pelayo a Valera, se lee:

Nuestros amigos de la Academia se han empeñado en elegir para la plaza vacante a un señor Eduardo Benot, autor o refundidor de los métodos Ollendorf. Me parece detestable nombramiento. ¿Por qué no elegir a Galdós, que trae consigo una verdadera popularidad literaria y méritos positivos de narrador?

(Artigas y Sainz-Rodríguez, 1946: 235)

${ }^{374}$ Según informa Zamora Vicente, ante el triunfo de Commelerán

El escándalo y la protesta tomaron cuerpo en la prensa, destacando el disgusto general. Incluso trascendió a la calle la trifulca habida entre Menéndez Pelayo y Mariano Catalina. Por fin, Galdós fue elegido en junio de 1989 [sic]. Sucedía a León Galindo y de Vera. En esta ocasión, los firmantes aparecen dispuestos a tapar la boca del alboroto exterior a la Casa: firman el director, conde de Cheste, Cánovas del Castillo y el secretario, Tamayo y Baus. Galdós obtuvo 24 votos favorables (frente a dos adversos) [...] La entrada solemne se hizo esperar ocho años.

(Zamora Vicente, 1999: 237)

Tamayo y Baus, de cuya amistad con Menéndez Pelayo y Juan Valera queda constancia en las cartas que se remiten el cordobés y el santanderino (Vid. Artigas y Sainz Rodríguez, 1930 y 1946), había defendido la candidatura de Commelerán frente a la de Galdós. Será, precisamente, Juan Valera, uno de los más firmes opositores al nombramiento del latinista, el encargado de darle la bienvenida. Su contestación a la lectura del nuevo académico se reviste -no puede ser de otra forma- de un tono muy distinto al habitual en este tipo discursos. Así refiere Valera los hechos acontecidos:

De ordinario, en el seno de esta corporación reina la más perfecta armonía [...]

Sólo en la elección del Sr. Commelerán hubo, según dicen, de aparecer entre nosotros la discordia, pero fué tan de paso y con tal disimulo, que los más no 
frutos podía dar el trabajo conjunto de estos cuatro hombres en los años en que los cuatro constituían la Comisión de Gramática. No parece demasiado arriesgado imaginar que el trabajo debió de estar mediatizado por los desencuentros personales. A lo cual se sumó, sin duda alguna, la continua prioridad que la Corporación fue concediendo a otros proyectos y tareas, entre ellos, la siempre presente reforma del Diccionario.

La renovación profunda de la GRAE fue materializada en un libro producto de la dedicación de varios años (inusualmente intensos en cuestiones relativas a la reforma de la Gramática) y del trabajo de una Comisión de la que formaban parte importantes nombres de la filología española: Alemany, catedrático de griego y buen conocedor de la lingüística indoeuropea; Commelerán, latinista de renombre y Menéndez Pidal, prestigioso romanista que, como bien es sabido, sentó las bases de la moderna filología hispánica. A ellos hay que sumar el nombre de José Rodríguez Carracido. No estamos en condiciones de calcular (ni siquiera de suponer) la aportación real de este académico a los trabajos de la Comisión, pero podríamos equivocarnos al

hubiéramos advertido nada, sin las hablillas, comentarios y exageraciones, que nacieron y cundieron fuera de aquí.

[...] Y como yo fuí uno de los que más se opusieron á la elección del señor Commelerán, me complací en que nuestro digno Director me designase para saludar en nombre de la Academia al que ésta había elegido, imaginando yo que así ponía el sello en el público testimonio de nuestra fraternal avenencia.

Conste, pues, que nadie entre nosotros se opuso á la elección del nuevo Académico, sino por el empeño de que entrase antes de él otro candidato, también ya electo, y contra el cual jamás hubo tampoco oposición, sino momentánea.

La Academia, mirando por su crédito, suele elegir, para ocupar las sillas vacantes, á aquellos hombres que de mayor nombradía gozan entre el pueblo por su valer como escritores; pero, suponiendo que la Academia se decidiese a favor de alguien que no fuese popular y conocido, la Academia estaría en su derecho, y nadie tendría menos autoridad que yo para censurarla. Mi pobre reputación de escritor, después de mi elección ha sido adquirida. Lo declaro sin falsa modestia: en mi elección hubo favor, y muy señalado. No me incumbe decir si en algún otro caso excepcional también le hubo; pero repito que la Academia llama generalmente á su seno á los que vienen a aumentar su lustre con propios merecimientos, ya reconocidos y patentes.

(Commelerán, 1890: 89-91) 
prejuzgar como negativa (en el sentido de poco productiva para la causa gramatical) su condición de científico: basta con recordar otro nombre del siglo XIX, el de Pedro Felipe Monlau -médico-, quien no solo contribuyó de forma decisiva en la reforma de la GRAE-1870 (el jalón decimonónico de mayor entidad), sino que, como hemos visto en el capítulo 5, fue autor de un Vocabulario gramatical en el que se desarrolla una doctrina más que interesante en la época.

Hemos comprobado que la Junta de académicos tuvo voto y voz en la reforma: las observaciones de Ribera, Picón y Cotarelo debieron de ayudar a la hora de dar cuerpo a la nueva doctrina, en la que, sin duda, rezuma la enseñanza aprendida de autores contemporáneos.

Iglesias Bango (2001) apunta la posible deuda contraída por la GRAE1917 con La lengua de Cervantes (en adelante, LLC), de Julio Cejador y Frauca. Es en 1907 cuando la Institución recibe esta obra y, a petición del Ministerio de Instrucción Pública, tiene que examinarla para informe. Curiosamente, es Mir, y no un miembro de la Comisión de Gramática, la persona elegida para llevar a cabo el encargo (Vid. ARAE, Libro 38 de Actas: fols. 173 v. ${ }^{\circ}$-junta de 24 de enero de 1907- y 189 r. ${ }^{\circ}$-junta de 4 de abril de 1907-). Varios meses antes de entrar a formar parte de la Comisión de Gramática, a Menéndez Pidal se le encomienda la elaboración de otro informe (también solicitado por el Ministerio) sobre la obra de Gisbert y Hoël Teoría y análisis de la oración gramatical (¿la tendría en cuenta Pidal para la reforma que le encarga la Comisión en 1910? No podemos saberlo porque desconocemos los términos de la reforma -vid. supra-). Destaco, de entre las muchas obras que de forma continua llegan a la Academia, la recepción y lectura de estos libros por las novedades doctrinales que contienen ${ }^{375}$. Para imaginar el alcance de tales

${ }^{375}$ La influencia de Julio Cejador es, en cierto modo, esperable, pues contamos con testimonios elogiosos (algunos de ellos, públicos) que de sus trabajos hicieron académicos de principios 
novedades, basta con tener en consideración, una vez más, un primer dato cuantitativo: el de publicación más temprana, el Tratado de Gisbert, es un texto de más de 390 páginas dedicadas exclusivamente al estudio de la oración; en LLC son prácticamente 300 las páginas reservadas a la sintaxis de la proposición. La obra de Cejador fue premiada en el Primer Certamen Literario del Ateneo de Madrid; en el informe que redactó el jurado, se destaca la originalidad de la doctrina sintáctica (el subrayado es mío):

del siglo XX. En la edición de LLC, tras el índice analítico y la fe de erratas, aparecen publicadas una carta que Menéndez Pelayo le envió felicitándole por su Gramática griega y la opinión que le mereció al todavía no académico José Alemany la serie de estudios titulada El Lenguaje. Considero oportuno traer a colación las palabras de ambos:

Sr. D. Julio Cejador y Frauca.

Muy señor mío y de todo mi aprecio: Felicito á usted sinceramente por la publicación de su Gramática Griega, de la cual he tenido la bondad de remitirme un ejemplar. En mi humilde parecer, esta obra significa el principio de una nueva era para los estudios helénicos, hoy tan decaídos entre nosotros.

Aventaja mucho, en método y copia de doctrina, á todas las Gramáticas publicadas en España, y no creo que quede deslucida en comparación con las extranjeras. Su autor se muestra enterado de todos los progresos de la filología clásica, $\mathrm{y}$ esto no de un modo atropellado y superficial, sino con pleno y maduro conocimiento, y con la habilidad necesaria para adaptar los resultados de esta investigación al estado actual de nuestra cultura.

La creo más útil para la enseñanza que la de Curtius, y más completa en algunos puntos.

Si la obra de usted llega á introducirse en nuestras escuelas, creo que ha de producir excelentes frutos, á pesar del corto tiempo que se dedica á esta clase tan fundamental.

De usted afectísimo seguro servidor, q.b.s.m.,

M. Menéndez y Pelayo.

Pero en donde resulta probada hasta la evidencia más convincente la unidad originaria de todas las lenguas que se hablan en nuestro planeta, es en el estudio que el Sr. Cejador hace en el capítulo V de la obra, de los grupos NI y GU, empleados ambos para significar la primera persona, el YO y el NOS, por todas las lenguas del mundo.

Léase la obra del Sr. Cejador; estúdiese con el detenimiento que merece objeto tan profundo y tan transcendente; téngase la debida preparación para comprender algunos cambios fónicos que son muy normales y ordinarios y concede todo el que haya estudiado, no muchas lenguas, sino sólo las de una familia, y se verá que las deducciones del Sr. Cejador son tan lógicas y conformes á las leyes de la lingüística, que puede afirmar, como lo hace, que no ha torturado ningún grupo fónico para derivarlo de otro. Y no puede menos de suceder esto; y no puede ser más legítima la conclusión del autor, dada la base sobre que asienta su teoría. 
En la primera parte, que es la Gramática, se exponen con suma claridad las doctrinas esenciales hasta hoy imperantes respecto de nuestro idioma, y se da cabida á otras nuevas, cuya originalidad $\underline{\text { llamará la atención de todos los filólogos y gramáticos, especialmente }}$ en lo relativo á la sintaxis; doctrinas que indican en su autor profundísimo conocimiento de la Gramática comparada de las lenguas neolatinas y de las clásicas en que éstas tienen sus raíces. 376

De los puntos de coincidencia existentes entre la GRAE-1917 y estos tratados daremos cuenta en el punto que sigue, dedicado al análisis somero del giro sintáctico que supone la 30. a edición.

La asunción de supuestos teóricos defendidos con anterioridad por otros gramáticos, si existe además constancia del conocimiento por parte de la Institución de las obras en las que fueron expuestos, debe responder a una deuda doctrinal, al poso que las continuas lecturas de tratados contemporáneos tenían que dejar necesariamente en los miembros de la Corporación. Parece difícil, por otra parte, aceptar que el paso de Benot por la RAE no dejara ninguna huella en la obra de la Corporación, a pesar de que el texto de la Gramática no revele deudas directas y aunque la documentación disponible muestre que Benot anduvo más ocupado en otros menesteres que en los estrictamente gramaticales. Cuesta, por último, creer que la docta Casa

\footnotetext{
376 El jurado, designado por la Junta directiva del Ateneo, lo constituyeron Miguel Mir (representante de la RAE), José Alemany (catedrático de griego -no ingresará en la Academia hasta 1909-) y Francisco Navarro y Ledesma (Presidente de la Sección de Literatura del Ateneo). El informe aparece publicado en la edición del texto, cuyo título completo (La lengua de Cervantes, gramática y diccionario de la lengua castellana en "El ingenioso hidalgo don Quijote de la $\left.M a n c h a^{\prime \prime}\right)$ responde al tema sobre el que debían versar los trabajos presentados a concurso: Gramática y vocabulario del Quijote. El Certamen se había convocado, en efecto, con motivo del III centenario de la publicación del Quijote.
} 
hiciera oídos sordos ante las constantes críticas y severos juicios de los que era objeto la doctrina gramatical defendida.

Sabemos que, en la historia de la GRAE, no son pocos los ataques que reciben las distintas ediciones, ante los cuales «la Academia no se irrita ni pierde la serenidad, que es prenda juntamente de acierto y decoro», decía Tamayo y Baus, secretario de la Corporación en la segunda mitad del siglo XIX (cf. Tamayo y Baus, 1881: 23). En la segunda década del siglo XX, los avances en los estudios gramaticales y filológicos imponían a la Academia la obligación moral e intelectual de desterrar del libro de Gramática unos preceptos obsoletos que habían seguido funcionando no por falta de perspicacia (ni de preparación) en los miembros de la docta Casa para llevar a cabo una reforma, sino por el oxidado engranaje que movía el funcionamiento interno de la Institución. Una institución que durante décadas se había despreocupado completamente de una obra que, quizá por su sello de oficial, se vio condenada a no evolucionar.

En los años previos a la reforma de 1917, la GRAE sigue siendo texto obligatorio pero empieza a ver amenazada su exclusividad:

La Academia quedó enterada de una carta del Sr. D. Emilio Álvarez Vilata, maestro de Mundaca, Vizcaya, que pregunta, si habiendo declarado el Ministerio de Instrucción Pública útiles para servir de texto otras gramáticas diferentes de la nuestra, que es el texto único y obligatorio en las escuelas públicas, pueden los maestros adoptarlos para la enseñanza oficial.

(ARAE, Libro 40 de Actas: fol. 69 v. ${ }^{\circ}$ ) 
Los datos que he podido recabar, y que quedan expuestos en las páginas precedentes, no permiten situar el comienzo oficial de la reforma en fechas anteriores a 1915, lo cual no debe dejar en la sombra dos hechos: i) que, desde finales del siglo XIX, la Corporación cuenta entre sus filas con miembros muy capaces de modificar los cimientos de la Gramática (basta con tener en consideración la obra que firman de forma individual); ii) que los frustrados amagos de proyectos de reforma (quizá impulsados en momentos concretos por el conocimiento directo de nuevas teorías) parecen ser consecuencia de la falta de coordinación y constancia en los trabajos, del constante relego de las tareas gramaticales $\mathrm{y}$, en último caso, de los roces personales. Cuando se intensifican los esfuerzos, cuando se presta atención continuada al proyecto y cuando parece imperar la normalidad en las relaciones personales, tenemos un producto que no solo no será superado en el siglo XX dentro de la propia tradición académica, sino que se convertirá en punto de referencia de los gramáticos posteriores. 



\subsubsection{Análisis ${ }^{377}$}

En el Prólogo de la GRAE-1917 se reconoce abiertamente la necesidad que se tenía de llevar a cabo una reforma a fondo de los planteamientos gramaticales hasta la fecha defendidos, en especial de los relativos al apartado sintáctico. Esta reforma no consiste en «innovaciones peregrinas», sino que responde a «una restauración de la doctrina tradicional» (GRAE-1917: VI).

La renovación anunciada en la Advertencia Preliminar se hace evidente en varios aspectos: cuantitativamente, el apartado sintáctico supone, en esta edición, casi el 55\% del libro de Gramática, lo que equivale a un importantísimo incremento de las páginas dedicadas al estudio de las relaciones ${ }^{378}$; distribucionalmente, nada tiene que ver esta segunda parte de la Gramática con las partes correspondientes de las GRAE anteriores; teóricamente, son muchos y relevantes los cambios producidos y las innovaciones introducidas en esta 30. a edición de la Gramática académica.

La Parte II del libro se va a someter a la siguiente subdivisión: una Primera parte se dedicará a la exposición de principios sintácticos básicos y al estudio de la Oración Simple, y una Segunda parte se reservará al estudio de la Oración Compuesta. Estos dos bloques fundamentales que articulan el estudio

\footnotetext{
377 En este trabajo, interesa llegar a la reforma de 1917 para dar cuenta del punto de inflexión que la 30. ${ }^{a}$ edición de la GRAE supone con respecto a la doctrina sintáctica sostenida por la Academia hasta esa fecha. Debido a la gran extensión que supondría un análisis minucioso e inmanente del reformado (en forma y fondo) capítulo de la Sintaxis (cuya doctrina ha llegado -con ligeras modificaciones- a nuestros días), me limito a dejar constancia de los puntos más importantes del cambio (en tanto que modificaciones o innovaciones).

378 Si comparamos con la Gramática inmediatamente anterior del corpus (GRAE-1916), comprobamos que prácticamente se ha triplicado el número de páginas dedicadas a la Sintaxis (de 107 hemos pasado a 305) y, dentro del libro, esta segunda parte ha pasado de representar poco más del $25 \%$ a representar casi el $55 \%$.
} 
sintáctico irán acompañados de unas páginas en las que se trata de la sintaxis figurada y de los vicios de dicción ${ }^{379}$.

379 El tratado IV de LLC, el dedicado a la Sintaxis, presenta una organización similar. Tres partes configuran el tratado: las dos primeras se dedican, respectivamente, a la Sintaxis de la proposición simple y la Sintaxis de la proposición compuesta; en la tercera parte (de extensión considerablemente menor), se tocan cuestiones relativas a figuras sintácticas y estilo.

En el Tratado de Gisbert y Hoël, el estudio de la oración se distribuye en dos secciones principales: la dedicada a la oración simple, y la que trata de la oración compuesta o período. Una tercera y última parte de libro se destina al análisis (léxico-lógico, fonético-ortográfico, morfológico, etimológico, sintáctico, gramatical y lógico). 


\subsubsection{Sintaxis: Generalidades}

De entre la información ofrecida en las primeras páginas de la Parte Segunda del libro, interesa señalar los siguientes aspectos:

1. El objeto de la Sintaxis es, en esta edición, manifiestamente distinto del señalado en las ediciones anteriores: ahora, el estudio de las relaciones sintácticas tiene como objetivo fundamental el análisis de la oración gramatical, tanto simple (para cuyo estudio será necesario atender al enlace de las distintas partes de la oración) como compuesta (que se forma mediante la unión de oraciones simples).

2. El cambio en el objeto de estudio de esta subdisciplina gramatical (que ha dejado de centrarse exclusivamente en la palabra para atender a la oración como unidad analizable -y combinable-380) implica un cambio en la división de la misma: frente a las ediciones anteriores, se dividirá en Sintaxis de la oración simple y Sintaxis de la oración compuesta. Imaginamos que el lector de la Gramática académica echaría en falta, en esta presentación del estudio sintáctico, la referencia a las "famosas" reglas de régimen, construcción y concordancia, que hasta solo unos meses antes centraban la atención de la Sintaxis en la GRAE381.

\footnotetext{
380 Podemos decir que, en la 30. a edición de la Gramática, la unidad palabra interesa desde el punto de vista sintáctico solo en la medida en que es elemento integrante de una oración. En este sentido, la doctrina académica de 1917 coincide con la defensa hecha por Cejador (1905: 205) de que «la sintaxis trata de la reunion de las palabras; pero en cuanto forman cláusulas, ó sea frases que tienen sentido completo».

381 Será dentro del estudio de la oración simple donde encontremos un capítulo (el XI) dedicado a la concordancia (vid. infra). Las alusiones al régimen han desaparecido por completo, pero quedan restos de lo que fue en su día el capítulo dedicado a la regencia: después de tratar de la preposición (a la que se dedica el capítulo XVI de la Sintaxis [de la oración simple]), volvemos a encontrar la Lista de palabras que se construyen con preposición (que constituye el capítulo XVII). Cejador (1905: 369-377) también destinará un capítulo -el último de la parte dedicada a la Sintaxis de la proposición simple- a tratar del concepto y de los casos de concordancia.

Gisbert y Hoël (1902: 22-24), por su parte, reserva una sección para tratar de la concordancia (= relaciones de identidad) y el régimen (= relaciones de diferencia o dependencia) a propósito del estudio de la oración simple.
} 
El cambio en la unidad de partida y división de la Sintaxis queda manifiesto en las líneas que abren la parte dedicada a su estudio en el libro. Compárense las palabras de la GRAE-1916 con las de 1917:

Es la SINTAXIS la parte de la Gramática que enseña a enlazar los vocablos unos con otros, o sea la acertada construcción de las oraciones gramaticales.

Divídese en regular y figurada [...]

En la Sintaxis hay que considerar principalmente la concordancia, el régimen y la construcción.

(GRAE-1916: 213)

[...] La SINTAXIS nos enseña el modo como deben enlazarse unas palabras con otras para formar la oración gramatical, y también las oraciones entre sí para formar la oración compuesta o período. El objeto de la Sintaxis es, pues, el estudio de la oración gramatical, y según sea ésta simple o compuesta, se divide en Sintaxis de la oración simple y Sintaxis de la oración compuesta.

(GRAE-1917: 147, § 190)

Tanto en el Tratado de Gisbert como en la parte de Sintaxis de LLC se toma la oración como unidad de referencia. Como hemos indicado (vid. supra nota 508), en estas dos obras, la teoría sintáctica se estructura en dos partes principales (que coinciden con los dos tipos de oraciones reconocidos: simples y compuestas), equivalentes a los dos grandes bloques en torno a los cuales se organiza el estudio de la Sintaxis en el texto de 1917. 
3. Por primera vez, la explicación (que no llega a ser definición en sentido estricto en estas primeras páginas) de lo que es una oración gramatical se asocia claramente al concepto de predicación:

[Para formar lo que en Gramática se llama oración] es necesario que a un concepto substantivo o palabra usada con valor de tal se le agregue otra palabra que exprese atribución, o sea que afirme de dicho concepto o nombre substantivo una acción o una cualidad, estado o modo de ser, o sólo la mera existencia.

(GRAE-1917: 148, § 191) $)^{382}$

Esta idea es bastante próxima a la defendida por Gisbert y Hoël, quien, tras definir la oración o proposición como «la expresión de un pensamiento por medio de palabras» (pág. 3), aclara que

En cada pensamiento, y por tanto en cada oración, se distinguen dos términos: la actividad enunciada, que es el atributo; el ser, es decir, la persona ó cosa de quien se afirma la actividad, que es el sujeto.

(Gisbert y Hoël, 1902: 4)

También en LLC encontramos esta misma idea a propósito de la unidad que su autor llama oración, proposición o cláusula383. El «decir

\footnotetext{
382 Páginas después, en un capítulo dedicado a la oración gramatical, se nos dará una definición estricta de oración, en términos puramente lógicos y también basada en el concepto de predicación:
}

Oración gramatical es la expresión del juicio lógico, o sea la manifestación oral del acto del entendimiento en virtud del cual afirmamos una cosa de otra.

(GRAE-1917: 150, § 194,a)

Ídem GRAE-1920: 170, § 194, a, y 1924: 170, § 194, $a$.

$383 \mathrm{El}$ siguiente fragmento puede servirnos de botón de muestra de la equivalencia de los tres términos en la obra de Cejador: 
algo de algo» es la esencia de la proposición (= expresión oral del pensamiento / $\approx$ oración, cláusula) para Cejador (1905: 208, § 79), concepción que conduce a la defensa de que son necesarios dos elementos para hablar de oración: sujeto y verbo. Estas son sus palabras:

[...]El pensamiento es el acto de juzgar mentalmente acerca de algo: ese algo de que se juzga, se llama sujeto, y el juzgar de él, predicado. La proposicion simple, expresion de un pensamiento simple, consta de dos elementos esenciales, uno expresivo de un concepto sustantivo, y otro expresivo de un concepto verbal ${ }^{1}[\ldots]$

[...] Sea cualquiera la expresion oral de tales oraciones, el verbo tiene que estar expreso ó tácito, y á parte ó en el verbo tiene que estar el sujeto: la elipsis es comunísima en el habla; pero la elipsis consiste en omitir, no en faltar un elemento necesario, por lo menos en la mente.

[...] No hay en el pensamiento y en el habla mas que dos nociones esenciales y una accidental, á las cuales tres fundamentales no puedan reducirse las demas. Las esenciales de todo pensamiento y de toda expresion oral son las de sujeto del cual se juzga y dice, y la de predicado que es lo que se juzga y dice del sujeto. La noción de sujeto es la de un concepto sustantivo, de un concepto que representa lo que representa como una entidad [...] La nocion de predicado es la de un concepto que dice relacion á un sujeto: tal es el verbo [...]

El pensamiento se reduce á uno ó mas juicios eslabonados entre sí: en el primer caso su expresion completa es la proposicion simple, en el segundo la proposicion compuesta. Puede faltar en el habla alguno ó algunos términos de los que existen en el pensamiento, por el principio de la economía. De todos modos la expresion oral de un pensamiento simple es una cláusula, una ó mas palabras que forman sentido completo. Oracion se llama lo mismo á la cláusula simple que á la expresion de un pensamiento compuesto. En el segundo caso tenemos el período, ú oracion en que se expresa un juicio compuesto con varias circunstancias, formando un todo de alguna amplitud y rotundidad $[\ldots]$

[...] La proposicion simple, expresion de un pensamiento simple, consta de dos elementos esenciales, uno expresivo de un concepto sustantivo, y otro expresivo de un concepto verbal.

(Cejador, 1905: 205-207, § § 78 y 79) 


\footnotetext{
${ }^{1}$ Que esta distincion de los dos elementos no sea exclusivamente lógica, sino tambien gramatical, puede verse en Steinthal, Charakteristik der hauptsachlichsten Typen des Sprachbaues. Berlin 1860.
}

(Cejador, 1905: 207-209, § 79)

4. El concepto de complementación adquiere, en la Gramática académica, rango de relación sintáctica de primer orden, como prueba el hecho de que, ya en las páginas introductorias de la Parte II del libro, se precise lo que en Sintaxis se entiende por complemento, que no es otra cosa que «las palabras que sirven para determinar y precisar la significación de otras» (GRAE-1917: 149, § 192).

La complementación es, en la obra de Gisbert y Cejador, pieza clave en el engranaje de la oración, tanto simple como compuesta. Los dos autores delimitan el concepto de complemento (y el de términos parcialmente equivalentes) antes de abordar de forma pormenorizada el estudio interno de la oración y de los tipos oracionales.

5. La división de la Sintaxis en regular y figurada pasa a un segundo plano, como ya se ha comentado (vid. supra) y, además, ambos tipos quedan definidos ahora en términos distintos de los habituales: la división sigue estando ligada a cuestiones de orden, pero ya no se habla de regencia, sino de determinación ${ }^{384}$.

Tras estos apuntes introductorios, la Academia dedica algunos capítulos al estudio separado de ciertos aspectos y nociones básicas que fundamentan el 
análisis sintáctico, tales como qué es y cómo se articula una oración gramatical; qué función desempeñan en la oración las categorías gramaticales básicas (Nombre, Adjetivo, Verbo); qué requisito formal deben cumplir las palabras que entran en una relación de dependencia; etc. Entre toda la información dada, parece oportuno destacar los siguientes aspectos, por cuanto suponen un importante cambio con respecto a lo sostenido en las ediciones anteriores y, también, un evidente avance en cuanto a capacidad explicativa de la doctrina defendida y en cuanto a profundidad descriptiva de las relaciones que fundamentan el análisis sintáctico:

1) Por primera vez, encontramos el término predicado al hablar de la articulación bimembre de la oración, novedad terminológica con la que se hace alusión a la función conjunta de todo el SV y que aporta coherencia a la doctrina académica. Efectivamente, decir que la oración consta de sujeto y verbo, como podemos leer en las ediciones anteriores (sobre todo, desde la GRAE-1870), no resultaba demasiado satisfactorio, puesto que el primer concepto alude a función dentro de la oración y el segundo, a categoría gramatical. El término predicado acoge ahora al verbo y sus complementos si los tiene-, al igual que sujeto hace referencia al nombre con o sin modificadores 385 .

${ }^{385} \mathrm{El}$ concepto de predicado que encontramos en la GRAE-1917 difiere del concepto defendido por Gisbert y Hoël, para quien el predicado es un tipo de determinativo, cualquier «palabra y expresión que particulariza la idea expresada por el sustantivo». Será predicado maduro en El trigo está maduro; buenos en Dios ama a los niños buenos; de Pedro en El libro de Pedro; o siete en La semana tiene siete días. Este gramático aplica la etiqueta predicado a nuestros Atributos, Adyacentes/Complementos del Nombre y Determinantes. Si el determinativo particulariza la idea expresada no por el sustantivo sino por el verbo, entonces se habla de objeto. (Vid. Gisbert y Hoël, 1902: 4-7).

La doctrina académica coincide, en este punto, con la concepción de predicado defendida en LLC. Dice Cejador a propósito de esta parte indispensable de la proposición:

El predicado es el elemento de la proposicion que enuncia algo del sujeto. Contiene en sí lo que se predica y el acto de predicar, y por lo mismo no puede ser mas que un verbo [que puede llevar complementos]: si éste falta, el predicado no está expreso.

(Cejador, 1905: 211, § 81) 
Amén de esta novedad terminológica (y de sus importantes consecuencias doctrinales), también es de destacar, en lo tocante a la estructura /Suj. + Pred./ (o /Sust. + Vb./, si la reducimos a sus núcleos constitutivos), que, por primera vez, la Academia argumenta su defensa de la estructuración bimembre de la oración y refuta, al mismo tiempo, la idea de que el verbo es la palabra más importante. Tres son los argumentos de la Institución:

- Es necesaria la relación predicativa para hablar de oración, y esta relación sólo la puede garantizar la existencia de dos conceptos, uno sustantivo, representado por el nombre, y otro atributivo, significado por el verbo.

- Los verbos predicativos, cuando están conjugados, siempre llevan implícita la idea de un sustantivo (por cuanto, incluso en los casos en que no hay un sustantivo expreso, podemos hablar de estructura bimembre).

- $\quad$ No se puede defender que el verbo es la parte más importante de la oración, aun siendo cierto lo dicho en el punto anterior, puesto que hay verbos (los llamados copulativos) que son totalmente prescindibles, cuya supresión no impide que se siga hablando de oración, ya que el peso de la predicación no descansa sobre ellos ${ }^{386}$. 
La defensa de la estructura bimembre no es incompatible con el reconocimiento de que basta con que haya un predicado verbal expreso (constituido por un solo verbo atributivo ${ }^{387}$ ) para poder hablar de oración:

Vemos, pues, que de los dos elementos esenciales de la oración puede omitirse la expresión del sujeto y también la de la cópula en algunos casos; pero nunca la del predicado, que cuando es verbal contiene en sí al sujeto, sea determinado o indeterminado, y equivale por sí solo a una oración completa.

(GRAE-1917: 155-156, § 202)

La convicción de que toda oración consta de Sujeto y Predicado queda claramente manifiesta en la exposición de las oraciones etiquetadas en el texto como impersonales y unipersonales: en la explicación de ambas encontramos un apartado dedicado a el sujeto de estas oraciones (cf. GRAE1917: 260-266, §§ 279-284) ${ }^{388}$. Por encima de interpretaciones que hoy no

elementos esenciales de la oración gramatical, y por esto se dice que es la parte más importante del discurso.

(GRAE-1917: 247, § 266 )

Ídem GRAE-1920: 267, § 266 y GRAE-1924: 267, § 266.

387 Verbo atributivo equivale a nuestro verbo predicativo, esto es, el no copulativo.

388 Con todo, la explicación que ofrece de las oraciones impersonales la GRAE-1917 ha ganado en precisión. Frente a la doctrina imperante desde el jalón de 1870, en la que únicamente se reconocen como impersonales las oraciones de verbo unipersonal atmosférico y las del «pronombre indeterminado se» (oraciones en las que, por otra parte, no se descarta la existencia de sujeto -vid. supra 6.2.5.2.-), ahora se acogen en el grupo de las unipersonales las oraciones de verbos como haber o hacer en expresiones temporales o climáticas. Y de ellas se dice lo que sigue:

Los verbos haber y hacer necesitan más detenida explicación. Cuando decimos hubo fiesta o hace calor, parece a primera vista que los vocablos fiesta y calor son sujeto en sus respectivas oraciones; pero es porque nos desentendemos de la primitiva significación de dichos verbos y les atribuimos otra que no es la real y verdadera. $\underline{\mathrm{Si}}$ analizamos una oración en que entre el verbo haber en una de las seis acepciones ( $4 \mathrm{a}$ 10) que como unipersonal tiene en nuestro Diccionario, veremos que todas ellas se reducen a la acepción primitiva de este verbo, que es la de tener, con sujeto tácito. Así, en hubo fiesta se sobrentiende que la gente, reunida en tal o cual lugar, o el pueblo, etc., tuvo fiesta; y lo mismo el verbo hacer en las acepciones 32 y 33 del Diccionario. Hace calor es como si dijéramos el tiempo, la estación hace o produce CALOR, como decimos esta leña hace HUMO, por esta leña produce, causa u origina HUMO. Luego los substantivos fiesta y calor, en los anteriores ejemplos son complemento directo de los verbos haber y hacer. Por eso construímos el verbo en singular cuando decimos HUBO toros, HUBO 
aceptamos o ponemos en tela de juicio, lo más destacable del nuevo plantemiento es que, por primera vez, contempla la concordancia verbosustantivo sujeto (reconocida en todas las ediciones de la GRAE, según hemos podido comprobar) como criterio aplicable para el reconocimiento de la función Sujeto.

Por otra parte, la cita reproducida en la nota 517 revela que la Institución empieza a legitimar criterios formales como el de la pronominalización para descubrir funciones sintácticas.

2) La noción de complemento se extiende a la idea de Modificador del Nombre (ya se trate de casos de aposición, adyacencia o dependencia oracional) ${ }^{389}$ y de otras categorías no verbales ${ }^{390}$ (desde 1870, se aplicaba el término de forma restringida a los Complementos del Verbo).

Se reconocen, a partir de 1917, tres tipos fundamentales de complementos: complementos del sujeto, complementos del predicado verbal y predicados de complemento -que se refieren, simultáneamente, al sujeto y al predicado- (nuestros Complementos Predicativos), de los que se dice que funcionan, al mismo tiempo, como adjetivos y como adverbios (Vid. GRAE1917: 156, § 203).

sustos, y no hubieron toros, ni hubieron sustos. Y por eso también, cuando se nos pregunta: ¿Hubo heladas?, contestamos diciendo: LAS hubo, empleando la forma las del pronombre, que sabemos es de acusativo y no de nominativo [...]

(GRAE-1917: 264-265, § 284, c. El subrayado es mío)

Ídem GRAE-1920: 284-285, § 284, c y 1924: 284-285, § 284, c.

389 En los distintos oficios que el nombre desempeña en la oración, puede llevar como complementos: otro nombre o adjetivo sustantivado en aposición, uno o más adjetivos, un caso con preposición, o una oración entera.

(GRAE-1917: 170, § 221)

Ídem GRAE-1920: 190, § 221 y 1924: 190, § 221.

390 El vocablo complemento del adjetivo puede ser un nombre, un pronombre o un infinitivo con preposición, y también un adverbio o modo adverbial [...]

Ídem GRAE-1920: 204, § 235 y 1924: 204, § 235.

(GRAE-1917: 184, § 235) 
En la teoría de la complementación (sobre la que volveremos en 6.3.2.2.), la Academia pudo haber seguido de cerca la doctrina de Cejador, para quien

Tanto el sujeto como el predicado pueden completarse con otras palabras, que los declaran mas en sí mismos ó en las circunstancias en que se encuentran.

(Cejador, 1905: 210, § 80)

Los complementos del sustantivo que por primera vez reconoce la GRAE equivalen a los llamados por Cejador complementos atributivos, que son palabras o frases que permiten aclarar o especificar la comprehensión del nombre o pronombre (vid. Cejador, 1905: 289, §132). Los complementos del predicado y los complementos predicativos en LLC responden, respectivamente, a los complementos del predicado verbal y predicados de complemento en la GRAE-1917 (vid. infra) ${ }^{391}$.

3) Los conceptos de transitividad / intransitividad dejan de considerarse consustanciales a la naturaleza verbal y se aplican a tipos de estructuras. Las ahora llamadas oraciones transitivas y oraciones intransitivas responden, respectivamente, a las antiguas primeras de activa y segundas de activa. Pero no es hasta 1917 cuando encontramos por primera vez el reconocimiento explícito de que un mismo verbo puede tener usos transitivos e intransitivos:

Así como tenemos verbos transitivos que dejan de serlo cuando se calla el complemento directo, tenemos también verbos que, considerados como intransitivos en su acepción propia, pasan a ser

${ }^{391}$ Distinto es el concepto de complemento defendido por Gisbert y Hoël (1902: 3-7), pues en el Tratado de este autor, tal etiqueta queda reservada para los objetos o complementos del verbo (directos e indirectos), excluyendo los circunstanciales (de tiempo, lugar, modo, causa o fin). 
transitivos cuando les damos un complemento sobre el que hacemos que recaiga su significación.

(GRAE-1917: 253, § 273, b) $)^{392}$

4) Se distingue, por primera vez en las GRAE del corpus, entre reflexividad y reciprocidad. Esta distinción da lugar a dos tipos diferenciados de oraciones:

- Las reflexivas, aquellas oraciones en que «es uno mismo el que ejecuta y el que recibe la acción expresada por el verbo», pueden ser directas si el pronombre clítico funciona como CD- e indirectas -si hay un CD expreso en la oración y el clítico cumple el oficio de CI- (vid. GRAE1917: $257, \S 276, a)^{393}$.

- Las recíprocas, de las que se dice que «son una especie de las reflexivas, en las cuales dos o más sujetos ejecutan la acción del verbo, que mutuamente reciben a la vez» ${ }^{394}$. Estas oraciones obligatoriamente tienen que construirse con verbos transitivos, «porque si son intransitivos no puede verificarse la reciprocidad» (GRAE-1917: 260, § 278).

La distinción que encontramos en LLC entre verbos reflexivos y verbos recíprocos es, básicamente, la que establece la Academia en 1917.

392 Ídem GRAE-1920: 273,§ 273, b y 1924: 273,§ 273, $b$.

393 Esta misma distinción la encontramos en LLC:

La reflexión indirecta consiste en que el reflexivo no es objeto ó acusativo, sino término indirecto ó dativo, de modo que el objeto es distinto de la persona agente y el dativo es la misma persona: alçandose la visera..., el acusativo de alçar es la visera, se es dativo, mientras que es acusativo en alçandose como pudo [...]

(Cejador, 1905: 225, § 89, 6)

394 Cejador entiende por recíprocos aquellos verbos que en la forma reflexiva, esto es, conjugados con pronombre en todas sus formas, «tienen por sujeto-agente dos ó mas personas, cada una de las cuales ejerce una accion sobre las otras y la recibe de ellas» (Cejador, 1905: 225, $\S 90)$. 


\begin{tabular}{|c|c|c|c|c|c|}
\hline & \multicolumn{2}{|c|}{ Cejador (1905) } & \multicolumn{3}{|c|}{ GRAE-1917 } \\
\hline \multirow{8}{*}{ 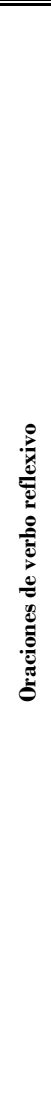 } & \multicolumn{2}{|c|}{$\begin{array}{l}\text { Verbos reflexivos] En general son aquellos que llevan el } \\
\text { pronombre reflexivo en todas las personas: me veo, te ves, se ve, } \\
\text { etc. (pág. } 221, \S 89 \text { ). }\end{array}$} & \multicolumn{3}{|c|}{$\begin{array}{l}\text { Reflexivo o reflejo es aquel verbo cuya accion recae en la misma persona } \\
\text { o cosa que la produce, representada o suplida por un pronombre } \\
\text { personal }[\ldots](\text { pág. } 39, \S 85, e) \text {. }\end{array}$} \\
\hline & \multicolumn{2}{|c|}{ TIPOS } & \multicolumn{3}{|c|}{ TIPOS ${ }^{395}$} \\
\hline & $\begin{array}{c}\text { Verbos activos transitivos } \\
\text { cuyo objeto es el mismo } \\
\text { sujeto-agente }\end{array}$ & Yo me vuelvo & $\begin{array}{l}\text { Reflexivas de verbos que } \\
\text { actualmente no admiten } \\
\text { otro modo de expresión }\end{array}$ & \multicolumn{2}{|c|}{$\begin{array}{l}\text { Yo me arrepiento. Miguel se quejaba. } \\
\text { Tú te atreves. Juan se jacta de valiente. }\end{array}$} \\
\hline & \multirow{2}{*}{$\begin{array}{c}\text { Verbos cuyo sujeto es un } \\
\text { ser inanimado cuando se } \\
\text { trata de sus acciones o de } \\
\text { los sucesos que acaecen en } \\
\text { ellos }^{396}\end{array}$} & \multirow{2}{*}{$\begin{array}{l}\text { Se abriera debaxo de sus pies la } \\
\text { tierra. } \\
\text { Cerrose con esto la noche. } \\
\text { Porque se me va mucha sangre de } \\
\text { la herida. } \\
\text { Se le pasaban las noches leyendo. } \\
\text { Por mchas partes se le descubrian } \\
\text { las carnes. }\end{array}$} & \multirow[t]{2}{*}{$\begin{array}{l}\text { Reflexivas de verbos } \\
\text { transitivos }\end{array}$} & $\begin{array}{l}\text { Directas } \\
(\text { el sujeto es } \\
\text { agente) }\end{array}$ & \begin{tabular}{l}
\multicolumn{1}{c}{ Indirectas } \\
(el sujeto es agente \\
o no lo es y pueden \\
llevar \\
complemento)
\end{tabular} \\
\hline & & & & $\begin{array}{l}\text { Yo me vuelvo. } \\
\text { Tú te lavas. }\end{array}$ & $\begin{array}{l}\text { Juan se da buena } \\
\text { vida. } \\
\text { Juan se ha hecho un } \\
\text { traje. }\end{array}$ \\
\hline & $\begin{array}{l}\text { Verbos que expresan } \\
\text { emociones y estados } \\
\text { anímicos } \\
\text { and }^{397}\end{array}$ & $\begin{array}{l}\text { Alegrándose sobremanera. } \\
\text { Dama de quien enamorarse. } \\
\text { Ninguno se atreuio a seguillo. } \\
\text { No se arrepienta de auer tomado } \\
\text { mi consejo }{ }^{398} \text {. }\end{array}$ & $\begin{array}{l}\text { Reflexivas de verbos } \\
\text { intransitivos }\end{array}$ & $\begin{array}{l}\text { Característica del } \\
\text { En ellas, el } \\
\text { complemento di } \\
\text { dativo, «que vi } \\
\text { sujeto no es mer } \\
\text { verbo, sino que } \\
\text { cierto modo, y la } \\
\text { provecho, hacier } \\
\text { aunque sea de ur } \\
259, \S 277, c) \text {. }\end{array}$ & $\begin{array}{l}\text { upo: } \\
\text { pronombre no es } \\
\text { cto, sino indirecto o } \\
\text { a significar que el } \\
\text { gente de la acción del } \\
\text { interesa en ella en } \\
\text { erifica para sí o en su } \\
\text { que refleje sobre él, } \\
\text { nodo indirecto» (pág. }\end{array}$ \\
\hline & Verbos de estado & $\begin{array}{l}\text { Bien se está San Pedro en Roma. } \\
\text { Mucho os vays tras la opinion del } \\
\text { Boticario. } \\
\text { Se quedó toda aquella noche con la } \\
\text { celada puesta. }\end{array}$ & & $\begin{array}{l}\text { Ejemplos: } \\
\text { Yo me quedo en } \\
\text { casa). } \\
\text { Juan se va (vs. } J \\
\text { Yo me salgo (vs. } \\
\text { Mi amo se sale, } s\end{array}$ & $\begin{array}{l}\text { asa (vs. Yo quedo en } \\
\text { n va) } \\
\text { salgo) } \\
\text { se sin duda [...] }\end{array}$ \\
\hline & & $\begin{array}{l}\text { Mi amo se sale, sálese sin duda } \\
{[\ldots]}\end{array}$ & Con ser y estar & $\begin{array}{l}\text { Asno se es de la c } \\
\text { Bien se está San }\end{array}$ & $\begin{array}{l}\text { a a la mortaja. (Quij.) } \\
\text { dro en Roma. (Quij.) }\end{array}$ \\
\hline
\end{tabular}

395 Conviene advertir que todos los ejemplos de verbo reflexivo o reflejo que encontramos en la parte de Analogía responden a verbos estrictamente pronominales, aquellos que no cuentan con un correlato no pronominal: quejarse, arrepentirse, condolerse, dignarse, de los que se apunta que «no tienen uso de otro modo, pues no puede decirse yo quejo, tú dignas, aquél arrepiente, etc.» (GRAE-1917: 39, § 85, e). En la Analogía solo se contempla el primero de los cuatro grupos que se establecen en la Sintaxis.

396 Sobre estos casos concretos se advierte que

Aquí ya no hay reflexion propia, sino metafórica, como si tales seres inanimados tuviesen reflexion. Este empleo es antiquísimo en todas las lenguas, tanto como lo es la metáfora.

(Cejador, 1905: 222, § 89, 2)

397 De ellos se dice que «en vez de la reflexion material, declaran en la forma reflexiva la conciencia del sentimiento ó sea la reflexion del alma» (Cejador, 1905: 222-223, § 89,3).

398 A propósito de ejemplos como los dos últimos (dados para mostrar que este grupo de reflexivos rara vez se emplean exclusivamente como reflejos, sin admitir otro objeto), se hace una aclaración sobre su antiguo uso (vid. grupo 1 GRAE-1917):

Fueron en su origen activos que llevaban cualquier término objetivo; pero que despues se limitaron al objeto reflexivo. No jacto valor en Ruiz de Alarcon, atreverse como activo hasta el siglo XVII: «que al cielo atrevian. Locas pesadumbres » (Tirso apud Bello). Hoy entumecerse; en Cervantes entumecer...

(Cejador, 1905: 223-224: § 89, 4) 


\begin{tabular}{|c|c|c|}
\hline 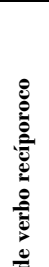 & $\begin{array}{l}\text { Características que lo distinguen del reflexivo: } \\
\text { 1. El sujeto agente tienen que ser dos o más personas. } \\
\text { 2. Cada persona del sujeto ejerce una acción sobre la otra y } \\
\text { recibe de la otra la misma acción. } \\
\text { 3. Para evitar la posible ambigüedad (puesto que verbos } \\
\text { reflexivos y recíprocos son iguales en forma) o bien para dar } \\
\text { énfasis, se peden usar refuerzos del tipo los unos a los otros, } \\
\text { mutuamente, entre sí, etc. (frente a a sí mismo que vale para } \\
\text { precisar la reflexividad). }\end{array}$ & $\begin{array}{l}\text { Características que lo distinguen del reflexivo: } \\
\text { 1. Dos o más sujetos ejecutan a acción del verbo. } \\
\text { 2. Esa acción es mutua y la reciben a la vez. } \\
\text { 3. El verbo tiene que ser transitivo. } \\
\text { 4. Para evitar confusiones que a veces pueden darse entre la } \\
\text { significación reflexiva y la recíproca, en estos últimos casos se precisa la } \\
\text { significación con expresiones como mutuamente, recíprocamente, el uno } \\
\text { al otro, enre sí (frente a los refuerzos reflexivos del tipo a símismo). }\end{array}$ \\
\hline 苋 & $\begin{array}{l}\text { Ejemplos: } \\
\text { Preguntándose los unos a los otros. } \\
\text { Que despues todos nos entenderemos. } \\
\text { Sansón y el cura se miraron el uno al otro. }\end{array}$ & $\begin{array}{l}\text { Ejemplos: } \\
\text { Juan y Pedro se tutean (inconfundiblemente recíproca). } \\
\text { Juan y Pedro se atormentan mutuamente / recíprocamente (vs. a sí } \\
\text { mismos). }\end{array}$ \\
\hline
\end{tabular}

Cuadro 66: Verbo reflexivo vs. Verbo recíproco en Cejador (1905) y la GRAE-1917

5) Se diferencia igualmente entre oraciones con verbo unipersonal y oraciones impersonales. Los verbos unipersonales son los que «en su acepción propia sólo se usan en la tercera persona de singular, como llueve, nieva...» (GRAE-1917: 248, § 268) y los verbos usados en construcción impersonal son aquellos que «siendo por su índole transitivos o intransitivos, se usan algunas veces sin sujeto determinado, como se dice, o dicen» (GRAE-248-249, § 268). Es evidente que la etiqueta de impersonalidad no se asocia en esta Gramática a la inviabilidad o inexistencia de sujeto sintáctico, sino a la indeterminación de un sujeto agente. La Academia lo expresa claramente:

Si decimos anuncian la derrota de los moros; aseguran que será buena la cosecha, enunciamos dos oraciones primeras de activa, cuyo sujeto no expresamos por ser indefinido y genérico y no poder referir el verbo a persona determinada. Estas oraciones se llaman impersonales.

(GRAE-1917: 260, § 279) 399

La distinción entre verbos unipersonales e impersonales se hace en términos que recuerdan la exposición de LLC.

${ }^{399}$ Cf. GRAE-1920: 280, § 279 y 1924: 280, § 279. 



\begin{tabular}{|c|c|c|c|c|c|c|c|c|c|c|c|c|}
\hline \multirow[b]{3}{*}{$\begin{array}{l}\text { ORACIONES } \\
\text { CON VERBOS } \\
\text { IM- } \\
\text { PERSONALES }\end{array}$} & & \multicolumn{6}{|c|}{ Cejador (1905) } & \multicolumn{5}{|c|}{ GRAE-1917 } \\
\hline & $\begin{array}{l}\text { Requisitos } \\
\text { para ser } \\
\text { impersonal }\end{array}$ & \multicolumn{6}{|c|}{ Cuando el verbo se usa sin sujeto definido (pág. $228, \mathbb{\$} 92$ ). } & \multicolumn{5}{|c|}{$\begin{array}{l}\text { Los verbos aparecen en construcción impersonal cuando «se usan algunas veces sin } \\
\text { sujeto determinado» (pág. 248-249, } \$ 268 \text { ). }\end{array}$} \\
\hline & 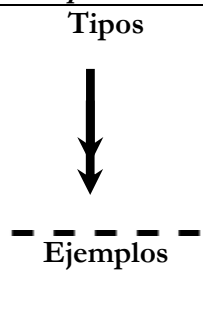 & \multicolumn{6}{|c|}{ 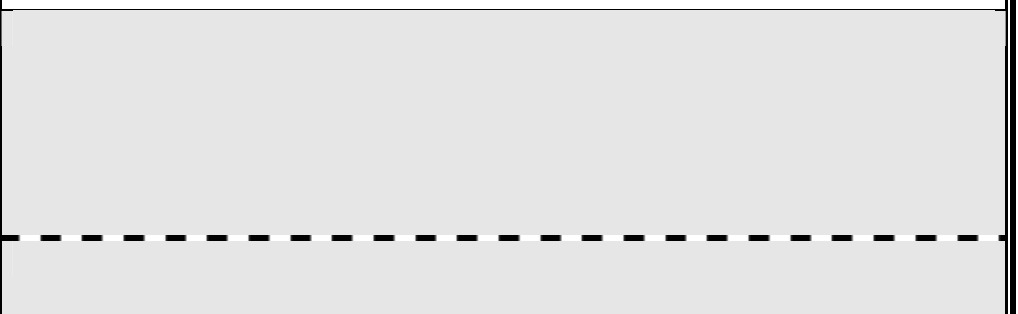 } & \multicolumn{2}{|c|}{$\begin{array}{l}\text { Llevan CD (que pasa a Sujeto en la } \\
\text { construcción pasiva). Tanto en la } \\
\text { construcción activa como en la } \\
\text { pasiva duada siempre } \\
\text { indeterminado el agente de la } \\
\text { acción del verbo. } \\
\text { Anuncian la derrota de los moros } \\
\text { Aseguran que será buena la cosecha }\end{array}$} & \multicolumn{3}{|c|}{$\begin{array}{l}\text { Las oraciones impersonales intranitivas se } \\
\text { distinguen de las transitivas uen que en la } \\
\text { construcción activa llevan callado el complemento } \\
\text { directo, y en la pasiva el sujeto, por venir en uno y y } \\
\text { otro caso comprendido en la significación del } \\
\text { verbo" (GRAE-1917: 262, } \$ 281 \text { ) } \\
\text { Aquí riñen } \\
\text { Allí cantan }\end{array}$} \\
\hline \multirow{3}{*}{$\begin{array}{l}\text { ORACIONES } \\
\text { CON VERBOS } \\
\text { UNI- } \\
\text { PERSONALES }\end{array}$} & $\begin{array}{l}\text { Requisitos } \\
\text { para ser } \\
\text { unipersonal }\end{array}$ & \multicolumn{6}{|c|}{ 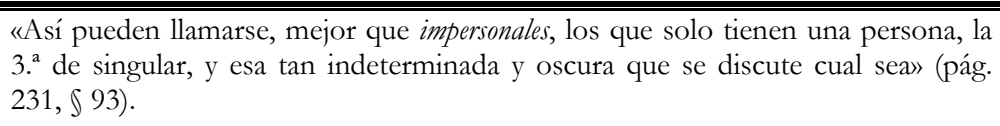 } & \multicolumn{5}{|c|}{$\begin{array}{l}\text { «Unipersonal es el que sólo se usa en el infinitivo y en la tercera persona de } \\
\text { singular de todos los tiempos» (pág. } 40, \$ 85 i \text { y pág. } 263, \S 283 \text { ). }\end{array}$} \\
\hline & \multirow{2}{*}{$\begin{array}{l}\text { Tipos } \\
\Downarrow \\
---- \\
\text { Ejemplos }\end{array}$} & \multirow{2}{*}{$\begin{array}{l}\text { Atmos- } \\
\text { féricos }^{1}\end{array}$} & \multirow{2}{*}{\begin{tabular}{|c} 
Sery \\
estar \\
(en \\
expresio \\
nes que \\
tienen \\
que ver \\
con \\
tiempo o \\
clima) ${ }^{2}$ \\
\\
\\
- Era - - \\
verano.
\end{tabular}} & $\begin{array}{c}\text { Ser y } \\
\text { auxiliares (con } \\
\text { subordinada } \\
\text { como sujeto) }\end{array}$ & $\overline{\text { Bastar }}{ }^{4}$ & Haber y hacer & \begin{tabular}{c|} 
Otros: \\
Poder ser, \\
parecer, pesar...6
\end{tabular} & 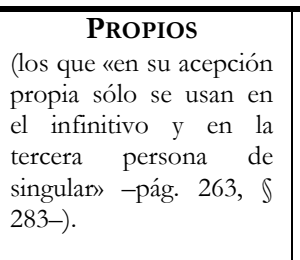 & \multicolumn{4}{|c|}{$\begin{array}{l}\text { IMPROPIOS } \\
\text { (aquellos que «no siendo unipersonales de suyo, toman a veces } \\
\text { este carácter»-pág. 264, } ₫ 284-\text { ). }\end{array}$} \\
\hline & & & & $\begin{array}{l}\text { No es posible, } \\
\text { que el mal, ni el } \\
\text { bien sean } \\
\text { durables. }\end{array}$ & 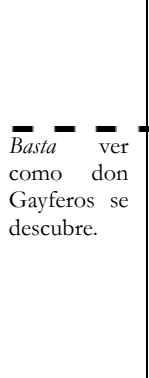 & $\begin{array}{l}\overline{\text { Ha }} \text { pocos días } \\
\text { que estoy en } \\
\text { este pueblo. } \\
\text { Si bace la noche } \\
\text { tan escura. }\end{array}$ & $\begin{array}{l}\text { Podria ser que fuesen } \\
\text { estas truchuelas } \\
\text { como la ternera. } \\
\text { Pésame, cuanto } \\
\text { pesarme puede, que. } \\
\text { A Rocinante levino } \\
\text { en deseo de } \\
\text { refocilarse con las } \\
\text { señoras facas. }\end{array}$ & 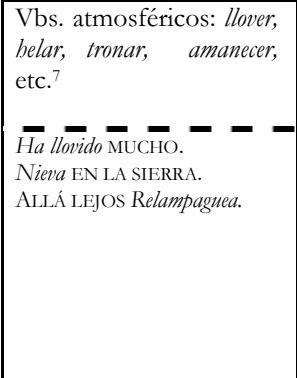 & $\begin{array}{l}\text { Ser } \\
\text { (significa: } \\
\text { tiempo, } \\
\text { clima) } \\
\overline{\text { Es tarde. }} \\
\text { Es verano. }\end{array}$ & 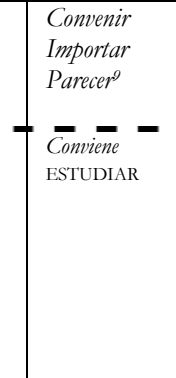 & $\begin{array}{l}\text { Haber } \\
\text { Hacer }^{10} \\
\\
\text { Hübo fésta. } \\
\text { Hace calor: } \\
\text { Tres años ha. }\end{array}$ & 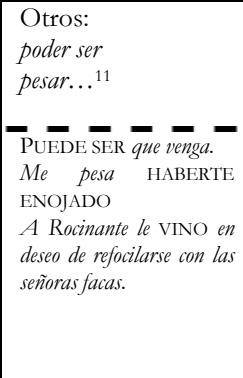 \\
\hline
\end{tabular}

Cuadro 67: Verbo unipersonal vs. Verbo impersonal en Cejador (1905) y la GRAE-1917

Son comunes como unipersonales los verbos que indican las variaciones atmosféricas [...] Creen los gramáticos que el sujeto es la naturaleza ó Dios, porque también se dice amanecerá Dios [...] que equivale á amanecerá. Equivale en la idea pero no en la forma. Nadie se refiere á Dios al decir amanecerá, llueve, nieva: amanecerá Dios vale Dios hará que llegue la mañana, lo cual es distinto de amanecerá, donde para nada se hace referencia al agente. Lo que hay que buscar no es el agente, pues no se trata de verbos activos, sino el sujeto. Dios es el agente aquí, lo mismo que en Juan cayó en un hoyo; pero tan impertinente es referirse á él en un caso como en otro. Lo que amanece, eso es el sujeto, como en el rio corre lo es lo que corre: y lo que amanece no es mas que la mañana, verdadero sujeto del verbo de estado amanecerá, que no se enuncia por ir embebido en el predicado. Todos los verbos fueron primitivamente de estado, indicaban el modo de ser del sujeto: el modo de ser que consiste en amanecer solo puede predicarse de la mañana. De aquí que no haya mas que $3{ }^{a}$ persona, la mañana, y que ésta no se enuncie por estar clara en amanecerá [sin cursiva]. Llueve es otro unipersonal equivalente á cae agua lluvia ó agua de la atmósfera, el sujeto es agua llwvia, que se calla.

(Cejador, 1905: 231, ( 93,1$)$ Con los verbos ser y estar el sujeto está claro: como era Verano... -aun es temprano... -antes que fuera muy noche... Y con ser de, por tomarse como una parte de la duracion: es ahora de dia..

(Cejador, 1905: 232, \93, 2)

Con el verbo ser y demas auxiliares se forman muchos unipersonales, cuyo sujeto es toda una proposicion subordinada sujetiva con infinitivo ó con verbo finito y que: no es cosa extraño ver con quanta facilidad cree este... - no es possible, que el mal, ni el bien sean durables... (Véanse otros ejemplos en las Oraciones sustantivas sujetivas.)

(Cejador, 1905: 232, \$93,3)

Con otros muchos verbos se emplea la misma construccion: basta ver como don Gayferos se descubre... - basta que en la narracion del no se salga un punto de la verdad...

(Cejador, 1905: 232, , §93, 4)

El impersonal de haber, hay, habia, hubo, habrá, se originó por contaminacion con el de ser, es, era, fue, será. Decíase «Grand alegria es entre todos essos christianos (Cid, 1236) [...] Por otra parte con haber por tener: «El pueblo e la villa houo grant alegria» (Apol.621) [...]

Fundidas ambas construcciones, una vez tomado baber como mero auxiliar, resultó: fueron guerras en España + España hubo buerras = bubo guerras en España. [...] Solía añadirse el

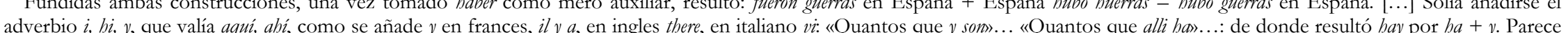
traslucirse el acusativo de haber en los pronombres: En esto de Gigantes ay diferentes opiniones, si los ha auido, ó no en el mundo: pero la Santa Escritura nos muestra que los huro... De todos modos resultó que el verbo no llevaba sujeto, de manera que estando en la $3 .^{a}$ p. del sing. el que parece sujeto puede ir en plural por ser en su origen un acusativo. Ejemplos: y a mi se me trasluze, que no ha de auer nacion, ni lengua, donde no se traduzga... -y ha pocos dias que estoy en este pueblo... -y que ay historias impressas de verdaderas cauallerias! [...]

Por analogía con haber se empleó hacer como unipersonal, que tambien pide acusativo, y lo que mas es, el verbo ser y otros verbos, á imitacion de haber y hacer, pudieron llevar plural: hąia calor..., é «hizo grandes calores». -si haze la noche tan escura... -Este hara veynte y dos años, que Sali de casa de mi padre... E verbo ser y otros llevan plural en estos ejemplos por analogía; hoy nos chocaría $[\ldots]$

Aquí se ve claramente la tendencia á no considerar como sujeto el que de hecho lo es lógicamente, sino á dejarlo oculto tomándose la 3.! P. como indefinida. Esta tendencia es mas de notar cuando el castellano no tiene propiamente acusativo, como el latin. Tales plurales en el carácter de nuestra lengua está que no sean acusativos, sino nombres libres adverbiales sin preposicion, como en: no se les da dos marauedis, lo cual debió contribuir á la generalizacion del unipersonal.

(Cejador, 1905: 232-33, \$ 93, 5 y 6 )

Por analogía, pues, con ser, haber y hacer, se emplearon otros verbos de estado y activos como unipersonales: Podria ser que fuessen estas truchuelas como la ternera... [...] -a Rocinante le vino en desseo de refocilarse con las señoras facas... - pero vinole bien a Don Quixote que sabia nadar como un ganso... - -no me pesa... de... [...] -solo se nos acuerda muy bien a mi, y al alma, que... -no se le acordana de ninguna promesa... [...]-Pesame, quanto pesarme puede, que.

Nótese que á veces Cervantes concierta el unipersonal: parecieron en esto, que por el patio venian hasta seys dueñas en procession [...]

${ }^{7}$ De ellos se dice que

(Cejador, 1905: 233-234, 93, 7)

Llevan callado el sujeto, por ser muy determinado. En latín es Júpiter, en griego, Zeus, y en castellano, Dios, el Cielo o la Naturaleza. Pero conviene advertir que la significación de estos verbos es causativa, o sea que el sujeto en ellas no es el que materialmente ejecuta la acción, sino el que hace que ésta se verifique; así que cuando a veces expresamos el sujeto y decimos, por ejemplo, cuando Dios amanezca, no expresamos que Dios es el que ba de amanecer, sino el que ba de bacer que amanezca o que venga la mañana; y de aquí que se considere también como sujeto a la mañana, y digamos amanecía LA más bella MAÑANA de primavera, y también amaneció EL DíA.

(GRAE-1917: 263-264, \$283a)

Con el verbo ser omitimos el sujeto, a no ser que éste sea una oración. Así, cuando decimos es tarde, es verano, el sujeto no lo forma el vocablo tarde ni verano, sino el momento del tiempo o la estación a que referimos el predicado, constituído por las dos palabras es tarde o es verano; y lo mismo cuando decimos es de día. Pero cuando decimos es de admirar LO HACENDOSAS QUE SON TUS HIJAS, el predicado, es de admirar, se refiere al sujeto constituído por el resto de la oración.

(GRAE-1917: 264, \284, a).

Con convenir, importar y parecer, el sujeto es el infinitivo o la oración a que dichos verbos se refieren; v. gr.: conviene ESTUDIAR; no importa QUE TE HAYA DICHO ESO; parece QUE VIENE JUAN.

(GRA-1917: 264, \$284, a)

10 Vid supra nota 517

Finalmente, empleamos como unipersonales otros muchos verbos en construcciones como las siguientes: puede ser que venga [...] pese a mi amo; bien se me alcanza [...]

El verbo pesar como unipersonal se construye con el pronombre en dativo, y el complemento de causa con de; v, gr: me pesa de mis culpas; me pesa de haberos ofendido. Cuando el complemento de causa venga expresado por un infinitivo o por una oración, puede callarse la preposición, y queda entonces el infinitivo o la oración como sujeto del verbo unipersonal; v.gr.: me pesa HABERTE enojado. Mucho me pesa, Sancho, QUE HAYAS DICHO y que digas que... [sin versales] (Qijote, II, 2). 

6) Seguimos encontrando un capítulo dedicado a la Concordancia, pero ésta ya no se considera en modo alguno un tipo de relación de dependencia ${ }^{400}$, y tampoco se presenta como capítulo básico en el estudio de la Sintaxis, a pesar de que sí son importantes las reglas dadas en él, puesto que siempre que una palabra -variable- complementa a otra tiene que adaptar sus accidentes gramaticales a los de la palabra modificada.

Con respecto a las reglas de concordancia, interesa marcar que se ha desterrado del texto de la Gramática la referencia a la concordancia de caso, que -como dijimos más arriba- pudo ser consecuencia de una desacertada extrapolación "formal" del concepto semántico-funcional de caso en las ediciones publicadas a partir del jalón de 1880 (vid. supra 6.2.3.2.). En la GRAE-1917, se sigue haciendo uso de la terminología latina (nominativo, acusativo...), pero ahora de forma inequívoca se utiliza esta nomenclatura tradicional para aludir a funciones que desempeñan las palabras dentro de la oración, según advierten los académicos. El empleo de la terminología alusiva al caso latino sí recuerda ahora el concepto (funcional) benotiano (vid supra 6.2.3.2. $-1 .^{a}$ concordancia-).

[...] Y como hasta nosotros mismos nos vemos en la precisión de emplear una nomenclatura gramatical que en la enseñanza del idioma nos sirva para distinguir los distintos oficios que el nombre desempeña en la oración, creemos conveniente y hasta necesario conservar la tradicional nomenclatura de los casos y su distinción.

[...] Diremos que está en nominativo el nombre que desempeña en la oración el oficio de sujeto o de predicado nominal, y también los adjetivos, artículos y nombres en aposición que se refieran al sujeto o al predicado nominal [...]

(GRAE-1917: 164, §§ 214 y 215, a) $)^{401}$

\footnotetext{
400 Recordemos que, aunque nunca fue definida como dependencia -tal como se ha dicho-, siempre se estudió en la Parte II del libro, como un tipo más de dependencia (junto con el Régimen -y la Construcción, desde 1796-); la Sintaxis era definida como orden y/o dependencia y se reducía a tres tipos de reglas básicas (dos en 1771), uno de las cuales respondía a las reglas de la Concordancia.

${ }^{401}$ Cf. GRAE-1920: 184, §§ 214 y 215, a y GRAE-1924: 184, §§ 214 y 215, a.
} 


\subsubsection{2. $\quad$ Sintaxis de la Oración Simple}

El estudio de la Oración Simple, la que consta «de un sujeto y un predicado»(GRAE-1917: 249, § 269), se basa en el reconocimiento de todo un sistema de adyacencias y complementaciones que sustenta la oración gramatical. Sustantivo y Verbo serán considerados "categorías base" en torno a las cuales se articula todo el entramado de relaciones sintácticas que dan lugar a (y tienen lugar en) la unidad oración.

En este primer bloque de la Sintaxis, la atención se centrará, por tanto, en el análisis de las funciones de Sujeto y Predicado y las complementaciones que se dan en cada una de ellas, por lo que encontraremos capítulos dedicados al Nombre sustantivo: sus oficios y complementos; al Adjetivo: sus oficios $y$ complementos y a los Complementos del verbo. De la doctrina expuesta por la Institución en estos capítulos y otros de esta primera parte de la Sintaxis, cabe destacar el importante paso que supone en lo tocante a las relaciones sintagmáticas intraoracionales y, por extensión, a las relaciones de dependencia oracional:

$\left.1^{\circ}\right)$ Se lleva a cabo un esfuerzo sin precedentes en la tradición gramatical interna de la Institución por basar el análisis sintáctico en el oficio de las palabras dentro de la oración.

Prueba de que, a partir de 1917 se privilegia el papel que desempeñan unas las palabras respecto de otras (por encima de la categoría o clase de palabra) es la nueva definición de la función de sujeto, que ya no es «la palabra, o conjunto de ellas, que realiza la acción o en que se cumple la atribución expresada por el verbo», sino 
Un nombre substantivo $\underline{u}$ otra palabra que en la oración haga sus veces, y a la cual se refiera la atribución expresada por el predicado.

(GRAE-1917: 150, § 195) 402

Por otra parte, el hecho de que ya no se le atribuya al sujeto la “realización de la acción expresada por el verbo" está en consonancia con la noción de predicación que sustenta el nuevo concepto de oración (vid. supra).

$2^{\circ}$ ) Hay un intento riguroso de dar cuenta de la jerarquía de complementaciones y adyacencias que tienen lugar en el seno de la oración y de mostrar que las palabras no funcionan aisladamente: no se trata ya de que entre el Sustantivo (sujeto) y el Verbo puedan mediar palabras gracias a las "flexibles" reglas de la construcción -como se explicaba en las ediciones precedentes-, sino de que el sustantivo puede estar determinado por ciertos complementos junto con los cuales desempeña la función de sujeto (o cualquier otra función que le sea propia).

Es, precisamente, el desarrollo de la teoría de la complementación lo que parece estar en la base del replanteamiento que experimenta el

402 La Academia no solo re-define el concepto de sujeto, también, por primera vez, lo caracteriza formalmente de forma minuciosa. Pueden desempeñar el oficio de sujeto:

- Un nombre sustantivo siempre en 3. ${ }^{a}$ persona (con o sin artículo): Juan estudia; El manantial fluye.

- Un pronombre en cualquiera de las tres personas (sin artículo): Yo leo; Alguien vendrá. Cuando el sujeto es sustantivo y/o pronombre, pueden aparecer ciertas preposiciones como entre (pero la forma del pronombre personal seguirá siendo yo, tú...).

- Cualquier palabra, locución u oración completa sustantivada por el artículo o por un demostrativo: El estudioso aprende; Ese perro me disgusta; Los de aquí no me agradan; El que no hubiesen llegado a tiempo los socorros fue causa de que la plaza se rindiese.

- Una oración con valor de sustantivo: Mejor será que nos salgamos fuera de la ciudad.

- Un infinitivo (con artículo o sin él): No me gusta importunar; No está en mi mano el pensar.

- Locuciones formadas con adverbios o preposiciones seguidos de un numeral y un nombre: Se perdieron más de cuatrocientos hombres en aquella jornada; o con un adverbio de cantidad y un nombre que indique también cantidad: Cerca de quinientos viajaban hoy en el correo.

Vid. GRAE-1917: 150-152, § 195. También GRAE-1920: 170, § 195 y GRAE-1924: 170, § 195. 
estudio interno de la oración en 1917, que consiste en no atender tanto a los vínculos entre palabras -categorías morfológicas- sino a las relaciones entre funciones. La Academia reconoce teóricamente la recursividad de las relaciones de complementación, fenómeno que obliga a mirar las palabras según la función que desempeñan:

Resulta de todo lo dicho en los párrafos de este capítulo que el sujeto y el predicado, o sea el nombre substantivo y el verbo, que son los que desempeñan la función de tales, son las dos palabras a las cuales se refieren inmediata o mediatamente todas las demás de la oración simple, por compleja que ésta sea; y también que la Sintaxis, en la parte que trata de la oración simple, tiene reducido su objeto a este particular, o sea a estudiar el nombre y el verbo en su oficio de sujeto y predicado, y luego los complementos que uno y otro pueden tener; pero como la palabra que desempeñe la función de complemento puede a su vez tener otro complemento y éste puede tener también otro, y como la única expresión en Gramática de tales complementos son las palabras, de ahí la necesidad de estudiar el oficio de éstas y el modo de relacionarlas entre sí, que es lo que constituye el objeto de la primera parte de la Sintaxis.

(GRAE-1917: 156, § 204) $)^{403}$

La atención al oficio de las palabras dentro de la oración, como foco de la sintaxis de la proposición simple, descubre a LLC como texto que pudo inspirar a los redactores de la reforma. La visión "funcional" de Cejador alenta algunas afirmaciones contenidas en LLC que hoy llaman nuestra atención por su modernidad:

El análisis no ha de destrozar lo que se analiza, sino explicar las partes en el todo que forman. Preguntar si ver es nombre ó verbo, si tu es adjetivo, nombre ó pronombre, es una vaciedad, pues son una ú otra cosa según funcionen en la cláusula.

(Cejador, 1905: 205, § 78)

${ }^{403}$ GRAE-1920: 176, § 204 y GRAE-1924: 176, § 204. 
$\left.3^{\circ}\right)$ Se elimina la incoherencia que caracterizaba el análisis de ciertas clases de palabras en las ediciones anteriores. Por ejemplo, la preposición ahora se entiende exclusivamente como elemento de relación y su papel dentro de la oración se estudia como "cierre" de la doctrina de los complementos (antes de abordar el análisis de los tipos oracionales), ya que

con excepción de la aposición, de algunos acusativos, objeto directo o circunstancial, y de las formas átonas de los pronombres, todos los demás complementos, cuando el término complementario es un substantivo, se expresan en castellano por medio de una preposición.

(GRAE-1917: 203, § 257, a) $)^{404}$

$\left.4^{\circ}\right)$ Aunque no es novedoso el reconocimiento de que una oración entera puede ser complemento de una palabra, sí es la primera vez que la Academia va a llevar a cabo un estudio detenido de las relaciones de dependencia oracional, que se abordará en la segunda parte del estudio sintáctico, la reservada a la llamada Oración compuesta.

En el cuadro que sigue, resumo el sistema de funciones $\mathrm{y}$ complementaciones que la Institución reconoce como básicas dentro de la Oración simple (incorporo -con sombreado- los casos de dependencia oracional, que atañen a la oración compuesta -vid. infra-). Independientemente de la función que cumplan las categorías de sustantivo y adjetivo, siempre podrán ir modificadas por los complementos que les son propios.

${ }^{404}$ GRAE-1920: 223, § 257, a y GRAE-1924: 223, § 257, $a$. 

SISTEMA DE COMPLEMENTACIONES EN LA GRAE-1917

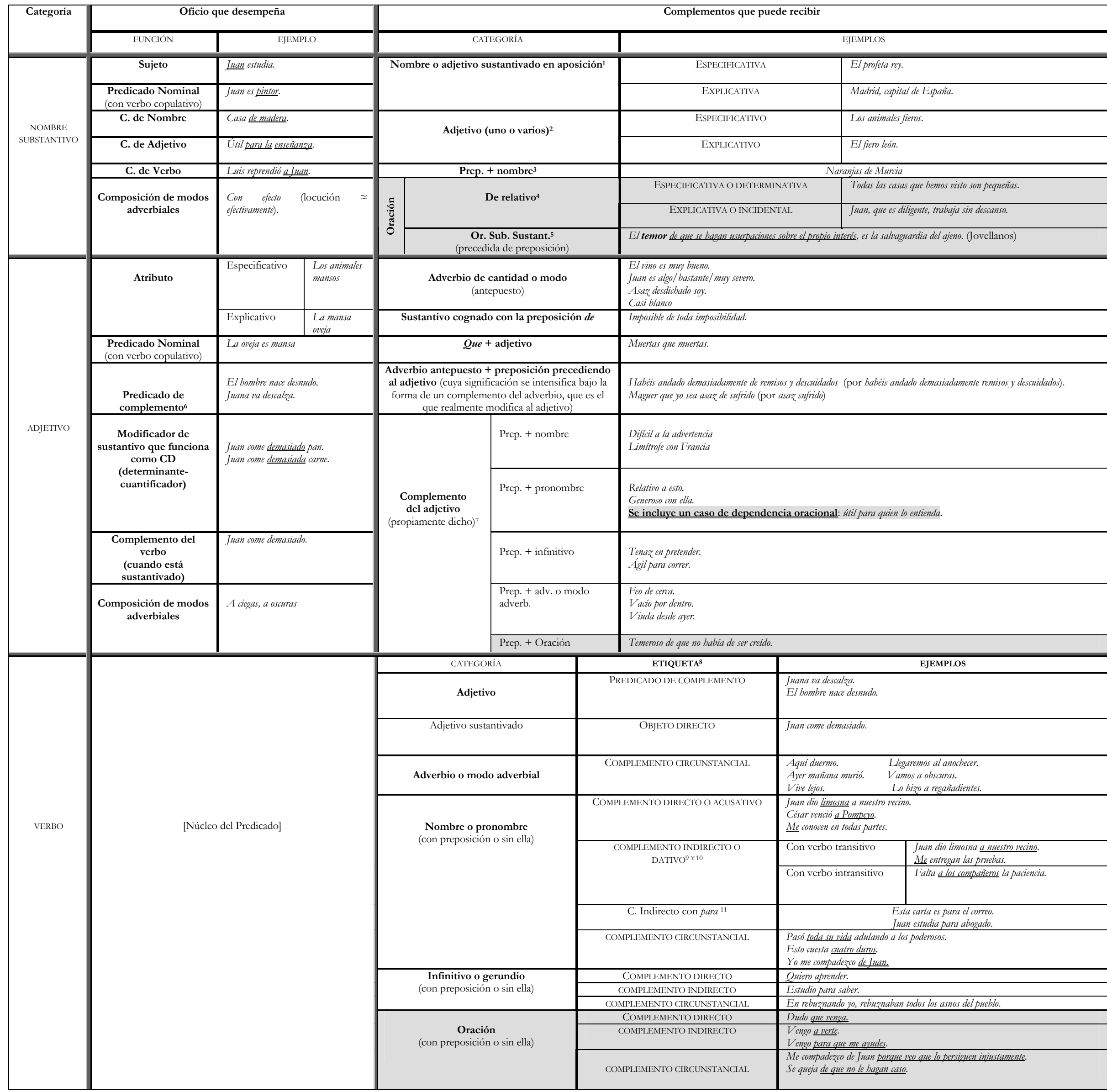

Cuadro 68: "Sistema de complementaciones en la GRAE-1917"

${ }^{1}$ No solo es novedosa la inclusión de sustantivos en aposición complementando a otros sustantivos, sino que es la primera vez que la GRAE alude a este tipo de construcciones (recordemos que no se recogían en la casuística del Caso (1) de Régimen (vid. supra).

Lo mismo que el nombre en aposición, el adjetivo que como atributo se refiere a un substantivo, puede completar la significación de éste de dos maneras: unas veces lo especifica, y otras lo explica. En el primer caso el adjetivo restringe la significación del substantivo, disminuyendo su extensión y aumentando su comprensión (véase 193, nota I); en el segundo no hace más que explicar o desenvolver el concepto del substantivo, expresando una nota o cualidad característica y propia del mismo.

La significación del nombre substantivo puede también completarse mediante un nombre con preposición, pero siempre que el concepto expresado por la preposición y el no (GRAE-1917: 172, \$223, a) adjetivo o a una oración de relativo.

(GRAE-1917: 174, \224, a)

Como el adjetivo complemento de un nombre (véase 223), pueden estas oraciones ser especificativas o determinativas y explicativas o incidentales. Las primeras determinan al antecedente, especificándolo; las segundas no hacen más que expresar una circunstancia del mismo.

(GRAE-1917: $315, \$ 350$, a)

Lo mismo que el substantivo, pueden estas oraciones ser complemento de un nombre o adjetivo, y de un verbo. Cuando son complemento de un nombre o adjetivo, llevan la preposición de; cuando lo son de un verbo, llevan la preposición que corresponda a la clase de complemento circunstancial a que la oración sea equivalente.

[El adjetivo] puede también completar la idea de un predicado verbal, sin dejar de referirse al nombre. Así, cuando decimos: el hombre nace desnudo; Juana va descalva, los adjetivos (GRAE-1917: 355-356, \$399) estos adjetivos que se refieren a la vez al sujeto y al predicado verbal, los llamamos predicados de complemento.

El vocablo complemento del adjetivo puede ser un nombre, un pronombre o un infinitivo con preposición, y también un adverbio o modo adverbial.

GRAE-1917: 180, \$228, a)

(GRAE-1917: 184, § 235)

.... aquél [... Se también la de verbos intransitivos, según se dice en el número 243, d y e. [. ] Y Llamamos complemento cirrunstancial al vocablo, modo adverbián del verbo transitivo ejercida ya sobre el significación del verbo, denotando una circunstancia de lugar, tiempo, modo, materia, contenido, etc. [...]

Para la etiqueta "predicado de complemento", vid. supra nota 6.

(GRAE-1917: 186-187, § 239)

El complemento indirecto puede ir con verbos transitivos, intransitivos y de estado, y lleva siempre la preposición $a$, excepto cuando sea un pronombre átono.

${ }^{10}$ Se incluyen casos de dativo ético y posesivo: Me han muerto a mi hijo; Se le han caído los dientes.

La preposición para indica también el complemento indirecto pero bajo la relación de fin, o sea el destino que se da a una cosa o el fin que nos proponemos en una acción [...] Esta preposición puede indicar otros complementos, como se dice en el número $265, l l$. 

Dando este sistema de funciones y complementaciones como base de articulación de la oración gramatical, la Academia establece, por vez primera, una doble clasificación de las oraciones (ahora bien diferenciada y explicada) siguiendo dos criterios:

(a) Atendiendo a la ÍnDOLE DEL VERBo, a partir de 1917 se diferencian ocho tipos de oraciones. La siguiente tabla permite cotejar el sistema de 1870 con el nuevo:

\begin{tabular}{l||l}
\multicolumn{1}{c||}{ MODELO 1917} & \multicolumn{1}{c}{ MODELO 1870} \\
\hline \hline Oraciones de verbo copulativo & oraciones de verbo sustantivo \\
\hline \multicolumn{1}{c||}{ Transitivas } & oraciones de verbo en voz activa \\
\hline Intransitivas & oraciones de verbo neutro \\
\hline Pasivas405 & de verbo en voz pasiva \\
\hline Reflexivas & de verbo reflexivo o reciproco \\
\hline De verbo recíproco & impersonales \\
\hline Impersonales & \\
\hline Unipersonales & De modo imperativo \\
\hline \multicolumn{2}{|c|}{ Cuadro 69: “Sistema de oraciones en 1870 y 1917 " }
\end{tabular}

(b) Atendiendo al MODO DEL VERBO, las oraciones pueden ser ${ }^{407}$ :

- $\quad$ Aseverativas: las que afirman o niegan la realidad de un hecho o la posibilidad del mismo. Ejemplos: Juan tendría cincuenta años. No le he oído eso.

\footnotetext{
$405 \mathrm{Al}$ tratar de estas oraciones, se emplea por primera vez la etiqueta "complemento agente" (que, aunque se reconoce, no se recoge entre los complementos del verbo). El concepto no es nuevo y tampoco lo es su caracterización formal: este complemento, necesariamente, debe llevar la preposición por o de. (vid. GRAE-1917: 255, § 275). En las ediciones anteriores, desde 1870, se hablaba de «un complemento regido por las preposiciones de o por, que es el verdadero agente».

${ }^{406}$ Las oraciones de relativo serán estudiadas en la GRAE-1917 dentro de la subordinación de las oraciones. Recordemos que, en las propuestas tipológicas de 1854 y 1870, este grupo resulta "anómalo", pues no responde, en rigor, al criterio clasificatorio de naturaleza o índole del verbo. 407 Vid. GRAE-1917: 278-290, § 304-313. También GRAE-1920: 298-310, § 304-313 y GRAE-1924: 298-310, § 304-313.
} 


\section{- Interrogativas directas:}

a) Las que expresan un estado mental intermedio entre la aseverativa afirmativa y la aseverativa negativa. Con ellas exponemos un juicio, pero ignoramos si el predicado conviene o no al sujeto. Ejemplos: ¿Ha venido Pedro?

b) Las que expresan una duda del hablante que recae en el sujeto o en una de las cualidades de este. Ejemplos: ¿Quién ha venido? (suponemos que ha venido alguien; afirmamos el predicado y preguntamos el sujeto); ¿Qué libro es ese? (preguntamos por la cualidad del sujeto libro).

c) Las que expresan duda sobre el Predicado Nominal del sujeto. Ejemplo: ¿Qué es Gramática?

d) Las que expresan duda sobre alguno de los complementos del verbo. Ejemplos: ¿A quién prefieres? (dudamos sobre el complemento directo); ¿A quién has dado el papel? (dudamos sobre el complemento indirecto); ¿Con quién has venido? (preguntamos por el complemento circunstancial).

- Interrogativas dubitativas ${ }^{408}$ : se corresponden a las aseverativas que expresan el hecho como probable, y son aquellas en que uno se hace la pregunta a sí mismo, manifestando a la vez la duda e incertidumbre que tiene acerca de lo que pregunta. Suelen aparecer en ellas adverbios de duda o el si dubitativo. Ejemplo: ¿Si será verdad lo del testamento?

\footnotetext{
${ }^{408}$ Antes de pasar al siguiente grupo según la modalidad, se inserta un párrafo en el que se advierte que la interrogación no siempre supone duda o desconocimiento en el emisor: «a veces se niega con ella lo mismo que se pregunta. El contexto y el tono bastan en ocasiones para determinar la índole de la respuesta» (GRAE-1917: 286, § 310).
} 
- Admirativas o exclamativas: con ellas, ni afirmamos (como en las aseverativas) ni preguntamos (como en las interrogativas), sino que manifestamos sorpresa o admiración. Por el tono con que las expresamos, reciben el nombre de exclamativas; el término admirativa se debe a «la suspensión en que parece queda el espíritu al proferirla». Ejemplos: ¡Cuánto puede el amor!; ¡Cómo llueve!

- Desiderativas 409 : las que expresan el deseo de que se verifique o no un hecho.

a) Aparece en ellas habitualmente el presente de subjuntivo (para enunciar un deseo que consideramos realizable) o el imperfecto de subjuntivo (cuando consideramos imposible la realización del deseo). Ejemplos: Ventura te dé Dios; muriérase ella... y dejáranme a mí en mi casa (Quijote).

b) Se puede expresar con el verbo desear y /que + subjuntivo/ dependiendo de él. Se trata de casos de oraciones compuestas. Ejemplo: Deseo que sea enhorabuena.

c) Muchas veces la oración lleva la interjección ojalá o el adverbio así. Ejemplos: Ojalá tengas buen éxito; Así Dios te ayude.

- Exhortativas: son las que indican:

a) Exhortación, esto es, un mandato atenuado, sin la crudeza del imperativo. Por ser un mandato que a la vez incluye un ruego, se utiliza el presente de subjuntivo. Ejemplo: Desnúdese vuestra merced y vístase a sus solas (Quijote).

\footnotetext{
${ }^{409} \mathrm{Al}$ final de la exposición de este grupo, se apunta la idea de que en una misma oración pueden confluir las modalidades desiderativa y exclamativa. Es lo que sucede, por ejemplo, en ¿Que no fuese yo un dios!
} 
b) Mandato, que queda reducido a la 2. ${ }^{a}$ persona. Usamos el imperativo o, para manifestar respeto, el presente de subjuntivo en 3. ${ }^{a}$ persona. Ejemplos: Niños, estudiad; Ande despacio, señor. Si el mandato se dirige a una persona ausente, también se usa el subjuntivo. Ejemplo: El negligente pague su dejadez.

c) Prohibición, que exige el uso del presente de subjuntivo, incluso para la 2. ${ }^{\mathrm{a}}$ persona. Ejemplo: No engañes nunca a nadie. La prohibición puede expresarse con palabra de significado negativo distinta de no. Ejemplo: Nunca te guíes por la ley del encaje (Quijote).

Es en 1917 cuando la Academia muestra, por primera vez, interés en el estudio de aspectos relativos a la modalidad oracional: en esta edición, frente a las GRAE precedentes, se dedica un capítulo independiente a esta otra forma de clasificar y analizar las oraciones.

La atención a la modalidad es otro punto de la nueva doctrina gramatical de la GRAE que acerca el libro de 1917 a la obra de Cejador y Frauca. 


\subsubsection{3. $\quad$ Sintaxis de la Oración Compuesta}

Como puede verse en los fragmentos expuestos en 4.1., ya en 1870, la RAE alude a la unión de oraciones en una unidad distinta (superior, se entiende) llamada período 410 . Pese a esta observación hecha en las páginas introductorias de algunas ediciones del XIX, y pese a que, efectivamente, desde la GRAE-1870 se reconoce, en el apartado sintáctico, la existencia de oraciones compuestas (vid. supra 6.2.), tendremos que esperar a 1917 para encontrar un análisis detenido de la unión de oraciones. Al estudio de los tipos y los resultados de estos enlaces se dedicará casi la mitad de la segunda parte del libro.

Lo primero que llama la atención es la nueva definición que la Academia da de oración compuesta (recordemos que en este cambio pudo haber influido la crítica de Oca y Merino -vid. supra 6.3.1.-): si denominamos oración simple a la que consta de un solo sujeto y un solo predicado, «diremos que una oración es... compuesta cuando consta de más de un sujeto o más de un predicado»(GRAE-1917: 249, § 269). Esta afirmación implica -teóricamenteque Pedro viene es una oración simple, pero Pedro y Juan vienen es una oración compuesta. Tal concepción recuerda la defensa que la GRAE-1870 hacía en su "teoría de la conjunción", según la cual, en virtud del fenómeno de la elipsis, siempre que una conjunción une dos palabras está enlazando, en rigor, dos oraciones (vid. supra 6.2.4.1.).

Conviene apuntar que, en el sistema oracional establecido en la GRAE1870 (edición en la que por primera vez se define el concepto de sujeto) la idea de sujeto compuesto nunca estuvo asociada a la de sintagma compuesto por coordinación (a la idea de sujeto con más de un núcleo), sino que por tal se entendía el sujeto que contaba con adjuntos calificativos. En otras palabras, en

${ }^{410}$ Alusión que se pierde en la GRAE-1888. Vid. Glosario final, s.v.gramática. 
la tradición académica, la composición se había vinculado de forma clara a la idea de subordinación, no así a la de coordinación ${ }^{411}$.

No obstante la definición dada, el estudio detenido de la Oración compuesta en la GRAE-1917 no va a atender a casos de sujeto doble o múltiple con un solo predicado, sino a casos de más de un predicado.

La Institución entiende que las oraciones se unen en el período de dos modos: siguiéndose unas a otras, sin que haya influencia entre ellas, o de tal modo que unas sean complemento de otras, a las cuales se subordinan semántica y sintácticamente. Esta distinción básica da paso al estudio separado de la coordinación y la subordinación de oraciones.

411 Cabe plantearse la duda sobre los llamados complementos compuestos. La afirmación explícita de la Academia sobre la estructura interna de sujetos y complementos es la que sigue:

\footnotetext{
Hay, pues, en las oraciones sujetos simples, que constan sólo de un nombre, ó de un artículo y nombre, ó de un nombre y un apellido, etc., y hay sujetos compuestos que van acompañados de adjuntos calificativos.

Hay complementos simples, que constan solamente de un adjetivo ó nombre propio, ó de un nombre comun entre un artículo y un adjetivo, etc.; y hay complementos compuestos, que constan de varios términos, primero, segundo, tercero, etc.
}

(GRAE-1870: 212)

¿Cómo debemos entender lo de "varios términos"? Las palabras reproducidas se refieren a los ejemplos: San Fernando conquistó á Sevilla (oración con sujeto simple: San Fernando, y complemento simple: á Sevilla) y El infatigable caudillo, el bienaventurado rey San Fernando, conquistó, para gloria suya y de la religión verdadera, la ínclita ciudad de Sevilla, rica posesión de las agarenos en España. En la segunda oración -se deduce- tenemos un sujeto compuesto (El infatigable caudillo, el bienaventurado rey San Fernando) y un complemento compuesto en el que solo hay relaciones de dependencia (la ínclita ciudad de Sevilla, rica posesión de los agarenos en España). Si del sujeto y complemento señalado en la segunda oración deducimos que son compuestos por la afirmación que se hace en la cita que hemos reproducido en esta nota, de para gloria suya y de la religión verdadera (donde hay coordinación), se dice expresamente:

El verbo conquistó aparece solo en la primera oración [San Fernando conquistó á Sevilla]; en la segunda le sigue la cláusula: Para gloria suya y de la religion verdadera.

(GRAE-1870: 212)

¿Es para gloria suya y de la religión verdadera complemento compuesto o no? 
Tanto Gisbert y Hoël como Cejador habían atendido en sus obras a estos dos tipos básicos de unión de oraciones. Y ambos tratados pudieron inspirar a la Comisión de Gramática.

La coordinación de oraciones, al igual que la yuxtaposición, responde al primer tipo señalado de unión dentro del período; pero, si el denominador común es la no influencia entre las oraciones enlazadas, la nota discordante es que, frente a la yuxtaposición, consistente en una suma asindética de oraciones, la coordinación se lleva a cabo por medio de conjunciones. Y es ahora cuando, por fin, la RAE establece una clasificación (implícita ${ }^{412}$ ) de tipo sintáctico de los nexos conjuntivos: todas las conjunciones que, en las GRAE anteriores y en las páginas precedentes de ésta, habían sido etiquetadas como copulativas, disyuntivas, adversativas y causales darán lugar (y cederán su nombre) a sendos tipos de coordinación, a los cuales se une un quinto tipo íntimamente relacionado con la coordinación causal-: el enlace por coordinación consecutiva, llevado a cabo por las antes conocidas como conjunciones ilativas.

El estudio de las relaciones de coordinación entre oraciones es algo totalmente novedoso en la tradición gramatical académica. Hasta la fecha, la Institución ha recogido y analizado -aunque no en profundidad-casos de dependencia oracional (casos de unión de oraciones una de las cuales depende de la otra), bien entendidos como régimen, bien como complemento, pero no se ha analizado la unión de estructuras oracionales sintácticamente independientes (aunque sí se han recogido casos de coordinación con una pura finalidad ilustrativa, por ejemplo, para ejemplificar que una conjunción puede

\footnotetext{
412Todavía en la GRAE-1917, en la Analogía, seguimos encontrando una clasificación puramente semántica de las conjunciones, que ahora se da como simple nómina -no hay análisis ni explicación de los tipos-. En realidad, el capítulo de la conjunción se ha reducido considerablemente y con esta reducción se pierden también las alusiones a la conjunción como elemento que puede dominar sobre otro. Al igual que sucede con la preposición, en esta $30^{\mathrm{a}}$ edición de la GRAE, no se duda en considerarla únicamente como elemento de relación.
} 
enlazar dos cláusulas). En este aspecto, la doctrina de la RAE experimenta una evolución paralela a la de nuestra tradición no académica, en la que se desarrolló antes el concepto de subordinación sintáctica que el de coordinación (vid. Gómez Asencio, 1987).

Del concepto de período coordinado o de oraciones relacionadas por coordinación, cabe destacar que la GRAE-1917 presenta una doctrina que hoy se tiende a considerar más acertada que la que defendida en 1973 en el último texto gramatical firmado por la Institución. Así, construcciones del tipo:

(1) Sin duda está malo, puesto que no ha venido;

Causa

(2) Sufre la pena, pues cometiste la culpa;

Causa

(3) Tú cometiste la culpa; $\frac{\text { sufre, pues, la pena; }}{\text { Consecuencia }}$

(4) Gasta más de lo que tiene: por consiguiente, no tardará mucho en arruinarse; Consecuencia

son recogidas, en la 30a edición de la Gramática académica (1917), en el apartado de la coordinación, puesto que no hay influencia sintáctica de ninguna de las dos oraciones sobre la otra. Frente a esta postura, el Esbozo (1973) estudiará todos estos casos y otros similares dentro del grupo de las oraciones subordinadas circunstanciales, en base a un criterio de dependencia semántica que se hace extensivo a la sintaxis.

El cuadro que sigue da cuenta de la proximidad existente entre la teoría de la coordinación de oraciones expuesta en el Tratado de Gisbert (1902), LLC (1905) y la GRAE-1917. 


\section{ORACIONES COMPUESTAS POR COORDINACIÓN}

\begin{tabular}{|c|c|c|c|c|c|c|c|c|}
\hline & \multicolumn{3}{|c|}{ Gisbert y Hoël (1902) } & \multicolumn{3}{|c|}{ Cejador y Frauca (1905) } & \multicolumn{2}{|c|}{ GRAE-1917 } \\
\hline $\begin{array}{l}\text { Definición/ } \\
\text { Explicación }\end{array}$ & \multicolumn{3}{|c|}{$\begin{array}{l}\text { «El período de coordinación está formado por dos ó más } \\
\text { oraciones gramaticalmente independientes, que } \\
\text { expresan pensamientos diferentes, aunque lógicamente } \\
\text { relacionados entre sí» (pág. } 7, \S 11 \text { ). } \\
\text { «La coordinación es la relacion de igualdad... entre las } \\
\text { diferentes oraciones, cuyo conjunto constituye una frase } \\
\text { ó período» (pág. } 72, \S 108 \text { ). }\end{array}$} & \multicolumn{3}{|c|}{$\begin{array}{l}\text { «La unidad lógica del pensamiento y de su expresion } \\
\text { puede ser mas ó menos íntima, por mera yuxtaposicion ó } \\
\text { coordinacion de juicios y proposiciones, o por } \\
\text { subordinacion y dependencia total. El primer } \\
\text { procedimiento, mas infantil y analítico, es el que forma la } \\
\text { Parataxis ó Coordinacion, el segundo mas sabio, } \\
\text { reflexivo y sintético, es el que forma la Hipotaxis ó } \\
\text { Subordinacion» (pág. } 377 \text {, } 199 \text { ). } \\
\text { «En la parataxis cada una de las proposiciones } \\
\text { yuxtapuestas forma sentido completo, es una oracion» } \\
\text { (pág. } 398, \S 211) \text {. }\end{array}$} & \multicolumn{2}{|c|}{$\begin{array}{l}\text { «[...] las oraciones se unen en el período de dos modos: o } \\
\text { siguen unas a continuación de otras, sin tener influencia } \\
\text { recíproca entre sí, como en Juan desea, Antonio viene, papá } \\
\text { descansa, o se relacionan de tal modo que una se nos ofrece } \\
\text { como complemento de otra, a la cual se subordina no sólo en } \\
\text { la manera de concebirla el entendimiento, sino también en el } \\
\text { modo de expresión [...]» (pág. } 291, \S 315, \text { a). } \\
\text { «Decimos que dos o más oraciones están coordinadas cuando } \\
\text { el juicio enunciado en cada una de ellas se expresa como } \\
\text { independiente del indicado por las demás, y de manera que } \\
\text { puede enunciarse solo, sin que por ello deje de entenderse } \\
\text { clara y distintamente» (pág. } 292, \S 316 \text { ). }\end{array}$} \\
\hline $\begin{array}{l}\text { Forma de expresión } \\
\text { de la coordinación }\end{array}$ & \multicolumn{3}{|c|}{$\begin{array}{l}\text { - «Por el sentido, cuando las oraciones van simplemente } \\
\text { colocadas una al lado de otra » (pág. } 72, \S 109) \text {. En este } \\
\text { caso, se habla de yuxtaposición de las oraciones o de } \\
\text { oraciones coordinadas asindéticas. } \\
\text { - Por conjunciones coordinativas. En este caso, hay } \\
\text { coordinación propiamente dicha. Se trata de oraciones } \\
\text { coordinadas sindéticas. }\end{array}$} & \multicolumn{3}{|c|}{$\begin{array}{l}\text { La parataxis o coordinación reúne en el período o discurso } \\
\text { dos o más proposiciones «por mera yuxtaposición } \\
\text { extrínseca, expresada por medio de las llamadas } \\
\text { conjunciones de coordinación» (págs. } 377-378, \S 199 \text { ). }\end{array}$} & \multicolumn{2}{|c|}{$\begin{array}{l}\text { «La coordinación se verifica por medio de conjunciones, y } \\
\text { cuando éstas se omiten, decimos que las oraciones se hallan } \\
\text { yuxtapuestas o unidas por yuxtaposición. Pero no se crea por } \\
\text { esto que en el desarrollo del lenguaje haya sido la } \\
\text { coordinación anterior a la yuxtaposición, sino al contrario» } \\
\text { (pág. 292, §316). }\end{array}$} \\
\hline \multirow{10}{*}{ Tipos } & \multicolumn{2}{|c|}{ NOMBRE DEL PERÍODO } & EXPRESIÓN & \multicolumn{2}{|c|}{ NOMBRE DEL PERÍODO } & EXPRESIÓN & NOMBRE DEL PERÍODO & EXPRESIÓN \\
\hline & \multirow[t]{2}{*}{ Copulativo } & De adición & $y, \hat{e}$ & \multirow[t]{2}{*}{\begin{tabular}{|l|} 
Copulativo \\
\end{tabular}} & De adición & & \multirow[b]{2}{*}{ Coordinada copulativa } & \multirow[t]{2}{*}{$y, e, n i$} \\
\hline & & De extensión & & & De gradación & $n o \ldots n i ; n i \ldots n i$ & & \\
\hline & \multirow{2}{*}{\multicolumn{2}{|c|}{ Disyuntivo o alternativo }} & $\sigma, u ́$ & \multirow{2}{*}{\multicolumn{2}{|c|}{ Disyuntivo }} & $o ; o \ldots o$ & Coordinada disyuntiva & $o, u$ \\
\hline & & & & & & & Enumerativa o distributiva & Uno... otro; ya.. ya \\
\hline & \multirow[t]{3}{*}{ Adversativo } & \begin{tabular}{|l|} 
De exclusión \\
\end{tabular} & \multirow{3}{*}{ mas, pero... } & \multirow[t]{2}{*}{\begin{tabular}{|l|} 
Adversativo \\
\end{tabular}} & \begin{tabular}{|l|} 
Exclusivo \\
\end{tabular} & \begin{tabular}{|l|} 
Sino, antes... \\
\end{tabular} & \begin{tabular}{|l|} 
Coordinada adversativa \\
\end{tabular} & pero,mas, aunque \\
\hline & & De restricción & & & \begin{tabular}{|l|} 
restrictivo \\
\end{tabular} & $\begin{array}{l}\text { Pero, aunque, no } \\
\text { obstante... }\end{array}$ & y correctiva & sino \\
\hline & & De contraste & & \multirow[t]{3}{*}{ Causal o ilativo } & De causa & Porque, pues, que... & \begin{tabular}{|l|} 
Coordinada causal \\
\end{tabular} & porque, puesto que, pues que \\
\hline & \multirow[t]{2}{*}{ causal } & De razón & \multirow{2}{*}{ pues, porque } & & & & & \\
\hline & & De deducción & & & \begin{tabular}{|l|} 
De \\
consecuencia
\end{tabular} & $\begin{array}{l}\text { Así que, así es que, } \\
\text { luego, por eso }\end{array}$ & y consecutiva & $\begin{array}{l}\text { Con que, por consiguiente, } \\
\text { luego. }\end{array}$ \\
\hline
\end{tabular}

Cuadro 70: Coordinación de oraciones en Cejador (1905) y la GRAE-1917 
En cuanto a la subordinación de oraciones, interesa apuntar varios aspectos:

1. Se reconoce que, sintácticamente, estas oraciones «desempeñan en la oración compuesta el mismo oficio que los complementos del nombre o del verbo en la oración simple»(GRAE-1917: 314, § 349). Aunque en esta primera afirmación parecen olvidarlo, los académicos no dejan de reconocer que las llamadas subordinadas sustantivas pueden desempeñar también la función de sujeto, como es propio del sustantivo; de hecho, se dedicará un apartado a este tipo concreto de subordinación.

2. El reconocimiento de que la Oración compuesta por subordinación equivale estructuralmente a la Oración simple parece tener reflejo también en la estructuración del estudio de ambas unidades. Se podría establecer la siguiente correspondencia (no total):

\begin{tabular}{|c|c|}
\hline ORACIÓN SIMPLE & $\begin{array}{l}\text { ORACIÓN COMPUESTA POR } \\
\text { SUBORDINACIÓN }\end{array}$ \\
\hline $\begin{array}{l}\text { CAP. XIII: DEL NOMBRE SUBSTANTIVO: } \\
\text { SUS OFICIOS Y COMPLEMENTOS. }\end{array}$ & $\begin{array}{l}\text { CAP.XXIII: ORACIONES SUBSTANTIVAS. } \\
\text { - de sujeto } \\
\text { - de C.D. } \\
\text { - de C.I. } \\
\text { - de C.C. } \\
\text { - de Complemento con Preposición }\end{array}$ \\
\hline $\begin{array}{l}\text { CAP. XIV: DEL ADJETIVO: SUS OFICIOS } \\
\text { Y COMPLEMENTOS. }\end{array}$ & $\begin{array}{l}\text { CAP. XXII: ORACIONES ADJETIVAS O DE } \\
\text { RELATIVO. } \\
\text { - oraciones especificativas } \\
\text { - oraciones explicativas }\end{array}$ \\
\hline $\begin{array}{l}\text { CAP. XV: LOS COMPLEMENTOS } \\
\text { DEL VERBO. }\end{array}$ & $\begin{array}{l}\text { CAP. XXIV: ORACIONES ADVERBIALES } \\
\text { - de lugar } \\
\text { - temporales } \\
\text { - de modo } \\
\text { - comparativas } \\
\text { - consecutivas (sólo algunos casos) } \\
\text { - condicionales } \\
\text { - concesivas }\end{array}$ \\
\hline
\end{tabular}


3. Tanto al hablar de los complementos (vid. GRAE-1917: 156) como al interpretar las oraciones compuestas por subordinación (vid. GRAE-1917: 291), la Academia defiende una teoría que no concuerda con lo dicho en las ediciones anteriores: las oraciones compuestas en las que hay un constituyente oracional (una oración subordinada) se analizan distinguiendo entre oración principal y oración subordinada, entendiendo que aquélla es la única que tiene sentido por sí misma. Si bien esta forma de concebir la subordinación podría darse por válida -no sin reservas- en muchos casos de oraciones subordinadas adjetivas y adverbiales, parece desacertada en lo que concierne a las llamadas oraciones subordinadas sustantivas, ya que no se puede decir con la Academia que, en la oración compuesta Juan desea que venga Antonio, «la única oración que tiene sentido por sí misma es Juan desea» (GRAE-1917: 291). Hasta la fecha, la Institución ha insistido, en todas sus Gramáticas, en que los verbos transitivos necesitan de un término que complete su significación, no por otra razón se justifica la secular división de las oraciones en primeras y segundas; sin embargo, en la GRAE-1917, podemos leer que «si decimos Fernando conquistó, tenemos una oración completa, con sus dos elementos esenciales y sin ningún complemento» (pág. 156). Aunque hoy no consideremos acertada esta interpretación, la Academia, al menos, ha modificado coherentemente su doctrina: si se dice que las oraciones subordinadas equivalen funcionalmente a complementos, es de obligación interpretar el fenómeno de la subordinación y el de la complementación de manera análoga.

4. Las relaciones de dependencia oracional no son otra cosa, en definitiva, que un caso "complejo" (estructuralmente hablando) de complementación. 
El concepto de subordinación que exponen los académicos de 1917 coincide, básicamente, con la teoría de Gisbert (1902) ${ }^{413}$ y Cejador (1905), como puede comprobarse en el cuadro de abajo. La propuesta teórica de estos autores de equiparar las oraciones subordinadas con constituyentes de la oración simple (lo que conduce a la clasificación tripartita de las oraciones subordinadas en sustantivas, adjetivas y adverbiales) coincide -por encima de evidentes diferencias en cuestiones de terminología y de estructuración de los contenidos- con la doctrina de Benot (académico de número -no lo olvidemos- durante casi dos décadas): no es difícil encontrar paralelos entre estas tres clases de oraciones subordinadas y los complexos de carácter substantivo, de carácter adjetivo y de carácter adverbial de los que habla el gaditano ya en las últimas décadas del siglo XIX.

${ }^{413}$ Es el mismo Gisbert quien revela, en la conclusión de su obra, la fuente de la que bebe: la $4 .^{a}$ edición de la Grammaire comparée de la langue française de Ayer. Cotejar su doctrina con la del gramático suizo excedía los límites de esta tesis. No obstante, se abre aquí una interesante y prometedora línea de investigación, cuyos resultados -con casi total seguridad- serían muy útiles para perfilar la historia de la gramática española de la primera mitad del siglo XX. 


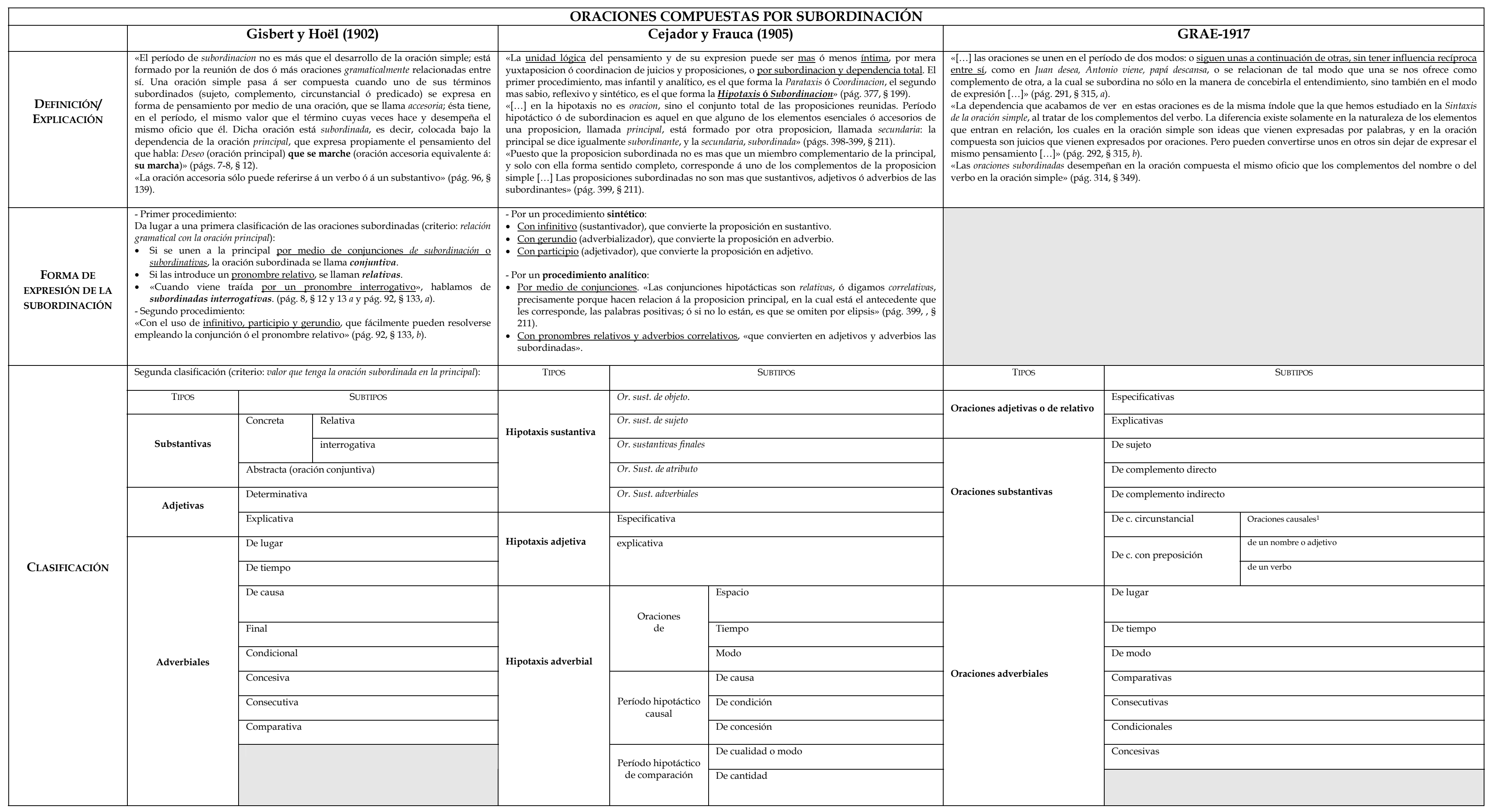

Cuadro 72: Oraciones compuestas por subordinación en Gisbert (1902), Cejador (1905) y la GRAE-1917

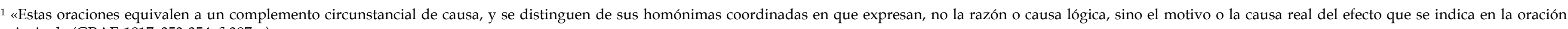
principal» (GRAE-1917: 353-354, § 397, a). 



\section{CONCLUSIONES PARCIALES}

Dentro de los textos gramaticales, la Sintaxis ocupa, sistemáticamente, el segundo bloque temático después del dedicado a la Analogía. Este orden "físico", de ubicación, coincide con el orden de importancia ("secundario") concedido a esta materia dentro de la Gramática (disciplina y libro): los asuntos de sintaxis, de obligado tratamiento en el Arte gramatical, parecen tener una atención garantizada en la medida en que constituyen una materia complementaria de las cuestiones de Analogía. Esto es así, básicamente, hasta la reforma de 1917. No son pocos los autores decimonónicos que aventajan a la Academia en atención cuantitativa y en profundidad descriptiva y casuística de los hechos sintácticos.

Los conceptos de orden y dependencia en que se sustenta la idea de sintaxis, así como la división interna del capítulo dedicado a su estudio (que, desde 1796, reserva sendos apartados a tratar de las reglas de concordancia, régimen y construcción; y, desde la GRAE-1854, dedica también una sección -nueva en el libro, pero no de contenido novedoso- a los tipos de oraciones) inserta el texto institucional dentro de la corriente más habitual en nuestra tradición. Tanto los conceptos que sirven de base como el tratamiento dado a las relaciones sintácticas revelan un fuerte sedimento lógico en la doctrina defendida por la docta Casa. Consecuencia clara y directa del logicismo es la distinción entre una sintaxis natural y una sintaxis figurada, otro punto de anclaje de la teoría académica con la práctica (y la concepción) común en los siglos anteriores

Si en los Diccionarios destaca una edición (la de 1884) como momento de inflexión o de cambio evidente en la doctrina sintáctica defendida por la Corporación, dentro de los textos gramaticales se pueden marcar dos hitos: los años de 1870 y 1917. 
En efecto, hemos podido ver que la gran reforma sintáctica no se lleva a cabo hasta la segunda década del siglo XX, pero algunos de los aspectos más importantes del cambio los vemos gestarse ya en la 12. ${ }^{\text {a }}$ edición de la Gramática (1870). La primera GRAE decimonónica (1854) presenta todavía un fuerte apego a la tradición y sólo muestra tímidamente y de forma esporádica ciertas notas de cambio (ocasional alusión a la función de complemento; uso aislado del término verbo subordinado; ciertos apuntes de interés en lo relativo a las relaciones de dependencia oracional: función de nominativo y de complemento desempeñada por una oración).

El giro doctrinal no cobra cuerpo hasta la GRAE-1870, la primera Gramática decimonónica que de forma clara avanza en la línea de lo funcional, al tiempo que supone un primer paso en el progesivo alejamiento de lo lineal como sustento de la doctrina sintáctica. Entre los textos que median entre 1870 y 1917, no encontramos cambios doctrinales de evidencia, si bien la GRAE1880 puede entenderse en ciertos puntos como un peldaño más que lleva hasta la gran reforma (en ella, por ejemplo, se pierde la alusión al lugar exacto que deben ocupar Palabra Regente y palabra regida, lo que ayuda, junto con otras declaraciones, a poder identificar de manera inequívoca las relaciones de régimen con las relaciones de dependencia, que gradualmente se han ido liberando de los corsés del orden secuencial; también en 1880 se pone más el acento en la naturaleza nexiva de la preposición). En otros aspectos, sin embargo, lo que se observa es un movimiento pendular que culmina en una toma de postura sin precedentes en la edición de 1917. Dos ediciones de rango E pueden mencionarse como libros que ocasionalmente introducen algún añadido o cambio: la GRAE-1874, como acabamos de decir, y la GRAE-1911.

La teoría sintáctica expuesta en la GRAE adolece de inconsistencia en lo que se refiere a las relaciones de dependencia, y no tanto porque las mismas 
estructuras sean tratadas en distintos capítulos, sino porque sobre ellas encontramos afirmaciones contradictorias, irreconciliables. En lo concerniente al papel de la preposición, podemos decir que la doctrina académica del régimen nos invita a una ceremonia de la confusión. Son muchas las preguntas que el lector de hoy se hace al leer las páginas dedicadas a las relaciones de regencia: muchas de ellas las formularon explícitamente gramáticos contemporáneos de los textos de nuestro corpus (recuérdense las cuestiones planteadas por Noboa a propósito las relaciones de dependencia en las que participa algún elemento nexivo).

El jalón de 1870, aunque es el primer y principal hito en la evolución de la teoría sintáctica de la RAE en el siglo XIX, va a la zaga de las doctrinas defendidas por gramáticos contemporáneos. El "retraso" es especialmente evidente en lo que atañe a las relaciones de dependencia, cuyo estudio en el texto institucional no supera los límites de la oración (y podemos decir que no contempla casos de dependencia intraoracional de carácter oracional -con una formulación teórica explícita- hasta la 12. ${ }^{a}$ edición, en la que tampoco se hace un estudio exhaustivo). Autores de mediados del XIX como Giró, Herrainz o Martínez Sevilla reconocen (y tratan con atención suficiente) los vínculos que se establecen entre oraciones. Tampoco ellos habían sido los primeros en observar que las relaciones de dependencia pueden darse entre elementos/miembros de una oración o entre esquemas oracionales.

Teniendo en cuenta lo dicho, no es desmesurado calificar la doctrina de 1917 como la mayor y mejor teoría sintáctica defendida por la Institución. No solo no tiene precedentes (el texto de la 30. ${ }^{a}$ ed. no es, en rigor, una reforma doctrinal, sino una quiebra, una auténtica ruptura con los preceptos defendidos hasta la fecha, amortajados con el libro de 1916), sino que tampoco será superada en las ediciones siguientes de la Gramática. Los hombres que redactaron el nuevo libro tuvieron en cuenta (a juzgar por los paralelismos 
IV. Sintaxis y Relaciones de Dependencia

textuales y por los datos extra-doctrinales que se han expuesto) la doctrina defendida por dos gramáticos españoles de principios del siglo $\mathrm{XX}$, uno de ellos, deudor de teorías foráneas, según sus propias declaraciones. 


\section{V}

CONCLUSIONES 



\section{CONCLUSIONES GENERALES}

I. Las ediciones de la GRAE que constituyen el corpus de esta investigación pueden someterse a la siguiente jerarquización:

- GRAE-1854 [J]

o GRAE-1858 [E]

- GRAE-1862, 1864, 1865, 1866 y 1867 [R]

- GRAE-1870 [J]

o GRAE-1874 [E]

- GRAE-1878 [R]

- GRAE-1880 [J]

- GRAE-1883, 1885, 1888, 1890 y 1895 [R]

- GRAE-1900, 1901 [R]

o GRAE-1904 [E]

- GRAE-1906, 1908, 1909 [R]

o GRAE-1911 [E]

- GRAE-1913, 1916 [R]

- GRAE-1917 [J]

o GRAE-1920 [E]

- GRAE-1924 [R]

No todos los jalones se revelan igual de importantes en cuanto al alcance doctrinal de la teoría expuesta en ellos. El primer jalón (1854), modelo de los años cincuenta y sesenta, desarrolla una teoría heredera de la GRAE-1796. Es el análisis textual el que pone de evidencia esta continuación, en términos generales, de la doctrina dieciochesca; las páginas introductorias, sin embargo, generan la expectativa de una Gramática acorde con las teorías defendidas en la primera mitad del siglo XIX por Salvá y Bello. El segundo 
jalón (1870) constituye el avance más firme desde el punto de vista doctrinal; en esta ocasión, se anuncian cambios y, efectivamente, se aprecian avances importantes: es en este libro donde cristalizan (algunos de) los supuestos teóricos de don Vicente y don Andrés. La GRAE-1870 supone un cambio de modelo en la concepción de la disciplina y de las relaciones sintácticas. Este modelo, en un sentido amplio, será el vigente hasta la reforma de 1917. Pero la toma de postura que, en algunos asuntos, supone la edición de 1870 solo se mantendrá en las dos ediciones que le siguen, de manera que debemos entender que hay, si no un cambio, sí una reforma del modelo. El último jalón decimonónico (1880) rompe (por omisión, por supresión) con la toma de postura explícita que la GRAE-1870 había supuesto respecto de varias cuestiones doctrinales. La anodina Introducción marca la pauta de lo que va a ser el tono general de este libro. En muchos aspectos, la 15. a edición supone un silencio por parte de los académicos respecto de algunas cuestiones (por ejemplo, en lo relativo a la concepción de la disciplina); en otros asuntos, sin embargo, sutiles cambios o añadidos contribuyen a consolidar los pasos iniciados en 1870 (lo hemos visto a propósito de algunos de los aspectos tratados en las relaciones de régimen). A veces incluso las supresiones de esta edición contribuyen indirectamente a una consolidación de la doctrina (al eliminar, con la supresión, ciertas incoherencias; o al invalidar, también en virtud de la no mención, algunos "pasos atrás" que parecían darse en ediciones posteriores a 1870).

Las ediciones de rango E previas a la gran reforma se presentan como pequeños peldaños en la lenta evolución doctrinal de la Academia. La GRAE1858 supone, sobre todo, un cambio en la concepción del libro de Gramática; la nueva disposición textual que presenta así lo pone de manifiesto. El cuerpo de doctrina modifica en aspectos muy puntuales (alguna definición, ejemplificación, etc.) la teoría de 1854, pero no supone un cambio (ni siquiera 
una reforma) de modelo ni en la concepción de la disciplina ni en la concepción de las relaciones sintácticas. Lo mismo podemos decir de la GRAE-1874: esta edición, en ciertos aspectos, supone un avance en la consolidación de la nueva teoría sintáctica, pero, en otras cuestiones, mantiene o recupera afirmaciones que parecen interpretarse como un "paso atrás".

En los primeros años del siglo $\mathrm{XX}$, las ediciones de rango $\mathrm{E}$ son anodinos precursores de la gran reforma de 1917. No podemos negarles el rango de "nueva edición" en sentido riguroso (sobre todo, a la GRAE-1911), pues en ellas se pueden apreciar cambios, pero, en la materia a la que hemos atendido, no suponen aportaciones importantes. El texto de 1920, por su parte, completa la reforma morfológica que se había iniciado con el jalón de 1917 (por la necesidad de «armonizar el contenido» con la nueva Sintaxis). La gran aportación de la GRAE-1920 es un nuevo capítulo sobre formación de palabras por derivación y composición. La novedad se anuncia en el último párrafo de la Advertencia preliminar. El resto del libro, el resto de la doctrina, mantiene el espíritu y la letra de 1917.

II. En lo tocante a cuestiones concretas de doctrina, los textos académicos sometidos a examen muestran varios aspectos que interesa sintetizar:

En cuanto a la concepción de la disciplina gramatical, la Corporación coincide con la tradición que le precede en entender que la Gramática es un arte, y como tal, tendrá un fin utilitario (con una doble faceta: de enseñanza y de prescripción). Desde la GRAE-1858, de forma paulatina, y como consecuencia de la publicación de textos independientes de carácter eminentemente pedagógico (Epítomes y Compendios), los libros de Gramática empiezan a desprenderse de carga didáctica. De forma paralela, en las GRAE se deja ver, a partir de las últimas décadas del siglo XIX, una mayor conciencia 
normativa por parte de la Institución. Es en el texto de 1870 (y, por extensión, en los de 1874 y 1878) donde encontramos las manifestaciones explícitamente más coercitivas. Tras los años setenta, las declaraciones se suavizan, pero seguimos encontrando indicios de una conciencia prescriptiva más acentuada que en las primeras ediciones del siglo XIX (1854, 1858 y libros de los años sesenta): por ejemplo, la inclusión de un capítulo dedicado exclusivamente a censurar usos o la propia definición de la disciplina (Arte de hablar y escribir correctamente), en la que los Diccionarios de la primera mitad del siglo XIX habían introducido las primeras notas de normativismo en sentido prescriptivo.

Siguiendo también la tradición anterior y la concepción generalizada en la segunda mitad del siglo XIX y primer cuarto del XX, la Academia considera que el estudio gramatical debe atender a la lengua hablada y a la escrita, a la que se concede privilegio especial (sobre todo a la lengua escrita literaria), y esto a pesar de que en las primeras ediciones de la GRAE (hasta la de 1854 inclusive-) en la definición solo aparece el término hablar. Hemos comentado el caso de otros autores anteriores y coetáneos que también centran la definición en la lengua hablada, aunque no dudan en considerar en su obra la lengua escrita; recordemos ahora el caso de Vicente Salvá, que, pese a defender una gramática sincrónica actual tanto de la lengua hablada como de la lengua escrita, titula su libro Gramática de la lengua castellana según ahora se habla.

La doctrina gramatical de don Vicente parece tener eco en la GRAE1870, primera Gramática en la que la Institución participa de una práctica habitual en la época que ha centrado nuestro interés: la distinción explícita en el libro de Gramática entre las dos formas básicas de estudio gramatical (la propia de una Gramática General y la que debe caracterizar la Gramática 
Particular), y toma partido -por primera vez de forma explícita- por el segundo método de trabajo. Como sucede con otros aspectos, las declaraciones expresas desaparecen una vez pasada la barrera de los años setenta, lo cual no supone necesariamente un verdadero abandono (la Institución se sigue decantando por la Gramática Particular, aunque haya decidido no hacer mención de ello).

En la GRAE-1870 confluyen tres tomas de postura esenciales en la concepción de la disciplina:

- una toma de postura en cuanto al fin esencial de la Gramática (la prescripción de usos);

- una toma de postura explícita en cuanto a la metodología (una Gramática Particular -decantación metodológica que hasta la fecha solo había sido implícita y que en autores coetáneos es fácil encontrar de forma expresa, casi siempre en las primeras páginas de los textos);

- y una toma de postura en cuanto a los contenidos que deben integrar el texto de la Gramática (dejando atrás vacilaciones anteriores).

Si bien las declaraciones de misión normativo-coercitiva y de apuesta metodológica acaban difuminándose en las ediciones que siguen, las cuatro partes de la Gramática (disciplina y libro) establecidas en 1870 no se modificarán en las ediciones posteriores que integran el corpus. El libro de Gramática atiende, así, desde esta $12^{\mathrm{a}}$ edición de la GRAE, a la Analogía, Sintaxis, Prosodia y Ortografía, pero el protagonismo lo compartirán las dos 
primeras partes (hasta 1916 -inclusive-, el mayor peso recae en el apartado de la Analogía; a partir de 1917, la carga se deja sentir más en la Sintaxis).

Por último, las GRAE decimonónicas ya se desprenden de ciertos tópicos que la propia Academia había alimentado en el siglo XVIII (por ejemplo, la idea de que el artificio gramatical es un modo idóneo de fijar el esplendor de una lengua; la necesidad de justificar la publicación de una Gramática de la lengua materna; o la idea de que la Gramática es "arte propedéutica"). Estos tópicos están directamente vinculados con la situación político-social y, por ello, están condenados a desaparecer cuando cambia la situación.

Las partes en que se divide la disciplina gramatical es asunto controvertido: la falta de conciliación entre los puntos de vista mantenidos por varios académicos en los discursos preparatorios de la primera Gramática tiene su paralelismo en los libros del corpus. Analogía y Sintaxis son las partes indiscutibles en los libros de Gramática. En la GRAE, Ortografía y Prosodia no son partes constituyentes del libro hasta la edición de 1870 (la primera en la que, en este asunto, coinciden teoría y práctica). Todo parece apuntar a que la única edición que defiende una concepción teórica bipartita de la disciplina es la GRAE-1771; la GRAE-1854 parece tomar la letra pero no el espíritu de la primera edición. Es posible que, a partir de la GRAE-1796, la decisión de no incluir en el libro los asuntos ortográficos y prosódicos se deba a dos razones: el intento de salvaguardar el éxito de la Ortografía, y la falta de una preceptiva prosódica elaborada por la Institución. Por lo que respecta a los Diccionarios, Sintaxis y Prosodia son las subdisciplinas que se vinculan a la Gramática en todas las ediciones. 
En lo que atañe a la doctrina sintáctica y el tratamiento de las

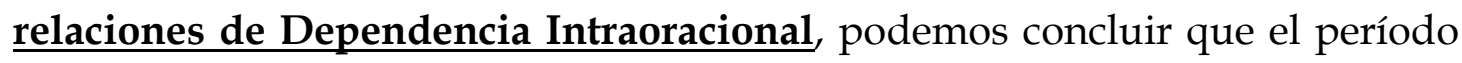
acotado como foco de atención en este trabajo (segunda mitad del siglo XIX y primer cuarto del XX) se presenta como período de importancia capital en el "avance" de los textos académicos en materia sintáctica.

De forma general, podemos delimitar tres momentos en las Gramáticas:

- Un primer momento (GRAE de 1854 a 1867) de adhesión a lo establecido.

- Un segundo momento (iniciado con la GRAE-1870) de brote de cambios, que irán madurando a lo largo de las ediciones siguientes (sobre todo, las de 1874 y 1880 -y, en algún asunto aislado, también 1883 y 1911-, que se presentan como introductoras de ciertas modificaciones en aspectos distintos).

- Un tercer momento -definitivo- (GRAE-1917) de "ruptura" (los planteamientos ya resultan familiares al lector de hoy).

Por su parte, los Diccionarios estrictamente coetáneos serán receptores, en términos generales, de los cambios que se dan en 1870: las diferencias de planteamiento de los DRAE de 1852-1869 y el DRAE-1884 en materia sintáctica hacen pensar en un influjo de las Gramáticas en los Diccionarios publicados después de los años setenta. Es curioso comprobar que el cambio de 1870 tiene más eco en los Diccionarios que el giro de 1917 (por ejemplo, el último DRAE del corpus -1925- sigue sin recoger una acepción gramatical de coordinación y subordinación, a pesar de que estos dos tipos de relaciones sintácticas ya se estudian de forma diferenciada desde la "gran reforma"; tampoco tienen eco -por poner otro ejemplo- las novedades introducidas en la concepción y tratamiento de la oración gramatical. 
De los puntos expuestos al comienzo del capítulo 5, a los que se pretendía dar respuesta con el examen llevado a cabo en el bloque IV, se puede concluir que:

$\left.1^{\circ}\right)$ Efectivamente -tal como se suponía-, la esencia de los planteamientos de las obras lexicográficas y gramaticales es coincidente (a pesar de que no faltan puntos de separación o de "no coincidencia"):

- Es coincidente la concepción general de la Sintaxis, muy próxima al concepto de construcción, y basada en las nociones de orden y dependencia, condicionadas, a su vez, por criterios lógicos. El logicismo en materia sintáctica se manifiesta de forma especialmente evidente en la sistemática distinción entre Sintaxis natural y Sintaxis figurada, distinción de orden primario en las GRAE hasta la reforma de 1917 y que tampoco se pierde con esta edición (aunque pase a un segundo plano). En esta división de la Sintaxis, los Diccionarios van a la zaga de las Gramáticas, puesto que en los textos lexicográficos no se hace referencia a la misma hasta el DRAE-1884, mientras que todas las ediciones de la GRAE, desde 1771, apuntan tal deslinde. Otro aspecto básico que los Diccionarios tardan en recoger (y que también muestran todas las Gramáticas) es la consideración de la Concordancia y el Régimen como dos tipos de reglas que fundamentan el estudio de la Sintaxis.

En cuanto a la unidad de análisis sintáctico, los DRAE no se suman a la propuesta de 1917: desde la 30. a edición de la GRAE, la atención se pone igualmente en la palabra y en la oración como unidad analizable (no es solo unidad de llegada del estudio sintáctico, también se considera unidad de partida: la Sintaxis estudia la unión de palabras 
-que forma la oración- y la unión de oraciones -que forma otra unidad superior-), sin embargo, en el DRAE-1925 la mirada se sigue poniendo en la palabra (la oración es solo el resultado final).

- También coinciden Gramática y Diccionario en el progresivo abandono de lo lineal y el paralelo acercamiento (también progresivo) a lo funcional en la doctrina sintáctica defendida. Se está matizando en estas conclusiones que el cambio esencial se produce en la GRAE-1870 y se recoge en el DRAE-1884 (Diccionario que también decide recoger aspectos defendidos por la Gramática desde el siglo XVIII, como se acaba de decir líneas más arriba), sin embargo, no podemos olvidar que, en determinados aspectos, el DRAE-1869 se presenta como “diccionario puente" entre el DRAE-1852 y el de 1884.

$2^{\circ}$ ) No cabe duda de que, a lo largo del período delimitado, hay evolución doctrinal en los textos académicos, si bien en los DRAE la evolución en materia sintáctica parece culminar, en términos generales, a finales del XIX (1884), mientras que las GRAE experimentarán el cambio de mayor entidad a principios del XX (1917). De modo que ciertos cambios de interés que se producen en las últimas Gramáticas del corpus no se recogerán en el DRAE1925 (tal como ha quedado apuntado arriba), el único del corpus publicado tras la reforma de 1917.

$\left.3^{\circ}\right)$ No podemos afirmar taxativamente que los cambios estén condicionados de forma sistemática por el tipo de obra, pues, aunque es cierto el hecho de que el primer cambio doctrinal básico se da en una Gramática (algo lógico, teniendo en cuenta la naturaleza de los cambios y de los dos tipos de texto de que hablamos) y de ella pasa a las GRAE y los DRAE posteriores, también es 
verdad que los Diccionarios, en determinados aspectos, anuncian actitudes que cuajarán con el paso del tiempo.

Atendiendo, por último, al tratamiento de las Relaciones de Dependencia, cabe destacar que, invariablemente, hasta la reforma de 1917, se atenderá a ellas en el estudio de las llamadas Reglas de Régimen. El concepto de regencia está presidido por un marcado logicismo hasta la GRAE-1870, en la que ya se empieza a aceptar que ciertas palabras que no significan 'sustancia' ni 'acción', sino 'circunstancia' o 'accidente', pueden ser palabra Reg., esto es, primer elemento en una relación de regencia. También se irá abandonando progresivamente la idea de que el orden es factor decisivo en las relaciones de dependencia (lo colocacional irá cediendo el terreno a lo funcional). Desde la primera GRAE del XIX (1854), encontramos apuntada muy ligeramente la idea de complementación, que cobrará mayor entidad en la segunda edición jalón del corpus (1870) coincidiendo, básicamente, con el concepto de regencia, si bien en un primer momento sólo se usa en los casos en que la palabra Reg. es un verbo. Con la reforma de 1917, el concepto de complementación destierra por completo al de régimen.

Es en el momento en que se puede considerar consolidada la doctrina de la complementación cuando la RAE acepta explícitamente los casos de dependencia oracional (= subordinación). Al defender que la oración compuesta por subordinación equivale estructuralmente a una oración simple, se hace obligado asimilar el funcionamiento de los esquemas / (S) + P/ dependientes de otro esquema / $(S)+P /$ como constituyentes (complejos, desde el punto de vista de su estructura) que funcionan como complemento (dependa o no de un núcleo verbal). 
En definitiva, hasta que no se produce un paso importante (que no decisivo) en la línea de lo "funcional" (1870), no se introduce de forma decidida en la doctrina académica el concepto de complemento (libre, en principio, del lastre lógico-lineal que arrastra la idea de regencia). El abandono definitivo del término régimen coincide con el destierro de la concepción colocacional-nocional como pilar de sustento de la teoría sintáctica y con el establecimiento de una Sintaxis apoyada (aunque no de forma exclusiva) en el oficio de las palabras. La idea de complemento entraña, a su vez, la de subordinación, término que la Academia reserva para un tipo especial de complementación: la llevada a cabo por una oración (un esquema $/(\mathrm{S})+\mathrm{P} /$ ), esto es, los casos de dependencia oracional. Los Diccionarios se harán eco de la idea sintáctica de complemento, no así de la idea de subordinación.

Tras el análisis llevado a cabo, podemos concluir que, en términos generales, el texto decimonónico que se revela como más innovador desde el punto de vista de la doctrina sintáctica es la GRAE-1870. El giro se dejará sentir en la lexicografía académica, como demuestra el primer Diccionario que ve la luz después del año apuntado (el DRAE-1884): sólo tras haberse publicado la edición que será preludio de la "gran reforma" de 1917 (el jalón de 1870), la Academia puede exponer en su Diccionario, por ejemplo, un concepto sintáctico de complemento, o puede defender que la preposición no es artífice de la regencia (concepción propia de una sintaxis lineal), sino índice de relación (concepción más cercana a una sintaxis funcional), con la ventaja sobre las Gramáticas de no incurrir en contradicciones internas.

Con la reforma de 1917, la Institución da su adiós a una doctrina secular que se había mantenido bien por respeto a la tradición, bien por inercia, o bien porque perpetuar la rutinaria Gramática podía permitirle a la Academia dedicar más tiempo a otros proyectos. Esta reforma supone, en 
términos generales, una deslatinización del marco: se crea otro marco tradicional pero no latinizante. Es en este nuevo modelo en el que la sintaxis recibe más atención que las restantes partes de la Gramática; es este nuevo modelo el que permite desarrollar una sintaxis oracional.

En lo concerniente al último aspecto sobre el que esta tesis pretendía dar algo de luz, el de la misteriosa autoría del libro de 1917, debemos advertir que las conclusiones a las que hemos llegado al final del capítulo 6 deben ir acompañadas de la cautela. Pese a que ahora sabemos qué nombres concretos estuvieron vinculados al proyecto de elaboración de la novedosa teoría sintáctica ("revolucionaria" en la trayectoria doctrinal de la Academia), hay algunas cuestiones que todavía no quedan del todo claras. Solo quedarán resueltas todas las dudas en el momento en que se lleve a cabo una investigación profunda sobre las Comisiones encargadas de redactar (o, simplemente, preparar para la publicación) cada una de las ediciones oficiales. 
VI

ANEXos 

ANEXo 1

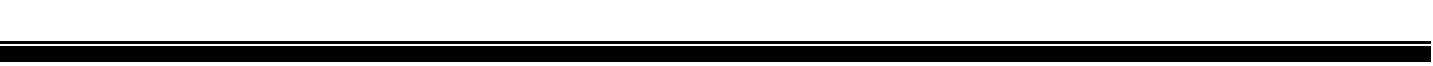





\begin{tabular}{|c|c|c|c|}
\hline \multicolumn{4}{|c|}{ Autor: Conde de la Viñaza } \\
\hline \multicolumn{4}{|c|}{ Título: Biblioteca histórica de la Filología castellana } \\
\hline \multicolumn{4}{|c|}{ Fecha: 1893} \\
\hline \multicolumn{4}{|c|}{ Ediciones de la Gramática recogidas } \\
\hline Año & $\begin{array}{l}\text { N.o } \\
\text { ed. } \\
\text { corres- } \\
\text { pond. }\end{array}$ & Registrada como & Comentarios del compilador \\
\hline 1771 & {$\left[1 .{ }^{\mathrm{a}}\right]$} & $\begin{array}{l}\text { Gramática } \mid \text { de la } \mid \text { Lengua Castellana, } \mid \text { compuesta } \mid \text { por } \\
\text { la Real Academia| Española. (Esc. de la Acad.) } \\
\text { Madrid. | Por D. Joachin de Ibarra, Impresor } \mid \text { de } \\
\text { Camara de S.M. | M.DCC.LXXI. }\end{array}$ & 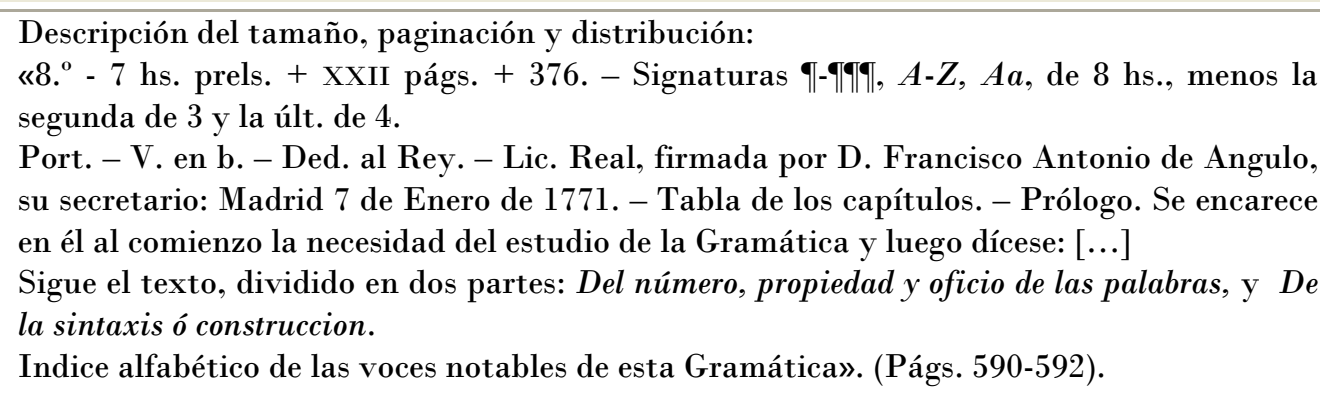 \\
\hline 1772 & $2 .^{a}$ & $\begin{array}{l}\text { Segunda edición: por el mismo impresor que hizo la } \\
\text { primera; año de } 1772 \text {. }\end{array}$ & 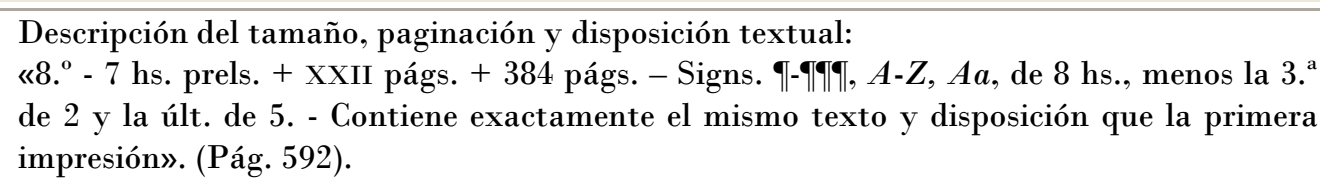 \\
\hline 1781 & $3 .^{a}$ & $\begin{array}{l}\text { Tercera edición: por el mismo impresor que la primera; } \\
\text { año de } 1781 \text {. }\end{array}$ & $\begin{array}{l}\text { Información sobre el número de páginas y el contenido: } \\
\text { «Consta de igual número de páginas que la anterior, y contiene la misma materia y } \\
\text { disposición». (Pág. 592). }\end{array}$ \\
\hline 1796 & $4 .^{\mathrm{a}}$ & $\begin{array}{l}\text { Cuarta edición: Gramática } \mid \text { de la lengua } \mid \text { castellana } \mid \\
\text { compuesta } \mid \text { por } \mid \text { la Real Academia } \mid \text { Española. } \mid \text { Quarta } \\
\text { edicion } \mid \text { corregida y aumentada. } \mid \text { (Esc. de la Acad.) } \mid \\
\text { Con superior permiso } \mid \text { por la viuda de D. Joaquin } \\
\text { Ibarra,| |impresora de la Real Academia. | Madrid } \\
\text { M.DCC.XCVI. }\end{array}$ & $\begin{array}{l}\text { Descripción del tamaño, paginación y distribución: } \\
\text { «8. }-3 \text { hs. prels. + XXV págs. }+479 .- \text { Signs. }{ }^{*}{ }^{* *}, A-Z, A a-G g, \text { de } 8 \mathrm{hs} . \\
\text { Port. - V. en b. - Ded. al Rey. - Tabla de los capítulos. - Prólogo. (Es el mismo de las } \\
\text { ediciones anteriores, pero con algunos párrafos intercalados, en los cuales se explican las } \\
\text { adiciones hechas en esta edición. He aquí los referidos párrafos:) [...] } \\
\text { Texto, dividido en dos partes: De la Analogía y De la Sintaxis. }\end{array}$ \\
\hline
\end{tabular}




\begin{tabular}{|c|c|c|c|}
\hline & & & Indice alfabético de las cosas notables de esta Gramática». (Págs. 592-594). \\
\hline ¡1858! & $5 .^{a}$ & Quinta edición: Madrid. En la Imprenta Nacional, 1858. & $\begin{array}{l}\text { Breve información sobre tamaño, páginas y contenidos del texto: } \\
\text { «4. } .^{\circ} \text { - VII-25l págs. - Reprodúcese en general el texto de la anterior impresión de 1854; } \\
\text { pero contiene algunas enmiendas que ya adoptó la Academia en el Compendio y en el } \\
\text { Epítome de la Gramática Castellana, reimpresos en el mismo año de 1858». (Pág. 594) }\end{array}$ \\
\hline 1862 & $6 .^{\mathrm{a}}$ & Sexta edición: Madrid. Imprenta Nacional, 1862. & $\begin{array}{l}\text { Escueta información sobre tamaño, páginas y contenidos del texto: } \\
\text { «4. } .^{\circ}-254 \text { págs. - Igual texto que la anterior pero sin las advertencias preliminares» (Pág. } \\
594) .\end{array}$ \\
\hline 1864 & 7. & Séptima edición: Madrid. Imprenta Nacional, 1864. & «Igual número de págs. y materia que la precedente». (Pág. 594). \\
\hline 1865 & $8 .^{a}$ & Octava edición: Madrid. Imprenta Nacional, 1865. & Sin comentarios. \\
\hline ¡1854! & ¡9. ${ }^{\text {a }}$ & $\begin{array}{l}\text { Novena edición: Gramática } \mid \text { de la lengua } \\
\text { castellana, | por|la Real Academia Española. | Nueva } \\
\text { edición. (Esc. de la acad.) Madrid. | En la Imprenta } \\
\text { Nacional. | 1854. }\end{array}$ & $\begin{array}{l}\text { Información sobre el tamaño, número de páginas, distribución y contenidos: } \\
\text { «4. } .^{\circ} \text { - x-226 págs. } \\
\text { Port. - Prólogo [...] } \\
\text { Texto. - Índice. - Erratas. } \\
\text { Igual número de páginas y materia que en las dos precedentes impresiones». (Pags. 594- } \\
\text { 599). }\end{array}$ \\
\hline 1866 & $10 .^{a}$ & Décima edicion: Madrid. Imprenta Nacional. 1866. & «Igual número de páginas y materia que en las tres precedentes». (Pág. 599). \\
\hline 1867 & $11 .^{a}$ & $\begin{array}{l}\text { Undécima edicion: Madrid. Imprenta de Miguel Ginesta, } \\
\text { calle de Isabel la Católica, núm. 4, } 1867 .\end{array}$ & «Igual número de páginas y materia que en las cuatro anteriores». (pág. 599). \\
\hline 1870 & $12 .^{a}$ & $\begin{array}{l}\text { Duodécima edicion: Nueva edicion, corregida y } \\
\text { aumentada. (Esc. de la Acad.) Madrid, imprenta y } \\
\text { estereotipia de M. Rivadeneyra, calle del Duque de } \\
\text { Osuna, núm. 3. } 1870 \text {. }\end{array}$ & $\begin{array}{l}\text { «4. } .^{\circ} \mathrm{xv}+39[1] \text { págs. + una de erratas. } \\
\text { Port. -Ind. de materias. - Advertencia [...] - Nociones preliminares. - Texto. - Indice } \\
\text { alfabético. - Erratas.» (Págs. 599-603). }\end{array}$ \\
\hline 1874 & $13 .^{a}$ & $\begin{array}{l}\text { Décimatercia edición: Nueva edicion, corregida y } \\
\text { aumentada. Madrid, imprenta y fundicion de Manuel } \\
\text { Tello, Isabel la Católica, 23, } 1874 \text {. }\end{array}$ & $\begin{array}{l}\text { Escuetísima información sobre el tamaño y el número de páginas: } \\
\text { «4. } .^{\circ}-423 \text { págs. + } 1 \text { de errat.» (Pág. 603). }\end{array}$ \\
\hline
\end{tabular}




\begin{tabular}{|c|c|c|c|}
\hline 1878 & $14 .^{\mathrm{a}}$ & $\begin{array}{l}\text { Décimacuarta edición: Madrid, Gregorio Hernando, } \\
\text { impresor y librero de la Real Academia Española. } 1878 .\end{array}$ & $\begin{array}{l}\text { Información exclusivamente sobre tipo de volumen y páginas: } \\
\text { «4. - } 423 \text { págs.» (Pág. 603). }\end{array}$ \\
\hline 1880 & $15 .^{\mathrm{a}}$ & $\begin{array}{l}\text { Décimaquinta edición: Madrid, Gregorio Hernando, } \\
\text { impresor y librero de la Real Academia Española, } 1880 .\end{array}$ & $\begin{array}{l}\text { Escueta información sobre tamaño del volumen y número de páginas: } \\
\text { «4. - } 418 \text { págs. }+1 \text { errat.» (Pág. 603). }\end{array}$ \\
\hline 1888 & $16 .^{\mathrm{a}}$ & $\begin{array}{l}\text { Décimasexta edición: Madrid, viuda de Hernando y } \\
\text { Compañía, impresores y libreros de la Real Academia } \\
\text { Española, 1888. }\end{array}$ & $\begin{array}{l}\text { Tipo de volumen y número de páginas, seguido de a información contenida en las actas } \\
\text { académicas de } 4 \text { de diciembre de } 1888 \text { sobre la publicación de la GRAE-1880: } \\
\text { «4. - } 418 \text { págs. } \\
\text { Acerca de las innovaciones introducidas en estas dos últimas impresiones de la Gramática } \\
\text { de la Academia Española (cuyo texto, en ambas, es idéntico), véase lo que dice el insigne } \\
\text { poeta y Secretario perpetuo de la misma Corporación, D. Manuel Tamayo y Baus, en el } \\
\text { Resumen de las actas de la Academia leído en Junta pública de } 4 \text { de diciembre de } 1881 \\
\text { (Madrid, imprenta de Manuel Tello, 1881), páginas } 23-26:[\ldots] » \text { (Pags. 603-607). }\end{array}$ \\
\hline
\end{tabular}




\begin{tabular}{|c|c|c|c|}
\hline \multicolumn{4}{|c|}{ Autor: Emilio Cotarelo y Mori } \\
\hline \multicolumn{4}{|c|}{ Título: Discurso acerca de las obras publicadas por la Real Academia Española } \\
\hline \multicolumn{4}{|c|}{ Fecha: 1928} \\
\hline \multicolumn{4}{|c|}{ Ediciones de la Gramática recogidas } \\
\hline Año & $\begin{array}{l}\text { N. } \\
\text { ed. } \\
\text { corres- } \\
\text { pond. }\end{array}$ & Registrada como & Comentarios del compilador \\
\hline 1771 & $1 .{ }^{a}$ & $\begin{array}{l}\text { Gramática } \mid \text { de la } \mid \text { Lengua Castellana, } \mid \text { compuesta } \mid \text { por la Real } \\
\text { Academia } \mid \text { Española. (Emblema de la Acad.) Madrid. } \mid \text { Por D. } \\
\text { Joachin de Ibarra, Impresor | de Cámara de S.M. } \mid \text { M.DCC.LXXI }\end{array}$ & $\begin{array}{l}\text { Información sobre tipo de volumen, número y distribución de páginas: } \\
\text { «8. }{ }^{\circ} ; \text { hojas prels. + XXII págs. }+376 \text { de texto. } 1 .^{a} \text { edic. Dedicatoria al } \\
\text { Rey firmada por D. Francisco Antonio de Angulo, secretario de la } \\
\text { Academia: Madrid, } 7 \text { de enero de } 1771 » . \text { (Pág. } 39) \text {. }\end{array}$ \\
\hline 1772 & $2 . .^{a}$ & $\begin{array}{l}\text { Gramática } \mid \text { de la } \mid \text { Lengua Castellana, } \mid \text { compuesta } \mid \text { por la Real } \\
\text { Academia | Española.| Segunda impresion. } \mid \text { (Emblema de la } \\
\text { Academia.) Madrid.| Por D. Joachin Ibarra, Impresor } \mid \text { de Cámara } \\
\text { de S.M.| M.DCC.LXXII. }\end{array}$ & $\begin{array}{l}\text { Información sobre características físicas del libro y sobre el éxito } \\
\text { editorial que alcanzó la primera edición: } \\
\text { « } 8 .^{\circ} ; 7 \text { hojas prels. + XXII págs. de pról. }+384 \text { págs. de texto. El } \\
\text { público se apresuró a adquirir la nueva Gramática y hubo que } \\
\text { reimprimirla al año siguiente sin poder modificarla ni aun corregirla } \\
\text { con algún esmero». (Pág. } 39 \text { ). }\end{array}$ \\
\hline 1781 & $3 .^{a}$ & $\begin{array}{l}\text { Gramática } \mid \text { de la } \mid \text { Lengua castellana }|\ldots| \text { Tercera impresion. } \mid \\
(\text { Emblema }) \mid \text { Con superior permiso: } \mid \text { en Madrid | Por D. Joaquin de } \\
\text { Ibarra, Impresor de Cámara } \mid \text { de S.M. y de la Real Academia } \mid \\
\text { MDCCLXXXI. }\end{array}$ & $\begin{array}{l}\text { Información sobre volumen y número de páginas: } \\
\text { «8. }{ }^{\circ} ; \text { hojas prels.; XXI págs. de prólogo y } 384 \text { págs. de texto». (Pág. } \\
39 \text { ). }\end{array}$ \\
\hline 1796 & $4 .^{a}$ & $\begin{array}{l}\text { Gramática } \mid \text { de la Lengua } \mid \text { Castellana } \mid \text { compuesta } \mid \text { por } \mid \text { la Real } \\
\text { Academia } \mid \text { Española. | Quarta edicion | Corregida y aumentada. } \\
\text { (Emblema de la Academia) Con superior permiso | Por la viuda de } \\
\text { Don Joaquin Ibarra, | Impresora de la Real Academia. | Madrid M } \\
\text { DCC XCVI. }\end{array}$ & $\begin{array}{l}\text { Información sobre características físicas de la edición y noticia de } \\
\text { novedades y reimpresión posterior del texto: } \\
\text { «8. }{ }^{\circ} \text {; hojas prels. }+\mathrm{XXV} \text { págs. de prólogo, }+479 \text { págs. de texto. } \\
\text { En esta edición se hicieron varias adiciones de interés, que se } \\
\text { especifican en el prólogo. Se reimprimió en "Madrid, M.DCCCLII| } \\
\text { Imprenta de la Compañía de Impresores | y Libreros del Reino" a } \\
\text { plana y renglón de la anterior. Al principio va una advertencia en la que } \\
\text { la Academia dice que en este año de } 1852 \text { debía haberse publicado una }\end{array}$ \\
\hline
\end{tabular}




\begin{tabular}{|c|c|c|c|}
\hline & & & $\begin{array}{l}\text { nueva edición de la Gramática, pero que la larga y grave enfermedad } \\
\text { de su Secretario (Gallego) lo había impedido por ser él el especialmente } \\
\text { encargado de esta obra. Pero a fin de satisfacer en tanto la necesidad } \\
\text { que el público tenía de esta obra se repetía exactamente la edición } \\
\text { anterior de 1796». (Pág. } 39 \text { ). }\end{array}$ \\
\hline 1854 & {$\left[5 .^{\mathrm{a}}\right]$} & $\begin{array}{l}\text { Gramática } \mid \text { de la Lengua Castellana, } \mid \text { por } \mid \text { la Real Academia } \\
\text { Española. | Nueva edicion. (Emblema de la Academia.) Madrid.| } \\
\text { En la Imprenta Nacional. | } 1854 .\end{array}$ & $\begin{array}{l}\text { Información sobre el volumen y número de páginas, seguida de una } \\
\text { observación sobre la práctica académica de numerar las ediciones y } \\
\text { una advertencia sobre el error contenido en el catálogo de la Viñaza y } \\
\text { sobre la novedad que supone esta edición de la Gramática: } \\
\text { «4. } .^{\circ} \text { x-226 págs. Desde esta impresión dejaron de numerarse las } \\
\text { ediciones: la que se ha puesto en la Bibliogr. del Conde de la Viñaza } \\
\text { está equivocada, por haberse colocado mal esta impresión de } 1854 \text {. } \\
\text { Esta edición es muy distinta de la de } 1796 \text {, pues se han tenido } \\
\text { presentes, entre otras, las Gramáticas de D. Vicente Salvá y D. Andrés } \\
\text { Bello». (Págs. } 39-40) \text {. }\end{array}$ \\
\hline 1858 & {$\left[6 .^{\mathrm{a}}\right]$} & $\begin{array}{l}\text { Gramática } \mid \text { de la lengua castellana, } \mid \text { por la } \mid \text { Real Academia } \\
\text { Española. } \mid \text { (Emblema de la Acad.) } \mid \text { Madrid. } \mid \text { En la Imprenta } \\
\text { Nacional. 1858. }\end{array}$ & $\begin{array}{l}\text { Escueta información relativa al tamaño del volumen y al número de } \\
\text { páginas: } \\
\text { «4. }{ }^{\circ} \text {; VII-251 págs». (Pág. 40). }\end{array}$ \\
\hline 1862 & {$\left[7 .^{\mathrm{a}}\right]$} & $\begin{array}{l}\text { Gramática } \\
\text { Nacional. } \mid \ldots(\text { como la anterior }) \\
\text { Nat. }\end{array}$ & «4. ${ }^{\circ} ; 254$ págs. Se ha suprimido el prólogo». (Pág. 40). \\
\hline 1864 & {$\left[8 .^{\mathrm{a}}\right]$} & $\begin{array}{l}\text { Gramática }|\ldots| \text { (como la anterior)... Madrid. | Imprenta Nacional. } \\
\text { 1864. }\end{array}$ & «4..$^{\circ} ; 254$ págs». (Pág. 40). \\
\hline 1865 & {$\left[9 .{ }^{\mathrm{a}}\right]$} & 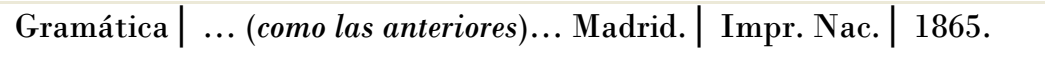 & «4. ${ }^{\circ} ; 255$ págs». (Pág. 40). \\
\hline 1866 & {$\left[10 .^{a}\right]$} & $\begin{array}{l}\text { Gramática } \mid \ldots \text { (como las anteriores)... Madrid | Imprenta Nacional. } \\
1866 .\end{array}$ & «4. $; 255$ págs». (Pág. 40). \\
\hline 1867 & {$\left[11 .^{\mathrm{a}}\right]$} & $\begin{array}{l}\text { Gramática } \mid \text { de la } \mid \text { Lengua Castellana, } \mid \text { por la } \mid \text { Real Academia } \\
\text { Española. | (Emblema) Madrid | Imprenta de Miguel Ginesta } \mid \text { calle } \\
\text { de Isabel la Católica, núm. 4. } \mid 1867 .\end{array}$ & $\begin{array}{l}\text { «4. }{ }^{\circ} ; 254 \text { págs. y una hoja de anuncios de las demás obras de la } \\
\text { Academia». (Pág. 40). }\end{array}$ \\
\hline
\end{tabular}




\begin{tabular}{|c|c|c|c|}
\hline 1870 & {$\left[12 . .^{a}\right]$} & $\begin{array}{l}\text { Gramática } \mid \text { de la } \mid \text { Lengua Castellana, | por la Real Academia } \\
\text { Española. | Nueva edicion, corregida y aumentada.| (Emblema) } \\
\text { Madrid, | Imprenta y estereotipia de M. Rivadeneyra, | calle del } \\
\text { Duque de Osuna, número 3.| } 1870 .\end{array}$ & $\begin{array}{l}\text { «4. }{ }^{\circ} \text { xv-391 págs., y } 2 \text { hojas para erratas y anuncios. Tiene bastantes } \\
\text { innovaciones, como la de separar el adjetivo del substantivo y } \\
\text { principalmente incluír ahora las dos partes de la Gramática, Prosodia y } \\
\text { Ortografía, que faltaban en las anteriores ediciones». (Pág. 40). }\end{array}$ \\
\hline 1874 & {$\left[13 . .^{a}\right]$} & $\begin{array}{l}\text { Gramática } \mid \ldots \text { (como la anterior) Madrid,| Imprenta y fundicion de } \\
\text { Manuel Tello, | Isabel la Católica, } 23, \mid 1874 .\end{array}$ & «4. ; 423 págs. y 2 hojas más para erratas y anuncios». (Pág. 40). \\
\hline 1878 & {$\left[14 . .^{\mathrm{a}}\right]$} & $\begin{array}{l}\text { Gramática } \mid \ldots \text { (como la anterior) Madrid } \mid \text { Gregorio Hernando, } \\
\text { Impresor y librero| de la Real Academia Española.| } 1878 .\end{array}$ & «4. ${ }^{\circ} ; 423$ págs. y 2 hojas más de erratas y anuncios». (Pág. 40). \\
\hline 1880 & {$\left[15 .^{\mathrm{a}}\right]$} & $\begin{array}{l}\text { Gramática } \ldots \text { (como la anterior }) \text { Nueva edición } \mid \text { (Emblema) } \\
\text { Madrid | Gregorio Hernando... } \mid 1880 .\end{array}$ & $\begin{array}{l}\text { "4. }{ }^{\circ} 418 \text { págs. y } 2 \text { hojas de erratas y anuncios. Se ha suprimido la } \\
\text { "Advertencia" de las anteriores impresiones». (Pág. 40). }\end{array}$ \\
\hline 1883 & {$\left[16 .^{\mathrm{a}}\right]$} & $\begin{array}{l}\text { Gramática } \mid \ldots \text { (como la anterior) Madrid: | Gregorio Hernando ... } \\
1883 .\end{array}$ & «4. ; 418 págs. y una hoja más». (Pág. 40). \\
\hline 1885 & {$\left[17 .^{\mathrm{a}}\right]$} & $\begin{array}{l}\text { Gramática } \mid \ldots \text { (como las anteriores) Madrid | Gregorio Hernando ... } \\
1885 .\end{array}$ & $\begin{array}{l}\text { « } .^{\circ} ; 418 \text { págs. y } 1 \text { hoja de anuncios. Esta edición falta en la Filología } \\
\text { del Conde de la Viñaza». (Pág. 40). }\end{array}$ \\
\hline 1888 & {$\left[18 .^{a}\right]$} & $\begin{array}{l}\text { Gramática } \mid \text { (como las anteriores. }) \text { Madrid,| Viuda de Hernando y } \\
\text { Compañía, } \mid \text { impresores y libreros } \mid \text { de la Real Academia Española. | } \\
\text { 1888. }\end{array}$ & «4..$^{\circ} 418$ págs. y 1 hoja de anuncios». (Pág. 40). \\
\hline 1890 & {$\left[19 .^{\mathrm{a}}\right]$} & $\begin{array}{l}\text { Gramática } \mid \text {... como las anteriores) Madrid } \mid \text { Viuda de Hernando y } \\
\text { Compañía } \mid \text { Impresores y libreros } \mid \text { de la Real Academia Española. } \\
1890 .\end{array}$ & «4..$^{\circ} 418$ págs. y 1 hoja de anuncios». (Pág. 40). \\
\hline 1895 & {$\left[20 .^{\mathrm{a}}\right]$} & $\begin{array}{l}\text { Gramática } \mid \ldots \text { (como las anteriores) Madrid } \mid \text { Viuda de Hernando } \\
\ldots \mid 1895 .\end{array}$ & «4. $; 418$ págs. y una hoja más». (Pág. 41). \\
\hline
\end{tabular}




\begin{tabular}{|c|c|c|c|}
\hline 1900 & {$\left[21 .^{a}\right]$} & $\begin{array}{l}\text { Gramática } \mid \ldots \text { (como las anteriores }) \text { Madrid } \mid \text { Hernando y } \\
\text { Compañía } \mid \text { Impresores y libreros } \mid \text { de la Real Academia Española. } \\
\mid 1900 .\end{array}$ & «4. ${ }^{\circ} ; 418$ págs. y una hoja de anuncios». (Pág. 41). \\
\hline 1901 & {$\left[22 .{ }^{a}\right]$} & Gramática $\mid \ldots$ (como las anteriores) $\mid$ Madrid $\mid$ Hernando... 1901. & «4. ; 418 págs. y una hoja más». (Pág. 41). \\
\hline 1904 & {$\left[23 .^{a}\right]$} & $\begin{array}{l}\text { Gramática } \mid \text { de la } \mid \text { Lengua castellana } \mid \text { por } \mid \text { la Real Academia } \\
\text { Española } \mid \text { Nueva edición. } \mid \text { (Emblema.)| Madrid. | Perlado, Páez y } \\
\text { Compañía } \mid \text { (sucesores de Hernando) } \mid \text { Impresores y libreros } \mid \text { de la } \\
\text { Real Academia Española. } \mid 1904 .\end{array}$ & «4. ${ }^{\circ} ; 414$ págs. y una hoja de anuncios». (Pág. 41). \\
\hline 1908 & {$\left[24 . .^{a}\right]$} & $\begin{array}{l}\text { Gramática } \mid \ldots \text { (como las ants.) Madrid } \mid \text { Perlado, Paez y Compañía } \mid \\
\text { (Sucesores de Hernando) } \mid \text { Impresores y libreros } \mid \text { de la Real } \\
\text { Academia Española. } \mid 1908 .\end{array}$ & «4. ${ }^{\circ} ; 414$ págs. y una hoja de anuncios». (Pág. 41). \\
\hline 1909 & {$\left[25 .^{a}\right]$} & \begin{tabular}{l|l|l|l|l} 
Gramática & $\ldots$ (como las anteriores $)$ & Madrid $\mid$ Perlado ... & 1909.
\end{tabular} & «4..$^{\circ} 414$ págs. y una hoja más». (Pág. 41). \\
\hline 1911 & {$\left[26 .^{\mathrm{a}}\right]$} & Gramática $\mid \ldots$ (como las anteriores) | Madrid | Perlado... 1911. & $\begin{array}{l}\text { « } 4 .^{\circ} ; 420 \text { págs. y } 2 \text { hojas más de anuncios de obras de la Academia. Se } \\
\text { hicieron algunas correcciones y adiciones». (Pág. } 41) \text {. }\end{array}$ \\
\hline 1913 & {$\left[27 .^{\mathrm{a}}\right]$} & \begin{tabular}{l|l|l|l} 
Gramática & $\ldots$ (como las ants.) Madrid | Perlado ... & 1913.
\end{tabular} & «4. ${ }^{\circ} ; 20$ págs. y 2 hojas de anuncios». (Pág. 41). \\
\hline 1916 & {$\left[28 .^{a}\right]$} & $\begin{array}{l}\text { Gram. de la lengua Castell. }{ }^{a} \text { por la R. Acad. Esp. Nueva edic. Madr. } \\
\text { Perlado Paez y comp. }{ }^{a} \text { (Suces. de Hernando) Impresores y libreros de } \\
\text { la R. Acad. Esp. } 1916 .\end{array}$ & «4. ${ }^{\circ} ; 420$ págs.». (Pág. 41). \\
\hline 1917 & {$\left[29 .^{a}\right]$} & $\begin{array}{l}\text { Gram. de la leng. Cast. por la R. A. E. nueva edic. reformada Madr. } \\
\text { Perlado Paez y Comp. }{ }^{a} \text { (sucesores de Hernd.") Impresores y libreros de } \\
\text { la R. A. E., } 1917 .\end{array}$ & «4. ${ }^{\circ}$, VIII-548 págs.». (Pág. 41). \\
\hline 1920 & {$\left[30 .^{\mathrm{a}}\right]$} & $\begin{array}{l}\text { Gramática } \mid \ldots \text { (como las anteriores) } \mid \text { Nueva edición, reformada. } \\
\text { (Emblema.) Madrid, Perlado ... } \mid 1920 .\end{array}$ & $\begin{array}{l}\text { « } 4 .^{\circ} ; 564 \text { págs. y } 2 \text { hojas más. Como se ve por el número de páginas esta } \\
\text { edición recibió grandes aumentos y mejoras». (Pág. } 41 \text { ). }\end{array}$ \\
\hline 1924 & {$\left[31 .^{\mathrm{a}}\right]$} & $\begin{array}{l}\text { Real Academia Española. | Nueva edición, reformada. } \mid \text { (Emblema. }) \mid \\
\text { Madrid } \mid \text { Perlado ... } \mid 1924 .\end{array}$ & «4. ${ }^{\circ} ; 564$ págs. y 2 hojas más». (Pág. 41). \\
\hline
\end{tabular}




\begin{tabular}{|c|c|c|c|}
\hline 1928 & $32 .^{\mathrm{a}}$ & $\begin{array}{l}\text { Real Academia Española | Gramática | de la | Lengua española } \\
\mid \text { Nueva edición, reformada. | (Emblema de la Academia.) | Madrid } \\
\text { Librería y Casa editorial Hernando (S. A.) | (Fundada el año 1828) } \\
\text { Impresores y Libreros de la Real Academia Española | Calle del } \\
\text { Arenal, núm. II | } 1928 .\end{array}$ & «4. ${ }^{\circ} ; 564$ págs.». (Pág. 41). \\
\hline
\end{tabular}




\begin{tabular}{|c|c|c|c|}
\hline \multicolumn{4}{|c|}{ Autor: Antonio Palau y Dulcet } \\
\hline \multicolumn{4}{|c|}{ Título: Manual del librero hispano-americano, tomo I (voz "Academia") } \\
\hline \multicolumn{4}{|c|}{ Fecha: 1948} \\
\hline \multicolumn{4}{|c|}{ Ediciones de la Gramática recogidas } \\
\hline Año & $\begin{array}{l}\text { N. }{ }^{\circ} \text { de } \\
\text { ed. corres- } \\
\text { pondiente }\end{array}$ & Registrada como & Comentarios del compilador \\
\hline 1771 & {$\left[1 .^{\mathrm{a}}\right]$} & $\begin{array}{l}\text { Gramática de la lengua castellana. Madrid, Por D. } \\
\text { Joachin de Ibarra, Impresor de Cámara de S.M. } \\
\text { M.DCC.LXXI (1771) }\end{array}$ & $\begin{array}{l}\text { Información sobre el tipo de volumen y el número de páginas, seguida de una breve } \\
\text { información sobre la recepción en el extranjero y el precio: } \\
\text { «8. } 7 \text { h. XXII-376 p. } \\
\text { En el extranjero se da mucha importancia a esta primera edición. En tafilete rojo y } \\
\text { con las armas de Carlos III. } 12 \text { libras, } 2 \text { chelines. Maggs. Bros en 1923». (Pág. 39). }\end{array}$ \\
\hline 1772 & $2 .^{\mathrm{a}}$ & $\begin{array}{l}\text { Gramática. Segunda impresión. Madrid. Por D. } \\
\text { Joaquin Ibarra, Impresor de la Cámara de S.M. } \\
\text { M.DCC.LXXII (1772) }\end{array}$ & $\begin{array}{l}\text { Escueta información sobre tamaño y páginas: } \\
\text { «8. }{ }^{\circ} 7 \text { h. XXII-384 p.». (Pág. 39). }\end{array}$ \\
\hline 1781 & $3 .^{\mathrm{a}}$ & $\begin{array}{l}\text { Gramática. Tercera impresión. Con superior } \\
\text { permiso: en Madrid. Por D. Joaquin Ibarra, } \\
\text { Impresor de Cámara de S.M. y de la Real } \\
\text { Academia. MDCCLXXXI (1781) }\end{array}$ & $\begin{array}{l}\text { El mismo tipo de información que en la anterior: } \\
\text { «8. } 7 \text { h. XXI-384 p.». (Pág. 39). }\end{array}$ \\
\hline 1796 & $4 .^{\mathrm{a}}$ & $\begin{array}{l}\text { Gramática. Quarta edición. Corregida y aumentada. } \\
\text { Con superior permiso. Por la Viuda de D. Joaquin } \\
\text { Ibarra. Impresora de la Real Academia, Madrid, } \\
\text { MDCCXCVI (1796) }\end{array}$ & $\begin{array}{l}\text { Información sobre características físicas de la edición, así como sobre reimpresiones } \\
\text { posteriores, en España y en el extranjero: } \\
\text { «8. } 4 \text { h. XXV-479 p. } 25 \text { frs. París en } 1917 . \\
\text { Se reimprimió a plana y renglón: Madrid, M.DCCC.LII, Imprenta de la Compañía de } \\
\text { Impresores y Libreros del Reino, (1852) 8. } \\
\text { La de Madrid, } 1821, \text { 8. }^{\circ} 6 \text { chelines Inglaterra. Y la de Madrid, Joaquín Ibarra, 1781, } \\
\text { 8. } 7 \text { h. XXI-384 p. } 10 \text { pts. Barbazán. Después, Madrid, 1825, 8. } 6 \text { a } 8 \text { pts.». (Pág. 39). }\end{array}$ \\
\hline
\end{tabular}




\begin{tabular}{|c|c|c|c|}
\hline 1854 & {$\left[5 .^{a}\right]$} & $\begin{array}{l}\text { Gramática. Nueva edición. } \text { M., En la Imp. } \\
\text { Nacional, 1854. }\end{array}$ & $\begin{array}{l}\text { Información escueta sobre tamaño del volumen y número de páginas: } \\
\left.\text { «4. } .^{\circ} \text { X-226 p.». (Pág. } 39\right) .\end{array}$ \\
\hline 1858 & {$\left[6 .^{\mathrm{a}}\right]$} & Gramática. M., en la Imp. Nacional, 1858. & $\begin{array}{l}\text { La misma información de arriba: } \\
\text { «4. }{ }^{\circ} \text { VII-25l p.». (Pág. 39). }\end{array}$ \\
\hline 1862 & {$\left[7 .^{\mathrm{a}}\right]$} & Gramática. M., Imp. Nacional, 1862. & $\begin{array}{l}\text { La misma información de arriba: } \\
\text { «4. } 254 \text { p.». (Pág. } 39) \text {. }\end{array}$ \\
\hline 1864 & {$\left[8 .^{a}\right]$} & Gramática. M., Imp. Nacional, 1864. & $\begin{array}{l}\text { La misma información de arriba: } \\
\text { «4. } 254 \text { p.». (Pág. 39). }\end{array}$ \\
\hline 1865 & {$\left[9 .^{\mathrm{a}}\right]$} & Idem. Id., id., 1865 & $\begin{array}{l}\text { La misma información de arriba: } \\
\left.\text { « } .^{\circ} \mathrm{X}-226 \text { p.». (Pág. } 39\right) .\end{array}$ \\
\hline 1866 & {$\left[10 .^{\mathrm{a}}\right]$} & Idem. Id., id., 1866 & $\begin{array}{l}\text { La misma información de arriba: } \\
\left.\text { «4. }{ }^{\circ} 255 \text { p.». (Pág. } 39\right) \text {. }\end{array}$ \\
\hline 1867 & {$\left[11 .^{\mathrm{a}}\right]$} & $\begin{array}{l}\text { Idem. M., Imp. de Miguel Ginesta, calle de Isabel } \\
\text { la Católica, } 1867\end{array}$ & $\begin{array}{l}\text { La misma información de arriba: } \\
\text { «4. }{ }^{\circ} \mathrm{X}-226 \text { p.». (Pág. 39). }\end{array}$ \\
\hline 1870 & {$\left[12 .^{\mathrm{a}}\right]$} & $\begin{array}{l}\text { Idem. M., Imp, y Estereotipia de M. Rivadeneyra, } \\
\text { calle del Duque de Osuna, núm. } 3,1870\end{array}$ & $\begin{array}{l}\text { La misma información de arriba: } \\
\text { «4. }{ }^{\circ} \text { XV-391 p. } 2 \text { h.». (Pág. 39). }\end{array}$ \\
\hline 1874 & {$\left[13 .^{a}\right]$} & $\begin{array}{l}\text { Gramática. M., Imp. y fundición de M. Tello, } \\
\text { Isabel la Católica, 23. } 1874\end{array}$ & $\begin{array}{l}\text { La misma información de arriba: } \\
\text { « } .^{\circ} 423 \text { p. } 2 \text { h.». (Pág. 39). }\end{array}$ \\
\hline 1878 & $14 .^{\mathrm{a}}$ & $\begin{array}{l}\text { Idem. M., Gregorio Hernando impresor y librero } \\
\text { de la Real Academia Española, } 1878 .\end{array}$ & $\begin{array}{l}\text { La misma información de arriba: } \\
\text { «4. }{ }^{\circ} 423 \text { p. } 2 \text { h.». (Pág. 39). }\end{array}$ \\
\hline 1880 & $15 .^{\mathrm{a}}$ & Gramática. M., Gregorio Hernando, 1880 & $\begin{array}{l}\text { Información sobre el tipo de volumen y páginas de la edición más información sobre } \\
\text { las dos reimpresiones que se hicieron de ella en los años siguientes: } \\
« 4 .^{\circ} 418 \mathrm{p} .1 \mathrm{~h} \text {. }\end{array}$ \\
\hline
\end{tabular}




\begin{tabular}{|c|c|c|c|}
\hline & & & Después id. Id. 1883, 4. ${ }^{\circ} 418$ p. 1 h.; y Id. Id. 1885, 4. 418 p. 1 h.». (Pág. 39). \\
\hline 1885 & $17 .^{\mathrm{a}}$ & & \\
\hline 1888 & {$\left[18 .^{a}\right]$} & $\begin{array}{l}\text { Idem. M., Viuda de Hernando y Cía. impresores y } \\
\text { libreros de la Real Academia Española, } 1888\end{array}$ & $\begin{array}{l}\text { Información sobre el tamaño del volumen y el número de páginas: } \\
\left.\text { «4. }{ }^{\circ} \text { VI-418 p. } 1 \text { h.». (Pág. } 39\right) .\end{array}$ \\
\hline 1890 & {$\left[19 .^{a}\right]$} & Idem. Id. id. 1890 & $\begin{array}{l}\text { Información sobre el tamaño y número de páginas, seguida de información sobre } \\
\text { reimpresión: } \\
\text { «4. } 418 \text { p. } 1 \text { h.; y completamente igual en 1895». (Pág. 39). }\end{array}$ \\
\hline 1895 & $20 .^{\mathrm{a}}$ & & \\
\hline 1900 & {$\left[21 . .^{\mathrm{a}}\right]$} & $\begin{array}{l}\text { Idem. M., Hernando y Cía. Impresores y libreros } \\
\text { de la Real Academia Española, } 1900\end{array}$ & $\begin{array}{l}\text { La misma información que en el registro anterior (con información añadida sobre el } \\
\text { precio): } \\
\text { « } 4 .^{\circ} 418 \text { p. } 1 \text { h.; y completamente igual en } 1901,(5 ’ 5 \text { pts)». (Pág. } 39) \text {. }\end{array}$ \\
\hline 1901 & $22 .^{\mathrm{a}}$ & & \\
\hline 1904 & {$\left[23 .^{\mathrm{a}}\right]$} & $\begin{array}{l}\text { Idem. M., Perlado, Paez y Compañía (Sucesores } \\
\text { de Hernando) Impresores y libreros de la Real } \\
\text { Academia Española, 1904. }\end{array}$ & $\begin{array}{l}\text { Información sobre el tamaño y número de páginas, seguida de información sobre } \\
\text { reimpresión: } \\
\left.\text { «4. } 414 \text { p. } 1 \text { h. Después, id. id. } 1911,4 .^{\circ} 1 \text { h. } 420 \text { p.». (Pág. } 39\right) .\end{array}$ \\
\hline 1911 & {$\left[24 .{ }^{\mathrm{a}}\right]$} & & \\
\hline 1917 & {$\left[25 .^{\mathrm{a}}\right]$} & $\begin{array}{l}\text { Gramática... Nueva edición reformada. M., Imp. de } \\
\text { los Sucesores de Hernando, } 1917\end{array}$ & $\begin{array}{l}\text { Información sobre tipo de volumen, número de páginas y precio: } \\
\left.\text { «4. }{ }^{\circ} \text { VIII-548 p. (5 pts)». (Pág. } 39\right) \text {. }\end{array}$ \\
\hline 1920 & {$\left[26 .{ }^{\mathrm{a}}\right]$} & $\begin{array}{l}\text { Idem. M., imp. de los Sucesores de Hernando, } \\
1920\end{array}$ & $\begin{array}{l}\text { Información sobre tipo de volumen, número de páginas y precio, así como de las dos } \\
\text { reimpresiones que le siguen: } \\
\text { «4. } .^{\circ} 564 \text { p. (7 pts); y id., id., 1924, } 4 .^{\circ} \text { gran } 8 .^{\circ} 564 \text { p. } 2 \text { h (7 pts). Después: id., id., } \\
\left.1928,4 .^{\circ} 594 \text { p. (10 pts)». (Pág. } 39\right) .\end{array}$ \\
\hline 1924 & $27 .^{\mathrm{a}}$ & & \\
\hline
\end{tabular}




\begin{tabular}{|l|l||l|l|}
\hline 1928 & $28 .^{\text {a }}$ & \\
\hline 1931 & $29 .^{\text {a }}$ & Idem. M., Espasa-Calpe, 1931 & $\begin{array}{l}\text { Información sobre características físicas de la edición y precio de la misma: } \\
\text { «4. } 534 \text { p. (11 pts. Tela 13’50 pts.)». (Pág. 39). }\end{array}$ \\
\hline
\end{tabular}


ANEXo 2 

ANALOGÍA

\section{SIGLO XVIII}

Autoridades: «I.f. Relación, proporción, ò conveniéncia de algunas cosas entre si: como quando una cosa que es incierta se refiere à otra semejante, para probar lo incierto con lo cierto. Lat. Analogía. M. Agred. Tom. I. num. 249. por la correspondéncia y analogia que entre sí tienen estas Ciudades. PINEL. Retrat. Fol. 236. Los que eligieron por armas alguna figura que tuviesse semejanza, ò analogía con su apellído, ò estado [...]» (1726, pág. 280,1).

DRAE-1780: «s.f. La relacion, proporcion, ó conveniencia que tienen unas cosas con otras. Analogia» (pág. 70, 1).

DRAE-1783: «s.f. La relacion, proporcion, ó conveniencia que tienen unas cosas con otras. Analogia» (pág. 76, 2).

DRAE-1791: «s.f. La relacion, proporcion, ó conveniencia que tienen unas cosas con otras. Analogia» (pág. 71, 1).

GRAE-1771: No ofrece definición propiamente dicha. La Analogía es la parte de la Gramática «que trata del número, propiedad, y oficio de las palabras» (pág. 1).

GRAE-1796: Ya hay un propósito definidor más evidente que en 1771. La Analogía es el «conocimiento de las partes de la oracion, con sus accidentes y propiedades» (pág. 3).

\section{$1^{\text {a }}$ mitad del XIX}

DRAE-1803: «s.f. La relacion, y proporcion, ó conveniencia que tienen unas cosas con otras. Analogia.

AnAlogía. Gram. La segunda parte de la gramática, que trata de las partes de la oracion separadas, $\mathrm{y}$ de sus propiedades y accidentes. Analogia» (pág. 62, 3).

DRAE-1817: «s.f. La relacion y proporcion ó conveniencia que tienen unas cosas con otras. Analogia.

Analogía. Gram. La segunda parte de la gramática, que trata de las partes de la oracion separadas, y de sus propiedades $\mathrm{y}$ accidentes. Analogia» (pág. 62, 2). 
DRAE-1822: «s.f. La relacion y proporcion ó conveniencia que tienen unas cosas con otras. Analogia.

Analogía. Gram. La segunda parte de la gramática, que trata de las partes de la oracion separadas, $y$ de sus propiedades y accidentes. Analogia» (pág. 53, 2).

DRAE-1832: «f. La relacion y proporcion ó conveniencia que tienen unas cosas con otras. Analogia. If Gram. La segunda parte de la gramática, que trata de las partes de la oracion separadas, y de sus propiedades y accidentes. Analogia» (pág. 48, 1).

DRAE-1837: «f. La relacion y proporcion ó conveniencia que tienen unas cosas con otras. Analogia. If Gram. La segunda parte de la gramática, que trata de las partes de la oracion separadas, y de sus propiedades y accidentes. Analogia» (pág. 48, 1).

DRAE-1843: «f. La relacion y proporcion ó conveniencia que tienen unas cosas con otras. analogía. ㅇ. Gram. La segunda parte de la gramática, que trata de las partes de la oracion separadas, y de sus propiedades y accidentes. Analogia» (pág. $46,1)$.

\section{$2^{a}$ m. XIX - p. XX}

DRAE-1852: «f. La relacion, y proporcion ó conveniencia que tienen unas cosas con otras. Analogia. I Gram. La parte de la gramática que trata de las partes de la oracion separadas, y de sus propiedades y accidentes. Analogia» (pág. 44, 3).

GRAE-1854: Seguimos sin una definición en sentido estricto: «La analogía enseña el conocimiento de las palabras, que son partes de la oracion, con todos sus accidentes y propiedades» (pág 1).

GRAE-1858: Otra vez, en lugar de definición estricta, encontramos la alusión al objetivo de esta parte de la Gramática: «La analogía enseña el valor gramatical de las palabras con todos sus accidentes y propiedades» (pág.1).

GRAE-1862: «La analogía enseña el valor gramatical de las palabras con todos sus accidentes y propiedades» (pág.5). 
DRAE-1869: «f. Relacion de semejanza entre cosas esencialmente distintas. ๆ Gram. La seccion de la gramática que trata de las partes de la oracion separadas, y de sus propiedades y accidentes» (pág. 49, 2).

DRAE-1884: «(Del gr. $\dot{\alpha} \nu \alpha \lambda o \gamma i \alpha$, proporción, relación; de $\dot{\alpha} \nu \dot{\alpha}$, conforme á, y $\lambda \circ \gamma o \zeta$, razón.) f. Relación de semejanza entre cosas distintas. ๆ Gram. Parte de la gramática que trata de las partes de la oración, considerándolas separadamente, y examinando los accidentes y propiedades de cada una de ellas» (pág. 70, 2).

GRAE-1864: «La analogía enseña el valor gramatical de las palabras con todos sus accidentes y propiedades» (pág.5).

GRAE-1865: «La analogía enseña el valor gramatical de las palabras con todos sus accidentes y propiedades» (pág.5).

GRAE-1866: «La analogía enseña el valor gramatical de las palabras con todos sus accidentes y propiedades» (pág.5).

GRAE-1867: Igual que en las ediciones anteriores, lo que leemos no es una definición sino una explicación de cuál es la finalidad de la analogía: «La analogía enseña el valor gramatical de las palabras con todos sus accidentes y propiedades» (pág. 5).

GRAE-1870: Por primera vez encontramos en la Gramática una definición estricta de Analogía: «La Analogía es la parte de la Gramática que trata de cada una de las partes de la oracion, examinando sus propiedades y accidentes» (pág.7).

GRAE-1874: «La Analogía es... la parte de la Gramática que trata de cada una de las partes de la oracion, examinando sus propiedades y accidentes» (pág. 23).

GRAE-1878: «La Analogía es... la parte de la Gramática que trata de cada una de las partes de la oracion, examinando sus propiedades y accidentes» (pág. 23).

GRAE-1880: «La Analogía es... la parte de la Gramática que enseña el valor gramatical de las palabras, con todos sus accidentes y propiedades» (pág.7).

GRAE-1883: «La Analogía es... la parte de la Gramática que enseña el valor gramatical de las palabras, con todos sus accidentes y propiedades» (pág.7). 
DRAE-1899: «(Del gr. $\dot{\alpha} v \alpha \lambda o \gamma i \alpha$, proporción,

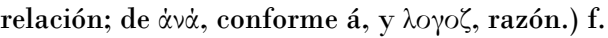
Relación de semejanza entre cosas distintas. ๆ Gram. Parte de la gramática, que trata de los accidentes y propiedades de las palabras, consideradas aisladamente» (pág. 63, 3).
GRAE-1885: «La Analogía es... la parte de la Gramática que enseña el valor gramatical de las palabras, con todos sus accidentes y propiedades» (pág.7).

GRAE-1888: «La Analogía es... la parte de la Gramática que enseña el valor de las palabras consideradas aisladamente, con todos sus accidentes y propiedades» (pág.7).

GRAE-1890: «La Analogía es... la parte de la Gramática que enseña el valor de las palabras consideradas aisladamente, con todos sus accidentes y propiedades» (pág.7).

GRAE-1895: «La Analogía es... la parte de la Gramática que enseña el valor de las palabras consideradas aisladamente, con todos sus accidentes y propiedades» (pág.7).

GRAE-1900: «La Analogía es... la parte de la Gramática que enseña el valor de las palabras consideradas aisladamente, con todos sus accidentes y propiedades» (pág.7).

GRAE-1901: «La Analogía es... la parte de la Gramática que enseña el valor de las palabras consideradas aisladamente, con todos sus accidentes y propiedades» (pág.7).

GRAE-1904: «La Analogía es la parte de la Gramática que enseña el valor de las palabras consideradas aisladamente, con todos sus accidentes y propiedades» (pág. 7).

GRAE-1906: «La Analogía es... la parte de la Gramática que enseña el valor de las palabras consideradas aisladamente, con todos sus accidentes y propiedades» (pág. 7).

GRAE-1908: «La Analogía es... la parte de la Gramática que enseña el valor de las palabras consideradas aisladamente, con todos sus accidentes y propiedades» (pág. 7).

GRAE-1909: «La Analogía es... la parte de la Gramática que enseña el valor de las palabras consideradas aisladamente, con todos sus accidentes y propiedades» (pág. 7).

GRAE-1911: «La ANALOGía es la parte de la Gramática que enseña el valor de las palabras consideradas aisladamente, con todos sus accidentes y según sus varios oficios» (pág. 7). 
DRAE-1914: «(Del lat. analogía, y éste del gr. $\dot{\alpha} \nu \alpha \lambda o \gamma i \alpha$, proporción, semejanza; de $\dot{\alpha} \nu \dot{\alpha}$,

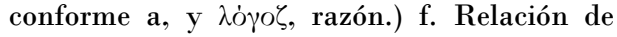
semejanza entre cosas distintas. If ${ }^{2}$ Gram. Parte de la gramática, que trata de los accidentes y propiedades de las palabras, consideradas aisladamente» (pág. 66, 1).

DRAE-1925: «(Del lat. analogía, y éste del gr. $\dot{\alpha} v \alpha \lambda o \gamma i \alpha$, proporción, semejanza; de $\dot{\alpha} \nu \dot{\alpha}$, conforme a, y $\lambda \dot{\gamma} \gamma \circ \zeta$, razón.) f. Relación de semejanza entre cosas distintas. If 2. Gram. Parte de la gramática, que trata de los accidentes y propiedades de las palabras, consideradas aisladamente» (pág. 78, 1).

GRAE-1913: «La ANALOGía es la parte de la Gramática que enseña el valor de las palabras consideradas aisladamente, con todos sus accidentes y según sus varios oficios» (pág. 7).

GRAE-1916: «La AnALOGía es la parte de la Gramática que enseña el valor de las palabras consideradas aisladamente, con todos sus accidentes y según sus varios oficios» (pág. 7).

GRAE-1917: «La ANALOGía es la parte de la Gramática que enseña el valor de las palabras consideradas aisladamente, con todos sus accidentes» (pág.1).

GRAE-1920: «La ANALogía es la parte de la Gramática que enseña el valor de las palabras consideradas aisladamente, con todos sus accidentes» (pág.9).

GRAE-1924: «La ANALOGía es la parte de la Gramática que enseña el valor de las palabras consideradas aisladamente, con todos sus accidentes» (pág.9 


\section{ARTE}

\section{SIGLO XVIII}

Autoridades: «f.f. La facultád que prescribe reglas y preceptos para hacer rectamente las cosas. Debaxo de este nombre se entiende la generalidád de las artes liberáles y mecánicas $[\cdots]$

ARTE. Se llama tambien la maña, destréza, sagacidád y astúcia de alguna persóna, y la habilidád con que dispóne las cosas [...]

ARTE. Se llama tambien el mismo libro en que están escritas las reglas y preceptos del arte. Por antonomásia se llama assi el de Nebrixa, en que se contienen las reglas de la Gramática. Lat. Institutiones Grammaticae. JaCINT. POL. fol. 283. Argüíle yo con el arte de António, y respondió el rapáz: No estudiamos acá por esse arte, sino por el de Amandi [...]» (1726, pág. 422,2 y 423,1 ).

\section{GRAE-1771:}

DRAE-1780: «s.m. y f. Conjunto de preceptos y reglas para hacer bien alguna cosa. Divídese en artes liberales y mecánicas [...]

ARTE. En general es todo lo que se hace por industria y habilidad del hombre, $y$ en este sentido se contrapone á naturaleza. Ars.

ARTE. El libro que contiene los preceptos del arte.Por antonomasia se entiende comunmente el de gramática latina, llamado de Nebrixa, Liber de grammatica latina, sive institutionum lingua latinae [...]» (pág.102, 3)

DRAE-1783: «s.m. y f. Conjunto de preceptos y reglas para hacer bien alguna cosa. Divídese en ARTES liberales y mecánicas [...]

ARTE. En general es todo lo que se hace por industria y habilidad del hombre, y en este sentido se contrapone á naturaleza. Ars.

ARTE. El libro que contiene los preceptos del arte.Por antonomasia se entiende comunmente el de gramática latina, llamado de Nebrixa, Liber de grammatica latina, sive institutionum lingua latinae [...]» (pág.111, 3 y 112, 1). 
DRAE-1791: «s.m. y f. Conjunto de preceptos y reglas para hacer bien alguna cosa. Divídese en ARTES liberales y mecánicas [...] 2. En general es todo lo que se hace por industria y habilidad del hombre, y en este sentido se contrapone á naturaleza. Ars. [...] 4. El libro que contiene los preceptos del arte. Por antonomasia se entiende comunmente el de gramática latina, llamado de Nebrixa. Liber de grammatica latina, sive institutionum linguae latinae [...]» (pág.102, 3 y 103, 1).

\section{GRAE-1796:}

\section{$1^{\text {a }}$ mitad del XIX}

DRAE-1803: «s.m. y f. Conjunto de preceptos y reglas para hacer bien alguna cosa. Divídese en ARTES liberales y mecánicas [...]

ARTE. Todo lo que se hace por industria y habilidad del hombre, y en este sentido se contrapone á naturaleza. Ars. [...]

ARTE. El libro que contiene los preceptos del arte. Por antonomasia se entiende comunmente el de gramática latina, llamado de Nebrixa, Liber de grammatica latina, sive institutionum lingua latinae [...]» (pág. 92, 3).

DRAE-1817: «s.m. y f. Conjunto de preceptos y reglas para hacer bien alguna cosa. Divídese en ARTES liberales y mecánicas [...]

ARTE. Todo lo que se hace por industria y habilidad del hombre, y en este sentido se contrapone á naturaleza. Ars, industria [...]

ARTE. El libro que contiene los preceptos de la gramática latina. Por antonomasia se entiende comunmente el que compuso Antonio Nebrija, Grammatica latina, ars grammaticae $[\ldots]$...] (pág. 92, 2).

DRAE-1822: «s.m. y f. Conjunto de preceptos y reglas para hacer bien alguna cosa. Divídese en ARTES liberales y mecánicas [...]

ARTE. Todo lo que se hace por industria y habilidad del hombre, y en este sentido se contrapone á naturaleza. Ars, industria [...]

ARTE. El libro que contiene los preceptos de la gramática latina, que compuso Antonio Nebrija. Grammatica latina, ars grammatica $[\ldots] »($ pág. 80, 1). 
DRAE-1832: «m. y f. Conjunto de preceptos y reglas para hacer bien alguna cosa. Divídese en ARTES liberales y mecánicas [...] ๆ Todo lo que se hace por industria y habilidad del hombre, $\mathrm{y}$ en este sentido se contrapone á naturaleza. Ars, industria [...] ๆ El libro que contiene los preceptos de la gramática latina, que compuso Antonio Nebrija. Grammatica latina, ars grammatica $[\ldots] »$ (pág. 72, 2).

DRAE-1837: «m. y f. Conjunto de preceptos y reglas para hacer bien alguna cosa. Divídese en ARTES liberales y mecánicas [...] T Todo lo que se hace por industria y habilidad del hombre, $\mathrm{y}$ en este sentido se contrapone á naturaleza. Ars, industria [...] ๆ El libro que contiene los preceptos de la gramática latina. Grammatica latina, ars grammatica [...]» (pág. $72,2)$.

DRAE-1843: «m. y f. Conjunto de preceptos y reglas para hacer bien alguna cosa. Divídese en ARTES liberales y mecánicas [...] ם Todo lo que se hace por industria y habilidad del hombre, $y$ en este sentido se contrapone á naturaleza. Ars, industria [...] Ø El libro que contiene los preceptos de la gramática latina. Grammatica latina, ars grammaticae [...]» (pág. 69,3).

\section{$2^{a}$ m. XIX - p. XX}

DRAE-1852: «s.m. y f. Conjunto de preceptos y reglas para hacer bien alguna cosa. Divídese en ARTES liberales y mecánicas [...] 9 Todo lo que se hace por industria y habilidad del hombre, $\mathrm{y}$ en este sentido se contrapone á naturaleza. Ars, industria [...] ๆ El libro que contiene los preceptos de la gramática latina. Grammatica latina, ars grammaticae [...]» (pág. 67).

GRAE-1854:

GRAE-1858:

GRAE-1862:

GRAE-1864:

GRAE-1865:

GRAE-1866: 
DRAE-1869: «m. y f. Conjunto de preceptos y reglas para hacer bien alguna cosa. Divídese en ARTES liberales y mecánicas [...] \| Todo lo que se hace por industria y habilidad del hombre, y en este sentido se contrapone á naturaleza [...] đ El libro que contiene los preceptos de la gramática latina $[. .]$.$» (pág.$ $74)$.

GRAE-1867:

GRAE-1870:

GRAE-1874:

GRAE-1878:

GRAE-1880:

GRAE-1883:

DRAE-1884: «(Del lat. ars, artis.) amb. Virtud, fuerza, disposición é industria para hacer alguna cosa [...] đ| Todo lo que se hace por industria y habilidad del hombre, y en este sentido se contrapone á naturaleza [...] ๆ Libro que contiene los preceptos de la gramática latina $[\ldots] »$ (pág. 104).

DRAE-1899: «(Del lat. ars, artis.) amb. Virtud, fuerza, disposición é industria para hacer alguna cosa [...] Todo lo que se hace por industria y habilidad del hombre, y en este sentido se contrapone á naturaleza $[\ldots]$ | Libro que contiene los preceptos de la gramática latina [...]» (pág. 96).

GRAE-1885:

GRAE-1888:

GRAE-1890:

GRAE-1895:

\section{GRAE-1900:}

GRAE-1901:

GRAE-1904: 
GRAE-1906:

GRAE-1908:

GRAE-1909:

GRAE-1911:

GRAE-1913:

DRAE-1914: «(Del lat. ars, artis.) amb. Virtud, fuerza, disposición e industria para hacer alguna cosa [...] ${ }^{3}$ Todo lo que se hace por industria y habilidad del hombre, $\mathrm{y}$ en este sentido se contrapone a naturaleza [...] I $^{5}$ Libro que contiene los preceptos de la gramática latina [...]» (pág. 99).

\section{GRAE-1916:}

GRAE-1917:

GRAE-1920:

GRAE-1924:

DRAE-1925: «(Del lat. ars, artis.) amb. Virtud, fuerza, disposición e industria para hacer alguna cosa $[\ldots]$ 3. Todo lo que se hace por industria y habilidad del hombre, y en este sentido se contrapone a naturaleza $[\ldots]$ If 4 . Conjunto de preceptos y reglas necesarios

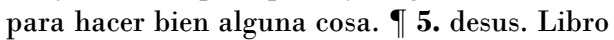
que contiene los preceptos de la gramática latina [...]» (pág. 117). 


\section{BIEN}

\section{SIGLO XVIII}

Autoridades: «[...] BIEN. adv. que equivále al bene de los Latinos. En fu mas genuino lignificado es lo mifmo que buena $\mathrm{y}$ rectamente, juftamente: $\mathrm{y}$ alsi se dice Bien ha dicho, bien ha obrado, bien ha vivido, \&.Lat. Benè. SANT. Ter. Mor. 7. Y doi por bién empleado el trabájo, aunque confiello que ha sido harto poco. C. LUCAN. cap. I. Como quiera que aquello era bién fecho para en aquella cofa [...]» (1726, pág. 603,2).

\section{GRAE-1771:}

RAE-1780: «BIEN. adv. m. Rectamente, con acierto, segun se debe, y así se dice: ha dicho BIEN, ha vivido BIEN. Bene, rectè, probè.

$[\cdots]$

BIEN. Junto con algunos verbos sirve para calificar la accion de ellos, y denota mayor intension, ó perfeccion, como creer BIEN, persuadirse BIEN, imponerse BIEN. Certò, rectè, perspicuè [...]» (pág. 143,3).

DRAE-1783: «BIEN. adv. m. Rectamente, con acierto, segun se debe; y así se dice: ha dicho BIEN, ha vivido BIEN. Bene, rectè, probè.

$[\ldots]$

BIEN. Junto con algunos verbos sirve para calificar la accion de ellos, y denota mayor intension, ó perfeccion, como creer BIEN, persuadirse BIEN, imponerse BIEN. Certò, rectè, perspicuè [...]» (pág. 156,1).

DRAE-1791: «5. adv. m. Rectamente, con acierto, segun se debe; y así se dice: ha dicho BIEN, ha vivido BIEN. Bene, rectè, probè. [...] 9. Junto con algunos verbos sirve para calificar la accion de ellos, y denota mayor intension, ó perfeccion, como creer BIEN, persuadirse BIEN, imponerse BIEN. Certò, rectè, perspicuè [...]» (pág. 142,3 y 143,1).

\section{$\mathbf{I}^{\mathrm{a}}$ mitad del XIX}

DRAE-1803: «BIEN. adv. m. Rectamente, con acierto, segun se debe; y así se dice: ha dicho BIEN, ha vivido BIEN. Bene, rectè, probè.

$[\ldots]$

BIEN. Junto con algunos verbos califica la accion de ellos, y denota mayor intension, ó perfeccion, como creer BIEN, persuadirse BIEN, imponerse BIEN. Certò, rectè, perspicuè 
[...]» (pág. 130,1-2).

DRAE-1817: «BIEN. adv. m. Rectamente, con acierto, segun se debe; y así se dice: ha dicho BIEN, ha vivido BIEN. Benè, rectè, probè.

[...]

BIEN. Junto con algunos verbos califica la accion de ellos, y denota mayor intension ó perfeccion, como creer BIEN, persuadirse BIEN, imponerse BIEN. Certò, rectè, perspicuè [...]» (pág. 129,2).

DRAE-1822: «BIEN. adv. m. Rectamente, con acierto, segun se debe; y así se dice: ha dicho BIEN, ha vivido BIEN. Benè, rectè, probè.

$[\ldots]$

BIEN. Junto con algunos verbos califica la accion de ellos, y denota mayor intension ó perfeccion, como creer BIEN, persuadirse BIEN, imponerse BIEN. Certò, rectè [...]» (pág. $115,3)$.

DRAE-1832: « adv. m. Rectamente, con acierto, segun se debe. Benè, rectè, probè [...] \I Junto con algunos verbos califica la accion de ellos, y denota mayor intencion [sic] ó perfeccion, como creer BIEN, imponerse BIEN. Certò, rectè [...]» (pág. 104,2-3).

DRAE-1837: « ๆ adv. m. Rectamente, con acierto, segun se debe. Benè, rectè, probè [...] If Junto con algunos verbos califica la accion de ellos, y denota mayor intencion [sic] ó perfeccion; como creer BIEN, imponerse BIEN. Certò, rectè [...]» (pág. 104,2-3).

DRAE-1843: «Q adv. m. Rectamente, con acierto, segun se debe. Benè, rectè, probè [...] ه Junto con algunos verbos califica la accion de ellos, y denota mayor intencion ó perfeccion; como creer BIEN, imponerse BIEN. Certò, rectè [...]» (pág. 100,3).

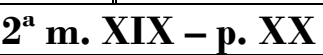

DRAE-1852: «ף adv. m. Rectamente, con acierto, segun se debe. Benè, rectè, probè [...] || Junto con algunos verbos califica la accion de ellos, y denota mayor intencion ó perfeccion; como creer BIEN, imponerse BIEN. Certò, rectè [...]» (pág. 97,1). 


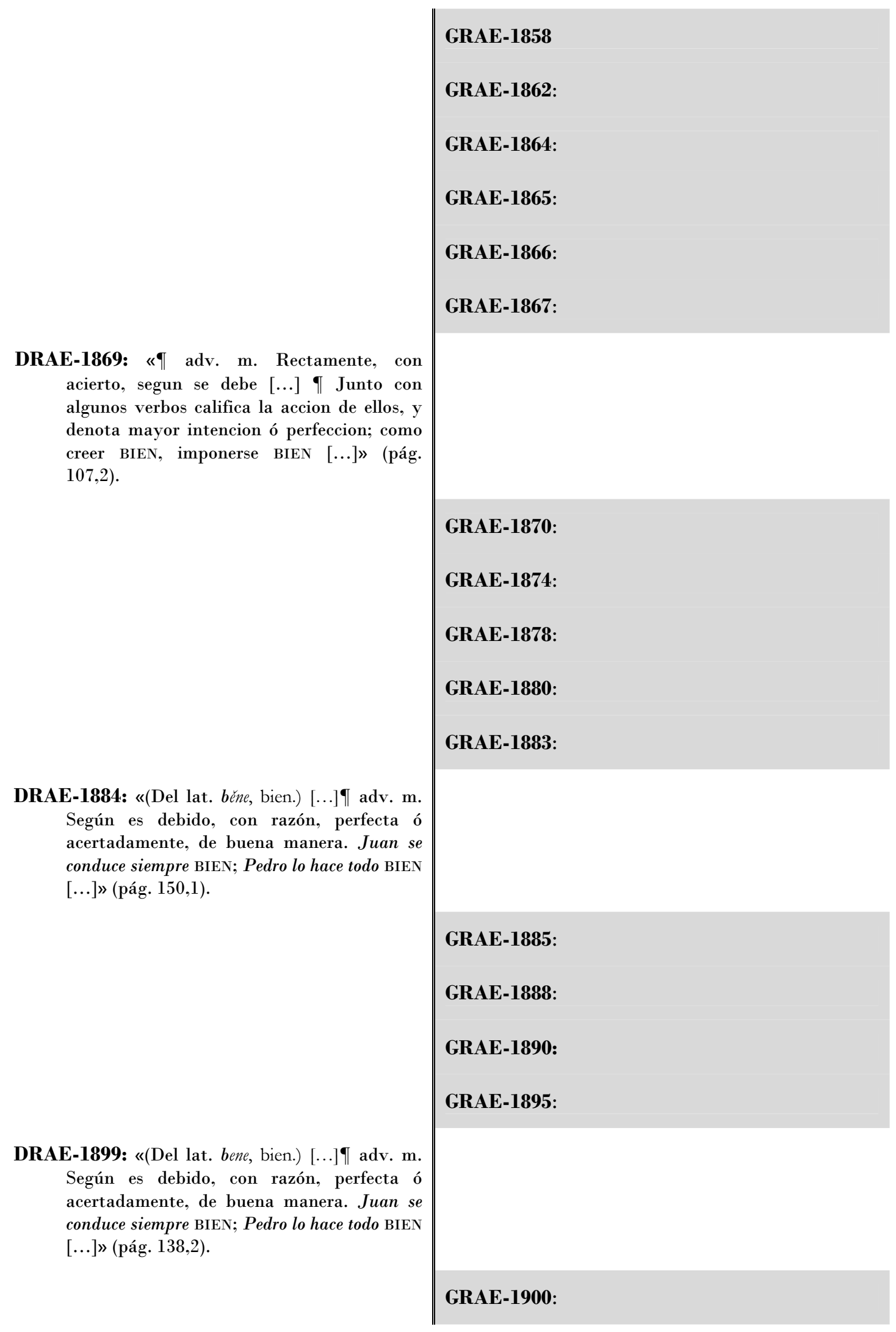


GRAE-1901:

GRAE-1904:

GRAE-1906:

GRAE-1908:

GRAE-1909:

GRAE-1911:

GRAE-1913:

GRAE-1916:

GRAE-1917:

GRAE-1920:

GRAE-1924:

DRAE-1925: «(Del lat. bene, bien.) [...] 4. adv. m. Según es debido, con razón, perfecta o acertadamente, de buena manera. Juan se conduce siempre BIEN; Pedro lo hace todo BIEN [...]» (pág. 167,1). 
CAS(1)

\section{SIGLO XVIII}

Autoridades: «f. m. $[\ldots]$ Caso. En la Gramática fe llama aquel en que varia la terminacion del nombre y fu fignificado. Los cafos fon feis, Nominativo, Genitivo, Dativo, Acufativo, Vocativo y Ablativo. Lat. Cafus Grammaticus. ANT. AGust. Dial. fol. 296. En algunas eftá en el primer cafo como Tarraco. Jacint. Pol. pl. 284. Advierte que en toda efta Gramática no hai mas que eftos dos cafos $[\ldots] »(1729$, pág. 217,1$)$.

DRAE-1780: «s.m. [...] CASO. En la gramática griega y latina se llama así la diversa inflexion de un mismo nombre con distinta significacion. Casus, varia nominum terminatio $[\ldots] »$ (pág. 205,1).

DRAE-1783: «s.m. [...] CASO. En la gramática griega y latina se llama así la diversa inflexîon de un mismo nombre con distinta significacion. Casus, varia nominum terminatio [...]» (pág. 219,2).

DRAE-1791: «s.m. [...] CASO. En la gramática de algunas lenguas se llama así la diversa inflexîon, ó terminacion de un mismo nombre. Casus, varia nominum terminatio [...]» (pág. 199,1).
GRAE-1771: No encontramos definición propiamente dicha; la concepción que sobre el caso se defiende se expresa en estas palabras: «DECLINACION en la Gramática latina es la variacion de un mismo nombre en diferentes casos, ó terminaciones con distinta significacion. [...] Nuestra lengua no admite esta variedad de casos, ó terminaciones en los nombres, y solo conoce diferencia entre el singular, y el plural de ellos [...] Para expresar el diferente oficio que cada caso tiene en latin nos servimos de preposiciones [...]» (págs. 2324).

GRAE-1796: «Estos diferentes modos de significar, ó lo que es igual, las variaciones de significado, que admiten las partes declinables de que hablamos, á excepcion del verbo, se llaman casos. Dáseles este nombre, porque ciertamente distinto caso es el de una palabra cuando significa la cosa de un modo, que quando la significa de otro, ó no está en el mismo caso una vez que otra» (pág. 6). 
DRAE-1803: «s.m. [...] CASO. Gram. La diferente significacion de los nombres por razon de la diversidad de sus terminaciones, ó por las preposiciones con que se juntan, como del hombre, ó para el hombre [...]» (pág. 182,2).

DRAE-1817: «s.m. [...] CASO. Gram. La diferente significacion de los nombres por razon de la diversidad de sus terminaciones, ó por las preposiciones con que se juntan; como del hombre, ó para el hombre. Casus, desinentia nominis [...]» (pág. 186,3).

DRAE-1822: «s.m. [...] CASO. Gram. La diferente significacion de los nombres por razon de la diversidad de sus terminaciones, ó por las proposiciones [sic] con que se juntan; como del hombre, ó para el hombre. Casus, desinentia nominis [...]» (pág. 171,1).

DRAE-1832: «m. [...] ๆ Gram. La diferente significacion de los nombres por razon de la diversidad de sus terminaciones, ó por las proposiciones [sic] con que se juntan; como del hombre, ó para el hombre. Casus, desinentia nominis [...]» (pág. 155,2).

DRAE-1837: «m. [...] ๆ Gram. La diferente significacion de los nombres por razon de la diversidad de sus terminaciones, ó por las proposiciones [sic] con que se juntan; como del hombre, ó para el hombre. Casus, desinentia nominis [...]» (pág. 155,3).

DRAE-1843: «m. [...] व Gram. La diferente significacion de los nombres por razon de la diversidad de sus terminaciones, ó por las proposiciones [sic] con que se juntan; como del hombre, ó para el hombre. Casus, desinentia nominis [...]» (pág. 150,2).

\section{$2^{\mathrm{a}} \mathrm{m} . \mathrm{XIX}$ - p. XX}

DRAE-1852: «m. [...] I Gram. La diferente significacion de los nombres por razon de la diversidad de sus terminaciones, ó por las preposiciones con que se juntan; como del hombre, ó para el hombre. Casus, desinentia nominis [...]» (pág. 145,2).

En el Suplemento de este mismo año se incorpora la acepción de casos oblicuos: «Gram. Todos los del nombre á excepcion del nominativo» (pág. 731,1). 
GRAE-1854: No hay una definición de caso al modo de la GRAE anterior. La información que se ofrece es la que sigue: «Los accidentes de la declinacion del artículo, del nombre, del pronombre $y$ del participio en la lengua castellana, se verifican solo en los números y en los géneros; no en los casos, como en el latin, porque estos se distinguen por medio de preposiciones... Exceptúanse los pronombres personales, que varían de forma segun los casos, y señalan algunos de ellos sin el auxilio de las preposiciones [...]» (pág. 2).

GRAE-1858: Lo mismo que en la GRAE anterior: «Los accidentes de la declinacion del artículo, del nombre, del pronombre y del participio en la lengua castellana, se verifican sólo en los géneros y en los números; no en los casos, como en el latin, pues estos se distinguen por medio de preposiciones... Exceptúanse los pronombres personales, que varían segun los casos, y forman algunos de éstos sin el auxilio de las preposiciones» (pág. 2).

GRAE-1862: Lo mismo que en las dos GRAE anteriores: «Los accidentes de la declinacion del artículo, del nombre, del pronombre y del participio en la lengua castellana, se verifican sólo en los géneros y en los números; no en los casos, como en el latin, pues estos se distinguen por medio de preposiciones... Exceptúanse los pronombres personales, que varían segun los casos, y forman algunos de éstos sin el auxilio de las preposiciones» (pág. 6).

GRAE-1864: Lo mismo que en las tres GRAE anteriores: «Los accidentes de la declinacion del artículo, del nombre, del pronombre y del participio en la lengua castellana, se verifican sólo en los géneros y en los números; no en los casos, como en el latin, pues estos se distinguen por medio de preposiciones... Exceptúanse los pronombres personales, que varían segun los casos, y forman algunos de éstos sin el auxilio de las preposiciones» (pág. 6).

GRAE-1865: Lo mismo que en las cuatro ediciones anteriores: «Los accidentes de la declinacion del artículo, del nombre, del pronombre y del participio en la lengua castellana, se verifican sólo en los géneros y en los números; no en los casos, como en el latin, pues estos se distinguen por medio de preposiciones... Exceptúanse los pronombres personales, que varían segun los casos, y forman algunos de éstos sin el auxilio de las preposiciones» (pág. 6). 
DRAE-1869: «m. [...] đ Gram. La diferente significacion de los pronombres personales por razon de la diversidad de sus terminaciones, ó la diferente aplicacion de los nombres por las preposiciones con que se juntan; como del hombre, ó para el hombre [...]» (pág. 160,3). CASOS OBLICUOS: «Gram. Todos, á excepcion del nominativo» (pág. 160,3).
GRAE-1866: Lo mismo que en las cinco ediciones anteriores: «Los accidentes de la declinacion del artículo, del nombre, del pronombre y del participio en la lengua castellana, se verifican sólo en los géneros y en los números; no en los casos, como en el latin, pues estos se distinguen por medio de preposiciones... Exceptúanse los pronombres personales, que varían segun los casos, y forman algunos de éstos sin el auxilio de las preposiciones» (pág. 6).

GRAE-1867: Lo mismo que en las Gramáticas anteriores desde 1854: «Los accidentes de la declinacion del artículo, del nombre, del pronombre y del participio en la lengua castellana, se verifican sólo en los géneros y en los números; no en los casos, como en el latin, pues estos se distinguen por medio de preposiciones... Exceptúanse los pronombres personales, que varían segun los casos, y forman algunos de éstos sin el auxilio de las preposiciones» (pág. 6).

GRAE-1870: Tampoco en esta Gramática se da una definición estricta de caso: "por la cual [la declinación por casos] se conoce la relacion que tiene ó el oficio que hace [la palabra] en cada oracion con respecto al significado del verbo; mas como en nuestra lengua castellana esta relacion se determina por las preposiciones, han decidido con mejor acuerdo los gramáticos suprimir aquella declinacion por inútil, pues que sólo en el pronombre nos queda un rastro de ella» (págs. 7-8).

En el apartado de la Concordancia, se incluye una nota al pie referida al caso:

«(1) Queriendo alguos preceptistas asimilar nuestra gramática á la latina más de lo que á veces consiente su respectiva índole, ó tal vez con el designio de preparar á los jóvenes para el estudio de aquel idioma, han establecido que en las concordancias se comprenda el caso, así como el género y el número; pero no habiendo casos en nuestra lengua, rigorosamente hablando, como se dijo en la primera parte, pues á falta de declinacion, que es una de las excelencias del latin, se distinguen por medio de preposiciones, es ocioso el añadir á las concordancias de género y número una más, y ésta ficticia. Exceptúanse los pronombres personales que por sus várias desinencias tienen verdaderos casos, según se dijo en su lugar correspondiente» (pág. $169)$. 
GRAE-1874: «Estos casos [los de la declinación latina] se distinguen por la variacion de desinencia que cada uno produce en el vocablo declinable, y por la cual se conoce la relacion que tiene ó el oficio que hace en cada oracion, con respecto al significado del verbo; mas como en nuestra lengua castellana esta relacion se determina por las preposiciones, mudaron de acuerdo los gramáticos, suprimiendo la declinacion. Forzoso es, sin embargo, reconocer que si esto es así respecto de la material alteracion de la estructura del vocablo (bajo cuyo aspecto la Analogía puede afirmar que sólo en algunos pronombres nos queda vestigio de la declinacion latina), la Sintáxis no debe desentenderse de que en aquella lengua... los casos denotan la función ideológica, el oficio de cada palabra en la oracion. Ya se verifique esto por alteracion de desinencias ó por aditamento de preposiciones, la variacion existe: hay, pues, casos en castellano y en todas las lenguas» (págs. 19-20).

GRAE-1878: «Estos casos [los de la declinación latina] se distinguen por la variacion de desinencia que cada uno produce en el vocablo declinable, y por la cual se conoce la relacion que tiene ó el oficio que hace en cada oracion, con respecto al significado del verbo; mas como en nuestra lengua castellana esta relacion se determina por las preposiciones, mudaron de acuerdo los gramáticos, suprimiendo la declinacion. Forzoso es, sin embargo, reconocer que si esto es así respecto de la material alteracion de la estructura del vocablo (bajo cuyo aspecto la Analogía puede afirmar que sólo en algunos pronombres nos queda vestigio de la declinacion latina), la Sintáxis no debe desentenderse de que en aquella lengua... los casos denotan la función ideológica, el oficio de cada palabra en la oracion. Ya se verifique esto por alteracion de desinencias ó por aditamento de preposiciones, la variacion existe: hay, pues, casos en castellano y en todas las lenguas» (págs. 19-20).

GRAE-1880: En esta edición encontramos un propósito de definición más evidente: «El caso, ó determinada situación y circunstancias en que está la palabra que se declina, indícase generalmente, en castellano, por medio de artículos y preposiciones: en otros idiomas, como por ejemplo el latin, se manifiesta por la terminación del vocablo. Sin embargo, el pronombre personal español varía de formas, como las voces declinables de la lengua latina [...]» (pág. 10). 
DRAE-1884: «(Del lat. cāsus.) m. [...] ๆ Gram. Relación que tienen ú oficio que hacen en la oración sus partes declinables; relación y oficio que en unas lenguas, como en la latina, se indican por la variación que en sus terminaciones experimentan tales palabras, $y$ en las castellana, por análoga alteración de desinencias en el pronombre personal, y por aditamento de artículos ó preposiciones, ó de aquéllos y éstas al par, en el mismo pronombre y en las demás voces declinables, ó bien exclusivamente por el enlace de unas de estas voces con otras. Los casos son seis: nominativo, genitivo, dativo, acusativo, vocativo y ablativo [...]» (pág. 223,2).
GRAE-1883: «El caso, ó determinada situación y circunstancias en que está la palabra que se declina, indícase generalmente, en castellano, por medio de artículos y preposiciones: en otros idiomas, como por ejemplo el latin, se manifiesta por la terminación del vocablo. Sin embargo, el pronombre personal español varía de formas, como las voces declinables de la lengua latina [...]» (pág. 10).

GRAE-1885: «El caso, ó determinada situación y circunstancias en que está la palabra que se declina, indícase generalmente, en castellano, por medio de artículos y preposiciones: en otros idiomas, como por ejemplo el latin, se manifiesta por la terminación del vocablo. Sin embargo, el pronombre personal español varía de formas, como las voces declinables de la lengua latina [...]» (pág. 10).

GRAE-1888: «El caso, ó determinada situación y circunstancias en que está la palabra que se declina, indícase generalmente, en castellano, por medio de artículos y preposiciones: en otros idiomas, como por ejemplo el latin, se manifiesta por la terminación del vocablo. Sin embargo, el pronombre personal español varía de formas, como las voces declinables de la lengua latina [...]» (pág. 10).

GRAE-1890: «El caso, ó determinada situación y circunstancias en que está la palabra que se declina, indícase generalmente, en castellano, por medio de artículos y preposiciones: en otros idiomas, como por ejemplo el latin, se manifiesta por la terminación del vocablo. Sin embargo, el pronombre personal español varía de formas, como las voces declinables de la lengua latina [...]» (pág. 10). 
DRAE-1899: «(Del lat. casus.) m. [...] ๑ Gram. Relación que tienen ú oficio que hacen en la oración sus partes declinables; relación y oficio que en unas lenguas, como en la latina, se indican por la variación que en sus terminaciones experimentan tales palabras, y en las castellana, por análoga alteración de desinencias en el pronombre personal, y por aditamento de artículos ó preposiciones, ó de aquéllos y éstas al par, en el mismo pronombre y en las demás voces declinables, ó bien solamente por el enlace de unas de estas voces con otras. Los casos son seis: nominativo, genitivo, dativo, acusativo, vocativo y ablativo [...]» (pág. 207,1).

GRAE-1895: «El caso ó determinada situación y circunstancias en que está la palabra que se declina, indícase generalmente, en castellano, por medio de artículos y preposiciones: en otros idiomas, como por ejemplo el latin, se manifiesta por la terminación del vocablo. Sin embargo, el pronombre personal español varía de formas, como las voces declinables de la lengua latina [...]» (pág. 10).

GRAE-1900: «El caso ó determinada situación y circunstancias en que está la palabra que se declina, indícase generalmente, en castellano, por medio de artículos y preposiciones: en otros idiomas, como por ejemplo el latín, se manifiesta por la terminación del vocablo. Sin embargo, el pronombre personal español varía de formas, como las voces declinables de la lengua latina [...]» (pág. 10).

GRAE-1901: «El caso ó determinada situación y circunstancias en que está la palabra que se declina, indícase generalmente, en castellano, por medio de artículos y preposiciones: en otros idiomas, como por ejemplo el latín, se manifiesta por la terminación del vocablo. Sin embargo, el pronombre personal español varía de formas, como las voces declinables de la lengua latina [...]» (pág. 10).

GRAE-1904: «El caso ó determinada situación y circunstancias en que está la palabra que se declina, indícase generalmente, en castellano, por medio de artículos y preposiciones: en otros idiomas, como por ejemplo el latín, se manifiesta por la terminación del vocablo. Sin embargo, el pronombre personal español varía de formas, como las voces declinables de la lengua latina [...]» (págs. 10-11). 
GRAE-1906: «El caso ó determinada situación y circunstancias en que está la palabra que se declina, indícase generalmente, en castellano, por medio de artículos y preposiciones; en otros idiomas, como por ejemplo el latín, se manifiesta por la terminación del vocablo. Sin embargo, también el pronombre personal español varía de formas, como las voces declinables de la lengua latina [...]» (págs. 10$11)$.

GRAE-1908: «El caso ó determinada situación y circunstancias en que está la palabra que se declina, indícase generalmente, en castellano, por medio de artículos y preposiciones; en otros idiomas, como por ejemplo el latín, se manifiesta por la terminación del vocablo. Sin embargo, también el pronombre personal español varía de formas, como las voces declinables de la lengua latina [...]» (págs. 1011).

GRAE-1909: «El caso ó determinada situación y circunstancias en que está la palabra que se declina, indícase generalmente, en castellano, por medio de artículos y preposiciones; en otros idiomas, como por ejemplo el latín, se manifiesta por la terminación del vocablo. Sin embargo, el pronombre personal español varía de formas, como las voces declinables de la lengua latina [...]» (págs. 10-11).

GRAE-1911: «El caso o determinada situación y circunstancias en que está la palabra que se declina, indícase generalmente en castellano por medio de preposiciones, o sólo mediante el lugar que el substantivo ocupa en la frase; en otros idiomas, como por ejemplo el latin, se manifiesta por la terminación del vocablo. Sin embargo, también el pronombre personal español varía de formas, como las voces declinables de la lengua latina [...]» (pág. 10).

GRAE-1913: «El caso o determinada situación y circunstancias en que está la palabra que se declina, indícase generalmente en castellano por medio de preposiciones, o sólo mediante el lugar que e substantivo ocupa en la frase; en otros idiomas, como por ejemplo el latín, se manifiesta por la terminación del vocablo. Sin embargo, también el pronombre personal español varía de formas, como las voces declinables de la lengua latina; y no usa siempre las preposiciones que vamos a indicar […]» (págs. 10). 
DRAE-1914: «(Del lat. casus.) m. [...] ๆ ${ }^{6} \mathrm{Gram}$. Relación que tienen u oficio que hacen en la oración sus partes declinables; relación y oficio que en unas lenguas, como en la latina, se indican por la variación que en sus terminaciones experimentan tales palabras, y en las castellana, por análoga alteración de desinencias en el pronombre personal, y por medio de preposiciones en el mismo pronombre y en las demás voces declinables, o bien solamente por el enlace de unas de estas voces con otras. Los casos son seis: nominativo, genitivo, dativo, acusativo, vocativo y ablativo [...]» (pág. 214,3).
GRAE-1916: «El caso o determinada situación y circunstancias en que está la palabra que se declina, indícase generalmente en castellano por medio de preposiciones, o sólo mediante el lugar que e substantivo ocupa en la frase; en otros idiomas, como por ejemplo el latín, se manifiesta por la terminación del vocablo. Sin embargo, también el pronombre personal español varía de formas, como las voces declinables de la lengua latina; y no usa siempre las preposiciones que vamos a indicar [...]» (págs. 10).

GRAE-1917: «[...] el castellano no sigue un procedimiento único para indicar los distintos oficios del nombre en la oración: unas veces determina este oficio la preposición, y otras el lugar que el nombre ocupa en la frase; pero hay también casos en que el nombre se usa sin preposición, y el lugar de su colocación en la frase es indiferente [...]; y si los que estamos connaturalizados con la lengua distinguimos sin dificultad la distinta función que el nombre desempeña en estos casos, no así el extranjero que la haya de aprender en los textos; y como hasta nosotros mismos nos vemos en la precisión de emplear una nomenclatura gramatical que en la enseñanza del idioma nos sirva para distinguir los distintos oficios que el nombre desempeña en la oración, creemos conveniente y hasta necesario conservar la tradicional nomenclatura de los casos y su distinción» (págs. 163-164).

GRAE-1920: «[...] el castellano no sigue un procedimiento único para indicar los distintos oficios del nombre en la oración: unas veces determina este oficio la preposición, y otras el lugar que el nombre ocupa en la frase; pero hay también casos en que el nombre se usa sin preposición, y el lugar de su colocación en la 
DRAE-1925: «(Del lat. casus.) m. [...] ब 6. Gram. Relación que tienen u oficio que hacen en la oración sus partes declinables. En unas lenguas, como en la latina, esta relación y oficio se indican por la variación que en sus terminaciones experimentan tales palabras, y en las castellana, por análoga alteración de desinencias en el pronombre personal, y por medio de preposiciones en el mismo pronombre y en las demás voces declinables, o bien solamente por el enlace de unas de estas voces con otras. Los casos son seis: nominativo, genitivo, dativo, acusativo, vocativo y ablativo [...]» (pág. 257,1). frase es indiferente [...]; y si los que estamos connaturalizados con la lengua distinguimos sin dificultad la distinta función que el nombre desempeña en estos casos, no así el extranjero que la haya de aprender en los textos; y como hasta nosotros mismos nos vemos en la precisión de emplear una nomenclatura gramatical que en la enseñanza del idioma nos sirva para distinguir los distintos oficios que el nombre desempeña en la oración, creemos conveniente y hasta necesario conservar la tradicional nomenclatura de los casos y su distinción» (págs. 183-184).

GRAE-1924: «[...] el castellano no sigue un procedimiento único para indicar los distintos oficios del nombre en la oración: unas veces determina este oficio la preposición, y otras el lugar que el nombre ocupa en la frase; pero hay también casos en que el nombre se usa sin preposición, y el lugar de su colocación en la frase es indiferente [...]; y si los que estamos connaturalizados con la lengua distinguimos sin dificultad la distinta función que el nombre desempeña en estos casos, no así el extranjero que la haya de aprender en los textos; y como hasta nosotros mismos nos vemos en la precisión de emplear una nomenclatura gramatical que en la enseñanza del idioma nos sirva para distinguir los distintos oficios que el nombre desempeña en la oración, creemos conveniente y hasta necesario conservar la tradicional nomenclatura de los casos y su distinción» (págs. 183-184). 


\section{COMHINAR}

\section{SIGLO XVIII}

Autoridades: «v.a. Comparar ò cotejar alguna cola con otra, examinando el refpecto ó relacion que tienen entre sí, yá lea de uniformidad, u de contrariedad: como la piedad de uno con la de otro, la liberalidad de uno, con la miféria de otro. Lat. Aliquid alicui confirre, comparare

[…] (1729, pág. 427,2 y 428,1).

GRAE-1771:

DRAE-1780: «v.a. Ordenar, disponer cosas entre sí diferentes con tal método, que resulte de ellas un compuesto; y así se COMBINAN las letras para formar una diccion, y los números para formar una cantidad. Combinare.

Combinar. Comparar, cotejar una cosa con otra, examinando los varios respectos, ó relaciones que tienen entre sí. Comparare, conferre.

[...]» (pág. 244,3).

DRAE-1783: «v.a. Ordenar, disponer cosas entre sí diferentes con tal método, que resulte de ellas un compuesto; y así se COMBINAN las letras para formar una diccion, y los números para formar una cantidad. Combinare.

Combinar. Comparar, cotejar una cosa con otra, examinando los varios respectos, ó relaciones que tienen entre sí. Comparare, conferre.

[...]» (pág. 259,1).

DRAE-1791: «v.a. Ordenar, disponer cosas entre sí diferentes con tal método, que resulte de ellas un compuesto; y así se COMBINAN las letras para formar una diccion, y los números para formar una cantidad. Combinare. 2. Comparar, cotejar una cosa con otra, examinando los varios respectos, ó relaciones que tienen entre sí. Comparare, conferre

[...]» (pág. 233,3). 


\section{$1^{\text {a }}$ mitad del XIX}

DRAE-1803: «v.a. Ordenar, disponer cosas entre sí diferentes con tal método, que resulte de ellas un compuesto; y así se COMBINAN las letras para formar una diccion, y los números para formar una cantidad. Combinare.

Combinar. Comparar, cotejar una cosa con otra, examinando los varios respectos, ó relaciones que tienen entre sí. Comparare, conferre. [...]» (pág. 209,1).

DRAE-1817: «v.a. Ordenar, disponer cosas entre sí diferentes con tal método que resulte de ellas un compuesto; y así se COMBINAN las letras para formar una diccion, y los números para formar una cantidad. In unum conjungere, aptare.

Combinar. Comparar, cotejar una cosa con otra, examinando los varios respectos ó relaciones que tienen entre sí. Comparare, conferre. [...]» (pág. 215,1).

DRAE-1822: «v.a. Ordenar, disponer cosas entre sí diferentes con tal método que resulte de ellas un compuesto; y así se COMBINAN las letras para formar una diccion, y los números para formar una cantidad. In unum conjungere, aptare.

Combinar. Comparar, cotejar una cosa con otra, examinando los varios respectos ó relaciones que tienen entre sí. Comparare, conferre. [...]» (pág. 197,3).

DRAE-1832: «a. Ordenar, disponer cosas entre sí diferentes con tal método que resulte de ellas un compuesto; y así se COMBINAN las letras para formar una diccion, y los números para formar una cantidad. In unum conjungere, aptare.

Combinar. Comparar, cotejar una cosa con otra, examinando las varias relaciones que tienen entre sí. Comparare, conferre. [...]» (pág. $180,3)$.

DRAE-1837: «a. Ordenar, disponer cosas entre sí diferentes con tal método que resulte de ellas un compuesto; y así se COMBINAN las letras para formar una diccion, y los números para formar una cantidad. In unum conjungere, aptare. ๆ Comparar, cotejar una cosa con otra, examinando las varias relaciones que tienen entre sí. Comparare, conferre [...]» (pág. 180,3). 
DRAE-1843: «a. Ordenar, disponer cosas entre sí diferentes con tal método que resulte de ellas un compuesto; y así se COMBINAN las letras para formar una diccion, y los números para formar una cantidad. In unum conjungere, aptare. Q Comparar, cotejar una cosa con otra, examinando las varias relaciones que tienen entre sí. Comparare, conferre [...]» (pág. 175,2).

\section{$2^{a}$ m. XIX - p. XX}

DRAE-1852: «a. Ordenar, disponer cosas entre sí diferentes con tal método que resulte de ellas un compuesto; y así se COMBINAN las letras para formar una diccion, y los números para formar una cantidad. In unum conjungere, aptare. - Comparar, cotejar una cosa con otra, examinando las varias relaciones que tienen entre sí. Comparare, conferre [...]» (pág. 169,2).

\section{GRAE-1854:}

GRAE-1858:

GRAE-1862:

GRAE-1864:

GRAE-1865:

GRAE-1866:

GRAE-1867:

DRAE-1869: «a. Ordenar, disponer cosas entre sí diferentes con tal método que resulte de ellas un compuesto; y así se COMBINAN las letras para formar una diccion, y los números para formar una cantidad. I Comparar, cotejar una cosa con otra, examinando las varias relaciones que tienen entre sí [...]» (pág. $169,2)$.

\section{GRAE-1870:}

GRAE-1874:

GRAE-1878:

GRAE-1880:

GRAE-1883: 
DRAE-1884: «(Del lat. combināre; de cum, con, y bini, dos.) a. Unir ó mezclar cosas diversas, de manera que formen un compuesto ó agregado. đ Comparar, cotejar una cosa con otra, examinando las varias relaciones que tienen entre sí $[\ldots]$ (pág. 261,3).

GRAE-1885:

GRAE-1888:

GRAE-1890:

GRAE-1895:

DRAE-1899: «(Del lat. combināre; de cum, con, y bini, dos.) a. Unir cosas diversas, de manera que formen un compuesto ó agregado [...]» (pág. 243,2).

DRAE-1914: «(Del lat. combināre; de cum, con, y bini, de dos en dos.) a. Unir cosas diversas, de manera que formen un compuesto o agregado [...]» (pág. 252,1).

\section{GRAE-1900:}

GRAE-1901:

GRAE-1904:

GRAE-1906:

GRAE-1908:

GRAE-1909:

GRAE-1911:

GRAE-1913:

GRAE-1916:

GRAE-1917:

GRAE-1920:

GRAE-1924:

DRAE-1925: «(Del lat. combināre; de cum, con, y bini, dos.) tr. Unir cosas diversas, de manera que formen un compuesto o agregado [...]» (pág. 305,3). 


\section{COMPLEMENTO}

\section{SIGLO XVIII}

Autoridades: «f.m. El lleno, cumplimiento y perfeccion de alguna cofa. Viene del Latino Complementum, que fignifica efto milm. M. AGRED. tom. I. num. 191. Sea única imagen y fimilitud de nueftra Divinidad, y fea en nueftra preféncia por todas las eternidades complemento de nueftro beneplácito y agrado. MoRet, Annal. Lib. I. cap. 3. Complemento de toda aculsacion atróz, y cargo el mas poderofo para con los Miniftros y Gobernadóres de los Príncipes. Palom. Vid. de Pint. Pl. 409. Las tres Artes juntas dán el complemento de la perfeccion à las obras, como le vé en los retablos antiguos [...]» (1729, pág. 451,2 y 452,1$)$.

GRAE-1771: No se habla de él.

DRAE-1780: «s.m. La perfeccion, el colmo de alguna cosa. Complementum» (pág. 249,1).

DRAE-1783: «s.m. La perfeccion, el colmo de alguna cosa. Complementum» (pág. 263,2).

DRAE-1791: «s.m. La perfeccion, el colmo de alguna cosa. Complementum» (pág. 237,3).

GRAE-1796: No se habla de él.

\section{$1^{\mathrm{a}}$ mitad del XIX}

DRAE-1803: «s.m. La perfeccion, el colmo de alguna cosa. Complementum» (pág. 212,3).

DRAE-1817: «s.m. La perfeccion, el colmo de alguna cosa. Complementum» (pág. 219,1).

DRAE-1822: «s.m. La perfeccion, el colmo de alguna cosa. Complementum» (pág. 201,2).

DRAE-1832: «m. La perfeccion, el colmo de alguna cosa. Complementum» (pág. 184,1).

DRAE-1837: «m. La perfeccion, el colmo de alguna cosa. Complementum» (pág. 184,1).

DRAE-1843: «m. La perfeccion, el colmo de alguna cosa. Complementum» (pág. 178,2). 


\section{$2^{\mathrm{a}}$ m. XIX - p. XX}

DRAE-1852: «m. La perfeccion, el colmo de alguna cosa. Complementum» (pág. 172,1).
GRAE-1854: Uso esporádico; no se define. Referencia al complemento encontramos en el fragmento que sigue: «La oracion primera de verbo recíproco se compone de nominativo, verbo, y un complemento, que puede ser otro verbo, ó un nombre, regidos por preposicion, v. gr.: Tú te abstienes de votar; Pabo se atreve á todo; ó un simple adverbio, como: Los poderosos se engrien fácilmente [...]» (págs. 165-166).

GRAE-1858: Uso esporádico; no se define. Referencia al complemento encontramos en el fragmento correspondiente al transcrito de la edición anterior con un cambio de redacción: «La oracion de verbo recíproco se compone de uno que lo sea, ó se use como tal, precediéndole el correspondiente nominativo, v. gr.: Miguel se queja. Muchas veces se le agrega algun complemento de nombre ó verbo regidos por preposicion, en esta forma: Tú te abstienes de votar; Pabo se atreve á todo; ó un simple adverbio, como: Los poderosos se engrien fácilmente» (pág. 183).

GRAE-1862: Uso esporádico; no se define. Referencia: «La oracion de verbo recíproco se compone de uno que lo sea, ó se use como tal, precediéndole el correspondiente nominativo, $\mathbf{v}$. gr.: Miguel se queja. Muchas veces se le agrega algun complemento de nombre ó verbo regidos por preposicion, en esta forma: Tú te abstienes de votar; Pabo se atreve á todo; ó un simple adverbio, como: Los poderosos se engríen fácilmente» (pág. 187).

GRAE-1864: Uso esporádico; no se define. Referencia: «La oracion de verbo recíproco se compone de uno que lo sea, ó se use como tal, precediéndole el correspondiente nominativo, $v$. gr.: Miguel se queja. Muchas veces se le agrega algun complemento de nombre ó verbo regidos por preposicion, en esta forma: Tú te abstienes de votar; Pablo se atreve á todo; ó un simple adverbio, como: Los poderosos se engrien fácilmente» (pág. 187).

GRAE-1865: Uso esporádico; no se define. Referencia: «La oracion de verbo recíproco se compone de uno que lo sea, ó se use como tal, precediéndole el correspondiente nominativo, $\mathbf{v}$. gr.: Miguel se queja. Muchas veces se le agrega algun complemento de nombre ó verbo regidos 
DRAE-1869: «m. La perfeccion, el colmo de alguna cosa» (pág. 191,2) por preposicion, en esta forma: Tú te abstienes de votar; Pablo se atreve á todo; ó un simple adverbio, como: Los poderosos se engrien fácilmente. (pág. 187).

GRAE-1866: Uso esporádico; no se define. Referencia: «La oracion de verbo recíproco se compone de uno que lo sea, ó se use como tal, precediéndole el correspondiente nominativo, $\mathbf{v}$. gr.: Miguel se queja. Muchas veces se le agrega algun complemento de nombre ó verbo regidos por preposicion, en esta forma: Tú te abstienes de votar; Pablo se atreve á todo; ó un simple adverbio, como: Los poderosos se engrien fácilmente» (pág. 187).

GRAE-1867: Uso esporádico; no se define. Referencia: «La oracion de verbo recíproco se compone de uno que lo sea, ó se use como tal, precediéndole el correspondiente nominativo, $v$. gr.: Miguel se queja. Muchas veces se le agrega algun complemento de nombre ó verbo regidos por preposicion, en esta forma: Tú te abstienes de votar; Pablo se atreve á todo; ó un simple adverbio, como: Los poderosos se engrien fácilmente» (pág. 187).

GRAE-1870: «por complemento se entiende la palabra, ó conjunto de ellas, en que termina la accion ó aplicación del verbo, ya directa, ya indirectamente» (pág. 206).

«Hay complementos simples, que constan solamente de un adjetivo ó nombre propio, ó de un nombre comun entre un artículo y un adjetivo, etc.; y hay complementos compuestos, que constan de varios términos, primero, segundo, tercero, etc. Puede, pues, haber sujetos y complementos que formen oraciones enteras» (pág. 212).

«El complemento puede ser directo ó indirecto. Será directo cualquiera palabra, precedida ó no de artículo, en que termine la accion del verbo, con la preposicion á ó sin ella [...] Cualquier otro complemento... que repugne este cambio [la conversión a pasiva] y lleve la preposicion á... será indirecto» (pág. 212).

GRAE-1874: «por complemento se entiende la palabra, ó conjunto de ellas, en que termina la accion ó aplicación del verbo, ya directa, ya indirectamente» (pág. 234).

«Hay complementos simples, que constan solamente de un adjetivo ó nombre propio, ó de un nombre comun entre un artículo y un adjetivo, etc.; y hay complementos compuestos, 
que constan de varios términos, primero, segundo, tercero, etc. [...]» (pág. 239).

«El complemento puede ser directo ó indirecto. Será directo cualquier palabra, precedida ó no de artículo, en que termine la accion del verbo, con la preposicion á ó sin ella [...] Cualquier otro complemento... que repugne este cambio [la conversión a pasiva] y lleve la preposicion á... será indirecto» (pág. 240).

GRAE-1878: «por complemento se entiende la palabra, ó conjunto de ellas, en que termina la accion ó aplicacion del verbo, ya directa, ya indirectamente» (pág. 234).

«Hay complementos simples, que constan solamente de un adjetivo ó nombre propio, ó de un nombre comun entre un artículo y un adjetivo, etc.; y hay complementos compuestos, que constan de varios términos, primero, segundo, tercero, etc [...]» (pág. 239)

«El complemento puede ser directo ó indirecto. Será directo cualquier palabra, precedida ó no de artículo, en que termine la accion del verbo, con la preposicion á ó sin ella [...] Cualquier otro complemento... que repugne este cambio [la conversión a pasiva] y lleve la preposicion á... será indirecto» (pág. 240).

GRAE-1880: «por complemento se entiende la palabra, ó conjunto de ellas, en que termina la acción ó aplicación del verbo, ya directa, ya indirectamente» (pág. 245).

«Hay complementos simples, que constan solamente de un adjetivo ó nombre propio, ó de un nombre común entre un artículo y un adjetivo, etc.; y hay complementos compuestos, que constan de varios términos, primero, segundo, tercero, etc. Puede, pues, haber sujetos y complementos de indefinida extensión» (pág. 250)

«El complemento puede ser directo ó indirecto. Será directo cualquier palabra, precedida ó no de artículo, en que termine la acción del verbo, con la preposición á ó sin ella [...] Cualquier otro complemento... que repugne este cambio [la conversión a pasiva] y lleve la preposición á... será indirecto» (págs. 250-251).

GRAE-1883: «por complemento se entiende la palabra, ó conjunto de ellas, en que termina la acción ó aplicación del verbo, ya directa, ya indirectamente» (pág. 245).

«Hay complementos simples, que constan solamente de un adjetivo ó nombre propio, ó de un nombre común con artículo, ó con artículo y adjetivo, etc.; y hay complementos compuestos, que constan de varios términos, primero, 
DRAE-1884: (Del lat. complemēntum) m. [...] ๆ Gram. Palabra ó frase en que recae ó á que se aplica la acción del verbo. I directo. Gram. El que recibe la acción del verbo directamente, mediando ó no preposición; v.gr.: San Fernando conquistó Á SEVILLA; Cervantes escribió EL QuiJote; y se distingue por la circunstancia de poder trocarse en nominativo ó sujeto de la oración pasiva, como se ve en los ejemplos siguientes: SEvILLA fué conquistada por San Fernando; EL QUiJote fué escrito por Cervantes. II indirecto. Gram. El que no puede experimentar el cambio en nominativo, y expresa el objeto final de la acción del verbo, recibiéndola con preposición indirectamente; v.gr.: Santiago vino Á EsPaÑa; doña Beatriz Galindo enseñó EL LATÍN (complemento directo) Á LA REINA CATÓLICA (complemento indirecto) (pág. 266,2). segundo, tercero, etc. Puede, pues, haber sujetos y complementos de indefinida extensión» (pág. 250).

«El complemento puede ser directo ó indirecto. Será directo cualquier palabra, precedida ó no de artículo, en que termine la acción del verbo, con la preposición á ó sin ella [...] Cualquier otro complemento... que repugne este cambio [la conversión a pasiva] y lleve la preposición á... será indirecto» (págs. 250-251).

GRAE-1885: «por complemento se entiende la palabra, ó conjunto de ellas, en que termina la acción ó aplicación del verbo, ya directa, ya indirectamente» (pág. 247).

«Hay complementos simples, que constan solamente de un adjetivo ó nombre propio, ó de un nombre común con artículo, ó con artículo y adjetivo, etc.; y hay complementos compuestos, que constan de varios términos, primero, segundo, tercero, etc. [...]» (pág. 252)

«El complemento puede ser directo ó indirecto. Será directo cualquier palabra, precedida ó no de artículo, en que termine la acción del verbo, con la preposición á ó sin ella [...] Cualquier otro complemento... que repugne este cambio [la conversión a pasiva] y lleve la preposición á... será indirecto» (págs. 252-253).

GRAE-1888: «por complemento se entiende la palabra, ó conjunto de ellas, en que termina la acción ó aplicación del verbo, ya directa, ya indirectamente» (pág. 245).

«Hay complementos simples, que constan solamente de un adjetivo ó nombre propio, ó de 
DRAE-1899: (Del lat. complementum.) m. [...] 9 Gram. Palabra ó frase en que recae ó á que se aplica la acción del verbo. T directo. Gram. El que recibe la acción del verbo directamente, mediando ó no preposición; v.gr.: San Fernando conquistó Á SEviLla; Cervantes escribió EL QUiJote; y se un nombre común con artículo, ó con artículo y adjetivo, etc.; y hay complementos compuestos, que constan de varios términos, primero, segundo, tercero, etc. [...]» (pág. 250)

«El complemento puede ser directo ó indirecto. Será directo cualquier palabra, precedida ó no de artículo, en que termine la acción del verbo, con la preposición á ó sin ella [...] Cualquier otro complemento... que repugne este cambio [la conversión a pasiva] y lleve la preposición á... será indirecto» (págs. 250-251).

GRAE-1890: "por complemento se entiende la palabra, ó conjunto de ellas, en que termina la acción ó aplicación del verbo, ya directa, ya indirectamente» (pág. 245).

«Hay complementos simples, que constan solamente de un adjetivo ó nombre propio, ó de un nombre común con artículo, ó con artículo y adjetivo, etc.; y hay complementos compuestos, que constan de varios términos, primero, segundo, tercero, etc. [...]» (pág. 250)

«El complemento puede ser directo ó indirecto. Será directo cualquier palabra, precedida ó no de artículo, en que termine la acción del verbo, con la preposición á ó sin ella [...] Cualquier otro complemento... que repugne este cambio [la conversión a pasiva] y lleve la preposición á... será indirecto» (págs. 250-251).

GRAE-1895: "por complemento se entiende la palabra, ó conjunto de ellas, en que termina la acción ó aplicación del verbo, ya directa, ya indirectamente» (pág. 245).

«Hay complementos simples, que constan solamente de un adjetivo ó nombre propio, ó de un nombre común con artículo, ó con artículo y adjetivo, etc.; y hay complementos compuestos, que constan de varios términos, primero, segundo, tercero, etc. [...]» (pág. 250)

«El complemento puede ser directo ó indirecto. Será directo cualquier palabra, precedida ó no de artículo, en que termine la acción del verbo, con la preposición á ó sin ella; v. gr.: Adán cultivó LA TIERRA; Caín mató Á $\mathrm{ABEL}$; no ofendáis Á DIOS; el nombre rige $\mathrm{AL}$ VERBo; escúchaMe. [...] Cualquier otro complemento... que repugne este cambio [la conversión a pasiva] y lleve la preposición á, como sucede en voy á Madrid, camino Á caballo, será indirecto» (págs. 250-251). 
distingue por la circunstancia de poder trocarse en nominativo ó sujeto de la oración pasiva, como se ve en los ejemplos siguientes: SEVILLA fué conquistada por San Fernando; EL QUiJote fué escrito por Cervantes. II indirecto. Gram. El que no puede experimentar el cambio en nominativo, y expresa el objeto final de la acción del verbo, recibiéndola con preposición indirectamente; v.gr.: Santiago vino Á ESPAÑA; doña Beatriz Galindo enseñó EL LATÍN (complemento directo) á LA REINA CATÓLICA (complemento indirecto) (pág. 247,3).
GRAE-1900: "por complemento se entiende la palabra, ó conjunto de ellas, en que termina la acción ó aplicación del verbo, ya directa, ya indirectamente» (pág. 245).

«Hay complementos simples, que constan solamente de un adjetivo ó nombre propio, ó de un nombre común con artículo, ó con artículo y adjetivo, etc.; y hay complementos compuestos, que constan de varios términos, primero, segundo, tercero, etc. [...]» (pág. 250)

«El complemento puede ser directo ó indirecto. Será directo cualquier palabra, precedida ó no de artículo, en que termine la acción del verbo, con la preposición á ó sin ella; v. gr.: Adán cultivó LA TIERRA; Caín mató Á ABEL; no ofendáis Á DIOS; el nombre rige $\mathrm{AL}$ VERBo; escúchaMe. [...] Cualquier otro complemento... que repugne este cambio [la conversión a pasiva] y lleve la preposición á, como sucede en voy Á Madrid, camino Á caballo, será indirecto» (págs. 250-251).

GRAE-1901: "por complemento se entiende la palabra, ó conjunto de ellas, en que termina la acción ó aplicación del verbo, ya directa, ya indirectamente» (pág. 245).

«Hay complementos simples, que constan solamente de un adjetivo ó nombre propio, ó de un nombre común con artículo, ó con artículo y adjetivo, etc.; y hay complementos compuestos, que constan de varios términos, primero, segundo, tercero, etc. [...]» (pág. 250

«El complemento puede ser directo ó indirecto. Será directo cualquier palabra, precedida ó no de artículo, en que termine la acción del verbo, con la preposición á ó sin ella; v. gr.: Adán cultivó LA TIERRA; Caín mató Á ABEL; no ofendáis Á DIOS; el nombre rige $\mathrm{AL}$ VERBO; escúchaMe. [...] Cualquier otro complemento... que repugne este cambio [la conversión a pasiva] y lleve la preposición á, como sucede en voy Á Madrid, camino Á caballo, será indirecto» (págs. 250-251). 
GRAE-1904: "por complemento se entiende la palabra, ó conjunto de ellas, en que termina la acción ó aplicación del verbo, ya directa, ya indirectamente» (pág. 239).

«Hay complementos simples, que constan solamente de un adjetivo ó nombre propio, ó de un nombre común con artículo, ó con artículo y adjetivo, etc.; y hay complementos compuestos, que constan de varios términos, primero, segundo, tercero, etc. [...]» (pág. 244)

«El complemento puede ser directo ó indirecto. Será directo cualquier palabra, precedida ó no de artículo, en que termine la acción del verbo, con la preposición á ó sin ella [...] Cualquier otro complemento... que repugne este cambio [la conversión a pasiva] y lleve la preposición á... será indirecto» (págs. 244-245).

GRAE-1906: "por complemento se entiende la palabra, ó conjunto de ellas, en que termina la acción ó aplicación del verbo, ya directa, ya indirectamente» (pág. 239).

«Hay complementos simples, que constan solamente de un adjetivo ó nombre propio ó de un nombre común con artículo, ó con artículo y adjetivo, etc.; y hay complementos compuestos, que constan de varios términos, primero, segundo, tercero, etc. [...]» (pág. 244)

«El complemento puede ser directo ó indirecto. Será directo cualquier palabra, precedida ó no de artículo, en que termine la acción del verbo, con la preposición á ó sin ella; v. gr.: Adán cultivó LA TIERRA; Caín mató Á $\mathrm{ABEL}$; no ofendáis Á DIOS; el nombre rige $\mathrm{AL}$ VERBo; escúchaMe. [...] Cualquier otro complemento... que repugne este cambio [la conversión a pasiva] y lleve la preposición á, como sucede en voy Á Madrid, camino Á caballo, será indirecto» (págs. 244-245).

GRAE-1908: «por complemento se entiende la palabra, ó conjunto de ellas, en que termina la acción ó aplicación del verbo, ya directa, ya indirectamente» (pág. 239).

«Hay complementos simples, que constan solamente de un adjetivo ó nombre propio, ó de un nombre común con artículo, ó con artículo y adjetivo, etc.; y hay complementos compuestos, que constan de varios términos, primero, segundo, tercero, etc. [...]» (pág. 244)

«El complemento puede ser directo ó indirecto. Será directo cualquier palabra, precedida ó no de artículo, en que termine la acción del verbo, con la preposición á ó sin ella; verbigracia: Adán cultivó LA TIERRA; Caín mató Á ABEL; no ofendáis Á DIOS; el nombre rige AL VERBo; escúchaMe. [...] Cualquier otro complemento... que repugne este cambio [la conversión a pasiva] y lleve la preposición á, 
como sucede en voy Á Madrid, camino Á caballo, será indirecto» (págs. 244-245).

GRAE-1909: "por complemento se entiende la palabra, ó conjunto de ellas, en que termina la acción ó aplicación del verbo, ya directa, ya indirectamente» (pág. 239).

«Hay complementos simples que constan solamente de un adjetivo ó nombre propio, ó de un nombre común con artículo, ó con artículo y adjetivo, etc., y hay complementos compuestos, que constan de varios términos, primero, segundo, tercero, etc. [...]» (pág. 244)

«El complemento puede ser directo ó indirecto. Será directo cualquier palabra, precedida ó no de artículo, en que termine la acción del verbo, con la preposición á ó sin ella; verbigracia: Adán cultivó LA TIERRA; Caín mató Á ABEL; no ofendáis Á DIOS; el nombre rige $\mathrm{AL}$ VERBO; escúchaME. [...]

Cualquier otro complemento... que repugne este cambio [la conversión a pasiva] y lleve la preposición á, como sucede en voy á Madrid, camino Á caballo, será indirecto» (págs. 244$245)$.

GRAE-1911: «complemento es la palabra, o conjunto de ellas, que recibe la acción o que completa o determina la atribución expresada por el verbo, ya directa, ya indirectamente» (pág. 245).

Hay complementos simples que constan solamente de un adjetivo o nombre propio, o de un nombre común con artículo, o con artículo y adjetivo, etc.; y hay complementos compuestos que constan de varios términos, primero, segundo, tercero, etc. [...]» (pag. 251).

«El complemento puede ser directo o indirecto. Será directo cualquier palabra, precedida o no de artículo, en que termine la acción del verbo, con la preposición $a$ o sin ella $[\ldots]$

Cualquier otro complemento... que repugne este cambio [la conversión a pasiva] y lleve la preposición a... será indirecto» (pág. 251).

GRAE-1913: «complemento es la palabra, o conjunto de ellas, que recibe la acción o que completa o determina la atribución expresada por el verbo, ya directa, ya indirectamente: Juan parte LEÑA; Juan es más bajo que PEDRO.» (pág. 245).

«Hay complementos simples que constan solamente de un adjetivo o nombre propio, o de un nombre común con artículo, o con artículo y adjetivo, etc.; y hay complementos compuestos que constan de varios términos, primero, segundo, tercero, etc. [...]» (pag. 251).

«El complemento puede ser directo o indirecto. Será directo cualquier palabra, precedida o no de artículo, en que termine la 
DRAE-1914: (Del lat. complementum.) m. [...] ब ${ }^{4}$ Gram. Palabra o frase en que recae o a que se aplica la acción del verbo. $\uparrow$ directo. Gram. El que recibe la acción del verbo directamente, mediando o no preposición; v.gr.: San Fernando conquistó a SEvilla; Cervantes escribió EL QUIJOTE; y se distingue por la circunstancia de poder trocarse en nominativo o sujeto de la oración pasiva, como se ve en los ejemplos siguientes: SEvILLA fué conquistada por San Fernando; EL QUiJote fué escrito por Cervantes. I indirecto. Gram. El que no puede experimentar el cambio en nominativo y expresa el objeto final de la acción del verbo, recibiéndola con preposición indirectamente; v.gr.: Santiago vino A ESPAÑA; doña Beatriz Galindo enseñó EL LATÍN (complemento directo) A LA REINA CATÓLICA (complemento indirecto) (pág. 256,3). acción del verbo, con la preposición $a$ o sin ella: v. gr.: Adán cultivó LA TIERRA; Caín mató A $\mathrm{ABEL}$; no ofendáis A DIOS; el nombre rige $\mathrm{AL}$ VERBO; escúchaME. [...]

Cualquier otro complemento... que repugne este cambio [la conversión a pasiva] y lleve la preposición $a$, como sucede en voy A Madrid, camino A caballo, será indirecto» (pág. 251).

GRAE-1916: «complemento es la palabra, o conjunto de ellas, que recibe la acción o que completa o determina la atribución expresada por el verbo, ya directa, ya indirectamente: Juan parte LEÑA; el padre de Juan es más bajo que PEDRO.» (pág. 245).

«Hay complementos simples que constan solamente de un adjetivo o nombre propio, o de un nombre común con artículo, o con artículo y adjetivo, etc.; y hay complementos compuestos que constan de varios términos, primero, segundo, tercero, etc. [...]» (pag. 251).

«El complemento puede ser directo o indirecto. Será directo cualquier palabra, precedida o no de artículo, en que termine la acción del verbo, con la preposición $a$ o sin ella: v. gr.: Adán cultivó LA TIERRA; Caín mató A ABEL; no ofendáis A DIOS; el nombre rige AL VERBO; escúchaME. [...]

Cualquier otro complemento... que repugne este cambio [la conversión a pasiva] y lleve la preposición $a$, como sucede en voy A Madrid, camino A caballo, será indirecto» (pág. 251).

GRAE-1917: «Las palabras que sirven para determinar y precisar la significación de otras, se llaman complementos» [p. 149]. «[...] De ahí la necesidad de otros vocablos que vengan a precisar la expresión del sujeto y la del 
DRAE-1925: (Del lat. complementum.) m. [...] ๆ 6. Gram. Palabra o frase en que recae o a que se aplica la acción del verbo. $\mid$ directo. Gram. El que recibe la acción del verbo directamente, mediando o no preposición; v.gr.: San Fernando conquistó a SEVILLA; Cervantes escribió EL QuiJote. Se distingue por la circunstancia de poder trocarse en nominativo o sujeto de la oración pasiva, como se ve en los ejemplos siguientes: Sevilla fué conquistada por San Fernando; EL QuiJote fué escrito por Cervantes. I indirecto. Gram. El que no puede experimentar el cambio en nominativo y expresa el objeto final de la acción del verbo, recibiéndola con preposición indirectamente; v.gr.: Santiago vino A ESPAÑA; doña Beatriz Galindo enseñó EL LATín (complemento directo) A LA REINA CATÓLICA (complemento indirecto) (pág. $310,3)$.

predicado. Estos vocablos se llaman complementos, y pueden referirse ya al sujeto sólo, ya al predicado sólo, ya a los dos a la vez, constituyendo en el primer caso lo que llamaremos complementos del sujeto; en el segundo, complementos del predicado verbal, y en el tercero, predicados de complemento» (pág. $156)$.

GRAE-1920: «Las palabras que sirven para determinar y precisar la significación de otras, se llaman complementos» [p. 169]. «[...] De ahí la necesidad de otros vocablos que vengan a precisar la expresión del sujeto y la del predicado. Estos vocablos se llaman complementos, y pueden referirse ya al sujeto sólo, ya al predicado sólo, ya a los dos a la vez, constituyendo en el primer caso lo que llamaremos complementos del sujeto; en el segundo, complementos del predicado verbal, y en el tercero, predicados de complemento» (pág. 176).

GRAE-1924: «Las palabras que sirven para determinar y precisar la significación de otras, se llaman complementos» [p. 169]. «[...] De ahí la necesidad de otros vocablos que vengan a precisar la expresión del sujeto y la del predicado. Estos vocablos se llaman complementos, y pueden referirse ya al sujeto sólo, ya al predicado sólo, ya a los dos a la vez, constituyendo en el primer caso lo que llamaremos complementos del sujeto; en el segundo, complementos del predicado verbal, y en el tercero, predicados de complemento» (pág. 176). 


\section{SIGLO XVIII}

Autoridades: «v.a. [...] Concertar. Vale afsimifmo Concordar, convenir una cofa con otra: y afsi fe dice en la Gramática que el subftantivo concierta con el adjetivo. En efte fentido es verbo neutro. Lat. Concordare. ALDRET. Orig. lib. 2. cap. 13. Porque Lengua que no fe derive de otra, ò nazca de un mifmo principio, no puede concertar ni convenir, como la nueftra concierta y conviene con la Latina. Paton, Eloq. fol. 174. La de nominativo y verbo conciertan en dos colas, en número y en persona: como Yo amo, tu amas» (1729, pág. 473, 1).

\section{GRAE-1771:}

DRAE-1780: «v.a. [... CONCERTAR. v.n. Concordar, convenir entre sí una cosa con otra. Convenire, quadrare» (pág. 252,3).

DRAE-1783: «v.a. [..] CONCERTAR. v.n. Concordar, convenir entre sí una cosa con otra. Convenire, quadrare» (pág. 267,1).

DRAE-1791: «v.a. [...] 8. v.n. Concordar, convenir entre sí una cosa con otra. Convenire, quadrare» (pág. 240,3).

\section{GRAE-1796:}

\section{$\mathbf{1}^{\mathrm{a}}$ mitad del XIX}

DRAE-1803: «v.a. [... CONCERTAR. v.n. Concordar, convenir entre sí una cosa con otra. Convenire, quadrare» (pág. 216,1).

DRAE-1817: «v.a. [...] CONCERTAR. v.n. Concordar, convenir entre sí una cosa con otra. Convenire, quadrare [...]» (pág. 222,1).

DRAE-1822: «v.a. [...] CONCERTAR. v.n. Concordar, convenir entre sí una cosa con otra. Convenire, quadrare [...]» (pág. 204,1).

DRAE-1832: «a. [...] ๆ n. Concordar, convenir entre sí una cosa con otra. Convenire [...]» (pág. 186,3). 
DRAE-1837: «a. [...] ๆ n. Concordar, convenir entre sí una cosa con otra. Convenire $[\ldots] »$ (pág. 186,3).

DRAE-1843: «a. $[\ldots]$ ○ n. Concordar, convenir entre sí una cosa con otra. Convenire [...]» (pág. 181,1).

\section{$2^{\mathrm{a}}$ m. XIX - p. XX}

DRAE-1852: «a. $[\ldots] \rrbracket$ n. Concordar, convenir entre sí una cosa con otra. Convenire [...]» (pág. 174,3).

DRAE-1869: «a. [...] $\mid$ n. Concordar, convenir entre sí una cosa con otra [...]» (pág. 194,1).

DRAE-1884: «(Del ital. Concertare.) a. [...] $\mid \mathbf{n}$. Concordar, convenir entre sí una cosa con otra. ๆ Gram. Concordar gramaticalmente entre sí dos ó más vocablos. Ú.t.c.a.» (pág. $270,1)$.
GRAE-1854:

GRAE-1858:

GRAE-1862:

GRAE-1864:

GRAE-1865:

GRAE-1866:

GRAE-1867:

GRAE-1870:

GRAE-1874:

GRAE-1878:

GRAE-1880:

GRAE-1883:

GRAE-1885:

GRAE-1888: 
GRAE-1890:

GRAE-1895:

DRAE-1899: «(Del lat. Concertare. $)$ a. $[\ldots]$ | $n$. Concordar, convenir entre sí una cosa con otra. ๆ Gram. Concordar en los accidentes gramaticales dos ó más palabras variables. Ú.t.c.a.» (pág. 251,1).

DRAE-1914: «(Del lat. Concertare. $)$ a. $\left.[\ldots]\right|^{8} \mathbf{n}$. Concordar, convenir entre sí una cosa con otra. I ${ }^{9}$ Gram. Concordar en los accidentes gramaticales dos o más palabras variables. Ú.t.c.a.» (pág. 260,1).

DRAE-1925: «(Del lat. Concertare. $)$ a. [...] \ 8. intr. Concordar, convenir entre sí una cosa con otra. 9 9. Gram. Concordar en los accidentes gramaticales dos o más palabras variables. Ú.t.c.tr.» (pág. 314,2).

\section{GRAE-1900:}

GRAE-1901:

GRAE-1904:

GRAE-1906:

GRAE-1908:

GRAE-1909:

GRAE-1911:

GRAE-1913:

GRAE-1916:

GRAE-1917:

GRAE-1920:

GRAE-1924: 


\section{CONCORIANCIA}

\section{SIGLO XVIII}

Autoridades: «f. f. Consonáncia ò correfpondéncia que tiene una cola con otra. Viene del Latino Concordia $[\ldots]$ Concordancia. En la Gramática es aquella debida colocación que han de tener las palabras unas con otras: y fe feñalan tres de nominatívo y verbo, de fubftantivo y adjetívo, y de relativo y antecedente. Patón, Eloq. fol. 174. Las concordáncias fon tres (como en Latin) de nominatívo y verbo, fubftantívo y adjetivo, relativo y antecedente....... La cortesía Efpañóla tiene algunos modos de hablar que pervierten de eftas concordáncias, ufando del plurál por singulár, y de la tercéra por fegunda perlóna

[...]» (1729, pág. 480,1-2).

DRAE-1780: «s.f. Correspondencia, ó conformidad de una cosa con otra. Conformitas, convenientia.

Concordancia. Gram. El modo de concordar las palabras, segun las reglas de la gramática de cada lengua. Verborum in re grammatica concorditas, concordia [...]» (págs. 253,3 y $254,1)$.

DRAE-1783: «s.f. Correspondencia, ó conformidad de una cosa con otra. Conformitas, convenientia.

Concordancia. Gram. El modo de concordar las palabras, segun las reglas de la gramática de cada lengua. Verborum in re grammatica concorditas, concordia [...]» (págs. 268,1-2).

DRAE-1791: «s.f. Correspondencia, ó conformidad de una cosa con otra. Conformitas, convenientia. 2. Gram. La conformidad, ó correspondencia de las palabras, segun las reglas de la gramática de cada lengua. Verborum in re grammatica concorditas, concordia $[\ldots] »$ (págs. 241,3).

GRAE-1771: «Este ajuste ó concierto de palabras se llama concordancia» (pág. 321).
GRAE-1796: No hay definición estricta. Se entiende que la concordancia es el concierto de unas palabras con otras -en propiedades y accidentes- (págs. 275-276). 


\section{$1^{\text {a }}$ mitad del XIX}

DRAE-1803: «s.f. Correspondencia, ó conformidad de una cosa con otra. Conformitas, convenientia.

Concordancia. Gram. La conformidad, ó correspondencia de las palabras segun las reglas de la gramática de cada lengua. Verborum in re grammatica concordia.

[...]» (pág. 216,3).

DRAE-1817: «s.f. Correspondencia ó conformidad de una cosa con otra. Conformitas, convenientia.

Concordancia. Gram. La conformidad ó correspondencia de las palabras segun las reglas de la gramática de cada lengua. Verborum in re grammatica concordia.

[...]» (pág. 223,1).

DRAE-1822: «s.f. Correspondencia ó conformidad de una cosa con otra. Conformitas, convenientia.

Concordancia. Gram. La conformidad ó correspondencia de las palabras segun las reglas de la gramática de cada lengua. Verborum in re grammatica concordia.

[...]» (pág. 205,1).

DRAE-1832: «f. Correspondencia ó conformidad de una cosa con otra. Conformitas, convenientia. I Gram. La conformidad ó correspondencia de las palabras segun las reglas de la gramática de cada lengua. Verborum in re grammatica concordia $[\ldots] »$ (pág. 187,3).

DRAE-1837: «f. Correspondencia ó conformidad de una cosa con otra. Conformitas, convenientia. ๆ Gram. La conformidad ó correspondencia de las palabras segun las reglas de la gramática de cada lengua. Verborum in re grammatica concordia $[\ldots]$...] (pág. 187,3).

DRAE-1843: «f. Correspondencia ó conformidad de una cosa con otra. Conformitas, convenientia.

Gram. La conformidad ó correspondencia de las palabras segun las reglas de la gramática de cada lengua. Verborum in re grammatica concordia $[\ldots]$ (... (pág. 181,3). 


\section{$2^{a}$ m. XIX - p. XX}

DRAE-1852: «f. Correspondencia ó conformidad de una cosa con otra._oncordancia, convenientia. ๑ Gram. La conformidad ó correspondencia de las palabras según las reglas de la gramática de cada lengua. Verborum in re_oncordan concordia $[\ldots] »$ (pág. 175,2).

DRAE-1869: «f. Correspondencia ó conformidad de una cosa con otra. I Gram. La conformidad ó correspondencia de las palabras según las reglas de la gramática de cada lengua [...]» (pág. 194,3).
GRAE-1854: No hay definición. Se entiende que la concordancia es el concierto, correspondencia y conformidad debidas entre las partes declinables de la oración (pág. 138).

GRAE-1858: Seguimos sin definición estricta; la concordancia es el concierto, correspondencia y conformidad debidas entre las partes declinables de la oración (pág. 148).

GRAE-1862: Lo mismo que en las GRAE anteriores. Por concordancia se entiende el concierto, correspondencia y conformidad debidas entre las partes declinables de la oración (pág. 152).

GRAE-1864: Lo mismo que en las GRAE anteriores. Por concordancia se entiende el concierto, correspondencia y conformidad debidas entre las partes declinables de la oración (pág. 152).

GRAE-1865: Lo mismo que en las GRAE anteriores. Por concordancia se entiende el concierto, correspondencia y conformidad debidas entre las partes declinables de la oración (pág. 152).

GRAE-1866: Lo mismo que en las GRAE anteriores. Por concordancia se entiende el concierto, correspondencia y conformidad debidas entre las partes declinables de la oración (pág. 152).

GRAE-1867: Lo mismo que en las GRAE anteriores. Por concordancia se entiende el concierto, correspondencia y conformidad debidas entre las partes declinables de la oración (pág. 151).

GRAE-1870: Concierto, correspondencia y conformidad debidas entre las partes variables de la oración (pág. 169).

GRAE-1874: Concierto, correspondencia y conformidad debidas entre las partes variables de la oración (pág. 197). 
DRAE-1884: «(De concordante) f. Correspondencia ó conformidad de una cosa con otra. I Gram. Conformidad ó correspondencia de unas palabras con otras en la oración. Sólo puede haberla entre las partes variables. Todas éstas, menos el verbo, concuerdan en género, número y caso; y el verbo con las demás, en número y persona [...]» (pág. 271,1-2).

DRAE-1899: «(De concordante.) f. Correspondencia ó conformidad de una cosa con otra. I Gram. Conformidad de accidentes entre dos ó más palabras variables. Todas éstas, menos el verbo, concuerdan en género y número; y el verbo con su nominativo, en número y persona [...]» (pág. 251,3).
GRAE-1878: Concierto, correspondencia y conformidad debidas entre las partes variables de la oración (pág. 197).

GRAE-1880: Concierto, correspondencia y conformidad debidas entre las partes variables de la oración (pág. 216).

GRAE-1883: Concierto, correspondencia y conformidad debidas entre las partes variables de la oración (pág. 216).

GRAE-1885: Concierto, correspondencia y conformidad debidas entre las partes variables de la oración (pág. 218).

GRAE-1888: Concierto, correspondencia y conformidad debidas entre las partes variables de la oración (pág. 216).

GRAE-1890: Concierto, correspondencia y conformidad debidas entre las partes variables de la oración (pág. 216).

GRAE-1895: Concierto, correspondencia y conformidad debidas entre las partes variables de la oración (pág. 216).

GRAE-1900: Concierto, correspondencia y conformidad debidas entre las partes variables de la oración (pág. 216).

GRAE-1901: Concierto, correspondencia y conformidad debidas entre las partes variables de la oración (pág. 216).

GRAE-1904: Concierto, correspondencia y conformidad debidas entre las partes variables de la oración (pág. 210).

GRAE-1906: Concierto, correspondencia y conformidad debidas entre las partes variables de la oración (pág. 210).

Anexo II: Glosario terminológico Lema: Concordancia 
DRAE-1914: «(Del b. lat._oncordancia, y éste del lat. Concordans, -antis, concordante.) f. Correspondencia o conformidad de una cosa con otra. $\|^{2}$ Gram. Conformidad de accidentes entre dos o más palabras variables. Todas éstas, menos el verbo, concuerdan en género y número; y el verbo con su nominativo, en número y persona $[\ldots]$ … (pág. 261,1).

DRAE-1925: «(Del b. lat. _oncordancia, y éste del lat. Concordans, -antis, concordante.) f. Correspondencia o conformidad de una cosa con otra. I 2. Gram. Conformidad de accidentes entre dos o más palabras variables. Todas éstas, menos el verbo, concuerdan en género y número; y el verbo con su nominativo, en número y persona [...]» (pág. $315,2-3)$.
GRAE-1908: Concierto, correspondencia y conformidad debidas entre las partes variables de la oración (pág. 210).

GRAE-1909: Concierto, correspondencia y conformidad debidas entre las partes variables de la oración (pág. 210).

GRAE-1911: Concierto, correspondencia y conformidad debidas entre las partes variables de la oración (pág. 214).

GRAE-1913: Concierto, correspondencia y conformidad debidas entre las partes variables de la oración (pág. 214).

GRAE-1916: Concierto, correspondencia y conformidad debidas entre las partes variables de la oración (pág. 214).

GRAE-1917: Como en las ediciones anteriores, seguimos sin definición estricta. Por concordancia se entiende la relación de conformidad determinada por los accidentes gramaticales comunes al adjetivo y nombre o al verbo y sujeto (págs. 157-159).

GRAE-1920: Igual que en la GRAE-1917: relación de conformidad determinada por los accidentes gramaticales comunes al adjetivo y nombre o al verbo y sujeto (págs. 177-179).

GRAE-1924: Igual que las dos Gramáticas anteriores: relación de conformidad determinada por los accidentes gramaticales comunes al adjetivo y nombre o al verbo y sujeto (págs. 177-179). 


\section{CONCORDAR}

\section{SIGLO XVIII}

Autoridades: «v.a. Acordar, conformar y componer lo que eftá defiguál ù difcorde. Viene del Latino Concordare, que fignifica efto mifmo [...]

CONCORDar. Vale tambien conciliar, ajuftar y pacificar lo que eftá difcorde y encontrado. Lat. Conciliare [...]

CONCORDAR. Significa alsimismo convenir una cofa con otra: y afsi se dice en las efcritúras y otros inftrumentos, de que dan cópia los Escribanos para autorizarlas, concuerda con fu original. Lat. Authographo ex/criptum ex fide refpondere..

[...]». (1729, págs. 480,2 y 481,1).

GRAE-1771:

DRAE-1780: «v.a. Conciliar y ajustar lo que está desigual, discorde, ó encontrado. Aptare, accommodare.

CONCORDAR. v.n. Convenir una cosa con otra; y así se dice de una copia de escritura, que concuerda con su original. Convenire, congruere, concordare» (pág. 254,1).

DRAE-1783: «v.a. Conciliar y ajustar lo que está desigual, discorde, ó encontrado. Aptare, accommodare.

Concordar. v.n. Convenir una cosa con otra; y así se dice de una copia de escritura, que concuerda con su original. Convenire, congruere, concordare» (pág. 268,2).

DRAE-1791: «v.a. Conciliar y ajustar lo que está desigual, discorde, ó encontrado. Aptare, accomodare [sic]. 2. v.n. Convenir una cosa con otra; y así se dice de una copia de escritura, que concuerda con su original. Convenire, congruere, concordare» (pág. 241,3 y 242,1).

GRAE-1796:

\section{$1^{\text {a }}$ mitad del XIX}

DRAE-1803: «v.a. Conciliar y ajustar lo que está desigual, discorde, ó encontrado. Aptare, accommodare.

ConcordaR. v.n. Convenir una cosa con otra; y así se dice de una copia de escritura, que concuerda con su original. Convenire, congruere, concordare» (pág. 216,3 y 217,1). 
DRAE-1817: «v.a. Conciliar y ajustar lo que está desigual, discorde ó encontrado. Aptare, accommodare.

CONCORDAR. v.n. Convenir una cosa con otra; y asi se dice de una copia de escritura, que concuerda con su original. Convenire, congruere, concordare» (pág. 223,1).

DRAE-1822: «v.a. Conciliar y ajustar lo que esta desigual, discorde ó encontrado. Aptare, accommodare.

CONCORDAR. v.n. Convenir una cosa con otra; y asi se dice de una copia de escritura, que concuerda con su original. Convenire, congruere» (pág. 205,1).

DRAE-1832: «a. Conciliar y ajustar lo que está desigual, discorde ó encontrado. Concordem reddere. $\uparrow \mathrm{n}$. Convenir una cosa con otra; y así se dice de una copia de escritura, que concuerda con su original. Convenire, congruere» (pág. $187,3)$.

DRAE-1837: «a. Conciliar y ajustar lo que está desigual, discorde ó encontrado. Concordem reddere. ๆ n. Convenir una cosa con otra; y así se dice de una copia de escritura, que concuerda con su original. Convenire, congruere» (pág. $187,3)$.

DRAE-1843: «a. Conciliar y ajustar lo que está desigual, discorde ó encontrado. Concordem reddere. $0 \mathrm{n}$. Convenir una cosa con otra; y asi se dice de una copia de escritura, que concuerda con su original. Convenire, congruere» (pág. $181,3)$.

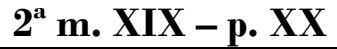

DRAE-1852: «a. Conciliar y ajustar lo que está desigual, discorde ó encontrado. Concordem reddere. $9 \mathrm{n}$. Convenir una cosa con otra; y así se dice de una copia de escritura, que concuerda con su original. Convenire, congruere» (pág. $175,2)$.

GRAE-1854:

GRAE-1858:

GRAE-1862: 


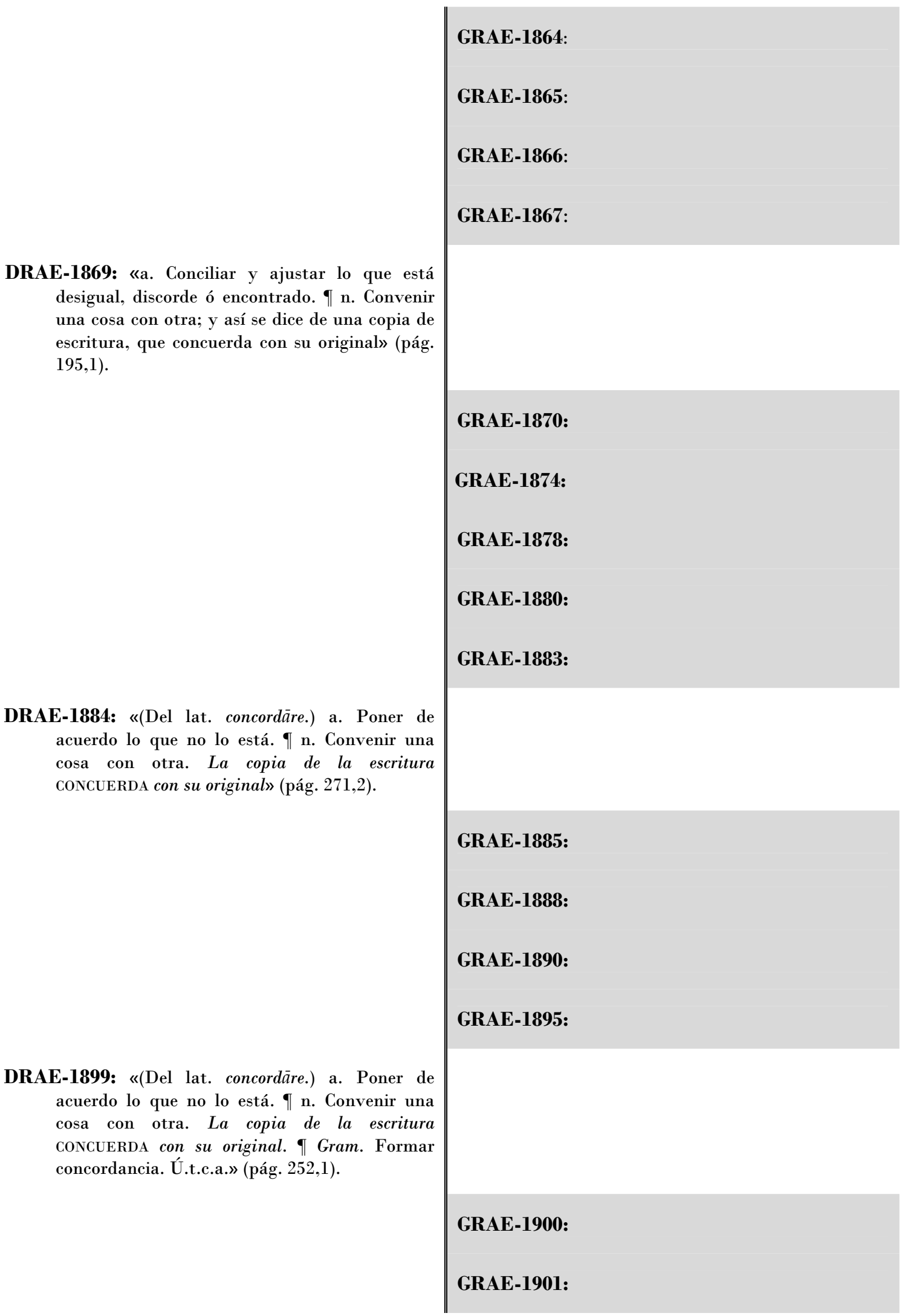


GRAE-1904:

GRAE-1906:

GRAE-1908:

GRAE-1909:

GRAE-1911:

GRAE-1913:

DRAE-1914: «(Del lat. concordāre.) a. Poner de acuerdo lo que no lo está. ๆ ${ }^{2} \mathrm{n}$. Convenir una cosa con otra. La copia de la escritura CONCUERDA con su original. If ${ }^{3}$ Gram. Formar concordancia. Ú.t.c.a.» (pág. 261,1).

GRAE-1916:

GRAE-1917:

GRAE-1920:

GRAE-1924:

DRAE-1925: «(Del lat. concordāre. $)$ tr. Poner de acuerdo lo que no lo está. \ 2. intr. Convenir una cosa con otra. La copia de la escritura CONCUERDA con su original. ๆ 3. Gram. Formar concordancia. Ú.t.c.tr.» (pág. 315,3). 


\section{CONFDRMIIDAD}

\section{SIGLO XVIII}

Autoridades: «f.f. Semejanza y proporción tan igual de una cola con otra, que entre si parezcan ò fean unas mifmas. Lat. Conformatio [...]

CONFORMIDAD. Se ufa tambien por concordáncia, igualdád y correspondéncia de una cola con otra $[\ldots]$

CONFORMIDAD. Vale tambien unión, concórdia, buena correfpondencia entre dos ò mas perfónas $[\ldots]$

CONFORMIDAD. Se fuele ufar afsimismo por fymetría, igualdad y debida proporción entre unas y otras partes, que le juntan para la compofición de un cuerpo, ù de algúna otra cola [...]» (1729, pág. 505,1)

DRAE-1780: «s.f. Semejanza entre dos personas. Similitudo.

CONFORMIDAD. Igualdad, correspondencia de una cosa con otra. Congruentia, consensio.

CONFORMIDAD. Union, concordia y buena correspondencia entre dos, ó mas personas. Concordia, unanimitas.

CONFORMIDAD. Simetría y debida proporcion entre las partes que componen un todo. Symmetria, proportio.

[...]» (pág. 257,3)

DRAE-1783: «s.f. Semejanza entre dos personas. Similitudo.

CONFORMIDAD. Igualdad, correspondencia de una cosa con otra. Congruentia, consensio.

CONFORMIDAD. Union, concordia y buena correspondencia entre dos, ó mas personas. Concordia, unanimitas.

CONFORMIDAD. Simetría y debida proporcion entre las partes que componen un todo. Symmetria, proportio.

[...]» (pág. 272,1)

DRAE-1791: «s.f. Semejanza entre dos personas. Similitudo. 2. Igualdad, correspondencia de una cosa con otra. Congruentia, consensio. 3. Union, concordia y buena correspondencia entre dos, ó mas personas. Concordia, unanimitas. 4. Simetría y debida proporcion entre las partes que componen un todo. Symmetria, proportio.

[...]» (pág. 245,1)

\section{GRAE-1771:}

GRAE-1796: 


\section{$1^{\text {a }}$ mitad del XIX}

DRAE-1803: «s.f. Semejanza entre dos personas. Similitudo.

CONFORMIDAD. Igualdad, correspondencia de una cosa con otra. Congruentia, consensio.

CONFORMIDAD. Union, concordia y buena correspondencia entre dos, ó mas personas. Concordia, unanimitas.

Conformidad. Simetría y debida proporcion entre las partes que componen un todo._imetría, proportio. [...]» (pág. 220,1)

DRAE-1817: «s.f. Semejanza entre dos personas. Similitudo.

CONFORMIDAD. Igualdad, correspondencia de una cosa con otra. Congruentia, consensio.

CONFORMIDAD. Union, concordia y buena correspondencia entre dos ó mas personas. Concordia, unanimitas.

Conformidad. Simetría y debida proporcion entre las partes que componen un todo._imetría, proportio. [...]» (pág. 226,2)

DRAE-1822: «s.f. Semejanza entre dos personas. Similitudo.

CONFORMIDAD. Igualdad, correspondencia de una cosa con otra. Congruentia, consensio.

CONFORMIDAD. Union, concordia y buena correspondencia entre dos ó mas personas. Concordia, unanimitas.

Conformidad. Simetría y debida proporcion entre las partes que componen un todo._imetría, proportio. [...]» (págs. 208,1-2)

DRAE-1832: «f. Semejanza entre dos personas. Similitudo. If Igualdad, correspondencia de una cosa con otra. Congruentia, consensio. I Union, concordia y buena correspondencia entre dos ó mas personas. Concordia, unanimitas. If Simetría y debida proporcion entre las partes que componen un todo._imetría, proportio.

[...]» (págs. 190,2)

DRAE-1837: «f. Semejanza entre dos personas. Similitudo. I Igualdad, correspondencia de una cosa con otra. Congruentia, consensio. I Union, concordia y buena correspondencia entre dos ó mas personas. Concordia, unanimitas. I Simetría y debida proporcion entre las partes que componen un todo._imetría, proportio.

[...]» (págs. 190,2)

DRAE-1843: «f. Semejanza entre dos personas. Similitudo. ם Igualdad, correspondencia de una cosa con otra. Congruentia, consensio. ㅁ Union, concordia y buena correspondencia entre dos ó mas personas. Concordia, unanimitas. Q Simetría y debida proporcion entre las partes que componen un todo._imetría, proportio. 


\section{$2^{a}$ m. XIX - p. XX}

DRAE-1852: «f. Semejanza entre dos personas. Similitudo. \ Igualdad, correspondencia de una cosa con otra. Congruentia, consensio. đ Union, concordia y buena correspondencia entre dos ó mas personas. Concordia, unanimitas. ๆ Simetría y debida proporcion entre las partes que componen un todo. Symmetria, proportio.

[...]» (págs. 178,1)

GRAE-1854:

GRAE-1858:

GRAE-1862:

GRAE-1864:

GRAE-1865:

GRAE-1866:

GRAE-1867:

DRAE-1869: «f. Semejanza entre dos personas. ब Igualdad, correspondencia de una cosa con otra. I Union, concordia y buena correspondencia entre dos ó más personas. II Simetría y debida proporcion entre las partes que componen un todo. [...]» (págs. 178,1)

DRAE-1884: «(Del lat. conformitas.) f. Semejanza entre dos personas. II Igualdad, correspondencia de una cosa con otra. ๆ Unión, concordia y buena correspondencia entre dos ó más personas. đI Simetría y debida proporción entre las partes que componen un todo. [...]» (págs. 275,2)

\section{GRAE-1870:}

GRAE-1874:

GRAE-1878:

GRAE-1880:

GRAE-1883: 


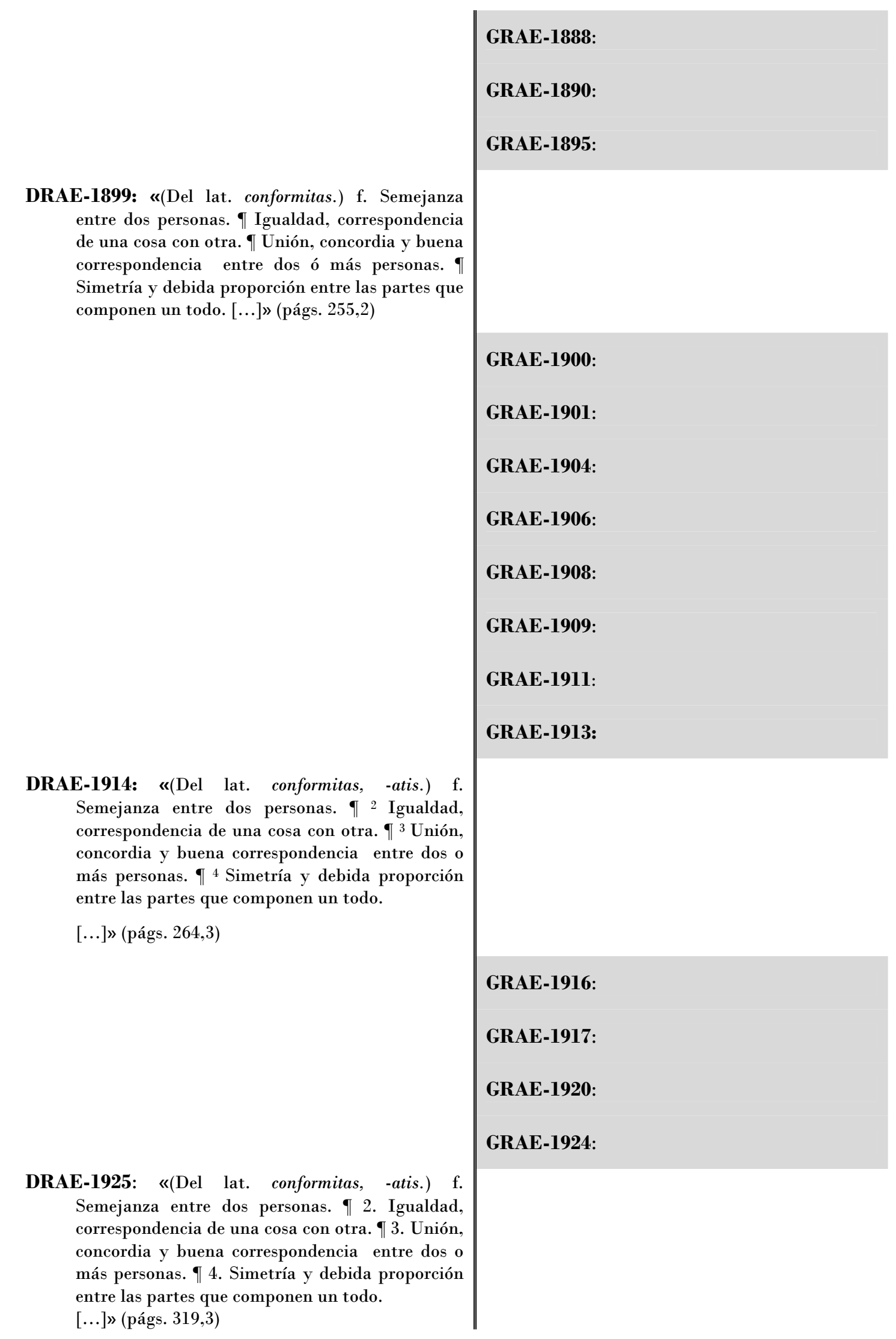




\section{SIGLO XVIII}

Autoridades: «[.f. Junta, unió ò concurrencia de dos ò mas cosas. Lat. Conjunctio, de donde viene [...] CONJUNCión. En la Gramática es aquella voz que traba y ata las partes de la oracion entre si milmas. Lat. Conjunctio, onis. Paton, Eloq. fol. 170. La construcción del comparativo es la conjunción Que: como Mas bueno que tú, ò mejór que otro. AlCaz. Perf. Lat. pl. 325. De las conjunciónes, unas fe anteponen, otras fe pospónen, y otras fon promilcuas. [...]» (1729, pág. $515,1-2)$.

DRAE-1780: «s.f. Junta, union. Conjunctio, unio. Conjuncion. Gram. Palabra, ó partícula que sirve para juntar, atar, ó trabar entre sí las demas partes de la oracion. Conjunctio. [...]» (pág. 259,1).

DRAE-1783: «s.f. Junta, union. Conjunctio, unio. Conjuncion. Gram. Palabra, ó partícula que sirve para juntar, atar, ó trabar entre sí las demas partes de la oracion. Conjunctio. [...]» (pág. 273,2).

DRAE-1791: «s.f. Junta, union. Conjunctio, unio. 2. Gram. Palabra, ó partícula que sirve para juntar, atar, ó trabar entre sí las demas partes de la oracion. Conjunctio. [...]» (pág. 246,1).
GRAE-1771: «CONJUNCion es una palabra que sirve para juntar, atar, ó trabar entre sí las demas partes de la oracion. Las conjunciones se dividen en copulativas, disyuntivas, adversativas, condicionales, causales, continuativas» (pág. 222).

GRAE-1796: «CONJUNCION es una parte de la oracion, que sirve para enlazar las palabras y las oraciones unas con otras. Divídense en copulativas, disyuntivas, adversativas, condicionales, causales, continuativas, comparativas y finales» (pág. 263).

\section{$1^{\text {a }}$ mitad del XIX}

DRAE-1803: «s.f. Junta, union. Conjunctio, unio. Conjuncion. Gram. Parte de la oracion que sirve para juntar, atar, ó trabar las palabras, y oraciones unas con otras. Conjunctio. [...]» (pág. $221,2)$.

DRAE-1817: «s.f. Junta, union. Conjunctio, unio. Conjuncion. Gram. Parte de la oracion que sirve para juntar, atar ó trabar las palabras, y oraciones unas con otras. Conjunctio.[...]» (pág. $227,2)$. 
DRAE-1822: «s.f. Junta, union. Conjunctio, unio. Conjuncion. Gram. Parte de la oracion que sirve para juntar, atar ó trabar las palabras, y oraciones unas con otras. Conjunctio. [...]» (pág. 209,2 ).

DRAE-1832: «f. Junta, union. Conjunctio. I Gram. Parte de la oracion que sirve para juntar, atar ó trabar las palabras, y oraciones unas con otras. Conjunctio [...]» (pág. 191,2).

DRAE-1837: «f. Junta, union. Conjunctio. If Gram. Parte de la oracion que sirve para juntar, atar ó trabar las palabras, y oraciones unas con otras. Conjunctio [...]» (pág. 191,2).

DRAE-1843: «f. Junta, union. Conjunctio. ם Gram. Parte de la oracion que sirve para juntar, atar ó trabar las palabras, y oraciones unas con otras. Conjunctio [...]» (pág. 185,2).

\section{$2^{\mathrm{a}} \mathrm{m} . \mathrm{XIX}-\mathrm{p} . \mathrm{XX}$}

DRAE-1852: «f. Junta, union. Conjunctio. ๆ Gram. Parte de la oracion que sirve para juntar, atar ó trabar las palabras, y oraciones unas con otras. Conjunctio [...]» (pág. 179,1).
GRAE-1854: «Conjuncion es una parte de la oracion, que sirve para enlazar las palabras y las oraciones unas con otras. Divídense las conjunciones en copulativas, disyuntivas, adversativas, condicionales, causales, continuativas, comparativas, finales é ilativas» (pág. 127).

GRAE-1858: «Conjuncion es una parte de la oracion, que sirve para enlazar las palabras y las oraciones unas con otras. Divídense las conjunciones en copulativas, disyuntivas, adversativas, condicionales, causales, continuativas, comparativas, finales, é ilativas» (pág. 136).

GRAE-1862: «Conjuncion es una parte de la oracion, que sirve para enlazar las palabras y las oraciones unas con otras. Divídense las conjunciones en copulativas, disyuntivas, adversativas, condicionales, causales, continuativas, comparativas, finales é ilativas» (pág. 140).

GRAE-1864: «Conjuncion es una parte de la oracion, que sirve para enlazar las palabras y las oraciones unas con otras. Divídense las conjunciones en copulativas, disyuntivas, adversativas, condicionales, causales, continuativas, comparativas, finales é ilativas» (pág. 140). 
GRAE-1865: «Conjuncion es una parte de la oracion, que sirve para enlazar las palabras y las oraciones unas con otras. Divídense las conjunciones en copulativas, disyuntivas, adversativas, condicionales, causales, continuativas, comparativas, finales é ilativas» (pág. 140).

GRAE-1866: «Conjuncion es una parte de la oracion, que sirve para enlazar las palabras y las oraciones unas con otras. Divídense las conjunciones en copulativas, disyuntivas, adversativas, condicionales, causales, continuativas, comparativas, finales é ilativas» (pág. 140).

GRAE-1867: «Conjuncion es una parte de la oracion, que sirve para enlazar las palabras y las oraciones unas con otras. Divídense las conjunciones en copulativas, disyuntivas, adversativas, condicionales, causales, continuativas, comparativas, finales é ilativas» (pág. 139).

DRAE-1869: «f. Junta, union. ๆ Gram. Parte de la oracion que sirve para juntar ó enlazar las palabras $\mathrm{y}$ oraciones unas con otras. If Las conjunciones se distinguen unas de otras con varias denominaciones, tomadas del diferente concepto en que se usan, como adversativas, condicionales, copulativas, disyuntivas, etc. [...]» (pág. 199,1). 
DRAE-1884: «(Del lat. Coniunctĭo.) f. Junta, unión. [...] ब Gram. Parte invariable de la oración, que denota la relación que existe entre dos oraciones, ó entre miembros ó vocablos de una misma oración, juntándolas ó enlazándolas siempre gramaticalmente, aunque á véces signifique contrariedad ó separación de sentido entre unas y otras. I adversativa. Gram. La que, como pero, denota oposición ó diferencia entre la frase que precede y la que sigue. If causal. Gram. La que, como porque, precede á la oración en que se motiva lo manifestado anteriormente. If comparativa. Gram. La que denota idea de comparación. I compuesta. Gram. Modo conjuntivo. I condicional. Gram. La que, como con tal que, denota condición ó necesidad de que se verifique alguna circunstancia. $\mid$ continuativa. Gram. La que implica ó denota idea de continuación; v.gr.: digo, PUES, que te engañas; ASÍ QUE, ésta, y no otra, fué la causa del alboroto. ๆ copulativa. Gram. La que, como $y$, que, etc., junta

GRAE-1878: «Conjuncion es aquella palabra ó frase que sirve para denotar la relacion que hay entre dos oraciones ó entre dos proposiciones de una misma oracion [...] La relacion que denotan las conjunciones es siempre una relacion de enlace [...] Las conjunciones no sólo denotan una relacion de enlace, sino que determinan tambien la naturaleza de este enlace. De ahí su division en copulativas, disyuntivas, adversativas, condicionales, causales, continuativas, comparativas, finales é ilativas» (pág. 183).

GRAE-1880: «Conjunción es aquella parte de la oración que sirve para enlazar las palabras y las oraciones unas con otras [...] Siempre denota una relación de enlace [...] Por determinar las conjunciones no sólo una relación de enlace, sino también la naturaleza de este enlace, divídense en copulativas, disyuntivas, adversativas, condicionales, causales, continuativas, comparativas, finales é ilativas» (pág. 205).

GRAE-1883: «Conjunción es aquella parte de la oración que sirve para denotar el enlace entre dos ó más palabras, cláusulas ú oraciones [...] Siempre denota una relación de enlace [...] Por determinar las conjunciones, no sólo una relación de enlace, sino también la naturaleza de este enlace, divídense en copulativas, disyuntivas, adversativas, condicionales, causales, continuativas, comparativas, finales é ilativas» (pág. 205). 
y enlaza simplemente una cosa con otra. I distributiva. Gram. La disyuntiva cuando se emplea de este modo: Tomando ORA la espada, ORA la pluma; YA de una manera, YA de otra. $\mid$ disyuntiva. Gram. La que, como ó, denota separación, diferencia ó alternativa entre dos ó más personas, cosas ó ideas. đI dubitativa. Gram. La que, como si, implica ó denota duda. đfinal. Gram. La que, como á fin de que, denota el fin ú objeto de lo manifestado anteriormente. $\uparrow$ ilativa. Gram. La que, como conque, enuncia una ilación ó consecuencia de lo que anteriormente se ha manifestado [...]» (pág. 276,3 y 277,1).
GRAE-1885: «Conjunción es aquella parte de la oración que sirve para denotar el enlace entre dos ó más palabras, cláusulas ú oraciones [...] Siempre denota una relación de enlace [...] Por determinar las conjunciones, no sólo una relación de enlace, sino también la naturaleza de este enlace, divídense en copulativas, disyuntivas, adversativas, condicionales, causales, continuativas, comparativas, finales é ilativas» (pág. 206).

GRAE-1888: «Conjunción es aquella parte de la oración que sirve para denotar el enlace entre dos ó más palabras, cláusulas ú oraciones [...] Siempre denota una relación de enlace [...] Por determinar las conjunciones, no sólo una relación de enlace, sino también la naturaleza de este enlace, divídense en copulativas, disyuntivas, adversativas, condicionales, causales, continuativas, comparativas, finales é ilativas» (pág. 204).

GRAE-1890: «Conjunción es aquella parte de la oración que sirve para denotar el enlace entre dos ó más palabras, cláusulas ú oraciones [...] Siempre denota una relación de enlace $[\ldots]$ Por determinar las conjunciones, no sólo una relación de enlace, sino también la naturaleza de este enlace, divídense en copulativas, disyuntivas, adversativas, condicionales, causales, continuativas, comparativas, finales é ilativas» (pág. 204).

GRAE-1895: «Conjunción es aquella parte de la oración que sirve para denotar el enlace entre dos ó más palabras, cláusulas ú oraciones [...] Siempre denota una relación de enlace $[\ldots]$ Por determinar las conjunciones, no sólo una relación de enlace, sino también la naturaleza de este enlace, divídense en copulativas,

Anexo II: Glosario terminológico Lema: Conjunción 
DRAE-1899: «(Del lat. Coniunctío.) f. Junta, unión. $[\ldots]$ I Gram. Parte invariable de la oración, que denota la relación que existe entre dos oraciones, ó entre miembros ó vocablos de una misma oración, juntándolas ó enlazándolas siempre gramaticalmente, aunque á véces signifique contrariedad ó separación de sentido entre unas y otras. If adversativa. Gram. La que, como pero, denota oposición ó diferencia entre la frase que precede y la que sigue. If causal. Gram. La que, como porque, precede á la oración en que se motiva lo manifestado anteriormente. If comparativa. Gram. La que denota idea de comparación. I compuesta. Gram. Modo conjuntivo. If condicional. Gram. La que, como con tal que, denota condición ó necesidad de que se verifique alguna circunstancia. $\mid$ continuativa. Gram. La que implica ó denota idea de continuación; v.gr.: digo, PUES, que te engañas; ASÍ QUE, ésta, y no otra, fué la causa del alboroto. ๆ copulativa. Gram. La que, como y, que, etc., junta y enlaza simplemente una cosa con otra. I distributiva. Gram. La disyuntiva cuando se emplea de este modo: Tomando ora la espada, ORA la pluma; YA de una manera, YA de otra. I disyuntiva. Gram. La que, como ó, denota separación, diferencia ó alternativa entre dos ó más personas, cosas ó ideas. I dubitativa. Gram. La que, como si, implica ó denota duda. Ifinal. Gram. La que, como á fin de que, denota el fin ú objeto de lo manifestado anteriormente. $\mid$ ilativa. Gram. La que, como conque, enuncia una ilación ó consecuencia de lo que anteriormente se ha manifestado [...]» (pág. 257,1). disyuntivas, adversativas, condicionales, causales, continuativas, comparativas, finales é ilativas» (pág. 204).

GRAE-1900: «Conjunción es aquella parte de la oración que sirve para denotar el enlace entre dos ó más palabras, cláusulas ú oraciones; v. gr.: Horacio Y Virgilio fueron dos grandes poetas; Juan no vendrá PORQUE está enfermo.

Siempre denota una relación de enlace, y de ahí el nombre de conjunción, del latín cum y jungere, juntar con. [...]

Por determinar las conjunciones, no sólo una relación de enlace, sino también la naturaleza de este enlace, divídense en copulativas, disyuntivas, adversativas, condicionales, causales, continuativas, comparativas, finales é ilativas» (pág. 204).

GRAE-1901: «Conjunción es aquella parte de la oración que sirve para denotar el enlace entre dos ó más palabras, cláusulas ú oraciones; v. gr.: Horacio Y Virgilio fueron 
dos grandes poetas; Juan no vendrá PORQUE está enfermo.

Siempre denota una relación de enlace, y de ahí el nombre de conjunción, del latín cum y jungere, juntar con. [...]

Por determinar las conjunciones, no sólo una relación de enlace, sino también la naturaleza de este enlace, divídense en copulativas, disyuntivas, adversativas, condicionales, causales, continuativas, comparativas, finales é ilativas» (pág. 204).

GRAE-1904: «Conjunción es aquella parte de la oración que sirve para denotar el enlace entre dos ó más palabras, cláusulas ú oraciones; v. gr.: Horacio Y Virgilio fueron dos grandes poetas; Juan no vendrá PORQUE está enfermo.

Siempre denota una relación de enlace, y de ahí el nombre de conjunción, del latín cum y jungere, juntar con. [...]

Por determinar las conjunciones, no sólo una relación de enlace, sino también la naturaleza de este enlace, divídense en copulativas, disyuntivas, adversativas, condicionales, causales, continuativas, comparativas, finales é ilativas» (pág. 199).

GRAE-1906: «Conjunción es aquella parte de la oración que sirve para denotar el enlace entre dos ó más palabras, cláusulas ú oraciones; v. gr.: Horacio Y Virgilio fueron dos grandes poetas; Juan no vendrá PORQUE está enfermo.

Siempre denota una relación de enlace, y de ahí el nombre de conjunción, del latín cum y jungere, juntar con. [...]

Por determinar las conjunciones, no sólo una relación de enlace, sino también la naturaleza de este enlace, divídense en copulativas, disyuntivas, adversativas, condicionales, causales, continuativas, comparativas, finales é ilativas» (pág. 199).

GRAE-1908: «Conjunción es aquella parte de la oración que sirve para denotar el enlace entre dos ó más palabras, cláusulas ú oraciones; v. gr.: Horacio Y Virgilio fueron dos grandes poetas; Juan no vendrá PORQUE está enfermo.

Siempre denota una relación de enlace, y de ahí el nombre de conjunción, del latín cum y jungere, juntar con. [...]

Por determinar las conjunciones, no sólo una relación de enlace, sino también la naturaleza de este enlace, divídense en copulativas, disyuntivas, adversativas, 
condicionales, causales, continuativas, comparativas, finales é ilativas» (pág. 199).

GRAE-1909: «Conjunción es aquella parte de la oración que sirve para denotar el enlace entre dos ó más palabras, cláusulas ú oraciones; v. gr.: Horacio Y Virgilio fueron dos grandes poetas; Juan no vendrá PORQUE está enfermo.

Siempre denota una relación de enlace, y de ahí el nombre de conjunción, del latín cum y jungere, juntar con. [...]

Por determinar las conjunciones, no sólo una relación de enlace, sino también la naturaleza de este enlace, divídense en copulativas, disyuntivas, adversativas, condicionales, causales, continuativas, comparativas, finales é ilativas» (pág. 199).

GRAE-1911: «Conjunción es aquella parte de la oración que sirve para denotar el enlace entre dos o más palabras, cláusulas u oraciones; v. gr.: Horacio Y Virgilio fueron dos grandes poetas; Juan no vendrá PORQUE está enfermo.

Siempre denota una relación de enlace, y de ahí el nombre de conjunción, del latín cum y jungere, juntar con.

$[\ldots]$

Por determinar las conjunciones no sólo una relación de enlace, sino también la naturaleza de este enlace, divídense en copulativas, disyuntivas, adversativas, condicionales, causales, continuativas, comparativas, finales e ilativas» (pág. 201).

GRAE-1913: «Conjunción es aquella parte de la oración que sirve para denotar el enlace entre dos o más palabras, cláusulas u oraciones; v. gr.: Horacio Y Virgilio fueron dos grandes poetas; Juan no vendrá PORQUE está enfermo.

Siempre denota una relación de enlace, y de ahí el nombre de conjunción, del latín cum y jungere, juntar con.

$[\ldots]$

Por determinar las conjunciones, no sólo una relación de enlace, sino también la naturaleza de este enlace, divídense en copulativas, disyuntivas, adversativas, condicionales, causales, continuativas, comparativas, finales e ilativas» (pág. 201).

DRAE-1914: «f. Junta, unión [...] ब ${ }^{4}$ Gram. Parte invariable de la oración, que denota la relación que existe entre dos oraciones, o entre miembros o vocablos de una misma oración, juntándolas o enlazándolas siempre gramaticalmente, aunque a veces signifique contrariedad o separación de 
sentido entre unas y otras. I adversativa. Gram. La que, como pero, denota oposición o diferencia entre la frase que precede y la que sigue. $\lceil$ causal. Gram. La que, como porque, precede a la oración en que se motiva lo manifestado anteriormente. ๆ comparativa. Gram. La que denota idea de comparación. I compuesta. Gram. Modo conjuntivo. I condicional. Gram. La que, como con tal que, denota condición o necesidad de que se verifique alguna circunstancia. $\mid$ continuativa. Gram. La que implica o denota idea de continuación; v.gr.: Digo, PUES, que te engañas; ASÍ QUE ésta, y no otra, fué la causa del alboroto. ๆ copulativa. Gram. La que, como $y$, que, etc., junta y enlaza simplemente una cosa con otra. I distributiva. Gram. La disyuntiva cuando se emplea de este modo: Tomando ORA la espada, ORA la pluma; YA de una manera, YA de otra. ๆ disyuntiva. Gram. La que, como o, denota separación, diferencia o alternativa entre dos o más personas, cosas o ideas. I dubitativa. Gram. La que, como $s i$, implica o denota duda. If final. Gram. La que, como a fin de que, denota el fin u objeto de lo manifestado anteriormente. I ilativa. Gram. La que, como conque, enuncia una ilación ó consecuencia de lo que anteriormente se ha manifestado [...]» (pág. 266,1-2).
GRAE-1916: «Conjunción es aquella parte de la oración con que se designa el enlace entre dos o más palabras, cláusulas ú oraciones; v. gr.: Horacio Y Virgilio fueron dos grandes poetas; Juan no vendrá PORQUE está enfermo.

Siempre denota una relación de enlace, y de ahí el nombre de conjunción, del latín cum y jungere, juntar con. [...]

Por determinar las conjunciones, no sólo una relación de enlace, sino también la naturaleza de este enlace, divídense en copulativas, disyuntivas, adversativas, condicionales, causales, continuativas, comparativas, finales e ilativas» (pág. 201).

GRAE-1917: «Conjunción es la palabra invariable que sirve para denotar el enlace entre dos o más palabras u oraciones [...] Por determinar las conjunciones no sólo una relación de enlace, sino también la naturaleza de este enlace, divídense en copulativas, como $y, e$; disyuntivas, como o; adversativas, como pero; causales, como pues; consecutivas, como luego; etc., etc.» (pág. 143).

GRAE-1920: «Conjunción es la palabra invariable que sirve para denotar el enlace entre dos o más palabras $u$ oraciones $[\ldots]$ Por determinar las conjunciones no sólo

Anexo II: Glosario terminológico Lema: Conjunción 
DRAE-1925: «f. Junta, unión [...] ๆ 4. Gram. Parte invariable de la oración, que denota la relación que existe entre dos oraciones, o entre miembros o vocablos de una de ellas, juntándolos o enlazándolos siempre gramaticalmente, aunque a veces signifique contrariedad o separación de sentido entre unos y otros. I adversativa. Gram. La que, como pero, denota oposición o diferencia entre la frase que precede y la que sigue. $\uparrow$ causal. Gram. La que, como porque, precede a la oración en que se motiva lo manifestado anteriormente. 1 comparativa. Gram. La que denota idea de comparación; p. ej.: como. đ compuesta. Gram. Modo conjuntivo. T condicional. Gram. La que, como con tal que, denota condición o necesidad de que se verifique alguna circunstancia. ? continuativa. Gram. La que implica o denota idea de continuación; v.gr.: Digo, PUES, que te engañas; ASÍ QUE ésta, y no otra, fué la causa del alboroto. ๆ copulativa. Gram. La que, como y, que, etc., junta y enlaza simplemente una cosa con otra. I distributiva. Gram. La disyuntiva cuando se reitera aplicada a términos diversos: Tomando ORA la espada, ORA la pluma; YA de una manera, YA de otra. I disyuntiva. Gram. La que, como o, denota separación, diferencia o alternativa entre dos o más personas, cosas o ideas. $\mid$ dubitativa. Gram. La que, como si, implica o denota duda. ๆ final. Gram. La que, como a fin de que, denota el fin u objeto de lo manifestado anteriormente. ๆ ilativa. Gram. La que, como conque, enuncia una ilación ó consecuencia de lo que anteriormente se ha manifestado [...]» (pág. 321,2-3). una relación de enlace, sino también la naturaleza de este enlace, divídense en copulativas, como $y$, e; disyuntivas, como o; adversativas, como pero; causales, como pues; consecutivas, como luego; etc., etc.» (pág. 138).

GRAE-1924: «Conjunción es la palabra invariable que sirve para denotar el enlace entre dos o más palabras u oraciones [...] Por determinar las conjunciones no sólo una relación de enlace, sino también la naturaleza de este enlace, divídense en copulativas, como $y$, e; disyuntivas, como o; adversativas, como pero; causales, como pues; consecutivas, como luego; etc., etc.» (pág. 138). 


\section{CONSTRUCCIÓN}

\section{SIGLO XVIII}

Autoridades: «f.f. [...]

Construcción. En la Gramática es la recta compofición de las partes de la oración entre sí. Lat. Partium orationis constructio. Paton, Eloq. fol. 50. Algúnas con/trucciónes y modos de hablar fe han preftado unas Naciónes à otras, como fe vé en las locuciones que el Latino del Griego toma, que fe llaman Helenifmos» (1729, pág. $537,2)$.

GRAE-1771: construcción $=$ sintaxis $($ pág. 231).

DRAE-1780: «s.f. $[\ldots]$

Construccion. Gram. La recta disposicion de las partes de la oracion entre sí. Compositio, constructio. [...]» (pág. 264,2).

DRAE-1783: «s.f. [...]

Construccion. Gram. La recta disposicion de las partes de la oracion entre sí. Compositio, constructio. [...]» (pág. 278,3).

DRAE-1791: «s.f. [...] 2. Gram. La recta disposicion de las partes de la oracion entre sí. Compositio, constructio [...]» (pág. 250,2).

GRAE-1796: «LA CONSTRUCCION de las partes de la oracion es otra especie de dependencia [como el Régimen] que las une, no con tanta precision como el régimen, sino con alguna mayor anchura y libertad; ya añadiendo unas, ya introduciendo otras entre las que van enlazadas por el régimen, para dar energía á las oraciones, y evitar la uniformidad que resultaria, si se guardaran constantemente en el uso las reglas del régimen y concordancia de las palabras» (págs. 326-327).

\section{$1^{\text {a }}$ mitad del XIX}

DRAE-1803: «s.f. $[\ldots]$

Construccion. Gram. La recta disposicion de las partes de la oracion entre si. Compositio, constructio. [...]» (pág. 225,2).

DRAE-1817: «s.f. [...]

Construccion. Gram. La recta disposicion de las partes de la oracion entre si. Compositio, constructio. [...]» (pág. 231,3). 
DRAE-1822: «s.f. $[\ldots]$

Construccion. Gram. La recta disposicion de las partes de la oracion entre si. Compositio, constructio. [...]» (pág. 213,1).

DRAE-1832: «f. [...] ๆ Gram. La recta disposicion de las partes de la oracion entre si. Compositio, constructio verborum $[\ldots]$ (pág. $194,3)$.

DRAE-1837: «f. [...] ๆ Gram. La recta disposicion de las partes de la oracion entre si. Compositio, constructio verborum [...]» (pág. 194,3).

DRAE-1843: «f. [...] ه Gram. La recta disposicion de las partes de la oracion entre sí. compositio, constructio verborum $[\ldots]$ (... (pág. 188,3).

\section{$2^{\mathrm{a}} \mathrm{m} . \mathrm{XIX}$ - p. XX}

DRAE-1852: «s.f. [...] ब Gram. La recta disposicion de las partes de la oracion entre sí. Compositio, constructio verborum [...]» (pág. 182,2).
GRAE-1854: «La construccion de las partes de la oracion es otra especie de dependencia [como el Régimen] que las une, no con tanta precision como el régimen, sino con alguna mayor libertad; ya añadiendo unas, ya introduciendo otras entre las que van enlazadas por el régimen, para explicar mejor los pensamientos, y evitar la uniformidad que resultaria si se guardaran constantemente en el uso las reglas del régimen y concordancia de las palabras» (págs. 156-157).

GRAE-1858: «La construccion de las partes de la oracion es otra especie de vínculo [como el Régimen] que las une, no con tanta precision como el régimen, sino con alguna mayor libertad; ya añadiendo unas, ya introduciendo otras entre las que van enlazadas por el régimen, para explicar mejor los pensamientos, y evitar la uniformidad que resultaria si se guardaran constantemente en el uso las reglas del régimen y concordancia de las palabras» (págs. 172-173).

GRAE-1862: «La construccion de las partes de la oracion es otra especie de vínculo [como el Régimen] que las une, no con tanta precision como el régimen, sino con alguna mayor libertad; ya añadiendo unas, ya introduciendo otras entre las que van enlazadas por el régimen, para explicar mejor los pensamientos, 
y evitar la uniformidad que resultaria si se guardaran constantemente en el uso las reglas del régimen y concordancia de las palabras» (pág. 176).

GRAE-1864: «La construccion de las partes de la oracion es otra especie de vínculo [como el Régimen] que las une, no con tanta precision como el régimen, sino con alguna mayor libertad; ya añadiendo unas, ya introduciendo otras entre las que van enlazadas por el régimen, para explicar mejor los pensamientos, y evitar la uniformidad que resultaria si se guardaran constantemente en el uso las reglas del régimen y concordancia de las palabras» (pág. 176).

GRAE-1865: «La construccion de las partes de la oracion es otra especie de vínculo [como el Régimen] que las une, no con tanta precision como el régimen, sino con alguna mayor libertad; ya añadiendo unas, ya introduciendo otras entre las que van enlazadas por el régimen, para explicar mejor los pensamientos, y evitar la uniformidad que resultaria si se guardaran constantemente en el uso las reglas del régimen y concordancia de las palabras» (pág. 176).

GRAE-1866: «La construccion de las partes de la oracion es otra especie de vínculo [como el Régimen] que las une, no con tanta precision como el régimen, sino con alguna mayor libertad; ya añadiendo unas, ya introduciendo otras entre las que van enlazadas por el régimen, para explicar mejor los pensamientos, y evitar la uniformidad que resultaria si se guardaran constantemente en el uso las reglas del régimen y concordancia de las palabras» (pág. 176).

GRAE-1867: «La construccion de las partes de la oracion es otra especie de vínculo [como el Régimen] que las une, no con tanta precision como el régimen, sino con alguna mayor libertad; ya añadiendo unas, ya introduciendo otras entre las que van enlazadas por el régimen, para explicar mejor los pensamientos, y evitar la uniformidad que resultaria si se guardaran constantemente en el uso las reglas del régimen y concordancia de las palabras» (pág. 175).

DRAE-1869: «f. [...] ๆ Gram. La recta disposición de las partes de la oracion entre sí [...]» (pág. $202,3)$. 
GRAE-1870: «La construccion de las partes de la oracion es otra especie de vínculo [como el Régimen] que las une, no con tanta precision como el régimen, sino con alguna mayor libertad, ya añadiendo unas, ya introduciendo otras entre las que van enlazadas por el régimen, para explicar mejor los pensamientos, y evitar la uniformidad que resultaría si se guardáran constantemente en el uso las reglas del régimen y concordancia de las palabras» (pág. 196).

GRAE-1874: «La construccion de las partes de la oracion es otra especie de vínculo [como el Régimen] que las une; pero no con tanta precision como el régimen, sino con alguna mayor libertad, ya añadiendo unas, ya introduciendo otras entre las que van enlazadas por el régimen, para explicar mejor los pensamientos, y evitar la uniformidad que resultaría si se guardaran constantemente en el uso las reglas del régimen y concordancia de las palabras» (pág. 224).

GRAE-1878: «La construccion de las partes de la oracion es otra especie de vínculo [como el Régimen] que las une; pero no con tanta precision como el régimen, sino con alguna mayor libertad, ya añadiendo unas, ya introduciendo otras entre las que van enlazadas por el régimen, para explicar mejor los pensamientos, y evitar la uniformidad que resultaría si se guardaran constantemente en el uso las reglas del régimen y concordancia de las palabras» (pág. 224).

GRAE-1880: «La construcción de las partes de la oración es otra especie de vínculo [como el Régimen] que las une; pero no con tanta precisión como el régimen, sino con alguna mayor libertad, ya añadiendo unas, ya introduciendo otras entre las que van enlazadas por el régimen, para explicar mejor los pensamientos y evitar la uniformidad que resultaría si se guardaran constantemente en el uso las reglas del régimen y de la concordancia de las palabras» (pág. 236).

GRAE-1883: «La construcción de las partes de la oración es otra especie de vínculo [como el Régimen] que las une; pero no con tanta precisión como el régimen, sino con alguna mayor libertad, ya añadiendo unas, ya introduciendo otras entre las que van enlazadas por el régimen, para explicar mejor los pensamientos $y$ evitar la uniformidad que 
DRAE-1884: «(Del lat. constructio.) f. [...] ๆ Gram. Ordenamiento y disposición á que se han de someter las palabras, ya relacionadas por la concordancia y el régimen, para expresar con ellas todo linaje de conceptos» (pág. 281,2). resultaría si se guardaran constantemente en el uso las reglas del régimen y de la concordancia de las palabras» (pág. 236).

GRAE-1885: «La construcción de las partes de la oración es otra especie de vínculo [como el Régimen] que las une; pero no con tanta precisión como el régimen, sino con alguna mayor libertad, ya añadiendo unas, ya introduciendo otras entre las que van enlazadas por el régimen, para explicar mejor los pensamientos y evitar la uniformidad que resultaría si se guardaran constantemente en el uso las reglas del régimen y de la concordancia de las palabras» (pág. 238).

GRAE-1888: «La construcción de las partes de la oración es otra especie de vínculo [como el Régimen] que las une; pero no con tanta precisión como el régimen, sino con alguna mayor libertad, ya añadiendo unas, ya introduciendo otras entre las que van enlazadas por el régimen, para explicar mejor los pensamientos y evitar la uniformidad que resultaría si se guardaran constantemente en el uso las reglas del régimen y de la concordancia de las palabras» (pág. 236).

GRAE-1890: «La construcción de las partes de la oración es otra especie de vínculo [como el Régimen] que las une; pero no con tanta precisión como el régimen, sino con alguna mayor libertad, ya añadiendo unas, ya introduciendo otras entre las que van enlazadas por el régimen, para explicar mejor los pensamientos y evitar la uniformidad que resultaría si se guardaran constantemente en el uso las reglas del régimen y de la concordancia de las palabras» (pág. 236).

GRAE-1895: «La construcción de las partes de la oración es otra especie de vínculo [como el Régimen] que las une; pero no con tanta precisión como el régimen, sino con alguna mayor libertad, ya añadiendo unas, ya introduciendo otras entre las que van enlazadas por el régimen, para explicar mejor los pensamientos y evitar la uniformidad que resultaría si se guardaran constantemente en el uso las reglas del régimen y de la concordancia de las palabras» (pág. 236).

Anexo II: Glosario terminológico Lema: Construcción 
DRAE-1899: «(Del lat. constructio. $)$ f. [...] ๆ Gram. Ordenamiento y disposición á que se han de someter las palabras, ya relacionadas por la concordancia y el régimen, para expresar con ellas todo linaje de conceptos» (pág. 261,1).
GRAE-1900: «La construcción de las partes de la oración es otra especie de vínculo [como el Régimen] que las une; pero no con tanta precisión como el régimen, sino con alguna mayor libertad, ya añadiendo unas, ya introduciendo otras entre las que van enlazadas por el régimen, para explicar mejor los pensamientos y evitar la uniformidad que resultaría si se guardaran constantemente en el uso las reglas del régimen y de la concordancia de las palabras» (pág. 236).

GRAE-1901: «La construcción de las partes de la oración es otra especie de vínculo [como el Régimen] que las une; pero no con tanta precisión como el régimen, sino con alguna mayor libertad, ya añadiendo unas, ya introduciendo otras entre las que van enlazadas por el régimen, para explicar mejor los pensamientos y evitar la uniformidad que resultaría si se guardaran constantemente en el uso las reglas del régimen y de la concordancia de las palabras» (pág. 236).

GRAE-1904: «La construcción de las partes de la oración es otra especie de vínculo [como el Régimen] que las une; pero no con tanta precisión como el régimen, sino con alguna mayor libertad, ya añadiendo unas, ya introduciendo otras entre las que van enlazadas por el régimen, para explicar mejor los pensamientos y evitar la uniformidad que resultaría si se guardaran constantemente en el uso las reglas del régimen y de la concordancia de las palabras» (pág. 230).

GRAE-1906: «La construcción de las partes de la oración es otra especie de vínculo [como el Régimen] que las une; pero no con tanta precisión como el régimen, sino con alguna mayor libertad, ya añadiendo unas, ya introduciendo otras entre las que van enlazadas por el régimen, para explicar mejor los pensamientos y evitar la uniformidad que resultaría si se guardaran constantemente en el uso las reglas del régimen y de la concordancia de las palabras» (pág. 230). 
GRAE-1908: «La construcción de las partes de la oración es otra especie de vínculo [como el Régimen] que las une; pero no con tanta precisión como el régimen, sino con alguna mayor libertad, ya añadiendo unas, ya introduciendo otras entre las que van enlazadas por el régimen, para explicar mejor los pensamientos y evitar la uniformidad que resultaría si se guardaran constantemente en el uso las reglas del régimen y de la concordancia de las palabras» (pág. 230).

GRAE-1909: «La construcción de las partes de la oración es otra especie de vínculo [como el Régimen] que las une, pero no con tanta precisión como el régimen, sino con alguna mayor libertad, ya añadiendo unas, ya introduciendo otras entre las que van enlazadas por el régimen, para explicar mejor los pensamientos y evitar la uniformidad que resultaría si se guardaran constantemente en el uso las reglas del régimen y de la concordancia de las palabras» (pág. 230).

GRAE-1911: «La construcción de las partes de la oración es otra especie de vínculo [como el Régimen] que las une, pero no con tanta precisión como el régimen, sino con alguna mayor libertad, ya añadiendo unas, ya introduciendo otras entre las que van enlazadas por el régimen, para explicar mejor los pensamientos y evitar la uniformidad que resultaría si se guardaran constantemente en el uso las reglas del régimen y la concordancia de las palabras» (pág. 235).

GRAE-1913: «La construcción de las partes de la oración es otra especie de vínculo [como el Régimen] que las une, pero no con tanta precisión como el régimen, sino con alguna mayor libertad, ya añadiendo unas, ya introduciendo otras entre las que van enlazadas por el régimen, para explicar mejor los pensamientos y evitar la uniformidad que resultaría si se guardaran constantemente en el uso las reglas del régimen y la concordancia de las palabras» (pág. 235).

DRAE-1914: «(Del lat. constructio, -onis.) f. [...] ๆ ${ }^{3}$ Gram. Ordenamiento y disposición a que se han de someter las palabras, ya relacionadas por la concordancia y el régimen, para expresar con ellas todo linaje de conceptos. $₫ 4$ Gram. V. Figura de construcción» (pág. $270,2)$.

$$
\text { wringmand }
$$


GRAE-1916: «La construcción de las partes de la oración es otra especie de vínculo [como el Régimen] que las une, pero no con tanta precisión como el régimen, sino con alguna mayor libertad, ya añadiendo unas, ya introduciendo otras entre las que van enlazadas por el régimen, para explicar mejor los pensamientos y evitar la uniformidad que resultaría si se guardaran constantemente en el uso las reglas del régimen y la concordancia de las palabras» (pág. 235).

GRAE-1917: No se habla de ella.

GRAE-1920: No se habla de ella.

GRAE-1924: No se habla de ella.

DRAE-1925: «(Del lat. constructio, -onis.) f. [...] ๆ 4. Gram. Ordenamiento y disposición a que se han de someter las palabras, ya relacionadas por la concordancia y el régimen, para expresar con ellas todo linaje de conceptos. If 5. Gram. V. Figura de construcción» (pág. 326,2). 


\section{CONSTRUIR}

\section{SIGLO XVIII}

Autoridades: «v.a. $[\ldots]$

Construir. En la Gramática es traducir literalmente una lengua en otra. Lat. Scriptorem ad verbum interpretari, verbum é verbo convertere. ANT. Agust. Dial. pl. 2. Sin conocer de ellas mas de lo que conoce qualquier Eftudiante que sabe leer y conftruir, ò poco mas. AlCaz. Perf. Lat. pl. 2. La única regal pues de aprender à conftruir, fea enfeñarse à refolver la colocación del Latin de artificiofa en naturál: y hecha efta diligencia, traducirle defpues palabra por palabra en Caftellano» (1729, págs. 537,2 y 538).

\section{GRAE-1771:}

DRAE-1780: «v.a. [...]

Construir. Gram. En las escuelas de gramática, es traducir gramaticalmente del latín al castellano. E latino in vernaculum sermonem grammaticè vertere, interpretari» (pág. 264,2).

DRAE-1783: «v.a. [...]

Construir. Gram. En las escuelas de gramática, es traducir gramaticalmente del latín al castellano. E latino in vernaculum sermonem grammaticè vertere, interpretari» (pág. 278,3).

DRAE-1791: «v.a. [...] 2. Gram. En las escuelas de gramática, es traducir gramaticalmente del latin al castellano. E latino in vernaculum sermonem grammaticè vertere, interpretari» (pág. 250,2).

\section{$1^{\text {a }}$ mitad del XIX}

DRAE-1803: «v.a. [...]

CONSTRUIR. Gram. En las escuelas de gramática, traducir gramaticalmente del latin al castellano. E latino in vernaculum sermonem grammaticè vertere, interpretari» (pág. 225,2).

DRAE-1817: «v.a. [...]

Construir. Gram. En las escuelas de gramática traducir gramaticalmente del latin al castellano. E latino in vernaculum sermonem grammaticè vertere, interpretari» (pág. 231,3).

DRAE-1822: «v.a. [...]

ConstruIR. Gram. En las escuelas de gramática traducir del latin al castellano. $E$ latino in vernaculum sermonem grammaticè vertere, interpretari» (pág. 213,1). 
DRAE-1832: «a. [...] đ| En las escuelas de gramática traducir del latin al castellano. $E$ latino in vernaculum sermonem vertere» (pág. 194,3).

DRAE-1837: «a. $[\ldots]$ ๆ En las escuelas de gramática traducir del latin al castellano. E latino in vernaculum sermonem vertere» (pág. 194,3).

DRAE-1843: «a. $[\ldots]$ ๑ En las escuelas de gramática traducir el latín al castellano. $E$ latino in vernaculum sermonem vertere» (pág. 188,3).

\section{$2^{\mathrm{a}}$ m. XIX - p. XX}

DRAE-1852: a. [...] ๆ En las escuelas de gramática traducir del latin al castellano. $E$ latino in vernaculum sermonem vertere (pág. 182,2).

GRAE-1854:

GRAE-1858:

GRAE-1862:

GRAE-1864:

GRAE-1865:

GRAE-1866:

GRAE-1867:

DRAE-1869: «a. [...] đ En las escuelas de gramática, traducir del latin ó griego al castellano» (pág. $202,3)$.

DRAE-1884: «(Del lat. construere; de cum, con, y struere, acumular, amontonar.) a. [...] En las escuelas de gramática, traducir del latín ó griego al castellano. đ Gram. Ordenar las palabras, ó unirlas entre sí con arreglo á las leyes de la construcción gramatical» (pág. 281,2).

\section{GRAE-1870:}

GRAE-1874:

GRAE-1878:

GRAE-1880:

GRAE-1883:

GRAE-1888: 
GRAE-1890:

GRAE-1895:

DRAE-1899: «(Del lat. construere; de cum, con, y struere, acumular, amontonar.) a. [...] En las escuelas de gramática, traducir del latín ó griego al castellano. I Gram. Ordenar las palabras, ó unirlas entre sí con arreglo á las leyes de la construcción gramatical» (pág. $261,1)$.

\section{GRAE-1900:}

GRAE-1901:

GRAE-1904:

GRAE-1906:

GRAE-1908:

GRAE-1909:

GRAE-1911:

GRAE-1913:

DRAE-1914: «(Del lat. construere; de cum, con, y struere, acumular, amontonar.) a. [...] $\rrbracket^{2}$ En las escuelas de gramática, traducir del latín o griego al castellano. If ${ }^{3}$ Gram. Ordenar las palabras, o unirlas entre sí con arreglo a las leyes de la construcción gramatical» (pág. $270,2)$.

\section{GRAE-1916:}

GRAE-1917:

GRAE-1920:

GRAE-1924:

DRAE-1925: «(Del lat. construere; de cum, con, y struere, acumular, amontonar.) tr. $[\ldots] \rrbracket \mathbf{2}$.. En las antiguas escuelas de gramática, traducir del latín o del griego al castellano. @| 3. Gram. Ordenar las palabras, o unirlas entre sí con arreglo a las leyes de la construcción gramatical (pág. 326,2). 


\section{COORIDINACIÓN}

\section{SIGLO XVIII}

Autoridades: «f.f. Méthodo y orden nuevamente puefto, à lo que eftaba defordenado y confufo. Es verbal del verbo Coordinar. Lat. Novus ordo» $(1729$, pág. 583,1$)$.

GRAE-1771: No se habla de ella.

DRAE-1780: «s. f. La accion y efecto de coordinar. Ordinatio» (pág. 274,1).

DRAE-1783: «s. f. La accion y efecto de coordinar. Ordinatio» (pág. 288,2).

DRAE-1791: «s. f. La accion y efecto de coordinar. Ordinatio» (pág. 258,2).

GRAE-1796: No se habla de ella.

\section{$1^{\text {a }}$ mitad del XIX}

DRAE-1803: «s. f. La accion y efecto de coordinar. Ordinario» (pág. 233,2).

DRAE-1817: «s. f. La accion y efecto de coordinar. Ordinatio» (pág. 239,2).

DRAE-1822: «s. f. La accion y efecto de coordinar. Ordinatio» (pág. 220,2).

DRAE-1832: «f. La accion y efecto de coordinar. Ordinatio» (pág. 201,2).

DRAE-1837: «f. La accion y efecto de coordinar. Ordinatio» (pág. 201,2).

DRAE-1843: «f. La accion y efecto de coordinar. Ordinatio» (pág. 195,1).

\section{$2^{\mathrm{a}} \mathrm{m}$. XIX - p. XX}

DRAE-1852: «f. La accion y efecto de coordinar. Ordinatio» (pág. 188,2).

GRAE-1854: No se habla de ella.

GRAE-1858: No se habla de ella.

GRAE-1862: No se habla de ella.

GRAE-1864: No se habla de ella. 
GRAE-1865: No se habla de ella.

GRAE-1866: No se habla de ella.

GRAE-1867: No se habla de ella.

DRAE-1869: «f. La accion y efecto de coordinar» (pág. 209,1).

DRAE-1884: «f. Acción y efecto de coordinar» (pág. 289,3).

DRAE-1899: «f. Acción y efecto de coordinar» (pág. 268,2).
GRAE-1870: No se habla de ella.

GRAE-1874: No se habla de ella.

GRAE-1878: No se habla de ella

GRAE-1880: No se habla de ella.

GRAE-1883: No se habla de ella.

GRAE-1885: No se habla de ella.

GRAE-1888: No se habla de ella.

GRAE-1890: No se habla de ella.

GRAE-1895: No se habla de ella.

GRAE-1900: No se habla de ella.

GRAE-1901: No se habla de ella.

GRAE-1904: No se habla de ella.

GRAE-1906: No se habla de ella.

GRAE-1908: No se habla de ella.

GRAE-1909: No se habla de ella.

GRAE-1911: No se habla de ella.

GRAE-1913: No se habla de ella. 
DRAE-1914: «(Del lat. coordinatio, -onis.) f. Acción y efecto de coordinar» (pág. 278,1).
DRAE-1925: «f. Acción y efecto de coordinar» (pág. 335,1).
GRAE-1916: No se habla de ella.

GRAE-1917: No se define el concepto de coordinación; por tal se entiende un tipo especial de unión de oraciones dentro del período sin que entre estas oraciones haya una influencia recíproca. Se distinguen cinco tipos de coordinación: la copulativa, la disyuntiva, la adversativa y correctiva, la causal y la consecutiva. (Págs. 291-313).

«Decimos que dos o más oraciones están coordinadas cuando el juicio enunciado en cada una de ellas se expresa como independiente del indicado por las demás, y de manera que puede enunciarse solo, sin que por ello deje de entenderse clara y distintamente» (pág. 292).

GRAE-1920: Seguimos sin definición propiamente dicha de este tipo de relación de oraciones que no conlleva influencias mutuas entre las mismas. Se mantiene la concepción y se mantienen los tipos. (Págs. 311-333).

«Decimos que dos o más oraciones están coordinadas cuando el juicio enunciado en cada una de ellas se expresa como independiente del indicado por las demás, y de manera que puede enunciarse solo, sin que por ello deje de entenderse clara y distintamente» (pág. 312).

GRAE-1924: La coordinación se sigue explicando como la relación de oraciones en el período sin influencias recíprocas entre ellas. Los tipos también son los mismos. (Págs. 311-333).

«Decimos que dos o más oraciones están coordinadas cuando el juicio enunciado en cada una de ellas se expresa como independiente del indicado por las demás, y de manera que puede enunciarse solo, sin que por ello deje de entenderse clara y distintamente» (pág. 312). 


\section{CODRDINAR}

\section{SIGLO XVIII}

Autoridades: «v.a. Diftribuir, colocar, poner de nuevo en orden y méthodo lo que antes eftaba defordenado, ò con el tiempo fe havia confundido, ò lo que no eftaba difpuesto con la proporcion y orden conveniente. Es voz compuefta de la prepofición Con y del verbo Ordenar. Lat. In ordinem plura redigere, ex ordine collocare, ordinatè ponere» (1729, pág. $583,1)$.

\section{GRAE-1771:}

DRAE-1780: «v.a. Poner en órden y método algunas cosas. Ordinare, in ordinem redigere» (pág. $274,1)$.

DRAE-1783: «v.a. Poner en órden y método algunas cosas. Ordinare, in ordinem redigere» (pág. $288,2)$.

DRAE-1791: «v.a. Poner en órden y método algunas cosas. Ordinare, in ordinem redigere» (pág. $258,2)$.

\section{GRAE-1796:}

\section{$1^{\text {a }}$ mitad del XIX}

DRAE-1803: «v.a. Poner en órden y método algunas cosas. Ordinare, in ordinem redigere» (pág. $233,2)$.

DRAE-1817: «v.a. Poner en órden y método algunas cosas. Ordinare, in ordinem redigere» (pág. $239,2)$.

DRAE-1822: «v.a. Poner en órden y método algunas cosas. Ordinare, in ordinem redigere» (pág. $220,2)$.

DRAE-1832: «a. Poner en órden y método algunas cosas. Ordinare, in ordinem redigere» (pág. $201,2)$.

DRAE-1837: «a. Poner en órden y método algunas cosas. Ordinare, in ordinem redigere» (pág. $201,2)$

DRAE-1843: «a. Poner en órden y método algunas cosas. Ordinare, in ordinem redigere» (pág. $195,1)$. 


\section{$2^{\mathrm{a}} \mathrm{m} . \mathrm{XIX}-\mathrm{p} . \mathbf{X X}$}

DRAE-1852: «a. Poner en órden y método algunas cosas. Ordinare, in ordinem redigere» (pág. 188,2).

DRAE-1869: «a. Poner en órden y método algunas cosas» (pág. 209,1).

GRAE-1854:

GRAE-1858:

GRAE-1862:

GRAE-1864:

GRAE-1865:

GRAE-1866:

GRAE-1867:

GRAE-1870:

GRAE-1874:

GRAE-1878:

GRAE-1880:

GRAE-1883:

DRAE-1884: «(De co por con, y el lat. ordinare, ordenar.) a. Ordenar cosas metódicamente» (pág. 289,3).

GRAE-1885:

GRAE-1888:

GRAE-1890:

GRAE-1895: 
DRAE-1899: «(De co por con, y el lat. ordinare, ordenar.) a. Ordenar cosas metódicamente» (pág. 268,2).

DRAE-1914: «(Del lat. co por cum, con, y ordinare, ordenar.) a. Ordenar cosas metódicamente» (pág. 278,1).

DRAE-1925: «(Del lat. co por cum, con, y ordinare, ordenar.) tr. Disponer cosas metódicamente» (pág. 335,1).
GRAE-1900:

GRAE-1901:

GRAE-1904:

GRAE-1906:

GRAE-1908:

GRAE-1909:

GRAE-1911:

GRAE-1913:

GRAE-1916:

GRAE-1917:

GRAE-1920:

GRAE-1924: 


\section{CORRECTO}

\section{SIGLO XVIII}

Autoridades: «adj. Lo mifmo que Corregido. El ufo de efta voz es regularmente hablando de libros ù otros efcritos. Lat. Emendatior, \& ius. RIBAD. Fl. Sanct. Vid. de S. Gerónymo. Emendó en Roma los Pfalmos... que la Igléfia lee y canta: y por orden de San Dámafo, el Teftamento nuevo, que en fu tiempo andaba no tan correcto. Maner. Prefac. §. I. Atenderé à feguir los origináles del doctifsimo Padre Juan Luis de la Cerda, por mas nuevamente correctos. CoLMen. Hift. Segob. cap. 24. §.8. Aunque fe queja (y con razón) de que efta priméra imprefsion falió poco correcta» (1729, págs. 607,1-2).

GRAE-1771:

DRAE-1780: «adj. Lo exâcto y conforme á las reglas. Dícese de los escritos, del estilo, del dibuxo, \&c. Correctus» (pág. 280,2).

DRAE-1783: «adj. Lo exâcto, y conforme á las reglas. Dícese de los escritos, del estilo, del dibuxo, \&c. Correctus» (pág. 294,2).

DRAE-1791: « p.p. ant. irr. de CORREGIR. 2. adj. Lo exâcto, y conforme á las reglas. Dícese de los escritos, del estilo, del dibuxo, \&c. Correctus» (pág. 264,1).

GRAE-1796:

\section{$1^{\text {a }}$ mitad del XIX}

DRAE-1803: « p.p. irreg. ant. de CORREGIR.

CORRECTO. adj. Lo exâcto, y conforme á las reglas. Dícese de los escritos, del estilo, del dibuxo, \&c. Correctus» (pág. 238,2).

DRAE-1817: « p.p. irreg. ant. de CORREGIR.

CORRECTO. adj. Lo exacto y conforme á las reglas. Dícese de los escritos, del estilo, del dibujo, \&c. Correctus» (pág. 245,1).

DRAE-1822: « p.p. irreg. de CORREGIR.

CORRECTO, TA. adj. Lo exacto y conforme á las reglas. Dícese de los escritos, del estilo, del dibujo, \&c. Correctus» (pág. 225,2).

DRAE-1832: « p.p. irreg. de CORREGIR. adj. Lo exacto y conforme á las reglas. Dícese de los escritos, del estilo, del dibujo, \&c. Correctus» (pág. 206,2). 
DRAE-1837: « p.p. irreg. de CORREGIR. If adj. Lo exacto y conforme á las reglas. Dícese de los escritos, del estilo, del dibujo, \&c. Correctus» (pág. 206,2).

DRAE-1843: «p.p. irreg. de CORREGIR. 口 adj. Lo exacto y conforme á las reglas. Dícese de los escritos, del lenguage, del dibujo, etc. Correctus» (pág. 200,1).

\section{$2^{\mathrm{a}} \mathrm{m} . \mathrm{XIX}-$ p. XX}

DRAE-1852: «p.p. irreg. de CORREgIR. If adj. Lo exacto y conforme á las reglas. Dícese de los escritos, del lenguaje, del dibujo, etc. Correctus» (pág. 193,1).

GRAE-1854:

GRAE-1858:

GRAE-1862:

GRAE-1864:

GRAE-1865:

GRAE-1866:

GRAE-1867:

GRAE-1870:

GRAE-1874:

GRAE-1878:

GRAE-1880:

GRAE-1883: 


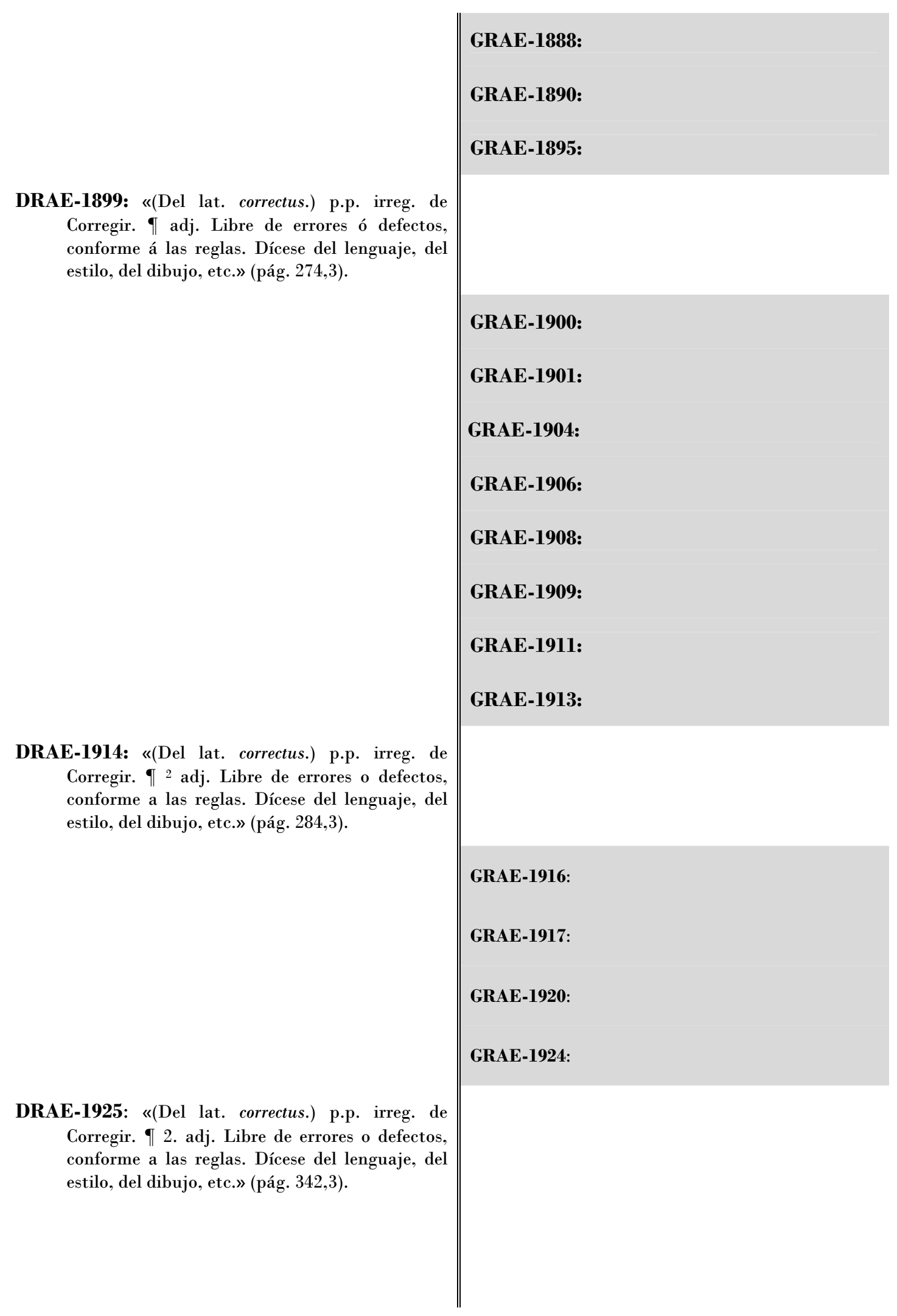




\section{SIGLO XVIII}

Autoridades: $:$ ss.f. Necefsidad de otra cofa, para fer ò exiftir. Lat. Mutua ratio duarum rerum inter ipfas. Hortens. Paneg. pl. 47. Eflo es fer efléncia purifsima primero, y fer fu raiz mas honda à nueftro modo de entender tofco, y fer por sí lin dependencia, ni necefsidad de otro fer. DePendencia. Vale tambien fubordinacion, reconocimiento à otro mayór poder y fuperioridad. Lat. Subjectio. Submifsio. SoLIS, Hift. de Nuev. Efp. lib. 2. cap. 6. Le importaba la autoridad de aquel Ayuntamiento y la dependéncia de aquellos fúbditos.

[...]» (1732, pág. 74,1).

\section{GRAE-1771:}

DRAE-1780: «s.f. Necesidad de otra cosa para ser, ó exîstir. Mutua ratio duarum rerum inter ipsas.

DEPENDENCIA. Subordinacion, reconocimiento á otro mayor poder y superioridad. Subjectio, submissio. [...]» (pág. 320,1).

DRAE-1783: «s.f. Necesidad de otra cosa para ser, ó exîstir. Mutua ratio duarum rerum inter ipsas.

DEPENDENCIA. Subordinacion, reconocimiento á otro mayor poder y superioridad. Subjectio, submissio. [...]» (pág. 334,2).

DRAE-1791: «s.f. Subordinacion, reconocimiento á otro mayor poder, ó autoridad. Subjectio, submissio [...]» (pág. 295,2).

\section{$1^{\text {a }}$ mitad del XIX}

DRAE-1803: «s.f. Subordinacion, reconocimiento á otro mayor poder, ó autoridad. Subjectio, submissio. [...]» (pág. 275,3).

DRAE-1817: «s.f. Subordinacion, reconocimiento á otro mayor poder ó autoridad. Subjectio, submissio. [...]» (pág. 285,3).

DRAE-1822: «s.f. Subordinacion, reconocimiento a otro mayor poder ó autoridad. Subjectio, submissio. [...]» (pág. 263,1).

DRAE-1832: «f. Subordinacion, reconocimiento á otro mayor poder ó autoridad. Subjectio, submissio. [...]» (pág. 241,1). 
DRAE-1837: «f. Subordinacion, reconocimiento á otro mayor poder ó autoridad. Subjectio, submissio. [...]» (pág. 241,1).

DRAE-1843: «f. Subordinacion, reconocimiento á otro mayor poder ó autoridad. Subjectio, submissio. [...]» (pág. 233,2).

\section{$2^{\mathrm{a}} \mathrm{m} . \mathrm{XIX}-\mathrm{p} . \mathrm{XX}$}

DRAE-1852: «f. Subordinacion, reconocimiento á otro mayor poder ó autoridad. Subjectio, submissio. [...]» (pág. 226,1).

DRAE-1869: «f. Subordinacion, reconocimiento de otro mayor poder ó autoridad $\uparrow[\ldots]$ ๆ pl. Las cosas que son accesorias de otra principal» (pág. $250,2)$.

DRAE-1884: «(De dependente.) f. Subordinación, reconocimiento de mayor poder ó autoridad \[...] \ pl. Cosas accesorias de otra principal» (pág. 348,1).

\section{GRAE-1854:}

GRAE-1858:

GRAE-1862:

GRAE-1864:

GRAE-1865:

GRAE-1866:

GRAE-1867:

GRAE-1870:

GRAE-1874:

GRAE-1878:

GRAE-1880:

GRAE-1883:

GRAE-1885:

GRAE-1888:

GRAE-1890: 
GRAE-1895:

DRAE-1899: «(De dependente.) f. Subordinación, reconocimiento de mayor poder ó autoridad 9 [... ๆ pl. Cosas accesorias de otra principal» (pág. 322,3).

GRAE-1900:

GRAE-1901:

GRAE-1904:

GRAE-1906:

GRAE-1908:

GRAE-1909:

GRAE-1911:

GRAE-1913:

DRAE-1914: «(Del lat. dependens, -entis, dependente.) f. Subordinación, reconocimiento de mayor poder o autoridad $₫[\ldots] \Upsilon^{5} \mathrm{pl}$. Cosas accesorias de otra principal» (pág. 335,1 ).

\section{GRAE-1916:}

GRAE-1917:

GRAE-1920:

GRAE-1924:

DRAE-1925: «(Del lat. dependens, -entis, dependente.) f. Subordinación, reconocimiento de mayor poder o autoridad $\llbracket[\ldots]$ \ 6. pl. Cosas accesorias de otra principal» (pág. 399,2-3). 


\section{ENLATAR}

\section{SIGLO XVIII}

Autoridades: "v.a. Unir y trabar una cofa con otra, atandolas con lazos, ò juntandolas y metiendolas en el lazo, de cuyo nombre fe forma efte verbo, antepuefta la prepoficion. En. Lat. Illaqueare. Innecter. Connectere [...] ENLAZAR. Metaphoricamente vale juntar, unir y trabar dos ò mas colas entre sí, mediante algun motivo, razón y ocafion: como de amiftad, parentefco, afecto, \&c. Lat. Implicare. Conjungere. Connectere [...]» (1732, pág. 480,1-2).

\section{GRAE-1771:}

DRAE-1780: «v.a. Unir y trabar una cosa con otra, atándolas con lazos, ó juntándolas y metiéndolas en el lazo. Illaqueare, innectere, connectere.

ENLAZAR. met. Juntar, unir y trabar dos, ó mas cosas entre sí, mediante algun motivo, razon y ocasion; como de amistad, parentesco, afecto, \&c. Implicare, conjungere, connectere» (pág. 408,2).

DRAE-1783: «v.a. Unir y trabar una cosa con otra, atándolas con lazos, ó juntándolas y metiéndolas en el lazo. Illaqueare, innectere, connectere.

ENLAZAR. met. Juntar, unir y trabar dos, ó mas cosas entre sí, mediante algun motivo, razon y ocasion; como de amistad, parentesco, afecto, \&c. Implicare, conjungere, connectere» (pág. 422,1-2).

DRAE-1791: «v.a. met. Dar enlace unas cosas con otras, como á los pensamientos, afectos, \&c. Conjungere, connectere» (pág. 372,3).

\section{$1^{\text {a }}$ mitad del XIX}

DRAE-1803: «v.a. Coger, ó atar alguna cosa con lazos.

ENLAZAR. met. Dar enlace á unas cosas con otras, como á los pensamientos, afectos, \&c. Conjungere, connectere» (pág. 352,2).

DRAE-1817: «v.a. Coger, ó atar alguna cosa con lazos.

ENLAZAR. met. Dar enlace á unas cosas con otras, como á los pensamientos, afectos, \&c. Conjungere, connectere» (pág. 363, 2). 
DRAE-1822: «v.a. Coger ó atar alguna cosa con lazos. Laqueis irretire.

ENLAZAR. met. Dar enlace á unas cosas con otras, como á los pensamientos, afectos, \&c. Conjungere, connectere» (pág. 336, 2).

DRAE-1832: «a. Coger ó atar alguna cosa con lazos. Laqueis irretire. I| met. Dar enlace á unas cosas con otras, como á los pensamientos, afectos, \&c. Connectere» (pág. $304,2)$.

DRAE-1837: «a. Coger ó atar alguna cosa con lazos. Laqueis irretire. I| met. Dar enlace á unas cosas con otras; como á los pensamientos, afectos, \&c. Connectere» (pág. $304,2)$.

DRAE-1843: «a. Coger, ó atar alguna cosa con lazos. Laqueis irretire. @ Dar enlace á unas cosas con otras; como á los pensamientos, afectos, etc. Connectere » (pág. 300,1).

\section{$2^{a}$ m. XIX - p. XX}

DRAE-1852: «a. Coger ó atar alguna cosa con lazos. Laqueis irrelire. đ Dar enlace á unas cosas con otras; como á los pensamientos, afectos, etc. Úsase también como recíproco. Connectere» (pág. 284,3).

GRAE-1854:

GRAE-1858:

GRAE-1862:

GRAE-1864:

GRAE-1865:

GRAE-1866:

GRAE-1867:

DRAE-1869: «a. Coger ó juntar alguna cosa con lazos. I Dar enlace á unas cosas con otras; como los pensamientos, afectos, proposiciones, etc. Úsase también como recíproco [...]» (pág. $313,1)$.

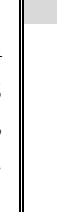

GRAE-1867:




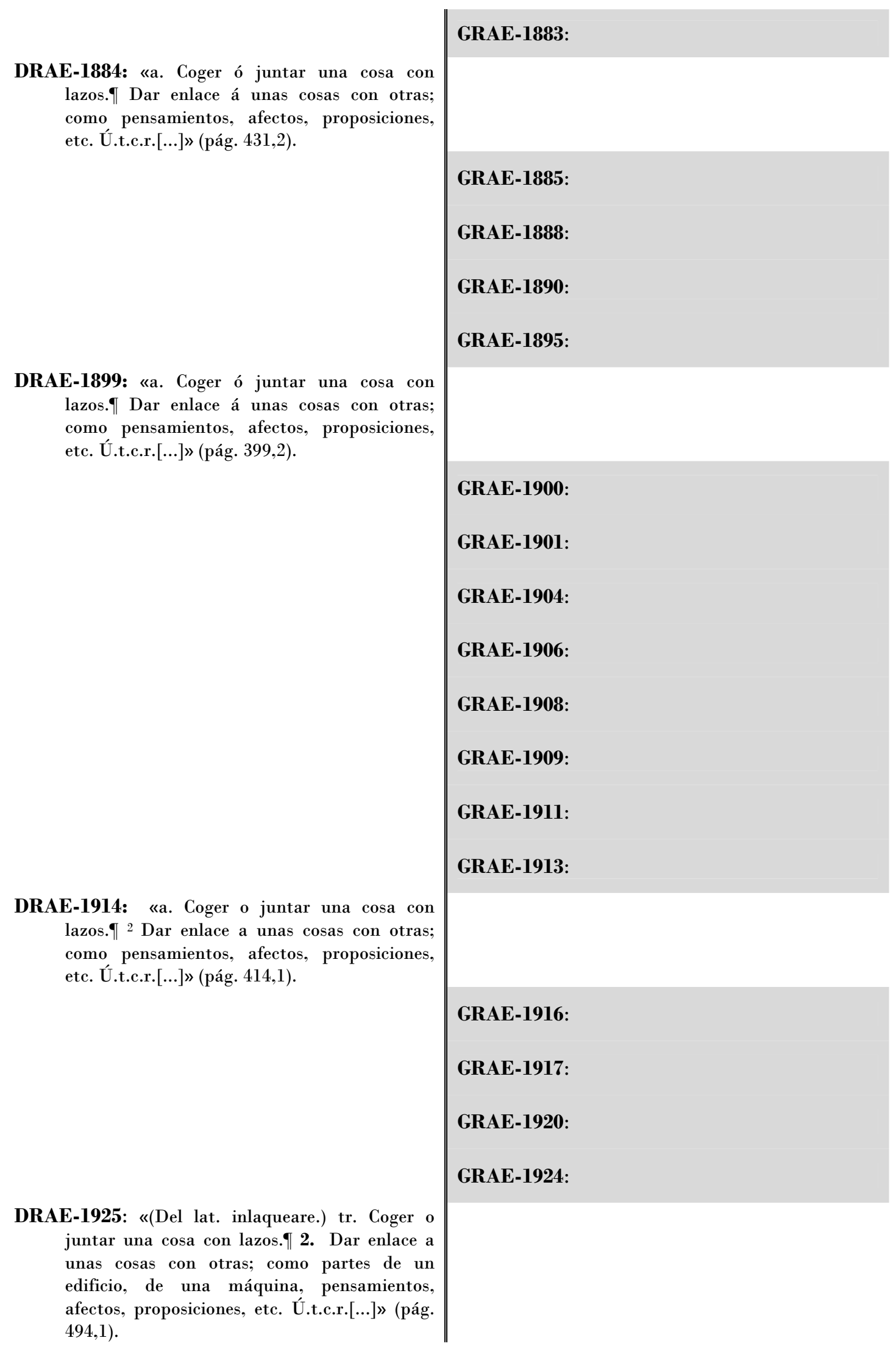




\section{GRAMÁTICA}

Autoridades: «l.f. El arte de bien hablar y efcribir. Es comun à todas las Lénguas, y particular à cada una, $\mathrm{y}$ prinicipio $\mathrm{y}$ fundamento de todas las ciencias. Enfeña la pronunciacion de las letras, la declinacion de los nombres, la conjugacion de los verbos, la conftruccion de las partes de la oracion, el fonido y accento diverfo de las palabras, la distincion de las vocáles y confonantes, y la orden de hablar con propriedad, pureza y policía. Es voz tomada del Griego Gramma, que fignifica Letra: y aunque fegun efte origen fe debiera efcribir con dos $m m$, el ufo le ha quitado la una, por fuavizar la pronunciación. Lat. Gramatica, ae. Paton, Eloq. f. 175. Con efto entiendo hemos dado un fuficiente principio à la Gramática Efpañola. Nieremb. Var. Iluftr. Vid. del Herm. Juan Fernandez. Efcribió... la Gramática en Léngua de los Japónes, y dos Diccionarios de la milma Léngua.

Gramatica. Por antonomália fe llama el eftudio de la Léngua Latina. Lat. Linguae latinae ftudium. Nieremb. Var. Iluftr. Vid. del P. Gonzalo Sylveira, § I. Era tan grande el defeo de aprovechar en la Gramática, que gaftaba buena parte de la noche eftudiando. Lop. Dorot. f. 132. De la edad que digo, yá fabía yo la Gramática, y no ignoraba la Rhetórica.

[...]» (1734, págs. 70,2 y 71,1$)$.

DRAE-1780: «s.f. El arte de bien hablar y escribir. Es comun á todas las lenguas, y particular á cada una, y prinicipio y fundamento de todas las ciencias. Enseña la pronunciacion de las letras, la declinacion de los nombres, la conjugacion de los verbos, la construccion de las partes de la oracion, el sonido y acento diverso de las palabras, la distincion de las vocales y consonantes, y la órden de hablar con propiedad, pureza y policía. Gramatica.

Gramática. El estudio de la lengua latina. Linguae latinae studium.

[...]» (pág. 506, 1).
GRAE-1771: «La GRAMÁtICA es arte de hablar bien. Divídese en dos partes: la primera trata del número, propiedad, yoficio de las palabras: la segunda del órden y concierto que deben tener entre si, para expresar con claridad los pensamientos» (págs. 1-2). 
DRAE-1783: «s.f. El arte de bien hablar y escribir. Es comun á todas las lenguas, y particular á cada una, y prinicipio y fundamento de todas las ciencias. Enseña la pronunciacion de las letras, la declinacion de los nombres, la conjugacion de los verbos, la construccion de las partes de la oracion, el sonido y acento diverso de las palabras, la distincion de las vocales y consonantes, y la órden de hablar con propiedad, pureza y policía. Gramatica.

Gramática. El estudio de la lengua latina. Linguae latinae studium. [...]» (pág. 519, 2).

DRAE-1791: «s.f. El arte de bien hablar y escribir. Es común á todas las lenguas, y particular á cada una, y prinicipio y fundamento de todas las ciencias. Enseña la pronunciacion de las letras, la declinacion de los nombres, la conjugacion de los verbos, la construccion de las partes de la oracion, el sonido y acento diverso de las palabras, la distincion de las vocales y consonantes, y la órden de hablar con propiedad, pureza y policia. Grammatica. 2. El estudio de la lengua latina. Linguae latinae studium [...]» (pág. 459,1).
GRAE-1796: «La GRAMÁTICA es el arte de hablar bien. Consta de quatro partes, que sonOrtografía, Analogía, Sintáxis y Prosodia» (pág. 1).

\section{$1^{\text {a }}$ mitad del XIX}

DRAE-1803: «s.f. El arte de hablar bien y escribir correctamente. Grammatica.

Gramática. El estudio de la lengua latina. Grammatica latina. [...]» (pág. 437,3).

DRAE-1817: «s.f. El arte de hablar bien y escribir correctamente. Grammatica.

Gramática. El estudio de la lengua latina. Grammatica latina [...]» (pág. 448,3).

DRAE-1822: «s.f. El arte de hablar bien y escribir correctamente. Grammatica.

Gramática. El estudio de la lengua latina. Grammatica latina [...]» (pág. 416,3).

DRAE-1832: «fr. [sic] El arte de hablar bien y escribir correctamente. Grammatica. I El estudio de la lengua latina. Grammatica latina [...]» (pág. 378,1).

DRAE-1837: «f. El arte de hablar bien y escribir correctamente. Grammatica. If El estudio de la lengua latina. Grammatica latina [...]» (pág. $377,3)$.

DRAE-1843: «f. El arte de hablar bien y escribir correctamente. Grammatica. Q El estudio de la lengua latina. Grammatica latina» (pág. 369, 3). 


\section{$2^{\mathrm{a}} \mathrm{m} . \mathrm{XIX}$ - p. XX}

DRAE-1852: «f. El arte de hablar bien y escribir correctamente. Grammatica. If El estudio de la lengua latina. Grammatica latina» (pág. 353, 1).

DRAE-1869: «f. El arte de hablar con propiedad y escribir correctamente. $\uparrow$ El estudio de la lengua latina [...]» (pág. 392,1).
GRAE-1854: «La Gramática es el arte de hablar bien» (pág. 1).

«[...] divídese en analogía y sintáxis [...]» (pág.1).

GRAE-1858: «La Gramática es el arte de hablar con propiedad y escribir correctamente». (pág. 1).

«[...] divídese en analogía, sintáxis, ortografía y prosodia $[\ldots] »($ pág. 1)

GRAE-1862: «La Gramática es el arte de hablar con propiedad y escribir correctamente» (pág. $5)$.

«[...] divídese en analogía, sintaxis, ortografía y prosodia $[\ldots] »$ (pág. 5).

GRAE-1864: «La Gramática es el arte de hablar con propiedad y escribir correctamente» (pág. $5)$.

«[...] divídese en analogía, sintáxis, ortografía y prosodia $[. .$.$] (pág. 5).$

GRAE-1865: «La Gramática es el arte de hablar con propiedad y escribir correctamente» (pág. $5)$.

«[...] divídese en analogía, sintáxis, ortografía y prosodia $[\ldots] »$ (pág. 5).

GRAE-1866: «La Gramática es el arte de hablar con propiedad y escribir correctamente» (pág. 5)

«[...] divídese en analogía, sintásis, ortografía y prosodia [...]» (pág. 5).

GRAE-1867: «La Gramática es el arte de hablar con propiedad y escribir correctamente» (pág.5).

«[...] divídese en analogía, sintáxis, ortografía y prosodia[...]» (pág. 5).

GRAE-1870: «Gramática es el arte de hablar y escribir correctamente» (pág. 1).

«El fin de toda GRAMÁTICA es enseñar á conocer, ordenar, pronunciar y escribir correctamente las oraciones y las partes todas de que constan, pues con las oraciones se forman los períodos, y con los períodos las obras literarias» (pág. 5). 
DRAE-1884: «(Del lat. grammatica.) f. Arte de hablar y escribir correctamente una lengua. ๆ Estudio de la lengua latina. ๆ comparada. La que estudia dos ó más idiomas comparándolos entre sí. ๆ general. Aquella en que se trata de los principios generales ó fundamentales de todos los idiomas [...]» (pág. 538,3).

GRAE-1874: «Gramática es el arte de hablar y escribir correctamente» (pág. 11). «El fin de toda GRAMÁTICA es enseñar á conocer, ordenar, pronunciar y escribir correctamente las oraciones y las partes todas de que constan [...] Tal es el resultado del estudio de la gramática, cuya division en las cuatro partes arriba dichas procede naturalmente de los cuatro fines que le hemos atribuido, á saber: conocer (ANALOGÍA), ordenar (SINTAXIS), pronunciar (PROSODIA), y escribir (ORTOGRAFÍA) correctamente» ( pág. 16).

GRAE-1878: «GRAMÁtica es el arte de hablar y escribir correctamente» (pág. 11).

«El fin de toda Gramática es enseñar á conocer, ordenar, pronunciar y escribir correctamente las oraciones y las partes todas de que constan [...] Tal es el resultado del estudio de la Gramática, cuya division en la cuatro partes arriba dichas procede naturalmente de los cuatro fines que le hemos atribuído, á saber: conocer (ANALOGÍA), ordenar (SINTAXIS), pronunciar (PROSODIA), y escribir (ORTOGRAFÍA) correctamente» (pág. 16).

GRAE-1883: «Gramática es el arte de hablar y escribir correctamente» (pág. 5).

«El fin de la Gramática es enseñar á conocer el valor y oficio de las palabras, el modo de formar con ellas oraciones y el de pronunciarlas y escribirlas. Agregando y enlazando oraciones resultan los períodos; y con éstos la conversación ó plática y toda clase de discurso hablado ó escrito, desde el más familiar hasta el más pulcro y galano. Así, pues, aquellas cuatro partes corresponden á los cuatro indicados fines, de conocer (ANALOGÍA), ordenar (SINTAXIS), pronunciar (PROSODIA) y escribir correctamente (ORTOGRAFÍA)» (pág. 5).

GRAE-1885: «GRAMÁtica es el arte de hablar y escribir correctamente» (pág. 5).

«El fin de la Gramática es enseñar á conocer el valor y oficio de las palabras, el modo de formar con ellas oraciones $y$ el de pronunciarlas $y$ escribirlas. Agregando y enlazando oraciones resultan los períodos; y con éstos la conversación ó plática y toda clase de discurso hablado ó escrito, desde el más familiar hasta el más pulcro y galano. Así, pues, aquellas cuatro partes corresponden á los cuatro indicados fines, de conocer (ANALOGÍA), ordenar (SINTAXIS), pronunciar (PROSODIA) y escribir correctamente (ORTOGRAFÍA)» (pág. 5). 
GRAE-1888: «GRAMÁtica es el arte de hablar y escribir correctamente» (pág. VI).

«Propónese [la gramática], por tanto, enseñar á conocer el valor y oficio de las palabras, el modo de formar con ellas oraciones y el de pronunciarlas y escribirlas; y se divide en cuatro partes, llamadas Analogía, Sintaxis, Prosodia y Ortografía, las cuales corresponden á los cuatro indicados fines, de conocer (ANAlogía), ordenar (SintaXis), pronunciar (Prosodia) y escribir correctamente (ORTOGRAFía)». (pág. Vi).

GRAE-1890: «GRAMÁtica es el arte de hablar y escribir correctamente» (Introducción, pág. VI. El subrayado es mío).

«Propónese [la gramática], por tanto, enseñar á conocer el valor y oficio de las palabras, el modo de formar con ellas oraciones y el de pronunciarlas y escribirlas; $y$ se divide en cuatro partes, llamadas Analogía, Sintaxis, Prosodia y Ortografía, las cuales corresponden á los cuatro indicados fines, de conocer (ANAlogía), ordenar (SINTAXIS), pronunciar (Prosodia) y escribir correctamente (ORTOGRafía)». (Introducción, pág. VI. El subrayado es mío).

GRAE-1895: «Gramática es el arte de hablar y escribir correctamente» (pág. VI).

«Propónese [la gramática], por tanto, enseñar á conocer el valor y oficio de las palabras, el modo de formar con ellas oraciones y el de pronunciarlas ó escribirlas; y se divide en cuatro partes, llamadas Analogía, Sintaxis, Prosodia y Ortografía, las cuales corresponden á los cuatro indicados fines, de conocer (ANAlogía), ordenar (SINTAXIS), pronunciar (Prosodia) y escribir correctamente (ORTOGRafía)» (pág. VI).

DRAE-1899: «(Del lat. grammatica.) f. Arte de hablar y escribir correctamente una lengua. ๆ Estudio de la lengua latina. ๆ comparada. La que estudia dos ó más idiomas comparándolos entre sí. - general. Aquella en que se trata de los principios generales ó fundamentales de todos los idiomas [...]» (pág. 500,3 y 501,1).

GRAE-1900: «Gramática es el arte de hablar y escribir correctamente» (pág. VI).

«Propónese [la gramática], por tanto, enseñar á conocer el valor y oficio de las palabras, el modo de formar con ellas oraciones y el de pronunciarlas ó escribirlas; y se divide en cuatro partes, llamadas Analogía, Sintaxis, Prosodia y Ortografía, las cuales corresponden á los cuatro indicados fines, de conocer (ANAlogía), ordenar (SINTAXIS), pronunciar (Prosodia) y escribir correctamente (ORTOGRafía)» (pág. VI).

Anexo II: Glosario terminológico Lema: Gramática 
GRAE-1901: «Gramática es el arte de hablar y escribir correctamente» (pág. VI).

«Propónese [la gramática], por tanto, enseñar á conocer el valor y oficio de las palabras, el modo de formar con ellas oraciones y el de pronunciarlas ó escribirlas; y se divide en cuatro partes, llamadas Analogía, Sintaxis, Prosodia y Ortografía, las cuales corresponden á los cuatro indicados fines, de conocer (ANAlogía), ordenar (SINTAXIS), pronunciar (Prosodia) y escribir correctamente (ORTOGRAFía)» (pág. VI).

GRAE-1904: «Gramática es el arte de hablar y escribir correctamente» (pág. VI).

«Propónese [la gramática], por tanto, enseñar á conocer el valor y oficio de las palabras, el modo de formar con ellas oraciones y el de pronunciarlas ó escribirlas; y se divide en cuatro partes, llamadas Analogía, Sintaxis, Prosodia y Ortografía, las cuales corresponden á los cuatro indicados fines, de conocer (ANALOGÍA), ordenar (SINTAXIS), pronunciar (PROSODIA), y escribir correctamente (ORTOGRAFÍA)». (pág. VI).

GRAE-1906: «Gramática es el arte de hablar y escribir correctamente» (pág. VI).

«Propónese [la gramática], por tanto, enseñar á conocer el valor y oficio de las palabras, el modo de formar con ellas oraciones y el de pronunciarlas ó escribirlas; y se divide en cuatro partes, llamadas Analogía, Sintaxis, Prosodia y Ortografía, las cuales corresponden á los cuatro indicados fines, de conocer (ANAlogía), ordenar (SINTAXIS), pronunciar (Prosodia), y escribir correctamente (Ortografía)» (pág. Vi).

GRAE-1908: «GRAMÁtica es el arte de hablar y escribir correctamente» (pág. VI).

«Propónese [la gramática], por tanto, enseñar á conocer el valor y oficio de las palabras, el modo de formar con ellas oraciones y el de pronunciarlas ó escribirlas; y se divide en cuatro partes, llamadas Analogía, Sintaxis, Prosodia y Ortografía, las cuales corresponden á los cuatro indicados fines de conocer (Analogía), ordenar (SintaXis), pronunciar (Prosodia) y escribir correctamente (ORTOGRafía)» (pág. VI).

GRAE-1909: «Gramática es el arte de hablar y escribir correctamente» (pág. VI).

«Propónese [la gramática], por tanto, enseñar á conocer el valor y oficio de las palabras, el modo de formar con ellas oraciones y el de pronunciarlas ó escribirlas; y se divide en cuatro partes, llamadas Analogía, Sintaxis, 
DRAE-1914: «(Del lat. grammatica, y éste del gr.

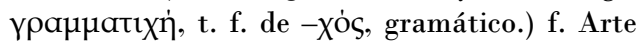
de hablar y escribir correctamente una lengua. $\mid$ Estudio de la lengua latina. If comparada. La que estudia dos o más idiomas comparándolos entre sí. ๆ general. Aquella en que se trata de los principios generales o fundamentales de todos los idiomas [...]» (pág. 518,1).
Prosodia y Ortografía, las cuales corresponden á los cuatro indicados fines de conocer (ANalogía), ordenar (SINTAXIS), pronunciar (Prosodia) y escribir correctamente (ORTOGRafía)» (pág. VI).

GRAE-1911: «GRAMÁtica es el arte de hablar y escribir correctamente» (pág. 6).

«Propónese [la gramática], por tanto, enseñar á conocer el valor y oficio de las palabras, el modo de formar con ellas oraciones y el de pronunciarlas ó escribirlas; y se divide en cuatro partes, llamadas Analogía, Sintaxis, Prosodia y Ortografía, las cuales corresponden á los cuatro indicados fines, de conocer (ANALOGÍA), ordenar (SINTAXIS), pronunciar (PROSODIA), y escribir correctamente (ORTOGRAFía)» (pág. 6).

GRAE-1913: «GRAMÁtica es el arte de hablar y escribir correctamente» (pág. 6).

«Propónese [la gramática], por tanto, enseñar a conocer el valor y oficio de las palabras, el modo de formar con ellas oraciones y el de pronunciarlas o escribirlas; y se divide en cuatro partes, llamadas Analogía, Sintaxis, Prosodia y Ortografía, las cuales corresponden á los cuatro indicados fines, de conocer (ANALOGÍA), ordenar (SINTAXIS), pronunciar (PROSODIA), y escribir correctamente (ORTOGRAFÍA)» (pág. 6).

GRAE-1916: «GRAmática es el arte de hablar y escribir correctamente» (pág. 6).

«Propónese [la gramática], por tanto, enseñar a conocer el valor y oficio de las palabras, el modo de formar con ellas oraciones y el de pronunciarlas o escribirlas; y se divide en cuatro partes, llamadas Analogía, Sintaxis, Prosodia y Ortografía, las cuales corresponden á los cuatro indicados fines, de conocer (ANALOGÍA), ordenar (SINTAXIS), pronunciar (PROSODIA), y escribir correctamente (ORTOGRAFÍA)» (pág. 6). 
GRAE-1917: «GRAMÁtica es el arte de hablar y escribir correctamente» (pág. VII).

«Propónese [la gramática], por tanto, enseñar a conocer el valor y oficio de las palabras, el modo de formar con ellas oraciones y el de pronunciarlas o escribirlas; $y$ se divide en cuatro partes, llamadas Analogía, Sintaxis, Prosodia y Ortografía, las cuales corresponden a los cuatro indicados fines, de conocer (ANALOGÍA), ordenar (SINTAXIS), pronunciar (PROSODIA), y escribir correctamente (ORTOGRAFÍA)». (pág. VII).

GRAE-1920: «GRAMÁtica es el arte de hablar y escribir correctamente» (pág. 7).

«Propónese [la gramática], por tanto, enseñar a conocer el valor y oficio de las palabras, el modo de formar con ellas oraciones y el de pronunciarlas o escribirlas; y se divide en cuatro partes, llamadas Analogía, Sintaxis, Prosodia y Ortografía, las cuales corresponden a los cuatro indicados fines, de conocer (ANALOGÍA), ordenar (SINTAXIS), pronunciar (PROSODIA), y escribir correctamente (ORTOGRAFÍA)». (pág. 8).

GRAE-1924: «GRAMÁtica es el arte de hablar y escribir correctamente». (Introducción, pág. 7. El subrayado es mío).

«Propónese [la gramática], por tanto, enseñar a conocer el valor y oficio de las palabras, el modo de formar con ellas oraciones y el de pronunciarlas o escribirlas; y se divide en cuatro partes, llamadas Analogía, Sintaxis, Prosodia y Ortografía, las cuales corresponden a los cuatro indicados fines, de conocer (ANALOGÍA), ordenar (SINTAXIS), pronunciar (PROSODIA), y escribir correctamente (ORTOGRAFÍA)». (Introducción, pág. 8. El subrayado es mío).

DRAE-1925: «(Del lat. grammatica, y éste del gr.

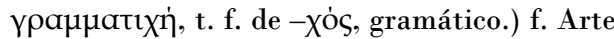
de hablar y escribir correctamente una lengua. ף 2. Estudio de la lengua latina. \ comparada. La que estudia dos o más idiomas comparándolos entre sí. đI general. Aquella en que se trata de los principios generales o fundamentales de todos los idiomas [...]» (pág. 621,1). 


\section{SIGLO XVIII}

Autoridades: «f.f. Suceflo, cafualidad, condicion que fobreviene accelforiamente à lo principál. Es voz puramente Latina. RECOP. Lib.2. tit.II. 1.33. Quando fe deduxere la hidalguia por incidéncia, para falir uno de la carcel, ù otros fines femejantes. Alcaz. Chron. Lib. Prelim. cap. 10. $§ 5$. Toda efta profperidád de fuceflos fe alteró con una incidéncia, perjudicial à los progreffos de la Religión.

[...]» (1734, pág. 238,2).

\section{GRAE-1771:}

DRAE-1780: «s.f. Suceso, casualidad, condicion que sobreviene accesoriamente á lo principal. Incidentia. [...]» (pág. 545,3).

DRAE-1783: «s.f. Suceso, casualidad, condicion que sobreviene accesoriamente á lo principal. Incidentia. [...]» (pág. 559,2).

DRAE-1791: «s.f. Suceso, casualidad, condicion que sobreviene accesoriamente á lo principal. Incidentia [...]» (pág. 496,1).

GRAE-1796:

\section{$1^{\text {a }}$ mitad del XIX}

DRAE-1803: «s.f. Lo que sobreviene en el discurso de algun asunto, ó negocio. Casus. [...]» (pág. 478,2).

DRAE-1817: «s.f. Lo que sobreviene en el discurso de algun asunto ó negocio. Casus. [...]» (pág. 487,3).

DRAE-1822: «s.f. Lo que sobreviene en el discurso de algun asunto ó negocio. Casus.

[...]» (pág. 453,3).

DRAE-1832: «f. Lo que sobreviene en el discurso de algun asunto ó negocio. Casus [...]» (pág. $412,2)$.

DRAE-1837: «f. Lo que sobreviene en el discurso de algun asunto ó negocio. Casus [...]» (pág. $412,1)$. 
DRAE-1843: «f. Lo que sobreviene en el discurso de algun asunto ó negocio. Casus [...]» (pág. $403,1)$.

\section{$2^{\mathrm{a}}$ m. XIX - p. XX}

DRAE-1852: «f. Lo que sobreviene en el discurso de algun asunto ó negocio. Casus [...]» (págs. $384,3$ y 385,1$)$.

DRAE-1869: «f. Lo que sobreviene en el discurso de algun asunto ó negocio [...]» (pág. 428,2).
DRAE-1884: «(De incidente.) f. Lo que sobreviene en el discurso de un asunto ó negocio [...]» (pág. $589,2)$.

DRAE-1899: «(De incidente.) f. Lo que sobreviene en el discurso de un asunto ó negocio [...]» (pág.
GRAE-1854:

GRAE-1858:

GRAE-1862:

GRAE-1864:

GRAE-1865:

GRAE-1866:

GRAE-1867:

GRAE-1870:

GRAE-1874:

GRAE-1878:

GRAE-1880:

GRAE-1883:

GRAE-1885:

GRAE-1888:

GRAE-1890:

GRAE-1895: 
GRAE-1900:

GRAE-1901:

GRAE-1904:

GRAE-1906:

GRAE-1908:

GRAE-1909:

GRAE-1911:

GRAE-1913:

DRAE-1914: «(Del lat. incidentia.) f. Lo que sobreviene en el discurso de un asunto o negocio [...]» (pág. 567,1).
GRAE-1916:

GRAE-1917:

GRAE-1920:

GRAE-1924:

DRAE-1925: «(Del lat. incidentia.) f. Lo que sobreviene en el discurso de un asunto o negocio y tiene con él alguna conexión [...]» (pág. 680,3). 


\section{INCIIIR}

\section{SIGLO XVIII}

Autoridades: «v.n. Caer ò incurrir en algo. Viene del Latino Incidere, que fignifica lo mifmo. RECOP. DE IND. lib. 9. tir. 33. 1. 33. Haciendo que fe cobre la pena impuefta, fi en ella huvieren incidido» (1734, pág. 239,1).

GRAE-1771:

DRAE-1780: «v. n. Caer, ó incurrir en algo. Incidere» (pág. 546,1).

DRAE-1783: «v. n. Caer, ó incurrir en algo. Incidere» (pág. 559,2).

DRAE-1791: «v. n. Caer, ó incurrir en algo. Incidere» (pág. 596,1).

\section{$1^{\text {a }}$ mitad del XIX}

DRAE-1803: «v. n. Caer, ó incurrir en algo. Incidere» (pág. 478,2).

DRAE-1817: «v. n. Caer ó incurrir en algo. Incidere» (pág. 488,1).

DRAE-1822: «v. n. Caer ó incurrir en algo. Incidere» (pág. 453,3).

DRAE-1832: «n. Caer ó incurrir en algo. Incidere» (pág. 412,2).

DRAE-1837: «n. Caer ó incurrir en algo. Incidere» (pág. 412,1).

DRAE-1843: «n. Caer ó incurrir en alguna falta, error, extremo, etc. Incidere» (pág. 403,1).

\section{$2^{\mathrm{a}}$ m. XIX - p. XX}

DRAE-1852: «n. Caer ó incurrir en alguna falta, error, extremo, etc. Incidere» (pág. 385,1).

GRAE-1854:

GRAE-1858: 
GRAE-1862:

GRAE-1864:

GRAE-1865:

GRAE-1866:

GRAE-1867:

DRAE-1869: «n. Caer ó incurrir en alguna falta, error, extremo, etc.» (pág. 428,2).

DRAE-1884: «(Del lat. incǐdĕre.) n. Caer ó incurrir en una falta, error, extremo, etc.» (pág. 589,2).

DRAE-1899: «(Del lat. incidĕre.) n. Caer ó incurrir en una falta, error, extremo, etc.» (pág. 550,2).

\section{GRAE-1870:}

GRAE-1874:

GRAE-1878:

GRAE-1880:

GRAE-1883:

GRAE-1885:

GRAE-1888:

GRAE-1890:

GRAE-1895:

GRAE-1900:

GRAE-1901:

GRAE-1904:

GRAE-1906: 


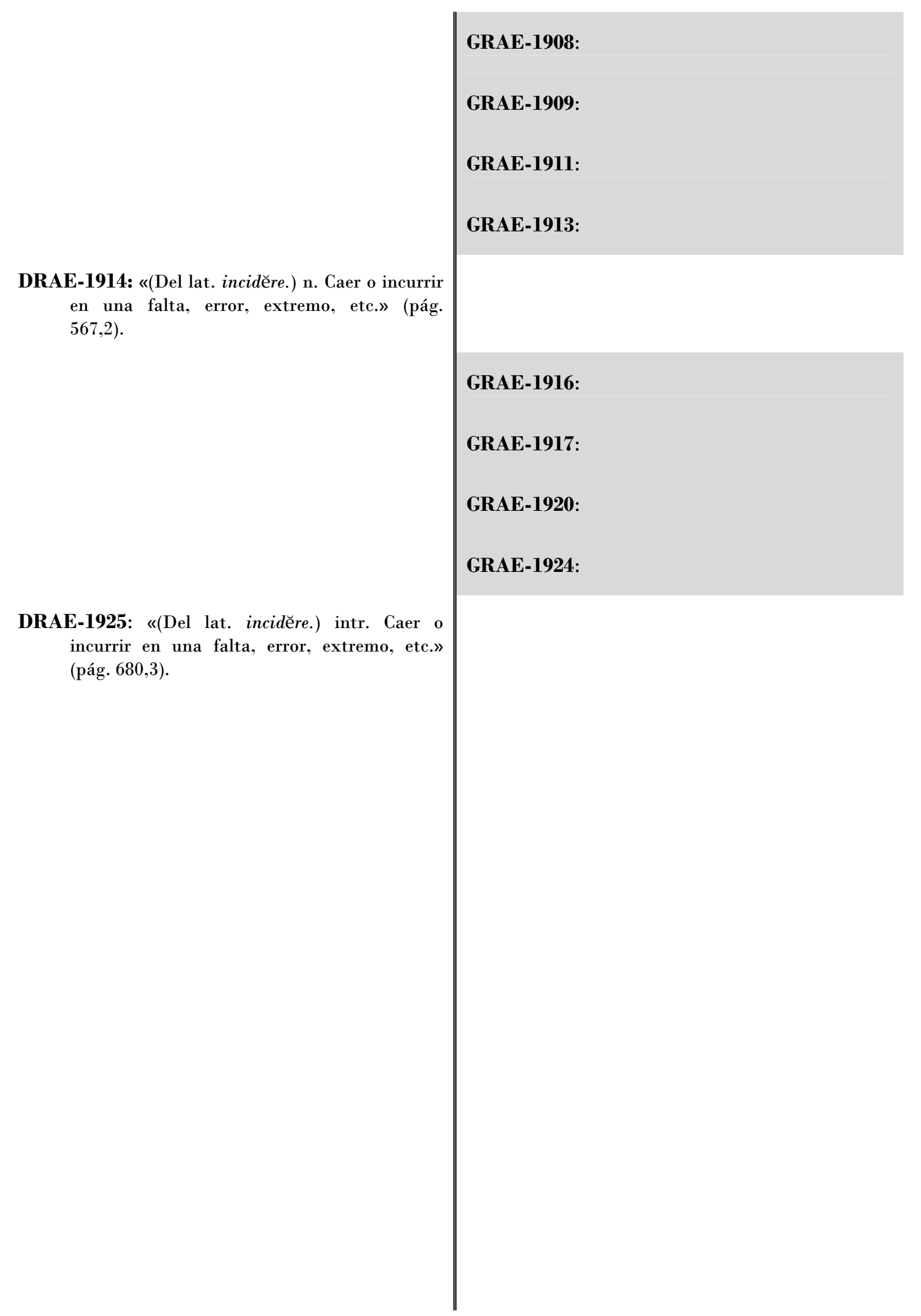




\section{SIGLO XVIII}

Autoridades: «f.f. Term. de Architectúra. Es un género de ornamento, que fe hace en la piedra dura y pulida, para contrapoficion en la fabrica. Lat. Incruftatio» (1734, pág. 247,1).

\section{GRAE-1771:}

DRAE-1780: «s.f. Arq. Un género de ornamento que se hace en la piedra dura y pulida para contraposicion en la fábrica. Incrustatio» (pág. $547,3)$.

DRAE-1783: «s.f. Arq. Un género de ornamento que se hace en la piedra dura y pulida para contraposicion en la fábrica. Incrustatio» (pág. $561,1)$.

DRAE-1791: «s.f. Arq. Un género de ornamento que se hace en la piedra dura y pulida para contraposicion en la fábrica. Incrustatio» (pág. $497,3)$.

\section{GRAE-1796:}

\section{$1^{\text {a }}$ mitad del XIX}

DRAE-1803: «s. f. La accion y efecto de incrustar. Incrustatio» (pág. 480,1).

DRAE-1817: «s. f. La accion y efecto de incrustar. Incrustatio» (pág. 489,3).

DRAE-1822: «s. f. La accion y efecto de incrustar. Incrustatio» (pág. 455,2).

DRAE-1832: «f. La accion y efecto de incrustar. Incrustatio» (pág. 414,1).

DRAE-1837: «f. La accion y efecto de incrustar. Incrustatio» (pág. 413,3).

DRAE-1843: «f. La accion y efecto de incrustar. Incrustatio» (pág. 404,2).

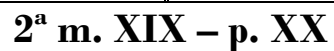

DRAE-1852: «f. La accion y efecto de incrustar. Incrustatio» (pág. 386,2).

\section{GRAE-1854:}




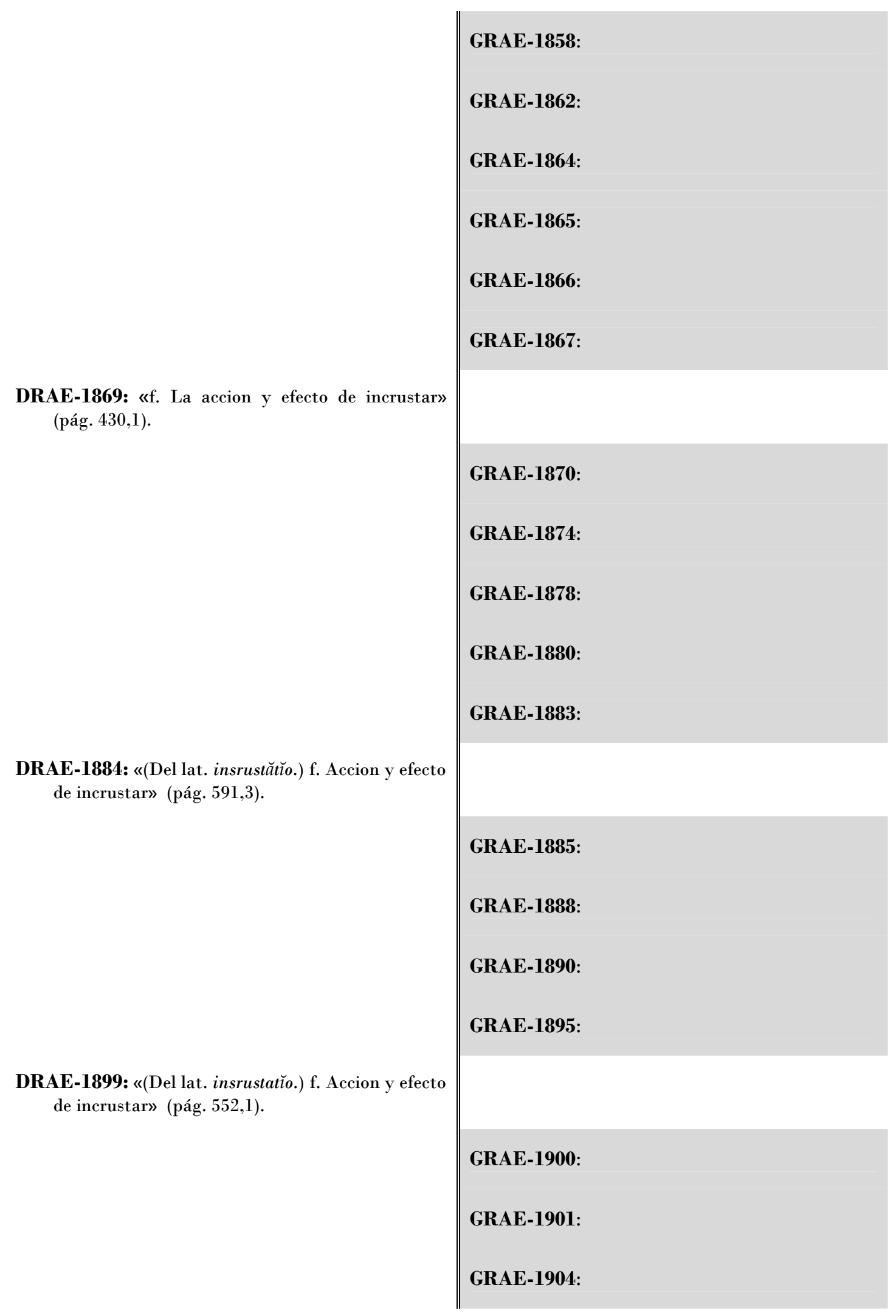


GRAE-1906:

GRAE-1908:

GRAE-1909:

GRAE-1911:

GRAE-1913:

DRAE-1914: «(Del lat. insrustatĭo, -ōnis.) f. Accion y efecto de incrustar. ๆ ${ }^{2}$ Cosa incrustada» (pág. $569,1)$

\section{GRAE-1916:}

GRAE-1917:

GRAE-1920:

GRAE-1924:

DRAE-1925: «(Del lat. insrustať̆o, -ōnis.) f. Accion y efecto de incrustar. \ 2. Cosa incrustada» (pág. $683,1)$. 


\section{INCRUSTAR}

\section{SIGLO XVIII}

Autoridades: «v.a. Adornar un edificio de mármoles y otras piedras brillantes, aplicadas en las entalladúras de los muros o parédes. Lat. Incruftare» (1734, pág. 247,1).

GRAE-1771:

DRAE-1780: «v.a. Adornar un edificio de mármoles y otras piedras brillantes, aplicadas en las entalladuras de los muros, ó paredes. Incrustare» (pág. 547,3).

DRAE-1783: «v.a. Adornar un edificio de mármoles y otras piedras brillantes, aplicadas en las entalladuras de los muros, ó paredes. Incrustare» (pág. 561,2).

DRAE-1791: «v.a. Adornar un edificio de mármoles $y$ otras piedras brillantes, aplicadas en las entalladuras de los muros, ó paredes. Incrustare» (pág. 497,3).

\section{$1^{\text {a }}$ mitad del XIX}

DRAE-1803: «v. a. Vestir con hojas delgadas de oro, mármoles, jaspes algun pavimento, pared, \&c. Incrustare» (pág. 480,1).

DRAE-1817: «v. a. Vestir con hojas delgadas de oro, mármoles, jaspes algun pavimento, pared, \&c. Incrustare» (pág. 489,3).

DRAE-1822: «v. a. Vestir con hojas delgadas de oro, mármoles, jaspes \&c. algun pavimento, pared \&c. Incrustare» (pág. 455,2).

DRAE-1832: «a. Vestir con hojas delgadas de oro, mármoles, jaspes \&c. algun pavimento, pared \&c. Incrustare» (pág. 414,1).

DRAE-1837: «a. Vestir con hojas delgadas de oro, mármoles, jaspes \&c. algun pavimento, pared \&c. Incrustare» (pág. 413,3).

DRAE-1843: «a. Vestir con hojas delgadas de oro, mármoles, jaspes etc. algun pavimento, pared etc. Incrustare» (pág. 404,2). 


\section{$2^{\mathrm{a}}$ m. XIX - p. XX}

DRAE-1852: «a. Vestir con hojas delgadas de oro, mármoles, jaspes etc. algun pavimento, pared etc. Incrustare» (pág. 386,2).
GRAE-1854:

GRAE-1858:

GRAE-1862:

GRAE-1864:

GRAE-1865:

GRAE-1866:

GRAE-1867:

GRAE-1870:

GRAE-1874:

GRAE-1878:

GRAE-1880:

GRAE-1883:

GRAE-1885:

GRAE-1888:

GRAE-1890:

GRAE-1895:

DRAE-1899: «(Del lat. incrustāre.) a. Embutir en una superficie lisa y dura piedras, metales, maderas, etc., formando dibujos para que sirvan de adorno. ๆ Cubrir una superficie con una costra dura» (pág. 552,1). 


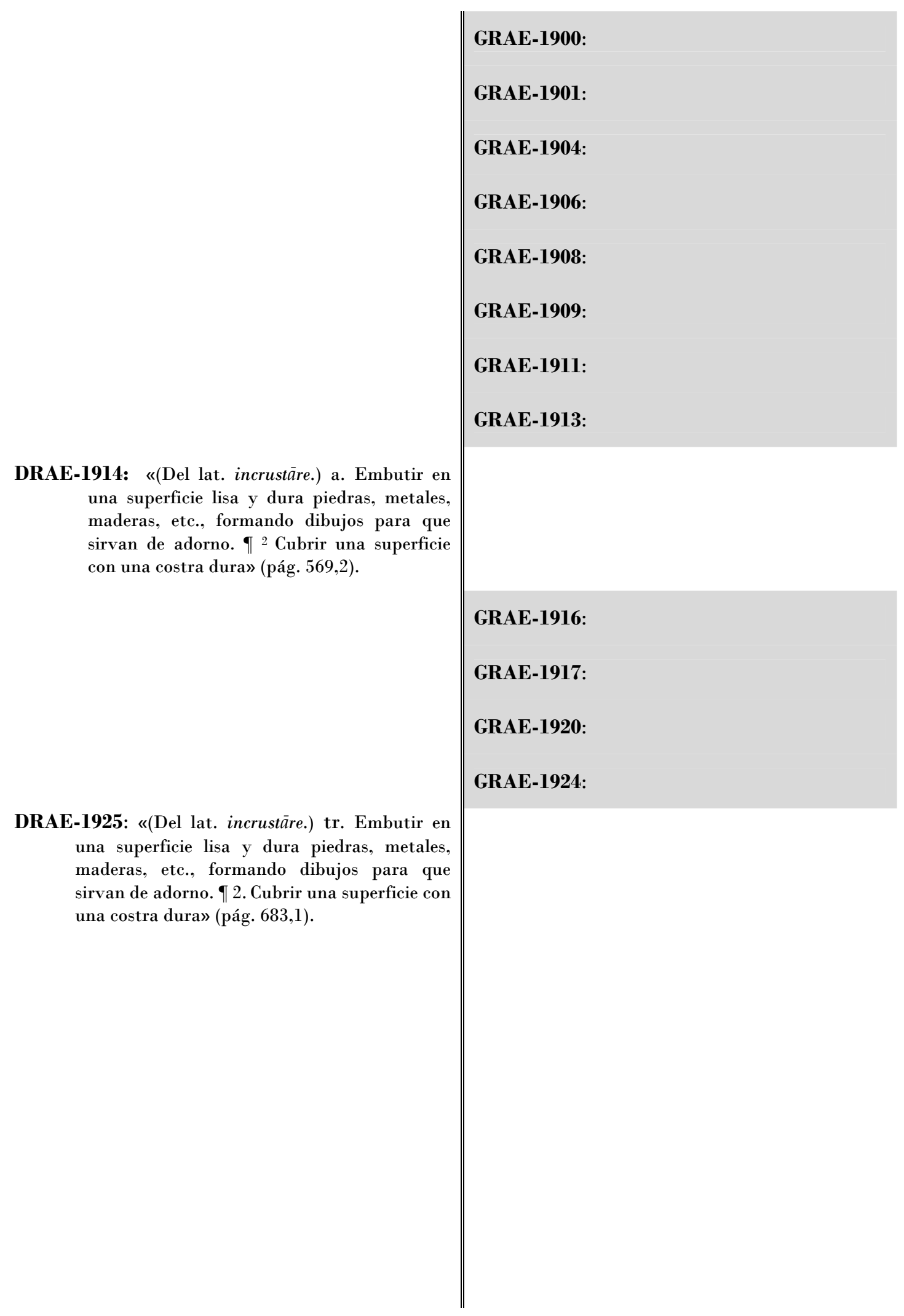




\section{MORFOLOGÍA}

\section{SIGLO XVIII}

Autoridades: No se registra.

GRAE-1771: No se utiliza el término (= Analogía)

DRAE-1780: No se registra.

DRAE-1783: No se registra.

DRAE-1791: No se registra.

GRAE-1796: No se utiliza el término (= Analogía)

\section{$1^{\text {a }}$ mitad del XIX}

DRAE-1803: No se registra.

DRAE-1817: No se registra.

DRAE-1822: No se registra.

DRAE-1832: No se registra.

DRAE-1837: No se registra.

DRAE-1843: No se registra.

\section{$2^{\mathrm{a}} \mathrm{m} . \mathrm{XIX}-\mathbf{p} . \mathbf{X X}$}

DRAE-1852: No se registra.

GRAE-1854: No se utiliza el término (= Analogía)

GRAE-1858: No se utiliza el término (= Analogía $)$

GRAE-1862: No se utiliza el término (= Analogía)

GRAE-1864: No se utiliza el término (= Analogía)

GRAE-1865: No se utiliza el término (= Analogía)

GRAE-1866: No se utiliza el término (= Analogía) 
DRAE-1869: No se registra.

DRAE-1884: No se registra.

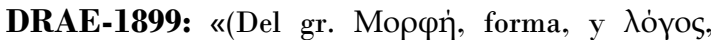
tratado.) f. Parte de la historia natural que trata de la forma de los seres orgánicos y de las modificaciones ó transformaciones que experimenta. T Tratado de las formas de las palabras y de sus transformaciones» (pág. 674,1).

(*) Se sigue dando entrada a analogía: «f. Gram. Parte de la gramática, que trata de los accidentes y propiedades de las palabras, consideradas aisladamente» (pág. 63).
GRAE-1867: No se utiliza el término (= Analogía)

GRAE-1870: No se utiliza el término (= Analogía)

GRAE-1874: No se utiliza el término (= Analogía)

GRAE-1878: No se utiliza el término (= Analogía)

GRAE-1880: No se utiliza el término (= Analogía)

GRAE-1883: No se utiliza el término (= Analogía)

GRAE-1885: No se utiliza el término (= Analogía)

GRAE-1888: No se utiliza el término (= Analogía)

GRAE-1890: No se utiliza el término (= Analogía)

GRAE-1895: No se utiliza el término (= Analogía)

GRAE-1900: No se utiliza el término (= Analogía)

GRAE-1901: No se utiliza el término (= Analogía)

GRAE-1904: No se utiliza el término (= Analogía)

GRAE-1906: No se utiliza el término (= Analogía)

GRAE-1908: No se utiliza el término (= Analogía)

GRAE-1909: No se utiliza el término (= Analogía) 
GRAE-1911: No se utiliza el término (= Analogía)

GRAE-1913: No se utiliza el término (= Analogía $)$

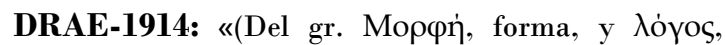
tratado.) f. Parte de la historia natural, que trata de la forma de los seres orgánicos y de las modificaciones o transformaciones que experimenta. ๆ ${ }^{2}$ Gram. Tratado de las formas de las palabras y de sus transformaciones» (pág. $693,3)$.

(*) Sigue teniendo cabida analogía: f. 2. Gram. Parte de la gramática, que trata de los accidentes y propiedades de las palabras, consideradas aisladamente (pág. 66).
GRAE-1916: No se utiliza el término (= Analogía)

GRAE-1917: No se utiliza el término (= Analogía)

GRAE-1920: No se utiliza el término (= Analogía)

GRAE-1924: No se utiliza el término (= Analogía $)$

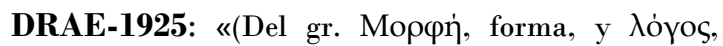
tratado.) f. Parte de la historia natural, que trata de la forma de los seres orgánicos y de las modificaciones o transformaciones que experimenta. I ${ }^{2}$ Gram. Tratado de las formas de las palabras» (pág. 828,3). 
(1)

\section{SIGLO XVIII}

Autoridades: «DECIMA quinta letra de nueftro Alphabéto, y quarta en el número de las vocáles, cuya figura es un circulo [...] Muchas veces es interjeccion, y firve para explicar varios afectos: como de admiracion... de exclamacion... de dolor o compafsion... de indignacion... y de efcárnio ò burla, ufada ironicamente...

La $O$ se ufa muchas veces para expreffar el deféo $[\ldots]$

Tómale tambien por articulo, que lleva y explica el vocativo $[\ldots]$

Sirve tambien de conjuncion disyuntiva: como, $\mathrm{O}$ rico, $\mathrm{O}$ pobre.

En términos de Arithmética la $\mathrm{O}$ fignifica el cero, cifra que no firve ni cuenta fin la unión de los numeráles.

$$
[\ldots] »(1737 \text {, pág. 1,1). }
$$

GRAE-1771:

DRAE-1780: «Décima quinta letra de nuestro alfabeto, y quarta en el número de las vocales, cuya figura es un círculo [...] Muchas veces es interjeccion, y sirve para explicar varios afectos; como de admiracion... de exclamacion... de dolor, ó compasion... de indignacion... y de escarnio, ó burla, usada irónicamente...

La $O$ se usa muchas veces para expresar el deseo $[\ldots]$

Tómase tambien por artículo, que lleva y explica el vocativo $[\ldots]$

Sirve tambien de conjuncion disyuntiva; como Ó rico, Ó pobre.

En términos de aritmética la $\mathrm{O}$ significa el cero, cifra que no sirve, ni cuenta sin la union de los numerales.

[...]» (pág. 655,1).

DRAE-1783: «Décima quinta letra de nuestro alfabeto, y quarta en el número de las vocales, cuya figura es un círculo [...] Muchas veces es interjeccion, y sirve para explicar varios afectos; como de admiracion... de exclamacion... de dolor, ó compasion... de indignacion... y de escarnio, ó burla, usada irónicamente... 
La $O$ se usa muchas veces para expresar el $\operatorname{deseo}[\ldots]$

Tómase tambien por artículo, que lleva y explica el vocativo $[\ldots]$

Sirve tambien de conjuncion disyuntiva; como: Ó rico, Ó pobre.

En términos de aritmética la $\mathrm{O}$ significa el cero, cifra que no sirve, ni cuenta sin la union de los numerales.

$[\ldots] »($ pág. 668,1).

DRAE-1791: «Décimaquinta letra de nuestro alfabeto, y quarta en el número de las vocales, cuya figura es un círculo [...] Muchas veces es interjeccion, y sirve para explicar varios afectos; como de admiracion... de exclamacion... de dolor, ó compasion... de indignacion... y de escarnio, ó burla, usada irónicamente... La O se usa muchas veces para expresar el deseo [...] Tómase tambien por artículo, que lleva y explica el vocativo [...] Sirve tambien de conjuncion disyuntiva; como: Ó rico, Ó pobre. En términos de aritmética la $O$ significa el cero, cifra que no sirve, ni cuenta sin la union de los numerales [...]» (pág. 595,1).

GRAE-1796:

\section{$1^{\text {a }}$ mitad del XIX}

DRAE-1803: «Décimaoctava letra de nuestro alfabeto, y quarta en el número de las vocales, cuya figura es un círculo [...] Muchas veces es interjeccion, y sirve para explicar varios afectos; como de admiracion... de exclamacion... de dolor, ó compasion... de indignacion... y de escarnio, ó burla, usada irónicamente... La O se usa muchas veces para expresar el deseo [...] Tómase tambien por artículo, que lleva y explica el vocativo [...] Sirve tambien de conjuncion disyuntiva; como: Ó rico, Ó pobre. En términos de aritmética la $\mathrm{O}$ significa el cero, cifra que no sirve, ni cuenta sin la union de los numerales [...]» (pág. 589,1).

DRAE-1817: «Decimaséptima letra de nuestro alfabeto, y cuarta en el número de las vocales [...] Cuando es particula disyuntiva se convierte en $u$ siempre que la palabra inmediata comienza con $o$, como diciendo: diez ú once, poeta ú orador, para evitar la cacofonía que resulta de colocar la $o$ entre ambas dicciones: y tiene ademas esta letra por si sola un uso muy vario, singular y espresivo en la oracion para manifestar los afectos del animo.[...]» (pág. 605,1-2-3 y 606,1). 
DRAE-1822: «Decimaséptima letra de nuestro alfabeto, y cuarta en el número de las vocales [...] Cuando es partícula disyuntiva se convierte en $u$ siempre que la palabra inmediata comienza con $o$, como diciendo: diez ú once, poeta ú orador, para evitar la cacofonía que resulta de colocar la $o$ entre ambas dicciones: y tiene ademas esta letra por sí sola un uso muy vario, singular y espresivo en la oracion para manifestar los afectos del animo.[...]» (pág. 568,1).

\section{DRAE-1832:}

DRAE-1837: «Décimaséptima letra de nuestro alfabeto, y cuarta en el número de las vocales [...] ๆ Partícula disyuntiva que se convierte en $u$ siempre que la palabra inmediata comienza con o; como diciendo: diez ú once, poeta ú orador, para evitar la cacofonía que resulta de colocar la o entre ambas dicciones. đT Tiene además esta letra por sí sola un uso muy vario, singular y espresivo en la oracion para manifestar los afectos del animo [...]» (pág. $516,1)$.

DRAE-1843: «Décimaséptima letra de nuestro alfabeto, y cuarta en el número de las vocales [...] - Partícula disyuntiva que se convierte en $u$ siempre que la palabra inmediata comienza con o; como diciendo: diez ú once, poeta ú orador, para evitar la cacofonía que resulta de colocar la $o$ entre ambas dicciones. ○ Tiene además esta letra por sí sola un uso muy vario, singular y espresivo en la oracion para manifestar los afectos del animo [...]» (pág. 504,1).

\section{$2^{\mathrm{a}} \mathrm{m} . \mathbf{X I X}-\mathbf{p} . \mathbf{X X}$}

DRAE-1852: «Décimaséptima letra de nuestro alfabeto, y cuarta en el número de las vocales [...] ब Particula disyuntiva que se convierte en $u$ siempre que la palabra inmediata comienza con o y tambien cuando principia con ho porque la $h$ no suena; como diciendo: diez ú once, poeta ú orador, mujer ú hombre, para evitar la cacofonía que resulta de colocar la o entre ambas dicciones. If Interj. de uso muy vario, singular y expresivo para manifestar los afectos del ánimo. Está ya mas en el uso el escribirla así ¡OH! [...]» (pág. 482,1). 
GRAE-1864:

GRAE-1865:

GRAE-1866:

GRAE-1867:

DRAE-1869: «Décimaoctava letra de nuestro alfabeto, y cuarta en el número de las vocales $[. .$.$] Ф$ Conj. disyuntiva, que se convierte en $u$ siempre que la palabra inmediata comienza con o y tambien cuando principia con ho porque la $h$ no suena; como diciendo: diez ú once, poeta ú orador, mujer ú hombre, para evitar la cacofonía que resulta de colocar la o entre ambas dicciones. I Interj. de uso muy vario, singular y expresivo para manifestar los afectos del ánimo. Está ya mas en el uso el escribirla así: OH! [...]» (pág. 544,1).

\section{GRAE-1870:}

GRAE-1874:

GRAE-1878:

GRAE-1880:

GRAE-1883:

DRAE-1884: «Décimaoctava letra del abecedario castellano, cuarta de sus vocales $[\ldots] \rrbracket$ f. nombre de esta letra.

\section{[...]}

ó. (Del lat. aut.) conj. disy. que denota diferencia, separación ó alternativa entre dos ó más personas, cosas, ó ideas. Antonio ó Francisco; blanco ó negro; herrar ó quitar el banco; vencer ó morir. I Suele preceder á cada uno de dos ó más términos contrapuestos. Lo harás ó de grado ó por fuerza. ๆ Denota además idea de equivalencia, significando ó sea, ó lo que es lo mismo. El protagonista, ó el personaje principal de la fábula, es Hércules.

[‥]» (pág. 749,1).

\section{GRAE-1885:}

GRAE-1888:

GRAE-1890:

Anexo II: Glosario terminológico Lema: $O$ 
GRAE-1895:

DRAE-1899: «Décimaoctava letra del abecedario castellano, cuarta de sus vocales $[. .$.$] | f. nombre$ de esta letra $[\ldots]$

[...]

ó. (Del lat. aut.) conj. disyunt. que denota diferencia, separación ó alternativa entre dos ó más personas, cosas, ó ideas. Antonio ó Francisco, banco ó negro, herrar ó quitar el blanco, vencer ó morir. I Suele preceder á cada uno de dos ó más términos contrapuestos. Lo harás ó de grado ó por fuerza. ๆ Denota además idea de equivalencia, significando ó sea, ó lo que es lo mismo. El protagonista, ó el personaje principal de la fábula, es Hércules.

[...]» (pág. 703,1).

GRAE-1900:

GRAE-1901:

GRAE-1904:

GRAE-1906:

GRAE-1908:

GRAE-1909:

GRAE-1911:

GRAE-1913:

DRAE-1914: «f. Décimaoctava letra del abecedario castellano, cuarta de sus vocales $[\ldots]$

$[\ldots]$

o. (Del lat. aut.) conj. disyunt. que denota diferencia, separación o alternativa entre dos o más personas, cosas, o ideas. Antonio o Francisco; blanco o negro; herrar o quitar el banco; vencer o morir. If ${ }^{2}$ Suele preceder a cada uno de dos o más términos contrapuestos. Lo harás o de grado o por fuerza. $\Upsilon^{3}$ Denota además idea de equivalencia, significando o sea, o lo que es lo mismo. El protagonista, o el personaje principal de la fábula, es Hércules.

[...]» (pág. 723,1). 
GRAE-1916:

GRAE-1917:

GRAE-1920:

GRAE-1924:

DRAE-1925: «f. Décimaoctava letra del abecedario español, cuarta de sus vocales [...]

$[\cdots]$

o. (Del lat. aut.) conj. disyunt. que denota diferencia, separación o alternativa entre dos o más personas, cosas, o ideas. Antonio o Francisco; blanco o negro; herrar o quitar el banco; vencer o morir. If 2. Suele preceder a cada uno de dos o más términos contrapuestos. Lo harás o de grado o por fuerza. \3. Denota además idea de equivalencia, significando o sea, o lo que es lo mismo. El protagonista, o el personaje principal de la fábula, es Hércules.

[...]» (pág. 861,1). 


\section{OBJETT}

\section{SIGLO XVIII}

Autoridades: «f.m. Lo que fe percíbe con alguno de los fentídos, ó acerca de lo qual se exercen. Viene del Latino Objectum $[\ldots]$

Овјето. Se llama tambien el término ó fin de los actos de las poténcias. Lat. Objectum.

ОвJето. Se toma tambien por el fin ó intento à que fe diríge ò encamina alguna cofa $[\ldots]$

Objeto. Se entiende tambien por la materia ó el fujéto de una ciencia: como el objeto de la Theología, que es Dios[...]» (1737, pág. 4,1).

GRAE-1771: No se utiliza el término.

DRAE-1780: «s.m. Lo que se percibe con alguno de los sentidos, ó acerca de lo qual se exercen. Objectum.

Овјето. Se llama tambien el término, ó fin de los actos de las potencias. Objectum.

ОвJето. El fin, ó intento á que se dirige, ó encamina alguna cosa. Finis, scopus, objectum.

ОвJето. La materia, ó el sugeto de una ciencia; como el OBJETo de la teologia, que es Dios [...]» (págs. 655,3 y 656,1).

DRAE-1783: «s.m. Lo que se percibe con alguno de los sentidos, ó acerca de lo qual se exercen. Objectum.

Овјето. Se llama tambien el término, ó fin de los actos de las potencias. Objectum.

Овјето. El fin, ó intento á que se dirige, ó encamina alguna cosa. Finis, scopus, objectum.

Овјето. La materia, ó el sugeto de una ciencia; como el овјето de la teología, que es Dios [...]» (pág. 669,1).

DRAE-1791: «s.m. Lo que se percibe con alguno de los sentidos, ó acerca de lo qual se exercen. Objectum. 2. Se llama tambien el término, ó fin de los actos de las potencias. Objectum. 3. El fin, ó intento á que se dirige, ó encamina alguna cosa. Finis, scopus, objectum. 4. La materia, ó el sugeto de una ciencia; como el OBJETo de la teología, que es Dios [...]» (pág. 596,1).

GRAE-1796: No se utiliza el término. 
DRAE-1803: «s.m. Lo que se percibe con alguno de los sentidos, ó acerca de lo qual se exercen. Objectum.

Овјето. Se llama tambien el término, ó fin de los actos de las potencias. Objectum.

Овјето. El fin, ó intento á que se dirige, ó encamina alguna cosa. Finis, scopus, objectum.

Овјето. La materia, ó el sugeto de una ciencia; como el овјето de la teología, que es Dios [...]

[...]» (pág. 590,2).

DRAE-1817: «s.m. Lo que se percibe con alguno de los sentidos, ó acerca de lo cual se ejercen. Objectum.

ОвJето. Se llama tambien el término ó fin de los actos de las potencias. Objectum.

Овјето. El fin ó intento á que se dirige ó encamina alguna cosa. Finis, scopus, objectum.

Овјето. La materia ó el sugeto de una ciencia; como el овјето de la teología, que es Dios [...]

[...]» (pág. 606,3).

DRAE-1822: «s.m. Lo que se percibe con alguno de los sentidos, ó acerca de lo cual se ejercen. Objectum.

ОвJETo. Se llama tambien el término ó fin de los actos de las potencias. Objectum.

ОвJето. El fin ó intento á que se dirige ó encamina alguna cosa. Finis, scopus, objectum.

Овјето. La materia y el sugeto de una ciencia; como el овјето de la teología, que es Dios [...]

[...]» (pág. 568,3).

DRAE-1832: «m. Lo que se percibe con alguno de los sentidos, ó acerca de lo cual se ejercen. Objectum. ๆ Se llama tambien el término ó fin de los actos de las potencias. Objectum. ๆ El fin ó intento á que se dirige ó encamina alguna cosa. Finis, scopus, objectum. ๆ La materia y el sujeto de una ciencia; como el овJETo de la teología, que es Dios [...]» (pág. 517,2).

DRAE-1837: «m. Lo que se percibe con alguno de los sentidos, ó acerca de lo cual se ejercen. Objectum. T Se llama tambien el término ó fin de los actos de las potencias. Objectum. \I El fin ó intento á que se dirige ó encamina alguna cosa. Finis, scopus, objectum. ๆ La materia y el sujeto de una ciencia; como el OBJETO de la teología, que es Dios [...]» (pág. 517,2). 
DRAE-1843: «m. Lo que se percibe con alguno de los sentidos, ó acerca de lo cual se ejercen. Objectum. వ Se llama tambien el término ó fin de los actos de las potencias. Objectum. Q El fin ó intento á que se dirige ó encamina alguna cosa. Finis, scopus, objectum. ه La materia y el sujeto de una ciencia; como el OBJETo de la teología, que es Dios [...]» (pág. 504,2).

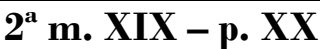

DRAE-1852: «m. Lo que se percibe con alguno de los sentidos, ó acerca de lo cual se ejercen. Objectum. \ Se llama tambien el término ó fin de los actos de las potencias. Objectum. ๆ El fin ó intento á que se dirige ó encamina alguna cosa. Finis, scopus, objectum. ๆ La materia y el sujeto de una ciencia; como el OBJETo de la teología, que es Dios [...]» (pág. 482,2).

GRAE-1854: No se utiliza el término.

GRAE-1858: No se utiliza el término.

GRAE-1862: No se utiliza el término.

GRAE-1864: No se utiliza el término.

GRAE-1865: No se utiliza el término.

GRAE-1866: No se utiliza el término.

GRAE-1867: No se utiliza el término.

DRAE-1869: «m. Lo que se percibe con alguno de los sentidos, ó acerca de lo cual se ejercen. ๆ Se llama tambien el término ó fin de los actos de las potencias. ๆ El fin ó intento á que se dirige ó encamina alguna cosa. ๆ La materia y el sujeto de una ciencia; como el овJETO de la teología, que es Dios [...]» (pág. 544,2-3).
GRAE-1870: No se utiliza el término.

GRAE-1874: No se utiliza el término.

GRAE-1878: No se utiliza el término.

GRAE-1880: No se utiliza el término. 
GRAE-1883: No se utiliza el término.

DRAE-1884: «(Del lat. obiēctus.) m. Lo que se percibe con alguno de los sentidos, ó acerca de lo cual se ejercen. ๆ Lo que sirve de materia ó asunto al ejercicio de las facultades mentales. $\emptyset$ Término ó fin de los actos de las potencias. ๆ Fin ó intento á que se dirige ó encamina una cosa. I Materia y sujeto de una ciencia. El OBJETO de la teología es Dios [...]» (pág. 750,1).
GRAE-1885: No se utiliza el término.

GRAE-1888: No se utiliza el término.

GRAE-1890: No se utiliza el término.

GRAE-1895: No se utiliza el término.

GRAE-1900: No se utiliza el término.

GRAE-1901: No se utiliza el término.

GRAE-1904: No se utiliza el término.

GRAE-1906: No se utiliza el término.

GRAE-1908: No se utiliza el término.

GRAE-1909: No se utiliza el término.

GRAE-1911: No se utiliza el término.

GRAE-1913: No se utiliza el término. 
DRAE-1914: «(Del lat. obiectus.) m. Lo que se percibe con alguno de los sentidos, o acerca de lo cual se ejercen. ๆ ${ }^{2}$ Lo que sirve de materia o asunto al ejercicio de las facultades mentales. ๆ 3 Término o fin de los actos de las potencias. ${ }^{4}$ Fin o intento a que se dirige o encamina una cosa. If ${ }^{5}$ Materia y sujeto de una ciencia. El OBJETO de la teología es Dios [...]» (pág. 724,1).

DRAE-1925: «(Del lat. obiectus.) m. Todo lo que puede ser materia de conocimiento o sensibilidad de parte del sujeto, incluso éste mismo. ๆ ${ }^{2}$ Lo que sirve de materia o asunto al ejercicio de las facultades mentales. $\Upsilon^{3}$ Término o fin de los actos de las potencias. \ ${ }^{4}$ Fin o intento a que se dirige o encamina una acción u operación. ๆ ${ }^{5}$ Materia y sujeto de una ciencia. El овJето de la teología es Dios [...]» (pág. $862,1)$.
GRAE-1916: No se utiliza el término.

GRAE-1917: Se usa como sinónimo de complemento $($ objeto directo $=$ complemento directo).

GRAE-1920: Se usa como sinónimo de complemento $($ objeto directo $=$ complemento directo).

GRAE-1924: Se usa como sinónimo de complemento $($ objeto directo $=$ complemento directo). 
DRACIÓN

\section{SIGLO XVIII}

Autoridades: $«[\ldots]$

OrACión. En la Gramática es la exprefión que con una ò muchas palabras, como partes fuyas hace fentido perfecto. Dividenla en primera y fegunda de activa y de pafsiva, fegun la voz del verbo con que fe forma, y los calos de nominativo, aculativo, ò ablativo de que confta. Quando folo tiene nominativo y verbo la llaman fegunda. Tambien la dividen en perfonál, imperfonál y femiimperfonál. Lat. Oratio. Paton, Eloq. Cap. 2. Decir que fe hable el Caftellano Efpañol puro, es que la oración vaya corregida $y$ emendada de folecifmos $y$ barbarifmos.

[...]» (1737, pág. 45,2).

DRAE-1780: «s.f. $[\ldots]$

Oracion. Gram. La expresion que con una, ó muchas palabras, como partes suyas hace sentido perfecto. Divídenla en primera y segunda de activa y de pasiva, segun la voz del verbo con que se forma, y los casos de nominativo, acusativo, ó ablativo de que consta. Quando solo tiene nominativo y verbo la llaman segunda. Tambien la dividen en personal, impersonal y semiimpersonal. Oratio.

[...]» (pág. 667,1).

DRAE-1783: «s.f. [...]

ORACION. Gram. La expresion que con una, ó muchas palabras, como partes suyas hace sentido perfecto. Divídenla en primera y segunda de activa y de pasiva, segun la voz del verbo con que se forma, y los casos de nominativo, acusativo, ó ablativo de que consta. Quando solo tiene nominativo y verbo la llaman segunda. Tambien la dividen en personal, impersonal y semiimpersonal. Oratio.

[...]» (pág. 680,1).
GRAE-1771: «El agregado de palabras ordenadas con que expresamos nuestros pensamientos se llama en el lenguage comun habla, y entre gramáticos oracion» (pág. 2). 
DRAE-1791: «s.f. [...] 4. Gram. La expresion que con una, ó muchas palabras, como partes suyas hace sentido perfecto. Divídenla en primera y segunda de activa y de pasiva, segun la voz del verbo con que se forma, y los casos de nominativo, acusativo, ó ablativo de que consta. Quando solo tiene nominativo y verbo la llaman segunda. Tambien la dividen en personal, impersonal y semiimpersonal. Oratio [...]» (pág. 606,1).

GRAE-1796: No se definie, pero se puede deducir que, al igual que en 1771, por oración se entiende aquel conjunto de palabras con que expresamos nuestros pensamientos (págs. 12).

\section{$\mathbf{1}^{\text {a }}$ mitad del XIX}

DRAE-1803: «s.f. [‥]

Oracion. Gram. La expresion que con una, ó muchas palabras, como partes suyas hace sentido perfecto. Divídenla en primera y segunda de activa y de pasiva, segun la voz del verbo con que se forma, y los casos de nominativo, acusativo, ó ablativo de que consta. Quando solo tiene nominativo y verbo la llaman segunda. Tambien la dividen en personal, impersonal y semiimpersonal. Oratio.

[...]» (pág. 601,2).

DRAE-1817: «s.f. $[\ldots]$

Oracion. Gram. La expresion que con una ó muchas palabras como partes suyas hace sentido perfecto. Divídenla en primera y segunda de activa y de pasiva, segun la voz del verbo con que se forma, y los casos de nominativo, acusativo ó ablativo de que consta. Cuando solo tiene nominativo y verbo la llaman segunda. Tambien la dividen en personal, impersonal y semiimpersonal. Oratio.

[...]» (pág. 617,2).

DRAE-1822: «s.f. [...]

Oracion. Gram. La expresion que con una ó muchas palabras como partes suyas hace sentido perfecto. Divídenla en primera y segunda de activa y de pasiva, segun la voz del verbo con que se forma, y los casos de que consta. Oratio.

[...]» (pág. 579,2). 
DRAE-1832: «f. [...] ๆ Gram. La expresion que con una ó muchas palabras como partes suyas hace sentido perfecto. Oratio [...]» (pág. 527,1).

DRAE-1837: «f. [...] ๆ Gram. La expresion que con una ó muchas palabras como partes suyas hace sentido perfecto. Oratio [...]» (pág. 527,1).

DRAE-1843: «f. [...] ם Gram. La expresion que con una ó muchas palabras como partes suyas hace sentido perfecto. Oratio [...]» (pág. 513,3).

\section{$2^{a}$ m. XIX - p. XX}

DRAE-1852: «f. [...] ๆ Gram. La expresion que con una ó muchas palabras como partes suyas hace sentido perfecto. Oratio [...]» (pág. 491,3).

DRAE-1869: «f. [...] ๆ Gram. La expresion que con una ó más palabras, como partes suyas, hace sentido perfecto [...]» (pág. 554,2).
GRAE-1854: «Dos ó más palabras, con que se expresa un concepto cabal, forman lo que gramaticalmente se llama oracion» (pág. 2).

GRAE-1858: «Dos ó más palabras, y á veces una sola, con que se expresa un concepto cabal, forman lo que en gramática se llama oracion» (pág. 2).

GRAE-1862: «Dos ó más palabras, y á veces una sola, con que se expresa un concepto cabal, forman lo que en gramática se llama oracion» (pág. 6).

GRAE-1864: «Dos ó más palabras, y á veces una sola, con que se expresa un concepto cabal, forman lo que en gramática se llama oracion» (pág. 6).

GRAE-1865: «Dos ó más palabras, y á veces una sola, con que se expresa un concepto cabal, forman lo que en gramática se llama oracion» (pág. 6).

GRAE-1866: «Dos ó más palabras, y á veces una sola, con que se expresa un concepto cabal, forman lo que en gramática se llama oracion» (pág. 6).

GRAE-1867: «Dos ó más palabras, y á veces una sola, con que se expresa un concepto cabal, forman lo que en gramática se llama oracion» (pág. 6). 
DRAE-1884: «(Del lat. orať̆o.) f. [...] ๆ Gram. Palabra ó conjunto de palabras con que se expresa un concepto cabal [...]» (pág. 762,2).
DRAE-1899: «(Del lat. oratı̆o.) f. [...] || Gram. Palabra ó conjunto de palabras con que se expresa un concepto cabal [...]» (pág. 715,3).
GRAE-1870: «La palabra ó reunion de palabras con que se expresa un concepto cabal se llama en Gramática oracion» (pág. 5).

GRAE-1874: «La palabra ó reunion de palabras con que se expresa un concepto cabal, se llama en Gramática oracion» (pág. 16).

GRAE-1878: «La palabra ó reunion de palabras con que se expresa un concepto cabal, se llama en Gramática oracion» (pág. 16).

GRAE-1880: «La palabra ó reunión de palabras con que se expresa un concepto cabal, se llama en Gramática oración» (pág. 8).

GRAE-1883: «La palabra ó reunión de palabras con que se expresa un concepto cabal, se llama en Gramática oración» (pág. 8).

GRAE-1885: «La palabra ó reunión de palabras con que se expresa un concepto cabal, se llama en Gramática oración» (pág. 8).

GRAE-1888: «La palabra ó reunión de palabras con que se expresa un concepto cabal, se llama en Gramática oración» (pág. 8).

GRAE-1890: «La palabra ó reunion de palabras con que se expresa un concepto cabal, se llama en Gramática oración» (pág. 8).

GRAE-1895: «La palabra ó reunión de palabras con que se expresa un concepto cabal, se llama en Gramática oración» (pág. 8).

GRAE-1900: «La palabra ó reunión de palabras con que se expresa un concepto cabal, se llama en Gramática oración» (pág. 8).

GRAE-1901: «La palabra ó reunión de palabras con que se expresa un concepto cabal, se llama en Gramática oración» (pág. 8).

GRAE-1904: «La palabra ó reunión de palabras con que se expresa un concepto cabal, se llama en Gramática oración» (pág. 8). 
GRAE-1906: «La palabra ó reunión de palabras con que se expresa un concepto cabal, se llama en Gramática oración» (pág. 8).

GRAE-1908: «La palabra ó reunión de palabras con que se expresa un concepto cabal, se llama en Gramática oración» (pág. 8).

GRAE-1909: «La palabra ó reunión de palabras con que se expresa un concepto cabal se llama en Gramática oración» (pág. 8).

GRAE-1911: «La palabra o reunión de palabras con que se expresa un concepto cabal, se llama en Gramática oración» (pág. 8).

GRAE-1913: «La palabra o reunión de palabras con que se expresa un concepto cabal, se llama en Gramática oración» (pág. 8).

DRAE-1914: «(Del lat. oratı̌o, -ōnis.) f. [...] \ ${ }^{6}$ Gram. Palabra ó conjunto de palabras con que se expresa un concepto cabal [...]» (pág. 736,1). 
GRAE-1920: «La palabra ó reunión de palabras con que se expresa un juicio, se llama en Gramática oración» (pág. 10).

«Pero dichos conceptos no forman todavía lo que en Gramática se llama oración: para esto es necesario que a un concepto substantivo o palabra usada con valor de tal se le agregue otra palabra que exprese atribución, o sea que afirme de dicho concepto o nombre substantivo una acción o una cualidad, estado o modo de ser, o solo la mera existencia» (pág. 168).

«La oración gramatical es la expresión del juicio lógico, o sea la manifestación oral del acto del entendimiento en virtud del cual afirmamos una cosa de otra. [...] Las partes esenciales de la oración gramatical son dos: el vocablo con que se designa el ser (persona, animal o cosa) de que se afirma algo, y que en el lenguaje gramatical se llama sujeto, y el que expresa la cosa afirmada, que se llama predicado» (pág. 170).

GRAE-1924: «La palabra ó reunión de palabras con que se expresa un juicio, se llama en Gramática oración» (pág. 10).

«Pero dichos conceptos no forman todavía lo que en Gramática se llama oración: para esto es necesario que a un concepto substantivo o palabra usada con valor de tal se le agregue otra palabra que exprese atribución, o sea que afirme de dicho concepto o nombre substantivo una acción o una cualidad, estado o modo de ser, o solo la mera existencia» (pág. 168).

«La oración gramatical es la expresión del juicio lógico, o sea la manifestación oral del acto del entendimiento en virtud del cual afirmamos una cosa de otra. [...] Las partes esenciales de la oración gramatical son dos: el vocablo con que se designa el ser (persona, animal o cosa) de que se afirma algo, y que en el lenguaje gramatical se llama sujeto, y el que expresa la cosa afirmada, que se llama predicado» (pág. 170).

DRAE-1925: «(Del lat. oratı̆o, -ōnis.) f. [...] \ ${ }^{6}$ Gram. Palabra ó conjunto de palabras con que se expresa un concepto cabal [...]» (pág. 736,1). 


\section{SIGLO XVIII}

Autoridades: «f.f. El arte que enseña à escribir correctamente, y con la puntuación y letras que son necesarias, para que se le dé el sentido perfecto, quando se lea. Es voz Griega, que significa recta escritura. Lat. Orthographia. AMBr. Mor. Lib. 8. cap. 55. Y assi mismo la pone Aldo Manuncio en su Orthographia ANT. AguST. Dial. De Med. pl. 23. Por las medallas se sabe la orthographía verdadera de muchos nombres proprios Romános» (pág. 61).

DRAE-1780: «s.f. El arte que enseña á escribir correctamente, y con la puntuacion y letras que son necesarias para que se le dé el sentido perfecto quando se lea. Orthographia.

[...]» (pág. 671,2).

DRAE-1783: «s.f. El arte que enseña á escribir correctamente, y con la puntuacion y letras que son necesarias para que se le dé el sentido perfecto quando se lea. Orthographia.

[...]» (pág. 684,2).

DRAE-1791: «s.f. El arte que enseña á escribir correctamente, y con la puntuacion y letras que son necesarias para que se le dé el sentido perfecto quando se lea. Orthographia.

[...]» (pág. 610,1).
GRAE-1771: Ni se define ni se trata de ella. No se contempla como parte de la Gramática.

GRAE-1796: «La Ortografía enseña el número y valor de las letras de que se forman las sílabas y palabras» (pág. 1). Se considera parte de la Gramática, pero no se estudia.

\section{$1^{\text {a }}$ mitad del XIX}

DRAE-1803: «s.f. El arte que enseña á escribir correctamente, y con la puntuacion y letras que son necesarias para que se le dé el sentido perfecto quando se lea. Ortographia.

[...]» (pág. 605,2).

DRAE-1817: «s.f. El arte que enseña á escribir correctamente, y con la puntuacion y letras que son necesarias para que se le dé el sentido perfecto cuando se lea. Orthographia.

[...]» (pág. 621,3). 
DRAE-1822: «s.f. El arte que enseña á escribir correctamente, y con la puntuacion y letras que son necesarias para que se dé el sentido perfecto cuando se lea. Orthographia.

[...]» (pág. 583,2).

DRAE-1832: «f. El arte que enseña á escribir correctamente, para que se dé el sentido perfecto cuando se lea. Ortographia [...]» (pág. 530,3).

DRAE-1837: «f. El arte que enseña á escribir correctamente, para que se dé el sentido perfecto cuando se lea. Ortographia [...]» (pág. 530,3).

DRAE-1843: «f. El arte que enseña á escribir correctamente, para que se dé el sentido perfecto cuando se lea. Ortographia [...]» (pág. 517,2).

\section{$2^{\mathrm{a}}$ m. XIX - p. XX}

DRAE-1852: «f. El arte que enseña á escribir correctamente, para que se dé el sentido perfecto cuando se lea. Ortographia [...]» (pág. 495,1).
GRAE-1854: Ni se define ni se trata de ella. Como en la GRAE-1771, no se contempla como parte de la Gramática.

GRAE-1858: «la ortografía establece reglas para el acertado uso de las letras y los demas signos con que se escribe un idioma» (pág. 1). Como en la GRAE-1796, se considera parte de la Gramática, pero no se estudia.

GRAE-1862: «[...] la ortografía establece reglas para el acertado uso de las letras y los demas signos con que se escribe un idioma» (pág. 5). No se estudia.

GRAE-1864: «[...] la ortografía establece reglas para el acertado uso de las letras y los demas signos con que se escribe un idioma» (pág. 5). No se estudia.

GRAE-1865: «[...] la ortografía establece reglas para el acertado uso de las letras y los demas signos con que se escribe un idioma» (pág. 5). No se estudia.

GRAE-1866: «[...] la ortografía establece reglas para el acertado uso de las letras y los demas signos con que se escribe un idioma» (pág. 5). No se estudia.

GRAE-1867: «la ortografía establece reglas para el acertado uso de las letras y los demas signos con que se escribe un idioma» (pág. 5). No se estudia. 
DRAE-1869: «f. El arte que enseña á emplear bien las letras y los demas signos auxiliares de la escritura [...]» (pág. 558,1).

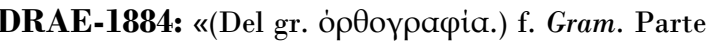
de la gramática, que enseña á escribir correctamente por el acertado empleo de las letras y demás signos auxiliares de la escritura [...]» (pág. 767,2).
GRAE-1870: Se deduce que es aquella parte de la Gramática cuyo fin es enseñar a escribir correctamente (pág. 5).

«Dos palabras griegas, que significan recta (ó buena) escritura, forman la voz Ortografía [...] La Ortografía establece cómo se han de emplear las letras y los signos auxiliares de la escritura» (pág. 309).

Por primera vez, se incluye su estudio en el libro de Gramática.

GRAE-1874: Parte de la Gramática cuyo fin es enseñar a escribir correctamente (pág. 16).

«Dos palabras griegas, que significan recta (ó buena) escritura, forman la voz Ortografía [...] La Ortografía establece cómo se han de emplear las letras y los signos auxiliares de la escritura» (pág. 335).

GRAE-1878: Parte de la Gramática cuyo fin es enseñar a escribir correctamente (pág. 16).

«Dos palabras griegas, que significan recta (ó buena) escritura, forman la voz Ortografía [...] La Ortografía establece cómo se han de emplear las letras y los signos auxiliares de la escritura» (pág. 335).

GRAE-1880: Parte de la Gramática cuyo fin es enseñar a escribir correctamente (pág. 5).

«La Ortografía enseña á escribir correctamente las palabras [...] La Ortografía establece cómo se han de emplear las letras y los signos auxiliares de la escritura (págs. 349$350)$.

GRAE-1883: Parte de la Gramática cuyo fin es enseñar a escribir correctamente (pág. 5).

«La Ortografía enseña á escribir correctamente las palabras [...] La Ortografía establece cómo se han de emplear las letras y los signos auxiliares de la escritura» (págs. 349-350). 


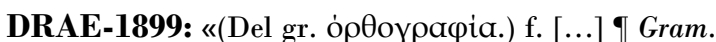
Parte de la gramática, que enseña á escribir correctamente por el acertado empleo de las letras y demás signos auxiliares de la escritura [...]» (pág. 720,3).
GRAE-1885: Parte de la Gramática cuyo fin es enseñar a escribir correctamente (pág. 5).

«La Ortografía enseña á escribir correctamente las palabras [...]. La Ortografía establece cómo se han de emplear las letras y los signos auxiliares de la escritura» (págs. 349-350).

GRAE-1888: Parte de la Gramática cuyo fin es enseñar a escribir correctamente (pág. VI).

«La Ortografía enseña á escribir correctamente las palabras» (pág. 349).

«La Ortografía establece cómo se han de emplear las letras y los signos auxiliares de la escritura» (pág. 350).

GRAE-1890: Parte de la Gramática cuyo fin es enseñar a escribir correctamente (pág. VI).

«La Ortografía enseña á escribir correctamente las palabras» (pág. 349).

«La Ortografía establece cómo se han de emplear las letras y los signos auxiliares de la escritura» (pág. 350)

GRAE-1895: Parte de la Gramática cuyo fin es enseñar a escribir correctamente (pág. VI).

«La Ortografía enseña á escribir correctamente las palabras» (pág. 349).

«La Ortografía establece cómo se han de emplear las letras y los signos auxiliares de la escritura» (pág. 350)

GRAE-1900: Parte de la Gramática cuyo fin es enseñar a escribir correctamente (pág. VI).

«La Ortografía enseña á escribir correctamente las palabras» (pág. 349).

«La Ortografía establece cómo se han de emplear las letras y los signos auxiliares de la escritura» (pág. 350).

GRAE-1901: Parte de la Gramática cuyo fin es enseñar a escribir correctamente (pág. VI).

«La Ortografía enseña á escribir correctamente las palabras» (pág. 349).

«La Ortografía establece cómo se han de emplear las letras y los signos auxiliares de la escritura» (pág. 350). 
GRAE-1904: Parte de la Gramática cuyo fin es enseñar a escribir correctamente (pág. VI).

«La Ortografía enseña á escribir correctamente las palabras» (pág. 343).

«La Ortografía establece cómo se han de emplear las letras y los signos auxiliares de la escritura» (págs. 343-344).

GRAE-1906: Parte de la Gramática cuyo fin es enseñar a escribir correctamente (pág. VI).

«La Ortografía enseña á escribir correctamente las palabras» (pág. 343).

«La Ortografía establece cómo se han de emplear las letras y los signos auxiliares de la escritura» (pág. 344).

GRAE-1908: Parte de la Gramática cuyo fin es enseñar a escribir correctamente (pág. VI).

«La Ortografía enseña á escribir correctamente las palabras» (pág. 343).

«La Ortografía establece cómo se han de emplear las letras y los signos auxiliares de la escritura» (pág. 344).

GRAE-1909: Parte de la Gramática cuyo fin es enseñar a escribir correctamente (pág. VI).

«La Ortografía enseña á escribir correctamente las palabras» (pág. 343).

«La Ortografía establece cómo se han de emplear las letras y los signos auxiliares de la escritura» (pág. 344).

GRAE-1911: Parte de la Gramática cuyo fin es enseñar a escribir correctamente (pág. 6).

«La ORTOGRAFÍA enseña a escribir correctamente las palabras (pág. 347).

La Ortografía establece cómo se han de emplear las letras y los signos auxiliares de la escritura» (pág. 348).

GRAE-1913: Parte de la Gramática cuyo fin es enseñar a escribir correctamente (pág. 6).

«La ORTOGRAFía enseña a escribir correctamente las palabras» (pág. 347).

«La Ortografía establece cómo se han de emplear las letras y los signos auxiliares de la escritura» (pág. 348). 
DRAE-1914: «(Del lat. orthographĭa, y éste del gr.

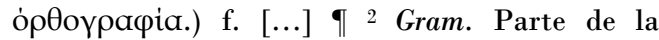
gramática, que enseña a escribir correctamente por el acertado empleo de las letras y demás signos auxiliares de la escritura [...]» (pág. $741,1)$.

DRAE-1925: «(Del lat. orthograpȟ̆a, y éste del gr.

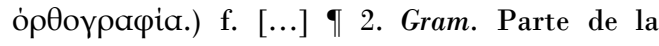
gramática, que enseña a escribir correctamente por el acertado empleo de las letras y demás signos auxiliares de la escritura [...]» (pág. $881,1)$.
GRAE-1916: Parte de la Gramática cuyo fin es enseñar a escribir correctamente (pág. 6).

«La Ortografía enseña a escribir correctamente las palabras» (pág. 347).

«La Ortografía establece cómo se han de emplear las letras y los signos auxiliares de la escritura» (pág. 348).

GRAE-1917: Parte de la Gramática cuyo fin es enseñar a escribir correctamente (pág. VIII).

«La Ortografía enseña á escribir correctamente las palabras» (pág. 475).

«La Ortografía establece cómo se han de emplear las letras y los signos auxiliares de la escritura» (pág. 476).

GRAE-1920: Parte de la Gramática cuyo fin es enseñar a escribir correctamente (pág. 8).

«La Ortografía enseña á escribir correctamente las palabras» (pág. 493).

«La Ortografía establece cómo se han de emplear las letras y los signos auxiliares de la escritura» (pág. 494).

GRAE-1924: Parte de la Gramática cuyo fin es enseñar a escribir correctamente (pág. 8).

«La Ortografía enseña á escribir correctamente las palabras» (pág. 493).

«La Ortografía establece cómo se han de emplear las letras y los signos auxiliares de la escritura» (pág. 494). 


\section{SIGLO XVIII}

Autoridades: $«[\ldots]$

Predicado. Term. Lógico, y ufado como subftantivo, es lo que fe afirma o niega del fujeto en la enunciación. Lat. Praedicatum» (1737, pág. $352,1)$.

GRAE-1771: No se habla de él.

DRAE-1780: $«[\ldots]$

PREDICADO. Lóg. Usado como substantivo es lo que se afirma, ó niega del sugeto en la enunciacion. Praedicatum» (pág. 744,1).

DRAE-1783: $«[\ldots]$

PREDICADO. Lóg. Usado como substantivo es lo que se afirma, ó niega del sugeto en la enunciacion. Praedicatum» (pág. 757,2).

DRAE-1791: «[...] 2. Lóg. Usado como substantivo es lo que se afirma, ó niega del sugeto en la enunciacion. Praedicatum» (pág. 676,1).

GRAE-1796: No se habla de él.

\section{$1^{\text {a }}$ mitad del XIX}

DRAE-1803: «[...]

PREDICADO. s.m. Lóg. Lo que se afirma, ó niega del sugeto en la enunciacion. Praedicatum» (pág. $678,2)$.

DRAE-1817: «[...]

PREDICADO. s.m. Lóg. Lo que se afirma ó niega del sugeto en la enunciacion. Praedicatum» (pág. 697,1-2).

DRAE-1822: $«[\ldots]$

PREDICADO. s.m. Lóg. Atributo de una proposicion, lo que se afirma ó niega del sugeto en ella. Praedicatum» (pág. 657,2-3).

DRAE-1832: «m. Lóg. Atributo de una proposicion, lo que se afirma ó niega del sujeto en ella. Praedicatum» (pág. 599,3). 
DRAE-1837: «m. Lóg. Atributo de una proposicion, lo que se afirma ó niega del sujeto en ella. Praedicatum» (pág. 599,3).

DRAE-1843: «m. Lóg. Atributo de una proposicion, lo que se afirma ó niega del sugeto en ella. Praedicatum» (pág. 583,1).

\section{$2^{\mathrm{a}}$ m. XIX - p. XX}

DRAE-1852: «m. Lóg. Atributo de una proposicion, lo que se afirma ó niega del sujeto en ella. Praedicatum» (pág. 558,2).

GRAE-1854: No se habla de él.

GRAE-1858: No se habla de él.

GRAE-1862: No se habla de él.

GRAE-1864: No se habla de él.

GRAE-1865: No se habla de él.

GRAE-1866: No se habla de él.

GRAE-1867: No se habla de él.

DRAE-1869: «m. Lóg. Atributo de una proposicion, lo que se afirma ó niega del sujeto en ella» (pág. $626,3)$.

GRAE-1870: No se habla de él.

GRAE-1874: No se habla de él.

GRAE-1878: No se habla de él.

GRAE-1880: No se habla de él.

GRAE-1883: No se habla de él.

DRAE-1884: «(Del lat. praedicātus.) m. Lóg. Atributo de una proposición, lo que se afirma ó niega del sujeto en ella» (pág. 858,1).

GRAE-1885: No se habla de él.

GRAE-1888: No se habla de él.

GRAE-1890: No se habla de él.

GRAE-1895: No se habla de él. 
DRAE-1899: «(Del lat. praedicātus.) m. Lóg. Atributo de una proposición, lo que se afirma ó niega del sujeto en ella» (pág. 805,2).
DRAE-1914: «(Del lat. praedicātus.) m. Lóg. Lo que se afirma del sujeto en una proposición» (pág. $827,1)$.

DRAE-1925: «[...] 2. m. Lóg. Lo que se afirma del sujeto en una proposición» (pág. 980,2).
GRAE-1900: No se habla de él.

GRAE-1901: No se habla de él.

GRAE-1904: No se habla de él.

GRAE-1906: No se habla de él.

GRAE-1908: No se habla de él.

GRAE-1909: No se habla de él.

GRAE-1911: No se habla de él.

GRAE-1913: No se habla de él.

GRAE-1916: No se habla de él.

GRAE-1917: «Las partes esenciales de la oración gramatical son dos: el vocablo con que se designa el ser (persona, animal o cosa) de que se afirma algo, y que en el lenguaje gramatical se llama sujeto, y el que expresa la cosa afirmada, que se llama predicado […]» (pág. 150).

GRAE-1920: «Las partes esenciales de la oración gramatical son dos: el vocablo con que se designa el ser (persona, animal o cosa) de que se afirma algo, y que en el lenguaje gramatical se llama sujeto, y el que expresa la cosa afirmada, que se llama predicado [...]» (pág. 170).

GRAE-1924: «Las partes esenciales de la oración gramatical son dos: el vocablo con que se designa el ser (persona, animal o cosa) de que se afirma algo, y que en el lenguaje gramatical se llama sujeto, y el que expresa la cosa afirmada, que se llama predicado […]» (pág. 170). 


\section{PREPOSICIÓN}

\section{SIGLO XVIII}

Autoridades: «f.f. Term. de Gramática. Parte indeclinable de la oración que precede al nombre, à quien rige ù determina. Sirven tambien las prepoficiones para la compolición ò formación de algunos verbos: como Anteponer, Predecir, Proclamar, \&c. Lat. Praepofitio. PATON, Gramat. f. 166. El nombre ha menefter alguna cola que le determine à efto ò aquello, y defto firve la prepofición» (1737, pág. 361,1).

DRAE-1780: «s.f. Gram. Parte indeclinable de la oracion que precede al nombre, á quien rige, ó determina. Sirven tambien las preposiciones para la composicion, ó formacion de algunos verbos; como Anteponer, Predecir, Proclamar, \&c. Praepositio» (pág. 746,1).

DRAE-1783: «s.f. Gram. Parte indeclinable de la oracion que precede al nombre, á quien rige, ó determina. Sirven tambien las preposiciones para la composicion, ó formacion de algunos verbos; como: en ANTEPONER, PREDECIR, PROCLAMAR, \&c. Praepositio» (pág. 759,2).

DRAE-1791: «s.f. Gram. Parte indeclinable de la oracion que precede al nombre, á quien rige, ó determina. Sirven tambien las preposiciones para la composicion; ó formacion de algunos verbos; como: en ANTEPONER, PREDECIR, PROCLAMAR, \&c. Praepositio» (pág. 678,1).

GRAE-1771: «PREPOSICION es una palabra llamada así, porque se pone ántes de otras partes de la oración. El oficio de la preposicion por sí sola es indicar en general alguna circunstancia que no se determina sino por la palabra que se le sigue; pero junta ya con ella, denota la diferente relacion ó respeto que tienen unas cosas con otras» (pág. 201).

GRAE-1796: «PREPOSICION es una parte indeclinable de la oración, que se antepone á otras para guiarlas y conducirlas al verdadero sentido de relacion, ó respeto que tienen entre sí las cosas que significan» (pág. 246).

\section{$1^{\text {a }}$ mitad del XIX}

DRAE-1803: «s.f. Gram. Parte indeclinable de la oracion que precede á la palabra á quien rige, ó determina. Sirven tambien las preposiciones para la composicion, ó formacion de algunos verbos; como: en ANTEPONER, PREDECIR, PROCLAMAR, \&c. Praepositio» (pág. 680,3). 
DRAE-1817: «s.f. Gram. Parte indeclinable de la oracion que precede á la palabra á quien rige ó determina. Sirven tambien las preposiciones para la composicion, ó formacion de algunos verbos, como en ANTEPONER, PREDECIR, PROCLAMAR \&c. Praepositio» (pág. 699,2).

DRAE-1822: «s.f. Gram. Parte indeclinable de la oracion que precede á la palabra á quien rige ó determina. Sirven tambien las preposiciones para la composicion, ó formacion de algunos verbos, como en ANTEPONER, PREDECIR, PROCLAMAR \&c. Praepositio» (pág. 659,3).

DRAE-1832: «f. Gram. Parte indeclinable de la oracion que precede á la palabra á quien rige ó determina. Sirve tambien para la composicion ó formacion de algunos verbos; como en ANTEPONER, PREDECIR, PROCLAMAR \&c. Praepositio» (pág. 602,1).

DRAE-1837: «f. Gram. Parte indeclinable de la oracion que precede á la palabra á quien rige ó determina. Sirve tambien para la composicion ó formacion de algunos verbos; como en ANTEPONER, PREDECIR, PROCLAMAR \&c. Praepositio» (pág. 601,3).

DRAE-1843: «f. Gram. Parte indeclinable de la oracion que precede á la palabra á quien rige ó determina. Sirve tambien para la composicion ó formacion de algunos verbos; como en ANTEPONER, PREDECIR, PROCLAMAR etc. Praepositio» (pág. 584,3).

\section{$2^{a} \mathrm{~m}$. XIX - p. XX}

DRAE-1852: «f. Gram. Parte indeclinable de la oracion que precede á la palabra á quien rige ó determina. Sirve tambien para la composicion ó formacion de algunos verbos; como en ANTEPONER, PREDECIR, PROCLAMAR etc. Praepositio» (pág. 560,2).

GRAE-1854: «Preposicion es una parte invariable de la oracion, que se antepone á otras para denotar la relacion que tienen éstas con el sujeto principal de la cláusula» (pág. 119).

GRAE-1858: «Preposicion es una parte invariable de la oracion, que se antepone á otras para denotar la relacion que tienen éstas con el sujeto principal de la cláusula» (pág. 124).

GRAE-1862: «Preposicion es una parte invariable de la oracion, llamada así porque siempre se antepone á otras. Su oficio es denotar la relacion que tienen entre sí dos nombres, dos verbos, un nombre con un verbo, \&c.» (pág. 128). 
DRAE-1869: «f. Gram. Parte invariable de la oracion que precede á la palabra regida por ella. Sirve tambien para la composicion de muchas palabras; como en ANTEPONER, DEMÉRITO, ENVOLVER, SOBRESUELDO, ANTEAYER, etc.» (pág. $628,3)$.

GRAE-1864: «Preposicion es una parte invariable de la oracion, llamada así porque siempre se antepone á otras. Su oficio es denotar la relacion que tienen entre sí dos nombres, dos verbos, un nombre con un verbo, \&c.» (pág. 128).

GRAE-1865: «Preposicion es una parte invariable de la oracion, llamada así porque siempre se antepone á otras. Su oficio es denotar la relacion que tienen entre sí dos nombres, dos verbos, un nombre con un verbo, \&c.» (pág. 128).

GRAE-1866: «Preposicion es una parte invariable de la oracion, llamada así porque siempre se antepone á otras. Su oficio es denotar la relacion que tienen entre sí dos nombres, dos verbos, un nombre con un verbo, \&c.» (pág. 128).

GRAE-1867: «Preposicion es una parte invariable de la oracion, llamada así porque siempre se antepone á otras. Su oficio es denotar la relacion que tienen entre sí dos nombres, dos verbos, un nombre con un verbo, etc.» (pág. 127).

GRAE-1870: «Preposición es una parte de la oracion que sirve para denotar la relacion que tienen entre sí las palabras dentro de una misma oracion gramatical» (pág. 143).

GRAE-1874: «Preposicion es una parte indeclinable de la oracion, que sirve para denotar el régimen ó dependencia que tienen entre sí dos palabras ó términos» (pág. 170).

GRAE-1878: «Preposicion es una parte indeclinable de la oracion, que sirve para denotar el régimen ó dependencia que tienen entre sí dos palabras ó términos» (pág. 170).

GRAE-1880: «Preposición es una parte indeclinable de la oración, que sirve para denotar el régimen ó dependencia que tienen entre sí dos palabras ó términos» (pág. 194). 
GRAE-1883: «Preposición es una parte indeclinable de la oración, que sirve para denotar el régimen ó dependencia que tienen entre sí dos palabras ó cláusulas» (pág. 191).

DRAE-1884: «(Del lat. praepositĭo.) f. Gram. Parte invariable de la oracion, cuyo oficio es denotar el régimen ó relación que entre sí tienen las palabras ó términos. Las preposiciones se dividen en separables é inseparables. Las primeras son las que para este fin se emplean aisladas; como á, con, de, etc., aunque también sirven de prefijos en voces compuestas; v. gr.: Aclamar, CONVENIR, DEponer: las segundas hállanse únicamente en composición; v. gr. DESpropósito, INcapaz, SUPERabundancia» (pág. $860,2)$.

DRAE-1899: «(Del lat. praepositı̆o.) f. Gram. Parte invariable de la oración, cuyo oficio es denotar el régimen ó relación que entre sí tienen las palabras ó términos. Las preposiciones se dividen en separables é inseparables. Las primeras son las que para este fin se emplean aisladas; como á, con, de, etc., aunque también sirven de prefijos en voces compuestas; v. gr.: Aclamar, CONVENIR, DEponer: las segundas hállanse únicamente en composición; v. gr. DESpropósito, INcapaz, SUPERabundancia» (pág. $807,3)$.

GRAE-1885: «Preposición es una parte indeclinable de la oración, que sirve para denotar el régimen ó dependencia que tienen entre sí dos palabras ó cláusulas» (pág. 191).

GRAE-1888: «Preposición es una parte indeclinable de la oración, que sirve para denotar el régimen ó dependencia que tienen entre sí dos palabras ó cláusulas» (pág. 189).

GRAE-1890: «Preposición es una parte indeclinable de la oración, que sirve para denotar el régimen ó dependencia que tienen entre sí dos palabras ó cláusulas» (pág. 189).

GRAE-1895: «Preposición es una parte indeclinable de la oración, que sirve para denotar el régimen ó dependencia que tienen entre sí dos palabras ó cláusulas» (pág. 189).

GRAE-1900: «Preposición es una parte indeclinable de la oración, que sirve para denotar el régimen ó dependencia que tienen entre sí dos palabras ó cláusulas» (pág. 189). 
GRAE-1901: «Preposición es una parte indeclinable de la oración, que sirve para denotar el régimen ó dependencia que tienen entre sí dos palabras ó cláusulas» (pág. 189).

GRAE-1904: «Preposición es una parte indeclinable de la oración, que sirve para denotar el régimen ó dependencia que tienen entre sí dos palabras ó cláusulas» (pág. 184).

GRAE-1906: «Preposición es una parte indeclinable de la oración, que sirve para denotar el régimen ó dependencia que tienen entre sí dos palabras ó cláusulas» (pág. 184).

GRAE-1908: «Preposición es una parte indeclinable de la oración, que sirve para denotar el régimen ó dependencia que tienen entre sí dos palabras ó cláusulas» (pág. 184).

GRAE-1909: «Preposición es una parte indeclinable de la oración que sirve para denotar el régimen ó dependencia que tienen entre sí dos palabras ó cláusulas» (pág. 184).

GRAE-1911: «Preposición es una parte indeclinable de la oración que sirve para denotar el régimen o dependencia que tienen entre sí dos palabras o cláusulas» (pág. 185).

GRAE-1913: «Preposición es una parte invariable de la oración, que sirve para denotar el régimen o dependencia que tienen entre sí dos palabras o cláusulas» (pág. 185).

DRAE-1914: «(Del lat. praepositĭo, -onis.) f. Gram. Parte invariable de la oración, cuyo oficio es denotar el régimen o relación que entre sí tienen dos palabras o términos. También se usa como prefijo. I inseparable. Gram. Prefijo, 2. ${ }^{\mathrm{a}}$ acep.» (pág. 829,1).

GRAE-1916: «Preposición es una parte invariable de la oración, que sirve para denotar el régimen o dependencia que tienen entre sí dos palabras o cláusulas» (pág. 185).

GRAE-1917: En esta edición, no encontramos definición propiamente dicha, sino una explicación del funcionamiento de la preposición:

«Esta partícula, de cuya índole y uso tratamos en la SINTAXIS, sirve para denotar la relación que media entre dos palabras, de las cuales la primera es siempre un nombre 
DRAE-1925: «(Del lat. praeposiť̌o, -onis.) f. Gram. Parte invariable de la oración, cuyo oficio es denotar el régimen o relación que entre sí tienen dos palabras o términos. También se usa como prefijo. I| inseparable. Gram. Prefijo, 2. ${ }^{\text {a }}$ acep.» (pág. 983,1). substantivo, adjetivo o verbo, y la segunda un substantivo u otra palabra o locución a él equivalente» (pág. 143).

«Esta partícula, llamada impropiamente parte de la oración, no tiene valor de por sí en el habla; es un elemento de relación cuya significación depende no sólo de ella, sino del valor de los vocablos por ella relacionados» (pág. 203).

GRAE-1920: «Esta partícula, de cuya índole y uso tratamos en la SINTAXIS, sirve para denotar la relación que media entre dos palabras, de las cuales la primera es siempre un nombre substantivo, adjetivo o verbo, y la segunda un substantivo u otra palabra o locución a él equivalente» (pág. 138).

«Esta partícula, llamada impropiamente parte de la oración, no tiene valor de por sí en el habla; es un elemento de relación cuya significación depende no sólo de ella, sino del valor de los vocablos por ella relacionados» (pág. 223).

GRAE-1924: «Esta partícula, de cuya índole y uso tratamos en la SINTAXIS, sirve para denotar la relación que media entre dos palabras, de las cuales la primera es casi siempre un nombre substantivo, adjetivo o verbo, y la segunda un substantivo $\mathbf{u}$ otra palabra o locución a él equivalente [p. 138]. Esta partícula, llamada impropiamente parte de la oración, no tiene valor de por sí en el habla; es un elemento de relación cuya significación depende no sólo de ella, sino del valor de los vocablos por ella relacionados» (pág. 223). 


\section{PRDPIEDA D}

\section{SIGLO XVIII}

Autoridades: [voz: PROPRIEDAD] «I.f. [...]

Propriedad. Se llama tambien aquella calidád particular, que conviene privativamente à alguna cofa[...]

PROPRIEDAD. Se toma tambien por la debida proporción, naturalidad ò perfeccion con que fe ufa de alguna cofa ò fe habla de ella, fin quitar ni añadir circunftancia, que la altere ù desluzca. Lt. Convenientia. Congruentia. Acost. Hift. Ind. lib. 4. cap. 16. El nombre de pan es allá tambien ufado con propriedád de fu lengua [...] $[\ldots]$

Propriedad. Se toma afsimifmo por femejanza ò perfecta imitación: como en la Pintúra, Múfica ù otras colas. Lat. Apta fimilitudo. Congruentia.

$[\ldots] »(1737,407,2)$.

DRAE-1780: «s.f. [...]

Propiedad. Aquella calidad particular, que conviene privativamente á alguna cosa. Proprium.

PROPIEDAD. La debida proporcion, naturalidad, ó perfeccion con que se usa de alguna cosa, ó se habla de ella, sin quitar, ni añadir circunstancia que la altere, ó desluzca. Convenientia, congruentia.

[...]» (pág. 755,2).

DRAE-1783: «s.f. $[\ldots]$

Propiedad. Aquella calidad particular, que conviene privativamente á alguna cosa. Proprium.

PROPIEDAD. La debida proporcion, naturalidad, ó perfeccion con que se usa de alguna cosa, ó se habla de ella, sin quitar, ni añadir circunstancia que la altere, ó desluzca. Convenientia, congruentia.

[...]» (pág. 768,2-3).

DRAE-1791: «s.f. [...] 4. Aquella calidad particular, que conviene privativamente á alguna cosa. Proprium. 5. La debida proporcion, naturalidad, ó perfeccion con que se usa de alguna cosa, ó se habla de ella, sin quitar, ni añadir circunstancia que la altere, ó desluzca. Convenientia, congruentia» (pág. 686,2). 
DRAE-1803: «s.f. [...]

Propiedad. Aquella calidad particular, que conviene privativamente á alguna cosa. Proprium.

PROPIEDAD. La debida proporcion, naturalidad, ó perfeccion con que se usa de alguna cosa, ó se habla de ella, sin quitar, ni añadir circunstancia que la altere, ó desluzca. Convenientia, congruentia.

[...]

PROPIEDAD. met. Semejanza, ó perfecta imitacion como en la pintura, música, ú otras cosas. Apta similitudo, congruentia.

[...]» (pág. 690,3).

DRAE-1817: «s.f. [...]

PRopiEdAD. Aquella calidad particular que conviene privativamente á alguna cosa. Proprium.

PROPIEDAD. La debida proporcion, naturalidad ó perfeccion con que se usa de alguna cosa ó se habla de ella, sin quitar ni añadir circunstancia que la altere ó desluzca. Convenientia, congruentia, decorum.

$[\ldots]$

PROPIEDAD. met. Semejanza ó perfecta imitacion, como en la pintura, música ú otras cosas. Apta similitudo, congruentia.

[...]» (pág. 708,3).

DRAE-1822: «s.f. [...]

Propiedad. Aquella calidad particular que conviene privativamente á alguna cosa. Proprium.

PROPIEDAD. La debida proporcion, naturalidad ó perfeccion con que se usa de alguna cosa ó se habla de ella, sin quitar ni añadir circunstancia que la altere ó desluzca. Convenientia, congruentia, decorum.

$[\ldots]$

PROPIEDAD. met. Semejanza ó perfecta imitacion, como en la pintura, música ú otras cosas. Apta similitudo, congruentia.

[...]» (pág. 669,1). 
DRAE-1832: «f. [...] ๆ La calidad particular que conviene privativamente á alguna cosa. Proprium. I Gram. La significacion ó sentido peculiar y exacto de una voz ó expresion. Decorum [...] đ met. Semejanza ó imitacion perfecta; como en la pintura, música ú otras cosas. Apta similitudo, congruentia [...]» (pág. $610,2)$.

DRAE-1837: «f. [...] ๆ La calidad particular que conviene privativamente á alguna cosa. Proprium. đI Gram. La significacion ó sentido peculiar y exacto de una voz ó expresion. Verborum proprietas; propria et nativa verbi significatio [...] đ met. Semejanza ó imitacion perfecta; como en la pintura, música ú otras cosas. Apta similitudo; congruentia [...]» (pág. $610,2)$.

DRAE-1843: «f. [...] ם La calidad particular que conviene privativamente á alguna cosa. Proprium. o Gram. La significacion ó sentido peculiar y exacto de una voz ó expresion. Verborum proprietas; propria et nativa verbi significatio $[\ldots]$ ם met. Semejanza ó imitacion perfecta, como en la pintura, música ú otras cosas. Apta similitudo, congruentia [...]» (pág. $593,1)$.

\section{$2^{\mathrm{a}} \mathrm{m} . \mathrm{XIX}-\mathbf{p} . \mathbf{X X}$}

DRAE-1852: «f. [...] ๆ La calidad particular que conviene privativamente á alguna cosa. Proprium. đ| Gram. La significacion ó sentido peculiar y exacto de una voz ó expresion. Verborum proprietas; propria et nativa verbi significatio [...] đ met. Semejanza ó imitacion perfecta, como en la pintura, música ú otras cosas. Apta similitudo, congruentia [...]» (pág. $568,2)$.

GRAE-1854:

GRAE-1858:

GRAE-1862:

GRAE-1864:

GRAE-1865:

GRAE-1866: 
GRAE-1867:

DRAE-1869: «f. [...] ๆ Atributo ó condicion esencial de una persona ó cosa. Gram. La significacion ó sentido peculiar y exacto de una voz ó expresion $[\ldots]$ | met. Semejanza ó imitacion perfecta, como en la pintura, música ú otras cosas [...]» (pág. $637,2)$.

\section{GRAE-1870:}

GRAE-1874:

GRAE-1878:

GRAE-1880:

GRAE-1883:

DRAE-1884: «(Del lat. propriětas.) f. [...] đ Atributo ó cualidad esencial de una persona ó cosa. ๆ fig. Semejanza ó imitación perfecta; como en la pintura, música ú otras cosas [...] đ Gram. Significado ó sentido peculiar y exacto de las voces ó frases $[\ldots] »$ (pág. 871,3).

DRAE-1899: «(Del lat. propriětas.) f. [...] ब Atributo ó cualidad esencial de una persona ó cosa. If fig. Semejanza ó imitación perfecta; como en la pintura, música ú otras cosas [...] ๆ Gram. Significado ó sentido peculiar y exacto de las voces ó frases [...]» (pág. 817,3).

\section{GRAE-1885:}

GRAE-1888:

GRAE-1890:

GRAE-1895:

GRAE-1900:

GRAE-1901:

GRAE-1904: 


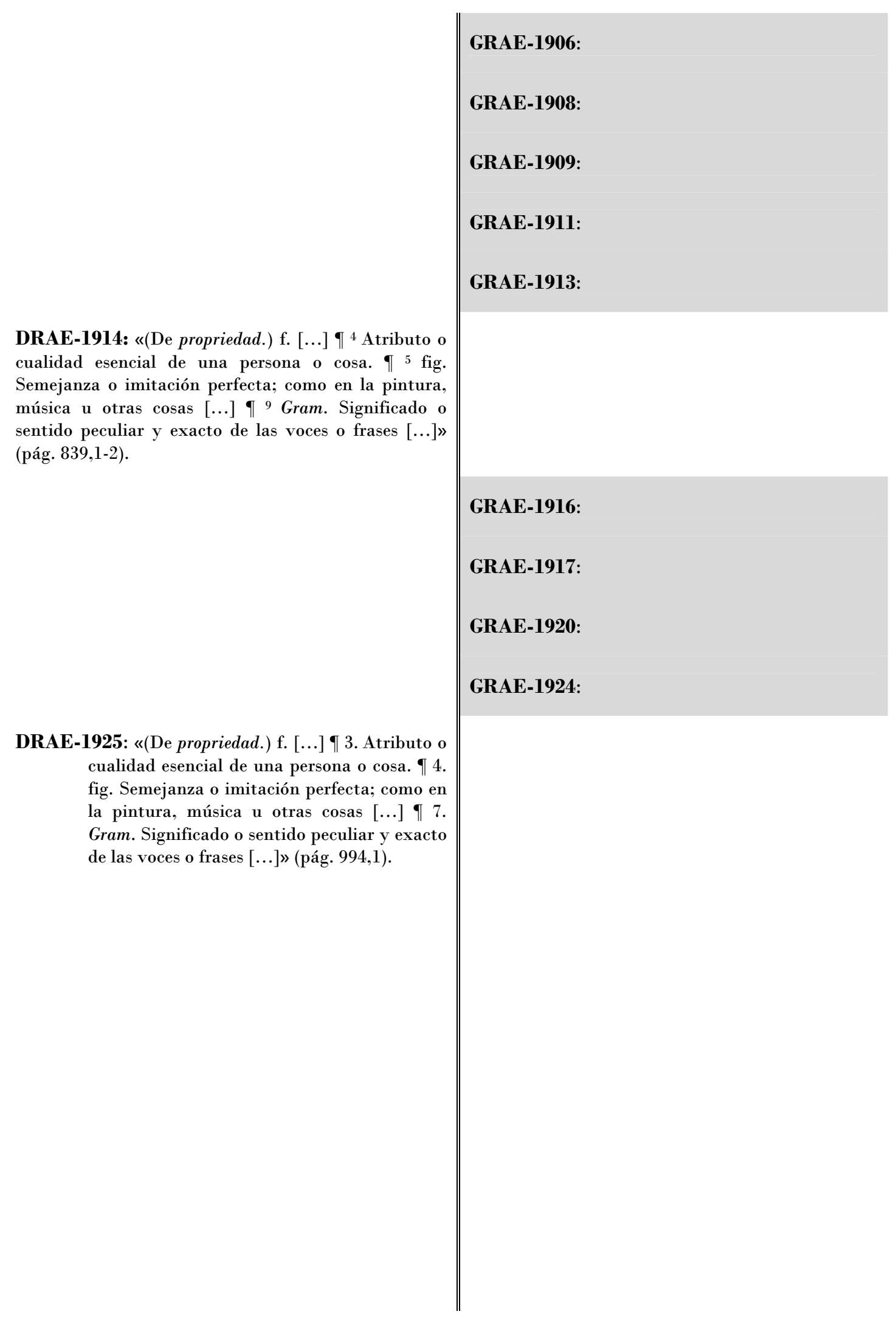




\section{PRDSAIDA}

\section{SIGLO XVIII}

Autoridades: «โ.f. Parte de la Gramática, que enfeña la pronunciación, feñala los accentos y la quantidad de las fylabas: y por confeqüencia à hacer y medir verfos Latinos ò Griegos. Es voz griega, que lignifica accento. Lat. Profodia. CASAN. Var. Iluftr. Vid. del P. Juan de Alloza. Bien cimentado en la Gramática, Profódia y Rhetórica, palló de nueftro Colegio de S. Pablo, y de fus clafles, al efpaciolo ámbito de la Univerfidad de S. Marcos.

[...]» (1737, pág. 410,2).

DRAE-1780: «s.f. Parte de la gramática que enseña la pronunciacion, señala los acentos y la quantidad de las sílabas, y por conseqüencia á hacer y medir versos latinos, ó griegos. Prosodia.

[...]» (pág. 756,3).

DRAE-1783: «s.f. Parte de la gramática que enseña la pronunciacion, señala los acentos y la quantidad de las sílabas, y por conseqüencia á hacer y medir versos latinos, ó griegos. Prosodia.

[...]» (pág. 770,1).

DRAE-1791: «s.f. Parte de la gramática que enseña la pronunciacion, señala los acentos y la quantidad de las sílabas, y por conseqüencia á hacer y medir versos latinos, ó griegos. Prosodia [...]» (pág. 687,3).

GRAE-1771: Ni se define ni se trata de ella. No se contempla como parte de la Gramática.

GRAE-1796: «la Prosodia [enseña] el sonido propio y verdadera pronunciación de las letras, sílabas y palabras, de que se compone el lenguage» (pág. 2). Se considera parte de la Gramática, pero no se estudia.

\section{$1^{\text {a }}$ mitad del XIX}

DRAE-1803: «s.f. Parte de la gramática que enseña la pronunciacion, señala los acentos y la quantidad de las sílabas, y por conseqüencia á hacer y medir versos. Prosodia.

[...]» (pág. 692,1). 
DRAE-1817: «s.f. Parte de la gramática que enseña la pronunciacion, señala los acentos y la cantidad de las sílabas, y por consecuencia á hacer y medir versos. Prosodia.

[...]» (pág. 710,1).

DRAE-1822: «s.f. Parte de la gramática que enseña la pronunciacion, señala los acentos y la cantidad de las sílabas, y por consecuencia á hacer y medir versos. Prosodia.

[...]» (pág. 670,2).

DRAE-1832: «f. Parte de la gramática que enseña la pronunciacion, señala los acentos y la cantidad de las sílabas, y por consecuencia á medir los versos. Prosodia [...]» (pág. 611,2).

DRAE-1837: «f. Parte de la gramática que enseña la pronunciacion, señala los acentos y la cantidad de las sílabas, y por consecuencia á medir los versos. Prosodia [...]» (pág. 611,2).

DRAE-1843: «f. Parte de la gramática que enseña la pronunciacion, los acentos y la cantidad de las sílabas, y por consecuencia la estructura de los versos. Prosodia [...]» (pág. 594,1).

\section{$2^{\mathrm{a}}$ m. XIX - p. XX}

DRAE-1852: «f. Parte de la gramática que enseña la pronunciacion, los acentos y la cantidad de las sílabas, y por consecuencia la estructura de los versos. Prosodia [...]» (pág. 569,2).
GRAE-1854: Ni se define ni se trata de ella. No se contempla como parte de la Gramática.

GRAE-1858: «[...] es objeto de la prosodia la verdadera pronunciacion de los vocablos» (pág. 1). Se considera parte de la Gramática, pero su estudio no se incluye en el libro.

GRAE-1862: «[...] es objeto de la prosodia la verdadera pronunciacion de los vocablos» (pág. 5).

GRAE-1864: «[...] es objeto de la prosodia la verdadera pronunciacion de los vocablos» (pág. 5).

GRAE-1865: «[...] es objeto de la prosodia la verdadera pronunciacion de los vocablos» (pág. 5). 
GRAE-1866: «[...] es objeto de la prosodia la verdadera pronunciacion de los vocablos» (pág. 5).

GRAE-1867: «[...] es objeto de la prosodia la verdadera pronunciacion de los vocablos» (pág. 5).

DRAE-1869: «f. Parte de la gramática que enseña la pronunciacion de los vocablos, y la acentuacion de las sílabas para el efecto de la estructura y medida de los versos» (pág. 638,3).
GRAE-1870: «parte de la gramática que enseña a pronunciar correctamente las oraciones y las partes de que constan» (pág. 5).

«La Prosodia es aquella parte de la Gramática que enseña la recta pronunciacion y acentuacion de las letras, sílabas y palabras» (pág. 287).

GRAE-1874: «parte de la gramática cuyo fin es enseñar a pronunciar correctamente» (pág. 16).

«La Prosodia es aquella parte de la Gramática, que enseña la recta pronunciacion y acentuacion de las letras, sílabas y palabras» (pág.315).

GRAE-1878: «parte de la Gramática cuya misión es enseñar la pronunciación (pág. 16).

«La Prosodia es aquella parte de la Gramática, que enseña la recta pronunciacion y acentuacion de las letras, sílabas y palabras» (pág. 315).

GRAE-1880: "parte de la Gramática cuya misión es enseñar la pronunciación [p. 5]. «La Prosodia es la parte de la Gramática que enseña la recta pronunciación y acentuación de las letras, sílabas y palabras» (pág. 321).

GRAE-1883: «parte de la Gramática cuya misión es enseñar la pronunciación» (pág. 5).

«Prosodia es la parte de la Gramática que enseña la recta pronunciación y acentuación de las letras, sílabas y palabras» (pág. 321). 


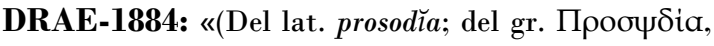
de про́s, hacia, у $\psi \delta \dot{n}$, canto.) f. Parte de la gramática, que enseña la recta pronunciación y acentuación de las letras, sílabas y palabras» (pág. 873,1).

DRAE-1899: «(Del lat. prosodĭa; del gr. Проб $\psi \delta i a$, de прós, hacia, у $\Psi \delta \dot{\eta}$, canto.) f. Parte de la gramática, que enseña la recta pronunciación y acentuación de las letras, sílabas y palabras» (pág. 819,1).
GRAE-1885: «parte de la Gramática cuya misión es enseñar la pronunciación» (pág. 5).

«Prosodia es la parte de la Gramática que enseña la recta pronunciación y acentuación de las letras, sílabas y palabras» (pág. 321).

GRAE-1888: «parte de la Gramática cuya misión es enseñar la pronunciación» (pág. VI).

«Prosodia es la parte de la Gramática que enseña la recta pronunciación y acentuación de las letras, sílabas y palabras» (pág. 321).

GRAE-1890: «parte de la Gramática cuya misión es enseñar la pronunciación» (pág. VI).

«Prosodia es la parte de la Gramática que enseña la recta pronunciación y acentuación de las letras, sílabas y palabras» (pág. 321).

GRAE-1895: «parte de la Gramática cuya misión es enseñar la pronunciación» (pág. VI).

«Prosodia es la parte de la Gramática que enseña la recta pronunciación y acentuación de las letras, sílabas y palabras» (pág. 321).

GRAE-1900: «parte de la Gramática cuya misión es enseñar la pronunciación» (pág. VI).

«Prosodia es la parte de la Gramática que enseña la recta pronunciación y acentuación de las letras, sílabas y palabras» (pág. 321).

GRAE-1901: «parte de la Gramática cuya misión es enseñar la pronunciación» (pág. VI).

«Prosodia es la parte de la Gramática que enseña la recta pronunciación y acentuación de las letras, sílabas y palabras» (pág. 321). 
GRAE-1904: «parte de la Gramática cuya misión es enseñar la pronunciación» (pág. VI).

«Prosodia es la parte de la Gramática que enseña la recta pronunciación y acentuación de las letras, sílabas y palabras» (pág. 315).

GRAE-1906: parte de la Gramática cuya misión es enseñar la pronunciación (pág. VI).

«Prosodia es la parte de la Gramática que enseña la recta pronunciación y acentuación de las letras, sílabas y palabras» (pág. 315).

GRAE-1908: «parte de la Gramática cuya misión es enseñar la pronunciación» (pág. VI).

«Prosodia es la parte de la Gramática que enseña la recta pronunciación y acentuación de las letras, sílabas y palabras» (pág. 315).

GRAE-1909: «parte de la Gramática cuya misión es enseñar la pronunciación» (pág. VI).

«Prosodia es la parte de la Gramática que enseña la recta pronunciación y acentuación de las letras, sílabas y palabras» (pág. 315).

GRAE-1911: «parte de la Gramática cuya misión es enseñar la pronunciación» (pág. 6).

«Prosodia es la parte de la Gramática que enseña la recta pronunciación y acentuación de las letras, sílabas y palabras» (pág. 321).

GRAE-1913: «parte de la Gramática cuya misión es enseñar la pronunciación» (pág. 6).

«Prosodia es la parte de la Gramática que enseña la recta pronunciación y acentuación de las letras, sílabas y palabras» (pág. 321).

DRAE-1914: «(Del lat. prosoď̆a, y éste del gr.

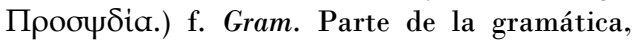
que enseña la recta pronunciación y acentuación de las letras, sílabas y palabras» (pág. 840,3). 
GRAE-1916: «parte de la Gramática cuya misión es enseñar la pronunciaciónm (pág. 6).

«Prosodia es la parte de la Gramática que enseña la recta pronunciación y acentuación de las letras, sílabas y palabras» (pág. 321).

GRAE-1917: «parte de la Gramática cuya misión es enseñar la pronunciación» (pág. VIII).

«Prosodia es la parte de la Gramática que enseña la recta pronunciación y acentuación de las letras, sílabas y palabras» (pág. 453).

GRAE-1920: «parte de la Gramática cuya misión es enseñar la pronunciación» (pág. 8).

«Prosodia es la parte de la Gramática que enseña la recta pronunciación y acentuación de las letras, sílabas y palabras» (pág. 473).

GRAE-1924: «parte de la Gramática cuya misión es enseñar la pronunciación» (pág. 8).

«Prosodia es la parte de la Gramática que enseña la recta pronunciación y acentuación de las letras, sílabas y palabras» (pág. 473).

DRAE-1925: «(Del lat. prosodĭa, y éste del gr.

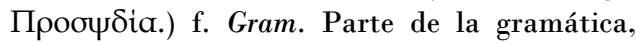
que enseña la recta pronunciación y acentuación de las letras, sílabas y palabras» (pág. 995,2). 


\section{RÉGIMEN}

\section{SIGLO XVIII}

Autoridades: «(Régimen) f.m. El modo de gobernarfe ò regirle en alguna cofa. Es voz puramente Latina. Regimen» (1737, pág. 545,1).

DRAE-1780: «s.m. El modo de gobernarse, ó regirse en alguna cosa. Regimen» (pág. 789,3).

DRAE-1783: «s.m. El modo de gobernarse, ó regirse en alguna cosa. Regimen» (pág. 803,1).

DRAE-1791: «s.m. El modo de gobernarse, ó regirse en alguna cosa. Regimen» (pág. 717,3).
GRAE-1771: «RÉGIMEN es el gobierno ó precedencia que tienen unas palabras respecto de otras: las que estan ántes rigen: las que estan despues son regidas.

Esta general significacion de la voz régimen se ciñe en la Gramática á determinar la relacion ó dependencia de unas palabras con otras» (pág. 235).

GRAE-1796: No se da definición en sentido estricto. Por régimen se entiende la dependencia precisa que se da entre las palabras, dependencia que consiste en que «unas rijan á otras, y estas sean regidas de las primeras baxo de ciertas reglas, quebrantadas las quales, ó alguna de ellas, quede la oración con un defecto muy considerable» (pág. 286).

\section{$\mathbf{1}^{\mathrm{a}}$ mitad del XIX}

DRAE-1803: «s.m. El modo de gobernarse ó regirse en alguna cosa. Regimen.

RÉGIMEN. La construccion de un verbo con la preposicion y caso, ó modo que pide, y de una preposicion con su caso correspondiente» (pág. $730,2)$.

DRAE-1817: «s.m. El modo de gobernarse ó regirse en alguna cosa con moderacion ó templanza. Regimen.

RÉGIMen. Gram. La construccion de un verbo con la preposicion y caso ó modo que pide, y de una preposicion con su caso correspondiente» (pág. 743,1).

DRAE-1822: «s.m. El modo de gobernarse ó regirse en alguna cosa con moderacion ó templanza. Regimen.

RÉGIMEN. Gram. La construccion de un verbo con la preposicion y caso ó modo que pide y de una preposicion en [sic] su caso correspondiente» (pág. 703,1-2). 
DRAE-1832: «m. El modo de gobernarse ó regirse en alguna cosa. Regimen. If Gram. La construccion de un verbo con la preposicion y caso ó modo que pide $y$ de una preposicion con su caso correspondiente» (pág. 640,1).

DRAE-1837: «m. El modo de gobernarse o regirse en alguna cosa. Regimen. If Gram. La construccion de un verbo con la preposicion y caso ó modo que pide $y$ de una preposicion con su caso correspondiente. Constructio, syntaxis» (pág. $640,2)$.

DRAE-1843: «m. El modo de gobernarse ó regirse en alguna cosa. Regimen. వ Gram. La construccion de un verbo con la preposicion y caso ó modo que pide, y de una preposicion con su caso correspondiente. Constructio, syntaxis» (pág. $621,3)$.

\section{$2^{\mathrm{a}}$ m. XIX - p. XX}

DRAE-1852: «m. El modo de gobernarse ó regirse en alguna cosa. Regimen. If Gram. La relacion gramatical que requiere cada verbo respecto del objeto á que se refiere, ya sea con preposición ó sin ella. T La dependencia que segun las reglas gramaticales tienen entre sí las partes de la oracion. Constructio, syntaxis» (pág. 596,2).

GRAE-1854: Seguimos sin una definición estricta. El régimen es la justa dependencia de las palabras en la oración; la regencia se establece bajo ciertas reglas, quebrantadas las cuales queda la oración defectuosa (pág. 143).

GRAE-1858: Se mantiene la misma idea: el régimen es el enlace o combinación de palabras que, bajo ciertas reglas, mantienen entre sí una justa dependencia (pág. 155).

GRAE-1862: En la línea de las Gramáticas anteriores, enlace y combinación de palabras que mantienen una justa dependencia en virtud de ciertas reglas inquebrantables para la recta construcción de oraciones (pág. 159).

GRAE-1864: La misma idea: enlace y combinación de palabras que mantienen una justa dependencia en virtud de ciertas reglas inquebrantables para la recta construcción de oraciones (pág. 159).

GRAE-1865: La misma idea: enlace y combinación de palabras que mantienen una justa dependencia en virtud de ciertas reglas inquebrantables para la recta construcción de oraciones (pág. 159).

GRAE-1866: La misma idea: enlace y combinación de palabras que mantienen una justa dependencia en virtud de ciertas reglas 
DRAE-1869: «m. El modo de gobernarse ó regirse en alguna cosa. ๆ Gram. La relacion gramatical que requiere cada verbo respecto del objeto á que se refiere, ya sea con preposición ó sin ella. đI La dependencia que segun las reglas gramaticales tienen entre sí las partes de la oracion» (pág. $667,1)$.

DRAE-1884: «(Del lat. reğ̌men.) m. Modo de gobernarse ó regirse en una cosa $[\ldots]$ ๆ Gram. Dependencia que entre sí tienen las palabras en la oración. Determínase por el oficio de unos vocablos respecto de otros, ya estén relacionados ó no por medio de las preposiciones; v. gr. respeto á mis padres; amo la virtud; saldré á pasear; quiero comer. I Gram. Preposición que pide cada verbo, ó caso que pide cada preposición; por ejemplo, el régimen del verbo atentar es la preposición á y el de esta preposición el caso de dativo ó el de acusativo $[\ldots]$... (pág. 913,1). inquebrantables para la recta construcción de oraciones (pág. 159).

GRAE-1867: La misma idea: enlace y combinación de palabras que mantienen una justa dependencia en virtud de ciertas reglas inquebrantables para la recta construcción de oraciones (pág. 158).

GRAE-1870: En la línea de las ediciones de los años cincuenta y sesenta, enlace y combinación de palabras que mantienen una justa dependencia en virtud de ciertas reglas inquebrantables para la recta construcción de oraciones (pág. 176).

GRAE-1874: La misma idea: enlace y combinación de palabras que mantienen una justa dependencia en virtud de ciertas reglas inquebrantables para la recta construcción de oraciones (pág. 204).

GRAE-1878: La misma idea: enlace y combinación de palabras que mantienen una justa dependencia en virtud de ciertas reglas inquebrantables para la recta construcción de oraciones (pág. 204).

GRAE-1880: Igual que en todas las ediciones nteriores, enlace y combinación de palabras que mantienen una justa dependencia en virtud de ciertas reglas inquebrantables para la recta construcción de oraciones (pág. 222).

GRAE-1883: Lo mismo: enlace y combinación de palabras que mantienen una justa dependencia en virtud de ciertas reglas inquebrantables para la recta construcción de oraciones (pág. 222). 
DRAE-1899: «(Del lat. reğ̌men. $)$ m. Modo de gobernarse ó regirse en una cosa $[\ldots]$ \ Gram. Dependencia que entre sí tienen las palabras en la oración. Determínase por el oficio de unos vocablos respecto de otros, ya estén relacionados ó no por medio de las preposiciones; v. gr. respeto á mis padres; amo la virtud; saldré á pasear; quiero comer. $\mid$ Gram. Preposición que pide cada verbo, ó caso que pide cada preposición; por ejemplo, el régimen del verbo atentar es la preposición á, y el de esta preposición el caso de dativo ó el de acusativo [...]» (pág. 856,1).
GRAE-1885: Enlace y combinación de palabras que mantienen una justa dependencia en virtud de ciertas reglas inquebrantables para la recta construcción de oraciones (pág. 224).

GRAE-1888: Enlace y combinación de palabras que mantienen una justa dependencia en virtud de ciertas reglas inquebrantables para la recta construcción de oraciones (pág. 222).

GRAE-1890: Enlace y combinación de palabras que mantienen una justa dependencia en virtud de ciertas reglas inquebrantables para la recta construcción de oraciones (pág. 222).

GRAE-1895: Enlace y combinación de palabras que mantienen una justa dependencia en virtud de ciertas reglas inquebrantables para la recta construcción de oraciones (pág. 222).

GRAE-1900: Enlace y combinación de palabras que mantienen una justa dependencia en virtud de ciertas reglas inquebrantables para la recta construcción de oraciones (pág. 222).

GRAE-1901: Enlace y combinación de palabras que mantienen una justa dependencia en virtud de ciertas reglas inquebrantables para la recta construcción de oraciones (pág. 222).

GRAE-1904: Enlace y combinación de palabras que mantienen una justa dependencia en virtud de ciertas reglas inquebrantables para la recta construcción de oraciones (pág. 216).

GRAE-1906: Enlace y combinación de palabras que mantienen una justa dependencia en virtud de ciertas reglas inquebrantables para la recta construcción de oraciones (pág. 216).

GRAE-1908: Enlace y combinación de palabras que mantienen una justa dependencia en virtud de ciertas reglas inquebrantables para la recta construcción de oraciones (pág. 216). 
GRAE-1909: Enlace y combinación de palabras que mantienen una justa dependencia en virtud de ciertas reglas inquebrantables para la recta construcción de oraciones (pág. 216).

GRAE-1911: Enlace y combinación de palabras que mantienen una justa dependencia en virtud de ciertas reglas inquebrantables para la recta construcción de oraciones (pág. 222).

GRAE-1913: Enlace y combinación de palabras que mantienen una justa dependencia en virtud de ciertas reglas inquebrantables para la recta construcción de oraciones (pág. 220).

DRAE-1914: «(Del lat. reğ̌men.) m. Modo de gobernarse o regirse en una cosa $[\ldots] \|^{3}$ Gram. Dependencia que entre sí tienen las palabras en la oración. Determínase por el oficio de unos vocablos respecto de otros, ya estén relacionados o no por medio de las preposiciones; v. gr. respeto a mis padres; amo la virtud; saldré a pasear; quiero comer. $\Upsilon^{4}$ Gram. Preposición que pide cada verbo, o caso que pide cada preposición; por ejemplo, el régimen del verbo atentar es la preposición $a$, y el de esta preposición, el caso de dativo o el de acusativo [...]» (pág. 878,3).

DRAE-1925: «(Del lat. reğ̌men.) m. Modo de gobernarse o regirse en una cosa [...] \ 3. Gram. Dependencia que entre sí tienen las palabras en la oración. Determínase por el oficio de unos vocablos respecto de otros, estén relacionados o no por medio de las preposiciones; $\mathrm{v}$. gr. respeto a mis padres; amo la virtud; saldré a pasear; quiero comer. I 4. Gram. Preposición que pide cada verbo, o caso que pide cada preposición; por ejemplo, el régimen del verbo aspirar es la preposición $a$, y el de esta preposición, el caso de dativo o el de ablativo [...]» (pág. 1038,2-3). 


\section{REGIR}

\section{SIGLO XVIII}

Autoridades: «v.a. Dirigir, gobernar, ò mandar [...] Viene del Latino Regere, que fignifica lo mifmo $[\ldots]$

$[\ldots]$

REGIR. En términos gramáticos, vale llevar, ò gobernar el verbo à cierto calo ù modo. Lat. Regere.

[...]» (1737, pág. 546,1).

GRAE-1771:

DRAE-1780: «v.a. Dirigir, gobernar, ó mandar. Regere.

$[\ldots]$ REGIR. Gram. Llevar, ó gobernar el verbo á cierto caso, ó modo. Regere. [...]» (pág. 790,1).

DRAE-1783: «v.a. Dirigir, gobernar, ó mandar. Regere.

$[\ldots]$ REGIR. Gram. Llevar, ó gobernar el verbo á cierto caso, ó modo. Regere. [...]» (pág. 803,2).

DRAE-1791: «v.a. Dirigir, gobernar, ó mandar. Regere [...] 3. Gram. Llevar, ó gobernar el verbo á cierto caso, ó modo. Regere [...]» (pág. 718,1).

GRAE-1796:

\section{$1^{\text {a }}$ mitad del XIX}

DRAE-1803: «v.a. Dirigir, gobernar, ó mandar. Regere. $[\ldots]$

Regir. Gram. Pedir un verbo tal ó tal preposicion, ó tal ó tal caso ó modo; ó pedir una preposicion éste, $o$ el otro caso.

REgIR. En los estudios de gramática colocar todas las palabras de un autor en su órden gramatical; y dar razon de lo que es cada una de ellas, y de la construccion que pide.

[...]» (pág. 730,3).

DRAE-1817: «v.a. Dirigir, gobernar ó mandar. Regere. [...]

Regir. Gram. Pedir un verbo tal ó tal preposicion, ó tal ó tal caso ó modo; ó pedir una preposicion este ó el otro caso.

REGIR. En los estudios de gramática colocar todas las palabras de un autor en su órden gramatical, y dar razon de lo que es cada una de ellas, y de la construccion que pide.

[...]» (pág. 743,1-2). 
DRAE-1822: «v.a. Dirigir, gobernar ó mandar. Regere. $[\ldots]$

Regir. Gram. Pedir un verbo tal ó tal preposicion, tal ó tal caso ó modo; ó pedir una preposicion este ó el otro caso.

REGIR. En los estudios de gramática colocar todas las palabras de un autor en su orden gramatical, y dar razon de lo que es cada una de ellas, y de la construccion que pide.

[...]» (pág. 703,2).

DRAE-1832: «a. Dirigir, gobernar ó mandar. Regere [...] đI Gram. Pedir un verbo tal ó tal preposicion, tal ó tal caso ó modo; ó pedir una preposicion este ó el otro caso. Requirere. $\mid$ En los estudios de gramática colocar todas las palabras de un autor en su órden natural y dar razon de lo que es cada una de ellas, y de la construccion que pide [...]» (pág. 640,1).

DRAE-1837: «a. Dirigir, gobernar ó mandar. Regere [...] ब Gram. Pedir un verbo tal ó tal preposicion, tal ó tal caso ó modo; ó pedir una preposicion este ó el otro caso. Requirere. $\llbracket$ En los estudios de gramática colocar todas las palabras de un autor en su órden natural y dar razon de lo que es cada una de ellas, y de la construccion que pide [...]» (pág. 640,2).

DRAE-1843: «a. Dirigir, gobernar ó mandar. Regere [...] ם Gram. Pedir un verbo tal ó tal preposicion, tal ó tal caso ó modo; ó pedir una preposicion este ó el otro caso. Requirere. Q $\mathrm{E}$ En los estudios de gramática colocar todas las palabras de un autor en su órden natural y dar razon de lo que es cada una de ellas, y de la construccion que pide [...]» (pág. 621,3).

\section{$2^{a}$ m. XIX - p. XX}

DRAE-1852: «a. Dirigir, gobernar ó mandar. Regere [...] ब Gram. Pedir un verbo tal ó tal preposicion, tal ó tal caso ó modo; ó pedir una preposicion este ó el otro caso. Requirere. . los estudios de gramática colocar todas las palabras de un autor en su órden natural y dar razon de lo que es cada una de ellas, y de la construccion que pide [...]» (pág. 596,2).

GRAE-1854:

GRAE-1858:

GRAE-1862:

GRAE-1864: 


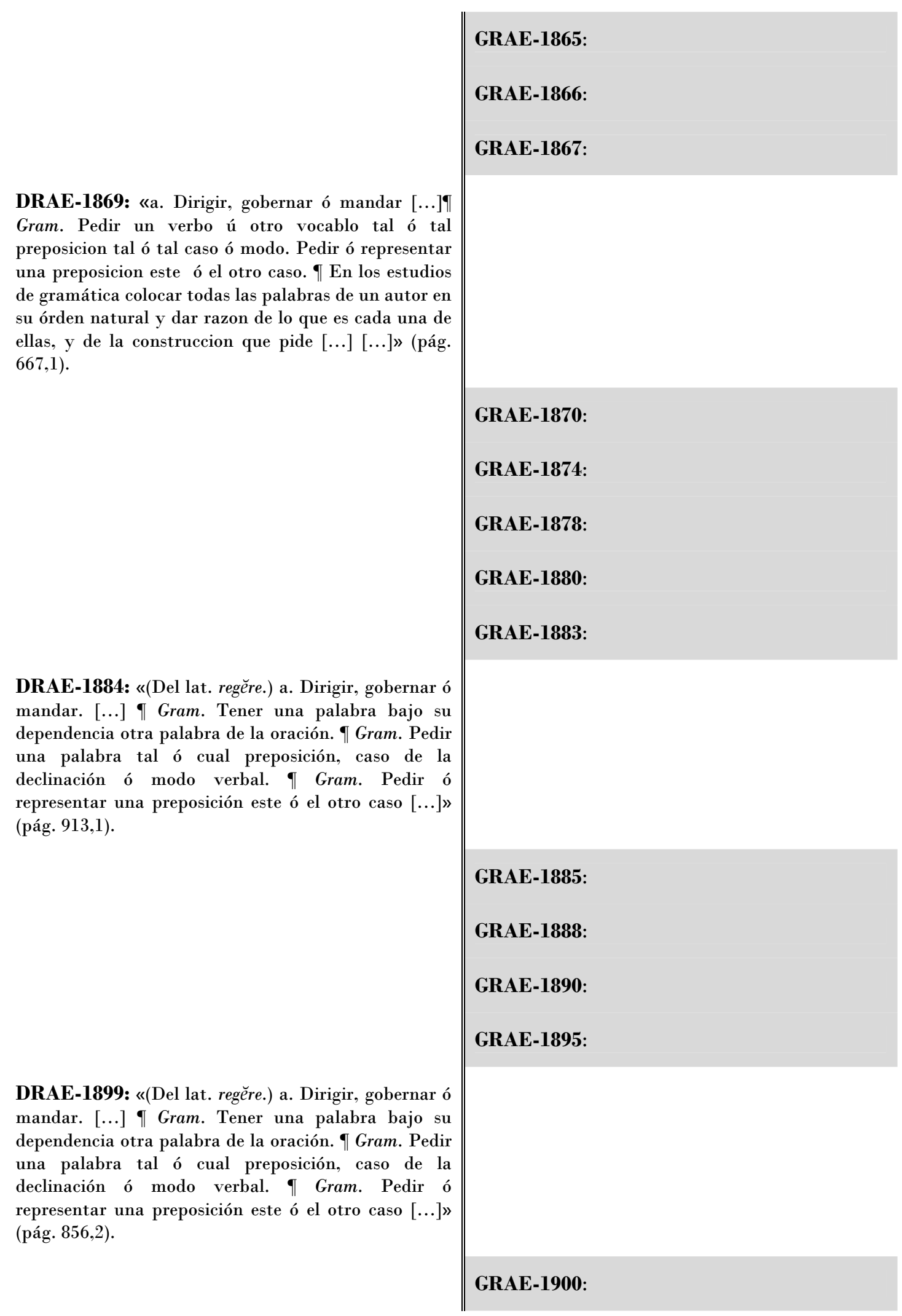


GRAE-1901:

GRAE-1904:

GRAE-1906:

GRAE-1908:

GRAE-1909:

GRAE-1911:

GRAE-1913:

GRAE-1916:

GRAE-1917:

GRAE-1920:

GRAE-1924:

DRAE-1925: «(Del lat. regĕre. $)$ tr. Dirigir, gobernar o mandar. [...] I 4. Gram. Tener una palabra bajo su dependencia otra palabra de la oración. I 5. Gram. Pedir una palabra tal o cual preposición, caso de la declinación o modo verbal. I 6. Gram. Pedir o representar una preposición este o el otro caso [...]» (pág. $1038,3)$.

DRAE-1914: «(Del lat. regěre.) a. Dirigir, gobernar o mandar. [...] \ ${ }^{4}$ Gram. Tener una palabra bajo su Pedir una palabra tal o cual preposición, caso de la declinación o modo verbal. \& 6 Gram. Pedir o tar una preposición este o el otro caso [...]» (pág. 878,3). 


\section{RELACIÓN}

\section{SIGLO XVIII}

Autoridades: 1.f. La narración ò informe que fe hace de alguna cola que fucedió. Lat. Relatio. Narratio $[\ldots]$

Relación. En lo forense fe llama aquel breve y fucinto informe que por perfona pública fe hace en voz o por efcrito, al Juez, del hecho de un procef[o. Lat. Recitatio, relatio $[\ldots]$

RELACIón. En la Lógica es una de las diez cathegorias que pertenece al accidente ò à la fubftáncia, confiftiendo toda fu effencia en aquel refpecto y orden que tiene una cola con otra $[\ldots]$ Lat. Relatio.

RELACIÓN. En las Comedias es la narración, que firve de epifódio ò explicacion del thema de la comedia. Lat. Recitatio comica.

RELACión. Se llama tambien aquel romance de algun fuceflo ò hiftoria, que cantan y venden los ciegos por las calles. Lat. Recitatio metrica.

RELACión. Vale afsimifmo adherencia ò parentefco à lo largo de una perfona con otra [...] Lat. Relatio, refpectus.

RELACión. Vale tambien correfpondencia, ò comunicación de una persona con otra [...] Lat. Commercium. Confuetudo.

RELACión. Significa tambien concernencia en lance, ò confonancia de una cofa à otra: y afsi fe dice, Efte difcurfo hace relación con el antecedente: Efte fucelfo tiene relación con los paflados. Lat. Relatio. Refpectus. [...] (1737, pág. 556,1-2).

DRAE-1780: «s.f. La narracion, ó informe que se hace de alguna cosa que sucedió. Relatio, narratio. Relacion. for. Aquel breve y sucinto informe, que por persona pública se hace en voz, ó por escrito al juez del hecho de un proceso. Recitatio, relatio.

RELACión. Lóg. Es una de las diez categorías, que pertenece al accidente, ó á la substancia, consistiendo toda su esencia en aquel respecto, y órden que tiene una cosa con otra [...]. Relatio.

RELACION. En las comedias es la narracion, que sirve de episodio, ó explicacion del tema de la comedia. Recitatio comica.

Relacion. Romance de algun suceso, ó historia, que cantan y venden los ciegos por las calles. Recitatio metrica.

RELACiON. Adherencia, ó parentesco á lo largo de una persona con otra [...] Relatio, respectus.

Relacion. Correspondencia, ó comunicacion de una persona con otra [...] Commercium, consuetudo. 
Relacion. Concernencia en lance [sic], ó consonancia de una cosa á otra; y así se dice: este discurso hace RELACION con el antecedente, este suceso tiene RELACION con los pasados. Relatio, respectus.

[...]» (pág. 792,2).

DRAE-1783: «s.f. La narracion, ó informe que se hace de alguna cosa que sucedió. Relatio, narratio.

Relacion. for. Aquel breve y sucinto informe, que por persona pública se hace en voz, ó por escrito al juez del hecho de un proceso. Recitatio, relatio.

Relación. Lóg. Es una de las diez categorías, que pertenece al accidente, ó á la substancia, consistiendo toda su esencia en aquel respecto, y órden que tiene una cosa con otra [...]. Relatio.

RELACION. En las comedias es la narracion, que sirve de episodio, ó explicacion del tema de la comedia. Recitatio comica.

Relacion. Romance de algun suceso, ó historia, que cantan y venden los ciegos por las calles. Recitatio metrica.

RELACion. Adherencia, ó parentesco á lo largo de una persona con otra [...] Relatio, respectus.

Relacion. Correspondencia, ó comunicacion de una persona con otra [...] Commercium, consuetudo.

Relacion. Concernencia enlace, ó consonancia de una cosa á otra; y así se dice: este discurso hace RELACION con el antecedente, este suceso tiene RELACION con los pasados. Relatio, respectus. […]» (pág. 805,2-3).

DRAE-1791: «s.f. La narracion, ó informe que se hace de alguna cosa que sucedió. Relatio, narratio. 2. for. Aquel breve y sucinto informe, que por persona pública se hace en voz, ó por escrito al juez del hecho de un proceso. Recitatio, relatio. 3 . Lóg. Es una de las diez categorías, que pertenece al accidente, ó á la substancia, consistiendo toda su esencia en aquel respecto, y órden que tiene una cosa con otra [...]. Relatio. 4. En las comedias es la narracion, que sirve de episodio, ó explicacion del tema de la comedia. Recitatio comica. 5. Romance de algun suceso, ó historia, que cantan y venden los ciegos por las calles. Recitatio metrica. 6. Adherencia, ó parentesco á lo largo de una persona con otra [...] Relatio, respectus. 7. Correspondencia, ó comunicacion de una persona con otra [...] Commercium, consuetudo. 8. Concernencia enlace, ó consonancia de una cosa á otra; y así se dice: este discurso hace RELACION con el antecedente, este suceso tiene RELACION con los pasados. Relatio, respectus [...]» (pág. 720,1). 


\section{$\mathbf{1}^{\mathrm{a}}$ mitad del XIX}

DRAE-1803: «s.f. La narracion, ó informe que se hace de alguna cosa que sucedió. Relatio, narratio.

Relacion. Concernencia, enlace, ó consonancia de una cosa con otra; y así se dice: este discurso hace RELACION con el antecedente, este suceso tiene RELACION con los pasados. Relatio, respectus.

Relacion. Correspondencia, ó comunicacion de una persona con otra [...] Commercium, consuetudo.

Relacion. Adherencia, ó parentesco á lo largo de una persona con otra [...] Relatio, respectus

RELACION. for. Aquel breve y sucinto informe, que por persona pública se hace en voz, ó por escrito al juez del hecho de un proceso. Recitatio, relatio.

Relación. Lóg. Aquel respecto y órden que tiene una cosa con otra; como todo el ser del padre en quanto padre está en el órden y respecto que tiene á su término, que es el hijo. Relatio.

Relacion. Romance de algun suceso ó historia, que cantan y venden los ciegos por las calles. Recitatio metrica.

RELACION. En las comedias es la narracion, que sirve de episodio ó explicacion del tema de la comedia. Recitatio comica.

[…] (pág. 733,2-3).

DRAE-1817: «s.f. La narracion, ó informe que se hace de alguna cosa que sucedió. Relatio, narratio.

Relacion. Concernencia, enlace, ó consonancia de una cosa con otra; y así se dice: este discurso hace RELACION con el antecedente, este suceso tiene RELACION con los pasados. Relatio, respectus.

RElacion. Correspondencia, ó comunicacion de una persona con otra [...] Commercium, consuetudo.

Relacion. Adherencia, ó parentesco remoto de una persona con otra [...] Relatio, respectus

Relacion. for. Aquel breve y sucinto informe, que por persona pública se hace en voz ó por escrito al juez sobre hecho de un proceso. Recitatio, relatio.

Relación. Lóg. Aquel respecto, órden ó enlaceque tiene una cosa con otra. Relatio.

RELACiOn. Romance de algun suceso ó historia, que cantan y venden los ciegos por las calles. Recitatio metrica.

RELACiOn. En las comedias es la narracion que hace un actor de ciertos hechos anteriores, y que constituye el prólogo ó argumento del drama. Narratio comica.

[...]» (pág. 746,1).

DRAE-1822: «s.f. La narracion, ó informe que se hace de alguna cosa que sucedió. Relatio, narratio.

Relacion. Concernencia, enlace, ó consonancia de una cosa con otra; y así se dice: este discurso hace RELACION con el antecedente, este suceso tiene RELACION con los pasados. Relatio, respectus. 
RELACiON. Correspondencia, ó comunicacion de una persona con otra [...] Commercium, consuetudo.

Relacion. Adherencia, ó parentesco remoto de una persona con otra [...] Relatio, respectus

Relacion. for. Aquel breve y sucinto informe, que por persona pública se hace en voz ó por escrito al juez sobre hecho de un proceso. Recitatio, relatio.

Relación. Lóg. Aquel respecto, órden ó enlaceque tiene una cosa con otra. Relatio.

Relacion. Romance de algun suceso ó historia, que cantan y venden los ciegos por las calles. Recitatio metrica.

RELACION. En las comedias es la narracion que hace un actor de ciertos hechos anteriores, y que constituye el prólogo ó argumento del drama. Narratio comica.

[‥]» (pág. 706,1-2).

DRAE-1832: «f. La accion y efecto de referir en sus dos primeras acepciones. Relatio, narratio. I Concernencia, correspondencia ó conexión de una persona ó cosa con otra. Relatio, respectus. \f for. El informe que hace la persona designada por la ley á un tribunal ó juez de lo sustancial de un proceso. Judicalis causae recitatio, relatio. @ Romance de algun suceso ó historia que cantan y venden los ciegos por las calles. Recitatio metrica. q En las comedias narracion y tambien discurso. Narratio comica [...]» (pág. 642,2).

DRAE-1837: «f. La accion y efecto de referir en sus dos primeras acepciones. Relatio, narratio. I Concernencia, correspondencia ó conexión de una persona ó cosa con otra. Relatio, respectus. \f for. El informe que hace la persona designada por la ley á un tribunal ó juez de lo sustancial de un proceso. Judicalis causae recitatio, relatio. @ Romance de algun suceso ó historia que cantan y venden los ciegos por las calles. Recitatio metrica. I En las comedias narracion y tambien discurso. Narratio comica [...]» (pág. 642,3).

DRAE-1843: «f. La accion y efecto de referir en sus dos primeras acepciones. Relatio, narratio. Concernencia, correspondencia ó conexión de una persona ó cosa con otra. Relatio, respectus. $\square$ for. El informe que hace la persona designada por la ley á un tribunal ó juez de lo sustancial de un proceso. Judicalis causae recitatio, relatio. Romance de algun suceso ó historia que cantan y venden los ciegos por las calles. Recitatio metrica. o En las comedias narracion y tambien discurso. Narratio comica [...]» (pág. 641,1). 


\section{$2^{\mathrm{a}} \mathrm{m} . \mathrm{XIX}-\mathrm{p.}$ XX}

DRAE-1852: «f. La accion y efecto de referir en sus dos primeras acepciones. Relatio, narratio. I Concernencia, correspondencia ó conexión de una persona ó cosa con otra. Relatio, respectus. \f for. El informe que hace la persona designada por la ley á un tribunal ó juez de lo sustancial de un proceso. Judicalis causae recitatio, relatio. I Romance de algun suceso ó historia que cantan y venden los ciegos por las calles. Recitatio metrica. If En las comedias narracion y tambien discurso. Narratio comica [...]» (pág. 598,2-3). dos primeras acepciones. I Concernencia, correspondencia ó conexión de una persona ó cosa con otra. 9 for. El informe que hace la persona designada por la ley á un tribunal ó juez de lo sustancial de un proceso. $\|$ Romance de algun suceso ó historia que cantan y venden los ciegos por las calles. I En las comedias narracion y tambien discurso [...]» (pág. 669,2).

GRAE-1854:

GRAE-1858:

GRAE-1862:

GRAE-1864:

GRAE-1865:

GRAE-1866:

GRAE-1867:

GRAE-1870:

GRAE-1874:

GRAE-1878:

GRAE-1880:

GRAE-1883: 
DRAE-1884: «(Del lat. relatı̆o.) f. Acción y efecto de referir (1. ${ }^{\mathrm{a}}$ y $2^{\mathrm{a}}$. aceps.) I Conexión, correspondencia de una cosa con otra. I Conexión, correspondencia, trato, comunicación de una persona con otra [...] @ En el poema dramático, trozo largo que dice un personaje, ya para contar ó narrar una cosa, ya con cualquiera otro fin. $\mid$ For. Informe que la persona designada por la ley hace de lo substancial de un proceso á un tribunal ó juez. Gram. Conexión ó enlace entre dos términos de una misma oración; v. gr.: en la frase amor de madre hay una relación gramatical cuyos dos términos son las voces amor y madre. [...]» (pág. 916,1).

GRAE-1885:

GRAE-1888:

GRAE-1890:

GRAE-1895:

DRAE-1899: «(Del lat. relatı̌o.) f. Acción y efecto de referir ( $\left(1 .^{\mathrm{a}}\right.$ y $2^{\mathrm{a}}$. aceps.) \ Conexión, correspondencia de una cosa con otra. If Conexión, correspondencia, trato, comunicación de una persona con otra [...] \ En el poema dramático, trozo largo que dice un personaje, ya para contar ó narrar una cosa, ya con cualquiera otro fin. $\mid$ For. Informe que la persona designada por la ley hace de lo substancial de un proceso á un tribunal ó juez. đ Gram. Conexión ó enlace entre dos términos de una misma oración; v. gr.: en la frase amor de madre hay una relación gramatical cuyos dos términos son las voces amor y madre. [...]» (pág. 858,3).

GRAE-1900:

GRAE-1901:

GRAE-1904:

GRAE-1906:

GRAE-1908: 
GRAE-1909:

GRAE-1911:

GRAE-1913:

DRAE-1914: «(Del lat. relatı̆o, -ŏnis.) f. Acción y efecto de referir o referirse, I. ${ }^{\mathrm{a}}$ y $2^{\mathrm{a}}$. aceps. If 2. Conexión, correspondencia de una cosa con otra. ๆ 3. Conexión, correspondencia, trato, comunicación de una persona con otra $[\ldots]$ ๆ 4 . En el poema dramático, trozo largo que dice un personaje, ya para contar o narrar una cosa, ya con cualquiera otro fin. I 5. For. Informe que un auxiliar hace de lo substancial de un proceso o de alguna incidencia en él, ante un tribunal o juez. ๆ 6. Gram. Conexión o enlace entre dos términos de una misma oración; v. gr.: en la frase amor de madre hay una relación gramatical cuyos dos términos son las voces amor y madre. [...]» (pág. $1042,1)$.

GRAE-1916:

GRAE-1917:

GRAE-1920:

GRAE-1924:

DRAE-1925: «(Del lat. relatĭo, -ŏnis.) f. Acción y efecto de referir o referirse, I. ${ }^{a}$ y $2^{\text {a }}$. aceps. If ${ }^{2}$ Conexión, correspondencia de una cosa con otra. I 3 Conexión, correspondencia, trato, comunicación de una persona con otra $[\ldots]$ 『 ${ }^{4}$ En el poema dramático, trozo largo que dice un personaje, ya para contar o narrar una cosa, ya con cualquiera otro fin. $\Upsilon^{5}$ For. Informe que la persona designada por la ley hace de lo substancial de un proceso ante un tribunal o juez. I ${ }^{6}$ Gram. Conexión o enlace entre dos términos de una misma oración; v. gr.: en la frase amor de madre hay una relación gramatical cuyos dos términos son las voces amor y madre. [...]» (pág. 881,2). 


\section{RELACIONAR}

\section{SIGLO XVIII}

Autoridades: «v.a. Hacer relación del hecho de alguna cofa. Lat. Referre. Narrare» (1737, pág. $556,2)$.

\section{GRAE-1771:}

DRAE-1780: «v.a. Hacer relacion del hecho de alguna cosa. Referre, narrare» (pág. 792,2).

DRAE-1783: «v.a. Hacer relacion del hecho de alguna cosa. Referre, narrare» (pág. 805,3).

DRAE-1791: «v.a. Hacer relacion del hecho de alguna cosa. Referre, narrare» (pág. 720,1).

\section{GRAE-1796:}

\section{$\mathbf{1}^{\mathrm{a}}$ mitad del XIX}

DRAE-1803: «v.a. Hacer relacion del hecho de alguna cosa. Referre, narrare» (pág. 733,3).

DRAE-1817: «v.a. Hacer relacion del hecho de alguna cosa. Referre, narrare» (pág. 746,2).

DRAE-1822: «v.a. Hacer relacion del hecho de alguna cosa. Referre, narrare» (pág. 706,2).

DRAE-1832: «a. Hacer relacion de un hecho. Referre, narrare» (pág. 642,3).

DRAE-1837: «a. Hacer relacion de un hecho. Referre, narrare» (pág. 642,3).

DRAE-1843: «a. Hacer relacion de un hecho. Referre, narrare» (pág. 624,1).

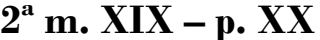

DRAE-1852: «a. Hacer relacion de un hecho. Referre, narrare» (pág. 598,3).

GRAE-1854:

GRAE-1858:

GRAE-1862:

GRAE-1864: 


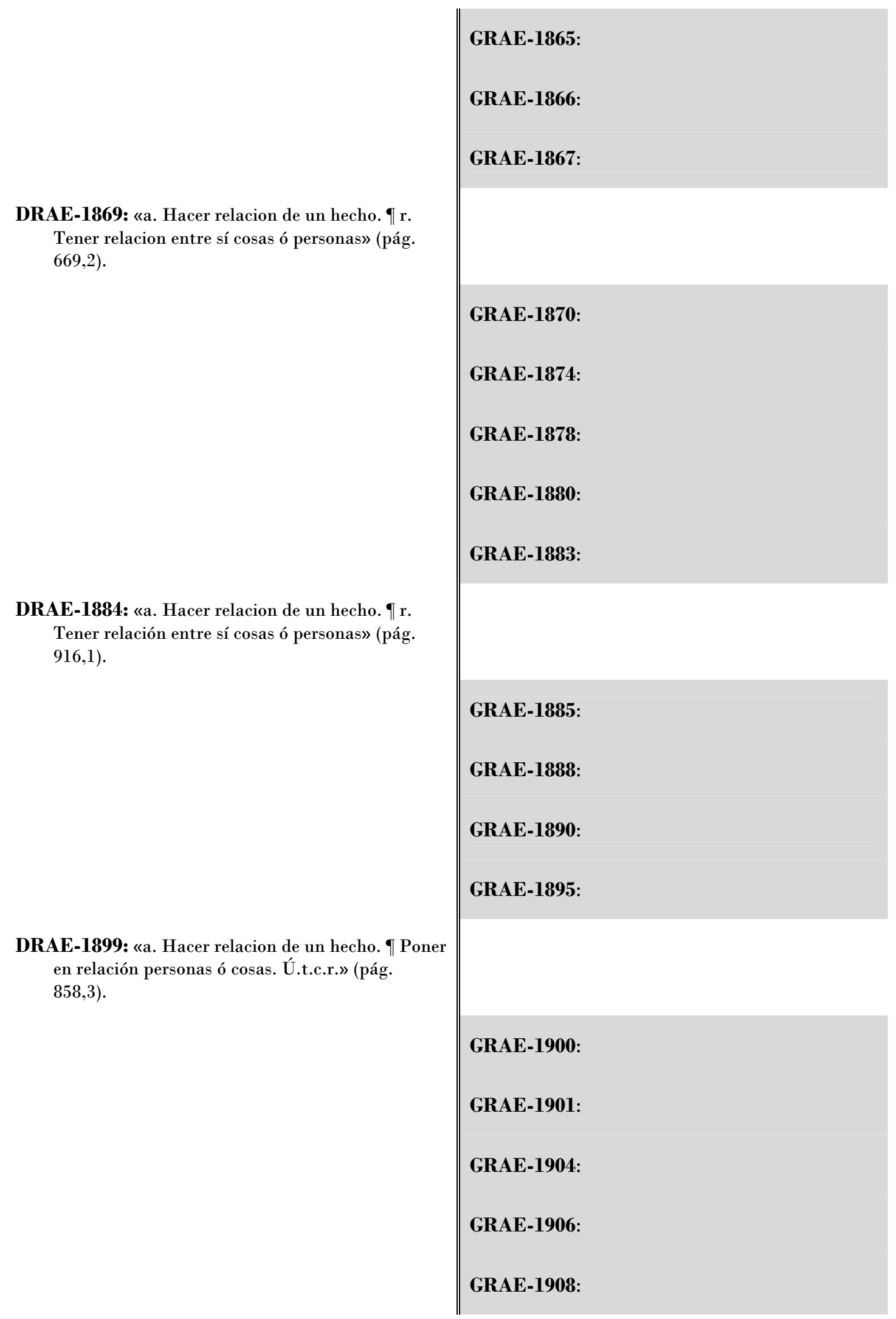


GRAE-1909:

GRAE-1911:

GRAE-1913:

DRAE-1914: «a. Hacer relacion de un hecho. ๆ ${ }^{2}$

Poner en relación personas ó cosas. Ú.t.c.r.» (pág. 881,2).

\section{GRAE-1916:}

GRAE-1917:

GRAE-1920:

GRAE-1924:

DRAE-1925: «tr. Hacer relacion de un hecho. ๆ 2.

Poner en relación personas o cosas. Ú.t.c.r.» (pág. 1042,1). 


\section{RETÓRICA}

\begin{tabular}{|c|c|}
\hline SIGLO XVIII & \\
\hline
\end{tabular}

Autoridades: «Veafe Rhetórica» (pág. 606,1).

[RHETóRICA] «l.f. El arte de hablar bien. Lat. Rethorica, ae. Paton Eloq. Cap. I. Ariftóteles de Rhetórica efcribió, mas no hallarán que en ella tratafle de las caufas [...]» (1737, pág. 618,1).

GRAE-1771:

DRAE-1780: «s.f. El arte de bien hablar. Rhetorica.

$[\ldots] »($ pág. 802,1).

DRAE-1783: «s.f. El arte de bien hablar. Rhetorica.

$[\ldots] »($ pág. 817,2).

DRAE-1791: «s.f. El arte de bien hablar. Rhetorica [...]» (pág. 730,3).

\section{$1^{\text {a }}$ mitad del XIX}

DRAE-1803: «s.f. El arte de bien hablar. Rhetorica.

[...]» (pág. 749,1).

DRAE-1817: «s.f. El arte de bien hablar. Rhetorica.

[...]» (pág. 761,1).

DRAE-1822: «s.f. El arte de bien hablar. Rhetorica.

[...] » (pág. 720,3).

DRAE-1832: «s.f. El arte de bien hablar y de ordenar rectamente un discurso. Rhetorica [...]» (pág. 655,1).

DRAE-1837:

DRAE-1843: «ORATORIA» (pág. 635,2) ${ }^{1}$.

$2^{\mathrm{a}}$ m. XIX - p. XX

DRAE-1852: «f. ORATORIA» (pág. 609,3)².

GRAE-1854:

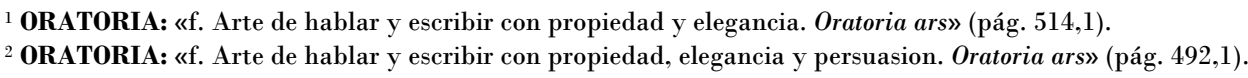

Anexo II: Glosario terminológico

Lema: Retórica 


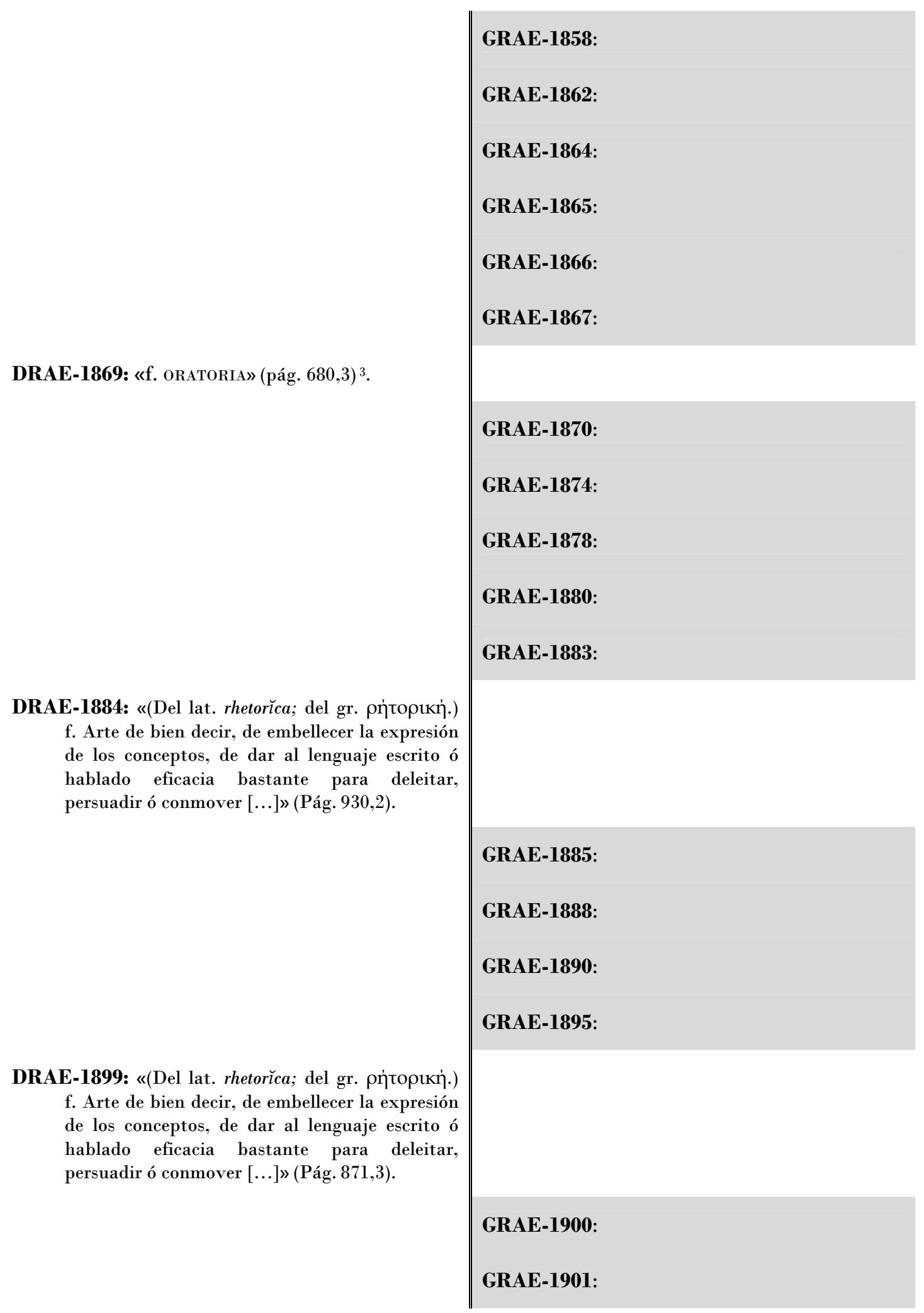

${ }^{3}$ ORATORIA: «f. Arte de hablar y escribir con propiedad, elegancia y persuasion. Oratoria ars» (pág. 554,3). 


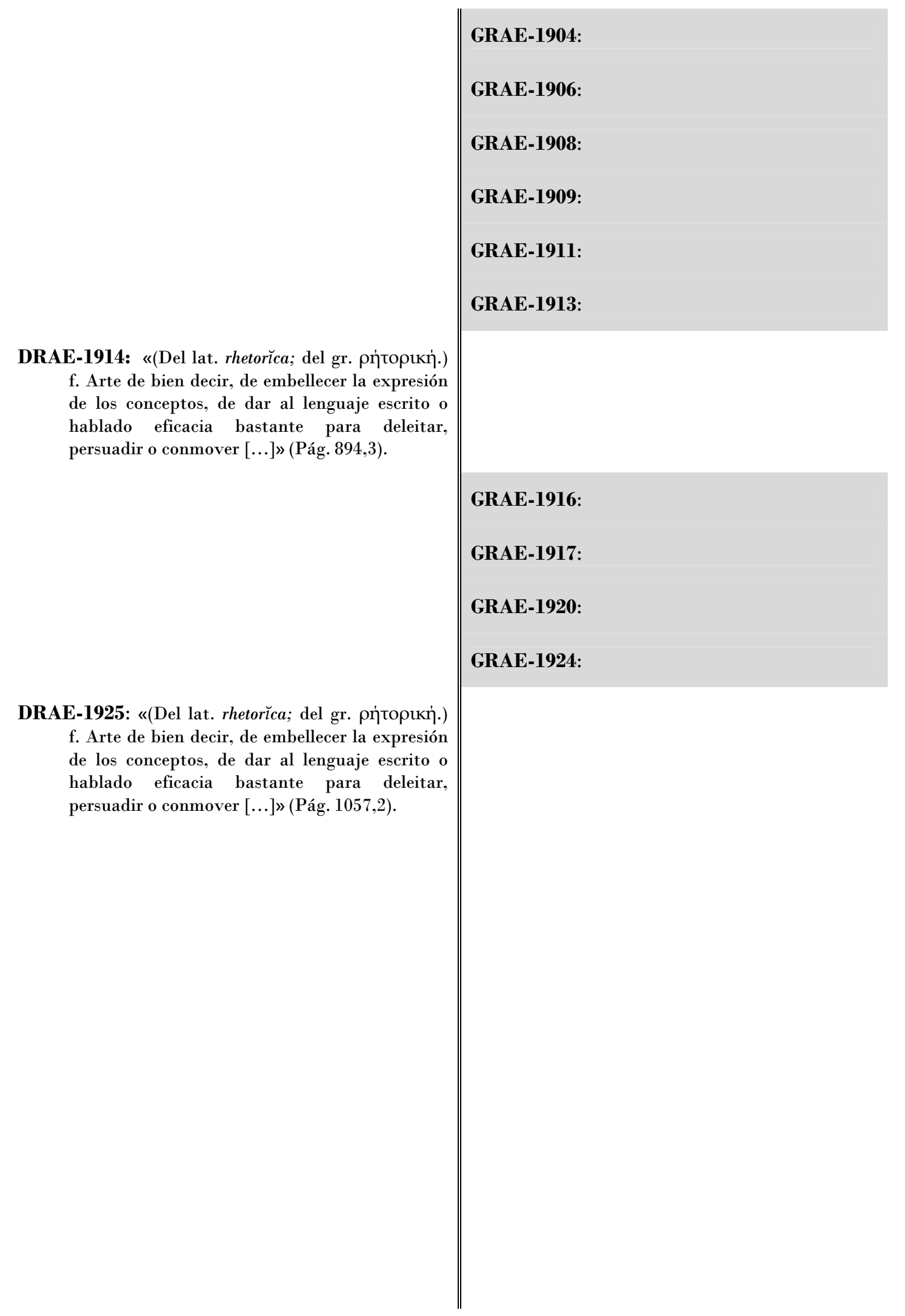




\section{SINTAXIS}

\section{SIGLO XVIII}

Autoridades: [Lema: SYNTAXIS. (Syntáxis)] «l.f. Modo de coordinar las oraciones, ò el tratado de Gramática, que enfeña los cafos, que pide cada verbo, y las oraciones Latinas. Es voz Griega. Lat. Constructio.

SYNTAXIS. Vale tambien la ordinación, que artificiolamente tienen las colas entre si. Lat.Syntaxis» (pág. 199,2).

DRAE-1780: [SINTAXîs] «s.f. Modo de coordinar las oraciones, ó el tratado de gramática, que enseña los casos que pide cada verbo, y las oraciones latinas. Constructio.

SINTAXîs La ordinacion que artificiosamente tienen las cosas entre sí. Syntaxis» (pág. 843,3).

DRAE-1783: [SINTÁXîs] «s.f. Modo de coordinar las oraciones, ó el tratado de gramática, que enseña los casos que pide cada verbo, y las oraciones latinas. Constructio.

SINTÁXÎS La ordinacion que artificiosamente tienen las cosas entre sí. Syntaxis» (pág. 858,3).

DRAE-1791: [SINTÁXîs] «s.f. Modo de coordinar las oraciones, ó el tratado de gramática, que enseña los casos que pide cada verbo, y las oraciones latinas. Constructio. 2. La ordinacion que artificiosamente tienen las cosas entre sí. Syntaxis» (pág. 768,2).
GRAE-1771: No tenemos definición propiamente dicha $($ Sintaxis $=$ Construcción $)$.

"[parte de la Gramática que trata] del órden y concierto que deben tener entre si [las palabras] para expresar con claridad los pensamientos» (págs. 1-2). «Esta union, trabazon ó enlace [de las partes de la oración], se llama entre los gramáticos sintáxîs, ó construccion, y sus reglas se reducen á declarar el órden con que deben juntarse las palabras para expresar con claridad los pensamientos« (pág. 232).
GRAE-1796: «[La Sintaxis enseña] el órden y dependencia de las palabras en las oraciones, con que explicamos nuestros pensamientos» (págs. 1-2).

«SINTÁXîs es el órden y dependencia que deben tener las palabras entre sí para formar la oracion» (pág. 273). 


\section{$1^{\text {a }}$ mitad del XIX}

DRAE-1803: [SINTÁXîs] «s.f. Modo de coordinar las oraciones, ó el tratado de gramática que enseña los casos que pide cada verbo, y las oraciones latinas. Constructio.

SINTÁXîs La ordinacion que artificiosamente tienen las cosas entre sí. Syntaxis» (pág. 796,3).

DRAE-1817: [SINTÁXIS] «Gram. s.f. Modo de coordinar las oraciones ó el tratado de gramática que enseña los casos que pide cada verbo y las oraciones latinas. Constructio.

SINTÁXIS La ordinacion que artificiosamente tienen las cosas entre sí. Syntaxis» (pág. 805,1).

DRAE-1822: [SINTÁxIS] «Gram. s.f. Modo de coordinar las oraciones, ó el tratado de gramática que enseña los casos que pide cada verbo y las oraciones latinas. Constructio.

SINTÁXIS La ordinacion que artificiosamente tienen las cosas entre sí. Syntaxis» (pág. 751,3 y $762,1)$.

DRAE-1832: «Gram. f. Coordinacion de las palabras en el discurso. Constructio» (pág. 691,1).

DRAE-1837: [SINTÁXIS] «Gram. f. Coordinacion de las palabras en el discurso. Constructio» (pág. $691,2)$.

DRAE-1843: [SINTÁXIS] «Gram. f. Coordinacion de las palabras en el discurso. Constructio» (pág. $669,3)$.

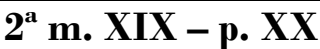

DRAE-1852: [SINTÁXIS] «f. Gram. Coordinacion de las palabras en el discurso. Constructio» (pág. $642,2)$.

GRAE-1854: «[La sintaxis enseña] el órden y dependencia de las palabras en las oraciones con que explicamos nuestros pensamientos» (pág. 1).

«Sintáxis es el órden y la dependencia que las palabras deben tener entre sí para formar la oracion. Este órden es de dos modos, regular y figurado. Regular se llama aquel en que se siguen estrictamente las reglas gramaticales; figurado es el que se observa para dar más vigor y elegancia á las oraciones, usando algunas licencias que se llaman figuras ó adornos de la oracion. [...]» (pág. 137). 
GRAE-1858: «[La sintaxis enseña] el órden y dependencia de las palabras en las oraciones con que explicamos nuestros pensamientos» (pág. 1).

«Sintáxis es el órden y la dependencia que las palabras deben tener entre sí para formar la oracion. Este órden es de dos modos, regular y figurado. Regular se llama aquel en que se siguen estrictamente las reglas gramaticales; figurado es el que se observa para dar más vigor y elegancia á las oraciones, usando algunas licencias que se llaman figuras ó adornos de la oracion. [...]» (pág. 147).

GRAE-1862: «[...] la sintaxis [enseña], el órden y dependencia de estas palabras en las oraciones con que explicamos nuestros pensamientos» (pág. 5).

«Sintáxis es el órden y la dependencia que las palabras deben tener entre sí para formar la oracion. Este órden es de dos modos, regular y figurado. Regular se llama aquel en que se siguen estrictamente las reglas gramaticales: figurado es el que se observa para dar más vigor y elegancia á las oraciones, usando algunas licencias que se llaman figuras ó adornos de la oracion. [...]» (pág. 151).

GRAE-1864: «[...] la sintáxis [enseña], el órden y dependencia de estas palabras en las oraciones con que explicamos nuestros pensamientos» (pág. 5).

«Sintáxis es el órden y la dependencia que las palabras deben tener entre sí para formar la oracion. Este órden es de dos modos, regular y figurado. Regular se llama aquel en que se siguen estrictamente las reglas gramaticales: figurado es el que se observa para dar más vigor y elegancia á las oraciones, usando algunas licencias que se llaman figuras ó adornos de la oracion.

[...]» (pág. 151).

GRAE-1865: «[...] la sintáxis [enseña], el órden y dependencia de estas palabras en las oraciones con que explicamos nuestros pensamientos» (pág. 5).

«Sintáxis es el órden y la dependencia que las palabras deben tener entre sí para formar la oracion. Este órden es de dos modos, regular y figurado. Regular se llama aquel en que se siguen estrictamente las reglas gramaticales: figurado es el que se observa para dar más vigor y elegancia á las oraciones, usando algunas licencias que se llaman figuras ó adornos de la oracion. [...]» (pág. 151). 
DRAE-1869: [SINTÁXIS] «f. Gram. Coordinacion de las palabras en el discurso» (pág. 715,3).
GRAE-1866: «[...] la sintáxis [enseña], el órden y dependencia de estas palabras en las oraciones con que explicamos nuestros pensamientos» (pág. 5).

«Sintáxis es el órden y la dependencia que las palabras deben tener entre sí para formar la oracion. Este órden es de dos modos, regular y figurado. Regular se llama aquel en que se siguen estrictamente las reglas gramaticales: figurado es el que se observa para dar más vigor y elegancia á las oraciones, usando algunas licencias que se llaman figuras ó adornos de la oracion. [...]» (pág. 151).

GRAE-1867: «[La sintaxis enseña] el órden y dependencia de las palabras en las oraciones con que explicamos nuestros pensamientos» (pág. 5).

«Sintáxis es el órden y la dependencia que las palabras deben tener entre sí para formar la oracion. Este órden es de dos modos, regular y figurado. Regular se llama aquel en que se siguen estrictamente las reglas gramaticales: figurado es el que se observa para dar más vigor y elegancia á las oraciones, usando algunas licencias que se llaman figuras ó adornos de la oracion. [...]» (pág. 150).

GRAE-1870: A la Sintaxis compete la explicación del papel que las palabras hacen en la oración. (Pág. 5).

«[La Sintaxis es] la acertada construccion de las oraciones gramaticales». «[Sin las nociones de Sintaxis] no sabríamos combinar y relacionar entre sí aquellos primordiales elementos del idioma [las palabras o partes de la oración], de forma que, prestándose mutuo auxilio, concurran á que seamos comprendidos cuando hablamos ó escribimos» (pág. 167).

«Dos maneras ú órdenes de Sintáxis reconocen los gramáticos, á saber: el regular y el figurado. Regular se llama aquel en que se siguen estrictamente las reglas gramaticales; figurado es el que se observa para dar más vigor y elegancia á las oraciones, usando algunas licencias, que se llaman figuras de construccion.

[...]» (pá. 167). 
GRAE-1874: Parte de la Gramática cuyo fin es el orden de las palabras en el discurso. (Pág. 16). «[La sintaxis es] la acertada construccion de las oraciones gramaticales». Sin las nociones de Sintaxis «no sabríamos combinar y relacionar entre sí aquellos primordiales elementos del idioma [las palabras o partes de la oración], de forma que, prestándose mutuo auxilio, concurran á que seamos comprendidos cuando hablamos ó escribimos» (pág. 195).

«Divídese [la Sintaxis] en regular y figurada: regular se llama aquélla en que se siguen estrictamente las reglas gramaticales; figurada es la que se observa para dar más vigor y elegancia á las oraciones, usando algunas licencias, que se dicen figuras de construccion.

[...]» (pág. 195).

GRAE-1878: Parte de la Gramática cuyo fin es el orden de las palabras en el discurso. (Pág. 16). «[La sintaxis es] la acertada construccion de las oraciones gramaticales». Sin las nociones de Sintaxis «no sabríamos combinar y relacionar entre sí aquellos primordiales elementos del idioma [las palabras o partes de la oración], de forma que, prestándose mutuo auxilio, concurran á que seamos comprendidos cuando hablamos ó escribimos» (pág. 195).

«Divídese [la Sintaxis] en regular y figurada: regular se llama aquélla en que se siguen estrictamente las reglas gramaticales; figurada es la que se observa para dar más vigor y elegancia á las oraciones, usando algunas licencias, que se dicen figuras de construccion.

[...]» (pág. 195).

GRAE-1880: Parte de la Gramática cuyo fin es el orden de las palabras en el discurso. (Introducción).

«La Sintaxis nos enseña á enlazar unos vocablos con otros, ó sea la acertada construcción de las oraciones gramaticales.

Divídese en regular y figurada: la regular, cuyo principal objeto es la claridad, pide que no haya falta ni sobra de palabras en la oración; que tengan todas su propia $y$ natural dependencia, y ocupen respectivamente el lugar que les corresponde: figurada es la que se observa para dar más vigor y elegancia á las oraciones.

[...]» (pág. 215). 
DRAE-1884: «(Del lat. syntāxis; del gr. $\sigma \dot{v} \tau \tau \alpha \xi \iota \varsigma$, de $\sigma u v \tau \dot{\alpha} \sigma \sigma \omega$, coordinar.) f. Gram. Parte de la gramática, que enseña á coordinar y unir las palabras para formar las oraciones y expresar conceptos. Divídese en regular y figurada. La primera pide que este enlace se haga del modo más lógico y sencillo. La segunda autoriza el uso de las figuras de construcción para dar á la expresión del pensamiento más vigor ó elegancia. La figurada no es, como pudiera creerse, hija de caprichoso artificio: empléase, por el contrario, instintivamente en el lenguaje hablado» (pág. 979,3).
GRAE-1883: Parte de la Gramática cuyo fin es el orden de las palabras en el discurso. (Introducción).

«La Sintaxis nos enseña á enlazar unos vocablos con otros, ó sea, la acertada construcción de las oraciones gramaticales.

Divídese en regular y figurada: la regular, cuyo principal objeto es la claridad, pide que no haya falta ni sobra de palabras en la oración; que tengan todas su propia $y$ natural dependencia, y ocupen respectivamente el lugar que les corresponde: figurada es la que se observa para dar más vigor y elegancia á las oraciones.

[...]» (pág. 215).

GRAE-1885: Parte de la Gramática cuyo fin es el orden de las palabras en el discurso (pág. 5).

«La Sintaxis nos enseña á enlazar unos vocablos con otros, ó sea la acertada construcción de las oraciones gramaticales.

Divídese en regular y figurada: la regular, cuyo principal objeto es la claridad, pide que no haya falta ni sobra de palabras en la oración; que tengan todas su propia $y$ natural dependencia, y ocupen respectivamente el lugar que les corresponde: figurada es la que se observa para dar más vigor y elegancia á las oraciones.

[…]» (pág. 217).

GRAE-1888: Parte de la Gramática cuyo fin es el orden de las palabras en el discurso. (Pág. VI).

«La Sintaxis nos enseña á enlazar unos vocablos con otros, ó sea la acertada construcción de las oraciones gramaticales.

Divídese en regular y figurada: la regular, cuyo principal objeto es la claridad, pide que no 
haya falta ni sobra de palabras en la oración; que tengan todas su propia $y$ natural dependencia, y ocupen respectivamente el lugar que les corresponde: figurada es la que se observa para dar más vigor y elegancia á las oraciones.

[...]» (pág. 215).

GRAE-1890: Parte de la Gramática cuyo fin es el orden de las palabras en el discurso. (Pág. VI).

«La Sintaxis nos enseña á enlazar unos vocablos con otros, ó sea la acertada construcción de las oraciones gramaticales.

Divídese en regular y figurada: la regular, cuyo principal objeto es la claridad, pide que no haya falta ni sobra de palabras en la oración; que tengan todas su propia $y$ natural dependencia, y ocupen respectivamente el lugar que les corresponde: figurada es la que se observa para dar más vigor y elegancia á las oraciones.

[...]» (pág. 215).

GRAE-1895: Parte de la Gramática cuyo fin es el orden de las palabras en el discurso. (Pág. VI).

«La Sintaxis nos enseña á enlazar unos vocablos con otros, ó sea la acertada construcción de las oraciones gramaticales.

Divídese en regular y figurada: la regular, cuyo principal objeto es la claridad, pide que no haya falta ni sobra de palabras en la oración; que tengan todas su propia $y$ natural dependencia, y ocupen respectivamente el lugar que les corresponde: figurada es la que se observa para dar más vigor y elegancia á las oraciones.

[...]» (pág. 215).

DRAE-1899: «(Del lat. syntaxis; del gr. $\sigma \dot{v} \tau \tau \alpha \xi \iota \varsigma$, de $\sigma \cup \nu \tau \dot{\alpha} \sigma \sigma \omega$, coordinar.) f. Gram. Parte de la gramática, que enseña á coordinar y unir las palabras para formar las oraciones y expresar conceptos. Divídese en regular y figurada. La primera pide que este enlace se haga del modo más lógico y sencillo. La segunda autoriza el uso de las figuras de construcción para dar á la expresión del pensamiento más vigor ó elegancia. La figurada no es, como pudiera creerse, hija de caprichoso artificio: empléase, por el contrario, instintivamente en el lenguaje hablado» (pág. 918,3).
[c. 
GRAE-1900: Parte de la Gramática cuyo fin es el orden de las palabras en el discurso. (Pág. VI).

«La Sintaxis nos enseña á enlazar unos vocablos con otros, ó sea la acertada construcción de las oraciones gramaticales.

Divídese en regular y figurada: la regular, cuyo principal objeto es la claridad, pide que no haya falta ni sobra de palabras en la oración; que tengan todas su propia y natural dependencia, y ocupen respectivamente el lugar que les corresponde: figurada es la que se observa para dar más vigor y elegancia á las oraciones.

[...]» (pág. 215).

GRAE-1901: Parte de la Gramática cuyo fin es el orden de las palabras en el discurso. (Pág. VI).

«La SiNTAXIS nos enseña á enlazar unos vocablos con otros, ó sea la acertada construcción de las oraciones gramaticales.

Divídese en regular y figurada: la regular, cuyo principal objeto es la claridad, pide que no haya falta ni sobra de palabras en la oración; que tengan todas su propia $y$ natural dependencia, y ocupen respectivamente el lugar que les corresponde: figurada es la que se observa para dar más vigor y elegancia á las oraciones.

[…]» (pág. 215).

GRAE-1904: Parte de la Gramática cuyo fin es el orden de las palabras en el discurso. (Pág. VI).

«La SinTaXis nos enseña á enlazar unos vocablos con otros, ó sea la acertada construcción de las oraciones gramaticales.

Divídese en regular y figurada: la regular, cuyo principal objeto es la claridad, pide que no haya falta ni sobra de palabras en la oración; que tengan todas su propia $y$ natural dependencia, y ocupen respectivamente el lugar que les corresponde: figurada es la que se observa para dar más vigor y elegancia á las oraciones.

[...]» (pág. 209).

GRAE-1906: Parte de la Gramática cuyo fin es el orden de las palabras en el discurso. (Pág. VI).

«La SINTAXIS nos enseña á enlazar unos vocablos con otros, ó sea la acertada construcción de las oraciones gramaticales.

Divídese en regular y figurada: la regular, cuyo 
principal objeto es la claridad, pide que no haya falta ni sobra de palabras en la oración; que tengan todas su propia $y$ natural dependencia, y ocupen respectivamente el lugar que les corresponde: figurada es la que se observa para dar más vigor y elegancia á las oraciones.

[...]» (pág. 209).

GRAE-1908: Parte de la Gramática cuyo fin es el orden de las palabras en el discurso. (Pág. VI).

«La SINTAXIS nos enseña á enlazar unos vocablos con otros, ó sea la acertada construcción de las oraciones gramaticales.

Divídese en regular y figurada: la regular, cuyo principal objeto es la claridad, pide que no haya falta ni sobra de palabras en la oración; que tengan todas su propia y natural dependencia, y ocupen respectivamente el lugar que les corresponde: figurada es la que se observa para dar más vigor y elegancia á las oraciones.

[...]» (pág. 209).

GRAE-1909: Parte de la Gramática cuyo fin es el orden de las palabras en el discurso. (Pág. VI).

«La SiNTAXIS nos enseña á enlazar unos vocablos con otros, ó sea la acertada construcción de las oraciones gramaticales.

Divídese en regular y figurada: la regular, cuyo principal objeto es la claridad, pide que no haya falta ni sobra de palabras en la oración; que tengan todas su propia $y$ natural dependencia, y ocupen respectivamente el lugar que les corresponde: figurada es la que se observa para dar más vigor y elegancia á las oraciones.

[...]» (pág. 209).

GRAE-1911: Parte de la Gramática cuyo fin es el orden de las palabras en el discurso. (Pág. 6).

«La Sintaxis nos enseña a enlazar unos vocablos con otros, o sea la acertada construcción de las oraciones gramaticales.

Divídese en regular y figurada: la regular, cuyo principal objeto es la claridad, pide que no haya falta ni sobra de palabras en la oración; que tengan todas su propia $y$ natural dependencia, y ocupen respectivamente el lugar que les corresponde: figurada es la que se observa para dar más vigor y elegancia a las oraciones.

[...]» (pág. 213). 
DRAE-1914: «(Del lat. syntaxis, y éste del gr. $\sigma \dot{v} v \tau \alpha \xi \iota \varsigma$, de $\sigma \cup \vee \tau \dot{\alpha} \sigma \sigma \omega$, coordinar.) f. Gram. Parte de la gramática, que enseña a coordinar y unir las palabras para formar las oraciones $y$ expresar conceptos. Divídese en regular y figurada. La primera pide que este enlace se haga del modo más lógico y sencillo. La segunda autoriza el uso de las figuras de construcción para dar a la expresión del pensamiento más vigor o elegancia. La figurada no es, como pudiera creerse, hija de caprichoso artificio: empléase, por el contrario, instintivamente en el lenguaje hablado» (pág. 943,2).
GRAE-1913: Parte de la Gramática cuyo fin es el orden de las palabras en el discurso (pág. 6).

«La SINTAXIS nos enseña a enlazar unos vocablos con otros, o sea la acertada construcción de las oraciones gramaticales.

Divídese en regular y figurada: la regular, cuyo principal objeto es la claridad, pide que no haya falta ni sobra de palabras en la oración; que tengan todas su propia y natural dependencia, y ocupen respectivamente el lugar que les corresponde: figurada es la que se observa para dar más vigor y elegancia a las oraciones.

[…]» (pág. 213).

GRAE-1916: Parte de la Gramática cuyo fin es el orden de las palabras en el discurso (pág. 6).

«Es la Sintaxis la parte de la Gramática que enseña a enlazar los vocablos unos con otros, o sea la acertada construcción de las oraciones gramaticales.

Divídese en regular y figurada: la regular, cuyo principal objeto es la claridad, pide que no haya falta ni sobra de palabras en la oración; que tengan todas su propia $\mathrm{y}$ natural dependencia, y ocupen respectivamente el lugar que les corresponde: figurada es la que se observa para dar más vigor y elegancia a las oraciones.

[...]» (pág. 213).

GRAE-1917: Parte de la Gramática cuyo fin es el orden de las palabras en el discurso (pág. VIII).

«La SINTAXIS nos enseña el modo como deben enlazarse unas palabras con otras para formar la oración gramatical, y también las oraciones entre sí para formar la oración compuesta o 
DRAE-1925: «(Del lat. syntaxis, y éste del gr. $\sigma \dot{v} \tau \tau \alpha \xi \iota \varsigma$, de $\sigma \cup v \tau \dot{\alpha} \sigma \sigma \omega$, coordinar.) f. Gram. Parte de la gramática, que enseña a coordinar y unir las palabras para formar las oraciones $y$ expresar conceptos. Divídese en regular y figurada. La primera pide que este enlace se haga del modo más lógico y sencillo. La segunda autoriza el uso de las figuras de construcción para dar a la expresión del pensamiento más vigor o elegancia. La figurada no es, como pudiera creerse, hija de caprichoso artificio: empléase, por el contrario, instintivamente en el lenguaje hablado» (pág. 1117,1).

período. El objeto de la sintaxis es, pues, el estudio de la oración gramatical, y según sea ésta simple o compuesta, se divide en Sintaxis de la oración simple y Sintaxis de la oración compuesta» (pág. 147).

GRAE-1920: Parte de la Gramática cuyo fin es el orden de las palabras en el discurso (pág. 8).

«La SINTAXIS nos enseña el modo como deben enlazarse unas palabras con otras para formar la oración gramatical, y también las oraciones entre sí para formar la oración compuesta o período. El objeto de la sintaxis es, pues, el estudio de la oración gramatical, y según sea ésta simple o compuesta, se divide en Sintaxis de la oración simple y Sintaxis de la oración compuesta» (pág. 167).

GRAE-1924: Parte de la Gramática cuyo fin es el orden de las palabras en el discurso (pág. 8).

«La SINTAXIS nos enseña el modo como deben enlazarse unas palabras con otras para formar la oración gramatical, y también las oraciones entre sí para formar la oración compuesta o período. El objeto de la sintaxis es, pues, el estudio de la oración gramatical, y según sea ésta simple o compuesta, se divide en Sintaxis de la oración simple y Sintaxis de la oración compuesta» (pág. 167). 


\section{SUBORIINACIÓN}

\section{SIGLO XVIII}

Autoridades: «f.f. Sujeción al orden, mando, ù dominio de otro. Lat. Subordinatio. Subjectio, onis. Alvar DE TOLED. Hift. de la Iglef.lib.2.cap.II. A la primera toca el conocer, y elegir, y á la fegunda el apetecer bienes fenfibles; pero con fubordinación à lo que ordena lu varon» (1739, pág. 169,2).

DRAE-1780: «s.f. Sujecion al órden, mando, ó dominio de otro. Subordinatio, subjectio» (pág. $855,1)$.

DRAE-1783: «s.f. Sujecion al órden, mando, ó dominio de otro. Subordinatio, subjectio» (pág. $869,3)$.

DRAE-1791: «s.f. Sujecion al órden, mando, ó dominio de otro. Subordinatio, subjectio» (pág. $778,3)$.

GRAE-1771: No se habla de ella.

GRAE-1796: No se habla de ella.

\section{$1^{\text {a }}$ mitad del XIX}

DRAE-1803: «s.f. Sujecion al órden, mando, ó dominio de otro. Subordinatio, subjectio» (pág. 809,3).

DRAE-1817: «s.f. Sujecion al órden, mando ó dominio de otro. Subordinatio, subjectio» (pág. $817,1)$.

DRAE-1822: «s.f. Sujecion á la órden, mando ó dominio de otro. Subordinatio, subjectio» (pág. $773,2)$.

DRAE-1832: «f. Sujecion á la órden, mando ó dominio de otro. Subordinatio, subjectio» (pág. $701,1)$.

DRAE-1837: «f. Sujecion á la órden, mando ó dominio de otro. Subjectio» (pág. 701,1).

DRAE-1843: «f. Sujecion á la órden, mando ó dominio de otro. Subjectio» (pág. 679,2). 


\section{$2^{\mathrm{a}}$ m. XIX - p. XX}

DRAE-1852: «f. Sujecion á la órden, mando ó dominio de otro. Subjectio» (pág. 651,2).
DRAE-1869: «f. Sujecion á la órden, mando ó dominio de otro» (pág. 725,2).
DRAE-1884: «(Del lat. subordinať̌o.) f. Sujeción á la orden, mando ó dominio de uno» (pág. 993,1).
DRAE-1899: «(Del lat. subordinať̌o.) f. Sujeción á la orden, mando ó dominio de uno» (pág. 931,1).
GRAE-1854: No se habla de ella.

GRAE-1858: No se habla de ella.

GRAE-1862: No se habla de ella.

GRAE-1864: No se habla de ella.

GRAE-1865: No se habla de ella.

GRAE-1866: No se habla de ella.

GRAE-1867: No se habla de ella.

GRAE-1870: No se habla de ella.

GRAE-1874: No se habla de ella.

GRAE-1878: No se habla de ella.

GRAE-1880: No se habla de ella.

GRAE-1883: No se habla de ella.

GRAE-1885: No se habla de ella.

GRAE-1888: No se habla de ella.

GRAE-1890: No se habla de ella.

GRAE-1895: No se habla de ella.

GRAE-1900: No se habla de ella.

GRAE-1901: No se habla de ella. 
GRAE-1904: No se habla de ella.

GRAE-1906: No se habla de ella.

GRAE-1908: No se habla de ella.

GRAE-1909: No se habla de ella.

GRAE-1911: No se habla de ella.

GRAE-1913: No se habla de ella.

DRAE-1914: «(Del lat. subordinatĭo, -ōnis.) f. Sujeción a la orden, mando o dominio de uno» (pág. 956,1).

GRAE-1916: No se habla de ella.

GRAE-1917: No se da una definición estricta del concepto de subordinación; por tal se entiende un tipo especial de unión de oraciones dentro del período que hace que éstas se relacionen de un modo más estrecho que en la coordinación, de modo que una se ofrece como complemento de la otra, a la cual se subordina no sólo en la manera de concebirla el entendimiento, sino también en el modo de expresión (pág. 291).

«Las oraciones subordinadas desempeñan en la oración compuesta el mismo oficio que los complementos del nombre o del verbo en la oración simple, y pueden ser adjetivas, substantivas $\mathrm{y}$ adverbiales» (pág. 314).

GRAE-1920: Como en 1917, no se da una definición estricta del concepto de subordinación; por tal se entiende un tipo especial de unión de oraciones dentro del período que hace que éstas se relacionen de un modo más estrecho que en la coordinación, de modo que un se ofrece como complemento de la otra, a la cual se subordina no sólo en la manera de concebirla el entendimiento, sino también en el modo de expresión (págs. 311-312).

«Las oraciones subordinadas desempeñan en la oración compuesta el mismo oficio que los complementos del nombre o del verbo en la oración simple, y pueden ser adjetivas, substantivas y adverbiales» (págs. 334). 
GRAE-1924: Como en las dos ediciones anteriores, no se da una definición estricta del concepto de subordinación; por tal se entiende un tipo especial de unión de oraciones dentro del período que hace que éstas se relacionen de un modo más estrecho que en la coordinación, de modo que un se ofrece como complemento de la otra, a la cual se subordina no sólo en la manera de concebirla el entendimiento, sino también en el modo de expresión (pág. 311-312).

«Las oraciones subordinadas desempeñan en la oración compuesta el mismo oficio que los complementos del nombre o del verbo en la oración simple, y pueden ser adjetivas, substantivas $\mathrm{y}$ adverbiales» (pág. 334).

DRAE-1925: «(Del lat. subordinať̌o, -ōnis.) f. Sujeción a la orden, mando o dominio de uno» (pág. 1132,2). 


\section{SUIORIDINAR}

\section{SIGLO XVIII}

Autoridades: «v.a. Sujetar, y poner à otro à fu orden, difposicion, ò mandato. Lat. Submittere. Subjicere $[\ldots]$

Subordinar. Se ufa tambien hablando de aquellas cofas, que eftán fujetas, y fon inferiores en orden à otras en cualquier efpecie, de las quales fe dice que fon, o eftan fubordinadas, y de las fuperiores que las fubordinan. Lat. Subordinare» (1739, pág. 169,2).

\section{GRAE-1771:}

DRAE-1780: «v.a. Sujetar y poner á otro á su órden, disposicion, ó mandato. Submittere, subjicere.

Subordinar. Se usa hablando de aquellas cosas que estan sujetas, y son inferiores en órden á otras en qualquier especie, de las quales se dice que son, ó estan subordinadas, y de las superiores que las SUBORDINAN. Subordinare» (pág. 855,1).

DRAE-1783: «v.a. Sujetar y poner á otro á su órden, disposicion, ó mandato. Submittere, subjicere.

Subordinar. Se usa hablando de aquellas cosas que están sujetas, y son inferiores en órden á otras en qualquiera especie, de las quales se dice que son, ó están subordinadas, y de las superiores que las SUBORDINAN. Subordinare» (pág. 869,3).

DRAE-1791: «v.a. Sujetar y poner á otro á su órden, disposicion, ó mandato. Submittere, subjicere. 2. Se usa hablando de aquellas cosas que están sujetas, y son inferiores en órden á otras en qualquiera especie, de las quales se dice que son, ó están subordinadas, y de las superiores que las SUBORDINAN. Subordinare» (pág. 778,3).

\section{$1^{\text {a }}$ mitad del XIX}

DRAE-1803: «v.a. Sujetar y poner á otro á su órden, disposicion, ó mandato. Submittere, subjicere.

Subordinar. Se usa hablando de aquellas cosas que están sujetas, y son inferiores en órden á otras en qualquiera especie, de las quales se dice que son, ó están subordinadas, y de las superiores que las SUbordinan. Subordinare» (pág. 809,3). 
DRAE-1817: «v.a. Sujetar y poner á otro á su órden, disposicion, ó mandato. Submittere, subjicere.

Subordinar. Se usa hablando de aquellas cosas que estan sujetas, y son inferiores en órden á otras en cualquiera especie, de las cuales se dice que son ó estan subordinadas, y de las superiores que las SUBORDINAN. Subordinare» (pág. 817,1).

DRAE-1822: «v.a. Sujetar, poner á otro á su órden, disposicion ó mandato. Submittere, subjicere.

Subordinar. Poner ó clasificar algunas cosas inferiores en orden respecto de otras. Subordinare» (pág. 773,2).

DRAE-1832: «a. Sujetar, poner á otro á su órden, disposicion ó mandato. Submittere, subjicere. ๆ Poner ó clasificar algunas cosas inferiores en órden respecto de otras. Subordinare» (pág. $701,1)$.

DRAE-1837: «a. Sujetar, poner á otro á su órden, disposicion ó mandato. Submittere, subjicere. ๆ Poner ó clasificar algunas cosas inferiores en órden respecto de otras. Alia aliis postponere» (pág. 701,1).

DRAE-1843: «a. Sujetar las personas ó cosas á la dependencia de otras. Submittere, subjicere. Poner ó clasificar algunas cosas inferiores en órden respecto de otras. Alia aliis postponere» (pág. 679,2).

\section{$2^{a}$ m. XIX - p. XX}

DRAE-1852: «a. Sujetar las personas ó cosas á la dependencia de otras. Submittere, subjicere. ๆ Clasificar algunas cosas inferiores en órden respecto de otras. Se usa tambien como recíproco. Alia aliis postponere» (pág. 651,2).

GRAE-1854:

GRAE-1858:

GRAE-1862:

GRAE-1864:

GRAE-1865: 
DRAE-1869: «a. Sujetar las personas ó cosas á la dependencia de otras. I Clasificar algunas cosas inferiores en órden respecto de otras. Se usa tambien como recíproco» (pág. 725,2).

GRAE-1866:

GRAE-1867:

GRAE-1870:

GRAE-1874:

GRAE-1878:

GRAE-1880:

GRAE-1883:

DRAE-1884: «(Del lat. sub, bajo, y ordināre, ordenar.) a. Sujetar personas ó cosas á la dependencia de otras. Ú.t.c.r. $\uparrow$ Clasificar algunas cosas inferiores en orden respecto de otras. Ú.t.c.r.» (pág. 993,1-2).

DRAE-1899: «(Del lat. sub, bajo, y ordināre, ordenar.) a. Sujetar personas ó cosas á la dependencia de otras. Ú.t.c.r. đI Clasificar algunas cosas inferiores en orden respecto de otras. Ú.t.c.r.» (pág. 931,1).
GRAE-1885:

GRAE-1888:

GRAE-1890:

GRAE-1895:

GRAE-1900:

GRAE-1901:

GRAE-1904:

GRAE-1906: 
GRAE-1908:

GRAE-1909:

GRAE-1911:

GRAE-1913:

DRAE-1914: «(Del lat. sub, bajo, y ordināre, ordenar.) a. Sujetar personas o cosas a la dependencia de otras. Ú.t.c.r. If ${ }^{2}$ Clasificar algunas cosas inferiores en orden respecto de otras. Ú.t.c.r.» (pág. 956,1).

\section{GRAE-1916:}

GRAE-1917:

GRAE-1920:

GRAE-1924:

DRAE-1925: «(Del lat. sub, bajo, y ordināre, ordenar.) tr. Sujetar personas o cosas a la dependencia de otras. Ú.t.c.r. If 2. Clasificar algunas cosas inferiores en orden respecto de otras. Ú.t.c.r.» (pág. 1132,2). 


\section{SUJETD}

\section{SIGLO XVIII}

Autoridades: [Lema Sugeto] «[.m. [...]

SugETO. En la Lógica es aquello de quien fe enuncia, y predica alguna cofa. Lat. subjectum» (1739, págs. 180,2 y 181,1).

[Lema Sujeto] «fegundo part. del verbo Sujetar, y mas conforme à fu origen. Antiguamente fe decia fubjecto. GraC. Juft. f. I. No era fubjecto à ningunas leyes $[\ldots]$

SUJETO. Vale tambien lo mifmo que expuefto, ò con capacidad para alguna cola. Lat. Obnoxius,a,um. FIGUER. Plaz. Difc.6. Manifiefta las particulas de los milmos miembros fujetos à diverfas enfermedades $[\ldots]$ » $(1739,181,2)$.

DRAE-1780: [Lema: Sugeto] «s.m. [...]

Sugeto. Lóg. Aquello de quien se enuncia y predica alguna cosa. Subjectum» (pág. 857,3).

[Lema Sujeto] «p.p. seg. de SUJETAR.

SUJETo. Lo mismo que expuesto, ó con capacidad. Obnoxius» (pág. 857,3).

DRAE-1783: [Lema: Sugeto] «s.m. [...]

Sugeto. Lóg. Aquello de quien se enuncia y predica alguna cosa. Subjectum» (pág. 872,2).

[Lema Sujeto] «p.p. seg. de SUJETAR.

SUJETO. Lo mismo que expuesto, ó con capacidad. Obnoxius» (pág. 872,2).

DRAE-1791: [Lema: Sugeto] «s.m. [...] 7. Lóg. Aquello de quien se enuncia y predica alguna cosa. Subjectum» (págs. 780,3 y 781,1).

[Lema Sujeto] «p.p. seg. de SUJETAR. 2. adj. Lo mismo que expuesto, ó con capacidad. Obnoxius» (pág. 781,1).
GRAE-1771: No se habla de él.

GRAE-1796: No se habla de él. 
DRAE-1803: [Lema: Sugeto] «s.m. [...]

SugETo. Lóg. Aquello de quien se enuncia y predica alguna cosa. Subjectum» (pág. 812,2).

[Lema Sujeto] «p.p. irreg. de SUJETAR.

SUGETO [sic]. adj. Expuesto ó propenso á alguna cosa.

SUJETO. Aquello de que se está tratando actualmente. Id de quo agitur» (pág. 812,2).

DRAE-1817: [Lema: Sugeto] «s.m. [...]

SugeTo. Lóg. Aquello de quien se enuncia y predica alguna cosa. Subjectum» (pág. 819,3).

[Lema Sujeto] «p.p. irreg. de SUJETAR.

SUJETO. adj. Expuesto ó propenso á alguna cosa.

SUJETO. Aquello de que se está tratando actualmente. Id de quo agitur» (pág. 819,3).

DRAE-1822: [Lema: Sugeto] «s.m. [...]

Sugeto. Lóg. Aquello de quien se enuncia y predica alguna cosa. Subjectum» (págs. 775,3 y $776,1)$.

[Lema Sujeto] «seg. p.p. irreg. de SUJETAR.

SUJETO. adj. Expuesto ó propenso á alguna cosa.

SUJETO. Aquello de que se está tratando actualmente. Id de quo agitur» (pág. 776,1).

DRAE-1832: [Lema: Sugeto] «m. [...]» (pág. 703,1).

[Lema Sujeto,ta] «seg. p.p. irreg. de SUJETAR. ๆ adj. Expuesto ó propenso á alguna cosa.

Proclivis. ๆ La materia, asunto ó tema de lo que se habla ó escribe. Argumentum, materia. $\uparrow$ Disposicion ó Ánimo. $\|$ Fil. Aquello en que se recibe y conserva alguna cosa. Subjectum. $\uparrow$ Lóg. Aquello de quien se enuncia ó predica alguna cosa. Subjectum» (pág. 703,1).

DRAE-1837: [Lema: Sugeto] «m. [...]» (pág. 703,12).

[Lema Sujeto,ta] «seg. p.p. irreg. de SUJETAR. ๆ adj. Expuesto ó propenso á alguna cosa. Proclivis. $\uparrow$ La materia, asunto ó tema de lo que se habla ó escribe. Argumentum, materia. ๆ Disposicion ó Ánimo. đ| Fil. Aquello en que se recibe y conserva alguna cosa. Subjectum. $\mid$ Lóg. Aquello de quien se enuncia ó predica alguna cosa. Subjectum» (pág. 703,2). 
DRAE-1843: [Lema: Sugeto] «m. [...]» (pág. 681,1).

[Lema Sujeto,ta] «seg. p.p. irreg. de SUJETAR. adj. Expuesto ó propenso á alguna cosa.

Proclivis. @ La materia, asunto ó tema de lo que se habla ó escribe. Argumentum, materia. ㅁ

Lóg. Aquello de quien se enuncia ó predica alguna cosa. Subjectum» (pág. 681,2).

\section{$2^{\mathrm{a}}$ m. XIX - p. XX}

DRAE-1852: «p.p. irreg. de suJEtar. ๆ adj. Expuesto ó propenso á alguna cosa. Proclivis. đ La materia, asunto ó tema de lo que se habla ó escribe. Argumentum, materia. 9 Lóg. Aquello de quien se enuncia ó predica alguna cosa. Subjectum [...]» (pág. 653,2).

GRAE-1854: No se habla de él.

GRAE-1858: No se habla de él.

GRAE-1862: No se habla de él.

GRAE-1864: No se habla de él.

GRAE-1865: No se habla de él.

GRAE-1866: No se habla de él.

GRAE-1867: No se habla de él.

DRAE-1869: «p.p. irreg. de SuJETAR. ๆ adj. Expuesto ó propenso á alguna cosa. đI La materia, asunto ó tema de lo que se habla ó escribe. ๆ Lóg. Aquello de quien o de que se enuncia alguna cosa. ๆ Gram. El nominativo ó agente de la oracion [...]» (pág. 727,3).

GRAE-1870: «Sujeto de la oracion es la palabra, ó conjunto de ellas, que da accion ó aplicacion al verbo» (pág. 206).

«Hay, pues, en las oraciones sujetos simples, que constan sólo de un nombre, ó de artículo y nombre, ó de un nombre y un apellido, etc., y hay sujetos compuestos, que van acompañados de adjuntos calificativos» (pág. 212).

GRAE-1874: «Sujeto de la oracion es la palabra, ó conjunto de ellas, que pone en accion al verbo» (pág. 234). 
«Hay, pues, en las oraciones sujetos simples, que constan sólo de un nombre, ó de artículo y nombre, ó de un nombre y un apellido, etc., y hay sujetos compuestos, que van acompañados de calificativos adjuntos» (pág. 239).

GRAE-1878: «Sujeto de la oracion es la palabra, ó conjunto de ellas, que pone en accion al verbo» (pág. 234).

«Hay, pues, en las oraciones sujetos simples, que constan sólo de un nombre, ó de artículo y nombre, ó de un nombre y un apellido, etc., y hay sujetos compuestos, que van acompañados de calificativos adjuntos» (pág. 239).

GRAE-1880: «Sujeto de la oración es la palabra, ó conjunto de ellas, que pone en acción al verbo» (pág. 245).

«Hay, pues, en las oraciones sujetos simples, que constan sólo de un nombre, ó de artículo y nombre, ó de un nombre y un apellido, etc., y hay sujetos compuestos, que van acompañados de calificativos adjuntos» (pág. 250).

GRAE-1883: «Sujeto de la oración es la palabra, ó conjunto de ellas, que pone en acción al verbo» (pág. 245).

«Hay, pues, en las oraciones sujetos simples, que constan sólo de un nombre, ó de un artículo y nombre, ó de un nombre y un apellido, etc., y hay sujetos compuestos, que van acompañados de calificativos adjuntos» (pág. 250).

DRAE-1884: «(Del lat. subiēctus.) p.p. irreg. de Sujetar. ๆ adj. Expuesto ó propenso á una cosa. 9 m. Asunto ó materia sobre que se habla ó escribe [...] ๆ Gram. El nominativo ó agente de la oración $\llbracket$ Lóg. Aquello de que se enuncia una cosa» (pág. 996,2).
GRAE-1885: «Sujeto de la oración es la palabra, ó conjunto de ellas, que pone en acción al verbo» (pág. 247).

«Hay, pues, en las oraciones sujetos simples, que constan sólo de un nombre, ó de un artículo y nombre, ó de un nombre y un apellido, etc., y hay sujetos compuestos, que van acompañados de calificativos adjuntos» (pág. 252) 
DRAE-1899: «(Del lat. subiectus.) p.p. irreg. de Sujetar. đI adj. Expuesto ó propenso á una cosa. ๆ m. Asunto ó materia sobre que se habla ó escribe [...] đ Gram. Palabra, ó conjunto de palabras, que expresa la idea de la cual el verbo afirma algo. ๆ Lóg. Ser del cual se predica ó enuncia alguna cosa» (pág. $934,1)$.

GRAE-1888: «Sujeto de la oración es la palabra, ó conjunto de ellas, que pone en acción al verbo» (pág. 245).

«Hay, pues, en las oraciones sujetos simples, que constan sólo de un nombre, ó de un artículo y nombre, ó de un nombre y un apellido, etc., y hay sujetos compuestos, que van acompañados de calificativos adjuntos» (pág. 250)

GRAE-1890: «Sujeto de la oración es la palabra, ó conjunto de ellas, que pone en acción al verbo» (pág. 245).

«Hay, pues, en las oraciones sujetos simples, que constan sólo de un nombre, ó de un artículo y nombre, ó de un nombre y un apellido, etc.; y hay sujetos compuestos, que van acompañados de calificativos adjuntos» (pág. 250)

GRAE-1895: «Sujeto de la oración es la palabra, ó conjunto de ellas, que pone en acción al verbo» (pág. 245).

«Hay, pues, en las oraciones sujetos simples, que constan sólo de un nombre, ó de un artículo y nombre, ó de un nombre y un apellido, etc., y hay sujetos compuestos, que van acompañados de calificativos adjuntos» (pág. 250).

GRAE-1900: «Sujeto de la oración es la palabra, ó conjunto de ellas, que pone en acción al verbo» (pág. 245).

«Hay, pues, en las oraciones sujetos simples, que constan sólo de un nombre, ó de un artículo y nombre, ó de un nombre y un apellido, etc., y hay sujetos compuestos, que van acompañados de calificativos adjuntos» (pág. 250).

GRAE-1901: «Sujeto de la oración es la palabra, ó conjunto de ellas, que pone en acción al verbo» (pág. 245).

«Hay, pues, en las oraciones sujetos simples, que constan sólo de un nombre, ó de un artículo y nombre, ó de un nombre y un apellido, etc., y hay sujetos compuestos, que van acompañados de calificativos adjuntos» (pág. 250). 
GRAE-1904: «Sujeto de la oración es la palabra, ó conjunto de ellas, que pone en acción al verbo» (pág. 239).

«Hay, pues, en las oraciones sujetos simples, que constan sólo de un nombre, ó de un artículo y nombre, ó de un nombre y un apellido, etc.; y hay sujetos compuestos, que van acompañados de calificativos adjuntos» (pág. 244).

GRAE-1906: «Sujeto de la oración es la palabra, ó conjunto de ellas, que pone en acción al verbo» (pág. 239).

«Hay, pues, en las oraciones sujetos simples, que constan sólo de un nombre, ó de un artículo y nombre, ó de un nombre y un apellido, etc.; y hay sujetos compuestos, que van acompañados de calificativos adjuntos» (pág. 244).

GRAE-1908: «Sujeto de la oración es la palabra, ó conjunto de ellas, que pone en acción al verbo» (pág. 239).

«Hay, pues, en las oraciones sujetos simples, que constan sólo de un nombre, ó de un artículo y nombre, ó de un nombre y un apellido, etc.; y hay sujetos compuestos, que van acompañados de calificativos adjuntos» (pág. 244).

GRAE-1909: «Sujeto de la oración es la palabra, ó conjunto de ellas, que pone en acción al verbo» (pág. 239).

«Hay, pues, en las oraciones sujetos simples que constan sólo de un nombre, ó de un artículo y nombre, ó de un nombre y un apellido, etc.; $\mathrm{y}$ hay sujetos compuestos qe van acompañados de calificativos adjuntos» (pág. 244).

GRAE-1911: «Sujeto de la oración es la palabra, o conjunto de ellas, que realiza la acción o en que se cumple la atribución expresada por el verbo» (pág. 245).

«Hay, pues, en las oraciones sujetos simples que constan sólo de un nombre, o de un artículo y nombre, o de un nombre y un apellido, etc.; y hay sujetos compuestos que van acompañados de calificativos adjuntos» (págs. 250-251). 
DRAE-1914: «(Del lat. subiectus.) p.p. irreg. de Sujetar. $\Upsilon^{2}$ adj. Expuesto o propenso a una cosa. I ${ }^{3} \mathrm{~m}$. Asunto o materia sobre que se habla o escribe $[\ldots]$ | ${ }^{6}$ Gram. Palabra, o conjunto de palabras, que expresa la idea de la cual el verbo afirma algo. If ${ }^{7}$ Lóg. Ser del cual se predica o enuncia alguna cosa» (pág. 959,2). conjunto de ellas, que realiza la acción o en que se cumple la atribución expresada por el verbo» (pág. 245).

«Hay, pues, en las oraciones sujetos simples que constan sólo de un nombre, o de un artículo y nombre, o de un nombre y un apellido, etc.; y hay sujetos compuestos que van acompañados de calificativos adjuntos» (págs. 250-251).

GRAE-1916: «Sujeto de la oración es la palabra, o conjunto de ellas, que realiza la acción o en que se cumple la atribución expresada por el verbo» (pág. 245).

«Hay, pues, en las oraciones sujetos simples que constan sólo de un nombre, o de un artículo y nombre, o de un nombre y un apellido, etc.; y hay sujetos compuestos que van acompañados de calificativos adjuntos» (pág. 250-251).

GRAE-1917: «Las partes esenciales de la oración gramatical son dos: el vocablo con que se designa el ser (persona, animal o cosa) de que se afirma algo, y que en el lenguaje gramatical se llama sujeto, y el que expresa la cosa afirmada, que se llama predicado $[. .$.

De la definición que hemos dado de los elementos esenciales de la oración se infiere que el sujeto de ésta ha de ser siempre un nombre substantivo u otra palabra que en la oración haga sus veces, y a la cual se refiera la atribución expresada por el predicado [...]» (pág. 150).

GRAE-1920: «Las partes esenciales de la oración gramatical son dos: el vocablo con que se designa el ser (persona, animal o cosa) de que se afirma algo, y que en el lenguaje gramatical se llama sujeto, y el que expresa la cosa afirmada, que se llama predicado $[. .$.

De la definición que hemos dado de los elementos esenciales de la oración, se infiere que el sujeto de ésta ha de ser siempre un nombre substantivo u otra palabra que en la oración haga sus veces, y a la cual se refiera la atribución expresada por el predicado [...]» (pág. 170). 
GRAE-1924: «Las partes esenciales de la oración gramatical son dos: el vocablo con que se designa el ser (persona, animal o cosa) de que se afirma algo, y que en el lenguaje gramatical se llama sujeto, y el que expresa la cosa afirmada, que se llama predicado $[. .$.

De la definición que hemos dado de los elementos esenciales de la oración, se infiere que el sujeto de ésta ha de ser siempre un nombre substantivo u otra palabra que en la oración haga sus veces, y a la cual se refiera la atribución expresada por el predicado [...]» (pág. 170).

DRAE-1925: «(Del lat. subiectus.) p.p. irreg. de Sujetar. ๆ 2. adj. Expuesto o propenso a una cosa. I 3. m. Asunto o materia sobre que se habla o escribe $[\ldots]$ ๆ 6 Gram. Substantivo, ora espreso, ora tácito, o palabras que hagan sus veces, para indicar aquello de lo cual el verbo afirma algo. ๆ 7. Lóg. Ser del cual se predica o enuncia alguna cosa» (pág. 1136,3). 


\section{UNIR}

\section{SIGLO XVIII}

Autoridades: «v.a. Juntar dos, ò mas colas entre si, haciendo de ellas un todo, ò un compuefto. Es del Latino Unire.

UNIR. Vale tambien mezclar, ò trabar algunas cofas entre si incorporandolas. Lat. Commifcere.

UNIR. Vale afsimifmo atar, ò juntar una cofa con otra, phyfica, ò moralmente. Lat. Conjungere. Copulare [...] Gong. Polyph. Oct. 9.

Cera, y cáñamo unió, que no debiera

$[\ldots]$

UNIR. Vale tambien acercar una cola à otra, apretandola, ò eftrechandola. Lat. Conjungere. SolIS. Hift. de Nuev. Efp. lib. I. cap. 19. Unieron $\int e$ todos para hacer el último effuerzo.

[...]» (1739, pág. 391,1).

DRAE-1780: «v.a. Juntar dos, ó mas cosas entre sí, haciendo de ellas un todo, ó un compuesto. Unire.

UNIR. Mezclar, ó trabar algunas cosas entre sí incorporándolas. Commiscere.

UNIR. Atar, ó juntar una cosa con otra física, ó moralmente. Conjungere, copulare.

UNIR. Acercar una cosa á otra, apretándola, ó estrechándola. Conjungere.

[...]» (pág. 908,1).

DRAE-1783: «v.a. Juntar dos, ó mas cosas entre sí, haciendo de ellas un todo, ó un compuesto. Unire.

UNIR. Mezclar, ó trabar algunas cosas entre sí incorporándolas. Commiscere.

UNIR. Atar, ó juntar una cosa con otra física, ó moralmente. Conjungere, copulare.

UNIR. Acercar una cosa á otra, apretándola, ó estrechándola. Conjungere.

[...]» (pág. 922,3).

DRAE-1791: «v.a. Juntar dos, ó mas cosas entre sí, haciendo de ellas un todo, ó compuesto. Unire. 2. Mezclar, ó trabar algunas cosas entre sí 
incorporándolas. Commiscere. 3. Atar, ó juntar una cosa con otra física, ó moralmente. Conjungere, copulare. 4. Acercar una cosa á otra, apretándola, ó estrechándola. Conjungere $[\ldots] »$ (pág. 826,3).

\section{GRAE-1796:}

\section{$1^{\text {a }}$ mitad del XIX}

DRAE-1803: «v.a. Juntar dos ó mas cosas entre sí, haciendo de ellas un todo ó compuesto. Unire.

UNIR. Mezclar ó trabar algunas cosas entre sí incorporándolas. Commiscere.

UNIR. Atar, ó juntar una cosa con otra física ó moralmente. Conjungere, copulare.

UNIR. Acercar una cosa á otra, apretándola ó estrechándola. Conjungere.

[...]» (pág. 867,1).

DRAE-1817: «v.a. Juntar dos ó mas cosas entre sí, haciendo de ellas un todo ó compuesto. Unire, adunare.

UNIR. Mezclar ó trabar algunas cosas entre sí incorporándolas. Commiscere.

UNIR. Atar ó juntar una cosa con otra física ó moralmente. Conjungere, copulare.

UNIR. Acercar una cosa á otra, apretándola ó estrechándola. Conjungere.

[...]» (pág. 871,1).

DRAE-1822: «v.a. Juntar dos ó mas cosas entre sí, haciendo de ellas un todo ó compuesto. Unire, adunare.

UNIR. Mezclar ó trabar algunas cosas entre sí incorporándolas. Commiscere.

UNIR. Atar ó juntar una cosa con otra física ó moralmente. Conjungere, copulare.

UNIR. Acercar una cosa á otra, apretándola ó estrechándola. Conjungere.

[...]» (pág. 825,3).

DRAE-1832: «a. Juntar dos ó mas cosas entre [sí], haciendo de ellas un todo ó compuesto. $[U]$ nire, adunare. I Mezclar ó trabar algu[nas] cosas entre sí incorporándolas. Commisc[ere]. \| Atar ó juntar una cosa con otra físic[a ó] moralmente. Conjungere, copulare. If Ac[er]car una cosa á otra, apretándola ó est[re]chándola. Conjungere [...]» (pág. 749,1). 
DRAE-1837: «a. Juntar dos ó mas cosas entre sí, haciendo de ellas un todo ó compuesto. Unire, adunare. ๆ Mezclar ó trabar algunas cosas entre sí incorporándolas. Commiscere. I Atar ó juntar una cosa con otra física ó moralmente. Conjungere, copulare. đI Acercar una cosa á otra, apretándola ó est[re]chándola. Conjungere [...]» (pág. 749,2).

DRAE-1843: «a. Juntar dos ó mas cosas entre sí, haciendo de ellas un todo ó compuesto. Unire, adunare. Q Mezclar ó trabar algunas cosas entre sí incorporándolas. Commiscere. Q Q Atar ó juntar una cosa con otra física ó moralmente. Conjungere, copulare. ㅇ Acercar una cosa á otra, apretándola ó estrechándola. Conjungere [...]» (pág. 725,2).

\section{$2^{\mathrm{a}}$ m. XIX - p. XX}

DRAE-1852: «a. Juntar dos ó mas cosas entre sí, haciendo de ellas un todo ó compuesto. Unire, adunare. \Mezclar ó trabar algunas cosas entre sí incorporándolas. Commiscere. I Atar ó juntar una cosa con otra física ó moralmente. Conjungere, copulare. $\mid$ Acercar una cosa á otra, apretándola ó estrechándola. Conjungere [...]» (pág. 696,1).

GRAE-1854:

GRAE-1858:

GRAE-1862:

GRAE-1864:

GRAE-1865:

GRAE-1866:

GRAE-1867:

DRAE-1869: «a. Juntar dos ó más cosas entre sí, haciendo de ellas un todo ó compuesto. q Mezclar ó trabar algunas cosas entre sí, incorporándolas. đI Atar ó juntar una cosa con otra, física ó moralmente. đ Acercar una cosa á otra, apretándola ó estrechándola. [...]» (pág. $774,1)$. 
GRAE-1874:

GRAE-1878:

GRAE-1880:

GRAE-1883:

GRAE-1885:

GRAE-1888:

GRAE-1890:

GRAE-1895:

GRAE-1900:

GRAE-1901:

GRAE-1904:

GRAE-1906:

GRAE-1908:

GRAE-1909:

GRAE-1911: 
GRAE-1913:

DRAE-1914: «(Del lat. unìre.) a. Juntar dos o más cosas entre sí, haciendo de ellas un todo o compuesto. If ${ }^{2}$ Mezclar o trabar algunas cosas entre sí, incorporándolas. ๆ ${ }^{3}$ Atar o juntar una cosa con otra, física o moralmente. ๆ ${ }^{4}$ Acercar una cosa a otra, apretándola o estrechándola. [...]» (pág. 1022,1-2).

GRAE-1916:

GRAE-1917:

GRAE-1920:

GRAE-1924:

DRAE-1925: «(Del lat. unīre.) tr. Juntar dos o más cosas entre sí, haciendo de ellas un todo. ๆ 2. Mezclar o trabar algunas cosas entre sí, incorporándolas. ๆ 3. Atar o juntar una cosa con otra, física o moralmente. ๆ 4. Acercar una cosa a otra, para que formen un conjunto o concurran al mismo objeto o fin. [...]» (pág. $1214,3)$. 


\section{SIGLO XVIII}

Autoridades: «f.m. [...] En la Gramática es una de las partes de la oración, que fe conjuga por modos, y tiempos. Consideran varias efpecies dél, como activo, palsivo, neutro, \&c. que le pueden ver en fus lugares. Lat. Verbum. PATON, Eloq. f. 166. El verbo fe conjuga por modos, y tiempos: como amo, amaba, ame. ToRR. Trad. de Oven, lib. 2. f. 124.

\section{El nombre optimos Latino \\ Le formaron de opto verbo, \\ Porque todos para si \\ Siempre lo optimo quifieron.}

VERBo. En la Lógica es la copula de la oracion, que fignifica con tiempo. Lat. Verbum» (1739, pág. 458,1-2).

DRAE-1780: «s.m. [...]

GRAE-1771: «EL VERBo es una parte tan principal de la oracion, que sin él no se puede formar sentido, ni expresar concepto alguno. Así lo manifiesta su mismo nombre verbo, que quiere decir palabra [...] Sobre su definicion hay una veriedad casi infinita de opiniones [...] El verbo es una parte principal de la oracion que sirve para significar la esencia, la exîstencia, la accion, pasion, y afirmacion de todas las cosas animadas, é inanimadas, y el exercicio de qualquiera facultad que tienen estas cosas, ó se les atribuye» (págs. 56-57).

verbo. Gram. Es una de las partes de la oracion, que se conjuga por modos y tiempos. Consideran varias especies de él como activo, pasivo, neutro, \&c. que se pueden ver en sus lugares. Verbum.

VERBo. Lóg. Es la cópula de la oracion que significa con tiempo. Verbum» (págs. 922,3 y 923,1).

\section{DRAE-1783: «s.m. $[\ldots]$}

VERBo. Gram. Es una de las partes de la oracion, que se conjuga por modos y tiempos. Consideran varias especies de él como activo, pasivo, neutro, \&c. que se pueden ver en sus lugares. Verbum.

VERBo. Lóg. Es la cópula de la oracion que significa con tiempo. Verbum» (pág.937,3). 
DRAE-1791: «s.m. [...] 3. Gram. Es una de las partes de la oracion que se conjuga por modos y tiempos. Consideran varias especies de él como activo, pasivo, neutro, \&c. que se pueden ver en sus lugares. Verbum. 5. Lóg. Es la cópula de la oracion que significa con tiempo. Verbum» (pág.839,3 y 840,1).

GRAE-1796: «VERBO es una parte de la oracion que significa la exîstencia, accion ó pasion de las personas ó cosas, con varias terminaciones de modos, tiempos, números y personas» (pág. 87).

\section{$\mathbf{1}^{\mathrm{a}}$ mitad del XIX}

DRAE-1803: «s.m. $[\ldots]$

verbo. Gram. Una de las partes de la oracion, que se conjuga por modos y tiempos. Verbum.

VERBo. Lóg. La cópula de la oracion que significa con tiempo. Verbum.

[...]» (pág.882,3).

DRAE-1817: «[...]

VERBo. Gram. Una de las partes de la oracion que se conjuga por modos y tiempos. Verbum.

[...]» (pág.885,3).

DRAE-1822: «[...]

verbo. Gram. Una de las partes de la oracion que se conjuga por modos y tiempos. Verbum.

[...]» (pág.840,1).

DRAE-1832: «[...] ๆ Gram. Una de las partes de la oracion, que se conjuga por modos y tiempos. Verbum. ๆ [...]» (pág.762,2).

DRAE-1837: «[...] ๆ Gram. Una de las partes de la oracion, que se conjuga por modos y tiempos. Verbum. ๆ [...]» (pág.762,2-3).

DRAE-1843: «[...] Gram. Una de las partes de la oracion, que se conjuga por modos y tiempos. Verbum. Q»(pág. 738,2).

\section{$2^{\mathrm{a}} \mathrm{m} . \mathrm{XIX}-$ p. XX}

DRAE-1852: «m. [...] Gram. Aquella parte de la oracion que expresa la accion, pasion ó estado de una persona ó cosa, y que se conjuga por modos y tiempos. Verbum. ๆ»(pág. 708,2). 
GRAE-1854: «Verbo es una parte de la oracion que significa la esencia, existencia, accion, estado, designio ó pasion de los seres vivientes y de las cosas inanimadas» (pág. $45)$.

GRAE-1858: «Verbo es una parte de la oracion que significa la existencia, esencia, accion, estado, designio ó pasion de los seres vivientes y de las cosas inanimadas» (pág. 44).

GRAE-1862: «Verbo es una parte de la oracion que significa la existencia, esencia, accion, estado, designio ó pasion de los seres vivientes y de las cosas inanimadas.» (pág. 48)

GRAE-1864: «Verbo es una parte de la oracion que significa la existencia, esencia, accion, estado, designio ó pasion de los seres vivientes y de las cosas inanimadas.» (pág. 48).

GRAE-1865: «Verbo es una parte de la oracion que significa la existencia, esencia, accion, estado, designio ó pasion de los seres vivientes y de las cosas inanimadas.» (pág. $48)$.

GRAE-1866: «Verbo es una parte de la oracion que significa la existencia, esencia, accion, estado, designio ó pasion de los seres vivientes y de las cosas inanimadas.» (pág. 48).

GRAE-1867: «Verbo es una parte de la oracion que significa la existencia, esencia, accion, estado, designio ó pasion de los seres vivientes y de las cosas inanimadas» (pág. 49).

DRAE-1869: «m. [...] Gram. Aquella parte de la oracion, y la más variable, que designa accion ó estado, con expresion de tiempo y persona.[...]» (pág. 788,1-2).

GRAE-1870: «Verbo es una parte de la oracion que designa accion ó estado, con expresion de tiempo y persona» (pág. 50).

GRAE-1874: «Verbo es una parte de la oracion que designa accion ó estado, casi siempre con expresion de tiempo y de persona» (pág. 72). 
DRAE-1884: Gram. Parte de la oración, la más variable de todas ellas, que designa esencia, acción, pasión ó estado, casi siempre con expresión de tiempo, número y persona» (pág. $1081,1)$.

DRAE-1899: «Gram. Parte de la oración, la más variable de todas ellas, que designa esencia, acción, pasión ó estado, casi siempre con expresión de tiempo, número y persona» (pág. $1012,3)$.

GRAE-1878: «Verbo es una parte de la oracion que designa accion ó estado, casi siempre con expresion de tiempo y de persona» (pág. $72)$.

GRAE-1880: «Verbo es una parte de la oracion que designa accion ó estado, casi siempre con expresion de tiempo y de persona» (pág. $61)$.

GRAE-1883: «Verbo es una parte de la oracion que designa accion ó estado, casi siempre con expresion de tiempo y de persona» (pág. $61)$.

GRAE-1885: «Verbo es una parte de la oracion que designa accion ó estado, casi siempre con expresion de tiempo y de persona» (pág. 61)

GRAE-1888: «Verbo es una parte de la oración que designa esencia, existencia, acción, pasión ó estado, casi siempre con expresión de tiempo y de persona» (pág. 61).

GRAE-1890: «Verbo es una parte de la oración que designa esencia, existencia, acción, pasión ó estado, casi siempre con expresión de tiempo y de persona» (pág. 61).

GRAE-1895: «Verbo es una parte de la oración que designa esencia, existencia, acción, pasión ó estado, casi siempre con expresión de tiempo y de persona» (pág. 61).

GRAE-1900: «Verbo es una parte de la oración que designa esencia, existencia, acción, pasión ó estado, casi siempre con expresión de tiempo y de persona» (pág. 61)

GRAE-1901: «Verbo es una parte de la oración que designa esencia, existencia, acción, pasión ó estado, casi siempre con expresión de tiempo y de persona» (pág. 61) 
DRAE-1914: «2 Gram. Parte de la oración, la más variable de todas ellas, que designa esencia, acción, pasión o estado, casi siempre con expresión de tiempo, número y persona» (pág. 1039,1).

DRAE-1925: «4. Gram. Parte de la oración, la más variable de todas ellas, que designa esencia, acción, pasión o estado, casi siempre con expresión de tiempo, número y persona» $(1234,1)$.
GRAE-1904: «Verbo es una parte de la oración que designa esencia, existencia, acción, pasión ó estado, casi siempre con expresión de tiempo y de persona» (pág. 61).

GRAE-1906: «Verbo es una parte de la oración que designa esencia, existencia, acción, pasión ó estado, casi siempre con expresión de tiempo y de persona» (pág. 61).

GRAE-1908: «Verbo es una parte de la oración que designa esencia, existencia, acción, pasión ó estado, casi siempre con expresión de tiempo y de persona» (pág. 61).

GRAE-1909: «Verbo es una parte de la oración que designa esencia, existencia, acción, pasión ó estado, casi siempre con expresión de tiempo y de persona» (pág. 61).

GRAE-1911: «Verbo es una parte de la oración que designa esencia, existencia, acción, pasión ó estado, casi siempre con expresión de tiempo y de persona» (pág. 59).

GRAE-1913: «Verbo es una parte de la oración que designa esencia, existencia, acción, pasión ó estado, casi siempre con expresión de tiempo y de persona» (pág. 59).

GRAE-1916: «Verbo es una parte de la oración que designa esencia, existencia, acción, pasión ó estado, casi siempre con expresión de tiempo y de persona» (pág. 59).

GRAE-1917: «Verbo es una parte de la oración que designa estado, acción o pasión, casi siempre con expresión de tiempo y de persona» (pág. 39).

GRAE-1920: «Verbo es una parte de la oración que designa estado, acción o pasión, casi siempre con expresión de tiempo y de persona» (pág. 45).

GRAE-1924: «Verbo es una parte de la oración que designa estado, acción o pasión, casi siempre con expresión de tiempo y de persona» (pág. 45). 
VII

REFERENCIAS BIBLIOGRÁFICAS 



\section{CORPUS CENTRAL DE LA INVESTIGACIÓN}

\section{A. Gramáticas}

Gramática de la lengua castellana, compuesta por la Real Academia Española. Madrid: Joachin de Ibarra, Impresor de Cámara de S.M. 1771 [ed. facsímil de Ramón Sarmiento. Madrid, Editorial Nacional, 1984].

Gramática de la lengua Castellana compuesta por la Real Academia Española. Quarta edición corregida y aumentada. Madrid: Viuda de don Joaquin Ibarra, Impresora de la Real Academia. 1796.

Gramática de la lengua castellana, por la Real Academia Española. NuEVA EDICIÓN. Madrid: Imprenta Nacional. 1854. (5. ${ }^{\text {e }}$ ed.).

Gramática de la lengua castellana, por la Real Academia Española. Madrid: Imprenta Nacional. 1858. (6. ${ }^{\mathrm{a}}$ ed.).

Gramática de la lengua castellana, por la Real Academia Española. Madrid: Imprenta Nacional. 1862. (7. ${ }^{\mathrm{a}}$ ed.).

Gramática de la lengua castellana, por la Real Academia Española. Madrid: Imprenta Nacional. 1864. (8. ${ }^{\mathrm{a}}$ ed.).

Gramática de la lengua castellana, por la Real Academia Española. Madrid: Imprenta Nacional. 1865. (9. ${ }^{\mathrm{a}}$ ed.).

Gramática de la lengua castellana, por la Real Academia Española. Madrid: Imprenta Nacional. 1866. (10. a ed.).

Gramática de la lengua castellana, por la Real Academia Española. Madrid: Imprenta de Miguel Ginesta. 1867. (11. a ed.). 
Gramática de la lengua castellana, por la Real Academia Española. Nueva edicion, corregida y aumentada. Madrid: Imprenta y estereotipia de M. Rivadeneyra. 1870. (12. ${ }^{\text {a }}$ ed.).

Gramática de la lengua castellana, por la Real Academia Española. NUEVA EDICION CORREGIDA Y AUMENTADA. Madrid: imprenta y fundición de Manuel Tello. 1874. (13. a ed.).

Gramática de la lengua castellana, por la Real Academia Española. NUEVA EDICIÓN. Madrid: Gregorio Hernando, impresor y librero de la Real Academia Española. 1878. (14. a ed.).

Gramática de la lengua castellana por la Real Academia Española. NUEVA EDICIÓN. Madrid: Gregorio Hernando, impresor y librero de la Real Academia Española. 1880. (15. ${ }^{a}$ ed.).

Gramática de la lengua castellana por la Real Academia Española. NuEVA EDICIÓN. Madrid: Gregorio Hernando, Impresor y Librero de la Real Academia Española. 1883. (16. ${ }^{\mathrm{a}}$ ed.).

Gramática de la lengua castellana por la Real Academia Española. NuEvA EDICION. Madrid: Gregorio Hernando, Impresor y Librero de la Real Academia Española. 1885. (17. ${ }^{\mathrm{a}}$ ed.).

Gramática de la lengua castellana por la Real Academia Española. NuEvA EDICION. Madrid: Viuda de Hernando y Compañía, impresores y libreros de la Real Academia Española. 1888. (18. ${ }^{a}$ ed.).

Gramática de la lengua castellana por la Real Academia Española. NuEVA EDICION. Madrid: Viuda de Hernando y Compañía, impresores y libreros de la Real Academia Española. 1890. (19. ${ }^{a}$ ed.).

Gramática de la lengua castellana por la Real Academia Española. NuEVA EDICION. Madrid: Viuda de Hernando y Compañía, impresores y libreros de la Real Academia Española. 1895. (20. ${ }^{\text {a }}$ ed.). 
Gramática de la lengua castellana por la Real Academia Española. NuEVA EDICION. Madrid: Hernando y Compañía, impresores y libreros de la Real Academia Española. 1900. (21. ${ }^{\mathrm{a}}$ ed.).

Gramática de la lengua castellana por la Real Academia Española. NuEVA EDICióN. Madrid: Hernando y Compañía, impresores y libreros de la Real Academia Española. 1901. (22. ${ }^{\mathrm{a}}$ ed.).

Gramática de la lengua castellana por la Real Academia Española. NUEVA EDICIÓN. Madrid: Perlado, Páez y Compañía (sucesores de Hernando) impresores y libreros de la Real Academia Española. 1904. (23. ${ }^{a}$ ed.).

Gramática de la lengua castellana por la Real Academia Española. NUEVA EDICióN. Madrid: Perlado, Páez y Compañía (sucesores de Hernando) impresores y libreros de la Real Academia Española. 1906. (24. ${ }^{a}$ ed.).

Gramática de la lengua castellana por la Real Academia Española. NuEVA EDICIÓN. Madrid: Perlado, Páez y Compañía (sucesores de Hernando) impresores y libreros de la Real Academia Española. 1908. (25. a ed.).

Gramática de la lengua castellana por la Real Academia Española. NUEVA EDICIÓN. Madrid: Perlado, Páez y Compañía (sucesores de Hernando) impresores y libreros de la Real Academia Española. 1909. (26. a ed.).

Gramática de la lengua castellana por la Real Academia Española. NuEVA EDICIÓN. Madrid: Perlado, Páez y Compañía (sucesores de Hernando) impresores y libreros de la Real Academia Española. 1911. (27. ${ }^{a}$ ed.).

Gramática de la lengua castellana por la Real Academia Española. NUEVA EDICIÓN. Madrid: Perlado, Páez y Compañía (sucesores de Hernando) impresores y libreros de la Real Academia Española. 1913. (28. ${ }^{\text {a }}$ ed.). 
Gramática de la lengua castellana por la Real Academia Española. NuEVA EDICióN. Madrid: Perlado, Páez y Compañía (sucesores de Hernando) impresores y libreros de la Real Academia Española. 1916. (29. a ed.).

Gramática de la lengua castellana por la Real Academia Española. NUEVA EDICIÓN, REFORMADA. Madrid: Perlado, Páez y Compañía (sucesores de Hernando) impresores y libreros de la Real Academia Española. 1917. (30. ${ }^{a}$ ed.).

Gramática de la lengua castellana por la Real Academia Española. NUEVA EDICIÓN, ReformadA. Madrid: Perlado, Páez y Compañía (sucesores de Hernando) Impresores y libreros de la Real Academia Española. 1920. (31. ${ }^{a}$ ed.).

Gramática de la lengua española por la Real Academia Española. NUEVA EDICIÓN, REFORMADA. Madrid: Perlado, Páez y Compañía (sucesores de Hernando) impresores y libreros de la Real Academia Española. 1924. (32. ${ }^{a}$ ed.). 


\section{B. Diccionarios}

Diccionario de la lengua castellana, en que se explica el verdadero sentido de las voces, su naturaleza y calidad, con las phrases o modos de hablar, los proverbios o refranes, y otras cosas convenientes al uso de la lengua. Dedicado al Rey Nuestro Señor Don Phelipe $V$ (que Dios guarde), à cuyas reales expensas se hace esta obra. Compuesto por la Real Academia Española. Tomo primero. Que contiene las letras A.B. Con privilegio. En Madrid: en la Imprenta de Francisco del Hierro, impresor de la Real Academia Española. Año de 1726. Tomo segundo. Que contiene la letra C. Con privilegio. En Madrid: en la Imprenta de Francisco del Hierro, impresor de la Real Académia Españóla. Año de 1729. Tomo tercero. Que contiene las letras D.E.F. Con privilegio. En Madrid: en la Imprenta de la Real Académia Españóla: por la viuda de Francisco del Hierro, año de 1732. Tomo quarto. Que contiene las letras G.H.I.J.K.L.M.N. Con privilegio. En Madrid: en la Imprenta de la Real Académia Españóla. Año de 1734. Tomo quinto. Que contiene las letras O.P.Q.R. Con privilegio. En Madrid: en la Imprenta de la Real Académia Españóla: por los Heredéros de Francisco del Hierro. Año de 1737. Tomo sexto. Que contiene las letras S.T.V.X.Y.Z. Con privilegio. En Madrid: en la Imprenta de la Real Académia Española: por los Herederos de Francisco del Hierro. Año de 1739.

[Conocido como Diccionario de Autoridades, título con el que aparece en la edición facsímil de la de 1726-1739 publicada por Gredos. Madrid. 1979. Cito por esta edición.].

Diccionario de la Lengua castellana compuesto por la Real Academia Española, reducido á un tomo para su mas fácil uso. Madrid. Por D. Joachin Ibarra, Impresor de Cámara de S.M. y de la Real Academia. MDCCLXXX (1 ${ }^{\mathrm{a}}$ ed.).

Diccionario de la lengua castellana compuesto por la Real Academia Española, reducido á un tomo para su mas fácil uso. Segunda edicion, en la qual se han colocado en los lugares correspondientes todas las voces del Suplemento, que se puso al fin de la edicion del año de 1780, y se ha añadido otro nuevo suplemento de artículos correspondientes las letras A, B y C. Madrid: Por D. Joaquin Ibarra, Impresor de Cámara de S. M. y de la Real Academia. MDCCLXXXIII. 
Diccionario de la Lengua castellana compuesto por la Real Academia Española, reducido á un tomo para su mas fácil uso. Tercera edicion, en la qual se han colocado en los lugares correspondientes todas las voces de los Suplementos, que se pudiéron al fin de las ediciones de los años de 1780 y 1783, y se han intercalado en las letras D.E. y F. nuevos artículos, de los quales se dará un suplemento separado. Madrid. Por la viuda de Don Joaquin Ibarra, Impresora de la Real Academia. MDCCLXXXXI.

Diccionario de la Lengua castellana, compuesto por la Real Academia Española, reducido á un tomo para su mas fácil uso. Quarta edicion. Madrid. Por la Viuda de Don Joaquin Ibarra, Impresora de la Real Academia. MDCCCIII.

Diccionario de la Lengua castellana por la Real Academia Española. Quinta edicion. Madrid en la Imprenta Real. Año de 1817.

Diccionario de la lengua castellana por la Academia Española. Sexta edicion. Madrid en la Imprenta Nacional. Año de 1822.

Diccionario de la lengua castellana por la Academia Española. Séptima edicion. Madrid en la Imprenta Real. Año de $\mathbf{1 8 3 2}$.

Diccionario de la lengua castellana por la Academia Española. Octava edicion. Madrid en la Imprenta Nacional. Año de 1837.

Diccionario de la Lengua Castellana por la Academia Española. Novena edicion. Madrid, Imprenta de Don Francisco Maria Fernández. Año de 1843.

Diccionario de la Lengua castellana por la Academia Española. Décima edicion. Madrid, en la Imprenta Nacional. Año de 1852.

Diccionario de la Lengua castellana por la Academia Española. Undécima edicion. Madrid, Imprenta de don Miguel Rivadeneyra. Año de 1869. 
Las Gramáticas de la Real Academia Española: teoría gramatical, sintaxis y subordinación (1854-1924)

Diccionario de la Lengua castellana por la Real Academia Española. Duodécima edición. Madrid. Imprenta de D. Gregorio Hernando, año de 1884.

Diccionario de la Lengua castellana por la Real Academia Española. Décimatercia edición. Madrid. Imprenta de los Sres. Hernando y Compañía. Año de 1899.

Diccionario de la Lengua castellana por la Real Academia Española. Décimocuarta edición. Madrid. Imprenta de los Sucesores de Hernando. Año de 1914.

Diccionario de la Lengua española. Madrid. 1925. 


\section{FUENTES DIRECTAS}

\section{A. Textos académicos}

\section{i. Gramáticas}

Gramática de la lengua castellana compuesta por la Real Academia Española -segunda impresión-. Madrid: Joachin de Ibarra, Impresor de Cámara de S.M. 1772

Gramática de la lengua castellana compuesta por la Real Academia Española -tercera impresión-. Madrid: Joachin de Ibarra, Impresor de Cámara de S.M. 1781

Gramática de la lengua Castellana compuesta por la Real Academia Española. Madrid: Imprenta de la Compañía de Impresores y Libreros del Reino. M.DCCCLII.

Gramática de la lengua española por la Real Academia Española. NUEVA EDICIÓN, REFORMADA. Madrid: Librería y Casa editorial de Hernando (S.A.) (fundada en el año 1828) Impresores y Libreros de la Real Academia Española. 1928. (33. a ed.).

Gramática de la lengua española. Nueva edición reformada. Espasa-Calpe, S.A. Bilbao, Madrid, Barcelona. 1931. (34. ${ }^{\text {e ed.). }}$

Gramática de la lengua española. Nueva edición, reformada, de 1931 y apéndice con las nuevas normas de prosodia y ortografía declaradas de aplicación preceptiva desde $1 .^{\circ}$ de enero de 1959. Madrid: Espasa-Calpe, S.A. 1959.

Gramática de la lengua española. Nueva edición, reformada, de 1931 y apéndice con las nuevas normas de prosodia y ortografía declaradas de aplicación preceptiva desde $1 .^{\circ}$ de enero de 1959. Madrid: Espasa-Calpe, S.A. 1962.

Esbozo de una nueva gramática de la lengua española. Madrid: Espasa-Calpe S.A. 1973. 


\section{ii. Diccionarios}

Diccionario de la lengua castellana compuesto por la Real Academia Española. Segunda impresión corregida y aumentada. Tomo primero. A-B. Madrid: Por D. Joachin Ibarra, Impresor de Cámara de S.M. MDCCLXX.

Diccionario de la Lengua española. Vigésima primera edición. Madrid. Espasa-Calpe. 1992. 2 vols.

Diccionario de la lengua española. Vigésima segunda edición. Madrid. Espasa-Calpe. 2001. 2 vols.

[Consulta en red: $<$ http://www.rae.es/>].

Nuevo Tesoro Lexicográfico de la Lengua española. Madrid. Espasa-Calpe. 2001. (Formato DVD).

[Consulta en red: $<\underline{\text { http: } / / \text { www.rae.es/ }>\text { ]. }}$

\section{iii. Compendios, Epitomes y Prontuarios de Ortografía}

Compendio de la Gramática de la lengua castellana, dispuesto por la Real Academia Española, para la segunda enseñanza. Madrid: en la Imprenta Nacional. 1857.

Epítome de la Gramática de la Lengua Castellana, dispuesto por la Real Academia Española para la primera enseñanza elemental. Madrid: en la Imprenta Nacional. 1857.

Epitome de la Gramática de la Lengua Castellana, dispuesto por la Real Academia Española para la primera enseñanza elemental. Segunda edicion aumentada con preguntas. Madrid: en la Imprenta Nacional. 1858.

Epitome de la Gramática de la Lengua Castellana, dispuesto por la Real Academia Española para la primera enseñanza elemental. Octava edicion arreglada en preguntas y respuestas. Madrid: en la Imprenta Nacional. 1861.

Epitome de la Gramática de la Lengua Castellana dispuesto por la Real Academia Española para la primera enseñanza elemental. Novena edicion arreglada en preguntas y respuestas. Madrid: en la Imp. Nacional. 1861.

Epítome de la Gramática de la Lengua Castellana, dispuesto por la Real Academia Española para la primera enseñanza elemental. Duodécima edicion. Madrid: en la Imp. Nacional. 1863.

Epítome de Analogía y Sintaxis según la Gramática castellana nuevamente publicada por la Academia Española y dispuesto por la misma para la primera enseñanza elemental. Madrid: Imprenta de José Rodríguez. 1870. 
Las Gramáticas de la Real Academia Española: teoría gramatical, sintaxis y subordinación (1854-1924)

Epitome de Analogía y Sintaxis según la Gramática castellana nuevamente publicada por la Real Academia Española y dispuesto por la misma para la primera enseñanza elemental. Segunda edicion. Madrid: Imprenta de José Rodríguez. 1871.

Epitome de Analogía y Sintaxis según la Gramática castellana nuevamente publicada por la Real Academia Española y dispuesto por la misma para la primera enseñanza elemental. Tercera edicion. Madrid: Imprenta de José Rodríguez. 1872.

Epítome de Analogía y Sintaxis según la Gramática castellana nuevamente publicada por la Real Academia Española y dispuesto por la misma para la primera enseñanza elemental. Cuarta edicion. Madrid: Imprenta de José Rodríguez. 1872.

Epitome de Analogía y Sintaxis según la Gramática castellana nuevamente publicada por la Real Academia Española y dispuesto por la misma para la primera enseñanza elemental. Quinta edicion. Madrid: Imprenta de José Rodríguez. 1872.

Epítome de Analogía y Sintaxis según la Gramática castellana nuevamente publicada por la Real Academia Española y dispuesto por la misma para la primera enseñanza elemental. Sexta edicion. Madrid: Imprenta de José Rodríguez. 1872.

Epitome de Analogía y Sintaxis según la Gramática castellana nuevamente publicada por la Real

Academia Española y dispuesto por la misma para la primera enseñanza elemental. Séptima edicion. Madrid: Imprenta de José Rodríguez. 1873.

Epitome de Analogía y Sintaxis según la Gramática castellana nuevamente publicada por la Real

Academia Española y dispuesto por la misma para la primera enseñanza elemental.

Octava edicion. Madrid: Imprenta de José Rodríguez. 1873.

Epitome de Analogía y Sintaxis según la Gramática castellana nuevamente publicada por la Real

Academia Española y dispuesto por la misma para la primera enseñanza elemental. Novena edicion. Madrid: Imprenta de José Rodríguez. 1874.

Epitome de Analogía y Sintaxis según la Gramática castellana nuevamente publicada por la Real Academia Española y dispuesto por la misma para la primera enseñanza elemental. Décima edicion. Madrid: Imprenta de José Rodríguez. 1874.

Epitome de Analogía y Sintaxis según la Gramática castellana nuevamente publicada por la Real Academia Española y dispuesto por la misma para la primera enseñanza elemental. Undécima edicion. Madrid: Imprenta de José Rodríguez. 1874.

Epítome de Analogía y Sintaxis según la Gramática castellana nuevamente publicada por la Real Academia Española y dispuesto por la misma para la primera enseñanza elemental. Duodécima edicion. Madrid: Imprenta de José Rodríguez. 1875. 
Epítome de Analogía y Sintaxis según la Gramática castellana nuevamente publicada por la Real Academia Española y dispuesto por la misma para la primera enseñanza elemental. Décima tercia edicion. Madrid: Imprenta de José Rodríguez. 1875.

Epítome de Analogía y Sintaxis según la Gramática castellana nuevamente publicada por la Real Academia Española y dispuesto por la misma para la primera enseñanza elemental. Décima cuarta edicion. Madrid: Imprenta de José Rodríguez. 1876.

Epítome de Analogía y Sintaxis según la Gramática castellana nuevamente publicada por la Real Academia Española y dispuesto por la misma para la primera enseñanza elemental. Décima-quinta edicion. Madrid: Imprenta de José Rodríguez. 1876.

Epítome de Analogía y Sintaxis según la Gramática castellana nuevamente publicada por la Real Academia Española y dispuesto por la misma para la primera enseñanza elemental. Décima-sexta edicion. Madrid: Imprenta de José Rodríguez. 1877.

Epítome de Analogía y Sintaxis según la Gramática castellana nuevamente publicada por la Real Academia Española y dispuesto por la misma para la primera enseñanza elemental. Décima-séptima edicion. Madrid: Imprenta de José Rodríguez. 1877.

Epitome de Analogía y Sintaxis según la Gramática castellana nuevamente publicada por la Real Academia Española y dispuesto por la misma para la primera enseñanza elemental. Décima-octava edicion. Madrid: Gregorio Hernando, impresor y librero de la Real Academia Española. 1878.

Epítome de Analogía y Sintaxis según la Gramática castellana nuevamente publicada por la Real Academia Española y dispuesto por la misma para la primera enseñanza elemental. Décima-nona edicion. Madrid: Gregorio Hernando, impresor y librero de la Real Academia Española. 1878.

Epítome de Analogía y Sintaxis según la Gramática castellana nuevamente publicada por la Real Academia Española y dispuesto por la misma para la primera enseñanza elemental. Vigésima edicion. Madrid: Gregorio Hernando, impresor y librero de la Real Academia Española. 1879.

Epítome de Analogía y Sintaxis según la Gramática castellana nuevamente publicada por la Real Academia Española y dispuesto por la misma para la primera enseñanza elemental. Vigésima primera edicion. Madrid: Gregorio Hernando, impresor y librero de la Real Academia Española. 1879.

Epítome de Analogía y Sintaxis según la Gramática castellana nuevamente publicada por la Real Academia Española y dispuesto por la misma para la primera enseñanza elemental. Vigésima segunda edicion. Madrid: Gregorio Hernando, impresor y librero de la Real Academia Española. 1880. 
Las Gramáticas de la Real Academia Española: teoría gramatical, sintaxis y subordinación (1854-1924)

Epítome de Analogía y Sintaxis según la Gramática castellana nuevamente publicada por la Real Academia Española y dispuesto por la misma para la primera enseñanza elemental. Vigésima tercera edicion. Madrid: Gregorio Hernando, impresor y librero de la Real Academia Española. 1880.

Epítome de Analogía y Sintaxis según la Gramática castellana nuevamente publicada por la Real Academia Española y dispuesto por la misma para la primera enseñanza elemental. Vigésima cuarta edicion. Madrid: Gregorio Hernando, impresor y librero de la Real Academia Española. 1881.

Epítome de Analogía y Sintaxis de gramática castellana para la primera enseñanza elemental por la Real Academia Española. Vigésima quinta edicion. Madrid: Gregorio Hernando, impresor y librero de la Real Academia Española. 1882.

Epítome de Analogía y Sintaxis de gramática castellana para la primera enseñanza elemental por la Real Academia Española. Vigésima sexta edicion. Madrid: Gregorio Hernando, impresor y librero de la Real Academia Española. 1884.

Epitome de Analogía y Sintaxis según la Gramática castellana nuevamente publicada por la Real Academia Española y dispuesto por la misma para la primera enseñanza elemental. Vigésima séptima edición. Madrid: Gregorio Hernando, impresor y librero de la Real Academia Española. 1885.

Epítome de Analogía y Sintaxis de gramática castellana para la primera enseñanza elemental por la Real Academia Española. Vigésima octava edición. Madrid: Gregorio Hernando, impresor y librero de la Real Academia Española. 1886.

Epítome de Analogía y Sintaxis de gramática castellana para la primera enseñanza elemental por la Real Academia Española. Vigésima novena edición. Madrid: Viuda de Hernando y Compañía, Impresores y libreros de la Real Academia Española. 1886.

Epitome de Analogía y Sintaxis de gramática castellana para la primera enseñanza elemental por la Real Academia Española. Trigésima edición. Madrid: Viuda de Hernando y Compañía, Impresores y libreros de la Real Academia Española. 1887.

Epítome de Analogía y Sintaxis de gramática castellana para la primera enseñanza elemental por la Real Academia Española. Trigésima primera edición. Madrid: Viuda de Hernando y Compañía, Impresores y libreros de la Real Academia Española. 1888.

Epitome de Analogía y Sintaxis de gramática castellana para la primera enseñanza elemental por la Real Academia Española. Trigésima segunda edición. Madrid: Viuda de Hernando. 1889. 
Epítome de Analogía y Sintaxis de gramática castellana para la primera enseñanza elemental por la Real Academia Española. Trigésima tercera edición. Madrid: Viuda de Hernando y Compañía, Impresores y libreros de la Real Academia Española. 1890.

Epítome de Analogía y Sintaxis de gramática castellana para la primera enseñanza elemental por la Real Academia Española. Trigésima cuarta edición. Madrid: Viuda de Hernando y Compañía, Impresores y libreros de la Real Academia Española. 1891.

Epítome de Analogía y Sintaxis de gramática castellana para la primera enseñanza elemental por la Real Academia Española. Trigésima quinta edición. Madrid: Viuda de Hernando y Compañía, Impresores y libreros de la Real Academia Española. 1892.

Epitome de Analogía y Sintaxis de gramática castellana para la primera enseñanza elemental por la Real Academia Española. Trigésima sexta edición. Madrid: Viuda de Hernando y Compañía, Impresores y libreros de la Real Academia Española. 1893.

Epitome de Analogía y Sintaxis de gramática castellana para la primera enseñanza elemental por la Real Academia Española. Trigésima séptima edición. Madrid: Viuda de Hernando y Compañía, Impresores y libreros de la Real Academia Española. 1894.

Epítome de Analogía y Sintaxis de gramática castellana para la primera enseñanza elemental por la Real Academia Española. Trigésima octava edición. Madrid: Hernando y Compañía, Impresores y libreros de la Real Academia Española. 1896.

Epítome de Analogía y Sintaxis de gramática castellana para la primera enseñanza elemental por la Real Academia Española. Trigésima novena edición. Madrid: Hernando y Compañía, Impresores y libreros de la Real Academia Española. 1897.

Epítome de Analogía y Sintaxis de gramática castellana para la primera enseñanza elemental por la Real Academia Española. Cuadragésima edición. Madrid: Hernando y Compañía, Impresores y libreros de la Real Academia Española. 1898.

Epítome de Analogía y Sintaxis de gramática castellana para la primera enseñanza elemental por la Real Academia Española. Cuadragésima primera edición. Madrid: Hernando y Compañía, Impresores y libreros de la Real Academia Española. 1899.

Epítome de Analogía y Sintaxis de gramática castellana para la primera enseñanza elemental por la Real Academia Española. Cuadragésima segunda edición. Madrid: Hernando y Compañía, Impresores y libreros de la Real Academia Española. 1900.

Epítome de Analogía y Sintaxis de gramática castellana para la primera enseñanza elemental por la Real Academia Española. Cuadragésima tercera edición. Madrid: Hernando y Compañía, Impresores y libreros de la Real Academia Española. 1901. 
Las Gramáticas de la Real Academia Española: teoría gramatical, sintaxis y subordinación (1854-1924)

Epitome de Analogía y Sintaxis de gramática castellana para la primera enseñanza elemental por la Real Academia Española. Cuadragésima cuarta edición. Madrid: Perlado, Páez y C. ${ }^{a}$ (Sucesores de Hernando) Impresores y libreros de la Real Academia Española. 1902.

Epitome de Analogía y Sintaxis de gramática castellana para la primera enseñanza elemental por la Real Academia Española. Cuadragésima quinta edición. Madrid: Perlado, Páez y C. ${ }^{\text {a }}$ (Sucesores de Hernando) Impresores y libreros de la Real Academia Española. 1903.

Epítome de Analogía y Sintaxis de gramática castellana para la primera enseñanza elemental por la Real Academia Española. Cuadragésima sexta edición. Madrid: Perlado, Páez y C. ${ }^{a}$ (Sucesores de Hernando) Impresores y libreros de la Real Academia Española. 1905.

Epítome de Analogía y Sintaxis de gramática castellana para la primera enseñanza elemental por la Real Academia Española. Cuadragésima séptima edición. Madrid: Perlado, Páez y C. ${ }^{a}$ (Sucesores de Hernando) Impresores y libreros de la Real Academia Española. 1906.

Epitome de Analogía y Sintaxis de gramática castellana para la primera enseñanza elemental por la Real Academia Española. Cuadragésima octava edición. Madrid: Perlado, Páez y C. ${ }^{a}$ (Sucesores de Hernando) Impresores y libreros de la Real Academia Española. 1907.

Epítome de Analogía y Sintaxis de gramática castellana para la primera enseñanza elemental por la Real Academia Española. Cuadragésima novena edición. Madrid: Perlado, Páez y C. ${ }^{a}$ (Sucesores de Hernando) Impresores y libreros de la Real Academia Española. 1909.

Epitome de Analogía y Sintaxis de gramática castellana para la primera enseñanza elemental por la Real Academia Española. Quincuagésima edición. Madrid: Perlado, Páez y C. ${ }^{a}$ (Sucesores de Hernando) Impresores y libreros de la Real Academia Española. 1910.

Epítome de Analogía y Sintaxis de gramática castellana para la primera enseñanza elemental por la Real Academia Española. Quincuagésima primera edición. Madrid: Perlado, Páez y C. ${ }^{a}$ (Sucesores de Hernando) Impresores y libreros de la Real Academia Española. 1912.

Epitome de Analogía y Sintaxis de gramática castellana para la primera enseñanza elemental por la Real Academia Española. Quincuagésima segunda edición. Madrid: Perlado, Páez 
y C. ${ }^{a}$ (Sucesores de Hernando) Impresores y libreros de la Real Academia Española. 1913.

Epítome de Analogía y Sintaxis de gramática castellana para la primera enseñanza elemental por la Real Academia Española. Quincuagésima tercera edición. Madrid: Perlado, Páez y C. ${ }^{a}$ (Sucesores de Hernando) Impresores y libreros de la Real Academia Española. 1915.

Epítome de Analogía y Sintaxis de gramática castellana para la primera enseñanza elemental por la Real Academia Española. Quincuagésima cuarta edición. Madrid: Perlado, Páez y C. ${ }^{a}$ (Sucesores de Hernando) Impresores y libreros de la Real Academia Española. 1916.

Epitome de Analogía y Sintaxis de gramática castellana para la primera enseñanza elemental por la Real Academia Española. Quincuagésima quinta edición. Madrid: Perlado, Páez y C. ' (Sucesores de Hernando) Impresores y libreros de la Real Academia Española. 1918.

Epítome de Analogía y Sintaxis de gramática castellana para la primera enseñanza elemental por la Real Academia Española. Quincuagésima sexta edición. Madrid: Perlado, Páez y C. ${ }^{\text {a }}$ (Sucesores de Hernando) Impresores y libreros de la Real Academia Española. 1920.

Epitome de Analogía y Sintaxis de gramática castellana para la primera enseñanza elemental por la Real Academia Española. Quincuagésima séptima edición. Madrid: Perlado, Páez y C. ${ }^{a}$ (Sucesores de Hernando) Impresores y libreros de la Real Academia Española. 1922.

Epitome de Analogía y Sintaxis de Gramática española para la primera enseñanza elemental. Quincuagésima octava edición. Madrid: Librería y Casa editorial Hernando (S. A.) Impresores y libreros de la Real Academia Española. 1925.

Epítome de Analogía y Sintaxis de la Gramática de la Lengua española para la primera enseñanza elemental. Quincuagésima novena edición. Madrid: Librería y Casa editorial Hernando (S. A.) Impresores y libreros de la Real Academia Española. 1928.

Epítome gramatical (morfología y sintaxis) para la primera enseñanza. Madrid: Librería y Casa Editorial Hernando. 1929.

Epítome de gramática española: (morfología y sintaxis) para la primera enseñanza elemental. Sexagésima primera edición. Madrid: Espasa-Calpe. 1931.

Epítome de gramática de la lengua española para la primera enseñanza. Sexagésima segunda edición. Zaragoza: Heraldo de Aragón. 1938. 
Prontuario de ortografía de la lengua castellana, dispuesto de real órden para el uso de las escuelas públicas por la Real Academia Española con arreglo al sistema adoptado en la novena edicion de su diccionario. Madrid: en la Imprenta Nacional. 1844.

Prontuario de Ortografía de la lengua castellana dispuesto de Real Orden para el uso de las escuelas públicas por la Real Academia Española con arreglo al sistema adoptado en la novena edicion de su Diccionario. Segunda edicion. Madrid: en la Imprenta Nacional. 1845.

Prontuario de Ortografía de la lengua castellana dispuesto de Real Orden para el uso de las escuelas públicas por la Real Academia Española con arreglo al sistema adoptado en la novena edición de su Diccionario. Tercera edición. Madrid: en la Imp. Nacional. 1850.

Prontuario de Ortografía de la lengua castellana dispuesto de Real Orden para el uso de las escuelas públicas por la Real Academia Española. Cuarta edición: corregida y aumentada. Madrid: en la Imprenta Nacional. 1853.

Prontuario de Ortografía de la lengua castellana dispuesto de Real Orden para el uso de las escuelas públicas por la Real Academia Española. Quinta edición. Madrid: en la Imprenta Nacional. 1854.

iv. Documentos varios: actas, memorias, libros de reglamento, etc.

ARCHIVO de la ReAl ACADEMIA ESPAÑOlA. Actas. Libro núm. 1.

Actas. Libro núm. 22.

Actas. Libro núm. 35.

Actas. Libro núm. 38.

Actas. Libro núm. 40.

Actas. Libro núm. 41.

(1903). Liquidaciones Comisión de Gramática. Caja 171, carpeta 6.

(1904). Liquidaciones Comisión de Gramática. Caja 172, carpeta 7.

(1907). Liquidaciones Comisión de Gramática. Caja 183, carpeta 9.

(1910). Liquidaciones Comisión de Gramática. Caja 181, carpeta 9.

(1915). Liquidaciones Comisión de Gramática. Caja 189, carpeta 2.

(1916). Liquidaciones Comisión de Gramática. Caja 196, carpeta 6.

(1917). Liquidaciones Comisión de Gramática. Caja 192, carpeta 2. 
Bretón De los Herreros, Manuel (1860). Resúmen de las Actas y Tareas de la Real Academia Española en el año académico de 1859 á 1860 por el secretario perpetuo de la misma corporación D. Manuel Bretón de los Herreros. Madrid: Imprenta Nacional. (1861). Resúmen de las actas y tareas de la Real Academia Española en el año académico de 1860 á 1861, leido en la junta pública de 29 de setiembre de 1861 por el secretario perpetuo de la misma corporacion D. Manuel Breton de los Herreros. Madrid: Imprenta Nacional.

(1862). Resúmen de las actas y tareas de la Real Academia Española en el año académico de 1861 á 1862, leido en la junta pública de 28 de setiembre de 1862 por el secretario perpetuo de la misma corporacion D. Manuel Breton de los Herreros. Madrid: Imprenta Nacional.

(1863). Resúmen de las tareas y actos de la Real Academia Española en el año académico de 1862 á 1863, leido en la junta pública de 27 de setiembre de 1863 por el secretario perpétuo de la misma Corporacion D. Manuel Breton de los Herreros. Madrid: Imprenta Nacional.

(1864). Resúmen de las tareas y actos de la Real Academia Española en el año académico de 1863 á 1864, leido en la junta pública de 25 de setiembre de 1864 por el secretario perpétuo de la misma Corporacion D. Manuel Breton de los Herreros. Madrid: Imprenta Nacional.

(1865). Resúmen de las tareas y actos de la Real Academia Española en el año académico de 1864 á 1865, leido en junta pública por el secretario perpetuo de la misma Corporacion D. Manuel Breton de los Herreros. Madrid: Imprenta Nacional.

(1866). Resúmen de las tareas y actos de la Real Academia Española en el año académico de 1865 á 1866, leido en junta pública por el secretario perpétuo de la misma corporacion D. Manuel Breton de los Herreros. Madrid: Imprenta Nacional.

(1867). Resúmen de las tareas y actos de la Real Academia Española en el año académico de 1866 á 1867, leido en junta pública por el secretario perpetuo de la misma corporacion D. Manuel Breton de los Herreros. Madrid: Imprenta de D. Alejandro Gomez Fuentenebro.

(1868). Resúmen de las tareas y actos de la Real Academia Española en el año académico de 1867 á 1868, leido en junta pública por el secretario perpetuo de la misma corporacion D. Manuel Breton de los Herreros. Madrid: imprenta y estereotipia de M. Rivadeneyra. 
(1869). Resúmen de las tareas y actos de la Academia Española en el año académico de 1868 á 1869, leido en junta pública por el secretario perpetuo de la misma corporacion D. Manuel Breton de los Herreros. Madrid: imprenta y estereotipia de M. Rivadeneyra. Manuscrito 3148. Lista de académicos de la RAE desde sus orígenes hasta 1866. S. XIX, papel, 8 ff., $32 \times 22 \mathrm{~cm}$.

MOLINS, marqués de (1870). Memoria sobre el estado y trabajos literarios de la Real Academia Española, presentada por su director el marqués de Molins en 30 de diciembre de 1869. Madrid: Imprenta y estereotipia de M. Rivadeneyra.

Real AcAdemia Española (1715). Fundación, y estatútos de la Real Acdémia Españóla. En Madrid: con las licencias necessarias. En la Imprenta Real por Joséph Rodríguez y Esobár, Impressór del Rey nuestro Señor, de su Conséjo de la Santa Cruzáda, y de la Real Académia Españóla. Año M. DCC. XV.

(1848). Estatutos de la Real Acdemia Española aprobados por S. M. Madrid: en la Imprenta Nacional.

(1859). Estatutos de la Real Academia Española: aprobados por S. M. Madrid.

(1861a). Reglamento de la Real Academia Española. Madrid: Imprenta de Manuel Galiano.

(1904). Estatutos y Reglamento de la Real Academia Española. Madrid: establecimiento tipográfico de Jaime Ratés.

(1870). Memorias de la Academia Española. Año I. tomo I. Madrid: Imprenta y estereotipia de M. Rivadeneyra.

SEGOVIA, Antonio María (1870). Resúmen de las tareas y actos de la Academia Española en el año académico de 1869 á 1870, leido en junta pública por el secretario accidental de la misma corporaion Don Antonio María Segovia. Madrid: imprenta y estereotipia de M. Rivadeneyra.

TAMAyO y BAUS, Manuel (1881). Resumen de las actas de la Real Academia Española leído en junta pública de 4 de diciembre de 1881 por el secretario perpetuo de la misma corporación D. Manuel Tamayo y Baus. Madrid: Imprenta y fundición de Manuel Tello. 


\section{iv. Discursos, disertaciones y documentos de gramática ${ }^{1}$}

ARCHIVO DE LA ReAl ACADEMIA EsPaÑola (s.a.). Disertación: [Que sea Gram[atica] su def[inición], etymologia, partes en que se divide, y si es ciencia, ó arte] del Sr. José Casani. Legajo 220/1.

(1741a). [Proyecto de Gramática] del Sr. Francisco Antonio de Angulo. Legajo 219/1 (doc. 1).

(1741b). [Proyecto de Gramática] del Sr. Ignacio de Ceballos. Legajo 219/1 (doc. 2).

(1746a). Disertación: [La division dela sintaxis en concordancia, y regimen, lo que importan estas voces entre grammaticos, y quantas concordancias ay en Castellano, con sus excepciones?] de Antonio Zapata. Legajo 221/3 (doc. 1).

(1746b). Disertación: [De las voces, concordancia, y regimen, en que se divide la syntaxis, y quantas concordancias hay en Castellano con sus excepciones] de Francisco Antonio Antonio Angulo. Legajo 221/3 (doc. 2).

(1746c). Disertación: [Della concordancia y régimen] de Ignacio de Luzán. Legajo $221 / 3($ doc. 3$)$

BENOT, Eduardo (1889). ¿Qué es hablar? Discurso de D. Eduardo Benot, leído en la recepción pública de la Real Academia Española el día 14 de abril de 1889. [Contestación de D. Víctor Balaguer]. Publicado en Discursos leídos en las Recepciones Públicas de la Real Academia Española. Serie segunda. II. Madrid. Aldus, S.A. 1946. Págs. 129-160.

CAtalina Del Amo, Severo (1861). Discursos leídos ante la Real Academia Española, en la recepción pública de don Severo Catalina del Amo, el día 25 de marzo de 1861. [Tema: “De las lenguas semíticas en su influencia sobre la castellana”. Contestación de D. Tomás Rodríguez Rubí]. Madrid: Establecimiento tipográfico de don Luis García. COMmelerÁn, Francisco (1890). Discursos leídos ante la Real Academia Española en la recepción pública del Sr. D. Francisco A. Commelerán y Gomez el día 25 de mayo de 1890. [Contestación de D. Juan Valera]. Madrid: Imprenta de A. Pérez Dubrull.

COTARelo y MORI, Emilio (1900). Discursos leídos ante la Real Academia Española en la recepción pública de don Emilio Cotarelo y Mori, el día 27 de mayo de 1900. [Tema: “Imitaciones castellanas del Quijote". Contestación de D. Alejandro Pidal y Mon]. Madrid: Imprenta Ducazcal.

\footnotetext{
${ }^{1}$ Recuerdo que, para la referencia de las disertaciones y apuntes sobre gramática, sigo el criterio aconsejado por el propio Archivo de la RAE: título atribuido entre corchetes. Número de legajo / número de carpeta (y número de documento).
} 
(1928). Discurso acerca de las obras publicadas por la Real Academia Española leido en junta pública de 7 de octubre de 1928 por el Excmo. Sr. D. Emilio Cotarelo y Mori Individuo de número y Secretario perpetuo de dicha Academia, con ocasión de celebrar la "Fiesta del libro" e inaugurar una exposición de las referidas obras. Madrid: Tipografía de la "Revista de Archivos".

CUTANDA, Francisco (1861). Discursos leídos ante la Real Academia Española, en la recepcion pública de D. Francisco Cutanda, el día 17 de Marzo de 1861. [Contestación de D. Juan Eugenio de Hartzenbusch]. Madrid: Imprenta y estereotipia de M. Rivadeneyra.

FERNÁNDEZ RAMíREZ, Salvador (1987). La nueva gramática académica: el camino hacia el Esbozo (1973). Madrid: Paraninfo (Colección Filología). [Volumen preparado por José Polo].

FERNÁNDEZ-GuERRA y ORBE, Aureliano (1857). Discursos leídos antes la Real Academia Española, en la recepción pública de D. Aureliano Fernández-Guerra y Orbe. [Tema: “Existencia real y verdadera del poeta D. Francisco de la Torre, y su carácter y estilo diferentes de los de D. Francisco de Quevedo". Contestación, sobre el mismo asunto, por el Excmo. Sr. Marqués de Molins]. Madrid: Imprenta y Estereotipia de M. Rivadeneyra.

GALINDO Y DE VERA, León (1875). Autoridad de la Academia Española en materia de lenguaje. Discurso leído en Junta Pública celebrada para darle posesión de plaza de número, el día 24 de febrero de 1875. [Contestación de D. Fermín de la Puente y Apezechea]. Madrid: Gaspar. Publicado también en las Memorias de la Real Academia Española. Tomo V. Madrid: Imprenta y Fundición de Manuel Tello, Impresor de Cámara de S.M. 1886. [Cito por la última edición].

MONLAU, Pedro Felipe (1859). Discursos leidos ante la Real Academia Española, en la recepcion pública del Ilmo. Sr. D. Pedro Felipe Monlau, el dia 29 de junio de 1859. Madrid: Imprenta y estereotipia de M. Rivadeneyra. [Contestación de D. Juan Eugenio de Hartzenbusch].

ReAl ACADEMia EsPaÑola (1861b). Dictámen de la Comision de Gramática leido en las juntas de 31 de enero y 7 de febrero de 1861. Madrid.

Tamayo y Baus, Manuel (1859). Discursos leídos ante la Real Academia Española en la recepción pública de Don Manuel Tamayo y Baus, el día 12 de junio de 1859. [Tema: “La verdad considerada como fuente de belleza en la literatura dramática. Contestación de D. Aureliano Fernández-Guerra y Orbe; tema: “Claras y perenales fuentes de la inspiración dramática"]. Madrid: M. Rivadeneyra. 
ViÑAZA, Cipriano Muñoz y Manzano, conde de la (1895). Discursos leidos ante la Real Academia Española en la recepción pública de don Cipriano Muñoz y Manzano el día 16 de junio de 1895. [Tema: "De la poesía satírico-política en España". Contestación de D. Alejandro Pidal y Mon]. Madrid: Imp. Asilo de Huérfanos. 


\section{B. Textos no académicos}

AbADIE, Federico N. (1896). La gramática de la lengua castellana por la Real Academia Española; aumentada á un nuevo método de enseñarla y ejercicios de composición por Federico N. Abadie. Montevideo: Imprenta Artística de Dornaleche y Reyes.

ALDRETE, Bernardo José de (1606). Del origen y principio de la lengua castellana o romance que oi se usa en España. [Cito por la ed. facsímil de Lidio Nieto. Madrid. CSIC. I1972; II-1975].

ANÓNIMO (1555). Útil y breve institucion para aprender los principios y fundamentos de la lengua hespañola. Lovaina. [Cito por la edición facsimilar con estudio e índice de Antonio Roldán. Madrid: CSIC. (Colección: Clásicos Hispánicos. Serie I. Ediciones facsímiles. Volumen XV). 1977].

ANÓNIMO (1559). Gramática de la lengua vulgar de España. Lovaina. [Cito por la edición facsímil de Rafael de Balbín y Antonio Roldán. Madrid: CSIC. (Colección: Clásicos Hispánicos. Serie I. Ediciones facsímiles. Volumen VIII). 1966].

ANTEQUeRA, JOSÉ MARÍA (1848). Gramática española. Filología. (Entrega 52, Tratado 56 de Instruccion para el pueblo. Cien tratados sobre los conocimientos mas utiles e indispensables. Madrid: Establecimiento tipográfico de Mellado.

ARAÚJO, Fernando (1880). Gramática razonada de la lengua francesa precedida de una introducción sobre la Historia de la Literatura francesa, dedicada á la juventud y al profesorado español por Fernando Araujo, escritor público, Director que ha sido de varias publicaciones, Profesor de Francés en el Instituto provincial de Salamanca y en la Escuela de Artes y Oficios de la misma, Licenciado en la Facultad de Filosofía y Letras en la Universidad de Salamanca, miembro de la Sociedad Geográfica de Madrid, etc. Salamanca: Imp. y Lit. de D. Sebastian Cerezo, editor.

ARNAULD, Antoine et Claude LANCELOT (1660). Grammaire générale et raisonnée. [Cito por la edición de Ramón Morillo-Velarde Pérez (1980): “Gramática general y razonada de Port-Royal. Seguida de la segunda parte de la lógica. Madrid: SGEL].

AVENDAÑO, Joaquín de (1886). Elementos de gramática castellana precedidos de unas ligeras nociones de lingüística y seguidos de algunas de literatura, retórica y poética por D. Joaquín Avendaño. Novena edición corregida, aumentada y reformada por el autor. Barcelona: Librería de Bastinos, Madrid: Librería de Hernando.

BALLOT, José Pablo (1842 [1796]). Gramática de la lengua castellana, dirigida á las escuelas por 
el Dr. D. José Pablo Ballot, presbitero. Arreglada á la última ortografía de la Real Academia Española, y mejorada y añadida por el mismo autor. Barcelona: Imprenta de don Antonio __*

BEAUZEE, M. (1767). Grammaire générale, ou exposition raisonnée des éléments nécessaires du langage, Pour fervir de fondement à l'étude de toutes les langues. Par M. Beauzée de la Société royale des fciencies \& arts de Metz, des Sociétés littéraires d'Arras \& d'Auxerre, profelfeur de Grammaire à l'Ecole royale militaire. Paris: De l'imprimerie de J. Barbou.

BELlO, Andrés (1860 [1847]). Gramática de la lengua castellana destinada al uso de los americanos. Con las notas de Rufino José Cuervo. [Cito por la edición de Ramón Trujillo. Madrid: Arco/Libros. 1988]

BENOT, Eduardo (1853). Breves apuntes sobre los casos y las oraciones, preparatorios para el estudio de las lenguas por el método del doctor Ollendorf, redactados para uso de los alumnos del colegio San Felipe Neri de Cádiz, por Eduardo Benot. Cádiz: Imprenta de D. Filomeno Fernández Arjona.

(h. 1889). Arquitectura de las lenguas por Eduardo Benot. Madrid: Administración Juan Muñoz Sánchez, editor. 3 tomos. [s. a.].

(1910). Arte de hablar. Gramática filosófica de la lengua castellana. Madrid: Librería de los sucesores de Hernando. [Cito por la edición facsímil de Ramón Sarmiento. Barcelona: Anthropos Editorial del hombre. (Colección: Autores, textos y temas Lingüística).

BUFFIER (1709). Grammaire françoise sur un plan nouveau por en rendre les principes plus clairs $\mathcal{E}$ la pratique plus aifée. Contenant divers traités sur la nature de la Grammaire en general; fur l'ufage; fur la beauté des Langues \& fur la maniere de les aprendre; fur le ftile; fur l'ortographe; fur les accens fur la longueur des filabes Françoises; fur la ponctuation, Ec. Par le Pere Buffier, de la Compagnie de Jesus. Paris: chez Nicolas le Clerc, Michel Brunet, Leconte et Montalant.

CEJADOR Y FRAUCA, Julio (1905). La lengua de Cervantes. Gramática y diccionario de la lengua castellana en El ingenioso hidalgo don Quijote de la Mancha. Obra premiada en el certamen público, abierto en el Ateneo de Madrid con ocasion del III centenario de la publicacion del «Quijote». Tomo I. Gramática. Madrid: establecimiento tipográfico de Jaime Ratés.

CHIFLET, Laur (1680). Essay dune parfaite Grammaire, de la langue françoise: Ou le Lecteur trouvera en bel ordre, tout ce que eft de plus neceffaire, de plus curieux, $\mathcal{E}$ de plus elegant, 
en la Pureté, en l'Orthographe, E en la Prononciation de cette Langue. Par le R. P. Laur Chiflet, de la Compagnie de Jesus. Sixiéme \& derniere Edition. Cologne: chez Pierre le Grand.

CONDILLAC, Etienne Bonnot de (1798). Principes généraux de grammaire pour toutes les langues, Avec leur application particulière à la langue française; Par Condillac. Pour servir aux Écoles Centrales. Nouvelle edition. Paris: chez A. J. Ducour, Libraire. [Edición en microficha. Paris: Microéditions Hachette. 1971].

CORREAS, Gonzalo (1625). Arte de la lengua española castellana compuesto por el Maestro Gonzalo Correas, catedrático de Griego y Hebreo en la Universidad de Salamanca. [Cito por la edición de Emilio Alarcos García. Madrid: RFE.- Anejo LVI. 1954]. (1627). Trilingüe de tres artes de las tres lenguas Castellana, Latina, i Griega, todas en romanze. Por el Maestro Gonzalo Correas Catedrático propietario de la Catedra de lēguas Hebrea, i Caldea, i de la maior de Griego en la Vniuerfidad de Salamanca. Dedicado al Catolico Rey Don Felipe IIII, nuestro Señor. Salamanca: en la Oficina de Antonia Ramirez. [Cito por la edición de Manuel Taboada Cid: Arte Castellana (1627). Universidad de Santiago de Compostela. 1984.]

CORTEJón, Clemente (1911). Curso de lengua castellana por D. Clemente Cortejón Correspondiente de la Real Academia Española. Barcelona: Tipografía La Académica, de Serra Hnos y Russell.

CRISTÓBAL y JARAmiLlo, Guillermo Antonio de (1793). Arte nuevo de ortología, gramática castellana, ortografía y calografía. Toledo: Herederos de Nicolás Alcuanzano.

Cuervo, Rufino José (1886-1893). Diccionario de Construcción y régimen de la lengua castellana por R. J. Cuervo; continuado y editado por el Instituto Caro y Cuervo. Barcelona: Herder. 1998.

DestutT De TRACY, M. (1822). Gramática general por M. Destutt, conde de Tracy, par de Francia. Traducida por Juan Angel Caamaño. Madrid: Imprenta de D. José del Collado.

DísColo, Apolonio (s. II d.C.). Sintaxis. [Cito por la edición de Vicente Bécares. Madrid: Editorial Gredos. 1987].

DOBRANICH, Baldmar F. (1893). Gramática castellana. Tercer año. Breves nociones de Lingüística y de Etimología. Sintaxis particular. Observaciones históricas y filológicas. Ejercicios. Por Baldmar F. Dobranich. Buenos Aires: "La Argentina"-Sociedad cooperativa de Librería y Papelería. 
Du MARSAIS, M. (1769). Logique et principes de grammaire, Par M. Du Marsais. Ouvrages pofthumes en partie, E en partie extraits de plufieurs Traités qui ont déja para de cet Auteur. Paris: Chez Briasson, Libraire; Le Breton, premier Imprimeur du Roi; Herissant Fils, Libraire.

Dublé, Ignacio (1911). Gramática de la lengua castellana (según la Real Academia Española) por Ignacio Dublé Catedrático de dicha asignatura y de Lengua Francesa en la Escuela Superior de Administración Mercantil de Barcelona. Barcelona: Establecimiento tipográfico de Mariano Galve.

FERNÁNDEZ ASCARZA, Victoriano (1924). Diccionario de legislación de primera enseñanza por Don Victoriano Fernández Ascarza, Ex Consejero de Instrucción pública, Director de El Magisterio Español, Abogado, Doctor en Ciencias, etcétera, etcétera. Tercera edición. [s.l.] Editorial Magisterio Español.

FERNÁNDEZ MONJE, Isidoro (1854). Curso elemental de la lengua española, redactado con la posible sujecion á los principios de la gramática general, por el profesor D. Isidoro Fernández Monje. Madrid: Librería de D. Leon Pablo Villaverde.

FERNÁNDEZ y FERNÁNDEZ NAVAMUEL, Manuel y Alfonso RETORTILlO Y TORNOS (1909). Tratado elemental de gramática castellana literatura preceptiva literatura española é historia literaria por D. Manuel Fernández y Fernández-Navamuel Doctor en Filosofía y Letras, Licenciado en Derecho, Maestro Normal, Profesor numerario, por oposición, de las Secciones de Letras y de Ciencias de Escuela Normal, Contador de fondos provinciales y municipales, por oposición, ex Inspector de enseñanza, Académico-Profesor de la Real de Jurisprudencia y Legislación, y por D. Alfonso Retortillo y Tornos Doctor en Filosofía y Letras, Doctor en Derecho, Maestro Normal, Profesor numerario, por oposición, titular de la Sección de Letras de la Escuela Normal de Maestros de Madrid, ex Catedrático numerario, por oposición también, de Literatura en el Instituto de Badajoz, Profesor auxiliar, por concurso, en la Facultad de Derecho de la Universidad Central, AcadémicoProfesor de la Real de Jurisprudencia y Legislación, miembro honorario de la Academia Mont-Real de Toulouse, precedido de una carta de D. Ramón Menéndez Pidal Académico de la Española. Madrid: Librería de los Sucesores de Hernando.

GAMBOA, Francisco A. (1893). Gramática práctica de la lengua castellana, conforme a las prescripciones de la Real Academia Española. 2a ed. - Nueva. San Salvador: Tipografía Católica. 
GIRÓ Y ROMA, José (1857). Gramática elemental de la lengua castellana, por D. José Giró y Roma. Aprobada para servir de texto en las escuelas normales de instruccion primaria del reino. Segunda edicion. Barcelona: imprenta de Roberto Torres.

(1871). Gramática elemental de la lengua castellana, por D. José Giró y Roma. Aprobada para servir de texto en las escuelas normales de instruccion primaria del reino. Tercera edicion. Barcelona: imprenta de Gómez é Inglada.

GISBERT Y HOËL, Luciano (1902 [1900]). Teoría y análisis de la oración gramatical por D. Luciano Gisbert y Hoël catedrático de lengua francesa en el Instituto de Córdoba. Madrid: Librería de Hernando y Compañía.

Gómez Asencio, José J. Comp. (2001). Antiguas gramáticas del castellano. Madrid: Fundación Histórica Tavera. CD-Rom.

GómEZ DE SAlAZAR, Fernando (1869). Gramática de la lengua castellana, por D. Fernando Gomez de Salazar. Madrid: Imprenta de F. Escamez.

(1874). Gramática de la lengua castellana, por D. Fernando Gomez de Salazar. Madrid: Imprenta de J. M. Lapuente.

Gómez Hermosilla, José (1841 [1835]). Principios de gramática general por D. Jose Gomez Hermosilla. Tercera edicion. Madrid: en la Imprenta Nacional.

Gramática de la lengua castellana compuesta por la Real Academia Española. [Manila]: reimpresa à costa de la Real Sociedad Económica de la Ciudad de Manila: en el Real Colegio de Santo Thomas, por Vicente Adriano. 1793.

Gramática de la lengua castellana. compuesta por la Real Academia Española. cuarta edicion, corregida y aumentada. Reimpresion escrupulosamente arreglada á la última edicion de la Academia que es del año 1796: y á la cual se han agregado Numerosas notas tomadas de Salvá y algun otro; La Prosodia y Métrica del mismo Salvá; La Ortografia de la precitada Academia, según la última edicion de 1850, con notas del editor; y Un nuevo Tratado de Ortografia Fonética, ó sea Sistema de escribir la lengua castellana según se pronuncia. New York: Imprenta Española. 1853.

Gramática de la lengua castellana compuesta por la Real Academia Española. Nueva edicion, Corregida con esmero, aumentada con el Prontuario de Ortografía compuesto de real órden por la misma Academia, que no se halla en ninguna de las anteriores, y con unas Nociones de Prosodia, de que carecia igualmente esta obra. Paris: Librería de Garnier Hermanos, sucesores de D. V. Salvá; Méjico: J. M. Andrade. 1855. 
Gramática de la lengua castellana compuesta por la Real Academia Española. Nueva ed. corregida con esmero, aumentada con el "Prontuario de Ortografía" compuesto de real órden por la misma Academia... y con unas "Nociones de Prosodia". Paris: Librería de Garnier Hermanos. 1874.

HERRAINZ, Gregorio (1869). Gramática castellana teórico-práctica en todas sus partes. Obra acomodada á las necesidades de esta enseñanza en las Escuelas Normales y escrita por D. Gregorio Herrainz, profesor de la de Guadalajara. Madrid: Imprenta de la Monarquía democratica.

(1885). Tratado de gramática razonada, con aplicacion decidida y constante al estudio del idioma español, por Don Gregorio Herrainz, Caballero de Carlos III, y Director de la Escuela Normal Superior de Maestros de Segovia. Segovia: Establecimiento tipográficode F. Santiuste.

[Edición digitalizada por José J. Gómez Asencio, comp., 2001].

HERRANZ Y QUIRÓS, Diego Narciso (1815). Elementos de gramática castellana. Madrid.

(1834). Gramática de la lengua castellana, ordenada en forma de diálogo y estilo matemático, para mejor instruccion de la juventud, por don Diego Narciso Herranz y Quirós, Profesor de primera educacion en esta Corte, y Revisor de letras, firmas y papeles sospechosos por nombramiento del real y supremo Consejo de Castilla. Madrid: Oficina de D. Julian Viana Razola.

ISIDORO DE SEVILLA (h. 620). Etimologías. [Cito por la edición bilingüe de José Oroz Retama y Manuel-A. Marcos Casquero. Introducción de Manuel C. Díaz y Díaz. Madrid. BAC. 2000].

JiMÉNEZ PATÓN, Bartolomé (1614). Instituciones de la Gramatica española. Dirigidas al Licenciado Sebastian de Cobarrubias Orozco, Capellan de su Majestad, Maestre escuela, y Canonigo de la Santa Iglesia de Cuenca, y consultor del santo oficio de la Inquisicion, y Autor del Tesoro de la lengua Española. Por el maestro Bartolomé Ximenez Paton. [Cito por la edición de Antonio Quilis y Juan Manuel Rozas. Madrid: CSIC. (Colección: Clásicos Hispánicos. Serie III. Ediciones históricas. Volumen V). 1965]. JOVELLANOS, Gaspar Melchor de (1795). Curso de humanidades castellanas, en Obras publicadas e inéditas de don Gaspar Melchor de Jovellanos (edición de Cándido Nocedal). Madrid: Atlas. 1963. (Biblioteca de Autores Españoles. 46).

Ley de 10 de enero de 1879, de la propiedad intelectual, publicada en La Gaceta de Madrid, n. ${ }^{\circ}$ 12, de 12 de enero de 1879.

[Consulta en red: <http://www.derecho-internet.org/node/365> (última consulta: abril de 2008)]. 
MARTÍNEZ GARCÍA, Ramón (1883). Curiosidades gramaticales ó complemento de la gramática castellana. Libro utilísimo á los profesores y alumnos de las academias, institutos, colegios, escuelas normales, escuelas de instrucción primaria, y á las personas de letras por D. Ramón Martínez y García Profesor de la Escuela pública superior de la capital de Puerto-Rico. Segunda edición. Madrid: Librería de D. Gregorio Hernando.

(1896). Curiosidades gramaticales. Gramática ampliada del idioma español y sus dialectos por D. Ramón Martínez García Caballero de Isabel la Católica, Profesor normal y ex Director de la Escuela pública superior de Puerto Rico. Obra premiada con medalla de oro y mencion honorable en las exposiciones universales de Barcelona y París, años 1888 y 1889. Tercera edición muy corregida, y aumentada con una Tercera parte. Madrid: Librería de la Viuda de Hernando y $C .{ }^{a}$

MARTíNEZ GÓMEZ GAYOSO, Benito (1769 [1743]). Gramática de la lengua castellana reducida a breves reglas, y facil méthodo para inftruccion de la Juventud; nuevamente añadida y emendada por su autor D. Benito Martinez Gomez Gayofo. Con Licencia. Madrid: en la Imprenta de D. Gabriel Ramirez.

[Edición digitalizada por José J. Gómez Asencio, comp., 2001].

MARTínEZ SEVILlA, Román (1851). Elementos de gramática española, por don Roman Martinez Sevilla, maestro de instrucción primeria superior en Burgos é individuo del tribunal de oposiciones á las escuelas de la misma provincia.Burgos: Imprenta de Pascual Polo.

Monlau, Pedro Felipe (1856). Diccionario etimológico de la lengua castellana (ensayo) precedido de unos rudimentos de etimología por el Dr. D. Pedro Felipe Monlau, catedrático que fue de Literatura é Historia en la Universidad de Barcelona, y ahora de Psicologia y Lógica en la Universidad de Madrid. Madrid: Imprenta y estereotipia de M. Rivadeneyra.

(1870). Vocabulario gramatical de la lengua castellana que contiene la definicion y explicacion de las voces técnicas usadas en gramática, con sus correspondientes observaciones y ejemplos; libro auxiliar y suplemento de todas las gramáticas elementares [sic]. Compuesto para uso de los Maestros, y de los discípulos que hayan terminado sus estudios elementares de Gramática en las Escuelas de primeras letras, Institutos y Colegios de segunda enseñanza, Escuelas Normales, etc., por 
D. Pedro Felipe Monlau. Madrid: Imprenta y Estereotipia de M. Rivadeneyra.

NebRIJA, Elio Antonio de (1492). Gramática de la lengua castellana. [Cito por la edición de Miguel Ángel Esparza y Ramón Sarmiento. Madrid: Fundación Antonio de Nebrija; SGEL. 1992. (Serie: Clásicos españoles)].

NobOA, A. M. de (1839). Nueva gramática de la lengua castellana segun los principios de la filosofía gramatical, con un apéndice sobre el arreglo de la Ortografia, por el Br. D. A. M. de Noboa. Madrid: Imprenta de don Eusebio Aguado.

[Edición digitalizada por José J. Gómez Asencio, comp., 2001].

NONELL, Jaime (1909). Gramática de la lengua castellana por el P. Jaime Novell de la Compañía de Jesús. Segunda edición. Barcelona: Eugenio Subirana Edit. y Lib. Pontificio.

ORÍO Y RUBIO, Millán (1897 [1875]). Tratado teórico-práctico de análisis gramatical y lógico de las oraciones. Madrid. Sucesores de Hernando.

PALAU y DUlCET, Antonio (1948). Manual del librero hispano-americano. Bibliografía general española e hispano-americana desde la invención de la imprenta hasta nuestros tiempos con el valor comercial de los impresos descritos, por Antonio Palau y Dulcet. Segunda edición, corregida y aumentada por el autor. Tomo primero. Barcelona: Librería Anticuaria de A. Palau.

(1962). Manual del librero hispanoamericano. Bibliografía general española e hispanoamericana desde la invención de la imprenta hasta nuestros tiempos con el valor comercial de los impresos descritos, por Antonio Palau y Dulcet, primer hijo predilecto de la villa ducal de Montblanc. Segunda edición, corregida y aumentada por el autor. Tomo XV, revisado y añadido por Agustín Palau, Profesor y Bibliotecario. Barcelona: Librería Palau.

PÉREZ y AGUADO, Sebastián (1872). Tratado de sintáxis de la lengua castellana, precedido de un breve análisis de las funciones de las palabras, y de ligeras nociones de ideología y de gramática genera. Granada: Impr. y libr. de D. Paulino V. Sabatel.

PONS Y ARGENTÓ, Francisco (1850). Gramática castellana fundada sobre principios filosóficos, por D. Francisco Pons y Argentó. Barcelona: Imrenta de Juan Gaspar.

PONTES Y FERNÁNDEZ, José María (1911). Gramática de la lengua española por D. José María Pontes y Fernández. Sustituto que fué de esta asignatura en la Normal Central de Maestros y exencargado de la misma y de Literatura Española en las Escuelas de Institutrices y de Comercio sostenidas por la Asociación para la Enseñanza de la Mujer. Tercera edición. Madrid: Imprenta de Ricardo F. de Rojas. 
QUiNTILIANO, Marco Fabio (h. 95). Instituio Oratoria. [Cito por la edición publicada en Ouvres Complètes de Quintilien. Traduction de la collection panckoucke par M. C. V. Ouizille. Nouvelle édition revue avec le plus grand soin par M. Charpentier Inspecteur honoraire de l'Académie de Paris, agrégé de la Faculté des Lettres. Paris: Garnier Frères, Libraires-éditeurs. 1863. 3 vols.].

RABOSO DE LA PEÑA, E. (1912). Elementos de gramática castellana. cuarta edición. Barcelona: Librería Hispano-Americana de Ruiz y Feliu.

REMENTERÍA, Mariano de (1843). Conferencias gramaticales sobre la lengua castellana, ó elementos esplanados de ella. Obra especialmente destinada á la enseñanza de los alumnos del seminario de la Escuela Normal de Instrucción Primaria de Madrid, y acomodada para todos los establecimientos de Educacion. Por D. Mariano de Rementería, profesor de Gramática castellana en dicho Seminario. Segunda edicion, corregida y aumentada. Madrid: Imprenta de Fuentenebro.

REYNA, Manuel (1914). Gramática razonada de la Lengua Española por el Licenciado Manuel Reyna. Madrid: Imprenta Española.

Rubel y VIDAL, Juan (1797). Compendio de gramática en lengua castellana, dispuesto en preguntas y respuestas. Y con arreglo a la quarta edicion de la Gramática que la Real Academia Española publico en el año próximo pasado de 1796. Barcelona: Sierra y Martí.

RUIZ DE LA PEÑA, Francisco (1889). Sintaxis filosófica y peculiaridades ortográficas y etimológicas del idioma español. Bilbao: Lib. de Segundo Salvador.

RUIZ MOROTE, Francisco (1880). Gramática castellana teórico-práctica, premiada en las exposiciones aragonesa, Viena y Madrid, por D. Francisco Ruiz y Morote, regente de la escuela práctica de la normal superior de maestros de Ciudad-Real. Sexta edicion corregida y metodizada. Ciudad-Real: Establecimiento tipográfico del Hospicio.

SALLERAS, Matías (1887 [1876]). Gramática razonada de la lengua española por M. Salleras profesor de la Escuela Normal de Barcelona. Segunda edición aumentada con el Tratado de Análisis del Lenguaje. Barcelona: Faustino Paluzíe, impresor-editor.

SALVÁ, Vicente (1847 [1830]). Gramática de la lengua castellana según ahora se habla. [Cito por la edición de Margarita Lliteras. Madrid: Arco/libros. 1988].

SAN PEDRO, Benito de (1769). Arte del romance castellano dispuesta segun sus principios generales $i$ el uso de los mejores autores por el P. Benito de San Pero de la Efcuela Pia. Con las licencias necessarias. Valencia: en la Imprenta de Benito Monfort, 
Impreffor del Colegio Andrefiano.

[Edición digitalizada por José J. Gómez Asencio, comp., 2001].

SÁNCHEZ DE LAS BROZAS, Francisco (1587). Minerva seu de causis linguae latinae.

Introducción, edición y traducción de E. Sánchez Salor (libros I, III y IV) y C. Chaparro (libro II). Universidad de Extremadura. 1995.

SAQUENIZA, Jacopo (1832). Gramática elemental de la lengua castellana, con un compendio de ortografía. Por J. S. Madrid: imprenta de don Norberto Llorenci.

[Edición digitalizada por José J. Gómez Asencio, comp., 2001].

TOMÁs DE AQuinO (h. 1265-1273). Suma de teología. [Cito por la edición dirigida por los Regentes de Estudios de las Provincias Dominicanas de España. Biblioteca de Autores Cristianos. 2005. CD-Rom].

Vicente GARCíA, Santiago (1854). Gramática de la lengua española. Por don Santiago Vicente Garcia. Madrid: Editor propietario, Eusebio Garcia Vazquez.

(1855). Examen crítico de la Nueva Gramática Castellana de la Real Academia Española, por don Santiago Vicente García. Madrid: Imprenta y estereotipia de M. Rivadeneyra.

VILlALÓN, Cristóbal de (1558). Gramatica Castellana. Arte breue y compendiosa para saber hablar y escreuir en la lengua Castellana congrua y deçentemente. Por el Licenciado Villalón. Amberes: Casa de Guillermo Simon. [Cito por la ed. facsímil de Constantino García. Madrid. CSIC. Colección Clásicos Hispánicos, serie I, vol XII. 1971].

VIÑAZA, Cipriano Muñoz y Manzano, conde de la (1893). Biblioteca histórica de la filología castellana por el conde de la Viñaza. Obra premiada por voto unánime en público certamen de la Real Academia Española. Madrid: Imprenta y fundición de Manuel Tello, impresor de cámara de S.M. 


\section{FUENTES INDIRECTAS}

ABAD NeBOT, Francisco (1986). “Las ideas lingüísticas en la modernidad española: Juan de Valdés, Bernardo de Aldrete, la Academia", en Homenaje a Pedro Sainz Rodríguez. Vol. 2. Estudios de lengua y literatura. Madrid: Fundación Universitaria Española. Págs. 1-17.

AHUMADA LARA, Ignacio (1988). “Información gramatical implícita en la definición lexicográfica", en TH, XLIII, págs. 81-94.

Alvar EZQUERRA, Manuel (1982). “Diccionario y gramática”, en LEA IV, págs. 151-212. (1997). “Algunos aspectos de la presencia gramatical en el diccionario", en Jesús Terrón González y José M. González Calvo (coords.): IV Jornadas de metodología y didáctica de la lengua española: Sintaxis. Universidad de Extremadura. Servicio de Publicaciones. Págs. 115-130.

(2002 [1993]). “El Diccionario de la Academia en sus prólogos”, en Manuel Alvar Ezquerra: De antiguos y nuevos diccionarios del español. Madrid: Arco/Libros.

ÁlVAREZ, Alfredo I. (1999). “Las construcciones consecutivas”, en Ignacio Bosque y Violeta Demonte (Dir.): Gramática descriptiva de la lengua española. Madrid: Espasa Calpe, S.A. Págs. 3739-3804.

Álvarez MARTíneZ, Ma Ángeles (1987). “Las oraciones subordinadas. Esbozo de clasificación", en VERBA: Anuario Galego de Filoloxía, 14, págs. 117-148.

ARENS, Hans (1976 [1969]). La lingüística. Sus textos y su evolución desde la Antigüedad hasta nuestros días. [Versión española de José María Díaz-Regañón López]. Madrid: Editorial Gredos (Biblioteca Románica Hispánica. III. Manuales. 37). 2 vols. [Primera edición en alemán].

ARIAS SOLÍs, Francisco (2004). “Ignacio de Luzán. La voz del Neoclasicismo”, en Arena y Cal, N. 110 (noviembre de 2004).

[Consulta en red: <http://www.islabahia.com/arenaycal/2004/11noviembre/arias110.htm> (última consulta: mayo de 2008)].

ARTigas FerRANDO, Miguel y Pedro SÁINZ y RodríGueZ (1930). Epistolario de Valera y Menéndez Pelayo publicado con una introducción y notas por Miguel Artigas Ferrando Director de la Biblioteca Menéndez Pelayo y Pedro Sáinz Rodríguez Catedrático de la Universidad de Madrid y Buenos Aires: Compañía IberoAmericana de Publicaciones. 
AZORÍN FERNÁNDEZ, Dolores (2000). Los diccionarios del español en su perspectiva histórica. Publicaciones de la Universidad de Alicante.

BACKER, Augustin de (1869-1876). Bibliothèque des écrivains de la Compagnie de Jésus ou Notices bibliographiques par Augustin de Backer de la Compagnie de Jésus avec la collaboration d'Alois de Backer de la méme compagnie. Nouvelle édition refondue et considérablement augmentée. 3 vols. Tome premier (A-G): Liége: chez L'auteur A. de Backer, Paris: chez L'auteur C. Sommervogel. 1869. Tome deuxième (H-Q): Liége: chez l'auteur A. de Backer, Lyon: chez l'auteur C. Sommervogel. 1872. Tome troisième (R-Z): Louvain: chez l'auteur A. de Backer, Lyon: chez l'auteur C. Sommervogel. 1876.

BÁEZ SAN JosÉ, Valerio (1972). “El concepto de oración en el estructuralismo europeo y americano", en Homenaje al Dr. Martínez. Bogotá. Págs. 22-33.

(1974). "La nueva escuela de Praga y el concepto de oración gramatical", en Millars II, págs. 127-169. (1987). “Oración y esquema oracional”, en LEA, IX, págs. 65-81.

BAÑUElos MARTíneZ, José Ma (2000). “D. Esteban Oca y Merino: un maestro ejemplar”, en Investigación humanística y científica en La Rioja: homenaje a Julio Luis Fernández Sevilla y Mayela Balmaseda Aróspide. Instituto de Estudios Riojanos. Págs. 317-330.

BARATIN, Marc (1989). La naissance de la syntaxe à Rome. Paris: Minuit.

BÉCARES BOTAS, Vicente (1987). “Introducción” a Sintaxis de Apolonio Díscolo. Madrid: Editorial Gredos (Biblioteca Clásica Gredos, 100).

BleCUA, José Manuel (2006). Principios del Diccionario de Autoridades. Discurso leído el día25 de junio de 2006 en su recepción pública por el Excmo. Sr. D. José Manuel Blecua. Y contestación del Excmo. Sr. D. José Antonio Pascual. Madrid.

BLEIBERG, Germán (1951). Antología de elogios de la lengua española. Madrid: Ediciones Cultura Hispánica.

Dir. (1979). Diccionario de Historia de España. Madrid: Alianza Editorial. 2. ${ }^{a}$ edición. 3 vols.

BLESA, José Antonio (1984). “De la interdependencia oracional”, en Estudis en memòria del professor Sanchis Guarner: Estudis de llengua i literatura. Universitat de València. Págs. 39-46.

BoOne, Annie (1994). "Présentation"a La subordination. Travaux de Linguistique. Revue Internationale de Linguistique Française. N ${ }^{o}$ 27. Lovain-la-Neuve: Éditions Duculot. Págs. 9-11 
BOSQUE, Ignacio (1997). “La investigación gramatical sobre el español. Tradición y actualidad", en Miguel Ángel Esparza y Maria do Carmo Enríquez (eds.): Estudios de lingüística. Departamento de Filología Española. Universidade de Vigo.

BRUCART, José M $M^{a}$ (1994). “Sintaxis y semántica en el análisis generativo de la oración”, en Francisco Hernández Paricio (ed.): Perspectivas sobre la oración. Universidad de Zaragoza. Págs. 9-69.

BUCETA, Erasmo (1925). “La tendencia a identificar el español con el latín: un episodio cuatrocentista", en Homenaje ofrecido a Menéndez Pidal. Madrid: Librería y casa editorial Hernando. Vol 1. Págs. 85-108.

CALAS, Frédéric y Anne-Marie GARAGNON (2002). La phrase complexe. De l'analyse logique à l'analyse structurale. Paris: Hachette.

Calero Vaquera, M. ${ }^{a}$ Luisa (1986). Historia de la gramática española (1847-1920). De A. Bello a R. Lenz. Madrid: Editorial Gredos (Biblioteca Románica Hispánica. II. Estudios y ensayos. 345).

(2007a). "Desarrollo de la sintaxis en la tradición gramatical hispánica", en Josefa Dorta y otros: Historiografía de la lingüistica en el ámbito hispánico. Fundamentos epistemológicos y metodológicos. Madrid: Arco/Libros. Págs. 89-118. (2007b). “Análisis lógico y análisis gramatical en la tradición española: hacia una revolución de la sintaxis". En prensa.

CAmpos Souto, Mar y José Ignacio Pérez Pascual (2006). El Diccionario de la Real Academia Española: ayer y hoy. Anexos de Revista de Lexicografía, 1. Universidade da Coruña.

CARriLlo Herrera, Gastón (1963). "Las oraciones subordinadas", en BFUCh, Vol. 15, págs. 165-221.

CASIELLES SUÁREZ, Eugenia (2000). “El tratamiento del orden de palabras en algunas gramáticas españolas de los siglos XIX y XX", en HL, XXVII: 2/3, págs. 415-436.

CERDÁ, Ramón (1986). Diccionario de lingüística. Madrid: E. G. Anaya.

CHERVEL, André (1977). Histoire de la grammaire scolaire. Paris: Payot

CHEVALIER, Jean-Claude (1968). Histoire de la syntaxe. Naissance de la notion de complément dans la grammaire française (1530-1750). Genève: Librairie Droz.

CotArelo VAlledor, Armando (1946). Bosquejo histórico de la Real Academia Española compuesto por su censor excelentísimo señor D. Armando Cotarelo Valledor y leído por su encargo en la sesión conmemorativa del centenario de Felipe V 
celebrada por el Instituto de España en los salones de la Real Academia de la Historia el dia 26 de octubre de 1946. Madrid: Imprenta de Editorial Magisterio Español.

CREspo Tobarra, Carmen. Coord. (1991). Catálogo de manuscritos de la Real Academia Española. Anejos del BRAE (anejo L). Madrid.

DelbecQue, Nicole y Béatrice LAMIROY (1999). “La subordinación sustantiva: Las subordinadas enunciativas en los complementos verbales", en Ignacio Bosque y Violeta Demonte (Dir.): Gramática descriptiva de la lengua española. Madrid: Espasa Calpe, S.A. Págs. 1965-2081.

Delesalle, Simone et Jean Claude CHEVAlIER (1986). La linguistique, la grammaire et l'école. 1750-1914. Paris: Armand Colin. (Collection: «Linguistique»).

DELGADO, Feliciano (1997). “Gramática clásica, gramática española, historia de la lingüística", en $R S E L, 7^{\prime 2} 2$, págs. 81-96.

Devís MÁrqueZ, P. Pablo (1994). “El concepto de subordinación. Criterios para la clasificación de las denominadas oraciones subordinadas en español", en Contextos, XII/23-24, págs. 71-106. (1997). “Relaciones sintácticas oracionales, funciones sintácticas oracionales y la teoría de los esquemas oracionales. Repercusiones en una gramática del español", en $L E A, \mathrm{XIX} / 1$, págs. 21-50.

DíAZ, Lourdes (1994). “Algunas precisiones sobre el concepto de evolución en sintaxis medieval: el caso de las subordinadas temporales", en Anuari de Filologia, Vol. XVII, págs. 9-39.

DIEGO, Gerardo (1963). “Un cuarto de milenio en la Real Academia Española”, en BRAE, 43, págs. 413-429.

DOMíNGUEZ, José M. a (1969). “«Limpia, fija y da esplendor»: La Real Academia Española de la Lengua", en Idioma 6, págs. 133-137.

CAPARRós, José (1976). “La Gramática de la Academia del siglo XVIII”, en RFE LXVIII, págs. 81-108

DONZÉ, Roland (1970). La Gramática general y razonada de Port-Royal. Contribución a la historia de las ideas gramaticales en Francia. [Traducción de Marino Ayerra Redín]. Editorial Universitaria de Buenos Aires (Manuales de Eudeba).

DRĂGANU, Nicolae (1970). Storia della sintassi generale. Opera postuma. Traduzione dal rumeno della Dott. Paola Bardelli Plomteux, con note, premesse e illustrazioni, di Carlo Tagliavini. Bologna: Casa Editrice Prof. Riccardo Pàtron. 
EGUIZÁBAL, José Eugenio (1879). Apuntes para una historia de la legislación española sobre imprenta desde el año de 1480 al presente, redactados por el Ldo.D. José Eugenio de Eguizábal, abogado de los I.I. Colegios de Madrid y de Valencia, despues Consejero de Estado y Senador Vitalicio. Madrid: Imprenta de la Revista de Legislación. MDCCCLXXIX.

ELIZALDE, Ignacio (1988). “Aportación de los jesuitas a la literatura española: Ensayo bibliográfico", en Varia bibliográfica. Homenaje a José Simón Díaz. Kassel Edition Reichenberger. Págs. 243-253.

Encinas Manterola, M. Teresa (2005). La gramática escolar de la Real Academia Española (los Epítomes 1857 a 1938). Trabajo de Grado inédito presentado en la Universidad de Salamanca.

EsPARZA, Miguel Ángel (1997). “Tareas de la historiografía lingüística”, en Miguel Ángel Esparza y Maria do Carmo Enríquez (eds.): Estudios de lingüística. Departamento de Filología Española. Universidade de Vigo. Págs. 69-86.

(2004). “De antiguos y modernos: «gramática tradicional», tradición gramatical y análisis gramaticográfico", en C. Corrales Zumbado y otros (eds.): Nuevas aportaciones a la historiografía lingüística. Actas del IV Congreso Internacional de la SEHL (La Laguna, 22-25 de octubre de 2003). Madrid: Arco/Libros. Págs. 455-468.

EsPARZA, Miguel Ángel y Ramón SARMIENTO (1992). “Introducción a la Gramática castellana (1492) de Elio Antonio de Nebrija". Madrid: SGEL; Fundación Antonio de Nebrija (Serie: clásicos españoles). Págs. 11-95.

ESTEVe SERRANO, Abraham (1982). "La teoría gramatical del Diccionario de Autoridades", en REL 12:1, págs. 141-143.

FERNÁNDEZ LEBORANS, Ma Jesús (1992). "La oración del tipo: «es que...»", en VERBA: Anuario Galego de Filoloxía, 19, págs. 223-239.

(2005). Los sintagmas del español. II El sintagma verbal y otros. Madrid: Arco/Libros. (Cuadernos de Lengua Española).

FERRER TORRES, Juan (2002). “Las expresión del modo verbal en las subordinadas adjetivas, comparativas y consecutivas", en Juan Antonio Moya Corral e Isabel Montoya Ramírez (eds.). Gramática y enseñanza de la lengua española. Actas de las VII Jornadas sobre la enseñanza de la lengua española. Universidad de Granada. Págs. 421-434.

FERRERES MASPla, Federico (1983). "Incidencia y subordinación en francés”, en Anuario de Filología, 9. Universidad de Barcelona. Págs. 245-258. 
FLAMENCO GARCíA, Luis (1999). "Las construcciones concesivas y adversativas", en Ignacio Bosque y Violeta Demonte (Dir.): Gramática descriptiva de la lengua española. Madrid: Espasa Calpe, S.A. Págs. 3805-3878.

FREIXAS AlÁS, Margarita (2003). Las autoridades en el primer Diccionario de la Real Academia Española. Tesis doctoral. Universitat Autònoma de Barcelona.

[Consulta en red: <http://www.tesisenxarxa.net/TESIS_UAB/AVAILABLE/TDX-0611104150443//mfa2de2.pdf> (última consulta: mayo de 2008)].

FRIES, Dagmar (1989). "Limpia, fija y da esplendor". La Real Academia Española ante el uso de la lengua (1713-1973). Madrid: SGEL (Serie: Clásicos españoles).

FUENTES RODRÍGUEZ, Catalina (1985). Sintaxis oracional. Sevilla: Ediciones Alfar.

GALÁN RodRíGUEZ, Carmen (1992). Las oraciones finales en español. Estudio sincrónico. Cáceres. Universidad de Extremadura.

(1999). "La subordinación causal y final”, en Ignacio Bosque y Violeta Demonte (Dir.): Gramática descriptiva de la lengua española. Madrid: Espasa Calpe, S.A. Págs. 3597-3642.

GARCíA FOLGADO, Ma José (2002). “La gramática escolar española entre dos siglos (17801913): la sintaxis", en Documents pour l'histoire du français langue étrangère ou seconde, vol. 29, págs. 126-144.

(2004a). "La sintaxis en el siglo XVIII", en Gerda Hassler y Gesina Volkmann (eds.): History of Linguistics in Text and Concepts... Münster: Nodus Publikationem. Vol. I, págs. 225-235.

(2004b). “Motivaciones para el estudio de la gramática española en el siglo XVIII", en Analecta Malacitana. Revista de la sección de Filología de la facultad de Filosofía y Letras. Universidad de Málaga. XXVII, 1, págs. 91-116.

(2005/2006). La gramática española y su enseñanza en la segunda mitad del siglo XVIII y principios del siglo XIX (1768-1813). Tesis doctoral. Universitat de València. Server de Publicacions.

[Consulta en red: <http://www.tesisenxarxa.net/TESIS_UV/AVAILABLE/TDX-1030106172201//folgado.pdf> (última consulta: mayo de 2008)].

García Pérez, Rafael y José Carlos De Hoyos Puente (1999). “La anticipación de la Academia a dos cuestiones históricas", en A. Ma . Aldama, Ma . F. del Barrio, M. Conde, A. Espigares y Ma. J. López de Ayala (eds.). La Filología Latina hoy. Actualización y perspectivas. Sociedad de Estudios Latinos. Madrid. Págs. 489-497. 
GARCÍA-Miguel GALLEGO, José Mª (1996). “Régimen y caso en las primeras gramáticas del español", en Scripta Philologica in memoriam Manuel Taboada Cid. Vol. 1. Págs. 109-122.

GARDES TAMINE, Joëlle (2003). “Phrase, proposition, énoncé, etc. Pour une nouvelle terminologie», en L'Information grammaticale, $\mathrm{n}^{\circ}$ 98, págs. 23-27.

GARRIDO VÍlCHEZ, Gema Belén (2001a). 'Gramática', 'sintaxis' y Relaciones de Dependencia Intraoracional en la Obra académica. Trabajo de Grado inédito presentado en la Universidad de Salamanca el 30 de noviembre de 2001.

(2001b). “La huella de Salvá en la GRAE de 1854”, en Bartol Hernández y otros (eds.): Nuevas aportaciones al estudio de la lengua española. Investigaciones filológicas. Luso-Española de Ediciones. Págs. 135-144.

(2002a). “¿Relaciones de la GRAE-1854 con Andrés Bello?”, en Miguel Ángel Esparza Torres y otros (eds.): SEHL 2001. Estudios de Historiografía Lingüística. Actas del III Congreso Internacional de la Sociedad Española de Historiografía Lingüística (Vigo, 7-10 de febrero de 2001). Hamburg: Helmut Buske Verlag. Págs. 165-178.

(2002b). “De la Gramática al Epítome: la GRAE ante la enseñanza gramatical. El caso de 1857", en Actas de las Terceras Jornadas de reflexión filológica (Salamanca, febrero-marzo de 2002). En prensa.

(2003a). “De la Gramática al Epítome: la GRAE ante la enseñanza gramatical. El caso de 1870", en Res Diachronicae. Anuario de la Asociación de Jóvenes Investigadores de Historiografía e Historia de la Lengua Española. Número 2. Págs. 135-143.

(2003b). “La Real Academia Española y el concepto de gramática: el aspecto pedagógico-normativo", en Carmen Alemany Bay y otros (eds.): Con Alonso Zamora Vicente. Actas del Congreso Internacional «La lengua, la Academia, lo popular, los clásicos, los contemporáneos...». Universidad de Alizante. Págs. 629-638.

(2006). "Comentario de un texto gramatical del siglo XVIII", en Cristina Pérez Cordón y José Luis Ramírez Luengo (eds.): El español en sus textos. Manual de comentarios lingüísticos e historiográficos. Lugo: Axac.

(2007). “Jalones decimonónicos en la concepción gramatical de la Real Academia Española", en Moenia, Revista Lucense de Lingüística y Literatura, 13. En prensa.

GILI GAYA, Samuel (1963). La lexicografía académica del siglo XVIII. Universidad de Oviedo (Cuadernos de la cátedra Feijoo, n. $\left.{ }^{\circ} 14\right)$. 
GÓMEZ ASENCIO, José J. (1981). Gramática y categoría verbales en la tradición española. 17711847. Ediciones Universidad de Salamanca.

(1985). Subclases de palabras en la tradición española (1771-1847). Ediciones Universidad de Salamanca.

(1987). “Naissance et développement de la notion de phrase composée dans les grammaires espagnoles (1771-1851)”, en HEL IX-2, págs. 117-132.

(1999). “Gramáticas latinizantes: deslatinización de la gramática”, en Jesús

Fernández González y otros (eds.): Lingüística para el siglo XXI. Actas del III Congreso de Lingüística General (Salamanca, 23-25 de marzo de 1998). Ediciones Universidad de Salamanca. Págs. 819-826.

(2000a). “El prólogo como programa. A propósito de la «GRAE» de 1771", en BRAE, Tomo LXXX, cuaderno CCLXXIX, págs. 27-46.

(2000b). "El prólogo como proemio: La GRAE de 1796", en Borrego Nieto y otros (eds.): Cuestiones de actualidad en lengua española. Ediciones Universidad de Salamanca; Instituto Caro y Cuervo.

(2001). "Lo latino de las gramáticas del español”, en Marina Maquieira y otros (eds.): Actas del II Congreso Internacional de la Sociedad Española de Historiografía Lingüística (León, 2-5 de marzo de 1999). Madrid: Arco/Libros. Págs. 35-54. (2002a). “Los prólogos académicos de 1854 y 1858”, en Miguel Ángel Esparza Torres y otros (eds.): SEHL 2001. Estudios de Historiografía Lingüística. Actas del III Congreso Internacional de la Sociedad Española de Historiografía Lingüística (Vigo, 7-10 de febrero de 2001). Hamburg: Helmut Buske Verlag. Págs. 197-211.

(2002b). "El prólogo como advertencia: el caso de la GRAE de 1870", en $\mathrm{M}^{\mathrm{a}}$ Tadea Díaz Hormigo (ed.): IV Congreso de Lingüística General (Cádiz, 3-6 de abril de 2000). Servicio de Publicaciones de la Universidad de Cádiz; Servicio de Publicaciones de la Universidad de Alcalá de Henares. Págs. 1229-1239. (2004). "El precio de las GRAEs", en Milka Villayandre Llamazares (coord.): Actas del V Congreso de Lingüística General, vol. 2. Págs. 1313-1325. (2006). “Los «Vicios de dicción» de las Gramáticas académicas (1880-1962)”, en Antonio Roldán y otros (eds.): Caminos actuales de la Historiografía Lingüística. Actas del V Congreso Internacional de la Sociedad Española de Historiografía Lingüística (Murcia, 7-11 de noviembre de 2005). Universidad de Murcia. Págs. 23-79.

Gómez Asencio, José J. y Gema B. GARRIDO VílChEZ (2005). “Las Gramáticas de la RAE en números", en Luis Santos Río y otros (eds.): Palabras, norma, discurso en 
memoria de Fernando Lázaro Carreter. Ediciones Universidad de Salamanca. Págs. 593-604.

GONZÁleZ CALVO, José Manuel (1989): “En torno al concepto de oración”, en AEF, XIII. Págs. 89-109.

(1991). "Acercamiento a una clasificación de la oración simple según el Dictum", en ELUA, 7, págs. 99-116.

(1998). "Parataxis e hipotaxis: texto y oración", en Martin Hummel und Christina Ossenkop (eds.): Lusitanica et Romanica. Festschrift für Dieter Woll. Hamburg: Helmut Buske Verlag. Págs. 285-292.

GONZÁlEz EsCRIBANO, José Luis (1990). Una teoría de la oración. Gijón: J. González, D.L.

GONZÁlez Monllor, Rosa María y Andamana BAUTiSTA García (2004): “La subordinación sustantiva en The Syntaxof Castilian Prose: The Sixteenth Century de H. Keniston", en Nuevas aportaciones a la historiografía lingüística. Actas del IV Congreso Internacional de la SEHL, La Laguna (Tenerife), 22 al 25 de octubre de 2003. Madrid: Arco Libros S.L. Págs. 709-718.

GONZÁLEZ RAMíreZ, María (2003). “Contribución al estudio diacrónico de las oraciones concesivas en el siglo XIII. El Libro de los buenos proverbios", en Margarita Borreguero Zuloaga y otros (eds.): Res Diachronicae. Anuario de la Asociación de Jóvenes Investigadores de Historiografía e Historia de la Lnegua Española. $\mathrm{N}^{0} 2$. Madrid. Págs. 163-172.

GRAFFI, Giorgio (2001). 200 years of syntax. A critical survey. Amsterdam: John Benjamins.

GUTIÉRREZ ORDÓÑEZ, Salvador (1994a). Estructuras pseudocomparativas. Madrid: Arco Libros S.L. (Cuadernos de Lengua española).

(1994b). "Problemas en torno a las categorías funcionales", en Francisco Hernández Paricio (ed.): Perspectivas sobre la oración. Universidad de Zaragoza. Págs. 71-99.

(1997a [1994]). Estructuras comparativas. Madrid: Arco Libros S.L. (Cuadernos de Lengua española). $2^{a}$ edición.

(1997b). La oración y sus funciones. Madrid: Arco Libros S.L.

(1999). “Qué es una oración subordinada?”, en Actas del III Congreso de Lingüística General (Salamanca, marzo de 1998). Págs. 49-72.

(2008). Del arte gramatical a la competencia comunicativa. Discurso leído el día 24 de febrero de 2008 en su recepción pública por el Excmo. Sr. D. Salvador Gutiérrez Ordóñez y contestación del Excmo. Sr. D. Ignacio Bosque Muñoz. Madrid. 
HASSLER, Gerda (1990). “Los «ideólogos» franceses y la continuidad de sus temas lingüísticos en el pensamiento español al inicio del siglo XIX", en Glosa, 1, págs. 135-156.

HERNÁNDEZ, Carlos y Ricard MORANT (1996). “Observacions metodològiques sobre la historiografia", en Manuel Prunyonosa (ed.). Historiografia lingüística valenciana. Valencia. Universitat. Págs. 27-36.

HERNÁNDEZ AlONSO, César (1980). “Revisión de la llamada «oración compuesta»", en RSEL, 10/2, págs. 277-305.

HERNÁNDEZ PARICIO, Francisco, ed. (1994a). Perspectivas sobre la oración. Universidad de Zaragoza.

(1994b). “Núcleos oracionales y oraciones nucleares: proyecciones funcionales, estructura de la cláusula y subordinación", en Francisco Hernández Paricio (ed.): Perspectivas sobre la oración. Universidad de Zaragoza. Págs. 101-144.

HERNANDO GARCÍA-CERVIGÓN, Alberto (2002). “Tradición e innovación en la doctrina gramatical de la GRAE (1771-1931)", en Res Diachronicae. Anuario de la Asociación de Jóvenes Investigadores de Historiografía e Historia de la Lengua Española. Número 1. Págs. 197-206.

(2003). "El problema del artículo en la tradición gramatical", en Res Diachronicae. Anuario de la Asociación de Jóvenes Investigadores de Historiografía e Historia de la Lengua Española. Número 2. Págs. 173-182. (2004). “El artículo en la GRAE (1771-1917)”, en C. Corrales Zumbado y otros (eds.): Nuevas aportaciones a la historiografía lingüística. Actas del IV Congreso Internacional de la SEHL (La Laguna, 22-25 de octubre de 2003). Madrid: Arco/Libros. Págs. 809-821.

(2006). El grupo del nombre en la Analogía de la GRAE (1771-1917). Madrid: Editorial Complutense.

Herraiz GAllegO, Ma Luisa (1999). "Sobre las cláusulas de suplemento", en Actas del XI Congreso Internacional de la Asociación de Lingüística y Filología de la América Latina (Las Plamas de Gran Canaria, 22-27 de julio de 1996). Págs. 239-243.

HERRERO, Gemma (1992). “Las oraciones ecuacionales en español”, en VERBA: Anuario Galego de Filoloxía, 19, págs. 201-222.

Herrero RuIZ De LOIZAGA, Francisco Javier (1990). Contribución al estudio de la sintaxis histórica: la oración compleja en la comedia humanística. 2 vols. Madrid. Universidad Complutense. 
HJELMSLEV, Louis (1969). Prolegómenos a una teoría del lenguaje. Madrid: Editorial Gredos. (1976). Principios de gramática general. [Versión española de Félix Piñero Torre]. Madrid: Editorial Gredos. (Biblioteca Románica Hispánica. II. Estudios y ensayos. 251).

HOCKETT, Charles Francis (1954). "Two models of grammatical description", en Word: Journal of the linguistic Circle of New York, International Linguistic Association, 10, págs. 210-231. Publicado también en Francis Katamba (ed.): Morphology. Critical concepts in linguistics. Taylor \& Francis. 2003. Págs. 110-136.

Hurtado Valero, Pedro M. (2002). Eduardo Benot: Una aventura gramatical. Madrid: Editorial Verbum. (2006). “La teoría de los casos en Eduardo Benot (1822-1907)”, en EliES, vol. 23. [Consulta en red: < http://elies.rediris.es/elies23/index.htm> (última consulta: mayo de 2008)]. ISBĂŞESCU HĂULICĂ, Cristina (1981). “Propuesta para una clasificación de las oraciones paratácticas en español", en Logos Semantikos Studia Lingüística in honores Eugenio Coseriu (1921-1981). Madrid: Editorial Gredos.

IGLESIAS BANGO, Manuel (2001). “La formación de las ideas sintácticas en las gramáticas académicas de principios de siglo: la posible influencia de J. Cejador y Frauca", en Marina Maquieira Rodríaguez y otros (eds.): Actas del II Congreso Internacional de la Sociedad Española de Historiografía Lingüistica (León, 2-5 de marzo de 1999). Madrid: Arco Libros.

JiMÉNEZ JULIÁ, Tomás (1992). "Sobre relaciones, oraciones y diferencias de marco teórico", en VERBA: Anuario Galego de Filoloxía, 19, págs. 177-200.

(1994). "Clases de construcciones, tipos de unidad y oraciones", en Francisco Hernández Paricio (ed.): Perspectivas sobre la oración. Universidad de Zaragoza. Págs. 145-183.

(1995). La coordinación en español. Aspectos teóricos y descriptivos. VERBA: Anuario Galego de Filoloxía, anejo 39. Universidad de Santiago de Compostela.

KovACCI, Ofelia (1999). "El adverbio", en Ignacio Bosque y Violeta Demonte (Dir.): Gramática descriptiva de la lengua española. Madrid: Espasa Calpe. Vol. I. Sintaxis básica de las clases de palabras. Págs. 705-786.

KUKENHEIM, Louis (1974 [1932]). Contributions à l'histoire de la grammaire italienne, espagnole et française à l'époque de la renaissance. Utrecht: H\&S Publishers.

LABORDA GIL, Xavier (1981). Racionalismo y empirismo en la lingüística del siglo XVII: John Wilkins y Port-Royal. Tesis Doctoral. Universidad de Barcelona. 
[Consulta en red: <http://www.tesisenxarxa.net/TESIS_UB/AVAILABLE/TDX-0920104113747//TESIS_LABORDA.pdf> (última consulta: mayo de 2008)].

LAUSBERG, Heinrich (1993 [1975]). Elementos de retórica literaria. Madrid: Editorial Gredos.

(Biblioteca Románica Hispánica. III. Manuales, 36). [Versión española de Mariano Marín Casero].

LAVACCHI, Leonardo y Ma Carlota NiCOLÁs MARTíneZ (1994). “Oraciones de aunque y pero", en VERBA: Anuario Galego de Filoloxía, 21, págs. 257-278.

LÁZARO CARRETER, Fernando (1960). Ignacio Luzán y el Neoclasicismo. Zaragoza: Facultad de Filosofía y Letras. Secretariado de publicaciones. (1972). Crónica del Diccionario de Autoridades (1713-1740), discurso leído el día 11 de junio de 1972, en el acto de su recepción, por el Exmo. Sr. Don Fernando Lázaro Carreter y contestación del Exmo. Sr. Don Rafael Lapesa Melgar. Madrid. (1985 [1949]). Las ideas lingüísticas en España durante el siglo XVIII (Prólogo de Manuel Breva Claramente). Barcelona: Editorial Crítica. (1987 [1953]). Diccionario de términos filológicos. Madrid. Editorial Gredos. Tercera edición corregida. (Biblioteca Románica Hispánica. III. Manuales, 6).

LÁzARO MorA, Fernando A. (1981). La presencia de Andrés Bello en la filología Española. Universidad de Salamanca.

LE GOFFIC, Pierre (1993). Grammaire de la phrase française. Paris: Hachette.

LE MEN, Janick (1992). “Algunos problemas sintácticos en las oraciones relativas”, en Contextos X/19-20, págs. 371-383.

LEEMAN, Danielle (2002). La phrase complexe. Les subordinations. Bruxelles: de Boeck \& Larcier S.A. Éditions Duculot.

LEON, Jacqueline (2003). “Proposition, phrase, énoncé dans la Grammaire: parcours historique", en L'Information grammaticale, nº 98, págs. 5-16.

LEONETTI, Manuel (1999). “La subordinación sustantiva: Las subordinadas enunciativas en los complementos nominales", en Ignacio Bosque y Violeta Demonte (Dir.): Gramática descriptiva de la lengua española. Madrid: Espasa Calpe, S.A. Págs. 20832103.

LLITERAS, Margarita (1988). "Estudio introductorio" a Gramática de la lengua castellana según ahora se habla de Vicente Salvá. Madrid: Arco/Libros. Págs. 7-64.

(1992). La teoría gramatical de Vicente Salvá. Madrid: SGEL (Colección: Historiografía de la Lingüística Española. Serie: Monografías). 
(1996). "De la Etimología a la Analogía en la historia gramatical española", en Scripta Philologica in memoriam Manuel Taboada Cid. Vol. 1. Págs. 131-142.

(1998). “Sobre la llamada «gramática tradicional» de la lengua española", en César Hernández Alonso (coord.): Homenaje al profesor Emilio Alarcos García en el centenario de su nacimiento (1895-1995). Secretariado de Publicaciones e Intercambio Científico Universidad de Valladolid; Consejería de Educación y Cultura, Junta de Castilla y León. Págs. 357-366.

Llorente MALdONADO, Antonio (1967). Teoría de la lengua e historia de la lingüística. Madrid: Ediciones Alcalá.

Antonio (1974). “Caracterización de la lingüística grecolatina: ensayo de fijación de criterios para historiar la ciencia del lenguaje", en Miscelánea de estudios dedicados al profesor Antonio Marín Ocete. Universidad de Granada. Págs. 515-537.

LOPE BLANCH, Juan M. (1979). El concepto de oración en la lingüística española. Universidad Nacional Autónoma de México, Instituto de Investigaciones Filológicas, Centro de Lingüística hispánica (Cuadernos de Lingüística 1).

(1979b). "La estructura de la cláusula en el habla y en la literatura”, en ALM, Vol. XVII, págs. 97-112.

(1981). “Unidades sintácticas. Recapitulación”, en RFE 61, págs. 21-63.

LÓPEZ GARCíA, Ángel (1994a). Gramática del español. I. La oración compuesta. Madrid: Arco Libros S.L. (Colección Biblioteca philológica).

(1994b). "Categorías y funcones en la percepción de la oración", en Francisco

Hernández Paricio (ed.): Perspectivas sobre la oración. Universidad de Zaragoza. Págs. 185-204.

(1999). "Relaciones paratácticas e hipotácticas", en Ignacio Bosque y Violeta Demonte (Dir.): Gramática descriptiva de la lengua española. Madrid: Espasa Calpe, S.A. Págs. 3507-3547.

LÓPEZ MartíneZ, M. a Isabel y Eulalia Hernández SÁnCHEZ (1994). Benito Martínez gómez Gayoso en la teoría gramatical del siglo XVIII. Universidad de Murcia.

LOZANO GUILLÉN, Carmen (1992). La aportación gramatical renacentista a la luz de la tradición. Secretariado de Publicaciones Universidad de Valladolid.

MAQUiEIRA, Marina (1997). "La Nueva gramática de la lengua castellana de Martínez de Noboa: la coherencia interna de una doctrina", en HL XXIV: 1/2, págs. 115-138.

MARCos MARÍN, Francisco (1994). Introducción a la Lingüística: Historia y Modelos. Madrid: Editorial Síntesis. 
MARTí SÁNCHEZ, Manuel (1988). El complemento en la tradición gramatical hispánica (14921860). Universidad Complutense de Madrid.

(1992). "Consideraciones sobre el suplemento desde la historia de la gramática", en Contextos X/19-20, págs. 149-165.

MARTínEZ, José Antonio (1996 [1994]). La oración compuesta y compleja. Madrid: Arco/ Libros (Cuadernos de Lengua española). $2^{a}$ edición.

MARTíneZ AlCALDE, M. a José (1998). “Gramáticas españolas preacadémicas del XVIII: sobre el llamado artículo indefinido", en César Hernández Alonso (coord.): Homenaje al profesor Emilio Alarcos García en el centenario de su nacimiento (18951995). Secretariado de Publicaciones e Intercambio Científico Universidad de Valladolid; Consejería de Educación y Cultura, Junta de Castilla y León. Págs. 357-366.

MARTÍNEZ ÁlVAREZ, Josefina (2002). “El análisis lingüístico. Estructuras oracionales”, en Juan Antonio Moya Corral e Isabel Montoya Ramírez (eds.): Gramática y enseñanza de la lengua española. Actas de las VII Jornadas sobre la enseñanza de la lengua española. Universidad de Granada. Págs. 31-42.

MARTíneZ GAVILÁN, M. ${ }^{a}$ Dolores (1984). “Las ideas lingüísticas de la Gramática de la Real Academia Española", en Contextos 11/4, págs. 191-199.

(1990). “Normativismo y antinormativismo en la tradición gramatical española del siglo XVII", en Contextos VIII/15-16, págs. 129-151.

(1994). "Tradición e innovación en la teoría gramatical española del siglo XVII", en R. Escavy y otros (eds.): Nebrija V centenario 1492-1992. Actas del Congreso Internacional de Historiografía Lingüística. Secretariado de Publicaciones e Intercambio Científico de la Universidad de Murcia.

(1997). “La originalidad de Gonzalo Correas y su influencia en la tradición gramatical española", en Enric Serra Alegre y otros (eds.): Panorama de la Investigació lingüistica a l'Estat Espanyol. Actes del I Congrés de Lingüística General (15-17 de febrero de 1994). Universitat de València. Vol. IV (Epistemologia del llenguatge. Història de la Lingüística. Joves Investigadors). Págs. 87-94.

MARTÍNEZ LiNARES, M. a Antonia (2001). Sobre las "partes de a oración" y el enfoque sintáctico funcional de la gramática de Eduardo Benot (1822-1907). Publicaciones Universidad de Alicante.

(2006). “El enfoque «atomístico» y la sintaxis en las gramáticas académicas del siglo XIX", en ELiEs, vol. 23. 
[Consulta en red: < http://elies.rediris.es/elies23/index.htm> (última consulta: mayo de 2008)].

MIRANDA VALDÉS, Javier (2005). Aureliano Fernández-Guerra (1816-1894). Un romántico, escritor y anticuario. Real Academia Española. Real Academia de la Historia.

MolinA ReDONDO, José Andrés de (1985). “En torno a la oración «compuesta» en español", en Philologica hispaniensia: in honorem Manuel Alvar. Vol. 2. Págs. 513527.

(1997). “En torno a la oración «compuesta» en español", Enric Serra Alegre y otros (eds.): Panorama de la Investigació lingüística a l'Estat Espanyol. Actes del I Congrés de Lingüística General (15-17 de febrero de 1994). Universitat de València. Vol. I (Conferències i pannells). Págs. 19-30.

MONTOLío DuRÁN, Estrella (1991). “Acerca de las construcciones de gerundio con valor condicional", en Anuari de Filologia, Vol. XIV, Págs. 21-36.

(1999). "Las construcciones condicionales", en Ignacio Bosque y Violeta Demonte (Dir.): Gramática descriptiva de la lengua española. Madrid: Espasa Calpe, S.A. Págs. 3643-3737.

Moreno DE AlbA, José G. (1979). “Coordinación y subordinación en gramática española", en ALM, XVII, págs. 5-58.

Morillo-Velarde Pérez, Ramón (1980). "Introducción" a "Gramática General y razonada" de Port-Royal seguida de la segunda parte de la lógica. Madrid: SGEL. Págs. 9-31.

Mourelle-Lema, Manuel (1968). La teoría lingüística en la España del siglo XIX. Premio “Conde de Cartagena” 1965 de la Real Academia Española. Editorial Prensa Española.

MOYA CORRAL, Juan Antonio (2002). “Las unidades constructoras de la «oración compuesta»", en Juan Antonio Moya Corral e Isabel Montoya Ramírez (eds.): Gramática y enseñanza de la lengua española. Actas de las VII Jornadas sobre la enseñanza de la lengua española. Universidad de Granada. Págs. 63-89.

MYRE, Annette Maria (1992). “Reflexiones sobre las conjunciones en las construcciones distributivas", en Antonio Vilanova (ed.): Actas del X Congreso Internacional de Hispanistas. Universidad de Barcelona. Págs. 1263-1271.

NARBONA JIMÉNEZ, Antonio (1989). Las subordinadas adverbiales impropias en español. Bases para su estudio. Málaga: Editorial librería Ágora S.A. (Cuadernos de Lingüística/8). 
(1990). Las subordinadas adverbiales impropias en español (II). Causales y finales, comparativas y consecutivas, condicionales y concesivas. Málaga: Editorial librería Ágora S.A. (Cuadernos de Lingüística/9).

NiEDEREHE, Hans-Joseph (1997). “La gramaticografía del siglo XVIII entre tradición y reorientación", en $H L$ XXIV: 1/2, págs. 41-55.

OSUNA GARCíA, F. (2007). “De nuevo sobre el concepto de oración”, en Language Design 8, págs. 5-33.

[Consulta en red: <http://elies.rediris.es/Language_Design/LD8/indice_vol8.html> (última consulta: mayo de 2008)].

PASTOR, José Francisco (1929). Las apologías de la lengua castellana en el Siglo de Oro. Madrid: Compañía Iberoamericana de Publicaciones. (Los clásicos olvidados, vol VIII).

PellizZA, Marie-Antoinette (2000). “Subordination, corrélation et insertion. Syntaxe de la concession dans Le Misanthrope et Georges Dandin de Molière", en L'Information grammaticale, $\mathrm{n}^{\circ} 84$, págs. $37-40$.

PeÑalver Castillo, Manuel (2002). “Indicativo y subjuntivo en oraciones complejas sustantivas y adverbiales", en Juan Antonio Moya Corral e Isabel Montoya Ramírez (eds.): Gramática y enseñanza de la lengua española. Actas de las VII Jornadas sobre la enseñanza de la lengua española. Universidad de Granada. Págs. 403-420.

Plata y MARCOS, Miguel de la (1882 [1879]). Colección bio-bibliográfica de escritores médicos españoles. Madrid: Impr. de Alejandro Gómez Fuentenebro.

PONS BORDERÍA, Salvador (1997). “¿Habla la tradición gramatical de los enlaces extraoracionales?", en Enric Serra Alegre y otros (eds.): Panorama de la Investigació lingüística a l'Estat Espanyol. Actes del I Congrés de Lingüística General (15-17 de febrero de 1994). Universitat de València. Vol. IV (Epistemologia del llenguatge. Història de la Lingüística. Joves Investigadors). Págs. 95-104.

PORROCHE BALLESTEROS, Margarita (1994). “El componente discursivo-textual en las relaciones oracionales (las oraciones adversativas)", en Francisco Hernández Paricio (ed.): Perspectivas sobre la oración. Universidad de Zaragoza. Págs. 205-227.

PORTO DAPENA, José-Álvaro (1997). Oraciones de relativo. Madrid: Arco/Libros. (Cuadernos de Lengua española).

POZUElO YVANCOS, José María (1984). “Norma, uso y autoridad en la teoría lingüística del siglo XVI", en HL XI: 1/2, págs. 
(1986). "Norma, uso y autoridad en la teoría lingüística del siglo XVI", en Antonio Quilis y Hans-Joseph Niederehe (eds.): The history of linguistics in Spain. Ámsterdam / Philadelphia: John Benjamins Publishing Company. Págs. 77-94 QUEREUIL, Michel (1996). "Subordination er parataxe dans les lais de Marie de France", en L'Information grammaticale, $\mathrm{n}^{\circ} 68$, págs. 1-5.

QUILIS, Antonio y Juan M. RozAS (1963). “La originalidad de Jiménez Patón y su huella en el «Arte de la lengua» del Maestro Correas, en RFE, XLVI, págs. 81-95.

RABANAles, Ambrosio (1965). “La Gramática de la Academia y el estado actual de los estudios gramaticales", en BFUCh, vol. 17, págs. 261-280.

RADA Y DELGADO, Juan de Dios de la (1894). “Excmo. Sr. D. Aureliano Fernández-Guerra y Orbe", en La Ilustración Española y Americana, año 38, n. ${ }^{\circ} 34$ (15 de septiembre de 1894), págs. 158-159 y 161. [Versión digital por el Gabinete de Antigüedades de la Real Academia de la Historia, en Antigua: Historia y Arqueología de las civilizaciones].

[Consulta en red: http://www.cervantesvirtual.com/FichaObra.html?Ref=22052 (última consulta: abril de 2008)].

RAMAJO CAÑO, Antonio (1987). Las gramáticas de la lengua castellana desde Nebrija a Correas. Ediciones Universidad de Salamanca (Acta salmanticensia. Estudios filológicos. 197).

(2002). “Dedicatoria y 'prólogo' de la primera gramática académica (1771)”, en $R E L$, n. $^{\circ} 32$, fasc. 2, págs. 591-606.

RICO, Francisco (1986). “De Nebrija a la Academia”, en Homenaje a Pedro Sainz Rodríguez.

T. II Estudios de Lengua y Literatura. Madrid: Fundación Universitaria Española. Págs. 519-525.

RIDRUEJO, Emilio (1989). “Los Rudimentos de gramática castellana de Jovellanos y la Gramática de la Real Academia", en Philologica II. Homenaje a D. Antonio Llorente. Salamanca: Ediciones Universidad. Págs. 399-414.

(1997). “Los epígonos del racionalismo en España. La aplicación al castellano de la Gramática general de Gómez Hermosilla", en HL, XXIV: 1/2, págs. 95-114.

RiVAROLA, José Luis (1981). “Observaciones sobre la hipotaxis y la parataxis en español”, en Lexis, vol. 5, nº 1, págs. 21-29.

RobINS, R. H. (1992 [1969]). Breve historia de la Lingüística. Sexta edición actualizada y ampliada. [Traducción de Enrique Alcaraz Varo. Adaptación y traducción a la $6 .{ }^{\text {a }}$ edición Ana Isabel Gutiérrez]. Madrid: Editorial Paraninfo. 
ROJO, Guillermo (1978). Cláusulas y oraciones. VERBA: Anuario Galego de Filoloxía, anejo 14. Universidad de Santiago de Compostela. (1983). Aspectos básicos de sintaxis funcional. Málaga: Librería Ágora. (Cuadernos de Lingüística/ 4). (1997). “Gramática y Diccionario”, en Jesús Terrón González y José M. González Calvo (coords.). IV Jornadas de metodología y didáctica de la lengua española: Sintaxis. Universidad de Extremadura. Servicio de Publicaciones. Págs. 33-48. (2001). El lugar de la sintaxis en las primeras gramáticas de la Academia. discurso leído el día 7 de octubre de 2001, en su recepción pública, por el Excmo. Sr. Don Guillermo Rojo y contestación del Excmo. Sr. Don Ignacio Bosque Muñoz. Madrid.

ROJO, Guillermo y Tomás JiMÉNEZ Juliá (1989). Fundamentos del análisis sintáctico funcional. Universidad de Santiago de Compostela.

SALAZAR GARCía, Ventura (1999). “A propósito del concepto de «incidencia» en la gramática tradicional", en Fernández González y otros (eds.). Lingüística para el siglo XX. Actas del III Congreso de Lingüística General (Salamanca, 23-25 de marzo de 1998). Ediciones Universidad de Salamanca.

SALVÁ, Miguel y Pedro SAINZ DE BARANDA (1852). Colección de documentos inéditos para la historia de España, por D. Miguel Salvá y D. Pedro Sainz de Baranda, individuos de la Academia de la Historia. Tomo XXI. Madrid: Imprenta de la Viuda de Calero.

SARMIENTO, Ramón (1977a)*. Aportación a la historia de la gramática de la Real Academia Española. Tesis doctoral presentada en la Universidad Autónoma de Madrid. (1977b). "Inventario de documentos gramaticales de los siglos XVIII y XIX", en $B R A E$, cuaderno CCX, págs. 129-142.

(1978). “La gramática de la Academia: historia de una metodología”, en REL, 8.1., págs. 105-115.

(1979). "Filosofía de la Gramática de la Real Academia Española", en ALM, vol. XVII, págs. 59-96.

(1981). "La doctrina gramatical de la Real Academia Española”, en ALM, vol. 19, págs. 47-74.

(1983). "La gramática académica del Siglo de las Luces", en Serta Philologica Fernando Lázaro Carreter. Madrid: Cátedra. Págs. 571-585. 
(1984a). "Introducción" a la Gramática de la lengua castellana compuesta por la Real Academia Española. Edición facsímil. Madrid: Editora Nacional (Colección: Clásicos para una biblioteca contemporánea).

(1984b). "The grammatical doctrine of the Real Academia Española (1854)", en HL XI: 1/2, págs. 231-261.

(1986). "La doctrina gramatical de la R.A.E.", en Revista de Filología Románica, vol. IV, págs. 213-224.

(1989). “Origen y constitución de la doctrina sintáctica en la época clásica”, en

Philologica II, Homenaje a D. Antonio Llorente. Ediciones Universidad de Salamanca. Págs. 419-438.

(1997a). “De la norma hispánica de la GRAE (1924) a la norma panhispánica del EGRAE (1973)", en ALH, XII, págs. 185-195.

(1997b). "La tradición gramaticográfica española: esbozo de una tipología”, en Miguel Ángel Esparza y Maria do Carmo Enríquez (eds.): Estudios de lingüística. Departamento de Filología Española. Universidade de Vigo. Págs. 39-68.

SATORRE GRAU, Javier (1996). “Los criterios de corrección en la Gramática de los siglos XVI y XVII", en Alegría Alonso González (coord.): Actas del III Congreso Internacional de Historia de la lengua española (Salamanca, 22-27 de noviembre de 1993). Madrid: Arco/Libros. Vol. 1. Págs. 923-938.

SECO, Manuel (1973). "La Academia, de la vieja a la nueva gramática", en Arbor 86. Separata, 6 págs.

Sommervogel, Carlos (ed.). (1890-1900). Bibliothèque de la Compagnie de Jésus. Première partie: bibliographie par les Pères Augustin et Aloys de Backer. Seconde partie: histoire par le Père Auguste Carayon. Nouvelle édition par Carlos Sommervogel. 9 vols. Bruxelles: Oscar Schepens, Paris: Alphonse Picard. Tome II: 1891, Tome V: 1894, Tome VI: 1895.

STATI, Sorin (1979 [1976]). La sintaxis. México: Editorial Nueva Imagen. [Primera edición en italiano. Bolonia: Nicola Zanichelli Editore. 1976]

SUÑER, Margarita (1999). "La sbordinación sustantiva: La interrogación indirecta", en Ignacio Bosque y Violeta Demonte (Dir.): Gramática descriptiva de la lengua española. Madrid: Espasa Calpe, S.A. Págs. 2149-2195.

SWIGGERS, Pierre (1981a). "The history writing of linguistics: a methodological note", General Linguistics, 21, págs. 11-16. 
(1981b). “Comment écrire l’histoire de la linguistique?”, en Lingua 55, págs. 6374.

(1986). Grammaire et théorie du langage au dix-huitième siècle: «mot», «temps», «mode» dans l'Encyclopédie Méthodique. Presses Universitaires de Lille.

(1997). Histoire de la pensée linguistique. Analyse du langage et réflexion linguistique dans la culture occidentale, de l'Antiquité au XIX siècle. Presses Universitaires de France.

TABOADA CID, José Manuel (1981). “Notas para una edición de las primeras gramáticas de la Real Academia Española (1771, 1772, 1781 y 1788)", en VERBA: Anuario Galego de Filoloxía, 8, págs. 79-112.

(1984). “Introducción” a la edición del Arte Kastellana de Gonzalo Correas (1627). Santiago de Compostela. Universidad de Santiago de Compostela. Págs. 9-84. (1991). “Primeras fuentes de la gramática de la R.A.E. de 1771 (1 $1^{\text {a }}$ edición)”, en Mercedes Brea y Francisco Fernández (coords.): Homenaxe ó profesor Constantino García. Tomo II. Universidad de Santiago de Compostela. Págs. 195-210.

TAYLOR, Daniel J. (1987). The History of Linguistics in the Classical Period. Amsterdam / Philadelphia: John Benjamins Publishing Company. (Series III. Studies in the History of the Language Sciences, volumen 46).

TUSÓN, Jesús (1987). Aproximación a la Historia de la Lingüística. Barcelona: Editorial Teide. (1996). "Problemes i mètodes de la historiografia lingüística", en Manuel Prunyonosa (ed.): Historiografia lingüística valenciana. Valencia. Universitat. Págs. $15-25$.

UnAMUNO, Miguel de (1906). “La enseñanza de la gramática”, en Boletín de la Institución Libre de Enseñanza, año XXX, núm. 561 (31 de diciembre de 1906), págs. 353-362.

URUbuRU VidAurRÁZAGA, Agustín (1975). Edición crítica a las tres primeras ediciones de la Gramática castellana de la RAE (1771-1781). Memoria de Licenciatura presentada en la Universidad de Deusto. Córdoba: Universidad de Córdoba, Servicio de Publicaciones. (Publicación en microficha). 1989.

(1989). "Resumen" introductorio a Edición crítica a las tres primeras ediciones de la Gramática castellana de la RAE (1771-1781). Uruburu Vidaurrázaga (1975).

VAL Álvaro, José F. (1992). Las ideas gramaticales en el «Diccionario de Autoridades». Madrid. Arco/Libros. 
(1994). “Formación léxica verbal y restricciones sobre la estructura oracional (verbos denominales)", en Francisco Hernández Paricio (ed.): Perspectivas sobre la oración. Universidad de Zaragoza. Págs. 229-255.

VÁZQUEZ ROZAS, Victoria (1990). “Algunos aspectos de la historia de las funciones sintácticas clausales en la gramática española", en VERBA: Anuario Galego de Filoloxía, 17, págs. 427-438.

VERA LUJÁN, Agustín (1981). “En torno a las oraciones concesivas: concesión, coordinación y subordinación", en VERBA: Anuario Galego de Filoloxía, 8, págs. 187204. (1989) “A propósito de las relaciones sintácticas oracionales. Categorías y clases de funciones", en ELUA, 5, págs. 127-144.

ZAMORA, Juan C. (1987). “Ideología, filología y lingüística en la gramática española del Renacimiento", en Hispania 70, 4, págs. 718-723.

ZAMORA Vicente, Alonso (1999). Historia de la Real Academia Española. Madrid: Espasa Calpe, S.A.

ZAS, Luz (1992). “La herencia de la gramática de Nebrija en la consideración de las clases de palabras de algunas gramáticas españolas del primer tercio del siglo XVII", en Actas del Congreso Internacional de Historiografía Lingüística. Nebrija V centenario, vol. III, págs. 639-649. 